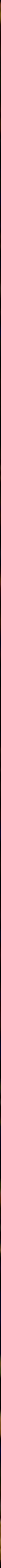




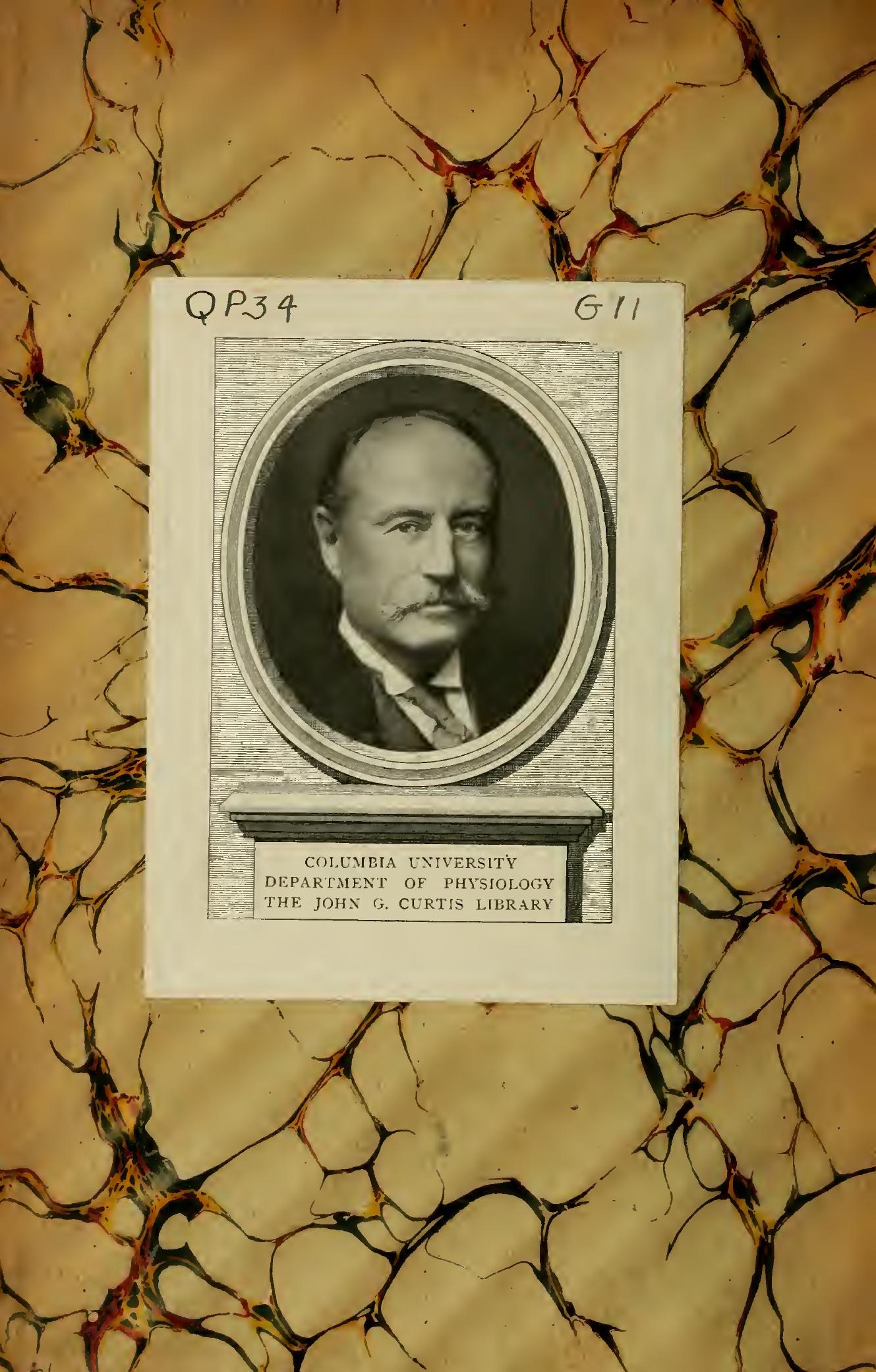




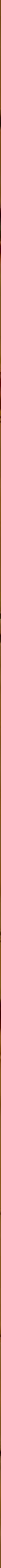



tit. 

I

r 



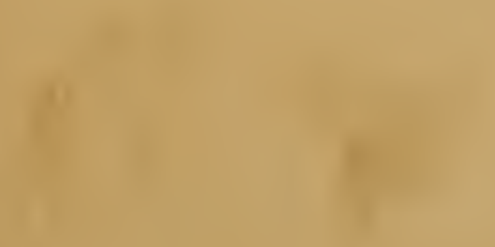




\title{
WREDENS SAMMLUNG
}

\section{IIEDIZINISCHER LEHRBÜCHER. BAND XVI.}

\author{
KURZES LEHRBUCH
}

DER

\section{PHYSIOLOGIE DES MENSCHEN}

VON

DR. JOHANNES GAD,

a. o. Professor an der Universität Perlin

UND

DR. J. F. HEYMANS,

Profossor an der Universität Gent.

P E R L I N,

VERLAG TON FRIEDRICII WREDEN. 


\section{KURZES LEHRBUCH}

IER

\section{PHYSIOLOGIE IDES MENSCHEN}

$\mathrm{V} \cup \mathrm{N}$

\section{JOHANNES GAD,}

a. o. Professor der I'liysiologie an der Universitit berlin

UND

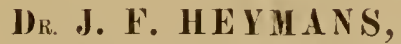

Professor an der Universitait Gent.

NIT G2 ABBILDUNGEN IN HOLZSCHNIT' UND 1 LITHOGR. TAFEL.

B E R L I N,

VERLAG VON FRIEDRICH WREDEN.

1892. 


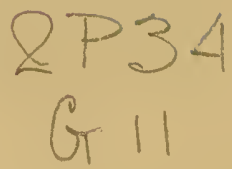

Alle Rechte vorbehalten.

1)ruck von $\Lambda$ p pelhans \& Pfenningstorfin Brauschweig. 


\section{Vorwort.}

Die Einfiihrung in die Physiologie des Menschen wird mit um so grösserem Nutzen an der Grundlegung für das Studium der Medicin betheiligt sein, je besser es bei ihr gelingt, den menschlichen Organismus nicht nur als ein Naturobject erkennen zu lassen, dessen äusserlich wahrnehmbares Verhalten unter rerschiedenen Bedingungen bestimmten Regeln folgt, sondern auch als ein solches, bei welchem die ursäcllichen Beziehungen zwischen dem Verhalten und den Bedingungen erkennbare - wenn auch bei weitem noch nicht durchweg erkannte sind. Das Interesse des Mediciners hat sich weniger darauf zu concentriren, was sich etwa aus den, am gesunden oder kranken Menschen wahrzunehmenden Erscheinungen in Bezug auf die äusseren Bedingungen schliessen lasse, unter denen sich der Mensch befindet oder befunden hat, als vielmehr durauf, welche inneren Vorgänge den gegenwärtigen äusseren Erscheinungen zu Grunde liegen, weil sich aus ihnen die Voraussicht auf das zukïnftige Verhalten ergeben kann, und die Beantwortung der Frage, ob überhaupt und mit welchen Mitteln ein Einwirken auf letzteres zu versuchen sei.

Nicht nur ganz allgemein, im Dienste des reinen Strebens nach theoretischer Erkenntniss, sondern anch in jedem einzelnen Falle des praktischen Bedürfnisses wird für das erforderliche Eindringen mit geistigem Ange unter die den änsseren Sinnen zugängliche Oberfläche eine Gedankenarbeit verlangt, welche sich nur auf Grund einer reichen und klaren Begriffsbildung ausfïhren lässt. Bei der Einführung in die Physiologie des Menschen muss deshalb auf diese Begriffsbildung das Hauptstreben gerichtet sein. Eine noch so grosse Sorgfalt in vollständiger Aufzählung aller als "Thatsachen" bezeichneten bisherigen Einzelangaben ist fruchtlos, so lange nicht die Begriffe ron den Eigenschaften und Vorgängen, auf welche sich die 



\section{Einleitung.}

Die Physiologie ist die physische Wissenschaft vom Leben. Sie behandelt mit naturwissenschaftlicher Methode diejenigen Erscheinungen, aus denen der Begriff des Lebens abstrahirt worden ist. Diese Erscheinungen sind einer bestimmten Gruppe von Naturkörpern eigenthümlich. welche man Organismen nénnt. Der Physiologie erstes Ziel ist, die Erscheinungen der organischen Natur oder des Lebens zu beobachechtèn und geordnet zu beschreiben. Dabei darf die Physiologie aber nicht stehén bleiben, sondern sie hat demnächst von den Vorgängen, deren sinnfälliger Ausdruck die beobachteten und beschriebenen Erscheinungen sind, eine naturwissenschaftlich begründete $\mathrm{mech}$ a $\mathrm{n}$ is $\mathrm{ch}$. Vorstellung auszuarbeitên. Die zweite Aufgabe ist gêlöst, wenn es gêfungen ist, diese Vorgänge als Glieder in der causalen Kêtte des, nach mechanischem Gesêtž sich vollztêtendén, grossen Naturprocesses zu denken ${ }^{2}$ Betrach-

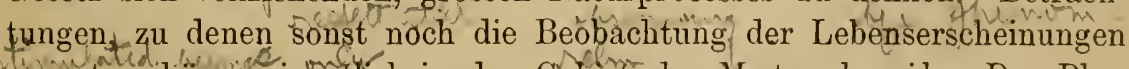
anregt, geliôn reir eigenthích in das Góbiêt der Metaphysik. Der Physiologe darf es aber nicht vermeiden, die Grenze/zwischen Pliysik und Metaphysik zu berüuren denn zu den Erscheinungen, welche das eigeré Ich bietét, dieser fïr jêden Einzelnen wichtigste organische Naturköper; gehören die Aenderungen des Bewusstseinszustandes, welche als nothwendige Glieder in der causalen Kette' des Naturprocesses nicht verstanden werden können. Das Gesetzmässige in der thatsächlichen Zusammengehörigkeit bestimmter Aenderungen des Bewusstseinszustandes mit bestimmten Aenderungen des Körperzustandes kann und muss der Physiologe nach naturwissenschaftlicher Methode selbst feststellen - die Speculationen iiber die Gründe dieser Zusammengehörigkeit wird er dem Metaphysiker iiberlassen.

Das auffallendste Gemeinsame, wodurch sich die Lebenserscheinungen von den meisten Vorgängen unterscheiden, die sich sonst in der Natur unserer Beobachtung darbieten, ist das Missverbältniss zwischen 
Einwirkung und Rückwirkung, beide nach dem in der Mechanik giltigen Maasse gemessen. Zu den gewöhnlichsten Erscheinungen auf unserem Erfahrungsgebiete gehört es, dass wir Naturkörper unter Ueberwindung äısserer widerstehender Kiräfte ihre Form und Lage im Raum ändern, ja beträchtliche Arbeit an anderen Körpern verrichten sehen, ohne dass es uns iiberhaupt gelingt, eine mechanische Veranlassung zur Kraftentfaltung wahrzunehmen. Solche Naturkörper erscheinen uns belebt und die (scheinbare) Spontaneïtät der Kraftentfaltung gilt als eine wesentliche Eigenthümlichkeit der Organismen.

Weniger in die Augen fallend, und doch weit mehr bezeichnend für das Wesen der Organismen ist die eigenthïmliche Art der Kraftaufspeicherung. Wenn in dem Missverhältniss zwischen den mechanischen Aequivalenten der auslösenden und der ausgelösten Vorgänge das alleinige Kriterium enthalten wäre, dann müsste man viele mechanische 7usammenstellungen belebt, manche chemische Substanzen lebende Substanzen nennen. Insofern ein Sprengstoff auf geringfügige Veranlassung hin explodirt, kann die chemische Constitution seiner Moleküle als Beispiel angesehen werden für die Art, in der wir uns die Atome innerhalb eines Molekïls lebender Substanz angeordnet denken könnten, wenn es sich allein um Erklärung der Spontaneïtät der Kraftentfaltung handelte. Aber die chemische Spannkraft des Sprengstoffes ist nach der Explosion erschöpft, während der durch Arbeitsleistung ermüdete Organismus sich bei Riuhe wieder erholt. Bezeichnend für die Organismen ist also, dass sie die bei der Kraftentfaltung verbrauchte Menge innerer Spannkraft scheinbar spontan wiederersetzen, dass sie unbelebten Stoff in sich aufnehınen, ihn der eigenen lebenden Körpersubstanz gleichmachen und sich dadurch zu immer neuer spontaner Kraftentfaltung, zum Wachsthum und zur Erzeugung neuer Naturkörper gleicher Art befähigen.

Die wesentlichsten Erscheinungen, derentwegen wir Naturkörper als Organismen bezeichnen, oder, was dasselbe sagen will, die wesentlichsten Lebenserscheinungen der Organismen sind also (scheinbar) spontane Kiraftentfaltung, Ermüdung und Erholung, Ernährung und Assimilation, Wachsthum und Zeugung. Zu diesen an allen Organismen ausser uns wie an uns selbst wahrnehmbaren Lebenserscheinungen tritt eine, nur der unmittelbaren Selbstbeobachtung zugängliche Crruppe ron Erscheinungen hinzu, welche den Bewusstseinsinhalt jedes Einzelnen ausmachen.

Ausser den Lebenserscheinungen an sich ist auch die zeitliche $\mathrm{Be}$ grenzung derselben bezeichnend für die Organismen. Sterben nennt man den Verlust der Fähigkeit, Lebenserscheinungen zu zeigen, und jeder Organismus stirbt nothwendig ab oder verfällt dem natürlichen 
Tode, nachdem er eineu seiner Art eigenthümlichen Cyclus ron Wandlungen durchgemacht hat, wenn er nicht schon vorher einer zufälligen Zerstörung anheimgefallen war.

Im Allgemeinen tritt uns jeder Organismus als ein gut umgrenzter Kö̈rper entgegen, dessen Theile ihre wesentlichen Eigenschaften nur in Verbindung mit dem Ganzen bewahren und dessen Ganzes als Organismus nur bei einem bestimnten Zusammenhang der 'Theile fortbesteht. Dies ist der Grund, weshall man den einzelnen Organismus ein Individuum nennt und es ist auch die empirische Grundlage des metaphysisch gefassten Ausspruches von $K$ ant: „Im Organismus sind die Theile un des Ganzen und ist das Ganze um der Theile willen da".

Die einfachste individuelle Form, in welcher Organismen vorkommen, ist die Zelle. Wesentliche Bestandtheile einer Zelle sind der Zellleib und der Zellkern. Viele, aber nicht alle Zellen besitzen eine verdichtete Wandschicht des Zellleibes, welche Zellmembran genannt wird. In dem Zellkern unterscheidet man oft einen oder mehrere kleine Körperchen, die Kernkörperchen. Die Substanz von Leib und Kern der Zelle ist gemischt aus der eigentlichen lebenden Substanz, Protoplasma genannt, und aus der Zellflüssigkeit, welche aus Wasser mit darin gelösten und suspendirten nicht lebenden Substanzen besteht.

Ein Theil des Protoplasmas bildet im Zellleibe sowohl wie im Zellkern ein schwammartiges Gerüst, das Spongioplasma, in dessen Maschen sich ein leichter nach allen Richtungen des Raumes verschiebliches Protoplasma, das Hyaloplasma, und die Zellflüssigkeit befinden. Manche lebende Zellen zeigen tropfenförmige Ansammlungen von Zellflüssigkeit, welche man Vacuolen nennt.

Nicht nur rom morphologischen sondern auch rom chemischen Standpunkt aus hat man verschiedene protoplasmatische Substanzen zu unterscheiden. Hierauf weist die Thatsache hin, dass die chemischen Substanzen, welche bei Zersetzung des Zellkerns entstehen, andere sind als die, welche bei Zersetzung des Zellleibes entstehen, und die Thatsache, dass durch künstliche Theilung entstandene Zellstücke einzelliger Organismen, welche keinen Zellkern enthalten, zwar weiter vegetiren, nicht aber sich vermehren können. Sehr beachtenswerth sind ferner die nenerdings genauer studirten feineren Structurverhältnisse am Spongioplasma des Zellkernes (Karyomitom). Die Glieder dieses Fadenwerkes zeigen eine Zusammensetzung aus kleinen, reihenartig angeordneten Körperchen (Mikrosomen), deren Substanz wegen ihrer hervorragenden Färbbarkeit Chromatin genannt wird. Das Cytomitom (Spongioplasma des Zellleibes) ist chromatinfrei, besteht aus feineren Fäden und steht zu einer bestimmten Stelle des Cytohyaloplasmas in besonderer Beziehuug. Diese Stelle, an welcher bei einigen Zellen auch schon eine 
besondere Sulstanz in Form eines kleinen Körnchens erkannt worden ist, das Centrosoma, änssert seinen Einfluss auf die Configuration des Cytomitoms und wahrscheinlich durch dessen Vermittelung auch auf das Karyounitom bei wesentlichen Lebensvorgängen der Zelle. Die Conplication der Structur der Zellen wächst in dem Maasse, als sie durch besondere Differenzirungen zur Uebernahme besonderer Functionen befähigt werden.

Allen Protoplasmaformen, das heisst allen zur Hervorbringung der fundamentalen Lebenserscheinungen befähigten Substanzen, müssen gewisse Eigenthiinlichkeiten der molecularen Structur gemeinsam sein. Die Anordnung der Atomgruppen im Molekül muss eine derartige sein, dass ungesättigte elektropositive und elektronegative Atome bis fast an die Grenze ihrer Wirkungssphäre einander genähert stehen. Das Gleichgewicht der Kräfte innerhalb eines Moleküls von derartiger Structur wäre ein labiles. Die Labilität eines Kräftesystems kann darauf beruhen, dass die Inteusität der einen Kraftgruppe bei einer Aenderung der iuneren räumlichen Anordnung der Kraftcentren fast unverändert bleibt oder stark abnimmt, während die Intensität der anderen Gruppe stark zuuimmt. Erstere Gruppe kann man die Henımungs-, letztere die Wirkungsgruppe des lahilen Kräftesystems nennen.

Zur Erläuterung diene folgendes anschauliche Beispiel: Man hänge zwei mit Elektricität entgegengesetzten Vorzeichens geladene Pendel in solcher Entfernung voneinander auf, dass der Anziehungskraft, welche beide Pendel aufeinander ausüben, durch die Schwerkraft gerade das Gleichgewicht gehalten wird. Ein kleiner Anstoss wird genügen, um die Pendel gegeneinander ausschlageu und dabei Arbeit leisten zu lassen. Die bei der Arbeitsleistung wirkende Kraft ist die elektrische Anziehuugskraft, die hemmenden Kräfte sind die Schwerkraft und die Reibung in den Pendelaxen. An Stelle der beiden Pendel kann man sich nun zwei benachbarte Atomcomplexe im Molekül denken.

Die an die lahile Structur des Moleküls geknüpfte Fähigkeit des Protoplasmas, kleine Einwirkungen mit unverhältnissmässig grosser Arheitsleistung zu beantworten, nennt man seine Erregbarkeit. Die Erregung erfolgt, wenn die beständig vorhandene intramoleculare Schwingungsbewegung der Atome derart gesteigert wird, dass positive und negative Atome die Grenzen ihrer beiderseitigen Wirkungssphären überschreiten.

I) mit der Erregung verbundene Arbeitsleistung wird bestritten durch chemische Spannkraft, welche im Molekïl angehäuft ist und zwar in Form ungesättigter Valenzen von Kohlenstoff und Wasserstoff einerseits, von Sauerstoff andererscits. Die Atomcomplexe, welche hierbei in Wechselwirkung treten, stellt man sich vor als an Seitenketten des 
Moleküls gebunden, dessen Kern bei dem Erregungsvorgang nicht angegriffen wird, so dass er die verbranchten Atomcomplexe durch Stoffalufnahme aus der Umgel)ung wieder ergänzen kann. In dieser Assimilation würde die Erholung nach Ermüilung durch Arbeitsleistung bei lirregung bestehen.

Die Assimilation dient aber nicht nur der Erholung. Die Wirkung chemischer Processe, welche sich in den protoplasmatischen Substanzen abspielen, tritt zwar bei der Arbeitsleistung oder Function dentlicher hervor, doch finden auch während der scheinbaren Ruhe und ohne dass sichtbare Arbeitsleistung vorhergegangen ist, fortwährend chemische Umsetzungen in den lebenden Substanzen statt. Die Assimilation führ't dann nicht nur zur Ergänzung ron Atomcomplexen in Wirkungsmolekülen, sondern auch zu einer Vermehrung der letzteren und zu einer Aufspeicherung ron Stoffen zu späteren Ergänzungen. Hierin besteht die Ernähırung der Zellen und der protoplasmatischen Substanzen, die Nutrition, welche zunächst zum Wachsthum rorhandener Elemente und dann zur Erzeugung neuer Elemente (Formation) führt.

Alle neuen Zellen gehen aus der Theilung älterer Zellen hervor. Es scheint verschiedene Arten der Zelltheilung zu geben, deren vollkommenste diejenige ist, welche durch regelmässige Stellungnahme des Karyomitoms und des Cytomitoms zu einander und zu dem Centrosoma eingeleitet wird und bei welcher sich die Theilung sichtlich bis auf alle einzelne Mikrosomen des Karyomitoms, wahrscheinlich iiberhaupt auf alle geformte und ungeformte Zellbestandtheile erstreckt. Dieser „mitotischen" Zelltheilung steht die "amitotische" gegenüber, bei welcher die Theilung mehr im Groben zunächst den Kern und dann die Zelle betrifft und deren Producte wohl selbst lebensfähig, aber nur in beschränktem Maasse, wenn ïberhaupt generationsfähig sind. Eine Ueberlegenheit der mitotischen ïber die amitotische Zelltheilung würde darauf hinweisen, dass der Satz: „nulla cellula nisi ex cellula“ auch auf einzelne Bestandtheile der Zelle auszudehnen wäre. Die wesentlichen protoplasmatischen Substanzen können wahrscheinlich nicht mehr aus unorganisirter Materie gebildet werden ohne Vermittelung derselhen Protoplasmaart, welche gebildet werden soll. Vielleicht entsteht kein Molekïl lebender Sulstanz ausser durch Theilung eines gleichartigen Molekïls. Dies würde einen symmetrischen Bau der Molekiile und die Ergïnzungsfähigkeit der Theilhälften aus unorganisirter Materie voraussetzen.

Die mitotische Form der Zelltheilung ist die bei Weitem am häufigsten vorkommende und die für dieselbe characteristischen Figuren des chromatischen Karyomitoms geben einen Anhalt zur Beurtheilung der Lebhaftigkeit, mit welcher die Zellbildung an bestimmten Stellen des Organismus ror sich geht. Ist an solchen Stellen eine fernere Zu- 
nahme der Zahl von Elementen ausgeschlossen, so bietet die Häufigkeit, in welcher Kerntheilungsfiguren gefunden werden können, auch ein Maass für die Lebensdauer der einzelnen Elemente.

Es giebt einzellige Organismen und bei diesen fällt der Begriff des Individuums mit dem der Zelle zusammen. In den mehrzelligen Organismen führt die einzelne Zelle zwar ebenfalls das individuell einheitliche Leben eines Elementarorganismus, doch ist sie mit demselben an die Wechselbeziehungen $\mathrm{zu}$ ihren Genossen gebunden, von denen getrennt sie ein selbständiges Leben nicht fortzuführen vermag; sie ist ein individueller, d. h. künstliche Theilung nicht ïberlebender Elementarorganismus, aber kein selbständiger Elementarorganismus. Sämmtliche Zellen eines untheilbaren und selbständigen vielzelligen Organismus stammen von einer befruchteten Eizelle ab; diese wird im weiblichen Organismus gebildet und nimmt bei der Befruchtung wesentliche Bestandtheile einer von dem männlichen Organismus derselben Art herrührenden Samenzelle in sich auf. Die Proliferation der befruchteten Eizelle geschieht durch noch verwickeltere und vollkommenere Theilungsvorgänge als die ungeschlechtliche mitotische Zelltheilung, welche sich an erstere anschliesst und zum Aufbau der Gewebe und Organe des neuen Organismus führt. Die verschiedenen Gewebe des Körpers verdanken ihre Entwickelung einer weitgehenden Differenzirung ihrer zelligen Elemente im Dienste der Arbeitstheilung. Die Zellnatur bleibt hierbei theilweise deutlich gewahrt, wie bei den Drüsenzellen und Nervenzellen, zum Theil wird sie verdeckt, wie bei den Nervenfasern und Muskelfasern. Auch innerhalb derselben Kategorie giebt es hierbei Verschiedenheiten, welche dann in Verschiedenheiten der Function ihren Ausdruck finden, so stehen zum Beispiel die Muskelfasern des Herzens der Zellnatur noch weit näher als diejenigen der Körpermuskeln.

Jedes Gewebe buisst in dem Maasse seiner, für die Uebernahme besonderer Functionen vorschreitenden Differenzirung an Selbständigkeit ein und beansprucht um so mehr die Durchdringung mit anderen Geweben. So entstehen die Organe, deren jedes einzelne zwar ein bestimmtes Gewebe, dem es seine specifische Function verdankt, in vorwiegendem Maasse enthält, das aber seinen eigenartigen Aufbau aus verschiedenartigen, sich durchdringenden Geweben dem Bedürfniss des specifischen Gewebes verdankt, mit den übrigen Geweben in Wechselwirkung zu treten.

Die physiologischen Betrachtungen knüpfen im Einzelnen zum Theil besser an Gewebe, zum Theil besser an Organe an. Die auffälligsten Erscheinungen am menschlichen Organismus sind diejenigen seiner Beziehungen zur Aussenwelt und unter diesen treten die Muskelleistungen besonders hervor. Wir beginnen deshalb mit der Physiologie des Muskel- 
gewebes, an welche sich naturgemäss die Betrachtungen der von den Muskeln direct bewegten Theile als Mechanik des Körperskelettes oder als Physiologie der Körperbewegungen anschliessen. Danu folgt die Physiologie des Nervengewebes, welches die Vernittelung der Einwirkung von Aussen mit der Rïckwirkung nach Aussen übernimmt und welches die Harmonie der functionirenden Elemente im Innern unterhält. Daran schliesst sich die Physiologie der Simne, welche die äusseren Eindriicke aufnehmen und diejenige der Stimme und Sprache, welche viel inneren Zusammenhang mit der physiologischen Akustik besitzt.

Die den Verkehr mit der Aussenwelt unterhaltenden Gewebe und Organe verrichten Arbeit; die zur Bestreitung der Lebensarbeit der functionirenden Elemente erforderlichen Einrichtungen und Processe werden als die vegetativen bezeichnet. In ihrer Mitte steht der durch Blut und Lymplse unterhaltene Stoffverkehr zwischen Geweben, Organen und Körperoberflächen. Diesem Stoffverkehr dienen die Eigenschaften von Blut und Lymphe, sowie ihre im Körper umlaufende Bewegung, die Circulation. In den arbeitsleistenden Organen werden gewisse Substanzen aus den kreisenden Säften aufgenommen und Schlackeı an dieselben abgegeben. Die Wiederbefähigung zur Unterhaltung der Arbeitsleistungen erhält das Blut in den Lungen durch die Respiration, in den Drïsen durch Ummischung (Metakrasie) und an der Darmfläche durch Resorption. Vorbedingung fiur diese Resorption ist die Aufnalıme und Verdauung der Nahrung. Die gesammten vegetativen Processe verlaufen in zweckmässiger Weise, wenn eine bestimmte Bilanz besteht zwischen Einnahme (resp. Bildung) und Ausgabe von Stoff, Wärme und Arbeit.

Nach diesem kurz skizzirten Plane wird im Folgenden das Wesentliche von der Physiologie des Mensehen besprochen werden. 


\section{Erster Abschnitt.}

\section{Das Muskelgewebe.}

Dem Muskelgewebe verdankt der Organismus die Fähigkeit, mechanische Arbeit zu leisten, sowohl nach aussen durch Körperbewegungen im Wettstreit gegen die Schwere und andere widerstehende Kräfte, als auch im Innern für den Haushalt des Organismus selbst. Ersterem Zweck dient ausschliesslich diejenige Art des Muskelgewebes, welche man wegen ihrer mikroskopischen Erscheinung die quergestreifte nennt, letzterem hauptsächlich die sogenannte glatte Musculatur.

Die quergestreifte Musculatur bildet das, was wir als rothes Fleisch im Schlächterladen sehen: es ist die Hauptmasse des Körpers. Bei der kunstgerechten Zergliederung des Körpers treten uns die Muskeln als anatomisch einheitliche Gebilde entgegen. Diese bestehen in ihrem fleischigen Theil, dem Muskelbauch, wesentlich aus quergestreifter Muskelsubstanz, deren histologisches Element ein Schlauch von mehreren bis zu 12 Centimetern Länge und mehreren bis zu $60 \mu$ Durchmesser ist. Unzählige solcher Schläuche sind im Muskel parallel angeordnet. Im Allgemeinen gehen sie nicht von einem Ende des Muskels zum andern, sondern sie fügen sich mit zugeschärften Enden aneinander an. Zusammengehalten werden sie durch Bindegewebe, in welchem sich auch die Nerven und Gefässe verbreiten. An den Enden des Muskels vereinigt sich das Bindegewebe zu festen fasrigen Strängen, den Endsehnen, deren jede mit einem Knochen fest verwachsen ist und durch deren Vermittelung die Muskelsubstanz die miteinander eingelenkten Knochen gegen einander zu bewegen vermag.

Die grob wahrnehmbaren Eigenschaften der Muskelsubstanz lassen sich am besten an möglichst einfachen anatomisch einheitlichen Muskeln beobachten, wie zum Beispiel an den Musculus sartorius vom Frosch. Dieser Muskel stellt einen kleinen Strang von grosser Biegsamkeit dar, 
welcher dem Eindruck des Fingers wenig Widerstand leistet, also auch als wैeich zu bezeichnen ist. Dem Versuch, den Strang in die Länge zu dehnen, setzt er einen anfänglich geringen Widerstand entgegen, und er kehrt nach Wegfallen der dehnenden Kräfte ziemlich genau zu seiner anfänglichen Länge zurück. Physikalisch ausgedrückt heisst dies, der Muskel besitzt eine kleine aber vollkommene Elasticität.

Die Grösse der Elasticität wird gemessen durch den sogenannten Elasticitätscoëfficienten, das heisst durch das Gewicht, welches erforderlich ist, damit der betreffende Körper um einen bestimmten Bruchtheil seiner ursprïnglichen Länge gedehnt werde. Ein Muskelbiindel des Frosches von ein Quadratmillimeter Querschnitt wird um ein Hundertstel seiner Länge durch die Kraft von nicht ganz $3 \mathrm{Gr}$. ausgedehnt, während $170000 \mathrm{Gr}$. erforderlich sind, um einen Stahldraht von gleichem Querschnitt um denselben Bruchtheil seiner Länge zu dehnen. Man kann also auch sagen, der Muskel ist in hohem Grade dehnbar. Das erste an den Muskel gehängte geringe Gewicht dehnt den Muskel am meisten und die Lüngenzunahme bei jedem folgenden zugefügten Gewicht gleicher Grösse wird kleiner und kleiner. Dies kommt am deutlichsten zur Anschauung in dem was man die Dehnungsurve des Muskels nennt. Dieselbe ist in Fig. 1 durch den Curvenzug AB zur Darstellung gebracht. Die Länge des Muskels bei der Belastung 0 ist zu 40 Millimeter angenommen; die mit zunehmender Belastung zunehmenden Längen des Muskels sind durch die gestrichelten Profillinien des (seitlich verschoben gedachten) Muskels angedeutet. Bei $\mathrm{Zu}$ nahme der Belastung von 0 zu $5 \mathrm{Gr}$. hat die Länge um 5 Millim. zugenommen; bei der Zunahme der Belastung von $5 \mathrm{zu}$ $10 \mathrm{Gr}$. hat die Länge nur etwa um 4 Millim. zugenommen und so fort, bis schliesslich bei Zunahme der Belastumg von 25 zu 30 Gr. die Zunahme der Länge nur etwa 1 Millim. beträgt. Die Deh-

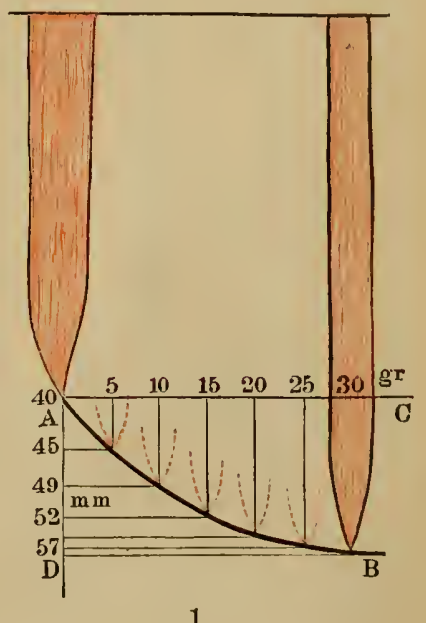

1.

Dehnungscurve des Muskels. nungscurve bringt also zur Anschauung, wie der Dehnungszuwachs des Muskels mit Zuuahme der Belastung abnimmt. Die Abscisse AC der Dehnungscurve AB wächst proportional der Belastung, die Ordinate AD proportional iler Länge. Die Dehmungscmrve von Köörpern mit den elastischen Eigenschaften des Muskels ist gegen die Abscisse concar.

Die beschriebenen Eigenschaften kommen dem Muskel in seinem 
gewöhnlichen Zustand, welchen man den der Ruhe nennt, zu. In der That fiilılen wir Muskeln unseres eigenen Körpers, wie zum Beispiel den Bauch des Musculus biceps Brachii, bei Ruhe des Armes mit dem tastenden Finger als weich und biegsam. Heben wir dagegen eine Last, so wird der Muskelbauch hart, er schwillt an und verkïrzt sich. Beim Uebergang aus der Ruhe in die Erregung wird der Muskel kürzer und dicker, während sein Volum sich so gut wie garnicht ändert. Wird der ausgestreckte Arn von iibermächtigem Widerstande an der Beugung verhindert, während wir ihn zu beugen streben, so bemerken wir kaum eine Formänderung an ihm, dafür erhalten wir unmittelbar das Gefühl der Spannung.

Um die mechanischen Unterschiede zwischen Ruhe und Erregung genauer $\mathrm{zu}$ erfahren, müssen wir uns wieder an möglichst einfache Muskelpräparate vom Frosch wenden. Durch Präparation können wir Nerv von Muskel nicht trennen, wohl aber ist dies möglich durch Anwendung eines Giftes, welches die Muskelsubstanz nicht angreift und welches die Nervenfasern an ihrer Verbindung mit den Muskelfasern tödtet, es ist dies das Curare, das amerikanische Pfeilgift. Haben wir einen Frosch mit Hülfe dieses Giftes gelähmt, so können wir die Erscheinungen, welche uns seine Muskeln darbieten, als Ausdruck der Eigenschaften betrachten, welche der Muskelsubstanz selbst zukommen.

Den curarisirten Muskel können wir auf mannigfache Art aus dem Zustande der Ruhe in denjenigen der Erregung überführen. Diese Ueberführung durch eine direkte Einwirkung auf die Muskelsubstanz nennen wir Reizung. Im Allgemeinen ist Muskelreiz jeder Eingriff, welcher die Muskelfasern an einer beschränkten Stelle ihres Verlaufs schädigt: Druck, Schlag, Aetzung, Brennen. Diese Mittel sind begreiflicher Weise für die nähere Untersuchung des Erregungszustandes wenig geeignet. Ein kurz dauernder elektrischer Strom, zum Beispiel ein Inductionsschlag, welcher den Muskel trifft, versetzt ihn in eine schnell vorübergehende Erregung, ohne ihn zu schädigen und es ist möglich und wichtig, die mechanischen Zustandsänderungen, welche der Muskel hierbei erfährt, zeitlich zu verfolgen. Bei dem wirklichen Gebrauch des Muskels handelt es sich in jeden einzelnen Falle um eine Combination von Längenänderung und Spannungsänderung. Je grösser die widerstehenden Kräfte, um so kleiner ist die Längenänderung, während die Spannung erhebliche Werthe erreichen kann und umgekehrt. Im Experiment kann man diese beiden Functionen trennen, und es ist zunäclıst zweckmässig, es zu thun.

Die Hülfsmittel, um den zeitlichen Verlauf der Längenänderungen des Muskels unter möglichstem Ausschluss von Spannungsänderungen 
zur Anschaunng zu bringen, sind rerhältnissmässig einfuch: Fig. 2 giebt in schematischer Form eine Vorstellung davon. Der an einem festen Stativ aufgehängte Muskel greift an einem einarmigen Hebel an, welcher sehr nahe an seinem Drehpunkt ein Gewicht trägt; dieses Gewicht darf gross sein, ohne dass durch die Trägheit der Masse die Versuchsbedingungen complicirt wïrden wegen der Kkleinheit der Verriickungen, welche die Masse hier erleidet. Ueber den Angriffspunkt des Muskels

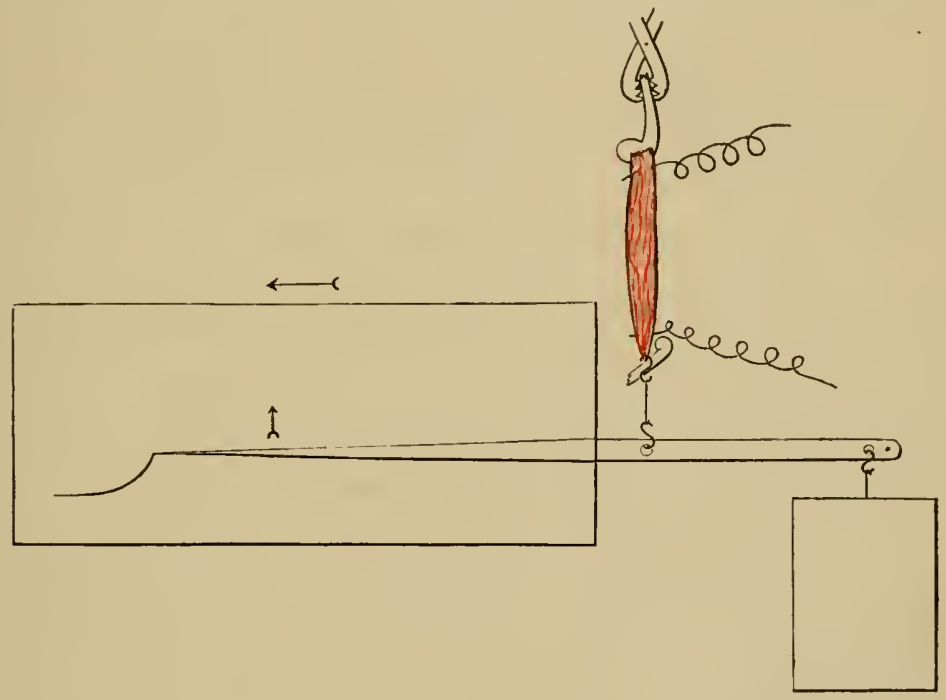

2.

Isotonische Myographie.

hinaus ist der Hehel beträchtlich verlängert, sodass die an seinem Ende angebrachte Schreibspitze die Längenänderung des Muskels in vergrössertem Massstab auf eine schnell vorbeibewegte berusste Fläche aufschreiben kann. Die Verbindung eines solchen Zeichenhebels mit einer bewegbaren Zeichenfläche nennt man ein Myographion.

In einer myographischen Curve, ron welcher Fig. 3 ein Beispiel giebt, ist also die Abscissenlänge proportional der abgelaufenen Zeit; gemessen wird dieselbe, indem man unter der myographischen Curve eine Stimmgabel von bekannter Schwingungszahl ihre Schwingungen aufschreiben lässt. An der myographischen Curve, welche der Zuckung des Muskels in Folge eines einmaligen Reizanstosses entspricht, nennt man den aufsteigenden Ast das Stadium der wachsenden Energie, den absteigenden Ast das Stadium der sinkenden Energie; bei mittlerer Temperatur und frischem Muskel ist die Curve im Ganzen symmetrisch zum Curvengipfel. Nur Anfang und Ende unterscheiden sich meistens: 
im Anfang geschieht die Erhebung über die Nulllinie mit einem kurzen gegen die Abscisse convexen Bogen, welcher bald in einen fast geradlinigen Anstieg übergeht; in Stadium sinkender Energie findet die Annäherung an die Nullinie zuletzt asymptotisch statt. Die ganze

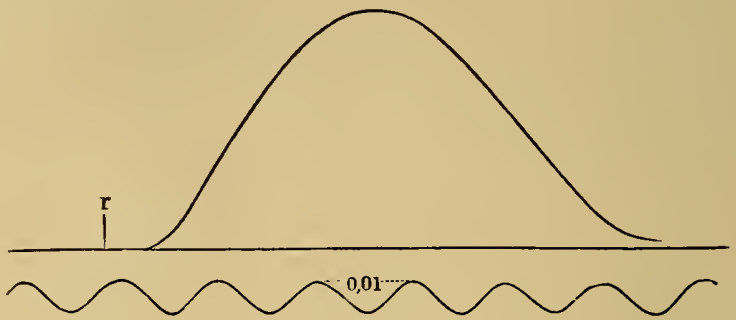

3.

Isotonisches Myogramm bei $19^{\circ} \mathrm{C}$

Zuckungsdauer beträgt unter den angegebenen Bedingungen etwa 0,1 Secunde.

Zuckungsdauer, Curvenhöhe und Curvenform sind in hohem Grade veränderlich mit der Temperatur und dem Grade der Ermüdung. Die Zuckungsdauer nimmt im Allgemeinen mit sinkender Temperatur $\mathrm{zu}$, mit steigender ab; die Curvenhöhe, welche die Hubhöhe des Muskels misst, ist am bedeutendsten bei etwa $30^{\prime \prime}$, nimmt bis $19^{\circ} \mathrm{ab}$, um bei weiter sinkender Temperatur bis gegen $0^{\circ}$ wieder zuzunehmen, ohne die frühere Höhe zu erreichen. Bei der Ermüdung nimmt die Hubhöhe ab, die Zuckungsdauer nimmt zu, und zwar durch Verlängerung des

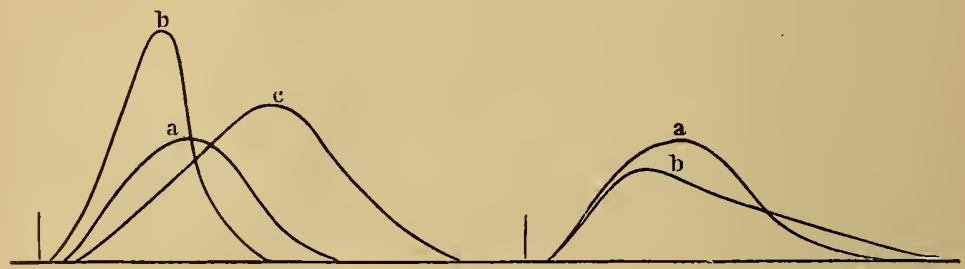

4.

Maximale Zuckung desselben Muskels. a bei $19^{\circ}$, b bei $30^{\circ}$, c bei $5^{\circ}$.
Maximale Zuckung desselben Muskels, a frisch, b mässig ermüdet.

Stadiums der sinkenden Energie, während die Verlängerung der Zuckungsdauer bei Abkühlung wesentlich auf Rechnung des Stadiums der wachsenden Energie kommt.

Die Hubhöhe kann auch erheblich variirt werden durch verschiedene Wahl in der Stärke der zur Reizung benutzten Inductionsschläge: lässt man diese Stärke von sehr kleinen Werthen an allmählich wachsen, so kann man den Punkt fixiren, bei welchem der Muskel eben anfängt, 
in sichtlicher Weise auf den Reiz zu reagiren; diesen Punkt nennt man die Reizschwelle. Die der Reizschwelle entsprechende Reizstärke nennt man den minimalen Reiz; die geringeren, die unterminimalen. Oberhalb der Reizschwelle liegt ein Intervall von Reizstärken, innerhalb dessen mit zumelmmender Reizstärke die Hubhöhe zunimmt, bis von einer gewissen höheren Reizstärke an eine fernere /unahme der Hubhöhe nicht mehr eintritt: diese Reizstärke nennt man die maximale; und Reize von grösserer Stärke (aber nicht grösserer Wirkung) nennt man übermaximale. Steigert man die Hubhöhe durch Steigerung der Reizstärke, so bleibt ceteris paribus die Zuckungsdauer im ganzen Intervall von der Reizschwelle bis zum maximalen Reiz und darüber hinaus gleich.

Das Latenzstadium. Die Mus-

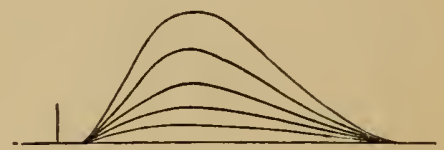

5.

Einfluss der Reizstärke. kelverkürzung beginnt nicht in dem Moment der Reizung, welcher bei Anwendung des elektrischen Reizes sehr genau bestimmt werden kann; der Punkt $r$ auf der Abscisse der /uckungscurve in Fig. 3 stellt den empirisch ermittelten Moment der Reizung dar: die der Abscissenlänge zwischen dem Reizmoment und dem Abhebungspunkt der Zuckungscurve entsprechende Zeit nennt man das Latenzstadium. Die Daner dieses Latenzstadiums ist in erheblicher Weise abhängig von den speciellen Versuchsbedingungen, weil die ersten mechanischen Zustandsänderungen, welche innerhalb des Muskels eintreten, nur unter ganz besonderen Versuchsbedingungen, namentlich bei Ausschluss träger Massen, auch sofort nach aussen zur Anschaumng gebracht werden können. Es scheint aber, dass in der That die ersten Aenderungen, welche in der Muskelsubstanz mit der Erregung eintreten, nicht mechanischer Natur sind und dass die Zeit zwischen den Reizmoment und der ersten mechanischen Zustandsänderung im Muskel mit sinkender Temperatur zu-, mit steigender Temperatur abnimmt. Unter gewöhnlichen Versuchsbedingungen zeigt das Latenzstadium eine Dauer von etwas weniger als $1 / 100 \mathrm{Sec}$.

Die bei möglichster Vermeidung von Spannungsänderungen gewonnene Znckungscurve nennt man die isotonische und im Gegensatz dazu die Curve, bei welcher die Spannungsänderungen unter Vermeidung von Längenänderungen möglichst rein zum Ausdruck kommen, die isometrische. Isometrische Myogramme gewinnt man auf folgende Weise: der Muskel greift, wie in Fig. 6 schematisch dargestellt ist, an einem sehr kurzen Arm eines zweiarmigen Hebels an, dessen längerer anderer Arm durch eine Feder in seiner Bewegung beschränkt ist; dieser Arm ist über den Angriffspunkt der Feder hinaus beträchtlich ver- 
längert und an seinem Ende mit einer Zeichenspitze versehen. Der Ordinaten-Werth des isometrischen Myogramms wird in Gewichten empirisch bestimmt und ist von der Stärke der angewendeten Feder ab-

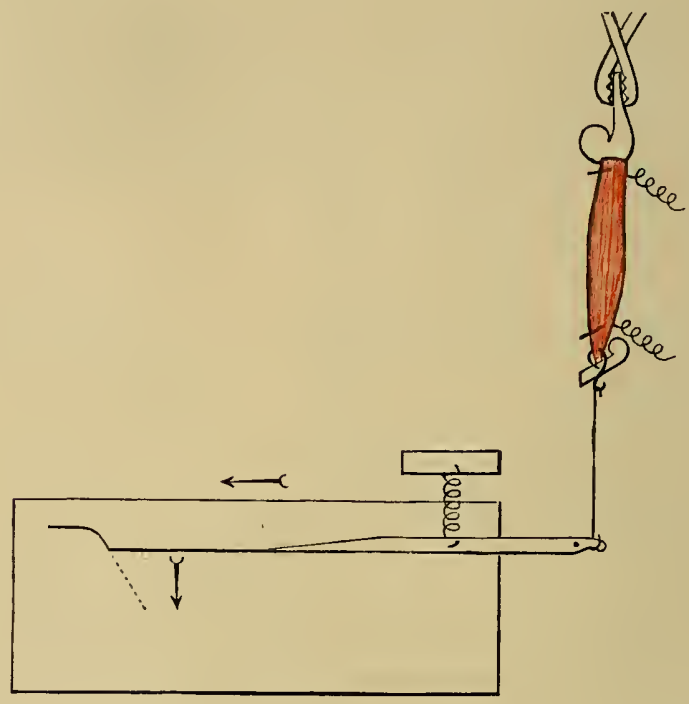

6.

Isometrische Myographie.

hängig. Bei mittlerer Temperatur weicht der zeitliche Verlauf der Spannungsentwickelung im Muskel bei verhinderter Längenänderung nicht sehr beträchtlich von demjenigen bei isotonischer Anordnung ab; dagegen ist dies bei etwas niedrigerer Temperatur der Fall und in Fig. 7
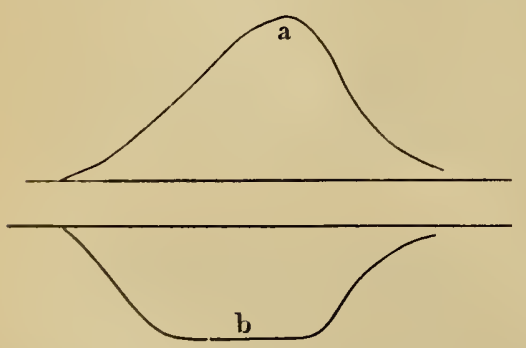

7.

a isotonisches, b isometrisches Myogramm von demselben Muskel bei 5". sind zwei zusammengehörige Myogramme von demselben Muskel dargestellt. Das obere ist das isotonische, das untere das isometrische; man sieht, dass der Muskel schneller das Maximum seiner Spannung als das Maximum seiner Verkürzung erreicht und dass das Maximum der Spannung eine Zeit lang unverändert festgehalten wird.

Die Bedingungen für Isotonie oder Isometrie des Muskels sind ausser in dem Experiment sehr selten realisirt. Bei den Verwendungen, welche der Muskel im Organismus findet, kommt es in den meisten der einzelnen Fülle darauf an, dass er eine gewisse Längenünderung gegen 
einen gewissen Widerstand erfährt; nur so kimn er mechanische Arbeit im physikalischen Sinne des Wortes leisten, dem diese wird gemessen durch dis Produkt der Kraft in den Weg, um welchen der Angriffspunkt der Kiraft rerrïckt wird. Aber für die Erforschung der immeren Vorgänge im Muskel ist die Gegenüberstellung der bei Isometrie und Isotonie zu beobachtenden Erscheinungen sehr nützlich, weil bei der Isometrie, mit dem Ausschluss der Formänderungen, die die Erscheinungen complicirenden Kräfte innerer Reibung und innerer Elasticität eliminirt werden. Die Spannungsänderungen, welche der Muskel bei Isometrie durchlïuft, enthalten den einfacheren Ausdruck für die Aenderungen der molecularen Längsattractionen, welche die unmittelbare Folge rles Erregungsprocesses im Muskel sein müssen.

Auch in einer anderen Beziehung weichen die bisher beschriehenen Versuche ron der Art ah, wie der Vuskel in Organismus thätig ist. Keine einzige Bewegung, welche wir ausfïhren, verdankt einer einfachen Muskelzuckung ihre Entstehung, es handelt sich stets um eine Reihe schnell aufeinander folgender Erregungsantriebe, deren Folge ein kiirzer oder lïnger daueruder, scheinbar gleichmässiger Erregungszustand des Muskels ist: diesen Zustand des Muskels nennt man seinen Tetanus.

Man kann den curarisirten Muskel in künstlichen Tetanus versetzen, wenn man in gewissen zeitlichen Intervallen einzelne Inductionsschläge auf ilın wirken lässt; trifft ein zweiter Reiz den Muskel, ehe die durch den ersten veranlasste Zuckung abgelaufen ist, so erhält man dias, was man eine summirte Zuckung nennt: der ersteu Zuckung superponirt sich die zweite, so dass der Currengipfel höher zu liegen kommt. Eine fernere Steigerung der Hubhöhe findet auch noch bei dem dritten, vierten, auch wohl fünften Reiz statt, bis eine Hubhöhe erreicht ist. über welche hinaus bei gleich bleibender Reizstärke eine weitere Steigerung nicht eintritt. Nimmt das Reizintervall einen erheblichen Bruchtheil der ganzen Dauer einer einzelnen Zuckung ein, so bemerkt man auf der Höhe des Tetanus ein wellenartiges Zu- und Abnehmen der Hublı̈he. Lässt man die Reize schneller und schneller aufeinander folgen, so erreicht man eine Reizfrequenz, bei welcher die Wellen rerschwinden und bei welcher der Muskel auf der Höhe des Tetanus in einem rollkommen gleichmässigen Zustand zu rerharren scheint.

Die für die Erreichung dieses Zustandes erforderliche Reizfrequenz ist bei rerschiedenen Muskeln auch desselben Thieres rerschieden und ausserdem abhängig ron der Reizstärke, der Temperatur und der Ermiidung. Je gestreckter der Verlauf der einzelnen Zuckungscurve ist, bei um so geringerer Reizfrequenz wird der vollkommene Tetanus erreicht: ausserdem hängt die hierzu erforderliche Häufigkeit der Erregungsimpulse ron der Natur dieser Impulse ab; beim gewöhnlichen 
Gebrauch unserer eigenen Körpermuskeln wird der vollkommene Tetanus derselben durch 8-16 Impulse in der Secunde erreicht.

Die Steigerung der tetanischen Hubhöhe durch Summation der Reize iiber die bei der einzelnen Zuckung erreichte Hubhöhe hinaus tritt āuch noch hervor, wemn durch Verstärkung des einzelnen Reizes eine Steigerung der einzelnen Hubhöhe nicht mehr zu erreichen ist, also auch bei maximalen und iibermaximalen Reizen. Reize, welche einzeln auf den Muskel angewendet, wegen zu geringer Stärke scheinbar unwirksam sind, sollen in tetanisirender Reizfolge sich wirksam er-
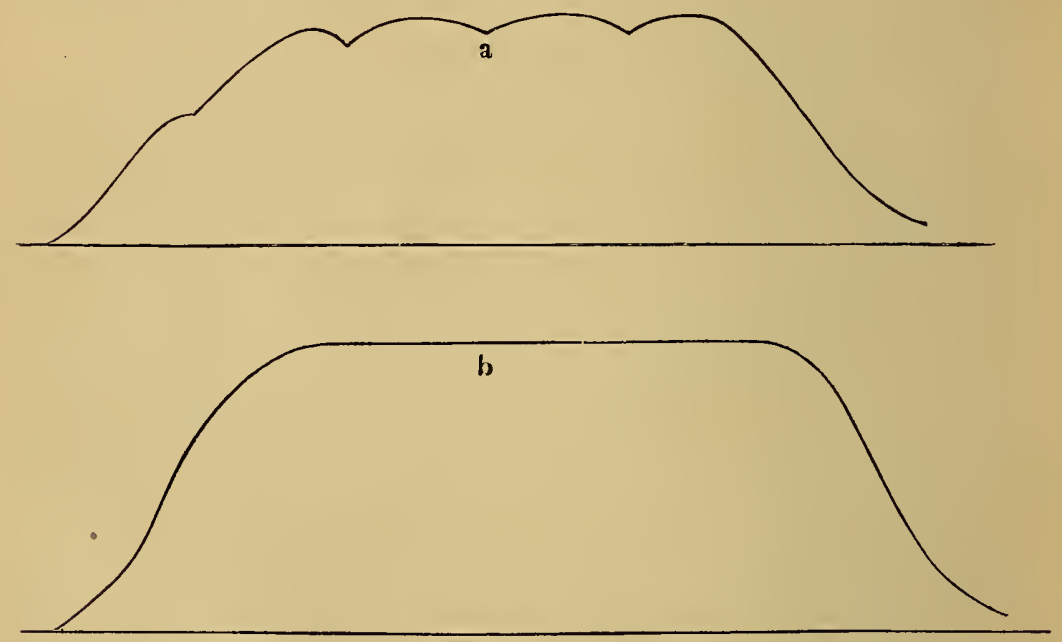

8.

Tetanus desselben Muskels, a unvollkommener bei 20 maximalen Einzelreizen in der Secunde; b vollkommener bei 40 maximalen Einzelreizen in der Secunde.

weisen. Man nennt dies die Summirung unterminimaler Reize; man könnte auch sagen, die Reizschwelle für den Tetanus liegt tiefer als für die einzelne Zuckung.

Es ist oben angeführt worden, dass Hubhöhe oder Spannungsentwickelung, welche die einzelne Erregung des Froschmuskels begleiten, bei einer Temperatur von $19^{\circ}$ kleiner sind als bei höheren und niedrigeren Temperaturen, es gilt dies für maximale und übermaximale Einzel-Reize. Der maximale Tetanus dagegen erhebt sich bei 19 " über denjenigen bei niedrigeren Temperaturen; der Vortheil, welchen niedrigere Temperaturen für die einzelne Erregung bieten, wird also bei mittleren Temperaturen durch eine bessere Fähigkeit des Muskels, die Wirkung einzelner Reize zu summiren, übercompensirt. Bei höheren Temperaturen ist zwar die anfängliche Tetanushöhe noch grösser, doch 
tritt hier schneller Ermiidung ein. Fine Ueberlegenheit scheint der Muskel bei niedrigen Temperatureu durch grössere Ausdatuer als bei mittlerer Temperatur zu zeigen, doch wird dies ausgeglichen durch die geringere Schnelligkeit, mit welcher der Muskel sich contrihtirt und mit welcher er wieder erschlafft. Bemisst man die Leistungsfïhigkeit des Muskels für die Zwecke les Organismus nach der 'Tetanushöhe, der Ausdaner nul lieweglichkeit, so muss man die mittlere Temperatur als ،lie dem Muskel giinstigste betrachten.

Un beurtheilen yn können, welche Arbeit der Muskel darlurch leisten kann, lass er in den erregten Zustand ibergeführt wird, muss

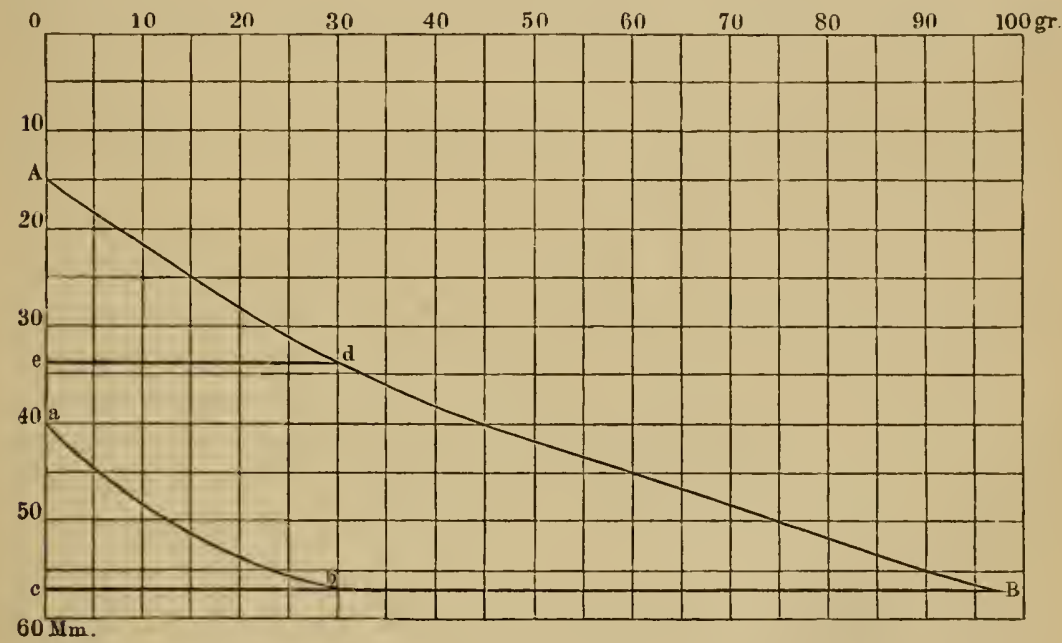

9.

Dehnungscurven: a b des ruhenden, AB des erregten Muskels.

man die Dehnungscurve des ruhenden und des erregten Muskels kennen, welche sich empirisch leicht bestimmen lassen und welche sich, wie zu erwarten ist, als verschieden herausstellen. Solche Dehnungscurven sind durch die Linien a b und A B der Fig. 9 dargestellt. Es ist angenommen, dass der ruhende Muskel in unbelastetem Zustande die Länge von $40 \mathrm{Mm}$ habe. Belastet man ihn mit $5 \mathrm{Gr}$., so wird er auf die Länge von $45 \mathrm{Mm}$ gedehnt; weitere Belastungszunahme um je $5 \mathrm{Gr}$. ertheilen ihm nach und nach die Längen von $49 \mathrm{Mm}, 52 \mathrm{Mm}$ u. s. f., schliesslich hat er die Spannung von $30 \mathrm{Gr}$. erreicht, bei einer Länge von $57 \mathrm{Mm}$. Die ersten an den Muskel angehängten $5 \mathrm{Gr}$, sanken mit dem Muskelende zusammen um $5 \mathrm{Mm}$; es wurde also eine positive Arbeit der Schwere von $25 \mathrm{Gr}$.-Mm verrichtet, während dem Muskel die Spannung von $5 \mathrm{Gr}$. ertheilt wurde. Als fernere $5 \mathrm{Gr}$. angehängt wurden, 
sanken $10 \mathrm{Gr}$. um $4 \mathrm{Mm}$, die Arbeit der Schwere beträgt also $40 \mathrm{Gr}$.Mm. Fiihrt man die Betrachtung in derselben Weise fort, so erfährt man die Arbeit der Schwere, welche angewendet ist, um den Muskel auf $57 \mathrm{Mm}$ zu dehnen und ihm dabei eine Spannung von $30 \mathrm{Gr}$. zu ertheilen.- Dieselbe Arbeit würde der Muskel im umgekehrten Sinne leisten, wenn man ihn nach und nach um je 5 Gr. entlastete; man sieht leicht ein, dass wenn man die Belastung nicht in endlichen Intervallen von je 5 Gr. sondern stetig wachsen und dabei den Muskel seine Längenänderung auf eine Zeichenfläche aufschreiben liesse, welche den Weg von $5 \mathrm{Mm}$ zurücklegt, während die Belastung um $5 \mathrm{Gr}$. wächst, der Muskel die hier gezeichnete Dehnungscurve $a b$ aufzeichnen würde, und dass die hierbei durch die Schwere an ihm geleistete Arbeit dem durch die Curve begrenzten Flächenraum abc proportional wäre: derselbe Flächenraum misst auch die Arbeit, welche der Muskel bei seiner eben so stetig rorgenommenen Entspannung durch allmähliche Hebung eines immer kleiner werdenden Gewichtes leisten würde.

Derselbe Muskel möge, nachdem er in Tetanus versetzt ist, ohne Belastung die Länge von $15 \mathrm{Mm}$ haben, und die Dehnungscurve des erregten Muskels sei in der Linie AB dargestellt; man sieht, dass man den erregten Muskel, um ihm dieselbe Länge zu geben, welche er unerregt bei $30 \mathrm{Gr}$. Belastung hat, mit $97 \mathrm{Gr}$. belasten müsste. Man kann sich nun folgenden Versuch vorstellen: der unerregte Muskel wird durch $30 \mathrm{Gr}$. Belastung auf die Länge von $57 \mathrm{Mm}$ gebracht; dann wird das angehängte Gewicht durch eine Unterstuitzung am ferneren Sinken verhindert und auf $97 \mathrm{Gr}$. gesteigert, man nennt diese Art den Muskel mit schwerer Masse zu verbinden, eine Ueberlastung: er ist in diesem Fall mit $30 \mathrm{Gr}$. belastet und mit ferneren $67 \mathrm{Gr}$. iiberlastet. Wird der Muskel jetzt in Tetanus versetzt, so entspricht seine Länge von $57 \mathrm{Mm}$ nicht mehr einer Spannung von $30 \mathrm{Gr}$., sondern einer solchen von 97 Gr.: er ist nicht mehr überlastet, sondern belastet, und er wird, wenn die Belastung um eine minimale Grösse abnimmt, den Rest der Belastung um eine minimale Grösse heben. Lässt man die Belastung in stetiger Weise von 97 bis $0 \mathrm{Gr}$. abnehmen, so verzeichnet das Muskelende auf einer proportional mit der Geschwindigkeit der Gewichtsabnahme bewegten Fläche die Dehnungscurve $\mathrm{AB}$ und leistet hierbei durch Hebung des allmählich abnehmenden Gewichtes eine Arbeit, welche durch das von der Dehnungscurve des erregten Muskels begrenzte dreieckige Flächenstück $\mathrm{ABc}$ gemessen wird. Bei einem so geleiteten Versuch wiirde der Muskel die grösste Menge von Arbeit leisten, deren er fähig ist. Allerdings ist ein Theil der vom Muskel gewonnenen Arbeit vorher durch Dehnung desselben im ruhenden Zustand verausgabt worden, so dass der wirkliche Arbeitsgewinn nur durch das zwischen den 
beiden Dehnungscurven A B und ab eingeschlossene Flächenstück repräsentirt ist. Hätte man dem Muskel vor seiner Erregung eine Anfangsspannung ron $30 \mathrm{Gr}$. mit Hilfe einer (genügend langen) Ferler ertheilt, so wiirde der Muskel bei dem Uebergang in den erregten Zustand die Lüngenänderung von b-d unter Innehaltung der Spannung von $30 \mathrm{Gr}$. vollzogen und dabei nur eine Arbeit geleistet haben, welche dem Flächenstück edch proportional ist.

In ammähernder Weise ist der idealisirte Fall maximaler Arbeitsleistung bei folgender Gelegenheit verwirklicht: hat man den ausgestreckten Arm horizontal erhoben und ein schweres Gewicht in die Hand genommen, so ist der Musculus brachialis, welcher nicht erregt zu sein braucht, gedehnt und überlastet: gedehnt, weil seine natürliche Ruhelänge kleiner ist als die jetzige Entfernung seiner Insertionspunkte, und iiberlastet, weil das Olecranon in der Fossa Olecrani an den oberen Armknochen stösst. Hebt man jetzt das Gewicht durch Beugung im Ellbogengelenk, so verringert sich der Hebelarm, an welchem es angreift, und der Biceps brachii wird in dem Maasse seiner fortschreitenden Verkürzung melr und mehr entlastet.

Einem weit wichtigeren Falle, in welchem die Fähigkeit eines Muskels Arbeit zu leisten durch Anfangsdehnung gesteigert wird, begegnen wir am Herzen: der Herzmuskel wird in der Ruhepanse vor seiner jedesmaligen Zusammenziehung durch das in die Herzkammern einströmende Blut stark ausgedehnt. Allerdings findet dann eine Abnahme des Widerstandes bei Zunahme der Muskelverkürzung hier nicht in erheblichem Naasse statt.

Aus dem Diagramm der Dehnungscurven ersieht man ohne Weiteres, wie die Arbeitsleistung in zwei Grenzfällen, selbst bei maximalem Tetanus, Null sein muss: einmal, wenn der Muskel sich contrahirt ohne belastet zu sein, und das andere Mal, wenn die Ueberlastung grösser ist und bleibt, als die Spannung, welche im erregten Zustande der Anfangslänge des Muskels entspricht. Ferner sieht man, dass die Last, welche der Muskel noch zu heben vermag, um so kleiner wird, je grösser die Verkürzung ist, welche der Muskel bei der Erregung schon erfahren hat; dass die Ueberlastung, welche der Muskel zu heben vermag, um so grösser ist, je grösser die Anfangsspannung, welche man ihm in ruhendem Zustand ertheilte; dass zur Aufhebung sehr verschiedener Belastungen von der Unterlage derselbe minimale Reiz ausreichen muss u. s. w., lauter Einzelheiten, auf welche zeitweise grosses Gewicht gelegt worden ist und zu deren Demonstration verwickelte Versuchsanordnungen ersonnen wurden.

Bei fortgesetztem Gebrauch desselben Muskels fühlen wir, dass derselbe ermüdet, woraus zu schliessen ist, dass er durch seine Thätig- 
keit wesentlich verändert wird; in der That muss dies so sein, denn bei der Arbeit wird kinetische Energie gebildet, was nur auf Kosten von Energie, die in anderer Form rorhanden war, möglich ist. Die Energie, aus deren Vorrath hierbei geschöpft wird, ist nur unter der Form chemischer: Spannkraft denkbar: Stoffe, welche Träger dieser Energieform sind, müssen bei der Muskelarbeit verbraucht werden, das heisst, die Muskelarbeit wird durch chemische Processe bestritten. Hierauf weist auch die Jeden geläufige Erfahrung hin, dass bei Körperarbeit, wie zum Beispiel beim Bergsteigen, das Athenbediüfniss zunimmt, sowie die experimentell leicht zu constatirende Thatsache, dass bei der so gesteigerten Athemthätigkeit die Menge der ausgeschiedenen Kohlensäure wächst. Das Auftreten von Kohlensäure weist auf Verbrennungsprocesse hin, welche $j a$ anch in der Dampfmaschine die Vernittlung zwischen chemischer Spannkraft und der Arbeitsleistung ïbernehmen. Die Kohlensäurebildung bei der Arbeitsleistung durch den Muskel ist iibrigens durch directe Versuche an den isolirten Organ festgestellt worden.

Die chemische Analyse der Muskelsubstanz hat uns folgende $\mathrm{Zu}$ sammensetzung derselben kennen gelehrt:

\begin{tabular}{|c|c|c|c|}
\hline Wasser & 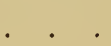 & 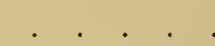 & \\
\hline Eiweisskörper & . & & \\
\hline Fette.. & & & \\
\hline Glyeogen und & andere & Kohlehydrate & \\
\hline Kreatin u. dgl & . . . & 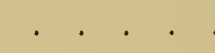 & \\
\hline Salze . . & . & . & \\
\hline
\end{tabular}

Von diesen Substanzen kommen für die Verbrennungsprocesse, deren Produkt Kiohlensäure ist, Eiweiss, Fett und Kohlehydrat in Betracht. Ein beträchtlicher Verbrauch von Eiweiss scheint bei der Muskelarbeit nicht einzutreten, da eine vermehrte Ausscheidung des hauptsächlichen Stoffwechselproduktes von Eiweiss, des Harnstoffes, beim Arbeiten gut ernährter Menschen und Thiere nicht eintritt.

Kohlehydrate und Fette werden bei dem Assimilationsprocesse in deu Pflanzen gebildet. In den grünen Pflanzentheilen findet unter Verbrauch rou Fnergic der Aetherschwingungen des Lichtes eine starke Arbeitsleistung statt, durch welche, im Widerstreit gegen die mächtige chenische Affinität zwischen Kohlenstoff und Wasserstoff einerseits und Sauerstuff andererseits, Kohlensäure gespalten wird. Kohlen- und wasserstoffireiche P'rodukte dieses Reductionsprocesses sind Kohlehydrate und Fette, lurch deren Verbreunung die bei der Reduction aufgewendete Allueit, znm Theil wierlergewonnen werden kann. Dieses findet in Inneren des thierischen Organisnus statt, wohin der Sauerstoff durch die Athmung unter Vermittlung des kreisenden Blutes gelangt und bei 
dessen Eruährung Kohlehycrlrate und l'ette eine wesentliche Rolle spielen.

Der aus dem Organismus entfernte und dem Verkehr mit dem kreisenden Blut entzogene Muskel kann bei kïnstlicher Reizung noch eine erhebliche Venge Arbeit leisten: auspumpbarer, also physikalisch oder locker chemisch rebundener Sauerstoff ist in einem solchen Muskel nicht rorhanden, und er kann im sauerstofflecren Raume arbeiten: die Verbrennung ron Kohlehydraten und Fetten im Muskel zu Kohlensäure und Wasser kam also nicht wie lie Verbrennung der liohle auf dem. Roste der Dampfmaschine unter Verbrauch freien Sanerstoft's erfolgen, wir sind vielniehr zu der Annahme gezwungen, dass die molekulare Structur desjenigen Theiles der Muskelsubstanz, an welchen der chemische Process gebunden ist, dadurch charakterisirt sei, dass die verbrenubaren Atomcomplexe sowohl als der zur Verbremnung erforderliche Sanerstoff schon vor der Verbrennung in demselben. Molekiil rereinigt sind, und zwar in solchen Stelhngen, diss es zunächst zu einer Vereinigung nicht kommen kaun. Die jerlenfalls sehr complicirte Structur des Eiweisses, welches einen grossen Theil der Muskelsubstanz ansmacht, lässt für die Vorstellung derartiger intramolekularer Anordnungen freien spielraum. Diese Betrachtungsweise, zu welcher wir durch Thatsachen gezwungen werden, erleichtert das Verständniss mancher Erscheinungen am Muskel. Die einzelne Zuckung des Muskels hat Aehnlichkeit mit einer Explosion, wobei jedoch das Merkwürdige eintritt, dass die Explosion sich hegrenzt und nur einen sehr kleinen unter bestimmten Bedingungen ganz hestimmten Theil der explosiblen Masse ergreift. In der That ist es weit weniger erstaunlich, dass der Muskel bei fast verschwindend kleiner Einwirkung ron aussen zuckt und hierbei eine verhältnissmässig grosse Arbeit leistet, als dass er sich nicht sofort völlig verausgabt, wie es eine explodirende Patrone thun würle. Der Muskel beantwortet gleichen Reiz in einer grossen Reihe von Zuckungen mit gleicher Leistung: intramolekulare Anordnungen, hei denen sich Verbrenumgen auf Atomcomplexe beschränken und jeder neue Anstoss einen neuen Atomcomplex trifft, sind wohl denkbar.

Lässt man den Inskel eine längere Rieihe ron Zuckungen bei gleicher Reizstärke ausführen, so macht sich die Ermüdung durch /unahme der Zuckungsdauer und Abnahme der Hulhöhe geltend. Lnterbricht man aber die Zuckungsreibe nur für kurze Zeit, so findet man, dass der Muskel sich theilweise wiedererholt hat. Es handelt sich um den isolirten, dem Blutkreislauf entzogenen Muskel. Es mïssen sich also in der kurzen Zeit Aenderungen in der Muskelsubstanz rollzogen haben, ron denen es weniger wahrscheinlich ist, dass sie mit Aufnahme neuen Stoffes in das wirksame Molekül rerbunden sind, als dass sie auf 
intramolekularer Umlagerung beruhen. Wir sind zu der Annahme berechtigt, dass die betreffenden Moleküle der Muskelsubstanz einen Kern besitzen, um welchen die Gruppirung der bei der Verbrennung in Betracht kommenden Atomcomplexe während der Ruhe immer wieder in derselben Weise erfolgt. Bei der Thätigkeit würde dieser Bildungskern selbst nicht angegriffen werden, die Produkte der intramolekularen Verbrennung würden das Molekül verlassen, die an Seitenketten zu denkenden oxydabeln Complexe würden sich neu ordnen und in dem Falle, dass der Muskel von dem lebenden Blut durchströmt wird, würde auch stets stofflicher Ersatz in dem Molekül eintreten.

Dass übrigens der als eiweissartig zu denkende Bildungskern bei angestrengter Muskelarbeit nicht ganz unangegriffen bleibt, geht daraus hervor, dass Vermehrung der Harnstoffausscheidung die Körperanstrengung zwar nicht begleitet, dass sie ihr aber doch in geringem Maasse später folgt. Der Eiweissverbrauch, auf welchen hieraus zu schliessen ist, kann nicht als Kraftquelle in Betracht kommen, er verhält sich zum Verbrauch von Kohlehydraten und Fetten wie die Abnützung von Maschinentheilen an der Dampfmaschine zu der Heizung derselben.

Man wird geneigt sein, den chemischen Zustand der ruhenden Muskelsubstanz als einen labilen zu betrachten. Man kann sich dies so vorstellen, dass Sauerstoff-Atome und verbrenubare Atomcomplexe im Molekül nahe bei einander stehen, aber doch eben entfernt genug, dass bei den gewöhnlichen intramolekularen Schwingungen die Grenzen ihrer Wirkungssphären sich nicht berühren: ein kleiner Anlass, welcher die intramolekularen Atomschwingungen $\mathrm{zu}$ steigern im Stande ist, wird dies an einem bevorzugten Orte zu Stande bringen und hier wird eine räumlich beschränkte Reaction erfolgen.

Dass bei der Verbrennung von Kohlehydrat und Fett zu Kohlensäure und Wasser chemische Spannkraft oder chemische potentielle Energie in molekulare Bewegung umgesetzt werden kann, kann man sich leicht vorstellen, schwer zu erklären ist aber, wie die molekulare Bewegung so geordnet wird, dass sie, in gleichem Sinne nach aussen wirkend, an äusseren Massen Arbeit verrichten kann. In der That tritt auch beim Muskel wie bei jeder Maschine nur ein Theil der verbrauchten potentiellen Energie in arbeitsleistender Form zu Tage; ein grosser Theil der erzeugten molekularen Bewegung bleibt ungeordnet und erscheint als Wärme. Die Wärmeentwickelung im Muskel kann man nicht einmal als unzweckmässige Begleiterscheinung auffassen wie die Erwärmung der Dampfmaschine, denn der Organismus ist bezüglich der Wärmeproduktion wesentlich auf die chemischen Processe im Muskel mit angewiesen. Auch für den Fortschritt unserer theoretischen Erkenntnisse hat sich die Erwärmung des Muskels als nützlich erwiesen, 
denn man kann den Muskel unter solche äussere Bedingungen rersetzen, dass die ganze bei seiner Thätigkeit umgewandelte Energie als Wärme erscheint, und in der Messung dieser Wärmemenge haben wir rorläufig das einzige Mittel für Abschätzung der Intensität der gesammten die Muskelthätigkeit bedingenden chemischen Processe. Das angedeutete Verfahren besteht darin, dass man mit feinen in die Muskelsubstanz eingebetteten Thermonadeln die Temperatursteigerung misst, welche der Muskel bei der Thätigkeit erfährt, wenn er ein frei an demselben hängendes Gewicht hebt und fallen lässt; da man das. Gewicht der angewendeten Mnskelmasse leicht bestimmen kann und die specifische Wärme der Muskelsubstanz annähernd kennt, so erfährt man auf diesem Wege die Zunahme des Wärmeinhalts des Muskels. Bei der E1hebung des Gewichtes ist ein Theil der umgewandelten Energie als äussere Arbeit erschienen, aber die dieser Arbeit äquivalente Wärmemenge wird durch die Erschuitterung ron Seiten des fallenden Gewichtes dem Muskel sofort mitgetheilt. Auf diese Weise ist zum Beispiel festgestellt worden, dass die Intensität des chenischen Processes unter sonst gleichen Bedingungen durch Erhöhung der Temperatur gesteigert wird. Ferner ist auf diesem Wege die schon früher vermuthete Thatsache bewiesen worden, dass die Intensität der chemischen Processe im Muskel wächst, wenn man ihm eine grössere Arbeit $\mathrm{zu}$ leisten aufgiebt, oder wenn man dafür sorgt, dass die mechanische Zustandsänderung mehr in Spannungszunahme als in Verkürzung zum Ausdruck kommt. Diese in hohem Grade erstaunliche Zweckmässigkeit der Muskelnıaschine entbehrt zunächst einer ausreichenden Erklärung, doch liegt die Vermuthung nahe, dass der Ablauf des chemischen Processes im Muskel sich ändert, je nachdem man die innere Verschiebungen in der Muskelsubstanz, welche die Formänderungen des Muskels begleiten müssen, frei giebt oder hemmt, wie letzteres am rollkommensten bei isometrischem Verfahren geschieht.

Leitet man den Wärmeversuch am Muskel so, dass man das durch den zuckenden Yuskel erhobene Gewicht auf der Höhe der Erhebung festhält, so erscheint nur diejenige Wärmenenge, welche nicht in mechanischer Arbeitsleistung ein Aequivalent gefunden hatte, und durch Subtraction dieser Wärmemenge ron der bei dem anderen Verfalıren gefundenen erfährt man diejenige Wärmemenge, welche der geleisteten Arbeit äquiralent sein muss. Letztere Grösse kann man leicht messen und man erhält so die Unterlage zur Bestimmung des mechanischen Aequiralentes der Wärme. Dass die nach diesem Plan ausgeführten Bestimmungen des mechanischen Wärme-Aequivalentes zu einer Zahl gefiihrt haben, welche mit der von den Physikern ermittelten nahezu übereinstimmt, ist ein schöner Beweis für die Zulässigkeit der angewendeten Methode. 
Die Zweckmässigkeit einer Dampfmaschine beurtheilt man unter Anderem nach dem Verhältniss desjenigen Antheiles der verausgabten Energiemenge - bemessen nach dem Verbrennungswerth des aufgewendeten Heizmaterials - welcher als mechanische Arbeitsleistung gewonnen werden kann, zu demjenigen Antheil, welcher, wie man sich hier mit Recht ausdrïckt, als Wärme verloren geht. Dieses Verhältniss kann man beim Muskel auf die angegebene Weise leicht feststellen und der Muskel erweist sich von diesem Gesichtspunkt aus als eine sehr zweckmässige Maschine. Bei den besten Dampfmaschinen kommen nur $7 \frac{1}{3}$ Procent des Heizwerthes der Kohlen als mechanische Arbeit zum Vorschein, bei den Gaskraftmaschinen beinahe 11 Procent; bei dem Muskel dagegen kommen 30 Procent und mehr von der umgesetzten Energiemenge der Arbeitsleistung zu Gute.

Eine für die Theorie der Muskelthätigkeit sehr wichtige Frage ist die, ob wir uns vorstellen dürfen, dass die als Arbeitsleistung erscheinende Energie vorher im Muskel als Wärme vorhanden gewesen sei, wie dies bei der Dampfmaschine der Fall ist, oder nicht? Diese Frage scheint durch folgende, aus Clausius' zweitem Satz der mechanischen Wärmetheorie hergeleitete Betrachtung endgiltig beantwortet $\mathrm{zu}$ sein. Als Wärme vorhandene Energie kann zur Arbeitsleistung nur dadurch nutzbar werden, dass der Process so geleitet wird, dass Wärme von einem wärmeren zu einem kälteren Körper übergeht und die Nutzbarmachung der Wärme ist im hohen Grade abhängig von der Temperaturdifferenz dieser beiden Körper. Die im Muskel vorkommenden Temperaturdifferenzen sind zu klein, als dass die Arbeitsleistung auf diesem Wege hergeleitet werden könnte.

Von den Hypothesen, durch welche man versucht hat, die Verbindung zwischen dem Verbrennungsprocess in der Muskelsubstanz und der Arbeitsleistung des Muskels herzustellen, steht folgende von Fick ausgesprochene mit den bisher bekannten Thatsachen am besten im Einklang: die Verbrennung von Kohlehydrat und Fett zu Kohlensäure und Wasser findet nicht in einem einzigen Akt statt, sondern es wird unter Anderem ein Zwischenprodukt gebildet, welches auf gewisse Theile der Muskelsubstanz im Sinne der Aenderung ihrer physikalischen Constanten wirkt, welche speciell die Längsattraction zwischen den Elementen einer den Muskelschlauch durchziehenden Substanz erhöht. Proportional der in der Muskelsubstanz jeweilig vorhandenen Menge dieses Zwischenproduktes würde die Längsattraction vermehrt sein, was je nach den äusseren Unständen durch Verkürzung oder Spannungsänderung zum Ausdruck kommen kann. In dem Maasse wie das Zwischenprodukt bei weiterem Fortschreiten des Verbrennungsprocesses zerstört wird, kelırt der Muskel in seinen früheren Zustand zurück. 
Dass hei der Muskelthätigkeit eine Substanz entsteht und sich zeitweise anhäuft, welche eincrseits als Oxydationsprodukt ron hohlehydrat orler lett aufgefasst werden kann und welehe andererseits bei ihrer Verbremnung Kohlensäure und Wasser liefert, ist kein /weifel: der fortgesetzt tetanisirte Muskel reagirt sehr deutlich saluer und er verdankt diese Renction einer fixen Sïure; diese säure ist, wenigstens zum grössten Theil, Milclıäure. Dieselbe säure bilket sich auch in Inskel bei den Processen, welche sein Absterben begleiten und welche ebenfalls mit Contraction einhergehen. Die erholende Wirkung, welche man auf den ermïdeten und in Folge dessen nach jeder einzelnen Contraction sich langsam und unvollkommen wieder ausilehnenden Muskel durch einfaches Ausspritzen mit physiologischer Kochsalzlösung ausühen kann, beruht wahrscheinlich auf Entferunng augesammelter Vilchs:̈ure. Auch das Blut, welches man kiinstlich durch iiberlebend erhaltene Warmbliitermuskeln leitet, reichert sich bei fortgesetytem 'Tetanus mit Milchsüure an, während das venöse Blut aus Muskeln, die unter normalen Berlingungen im Körper arbeiten, mit rermehrter Arbeit nur Steigerung des Kohlensäuregehaltes zeigt. Alles dies weist darauf hin, dass Milchsäure bei der Muskelthätigkeit auftritt, dass sie unter normalen Verhältnissen aber auch sofort weiter verbrannt wird. Wo letzteres nicht geschieht, zeigen sich dauernde ('ontractionszustände. Es ist also nicht unwahrscheinlich, dass auch die normale Contraction auf einer kurz vorïbergehenden Anwesenheit ron Milchsäure in der Muskelsubstanz beruht.

Die Wiedererschlaffung der Muskelfasern nach ihrer Contraction würde bei dieser Auffassungsweise als die Folge chemischer Arbeit zu betrachten sein; in der That kann es nicht als iiherfliissig erscheinen, wenn für die Zurïckfiihrung der Muskelsubstanz in ihren frïheren Zustand Energie verausgabt wird. Freilich kann diese Energiemenge nicht direct zur Leistung äusserer Arbeit verwendet werden. Lässt man einen Muskel, welcher frei beweglich auf einem ()bjektträger ruht, sich zusammenziehen und wieder erschlaffen, so sieht miln unter dem Mikroskop seine einzelnen Fasern ihren frïheren (Querschnitt, also auch ihre friihere Länge wieder einnehmen, der gesammte Muskel bleibt aber beträchtlich rerkiirzt, die einzelnen Fasern in demselben rerlaufen zickzackförmig. Man sieht hieraus, dass die Muskelfaser durch ein Spiel innerer Kräfte zwar in die frïhere Gleichgewichtsfigur, was Länge und Querschnitt anlangt, zuriickgeführt wird, dass aber seitliche Verschiebungen der Elemente gegen einander übrig bleiben, wenn sie nicht durch äussere Kräfte, etwa durch ein dehnendes Gewicht, beseitigt werden. Es ist die Biegsankeit der Muskelfasern, welche verhindert, dass der chemische Process des Stadiums der sinkenden Energie der äusseren Arbeitsleistung dienen kann. 
Damit aber der Muskel in einer gegebenen Zeit eine gewisse Menge Arbeit leisten könne, ist es ebenso wichtig, dass er schnell erschlafft, als dass er sich schnell contrahirt. Denn die bei einer einmaligen Contraction zu leistende Arbeitsmenge (Produkt von Gewicht in Hubhöhe) ist beschränkt; erst nach Rückkehr in den erschlafften Zustand kann der Muskel wieder von neuem dieselbe Menge Arbeit leisten. Dieses ist die Art, wie wir beim Bergsteigen unseren Körper auf beträchtliche Höhe erheben können.

Anderen Zwecken des Organismus wird allerdings dadurch gedient, dass der in Contraction versetzte Muskel für längere Zeit andauernd in Contraction erhalten wird, wie dies zum Beispiel mit den Muskeln der Beine und des Rumpfes beim Aufrechtstehen der Fall ist. Arbeit im physikalischeu Simne des Wortes wird hierbei nicht geleistet. Doch ist der Verbrauch chemischer Spannkraft hierbei sehr bedentend, es ist dies durch Wärmeversuche an isolirten Muskel erwiesen; die Wärmeproduktion in einem solchen tetanisirt erhaltenen Muskel ist sehr beträchtlich, wenn auch nicht so gross, wie sie bei demselben Muskel sein würde, wenn man ihn während der gleichen Zeit in möglichst kurzem Intervall zucken und dabei dasselbe Gewicht immer von Neuem heben lassen würde.

Es wäre denkbar, dass der Muskel durch einen kurz dauernden, mit verhältnissmässig geringem Energieverbrauch einhergehenden Process in einen Zustand übergeführt würde, in welchem er ohne weiteren Aufwand von Energie ein einmal gehobenes Gewicht erhoben halten könnte; diese Möglichkeit ist jedoch nicht realisirt, sondern iu dem, ein Gewicht dauernd erhoben haltenden Muskel befindet sich wahrscheinlich jede einzelne Faser fortwährend in einem Wechsel von Contraction und Erschlaffung, wobei sich verschiedene Fasern und verschiedene Theile derselben Faser in demselben Zeitmoment verschieden verhalten. Durch das fortwährende Entstehen und Vergehen des Contractionszustandes unterscheidet sich der in dauerndem Tetanus erhaltene Muskel von dem bei seinen Absterben erstarrten. Ein nur etwas verlängertes Verharren desselben Muskelelementes in contrahirtem Zustande scheint seine Beweglichkeit dauernd $\mathrm{zu}$ schädigen und ihn der Fähigkeit zu berauben, die feinen Abstufungen der Erregungsgrösse anzunehmen, welche für die Zwecke des Organismus erforderlich sind.

Es ist jetzt angezeigt, etwas näher auf deu inneren Aufbau der Muskelfaser einzugehen. Wir haben dieselbe als einen Schlauch hezeichnet, und in der That handelt es sich bei ihr um eine allseitig geschlossene festere Hülle, welche von einer beweglicheren Masse erfüllt ist: die Hiille, welche man das Sarkolemun nennt, zeigt sich ziemlich wirlerstandsfähig gegen die verschiedeuen chemischen Reagentien 
und hat auch in physikalischer Beziehung Aehnlichkeit mit den elastischen Gewebselementen; eine feinere Struktur lässt dieselbe nicht erkennen, ilıre Dicke ist nicht messhar. Der Inhalt des Sarkolemmschlauches erweist sich bei der histologischen Untersuchung als hochgradig differenzirt. Allerdings ist ein bei verschiedenen Muskelfasern an Menge sehr verschiedener Rest urspringlichen Protoplasmas vorhanden; an dentlichsten zeigt die Inhaltsmasse das Ansehen körnigen undifferenzirten Protoplasmas in der Ungebung von Kéernen, welche in grösserer oder kleinerer Zahl in allen Muskelfaseru vorhanden sind, zum Theil wandständig, zum Theil diffus zerstreut, zum Theil axial angeordnet. Das Protoplasma umgiebt die einzelnen Kerne und scheint dieselben mit einander in Verbindung zu erhalten; in welcher Weise es sich an der Struktur des übrigen Inhalts betheiligt, ist noch ungewiss. Das Sicherste, was wir über diese Struktur aussagen können, ist, dlass in der Längsrichtung des Muskels ganz regelmässig Schichten zweier das Licht verschieden brechender Substanzen mit einander abwechseln: dies erkennen wir schon am frischen noch lebenden Objekt bei schwacher Vergrösserung au dem regelmässigen Aufeinanderfolgen von hellen und dunklen Streifen, und hierauf beruht die Benennung als quergestreifte Muskelsubstanz; ferner wissen wir, dass bei Behandlung mit verschiedenen Reagentien die Muskelfaser entweder in Längsfibrillen zerfällt (Alkohol), oder in Querscheiben (Verdaunngsfliissigkeit, Säure). Der hieraus zu ziehende Schluss, dass innerhalb der Muskelfaser verschiedene Substanzen in ganz regelmässiger Weise der Länge und der Quere nach angeordnet sind, wird durch die feinere Untersuchung mit stärkeren optischen Hülfsmitteln und mit verschiedenen Fixirungs- und Färbungsmethoden bestätigt. Ob die hierdurch zur Darstellung gebrachten Scheidewände und Fasernetze in der lebenden Muskelfaser präformirt sind, mag dahingestellt bleiben. Das physiologische Vorstellungsbedürfniss ist zunächst darauf hingewiesen, daran festzulaalten, dass der Muskelfaserinhalt zwar sehr verschieblich ist, dass die Verschiebungen nach verschiedenen Richtungen des Raumes aber mit verschiedener Leichtigkeit erfolgen, und dass verschiedene Substanzen von verschiedener chemischer und physikalischer Natur in derartige regelmässige räumliche Beziehungen zu einander gebracht sind, dass die Folgen ihrer gegenseitigen Einwirkung sich $\mathrm{zu}$ einer Gesammtwirkung nach aussen summiren; es ist vorläufig nicht erforderlich, melır wie drei solcher Substanzen im Muskelinhalt anzunehmen, das undifferenzirte Protoplasma und daneben isotrope und anisotrope Substanz. Dass der die Arbeitsleistung bestreitende Process in einer anderen Substanz sich abspielen werde als in einer solchen, welche die Trägerin der mit der Erregung sich ändernden physikalischen Eigenschaften des Muskels sein kann, ist sehr wahrscheinlich. 
Festgehalten muss hier jedoch werden, dass die erstere Substanz einen erheblichen Antheil der Gesammtmasse atsmachen muss, weil die die Arbeitsleistung des Mnskels bestreitende Energiemenge ihr stoffliches Aequiralent haben muss. Wenn diese Substanz auch in der Masse nicht beschränkt sein darf, so kann ihr doch eine geringere räumliche Gebundenheit zuerkannt werden, als der anderen.

Bei alleu Versuchen, verschiedenen histologischen Elementen der Muskelsubstanz bestimmte Functionen zuzuweisen, werden folgende Thatsachen zu berïcksichtigen sein: die bei durchfallendem unpolarisirtem Licht wenig hell erscheinenden Streifen verschwinden bei senkrecht gekreuzten Nichol'schen Prismen, so dass die anderen im lichtleeren Ramme zu liegen scheinen. Hat man in den Gang der Lichtstrahlen noch ein dïmnes Glimmerplättchen eingeschaltet, so zeigen die hellen Streifen bei Drehung des einen Nichols regelmässigen Farbenwechsel: die Sulstanz der dunkeln Streifen ist also einfach brechend, die. der hellen doppelbrechend. Diese Erscheinungen treten auf, wenn man die Muskelfaser quer zur mikroskopischen Axe lagert. Feine Muskelquerschnitte dagegen zeigen keine Polarisationserscheinungen. Die Doppelbrechung im Muskel verhält sich also wie die in einaxigen Krystallen (beiläufig gesagt wie in einaxig positiven). Man wird also nicht umhin können, den elementaren Träger'n der Doppelbrechung im Muskel festen Aggregatzustand und bestimmte räumliche Lagerung zuzuerkennen. Ueber die Beziehung der Krystallform dieser Elemente zu derjenigen, welche bei pyroelektrischen Erscheinungen in Petracht kommt, können wir Nichts aussagen.

Bei stärkerer Vergrösserung sielıt man, dass die doppelbrechenden Querscheiben der Länge und Qnere nach durch einfach brechende Substanz unterbrochen sind, die einfach brechende Substanz scheint durch den ganzen Muskelinhalt zusammenzuhängen, während die doppelbrechende Substanz in regelmässig geformten und regelmässig angeordneten, mit einander nicht zusammenhängenden Partikelchen vorhanden ist (Briicke'sche Disdiaklasten).

Lässt man die Muskelfaser unter dem Mikroskop sich zusammenziehen, so sieht man, lass mit lem Dickerwerden der Faser die Höhe der einzehnen (vuerstreifen abnimmt, das Umgekehrte tritt ein, wenn min die Iluskelfaser dehnt. Ueber das Fintreten oder Ausbleiben von Aenderungen der Höhe der Querstreifen kann man sich auch auf folgende Weise ein Urtheil bilden: drückt man einen frischen Sartorius rom Frosch zwischen zwei Glasplatten und blickt durch das Präparat aus einiger Entfernung gegen den leuchtenden spalt des nicht völlig geschlossenen Fensterladens, so treten zu beiden Seiten des Spaltes, wie bei Anwendung irgend eines anderen beugenden Gitters, eines Mikro- 
meters oder dergleichen, alygeheugte Spertren in abnehmender Intensität und sihärfe in bestimmten Alständen und Breiten aut. Erregt nain den Inskel und lïsst ihn hierhei sich contrahiren, so werden die Abstände und Breiten der Spectren grösser, wie es dem Feinerwerden der heugenden structur entspricht. Diss Cmgekehrte tritt ein, wenn man den unerregten Muskel dehnt. Erregt man dagegren den Muskel während man ihn an der Contraction rerhindert, so bleibt jede Aenderung der spectren aus. Hieraus geht herror, diss die sich in den Aenderungen der Querstreifung zu erkennen gebenden inneren Lmlagerungen nur eintreten, wenn der Muskel in Folge seiner Frregung orler unter Wirkung äusserer hräfte auch seine äussere Form ändert, dass von solchen imneren Umlagerungen jedoch nichts zu bemerken ist, wenn der Muskel bei seiner Erregung verhindert ist, seine äussere Form zu ändern.

Aenderungen der optischen Constanten der Muskelsubstanz treten bei der Erregung nicht ein, mag die Erregung mit Formänderungen einhergehen oder nicht. Weder hat sich eine Aenderung in dem Brechungsrerhältniss der anisotropen Substanz, noch eine Aenderung des Brechungsindex des Muskelfaserinhaltes in Ganzen nachweisen lassen. Mannigfache Lmlagerungen zwischen isotroper und anisotroper Substanz. sind an Muskelfasern beschrieben worden, welche sich bei der Behandlung mit Fixirungsmitteln theilweise verdickten: man glaubte es in diesem rerdickten Theile mit dem in der Muskelfaser fixirten Erregungszustand zu thum zu haben und aus dem Vergleich feinerer histologischer Strukturunterschiede an rerdickten und nicht rerdickten stellen wichtige Schlüsse auf die innere Umlagerung bei dem Lebergang von der Ruhe in die Frregung ziehen zu können. Diese Schlïsse haben aber an Boden rerloren, seit man weiss, dass der an der lebenden Muskelfaser rorïbergehend auftretende Erregungszustand mit keiner Aenderung des Brechungsindex der Muskelsubstanz rerbunden ist, während die beim Absterben eintretenden Contractionswïlste das Licht wesentlich stärker brechen (wegen Wasseraustritt) als lebende Muskelsubstanz.

Die regelmässige Segmentirung des Muskelfaserinhaltes macht es leicht rerständlich, wie verschiedene Theile derselben Muskelfaser zu derselben Zeit sich in rerschiedenen Zuständen befiuden können, dass aber auch, wenn einnal ein Segment in Erregung gerathen ist, dieser Zustand sich von Segment zu Segment his zum Ende der Muskelfaser fortpflanzt. In der That kann man diese wellenartige Fortpflanzung der Erregung durch die Länge der Muskelfasern leicht zur Auschauung bringen. Man benutzt dazu die Verdickung, welche der Muskel bei der Erregung erfährt: man wählt eimen Muskel, bei welchem wie bei dem Musculus Sartorius rom Frosch die Muskelfasern von einem Ende des Muskels zum anderen durchgehen. Der Muskel wird auf einer 
festen Unterlage ausgespannt und quer über denselben wird nahe seinen beiden Enden je ein leichtes Fühlhebelchen aufgelegt, welches seine Bewegung auf eine bewegte Zeichenfläche aufschreiben kanu; durch Vermittelung zweier an dem einen Muskelende eingestochener Nadeln wird durch dieses Muskelende ein Inductionsschlag gesandt. Hierdurch wird zunächst dieses Muskelende erregt und man sieht an den Zeichnungen der beiden Fühlhebel, dass der Muskel sich in der Nähe der Reizstelle frïher verdickt hat als an den anderen Enden. Man kann auf dieselbe

Weise auch die Geschwindigkeit

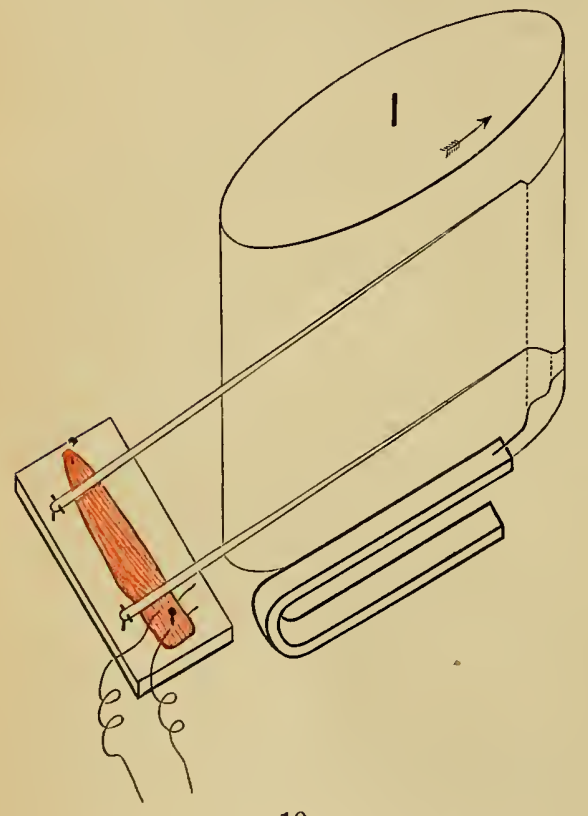

10.

Messung der Fortpflanzungsgeschwindigkeit der Erregung im Muskel.

bestimmen, mit welcher sich die Frregungswelle in der Muskelfaser fortgepflanzt hat, man braucht nur dafür zu sorgen, dass die Zeichenspitzen der beiden Hebel beim Beginn des Versuches genau über einander stehen und dass die Geschwindigkeit der Zeichenfläche mit Hülfe einer ihre Schwingungen aufschreibenden Stimmgabel bestimmt werde. Der Zeitwerth der horizontalen Entfernung zwischen dem Erhebungspunkte der beiden Verdickungscurven stellt die Zeit dar, welche die Erregungswelle gebraucht hat, um die Muskelfaser von dem Auflagerungspunkt des einen Fühlhebels bis zu dem des anderen zil durchlaufen, letzterer Abstand lässt sich leicht messen. An dem Sartorius des Frosches hat sich

die Fortpflanzungsgeschwindigkeit der Erregungswelle bei mittlerer Temperatur zu etwa 3 Meter in der Secunde ergeben; mit wachsender Temperatur nimmt dieselbe $z u$, und sie scheint bei dem menschlichen Muskel etwa 10 Meter in der Secunde zu betragen. Da die Dauer der einzelnen 7uckung etwa 1/10. Secunde beträgt, so würde die Länge der einzelnen Erregungswelle beim Frosch auf 25 Centimeter zu schätzen sein, während die Länge der Muskelfaser des Froschsartorius höchstens 5 Centimeter beträgt. Stellen wir uns vor, dass die Zuckung so verläuft, dass die Erregungswelle sich von dem einen Ende dieses Muskels durch denselben hindurch fortpflanzt, so folgt, dass das vordere Ende der Welle bei dem anderen Muskelende anlangt, lange ehe das zuerst von 
der Erregung ergriffene Muskelelement das Maximum seiner Zustandsänderung erreicht. Es wird dies aus Betrachtungen der Fig. 11 klar, in welcher die Erregungswelle in dem Moment dargestellt ist, wo sie das zweite Ende des Muskels erreicht; das erste Ende des Muskels wird sich in maximaler Erregung befinden, wenn der Gipfel der Erregungswelle dort angelangt ist, also hei den angenommenen Zahlenwerthen

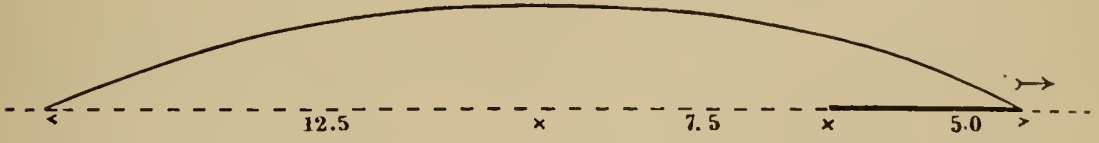

11.

Erregungswelle und Muskel.

1/10 Sec. später. Die Zuckung dauert von dem Moment, wo das vordere Ende der Erregungswelle in das erste Muskelende eintritt bis zu dem Moment, wo ihr hinteres Ende das zweite Muskelende wieder verlässt. Diese Zeit beträgt $1 / 10$ Sec. und in dieser Zeit durchläuft die Erregungswelle den zehnten Theil von 3 Metern, das heisst 30 Centimeter. Diese Strecke setzt sich zusammen aus der eigenen Länge der Welle und aus der Länge der Muskelfaser, die Länge der Welle würde also 25 Centimeter betragen. Wäre die Erregungswelle kürzer als die Muskelfaser, so würde ihr hinteres Ende früher ein- als ihr vorderes austreten, es würde eine Zeit geben, während welcher in jedem Zeitelement die Verkürzungszunahme ebenso gross wäre wie die Verkürzungsabnahme. Während einer solchen Zeit miisste die isotonische Zuckungscurve auf constanter Höhe verharren, statt des Gipfels miisste sich ein Plateau zeigen: dieses ist noch nie beobachtet worden.

Die Fähigkeit der Muskelsubstanz die Erregung zu leiten muss mit der Erregbarkeit des Muskelelementes innig zusammenhängen, denn die Fortpflanzung der Erregung durch die Muskelsubstanz können wir uns nur so vorstellen, dass der Erregungszustand in dem einen Querschnitt zum Reiz für den benachbarten Querschnitt wird. Bei dem frischen Muskel scheint auch die Erregungswelle in ihrem Ablauf durch die ganze Faserlänge an Intensität nicht abzunehmen; eine solche Abnahme tritt aber als erstes Zeichen der Schädigung sehr deutlich hervor, noch ehe die örtliche Erregbarkeit geschwunden ist. Schliesslich bleibt die Erregung auf den Ort ihrer Entstehung beschränkt, was an einem hier entstehenden Wulst (dem sogenannten idiomusculären Wulst) zu erkennen ist, welcher dort, wo man etwa mit dem Skalpell gestrichen hat, lange fortbesteht, um allmählich zu verschwinden, ohne sich auf andere Muskelpartien auszubreiten. 
Eine Mittheilung der Erregung von dem Inhalt eines Muskelschlauches zu dem des benachbarten finctet nicht statt.

Eine gleichzeitige Erregung aller Querschnitte einer Muskelfaser findet weder bei den normalen Vorgängen im Organismus statt, wo die Erregung ron der Nerrenendigung auf die Muskelfaser übergeht, noch scheint sie im Experiment realisirt werden zu können.

Es ist schon Eingangs gesagt worden, dass ein den Muskel treffender elektrischer Strom denselben in Erregung zu versetzen vermag; man sollte meinen, dass, wemn man den Muskel seiner ganzen Länge nach ron einem solchen Strom durchsetzen liesse, sich dann dessen erregende Wirkung an allen Punkten gleichzeitig äussern müsste. Dieses tritt jedoch nicht ein. Verbindet man die beiden Enden eines Musculus Sartorius vom Frosch durch Vermittlung eines Schlüssels mit den Enden eines constanten elektrischen Elementes, so erhält man bei dem Stromschluss und der Stromöffnung je eine Zuckung. Es lässt sich mit Hülfe zweier dem Muskel aufgelegter registrirender Fühlhebel zeigen, dass im ersten Falle die Erregung an der Austrittsstelle des Stromes aus dem Muskel (an der Kathode) entstanden ist und sich von hier iiber die Muskelfaser ausgebreitet hat, dass dagegen im zweiten Falle eine Erregungswelle von der Anode ausgegangen ist. Bei einem durch rlie ganze Länge des Muskels geleiteten Inductiousschlag, bei welchem gewissermaassen Stromschluss und Stromöffunng in verschwindend kleinem Zeitintervall auf einander folgen, geht die Erregung wenigstens hauptsächlich von der Kathode aus. Der elektrische Strom scheint also die Muskelsubstanz nur dort zu erregen, wo er in dieselbe ein- oder aus derselben austritt. Ein den Muskel querdurchsetzender elektrischer Strom erregt denselben ebenfalls, und auch hier zeigen sich dieselben polaren Unterschiede.

Während ein elektrischer Strom von constanter Dauer den Muskel durchfliesst, findet im Allgemeinen keine Erregung statt, doch kann man meistens eine Stromstärke ausfinden, bei welcher während des constanten Durchströmens eine sogenannte Dauercontraction eintritt; die Schliessungszuckung und Oeffnungszuckung sind jedenfalls stets höher als die Dauercontraction. Die Erregung überdauert auch häufig, wenn auch in geringem Grade, die Oeffnung des constanten Stromes, wenn die Stromdauer nicht sehr kurz war.

Der Muskel reagirt nicht nur durch Aenderung seines Erregungszustandes auf künstlich zugeleitete elektrische Ströme, sondern er ist auch selbst Sitz elektromotorischer Kräfte, von deren Vorhandensein man sich unter Anderem dadurch überzeugen kann, dass man von zwei rerschiedenen Punkten seiner Oberfläche Leitungen zu einer stromprüfenden Vorrichtung, etwa einer Boussole, herstellt; die Ableitung 
ron der Muskeloberfläche kamn nicht einfach durch Anlegen metallischer Drähte erfolgen, weil an den Berührungsstellen zwischen Metall und Muskel elektromotorische Wirkungen entstehen können, und weil der auf diese Weise abgeleitete Muskelstrom an den Berührungsstellen schnell Polarisation herrorrufen wïrde, welche den Ueljergang des Stromes in dic Leitung schwächen, ja ganz verhindern könnte. Die Ableitung muss rielmelı mit Hülfe ron unpolarisirbaren Leitercombinationen, mit sogenannten unpolarisirbaren Elektroden bewerkstelligt werden. Eine für diesen Zweek als zurerlässig erprobte Combination ist folgende: der Muskel wird unmittelbar rou einer passend geformten Spitze plastischen Thones berïhrt, welcher durch Ankneten trocknen Thonpulvers mit Kochsalzlösung von $0,75 \%$ hergestellt ist. Ein Glasrohr ist an seinem einen Ende durch Thon geschlossen, welcher mit concentrirter Zinkvitriollösung angeknetet ist. Salzthon und Zinkthon sind zu inniger Berührung gebracht, das Glasrohr ist mit concentrirter Zinksulfatlösung gefuillt, in welche eine gut amalgamirte Zinkplatte eintaucht. Das nicht eingetauchte Ende der Zinkplatte, welches auch nicht amalgamirt ist, kann mit jedem beliebigen metallischen Leitungsdraht direkt verbunden werden. Hat man das eine Ende eines Sartorius rom Frosch abgetödtet, etwa durch Eintanchen in heisse Chlornatriumlösung ron $0,75 \%$, und legt man die Thonspitze der einen unpolarisirbaren Electrode dem getödteten Muskelende an, während man die andere in einiger Entfernung ron dem thermischen Querschnitt, wie man in diesem Fall die Grenzfläche zwischen lebender und todter Muskelsubstanz nennt, mit der Oberfläche des Muskelbauches in Verbindung bringt, so zeigt die Boussole einen kräftigen Strom an, welcher innerhalb des lebenden Muskeltheiles von dem thermischen Querschnitt zu dem abgeleiteten Punkt der unrerletzten Oberfläche gerichtet ist. Im Gegensatz zu dem künstlichen Querschnitt nennt man die natiirliche Oberflïche des Muskelbauches natürlichen Längsschnitt, man kann also sagen, dass der Muskelstrom ausserhalb des Mnskels rom Längsschnitt zum Qnerschnitt fliesst, dass der Querschnitt negatir elektrisch im Verhältniss rom Längsschnitt ist; die elektromotorische Kraft dieses Muskelstromes kann mehr als 1/20 Daniell betragen, sie ninmmt zu mit dem Abstand der Längsschnittelectrode ron dem kïnstlichen Querschnitt, und ist unabhängig ron der Grösse des Querschnittes des Muskels, ja ein Bündelchen weniger einzelner Mnskelfasern mit der Pincette frisch ausgerissen und schnell in passender Weise mit den Electroden verbunden, kann einen Strom rou annähernd gleicher Kraft geben. Erheblich gesteigert kann die Kraft und Intensität des abgeleiteten Stromes werden, wenn man dem Querschnitt eine gegen die Faserrichtung geneigte Lage giebt, es entsteht 
dann eine säulenartige Anordnung, welche Veranlassung für die sogenannten Neigungsströme ist.

Klemmt man die beiden Enden eines an seinem einen Ende mit thermischem Querschnitt versehenen Sartorius so fest, dass der Muskel ausgespannt und bei seiner Erregung an der Contraction verhindert ist, leitet man von diesem Muskel den Längsquerschnitt-Strom ab und führt man dem lebenden Muskelende tetanisirende elektrische Reizstösse zn, so nimmt die Boussolablenkung während der Dauer der tetanischen Erregung erheblich ab, der Muskelstrom ist während dieser Dauer erheblich geschwächt. Man nennt diese die Erregung begleitende Schwächung des Muskelstromes die negative Schwankung desselben.

Man kann Einrichtungen treffen, durch welche bewirkt wird, dass der rom Muskel abgeleitete Strom nur für ein kurzes Zeittheilchen, in abstufbarem Intervall nach dem Reizmoment, durch die Multiplicatorrolle der Bonssole geschickt wird. Wiederholt man unter Benïtzung einer solchen als Rheotom bezeichneten Einrichtung den zuletzt beschriebenen Versuch mit der ferneren Modification, dass man als Reizmittel einen einzelnen Inductionsschlag benutzt, so erhält man, wenn die kurzdauernde Stromzuleitung zur Boussole unmittelbar nach Ablauf des Inductionsschlags erfolgt, kein Zucken des Boussolspiegels; rerlängert man von Versuch zu Versuch das zeitliche Intervall zwischen dem Reizmoment und der kurzdauernden Ableitung zur Boussole, so findet man ein Intervall, bei welchem der Boussolspiegel eben eine kleine Zuckung in negativem Sinne zeigt und bei dessen weiterer Vergrösserung die Grösse des negativen Stromstosses zunächst zu- und später abnimmt.

Man kann denselben Versuch auch an dem unversehrten (nicht mit thermischem Querschnitt rersehenen) Sartorius anstellen, indem man von zwei zur Muskelmitte symmetrischen Längsschnittpunkten zur Boussole ableitet. Hierbei beobachtet man während der Muskelruhe meist keine Ablenkung der Boussole, und wenn eine solche vorhanden ist, kann man sie durch Compensation leicht eliminiren; stellt man jetzt Rheotomversuche an, so erfolgt die erste Ablenkung der Boussole im Sinne eines Stromes, welcher in der Leitung von dem der Reizstelle entfernteren $A b$ leitungspunkt des Iä̈ngsschnittes zu dem der Reizstelle näheren gerichtet ist; diese $\Lambda$ usschläge nehmen zunächst $z u$, dann $a b$, und erhalten rlann umgekchrtes Vorzeichen. Es ist dies nur so zu verstehen, dass die Erregungswelle den Ableitungspunkt, unterhalb dessen sie momentan die grössere Intensität besitzt, elektrisch negativ macht gegen Punkte geringerer Erregung. Aus der zeitlichen Differenz des Negatirwerdens der beiden Ableitungspunkte in Verbindung mit ihrem räumlichen Alistand kamn man die Fortpflauzungsgeschwindigkeit der Er- 
regungswelle berechnen. Auf diese Weise hat sich ergeben, dass die elektrische Zustandsänderung sich mit gleicher Geschwindigkeit durch den Muskel fortpflanzt wie die mechanische.

Kennt man die Fortpflanzungsgeschwindigkeit der elektrischen $\mathrm{Zu}$ standsänderung im Muskel, so kann man auch der Entscheidung der Frage näher treten, ob es ein Latenzstadium für diese Zustandsänderung giebt. Giebt es ein solches, so muss die negative Schwankung an einem zur Boussole abgeleiteten Lüngsschnittpunkt später beginnen, als nach der Fortpflanzungsgeschwindigkeit der Welle und nach der Entfernung des abgeleiteten Punktes ron dem Reizpunkt zu erwarten wäre. Es hat sich herausgestellt, dass, wenn es ein elektrisches Latenzstadium gielst, dies nicht länger danern kann als etwa 0,001 Secunde. Hiernach scheint es, dass, wenn ein bestimmter Querschnitt der Muskelsubstanz. in Erregung rerfällt, die elektrische Zustandsänderung in demselben erheblich früher beginnt als die mechanische. Bei der Abmessung des Zeitintervalls zwischen dem Beginn dieser beiden Erregungsäusserungen darf aber nicht ausser Acht gelassen werden, dass das elektrische Latenzstadium fuir den einzelnen Muskelquerschnitt sich direkt bestimmen lässt, während die mechanische Wirkung des Nuskels nach aussen immer crst in die Erscheinung tritt, wenn innere Verschiebungen im Muskel abgelaufen sind. Es lässt sich zum Beispiel zeigen, dass während des Latenzstadiums fïr dic Längeänderung des Gesammtmuskels die zuerst in Erregung gerathenen Muskeltheile dehnend auf die übrigen wirken, und dass die Längeänderung des Gesammtmuskels erst beginnt, wenn die Verkiirzungen iiber die Dehnungen merklich die Oberhand gewinnen: immerhin scheint die elektrische Zustandsänderung im Muskelelement früher zu beginnen wie die mechanische und sie scheint auch von kïrzerer Gesammtlauer zu sein wie letztere. Nur kann der zeitweise als wichtig betrachtete Satz nicht aufrecht erhalten werden, dass die elektrische Zustandsänderung im Muskelelement abgelaufen sei, ehe dic mechanische beginnt.

Um sich ron dem Vorhandensein elektrischer Vorgänge im erregten Muskel zu iiberzeugen, bedarf es übrigens nicht einer Boussole: reizt man einen Muskel, zum Beispiel den Gastrocnemicus rom Frosch, durch Vermittlung seines Nerren, wobei die Versuchsanordnung leicht so getroffen werden kann, dass keine Spur der zur Nerrenreizung benutzten Inductionsschlïge sich auf dem Muskel ausbreitet, und lagert man auf diesen ersten Muskel seiner Länge nach den zu einem zweiten Muskel gehörigen Nerr, so erhält man bei Reizung des ersten Nerren durch den einzelnen Inductionsschlag nicht nur eine Zuckung des ersten Muskels, sondern auch der zweite Muskel führt eine Zuckung aus: man nennt diese die secundäre Zuckung. Auf analoge Weise crhält man auch 
einen secundären Tetanus, und das Eintreten des secundären Tetanus in dem Falle, dass der primäre Muskel bei seinem Tetanus in einem scheinbar gleichmässigen Zustand rerharrt, ist ein Beweis dafür, dass diese Gleichmässigkeit eben nur eine scheinbare ist. Der secundäre Tetanus ist nur so zu verstehen, dass in dem primär tetanisirten Muskel Erregungstrelle nach Erregungswelle abläuft, deren jede von einer negativen Schwankung des Muskelstromes begleitet ist. Secundäre Zuckung und secundärer Tetanus treten auch ein, wenn man den primären Muskel durch straffes Ausspannen an der Verkürzung verhindert.

Man kann den Muskel auch durch seinen eigenen Strom zur Zuckung reranlassen. Trennt man ron dem Sartorius des Frosches das eine Ende durch einen scharfen Schnitt ab, fasst den Muskel an der anderen Endsehne mit einer Elfenbein-Pincette und nähert den frischen Muskelquerschnitt vorsichtig der Oberfläche der denkbar indifferentesten Flüssigkeit (Kochsalzlösung von $0,75 \%$ ), so zuckt der Muskel in dem Augenblick, wo sein Querschnitt die Flüssigkeit berührt. Die angewendete Fliissigkeit kann weder reizend auf die am Querschnitt freiliegende Muskelsubstanz gewirkt, noch Veranlassung zur Bildung einer Flïssigkeitskette gegeben haben; dagegen hat sie bei ihrem capillaren Aufsteigen Längsschnitt und Querschnitt des Muskels elektrisch leitend rerbunden. In diesem flüssigen Leitungsbogen kann sich der Längs-Querschnittsstrom entwickeln und hierbei entsteht Erregung. Dieser Versuch deckt eine Fehlerquelle auf, welche bei der Prüfung der Reizwirkungen chemisch differenter Substanzen auf die Muskelfaser schwer zu rermeiden ist, insofern man diese Substanzen nicht in Gas- oder Dampfform auf den Muskel wirken lassen kann. Ein wirklich chemischer Reiz für die Muskelfaser ist Ammoniak. Geringe Spuren desselben in der Luft reranlassen den Muskel zu Zuckungen und es scheint, dass die Muskelsubstanz hierbei nicht geschädigt zu werden braucht.

Es ist wichtig, dass wir, ehe wir die Eigenschaften der lebenden Iuskelsubstanz verlassen, noch einen einfachen Beweis für die direkte Reizbarkeit der Muskelsubstanz beibringen; im Laufe des normalen Geschehens wird der Muskel ja freilich stets ron seinem Nerven aus erregt. In dem Curare besitzen wir ein Mittel, die Muskelsubstanz dem Finflusse der Nerren zu entziehen, der Beweis hierfuir ist aber nicht einfach und kann erst später erbracht werden. Bei dem Musculus Sartorius des Frosches dringen aber, und dies kann jeder Zeit mit dem Mikroskop demonstrirt werden, die intramusculären Nerrenfasern nicht bis zu den Endsehnen vor; schneidet man mit scharfer Scheere ein nachweislich nervenloses Stiick des Muskels ab; so zuckt der Muskel, der Schnitt muss also die Muskelsubstanz direct gereizt haben.

Der Muskel des Kaltblüters ïberlebt den Tod des Gesammt- 
organismus unter günstigen Bedingungen Iange Zeit; einen ausgeschnittenen Muskel rom Frosch, welchen man kïhl und vor Verdunstung geschintzt aufbewahrt, kam man noch bis nach 8 Tagen in kräftige Zuckungen rersetzen. Der Muskel des Warmbliter's zuckt noch 10 bis 20 Minuten nach einem plötzlichen Tode. Etwas länger iiberlebt die Erregbarkeit des Muskels, nemn man das Thier vor der Tödtung kïnstlich abgekiihlt hatte. Nachdem der Muskel bei dem Absterben seine Erregbarkeit verloren hat, verfiillt er in einen eigenthiimlichen Zustand, welchen man den der Todesstarre nennt. Die Muskelsubstanz wird trübe und starr, der isolirte Muskel rerkürzt sich unbelastet in hohem Grade, entwickelt aber, wemn man ihn an der Verkiirzung verhindert, nur wenig Spannung. Die Starre tritt momentan ein, wenn man die Gefäisse des Muskels mit destillirtem Wasser ausspritzt, oder wenn man den Muskel iiber eine gewisse Temperatur erwärmt. Diese Temperatur liegt für den Frosch etwa bei $42^{\circ}$ bis $43^{\circ}$, für das Säugethier zwischen $4 \tilde{a}$ und $50^{\circ}$. Die durch plötzliche Temperaturerhöhung hervorgerufene Starre neunt man die Wärmestarre. Das Starrwerden menschlicher Leichen, die Todtenstarre, beruht auf dem Eintreten der Todesstarre der Muskeln; die Todesstarre ergreift zuerst die Muskeln des Kopfes, daun die des Rumpfes, der oberen und schliesslich der unteren Extremitäten. Sie entwickelt sich um so schueller, je höher die Temperatur ist und je mehr Muskelanstrengungen dem Tode rorhergegangen sind. Muskeln, deren Nerven durchschnitten sind, werden langsamer todesstarr als solche, welche durch den Nerven mit dem absterbenden nerrösen Centralorgane in Verbindung stehen. In derselben Richtung, in welcher sich die Todesstarre ausbreitete, löst sie sich, nachdem sie unter gewöhnlichen Verhältnissen mehrere Stunden angedanert hatte. Beim Eintreten der Torltenstarre können Bewegungen kleinen Umfanges und jedenfalls sehr kleiner Krraft rorkommen. Während der Todesstarre (und Wärmestarre) reagirt der Muskel samer. Nach Lösung der Starre verfällt der sich selbst iiberlassene Muskel in Fäulniss. wobei seine Reaction alkalisch wird.

Wird ein Froschmuskel allmählich ïber $30^{\circ}$ erwärmt, während man in regelmässigen Interrallen seine Leistungsfähigkeit prïft, so findet man, dass Hubhöhe und Spannungsentwickelung mit wachsender Temperatur abnehmen, und dass die Erregbarkeit rollkommen verschwindet, noch ehe die Wärmestarre beginnt. Zuckungsdaner und Latenzdauer nehmen in diesem Intervall ebenfalls ab.

Kühlt man den Muskel allmählich unter $0^{0} \mathrm{ab}$, so wird seine Zuckung niedriger und niedriger, während sie selbst und das Latenzstadium an Dauer zunehmen; endlich bleibt jeder Reiz wirkungslos. Erwärmt man den Yuskel wieder, ehe letzteres eingetreten ist, so nimmt der 
Muskel sicher alle seine früheren Eigenschaften wieder an; dasselbe soll auch noch geschehen können, wenn der Muskel vollkommen kältestarr geworden war, doch ist dieses schwer $\mathrm{zu}$ demonstriren, und wird nur von zwei Autoren behauptet, von denen der eine ausserdem angiebt, dass der wieder aufgethaute Muskel zwar noch zuckt, aber sehr schnell auch bei niedriger Temperatur in Todesstarre verfällt.

Etwas Zuverlässiges über die chemische Struktur der lebenden Muskelsubstanz zu erfahren, ist begreiflicher Weise sehr schwer: der mikroskopische Befund weist darauf hin, dass Substanzen von verschiedenem Aggregatzustande und verschiedenem Lichtbrechungsvermögen, also anch wahrscheinlich von verschiedener chemischer Constitution an dem Aufbau der Muskelfaser betheiligt sind. Versuche, auf mechanischem Wege diese Substanzen zu trennen, scheiterten zunächst an dem Umstande, dass die Muskelfaser an jeder Stelle ihrer Verletzung in maximale Contraction und dann sofort in Todesstarre verfällt. Es scheint aber, dass man den langsam vollkommen gefrorenen Muskel in genügend stark abgekühlten Gefässen mit eben so kalten Instrumenten fein zerkleinern kann, ohne dass seine Substanz hierbei eine chemische Veränderung erleidet. Lässt man den so gewonnenen Muskelschnee sich erwärmen, so wird er bei $-3^{0} \mathrm{zu}$ einem leicht fliussigen Brei, welcher bei gewöhnlicher Temperatur sich selbst überlassen langsam, und bei kiiustlicher Erwärmung auf Körpertemperatur sofort $\mathrm{zu}$ einem festen Kuchen gerinnt und dabei eine klare Flïssigkeit, das Muskelserum, ausscheidet. Der Kuchen reagirt nach einiger Zeit sauer.

Die fliissige Substanz des beim Aufthauen des Muskelschnees entstehenden Breies kann man durch Verdünnen noch besser von den ungelösten Bestandtheilen trennen, wenn man mit dem Muskelschnee eine Vischung von einem Theile Kochsalz auf 100 Theile gewöhnlichen Schnees verreibt; man erhält dann das "Muskelplasma" in 1 procentiger Kochsalzlösung vertheilt und kann es abfiltriren. Das Filtrat reagirt neutral, gerinnt ebenfalls, wenn auch langsamer und noch weniger fest. Die Substanz des sich ausscheidenden Gerinnsels wird Myosin genannt. Die Gerinnung des Muskelplasmas bei gewöhnlicher Temperatur zeigt viele Analogieen mit der später ausführlich zu behandelnden Gerinuung des Blutes.

Das Muskelplasma enthält ausser der Myosin bildenden Substanz noch mehrere Eiweisskörper in Lösung; das Myosin kann man trennen durch Eintropfen des Muskelplasmas in destillirtes Wasser: es scheidet sich hierbei in Flocken aus. Es ist unlöslich in Wasser und Alcohol, sehı leicht löslich in Kochsalzlösung von 5 bis $10 \%$ und aus diesen Lösungen mit unveränderten Eigenschaften wieder ausfällbar durch gepulvertes Chlornatrium. Verdünnte Kali- oder Natriumlauge oder ver- 
diinnte Salzsäure lösen das Myosin unter Unwandlung desselben in Alkalialbuminat oder Acidalluminat; letzteres wird Syntonin genannt, es entsteht anch bei Einwirkung verdïnnter Salzsäure auf andere Eiweisskörper, doch geht das Myosin besonders leicht in Syntonin iiber. Wird Myosin gekocht, sei es in Lüsung, sei es ausgeschieren und etwa in Wasser vertheilt, so gerinnt es festcr und zeigt dann nur noch die Figenschuften aller durch Siedehitze bei Gegenwart von Wasser coagnlirten Eiweisskörper; das Myosin theilt mit dem Blutfibrin die Fähigkeit, Wasserstoffsuperoxyd zu zersetzen. Fin auffallender Unterschied zwischen beiden Substanzen besteht darin, dass Myosin in einer Lösung von kohlensaurem Kali fest wird, Fibrin dagegen sich löst. Das Muskelser'um, welches beim Eintropfen des Muskelplasmas in destillirtes Wasser und bei dem dadurch bewirkten Ausfallen des Myosins in Wasser gelöst bleibt, reagirt anfangs neutral, wird aber schnell sauer. Elwärmnt man diese Lösung, während man die Süure in dem Maasse wie sie sich bildet neutralisirt, so füllt, wenn sie von Froschmuskeln stammt bei $45^{\circ}$, wenn von Warmbliitern bei 50 bis $55^{\circ}$, ein Eiweisskörper in gerommenem Zustand aus, welchen man Musculin nennt. Die Ausfällungstemperatur des Musculins ist von (ler Reaction der Flïssigkeit unal)hïingig: in Salzlösungen ist das Musculin unlöslich. Ferner enthält das Muskelserum Alkalialbuminat, dessen Fällungstemperatur in neutraler Flüssigkeit löher liegt als die des Musculins, mit Zunalme der Säure aber sinkt. Die dritte Eiweissart des Muskelserums iiberwiegt an Menge die beiden ersten, stammt zum Theil aus dem accessorischen Gewebe des Muskels und ist von dem Eiweiss des Blutserums nicht verschieden. Das Muskelplasma ist in den lebenden Fasern wahrscheinlich flüssig und enthält die doppelbrechenden Elemente suspendirt. Die Disdiaklasten besitzen wahrscheinlich festen Aggregatzustand und ilıre Substanz scheint eiweissartiger Natur zu sein.

Eiweiss in ungelöster Form ist ferner in den Kernen und in den Granuli des undifferenzirten Protoplasmas enthalten. Die mehr oder weniger rothe Färbung des Muskels rïhrt nicht allein von dem in seinen Gefässen enthaltenen Blute her. Ein rother Farbstoft, identisch mit dem Hämoglobin der rothen Blutscheiben, ist in dem Muskelfaserinhalt gelöst. Je nach der Menge dieses Furbstoffes unterscheidet man sogenamnte weisse und rothe Muskeln. Mit dem Farbenunterschiede Hand in Hand gehen Unterschiede im Contractionsrorgang derart, dass der Zuckungsverlauf bei den weissen Muskelfusern im Allgemeinen jäher ist und zu einer grösseren Höhe führt als bei den rothen, dass dagegen die letzteren zu einer grösseren Spannungsentwickelung befähigt sind. Diese Unterschiede sind jedoch nicht unverbriichlich an die Farbe geknïpft. Von grössercm Einfluss scheinen riehmehr feine 
Strukturverschiedenheiten zu sein, welche noch nicht genau ermittelt sind.

Aus jeder Muskelsubstanz darstellbar ist Glykogen, welches identisch zu sein scheint mit dem Glykogen der Leber; die Unterschiede der aus verschiedenen Muskeln zu gewinnenden Glykogenmengen sind sehr bedeutungsvoll. Bei dem hungernden Thier schwindet aus dem arbeitleistenden Muskel das Glykogen vollständig. Nur in vollkommen ruhenden Muskeln, wie zum Beispiel im Brustmuskel des Huhnes, bleibt das Glykogen länger erhalten als in der Leber. Bei demselben Muskel nimmt die Ausbeute an Glykogen ab mit der Zeit, welche man von der Entfernung des Muskels aus dem Organismus bis zur chemischen Bearbeitung desselben vergehen lässt. Mit der Abnahme der Glykogenmenge Hand in Hand geht die Zunahme der Säuerung; am schnellsten verläuft dieser Process bei Versetzung des Muskels in Wärmestarre; die Säuerung des Muskels beruht auf der Bildung von Milchsäure. Diese scheint nicht direkt aus dem Glykogen zu entstehen; als Zwischenprodukt scheint eine dem Traubenzucker sehr nahestehende oder mit ihm identische Zuckerart aufzutreten, hierfiur spricht die Thatsache, dass ein solcher Zucker während, der Zeit des Säuerungsprocesses, wenu auch nur in geringer Menge, dargestellt werden kann, ferner, dass es gelungen ist, ein zuckerbildendes Ferment aus den Muskeln darzustellen. Dieses Ferment soll sehr empfindlich gegen kleinen Ueberschuss von Säure oder Alkali sein, und nur in genau neutraler Flüssigkeit seine Wirkung äussern.

In dem Herzmuskel kommt noch ein zweites Kohlehydrat, das siissschmeckende Inosit, vor, welches der Milchsäuregährung fähig ist. Der beständig arbeitencle Herzmuskel ist der einzige Muskel, dessen Substanz bei voller Leistungsfähigkeit stets saner reagirt.

Der Zuckergehalt der absterbenden Skelettmuskeln nimmt mit dem Fortschreiten der Starre zu, der Glykogengehalt ab; das Maximum des Zuckergehaltes findet sich, wenn kein Glykogen mehr zu gewinnen ist; später nimmt auch der Zuckergehalt ab, während die saure Reaktion noch zunimmt. Die bei der Starre gebildete Milchsäure entspricht annäher'nd dem anfänglichen Glykogengehalt des Mnskels. Glykogenfreie Muskeln hungernder Thiere werden bei der Starre nicht saner. Bei seinem Absterben bildet der Muskel Kohlensäure, am schnellsten und ausgiebigsten, wenn man ihn in Wärmestarre versetzt; diese Kohlensïurebildung ist ebenso wie die im arbeitenden Muskel nicht an die Gegenwart von freiem Sauerstoff gebunden. Das Gleiche gilt für die Zucker- und Vilchsäurebildung im erstarrenden Muskel.

Von stickstoffhaltigen Spaltungs-Produkten des Eiweisses findet man in den Muskeln aller Thiere Kreatin. Ob Harnstoff in den Muskeln höherer 
Thiere gebildet wird, kann noch zweifelhaft erscheinen; der Menge nach spielt er eine kleine Rolle. Die Muskeln einiger Fischarten, namentlich von Torpedinäen und Haien, enthalten grosse Mengen Harnstoffs. Von der Harnsiiure, dem Hypoxanthin, Xanthin und anderen Zwischenprodukten, welche aus dem Fleisch dargestellt worden sind, ist es zweifelhaft, ob sie im Muskel präiformirt sind. Die Herkunft stickstofflhaltiger Produkte des Eiweisses im Muskel kann eine zweifache sein, entweder aus dem bei der Arbeit nicht ganz ausbleibenden, wenn auch die Arbeit nicht bestreitenden Zerfall eigentlichen Muskeleiweisses oder aus Nahrungseiweiss, welches bei Fleischfressern den Glykogenbedarf des arbeitenden Muskels durch seinen Zerfall decken muss.

Dafür, dass Fett als solches in dem Inhalt normaler Muskelfasem vorkommi, besitzen wir keinen direkten Beweis; die gewölınliche Reaction auf Osniumsäure tritt in solchem Faserninhalt nicht ein. Das regelmässige Auftreten von derart reagirenden Granulationen bei leichten Ernährungs- und Functionsstörungen spricht dafür, dass Fett auch in der normalen Muskelsubstanz in irgendwie gebundener Weise vorhanden ist. Wegen dei grossen Rolle, welche das Fett bei der Ernährung und im allgemeinen Stoffwechsel spielt, wird man auch geneigt sein, dic Arbeitsleistung im Muskel wenigstens zum Theil auf Fettverbrauch zurïckzufuihren. In diesem Gedankengang wird man bestärkt durch die Thatsache, dass die glykogenfreien Muskeln hungernder Thiere noch beträchtliche Arbeit zu leisten im Stande sind.

Für die Aschebestandtheile der Muskelsubstanz ist charakteristisch, dass Natrium und Chlor fast gar nicht darin vertreten sind und dass del grösste Theil der 1 bis $1,5 \%$ des frischen Muskels betragenden Asche phosphorsaures Kali ist.

Das Wasser nimmt unter den Muskelbestandtheilen der Menge naclı den ersten Platz ein; der Wassergehalt schwankt nicht nur bei rerschiedenen Thierarten erheblich (85\% beim Krebs bis $70 \%$ beim Sperling), sondern er ist auch bei verschiedenen Muskelgruppen desselben Thieres verschieden (beim Kaninchen: Rückenmuskeln im Mittel $75,1 \%$, weisse Schenkelmuskeh 76,5\%). Das Herz scheint stets den grössten Wassergehalt zu haben. Auch experimentell lïsst sich der Wassergehalt der Muskeln leicht ändern. Spritzt man die Gefässe des Froschbeines mit einer Kochsalzlösung aus, welche etwas mehr wie $0,6 \%$ Kochsalz enthält, so werden die Muskelfasern an Wasser ärmer; ist die Lösung etwas verdünnter, so quellen sie unter Wasseraufnahme. Die trockene Muskelfaser ist reizbarer und leistungsfähiger. Analoge Aenderungen lassen sich durch kleine Mengen giftiger Substanzen erzielen. Spritzt man destillirtes Wasser ein, so erstarrt der Muskel sofort.

Die glatten Muskelfasern sind hüllenlose, spindelförmige Ge- 
bilde einer meist homogen, bei gewisser Behandlung längsfaserig erscheinenden Substanz, von 45 bis $230 \mu$ Länge und 4 bis $10 \mu$ Breite, mit je einem stäbchenförmigen Kerne, der 1 bis 2 glänzende Nucleoli enthïlt. In der Umgebung des Kernes befindet sich ein schmaler Saum körnigen Protoplasmas, von dem sich auch Längsfäden durch die Zelle erstrecken können. Fïr die nutritive und formative Thätigkeit der Zelle selbst kommt der Kern mit dem Rest undifferenzirten Protoplasmas in Betraclıt, für ihre Leistungen im Dienste des Gesammtorganismus die iibrige Substanz. Die glatten Muskelfasern bilden nur in wenigen Organen des Körpers compakte Massen, wie zum Beispiel im Uterus; sie liegen vielfach zerstreut im interstitiellen Gewebe (Milz, Niere), oder bilden röhrenförmige dünne Schichten, so in Gefässen, im Darm und im Ureter; oder plattenförmige Gebilde wie in der Iris. Der Uebergang der glatten Muskelfasern aus dem ruhenden Zustand in den erregten und umgekehrt erfolgt viel allmählicher als die Contraction und Erschlaffung bei den quergestreiften; iibrigens ist der Erregungszustand ebenfalls durch Verkürzung und Verdickung der Fasern charakterisirt. Die quergestreiften Muskelfasern gerathen normaler Weise nur in Folge nervös zugeleiteter Erregung in Thätigkeit; der Thätigkeitszustand der glatten Muskelfasern dagegen ändert sich vielfach unter dem direkten Einfluss der physikalischen und chemischen Bedingungen (Temperatur, Kohlensäureanhäufung, Belichtung). Während in quergestreiften Muskeln die Erregung genau auf die Fasern beschränkt bleibt, denen sie auf dem Wege der zugehörigen Nervenfasern zugeleitet wurde, scheint die Erregung sich in Gebilden, welche wie der Ureter aus dicht gelagerten glatten Muskelfasern bestehen, von Faser zu Faser durch die ganze Länge der zusammenhängenden Schicht fortzupflanzen. Die quergestreiften Muskeln sind der Willkür unterworfen; die contractilen Gewebe mit glatten Fasern sind dem Willens-Einfluss entzogen.

Es giebt Muskelfasern, welche nach dem Grade ihrer Differenzirung und nach ihren morphologischen und functionellen Eigenschaften eine Zwischenstellung einnehmen zwischen den eigentlich glatten und den eigentlich quergestreiften Muskelfasern: hierher gehören die Fasern des Herzmuskels, welche aus nackten, einkernigen verzweigten Elementen bestehen. Die Substanz derselben ist quergestreift. Die Erregung pflanzt sich von jeder Faser auf die mit ihrem Querschnitt unmittelbar anstossende fort; dem Einfluss der Willkür sind sie entzogen; ihre Zustandsänderungen folgen allmählicher als die der eigentlich quergestreiften und plötzlicher als die der glatten Muskelfasern. Sie neigen zu rhythmischen Thätigkeitsäusserungen.

Die chemische Reaction der glatten Muskelsubstanz wird als neutral oder schwach alkalisch angegeben; eine Säuerung derselben bei der 
Arbeit oder beim Absterben ist nicht so leicht zu demonstriren. Myosin, Musculin und Alkalialbuminat scheint in derselben vorhanden zu sein. Auch doppelbrechende Elemente soll die glitte Muskelfaser enthalten. Hämoglobin kommt in derselben vor, zum Beispicl in den glatten Muskelfasern des Rectums bein Menschen, scheint aber kein wesentlicher Bestandtheil zu sein. Glykogen ist in der Muskelhaut des Schweinemagens nachgewiesen. Kreatin wurde ebenfalls gefunden. Der Gehalt der organischen Muskeln an Fett, Wasser, Asche und Gasen ist noch nicht genauer bekaunt. In Bezug auf die Mineralbestandtheile wird angegeben, dass die Natriumverbindungen den Kaliumrerbindungen gegeniiber vorherrschen.

An die Bewegungserscheinungen, welche die Muskelfasern zeigen, reihen sich diejenigen an, welche an farblosen Blutkörperchen, Flimmerepithelien und Samenfäden beobachtet werden.

Die farblosen Blutkörperchen sind nackte Klümpchen körnigen Protoplasmas mit einem Kerne; die Bewegungen, welche auf erwärmbarem Objectglas bei Körpertemperatur beobachtet werden können, bestehen in dem Aussenden und Wiedereinziehen stumpfer Fortsätze, meist mehrerer auf gemeinschaftlicher breiterer Basis. Während ein Theil des Umfanges Fortsütze aussendet, pHlegt der übrige Theil zu ruhen. Ausgesendete Fortsätze können sich an fremde Elemente anheften, sodass beim Einziehen der Fortsätze der übrige Zellleib an diese herangezogen wird: auf diese Art kommen Ortsveränderungen zu Stande. Feste Partikelchen, wenn sie an Fortsützen haften bleiben, werden in die Leibessubstanz der Zelle mithineingezogen. Eine Aufnahme solcher Partikelchen geschieht auch dadurch, dass die Zellsubstanz dieselbe umfliesst. Die Berregung ist am lebhaftesten bei Körpertemperatur und in schwach alkalischer Fliissigkeit von der Concentration der Körpersäfte; schädigende Einfliisse, wie Druck, abnorme Concentration, Acidität oder Alkalinität, elektrische Schläge veranlassen zunächst Contraktion zu einer Kugel; war der Eingriff nicht stark, so kann bei Wiederherstellung normaler Bedingungen normale Beweglichkeit wiederkehren.

Die beweglichen Elemente an den Flimmerepithelien sind die Cilien, ron denen beim Menschen 10 bis 20 auf je einer Zelle aufsitzen; das einzelne Flimmerhaar ist kaum messbar dick und etwa $3 \mu$ lang, es erscheint durchaus homogen, glatt, farblos, ziemlich stark lichtbrechend (und zwar positiv einaxig doppeltbrechend). Die cilientragenden Zellen selbst sind rollsaftige Epithelzellen, deren Protoplasma nicht ohne Weiteres mit den Cilien zusammenzuhängen scheint. Trennung durch eine Zellmembran findet allerdings nicht statt; wo Flimmerzellen durch eine Membran gedeckt sind, wird diese ron den Cilien durchbrochen. An ihrer Basis scheinen die Cilien aber durch eine besondere 
Schicht einer hyalinen Substanz mit einander zusammenzuhängen. Beim Menschen finden sich Flimmerepithelien an folgenden Stellen: Schleimhaut der Nasenhöhle (mit Ausnahme des untersten Abschnittes und der Regio olfactoria), Thränenwege, obere Hälfte des Pharynx, Tuba Eustachii, Paukenhöhle, Kehlkopf (mit Ausnahme der Stimmbänder), Luftröhre und Bronchien bis zu den Alveolen, Eileiter, die Vasa efferentia Testis, Hirnhöhlen und im jugendlichen Zustand auch Centralcanal des Riickenmarks.

Die Beobachtung der Flimmerbewegung findet am leiclitesten an ler Rachenschleimhaut des Frosches statt; bestrent man diese in ihrer natïrlichen Lage mit Kohlenpulver, so sieht man, wie sich dasselbe mit ziemlicher Geschwindigkeit nach dem Schlundeingang bewegt. Bringt man in Wasser ein zusammengeklapptes Stiick der Schleimhaut unter das Mikroskop und beobachtet die Umschlagsfalte, so sieht man, wie feste Theilchen (Blutkörperchen, Kohlenpartikelchen) schnell dem Rande entlang bewegt werden; bei dem ganz frischen Präparat ist die Ursache der Bewegung kaum zu erkennen; allmählich wird die Bewegung langsamer und dann sieht man den Rand flimmern wie ein rom Winde bewegtes Kornfeld. An dem Ende des Präparates wird man einzelne Zellen finden, an denen die Bewegung der Cilien noch mehr verlangsamt ist, sodass man den Bewegungsmodus einzelner Cilien verfolgen kann. Jede Cilie pendelt hin und her, in der einen Richtung, in welcher die Körnchen fortbewegt werden, schneller, in der anderen langsamer'; die Hauptkrümmung findet hierbei an der Basis der Cilien statt.

Dass die Cilienbewegung einzelner Zellen eines Flimmerepithels nicht mabhängig ron der Bewegung benachbarter Flimmerzellen erfolgt, geht aus folgendem Versuch herror: beobachtet man die mit Kohlenpulver bestreute Rachenschleimhaut vom Frosch und tödtet ein punktförmiges Stück derselben durch ganz oberflächliche Verbrennung ab, so hört die Bewegung nicht nur in der nächsten Nähe der direkt geschädigten Stelle auf, sondern auch in einem dreieckigen Raume, dessen Spitze an lem gebrannten Punkt und dessen Basis am Schlundeingang liegt.

Der Werth der Flimmerbewegung für den Organismus besteht in der Fortführung von festen Theilchen und von Schleim nach bestimmter Richtung; dementsprechend findet der Cilienschlag aller einzelnen Cilienepithelien in ganz bestimmter Richtung statt, in den Luftwegen gegen die äussere Oeffnung $\mathrm{zu}$, in dem Eileiter gegen den Uterus, in dem Uterus gegen den Eileiter u. s. w. Die Grösse der Arbeitsleistung, deren die Flimmerbewegung fähig ist, erhellt aus Versuchen an der Rachenschleimhaut des Frosches, von welcher unter den gïnstigsten Bedingungen per Quadratcentimeter und Minute beinahe 7 Grammmillimeter Arbeit erhalten wurden. 
Die lebhafte Forthewegung der Samenfäden mit dem Kopfe voraus geschieht in Folge wellenartiger Bewegungen, welche an ihren Schwänzen ablaufen. Die Schwänze verhalten sich hierbei wie lange Cilien von niedrigen Organismen.

Die Bewegung sämmtlicher Cilien ist in ihrer Lebhaftigkeit von der Temperatur und der chemischen Zusammensetzung der Flïssigkeit sehr abhängig; schwache alkalische Reaction ist für dieselbe am günstigsten, etwas stïrkerer Alkali- oder Süure-Grad erhöht zwar zunächst die Beweglichkeit, welche dam aber namentlich in der Sïure sehr schnell schwindet, um bei Neutralisiren der Fliissigkeit wiederzukehren. An Schleimhäuten ron Warmbliitern findet Flimmerbewegung innerhalb enger Grenzen nur in der Nähe von Körpertemperatur statt; Samenfüden ertragen stärkere Temperaturherabsetzung.

Ebenso wie die Muskelbewegung sind auch die ïbrigen Protoplasmabewegungen, die der farblosen Blutkörperchen, der Flimmerhaare und der Samenfïden nicht an die Gegenwart freien Sanerstoffis gebunden. Sie erfolgen zunächst auch in sauerstofffreier Atmosphäre, erlahmen aber hicr viel schneller als bei Sanerstoffinutritt.

\section{'Zweiter Abschnitt.}

\section{Die Körperbewegungen.}

Das Knochengerüst mit seinen Gelenkrerbindungen ist der Apparat, durch dessen Vermittelung die Zustandsänderungen der an ihm ausgespannten quergestreiften Muskeln als Arbeitsleistungen in die Erscheinung treten: hierbci kommt zunächst in Betracht, wie dureh Zusanmenfügung ron Muskelfasern die einzelnen anatomisch einheitlichen Muskeln aufgebaut sind; dieser Aufbau kann so erfolgen, dass der gesammte Muskel bei grosser Länge einen kleinen Querschuitt besitzt und dass die Lüngsaxe der einzelnen Muskelfasern mit derjenigen des Gesammtmuskels zusammenfällt, wie zum Beispiel beim Musculus Sartorius. Ein solcher Muskel ist grosser Hubhöhe fähig, wird aber nur ein kleines Gewicht heben können. Denkt man sich einen solchen Muskel aus Fasern z.usammengesetzt, welche ron dem einen 7.1 dem anderen Ende durch- 
gehen, so übersieht man leicht, dass die Hubhöhe von der Faserlänge, und die Grösse des Gewichtes, welches eben von der Unterlage erhoben werden kann, von der Zahl der Muskelfasern oder von der Grösse des Inskelquerschnittes abhängen wird. Das Gewicht, welches bei maximaler Erregung des Muskels ehen von der Unterlage abgehoben wird, dividirt durch den Muskelquerschnitt, nennt man die absolute Kraft des Muskels; diese ist von der Natur der Muskelsubstanz abhängig und bei rerschiedenen Thierspecies verschieden; man schätzt sie bei den Menschen auf 8 Kilogramm für den Quadrat-Centimeter Muskelquerschnitt. Im Allgemeinen fällt die Faserrichtung nicht nit der Längsaxe des Muskels zusammen, ja sie weicht oft in schr erheblichem Maasse ron derselben ab, sodass olne Weiteres aus der Länge und aus dem Querschnitt eines Muskels seine Fähigkeit zur Längeänderung und Spannungsentwickelung nicht beurtheilt werden kann; für diese Beurtheilung kommt nicht die Grösse des Querschnittes senkrecht zur Längsaxe des Muskels (anatomischer Querschnitt), sondern senkrecht zur Faserrichtung in Betracht (physiologischer Querschnitt). Ein sehr häufig realisirtes Vorkommen ist dies, dass eine Endsehne sich tief in den Muskelbauch hineinerstreckt und dass sich ron hier aus Muskelfasern in schräger Richtung nach verschierlenen Seiten zı anderen, theils strangförmigen, theils flächenhaften (aponeurotischen) Selınen odcr auch direkt zu flächenhaften Muskelinsertionen an Knochen begeben; man nennt solche Muskeln gefiederte Muskeln.

Die feste Anheftung der Muskelfasern an Sehnen oder Knochen ist bewirkt durch Verwebung der lceren Enden der Sarkolemmschläuche mit Bindegewebsfasern und durch Eindringen letzterer zwischen die Muskelfaserenden. Wo die Entfernung von einer Muskelinsertion zu der gegenüberliegenden, gemessen in der Axenrichtung der Muskelfasern, mehr beträgt als 14 Centimeter, kann man mit Sicherheit darauf rechnen, dass die einzelnen Muskelfasern von einer Insertion nicht bis zur anderen lindurchgehen, sondern dass sich zugespitzte Muskelfaserenden innerhalb iler Muskelsubstanz finden. Bei langen Muskeln, wie bei dem Musc. Sartorius des Menschen, giebt es viele Muskelfasern, deren beide Enden innerhalb der Muskelsubstanz selbst liegen. Die Wirkung intramusculär endender Muskelfasern auf die Endsehnen geschielit durch Vermittelung des die Muskelfasern einscheidenden Bindegewebes.

Die Knochen können in Bezug auf die bei der Körperbewegung in Petracht kommenden Krüfte im Allgemeinen als starre Körper betrachtet werden; eine nennenswerthe Ausnahme hiervon machen nur die Rippen, welche bei den Athembewegungen des Thorax Biegungen und I'orfpuirungen um die Längsaxe erleiden. In dem Aufbau der einzelnen linochen macht sich eine merkwiirdige Anpassung an die gleichzeitige 
Anforderung möglichster Leichtigkeit und Festigkeit geltend: die compakte Knochensubstanz besitzt grössere Festigkeit, Dichtigkeit und Schwere: das Knochenmark ist weich, aber wegen seines grossen Fettgehaltes auch leicht. In festen Körpern, welche nach bestimnten Richtungen auf Druck oder Dehnung in Anspruch genommen werden, lassen sich nit Hülfe der analytischen Mechanik Flächen construiren, längs deren die Inanspruchnahme ein Maximum ist, sodass, wenn dem Techniker die Aufgabe gestellt wird, eine Construction unter gleichzeitiger Beruicksichtigung möghichst grosser Leichtigkeit und Festigkeit auszuführen, er die festen aber schweren Massen längs solcher Flächen vertheilt. Nach diesem Princip sind nachweislich die Knochen construirt; der Nachweis hierfür lüsst sich an allen Knochen durchführen, doch springt er am deutlichsten in das Auge an dem Os femoris. Dasselbe ist ein sogenannter Röhrenknochen; in seinem lïngsten mittleren Theil bildet die compakte Substanz eine dicke feste Röhre, welche mit Knochenmark gefuillt ist: an dem oberen Theil, wo wegen der Biegung rer Längsaxe die Bedingungen für die Inanspruchnahme auf Festigkeit complicirter werden, löst sich die compakte Substanz der Riöhre in Lamellensysteme ron ganz bestimmter Richtung auf, wie an jedem Längsschnitt zu erkennen ist; von diesen Lamellensystemen giebt die beigegebene Zeichnung (Fig. 12) eine Anschauung, und sie entsprechen genau den Flächen grössten Druckes und Zuges, wie sie sich bei Berücksichtigung der thatsächlichen BelastungsverhäItnisse aus der analytischen Mechanik ergeben. Es ist sehr bemerkenswerth, dass solche Lamellenziige der spongiösen Kinochensubstanz wesentliche Aen-

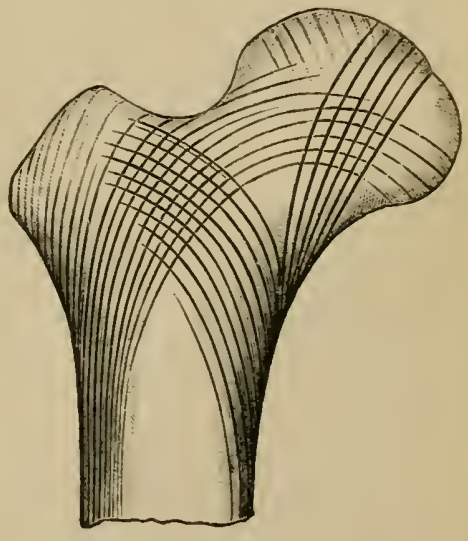

12.

Langsschnitt durch das Kopfende de Os femoris. derungen erleiden, wenn sich die Inanspruchnahme der Knochen unter pathologischen Verhältnissen, wie z.um Beispiel bei Gelenksteifigkeit oder nach Amputationen, ändert.

Die Zusammenfiigung der Knochen zu dem Kinochengerüst durch Vermittelung der Gelenke und Synchondrosen ist eine derartige, dass der gleichzeitigen Rücksicht auf den erforderlichen Grad ron Beweglichkeit einerseits und ron Festigkeit andererseits Rechunng getragen ist.

Synchondrosen bestehen darin, dass eimander zugekehrte Fliichen henachbarter Knochen durch eine Faserknorpelschicht mit einander verwachsen sind; auf diese Weise sind die Wirbelkörper durch die Zwischen- 
wirbelscheiben mit einander verbunden. Der Faserknorpel der Zwischenscheibe ist elastisch und turgescent; bei andauerndem Druck kann der Flüssigkeitsgehalt derselben und damit ihr Volum abnehmen. Körpermessungen, am Abende vorgenommen, ergeben eine erheblich geringere Länge als des Morgens nach der Nachtruhe. Die Beweglichkeit jedes einzelnen Wirbelkörpers gegen seinen Nachbar ist um so grösser, je grösser die Höhe und je kleiner der Durchmesser der Zwischenwirbelscheibe; im einzelnen Element ist sie freilich gering; durch Summation ron Glied zu Glied können aber doch beträchtliche Biegungen und Drehungen der Wirbelsäule zu Stande kommen. Bei den Biegungen muss stets der eine Theil der Zwischenwirbelscheibe gedehnt, der andere zusammengedrïckt werden. Die Beweglichkeit der Wirbelsäule ist in rerschiedenen Gegenden verschieden. Die Halsgegend zeigt eine allseitige Biegsamkeit und eine merkliche Drehbarkeit; in der Brustgegend fehlt die Biegsamkeit nach vorn und nach hinten fast ganz; seitliche Biegungen und Torsionen sind schwach. In der Lendenwirbelsäule ist wieder die Biegsamkeit nach allen Seiten, namentlich nach rechts und links, viel grösser, dagegen fehlt hier die Torquirbarkeit. Diese Verhältnisse sind zum Theil verständlich durch die Abmessungen der Zwischenwirbelscheiben, kleiner Querschnitt am Hals, bedeutende Höhe in der Lende, Niedrigkeit und Breite in der Brustgegend; zum Theil aber erst durch Berücksichtigung der gegenseitigen Lage der Wirbelbögen und ihrer schiefen Fortsätze. Die Gelenkflächen der Processus obliqui sind an der Lendenwirbelsäule sagittal gestellt und hemmen also die Torsion. An der Brustwirbelsänle wird die Biegsamkeit nach vorn und hinten durch die frontale Stellung der Gelenkflächen an den Processus obliqui verhindert.

Bei den Gelenkverbindungen sind die einander zugekehrten benachbarten Kinochen nicht mit einander verwachsen; die Ḱnochen enden vielmehr innerhalb der Gelenke frei mit überknorpelten Flächen; nur von den Rändern dieser Flächen zieht sich eine allseitig geschlossene bindegewebige Membran, das Gelenkinnere begrenzend, von einem Knochen \%um anderen, es ist dies die Kapselmembran des Gelenks, welche bei den verschiedenen Gelenken in verschiedenen Richtungen besondere verstärkte Faserziige, die Ligamenta accessoria, enthält. Eine Gelenklö̈hle bestcht nicht; so weit die Gelenkenden der Knochen sich nicht mit cinander decken, füllt die durch den äusseren Druck nach innen gewölbte Kapselmembran die veränderlichen Zwischenräume zwischen den Knochenenden aus. An dieser Ausfüllung betheiligen sich bindegewebige, blutgefässreiche, epithelbekleidete Auswiichse der ebenfalls mit Epithel hekleideten Kapselmembran, welche Synovialzotten genannt werden. Das Secret der Synorialzotten, die Synovia, ist eine klebrige, fadenzichende, 
klare und firblose Fliissigkeit, welche in diinner Schicht alle im relenk sich berïhrenten Flächen überzicht und sie schliipfrig erhält.

Der Unfing, in welchem zwischen den beiden Gelenkttächen der Kinochen Beriihrmng stattfindet, ist bei den verschiedenen Gelenkarten rersehieden; die vollkommenste Beriihnung findet statt und wird bei den verschiedensten Gelenkstellungen anch beibehalten, wenn die eine GelenkHïche einen 'Theil eines Rotationskïrper's darstellt, die andere ihren Aloguss. In diesem Falle können beide Flächen, ohne dass es zu Dehiscenzen kommt, auf cinander gleiten bei allen Drehnugen um die der Entstehung des Rotationskörpers ₹n Grunde liegende Rotationsaxe. Eine Kingel kann entstanden gedacht werden durch Rotation eines irgendwie im liamme orientirten Kreises um einen beliehigen seiner Inrchmesser. Ein convexer und ein hohler Kingelabschnitt von demselben Durchmesser kömmen also anf einander schleifen bei Drehung $n$ mede beliebige durch den Mittelpunkt gehende Axe. Die grösste Freiheit in der Bewegnngsart triftt man mithin bei den sogenamnten Kugelgelenken oder A throdiën, wie sie das Huift- und das Schultergelenk darstellen. Um Bewegungen ron solcher Mannigfaltigkeit leicht beschreiben zn können, stellt man sich jede wirklich ansgeführte Bewegung vor als herrorgebracht durch sncessive Drehnng mu drei auf einander senkrechte willk ̈̈rlich bestimmte Drehaxen. Diese Axen gehen durch den Mittelpunkt des die Gelenktläche darstellenden Kugelabschnittes und jede derselben indert bei der Drehung um eine der anderen ihre Richtung im Ramm. Die Drehung, welche im Hiiftgelenk um eine bei gewöhnlicher Grundstellung des Beines sagittal gerichtete Axe erfolgt, nennt man lateralwärts Abrluction, medialwärts Addnction; die Drehungen um eine bei gleicher Grundstellung transversal gerichtete Axe nach rorn Beugung, nach hinten Streckung; die dritte Axe fällt zusammen mit der Längsaxe des Oberschenkels und Drehungen um dieselle nennt man Rollungen. Bei horizontal erhobenem Oherschenkel, also in Bengestellung des Gelenkes, steht die Axe, mm welche Irehung hei Ahduction mod Adduction erfolgt, nicht sagittal, sondern senkrecht; 1 m die jetz.t sagittal gestellte Axe vollzieht sich die Rolhnng und so weiter.

Eine hei Weitem einfachere Bowegungsform ist gegehen. Wenn Cylinderflïchen anf einander schleifen; ein Theil eines Cylindermantels bleibt mit seinem Abguss nur in continuirlicher Berührung bei Drehung nm eine einzige Axe, mud zwar mn die $\Lambda$ xe res Cylinders. Gelenke mit dieser Form der (ielenktlïche nennt man Charniergelenke oder Ginglymi; einen Repriisentanten dieser Gelenkart stellt das Eillenhogengelenk dar. Arthrodiën mol (inglyni fisst man zusammen unter der Bezeiclınung ron Schleifgetenken.

Ansser der Bewegungsform kommit bei der Benrtheilung der Ge- 
lenke noch in Betracht der Bewegungsumfang; bei den Charniergelenken geniigt zur Angalle desselben die Angabe einer Winkelgrösse, da nur Drehung um eine Axe möglich ist. Bei den Arthrodiën ist er zum Theil charakterisirt durch den Mantel eines Kegels, dessen Spitze im Kugelmittelpunkt liegt und dessen Oeffnungswinkel in den verschiedenen axialen Ebenen reischieden gross ist; innerhalb dieses Kegelmantels kann die Axe des an der Einlenkung betheiligten Röhrenknochens jede beliebige Lage annehmen. Für jede dieser Lagen müsste dann aber noch die Winkelgrösse der möglichen Rollung angegeben werden. Bei den Schleifgelenken ist der Bewegungsumfang nicht durch die Form des Gelenkes bestimmt, sondern durch äussere Hemmungen, welche beim Anstossen ron Kínochenvorsprüngen orler bei der Spannung von Hülfsbändern der Gelenkkapseln eintreten.

Gelenke, welche bei unvollkommenem Schleifen der Gelenkflächen auf einander die Möglichkeit der Drehung um zwei zu einander senkrechte Axen gestatten, sind das Sattelgelenk und das Eigelenk. Ein Sattel ist auf seiner Sitzfläche in der Längsrichtung des Pferdes ausgehöhlt, in der Querrichtung convex; die Sitzfläche des Reiters dagegen ist in der Längsrichtung des Pferdes gewölbt, in der Querrichtung vertieft. Der Reiter kann, ohne den Schluss im Sattel zu verlieren, mehr nach der rechten oder der linken Seite des Pferdes hiniiberrutschen (Drehungen um eine Längsaxe des Pferdes), oder er kann sich mit dem Oberkürper nach hinten, mit den Beinen nach vorn neigen (Drehungen um eine (queraxe). Beide Bewegungen können auch bis zu einem gewissen Grade combinirt werden; ausgeschlossen ist die Drehung des als starr gedachten Reiters um seine Längsaxe. In dieser Weise reitet das Os metacarpi primum auf dem Os multangulum majus.

Ein Eigelenk stellt das Gelenk zwischen dem Radius und der Handwurzel dar; man kann sich die Gelenkfläche entstanden denken durch $\mathrm{Ab}$ schneiden eines Stückes von einem Rotationskörper, der durch Drehung einer Fllipse um ihre lange Axe entstanden ist rermittelst eines Schnittes, welcher parallel rer Rotationsaxe gefiihrt ist. Bei Drehung um letztere Axe (Heugung und Streckung der Hand) können die Gelenkflächen ohne Dehiscenz auf einander schleifen; hei Drehung um eine rlazu senkrechte und zur Sclnnittebene parallele Axe (Arlduction und Alduction) ist das Sichleifen unvollkommen, doch ist die Abweichung ron der Deckffäche niclit gross; Drehung um eine zu deu beiden genannten Axen senkrechite (Rollung) ist ausgeschlossen. Iic erste $\Lambda x e$, welche die vollkonmenste liewegung gestattet, ist im Handgelenk radio-ulnarwärts gerichtet.

Wiihrend man rlie Sattelgelenke und ligelenke noch $2 u$ den Sihloifgelenken rechnen kann, gielst es eine Kategorie von Gelenken, bei welcher die Gelenkflächen iiberhanpt niemals mit endlich ausge- 
dehnten Stiiclen in vollstimliger oler angenäherter Congruenz sind, wo sie sich rielmehr nur in rinen l'unkte oder lïngs einer linie berühren. Die Bewegung solcher Gelenkttichen anf einamiler kimn nan mehr einen Rollen als einem Schleifen rergleichen, man nenut sie Berührungs- oder Rollgelenke: ein wichtiges Beispiel derselben ist das líniegelenk. Die zwischen den (ielenkfläthen vorhandenen und hei den verschiedenen Gelenkstellungen verschieden grossen und verschieden gelagerten klaft'enden Räume werden nur zum Theil durch Faltungen der Gelenkhapsel selbst ausgefüllt; in den Synovialfalten sind vielmehr Massen eingeschlossen, welche den nöthigen Grad ron Weichheit besitzen, um sich den Formänderungen des übrig bleibenden Raumes zwischen den Gelenkflächen anzubequemen. Beim Kniegelenk sind die erforderlichen biegsamen Massen theils durch die Fibro-cartilagines semilunares repräsentirt, theils durch die Fettpolster in den Plicae synoviales. Für den Bewegungsmodus ist bei dem Kniegelenk ausser der Gelenkform die
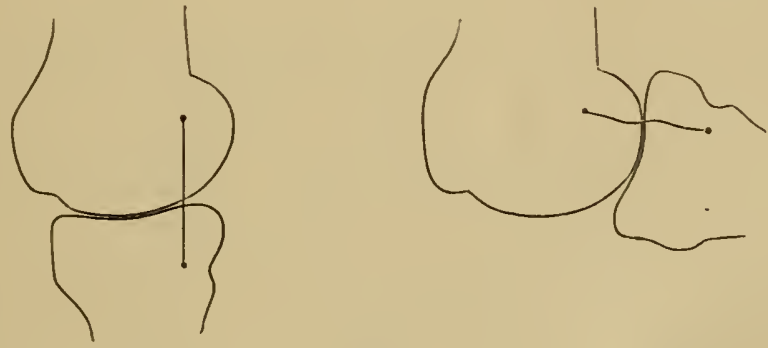

13.

Conchospirale der Kniegelenkfläche des 0 s femoris.

Anordnung der Ligamenta lateralia und rruciata maassgebend. Die Haupthewegung ist die Drehung um die Queraxe des Gelenks, bei welcher die Condylen des Femur auf den Tibiaflächen rollen und schleifen und zwar so, dass der äussere Condylus mehr rollt, der innere mehr schleift. Die Profillinie der Gelenktlïche des äusseren Condylus stellt eine Conchospirale dar, deren Mittelpunkt im Anheftungspunkt des Ligamentum laterale liegt. Bei der Streckung des Cnterschenkels gegen den Oberschenkel riickt die transiersale Berülnungslinie zwischen Condylus und Tibiafläche längs der Conchospirale immer weiter von dem Anheftungspunkt des Ligamentum laterale am Condylus al, so dass dis Ligament hierbei mehr und mehr gespannt wird. Dies ist der Cirund. weshalh beï gestrecktem Bein eine Drehung des Lnterschenkels um seine Längsaxe gegen den Oberschenkel nicht möglich ist. wie bei gebeugtem Knie.

Die Handwurzelknochen und die Fusswurelknochen kehren einander 
Gelenkflïchen zu, deren Beziehung zu den ihnen gestatteten Bewegungen schwer zu erkemen ist; diese Bewegungen sind iibrigens nicht nur wegen der verwickelten Form der Gelenkflächen, sondern auch wegen der Kürze und Straffheit der Hülfsbänder sehr beschränkt; solche Gelenke nennt man Amphiarthrosen oder Schlottergelenke.

Eine ebenso interessante wie schwer zu lösende Frage ist die nach den Kräften, welche bei dem Zusammenhalt der Gelenke eine Rolle spielen. Man hat die Frage einfach dahin beantwortet, dass man sagte: ler atmosphärische Druck erhalte die Gelenkflächen in gegenseitiger Berührung, ohne dass die Schwere durch Muskelkraft zu iiberwinden wäre. In der That, wenn man an der aufgehängten Leiche die das Hïftgelenk umgebenden Muskeln und die Kapsel dieses Gelenkes selbst mit ihren Ḧ̈lfsbändern durchschneidet, so bleibt der Gelenkkopf in der Fossa acetabuli ohne wahrnehmbare Senkung. Hier wird das Isein in der That durch den Luftelruck getragen, welcher dazu vollkommen ausreicht, da eine Luftsäule von der Höhe der Atmosphäre und dem Querschnitt des Pfanneneingangs mehr wiegt als das Bein. Macht man an der Leiche von der Innenseite des Beckens ans eine kleine Oeffnung in der Fossa acetabuli, sodass Luft rlurch dieselbe in das Gelenk eindringen kann, so fällt der Gelenkkopf mit zischendem Geräusch aus der Pfanne. So lange die Fossa acetabuli geschlossen war, hätte Luft in die Gelenkhöhle nur zwischen Schenkelkopf und Pfannenrand cindringen können, respective auf diesem Wege wäre eine Fortpflanzung des atmosphärischen Druckes auf die inneren Theile der Gelenkfliissigkeit möglich gewesen; zwischen Schenkelkopf und Pfannenrand befindet sich aber eine nur capillare Schicht einer viscösen Fliissigkeit, welche werler durch Luft verdrängt wird, noch auch leicht den Druck fortleitet. Das Haften capillar benetzter Flächen gegen senkrecht zu der Berïhrungsfläche wirkenden Zug spielt bei dem Haften des Schenkelkopfes eine untergeordnete Rolle. In der Tiefe der Pfanne, wo die Fossa acetabuli angebohrt wurde, ist die Berührung zwischen den Gelenkflächen nicht so imnig wie am Pfannenrande, sodass hier selbst bei kleincr ()effnung schnell genug Luft eindringt und das Gewicht der auf der (ielenkflïiche stehenden Luftsäule grösser wird, als das Gewicht der den Schenlicl nach oben driickenden Luftsiiule, verringert um das Gewicht des Sichenkels.

Bein lehenden Menschen kommen ansser der Schwere und dem Luftdruck ferner in Betracht der Tonus der Muskeln, der Turgor der Synovialgewcbe wnd der Druck, unter welchem die Synovia abgesondert wird; man hat gemeint, lass wegen des Luftdruckes keine Muskelkräfte erforlerlich wären, $1 \mathrm{~m}$ den Schenkel zu tragen, thatsächlich sind die Inskeh in Leben aber nie so erschlafft, lass sie nicht zum Aneinander- 
driicken der Gelenkflächen beitriigen. Der Druck, unter welchem die Synovialfliissigkeit abgesondert wird, muss mindestens so stark sein wie der Blutdruck in den Capillaren. Dieser Druck wirkt im Allgemenen in demselben Sinne wie die Schwere, das heisst anf Entfernung der (ielenkflïchen von einander. Zwischen diesen Kräften einerseits und d'n antagonistischen Krä̈ften andererseits muss stets Gleichgewicht bestehen. Bei der Beurtheilung dieses Gleichgewichtes ist zu bedenken, dass, wenn der äussere Luftdruck abnimmt, auch der Druck in den C'apillitren (seinem absoluten Werth nach) abnehmen muss. Wem dies alles beriicksichtigt wird, so kommt man zu der Einsicht, dass man zwar nicht in Kilogrammen genau angeben kann, wie viel den Muskeln an Anstrengung zum Tragen einer Extremitait und zum Zusammenhalten des (ielenkes durch den äusseren Luftdruck erspart wird, dass aber immerhin dieser Druck im Sinne einer solchen Ersparniss wirkt.

Die am meisten in das Auge fallende Wirkung der Muskelı bestelıt jedenfalls nicht in dem Zusammenhalten des Knochengerïstes, sondern in der regelmässigen Bewegung seiner Theile gegen einander. Der grössere Theil der Muskeln überspringt je ein Gelenk, das lieisst findet seine Insertionen an benachbarten Knochen; diese Muskeln nemnt man eingelenkige Muskeln, im Gegensatz zu den zwei- und mehrgelenkigen Muskeln. Ein eingelenkiger Muskel ist der Musculus brilchialis anterior, ein zweigelenkiger ist der Musculus semitendinosus.

Die Beurtheilung der Wirkung eingelenkiger Muskeln. welche (harniergelenke ïberspringen, ist verhältnissmässig einfich: im Allgemeinen kann der eine der dazu gehörigen Knochen als fest im Raume, der andere gegen denselben bewegt gedacht werden. Die Muskelkraft kommt fuir die Drehung nur in der Richtung der gradlinigen Verbindung zwischen den beiden Insertionspunkten zur Geltung. Sie greift stets in geringerer Entfernung von der Drehaxe an als die bei der Bewegung zu iiberwindende Kraft. In dem einfaehsten Falle, dass ein belastetes oder umbelastetes Glied gehoben werden soll, greift letztere Kruift im schwerpunkt der zu bewegenden Masse an und lat die Richtung der Schwerkraft. Die Bewegung wird erfolgen, wemn das Drehungsmoment der Muskelkraft grösser wird als das Drehungsmoment der Schwerkraft. Das Drehungsmoment findet man auf folgende Weise: in der Richtung der wirkenden Kraft zieht man von ihrem Angriffspunkt aus eine Linie, deren Länge man proportional dem Gewichte macht, welchem die Kraft das Gleichgewicht hält; nach dem Princip des Parallelogranmms der Kriafte zerlegt man diese Kraft in eine der Längsaxe des Knocliens parallele und in eine dazu senkrecht gerichtete: das Produkt letzterer Kraft in die Entfernung ihres Angriffspunktes ron der Drehaxe ist das Drehungsmoment. 
Dá der Angriffspunkt der Muskelkraft meistens sehr viel näher zur Drehaxe liegt als der Schwerpunkt der zu bewegenden Masse, so exzeugt der Muskel bei kleinen Längenänderungen verhältnissmässig umfangreiche Bewegungen und er hat hierbei verhältnissinässig grosse Spannungen zu entwickeln, was ihm, wie wir oben gesehen haben, um so leichter wird, je geringere Verkürzung er erleidet. Einen je kleineren Winkel die Richtung der Muskelkraft mit der Längsaxe des Knochens bildet, ein um so kleinerer Antheil derselben kommt für das Drehungsmoment in Betracht; ein Minimum hat dieser Winkel im Allgemeinen bei vollkommener Streckung des Gelenkes. In dieser Lage ist aber der Muskel auch am meisten ausgedehnt, sodass bei gleicher Erregungsgrösse hier seine Spannung am grössten ist. In dem Maasse wie die Bewegung im Gelenk fortschreitet, nimmt der fragliche Winkel zu und die Länge des Muskels ab, es ist jetzt ein grösserer Theil der Muskelkraft für die Drehbewegung wirksam, diese Kraft selbst hat aber abgenommen, sodass das Drehungsmoment bei der Bewegung sich nicht stark zu ändern braucht. Um eine Drehung von gleichem. Winkelgrade zu erzeugen, muss ein bei gestrecktem Glied schräg angreifender Muskel in der Gegend der Beugung von $90^{\circ}$ eine grössere Längeänderung exfahren, als in der Gegend der Streckung und grösseren Beugung.

Bei Gelenken mit grösserer Freiheit der Bewegung wird die Beurtheilung der Wirkungsweise der einzelnen Muskeln sofort sehr verwickelt, weil sich die Beziehungen jedes einzelnen Muskels zu der Drehaxe und zu der Längsaxe des beweglichen Knochens mit den Zustandsänderungen der übrigen Muskeln sofort mitändern. Noch verwickelter werden die Verhältnisse, wenn zweigelenkige Muskeln in das Spiel treten. Die Musculi semitendinosus, seminiembranosus, gracilis und sartorius bilden eine zweigelenkige Muskelgruppe, welche von den Beckenknochen zu den Unterschenkelknochen geht; fuir den Oberschenkel sind sie Dorsalffectoren, Adductoren und Einwärtsroller, für den Unterschenkel sind sie Beuger. Auf den Oberschenkel wirken sie am stärksten, wenn das Bein im Knie grestreckt ist; auf Kniebeugung wirken sie am stärksten, wenu der Oberschenkel an den Leib gezogen wird. In letzteren Falle bedingen sie sogar Kniebeugung, ohne dass sie in Erregung gesetzt werden, weil sie bei gestrecktem Knie- und Hüftgelenk iiber ilne Ruhelänge ausgedehnt sind. Eine sehr merkwürdige Rolle fällt dem zweigelenkigen Quadriceps femoris beim Bergsteigen oder Treppensteigen zu: das anf die höhere Stufe gesetzte Bein muss, damit die Körperlast gehoben wird, im Kuie- und Hüftgelenk gestreckt werden; der Quadriceps ist Strecker für das Knie- und Beuger fuir das Hüftgelenk, die Streckung des Hüftgelenkes geschieht hauptsächlich rlurch die Glutaei. Indem die Glutaei das Hüftgelenk strecken, üben sie zugleich, wenn der Quadriceps 
nicht gedehnt werden kam, durch dessen Vermittelung eine streckendo Wirkung auf das Kniegelenk aus; der (Quadriceps ger:ith nu so viel in Erregung, dass er die Wirkung der Glutari auf das Kniegelenk äbertragen kam, er verkiiryt sich hierbei nicht, sodass die eigentliche . Irbcit bei dem Steigen nicht ron ihm, sondern ron den Glutaei geleistet wird. Die Anbringung der grossen, dic Hauptarbeit leistenden Muskelmasse in der Nähe des Rumpfes, statt lïngs der in grösser'm limfange zı bewegenden Extremitäten, ist in hohem Gradle zweckmaissig. In höherem Grade als beim Menschen finden wir dies Princip bei den guten Läufern unter den Thieren rerwirklicht, wo der Zug grosser nahe dim Rumpt gelegener Muskelmassen durch lange, oft mehrere Gelenke ïberspannende Sehnen den weit entfernten Gliedern zugeleitet wird. llas anffallendste? Beispiel dieser Art findet sich beim Strauss.

Die wichtigsten Verrichtungen, bei denen die Vechanik des Körperskeletts in Betracht kommt, sind die Ortsbewegungen und die Innehaltung der aufrechten Stellung und Haltung. Das Gehen und Stchen in aufrechter Haltung sind Attribute des Menschengeschlechtes, durch welche sich dasselbe wesentlich ïber das Thier erhebt. Durch die aufrechte Haltung ist die freie Entfaltung der Brust und die Verwendung derselben im Dienste der Sprache gewährleistet, ihr verdankt der Mensch die Ausbildung der Arme und Hände zu der allseitigen Beweglichkeit, welche die Vorbedingung für die geschickte Verwendung im Dienste des Niitzlichen und Schönen ist; ihr die Erhebung des Hauptes und die Blickrichtung; welche nur bei ausgiebiger Drehung um die senkrechte und horizontale Axe freie Orientirung in der Aussenwelt gestattet.

Viel Aufmerksamkeit ist dem Studim der Frage zugewandt no1den, welche Einrichtungen im Bau des Skelettes und des Bänderaplarates vorhanden seien, um das Innehalten der aufrechten Stellung uml Haltung bei einem Mindestmaass von Muskelanstrengung zu ermöglichen. Erforderlich hierzu ist in erster Linie Feststellung der Unterschenkel auf den Fusswurzeln, der Oberschenkel auf den Unterschenkeln und des Beckens auf den Oberschenkeln. Gleichzeitige Rotation in beiden Fussund in beidlen Kniegelenken ist erschwert, wenn die Ixen dieser Charniergelenke durch Auswärtsrollung der Oberschenkel im Hüftgelenk zur Divergenz gebracht sind; in der That pflegen wir mit auswärts zeigenden Fussspitzen zu stehen. Das Loth durch den gemeinschaftlichen Schwerpunkt von Rumpf, Kopf und Armen faillt bei aufrechter Haltung hinter die Verbindungslinie beider Hïftgelenke, sodass die Schwere aul" Rïckwärtsdrehung des Beckens gegen die Oberschenkel hinwirkt; dieser Drehung setzt die Spannung beider Ligamenta ilio-femoralia eine enge Grenze.

Zweifellos wird durch diese Finrichtungen der Muskelapparat bei 
dem Innchalten der aufrechten Stellung sehr unterstuitzt, seiner steten Nitwirkung bei derselben aber nicht ïberhoben; eine noch viel wesentlichere Riolle fällt demselben zu bei der Balancirung des Kopfes auf dem Halse und bei der Streckung der Wirbelsäule, sowie bei der Znrïickziehung der Schultern, durch welche letztere beide Momente die freie Entfaltung der Brust bedingt ist. Das Zusammenwirken von Muskelgruppen zur Innehaltung der anfrechten Stellung und Haltung in bequemer aber doch wohlanständiger und der Gesundheit zuträglicher Form erfordert nach vollendeter Uebung nicht das Eingreifeni bewusster Willensimpulse, vielnehr werden die uniusbleiblichen zuf:illigen Aenderingen gleich in ihrem Entstehen durch einen Mechanismus compensirt, dessen Einrichtung in der Lehre vom Centralnervensystem behandelt werden wird, es handelt sich um zweckmässig geordnete Reflexe.

Das Gehen ist die horizontale Vorwärtsbewegung des Körpers durch das abwechselnde Spiel der Beine. Während das eine Bein, das Stïtzbein, dem in horizontale Geschwindigkeit nach vorn versetzten Kö̈rper zuerst zur Stiitze dient, während es dann durch Streckung und Abstossen vom Boden dem Schwerpunkt eine neue Beschleunigung nach vorn oben ertheilt, welche mit'der Beschleunigung der Schwerkraft zusammen eine Beschleunigung in annähernd horizontaler Richtung ergiebt, schwingt das andere Bein, das Schwungbein, an Rumpfe hängend, an dem Stiitzbein vorbei, um dann dessen Rolle zuerst zum Stiitzen, dann zum Stossen zu übernehmen.

Das Schwungbein wird zum Stuitzbein ( $a, 1$ und $d, r$ ), indem es, bei
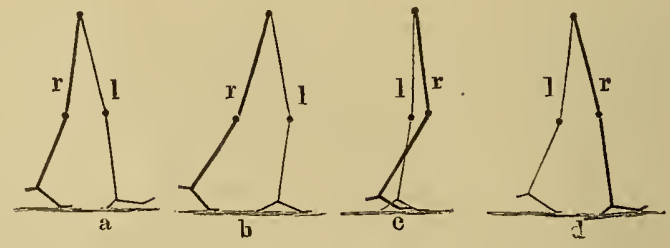

14.

Schwungbein und Stützbein.

kurzem Schritt, im Knie fast gestreckt, bei langem mehr gebeugt, eine halbe Schrittlänge vor der durch die augenblickliche Lage des Schwerpunktes gehenden Lothlinie mit der Ferse den Boden berïhrt, ehe noch das bisherige Stiitzbein ( $a, r$ und $d, l)$ den Boden verlassen hat. Nähert sich der mit Geschwindigkeit in horizontaler Richtung behaftete und in dieser durch den letzten Akt des bisherigen Stiitzbeins noch beschleunigte Schwerpunkt der durch die Ferse gehenden Lothlinie, so löst sich die Fussspitze des bisherigen Stiitzbeins (b, r) vom Boden. Inzwischen 
lat sich die Fusstlïche des numnehrigen Stiitzbeins (b, I) dem Fussboden angelegt und sein Kinic hat sich gebeugt. Ohne letztere Bewegung wiirde der Schwerpunkt seine jetat etwas nach rorn unten geneigte Bahn nicht ungehindert verfolgen kïnnen, er wiirde also eine muweckmässige Verzögerung erfahren. Sobald der Schwerpunkt des Körpers die Lothlinie über rler Ferse passirt hat, beginnt das Kinie sich wieder zu strecken (c, l); sobald er durch die Lothlinic ïber dem Capitulum ossis metatarsi primi gegangen ist, löst sich die Fer'se unter Tebergang dos Fusses in Plantarflexion vom Boden (d, l). 1)ureh die Streckung in Knic- und Fussgelenk erhält der Schwerpunkt jene schon oben erwähnte Beschleunigung nach vorn und oben, welche mit der Beschleunigung durch die Schwerkralt zusammen eine resultirende Besehleunigung in annähernd horizontaler Richtung ergiebt. Die dem Körper dadureh ertheilte lebendige Kraft muss zu der Unterhaltung der Bewegung des Schwerpunktes nach vorn ausreichen bis das andere Bein, zum Stiitzbein geworden, sich zu strecken beginnt.

Das Stiitzbein wird zum Schwungbein dadureh, dass die Strecknuskeln erschlaffen, in Folge dessen beginnt dies Bein, dem Pendelgesetz folgend, nach rorn zu schwingen; da der Oberschenkel schneller schwingt als der durch das lose gewordene Kniegelenk nit ihm rerbundene Unterschenkel, so wird schon hierdurch eine zunehmende Beugung im Kniegelenk eingeleitet. ' /u derselben Zeit ist das Stïtzbein in der durch die Bahn des Schwerpunktes bedingten Beugung seines líniegelenkes schon einigermaassen vorgeschritten $(b, 1)$. Das Schwungbein muss also, um frei durch die Luft schwingen zu können, ohue dass seine Fussspitze auf dem Boden schleift, auch seinerseits stark rerkürzt werden durch Beugung im Ḱniegelenk und Dorsalthexion des Fusses (e, r). Die durch den voran schwingenden Oberschenkel bedingte Kiniebeugung ist allein nicht im Stande, die Fussspitze über den Boden zu erheben, es muss active Beugung hinzukonmen. Würde die active Beugung im Kniegelenk durch Muskelı bewerkstelligt, welche ausser dem Kuniegelenk nicht auch das Hüftgelenk übersetzen, so könnte das Bein als freies Pendel schwingen. Der einzige zu derartiger Leistung befïhigte Muskel ist der Musculus gastroenemius, welcher aber gleichzeitig den Fuss plantar flectiren und durch letztere Wirkung das Bein um so viel verlängern würde, als es durch Kiniebengung rerkiirzt wird. An der nothwendigen activen Kniebeugung des Schwunghbeins mïssen also noch andere nieht gleichzeitig auf den Fuss wirkende Muskeln betheiligt sein, und hierfür sind nur solche disponibel, welche ausser dem Kniegelenk auch das Hüftgelenk übersetzen (semitendinosus, semimembranosus u. s. w.), und welche dadurch hemmend auf das freie Pendeln des Beines einwirken. 
Das Schwungbein verhält sich also nicht wie ein freies Pendel, son dern wie ein solches, welches unter dem Einfluss hemmender und wahrscheinlich auch antagonistischer (Quadriceps) die Schwingung beschleunigender Muskelzüge schwingt. Immerlin ist es ein Pendel, dessen von der Beinlänge beherrschte Schwingungsdauer auf die Schnelligkeit der Schrittbewegung von Einfluss sein muss. Die Pendellïnge des Schwungbeins, das heisst die Entfernung seines Schwerpunktes von der Hüftgelenkaxe ist ausser von der Körpergrösse abhängig von der Schritt-
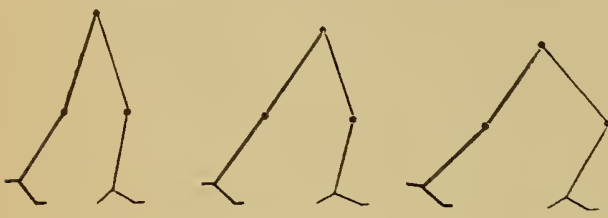

15.

Verschiedene Schrittlänge.

länge; je grösser der Schritt gemacht wird, um so tiefer muss das Hüftgelenk getragen werden nach einfachem geometrischem Gesetze, um so mehr muss also das Schwungbein durch Beugung verkürzt werden, um ohne Schleifen am Boden vorwärts schwingen zu können, um so kürzer wird also seine Schwingungsdauer. So kommt es, dass sich mit der Verlängerung des Schrittes ohne Weiteres eine Beschleunigung desselben vergesellschaftet und umgekehrt. Bis zu 77 Schritten in der Minute verlängert sich der Schritt mit zunehmender Schrittzahl, am stärksten zwischen 65 und 77 Schritt, um darïber hinaus wieder abzunehmen. Fine Ersparung an Muskelkraft ist fuir das Schwungbein dadurch gegeben, dass der Oberschenkelkopf durch Luftdruck in der Pfanne erhalten wird.

Bei der voraufgehenden Darstellung des Gehens wurde Gewicht darauf gelegt, dass es im Verlaufe jedes Schrittes eine Zeit giebt, während welcher beide Füsse den Boden beriihren; unter einem Schritt wird hier rasjenige verstanden, was sich in der Zeit zwischen dem Loslösen der einen Fussspitze rom Boden und dem der anderen abspielt. Das Verhältniss der Dauer des beiderseitigen Auftretens zu derjenigen des Schrittes ist abhängig ron der Schrittzahl in der Zeiteinheit, von der Körperbelastung und von der Ermiidung. Bei der Beschleunigung des Schrittes ohve Körperbelastung von 40 bis 100 in der Ninute nimmt die Dauer des beiderseitigen Auftretens schneller ab, als die des Schrittes, sodass tas Verhältniss beider sich von eincm Viertel bis auf ein Achtel verkleinert. In absolutem Maasse nimmt die Daner des beiderseitigen Auftretens hierbei von $7 / 40$ auf $2 / 40$ Secuude ab. Nit Zunahme der Körperbelastung wächst das genannte Verhältniss bis auf ein halb bei der grössten Belastung. Ausser der Belastung vergrössert auch die Ermürlung das Verhältniss, sodass letzteres als Maass der Ermüdung beim Marschiren beniitzt werden kann. Um Beobachtungen letztbezeichneter 
Art auszufïhren, bedient man sich des Odographen Marey's, dessen Princip darin besteht, dass Signale, welche von Apparaten aufgenommen werden, die zwischen Ferse und Stiefelsohle angebracht sind, einem rou dem Marschirenten getragenen Registrirapparat durch Luftleitung oder atuf elektrischem Wege mitgetheilt werden.

Beim La ufen wird die Dauer des beiderseitigen Auftretens zu Null und beim Sprunglauf, sowie bei sehr schnellem gewöhnlichem Lauf giebt es eine Zeit, wïlırend welcher kein Fuss den Boden berïhrt.

Die Zweckmässigkeit einer Gangart, das heisst das Verhältniss des erreichten locomotorischen Effectes zur aufgewendeten Muskelanstrengung, kann beurtheilt werden nach der Bahn, welche der Schwerpunt beschreibt, denn je gradliniger diese Bahn ist und je gleichmässiger die Geschwindigkeit, mit welcher sie rerfolgt wird, um so reiner kommt die aufgewendete Muskelarbeit dem locomotorischen Effekt zu Gute.

Vollkommen gradlinig und von constanter Geschwindigkeit ist die Bewegung des Schwerpunktes selbst bei der zweckmiissigsten Gangart nicht. Bei jedem Schritt wird der Schwerpunkt einmal gehoben und cinmal gesenkt; bei dem einen Schritt weicht er nach rechts, bei dem nächsten nach links ab; dazu kommt eine ebenfalls mit Verlust von Muskelarbeit verbundene Drehung der gemeinschaftlichen Hüftgelenkaxe unn die Lothlinie.

Am lö̈chsten ist der Schwerpunkt beim Durchgang durch die Lothlinic des Fussgelenkes, am tiefsten während des beiderseitigen Auftretens; nach rechts weicht er ab wïhrend das rechte Bein Stiitzbein ist, und die Pfanne des Schwungbeins bleibt während der ersten Hälfte des Schwingens hinter derjenigen des Stützbeins zurïck, um derselben während der zweiten Hälfte des Schwingens vorauszueilen. Am grössten ist die horizontale Geschwindigkeit des Schwerpunktes bei der Loslösung des Stïtzbeins vom Boden, an kleinsten während des ersten Theiles der Streckung des Stützbeins nach Durchgang des Schwerpunktes durch die Lothlinie des Fussgelenkes.

Bahn und Geschwindigkeit des Schwerpunktes, sowie der übrigen bei dem Gehen in Betracht kommenden Punkte und Linien können beurtheilt werden nach successiven photographischen Momentaufnahmen, welche von Versuchspersonen gewounen werden, auf deren sonst vollkommen schwarzer Kleidung die Punkte und Linien hell leuchtend gemacht sind: mit solchen Methoden sind die hier angedeuteten zeitlichen und quantitativen Verhältnisse der das Gehen ausmachenden Gliedbewegungen untersucht worden. In Bezug auf die \%weckmässigkeit verschiedener Gangarten ist bisher nur so riel ermittelt, dass bei Vermelrung der Schrittzahl der Gang bei 85 Schritt in der Minute insofern unzweckmässig wird, als er zur Herrorbringung einer kleineren Körper- 
geschwindigkeit als der Lauf von gleicher Sprungzahl liefert, eine grössere Arbeitsleistung erfordert. Der zweckmässige Gang wird erleichtert durch eine Fussbekleidung, welche einiges Gewicht hat und deren Sohle fest, elastisch und nach vorn etwas länger wie der Fuss ist.

Der Spr ung mit einseitigem Abstoss erfolgt, nachdem dem Schwerpunkte beim Anlauf eine grosse Geschwindigkeit in horizontaler Richtung ertheilt ist, durch eine plötzliche Streckbewegung des vorher stark gebeugten alustossenden Beines; die starke Beugung wird durch besondere Verlängerung des letzten Schrittes des Anlaufes erzielt, je grösser die Länge dieses Schrittes ist, um so tiefer wird die Beugung des vorgesetzten Beines. An der Streckbewegung betheiligen sich die Streckmuskeln des Hüft-, Knie- und Fussgelenkes. Ausserdem wird den Armen eine schnelle Bewegung nach vorn ertheilt, sodass die ihnen ertheilte lebendige Kraft die Vorwärtsbewegung des Gesammtkörpers befördern hilft. Sowie der Körper den Boden verlassen hat, beschreibt sein Schwerpunkt eine Parabel, an deren Bahn nichts weiter geändert werden kann. Die Lageänderung der einzelnen Gliedtheile gegen einander durch Muskelzug ist aber jeden Augenblick möglich; mit dieser sind Drehungen des Körpers um den Schwerpunkt verbunden. Vor dem Niedersprung werden die Beine nach vorne gestreckt, sodass die Fussspitzen zuerst den Boden beriihren. Durch Nachlass der Contraction der Strecker wird es bewirkt, dass die noch vorhandene lebendige Kraft in Dehnung derselben sich erschöpfen kann und dass ein Stoss durch Vermittelung der gestreckten Beine auf das Rïckgrat vermieden wird.

Bei dem Abspringen von einem bewegten Fuhrwerke hat der Schwerpunkt des Körpers im Moment der Berïhrung des Bodens noch annähernd die Geschwindigkeit nach vorn, welche das Fuhrwerk besitzt. Sobald der Boden berïhrt ist, muss also der Schwerpunkt mit dieser Geschwindigkeit einen Kreisbogen um den Berührungspunkt besclureiben, wenn nicht Muskelkräfte ins Spiel treten. Das Ueberfallen des Körpers nach vorn kann durch Wirkung der Beugung im Knie, namentlich aber durch die Wirkung der kräftigen Streckmuskeln des Hüftgelenks, der Glutaei, sowie der Rückenmuskeln weit leichter verhindert werden, als das Ueberfallen nach hinten durch die Bengung in der Hïfte und Strecknng im Knie: deshalb muss das Abspringen stets mit dem Blick nach der Fahrrichtung geschehen.

Der Sprung mit beiderseitigem Abstoss erfolgt so, dass die stark gebeugten Beine plötzlich gestreckt werden; hierbei erhält der Schwerpunkt rler unnittelbar bewegten Theile eine starke Beschleunigung nach oben, sorlass die lebendige Kraft der bewegten Masse weit mehr wie ausreicht, um die zunächst nach unten gedrüickten Füsse vom Boden zı lösen; selhstverständlich nuïssen die Fïsse, so lange dem Schwer- 
punkt weitere Beschlemnigung ertheilt wird, mit riner dieser Beschleunigung proportionalen kiraft dem Borlen angedrielit werden: solabl alser die Streckung vollkommen erfolgt ist und der Schwerpunkt nicht weiter beschleunigt wird, hört auch der Druck auf den Loden anf und die Füsse werden wegen ihres continuirliehen Zusammenhanges mit der weit grösseren bewegten Masse von dieser mitgcnommen. Der Druck, welcher vor dem Absprung auf den Boden ausgeül)t wirl, lïsst sich sehr gut reranschaulichen und anch messen, wenn der Absprumg von ciner vorher iquilibrirten Brïckenwaage erfolgt.

Die erstamliche Gelenkigkeit, welehe die sogenamnten Schlangenmenschen oder Kantschukmänner zur Schan tragen, verdanken dieselben nicht einer abnormen Biegsamkeit ihrer Knochen oder einer aussergewöhnlichen Dehnbarkeit ihres Bänderapparates, sondern der von Jugend an auf diesen Punkt gerichteten Uebung ihres Nervmuskelsystems. An der Leiche eines heliebigen gewöhnlichen Menschen lassen sich die anffallendsten Körperhaltungen von Schlangenmenschen nachahmen, ohme dass Zerreissungen erfolgen.

\section{Dritter Abschnitt.}

\section{Das Nervengewebe.}

Dem Nervengewelo rerdankt es der thierische Organismus, diss in demselhen eintretende Zustandsünderungen mit grosser Schnelligkeit und Sicherheit entsprechende Zustandsänderungen in entfernten Organen und Gewebselementen hervorufen können: bei den Pflanzen stehen weit ron einander entfernte Elemente ebenfalls in Wechselbeziehung, wie zum Peispiel die Spaltïffnungszellen an der Epidermis der Bliitter und das resorbirende Epithel der Wurzelscheiden, bei Aenderung der Transpiration in der Luft :indert sich auch die liesorption in lem Boden. Ilier ist aber der regulirende Finfluss an sehr mannigfaltige Processe gebunden, welehe sich in zwischenliegenden verschiedenartigen Elementen ahspielen. Bei dem Thiere bestehen besondere Bahnen, welche einen eigenartigen Process anf grosse Strecken mit grosser Geschwindigkeit in der homogenen Substanz eines eigens differenzirten Protoplasmas fortzuleiten im Stande sind. Jede solcher Bahnen hat zwei Endapparate, von denen 
der eine im Allgemeinen in der Peripherie, der andere im Centrum gelegen ist. Peripherische Apparate sind grossentlieils solche, welche an der empfindlichen Oberfläche gelegen, durch Einwirkung von aussen in Erregung rersetzt werden: dies sind die Aufnahmeapparate peripherischer Nerren. Die in ihnen erzeugte Erregung pflanzt sich in den zugehörigen Nervenfasern centralwärts fort; diese Nervenfasern nennt man deshalb centripetale. Im Centralnervensystem, das heisst im Rückenmark und im Gehirn, sind die centripetalen Nervenfasern durch Schaltstiicke mit anderen Nerrenfasern verbunden, welche die Erregung centrifugal leiten; die peripherischen Endapparate dieser centrifugalen Nervenfasern nennt man Erfolgsapparate, zu ihnen gehören in erster Linie die quergestreiften und glatten Muskelfasern, welche durch besondere nerröse Endapparate mit den Nervenfasern verbunden sind.

Die centralen Endapparate der centrifugalen und wahrscheinlich der centripetalen Nervenfasern sind Nervenzellen; diese Zellen sind durch intracentrale Leitungsbahnen mit einander verbunden. Die physiologischen Elemente, aus denen sich das Nervensystem aufbaut, sind also je eine Leitungsbahn mit zwei zugehörigen Endapparaten; die Leitungsbahnen sind durch Nervenfasern repräsentirt, die Endapparate einerseits durch Nervenzellen, andererseits durch besonders modificirte nervöse Gebilde, welche zum Theil zur Aufnahme der Erregung, zum Theil zur Tebertragung dersellen auf andere Gewebselemente dienen.

Die Eigenschaften der Nervenfasern können wir am besten an den peripherischen Nervenstämmen studiren. Ein peripherischer Nerv besteht aus einer grossen Anzahl ron Nervenfasern, welche durch Bindegewebe zusanmengehalten werden. Auf dem Querschnitt sieht man den ganzen Nerr ron einer bindegewebigen Haut umfasst, ron welcher sich Scpta in das Innere erstrecken; diese Septa anastomosiren, spalten sich mehrfach in ebenfalls contluirende Septat und so fort, sorlass die Querschnitte der Nervenfasern selbst in Gruppen abgetheilt erscheinen durch rlie interfasciculären Nerrenscheiden. Die feinsten Septa umschliessen primäre Gruppen; gröbere eine Anzahl solcher primären zu secundären und so fort. Das Bindegewebe ist je nach den mechanischen Bedingungen, welchen der Nerr wegen seiner Lage ausgesetzt ist, verschieden r'eichlich; es entliält an manchen Orten in den äusseren Schichten Fettzcllen eingelagert. I):s Bindegewebe der Nerven fuihrt Blutgefitisse, welche aber spärlich sind. Die Nervenfasern scheinen in den ungcdehnten Nerven einen leicht geschlängelten Verlauf zu lıben, sorlass sie sich bei der Dehnung der Nerven, wie sie manche Gliedbewegung brgleiten muss, nur zu strecken brauchen, ohne selbst gedehnt zu werden: lierauf wrist eine regelmässige, mit blossem Auge sichtbare Querstreifung zartur Terren, wie zum Beispiel des Nervus vagus des Kanin- 
chens und des Ischiarlicus vom Frosch hin; man nennt sie die Fontana'sche Bïnderung. Die interfasciculären Scheiden senten feinste bindegewebige Ausläufer zwischen die einzelnen Fasern der primären Gruppen. Jede dieser intrafasciculären Bindegewebsscheiden findet einen röhrenartigen Abschluss durch ein endothelartiges Häutehen (Henle'sche Scheirle), in welcher Röhre die Nervenfaser frei in einer dïnnen Schicht Gewebsfliissigkeit suspendirt liegt. Die Nerrenfaser selbst ist äusserlich begrenzt durch eine structurlose Membran, die Schwann'sche Scheide, an deren innerer Wand in regelmässigen Abständen líerne mit kleinen Resten undifferenzirten Protoplasmas liegen. Das Centrum der Nervenfaser wird ron einer durch Tinctionsfähigkeit ausgezeichneten Substanz eingenommen, welche den Axencylinder der Nervenfaser billet. Bei gewisser Behandlungsweise, speciell mit Silbernitrat, erscheint der Axencylinder fein längsgestreift und zeigt gelegentlich auch eine Querstreifung. Letzteres soll besonders dann eintreten, wenn der Nerr ganz frisch in Behandlung genommen war, nachdem man ihn vorher stark und andauernd erregt hatte. Den Raum zwischen dem Axencylinder und der Schwann'schen Scheide mit den Kernen und Protoplasmaresten nimmt eine das Licht stärker als der Axencylinder brechende Substanz ein, das Iyelin, welches sich mit Osmimmsäure schwarz fürbt und welches beim $\mathrm{Ab}$ sterben eigenthïmlich knollige Formen amimmt, in denen es anch beim Zerzupfen frischer Nerren in destillirtem Wasser herrorquillt. Das Myelin bildet die sngenannte Markscheide der meisten Nervenfasern. Diese Markscheide besitzt bei verschiedenen Nervenfisern eine rerschieden starke Entwickelung und scheint auch entweder ganz fehlen orler aus einer Substanz mit anderen Eigenschaften als das Myelin bestehen zu können, sodass man myelinhaltige und myelinfreie Nervenfasern unterscheidet. Die myelinhaltigen Nerventasern überwiegen in den peripherischen Nerren, sodass man auf dem gefärbten Querschnitt derselben meist jerlen farbigen Axencylinder ron einem Hof ron Myelin umgeben sieht, welcher farblos sein kann oder nach Osmiumbehandlung schwarz ist. Bei vielen Behandlungsweisen verliert die Markscheide ihr homogenes Ansehen und lässt ein vielgestaltiges Gerïst einer gegen starke Agentien sehr widerstandsfähigen Substanz (Hornsubstanz, Yeurokeratin) erkennen. Has Myelin stimmt in rielen seiner Eigenschaften mit dem Lecithin aus Eidotter iiberein.

Der (Knerschnitt der myelinhaltigen Nervenfasern ist sehr verschieden, solche ron $1-4 \mu$ Durchmesser nemnt man feine, ron $4-8 \mu$ mitteldicke, von 9-20 $\mu$ dicke. Die Länge der Tervenfasern ist oft sehr beträchtlich und der Axencylinder geht ron dem einen Endapparat zu dem anderen continuirlich hindureh; die ïbrigen Theile der Nerrenfaser sind segmentirt: die Vitte jerles Segmentes nimmt ein Kern ein. zu 
dessen beiden Seiten in ungefähr gleichem Abstand die Schwann'sche Scheide und die Markscheide eine Einschnürung zeigen, die Ranvier"sche Einschnürung. Die Länge der einzelnen Segmente ist an derselben Nervenfaser ziemlich gleich, bei verschierlenen Nervenfasern jedoch verschieden, bei den dickeren grösser wie bei den feineren, sie kann von $80-900 \mu$ betragen.

Bei den Verästelungen der peripherischen Nerven findet im Allgemeinen nur Abgabe von Fasergruppen statt, keine Verästelnng ron Primitivnervenfasern; die Nerven für die Muskeln weisen erst innerhalb oder ganz nahe derselben Faserverzweigungen auf. Durch Vermittelung dieser terminalen Verzweigungen tritt die einzelne. Primitivnervenfaser mit einer grösseren Anzahl von Muskelfasern in erregungsleitende Beziehnng, indem jede Terminalfaser die Nervendigung an eine besondere Muskelfaser trägt. Diese Nervenendigung liegt innerhalb des Sarkolemmschlauchs und besteht in einer Terzweignng und Ausbreitung des Axencylinders der Nervenendplatte. Eine kernreiche Substanz, welche bei den Säugethieren eine compakte Anhäufung darstellt und hier Plattensohle heisst, bildet den Uebergang von der Axencylindersubstanz zu der Muskelsubstanz.

Ein rom Organismus getrennter peripherischer Nerv geniigt nicht zum Studium der physiologischen Leistungen der Nervenfasern, wie uns der möglichst rein isolirte Muskel genïgt hat, um die fundamentalen Thatsachen kennen zu lernen, welche die Wirkungsweise der Muskelfasern betreffen. Auf die ohne Weiteres nicht zu Tage tretenlen Zustandsänderungen in den Nervenfasern können wir schliessen aus den Zustandsänderungen, welche wir in Erfolgsorganen beobachten, die mit den Nerrenfasern in ihrer natürlichen Verbindung geblieben sind. Das hierzu am besten geeignete Erfolgsorgan ist der quergestreifte Muskel. Fin in Uebrigen rom Organismus getrennter Muskel mit einem genügend langen Stïck seines zugehörigen Nerven stellt ein Nervmuskelpräparat llar. Verschiedenartige Einwirkungen, welche den Nerv eines Nervmuskelpräparates in beliebiger Lintfernung rom Muskel treffen, etwa (in Scheerenschnitt, reranlassen eine Frregung res Muskels. Es ist dies nur so zu verstehen, dass der Eingriff am Orte seiner Einwirkung als Reiz auf die Nerrensubstan\% gewirkt hat, und dass die am Reizort entstandene Erregung durch die Nerrenfasel'n dem Muskel zugeleitet und hier auf die Muskelsubstan\% iilsertragen worden ist. Wir muissen dem Nerven also Reizbarkeit und Leitungsfäligkeit für Lrregung als zwei fundamentale Vügenschaften zuschreiben. Legt man zwischen der Reizstolle und dem Muskel eine festgeschlungene Ligatur um den Nerren, so bleilht die Tieizung olne Wirkung auf den Mluskel. Legt man die Ligatur dagegen жwischen zwei lieiz-Elektroden an, so kann man 
bei passender Stromrichtung den Muskel zucken machen. Fine Ligatur also, welche die elektrische Leitung im Nerven nicht unterbricht, setzt der Fortpflanzung der kiregung eine undurchdringliche Schranke. Ein Ueberspringen der Erregung von einer gereizten Nervenfaser auf cine benachbarte kommt unter normalen Verhältnissen nicht ror, jede Nerrenfaser stellt rielmehr eine isolirte Leitungsbahn fiir Erregung dar.

Der Nerv kann mechanisch, chemisch, thermisch oder clektrisch gereizt werden. Die meisten Einwirkungen, welche die Nervensubstanz zerstören, wirken, ehe sie den Nerv tölten, erregend. Zerquetscht man den Nerven, so zuckt der zugehörige Muskel, und er thut dies auch, wenn man die Continuität mit einem ganz scharf schneidenden Instrumente trennt; ebenso wirkt Brennen und chemisches Aetzen mit Säuren und Alkalien, oder mit Salzen der schweren Metạlle. Mit concentrirter Ammoniaklösung kann man jedoch den motorischen Nerr zerstören, ohne dass es zu einer Zuckung im Muskel kommt. Allmähliche Temperaturänderungen erregen den motorischen Nerven nicht, doch zuckt der Muskel, wenn der zugehörige Nerv gefriert. Die einzigen Einwirkungen, mit deren Hülfe man den Nerven wiederholt reizen kann, ohne seiu inneres Gefüge dauernd zu verändern, sind elektrische und mechanische. Gegen schwachen Druck oder Schlag ist die Nerrensubstanz weit empfindlicher, als die Muskelsubstanz, und bei rorsichtiger Abstufung des Schlages kann man dieselbe Stelle des Nerren sehr oft hintereinander in regelmässiger, mit der Stärke des Schlages zu- und abnehmender Weise reizen. In noch feiner abstufbarer Weise gelingt dies durch elektrische Einwirkungen, nicht aber auf thermischem und chemischem Wege. Wasserentziehende Substanzen, wie concentrirte Kochsalzlösung oder concentrirtes Glycerin, reizen den Nerven, aber nicht in regehmässiger Weise, und es muss zweifelhaft bleiben, ob es sich hierbei um chemische Processe handelt, oder ob beim Schrumpfen der Zwischengewebe durch Wasserentziehung mechanische Einwirkungen auf die Nervensubstanz ausgeiibt werden; denn schon beim einfachen Austrocknen des Nerren an der Luft treten Zuckungen in den zugehörigen Muskeln auf, welche beim Anfenchten des Nerven mit Kochsalzlösung von $0,75 \%$ wieder rerschwinden.

Während ein elektrischer Strom ron constanter Intensitiit eine beliebige Nerrenstrecke des Nervmuskelpräparates durchfliesst, bleibt der Muskel meist in Ruhe, worans freilich nicht geschlossen werden darf, dass der Nerr selbst in Ruhe rerharrt. Gegen Intensitätsschwankungen des elektrischen Stromes, namentlich, wenn sie plötzlich erfolgen, ist aber das Nerrmuskelpräparat selır empfindlich. Darum gehören zu den stärksten Nervenreizen die Inductionsströme und von diesen in hervor- 
ragender Weise die Oeffnungsinductionsschläge, deren Verlauf plötzlicher ist, als der der Schliessungsinductionsschläge.

Als vorzüglichstes Maass iler Reizbarkeit des Nerven dient diejenige Stärke-des Oeffnungsschlages, welche eben ausreicht, den zugehörigen Muskel zu einer minimalen Zuckung zu veranlassen. Die Stärke des Oeffnungsschlages selbst wird abgemessen durch die Entfermung, in welcher sich die die Inductionsschläge liefernde secundäre Spirale des Inductionsapparates von der primären befindet.

Prïft man die Reizbarkeit eines Nerven mit diesem Mittel in der Nähe einer unpolarisirbaren Elektrode, durch welche ein constanter Strom in den Nerven eintritt (Anode), und in der Nähe einer anderen, durch welche er ihn rerlässt (Kathode), so findet man sie in der Umgebung

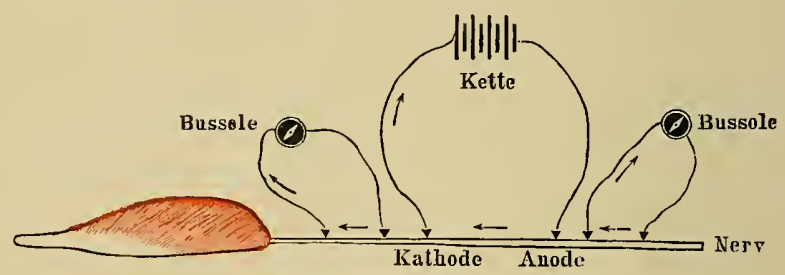

$16 \mathrm{a}$.

Absteigender Elektrotonus.

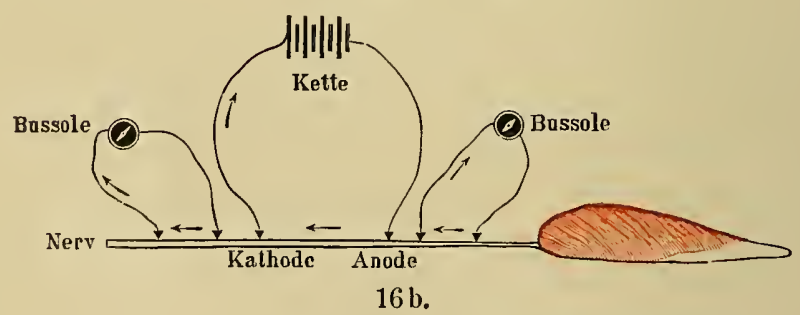

Autsteigender Elektrotonus.

der Anode herabgesetzt, in der Umgebung der Kathode erhöht. Die rurch den constanten elektrischen Strom hervorgerufeuen Zustandsänderungen im Nerven, von denen diese Reizbarkeitsänderungen eine Theilerscheinung darstellen, nennt man die elektrotonischen, und man unterscheidet den Anelektrotonus und den Katelektrotonus. Die elektrotonischen Zustände sind sofort nach Schluss les elektrotonisirenden Stromes da. Mit Oeffinung des letzteren schlagen sie in ihr Gegentheil un, ehe sie verschwinden, das lieisst an die Stelle der katelektrotonischen Erhı̈hnng der Reizbarkeit tritt zunächst eine Herabsetzung derselben. Im starken Anelektrotonus ist die Leitungsfähigkeit für Erregung aufgehoben, ebenso in einem Nervenabschnitt, welcher sich eben im starken Katelektrotonus befunden hatte. 
Mit den elektrotonischen Aendermugen der Reizharkeit und Leitungsfähigkeit Hand in Hand gehen merkwïrdige elektrische Erscheinungen an Nerven, welche man ebenfalls als elektrotonische bezeichnet und deren Grundphänomen darin hesteht, dass sich von Nerrenstrecken obcrhalb der Anode und unterhalb der Kathode (also ron extrapoliaren Strecken) Ströme mit unpolarisirbaren likktroden ableiten lassen (Fig. 16), deren Richtung in Nerven derjenigen des elektrotonisirenden Stromes gleichliufend ist. Die elektrotonischen Ströme haben eine verhältnissmässig grosse Intensitït in der Nühe der Elelitroden des polarisirenden Stromes; diese Intensität nimmt aber bei gleichbleibendem Abstand zwischen den ableitenden Elektroden mit der Entfernung von der Anode oder Kithode sehr schnell ab. Die elektromotorische Kraft dieser Ströme nimmt mit Verlängerung der Strecke zwischen den ableitenden Elektroden zu. Für die elektrischen Erscheinungen des Eldrotonus gilt in Bezug auf die Zeit der Entwickelung und in Bezug auf die Umkehr vor dem Abklingen dasselbe wie für die elektrotonischen Reizbarkeitsändel'ungen.

Bei Schluss und Oeffnmmg eines den Nerven längsdurchfliessenden constanten Stromes tritt im Allgemeinen bei einer mittleren Intensituit des Stromes je eine Reaction des Muskels ein. Bei Schluss des im Nerren absteigenden Stromes, bei welchem also die Kathode dem Nuskel näher gelegen ist, rerfliesst eine messbar kleinere Zeit zwischen Stromschluss und Inskelreaction, als bei Schluss des aufsteigenden Stromes: aus dieser 'Thatsache folgt, dass bei Stromschluss die Erregung an der Kathode entsteht und aus analogen Thatsachen, dass bei Stromöffnung der Reizort an der Anode liegt, sowie bei Inductionsschlägen an der Kathode. Mau drïckt dies auch so aus, dass man sagt: Entstehen des Katelektrotonus und Vergehen des Anelektrotonus sind mit Erregung des Nerren verbunden; ersteres scheint in höherem Maasse der Fall zu sein als letzteres, denn wenn man den constanten Strom von unwirksamer Stärke an allmählich wachsen lässt, so treten zunächst nur bei Schliessungen des Stromes Muskelreactionen auf, sowohl bei aufsteigend als bei absteigend im Nerven gerichtetem Strome. Bei Oeffnung des Stromes dagegen bleibt der Muskel zunächst in Ruhe. Steigert man die Intensitüt des constanten Stromes, so findet man eine gewisse Breite der Stromstärken, innerhalb welcher Oeffnung und Schliessung des im Nerven aufund absteigenden Stromes ron Muskelreaction begleitet wird.

Dariiber linaus giebt es Stromstärken, bei welchen der Muskel auf Schluss des aufsteigenden und auf Oeffnung des absteigenden Stromes in Ruhe bleibt und nur bei Oeffnung des aufsteigenden und bei Schluss des alsteigenden Stromes reagirt. Die Muskelruhe in len beiden genannten Fällen erklärt sich, wenn man bedenkt, dass die Erregungs- 
welle in einem Nervenabschnitt erlischt, welcher sich in einem genügend starken Anelektrotonus befindet, oder welcher sich eben im genügend starken Katelektrotonus befunden hatte. Den Inbegriff der angegebenen Thatsachen, welche die Muskelreaction oder die Muskelruhe bei Stromschluss oder bei Stromöffnung des im Nerven auf- oder absteigenden Stromes verschiedener Intensität betreffen, nennt man das $\mathrm{Zuckungs-}$ gesetz.

Tabelle 1 .

\begin{tabular}{|l||c|c||c|c||c|c|}
\hline \multicolumn{1}{|c|}{} & \multicolumn{2}{c||}{ Schwach } & \multicolumn{2}{c||}{ Mittel } & \multicolumn{2}{c|}{ Stark } \\
\hline \hline$\hat{\imath}$ & S. Z. & Ö. R. & S. Z. & Ö. Z. & S. R. & Ö. Z. \\
\hline$\downarrow$ & S. Z. & Ö. R. & S. Z. & C̈. Z. & S. Z. & Ö. R. \\
\hline
\end{tabular}

In Folge eines einzelnen Inductionsschlages, welcher den Nerven trifft, oder in Folge eines einmaligen Schliessens oder Oeffnens des dem Nerv zugeleiteten constanten Stromes, durchläuft eine einzelne Erregungswelle die Muskelfasern des zugehörigen Muskels; die Zuckungshöhe oder Spannungsentwickelung ist ein Maass für die Intensität der Nervenerregung, sie wächst bis zu einer gewissen Grenze mit der Verstärkung des Nervenreizes: maximal nennt man die Stärke des Nervenreizes, wenn eine weitere Steigerung derselben zu keiner Steigerung der Zuckungshöhe führt. Bei weiterer Verstärkung der Inductionsschläge nimmt die Muskelreaction wieder ab und kann sogar verschwinden, um bei weitergehender Verstärkung des Reizes dann wieder zu erscheinen und ein zweites Maximum zu erreichen.

Die Reizschwelle liegt für den Nerven bei einer geringeren Stromdichte, als für den Muskel; man beweist dies folgendermaassen. Ein curarisirter. Muskel wird an seinen beiden Enden durch hier angebrachte Elektroden mit der secundären Spirale eines Inductoriums verbunden; diesem Muskel wird seiner Länge nach ein Nerv eines nicht curarisirten Muskels aufgelegt. Sendet man durch den Muskel einen Inductionsschlag, so ist die Stromdichte in jeder Einheit des Querschnittes des Muskels und des ihm anliegenden Nerven ungefähr gleich; nähert man jetzt die secundäre Spirale, von unwirksamer Stellung an, der primären und sucht die Stellung, bei welcher die erste Wirkung eintritt, so zuckt zuerst der von seinem Nerven aus gereizte Muskel und dann bei weiterer Verkleinerung des Rollenabstandes auch der unmittelbar gereizte. Das Intervall zwischen dem Schwellenwerthe des Reizes und der maximalen Reizstärke ist bei dem Nerven im Allgemeinen kleiner, wie bei dem Muskel. Es gielst aber eine Muskelart, bei welcher dies Intervall sogar Null ist, 
dies ist der Her\%muskel des Kaltblïters, welcher durch den elektrischen Schlar entwerler gar nicht oder sofort maximal gereist wird.

Folgen sich einzelne Reize in kür\%crem Intervall als das Stadium der wachsenden linergie der einzelnen Muskelzuckung beträgt, so verharrt der Muskel in dauernd gleichmïssiger Contraction, in Tetanus; diejenigen lieize, welche auf den Nerven des Nervnuskelpräiparates angewendet, den Muskel in T'etanus rersetzen, nennt man tetanisirende Nervenreize. Wächst die Frequenz der einzelnen Reize über eine gewisse Grösse hinats, so findet man Stromstärken geringen Werthes, bei denen nur der erste Reiz eine Zuckung auslöst, es tritt statt eines Tetanus nur eine Anfingszuckung auf.

Fiir jede Temperatur giebt es eine Reizfrequenz, deren tetanisirende Wirkung auf den Nerren ein Optimum ist. Mit wachsender Temperatur nimmt diese optimale Reizfrequenz im Allgemeinen zu. Wie bei dem Muskel so findet auch bei dem Nerven - hier jedoch in weit ausgesprochenerer Weise - eine Summirung unterminimaler Reize statt, das heisst Stromstärken, welche bei einzelnem Reiz unwirksam sind, können in passender Reizfolge einen schwachen Tetanus erzengeu. Durch maximale tetanisirende Nervenreize lässt sich der Muskel zu intensiverer Thätigkeit bringen, als durch maximale einzelne Reize. Jerle dem motorischen Nerven in dem natürlichen Gange des Geschehens von dem Centrum mitgetheilte Erregung ist eine tetanische. Die Intensitit dieses Tetanus, gemessen durch die Spannungsentwickelung, lässt sich durch Willensanstrengung auf eine höhere Stufe bringen, als durch maximale elektrische Reizung des Nerven in seinem Verlauf.

Die einzelne Erregung pflanzt sich im Nerven ron ihrem Entstehungsort aus wellenartig fort; die Fortpflanzungsgeschwindigkeit dieser Welle kann an dem Nervmuskelpräparat bestimmt werden. An den Ischiadicus eines grossen Frosches kann man zwei Paar Reizelektroden im Abstande ron 5 Centimeter anlegen; Zuckungscurven des zugehörigen Gastrocnemius werden auf einer schnell rotirenden Zeichenfläche derart aufgeschrieben, dass die Stellung der Zeichenspitze auf der Zeichenfläche jedesmal im Reizmomente dieselbe ist: bei Beniitzung der rom Muskel entfernteren Reizelektroden erhebt sich die Zuckungscurve später ron der Abscisse, als bei Beniitzung der dem Muskel näher gelegenen Elektroden; der zeitliche Werth der Abscissenlänge zwischen den beiden Abhebungspunkten wird mit Hülfe ron gleichzeitig mit den Zuckungscurven geschriebenen Stimmgabelcurven bestimmt. Es ist dies die Zeit, welche die Erregungswelle gebraucht hatte, um eine Strecke ron 5 Centimeter zu durchlaufen. Bei nittlerer T'emperatur beträgt die Fortpflanzungsgeschwindigkeit der Erregungswelle im motorischen Froschnerven 29 bis 30 Meter in der Secunde; durch Abkïhlung des Nerven kann 
die Fortpflanzungsgeschwindigkeit erhehlich rerringert werden. Bei Menschen hat sich die Fortpflanzungsgeschwindigkeit der Erregung im motorischen Nerven durch Versuche, welche wesentlich nach demselben Plan angestellt waren, nur ein wenig grösser, zu 30 bis 3:3 Meter in der Secunde ergeben, und es liegt kein Grund für die Annahme vor, dass die Fortpflanzungsgeschwindigkeit in sensiblen Nerven des Menschen eine andere wäre; directe Bestimmungen sind hier mit eigenthümlichen Schwierigkeiten verbunden.

Leitet man rom frischen Querschnitt eines Froschnerven und ron einem Punkte seiner natürlichen Oberfläche (des natïrlichen Längsschnittes) mittelst unpolarisirbarer Elektroden zu einer Bussole ab, so zeigt diese einen Strom im Leitungsbogen vom Längsschnitt zum Querschnitt an, also im Nerven selbst vom Querschnitt zum Längsschnitt. Dieser Strom nimmt ab, zeigt eine negative Schwankung, wenn eine Erregungswelle den abgeleiteten Längsschnittspunkt passirt. An einem genügend langen isolirten Nerven mit zwei künstlichen Querschnitten kann man zu jedem Längsschnittspunkt einen zugehörigen Längsschnittspunkt von gleicher elektrischer Spannung finden, das heisst bei Ableitung von solchen Punkten zur Boussole zeigt diese keinen Strom an; beim Durchlaufen einer Erregungswelle durch den Nerven ist dann aber der von der Erregungswelle erfasste Längsschnittspunkt negativ gegen den anderen. Aus dem zeitlichen Intervall des Eintretens dieser elektrischen Zustandsänderungen an den beiden abgeleiteten Punkten und aus dem räumlichen Abstand zwischen demselben kann man ebenfalls die Fortpflanzungsgeschwindigkeit der Erregungswelle berechnen. Auf diesem Wege ist man zu demselben Werth fuir die Fortpflanzungsgeschwindigkeit der Erregungswelle gelangt, wie auf dem rorher beschriebenen.

Die Grösse der negativen Schwankung des Nervenstromes kann ebenso als Maass für die Erregungsintensität des Nerven benützt werden, wie die Zuckungshöhe oder die Spannungsentwickelung des mit dem Nerven verbundenen Muskels, ja sie scheint sogar ein trenerer Ausdruck derselben zu sein, denn elektrische Reize, welche, nach der Reaction des mit dem Nerven verbundenen Muskels heurtheilt, als maximale erscheinen, sind in Bezug auf die negative Schwankung noch untermaximal, das heisst während bei weiterer Steigung des Reizes keine \%unahme der Muskelreaction eintritt, kann die Grösse der negativen Schwankung des Nerven noch erheblich gesteigert werden.

Secundäre Erregung eines einem primär erregten Nerven angelagerten Nerven, durch die negative Stromschwankung des ersteren, analog der oben beschriebenen secundären Erregung vom Muskel auf Nerv ist nicht sicher beobachtet worden, nur ein wie es scheint schwer gelingender Versuch wurde beschrieben, welcher auf die Möglichkeit eines 
solchen Vorkommens hinweist. Die Nerren von Fröschen, welche in Kalten anflewahrt waren und dann in das warme Zimmer gebracht wurden, zeigen einen besonders hohen (Grarl von Reizbarkeit: präparirt man den Ischiadicus eines solchen Frosches derart, dass er durch den Nervus tibialis mit dem Gastrocnemius zusammenhängt, und dass auch ein gutes Stïck res Nervus peroneus an ihm erhalten ist, so kann man unmittelbar nach Anlegen eines frischen Querschnittes an dem oberen Ende des Ischiadicus bei Reizung des Peroneus durch einen Inductionsschlag eine Zuckung des Gastrocnemins zu sehen bekommen. Da bei diesen Versuchen alle Fehler durch unbeabsichtigte Ausbreitung des clektrischen Stromes vermieden waren, so ist das Resultat nur so zu deuten, dass die negatire Schwankung der Peroneusfaseru an dem frischen Querschnitt des Ischiadicus als Reiz auf die Tibialisfasern gewirkt hat. Bei Schliessung eines starken constanten Stromes durch den Peroneus des gleichen Präparates, auch ron weniger empfindlichen Fröschen, kann man freilich ebenfalls Zuckung des Gastrocnemius zu sehen bekommen, hier ist es aber wahrscheinlich die Entstehung des starken elektrotonischen Stromes und nicht die negative Schwankung, welche von Nervenfasern auf benachbarte Nervenfasern erregend wirkt; das zuletzt beschriebene Phänomen nennt man die paradoxe Zuckung.

In einem isolirten Nerven, in welchem centripetale und centrifugale Nerrenfasern gemischt sind, erweist sich die Ableitung ron beiden frischen Querschnitten als stromlos; der stärkste Strom kanu abgeleitet werden von der Mitte des Längsschnitts (dem Aequator) und einem der beiden Querschnitte, welche sich beide anch in dieser Beziehung gleich rerlaalten. Nimmt man dagegen einen Nerven, der möglichst rein aus
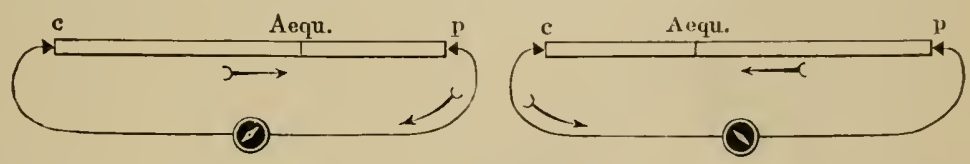

17.

Centripetaler Nerv.

Centrifugaler Nerv

Axia'er Nervenstrom du Bois-Reymond's.

Fasern einer der beiden Kategorien besteht und rersieht-ihn mit zwei künstlichen Querschnitten, so verhält sich bei dem centripetalen Nerven der centrale Querschnitt elektrisch negativ gegen den peripherischen Querschnitt und bei dem centrifugalen umgekehrt. Der Aequator liegt nicht in der Mitte beider Querschnitte, sondern bei dem centripetalen Nerven näher dem peripherischen und bei dem centrifugalen näher dem centralen Querschnitt. Dieses Verhalten ist mit aller Dentlichkeit be- 
obachtet worden bei dem rein centrifugalen elektrischen Nerven von Torpedo und bei den rein centripetalen hinteren Rückenmarkswurzeln des Frosches. Man kann dem Sachverhalt dadurch Ausdruck geben, dass man sich jeden dieser Nerven von einem elektrischen Strom, dem "axialen Nervenstrom", durchflossen vorstellt, und dass man sagt, der axiale Nervenstrom habe die umgekehrte Richtung als diejenige, in welcher sich die Erregungswelle unter normalen Bedingungen fortpflanzt. Dies ist der einzige objectiv wahrnehmbare Unterschied, welcher sich bisher zwischen centrifugalen und centripetalen Nervenfasern hat nachweisen lassen. Sowohl in ihrem Bau als in der Form ihrer eigenen Thätigkeit scheinen die centrifugalen und centripetalen Nervenfasern wesentlich gleich $\mathrm{zu}$ sein. Die Verschiedenheit der in die äussere Erscheinung tretenden oder der subjectiv zu beobachtenden Wirkungen scheint hauptsächlich auf der Verschiedenheit der Aufnahme- und Erfolgsapparate zu beruhen, mit denen die Nervenfasern verbunden sind. In Bezug auf die elektrotonische und in Bezug auf alle übrigen elektrischen Erscheinungen, mit Ausnahme derjenigen des "axialen Nervenstromes", verhalten sich centripetale und centrifugale Nerven gleich, ja auch Nerven mit myelinfreien Fasern (Olfactorius von Fischen) gleich denen mit myelinhaltigen Fasern.

Wenn auch jede der verschiedenen Kategorien der Nervenfasern die Erregung für gewöhnlich nur in einer Richtung fortleitet, da die physiologische Erregung ja immer an demselben Ende derselben Nervenfaser entsteht, so ist doch jede Nervenfaser im Stande, eine durch künstlichen Reiz an einem Punkte ihres Verlaufes erzeugte Erregung nach beiden Richtungen fortzuleiten: diese Thatsache nennt man die Doppelsinnigkeit der Erregungsleitung im Nerven. Sie fällt nicht ohne Weiteres in die Augen, da immer nur das eine Ende der Nervenfaser mit einem Erfolgsapparat verbunden ist, doch kann man sie durch mehrere Experimente beweisen.

Das schlagendste dieser Experimente bezieht sich auf einen rein centrifugalen Nerven und ist folgendes: der elektrische Nerv jeder Seite vom Malopterurus wurzelt in je einer aussergewöhnlich grossen Nervenzelle und enthält in seinem Stamm nur einen einzigen Axencylinder von grossem Querschnitt, aus dessen Verzweigungen die Axencylinder aller Aeste und Aestchen wie bei Terminalverzweigungen hervorgehen, sodass der ganze Axencylinderbaum dieses Nerven ein einziges Continuum darstellt. Durchschneidet man einen Ast des Nerven und rcizt sein centrales Ende, so beantworten die von den übrigen Aesten innervirten Theile des elektrischen Organes den Reiz mit einem Schlage. Es ist dies nur erklärlich, wenn man annimmt, dass die Erregungswelle, ihrer gewöhnlichen Fortpflanzungsrichtung entgegen, bis 
zur Abspaltungsstelle der Axencylinder der iibrigen Aeste centripetal und von da aus damn normal, das heisst centrifugal verlatufen ist.

Auf demselben Prineip berulit ein Versuch, welcher an einem leichter zugänglichen Objecte angestellt werden kann, dessen Berlingungen aber nicht so iibersichtlich sind und dessen Gelingen ron einem nicht beherrschbaren Umstand ahhängt. Spaltet man das eine Fude des Sartorius vom Frosch durch einen nicht zu lingen Jängsschnitt in zwei gleiche Zipfel, so kamn es vorkommen, dass man hei Querschneidung des einen Zipfels Muskelfaserbiindel in dem anderen Zipfel zucken sieht; wenn dies eintritt, so ist es nur so zu deuten, dass sich Terminalverzweigungen derselben Primitivnervenfasern in beirle Zipfel erstreckt haben und dass bei Querschneidung des einen Zipfels Terminalverzweigungen von Nervenfasern gereizt sind, in welchen sich die Erregungswelle centripetal fortgeptlanzt hat, sodass sich auf diesem Wege der Erregungszustand Terminalverzweigungen des anderen Zipfels hat mittheilen können. Man hat es leider nicht in der Gewalt, den Längsschnitt so zu führen, dass in beiden Zipfeln Terminalverzweigungen derselben Primitivnervenfaser endigen. Immerhin ist der Versuch, wenn er gelingt, ein guter Beweis für die Doppelsinnigkeit der Leitung in der motorischen Nervenfaser, und wenn er nicht gelingt, kein Beweis gegen dieselbe.

Da die elektrische Zustandsänderung, welche wir als negative Schwankung keunen gelernt haben, sicher mit

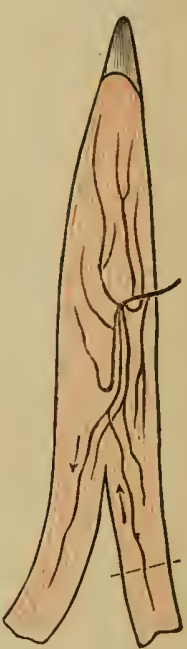

18.

Kühne's Zweizipfelversuch. dem Erregungszustande des Nerven verbunden ist, kann auch dem Verlauf dieser Frscheinung ein Beweis für die Doppelsinnigkeit der Leitung im Nerven entuommen werden. Versieht man einen Nerren, welcher nur eine Kategorie von Nervenfasern enthält, etwa nur centripetale, wie der Olfactorius, mit zwei kïnsthichen Querschnitten, einem centralen und einem peripherischen, so kann man unter Ableitung eines Stromes ron dem centralen Querschnitt, sowie einem Punkt des Iä̈ngsschnittes und bei Reizung des Nerven in der Nähe des peripherischen Qnerschnittes die negative Schwankung demonstriren; es ist dies zu erwarten, da in diesem Falle die Erregungswelle in der Richtung der normalen Erregungsleitung abläuft; aber auch bei umgekehrter Anordnung des Versuches, bei welcher die Reizung in der Nühe des centralen Querschnittes erfolgt, zeigt der von dem peripherischen Theil des Nerven abgeleitete Längs-()uerschnittstrom die negative Schwankung: hier hat sich die Erregungswelle in dem centripetalen Nerven centrifugal fortgepflanzt.

Viele Mühe ist auf eine andere Art der Beweisführung für die 1)op- 
pelsinnigkeit der Leitung des Nerven verwandt worden, und es wurden dahei sehr merkwiirdige Thatsachen an das Licht gefördert, ohne dass rler eigentliche Zweck erreicht worden wäre. Es gelingt bei dem Warmbliiter, nachdem der Nervus lingualis sowohl als der Nervus hypoglossus durchschnitten ist, den centralen Stumpf des ersteren mit dem peripherischen Stumpf des letzteren zur Verwachsung zu bringen. Nachdem die Verwachsung eingetreten war, durchtrennte man den Lingualis central von seiner Verwachsungsstelle mit dem Hypoglossus und gewann so eine Nervenstrecke, welche in der Peripherie aus den centrifugalen Fasern des Hypoglossus und am centralen Ende aus centripetalen Fasern des Lingualis bestand. Bei Reizung dieses Nerven im Bereich der letzteren Strecke erhielt man Bewegungen in der Zunge und zog hieraus den Schluss, dass die centripetalen Fasern des Lingualis die Erregung in centrifugaler Richtung den mit ihnen verwachsenen Hypoglossusfasern zugeleitet lätten, durch welche sie dann in normaler Richtung der Zungenmuskulatur mitgetheilt worden wäre. Da die hierfïr benutzte Strecke des Lingualis peripher von dem Abgang der centrifugalen Chordafasern für die Submaxillar-Drïse lag, glaubte man es mit einem Nerrenstiick $\mathrm{zu}$ thun $\mathrm{zu}$ haben, welches keine centrifugalen Fasern weiter enthielt: diese Voraussetzung hat sich aber als irrig erwiesen, denn der Nervus lingualis führt Erweiterungsnerven für die Gefässe der Zunge. Es kann sich also bei dem Experiment um Verwachsung centrifugaler Fasern des Lingualis mit den Hypoglossusfasern gehandelt haben.

Die centripetalen und centrifugalen Nerven verhalten sich zwar verschiedenen künstlichen Reizen gegenüber scheinbar verschieden, doch beruht die Verschiedewheit der Wirkung nur auf der Verschiedenheit der Erfolgsapparate, mit denen die eine und die andere Kategorie verbunden ist. Stoss oder Kälte auf den Nervus ulnaris am Ellenbogen applicirt, erzeugen Sensationen im sensiblen Ausbreitungsgebiet des Nerven, die von demselben Nerven abhängigen Muskeln dagegen bleiben in Ruhe. Mit concentrirter Ammoniaklösung kann man den motorischen Froschnerv tödten, ohne dass eine Zuckung in seinen Muskeln auftritt; dieselbe Lösung auf den Nervus vagus des Kaninchens angewendet, ruft in diesem Erregungen hervor, welche sich dem Centralnervensystem mittheilen und durch dessen Vermittelung die Athembewegungen beeinflussen. Das Umgekehrte gilt von liälte unter $0^{0}$; man kann einen Tervus vagus hart gefrieren lassen, ohne dass Aenderungen der Athembewegungen eintreten; beim Uebergang des Nervus ischiadicus des Frnsches in den gefrorenen Zustand gerathen die zugehörigen Muskeln in heftige Zuckungen.

Ein iihersichtliches Experinent, um die scheinbare Verschiedenheit des Verhaltens centrifugaler und centripetaler Nervenfasern gegen den- 
selben Fingrift zu demonstriren, ist folgendes: man legt bei einem grossen Froseh den Ischiadicus der einen Scite in der gatuzen Austehmung des ())erschenkels frei und durchschneilet ilı in der Mitte dieser Strecke; dann wird der Schenkel im Hüftgelenk exarticulirt, sodkass mit dem 'Thiere nur das centrale Stiick des Ischiadicus als einziger Rest des entfernten schenkels in Verhindung bleiht. An dem abgeschnittenen schenkel werden alle Oherschenkehmuskeh entfernt, sorlass man ein Präparat erhält, bestehend aus dem Femur mit dem diran hängenden Enterschenkel und einem Stïck des Ischiadicus. An diesem Prïparat kann man das Verhalten centrifugaler Nervenfasem, an dem anderen das Verhalten der centripetalen studiren. Taucht man beide Hälften des Ischiadicns in physio-

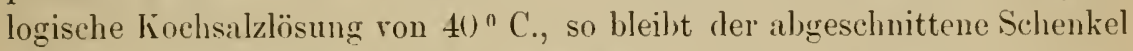
in Ruhe, während das Thier Bewegungen macht, und lässt man dimn concentrirte Kinchsalzlösung auf die beiden Nervenstücke einwirken, so erfolgt das Umgekehrte, der abgeschnittene Schenkel rerfällt in Zuckungen, das Thier bleilut in liuhe. Auf den ersten Blick mag es erscheinen, als wenn nur die centripetalen Fasern durch Temperaturerhöhung auf 4$)^{n}$ erregt wiirden, die centrifugalen dagegen nicht, und dass concentrirtes Kóchsilz nur centrifugale reizte, centripetale dagegen in Ruhe liess. Bei dem völligen Fehlen irgend eines morphologischen, chemischen orler sonstigen functionellen Unterschiedes müssen wir aber ernste.Bedenken tragen, einen solchen Schluss aus der Erscheinung zu ziehen, wir werden uns bei einem Versuch der Erklärung überdies nach dem Princip der einfachsten Aunahmen an die Voraussetzung halten miissen, dass der Erregungsprocess, mag er in einer centripetalen oder in einer centrifugalen Faser verlaufen, in seinem Wesen stets gleichartig und nur quantitativer Unterschiede fähig ist. Der eimzige Unterschied, welcher sich als ein qualitativer bezeichnen liesse, kann in der Art der zeitlichen Veränderung der Erregungsintensität liegen; man kanu sich sehr gut rorstellen, dass der Frregungsprocess in allen Nervenfasern bei der Erwärmung auf $40^{\circ}$ in gleichem Rhythmus verläuft, dass dieser Rhythmus aber rerschieden ist ron demjenigen, welcher durch concentrirte Salzlösung bewirkt wird, und dass die Erfolgsapparate centrifugaler Fasern auf einen anderen Rhythmus ansprechen, als diejenigen der centripetalen.

Wir haben oben als fundamentale Eigenschaften von Nervenfasern ihre Reizbarkeit und ihre Leitungsfähigkeit für Erregung bezeichnet: so leicht es auf den ersten Blick scheint diese beiden Eigenschaften begrifflich ron einander zu trennen, so schwer ist es, lie wahren Beziehungen zwischen denselben festzustellen. \%weifellos ist die Function, durch welche die Nervenfaser dem Organismus ihre Dienste leistet, die Erregungsleitung; wenn wir in Experiment die Reizbarkeit der Nerven- 
faser prïfen, so führen wir stets Bedingungen ein, wie sie im normalen Organismus nicht vorkommen; es liesse sich denken, dass die Nervenfaser auf keines der von uns angewendeten Reizmittel reagirte, und dass sie trotzdem vollkommen im Stande wäre dem Zwecke des Organismus zu genügen; normaler Weise entsteht ja die Erregung niemals in Verlaufe des Nerven, sondern sie wird der Nervenfaser stets an dem einen ihrer Enden von dem dortigen Endapparat mitgetheilt; in der That ist auch für Faserkategorien des centralen Nervensystems die Behauptung aufgestellt worden, dass sie nicht reizbar seien und nur fähig die Erregung zu leiten. Man kann auch im Experiment den peripherischen Nerven so modificiren, dass seine Fähigkeit die Erregung zu leiten, sich in anderer Weise ändert, als seine Fähigkeit durch einen künstlichen Reiz erregt zu werden; man muss aber doch daran festhalten, dass der Process der Erregungsleitung nicht gut ander's rorgestellt werden kann, als durch die Annahme, dass der in einem Querschnitt entstandene Erregungszustand als Reiz auf den benachbarten Querschnitt wirkt; die Leitungsfähigkeit erscheint somit als eine besondere Form der Reizbarkeit, nämlich als die Empfindlichkeit gegen Eintlüsse, welche die Nervensubstanz in der Richtung der Längsaxe treffen. Bei allen künstlichen Mitteln, welche wir besitzen, die Reizbarkeit des Nerven zu prïfen, wird die Nervensubstanz vorwiegend in querer Richtung getroffen.

Der Anschein einer Trennung von Leitungsfähigkeit und Reizbarkeit im Nerven wird durch folgendes Experiment erweckt:

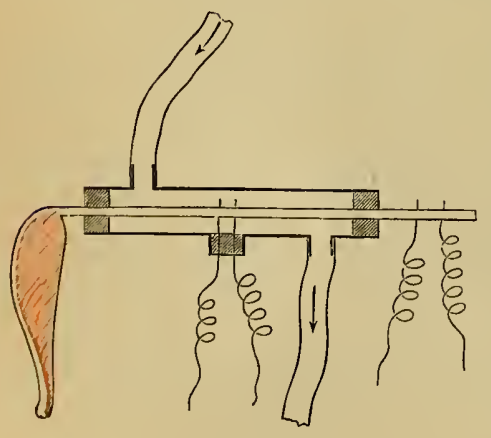

19.

Girun lı agen 's 'T'rennung von Reizbarkeit und Erregungsleitung. den Nerven eines Nervmuskelpräparates vom Frosch zieht man durch eine Glasröhre, welche an ihren beiden Enden durch plastischen Thon verschlossen wird, der durch Ankneten mit physiologischer Kochsalzlösung hergestellt ist; die weiche Masse des Thons umschliesst den Nerven ohne ihn zu drücken, sodass der Verschluss der Glasröhre luftdicht wird. Die Glasröhre besitzt an diametral entgegengesetzten Stellen je ein Ansatzrohr zum Durchleiten von Gas und ein drittes Ansatzrohr, durch welches ein Paar Platinelektroden luftdicht eingeführt werden kann; ein zweites Paar Platinelektroden wird dem Nerven central von dieser kleinen Gaskammer angelegt. Man stellt nun den Schwellenwerth des Reizes fest für Reizung des Nerven oberhalh und innerhalb der Gaskanmer, leitet Kohlensäure durch die letztere und findet bei wiederholter Prüfung, dass der Schwellenwerth inner- 
halb der Gaskammer schnell steigt (das heisst, lass immer stärkere Reize zи einem minimalen Erfolg erforderlich sind), wïhrend der Schwellenwerth oberhall, der Gaskammer znnäichst unverïndert bleibt und jerlenfalls langsamer steigt; es kommt damn ein Zustand, hei welchem der Muskel auf starke dem Nerven immerhall) der Kohlensäure-Atmosphüre zingeleitete Rieize nicht mehr reagirt, während verhältnissmässig schwache oben angehrachte Reize sich noch sehr wirksam erweisen. Die Nervenstrecke, welche der Kohlensäure-Finwirkung ausgesetrt ist, leitet also noeh sehr gut eine Erregung, welche an anderer Stelle entstanden ist, ist aber selbst für den elektrischen und, wie hinzugefiigt werlen kann, auch für den mechanischen Reiz unempfindlich. Umgekehrt sieht man bei Hindurchleiten von Alkoholdampf clureh die Gaskammer die Leitungsfïligkeit schneller sinken wie die Reizbarkeit; hier kann man sogar beobachten, dass die Reizbarkeit anfünglich steigt, während die Leitungsfähigkeit schon erheblich in Sinken begriffen ist. Die Erhebung der Reizbarkeit tritt in letzterem Falle stärker hervor, wenn man durch geeignete Hiilfsmittel daffïr sorgt, dass der Reizstrom den Nerven rorwiegend in querer Richtung und nicht, wie bei der gewöhnlichen Anlegungsweise der Elektroden, vorwiegend in der Läingsrichtung durchfliesst.

Wir werden aus der scheinbaren Trennung der Leitungsfähigkeit und (ler Reizbarkeit also nicht schliessen diirfen, dass es eine Leitungsfäligkeit ohne Reizbarkeit gebe, sondern dass die Empfindlichkeit der Nervensulsstanz für Längseinwirkungen eine andere ist, als für Quereinwirkungen, und dass die Empfindlichkeit in der einen und in der anderen Richtung durch verschiedene Mittel verschieden verändert wird. Dass der Nerv für Quercomponenten des elektrisehen Stromes und nicht, wie wiederholt behauptet worlen ist, nur fiir Längscomponenten desselben Empfindlichkeit besitzt, geht aus der iiberwiegenden Reizbarkeiterhöhung bei (uerdurchströmung unter Alkohol-Einfluss mit Sieherheit hervor.

Fïr die Leitungsfähigkeit des Nerven ist erforderlieh und ausreiehend die Continuitït des Axencylinders; die Nervenfasern des eentralen Nervensystemes besitzen keine Schwann'sche Scheide; vielen centralen und peripherisehen Nervenfasern, pamentlich den sogenannten sympathisehen, fehlt auch die Myelinscheide. Bei sämmtlichen myelinhaltigen peripherischen Nervenfasern ist der Markmantel an jeder Ranvier'schen Einschnïrung unterbrochen und alle diese Fasern leiten die Erregung. Hat man aber eine Nervenfaser mit noeh so scharfem feinem Messer durchschnitten, und bringt man die frischen Schnittflächen in noch so genaue Berührung mit einander, so ist die Erregungsleitung unterbrochen, wïhrend die Leitungsfïhigkeit für den elektrischen Strom kaum veräṇlert ist. 
Für die Dienste, welche die Nerven im Organismus zu leisten haben, ist ebenso wichtig wie die Continuität der Erregungsleitung die Isolation derselben. In fist jerlem Nerven liegen Fasern verschiedensten Urspranges mit einander gemischt, Fasern, welche den rerschiedensten Functionen dienen, und es müsste eine heillose Verwirrung geben, wenu die Erregung von einer Faser auf die benachbarte überspringen könnte. In der That gelingt es auch nur unter ganz besonderen Umständen, welche wir oben als eine der paradoxen Nervenreizung analoge Erscheinung kennen gelernt laben, zu veranlassen, dass Zustandsände. rungen in einer Kategorie ron Nervenfasern zum Reiz für andere Nervenfasern werden, welche in demselben Nervenstamm enthalten sind. Es kann also gar keinem Zweifel unterliegen, dass ein Frregungsprocess, welcher normaler Weise in einer Nervenfaser abläuft, die benachbarten Nervenfasern umberïhrt lässt, nur die Terminalverzweigungen dieser Nervenfasern nehmen selbstverständlich an ihrer Erregung Theil. Eine andere Frage ist die, ob jeder Axencylinder eine Erregungseinheit darstellt, oder ob der im Axencylinder darstellbaren Längsstreifung ein System von Fißrillen zu Grunde liegt, deren jede für sich einer isolirten Erregungsleitung fähig ist: die letzte Alternative scheint verneint werden zu müssen.

Am klarsten liegen die Verhältnisse bei den motorischen Nervenfasern; hier entspringt jeder Axencylinder sicher in seiner Totalität ans einer einzigen Nervenzelle des Centralnervensystems, in der Peripherie spaltet er sich freilich und giebt die Terminaläste ab, deren Gesammtquerschnitt aber bei weitem grösser ist, als der Querschnitt des Axencylinders vor seiner Verzweigung, was nicht zu verstehen wäre, wenn es bei der Verzweigung auf die Theilung isolirt leitender Fibrillenbahnen ankäme; auch der oben beschriebene und zum Beweis der Doppelsinnigkeit der Leitung verwandte Versuch am elektrischen Nerv vom Malopterurus ist mit der Annahme isolirter Leitung in Axencylinderfibrillen nicht gut zu vereinen. Die Ueberleitung der Erregung aus der centripetalen in die centrifugale Richtung ist hier nur verständlich bei der Annahme der vollständigen Leitungscontinuitait in der Axencylindersubstanz.

Für die Vorstellung von der,Art, wie sich die Erregung von der Nervenfaser der Muskelfaser mittheilt, ist der Nachweis von einschneidender Bedeutung geworden, dass der Axencylinder der terminalen Nervenverzweigung das Sarkolemm durchdringt und dass es einen hypolemnal gelegenen Nervenendapparat giebt; so lange man die Nervenendigungen epilemnal anzunehmen sich genöthigt sah, hatte man Schwierigkeit, sich vor\%ustellen, wie sich die Erregung durch eine, sellsst nicht erregbare Zwischenschicht, das Sarkolemm, fortpflanzen 
sollte, und man hatte Grund zu der Annahme, dass dies durch Vermittelung der elektrischen negativen Schwankung geschehe, welche die krregung im Nerven begleitet; in der That heobachtet man ja bei manchen 'Thieren, den elektrisehen Fischen, sehr erhebliche Wirkungen von elektrischen Spannungsdifferenzen, welche sich unter der Einwirkung der Nerven in besonderen mit diesen zusimmenhängenden Gebilden, den elektrischen Platten, entwickeln. Wemn auch nicht die Nervenendplatte selbst, sondern die Muskelfaser der elektrischen Platte homolog ist, so discutirte man doch die Möglichkeit, dass von der epilemnalen Nerrenendplatte analog wie ron der elektrischen Platte ein Schlag alusginge, welcher die Vermittelung der Erregungsübertragung von Nerv anf II skel durch das Sarkolemm hindurch ïbernähme. Diese Annahme nannte man die Entladungshypothese. Seitdem wir wissen, dass die motorische Nervenendplatte immerhalb des Sarkolemm-Schlauches liegt, besteht ein Grund für solche Annahme nicht mehr. Allerdings ist es nicht ausgemacht, dass die Axencylindersubstanz in directer Continuität steht mit der erregbaren Muskelsubstanz, was aber etwa dazwischen liegt, ist protoplasmatischer Natur und kilmn selbst der Erregung fähig sein. I)ie Annahme eines elektrischen Processes zur Vermittelung der Erregungsïbertragung ist übrigens nicht nur hierdurch überfliissig geworden, sondern sie ist auch schwer mit anderen Thatsichen zu vereinigen; erstens hat man mit ziemlicher Sicherheit ermitteln können, dass die Uebertragung der Frregung von Nerv auf Huskel eine, wenn auch kleine, so doch messbare Zeit erfordert, und zweitens kann nicht darau gezweifelt werden, dass die Erregung ron jeder Nervenfaser nur auf diejenige Muskelfaser übergeht, imnerhalb deren Sarkolemm-Schlanch sie endigt. Namentlich letzterer Umstand spricht stark gegen die Entladungshypothese, welche Form man derselben auch geben möge, denn da die Isolirung der Erregungsleitung auch bei maximalen Erregungen besteht, so müsste man besondere Einrichtungen annehmen, durch welche die Ausbreitung wirksamer Stromschleifen auf die benachbarten Muskelfisern verhindert wäre.

Die Verzögerung, welche die Erregung bei dem Uebergang rom Nerv zum Muskel erleidet, würde am leichtesten verständlich sein bei der Annahme einer Zwischensubstanz, in welcher von Seiten des Nerven ein chemischer Process ausgelöst würle, dessen Product die Nuskelsubstanz reizte; das undifferenzirte, mit Kernen versehene Protoplasma, welches die hypolemnale Axencylinderendigung begleitet, könnte hierzu geeignet sein, auch wenn sie sich, wie es scheint, nicht stets in Gestalt einer besonderen Plattensohle zwischen Axencylinder und Muskelsubstanz einschiebt. Der als chemisch zu denkende Erregungsprocess in der Axencylindersubstanz selbst künnte aber auch direct auf die Muskelsubstimz 
wirken und die Verzögerung könnte darauf beruhen, dass dieser Process in der ausgebreiteten Axencylindersubstanz anders verliefe, als in dem Axencylinderfaden der Primitivfaser, oder auch darauf, dass er in der Ausbreitung eine gewisse Höhe erreicht haben mïsste, ehe sein Produkt die Reizwirkung entfalten kann.

Wenn es auch zweifelhaft erscheinen mag, ob die Plattensohlensubstanz die Uebertragung des einzelnen Erregungsvorganges übernimmt, so spricht doch vieles dafür, dass die dauernde Fähigkeit der Erregungsiibertragung an diese Substanz gebunden ist. Von dem Gesammtprocess der Erregung im Nervmuskelpräparat ist der Uebertragungsvorgang von Nerv auf Muskel der hinfälligste Theil; der Verknïpfungspunkt zwischen Nerv und Muskel wird von allen das Nervmuskelpräparat schädigenden Einflüssen bei Weitem am frïhesten ergriffen. Die Entnervung des Muskels durch Curare, von welcher wir beim Studium der reinen Muskelsubstanz Gebrauch gemacht haben, beruht auf der Lähmung der Nervenendigung durch dieses Gift; dass die Muskelsubstanz selbst durch dasselbe nicht angegriffen wird, haben wir damals gesehen, und man kann auch leicht zeigen, dass die Reactionslosigkeit des curarisirten Muskels bei Behandlung seines Nerven mit starken elektrischen Reizen nicht auf einer Lähmung der Nervenfasern selbst beruht; die negative Schwankung ist an diesem Nerven eben so stark zu beobachten, als wenn das Präparat nicht curarisirt wäre. Ueberdies werden auch die centripetalen Nervenfasern durch das Curare nicht gelähmt. Der Beweis hierfür liegt in Folgendem: curarisirt man einen Frosch, dessen eine Hinterextremität durch Unterbindung ihrer Arteria iliaca der Giftwirkung entzogen wurde, legt den Ischiadicus der anderen Seite frei und tetanisirt ihn, so bleiben die zugehörigen Muskeln in Ruhe, während das andere Hinterbein durch Vermittelung der gereizten sensiblen Fasern und des Riückenmarkes Bewegungen ausführt.

Beim Warmblüter tritt nach Unterbindung der Bauchaorta sehr schnell motorische Lähmung der Hinterbeine ein, während die sensiblen Nerven zunächst noch erregbar sind und die Muskeln noch lange ihre directe Reizbarkeit bewahren; auch für die Ermüdung lässt sich zeigen, dass ihr bei weitem früher die Nervenendigungen verfallen, als die Nerven- und Muskelfasern. Es weist dies Alles darauf hin, dass an der Verbindungsstelle von Nerv und Muskel eine Substanz liegt von anderem chemischem Gefüge, als Axencylinder und Muskelsubstanz, und zwar eine Substanz mit regem Stoffwechsel.

Die Nervenfuser selbst scheint nahezu unermüdlich zu sein, so lange sie mit ihren Enden in normalem Zusammeuhang steht; man kann dies auf folgende Weise demonstriren: man legt bei zwei Katzen je einen Nervus ischiadicus frei, die eine Katze curarisirt man stark genug, 
dass motorische Lähmung eintritt, aber nicht so stark, dass sie sich bei Unterhaltung kïnstlicher Athmmng nicht wiederholen künnte; die 'Thiere kömnen ausserdem durch starke Morphiumgaben mempfindlich gemacht werden. Tetanisirt man num beide freigelegte Nerven, so gerïth das zugehörige Bein des nicht curarisirten Thieres zunächst in starke Contraktion, erlahmt aber nach und nach. Das entsprechende Bein der anderen Katze ist natürlich in Rulıe geblieben, wïhrend der zugehörige Nerv ebenso stark tetanisirt wurle. Man lässt nun die tetanisirenden Ströme unausgesetzt in gleicher Stärke auf beide Nerren einwirken, und wenn sich nach Verlauf ron ein bis zwei Stunden das eurarisirte Thier von der Vergiftung erholt, so geräth sein Bein in Tetanus, während das des anderen Thieres schon längst erschlafft daliegt: die Nervenendigungen des letzteren sind erschöpft, während die des anderen beines dureh das Curare vor der Ersehöpfung bewahrt wurden und dadurch im Stande sind, auf die ungeschwächt von dem fortgesetzt tetanisirten Nerren zugeleiteten Erregungen zu reagiren. Man kam die Nervenendigungen im Muskel bei derartigen Versuchen auch dadurch ror der Ermiidung bewahren, dass man zwischen der tetanisirten Nervenstrecke und dem Muskel einen eonstanten Strom durch den Nerven sendet: ein genïgend starker Anelektrotonus verhindert die Erregung, sich ron der lieizstrecke aus durch den Nerven dem Muskel mitzutheilen. Zum Vergleich tetanisirt man einen anderen Ischiadicus ohne Erzengung ron Anelektrotonus: ist hier der tetanisirende Reiz wegen Frmüdung unwirksam geworden und hebt man den Anelektrotonus an dem anderen Nerven auf, so verfällt der zugehörige Sehenkel in so kräftigen Tetanus, als wenn man eben erst begonnen hätte, seinen Nery zu tetanisiren.

Die geringe Ermïdbarkeit der Nervenfasern weist anf einen sehr geringen Umfang rles Stoffumsatzes in denselben hin, um so mehr, als wir wissen, dass die Versorgung der Nerven mit Blutgefässen eine spärliche ist. Auch ist es nicht gelungen, Wärmebildung oder Säuerung in Nerven in Begleitung oder als Folge seiner Erregung nachzuweisen, und doch miissen wir annehmen, dass die Erregung im Nerven mit einem chemischen Process verbunden ist, denn erstens ist die physikalische Beschaffenheit des Nerven keine derartige, dass wir iln die isolirte Fortpflanzung einer mechanischen Zustandsänderung zutranen könnten, und zweitens weisen auch die mit der Erregung verbundenen elektrischen Zustandsänderungen auf einen chemischen Process hin.

Die Intensitä des ehemischen Processes in den Nerrenfasern darf man sich, selbst bei starken und andauernden Erregungen, als klein vorstellen, weil die durch denselben zu leistende Arbeit eine kleine ist; es handelt sich um Auslösungsrorgäinge an den NerrenendiGad u. Ileymans, Physiolngie. 
gungen und um einen Process von grosser Intensität in einer labil gebauten chemischen Substanz auszulösen, bedarf es minimaler Anstösse: man denke an die Entzïndung einer explosiblen Minenfüllung durch einen schwachen elektrischen Funken, oder an das Verhältniss der in einer Z̈̈̈ndschnur verbrauchten chemischen Energie zu der Arbeitsleistung durch die explosible Masse selbst. Immerhin muss der Erregungsprocess in der Nervenfaser mit einem Energieverbranch verbunden sein und zwar mit einem solchen, bei welchem chemische Umsetzungsprodukte von geringerer Verbrennungswärme entstehen, und es bleibt sehr auffallend, dass von solchen Produkten in den Nerven auch nach starker und andanernder Erregung derselben Nichts nachzuweisen ist. Auch die Unermüdbarkeit der Nervenfasern weist darauf hin, dass ihre Substanz bei der Erregung nicht dauernd chemisch modificirt wird; es lässt sich dies wohl nur so verstehen, dass die Restitution der bei der Erregung modificirten Substanz eines Quer'schnitts sofort auf Kosten des benachbarten Querschnittes eintritt und dass hierauf die Fortpflanzung der Erregung beruht.

Die an dem Endapparat, von welchem die Erregung ausgeht, eingeleitete chemische Umwandlung könnte die Constitution der Moleküle des benachbarten Querschnittes so modificiren, dass freie Affinitäten in diesen Molekülen entständen, welche auf Kosten der nächsten Molekülreihe gesättigt wïrden und so fort, sodass nur an dem anderen Nervenende ein dem molekularen Zerfall entstammendes Stoffwechselprodukt der Nervensubstanz aufträte, durch dessen Vermittelung die Erregung auf andersartige Substanzen (Muskelsubstanz) übertragen würde. An dieser Stelle würde sich die Ermüdung am schnellsten geltend machen, und hier würden besondere Processe einzugreifen haben, um die Functionsfähigkeit dauernd zu unterhalten. Die Anhäufungen undifferenzirten kernhaltigen Protoplasmas, welche die hypolemnalen Nervenendigungen umgeben, und zwar bei dem Warmbliuter in erheblicher Menge, könnten Träger dieses Processes sein; die chemische Integrität der Nervensubstanz wäre auf diese Weise vorwiegend an Processe gebunden, deren Unterhaltung von den Enden der Nervenfasern ausginge, sodass auch nur dort ausgiebige Beziehungen zu dem Blutstrome zu erwarten wären, welcher Stoffiwechselprodukte zu entfernen und Nahrungsmaterial zuzuführen hat; in der That sind ja auch die Organe, welche Nervenendapparate enthalten, reichlicher vascularisirt.

Die Functionsfähigkeit der Nervenfasern bleibt nur erhalten, so lange sie sich im normalen Zusammenhange mit bestimmten Endapparaten befinden; schneidet man beim Warmbliiter ein Stück aus einem motorischen Nerven herans, ohne sonst den Organismus zu schädigen, 
so gelingt es nach etwa drei Tagen nicht mchr, die zugehörigen Muskeln durch Reizung des Nerven zu erregen, wïhrend der Muskel auf directe Reizung gut reagirt; eine histologische Veränderung ist \%u dieser Zeit nicht deutlich nachgewiesen, abgesehen ron der Umgebung der Schnittstelle: hier ist ein Zerfall der Nervenfasern eingetreten, welcher sich abor merkwïrdiger Weise innerhalb jeder Nervenfaser an der nächsten Ranvier'schen Einschnürung begrenzt. Es spricht dies dafïr, dass jedes Nerronsegment in seinen Lebensbedingungen eine gewisse Unabhängigkeit von den benachbarten bewahrt, wie ja auch die regelmässige $\Lambda$ nordnung der Kerne auf die genetische Beziehung jedes Segmentes zu je einer Zelle schliessen lässt. Dass aber diese Unabhängigkeit keine durchlgreifende ist, geht aus dem bald auftretenden Functionsausfall und aus dem allmählich sich einstellenden histologischen Zerfall der Nervenfasern peripher von der Durchschneidungsstelle hervor; der die Nervendegeneration begleitende Zerfall ist deutlich etwa 3 bis 4 Wochen nach der Durchschneidung zu demonstriren. Der Axencylinder ist verschwunden, das Nervenmark krïmlig zerfallen, statt des einen Kernes in jedem Segment ist eine grössere Anzahl derselben vorhanden, welche in einer reichlichen Menge körnigen Protoplasmas liegen. Die Schwann'sche Scheide ist erhalten. Später tritt Regeneration ein, bei welcher die Axencylinder aus dem centralen Stumpf in die Schwann'schen Scheiden des peripherischen hineinwachsen; erst später als die Continuität der Axencylindersubstanz wiederhergestellt ist, tritt die Restitution der Markscheide ein; der mit dem Centrum in Verbindung gebliebene Theil des Nerven hat während der ganzen Zeit keine Aenderung seiner Structur erfahren.

Das aus dem Organismus entfernte Nervmuskelpräparat rom Warmbliiter stellt seine Reactionen auf Reizung des Nerren in wenigen Minuten ein und zwar wegen des Functionsausfalles der motorischen Endigungen; der Nerv selbst zeigt noch längere Zeit negative Schwankung und der Muskel bleibt eben so lange oder noch länger direct reizbar; etwas hinausschieben kann man das Absterben des Nervmuskelpräparates rom Warmblïter, wenn man die innere Temperatur des Thieres vor seiner Tödtung allmählich auf einen möglichst niedrigen Grad bringt. Die Gewebe verhalten sich dann ähnlich denen, des Kaltblïter's. Die Nerven und Muskeln ganzer Hinterextremitäten von Warmblïtern kann man zum Zwecke ausgedehnter Versuchsreihen mittelst Durchströnung der Blutgefüsse mit körperwarmem Blut iiberlebend erhalten.

An dem Nervmuskelpräparat des Frosches sterben nicht zuerst die Nervenendigungen ab, sondern das Absterben schreitet ron der Schnittstelle aus langsam nach der Peripherie ror. In ersten Stadium des $A$ bsterbens ist die Erregbarkeit gesteigert und damn nimmt sie ab. Dieser 
Vorgang setzt sich nicht gleichmässig von der Schnittstelle des Nervenstammes aus durch denselben fort, sondern weiter peripher gelegene Stellen, wo abgehende Aeste bei der Präparation durchschnitten worden sind, eilen centraler gelegenen Stellen roraus und zwar schwindet hier die Reizbarkeit schneller, als die Leitungsfühigkeit, sodass eine Abgangsstelle ron Nerrenästen gegen directe Einwirkung des elektrischen Stromes unempfindlich sein kann, während sie die weiter central erzeugte Erregung noch ganz gut zu leiten fähig ist.

Auch am frischen Nervus ischiadicus des Frosches ist die Erregbarkeit in einer nicht einfach zu übersehenden Weise über die Länge des Nerren vertheilt; am besten lassen sich die verwickelten hierauf bezüglichen Erscheinungen unter dem Gesichtspunkt ordnen, dass ïberall, wo frischer Nervenquerschnitt vorliegt, sowohl an der Durchschneidungsstelle des Stammes als anch an denen der Seitenäste, Ströme im Nerven kreisen, welche innerhalb der Nervenfasern vom Querschnitt zum Längsschnitt und in adventitiellen Substanzen, die sich wie ein angelegter Leitungsbogen verhalten, vom Längsschnitt zum Querschnitt zurïck gerichtet sind. Die Stellen in der Nähe von Querschnitten verhalten sich wie im Katelektrotonus; Schliessung eines aufsteigenden Stromes ist hier wirksamer wie die eines absteigenden u. s. f.

Die Erscheinungen werden dadurch complicirt, dass die Nervenfasern von der Schnittstelle bis zur nächsten Ranvier'schen Einschnürung weit schneller absterben, als im iibrigen Verlaufe, und dass in dem Maasse wie das Absterben das Ende des direct verletzten Segmentes erreicht, der Nervenstrom abnimmt und Null wird: ein frischer in ziemlicher Nähe zu dem ersten angelegter Querschnitt lässt den Nervenstrom wieder ungefähr in der alten Höhe erscheinen, gleichzeitig damit ist auch wieder die Erregbarkeit in der Nähe des frischen Querschnittes gesteigert.

Eine Frage von principieller Bedeutung ist die, ob die Erregungswelle beim Ablauf durch die Nervenfaser regelmässig an Intensität zunimmt, gleichbleibt oder abnimmt: eine regelmässige Zunahme ist behauptet und lawinenartiges Anschwellen genannt worden; wäre dieses lawinenartige Anschwellen der Lrregung in einigem Umfange nothwendig an den Ablauf des Erregungsprocesses im Nerven gebunden, so müssten wir unsere Vorstellung ron dem Chemismus dieses Vorganges ändern, denn das Anschwellen der Lawine könnte nur durch einen Stoffverbrauch auf der ganzen Länge der durchmessenen Strecke zu Stande kommen; es müsste dann um so grössere Verwunderung erregen, dass es nicht gelingt, Zeichen eines solchen Stoffumsatzes in der Länge der Nervenfaser nachzuweisen. Thatsächlich ist der Beweis für das regelmässige Eintreten des lawinenartigen Anschwellens nicht einwandfrei zu fuihren; 
denn wenn ein an centralerer Nervenstelle einwirkender Reiz zu einer stärkeren Reaction des Muskels führt, so kann dies immer auf die zeitliche Veränderung der Erregbarkeit in der Nähe des Querschnittes bezogen werden.

Die chemische Constitution der lebenden Nervensubstanz ist unbekaunt, dagegen sind sehr interessante chemische Produkte aus der weissen Substanz des Centralnerrensystems dargestellt worden, welche vorwiegend aus myelinhaltigen Nervenfasern besteht. Hierher gehört in erster Linie das Protagon, welches sich olne verhältnissmässig tiefe Eingriffe aus der weissen Hirnsubstanz darstellen lässt, wegen seiner Löslichkeit in warmem Alcohol und seiner. Unlöslichkeit in kaltem Alcohol und Aether; neben viel Kohlenstoff enthält das Protagon Wasserstoff und Sauerstoff, Stickstoff und Phosphor. Es darf wohl mit Sicherheit als eine chemisch einfache Substanz betrachtet werden, aus welcher sich ohne tiefgreifende Zersetzung Cerebrin und Lecithin abspalten lassen. Das .Cerebrin giebt beim Kochen mit Schwefelsäure einen Zucker, die Cerebrose, welche identisch mit Galaktose sein soll. In dem aus dem Protagon abgespaltenen Lecithin ist der Phosphor des Protagons (vielleicht nicht aller) enthalten; eines seiner Spaltungsprodukte ist die Glycerinphosphorsäure; diese beiden Körper und das Nucleïn sind die einzigen phosphorhaltigen Substanzen des Organismus. Nuclein ist ein wesentlicher Bestandtheil aller Zellkerne, so auch der Kerne der Schwann'schen Scheide, und Lecithin kommt in allen entwickelungsfähigen Zellen vor. Ausser dem aus dem Protagon abspaltbaren Lecithin enthält die Markscheide des myelinhaltigen Nerven noch Lecithin in freiem Zustande. Diesem Lecithin rerdankt das Nerrenmark seine Färbbarkeit mit Osmiumsäure und seine Quellungsfähigkeit in Wasser. Auf letzterer beruht das Hervorquellen des Nerrenmarkes an in Wasser zerzupften Nervenpräparaten in den eigenthümlich knolligen Formationen, welche man Myelinformationen genannt hat. Das Myelin ist also chemisch freies oder chemisch nur locker gebundenes (durch Wasser abspaltbares) Lecithin. Die trockene Substanz der weissen Hirnmasse enthält ron Lecithin und Cerebrin je etwa $10 \%$. Der Nenge nach spielt das Cholesterin die Hauptrolle, welches etwa $52 \%$ der trockenen Substanz ausmacht; es ist identisch mit dem Cholesterin der Gallensteine.

Nach Erschöpfung der getrockneten weissen Hirnsubstanz mit heissem Alcohol und Aether bleiben etwa $28 \%$ Riickstand, woron die Albuminstoffe die Hauptmasse ausmachen. Etwa 1/6 daron ist eine dem Hornstoff nahestehende Substanz, das Neurokeratin; es ist gegen die rerschiedenen Säuren, Alkalien und anderen Lösungsmittel sehr resistent und wird durch Trypsin bei Körperwärme nicht verdaut, nur in heisser 
concentrirter Kalilauge oder Schwefelsäure ist es löslich. Beim Kochen nit Schwefelsäure erhält man aus ihm Tyrosin und Leucin, aber mehr Tyrosin und weniger Leucin als aus Rinderhorn; das Neurokeratin enthält etwa $3 \%$ Schwefel. Von der Natur der iibrigen Albuminstoffe ist sehr renig bekannt.

Dass der Axencylinder hauptsächlich aus Albuminstoff besteht, kann nach seinem Verhalten gegen Reagentien kaum bezweifelt werden; welche weiteren Bestandtheile ausser dem Wasser an seiner Bildung theilnehmen, ist unbekannt, anch ist nicht anzugeben, welche Gruppe der Eireissstoffe dem Axencylinder der lebenden und welche Gruppe dem Axencylinder der todten Nerren zugehört. Die starke Schrumpfung des Axencylinders bei Behandlung des Nerren mit Alcohol weist auf einen starken Wassergehalt seiner eiweissartigen Substanz hin.

Nach der Behandlung des Nerren mit heissem Alcohol und Aether erscheint in dem Paum zwischen dem geschrumpften Axencylinder und der Schwann'schen Scheide ein faseriges Gerïst aus Neurokeratin.

Die Aschenbestandtheile der reissen Hirnsubstanz oder anderer Iassen ron myelinhaltigen Nerrenfasern sind noch nicht untersucht.

An dem Aufbau des Nerrensystems betheiligen sich ausser den Nerrenfasern die Nerrenzellen, welche man auch Ganglienzellen nennt: im Allgemeinen bilden die Nerrenzellen Schaltstuicke zwischen Nerrenfasern. Die einfachste Art der Einfügung der Nerrenzellen in den Verlauf der Nerrenfasern findet sich in sogenannten bipolaren Ganglienzellen der Spinalganglien ron Fischen; hier erscheint die Nerrenzelle einfach als Verbindungsglied zmischen zwei an entgegengesetzten Polen der Zelle zu- und abtretenden myelinhaltigen Nerrenfasern, die Schwann'sche Scheide setzt sich ron einer Terrenfaser iiber die Zelle zur anreren Nerrenfaser fort. Markscheide und Axencylinder erscheinen unterbrochen durch den stark granulirten Zellleib mit centralem Zellkern. Das Myelin endigt sichtlich bei der Verbindung der Fasern mit der Zelle, während der Axencylinder sich faserig in die Substanz des Zellleibes aufzulösen scheint.

Während bei diesen einfachen bipolaren Nerrenzellen die zu- und abtretenden Fasern den Eindruck der Gleichwerthigkeit machen, giebt es höher differenzirte Nerrenzellen, welche sich nicht nur durch die grösssere Zahl der ron ihnen ausgehenden Fasern oder Fortsätze, sondern anch durch die deutliche Verschiedenwerthigkeit derselben auszeichnen: es siur dies die multipolaren Nerrenzellen. Als Prototyp dieser Kategorie ist die Art ron Nerrenzellen zu betrachten, welche sich in Verbindung mit dem centralen Ende dor motorischen Nerrenfaser im Rückenmark finlet. Es sind dies hïllenlose Zellen ron rerhältnissmässig grossem Umfange und unregelmüssiger Form; das granulirte Protoplasma des Zell- 
leibes umschliesst einen Kern und enthält in dessen Nähe mchr oder weniger eines bräunlichen Pigmentes. Der Kern ist bläschenförmig, enthält ein Kernkörperchen mit stark tingirbarem Gerüst, nimmt aber selbst wenig Farbstoff an. In seiner Peripherie sendet ier Zellleib nach allen Richtungen starke Aeste aus, welche sich unter mannigfacher Verzweigung weithin erstrecken, ein reiches Astwerk - die Dendritenfasern bildend: ausser diesen Fortsätzen, welche man die Protoplasmafortsätze nennt, besitzen die Nerrenzellen, welche nach dem Typus der motorischen Ganglienzellen gebaut sind, je noch einen glattrandigen, mehr homogenen, gar nicht oder wenig rerzweigten Fortsatz, welcher aus Axencylindersubstanz zu bestehen scheint, mit einer Ausbreitung dieser Substanz ron conischer Form und scheinbar faseriger Struktur in dem Protoplasmaleib der Zelle wurzelt und andererseits in den Axencylinder einer myelinhaltigen Nervenfaser übergeht; man nennt ihn Axencylinderfortsatz der Nerrenzelle. Dieser Fortsatz und der ganze Axencylinder der zugehörigen Nerrenfaser scheint genetisch der Nerrenzelle zuzugehören.

Ausser den bipolaren und multipolaren Nervenzellen giebt es auch solche, welche ihrer histologischen Erscheinung nach als unipolare bezeichnet werden könnten: dieselben kommen in den Spinalganglien höherer Vertebraten ror. Der einzige aus diesen Ganglienzellen entspringende Axencylinder umgiebt sich sehr bald mit einer Myelinscheide und ist gemeinschaftlich mit der Zelle in eine kernreiche und protoplasmahaltige Kiapsel eingeschlossen, welche beim Beginn der Myelinscheide den Charakter der Schwann'schen Scheide annimmt. Nur ein kurzes Nerrensegment entspricht dem Ursprungstheil der Nervenfaser; an dem Ende dieses Segmentes findet sich eine Einschnürung und die Faser theilt sich in zwei entgegengesetzte Richtungen: wegen des so entstehenden Bildes eines $\mathrm{T}$ nennt man diese Theilungsform die $\mathrm{T}$-förmige: da die Ganglienzellen mit T-förmig getheilten Nerrenfasern in früheren Entwickelungsstadien bipolar sind, und da die Gabelungsstelle vergleichend histologisch in rerschiedener Entfernung, gelegentlich auch ganz nah an der Ganglienzelle gefunden werden kann, so müssen auch diese unipolaren Zellen als den bipolaren sehr nahestehend betrachtet werden.

Eine physiologisch rerständliche Bedeutung könnte unipolaren Nerrenzellen nur zukommen, wenn sie Entstehungsorte ron Erregung darstellten. Wir haben Grund zu der Annalıme, dass es Nerrenzellen giebt, in denen Erregung bei Zustandsänderungen der unmittelbaren Umgebung entsteht, statt dass sie, wie sonst die Regel sein diirfte, auf der Bahn ron Nerrenfasern zugeleitet wiirde: der Theil des Centralnerrensystems, ron welchem die Athembewegungen ablängen, scheint solche 
Nerrenzellen zu enthalten. Man hat diese Art der Entstehung von Erregung als automatische bezeichnet.

Aber auch die automatisch erregungsfähigen Nervenzellen scheinen nicht unipolar zu sein, sie scheinen vielmehr in ihrem Erregungszustand nicht nur ron den Bedingungen der unmittelbaren Umgebung, sondern auch von Erregungen abzuhängen, welche auf Nerrenbahnen zugeleitet werden: ein Grund zur Annahme unipolarer Nervenzellen liegt also überhaupt nicht ror.

Die in den lebenden Nerrenzellen sich abspielenden chemischen Processe scheinen lebhaft zu sein, es ist dies zu schliessen aus der starken Vascularisation der Nervenzellenanhäufungen und aus der Empfindlichkeit nerrenzellenhaltiger Gewebe gegen Blutmangel und gegen minimale Mengen gewisser Gifte. Ueber die Natur dieser chemischen Processe wissen wir nichts. Da jedoch bei vermehrter Thätigkeit des centralen Nervensystems keine Vermehrung der Kohlensäureausscheidung auftritt, wie bei rermehrter Muskelthätigkeit, so müssen wir annehmen, dass es sich in Nerven und Nervenzellen nicht um Verbrennungen handelt. Beim Absterben nehmen nervenzellenreiche Gewebe, wie die grane Hirnsubstanz, schnell eine saure Reaction an. Sichere Kriterien dafür, ob eine Nervenzelle vor ihrer zur histologischen Untersuchung nothwendigen Abtödtung thätig oder in Ruhe gewesen ist, besitzen wir nicht: freilich hat man an scheinbar gleichwerthigen Nervenzellen Verschiedenheiten in der Färbbarkeit der Zellkörner, der Zellgrundsubstanz und des Zellkernes beobachtet; es ist also zu rermuthen, dass die Thätiçkeit erkennbare Spuren in der Nervenzelle zurïcklässt.

Die Functionen, welche die Nervenzellen als Schaltstücke zwischen den Nerrenfasern zu erfüllen haben, können wir erst bei Besprechung des Centralnerrensystems abhandeln. 


\section{Vierter Abschnitt.}

\section{Das Centralnervensystem.}

Nerrenfasern und Nervenzellen sind durch Bindegewebe und andersartige Zwischensubstanzen zu dem Nerrensystem verbunden: dieses besitzt eime centrale Axe, Centralnervensystem genannt, ron welcher die Nerrenstämme nach der Peripherie hin ausstrahlen, unter Plexusbildungen und Verästelungen. Jeder Theil des Kööpers ist durch centripetale oder centrifugale Nerrenfasern derart mit dem Centralnerrensystem rerknüpft, dass man dort gewissermaassen seine Projection wiederfindet. Das Centralnervensystem ist der Ort, wo die peripherischen Nervenendigungen ihre erste Projection in Nerrenzellen finden, und es enthält mannigfaltige Verknuipfungen zwischen diesen ersten Projectionen. Ausser im Centralnerrensystem finden sich noch anderweitige Nerrenzellenanhäufungen im Körper; welche man Ganglien nennt. Von diesen gehören die Spinalganglien sichtlich zum Centralnerrensystem: ron ihm geschieden hat man die ïbrigen Ganglien mit ihren verbindenden Nerrensträngen, als das sympathische Nerrensystem.

Zum Zwecke der physiologischen Betrachtung gliedert man das Centralnerrensystem der Säugethiere zweckmässig in Rückenmark, Hirnstamm und Hirnmantel.

Das R ïckenmark des Nenschen stellt sich der anatomischen Ijetrachtung als ein solider cylindrischer Strang von mässiger Consistenz und bedeutender Biegsamkeit dar, welcher im Wirbelkanal gelagert nach oben ohne scharfe Abgrenzung in das Gehirn uibergeht und nach unten ling zugespitzt endigt; der Querschnitt ist im Allgemeinen oval, mit transrersal rerlaufendem grösstem Durchmesser.

Jedem Segment der Wirbelsäule, das heisst jedem Wirbel entspricht ein bestimmtes Segment des Rïickenmarkes. Diese Segmentirung, welche sich bei niedrigen Vertretern der Wirbelthierreihe in regelmässiger Zunahme und Ahnahme des Querschnittes zu erkennen giebt, ist bei dem Menschen äusserlich nur dadurch angedentet, dass die zur Seite des Rückenmarkes aus- und eintretenden Nervenfasern, welche man Wurzelfasern nennt, sich zu ebenso vielen Nerrensträngen vereinigen, als es Zwischenwirbellöcher giebt.

Die Höhe des einzelnen Rückenmarksegmentes ist bei den Wirbelthieren nicht gleich der Höhe des entsprechenden Wirbels, sondern sie 
nimmt im Allgemeinen von oben nach unten ab, sodass die Länge des Riickenmarkes bei Weitem nicht die Länge des Wirbelkanals erreicht (nur etwa drei Viertel), und dass die Riickenmarkswurzeln je weiter nach unten-einen um so mehr longitudinal gerichteten und längeren Weg zurïckzulegen haben, um die entsprechenden Zwischenwirbellöcher zu erreichen. Der untere Theil des Wirbelkanals enthält also ein Bündel zahlreicher Rïckenmarkswurzeln, welches als Cauda equina den fadenförmigen Ausläufer des eigentlichen Rïckenmarks, das Filum terminale, umgiebt.

Die Grenze zwischen Rïckenmark und Gehirn verlegt man an die Austrittsstelle der obersten Wurzelfasern des ersten Halsnerrenpaares; bald unterhalb dieser Stelle beginnt das Rückenmark anzuschwellen. Die Anschwellıng, welche man die Halsanschwellung des Riickenmarks nennt und welche das Gebiet der Wurzeln für die Nerven der oberen Extremitäten umfasst, erreicht ihr Maximum in der Höhe des fünften oder sechsten Halswirbels und ihr unteres Ende in der Gegend des zweiten Brustwirbels. Eine zweite Anschwellung, die Lendenanschwellung, umfasst die Wurzeln der Nerven der Unterextremitäten, beginnt in der Gegend des zehnten Brustwirbels und erreicht ihr Naximum in der Höhe des zwölften Brustwirbels. Von da ab spitzt sich das Rïckenmark kegelförmig zu als Conus medullaris, dessen Ende beim Uebergang in das Filum terminale in der Höhe des ersten oder zweiten Lendenwirbels liegt.

Die Anbringung des Rückenmarkes im Wirbelkanal ist eine derartige, dass es vor Druckwirkungen von aussen rollkommen geschiitzt ist, dass die pulsatorischen Druckschwankungen seine eigentliche Substanz wenig treffen können, und dass es die ihm durch die Bewegung der Wirbelsäule aufgenöthigten Biegungen und Verschiebungen leicht ausführen kann, ohne Zerrungen zu erleiden. Das ganze Rüickenmark steckt in einem allseits geschlossenen geräumigen Sack, dessen Wand durch eine starke bindegewebige Haut, die Dura mater, gebildet wird. Die Dura ist an allen den Stellen, an welchen sich ihre die Nervenwurzeln umkleidenden Ausbuchtungen in die Intervertebrallöcher einsenken, mit der den Wirbelkanal auskleidenden Knochenhaut fest verwachsen; an den übrigen Stellen ist der. Raum zwischen Dura mater und Periost durch reichliche Venenplexus und durch Fettgewebe ausgepolstert. Innerhalb des Duralsackes ist das Rückenmark schwimmend aufgehüngt; seine unmittelbare Umkleidung ist gebildet von einer zarten, gefässreichen, bindegewebigen Hant, der Pia mater, welche vielfache, als Fortsetzungen ihrer inneren Gewebslage anzusehende Septa in die Substanz des Riiickenmarkes hineinentsendet, und welche sich nach aussen in der 'Transrersalebene jederseits zu einem flïgelartigen Fortsatze er- 
hebt; letzterer spitzt sich zwischen je zwei Wurzelgebieten zu einem zahnartigen mit der Dura mater verwachsenen Fortsatze zu und wird deshall) dis Ligamentum denticulatum genamut. Die P'ia mater iiberkleidet auch die Nervenwurzeln bis zu ihrem Eintritt in die Wand des Duralsackes. Ausser auf diesem Wege und durch das Ligamentum denticulatum hängt die Pia mit der Dura durch zahlreiche sehr feine, spinngewebsartige Fascrn znsammen, deren Gesammtheit die Spinngewebshaut, die Arachnoidea, ausmacht; diese Fasern, sowie die einander zugekehrten Flächen der Pia und der Dura sind mit Endothel bekleidet, und der ibrig bleibende reichliche Raum, der Arachnoidealraum, oder auch Subarachnoidealraum genannt, ist mit lymphoider Fliissigkeit, der Cerebrospinalfliissigkeit, gefüllt. Letztere wird beständig neu gebildet und findet ihren regehmässigen Abfluss durch Lymphspalten, welche die Nerveuwurzeln an ihrer Oberflïche begleiten.

Das aus dem Duralsack entfernte, mit der Pia mater bekleidete und mit den Wurzeln der Spinaherven versehene Rückenmark zeigt auf der Vorderfläche eine tiefe, ziemlich breite, mediale Lüngsspalte, an deren Auskleidung die Pia mit allen ihren Schichten Theil nimmt, es ist die Fissura longitudinalis anterior. Längs der Medianlinie der Hinterfläche läuft eine leichtere Furche herab, an deren Grunde sich aber die inneren Schichten der Pia tief in die Rückenmarksubstanz einsenken, sodass nach Abziehen der Pia mater auch hier eine Längsspalte sichtbar wird, die Fissura longitudinalis posterior, welche tiefer aber schmäler ist, als die vordere Längsspalte. Die Wurzeln der Spinalnerven entspringen jederseits aus zwei seitlichen längslinien, einer hinteren und einer vorderen. Für die hinteren Wurzeln gilt dies wörtlich, denn ihre Fasern treten aus dem Grunde einer ohne Weiteres erkeunbaren schmalen Läingsfurche, des Sulcus lateralis posterior hervor. Das Austrittsgebiet der vorderen Wurzeln ist breiter und weniger deutlich durch eine Längsfurche gekennzeichnet: eine solche ist aber nach Abziehen der I'ia mater und nach Entfernen der Wurzelfasern $z u$ erkennen und wird Sulcus lateralis anterior genannt.

Zwischen dem Wurzelgeljiete je zweier auf einander folgender Spinahnerven bleibt sowohl im Bereich der hinteren als auch der vorderen Wurzehn eine kleine Strecke der Rückenmarksoberflïche ron austretenden Fasern frei: am deutlichsten ist dieses Verhältniss an den vorderen Wurzeln des Brustmarkes, wo die freien Zwischenräume bis zu 5 Millimeter betragen. Die Fasern jeder vorderen und der zugehörigen hiuteren Wurzeln vereinigen sich imnerhalb des Duralsackes zu je einem geschlossenen Bündel: die zusammengehörigen liuteren und vorderen Wurzelbïndel convergiren gegen die gemeinschaftliche Anstrittsstelle aus dem Duralsack, und unmittelbar vor der Vereinigung beider Bündel 
trägt das hintere derselben eine grane Anschwellung der Spinalganglien.

Im Halstheile des Rückenmarkes findet sich ausser den schon angegebenen longitudinalen Furchen noch eine von der Medulla oblongata aus auf das Rïckenmark sich fortsetzende bilaterale feine Längsfurche, welche oben etwa 1 Millimeter seitlich von der hinteren Längsspalte ge-

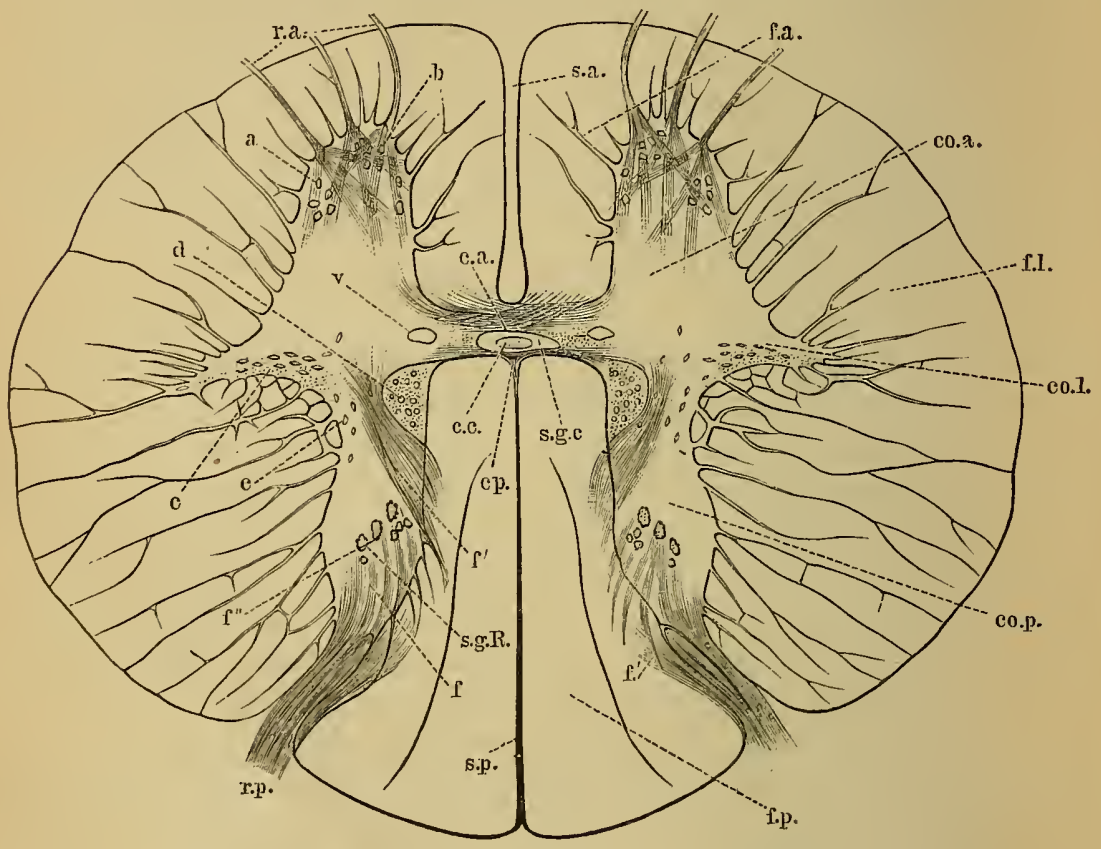

20.

Querschnitt des $k$ ückenmarks in der Höhe des achten Dorsalnerven. (Vergrösserung 10:1) (nach Schwalbe).

s. a. Fissura longitudinalis anterior. s. p. Septum posterius, die Fissura longitudinalis posterior ausfüllend. c. a. Vordere Commissur. s. g. c. Substantia gelatiuosa centralis. c. c. Centralcanal. c. p. Hintere Commissur. v. Vene. co. a. Vorderhorn. co.l. Seitenhorn, dahinter der Processus reticularis. co. p. Hinterhorn. a Vordere laterale, b vordere mediale Gruppe der Ganglienzellen. c Zellen des Seitenhorns, d Zellen der Clarke'schen Säulen. e Solitäre Zellen des Hinterhorns. r. a. Vordere Wurzeln, r. p. hintere Wurzeln, f, deren Hinterhormbûndel, f' Hinterstrangbündel, f" longitudinale Fasern des Hinterhorns, s. g. R. Substantia gelatinosa Rolandi, f. a. Vorderstrang. f. l. Seitenstrang. f. p. Hinterstrang.

legen ist, und welche nach unten gegen die lintere Längsspalte convergirt, man nennt sie Sulcus intermedius posterior.

Auf Querschnitten zeigt das Riückenmark Lmgrenzungslinien, deren allgemeine Form aus dem, was vorstehend ïber die Lüngsspalten und luurchen angegeben ist, hervorgeht. Zwischen dem Grunde der vorderen und dem der tieferen hinteren Medialfissur bleibt eine schmale Briieke Rïickenmarksubstanz bestehen, welche die beiden Rïckenmarkshälften ver- 
bindet. Wenn anch das Riückenmark principiell hilateral symmetrisch angelegt ist, so lassen doch beide Hälften anch unter normalen Verhältnissen deutliche Abweichungen ron der Symmetrie erkennen. Innerhall, der Verbindungsbrücke näher łem Grunde der hinteren Längsspalte sieht man den Querschnitt des Centralcanals, wolcher dem Hohlraum des embryonalen Medullarrohres entspricht. Der Centralcanal durchrieht, urspriinglich mit Flimmerepithel ausgekleidet, die ganze Iänge des Rückenmarkes, ron dem unteren 'Theil des Filum terminale his 7. seiner Eröffnung in den rierten Ventrikel, doch findet man ihn beim Erwachsenen auch unter normalen Verhältnissen nicht solten streckenweise obliterirt. Wo er erhalten ist, ist er mit Cerehrospinalfliissigkeit gefüllt.

Die Fläche der Rückenmarksquerschnitte ist durch zwei schon dem blossen Auge verschieden erscheinende Substanzen eingenommen, eine am frischen Präparat grauröthlich durchscheinende und eine opak weisse.

Die weisse Substanz umgiebt mantelartig die, im Ganzen central gelegene, graue Substanz. Der Querschnitt der letzteren erscheint in einer selır charakteristischen mit einem $\mathrm{H}$ rergleichbaren Figur. Der dem horizontalen Verbindungsstrich entsprechende Theil enthält den Centralcanal und diesen einhüllend die sogenannte grane Commissur. Diese Commissur stösst unmittelbar an den Boden der hinteren Medialfissur und ist ron dem Boden der vorderen durch weisse Substanz, die weisse Commissur, getrennt; die beiden Commissuren werden auch als hintere und rordere Commissur des Rïickenmarkes unterschieden. An jedem der die rerticalen Grundstriche des $\mathrm{H}$ rertretenden Theile wird cin vorderer und ein hinterer Abschnitt unterschieden, das vordere Horn und das hintere Horn. Das rordere Horn ist im Allgemeinen kürzer und dicker, es erreicht nicht die Oberfliche des Rückenmarkes, sondern ist an seiner medialen, ventralen und lateralen Seite ron weisser Substanz umgeben. Der rentrale Theil des weissen Mantels wird in amnähernd radiürer Richtung von Bündeln vorderer Wrurzelfasern durchsetzt, ron denen auf demselben Querschnitt mehrere nebeneinander liegen. Die hinteren Hörner sind länger und schlanker gebaut, als die rorderen Hörner und leicht nach aussen gebogen. Nahe ihrer Basis sind sie rerdünnt zu der Cervix cornu anterioris, nach hinten schwellen sie zu dem Caput cornu posterioris an, welches sich nach hinten und aussen zu den Apex cornu posterioris zuspitzt.

Die hinteren Wurzelfasern treten aus dem Apex cornu posterioris als ein geschlossenes Bündel zum Grunde des Sulcus lateralis posterior, die Continuität des weissen Mantels vollkommen unterbrechend; als eine eigenthümliche, dem vorderen Horn angehörende Bildung ist rin rlem. hinteren Rande eines jerlen rorderen Hornes lateral aufsitzen- 
der und mit ihm continuirlicher Vorsprung von dreiseitiger Gestalt zu betrachten, der mit seiner Spitze in die weisse Substanz hineinragt und etwa in der Frontalebene des Centralcanals gelegen ist; er wird als Seitenhorn (mittleres Horn, Tractus intermedius lateralis) bezeichnet, nimmt im Dorsalmark nach unten allmählich bis zum Verschwinden ab, während er im oberen Dorsaltheile des Rückenmarkes eine gute Entwicklung erreicht, im Halsmark mit dem hier mässig entwickelten Vorderhorn zusammenfliesst. Dieses Seitenhorn wird stets ror dem Cervix cornu posterioris, also im Bereiche des Vorderhornes gefunden, dagegen entspricht dem einspringenden Winkel zwischen Seitenhorn und hinterem Horn eine nicht mit dem ersteren zu verwechselnde Formation, der Processus reticularis. Derselbe besteht aus netzförmig angeordneten Balken graner Substanz, welche grössere und kleinere Felder weisser Substanz umschliessen; seine Ausbildung nimmt nach dem Lendenmark ab, nach dem oberen Ende des Rïickenmarkes dagegen continuirlich zı.

Wenn man die einzelnen Theile der grauen Substanz nicht mit Riicksicht auf ihre Erscheinungsweise am Querschnitt, sondern im Hinblick auf ihre räumliche Continuität nach der Längsaxe des Rückenmarkes betrachtet wissen will, so spricht man nicht von Hörnern, sondern von Säulen; statt "vorderes Horn der grauen Substanz" sagt man "graue vordere Säule des Rückenmarkes" u. s. w.

Der Mantel weisser Substanz ist auf dem Querschnitt an zwei Stellen durchbrochen, am Boden der hinteren Medialspalte durch die grane Commissur, am Boden der hinteren Seitenfurche durch die Spitze des hinteren Hornes mit den hinteren Wurzelbündeln. Am Boden der rorderen Medialfurche rerbindet die weisse Commissur die beiden Seitenhälften des weissen Mantels. An letzterem unterscheidet man die Vorderstränge, die Seitenstränge und die Hinterstränge; die beiden letzteren finden ilıre natürliche und bestimmte Abgrenzung gegen einander in der Unterbrechung der weissen Substanz am Boden der hinteren Seitenfurche. Die Unterscheidung der Vorder- und Seitenstränge ist nur grob typographisch zu rerstehen, sie ist weder durch die Entwicklungsgeschichte, noch durch die feinere Anatomie, noch durch die Physiologie gerechtfertigt, man fasst deshalb häufig die ganze Formation als Vorder-Seitenstrang zusammen. Von der systematischen Gliederung, welche innerhalb der weissen Riickenmarkstränge besteht, ohne an dem Rückenmark des erwachsenen gesunden Nenschen anatomisch erkennbar zu sein, wird weiter unten gehandelt werden.

Las Gröissenverhältniss zwischen den Flächenräumen, welche graue und weisse Substanz auf dem Querschnitt einnehmen, ïndert sich sehr hedeutend mit der Lage des Querschnittes am Rïckenmarke. Am Ende des Conus medullaris ist der Quersehnitt rowwiegend aus graner Sub- 
stanz gebildet, die nur von einem schmalen Saun weisser umhiillt wird; am fünften Sacrahnerven ist das Verhältniss von weisser zu gramer Sul)stan\% 1:2,75. Die /unahme der weissen Sulstanz ist im Bereich der Lumbalanschwellung aber so bedeutend, dass am oberen Ende dersolben, an der Austrittsstelle des vierten Lumbarnerven graue und weisse Sulstanz nahezu gleichen liam eimnelmen. Von hier an nach oben kehrt sich das Verhältniss um, so dass stets die weisse Substanz einen grösseren Flächeninhalt besitzt, als die graue. Selbst die Cervicalanschwellung, durch bedentende absolute Zunahme der granen Substanz charakiterisirt, vermag an diesem allgemeinen Verhältniss nichts zu ändern, obwohl sie die im Dorsalmark stark zuriiekgetretene grane Sul)stanz ( $1 / 5$ der weissen) wieder zur Hälfte des Betrages der weissen rermehrt zeigt.

In ihrer Gesammtheit betrachtet, lässt die weisse Substanz roun unteren Ende an bis zum oberen Theil der Halsanschwellung eine stete Zunahme erkennen, die nur in dem Bereiche vom dritten Lumbarnerven bis zum zwölften Brustnerven durch eine umbedeutende Abnalme gestört wird, und welche am unteren Ende jeder der beiden Anschwellungen rascher erfolgt, als an anderen Stellen. Vom vierten Cervicalnerven bis zur Medulla oblongata ist eine geringe Abnahme der weissen Substanz zu constatiren. Wie sich die einzehnen Systeme der weissen Stränge an diesen Aenderungen betheiligen, wird weiter unten zur Anschauung kommen.

Die graue Substanz ist am mächtigsten da, wo die grossen Extremitätennerven entspringen, also in der Lenden- und Halsanschwellung. Von der Spitze des Conus medullaris lis zur Mitte der Lendenansehwellung zeigt sie sich in stetiger Zunahme, nimmt darauf im Brustmark sehr beträchtlich ab und schwilt in der Cervicalintumescenz abermals bedentend an, um nach dem oberen Theil des Halsmarkes sich wieder langsam zu verminclern. Die Zunahme der grauen Substanz im Bereiche der Lenden- und Halsanschwellung kommt lauptsächlich auf Rechnung ihrer vorderen Säulen. Die Hintersäulen sind hier stets ron kleinerem Querschnitt wie die vorderen Säulen, wälnend sie in den dazwischen liegenden Partieen und am untersten Eude des Riickenmarkes dieselben um ein Geringes an Grösse ïbertreffen. Auch die Stärke der grauen Commissur nimmt mit der Mächtigkeit der Spinalnerven zu und ab, was von der weissen Commissur nicht gesagt werden kann.

An dem histologischen Aufbau des Riickenmarkes betheiligeu sich erstens rein nervöse Elemente, ferner zwei dem Centralnervensystem eigenthümliche Kitt- und Stiitzsubstanzen, welche als Neuroglia und als Sulsstantia gelatinosa bezeichnet werden; schliesslich Bindegewebe und Gefässe. Die nervösen Elemente sind Zellen und Fasern. 
Die Nervenzellen des Rï ckenmarkes sind multipolare Ganglienzellen verschiedener Grösse; sie besitzen sämmtlich einen hellen, bläschenförmigen Kiern, mit einem stark glänzenden, tingirbaren Kernkörperchen. Der nackte Zellkörper enthält gewöhnlich gelbliches oder bräunliches körniges Pigment zu einem diffusen Haufen gruppirt und zerstreute körnige Einlagerungen von verschiedener 'Tinctionsfäligkeit; jede Zelle besitzt wenigstens einen Axencylinderfortsatz und eine verschieden grosse Zahl von verästelten Protoplasmafortsätzen. Die grössten Ganglienzellen liegen in den vorderen Partien der vorderen grauen Säulen; ilnr Protoplasmaleib sendet seine Fortsätze nach allen Richtungen aus und jeder Axencylinderfortsatz derselben ist mit einer vorderen Wurzelfaser in Contimuität. Zwischen einander nahe gelegenen Individuen dieser grossen Ganglienzellen der Vordersäulen scheinen öfters gröbere Verbindungen der Protoplasmaleiber vorzukommen und manche dieser Zellen scheinen auch mehr wie einen Axencylinderfortsatz auszusenden. Die typischén Formen dieser Kategorie bilden zwei Gruppen in der vorderen Partie der Vordersäule, eine mediale und eine laterale. Die Zellenzahl dieser Gruppen erreicht innerhalb des Ausstrahlungsgebietes jeder Spinalnervenwurzel, namentlich des Dorsalmarkes, ein relatives Maximum, hierdurch den segmentalen Aufbau des Rïckenmarkes andentend; ansserdem wächst die Zahl in hervorragender Weise mit der Stïrke der Spinalwurzeln, ist also am grössten in den Gebieten der Hals- und Lendenanschwellung. Ein dritter in das Gebiet der Vordersäule gehöriger Zellenhaufen liegt im Seitenhorn. Innerhalb des Dorsalmarkes, wo das Seitenhor'n als besondere Formation hervortritt, ist auch dieser Zellenhaufen deutlich ron den beiden erstgenannten gesondert, um in den Gebieten der Anschwellungen wegen der grossen Zunahme aller Gruppen mit denselben zu verschmelzen. Die Ganglienzellen des Seitenhornes sind kleiner, als die des Vorderhornes; sie erscheinen meist spindelförmig, mit ihrer Längsaxe der Spitze des Seitenhornes zugerichtet.

Im Gebiete der grauen Hintersäule findet sich ebenfalls jederseits eine wenigstens innerhalb des Dorsalmarkes gut abgegrenzte Formation von Ganglienzellen. Die Zellen dieser Formation sind multipolar, aber kleiner als diejenigen der vorderen Gruppen der vorderen Sänlen; sie bilden oval begrenzte Haufen jederseits in der medialen Hälfte der Hinterhornbasis. Im Dorsal- und oberen Lumbarmark bilden diese Zellengruppen zusammenhängende Säulen und werden hier als Clarke'sche Columnae resiculares bezeichnet. Auch im Halsmark und im unteren Lumbarmark tritt die Formation in einiger Länge wieder geschlossen anf und heisst an letzterer Stelle Sacralkern, an ersterer (dritter und vierter Halsnerv) Cervicalkern (Stilling). An den dazwischenliegenden Theilen des Rïckemmarkes finden sich ebenfalls zorstrente Gruppen von Zellen, 
welche sich ihrer Form und Lage nach als dieser Furmation zugehörig erweisen. In ihrer Lntwickelung zeigt letrtere einen gewissen Gegensatz zu den rorderen Zellsäulen, indem sie dort stärker ausgebildet ist, wo diese an Stärke zuriektreten. In der nach Abzug des Gebietes der Clarke'schen Süulen und der durch gelatinöse Substanz eingenommenen Hinterpartie der Hinterhörner iibrig bleihenden Masse der grauen Hintersäulen einschliesslich der grauen Substanz des Processus reticularis liegen unregelmässig zerstreut die sogenannten solitären Ganglienzellen der Hinterhörner. Es sind mittlere und kleinere Nervenzellen, welche meist durch spindelförmige Gestalt ilıres Zellkörper's und durch Beschränkung der ron ihnen abgehenden Fortsätze auf die Spindelenden ausgezeichnet sind.

An Nervenfasern führt das Riickenmark myelinhaltige und myelinfreie, sümmtlich ohne Schwann'sche Scheide. Das Caliber der myelinhaltigen Fasern ist sehr rerschieden, rom grössten bis zu dem kleinsten: die stärksten Nervenfasern sind in den rorderen Wurzeln und in den äusseren Partien der Vorder-Seitenstränge enthalten. Etwas dïnuer sind die Faser'n der hinteren Wurzehn und der Hinterstränge; noch diinner diejenigen der vorderen Commissur und der die graue Substanz lateral begrenzenden Partie der Seitenstränge. Sehr feine markhaltige Nerrenfasern fülnt die hintere Commissur. Uebrigens liegen vielfach Fasern sehr rerschiedlenen Calibers durcheinander gemischt; die allgemeine Verlaufsrichtung der myelinhaltigen Fasern ist in den Wurzeln radial, in den Hintersträngen und Vorder-Seitensträngen longitudinal, in den Commissuren transrersal. In der grauen Substanz kreuzen sich markhaltige Nervenfasern einzeln und bündelweise von rerschiedenster Verlanfsrichtung; aber auch in anderen Gebieten, namentlich an deren Grenzen. kommt vielfach Umbiegung aus einer Richtung in die andere ror.

Die myelinfreien Nervenfasern sind sehr fein und bilden in der grauen Substanz ein unentwirbar rerschlungenes Netz, das Gerlach"sche Netz genannt; zweifellos gehen Faseru dieses Netzes aus der Verästelung und Verfeinerung der Protoplasmafortsätze herror, sodass es selbst als eine ungemein mannigfaltige Anastomosenbildung zwischen den Protoplasmakörpern der letzteren aufgefasst worden ist; ausserdem sollen auch hintere Wurzelfaseru durch direkte Verästelung ihres Axencylinders (ohne Zwischenkunft ron Ganglienzellen) an dem Aufban des Netzes betheiligt sein. Neuerdings sind berechtigte Zweifel daran lant geworden. ob es sich hier um eine wirkliche Anastomosenbildung handelt. Die mikroskopischen Bilder, welche bei Anwendung rerschiedener und auch scheinbar der besten Färbemittel gewonnen werden, berechtigen mit Sicherheit nur zu der Annahme eines sich rielfach durchsetzenden Astwerkes; ob das Geäst eines Protoplasmafortsatzes, welches sich nit den 


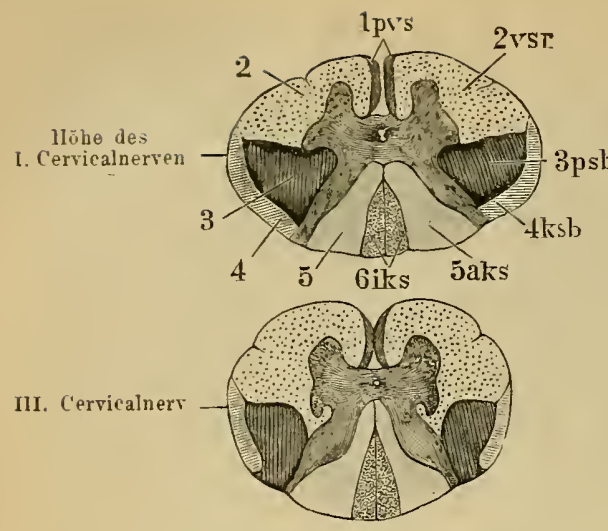

VI. Cervicalnert

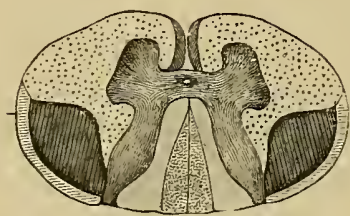

III. Dorsalnerv

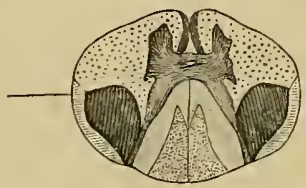

VI. Dorsalnerv

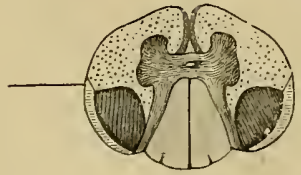

XIl. Dorsalnery

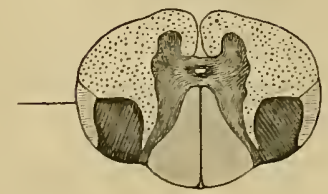

IV. Lumbalnerv

21.

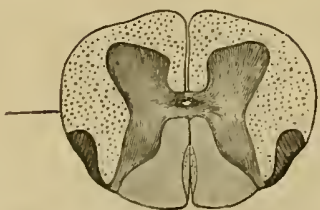

Scheisa der Vertheilung der Manptbahnen des liücken-

$\mathrm{lpv}=$ Pramiden - Vorderstrangbahnen (ungekreuzt). 2 v8 $r=$ Vorderseitenstrangreste (nach Flechsig zerfallend in Grundbūndel der Vorderstränge und in Seitenstrangreste). $\quad 3 \mathrm{ps} \mathrm{b}=$ Pyramidenseitenstrangbahnen (gekreuzt). $4 \mathrm{ks} \mathrm{b}=$ Kleinhirnseitenstrangbahnen. $5 \mathrm{aks}$ $=$ Aelissere (Burdach'sche) Keilstrünge. "i iks = Innere Goll'sche Keilstränge, Vergr. 2 fach.
Geästen anderer Protoplasmafortsätze durchsetzt, durch seine Faserenden mit denen der letzteren continuirlich zusammenhängt, oder ob die Fasern frei enden, durch eine dünne Schicht andersartiger Substanz ron einander getrennt, ist vor der Hand nicht zu entscheiden.

Obgleich das Querschnittsbild des weissen Markmantels vom Riickenmark des gesunden erwachsenen Menschen weder frisch, noch nach irgend welcher Behandlung Kriterien für eine feinere Gliederung der Längsfaserung erkennen lässt, so ist es doch auf Grund ron entwickelungsgeschichtlichen Studien und von pathologischen Erfahrungen beim Menschen, sowie von Durchschneidungsversuchen bei Thieren gelungen, hier eine ganz typische systematische Gliederung zu constatiren. Auf entwickelungsgeschichtlichem Gebiet hat sich die Beobachtung von bahnbrechender Tragweite erwiesen, dass die Ausbildung des Myelinmantels an den einzelnen Längsfasern des Rïickenmarkes nicht zu gleicher Zeit eintritt, aber auch nicht regellos zerstreut, sondern derart, dass die Reihenfolge in der Entwickelung des Myelinmantels geschlossener Fasersysteme eine typische ist. Einzelne dieser Systeme waren schon früher den Pathologen aufgefallen dadurch, dass jedes derselben bei bestimmten Erkrankungsformen der Degeneration verfiel. Solche De- 
generationen liessen sich auch durch bestimmte Durchschneidungen am 'Thier experimentell hervorrufen. Nit Hülfe dieser rerschiedenen Forschungsmethoden ist man zu gut iibereinstimmenden Resultaten betreffs der systematischen Gliederung der weissen Rückcmmarkssubstanz gelangt.

Die wichtigsten Einzelheiten, welche Lage, Verlauf und Bezeichnung der einzelnen Fasersysteme betreffen, gehen aus der Reihe systematischel Zeichnungen der beigegebenen Figur 21 herror. Aus der Betrachtung dieser Zeichnungen ergieht sich sofort die wichtige Eintheilung der Systeme in zwei Gruppen. Die eine derselben umfasst die Pyramidenbahnen des rorderen wie des Seitenstranges, die Kleinhirn-Seitenstrangbahn und den Goll'schen Keilstrang und ist durch continuirliche Zunahme des Querschnittsareals ron unten nach oben ausgezeichnet. Die Glieder der anderen Gruppe: äusserer Keilstrang und Vorder-Seitenstrangreste sind in der Lendenanschwellung, wo die anderen Systeme erst auftauchen, schon stark entwickelt, sie nehmen nach oben nicht continuirlich zu, sondern lassen in der Grösse ihres Querschnittes deutliche Beziehungen zu der Stärkc der Wurzelfaserentwickelung des betreffenden Gebietes erkemnen.

Aus diesen 'Verhältnissen ergiebt sich sofort der auch anderweit bestätigte Umstand, dass die Systeme der ersten Gruppe Leitungsbahnen enthalten, welche die directe Verloindung zwischen Elementen des Gehirns mit solchen des Rïckenmarkes rermitteln, und dass die zweite Gruppe Systeme von Fasern umschliesst, welche Rïckenmarkselemente verschiedener Höhenlage unter einander rerbinden. In der Umkleidung der Axencylinder mit Myelinscheiden schreiten die Systeme der zweiten Gruppe denen der ersten voraus; die Reihenfolge ist: Grundbiindel der Vorderstränge, Grundbündel der Hinterstränge (Burdach'sche Kieilstränge), Grundbündel der Seitenstränge (erst in ihrer peripherischen grobfaserigen, dann ihrer der granen Substanz angrenzenden Schicht), die Goll'schen Stränge, die Ḱleinhirn-Seitenstranglahn und zuletzt die Pyramidenbahnen.

Einige Einzelnheiten sind noch in Betreff der verschiedenen Systeme anzugeben. Die Fasern der Vorderstrangpartie der Pyramiden bahne n stammen ungekreuzt aus der Pyramide derselben Seite, diejenigen des Seitenstranges dagegen gehen theils direct aus der Decussatio Pyramidum, theils weiter unten ans der Vorderstrangpartie der anderen Seite hervor. Ein Theil der Fasern der rorderen Commissur dient letzterer Krenzung; das Verhältniss der Mächtigkeit beider Partien variirt stark, nicht nur bei rerschiedenen Menschen, sondern auch bei denselben Menschen auf den beiden Seiten. Letztere Verschiedenheit ist nicht selten Veranlassung zu grob wahmehmbarem asymmetrischem Bau des Riickenmarkes heim gesunden Menschen. Die von oben nach unten con- 
tinuirliche Abnahme der Mächtigkeit der Pyramidenbahnen beruht auf der allmählichen Einstrahlung ihrer Fasern in die graue Substanz, wo sie mit den grossen Ganglienzellen der Vordersäulen in Verbindung treten. Ein directer Uebergang von Pyramidenbahnfasern in Wurzelfasern kann als ausgeschlossen betrachtet werden. Im Allgemeinen liegen die terminalen Verkniipfungen der Pyramidenbahnfasern mit spinalen Nervenzellen contralateral zu der betreffenden Pyramide, es sollen aber auch, namentlich bei stärkerer Entwickelung der Vorderstrangpartie, ungekreuzte Verbindungen in grösserer Zahl rorkommen. Die ans dem Verlauf der centralen Fortsetzungen der Pyramidenbahnen (zu der motorischen Hirnrindensphäre) gefolgerte Annahme ihrer centrifugalen Leitungsrichtung wird durch die Thatsache erhärtet, dass sie nach Continuitätstrennungen unterhalb der Trennungsstelle degeneriren. Diese sogenannte absteigende Degeneration erstreckt sich aber, so lange die grossen Ganglienzellen der granen Vordersäulen intact sind, nie auf die vorderen Wurzelfasern; dieses ist einer ron den Gründen, aus denen man schliessen muss, dass Pyramidenstrangfasern nicht zu vorderen Wurzelfisern werden, ohne vorher zu Nervenzellen in nahe Beziehung getreten zu sein. Fïr diese Annahme spricht auch das Ergebniss folgenden Experimentes. Hat man rom Frosch ein Präparat hergestellt, welches aus den Unterextremitäten, dem Lumbalplexus und dem damit verbundenen Rückenmark besteht, so erhält man durch einzelne isolirte elektrische Reize, welche den obersten Theil des Ruickenmarkes treffen, Zuckungen in den Beinen: man kann sämmtliche Muskeln des Präparates dadurch in gleichem Sinne wirken lassen, dass man die zusammengebundenen Zehenspitzen beider Beine mit dem isotonischen Muskelhebel rerbindet, nachdem man Stïcke beider oberen und unteren Schenkelknochen entfernt hat. Misst man die Zeit, welche zwischen dem Reizmoment und dem Beginn der Wirkung auf den Muskelhebel vergeht, und zieht davon die Latenzzeit ab, welche sich bei directer Reizung der' Nerven des Lumbalplexus ergiebt, so erhält man fuir die Latenzzeit in Riiickenmark einen Werth, welcher weit grösser ist, als derjenige, welcher sich aus der Fortpflanzungsgeschwindigkeit der Erregung in einem gleich langen Nerven ergeben würde. Jede einzelne derjenigen Nervenfasern, deren Reizung im oberen Theile des Riickenmarkes irgend eine Contraction in den Beinmuskeln auslöst, muss also ror dem Eintritt in das Wurzelgebiet wenigsteus ein mit besonderer Verzögerung der E1regungsleitung rerbundenes Schaltstuick passirt haben.

D) ie Kleinhirnseitenstrangbahnen leiten Erregungen in cerebropetaler Richtung, was aus der Thatsache geschlossen werden kann, dass sie oberhalb von Durchtrennungsstellen degeneriren. Ihre Fasern sollen direct Axencylinderfortsätzen der Zellen der Clarke'schen Säulen, 
indirect hinteren Wurzelfascrn entstammen, und sie gehen ohne weitere Unterbrechung in die linteren Kleinhirnschenkel ïber. Die Fasern der Goll'schen Keilstränge leiten ebenfalls in cerehropetaler Richtung, sie entstammen (direct oder indirect?) linteren Wurzelfasern und finden cine celluläre Unterbrechung im Kern der zarten Stränge der Medulla oblongata. Die Grundbündel der Hinterstränge und der Vorderseitenstränge nehmen im ganzen Verlauf des Riickenmarkes Fasern aus der grauen Substanz auf und geben dafür andere dorthin ab, sie stellen intersegmentäre Verknuipfungen her. Erstere führen auch longitudinal aufsteigende und absteigende Fasern, welche direct aus den linteren Wurzeln der gleichen Seite stammen. I)ie Grundbündel der Vorderstränge führen nach Ansicht einiger Autoren solche Fasern, welche auf dem Wege der vorderen Commissur direct aus den vorderen Wurzeln der anderen Seite zu ihnen gelangen sollen. Longitudinale Faserbündel kommen auch innerhalb der grauen Substanz vor, namentlich im Kopf des Hinterhornes, wo hintere Wurzelfasern nach entsprechender Richtungsänderung streckenweise longitudinal verfolgt werden können. Viele solcher longitudinal verlaufender Hinterwurzelfasern sollen sich spalten in einen aufsteigenden und einen absteigenden Hauptzweig. Von diesen Hauptzweigen sollen schwächere Seitenfasern abgehen, welche sich in Endverästelungen auflösen (Collateralfasernn).

Die Axencylinderfortsätze sümmtlicher grosser Ganglienzellen der grauen Vordersäulen werden zu Nervenfasern der vorderen Wurzeln. Beim Frosch ist die Zahl der letzteren nachweislich erheblich grösser wie die der ersteren. Zählungen, welche ein anderes Resultat ergaben, nämlich die Gleichheit der Zahl grosser Ganglienzellen mit derjenigen vorderer Wurzelfasern, waren mit dem Fehler behaftet, dass dic Querschnitte der zur Zählung benutzten Schnittserien erheblich diinner waren, als die longitudinale Ausdehnung der Ganglienzellen, sodass ein grosser Theil der Ganglienzellen melıffach gezählt worden war. Da cerebromedulläre Bahnen nicht direct zu vorderen Wurzeln werden und da die Zahl der grossen Ganglienzellen im Froschrickenmark kleiner ist als die der vorderen Wurzelfasern, so muss entweder ein beträchtlicher Theil der letzteren aus Axencylinderfortsätzen kleiner (solitärer) Ganglienzellen der hinteren Säulen entstehen, oder man muss annehmen, dass es grosse Ganglienzellen der vorderen Säulen mit mehr als einem Axencylinderfortsatz gieht. Wahrscheinlich trifft beides zu. Bei Menschen sind Axencylinderfortsätze solitärer Ganglienzellen in der Richtung nach den vorderen Wurzeln hin verfolgt worden.

Ein Theil der vorderen Wrurzelfaser'n stammt aus Axencylinderfortsätzen contralateral gelegener Ganglienzellen der vorderen Säulen. Der Verbindungsweg geht durch die rordere Commissur. In Allge- 
meinen liegen die Ursprungszellen der vorderen Wurzelfasern in demselben Segment wie die zugehörigen Wurzeln.

Axencylinderfortsätze von Ganglienzellen der Hintersäulen sind bisher nur bei Petromyzon in hintere Wurzelfasern verfolgt worden; letztere stehen beim Menschen, wie man annehmen muss, zwar mit Zellen der Clarke'schen Säulen, mit solitären Zellen des Hinterhornes, wahrscheinlich auch mit Zellen der Seitenhörner in Verbindung, aber in complicirterer Weise und auf verschiedenen Wegen. Auffallend ist schon die Trennung jeder hinteren Wurzel in ein Bündel, welches sofort in die graue Substanz des hinteren Hornes eintritt (Hinterhornbündel), und ein solches, welches in den Hinterstrang abbiegt (Hinterstrangbündel). Die Fasern beider Bündel nehmen zunächst, ehe sie zu Elementen der eigentlichen grauen Substanz werden, longitudinale Richtung (aufsteigende und absteigende) an, diejenigen des Hinterhornbündels nur fïr eine kürzere, den Bereich eines Segmentes kaum überschreitende Strecke, diejenigen des Hinterstrangbündels aber für einen weiteren Weg, nach dessen Zurücklegung sie erst, wenn überhaupt im Rückenmark, wieder in die grane Substanz (Basis des Hinterhornes) einbiegen. Mit den Zellen vorgenannter Kategorien scheinen alle diese Fasern erst durch Vermittelung der dendritischen Collateralfasern in Verbindung zu treten. Eine grosse Zahl der hinteren Wurzelfasern oder ihrer indirecten, aus eingeschalteten Zellen wiedererstandenen Fortsetzungen geht in der hinteren Commissur des Rïckenmarkes eine Kreuzung ein.

Die nervösen Elemente des Rückenmarkes, so dicht gelagert sie auch sind, können wegen ihrer abgerundeten Formen den Raum nicht völlig ausfüllen; die bestehenden Lïcken werden zum Theil durch eigenthümliche Kitt - und Stützsubstanzen eingenommen, Neuroglia und Substantia gelatinosa, zum Theil durch gewöhnliches Bindegewebe, welches letztere in Gestalt verästelter Septa von der Pia aus in die Rückenmarksubstanz vordringt.

Die Substantia gelatinosa bildet im Allgemeinen eine nur sehr dünne Belegschicht längs der Pia und ihrer Septa, verbreitet sich aber im Apex und Caput cornu posterioris zu einem unfangreichen Gebilde, indem sie den hinteren Wurzelfasern, welche sich hier wie die Meridiane einer Kugel ausbreiten, eine besondere Stïtze gewährt. Diese Formation nennt man die Substantia gelatinosa Rolandi. Einen zweiten Ort beträchtlicher Entwickelung findet diese Substanz in der Umgebung des Centralcanals, wo sie als Substantia gelatinosa centralis die Grundlage des sogenannten Ependymfadens bildet. Der wesentliche Bestandtheil der Substantia gelatinosa ist ein netzförmiges Balkensystem ans Neurokeratin, welches vereinzelte kernartige Gebilde trägt (und in seinen feineren Maschen mit flïssiger Substanz ausgefüllt zu sein scheint). Der 
Ependymfaden trägt als unmittelbure Begrenzung des Centralcanals eine einfache Sehicht cylindriseher Epithelzellen, welche in Jugendzustand flimmern und von deren jeder sich ein langer dünner Fortsatz in das unterliegende Gewebe erstreckt, dessen Verbindungsweise nicht aufgeklairt ist.

Diejenigen feineu Lücken zwischen den nervösen Elementen, bis zu welchen die bindegewebigen Septa der Pia nicht vordringen, werden an den Stellen, wo lieine gelatinöse Substanz liegt, durch die sogenamnte Neuroglia ausgefïllt. Letztere ist im Leben weich und homogren, zeigt die Reactionen der Kittsubstanz von Epithelien und gerinnt im Tode zu einem Fasernetz, welches durch Kochen in Wasser nicht wieder gelöst wird. Die Zellen der Neuroglia sind von ähnlicher Beschaffenheit wie die platten Zellen des Bindegewebes. Da ihre Kerne gewöhnlich an den Knotenpunkten der Fasérkreuzung (nach der Gerinnung) liegen, so entsteht der Eindruck der Zusammengehörigkeit beider Formelemente (Boll's Pinselzellen). Der Neuroglia wird eine erhöhte Bedeutung zugeschrieben werden müssen, wenn es sich bestätigt, dass die Dendritenfasern verschiedener Herkunft in Gerlach'schen Netz nicht continuirlich in einander ïbergehen, wie man lange geglaubt hatte, sondern dass jedes Astwerk frei endigt. Von jedem Astwerk aus muss die bis dahin fortgeleitete Erregung auf Astwerke, welche mit ihm durchwachsen sind, übergehen können, und wenn dies nicht in rer Continuität von Fasern geschieht, muss die an Ende eines Astwerkes angelangte Erregung in der umgebenden Substanz einen Process auslösen, dessen Produkt als Reiz für benachbarte Fasern wirkt. Dass solche chemischen Processe bei der Uebertragung der Erregung von einer centralen Leitungsbahn auf eine oder mehrere andere Platz greifen, darf man annehmen, da die Zeit, welche die intracentrale Erregungsleitung in Anspruch nimmt, verhältnissmässig gross ist.

Von der ganzen Oberfläche des Rückenmarkes dringen bindegewebige Septa in das Innere der Substanz vor, zunächst in radiärer Richtung, dann sich verästelnd, sich verfeinernd, und zum Theil unter einander anastomosirend. In der weissen Substanz entstehen auf diese Weise mehr oder weniger geschlossene Lüngsfächer für die Faserbïndel. Die Septa der Pia dienen der /u- und Ableitung der Gefässe.

Die Arterien, welche das Rïckenmark versorgen, sind: erstens die beim Ursprung aus den Vertebrales bilaterale, bald aber einfach werdende mediane Arteria spinalis anterior, welche am Eingange zur vorderen Längsfissur, ohne merklich an Caliber abzunehmen, zum unteren Ende des Riickenmarkes hinabzieht, und zweitens die beiden ron der Reihe der hinteren Nervenwurzeln gedeckten Arteriae spinales posteriores. Letztere stammen ebenfalls aus den Arteriae vertebrales; sie 
inastomosiren am Conus medullaris mit der Arteria spinalis anterior, und sie entsenden in regelmäissiger Weise durch jedes Zwischenwirbelloch je eine Anastomose zu der entsprechenden Intercostalarterie. Seltenere grössere, unregelmässig vertheilte anastomotische Aeste gehen von der Arteria spinalis anterior mit den vorderen Nervenwurzeln eben dahin. Ausserdem entsendet letztere in ihrem ganzen Verlaufe horizontal gerichtete feine Zweige zur Tiefe der vorderen Längsspalte, wo dieselben jederseits in einer Reihe durch die vordere Commissur hindurch in die Riickenmarkssubstanz hineintreten. Im ganzen Umfange des Rückenmarkes dringen von den Arteriae spinales posteriores und ron den in der Pia sich ausbreitenden Zweigen derselben Aestchen in radiärer Richtung in die Rückenmarkssubstanz hinein. Ihr Verlauf ist durch das Septensystem vorgezeichnet, von dessen Bindegewebe begleitet auch kleine arterielle Zweige in grosser Zahl zur grauen Substanz gelangen. Von den kleineren Arterienzweigen gehen immerhalb der weissen Substanz solche ab, welche sich alsbald in ein die Nervenfaserbündel umspinnendes Capillarnetz auflösen; die Maschen desselben sind in der Richtung der longitudinalen Faserung des Riickenmarkes lang gestreckt. Die in die graue Substanz eindringenden Arterien bilden ein weit dichter'es Capillarnetz mit engen polygonalen Maschenräumen.

Aus dem beschriebenen Capillarnetze besonders der grauen Substanz sammelt sich das venöse Blut zunächst in zwei grösseren Venen, die jederseits im Gebiete der vorderen Commissur gelegen sind und als die beiden Centralvenen des Rückenmarkes bezeichnet werden. Sie stehen vielfach durch feine quere Verbindungsvenen untereinander, sowie durch eine Reihe anderer Zweige, welche von der Tiefe der vorderen Längsspalte zu deren Oberfläche horizontal vordringen, mit der Vena spinalis anterior in Verbindung. Letztere liegt somit am Eingange der vorderen Längsfissur, nach aussen hin aber noch gedeckt von der Arteria spinalis anterior. Ein anderer Theil der Abzugsbahnen für das venöse Blut des Rïckenmarkes geht radiär durch die weisse Substanz in die Venen der Pia oder in die längs verlaufende Vena spinalis medialis posterior ïber.

Die Lymphbahnen des Rückenmarkes begleiten in Form von Lymphscheiden die Arterien und Venen und werden wegen dieses rüumlichen Verhältnisses als perivasculäre Lymphräume bezeichnet. Sie lassen sich von den Lymphgefässen der Pia aus leicht injiciren und erweisen sich durch eine Endothelmembran gegen die Rückenmarksubstanz abgegrenzt. Ausserdem scheinen schmale für die Fortbewegung von Gewebssaft geeignete Spalträume ziemlich allseitig die nervösen Elemente des Riiickenmarkes unmittelbar zu umgeben; über den Zusammenhang dieser Saftspalten und Saftcanälchen mit eigentlichen Lymphgefässen ist aber noch nichts bekannt. Die Einlagerung der Blutgefässe und der nervösen 
Elemente in Lymphscheiden sichert letztere gegen pulsatorische Stösse und gegen Zerrungen, wie sie bei Aenderungen im Blutgehalt der Gefüsse eintreten würden, wenn nicht die leicht verschicbliche Lymphe ein schützendes Polster abgäbe. Die Einscheidung nerröser Elemente in Lymphbahnen muss auch der geregelten Ernährung derselben zu Gute kommen. Für die Erkenntniss der Faserung im Rïckenmark können die Lymphscheiden der Nervenfasern verhängnissvoll werden, wenn man sich zu sehr aut Tinctionsmethoden verlässt, bei denen nicht nur Nervenzellen, Axencylinder oder Myelinscheiden, sondern anch Endothelscheiden gefärbt werden. Die Lymphscheiden der Nervenfasern und Nervenzellen werden Lymphspalten absenden, welche nerröse Elemente nicht zu enthalten brauchen, welche aber bei solchen Tinctionsmethoden daron nicht unterschieden werden können.

In Bezug auf seine Function kamn das Riickenmark als dasjenige Organ bezeichnet werden, welches alle von der Peripherie, mit Ausnahme des liopfes, ausgehenden Erregungen sammelt, um sie entweder sofort in zweckmässigen Combinationen auf centrifugale Bahnen zu reflectiren, oder um sie nach Centralstationen höherer Ordnung, das heisst nach solchen mit mannigfaltigeren Combinationsmöglichkeiten im Hirnstamm und im Hirnmantel weiter zu leiten. Dieser Leistung entsprechend enthält das Riickenmark eine rollständige Projektion aller Elemente der Erfolgsapparate (mit Ausnahme des Kopfes) in solchen räumlichen Zusammenordnungen und erregungsleitenden spinalen, sowie cerebrospinalen Verbindungen, dass dadurch das Eintreten geläufiger und zweckmässiger Synergien ein für allemal gesichert ist.

Von der systematischen Strenge, welche den Aufbau des Rückenmarkes beherrscht, erhalten wir eine Andeutung, wenn wir die Thatsache betrachten, dass alle Nervenbahnen, welche Erregungen von der Peripherie zum Rüickenmark hinleiten, einen anderen Weg einschlagen, als diejenigen, deren Erregungswellen umgekehrt gerichtet sind; jedenfalls sind alle sensiblen Bahnen (wahrscheinlich ïberhaupt alle centripetalen) in den hinteren Nerrenwurzeln des Rückenmarkes enthalten, alle motorischen (wahrscheinlich überhaupt alle centrifugalen) in den vorderen Wurzeln. Den Ausdruck dieser Thatsache nennt man das Bell'sche Gesetz, ron dessen Richtigkeit man sich auf die einfachste Weise beim Frosch ïberzeugen kann. Bei diesem Thiere kann man den distalen Theil des Wirbelcanals olıne zu schwere Störungen des Gesammtorganismus eröffnen und dann liegen die die Cauda equina bildenden langen Wurzeln der die hinteren Extremitäten versorgenden Spinalnerven ( 7 te bis 10 te) ron ihrem Ursprung aus dem Conus medullaris bis zu ihrem Eintritt in die Zwischenwirbellöcher frei vor.

Durchschneidet man nun auf der einen Seite die hinteren, auf der 
anderen Seite die vorderen Wurzeln der genammten Nerven, näht die Wunde sorgfältig zu, lässt das Thier sich von dem Eingriff etwas erholen und untersucht es dann, so beobachtet man, dass es die Extremität, wo die vorderen Nervenwurzeln durchschnitten sind, bei allen Bewegungen wie eine todte Masse nach sich zieht, während die Bewegungen des anderen Beines normalen Eindruck machen. Wartet man nun $a b$, bis das Thier zur Ruhe gekommen ist und still sitzt, so kann man das Bein, dessen hintere Nervenwurzeln durchschnitten sind, mit den stärksten Aetzmitteln behandeln oder mit der Pincette kneifen, ohne dass das Thier sich aus seiner Ruhe stören lässt, während Betupfen des anderen Beines mit schwacher Essigsäure sofort Flucht- oder Wischbewegungen veranlasst, an welchen sich jedoch dieses Bein selbst activ nicht betbeiligt. Die Durchschneidung der hinteren Wurzeln hat also sensible, die der vorderen motorische Lähmung zur Folge gehabt.

Etwas schwieriger auszufuihren, aber in mancher Beziehung lehrreicher ist folgendes Versuchsverfahren. Man durchschneidet alle Wurzeln des 7 ten bis 10 ten Paares auf der einen Seite möglichst weit proximal, auf der anderen möglichst weit distal innerhalb des Wirbelcanals und verschafft sich auf diese Weise vier Wurzelbündel folgender verschiedener Kategorien: erstens hintere Wurzeln in Verbindung mit der Peripherie, zweitens vordere in Verbindung mit der Peripherie, drittens hintere in Verbindung mit dem Centrum, viertens vordere in Verbindung mit dem Centrum. Lagert man nun jedes der vier Bündel auf je ein untergeschobenes Glimmerplättchen, so kann man bei vorsichtiger elektrischer Reizung, das heisst unter Vermeidung fehlerhafter Ausbreitungen der Elektricität, Folgendes beobachten. Bei Reizung von 1, keinen Erfolg; von 2, Bewegung der zugehörigen Hinterextremität; von 3, Bewegung des vorderen Thieres; von 4, keinen Erfolg. Die Bedeutung dieser Resultate in Beziehung zu der Vertheilung der motorischen und sensiblen. Bahnen auf die vorderen und hinteren Wurzeln liegt auf der Hand. $\mathrm{Zu}$ weitergehenden Schlussfolgerungen fordert aber die am Bündel 4 gemachte Beobachtung auf. Ehe wir jedoch hierauf eingehen, muss vorher noch einer Verwicklung gedacht werden, welche bei Anstellung ähnlicher Versuche am Säugethier eintritt, und welche, ehe sie aufgeklärt war, ernstlich drohte, das Bell'sche Gesetz in Missachtung zu bringen. Als man beim Säugethier die undurchschnittenen vorderen Wurzeln reizte, bekam man nicht nur Bewegungen in der zugehörigen Extremität, sondern auch allgemeine Schmerzäusserungen des Thieres zu sehen. Es ergab sich also, dass hier auch die vordere Wurzel sensible Fasern fuihrt. Die Schmerzbewegungen blieben aber aus, wenn die undurchschnittene vordere Wurzel nach Durchschneidung der zugehörigen Hinterwurzel, oder wenn der mit dem Centrum verbundene Stumpf der durch- 
schnittenen vorderen Wurzel gercizt wurde. Dit die Schmer\%̈̈usserungen nun aber noch eintraten, wenn man den peripherischen Stumpf einer durchschnittenen rorderen Wurzel reizte, so linge die zugehörige Hinterwurzel intact war, musste man schlicssen, dass die sensiblen Fasern, welche in rorderen Spinalwurzeln von Sïugethieren enthalten sind, nicht mit den übrigen Fasern der vorderen Wurzeln, sondern mit den dazu gehörigen hinteren Wurzelı in die Rückemmarkssubstanz eintreten. In der That handelt es sich um sensibele Nerrenfascrn der Hirnhäute, welche, um zu ihrer legitimen Eintrittsbahn in das Rückenmark zu gelangen, sich den rorderen Wurzelfasern zugescllen, mit diesen eine kurze Strecke iiber die Vereinigungsstelle der vorderen und hinteren W'urzel fortlaufen, dort umbiegen und sich den sensiblen Fasern des Spinalnerren beimischen. Der paradoxen Erscheinung selbst hat man den Namen der .sensibilité récurrente" gegeben und man hat sie später auch an peripherischen Nerven aufgefunden, so zum Beispiel an Aesten des motorischen Nervus facialis, welche ihre rïckläufige Empfindlichkeit sensiblen Fasern verdanken, die sich ihnen streckenweise aus dem Nervus trigeminus beigesellen. Also auch die Ausnahme hat hier zur Bestätigung der Regel beigetragen und das Bell'sche Gesetz ist fiir das Säugethier ebenso zweifellos anzuerkennen, wie für den Frosch.

Gehört der Inhalt des Bell'schen Gesetzes zu den best constatirten Thatsachen der Physiologie, so gilt das Gleiche von der anatomischen Erkenntniss des Zusammenhanges je einer vorderen oder motorischen Wurzelfaser mit je einem Axencylinderfortsatz grosser G anglienzellen der grauen Vordersäulen des Rückenmarkes, welche deshalb anch mit Recht motorische Ganglienzellen genannt werden. Ueber eine wichtige Eigenschaft dieser Ganglienzellen erhalten wir nun durch das oben lervorgehobene Resultat bei Reizung des rorderen, in Zusammenhang mit dem Centrum stehenden Wurzelbündels Auskunft. Da wir nänlich aus den die doppelsinnige Leitung beweisenden Experimenten sicher wissen, dass jede Nerrenfaser die durch künstliche Reizung erzeugte Erregung in beiden Richtungen fortleitet, so müssen wir schliessen, dass bei Reizung des genannten Wurzelbiindels die Erregung durch Axencylinderfortsätze in motorische Ganglienzellen eintritt. Die Erfolglosigkeit der Reizung jedes Bündels weist also darauf hin, dass die Protoplasmafortsätze dieser Zellen, welche offenbar bestimmt sein müssen, ihnen centrifugale Erregungen zuzuleiten, in umgekehrter Richtung für die Erregungswelle nicht offen stehen, denn sonst müssten wegen der mannigfachen erregungsleitenden Verbindungen, welche die Protoplasmafortsätze nach ihren Verästelungen eingehen, Bewegungen an entfernten Stellen des Thieres zu erwarten sein. Als eine Function von Ganglienzellen lernen wir also die Beschränkung der bei gewöhnlichen Ner- 
venfasern doppelsinnigen Erregungsleitung auf eine einzige Richtung kennen.

Jede motorische Ganglienzelle stellt die Projection einer gewissen Summe von Primitivmuskelfasern dar; mit der Erregung der ersteren ist diejenige der letzteren ohne Weiteres gesetzt. Die grosse Mannigfaltigkeit der Verbindungen, welche die erstere durch ihre erregungsleit enden Protoplasmafortsätze eingeht, scheint der Möglichkeit zu dienen, dass letztere, verschiedenen Zwecken entsprechend, in der mannigfaltigsten Combination nit anderen Gruppen von Muskelfasern zur Thätigkeit angeregt werden können. Auch liegt die Möglichkeit vor, dass dieselbe Ganglienzelle mit ihren zugehörigen Muskelfasern auf der Bahn verschiedener Protoplasmafortsätze ihren Erregungsanstoss erhält, je nachdem der Bewegungscomplex, zu welchem die Thätigkeit der Muskelfasern gehört, auf dem Wege des Reflexes oder der Willkür zu Stande kommt. Sicher findet die Erregung jeder Muskelfaser ein für allemal durch Vermittelung derselben motorischen Ganglienzelle statt. Motorische Leitungsbahnen, welche das Rückenmark durchsetzten, obne durch motorische Ganglienzellen unterbrochen zu werden, und welche direct in vordere Wurzelfasern übergingen (zum Beispiel sogenannte directe Willkïrbahnen), giebt es nicht. Ferner ist daran zu denken, dass die auf der Bahn gewisser Protoplasmafortsätze der motorischen Ganglienzelle zugeleiteten Erregungswellen hemmend in den von anderer Seite inducirten Thätigkeitszustand der Zelle eingreifen.

Was die räumliche Anordnung der motorischen Ganglienzellen anlangt, so scheint es geschlossene Projectionen der einzelnen anatomisch einheitlichen Muskeln nicht zu geben, vielmehr scheinen Zellen, die Fasern verschiedener Muskeln zugehören, im Rückenmark so zusammenzuliegen, dass jede Gruppe derselben einer der geläufigen Synergien entspricht. Die motorischen Ganglienzellen gehören im Allgemeinen vorderen Wurzelfasern desselben oder eines nahe benachbarten Rückenmarkssegmentes an, und dies ist mit ihrer Zusammenordnung nach functioneller Zusammengehörigkeit in gewissem Grade verträglich, da derselbe Muskel auf der Bahn mehrerer auf einander folgender Spinalwurzeln seine motorische Innervation erhält.

Jeder Muskel der Hinterextremität des Frosches kann von wenigstens zwei Spinalwurzeln aus erregt werden, mancher sogar von dreien. Man kann sicher darauf rechnen, den Musculus gastrocnemius durch Reizung der 8 ten und 9 ten Wurzel zum Zucken zu bringen. Es drängt sich nun die Frage auf, ob der Muskel bei Reizung nur der einen Wurzel auch nur mit einem Theil seiner Muskelfasern reagirt, oder ob er, nöge ihm die Erregung durch die eine oder die andere Wurzel zufliessen, jedesmal mit allen seinen Fasern in Thätigkeit geräth; es könnte dies in ge- 
wissem Maasse als zweckmässig erscheinen, weil dahlurch eine grössere Leistungsfithiglieit des Muskels bei rerschiedenen Synergien gesichert sein könnte. Vorrichtungen, welche in dieser Richtung wirkten, wären leicht denkbar: es brauchte zum Beispiel nur jede Muskelfaser mehrere Nerrenendigungen zu erhalten, ron denen die eine mit Nerrenfasern der einen, die andere mit Nervenfasern der anderen Spinalwurzeln zusammenhinge, oder die Erregung brauchte nicht auf die Muskelfaser beschränkt zu bleiben, welche mit der in Erregung gerathenen Nervenfisser in continuirlichem Zusammenhang steht, sondern sie könnte auch auf benachbarte Muskelfasern ïbergreifen; letzteres wäre unter Voraussetzung der Richtigkeit der Entladungshypothese sogar zu erwarten.

Es lïsst sich aber beweisen, dass eine Erregung, welche central nur einen Theil der Muskelprojection ergreift, sich auch nur einem aliquoten Theile der Muskelfasern mittheilt: jede central partielle Muskelerregung bleibt auch peripherisch partiell. Einen Anhalt für Beurtheilung des Antheiles von Muskelfasern eines Muskels, welcher in Erregung gerathen ist, bietet die Messung der rom Muskel entwickelten Spannung dar; denn diese ist, gleiche Erregungsintensität vorausgesetzt, proportional dem Querschnitt des erregten Muskels oder Muskelantheiles. Misst man num bei stets maximaler Reizung die Spannung, welche der Muskel durch Erregung ron der einen Spinalwurzel aus erhält $\left(t_{a}\right)$, ferner die analoge Spannung $\left(t_{b}\right)$ und diejenige Spannung, welche er erhält, wenn man beide Wurzeln gleichzeitig der Reizung unterwirft $t_{a}+b$, so findet man, dass $t_{a}+t_{b}=t_{a}+b$.

Die einfachste Art, auf welche motorische Ganglienzellen des Rückenmarkes in Erregung gerathen können, ist realisirt, wenn der Anstoss hierzu durch Erregungen erfolgt, welche auf der Bahn sensibler Wurzeln desselben Segmentes zugeleitet werden. Zur Demonstration dieses Vorganges können Frösche dienen, denen das Rïckenmark unmittelhar hinter dem Austritt des achten Wurzelpaares durchtrennt ist, und welche sich von dem Ëingriff erholt haben. Da sich das zehnte (das letzte) Wurzelpaar an der Innervation der Hinterextremitäten sehr wenig betheiligt, so stehen motorische und, sensible Nerven der letzteren dann nur noch durch das neunte Rïckenmarkssegment mit einander in Verbindung und da man auf Reizung der Haut einer Hinterextremität Bewegungen in derselben und in der anderseitigen Hinterextremitit beobachtet, so muss die motorische Erregung durch Vermittelung desselben Riickenmarkssegnentes erfolgt sein, in welche die sensible Erregung ihren Eintritt genommen hatte. Die Elemente, welche für die Uebertragung der Erregung zur Verfügung stehen, sind hintere Wurzelfasern, kleine Ganglienzellen der Hintersäulen, Gerlach'sches Fasernetz, grosse Ganglienzellen der rorderen Säulen, vordere Wurzelfasern; den 
Yorgang der Uebertragung selbst nennt man einen Reflex. Die Kiette der den Vorgang vermittelnden Elemente einen Reflexbogen und zwar in diesem Falle, wo sich die Uebertragung innerhalb desselben Rückenmarkssegmentes abspielt, einen kurzen Reflexbogen.

Durch Vermittelung ähnlicher kurzer Reflexbögen des Rückenmarkes treten beim Menschen wahrscheinlich die sogenannten Sehnenreflexe ein, deren Prototyp das sogenannte Kniephäṇomen ist. Sitzt man mit übergeschlagenem Beine da, sodass der Oberschenkel unterstiitzt ist, der Unterschenkel aber frei herunter hängt, so erhält man durch kurzen Schlag mit der Kante einer ausgestreckten Hand auf das Ligamentum patellare eine plötzliche Contraction des Musculus quadriceps, durch welche der Unterschenkel emporgeschleudert wird. Man hat versucht, diese Erscheinung auf eine directe Muskelreizung durch plötzlichen Zug oder plötzliche Dehnung zurückzuführen, es ist hiergegen jedoch anzuführen, dass es an isolirten Muskeln bisher nicht gelungen ist, eine Reizwirkung durch Zug oder Dehnung hervorzurufen. Dagegen hat man bei Thieren, an welchen sich ebenfalls Sehnenreflexe demonstriren lassen, diese Reflexe nach Durchschneidung des Hauptnervenstammes oder der Spinalwurzeln der Extremität schwinden sehen, während sie nach Durchtrennung des Rückenmarkes oberhalb seines Lumbaltheiles bestehen blieben. Es sind also ebenfalls Reflexe mit im Spiel, welche durch das Lumbalmark selbst vermittelt werden.

Aehnlichen Ursprungs durch Vermittelung kurzer Reflexbögen scheint der dauernde Tonus zu sein, in welchem sich die gesammte Körpermuskulatur fortwährend, abgesehen von ihrer Inanspruchnahme für specielle Zweckerfïllungen, befindet. Dieser Tonus der Körpermuskulatur tritt sehr deutlich hervor, wenn man an einem aufgehängten decapitirten Frosch die Haltung der beiden Hinterextremitäten vergleicht, von denen die eine ihrer nervösen Verbindung mit dem Centralnervensystem beraubt ist. Während die andere Extremität in allen Gelenken leicht gebeugt ist und in dieser Haltung lange Zeit verharrt, ist diejenige, deren Nerven durchschnitten sind, rom ersten Moment der Durchschneidung an so weit gestreckt, wie es durch die alleinige Wirkung der Schwerkraft bedingt ist.

Ehenfalls kurze, im Lumbalmark ihren Schluss findende Reflexlögen sind diejenigen, welche den reflectorischen Theil der Defäcation, der Harnblasenentleerung, der Erection und Ejaculation, sowie der Uterusbewegungen vermitteln; es muss aber beachtet werden, dass in den normalen Ablauf dieser Vorgänge Erregungen eingreifen, welche auf Grund weithin fortgeleiteter centripetaler Erregungen rom Gehirn herabgesanolt werden. Durch Anfüllung der Blase zum Beispiel werten Nerven in deren Wand gereizt; die Reizung lïst rein reflectorisch, 
durch Vermittelung des Lumbalmarkes (im Gebiete des dritten bis fünften Sacralnerven) Zusammenzielung des Detrusor resicac aus. Die Harnentlermug kam damn noch hintangehalten werden durch willkürliche Contration des Sphincters, tritt aber sofort ein, weun entweder kein (irund für jenen Willkiirakt vorliegt, oder wenn die Riickenmarksleitung oberhalb des kurzen lieflexbogens nnterbrochen ist. Am Schluss der Ilarnentleerung erfolgt zunächst rein reflectorisch rom lumbalmark aus rhythmische Contraction der Harnröhremmuskeln, welche aljer willkürlich fortgesetzt oder unterbrochen werden kann. Die Contraction des Detrusor ist dem dirceten Einfluss der Willkïr entzogen, kann aber durch willkiirlich festgehaltene anf die Harnentleerung bezïgliche Vorstellungen bei bestehender, an sich die Schwelle noch nicht iiberschreitender Blasenreizung angeregt werden: die Betheiligung der Bauchpresse an der Harnentleerung ist rorwiegend willkürlich, kann aber bei starkem Harndrang auch reflectorisch erfolgen. Aehnliches gilt mutatis mutandis ron den ïbrigen Verrichtungen der Lnterleibsorgane.

Lange Reflexbögen, das heisst solche, welche in Riickenmarksscgmenten ihren Schluss finden, die ron den Ein- und Austrittsstellen der zugehörigen centripetalen und centrifugalen Wurzelfasern entferut liegen, sind im Riückenmark des Frosches anf folgende Weise nachgewiesen worden. Nach Köpfung des Thieres werden die Vorderextremitäten mit dem Schultergiirtel und die Baucheingeweide entfernt, dann die oberen vier Wirbel mit sorgfältiger Schonung des Riickenmarkes abpräparirt. Den auf diese Weise freigelegten obersten Theil des Rückenmarkes kann man, auf Fliesspapier gelagert, einer strenge localisirten Einwirkung ron Strychninlösung aussetzen; das Strychnin besitzt die Fähigkeit, die Reflexe zı steigern. Nach einer gewissen Zeit seiner localisirten Einwirkung auf den oberen Theil des Riickenmarkes erhält man bei Reizung der Hant der Hinterextremitäten starke Bengekrämpfe der letzteren, welche nicht mehr eintreten, wenn man den strychnisirten Theil des Riickenmarkes abschneidet. In dem oberen Theil des Froschrückenmarkes mïssen also Elemente liegen, welche centripetal ron Lumbalwurzeln aus zugeleitete Erregungen auf centrifugale ehenfalls den Lumbalwurzeln angehörige Bahnen ïberleiten, und welche in ihrer Erregbarkeit durch Strychnin stark beeinflusst werden; da das Strychnin nicht erregbarkeitssteigernd auf peripherische Nervenfasern wirkt, so haben wir Grund anzunehmen, dass jene den Retlex remittelnde Elemente Zellen sind. Grosse motorische Ganglienzellen für Muskeln der Hinterextremitäten giebt es im oberen Theil des Riickenmarkes nicht. Es folgt dies aus der schon frïher angefuihrten Verzögerung des motorischen Erfolges bei Reizung dieses Rückenmarkstheiles. Als nervöse Elemente also, welche im Riickenmark Reflexe vermitteln, und zwar 
Reflexe, welche eine hestimmte Kategorie synergischer Muskelgruppen ergreifen (hier die Beugemuskeln), lernen wir hierdurch kleine Ganglienzellen des Rückenmarkes kennen.

Es handelt sich hier wahrscheinlich um ein Coordinationscentrum für die Einnahme rer sprungbereiten Stellung, welche in dem Leben des Frosches eine sehr wichtige Rolle spielt. Dies Centrum besteht also wahrscheinlich aus einer Summe kleiner Ganglienzellen der grauen Hintersäulen, welche dic zu ihnen gelangten Erregungen auf zum Theil weit entfernt liegende motorische Ganglienzellen in solchen Combinationen überleiten, dass die zur Erreichung der sprungbereiten Stellung erforderlichen Bewegungscomplexe zu Stande kommen. Die Nervenzellen dieses Coordinationscentrums können ihre Erregung ron hinteren Wurzelfasern aus zugeleitet erhalten, und sie wirken dann reflexvermittelnd oder auf dem Wege cerebromedullärer Bahnen und sie dienen dann der Willkür.

Dafür dass im Rückenmark von Säugethieren ähnliche Einrichtungen vorhanden seien, welche zur Vollendung zweckmässiger, complicirt coordinirter Bewegungen ausreichten, sind wenige Anzeichen bekannt. Allerdings mïssen wir annehmen, dass auch hier durch entsprechende Leitnngen und Schaltungen für das synergische Thätigwerden complicirter Combinationen motorischer Elemente Vorsorge getroffen ist; doch erfolgt die Zusammenfassung solcher spinaler Synergien behufs Ausführung von Bewegungen, welche vollkommener Zweckerfüllung dienen, wahrscheinlich oberhalb des Rïckenmarkes selbst. Wenn also auch das Rückenmark der Säugethiere sehr reich an Gliedern ist, welche zum Aufhau langer Reflexbögen gehören, so kommen diese Bögen doch nicht im Rückenmark selbst zum Schluss, sondern an höheren Stellen des Centralnervensystems, wo nicht nur die auf der Bahn spinaler, sondern auch cerebraler Nerven zugeleiteten sensiblen Eindrücke sich bei der Anpassung der auszuführenden Bewegungscomplexe an die speciellen äusseren Bedingungen betheiligen können.

$\mathrm{Zu}$ den Erfolgsapparaten, deren Elemente durch Projectionen in Rückenmark vertreten, rlas heisst mit Nervenzellen derselben durch einfache centrifugale Erregungsleitung derart verbunden sind, dass ihre Thätigkeit mit der Erregung der letzteren ohne Weiteres gesetzt ist, gehören ausser den Muskeln des Körperskeletts und ausser den Muskeln der oben genannten Eingeweide, die Drüsen, namentlich die Schweissdrüsen, und der Gefässapparat. Für die Schweissdrüsen sind zweifellos celluläre Elemente im Rïckenmark enthalten, welche sensibele, von der Haut zugeleitete Reize auf secretorische Nerven zu reflectiren in Stanrle sind; dieselben Elemente treten voraussichtlich auch in Thätigkeit, wenn Schweisssecretion von Centren angeregt wird, die oberhalb 
des Rückenmarkes liegen und sie scheinen auch automatisch erregbar, das heisst solcher Erregung fähig zu sein, welche autochthon unter der Einwirkung gewisser Beschaffenheiten des Blutes entsteht. Die Summe solcher Elemente kann man als die Schweisscentren des Rückenmarkes bezeichnen. Genaueres über die Art ihrer Lage und ihrer intracentralen Verbindungen ist nicht bekanut.

Letzteres gilt auch von den Gefässcentren des Rückenmarkes, über deren Existenz im Uebrigen kein Zweifel sein kann. Was ihre Verbindung mit der Peripherie anlangt, so ist so viel bekannt, dass die derselben dienenden Nervenfasern durch Vermittelung der Rami communicantes zum Sympathicus gelangen, um sich nach kürzerem oder längerem Verlauf in dem Grenzstrang desselben, peripherischen Nervenstämmen anzuschliessen. Für die gefässverengernden Nerven der hinteren Extremitäten des Frosches und für die Nervi erigentes von Säugethieren, welche gefässerweiternde Nerren der Schwellkörper des Penis sind, ist der Ursprung aus vorderen Spinalwurzeln nachgewiesen. Für die im Ischiadicus von Säugethieren vorhandenen gefässerweiternden Nerven wird der Ursprung aus hinteren Wurzeln behauptet.

Als unentschieden muss es angesehen werden, ob sich die gefässverengernden und erweiternden Nervenfasern direct zu den Muskelfasern der Gefässe begeben, oder durch Vermittelung peripher gelegener Nerrenzellen. Es ist die Hypothese aufgestellt worden, dass in der Peripherie Ganglienzellen liegen, ron deren Erregungszustand der Tonus der Gefässe abhängt und deren Thätigkeit selbst durch die constrictorischen Nerren erhöht, durch die dilatatorischen vermindert werde. Man muss aber bedenken, dass ausser im Gebiete der Nervi erigentes solche peripherischen Ganglienzellen der Gefässe mit Sicherheit noch nicht haben nachgewiesen werden könmen.

In Analogie zu den Centren der Vasoconstrictoren steht das Centrum ciliospinale Budge's, ferner pulsbeschleunigende Centren im oberen Dorsalmark und Centren fuir Contractionen des Mastdarmes im Lumbalmark. Das Centrum ciliospinale liegt im unteren Theile des Halsmarkes, entsendet Fasern durch Vermittelung des Ganglion stellatum zu dem Halssympathicus und bewirkt bei Steigerung seiner Thätigkeit Erweiterung der Pupille; es kann durch stärkere sensible Reize von der ganzen Hautoberfläche aus oder von einem höher gelegenen Centrun im Hirnstamm in Thätigkeit gesetzt werden.

Die pulsbeschleunigenden Centren des oberen Dorsalmarkes entsenden Fasern durch die sechs oberen Rami communicantes zum Grenzstrang des Sympathicus, von wo sie durch Vermittelung des Ganglion stellatum als Rami accelerantes zum Herzen gelangen.

$\mathrm{Zu}$ dem Mastdarm begeben sich beim Hunde zwei Kategorien 
ron Fasern, welche wahrscheinlich im Lumbahmark ihr Centrum haben, und ron denen die einen den Weg durch die Nervi erigentes nehmen, die anderen durch die Nervi hypogastrici. Erstere wirken erregend auf die Längs- und hemmend auf die Ringmuskeln, letztere erregend auf die Ringmuskeln und hemmend auf die Längsmuskeln des Mastdarms. Fasern ersterer Art für den Dünndarm verlaufen in den Nervi splanchnici, letzterer Art in den Nervi vagi.

Eine eigenthümliche, ihrer Existenz nach ebenso unbestreitbare wie ihrem Wesen nach dunkele Kategorie von Wirkungen, welche das Rückenmark auf peripherische Gewebselemente ausübt, ist die Trophik. Die am sichersten bekannte hierher gehörige Thatsache ist die, dass die motorischen Nervenfasern und ihre nerrösen Endglieder in den Muskeln degeneriren, wenn sie ron den zugehörigen motorischen Ganglienzellen der grauen vorderen Säulen getrennt werden, oder wenn diese selbst erkranken oder untergehen. Die Muskelfasern scheinen einerseits hierbei nicht mit degeneriren zu brauchen, andererseits aber auch der Degeneration verfallen zu können, wenn ihre motorischen Ganglienzellen mit den zugehörigen Nerrenfasern und Nervenendigungen intact sind. Die centripetalen Nerrenfasern haben ihre trophischen Centren in den Spinalganglien; sind sie von diesen getrennt, so degeneriren sie und zwar gilt dies ron ihrem Verlauf sowohl in den peripherischen Nerven, als auch in den hinteren Wurzeln und deren Fortsetzung in ihr Leitungssystem des Rückenmarkes. Für gewisse Gewebselemente der Knochen, des interstitiellen Bindegewebes und der Haut ist die trophische $\mathrm{Ab}$ hängigkeit vom Riickenmark ebenfalls sehr wahrscheinlich. Die trophischen Einflüsse scheinen ron demselben Segmente des Rückenmarkes und zwar ron dessen graue: Substanz auszugehen, in welchem die zu den betreffenden Gebilden verlaufenden Nerven wurzeln.

Es sind hauptsächlich klinische Erfahrungen, welche immer wieder zu der Annahme führen, dass peripherische Gewebselemente in ihren Ernährungsverhältnissen direct von Nerven heeinflusst werden; ein typisches Beispiel bietet die mit Schmerzen einhergehende Eruption von Bläschen auf der Haut im Verlauf und im Ausbreitungsgehiet der Intercostalnerven bei Erkrankung dieser oder der zugehörigen Spinalganglien (Herpes zoster). Auf experimentellem Gebiete treffen wir als eine nach Nervendurchschneirlung sicher auftretende Ernährungsstörung die Verschwärung der Hornhaut nach intracranieller Trigeminus-I)urchschneirlung, es ist aber mit Recht bezweifelt worden, ob hier rer Frfolg dem Ausfall eines trophischen Nerreneinflusses zuzuschreiben ist, da durch die Nervendurchschneidung das Auge und seine Umgebung mempfindlich wird und das Thier somit eines Mittels beraubt ist, das Auge vor Schädlichkeiten zu bewahren. Die Verschwärung bleibt in der 'That 
aus, wenn man die Augenlider zunäht, oder wenn man das Ohr eines Kaninchens, an welchem dieser Versuch angestellt ist, durch Hautnähte in eine das Auge schiitzende Lage bringt. Eine andere experimentelle Erfahrung betrifft den nicht regelmässig, aber doch in einer ziemlichen Anzahl von Fällen eintretenden Haarausfall an einer bestimmten, durch ihre Lage sehr geschützten Stelle hinter dem Ohr der Katze nach Durchschneidung des zweiten Halsnerven an seiner Austrittsstelle aus dem Wirbelcanal. Hier kann die gestörte Sensibilität nicht beschuldigt, wohl aber muss dem Einwand Rechnung getragen werden, dass die Gefässinnervation an der betreffenden Stelle gelitten hat. Es ist freilich wahrscheinlich gemacht worden, dass Gefässnerven auf dem Wege der zweiten Cerricalwurzel - wie ïberhaupt der cervicalen und der ersten beiden Dorsalwurzeln - das Rückenmark nicht rerlassen: ein strenger Beweis hierfïr fehlt aber noch.

Principiell hat es keine Schwierigkeiten, sich einen trophischen Nerveneinfluss auf Gewebselemente rorzustellen. Wo wir den Einfluss der Nerven auf erregbare Gebilde gut kemnen, wie bei den Muskeln und Drïsen, sehen wir, dass sich unter dem Nerveneinfluss die Thätigkeitsform ändert; Thätigkeitsformen erregbarer Gebilde sind: Function, Nutrition und Formation. Jedes erregbare Gebilde kann als solches nur gedacht werden anf Grund der Annahme chemischer Processe, welche sich fortwährend in seinem Innern abspielen; der Verlanf dieser chemischen Processe muss veränderlich sein und, je nachdem er die eine oder die andere Richtung einschlägt, wird er zu dem führen, was wir Function, Nutrition oder Formation nennen. Bei der Function wird aufgespeicherte Spannkraft für Wirkungen nach aussen frei, die Muskelfaser contrahirt sich, die Drüsenzelle secernirt. Bei der Nutrition wird durch Stoffaufnahme chemische Spannkraft angesammelt und das Volum wird rergrössert; bei der Formation treten morphologische Differenzirungen oder Theilungen in eine grössere Individuenzahl ein. Welche Richtung der chemische Process in dem erregbaren Gebilde einschlägt, hängt in erster Linie sicherlich von den Bedingungen der unmittelbaren Umgebung ab, ausserdem aber in gewissen Fällen nachgewiesenermaassen ron der auf Nervenbahnen zugeleiteten Erregung, so die functionelle Richtung bei Muskeln und Drüsen, und die Nutrition bei Drïsen. Die Annahme, dass auch in anderen Gewebselementen nutritive Processe durch Nerveneinfluss beherrscht werden können, hat also nichts Gezwungenes.

An den bisher berührten Functionen des Rückenmarkes sind ausser seinen Nervenfasern auch seine Ganglienzellen sehr wesentlich betheiligt. Die Nervenzellen sind überall als Schaltstücke der Erregungsleitungen aufzufassen, doch kommt mancher derselben auch die Fähigkeit zu, bei Aenderungen der physikalischen und chemischen Zustände ihrer unmittel- 
baren Umgebung in autochthone Erregung zu gerathen (sogenannte Automatie), das heisst in Erregung, welche nicht auf Nervenbahnen zugeleitet wurde, welche aber einmal entstanden mittelst nervöser Leitungsbahnen anderen centralen oder peripherischen Elementen mitgetheilt wird. Prototyp solcher autochthon erregbaren Ganglienzellen sind diejenigen des sogenannten Athemcentrums in der Medulla oblongata, welche durch Kohlensäuregehalt oder Fieberwärme des Blutes erregt werden. Von manchen Forschern wird auch den motorischen Ganglienzellen des Rückenmarkes, aus welchen die motorischen Nervenfasern der Athemmuskeln direct hervorgehen und welche man - im Gegensatz zu dem die ganze Athmungsthätigkeit regulirenden Athmungscentrum in der Medulla oblongata - als Athenmuskelcentren bezeichnen kann, autochthone Erregung zugesprochen in dem Sinne, dass die zur Unterhaltung der normalen Athembewegungen erforderlichen Erregungen in ihnen selbst entstehen könnten, oder wohl gar für gewöhnlich entstünden. Bei niederen Thieren (Insekten) oder bei ganz jugendlichen Zuständen höherer Thiere kann dies zutreffen. Bei erwachsenen Säugethieren, welche sich ron dem Eingriff der Enthauptung unter stundenlang fortgesetzter künstlicher Athmung einigermaassen erholt haben, sind nach Unterbrechung der künstlichen Athmung Veränderungen in der Weite des Thorax zu beobachten, welche aber sehr unregelmässig sind und nur darum für einige Zeit das Leben solcher Thiere $\mathrm{zu}$ fristen vermögen, weil die Temperatur derselben und Hand in Hand damit die Lebhaftigkeit der chemischen Processe ihrer Gewebe sehr stark gesunken ist.

Für die Ganglienzellen der Sclıweisscentren des Rückenmarkes ist es, wie schon oben angedeutet wurde, wahrscheinlich gemacht, dass bei ihnen autochthone Erregbarkeit unter normalen Bedingungen eine Rolle spielt. Unter abwormen Verhältnissen kann übrigens wohl in allen Nervenzellen des Rï̈ckenmarkes Erregung entstehen, wie aus pathologischen Erscheinungen am Menschen und aus den dem Tode vorhergehenden Krämpfen mancher Thiere nach ihrer Decapitation hervorgeht. Alle Nervenzellen des Rückenmarkes, auch diejenigen, welche normaler Autochthonie fähig sind, scheinen übrigens Schaltstücke in Erregungsleitungen zu bilden und mindestens bipolar zu sein, sodass sie nicht nur in ihnen entstandene, soudern auch auf Nervenbahnen ihnen zugeleitete Erregungen weiter zu leiten haben.

Als Schaltstücken der nervösen Leitungsbahnen fallen den Nervenzellen wichtige Functionen zu; die beträchtliche Verzögerung, welche die Erregungsleitung erfährt, sobald in die der Zeitmessung unterworfenen Leitungsbahnen Theile des Centralnervensystems eingeschlossen sind, hat man wohl mit Recht auf eigenartige Processe bezogen, an welche die Durchleitung der Frregung durch Nervenzellen gebunden ist. Eine Ver- 
zögerung könnte auch in dem Gerlach'schen Fasernetz, besonders wenn eine Continuität zwischen den Dendriten desselben nicht besteht, in der die Erregung iibertragenden Zwischensubstanz stattfinden. Man darf sie überall da erwarten, wo die Leitungsbahn eine andere histologische Structur und chemische Reaction zeigt, als in der peripherischen Nervenfaser. In den Spinalganglien ist ausser den Zellen hiervon Nichts vorhanden und da auch hier Verzögerung der Erregungsleitung statthat, muss man sie auf den Durchgang durch Zellen beziehen.

Die Nervenzellen dienen als Sammelstellen für die auf verschiedenen Bahnen zugeleiteten Erregungen behufs Weiterleitung auf eine oder wenige ableitende Bahnen, wie wir es bei den motorischen Ganglienzellen der grauen Vordersäulen kennen gelernt haben, oder sie theilen die auf einer oder wenigen Bahnen zugeleiteten Erregungen durch Vermittelung vieler ableitender Bahnen ganzen Gruppen von Elementen mit, behufs gleichzeitiger Inanspruchnahme der letzteren zur synergischen Thätigkeit. Diese Function kommt beispielsweise den kleinen Ganglienzellen im Beugecentrum des Froschrückenmarkes $\mathrm{zu}$, wie wir aus dem Erfolg localisirter Strychnisirung des proximalen Theiles des letzteren mit Wahrscheinlichkeit schliessen konnten. (Vergleiche Seite 111.)

Bei dem Durchgang der Erregungswellen durch die Nervenzellen erfahren erstere im Allgemeinen Aenderungen ihrer Intensität. Sinn und Grösse dieser Aenderungen hängt ron Zuständen der Zellen ab, die durch gleichzeitig anf anderer Bahn zugeleitete Erregungen beeinflusst werden. Ein besonderer Fall solcher Aenderungen ist der, dass zugeleitete Erregungen, welche für gewöhnlich auf motorische Bahnen weiter geleitet werden, ganz unterdriickt werden, sodass Bewegungen, welche sonst zu erwarten wären, nicht eintreten. Diese Vorgänge nennt man Hemmungen und die Bahnen, auf welchen solche hemmenden Einflüsse Nerrenzellen zugeleitet werden, Hemmungsbahneu. Im Centralnervensystem des Frosches gehen Hemmungsbahnen für Nervenzellen des Rïckenmarkes ron den Lobi optici aus. Bei dem Menschen sind solche cerebromedullären Hemmungsbahnen wahrscheinlich sehr stark entwickelt. Hierfür spricht die auffallende Thatsache, dass der Rumpf der geköpften Menschen schlaff hinfällt, olıne krampfartige Bewegung und Spannung, während der Rumpf ron Hunden und Kaninchen nach der Köpfung starke Krämpfe zeigt.

Höchst wahrscheinlich ist es, dass die Auswahl der wirklichen Weiterleitung von Erregungen, welche aus den gegebenen Möglichkeiten der Weiterleitung getroffen wird, durch Zustände der Nerrenzellen bedingt ist, welche rou anderen gleichzeitig zugeleiteten Erregungen abhängen. Es muss wenigstens zugegeben werden, dass solche Einrichtungen für die Anpassung der Bewegungscomplexe an die jeweiligen äusseren Be- 
dingungen und an die durch letztere hervorgerufenen sinnlichen Eindriicke sehr förderlich sein müssten. In den Streckkrämpfen bei allgemeiner Strychninvergiftung hat man es vor Augen, ein wie zweckwidrigesOrgan-das Riickenmark wird, wenn eine Auswahl unter den verschiedenen durch präformirte Bahnen gegebenen Möglichkeiten der Erregungs leitung nicht mehr eintritt, sondern wenn alle Bahnen gleichzeitig in gleicher Intensität beschritten werden.

Die Nervenfasern kommen im. Rückenmark wie überall nur für die Erregungsleitung in Betracht. Normaler Weise entsteht in ihnen niemals Erregung. Es ist auch behauptet worden, dass die Nervenfasern des Rückenmarkes ausser denjenigen, welche die directen Fortsetzungen der Wurzelfasern bilden, keine künstliche Reizung mit Erregung beantworten. Die einen sollten „aesthesodisch", selbst aber unempfindlich, die anderen „kinesodisch", aber nicht eigentlich motorisch sein. In Betreff der letzteren Kategorie hat sich die Behauptung an den vorderen Strängen des Froschrückenmarkes mit grosser Wahrscheinlichkeit widerlegen lassen.

Spaltung einzelner erregungsleitender Bahnen in eine grössere Zahl derselben kommt innerhalb des Centralnervensystems am häufigsten durch Vermittelung eingeschalteter Nervenzellen zu Stande, ist aber ohne solche Vermittelung bei dem Uebergang hinterer Wurzelfasern in das Gerlach'sche Fasernetz gesehen worden.

Was die durch Nervenfasern hergestellten Leitungssysteme im Rückenmarke anlangt, so sind drei Kategorien derselben zu unterscheiden. Das Gerlach'sche Fasernetz stellt innerhalb der grauen Substanz eine sehr grosse Mannigfaltigkeit von erregungsleitenden Verbindungen aller zelligen Elemente des Rückenmarkes untereinander her; eine viel grössere Mannigfaltigkeit als voraussichtlich jemals im individuellen Leben zur Erregungsleitung benutzt wird. Eine zweite Kategorie biegt innerhalb des Rückenmarkes aus der grauen Substanz in die weisse ein und aus letzterer auch wieder in die erstere zurück. Die Fasern dieser Kategorie verbinden Ganglienzellen des Rückenmarkes in systematischer Weise untereinander, und dienen der Herstellung zweckmässiger und geläufiger Synergien. Die dritte Kategorie bleibt, nachdem sie aus der grauen Substanz in die weisse übergetreten ist, dauernd in letzterer und begiebt sich, ohne weitere Unterbrechung im Rückenmark zu finden, direct zu zelligen Elementen des Hirnstammes, vielleicht theilweise auch ohne celluläre Unterbrechung in Hirnstamm, direct zu Ganglienzellen des Hirnmantels.

Die Fasern der zweiten Kategorie sind offenbar in denjenigen Systemen des weissen Mantels des Rückenmarkes zu suchen, welche keine continuirliche Zunahme ihres Querschnittes von unten uach oben erkennen lassen, sondern welche mit der Zahl der zelligen Elemente der 
grauen Substanz an- und abschwellem. Es sind dies die Burdach'schen Keilstränge und die Vorderseitenstrangreste. I)ie dritte Kategorie von Fasern ist dagegen zu erwarten in den von unten nach oben continuirlich zunehmenden Fasersystemen, also in den Goll'schen Keilsträngen, in den Pyramidenbahnen der Vorder- und Seitenstränge und in der Kleinhirnseitenstrangbahn. lhre functionelle Bedeutung ist eine mannigfaltige. In Allgemeinen stellen sie systematische Verbindungen von (ianglienzellengruppen des Rïickenmarkes mit Ganglienzellengruppen des lirmstammes und Hirnmantels her im Dienste zweckmässig reflectorischer und willkürlicher Bewegungscoordinationen, sowie der bewussten Empfindung.

Am besten bekannt sind die Verbindungen und Functionen der Pyramidenbahnen. Sie stellen centrifugale Fortsetzungen von Stabkranzfasern dar, welche aus der als motorische Sphäre bezeichneten Partie der Hirnrinde stammen und sie dienen der Ausfïhrung willkïrlicher Bewegungen. Sie degeneriren nach Continuitätstrennungen in absteigender Richtung. Diese Degeneration setzt sich nicht auf die vorderen Wurzeln fort. Nan muss also annehmen, dass die Pyramidenbahnen sämmtlich in die graue Substanz einbiegen und hier durch Vermittelung von Nervenzellen, wahrscheinlich derselben grossen Ganglienzellen der grauen Vordersäulen, welche auch den reflectorischen Bewegungen dienen, zu motorischen Wurzelfasern in Beziehung treten.

Die Pyramidenbahnen dienen Bewegungsimpulsen für zweckmässig coordinirte Bewegungen zur Leitung und gehen in der Decussatio Pyramidum oder weiter unten durch die vordere Commissur meist vollkommen auf die andere Seite hiniiber. Auf Reizung der um den Sulcus cruciatus beim Hunde gelegenen motorischen Sphäre der Hirnrinde erhält man aber nicht nur coordinirte Bewegungen in der gekreuzten Hinterextremität, sondern auch tonischen Krampf in der gleichseitigen. Die diese Einwirkung vermittelnden Fasern machen die Kreuzung in der Decussatio Pyramidum mit und gelangen zwischen dem zweiten Halsund dem zwölften Brustwirbel wieder auf die erste Seite zuriick, iibersclureiten also zweimal die Mittellinie. Ausser in den Pyramidenbahnen sind noch viele motorische Leitungswege im Rïckenmark enthalten, welche der Herstellung von Synergien dienen und zum Theil durch marklose Fasern des Gerlach'schen Fasernetzes in der grauen Substanz, zum Theil durch markhaltige Nervenfasern ebenfalls der grauen Substanz, ferner der vorderen Commissur und namentlich der Vorderseitenstrangreste repräsentirt sind. Zn ihnen gehören zum Beispiel motorische Bahnen in den Seitensträngen, welche Zellen des Athemcentrums der Medulla oblongatia mit Zellen der spinalen Athemmuskelcentren verbinden. In nächster functioneller Beziehung zu den moto- 
rischen stehen die Hemmungsbahnen, doch ist über ihren Verlauf im Rückenmark nichts Sicheres bekannt.

Für die centripetale Leitung kommen innerhalb des Rückenmarkes in Betracht erstens Bahnen, welche localisirbare Sinnesempfindungen verschiedener Qualität dem Bewusstsein vermitteln, zweitens Bahnen, welche der Entstehung von Gemeingefühlen, deren wichtigstes der Schmerz ist, dienen; drittens Bahnen, welche Theile kürzerer oder längerer Reflexbögen bilden. Die Thatsache, dass wir die sensiblen Eindrücke der Haut innerhalb enger Grenzen genau zu localisiren vermögen, und dass wir zur Annahme besonderer Leitungsbahnen für die Druck-, Wärmeund Kälteempfindungen gezwungen sind, machen es wahrscheinlich, dass die Fasern der erst genannten Kategorie directe Leitungsbahnen zum Grosshirn darstellen, wodurch die Annahme nicht ausgeschlossen ist, dass die Fasern der zweiten und dritten Kategorie als Abzweigungen aus denen der ersten Kategorie hervorgehen. Es liegt nahe, die directen Leitungen zum Grosshirn in die Goll'schen Keilstränge zu verlegen. Jedenfalls werden die Tasteindrücke durch die weissen Hinterstränge geleitet. Die sensiblen Bahnen kurzer Reflexbögen liegen voraussichtlich in dem Grundbündel des Hinterstranges und für die unteren Extremitäten auch in dem Grundbündel des Seitenstranges.

Für die Entstehung des Schmerzes kommt ausschliesslich die Leitung durch die graue Substanz in Betracht. Für die die Wärmeempfindung vermittelnde Leitung wird ebenfalls die graue Substanz in Anspruch genommen, während die der Kälteempfindung dienende von allen Autoren in die weissen Hinterstränge verlegt wird. Sicher ist, dass Schmerz und Wärmegefühl veranlassende Eindrücke schneller in dem Bewusstsein erscheinen, als solche, welche Tast- oder Kälteempfindung veranlassen.

Alle Kategorien sensibler Leitung erfahren eine wenigstens theilweise Kreuzung auf dem Wege der hinteren Commissur und zwar bald nach ihrem Eintritt durch die hinteren Wurzeln in das Rückenmark; eine sehr merkwürdige, die sensible Leitung im Rückenmark betreffende Thatsache ist die, dass nach Hemisection des Rückenmarkes, unterhalb der Schnittstelle auf der entgegengesetzten Seite Anästhesie, auf der gleichen Seite aber Hyperästhesie besteht.

Eine wichtige Art sensibler Theile von langeu Reflexbögen ist durch Fasern repräsentirt, welche die durch Gliederbewegungen oder Muskelspannungen erzeugten Erregungen sensibler Endapparate in den Muskeln, Sehnen, Gelenken und in der Haut zum Hirnstamm leiten, wo sie in die zweckmässige, den jeweiligen Bedingungen des Körpergleichgewichtes und des äusseren Widerstandes Rechnung tragende Regulirung rer Bewegungscomplexe eingreifen. Die Fasern dieser Kategorie hat 
man in nicht glücklicher Weise als diejenigen des Muskelsinnes bezeichnet und man hat ihren Zutritt zum Rückenmark in die vorderen Wurzeln verlegt. Die Berechtigung hierzu kann angezweifelt werden. Sicher ist, dass die locomotorische $\Lambda$ taxie, welche auf Leitungsunterbrechungen in Fasern dieser Kategorie bezogen werden muss, mit Erkrankungen der weissen Hinterstränge verbunden ist. Ausserdem gehören zu dem System dieser Fasern wahrscheinlich diejenigen der Kleinhirnseitenstrangbahn, deren centripetale Natur aus ihrer Degeneration central von Continuitätstrennungen hervorgeht.

Die best constatirten Thatsachen, welche die Leitungsverhältnisse des Rückenmarkes betreffen, wollen wị noch einmal in kurzen Sätzen zusammenfassen.

1. Durchschneidung oder Erkrankung der weissen Hinterstränge hebt die Tastempfindung in den dahinter gelegenen Theilen auf, lässt aber die Schmerzempfindung bestehen.

2. Leitungsstörung der grauen Substanz in beschränkter Längsausdehnung hebt die Schmerzempfindung auf und lässt die Tástempfindung bestehen.

3. Verletzung oder Erkrankung der Hinterstränge in der Höhe des Lendenmarkes führt zur Abnahme der Tastempfindung am Anus und Perinaeum, während Sensibilität und Motilität der unteren Extremitäten intact bleiben; dagegen haben Läsionen in den Seitensträngen des Lendenmarkes für die unteren Extremitäten dieselbe Bedeutung wie die der Hinterstränge im Dorsal- und Halsmark für die oberen Extremitäten.

4. Wenn ein Theil des Querschnittes der grauen Substanz zerstört ist, bei gleichzeitiger Erkrankung der hinteren Stränge, so tritt Verlangsamung der Empfindung ein und zwar um so hochgradiger, je kleiner der Querschnitt erhaltener grauer Substanz ist; ist aber dabei die Leitung in den hinteren Strängen erhalten, so scheint sich die Verlaugsamung nur auf die Schmerz- und Wärmeempfindung zu erstrecken, während die Leitung der Tast- und Kälteempfinduug mit normaler Geschwindigkeit geschieht.

う. Longitudinal beschränkte Zerstörungen des ganzen Querschnittes der Hinterstränge und des ganzen Querschnittes der grauen Substanz haben völlige Anästhesie der dahinter gelegenen Körpertheile und geschwächte Bewegung oder partielle Lälımung zur Folge.

6. Desorganisation eines Vorderstranges und Seitenstranges und des grössten Theiles der grauen Substanz ruft auf der gleichen Seite motorische Lähmung hervor.

7. Halbseitige Läsion des Rückenmarkes hat nahezu vollständige motorische Lähmung und erhöhte sensible Reizbarkeit auf der verletzten 
Seite, sehr geringe Bewegungsstörung und aufgehobene Sensibilität auf der entgegengesetzten Seite zur Folge.

8. Völlige Compression oder Trennung des Rïckenmarkes erhöht die Reflexe in dem dahinter gelegenen Abschnitt.

9. Bei umschriebener Zerstörung des Rüickenmarkes gehen die vom Lendenmark vermittelten Reflexe (Harn- und Kothentleerung, Gefässtonus) in nahezu ungestörter Weise vor sich; sie können nur nicht mehr durch den Willen modificirt werden.

10. Die Ernährung peripherischer Theile (Muskeln, Nerven, Knochen, Gelenke, Haut u. s. w.) bleibt bei den verschiedenen Rückenmarkskrankheiten intact, soweit die dazu gehörige graue Substanz intact bleibt.

\section{Hirnmantel.}

Bei dem Studium des Rückenmarkes haben wir in eingehenderer Weise diejenigen Elemente kennen gelernt, welche zum physiologischen Verständniss des Aufbaues eines centralen Nervensystemes ausreichen; dieselben oder analoge Elemente kehren in anderen zum Theil sehr verwickelten Zusammenordnungen im Gehirn wieder. Auch hier handelt es sich um Anhäufungen weisser Substanz, in welcher ausschliesslich nervöse Leitungsbahnen vorhanden sind, und grauer Substanz, in welcher die cellulären Elemente vorherrschen. Am übersichtlichsten sind die Beziehungen zwischen der grauen und weissen Substanz im Hirnmantel, welcher, aus den beiden durch den Balken verbundenen Grosshirnhemisphären bestehend, bis zu den grossen Stammganglien hinabreicht. Eine zusammenhängende Schicht grauer Substanz bildet die Oberfläche der Hemisphären, unterhalb welcher mächtig entwickelte weisse Markmassen liegen. Die Oberfläche ist vielfach gewunden; tief eindringende Furchen, Sulci genannt, trennen die dazwischen liegenden Wülste „Gyri“. Auf diese Weise ist die für das Rindengrau disponible Fläche stark vergrössert. Die Hirnhäute sind ganz analog den Rückenmarkshäuten gebaut; das Hirn mit der dasselbe unmittelbar umkleidenden Pia mater ist in dem Duralsack gleichsam schwimmend angebracht. Die Pia des Hirnes ist sehr gefässreich und umkleidet die einzelnen Gyri bis zum Grunde der Sulci, überall den Zutritt von Blutgefässen zum Rindengrau vermittelnd. Der Aufbau des letzteren aus Schichten verschiedenartiger Zellenelemente ist ziemlich verwickelt und an verschiedenen Theilen der Rinde und an den einzelnen Stellen der Rinde andersartig, doch sind die physiologischen Bedeutungen dieser Verschiedenheiten nocb nicht klar.

In der weissen Markmasse des Hirnmantels sind drei Fasersysteme zu unterscheiden; erstens Commissurfasern, welche durch Vermittelung des Balkens correspondirende Stellen beider Hemisphären mit einander 
verbindend die Hauptcommissur des Hirnmantels darstellen. Zweitens Fasern, welche von der Hirnrinde jederseits dem Hirnstamm zustreben, und drittens Fasern, welche verschiedene Rindenstellen derselben Hemisphäre mit einander in Beziehung setzen. Die Fasern der zweiten Kategorie, welche als Stabkranzfasern bezeichnet werden, kreuzen sich mit den Balkenfasern in dem die Ilauptmasse weisser Substanz im Hirnmantel darstellenden Centrum semiovale Vieussenii. Die Fasern der dritten Kategorie, welche man Associationsfasern nenut, haben einen bogenförmigen Verlauf. Durch die Stabkranzfasern und analoge Faserziige, wie zum Beispiel diejenigen der Gratiolet'schen Sehstrahlung, welche von der Rinde des Hinterhauptlappens zum Hirnstamm zieht, wird das Rindengrau theils direct, theils nach cellulärer Unterbrechung im Hirnstamm mit centrifugalen und centripetalen Leitungsbahnen des Rückenmarkes und mit den Nerven des Hirnstammes, namentlich mit denen der Sinnesnerven, in Verbindung gesetzt.

Das Gehirn ist dasjenige Organ, in welchem die durch die sensiblen Bahnen des Rückenmarkes und die Pforten der höheren Sinne zugeleiteten centripetalen Erregungen in zweckmässige und coordinirte centrifugale Bewegungsimpulse umgesetzt werden. Dieser Theil der Hirnfunctionen ist nach dem allgemeinen Schema der Reflexe auf den einfachen Causalnexus des mechanischen Geschehens zurïckzuführen. Ausserdem besteht die dem mechanischen Verständniss nicht zugängliche Thatsache, dass gleichzeitig mit dem mechanisch definirbaren Erregungszustande bestimmter Hirnelemente bestimmte nur der inneren Selbstbeobachtung zugängliche Zustände des Bewusstseins eintreten können. Diese thatsächlich vorhandene, weun auch mechanisch unfassbare Verknüpfung materieller Zustandsänderungen im Hirn mit Zustandsänderungen des Bewusstseins macht das Gehirn zum Organe der Seelenthätigkeit. Wenn das Wesen der Verknüpfung für uns auch unfassbar bleibt, so ist sie selbst doch nicht gesetzlos, und wir können auf Grund von Combinationen zwischen Erfahrungen der äusseren Sinne einerseits und der inmeren Selbstbeobachtung andererseits Einiges über diese Gesetze aussagen.

Wenn sich mit iner bestimmten materiellen Zustandsänderung eines bestimmten Hirnelementes eine Aenderung des Zustandes unseres Bewusstseins verknüpft, so ist letztere ebenfalls eine ganz bestimmte, doch ist es nicht von dem materiellen Zustand allein abhängig, ob diese Verkuüpfung eintritt oder nicht. Wenn dasselbe Hirnelement zu verschiedenen Zeiten dieselben Zustandsänderungen erfährt, so kann der entsprechende immaterielle Vorgang einmal damit verbunden sein (er kann die Schwelle des Bewusstseins überschreiten), ein anderesmal nicht. Die die Entscheidung hierüber beherrschenden Gesetze können wir für jetzt 
nicht näher formuliren, wir wissen nicht, ob die Entscheidung ausser von den Zustandsänderungen in dem einzelnen Element nur noch von den gleichzeitigen Zuständen und Zustandsänderungen der übrigen Hirnelemente oder ausserdem noch von sonst etwas abhängt; wir umschreiben nur den Vorgang, indem wir von willkürlicher Lenkung der Aufmerksamkeit oder von willkürlichem Erheben über die Schwelle des Bewusstseins reden.

Wenn die in Frage stehende Verknüpfung eintritt, so können es Empfindungen bestehender Bedürfnisse oder ihrer Befriedigung sein, welche in das Bewusstsein treten oder Sinneswahrnehmungen; oder es können Vorstellungen von äusseren Objekten sein, deren jede aus einer Summe von Attributen besteht, die durch Beziehung des wiederholt gleichzeitig mittelst verschiedener Sinne Wahrgenommenen auf einen Gegenstand gebildet ist, oder es können Vorstellungen von Bewegungen des eigenen Körpers sein und von den durch letztere zu erreichenden Zwecken. Die einfachste Zweckvorstellung ist die Vorstellung von der durch eine vorgestellte Bewegung zu erreichenden Empfindung der Befriedigung eines Bedürfnisses. Dies sind die Elemente des psychischen Geschehens, welche allein hier in Betracht kommen können.

Wenn ein Mensch eine Traube ergreift, nachdem er sie erblickt hat, so steht der materielle Erregungsvorgang in den motorischen Nerven des Armes und der Hand sicher in einem mechanischen Causalnexus mit dem materiellen Erregungsvorgang im Nervus opticus, welcher vorherging und mehrere Glieder der ganzen Kette des materiellen Geschehens liegen gewiss im Gehirn. Mit der reihenweisen Erregung von Stationen in letzterem $\mathrm{kann}$ sich nun folgender psychischer Vorgang verbinden: die optische Sinneswahrnehmung des Blauen in einer bestimmten Form erregt die Vorstellung auch der übrigen Attribute der Traube (und damit dieser selbst). $\mathrm{Zu}$ diesen durch frühere wiederholt gleichzeitige Sinneswahrnehmungen und Empfindungen combinirten Attributen gehört auch die durststillende Fähigkeit. Die Vorstellung der Durststillung ruft die Vorstellung von Bewegungen hervor, durch welche diese selbst (als vorgestellter Zweck) erreicht werden kann. So gestaltet sich der psychische Vorgang in seiner einfachsten Form, und wenn alle Glieder der Kette die Schwelle des Bewusstseins iiberschreiten; er kann aber einerseits durch Ueberlegungen ethischer und anderer Natur complicirt werden, andererseits können mehrere oder auch alle Glieder des Vorganges unter der Schwelle des Bewusstseins bleiben, wodurch in der Form des äusseren Effektes Nichts geändert zu werden braucht. Wir haben überhaupt keinen Grund anzunehmen, dass irgend ein Glied des inateriellen Vorganges sich anders $z u$ gestalten braucht, je nachdem die ihm entsprechende Empfindung, Wahrnehmung oder Vorstellung in das Bewusstsein tritt oder nicht. 
Die Ueberzeugung, eine Bewegung willkürlich ausgeführt zu haben, kann entstehen, wenn wenigstens die Vorstellung des Zweckes in das Bewusstsein getreten war. So ist das wesentliche Kriterium der willkürlichen Bewegung ganz immateriell und nur der inneren Selbstbeobachtung zugänglich; der materielle Vorgang bei willkürlichen Bewegungen ist wesentlich kein anderer, als bei Reflexbewegungen; ersterer unterscheidet sich nur dadurch von letzterem, dass bei ihm solche materielle Glieder in den Erregungsvorgang hineingezogen werden, mit deren Erregung sich Bewusstseinsänderungen vergesellschaften können. Derartige nervöse Elemente haben wir Grund nur in der Hirnrinde anzunehmen. In diesem Sinne nennen wir die Hirnrinde das Organ der willkürlichen Bewegungen und in analogem Sinne nennen wir sie das Organ der Empfindungen, Wahrnehmungen und Vorstellungen.

Die einzelnen Elemente der Hirnrinde unterscheiden sich von einander ausser durch mannigfache histologische Besonderheiten, über deren Bedeutung noch wenig auszusagen ist, wesentlich durch ihre Verknüpfungen mit den rerschiedenen centripetalen und centrifugalen Erregungsleitungen. Mit letzteren sind direct nur die zelligen Elemente der sogenannten motorischen Sphäre der Hirnrinde verbunden (beim Menschen, Gyrus centralis anterior und posterior; Gyrus frontalis inferior sinister; Gyrus supramarginalis und angularis), mit ersteren sowohl die sogenannte motorische Sphäre, als auch die sensoriellen corticalen Felder und zwar: Occipitallappen für das Gesicht, Temporallappen für das Gehör, Lobi olfactorii und Gyrus fornicatus mit Cornu ammonis für den Geruch, die sogenannte motorische Sphäre für das Getast- und für die Bewegungsgefühle.

Am übersichtlichsten lässt sich die Bedeutung dieser Verbindungen auf Grund der anatomischen Thatsachen der physiologischen Experimente und der pathologischen Erfahrungen beziiglich der sensoriellen Sphäre des Gesichts und des Gehörs darstellen, welche schlechtweg die Sehsphäre und die Hörsphäre genannt werden.

Die erregungsleitenden Bahnen des Nervus opticus setzen sich nach einigen subcorticalen gangliösen Einschaltungen (welche unbewusste coordinirte Reflexe vermitteln) zunächst auf dem Wege der Gratiolet'schen Sehstrahlung zu zelligen Elementen der Rinde des Occipitalhirns fort. Mit der Thatsache, dass sich von einem bestimmten Punkte der Retina aus auf dem Wege einer bestimmten Nervenfaser eine Erregung bis in ein bestimmtes zelliges Elenent der Rinde des Occipitalhirns fortpflanzt, kann sich in oben besprochener Weise die Thatsache verbinden, dass eine Wahrnehmung von bestimmtem optischem Charakter in das Bewusstsein tritt. Diese Wahrnehmung wird die specifische Energie der betreffenden Nervenfaser genaunt, und die Lehre vou den specifischen 
Energien der Sinnesnerven erkennt sowohl für die materiellen Erregungsrorgänge in der einzelnen Nervenfaser mit ihren peripherischen und centralen Endapparaten als auch für die zugehörigen Bewusstseinsänderungen nur quantitative und keine qualitativen Abstufungen an. Nach dieser Lehre müssen wir in der Sehsphäre mindestens so viele gesonderte sensorielle Elemente annehmen, als es qualitativ (dem Ort und der Farbe nach) unterscheidbare Elemente der Gesichtswahrnehmungen giebt. Ganz Analoges gilt für das Gehör.

Wenn nun wiederholt verschiedene corticale sensorielle Elemente gleichzeitig ron den ihnen zugehörigen peripherischen Sinneselementen aus erregt werden - und dies geschieht, wenn wiederholt derselbe Gegenstand mit seinen Eigenschaften auf unsere Sinne einwirkt - so scheinen sich erregungsleitende Bahnen zwischen diesen corticalen Elementen auszubilden derart, dass sich späterhin mit der Erregung des einen auch eine Erregung des anderen verbindet, selbst wenn dann nur die dem einen zugehörige peripherische Sinnesnervenendigung von ihrem adaequaten Reiz getroffen wird. So kann es geschehen, dass, wenn später derselbe Gegenstand nur mit einem Theile seiner Eigenschaften, etwa mit den dem sensoriellen Qualitätenkreise "Gesichtssinn" zugehörigen, der Wahrnehmung sich darbietet und auch mit diesem Theile nur unvollkommen, sofort die Vorstellung nicht nur aller optischen Attribute in dem Bewusstsein erscheinen kann (optisches Erinnerungsbild des Gegenstandes), sondern auch sein akustisches Erinnerungsbild und die den übrigen Sinnen zugehörigen Erinnerungsbilder, ja bei entsprechendem Umfang der Erfahrung auch die Vorstellung der durch den Gegenstand zu befriedigenden Bedürfnisse und der zur Herbeiführung der Befriedigung erforderlichen Bewegungen hervorgebracht werden können.

Somit besteht ein wesentlicher Theil des materiellen Substrates für das Wiedererkennen und für den zweckmässigen Gebrauch eines Gegenstandes in erregungsleitenden Bahnen, die sich durch Erfahrung zwischen corticalen Elementen eines und desselben, sowie verschiedener Rindengebiete ausbilden, und welche man, da sie der Association von Vorstellungen dienen, Associationsfasern nennt. Das System der Associationsfasern macht einen wesentlichen Theil des weissen Marklagers der Grosshirnhemisphären aus.

Die allgemeine physiologische Bedeutung der Stabkranzfasern, welche die corticopetalen und die corticofugalen Erregungsleitungen darstellen, liegt auf der Hand. Die Commissurfasern namentlich der Balkenstrahlungen, welche gleichwerthige Rindenelemente beider Hemisphären mit einander verbinden, setzen die von den Sinnen der beiden bilateralsymmetrischen Körperhälften gelieferten Erfahrungen in derartige Be- 
ziehungen zu einander, dass sie unter dem Gesichtspunkte des einheitlichen Ich im Bewusstsein erscheinen können.

Ein riel umstrittener Begriff der Physiologie des Grosshirns ist der der Localisation. Es handelt sich um die Frage, ob verschiedenen Stellen der Grosshirmrinde verschiedene Functionen zuerkannt werden können.

Der Natur der Sache nach muss jedes Rindenelement zunächst als ein Durchgangsort für Nervenerregungen aufgefasst werden. Wegen der Mannigfaltigkeit der Orte, von denen aus der einzelnen Rindenzelle Erregungen zufliessen können und derjenigen, wohin sie Erregungen weiter senden kann, wird der Spielraum der centralen Processe, an denen sich die Zelle betheiligen kann, also der Spielraum ihrer Function, eine gewisse Breite haben. Die erkennbare Function einer Rindengegend wird also nicht eine so eng begrenzte sein können, wie zum Beispiel die Function des Secretionsepithels einer Drüse. Nicht in demselben Sinne wie man ron einer Epithelzelle eines gewundenen Harncanälchens sagen kann, sie secernirt Harn, kann man von einer Rindenzelle des Grosshirns sagen, sie will eine Bewegung oder sie sieht, sondern nur: sie ist an einem centralen Process betheiligt, dessen Endglied eine Muskelinnervation ist, oder an einem solchen, der durch einen Gesichtseindruck eingeleitet wurde.

Immerhin kann unter den erregungsleitenden Nervenbahnen, welche durch eine Rindenzelle mit einander verknüpft sind, eine einzelne derart prävaliren und die Zelle selbst kann in einer bestimmten Erregungsbahn eine so herrorragende Stellung einnehmen, dass ihrer Function ein greifbarer Charakter aufgedriickt wird. So gehen von Rindenzellen der Centralwindungen und ihrer nächsten Umgebungen anatomisch nachweisbar Fasern aus, welche durch Stabkranz, innere Kapsel, Hirnschenkelfuss, Brücke, Pyramiden und Pyramidenbahn des Rückenmarkes mit motorischen Nervenzellen der grauen Tordersäulen des letzteren zusammenhängen. Auf sicherer anatomischer Grundlage ist darum zu erwarten, dass das Ausbreitungsgebict dieser Stal)kranzfasern in der Hirnrinde zu den unter Vermittelung derselben iiberhaupt eintretenden Körperbewegungen in herrorragender innerer Beziehung steht.

In der That treten nun nach Verletzungen im Bereich der genannten Hirngegend beim Menschen sicher Störungen im willkürlichen Gelirauch der Skelettmuskeln ein, und durch localisirte, auf die Rindenelemente heschränkte elektrische Reizung bestimmter Rindenstellen des genannten Gebietes kann man bestimmte Muskelgruppen in bestimmte coordinirte Thätigkeit rersetzen. Da sich das genannte Rindengebiet hierin wenigstens quantitatir auftallender Weise ron der übrigen Hirn- 
rinde unterscheidet, so ist man vollauf berechtigt, dasselbe als die motorische Sphäre der Hirnrinde zu bezeichnen.

Ferner steht die Rinde des Hinterhauptlappens durch einen stets darstellbaren Faserzug des weissen Marklagers (durch die Sehstrahlung Gratiolet's) mit den dem Tractus opticus zum Ursprung dienenden Ganglien des Hirnstammes (im vorderen Vierhügel, Geniculum externum und Pulvinar Thalami optici) in anatomisch nachweisbarer directer Verbindung, und da ausserdem nach ausgedehnter Rindenläsion weit sicherer, wenn sie im Occipitalhirn, als wenn sie anderswo auftritt, Sehstörungen beobachtet werden, so hat es einen nicht misszuverstehenden Sinn, wenn man diese Rindenpartie die Sehsphäre nennt.

In analogem Sinne, wenn auch nicht mit dem gleichen Grade von Sicherheit, betrachtet man die Rinde des Schläfenlappens als Hörsphäre und die Rinde im Gebiet der Substantia perforata antica und des Ammonshornes als Riechsphäre. In ersterer Beziehung lässt die Begründung durch die anatomische Zergliederung, in letzterer diejenige durch die pathologische und physiologische Erfahrung noch zu wünschen übrig.

Das physiologische Experiment und die Beobachtung am Krankenbette und am Secirtische drängen dazu, der Fühlsphäre dasselbe Rindengebiet zuzuweisen wie der motorischen Sphäre. Tritt bei Läsionen in diesem Gebiete Bewegungsstörung in einer Extremität auf, so zeigt dieselbe Extremität auch gleichzeitig eigenartige Empfindungsstörungen. Ein Hund, welcher auf diese Weise im Gebrauch einer Vorderpfote geschädigt ist, fühlt nicht, ob er diese Pfote mit dem Fussrücken oder mit dem Fussballen aufsetzt. Es kann dies nicht Wunder nehmen, wenn man bedenkt, dass die durch die Haut und die sensiblen Theile der Gelenke, Sehnen und Muskeln vermittelten Empfindungen, welche die Gliederbewegungen begleiten, zur Bildung der Bewegungsvorstellungen erforderlich sind und dass das Eintreten von Bewegungsvorstellungen in das Bewusstsein ein wesentliches Kriterium für das Unterscheiden der Willkürbewegung von der Reflexbewegung ausmacht.

Ueber diejenigen Functionen, zu welchen die Rinde des Stirnlappens in nächster Beziehung stehen mag, ist eine Klärung der Ansichten noch nicht erzielt.

Was das Positive in den vorstehenden Angaben betrifft, so wird es kaum von irgend einem der Forscher, welche sich in neuerer Zeit an der Discussion über die Localisationsfrage betheiligt haben, bestritten werden. Worüber augenblicklich die Ansichten noch weit auseinander gehen, das sind hauptsächlich die Fragen nach dem Grade der Abgrenzbarkeit der einzelnen Sphären gegen einander und nach der Möglichkeit des Nachweises einer feineren Gliederung der Functionen innerhalb der einzelnen Sphären. 
Was den ersteren Punkt anlıngt, so ist eine "landkartenähnliche" Abgrenzung zwischen Gebieten verschiedener Functionen auf Grund der anatomischen Verhältnisse nicht zu erwarten, denn so weit Structurverschiedenheiten in der gramen Rinde und ihrem weissen Marklager nachgewiesen sind, zeigen sich die Uebergänge sehr allmählich. Darum lraucht man nicht so weit zu gehen, dass man zum Beispiel auf Grund ron Sehstörungen, welche man nach Verletzungen im Stirnhirn von Thieren beobachtet, der betreffenden Rindenpartie dieselbe Bedeutung für das Sehen zuschreibt, wie der Rinde des Hinterhauptlappens. Für eine solche Gleichstellung fehlt die anatomische Grundlage, und man muss bedenken, dass ein centraler Process, welcher durch einen Gesichtseindruck eingeleitet wurde, der Intactheit noch mancher centraler Verbindungen und corticaler Durehgangsstationen bediurfen wird, um in Form einer entsprechenden Bewegung in die objective Erseheinung zu treten.

Was die feinere Gliederung der Function betrifft, so ist man zu dem am allgemeinsten anerkannten Resultate auf dem Gebiete der motorischen Sphäre gelangt. Die einzelnen Theile der Centralwindungen sind dadurch charakterisirt, dass bei einer so schwachen elektrischen Reizung derselben, dass die erste motorische Wirkung zu beobachten ist, jedesmal eine ganz bestimmte Muskelgruppe in Thätigkeit geräth, entweder Muskeln des Gesichts oder der Arme oder der Beine u. s. w. Die auf diese Weise charakterisirten Rindenstellen der Beinmuskeln zum Beispiel nennt man das "absolute Rindenfeld" derselben, im Gegensatz zu dem weiter ausgedehnten "relativen“, ron dessen Theilen aus ebenfalls, aber bei mehr odęr weniger beträchtlicher Verstärkung des Reizes Bewegungen in den Beinmuskeln zu erzielen sind. Die Unterscheidung der relativen und absoluten Rindenfelder verschiedener Muskelgruppen hat sich für die Dentung der pathologischen Befunde als zweckmässig erwiesen.

Algemein anerkannt ist ferner, dass jedes motorische Rindenfeld vorzugsweise, aber nicht ausschliesslich, zu der betreffenden Muskelgruppe der entgegengesetzten Körperhälfte in Beziehung steht. Das besondere Verhalten geht aus folgendem Beispiel hervor. In der motorischen Sphäre des Kaninchenhirns giebt es ein absolutes Rindenfeld fïr Auswärtsbewegung des gekreuzten Vorderbeins. Durch Verstärkung des Reizes an der betreffenden Rindenstelle erhält man auch Bewegung der gleichnamigen vorderen Extremität, doch betrifft diese Bewegung nicht die symmetrische Muskelgruppe, soidern diejenige, welche die Bewegung zu einer mit der des anderen Beines gleichgerichteten macht. Dieser Erfolg tritt anch nach strenger Localisation der elektrischen Ströme anf die betreffende Hirnhemisphäre und nach Durch- 
schneidung des Balkens auf, es kamn also nicht daran gezweifelt werden, dass die Stabkranzfaserung einer Seite den zu beiden Extremitäten gelangenden Bewegungsimpulsen zur Leitung dient.

Eine analoge Erfahrung ron grosser Bedeutung, welche jetzt ebenfalls allgemein anerkannt sein diurfte, betrifft die Sehsphäre. Nach Zerstörung der Rinde eines Occipitallappens tritt Sehstörung in der gleichseitigen Hälfte beider Netzhäute ein (bilaterale homonyme Hemiopie), sodass also die Projection jeder Hälfte des Gesichtsfeldes durch Vermittelung beider Augen in nur einem Occipitallappen und zwar in dem contralateralen zu Stande kommt.

Eine ganz besondere Rolle hat in der Entwickelung der Localisationslehre die Beziehung der linken dritten Stirnwindung zur Sprache gebildet. In einer grossen Anzahl von Fällen hat sich eine an Patienten beobachtete Aufhebung des Sprechvermögens (Aphasie) auf Zerstörung dieses Rindengebietes zurückführen lassen. Aber auch nach anderweiten Hirnläsionen wurden Sprachstörungen beobachtet. Seitdem man verschiedene Formen der Aphasie zu unterscheiden gelernt hat, weiss man, dass mit der linken dritten Stirnwindung diejenige Form zusammenhängt, welche auf der Störung der zum Aussprechen des Wortes erforderlichen Bewegungscoordinationen beruht, und welche man die ataktische nennt. Zum Sprechen gehört aber mehr, vor allem die richtige Association von Vorstellungen, welche früheren gleichzeitig erhaltenen Eindrïcken entsprechen und kraft deren die Wiedererkennung rou Gegenständen und die Erinnerung an ihre optischen oder akustischen Symbole in Schrift und Laut erfolgt. Verschiedene Formen von Aphasie sind also bei Läsionen in verschiedenen Sinnessphären der Rinde und den zugehörigen Associationsfasersystemen nicht nur beobachtet worden, sondern sie sind auch der Natur der Sache nach hier zu erwarten gewesen.

\section{Hirnstamm.}

Der Hirnstamm rerbindet den Hirnmantel und das Rïckenmark mit einander; er umfasst die Medulla oblongata, den Pons Varolii, das Cerebellum, die Hirnschenkel, sowie die basalen Ganglien des Grosslimns, und ist nicht nach so leicht ïhersehbarem Plan gebaut, wie dic bisher behandelten Theile dos Contralnervensystems. Das Verständniss des Folgenden wird durch aufmerksame Vergleichung der beigegebenen Tafel und der zugehörigen Beschreibung erleichtert werden.

In rem Hirustamm liegen auf engem Raume theils neben, theils durch einander vertheilt Apparate, die sowohl der Function nach, welcher sie dienen, als auch dem Verhältnisse von Subordination, Coordination und Pracordination nach, in dem sie zu cinander und zu anderen 



\section{Tafelbeschreibung.}

(Die allgemeine Form des Schemas ist Aeby entlehnt.)

\section{Dem Hirnmantel gehören an:}

Grane Rinde (schwarz schraffirt) und weisses Marklager der Grosshiımhemisphären. Letzteres enthält: Associationsfasern, Balkenstrahlung und Stabkranzfasern. Die Associationsfasern (schwarz) verbinden verschiedenwerthige Stellen derselben Hemisphäre unter einander. Die Balkenfasern (orange) sind Commissurfasern, sie verbinden symmetrische Stellen beider Hemisphären miteinander. Die übrigen Faseru (roth, blau, griin) gehören der Stabkranzfaserung an, welche ron der Capsula intema (C.i.) ausstrahlt.

II. Der Hirnstamm besteht aus:

1. Basalganglien, schwarz schraffirt: Sehhïgel, Thalamus opticus, Th. - Linsenkern, Nucleus lentiformis, N.l. - Schwanzkern, Nucleus candatus, N.c.; dazwischen liegt (nicht schraffirt) die grosse gemischte Leitungsbahn der inneren Kapsel, Ca psula in terna, C. $i$, enthaltend blan: lange sensible Bahnen aus den Goll'schen Strängen des Rückenmarkes; roth: lange motorische Bahnen der Pyramidenstränge; grïn: Coordinationsbahnen zwischen Hirnmantel und Hirnstamm.

2. Hirnschenkel mit Haubenregion (Vierhügel, Corpora quadrigemina, C.q.) und Fussregion (Pedunculi cerebri, P.C.) In der Haube: graue Kerne der Vierhügelregion (schraffirt) und Kreuzung coordinirender Bahnen rom Kleinhirn zum Hirnmantel (grün). Im Hirnschenkelfuss: mediale Zone, motorische Bahnen von Hirnrinde zu Brückenkernen (roth); mittlere Zone, durchgehende motorische Bahnen vou Hirurinde (nach theilweiser Unterbrechung im Linsenkeru) zum Rïckenmark (roth); laterale Zone, lange sensible Bahnen aus den Goll'schen Strängen des Rïckenmarkes zur Hirnrinde.

3. Formation des Kleinhirns und der Brücke (Pons, P.), verbunden durch die Kleinhirnschenkel (Pedunculi cerebelli, P.c.). Graue Substanz: Rinde des Kleinhirns, gezahnter Kern (Nucleus dentatus, n.d.) und Brückenkerne (Nuclei pontis, n. p.).

4. Medulla ablongata. Graue Massen: Formatio reticularis, F. r., Oliven, o. Kerne der zarten Stränge $\uparrow$ und der Keilstränge *; sensible Kreuzung Meynerts (blau) und motorische Kreuzung (Decussatio Pyramidum, $D$. $P$., roth).

\section{Rückenmark:}

a. Pyramidenfasern der Vorderstränge, ungekreuzt, oder in der vorderen (weissen) Commissur des Riickenmarks gekreuzt.

b. Grundbündel der Vorderseitenstränge nnd grane Vordersäulen (Segmente und intersegmentäre Verbindungen).

c. Pyramidenfasem der Seitenstränge, in der Decussatio Pyramidum gekreuzt.

d. Goll'sche Stränge.

e. Clarke'sche Säulen mit intersegmentären Verbindungsbahnen, letztere zum Theil auch in $g$ enthalten.

f. Kleinhirnseitenstrangbahn.

g. Grundbündel des Hinterstranges, bestehend aus dem Burdach'schen Strange zu dem Kern des Keilstranges und collateralen Verbindungsfasern zu b, nebst Kreuzungen in der granen Commissur, welche in der 'Leichnung nicht ausgedrückt sind. 


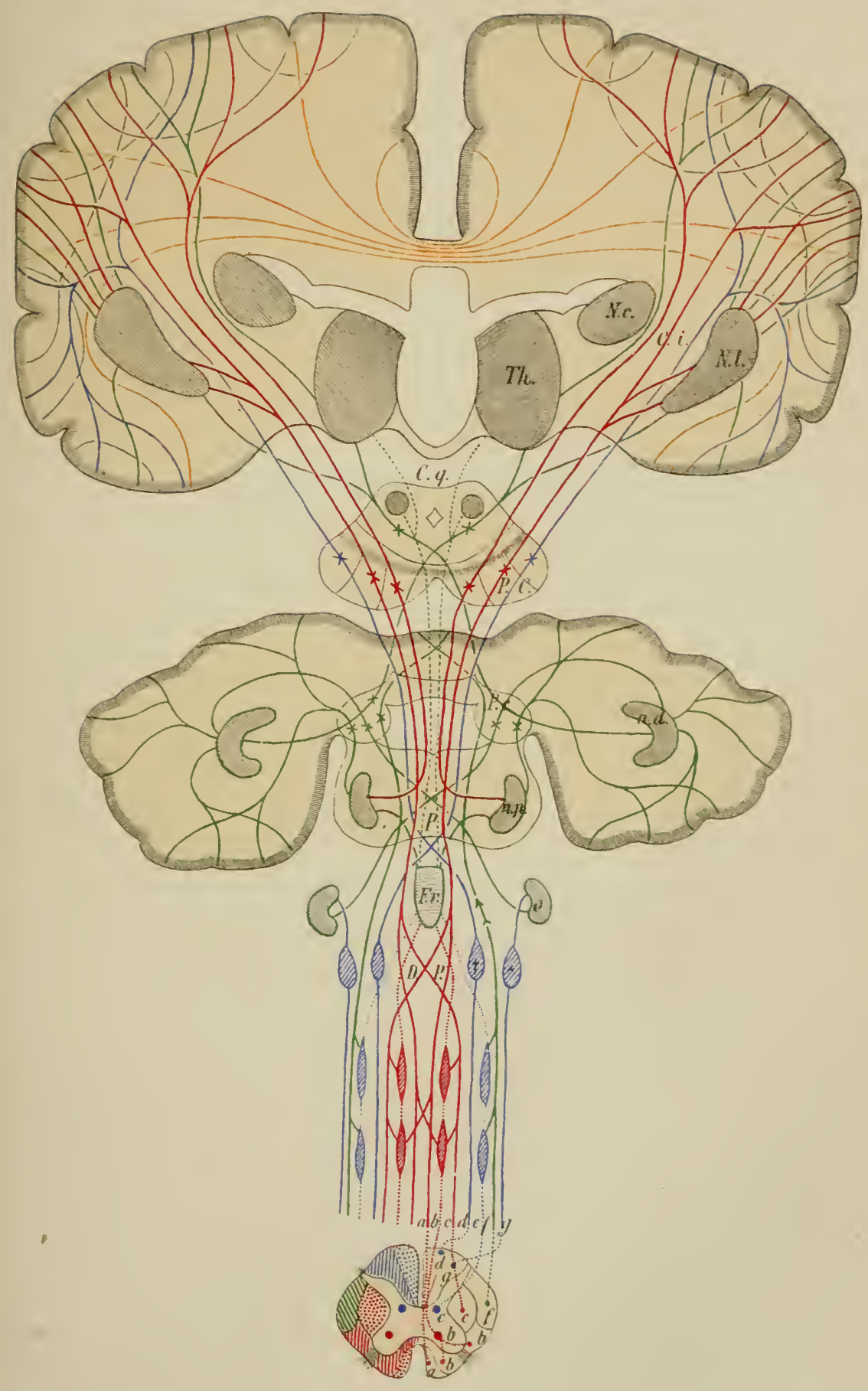



Apparaten stehen, sehr verschiedenwerthig sind. Dies erklïrt genügend die Unsicherheit, welche zur \%eit weniger unsere Yorstellung ron den functionen des Hirnstammes im Allgemeinen, als vielmeln die specielle Kenntniss ron den Beziehungen der einzelnen Functionen zu den einzelnen anatomisch unterscheidloaren Gebilden desselben beherrscht.

Wenn man als functionell wesentlich für den Hirnmantel die Association, für das Rüickenmark den Reflex bezeichnen kann, so ist die charakteristische Function des Hirnstammes die Coordination. Als Reflexapparat erscheint das Riickenmark, namentlich insofern als in ilm die grösste Summe derjenigen Vorrichtung enthalten ist, durch welche centripetal und intracentral fortgeleitete Erregungen auf die peripherischen Bewegungsapparate zurückgelenkt werden; es geschieht dies durch die grossen Gauglienzellen der grauen Vordersïulen. Ferner sammelt es eine grosse Anzahl der centripetalen Leitungsbahnen: seine intracentralen Verbindungen zwischen letzteren und den centrifugalen sind rerhältnissmässig einfach.

Als Sammelapparat für centripetale Erregung schliesst sich nun der Hirnstamm dem Riickenmark an, indem er den sensoriellen Leitungsbahnen für Gesicht, Gehör, Geschmack, sowie der grossen sensiblen Trigeminusbahn zum Eintritt dient und auch die im Riickenmark fortgeleiteten sensiblen Eindrïcke aufnimmt. Ebenso setzen sich die motorischen Endstationen intracentraler Leitung als Verlängerung der grauen Vordersäulen aus dem Rückenmark in den Hirustamm fort, wo sie sogar in rereinfachter Form als Lierne der motorischen Hirnnerren des Oculomotorius, Trochlearis, Facialis und Hypoglossus erscheinen. Auch in der Einfachheit einiger reflectorischer Verknïpfungen ahmt der Hirnstamm noch das Riickenmark nach. Im Allgemeinen zeichnen sich aber die durch ersteren vermittelten Vorgänge dadurch aus, dass bei ihnen complicirte Muskelcombinationen im Interesse einheitlicher Zweckerfüllungen geordnet zusammenwirken. Wohl entbehrt auch das Rückenmark nicht coordinatorischer Verknipfungen, doch treten dieselben hier nicht so in den Vordergrund wie im Hirnstamm. Von der bewussten Zweckerfiillung aber, welche durch den Hirmmantel rermittelt wird, unterscheilet sich die durch den Hirnstamm zweckmässig geordnete Bewegung dadurch, lass sie nicht wie jene an die Association von simnlichen Erinnerungsbildern oder von Vorstellungen, die aus solchen abstrahirt sind, mit Bewegungsvorstellungen gebunden ist. Die Coordination durch den Hirnstamm rollzieht sich stets und ganz unterhalb der Schwelle des Bewusstseins.

Ausser den sensiblen und motorischen Endstationen centraler Natur und ausser den einfachen reflectorischen und den complicirteren conrdinatorischen Verknüpfungen besitzt der Hirnstamm anatomisch gut unter- 
scheidbare Gebilde, welche der ganz einfachen intracentralen Erregungsleitung dienen. Es sind dies die rein weissen Partien des Hirnstammes, namentlich also innere Kapsel, Hirnschenkelfuss und Pyramiden, s̄owie Schenkel und Marklager des Kleinhirns. Dass geschlossene Massen weisser Substanz im Hirnstamm weniger hervortreten wie im Hirnmantel und im Rückenmark erklärt sich zum Theil aus den räumlichen Verhältnissen. Im Hirmmantel erzeugt die unilaterale und bilaterale (associatorische und commissurale) Verbindung der in der Hirnrindenfläche weit ausgebildeten gangliösen Elemente unter einander und die Verbindung der letzteren mit dem Hirnstamm compakte Massen weisser Substanz; im Rïckenmark bedingt die Länge des Weges, zwischen den in grosser Zahl unter einander und mit dem Hirnstamm in Verbindung zu setzender sensibler und motorischer Endstationen das Hervortreten geschlossener, der reinen Erregungsleitung dienender Stränge ron grosser Ausdehnung. Im Hirnstamm dagegen liegen die unter einander durch einfache Erregungsleitung zu verbindenden nervösen Schaltstiicke auf engerem Raum beisammen, ja ganze Systeme solcher Schaltstiicke durchdringen sich hier gegenseitig, sodass ein grösseres Hervortreten geschlossener Leitungsbalnen nur zu erwarten wäre, wenn ein erheblicher Antheil der aus dem Rïckenmark dem Hirnmantel und aus dem Hirnmantel dem Rückenmark zustrebenden Leitungen den Hirnstamm durchsetzte, ohne in dessen Systemen grauer Massen eine Unterbrechung durch Schaltstiicke zu erfahren.

Es muss aber als zweifelhaft bezeichnet werden, ob der Hirnstamm derartige directe Leitungen zwischen Hirnmantel und Rückenmark überhaupt enthält. Man kann sie auf dem Wege vom Stabkranz durch die innere Kapsel, den Hirnschenkelfuss, die Brïcke und die Pyramide zu den Pyramidenbahnen des Rïckenmarkes erwarten. Im vorderen Schenkel der inneren Kapsel sind nun allerdings geschlossene Leitungsbahnen vorhanden, welche, aus dem Stabkranz stammend und bei Linsenkern und Sehhügel vorbeiziehend, ohne Unterbrechung in den Hirnschenkelfuss (inneres Drittel) gelangen. Diese Bahnen finden aber, ehc sie die Pyramide erreichen, in der Brücke eine Unterbrechung durch Ganglienzellen. Andererseits ist das mittlere Drittel des Hirnschenkelfusses aus Fasern zusammengesetzt, welche zwar mit solchen der Pyramide ununterbrochen zusammenhängen, welche aber den Stabkranz des Hirnmantels zum grossen Theile durch Vermittelung von Ganglienzellen dos Linsenkernes erreichen. Ein Theil dieser Fasern soll allerdings eine directe Pyramidenbahn zum Hirnmantel darstellen.

Mit grösserer Sicherheit scheint anatomisch festgestellt $\mathrm{zu}$ sein, dass von dem Stab)kranz des Schläfen- und Occipitallappens Fasern an der hinteren Kante des Linsenkêrnes rorbei zum Hirnschenkelfuss gelangen, 
dessen äusserste Bündel sie darsteilen und von dem aus sie sich direct (oder durch Vermittelung der Kerne der zarten Stränge) bis in die weissen Hinterstränge des Rïckenmarkes fortsetzen. Aus den Erfalrungen über Degenerationen geht hervor, dass diese Fasern Erregungen rom Rückenmark zum Hirn leiten, alle iibrigen Fasern des Hirnschenkelfusses aber motorisch sind. Allerdings scheint auch die Thatsache des Localisationsvermögens für Tast- und Temperaturempfindungen zu ihrer Erklärung die Annahme directer Erregungsleitungen von der Peripherie bis zur Hirnrinde zu verlangen, während wir keine Nöthigung empfinden, uns Bahnen, welche den Willkürbewegungen dienen, so weit letztere coordinirt sind, einfach vorzistellen. In Gegentheil müssen wir wohl annehmen, dass es eine Ausnahme sein wïrde, wenn eine Willkürbewegung des Rumpfes und der Unterextrenitäten ohne die Betheiligung von unbewusst im Interesse des Körpergleichgewichtes coordinirenden Apparaten zu Stande käme.

Eine sehr wichtige Leitnngseigenthïmlichkeit wird in Hirnstamm auch denjenigen Bahnen aufgedruickt, welche diesen Hirntheil wenig oder gar nicht unterbrochen durch Schaltstücke durchsetzen; sie werden, wenn auch nicht in ihrer Totalität, so doch meist ihrer grössten Masse nach (es herrschen hier individuelle Verschiedenheiten) gekre uzt, das heisst von der einen Körperseite in die andere ïbergeleitet. Der Ort dieser Umlagerung ist für die motorischen Antheile des Hirnschenkelfusses die Decussatio pyranidum, für den sensiblen Antheil die obere Pyramidenkreuzung Meynert's. Von sonstigen Kreuzungen, an denen der Hirnstamm sehr reich ist, sei hier noch erwähnt die Semidecussatio im Chiasma nervorum opticorum, die (zweifelhafte) Krreuzung des Trochlearis, die theilweise Abhängigkeit jedes Musculus rectus internus rom Abducenskerne der anderen Seite, die (in der Schleife der Hirnschenkelhaube) gekreuzte Beziehung jedes Nervus acusticus zu dem Schläfenlappen (und zum Corpus geniculatum internum, sowie zum hinteren Vierhïgel) der anderen Seite, der Zusammenhang jeder Kleinhirnhemisphäre durch ihren Bindearm mit dem rothen Haubenkern und den Haubenganglien der anderen Seite, sowie durch ihren strickförmigen Körper und die Olive der anderen Seite mit dem Keilstrang der entgegengesetzten Rückenmarkshälfte. Physiologischer Dentung sind für jetzt Kreuzungen nur zugänglich, insofer'n sie partial sind, demu nur solche können ein wirksames Mittel für die functionellen Coordinationen beider Körperhälften und für die Verschmelzung des bilateral-symmetrischen Doppelwesens zu einem Individuum mit einheitlichem Selbstbewusstsein bieten. Bis jetzt hat sich auch gezeigt, dass, je genauer die einzelnen Kreuzungen erforscht worden sind, sie sich um so sicherer als partial (bei Menschen und den höheren Sïugethieren) erwiesen haben. 
As charakteristische Function des Hirnstammes ist die Coordination bezeichnet worden: offeubar sind die Grundzüge seines anatomischen Aufbaues beherrscht durch die Rücksicht auf Herstellung derjenigen Bewegungscoordinationen, welche der Erhaltung des Körpergleichgewichtes und der Locomotion dienen. Soll unter dem Wechsel der äusseren Bedingungen und bei der Ausfïhrung jedes beliebigen Willensimpulses das Gleichgewicht des Körpers erhalten bleiben, so ist dies nur möglich, wenn die Intensität der zur Verrückung des Schwerpunktes führenden (und der ihnen antagonistischen) Bewegungsimpulse dem EinHuss von centripetalen Erregungen unterworfen ist, welche der Orientirung im Raume dienen. Durch jede Aenderung der Lage oder der Haltung unseres Körpers wird eine Anzahl sinnlicher Eindrücke erzeugt, die, ohne dass sie zu bewussten Sinneswahrnehmungen zu führen brauchen, cinen Einfluss auf die Innervation der Körpermuskulatur ausüben; die peripherischen Sinnesflächen, welche hierbei in Betracht kommen, sind die Retina, die äussere Haut, die Nervenausbreitung in den Sehnen, Muskeln und Gelenken, sowie der Otolithen- und Bogengangsapparat des Ohrlabyrinthes; die adaequaten Reize beziehentlich: das Licht, der Druck, dem die Haut der unterstiitzten Körpertheile unterliegt, die Spaunung der Haut iiber den Gelenken, der Zug, der an den Muskelı durch ihre Antagonisten, an den Sehnen durch die eigenen und antagonistischen Muskeln ausgeïbt wird, der Druck der Gelenkflächen gegen einander und der Druck oder die Bewegung der Lymphe in dem Vorhofe und in den Ampullen des Ohres.

So lange der Körper vollkommen unterstiitzt ist, werden sich alle diese Erregungen das Gleichgewicht halten, sodass es durch dieselben entweder ïberhaupt zu keiner Innervation von Muskeln kommt, oder, wenn dies doch geschieht, zu je dem Bewegungsmoment ein antagonistisches von gleicher Intensität erzeugt wird. Jede Abweichung von der Vollkommenheit der Unterstiitzung, mag diese Abweichung durch innere oder äussere Ursachen hervorgerufen sein, wird zu einer Summe entsprechender sensibler Reizungen fiihren, deren unbewusst sich vollziehender Schlusseffekt eine Summe regulirender Muskelinnervationen ist. Apparate, welche die zu diesem Schlusseffekt führenden centralen Vorgänge vermitteln, haben wir Grund im Hirnstamm anzunehmen. Solche Apparate müssen ergiebige Bahnen jener sensiblen Erregungen in sich atufnehmen und zu den motorischen Endstationen des Rïckenmarkes in leitender Beziehung stehen. Ihre intracentralen Verknüpfungen zwischen den ein- und austretenden Bahnen werden sehr complicirter Natur sein und einen grossen Aufwand von Schaltstücken, der in starker EntwickeIung grauer Substan\% seinen Ausdruck findet, erfordern. Zwei anatomische Systeme des Hirnstammes scheinen nun allerdings mit Rüicksicht 
auf diese Anforderungen angelegt zu sein; das eine dieser Systeme ist das Kleinhirn mit seinen Schenkeln und nit der Briicke, das andere die Haube des Hirnschenkelfusses mit den Vier- und Sehhügeln.

Die physiologische Bedeutung des ersten dieser Systeme scheint ganz in der Coordination der die Erhaltung des Körpergleichgewichtes vermittelnden Muskelinnervationen aufzugehen und doch nicht die einzige Vorrichtung zu sein, durch welche diese Coordination erhalten werden kann. Letzteres geht daraus hervor, dass, wenn es gelingt, Hunde nach vollständiger Exstirpation des Kleinhirns läugere Zeit am Leben zu erhalten, diese die Beherrschung ihres Gleichgewichtes beim Stehen und Laufen einigermassen wiedererlangen, womit anch einige wenige pathologische Erfahrungen am Mensehen ïbereinstimmen.

Ob der Hirumantel oder ob die Haubenganglien hier vicariirend für das Kleinhirn eintreten, oder ob der Ausfall der Functionen des Kleinhirns darum einigermaassen ertragen werden kann, weil, wie behauptet worden ist, uur die Fixirung der Wirbelsäule, nicht die Coordination dor Extremitätenmuskulatur vom Kleinhirn abhängen soll, ist leider unbekannt. Dass Hunde, denen das Kleinhirn fehlt, schnell ermiiden, und dass sie beim Schwimmen einen viel geringeren Ausfall an Geschicklichkeit und Kraft zeigen, als bei den Bewegungen auf dem Lande, könnte man versucht sein in letzterem Sinne zu deuten, oder wenigstens diahin, dass das Kleinhirn, wenn es auch die Extremitätenmuskulatur coordinirt, dies nur thut, insofern letztere für die Erhaltung des Gleichgewichtes beim Stehen und Gehen und nicht insoforn sie fiir die Locomotionen selbst in Anspruch genommen wird.

Selır bezeichnend für die Art, in welcher das Kleinhirn coordinirend thätig ist, ist die Erfahrung, dass nicht der Umfang von Zerstörungen im Bereich seiner Hemisphären oder Sclienkel für die Grösse der zu beobachtenden Bewegungsstörungen maassgebend ist, sondern die Asymmetrie derselben. Es tritt dies besonders hervor und ist auch am besten verständlich bei Verletzungen im Bereich der sensibehn und motorischen Verbindungen der Kleinhirnhemisphären, mögen diese die Kleinlirnschenkel selbst oder deren cerebrale beziehentlich medullare Fortsetzungen treffen. Es muss offenbar weit störender sein, wemn eine der oben aufgeführten, der Orientirung im Raume dienenden sensiblen Bahnen nur einseitig zerstört ist, wo daun die auf der anderseitigen Balı bestïndig zugeleiteten Erregungen fortwirken, ohne von den bisher thätigen einen compensirenden Eintluss zu erfahren, als wem eine oder mehrere orientirende Sinnesgebiete für das Kleinhirn ganz ausgefallen sind. Unter diesem Gesichtspunkt sind die mannigfaltigen Zwangshaltungen und $Z$ wangslagen zu betrachten, welche bei Thieren nach einseitigen 
Zerstörungen in den angedeuteten Gebieten auftreten, und welche nach Anbringung der symmetrischen Verletzungen schwinden.

$\mathrm{Zu}$ wirklichen $\mathrm{Z}$ wangsbewegungen, das heisst zu solchen, bei denen nicht nur die Richtung und Form der Bewegung, sondern auch der Antrieb zu derselben unter Zwang steht, würde es in Folge Zerstörung sensibler Bahnen eines Coordinationsapparates kaum kommen können; eine wahre Zwangsbewegung wird aber durch einseitige Zerstörung im Bereich der motorischen Verbindungen des Kleinhirns, die in seinen mittleren Schenkeln enthalten sind, hervorgerufen. Dass bei einseitiger Zerstörung motorischer Orientirungsinnervationen eine Zwangshaltung resultiren muss, erscheint als selbstverständlich. Ist aber der centripetale und centrale Orientirungsapparat vollständig erhalten, so muss die Zwangshaltung zur Aussendung von Regulirungsinnervationen fïhren, die an sich ganz normal sind, die aber nun wegen der Mängel in der centrifugalen Leitung unsymmetrisch wirken, die Haltung oder Lage weiter verschlechtern können und so fort. In solchen Fällen werden also die zwangsmässigen Bewegungsimpulse von dem Coordinationsapparat selbst ansgehen. Die in ihrer Heftigkeit und Ausdauer an das Wunderbare grenzenden Rollbewegungen um die Längsaxe des Körpers, welche als Folge der Durchschneidung eines Kleinhirnschenkels zur Briicke eintreten, sind auf ähnliche Weise gedeutet worden. Auch diese Zwangsbewegungen hören auf, wenn der einseitigen Verletzung die symmetrische hinzngefügt worden ist.

Es ist schon darauf hingewiesen worden, wie unwahrscheinlich es ist, dass durch Pyramidenbahnen Willkürbewegungen vermittelt werden, ohne dass gleichzeitig ein die Erhaltung des Körpergleichgewichtes controlirender Apparat in die Thätigkeit mit hineingezogen würde. Diese Ansicht findet eine Stïtze in der Betrachtung der anatomischen Beziehung, in welche die Pyramidenfasern innerhalb der Brïcke zu deren Querfasern und zu den Brückenschenkeln des Kleinhirns treten.

Durch Selbstbeobachtung kann man sich davon ïberzeugen, dass die durch einmaligen Willensimpuls eingeleitete Locomotionsbewe$\mathrm{g} u \mathrm{ng}$ in regelmässiger Weise fortgesetzt, ja zweckmässig kleinen Aenderungen der äusseren Bedingungen angepasst wird, selbst wenn die Aufmerksamkeit vollkommen durch anderweitiges Bewusstseinsmaterial in Anspruch genommen ist. Diese Thatsache, sowie die experimentelle Erfahrung, dass Kaninchen nach Entfernung des Hirnmantels noch regelmässig hüpfen können, legt die Annahme nahe, dass im Hirnstamm ein Apparat vorhanden ist, der, einmal zur Thätigkeit angeregt, immer neue, dem zeitlichen und intensiven Verhältniss nach geregelte Impulse deu der Locomotion dienenden Muskeln zusendet, und dass die Regelung dieser Impulse dem Einflusse der centripetalen Orientirungserregungen 
zugänglich ist. Die Existenz eines solelıen Apparates vermuthen wir in dem Systeme der Haube des Hirnsclienkelfusses mit den Vierhïgeln und Sehhiigeln.

Diese Localisation des postulirten Apparates wird einigermaassen wahrscheinlich gemacht durch die schon angedentete Erfahrung, dass Kaninchen nach Entfernung des Grosshirus inchusive Streifenhïgel und Linsenkern noch regelmässig hïpfen können, und durch die fernere Erfallrung, diss Hunde, denen das Kileinhirn exstirpirt war, noch liefen. Zudem wissen wir sicher, dass die Coordination wenigstens eines Bewegungscomplexes, der zur Regulirung der Locomotions- und Equilibrirungsinnervationen in naher Beziehung steht, durch jenes System vermittelt wird; es ist dies die Coordination der Augenmuskelbewegungen, ohne welche die Gesichtseindriicke nicht Verwerthung zur Raumorientirung finden können.

Für eine Vorstellung davon, wie sich die einzelnen anatomisch unterscheidbaren Gebilde des Haubensystems an der Locomotions-Coordination betheiligen, haben wir katm einen Anhaltspunkt. Hervorzuheben ist in dieser Beziehung nur, dass Reizung des Sehh iigels keinen motorischen Erfolg hat, und dass weder partielle noch totale Zerstörung eines oder beider Sehhiigel auffallende Bewegungsstörungen hervorruft, dass jedoch ein Kaninchen, dem ein Sehhügel total zerstört ist, die anderseitigen Extremitäten, und ein solches, bei dem diese Verletzung doppelseitig erfolgte, alle Extremitäten in Stellungen bringen lässt, welche von dem Thier erst erheblich geändert werden mïssen, ehe es einen Sprung ausführen kann. Man kann also sagen, dass die Sehhügel des Kaninchens zur reflectorischen Erhaltung der Sprungbereitschaft während der Ruhe in naher Beziehung stehen.

Wo im Hirnstamm die Sprungbewegung selbst coordinirt, und wo in Folge der Sinneserregungen, die ein Sprung gesetzt hat, der Antrieb zu der coordinirten Reflexbewegung des nächsten Sprunges entsteht, wissen wir nicht. Dass aber ein Apparat, der dieses leistet, im Hirnstamm vorhanden ist, und dass das Corpus striatum zu diesem Apparat in auffallender Beziehung steht, geht daraus hervor, dass Kaninchen nach Verletzung eines der Streifenhïgel an eng umschriebener Stelle reflectorische Paroxysmen regelmässiger Sprungbewegungen zeigen, denen nur durch starke Widerstände, oder wenn diese fehlen, durch die E1mattung des Thieres eine Grenze gesetzt wird. Diese Stelle, welche man den Nodus cursorius genannt hat, liegt ganz nahe dem freien, dem Ventrikel zugekehrten Rande des Nucleus caudatus, etwa in der Nitte der Länge.

Wir wissen nicht, welche Bahnen den ersten Inpuls dem Bewegungsapparat im Hirustamm zufiihren, sobald die Willensintention sich auf 
die Locomotionsbewegung richtet. Wir wissen auch nicht, auf welchem Wege und durch welche Mittel die Aufmerksamkeit, wenn sie der Locomotionsbewegung zugewandt bleibt, vom Hirnmantel aus speciell regulirend in die maschinenmässige Thätigkeit jenes Apparates eingreift. So viel steht jedoch ziemlich fest, dass die Stabkranzfaserung des Sehhïgels hierfür nicht in Anspruch genommen werden darf. Diese scheint vielmelır Erregungen zum Hirnmantel hinzuleiten und man hat vermuthet, dass sie die Bahnen enthalte, auf welchen der Hirnrinde das Material zur Bildung der Bewegungsvorstellungen geliefert werde. Dies Material würde bestehen aus den Empfindungscomplexen der Raumorientirungssinne, mit denen sich zur Erzeugung von Bewegungsvorstellungen Innervationsgefühle zu combiniren hätten. Unter In nervationsgef ühl versteht man ein unmittelbares Bewusstsein von der Thatsache, dass und von der Stärke, in welcher bestimmte Muskelgruppen willkïrlich in Thätigkeit gesetzt werden. Die Möglichkeit, Innervationsgefuihle von einander zu unterscheiden und in richtiger Weise auf bestimmte Combinationen von Muskelerregungen zu beziehen, wird dadurch gegeben, dass jeder dieser Combinationen ein bestimmter Empfindungscomplex der Orientirungssinne entspricht und zwar derjenige, welcher durch die resultirende Körperbewegung erzeugt wird. Eine Bewegungsvorstellung besteht aus der Combination eines Innervationsgefühls mit dem entsprechenden Empfindungscomplex der Orientirungssinne; für die Zuleitung des letzteren wird die Stabkranzfaserung des Sehhügels in Anspruch genommen, das materielle Substrat des Innervationsgefühls kennen wir nicht.

Das System der Haube steht zu dem optischen Apparat in mehrfacher wichtiger Beziehung. Die schon erwähnte Coordination der Bewegungen der Augäpfel erfolgt durch Vermittelung der Tractus optici, der Vierhïgel und der Augenmuskelkerne. Diesem Coordinationsapparate werden regulirende Erregungen auch noch von anderen Orientirungssinnen als vom Auge zugefïhrt, namentlich vom Ohrlabyrinth, du'ch Vermittelung des Acusticus, des Kleinhirns und der Oliven. Nach Verletzungen in diesem Gebiet treten abnorme Augenbaltungen nnd eigenthïmliche ruckende Bewegungen der'selben auf, welche man Nystagmus uennt. Eine für unsere Vorstellungen von dem Coordinationsmechanismus besonder's wichtige Coordination zwischen dem Musculus rectus internus der einen und dem Musculus abducens der anderen Seite wird weiter unten in einem die Coordination behandelnden Abschnitt genauer besprochien werden.

Derselhe Apparat, welcher die Bewegungen der Augäpfel coordinirt, setzt auch mit diesen Bewegungen die Anpassung des dioptrischen Apparates des Auges für dạ Sehen in die Nähe und ị̣ dịe Ferne in Ein- 
klang. Von den Augenmuskelkernen ist hieran aber nur derjenige des Nervus oculomotorius betheiligt.

Die Anpassung der Pupillenweite an den Lichtreiz findet ebenfalls unter Vermittelung des Haubensystems statt; bei Vermehrung des Lichteinfalls in das Auge tritt reflectorisch Pupillenverengerung ein, und dieser Reflex kommt im Hirnstamm zu Stande. Fine Erweiterung der Pupille tritt nicht nur bei Abnahme der das Auge treffenden Lichtmenge ein, sondern auch in Folge anderweitiger Sinneseindrücke; zum Beispiel in Folge stark schmerzhafter Hautreize. Dem entsprechend giebt es nicht nur ein pupillenerweiterndes Centrum im Hirustamm, sondern auf dem Wege von hier durch das Riickenmark bis zu den Wurzeln des Halssympathicus liegen noch andere pupillenerweiternde Centralapparate eingeschaltet, von denen wir eines im unteren Halsmark als Centrum ciliospinale schion kennen gelernt haben.

Beim gesunden Menschen ist die Pupillenweite beiderseits stets gleich, auch wenn jedes Ange von einer verschieden grossen Lichtmenge getroffen wird. Die wechselseitige Ausgleichung der Pupillenweite beider Augen bei beiderseits verschieden starkem Lichteinfall geschieht wahrscheinlich durch Vermittelıng der Commissura posterior und des Ganglion Habenulae. Das Urbild aller Reflexe, an dem Descartes diesen Begriff entwickelt hat, der reflectorische Lidschlag beim Erblicken eines das Auge bedrohenden Fremdkörpers und bei Reizung der Cornea vollzieht sich ebenfalls (bis auf die Betheiligung des Nervus facialis) im Haubensystem.

Eine für die Physiologie des Gehirns sehr wichtige Frage, welche die Leistungen der Haube mit ihren Ganglien betrifft, ist die, ob letztere zur Vermittelung des Einflusses optischer Simneseindriicke auf die zweckmässige Regulirung der Locomotionsbewegungen ausreicht, oder ob bei den Säugethieren diese Vermittelung nur unter Betheiligung der Grosshirminde zu Stande kommt. Die Beantwortung dieser Frage hängt ron der scheinbar leicht, thatsächlich aber sehr schwer zu fällenden Entscheidung ab, ob Hunde und Kaninchen nach Entfernung des Hirnmantels stets sofort dauernd und total erblinden, oder ob sie nach diesem Eingriff sich noch insofern wie sehende Thicre verhalten, dass sie Hindernissen ausweichen, wenn ihnen nur optische Kunde von dem Vorhindensein derselben werden kann.

Von den dem Hirnmantel zunächst gelegenen Gebilden des Hirnstammes, dem Streifenhïgel mit geschwänztem Kern und Linsenkern und der inneren Kapsel ist die Bedeutung der letzteren am wenigsten in Dunkel gehïllt; sie enthält nur Leitungsbahnen und der physiologische Versuch an Hunden und Affen hat gelehrt, dass sie elektrisch reizbar ist und dass ungrenzte motorische Erfolge erzielt werden, wenn man 
umschriebene Punkte derselben localisirt reizt; die functionelle Systematisirung der weissen subcorticalen Bahnen scheint sich bis in die innere Kapsel fortzusetzen und im Allgemeinen der im motorischen Gebiet der Hirnrinde nachzuweisenden functionellen Gliederung zu entsprechen. Bemerkenswerth ist jedoch, dass die innere Kapsel noch reizbar bleiben soll, wenn uach Abtrennung der motorischen Rindenregion die entsprechenden Züge des Centrum semiovale durch absteigende Degeneration unerregbar geworden sind; es würde dies, wenn es sich bestätigte, darauf hinweisen, dass noch von anderen Punkten der Hirnrinde aus motorische Impulse durch die Bahnen der inneren Kapsel nach abwärts gesandt würden.

Umgekehrt scheint die innere Kapsel auch nicht alle Stabkranzfasern aus der motorischen Rindenregion aufzunehmen, denn nur nach Zerstörung von innerer Kapsel und Linsenkern tritt vollkommener Ausfall der Willkürbewegungen ein. Ueber die wahre physiologische Bedeutung, welche der Unterbrechung eines grossen Theiles der cortico-motorischen Leitungen durch Ganglien des Linsenkernes zukommt, sind zur Zeit kaum Vermuthungen zu ersinnen.

Eine bisher noch ziemlich unvermittelt dastehende Thatsache von grosser Tragweite, welche die Physiologie des Streifenh ïgels zu betreffen scheint, ist in neuerer Zeit entdeckt worden. Bei Kaninchen, Meerschweinchen und Hunden ruft ein von der Oberfläche des Vorderhirns geführter Stich, wenn er das Hirn bis zur Basis so durchdringt, dass er die mediale Seite des Caput corporis striati (vor dem Nodus cursorius) trifft, Steigerung der Temperatur bis zu der des Fiebers hervor; Rinde und weisse Substanz des Vorderhirns sind an dem Erfolg unbetheiligt. Vieles spricht dafür, dass es sich um eine Reizerscheinung handelt und dass vermehrte Wärmeproduktion den hervorragenden Antheil an der beobachteten Wärmesteigerung besitzt, ohne dass jedoch die Mitbetheiligung der die Wärmeabgabe regulirenden Apparate mit Sicherheit auszuschliessen wäre. Auch Durchschneidung des Hirnstammes an der unteren Grenze der Brücke soll beträchtliche Temperatursteigerung zur sicheren Folge haben. Diese ebenfalls auf vermehrte Wärmeproduktion zurückgeführte Temperatursteigerung wird nicht als Reizerscheinung betrachtet, sondern als Folge des Ausfalls moderirender Centren, ïber deren Lage nichts Näheres bekannt ist.

Von den anatomisch unterscheidbaren Gebilden des Hirnstammes haben wir Eines bisher ganz unberührt gelassen, es ist dies das als Höhlengrau des vierten Ventrikels von älteren Anatomen abgegrenzte Gebiet, umfassend die Kerne des Vagus, Glossopharyngeus, Trigeminus, Hypoglossus und Facialis, sowie die Formatio reticularis. Dieses Gebiet scheint sehr reich an coordinatorischen Einrichtungen zu sein, 
deren für das Leben wichtigste im Dienste der Anpassung ron Athmung und Krreislanf an die jeweiligen Bedürfnisse und Zustände des Organismus stehen: das hierïber Bekannte wird bei der Lehre des Kreislaufs und der Athmung abzuhandeln sein. Ausserdem vollzieht sich die Coordination der Articulationsbewegungen für Stimme und Sprache wesentlich in diesem Gebiete.

Eine die Function der Medulla oblongata betreffende Thatsache, deren causale Beziehungen aber noch sehr wenig durchschaut sind; ist die, dass nach Einstich in eine ziemlich eng begrenzte Stelle am Boden des vierten Ventrikels (Mittellinie, hintere Partie der vorderen Hälfte) vorïbergehend Zucker im Harn auftritt. Der Erfolg tritt in voller Stärke ein und die Thiere überstehen die Operation besser, wenn der Stich die Brïcke unverletzt lässt. Auch durch protrahirte centripetale Vagusreizung soll das Auftreten von Zucker im Harn hervorgerufen werden können.

\section{Coordination, Reflex und Willkiur.}

In dem Vorstehenden haben wir so oft die Ausdrücke Coordination, Reflex, coordinirter Reflex und anch Willkür gebrauchen müssen, dass es wïnschenswerth erscheinen muss, eine genauere Begründung dieser Begriffe auf dem Boden des thatsächlich Bekannten und eine Abgrenzung derselben gegen einander zu versuchen.

Coordination nent man die functionelle Zusammenordnung verschiedener Muskeln in Dienste einheitlicher Zweckerfüllung. Als einheitlichen Zweck für die Thätigkeit des Bewegungsapparates können wir zum Beispiel die Fortbewegung des Organismus in einer gewissen Richtung mit einer gewissen Geschwindigkeit auffassen. Damit dieser Zweck auf die einfachste Weise und mit dem geringsten Kraftaufwand erreicht werde, ist erforderlich, dass eine Anzahl anatomisch einheitlicher Muskeln (anatomische Muskelindividuen, wie der Musculus gastrocnemius, Musculus tibialis anticus u. s. w.) theils gleichzeitig, theils in regelmässiger zeitlicher Aufeinanderfolge und in bestimmten Intensitätsverhältnissen zur Thätigkeit angeregt werden. Die Anregung zur Thätigkeit empfangen die Muskeln im Laufe des normalen Geschehens ausnahmslos vom Centralnervensysten, deshalb haben wir auch die Einrichtungen, durch welche die zu coordinirter Muskelthätigkeit erforderliche zweckmässige Zusammenordnung der Erregungen gesichert ist, im Centralnervensystem zu suchen. Um die Frage nach der Natur dieser coordinirenden Einrichtungen zu beantworten, miissen wir etwas weiter ausholen.

Jedes einzelne der Elemente, aus denen sich der motorische Apparat aufbaut, besteht aus einer motorischen Nervenfaser mit peripherischem 
und centralem Endapparat. Der centrale Endapparat ist diejenige grosse Ganglienzelle einer Vordersäule des Rückenmarkes, respective eines Nerrenkernes des verlängerten Markes, aus dessen Axencylinderfortsatz der Axencylinder der motorischen Nervenfaser entsteht; der peripherische Endapparat ist die Summe derjenigen Primitivmuskelfasern, mit denen die Terminalverzweigungen der motorischen Nervenfaser in erregungsleitender Verbindung stehen. Peripherische Endapparate gerathen in Erregung, das heisst es entsteht Bewegung, oder, wenn antagonistische Elemente gleichzeitig in Erregung gerathen, vermehrte Spannung, nachdem vorher die centralen Endapparate, das sind motorische Ganglienzellen, in Erregung gerathen waren.

Erregung, das heisst Anregung zu der functionellen Thätigkeit, welche sich in Aussendung von Erregungswellen nach der Peripherie äussert, können Ganglienzellen des Centralnervensystems erhalten, entweder dadurch, dass sie ihnen auf nervöser Leitungsbahn anderswoher übermittelt wird, oder dadurch, dass Aenderungen im physikalischen oder chemischen Zustande ihrer unmittelbaren, nicht nervösen Umgebung als Reiz auf dieselben wirkt. In dem letzteren Falle der autochthonen Entstehung der Erregung spricht man von automatischer, in dem ersteren entweder von reflectorischer oder von willkürlicher Erregung. Den Unterschied zwischen Reflex und Willkür werden wir später genauer zu formuliren haben.

Damit eine geordnete, das heisst eine einem einheitlichen 7 weck dienende Bewegung, sei es eine automatische, reflectorische oder willkürliche, zu Stande komme, ist erforderlich, dass eine gewisse Summe ron Muskelfasern, die im Allgemeinen sehr verschiedenen anatomisch einheitlichen Muskeln angehören werden, gleichzeitig in Erregung gerathen. Jede Construction a priori, welche sich rom Zweckmässigkeitsgedanken leiten lässt, wird die Annahme machen müssen, dass den in der Peripherie räumlich getrennten Muskelelementen, welche im Dienste einer einheitlichen Zweckerfüllung zusammen zu wirken hahen, je ein Complex räumlich zusammengeordneter gangliöser Elemente in Centralnerrensystem entspreche. Demjenigen, der diese Annahme gemacht hat, rrängt sich in logischer Consequenz die Frage auf, ob er sich nicht als diejenigen gangliösen Elemente, durch deren räumliche Zusammenordnung in C'entralnervensystem die Coordination rer Bewegung gesichert ist, die motorischen Ganglienzellen rler Vordersüulen oder Nervenkerne vorstellen soll.

Der Grad der Berechtigung zu dieser Vorstellung hängt davon ab, wie die Frage nach der Einheitlichkeit oder Mehrspältigkeit der ersten centralen Projectionen anatomisch einheitlicher Muskeln $z u$ beantworten ist. Diese Frage ist folgendermatassen zu formuliren: entspricht jedem 
anatomisch einheitliehen Muskel eine einheitliche erste Projection im Centralnervensystem, das heisst nehmen die Ganglienzellen, welche dic centralen Endigungen der Nerrenfasern eines solchen Muskels darstellen, einen zusammenhängenden Raum ein, etwa in Gestalt von Kernen und Sïulen, oder findet die erste Projektion der Muskeln im Centralnervensystem derart statt, dass die jeden Muskel im Centrahervensystem rertretenden motorisehen Ganglienzellen in so viele Gruppen gespalten sind, als rerschiedene Combinationen existiren, in denen der Muskel ini Interesse rerschiedener Zweckerfiillungen mit anderen Muskeln gemeinschaftlich $\mathrm{zm}$ wirken berufen ist? Hieran schliesst sich die Frage an, ob die den Muskeln dieser einzelnen functionellen Combinationen zugehörigen Ganglienzellengruppen etwa ihrerseits räumlich zusammengeordnet liegen.

Was die Beantwortung der Frage nach der Einheitlichkeit oder Mehrspältigkeit der ersten centralen Projection des Muskels anbelangt, so ist zunächst herrorzuheben, dass sie rersehieden ausfallen wird, je nachdem es sich um höher oder tiefer stehende Repräsentanten der Wirbelthierreilıe handelt. Bei den niederen Wirbelthieren, bei denen am Rïickenmark entweder schon äusserlich oder auf Querschnittserien durch wechselnde Häufigkeit der Ganglienzellen eine den Körpermetameren entsprechende Segmentirung deutlich zu erkennen ist, werden die Muskeln jedes Körpersegmentes in dem entsprechenden Rïckenmarkssegment ihre räumlich geschlossene Projection finden; wo aber mit dem Vorschreiten der anatomischen Individualisirung von Extremitätenmuskulatur das Verwischen der Segmentirung des Riickenmarkes Hand in Hand zunimmt, mehren sich die Anzeichen, welche gegen die Einheitlichkeit der Projection anatomisch einheitlicher Muskeln sprechen.

Vom Frosche aufwärts gilt als allgemeine Regel, dass jeder Extremitätenmuskel ans mehreren auf einander folgenden rorderen Rïickenmarkswurzeln motorische Nervenfasern erhält. Hierzu kommt die nicht nur bei niederen Säugethieren, sondern auch am Affen constatirte Thatsache, dass die elelitrisehe Reizung einzelner vorderer Wurzeln des Cervical- oder Lumbalplexus coordinirte Bewegungen auslöst, welche in hohem Grade solchen Bewregungen ähnlich sehen, die von der betreffenden Thierspecies hïufig und zur Erreichung hestimmter Zwecke ausgeführt werden.

Man muss hieraus schliessen, dass in den motorischen Wurzeln wesentlich functionell zusammengehörige Muskeh rertreten sind, und zwar jeder mit einem Theil der ihn rersorgenden Nervenfasern. Die Zusammenfassung functionell zusammengehöriger Nervenfaseru braucht nicht im Riickenmark zu erfolgen, da die Plexusbildungen der Nerrenstämme lierfiir reichlich Gelegenheit bieten. Da der Austritt aus dem 
Rückemmark aber dennoch schon in functionell geordneter Weise geschieht, so ist anzunehmen, dass ein Grund für die Zusammenordnung schon im Rückenmarke besteht; ein solcher Grund kann in der Zweckmässigkeit räumlicher Zusammenordnung ganglionärer Vertreter der functionell zusammengehörigen Muskeln liegen. Die Zweckmässigkeit einer solchen Anordnung beruht darauf, dass die Erregungen, welche von höher gelegenen Centren nach unten ausstrahlen, sich von Anfang an nicht auf eben so vielen getrennten Bahnen zu bewegen brauchen, als schliesslich Primitivnervenfasern in Erregung gerathen, sondern dass durch Vermittelung weniger Bahnen ganze Territorien grauer Rückenmarksubstanz mit ihren motorischen Ganglienzellen in Action versetzt werden.

Wenn es functionelle Territorien im Centralnervensystem giebt, wo die, bestimmten einfachen Zwecken gemeinschaftlich dienenden Muskeln ihre räumlich zusammengehörige ganglionäre Vertretung finden, so ist zu erwarten, dass jeder dieser Muskelu im Allgemeinen in einem bestimmten derartigen Territorium nur mit einem Theile seiner Nervenfasern vertreten sein wird. Die centrale Projection jedes Muskels nüsste auf so viele Territorien vertheilt gedacht werden, als es Combinationen von Muskeln giebt, zu denen er unter dem Gesichtspunkt einheitlicher Zweckerfüllung gehört. Es ist dann ferner zu erwarten, dass die pathologische Erfahrung Fälle aufweise, in denen bei centraler Erkrankung ein bestimmter Muskel nur insofern gelähmt erscheint, als er einer bestimmten Muskelcontraction angehört, während er im Zusammenspiel mit anderen Muskeln normales Verhalten zeigt. Diese Consequenz aus der Annahme einer Mehrspältigkeit der ersten centralen Muskelprojektion ist nicht durch Beobachtungen über centrale Lähmungen von Extremitätemmuskeln, wohl aber durch Erfahrungen bewahrheitet worden, welche centrale Augenmuskellähmungen betreffen.

Es giebt Fälle von Augenmuskellähmungen, bei denen der Abducens der einen, etwa der rechten Seite zugleich mit dem Rectus internus der anderen Seite an Kraft eingebüsst hat. Ein mit solcher Lähmung behafteter Patient kann den Blick nicht nach einem rechts von ihm befindlichen Gegenstand wenden. Wird der Gegenstand, etwa ein Licht, nach rechts bewegt, so entschwindet er aus dem Gesichtsfeld des Patienten, wenn dieser verhindert ist, den Kopf zu drehen. Um dem Lichte mit dem Auge zu folgen, miissten der rechte $\Lambda$ bolucens und der linke Rectus internus gleichzeitig in Thätigkeit versetzt werden. Den Rectus internus kann man aber noch auf andere Weise bezüglich seiner Leistungsfähigkeit prüfen. Man kaun den Patienten veranlassen, den Blick an einem Gegenstand festzuhalten, welcher in der Mediallinie angenähert wird: zur Frreichung dieses Zweckes müssen beide Recti interni in Wirksamkeit treten und es kommt vor, dass derselbe Rectus 
internus, welcher den Dienst versagt, wenn man ihm eine durch Synergie mit dem anderseitigen Abducens zu lösende $\Lambda$ ufgabe stellt, sich in der Synergie mit dem anderseitigen Rectus internus als vollkommen leistungsfähig erweist.

Da es sich in derartigen Erkrankungsfällen erwiesenermaassen um centrale Läsionen handelt, so erscheint Nichts berechtigter, als die Annahme, dass jeder innere grade Angenmuskel mindestens in zwei centralen T'erritorien ganglionär vertreten ist, und zwar in dem einen zusammen mit dem Abducens, in dem anderen mit dem Rectus internus der gegenüber liegenden Seite. In der That sind bei der Katze Nervenfaserziige gefunden worden, die, rom Abducenskern ausgehend, bei dem Oculomotoriuskern der anderen Seite rorbei in den Oculomotoriusstamm sich begeben.

Mit einem hohen Grade von Wahrscheinlichkeit ist also die oben formulirte Frage dahin zu beantworten: als allgemeine Regel kann es nicht gelten, dass jedem anatomisch einheitlichen Muskel eine einheitliche Projection im Centralnervensystem entspricht, vielmehr spielt in dem Gesetz der räumlichen Vertheilung dieser Projektion die Rücksicht auf Combination des functionell Zusammengehörigen eine wesentliche Rolle. Für den Fall der coordinirten Augenbewegung, welcher allerdings der denkbar einfachste ist, scheint es sogar ziemlich sicher erwiesen zu sein, dass die Bewegungscoordination wesentlich auf der räumlichen Zusammenordnung von motorischen Ganglienzellengruppen functionell zusammengehöriger Muskeln beruhe. Die oben a priori entwickelte Vorstellung muss also als berechtigt iiberhaupt anerkannt werden, es fragt sich aber noch, welcher Umfang dem Geltungsbereich derselhen zukomme.

Was in dieser Richtung zu erwarten ist, wird namentlich von der Beantwortung der auch sonst fiir die Lehre von der Coordination fundamentalen Frage abhängen, ,reagirt ein anatomisch einheitlicher Muskel auf die gruppenweise central gesonderte Erregung mit gleichfalls partieller oder ein für allemal mit totaler Erregung?" Beantwortet sich die Frage dahin, dass wir, $u m$ bei dem erörterten Beispiel der Augenmuskeln zu bleiben, ammehmen muissen, dass von einem Musculus rectus internus, wenn er mit dem Abducens der anderen Seite synergisch ist, nur der eine Theil, wenn er mit dem anderen Musculus internus zusammenwirkt, nur der andere Theil seiner Muskelfasern in Thätigkeit trete, so werden wir kaum erwarten dürfen, dass die einfache Coordinationseinrichtung, wie wir sie bei den Augenmuskeln kennen gelernt haben, auch für die Bewegungsordnung anderer Muskeln ausreichen werden, die wie die Extremitätemmuskeln je in einer grossen Zahl verschiedener Combinationen zu verschiedenen einfachen Zweckerfüllungen 
in Thätigkeit zu treten haben. Die Gliederung jedes einzelnen dieser Muskeln in eine grössere Zahl functionell verschiedenwerthiger Fasergruppen würde seine Leistungsfähigkeit im Dienste jeder einzelnen Combination zu sehr schwächen. Mit anderen Erwartungen hätten wir an die Untersuchung der Coordinationseinrichtungen heranzutreten, wenn sich ergeben sollte, dass eine central partielle Erregung stets zur totalen Muskelerregung führe.

Dass innerhalb der Muskeln Einrichtungen beständen, durch welche jede central partielle Erregung zu einer peripherisch totalen würde, liesse sich sehr wohl vorstellen. Setzen wir den Fall, es handele sich um einen Muskel, dessen Nerv in zwei Gruppen seiner Fasern partiell rom Centrum aus erregt werden kann, so ist es denkbar, dass jede Muskelfaser zwei Nervenendigungen erhält, deren eine der Nervengruppe a, deren andere der Gruppe $\mathrm{b}$ angehört. Es scheint dies jedoch nicht der Fall zu sein, denn, wie wir schon in einem früheren Abschnitt erörtert haben, ist durch das Experiment festgestellt, dass der Froschmuskel bei Reizung jeder einzelnen an seiner Innervation betheiligten Wurzel nur mit einem Theile seiner Muskelfasern in Erregung geräth. Wir werden also zu erwarten haben, dass die einfachste Art der Coordinationseinrichtung (nach dem Typus der Augenmuskelcoordination) nur in einer beschränkten Zahl von Fällen den Bedürfnissen des Organismus genügt.

Wir haben ebenfalls in einem früheren Abschnitt darauf hingewiesen, dass in dem proximalen Theile des Froschrückenmarkes eine Anordnung vorhanden sein muss, durch welche die Coordination der Beugemuskeln behufs Einnahme der sprungbereiten Haltung gesichert ist. Aus der Steigerung des Beugereflexes bei localisirter Strychnineinwirkung schlossen wir, dass Zellen einen wesentlichen Theil dieser Anordnung bilden. Da es sich ferner wahrscheinlich machen liess, dass die Muskeln der hinteren Extremität an dieser Stelle durch motorische Ganglienzellen nicht vertreten sind, so nahmen wir an, dass kleinen Ganglienzellen der Hintersäulen die Vermittelıng der Coordination übertragen sei. Durch die räumliche Zusammenordnung dieser Zellen kann man sich die coordinirte Thätigkeit der von ihnen direct abhängigen und unter einander nicht rüumlich zusammengeordneten motorischen Ganglienzellen der Beuger im Dienste der Einnahme der sprungbereiten Haltung gesichert denken.

Es ist klar, dass Coordinationseinrichtungen nach letzterem Schema gewisse Vorzüge vor den einfacheren, wie wir sie für die Augenmuskeln kennen gelernt haben, voraus haben werden: der wesentliche Vorzug besteht darin, dass bei ersteren jede Muskelfaser im Dienste der verschiedensten '/weckerfiillung, das heisst in den mannigfaltigsten Combinationen mit anderen Muskelfasern in Thätigkeit gesetrt werden kann. 
Je zahlreicher die Combinationen sind, in denen ein Muskel mitzuwirken bestimmt ist, um so wahrscheinlicher ist es, dass seine Muskelfasern und seine motorischen Ganglienzellen in Coordinationsapparaten höherer Ordnung vertreten sind. Eine gruppenweise räumliche Zasammenordnung motorischer Ganglienzellen selbst, die zu diesen Muskeln gehöreu, mit Gruppen solcher, welche zu anderen gehören, im Dienste der einfacheren Bewegungscombinationen ist dadurch nicht ausgeschlossen. Für die Existenz solcher einfachen Coordinationseinrichtungen im Rückenmark des Menschen, Muskeln betreffend, die ausserden auch in Coordinationseinrichtungen höherer Ordnung vertreten sein müssen, lassen sich pathologische Erfahrungen geltend machen.

Des Weiteren müssen wir sagen, dass je grösser die Zahl ron Muskeln ist, die zur Erfüllung eines bestimmten Zweckes in geordneter Weise thätig sein müssen, um so wahrscheinlicher es ist, dass für diese Zusammenordnung Coordinationseinrichtungen höherer Ordnung bestehen, deren Ort dann auch höher im Centralnervensystem, das heisst oberhalb des Rückenmarkes zu vermuthen ist; es wird dies um so mehr gelten, je mehr die Muskelthätigkeit, um geordnet zu bleiben und den Zweck zu erfüllen, sich wechselnden äusseren Umständen anpassen muss, je mehr also centripetale, auf den verschiedensten sensiblen und sensoriellen Bahnen zugeleitete Erregungen auf die Regulirung der centrifugalen Erregung Einfluss zu üben haben. In ausgiebigster Weise findet dies statt bei Zusammenordnung derjenigen Muskelerregungen, welche vorhanden sein müssen, damit den jeweiligen Umständen entsprechend das Körpergleichgewicht erhalten bleibe. Im Interesse der Erhaltung des Körpergleichgewichtes sind die meisten Körpermuskeln beständig in Erregung in einem Intensitätsverhältniss, welches den jeweiligen Umständen angepasst sein muss. Bei plötzlichen Aenderungen dieser Unstände müssen die gerade lestehenden Erregungen ganzer Muskelgruppen auch ebenso plötzlich gehemmt werden können.

Bedenken wir dies Alles, so müssen wir erwarten, dass der die Erhaltung des Körpergleichgewichtes sichernde Coordinationsapparat im Centralnervensystem ein sehr complicirter sei und dass die Schaltstücke, welche alle concurrirenden centripetalen Erregungen auf die in Mitleidenschaft zu ziehenden motorischen Elemente überleiten, nicht an einer eng umschriebenen Stelle des Centralnervensystems zusammengeordnet liegen, dass es mit anderen Worten kein eng umschriebenes Coordinationscentrum für Erhaltung des Körpergleichgewichtes gebe.

Der Begriff des Reflexes ist ron Descartes aus der Erfahrung abgeleitet worden, dass bei Annäherung eines das Auge bedrohenden Gegenstandes Lidschluss eintritt und zwar mit einem unserem Willen überlegenen 7wange. In Folge des optischen Eindruckes läuft eine Er- 
regungswelle durch den Sehnerv in das Centralnervensystem, wird hier aus der centripetalen in die centrifugale Richtung zurückgebeugt, reflektirt, und gelangt so zu denjenigen Muskelfasern, welche das Lid schliessen; damit ein Reflex zu Stande komme, sind also erforderlich: ein reizaufnehmender Apparat mit seinen centripetal erregungsleitenden Nervenbahnen und ein reflektirender Apparat, durch welchen die Ueberleitung der auf den centripetalen Bahnen anlangenden Erregungswellen in die bestimmten centrifugalen Bahnen vermittelt wird.

Dass man die Summe der zur Entstehung eines Reflexes erforderlichen Einrichtungen einen Reflexbogen nennt, welche Elemente im Rückenmark an der Zusammensetzung von Reflexbögen betheiligt sind, und was man unter kurzen und langen Reflexbögen zu verstehen habe, ist früher besprochen worden.

Es ist wahrscheinlich, dass die durch die kurzen Reflexbögen vermittelten Bewegungen in einfacher Beziehung zu den vom Reiz getroffenen Hautstellen stehen und zwar derart, dass die Bewegung je nach Ort und Art des Reizes entweder zur Entfernung der Hautstelle vom Reizobjekt führt oder zur Umklammerung des Reizobjektes. Kurze Reflexbögen, welche letzteren Akt vermitteln, kommen innerhalb des Rückenmarkes des männlichen Frosches, und zwar im proximalsten Theile desselben vor; sie nehmen zur Begattungszeit einen höheren Grad von Erregbarkeit an und sichern die feste Umklammerung des Weibchens während des tagelang andauernden Begattungsaktes.

Entfernen der Reizstelle vom Reizobjekte und Umklammern des Reizobjektes sind die einfachsten denkbaren Bewegungen, welche dem Organismus nützlich sein können. Für verwickeite zweckmässig geordnete Bewegungen können kurze Reflexbögen begreiflicherweise nicht ausreichen, da bei solchen Bewegungen Muskelgruppen in Synergie treten müssen, welche aus verschiedenen, vielleicht weit von einander entfernten Rückenmarksegmenten ihre Innervation erhalten. Ob innerhalb des Rückenmarkes lange Reflexbögen zum Schluss kommen, ist gleichbedeutend mit der Frage, ob im Rückenmark Einrichtungen für zweckmässige Bewegungscoordinationen bestehen. Im Rückenmark der Säugethiere scheint dies nur in sehr beschränktem Maasse der Fall zu sein. Bei Menschen sind die nach traumatischen Rückenmarksdurchtrennungen zur Beobachtung kommenden reflectorischen Körperbewegungen unterhalb der Durchtrennungsstelle stets sehr einfacher Natur und bei Kaninchen kommt Ausbreitung reflectorischer Bewegungen auf nicht vom Reiz getroffene Extremitäten nur zu Stande, so lange die Medulla oblongata noch in Verbindung mit dem Rückenmark ist. Beim Säugethier scheinen also die im Rückenmark gewiss sehr reichlich vorhandenen auf- 
steigenden und absteigenden Theile langer Reflexbögen hauptsächliclı oberhalb des Rïckenmarkes zum Schluss zu kommen.

Anders ist dies beim Frosch, der nach der Decapitation ohne äusseren Reiz zwar bewegungslos ist, dessen von der Medulla oblongata abgetrenntes Rïckenmark reflectorisch aber noch so hoch coordinirte Bewegungen vermittelt, wie Einnahme der sprungbereiten Stellung, Sprung und zweckmässige, bei Modification der Bedingungen sogar zweckmässig modificirte, Wischbewegungen. Diese Wischbewegungen haben zur Co11ception der später zu besprechenden Vorstellung von einer Rückemnarksseele Veranlassung gegeben.

Eine zweckmässige Reaction des Frosches auf unerwartete Berülrung ist der Sprung, und da der Sprung nur aus sprungbereiter Stellung möglich ist, so erscheint es ganz natürlich, dass die am Reflexpräparate des Frosches auf Reize mässiger Intensität eintretenden Bewegungen meistens solche sind, welche zur Einnahme der sprungbereiten Stellung gehören. Es sind dies wesentlich Beugebewegungen, welche, wenn der Rieiz schwach ist, nur einzelne Gelenke der vom Reiz getroffenen Extremität betreffen und schnell vorübergehen, welche aber, wenn der Reiz verstärkt wird, sich ränmlich auf mehr Gelenke derselben und der entgegengesetzten Extremität ausbreiten, sowie der Intensität und zeitlichen Dauer nach zunehmen, dann zur Einnahme der sprungbereiten Stellung und weiterhin zum Sprunge führen. An die Stelle des Sprunges, welcher in einfacher und gleichzeitiger Streckung aller Gelenke besteht, treten bei zeitlicher, räumlicher oder intensiver Ausdehnung des Reizes und bei Verhinderung des Sprunges verwickelte Abwehr- oder Wischbewegungen.

Dass im proximalen Theile des Froschrïckenmarkes Reflexcentren für Beugebewegungen liegen, ist schon angeführt worden. Distal vom vierten Wirbel liegen die Streckcentren. Mit der Wichtigkeit, welche die Einnahme der sprungbereiten Haltung im Leben des Frosches hat, scheint es zusammenzuhängen, dass bei ihm Reflexe durch die schwächsten Reize nur dann ausgelöst werden können, so lange der proximale Theil des Rückenmarkes erhalten ist, und dass die hierbei entstehenden Bewegungen Beugungen sind. Die proximal gelegenen Beugecentren scheinen leichter erregbar zu sein, als die distal gelegenen Streckcentren, sodass die langen Reflexbögen im Rïckenmark des Frosches leichter ansprechen als die kurzen. Wenn eine, alle vorhandenen Bahnen verfolgende Erregungswelle vom Hirn aus das Rückenmark durchläuft, so muss es beim Frosch ohne Weiteres zuerst zur Einnahme der sprungbereiten Haltung, dann zum Sprunge kommen.

Für die Ausbreitung der Reflexe bei Verstärkung der Reize gelten folgende aus Versuchen am decapitirten Frosche (Reflexpräparat) abstrahirte Regeln (Pflüger): 
1. Wenn einem Hautreize eine einseitige Bewegung am Körper folgt, so liegt diese stets auf der gereizten Seite.

2. Fügen sich den Bewegungen auf der gereizten Seite solche der anderen hinzu, so treten diese in den Muskeln auf, welche auf der primär erregten Seite getroffen waren. Es werden mithin doppelsinnige Reize durch das Rückenmark nie in gekreuzter Richtung vermittelt. So kann man zum Beispiel durch Erregung der sensiblen Nerven einer Hinterextremität nie diese nebst der vorderen der entgegengesetzten Seite allein erregen. Erst dann gelingt letzteres, wenn am Reflexpräparat sich noch ein Stück der Medulla oblongata vorfindet.

3. Wenn der auf einer Seite angebrachte Reiz auf beiden Seiten Reflexe derart auslöst, dass sie auf. einer Seite heftiger als auf der anderen sind, so finden die stärkeren Bewegungen auf der gereizten Seite statt.

4. Wenn in Folge der Reizung eines Empfindungsnerven primär ein motorischer Nerv angeregt worden ist und nun die Erregung auf andere entferntere motorische Bezirke ïbergeht, so geschieht dieses Fortschreiten im Gehirn nach unten und im Rückenmark nach oben, also in beiden Fällen in der Richtung nach dem verlängerten Marke zu.

Schon bei dem einfachen Nervmuskelpräparat haben wir gesehen, dass es sogenannte „unterminimale" Reize giebt, das heisst solche, deren jeder Einzelne auf das Präparat angewendet, dieses nicht zu einer merklichen Reaction veranlasst, welche aber, wenn sie sich in kurzem zeitlichem Intervall folgen, durch "Summation“ der Erregungen den Muskel zur Contraction bringen. Bei dem Nervmuskelpräparat ist der Einfluss dieser Summation nur schwach angedeutet, bei dem Reflexpräparat dagegen tritt er so stark hervor, dass er das ganze Erscheinungsbild beherrscht. Die stärksten Reize ron momentaner Dauer, zum Beispiel sehr intensive Inductionsschläge, können hier wirkungslos bleiben, während sehr schwache Reize heftige Bewegungen auslösen, wenn sie nur in passendem zeitlichen Intervalle sich folgen.

Um beim Reflexpräparat noch Wirkungen zu erzielen, dürfen die summirten einzelnen Reize namentlich dann sehr schwach sein, wenn sie. auf die sensible Hautfläche applicirt werden, deun während das Nervmuskelpräparat auf Reize, welche den motorischen Nervenstamm treffen, selır leicht reagirt, ist das Reflexpräparat gegen Reizungen des sensiblen Nervenstammes relativ wenig empfindlich. Die Ueberlegenheit der Enıpfindlichkeit des Reflexpräparates bei Reizung der sensiblen Fläche iiber diejenige bei Reizung des sensiblen Nervenstammes, kann daran liegen, dass die Energie der von dem sensiblen peripherischen Endapparate ausgehenden Erregungswellen in Summa grösser ist, als die Energie des denselben treffenden reizenden Agens, dass die Energie also 
durch chemische in diescm Apparate sich abspielende Processe einen Zuwachs erhält, oder daran, dass diese Endıpparate die centripetalen Erregungswellen unabhängig vom Rhythmus der Reizeinwirkungen in einer solchen zeitlichen Folge dem reflectirenden Apparat zusenden, welehe für letzteren besonders adäquat ist. Es ist wahrscheinlich, dass letzterer Factor überwiegt, denn wir haben schon gesehen, dass die zeitliche Folge der Reize auf dem Gebiet der Reflexe von grösserem Belang ist, als die Intensität der einzelnen Reize. Wir haben uns anch schon frïher veranlasst gesehen, den Unterschied im Verhalten des Reflexprïparates und des Nervmuskelpräparates gegen dieselben Einwirkungen (concentrirtes Kochsalz einerseits, Temperatur von $40^{\circ}$ andererseits) auf einen Unterschied im Rhythmus der Reizentstehung zuriickzufiihren.

Wit der Grösse des Einflusses, welchen der Rhythmus der dem reflectirenden Apparate zuströmenden Erregungswelle darauf ausübt, ob Reaction erfolgt oder nicht, diirfte es in nahom Zusammenhange stehen, lass der Rhythmus der von diesen Apparaten centrifugal ausgesandten Erregungswellen nur innerhalb sehr enger Grenzen variirt, ja beinahe als constant betrachtet werden kann. Während der Muskel auf Reizung seines motorischen Nerven durch successive elektrische Reizstösse mit einem Zustandswechsel antwortet, dessen Frequenz in gleicher Weise variirt wie die Reizfrequenz, folgen sich die Zustandsänderungen de’s Muskels am Reflexpräparat bei jeder beliebigen Art der Reflexauslösung stets in annähernd constantem Intervall von circa 1/s Secunde.

Wegen der Ueberlegenheit, welche die Reactionsfähigkeit des Reflexpräparates bei Reizung sensibler Hautflïchen zeigt gegenüber denjenigen bei Reizung sensibler Nerrenstämme, giebt man ersterer Applicationsstelle des Reizes den Vorzug, wenn es sich darum handelt, den Einfluss verschiedener Umstände auf die Erregbarkeit der reflectirenden Apparate zu studiren. Zur Reizung eignen sich mechanische, thermische, chemische und elektrische Einwirkungen. Dass bei letzteren die Summirung der einzelnen Reize ron besonderem Einflusse ist, wurde schon hervorgehoben. Für die drei ersteren ist zu erwähnen, dass sie nur Erfolg haben, wenn die Einwirkung mit einiger Plötzlichkeit einsetzt. Druck, Hitze, Aetzung höchsten Grades können erfolglos bleiben, wenn sie, von minimalem Werthe beginnend, ganz allmählich gesteigert werden. Besouder's geeignet zur wiederholten gleichmässigen Reizung ist, ausser tetanisirenden Inductionsschlägen auch das Eintauchen der Beine des Reflexpräparates in rerdünnte Säurelösung. Nan beobachtet hierbei die Zeit, welche vergelit, bis die Beine aus der Lösung herausgezogen werden. Ein holıer Grad von Gleichmässigkeit der Einwirkung ist hierbei zu erzielen, wenn man das Eintauchen mit stets gleicher Schnelligkeit 
vollzieht, und weun man sofort nach beobachteter Reaction die saure Lösung mit Wasser abspült.

Zur Beurtheilung des Grades von Erregbarkeit der reflectirenden Apparate können Beobachtungen dienen erstens über die Schnelligkeit, mit welcher die Reaction dem Reize folgt, zweitens iiber die Intensität der Contractionen eines einzelnen oder mehrerer der an dem Reflex betheiligten Muskeln, drittens ïber die kleinste Reizstärke, welche eben genïgt, um minimale Reflexbewegungen auszulösen, oder viertens über den Umfang der Ausbreitung des Reflexes.

Die Latenzzeit der Reflexbewegung oder die "Reflexzeit" ist ausser von der Erregbarkeit des reflectirenden Apparates in hohem Grade abhängig von der Stärke des Reizes. Bei genügender Stärke des Reizes kann die Reflexzeit so klein werden, dass sie sich der Beobachtung mittelst des unbewaffneten Zeitsinnes entzieht, doch beträgt sie unter den günstigsten Bedingungen immer noch etwa das Zwölffache der Zeit, welche zur Leitung der Erregungswelle durch einen peripherischen Nerven von der Länge des Reflexbogens erforderlich sein würde. Durch Schwächung des Reizes, zum Beispiel durch entsprechende Verdünnung der sauren Lösung, kann das Zeitintervall zwischen Beginn der Reizeinwirkung und Beginn der Reaction so verlängert werden, dass es selbst, sowie die Veränderungen, welche es bei Aenderungen der Bedingungen zeigt, durch Abzählen von Metronomschlägen gemessen werden kann (T'ürck'sche Methode). Mit Hülfe dieser Methode kann man unter Anderem die merkwürdige Thatsache am Reflexpräparate des Frosches demonstriren, dass nach halbseitiger Durchschneidung des Rückenmarkes die Reflexempfindlichkeit auf der Seite der Durchschneidung gesteigert und auf der anderen Seite herabgesetzt ist.

Die auffallendste Veränderung zeigt die Erregbarkeit -der reflectirenden Apparate unter der Einwirkung des Strychnins: bei kleinen Gaben äussert sich dieselbe durch Erniedrigung des Schwellenwerthes des Reizes oder bei gleicher Reizstärke durch Steigerung der Intensität und durch grössere Ausbreitung der Reflexbewegungen, welche zunächst jedoch noch den gewöhnlichen coordinirten Charakter bewahren. Die Reflexzeit soll hierbei nach einigen Angaben verkürzt, nach anderen verlängert sein.

Nimmt die Strychninwirkung höhere Grade an, so tritt eine Erscheinung hinzu, welche zwar auch auf eine weitergehende Erregbarkeitszunahme der reflectirenden Apparate bezogen werden könnte, welche aber doch mehr zu einer anderen Deutung auffordert. Jeder irgendwo angebrachte Reiz ist dann von einem tonischen Krampf sämmtlicher Muskeln des Thieres oder des Reflexpräparates gefolgt. Die Haltung, welche das Thier oder das Präparat hierbei einnimmt, ist eine ganz 
typische; sie kaun als maximale Streckung bezeichnet werden, kommt aber nicht dadurch zu Stande, dass die Streckmuskeln allein oder vorwiegend in Contraction gerathen, sondern dadurch, dass, wenn alle Muskeln gleichmüssig maximal contrahirt sind, die Strecker in der Gesammtwirkung ihre Antagonisten weit iiberwiegen.

Man muss hieraus schliessen, dass jeder Punkt der sensiblen OberHäche mit jeder Muskelfaser durch Vermittelung des Centralnervensystems in erregungsleitender Verbindung steht, dass aber dem Uebergang der Erregungswellen auf den grössten Theil dieser Bahnen und zwar auf alle diejenigen, welche nicht geeignet sind zweckmässig coordinirte Bewegungen zu vermitteln, für gewöhnlich besondere Hindernisse entgegenstehen, die durch die Einwirkung des strychnins sämmtlich beseitigt werden. Es ist nothwendig, zwischen den beiden Wirkungsarten des Strychnins, das heisst zwischen der einfachen Erregbarkeitserhöhung der reflectirenden Apparate unter Bewahrung gewöhnlicher Coordinationen und zwischen der Beseitigung oder Ueberwindung sämmtlicher Hindernisse für die Ausbreitung der Erregungswellen auf alle präformirten centralen Bahnen, wenigstens symptomatisch zu unterscheiden. In Bezug auf den Causalnexus muss freilich zugegeben werden, dass beide Erscheinungsweisen auf denselben wesentlich gleichen, nur dem Grade nach verschiedenen Ursachen beruhen können. Denn die allgemeine Ausbreitung der Erregungen, welche wir geneigt sind auf die directe Beseitigung besonderer Hindernisse unter der Einwirkung des Strychnins zurückzuführen, könnte wohl auch durch Ueberwindung aller Hindernisse in Folge maximaler Erregharkeitssteigerung sämmtlicher reflectirender Apparate erklärt werden.

In demselben Sinne wie Strychnin wirkt Picrotoxin, Morphium und Brucin; in entgegengesetztem Chloroform. Dem durch das Strychnin herrorgerufenen Zustande sehr ähnlich sind die pathologischen Zustände bei Tetanus traumaticus und bei Hydrophobie; eine periodisch wiederkehrende Erregbarkeitserhöhung zeigt das Reflexcentrum für den Begattungskrampf bei dem männlichen Frosche. Erhöhung und Erniedrigung der Temperatur des Froschrïickenmarkes sollen beide die Reizschwelle herabsetzen und die Intensität der Reflexbewegung steigern. Erstere soll mit einer Verkürzung, letztere mit einer Verlängerung der Reflexzeit einhergehen, und erstere soll die Dauerbarkeit der Reflexpräparate, welche iiberhaupt sehr leicht ermüden, noch mehr verringern. Die Angaben über die Wirkung des constanten Stromes auf die reflectorische Erregbarkeit des Froschrückenmarkes bestehen aus ungelösten Widersprüchen.

Yon hervorragender Bedeutung für die Theorie der centralen Processe ist die Thatsache, dass die als Reflex bezeichnete Ueberleitung 
centripetal fortschreitender Erregungswellen auf centrifugale Bahnen in sehr beträchtlicher Weise gehemmt werden kann durch Erregungswellen, welche dem reflectirenden Apparate gleichzeitig von anderer Seite her zugehen. Diese zur "Hemmung des Reflexes" führenden Erregungswellen können entweder auf sensiblen Bahnen von der Peripherie her zugeleitet werden oder auf cerebromedullären Bahnen aus dem Gehirn. Zur Beobachtung der hierher gehörigen fundamentalen Thatsachen ist die Türck'sche Methode besonders geeignet. Unter Anwendung derselben kann man an Fröschen, denen das Gehirn vor den Lobi optici entfernt ist, zeigen, dass die Zahl der Metronomschläge, welche zwischen dem Eintauchen der herabhängenden Schenkel in die verdïnnte saure Lösung und dem reflectorischen Herausziehen derselben gezählt wird, erheblich zunimmt, wenn die Lobi optici durch aufgelegte Kochsalzkryställchen gereizt werden (Setschenow).

Dass übrigens von dem centralen Apparate, welcher bei dieser Versuchsweise in erhöhte Thätigkeit ver'setzt wird, auch ohne besonderen Reiz beständig Erregungswellen ausgehen, welche die Reflexe verzögern, gelit daraus hervor, dass die Reflexzeit in Allgemeinen bei dem vollständig enthirnten Reflexpräparat kürzer ist, als bei demjenigen, dessen Lobi optici durch die Medulla oblongata mit dem Rückenmark noch in Verbindung stehen. Unmittelbar nach der Enthirnung, hinter der Medulla oblongata, ist die Reflexzeit verlängert und man bezieht diese Verlängerung wohl mit Recht auf eine Reizung der Verbindungsfasern vom Hemmungscentrum der Lobi optici zu den reflectirenden Apparaten des Rückenmarkes. Die von den Lobi optici nachweislich ausgehende Hemmungswirkung gewährt dem denkenden Beobachter darum so hohe Befriedigung, weil sie auf eine organische Einrichtung hinweist, durch welche der Zwang von Reflexen, welche den Einwirkungen auf ein einziges Sinnesgebiet (sensible Hautfläche) ihre Entstehung verdanken und darum unzweckmässig sein können, nöthigen Falles aufgehoben werden kann.

Weniger verständlich in ihrer Bedeutung ist die Thatsache, dass auch an dem vollständig enthirnten Reflexpräparat die Reflexzeit verlïngert oder der Reflex sogar ganz unterdrückt wird, wenn gleichzeitig mit der Application eines Reizes von der zur Hervorrufung eines Reflexes geeigneten Form und Stärke auf anderen sensiblen Bahnen sehr starke Erregungen dem Rückenmark zugeleitet werden. Es darf übrigens nicht unerwähnt bleiben, dass man versucht hat, hieraus und aus der Schwierigkeit, durch Reizung sensibler Nervenstämme der Haut Reflexe auszulösen, auf die Existenz besonderer Nervenfasern zu schliessen, deren specifische Wirkungsweise ein für allemal Hemmung von Reflexen sei.

Wenden wir jetzt unsere Betrachtung der Rolle zu, welche die durch 
das Riuckenmark vermittelten Reflexe in dem Leben des Warmblüters spielen, so ist zunächst daran zu erinnern, dass, wie schon erwähnt wurde, in dem Rïckenmark des Säugethieres ausschliesslich oder vorwiegend nur kurze Reflexbögen ihren Schluss finden. An enthirnten Säugethieren, bei welchen künstliche Athmung unterhalten wird und an Menschen, die eine Continuitätstrennung des Rückenmarkes erlitten haben, lassen sich solche durch kurze Reflexbögen vermittelten Reflexe, welche Reizungen der äusseren Haut ihre Entstehung rerdanken und in Körperbewegungen ihren Ausdruck finden, leicht demonstriren, doch ist ihre Bedeutung für die Zwecke des Lebens nicht leicht zu erkennen, es handelt sich meistens um sehr einfache zuckende Bewegungen, welche zwar geeignet sind, die gereizte Stelle von dem reizenden Objekt zu entfernen, welche aber im normalen Zustande in dieser Form kaum zur Beobachtung kommen, höchstens im Schlaf und in der Narkose.

Dariiber, dass Bewegungscomplexe höherer Coordination und von dem Charakter derjenigen, welche im gewöhnlichen Wechselverkehr des Individuums mit der Aussenwelt vorkommen, durch einen Rückenmarkstheil des Säugethieres vermittelt werden können, liegen nur vereinzelte Beobachtungen vor. Bei einer Hündin, welcher im Alter von 9 Monaten das Lumbalmark vom Brustmark getrennt worden war, zeigte sich im vierten Monat nach der Operation Folgendes. Beim Emporheben des Thieres am Nacken wurden jedesmal zuerst beide Hinterbeine unter Beben stark und krampfhaft eine Weile gestreckt, dann folgten Bewegungen derart, dass gleichzeitig mit der Beugung des linken Beines das rechte gestreckt wurde und umgekehrt. Dieses dauerte mit allmählicher Verlangsamung des Tempos so lange fort, als das Thier erhoben gehalten wurde; die Bewegungen hatten also Aehnlichkeit mit denen beim Laufen des Thieres. Bei Vögeln ist mehr Derartiges beobachtet worden. Rhythmische alternirende Bewegungen der Beine nach Art der Schreitbewegungen zeigten sich bei Tauben, welche die Trennung des Lumbalmarkes rom Dorsalmarke längere Zeit überlebten. Die Bewegungen konnten durch leichte Reizung an den Zehen des gewölnnlich auf dem Rücken liegenden Thieres ausgelöst werden und wurden dann scheinbar spontan lïugere Zeit fortgesetzt. Enten, denen das Lumbalmark abgetrennt oder das Halsmark zwischen viertem und fünftem Halswirbel durchschnitten war, konnten normal schwimmen; die in letzterer Weise operirten Thiere, bei denen künstliche Athmung unterhalten wurde, machten noch ausserhalb des Wassers, wenn ihre Beine in der Luft waren, längere Reihen lebhafter Schwimmbewegungen, die durch Ruhepausen unterbrochen waren, nur durften die Füsse nicht den Boden berühren, denn dann wurden Stehen, Gehen und jede zweckmässige Bewegung durch tetanische Muskelcontractionen wie in Strychnintetauus gehindert. 
In Allgemeinen bekommt man den Eindruck, dass die hier beschriebenen Bewegungen weniger auf Erregungen zu beziehen sind, welche durch sensible Apparate der äusseren Haut vermittelt werden, als auf Erregungen, welche in Theilen des Bewegungsapparates selbst bei gewissen Haltungen und Bewegungen der Glieder entstehen. Als einen derartigen durch kurze Reflexbögen im Rückenmark der Säugethiere vermittelten Reflex sehr einfacher Natur haben wir schon das sogenannte Kniephänomen kennen gelernt. Da ähnliche Erscheinungen auch an anderen Muskeln als am Musculus quadriceps cruris $\mathrm{zu}$ beobachten sind, zum Beispiel am Musculus triceps brachii und am Musculus gastrocnemius, so ist es wahrscheinlich, dass es sich bei diesen sogenannten Sehnenreflexen um eine Einrichtung von allgemeiner Bedeutung handelt, welche darin besteht, dass jeder Muskel durch die Dehnung, welche er mitsammt seiner Sehne bei Contractionen seiner Antagonisten erleidet, reflectorisch in eine Contraction versetzt wird, welche geeignet ist, die durch die Antagonisten veranlasste Bewegung abzurunden. Es ist möglich, dass die vorstehend erwähnten, durch Rückenmarkstheile vermittelten rhythmisch alternirenden Bewegungen auf einem ganz ähnlichen, nur etwas verwickelteren Mechanismus beruhen.

Nach einiger Ueberlegung kann es nicht Wunder nehmen, dass bei Vögeln weniger wie bei Amphibien und bei Säugethieren noch weniger wie bei Vögeln durch Vermittelung des Rückenmarkes allein solche Bewegungscomplexe höherer Coordination zur Ausführung gelangen können, welche in der Reaction des Thieres gegen die Aussenwelt eine wesentliche Rolle spielen. Je mannigfaltiger sich die Lebensweise und die möglichen Lebenslagen des Thieres gestalten, um so zweckmässiger muss es erscheinen, wenn die langen Reflexbögen in höhere Theile des Centralnervensystems aufsteigen, um erst dort ihren Schluss in reflectirenden Apparaten zu finden. Leichter als im Rückenmark vollziehen sich gewiss im Hirnstamm alle diejenigen nervösen Verknüpfungen, welche den durch sänmtliche Sinnespforten zufliessenden Erregungen in jedem einzelnen Falle eine Mitwirkung an der Gestaltung der speciellen Form der Reflexbewegung gewähren. Bei der Lage der reflectirenden und zugleich coordinirenden Apparate im Hirnstamm sind auch einfachere Möglichkeiten für Verbindungen derselben mit dem Hirnmantel gegeben, sodass dieselben Apparate ebenso den von dort angeregten, als willkürlich betrachteten Bewegungen zur Vermittelung dienen können, wie den rein reflectorischen.

Wir müssen jetzt versuchen, eine Grenzlinie $z$ wischen den Begriffen Reflex und Willkür zu ziehen, eine Aufgabe, deren strenge Lösung auf erhebliche Schwierigkeiten stösst. Was die eigenen liewegungen anlangt, so kann man sich freilich über die Schwierigkeiten 
hinwegtïuschen, indem man als Kriterium den eigenen Bewusstseinsinhalt annimmt, wolcher uns bei einer ausgeführten Bewegung darüber auszusagen gestattet, ob sie mit oder ohne, oder auch wobl gegen unseren Willen zu Stande gekommen ist.

Als willkürlich erscheint uns eine Bewegung, wenn vor ihrer Ausführung die Vorstellung der Bewegung selbst oder des durch dieselbe zu erreichenden Zweckes in unserem Bewusstsein erschienen war. Deutlicher ist der Eindruck der Willkürlichkeit, wenn die Bewegungs- oder $Z$ weckvorstellung einer längeren Vorstellungsreihe angehörte, deren directe äussere Veranlassung uns entgangen ist, und wenn mehrere Zweckvorstellungen in einen Wettstreit mit einander gerathen waren, dessen Ausgang durch die uns deutliche Vorstellung der Folgezustände der concurrirenden möglichen Bewegungen bestimmt wurde. Hiernach kann es nicht Wunder nehmen, dass der Eindruck der Willkürlichkeit in seinerDeutlichkeit sehr schwankend ist, ja dass, wenn wir unter scheinbar gleichen äusseren Umständen dieselbe Bewegung ausgeführt haben, wir uns das eine Mal eines Willensaktes bewusst sein können, ein anderes Mal nicht.

Nun giebt es freilich Bewegungen, welche sich als reflectorische in sehr deutlichen Gegensatz zu den willkürlichen stellen: hierher gchört zum Beispiel das Niesen, welches wir willkürlich zwar einigermaassen nachahmen, nicht aber in aller Vollständigkeit ausführen können, und welches, wenn ein kitzelnder Reiz gewisse Stellen der Nasenschleimhaut trifft, mit einem solchen Zwange eintritt, dass wir mit dem Willen nur schwer dagegen ankämpfen können. Letzteres gilt auch von dem Lidschluss bei Reizung der Conjunctiva, und man könnte noch einige Beispiele heranziehen. Bei der weitaus grössten Mehrzahl der Bewegungen ist jedoch das durch den eigenen Bewusstseinsinhalt gegebene Kriterium ein unsicheres und gilt bestenfalls doch nur für die von uns selbst ausgeführten Bewegungen, während unsere Urtheile ïber die Classificirung der Bewegungen anderer Menschen und nun gar der Thiere, wenn der Bewusstseinsinhalt der Classificirung zu Grunde gelegt werden soll, auf Analogieschlüssen beruhen, welche im Grossen und Ganzen wohl erlaubt sein mögen, welche aber in den meisten einzelnen Fällen berechtigten Zweifeln Raum geben.

Wir wollen also sehen, wie weit wir mit dem Definirungsversuch kommen, wenn wir von der rein materiellen Seite der Vorgänge ausgehen. Als Grundsatz, auf welchen die Betrachtung aufgebaut werden kann, darf die Behauptung ausgesprochen werden, dass alle Erregungswellen, welche das Centralnervensystem verlassen und in Körperbewegungen ihren Ausdruck finden, zu Erregungswellen, welche vorher auf centripetalen Bahnen in das Centralnervensystem eingetreten waren, in 
mechanischem Causalnexus stehen (wir sehen hier von den sogenannten automatischen Bewegungen ab, deren Gegensatz zu den reflectorischen ein sehr klarer ist und deren Vorkommen auf dem Gebiete der Willkür kaum Vertreter finden dürfte). Am einfachsten ist der Causalnexus bei den kurzen Reflexbögen des Reflexpräparates vom Frosch, an welchem nur die beiden letzten Rückenmarkssegmente erhalten geblieben sind. Hier besteht der Mechanismus des Vorganges in der Ueberleitung der centripetal zuströmenden Erregungswellen durch die wenigen vorhandenen Schaltstücke auf die wenigen vorhandenen centrifugalen Bahnen. Eine grössere Mannigfaltigkeit der Möglichkeiten ist nicht vorhanden.

Etwas verwickelter, wenn auch noch verhältnissmässig einfach ist der ursächliche Zusammenhang bei den gewöhnlichen Reflexen, welche das Reflexpräparat des Frosches zeigt, dessen ganzes Rückenmark erhalten ist. Wir haben die Vorbereitung zum Sprung, den Sprung, die Abwehrbewegungen und die gewöhnlichen Wischbewegungen im Auge; von den modificirten Wischbewegungen sehen wir zunächst ab. Die Mannigfaltigkeit der Ueberleitungen, welche hier möglich sind, ist zwar eine sehr grosse, doch kann die Auswahl auf verhältnissmässig einfache Weise dadurch zu Stande kommen, dass eine zweckmässige Stufenfolge der Leitungsfähigkeit der verschiedenen Leitungsbahnen und der Erregbarkeit der die Ueberleitung vermittelnden cellulären Schaltstïcke bestelit.

Eine neue Verwickelung tritt bei denjenigen langen Reflexbögen, welche im Hirnstamm ihren Schluss finden, dadurch hinzu, dass die Auswahl unter den möglichen Ueberleitungen nicht nur durch Ort und Art von Reizen bestimmt wird, welche allein dem Gebiete des Tastsinnes angehören, sondern dass auf die specielle Form der erfolgenden Bewegungen auch Erregungen von Einfluss sind, welche anderen Sinnesgebieten entstammen. Im Allgemeinen können wir aber wohl sagen, dass auch bei den durch den Hirnstamm vermittelten Reflexen der Erfolg, ausser von dem Plan der ein für allemal vorhandenen, sei es angeborenen oder im individuellen Leben durch Uebung erworbenen Velbindungen, nur von den momentan zufliessenden sinnlichen Erregungen abhängen wird, aus deren Einfluss eine solche Stufenfolge in Leitungsfäligkeit und Erregbarkeit aller möglichen Bahnen resultirt, dass eine zweckmässige Combination der wirklich beschrittenen Bahnen die Folge davon ist.

Je höher ein Thier in der Entwickelungsreihe der Organismen steht, je mannigfaltiger sich seine Lebensbedingungen und Lebenslagen, sowie die Möglichkeiten seines Verhaltens gestalten, um so mehr ist es darauf angewiesen, dass seine Bewegungen nicht nur unter dem Einfluss der gerade im Augenblick vorhandenen Sinneserregungen zu Stande kommen, 
sondern dass sein jedesmaliges Verhalten in allen lebenslagen durch eine grosse Anzahl früher erhaltener Sinneseindrücke mit bestimmt wird. Um den vergangenen Sinnescindrücken cinen Einfluss auf die Form der jeweiligen motorischen Innervationseomplexe zu sichern, erscheint das System der Associationsbahnen im Hirnmantel besonders geeignet.

Das Wesentliche des Associationssystems besteht in Folgendem: jedem Sinnesapparat gehört ein Gebiet der Hirnrinde zu, wohin die diesen Sinn treffenden Eindrücke in Gestalt von Erregungswellen geleitet werden und von wo aus Bahnen für die Weiterleitung dieser Erregungswellen zu motorischen Coordinationsapparaten des Hirnstammes fülıren. Ausserdem sind aber die einzelnen Rindensphären der verschiedenen Sinnesgebiete auf so mannigfache Weise durch erregungsleitende Bahnen unter einander verknüpft, dass die diesen Verknüpfungen dienenden Fasersysteme, die "Associationssysteme“, den Bau des Hirnmantels wesentlich beherrschen.

Für die Entstehung orler besondere Bahnung der einzelnen associatorischen Verknïpfungen scheint es maassgebend zu sein, welche von den Sinneseindrücken wiederholt gleichzeitig zu Stande kommen. Je zwei Punkte der Sinnessphären der Hirnrinde, welche zu zwei wiederholt gleichzeitig eingetretenen Sinneseindrücken gehören, verknüpfen sich derart miteinander, dass, wenn später nur für den einen der beiden Simneseinchücke ein äusserer Anlass vorliegt, doch beide Rindenpunkte in gleichzeitige Erregung gerathen, sodass auch von jedem derselben solche absteigenden Erregungswellen ausgehen können, welche in die Gestaltung des resultirenden Bewegungscomplexes einzugreifen geeignet sind, sei es erregend oder hemmend.

Bisher haben wir uns rein mechanischer auf die materielle Seite der Vorgänge beschränkter Begriffe bei der Betrachtung bedient und wir haben dabei die dmrch den Hirnmantel vermittelten Bewegungen in den allgemeinen Typus der Reflexrorgänge miteinbeziehen können. Wir haben freilich als ein besonderes, sie von den übrigen Reflexen unterscheidendes Kriterium erkannt, dass auf ihre Gestaltung nicht nur die augenblicklich vorhandenen, sondern auch die Summe der im individuellen Leben vorausgegangenen Sinneseindrücke von Einfluss sind. Die hiermit rerbundene grössere Complicirtheit des mechanischen Gesehehens könnte aber keine Veranlassung für uns sein, sie als etwas Eigenartiges den übrigen Reflexen gegenüber zu stellen. Nun erscheint aber das Associationssystem des Hirnmantels nicht nur geeignet den Einfluss vergangener Sinneseindrücke auf die Gestaltung der jeweiligen Bewegungscomplexe mechanisch zu vermitteln, sondern es spiegelt sich in seinem Mechanismus auch die Entstehungsart der Vorstellungen in unserem Bewusstsein durch Verknïpfung der von verschiedenen Sinnen gleichzeitig ge- 
lieferten Wahrnehmungen so treu wieder, dass wir diesen Mechanismus als das mechanische Correlat der psychischen Processe anzusehen nicht umhin können, wenn wir auch von der Art der Verbindung bestimmter Bewusstseinszustände mit bestimmten Zuständen des Gehirns Nichts verstehen.

Thatsache ist, dass alle Vorstellungen, welche uns zur Orientirung in der Aussenwelt dienen und in dem richtigen Verhalten gegen dieselbe unterstützen können, aus Erinnerungsbildern verschiedener Sinnesgebiete zusammengesetzt oder abstrahirt sind. Wenn der Entstehungsart dieser Vorstellungen ein materielles Correlat entsprechen soll, so kann dies nur das Associationssystem des Hirnmantels sein, der Hirnstamm erscheint nach seiner inneren Structur und das Rückenmark aus dem gleichen Grunde, sowie wegen der Ausschliesslichkeit seiner directen Verbindung mit nur einem Sinne, dem Tastsinn, hierzu ungeeignet. Wenn man das Rückenmark zu psychischen, die Gestaltung von Bewegungscomplexen begleitenden Processen in directe Beziehung setzt, wie es geschehen ist, als man auf Grund zweckmässig modificirter Wischbewegungen am Reflexpräparat des Frosches eine "Rückenmarkseele" statuirte, muss man dem Rückenmark die Fähigkeit zur Association von Sinneseindrücken verschiedener Sinnesgebiete zutrauen, was wir nicht können. Da auch dem Hirnstamm diese Fähigkeit-nach unserer Auffassung nicht zukommen kann und da im Gegensatz dazu der Hirnmantel die ausgiebigsten Einrichtungen für solche Associationen aufweist, so erscheint es allerdings geboten, den Begriff des reinen Reflexes auf die allein durch Rückenmark und Hirnstamm vermittelten Bewegungen (mit Ausschluss der automatischen) zu beschränken und in Gegensatz dazu diejenigen zu stellen, auf deren Gestaltung der Hirnmantel einen bestimmenden Einfluss hat. Für die Begründung dieser Gegenüberstellung reicht es aus, dass mit der Ausübung des genannten Einflusses sich der Eindruck der Willkïrlichkeit im subjectiven Bewusstsein wenigstens verbinden kann, wenn er es auch nicht in jedem einzelnen Falle thut.

Die Zweckmässigkeit dieser Abgrenzung möge durch ein einfaches Beispiel belenchtet werden. Die ersten Akte der Nahrungsaufnahme bestehen erstens aus dem Beissen und Kauen, zweitens aus dem Formen und Zurückschieben des Bissens, drittens aus dem Schlucken. Bei dem Kaninchen, dem der ganze Hirnmantcl exstirpirt ist, vollziehen sich Akt eins und drei mit maschinenmässiger Regelmässigkeit, sobald man einen entsprechenden Reiz an der richtigen Stelle einwirken lässt. Der Akt zwei bleibt aber bei dem so operirten Thier stets aus. Schiebt man demselhen ein Stück Kohlblattstiel in die Lücke zwischen die Schneideund Mahlzähne, so beisst und kaut es auf demselben herum, wohei es 
zu einer leidlichen Zerkleinerung kommt. Aus der zerkleinerten Masse wird aber kein Bissen gebildet, sie bleibt vielmehr ungeordnet in rorderen Theile des Maules liegen und fällt dann allmählich heraus. Schielst man einen Blattstiel in die hinteren Maulpartien, so wird bei jedesmaliger Beriihrung der Gaumenbögen oder der hinteren Pharynxwand eine Schluckbewegung ausgelöst. Beissen, Kauen und Schlucken sind beim Kaninchen reine Reflexe, rermittelt durch den Hirnstamm; das Formen und Zuriickschieben des Bissens dagegen steht unter Controlle des Hirmmantels. Es lenchtet als zweckmässig ein, dass bei einem 'Thier, in dessen Leben die Nahrungsaufnahme eine so herrorragende Rolle spielt wie beim Kraninchen, ein guter Theil der Fressbewegungen sich mit Aufbietung eines möglichst geringen $\Lambda$ pparates vollzieht. Doch würde das Thier sicher grossen Gefahren ausgesetzt sein, wenn nicht wenigstens ein Glied in der Kette des Fressaktes unter die Controlle der individuellen Erfahrung gestellt wäre. Wégen seiner Abhängigkeit ron dem Hirmmantel rermuthen wir dies für den mit zwei bezeichneten Fressakt und wir können denselben deshalb auch in berechtigter Analogisirung als einen willkiirlichen Akt bezeichnen, wenn wir über die Thatsache der Willkïrlichkeit hier wie in vielen anderen Fällen auch nichts wissen. Es hat sich nun auch zeigen lassen, dass zur Aufhebung des zweiten Theiles des Fressaktes nicht die Entfernung des ganzen Hirnmantels erforderlich ist, sondern nur die eines bestimmten Bezirkes der Hirnrinde. Es ist dies dieselbe Rindenpartie, an deren Intactheit auch die Reactionsfähigkeit des 'Thieres gegen schmeckende Substanzen gebunden ist. Auf den als willkïrlich bezeichneten Theil des Fressaktes haben also wenigstens zwei Sinne Einfluss, das Getast und der Gesehmack, während fuir die reinen Reflexe rom Hirnstamm die Tasteindriicke ausreichen. 


\section{Fïnfter Abschnitt.}

\section{Specielle Nervenphysiologie.}

Die Nervenfasern gruppiren sich auf ihrem Wege von dem, durch Hirn, Rückenmark und Spinalganglien repräsentirten nervösen Centralorgan zu ihren peripherischen Endapparaten in Nervenstämmen, welche, je nachdem sie aus Hirn oder Rückenmark ihren Ursprung nehmen, als Gehirnnerven und Rïckenmarksnerven unterschieden werden. Ferner unterscheidet man die den Bewegungs- und Sinnesapparaten zugehörigen Nerven als somatische, von den die Eingeweide versorgenden visceralen. Die Visceralnerven durchsetzen auf ihrem Wege rom nervösen Centralorgan bis zu den Eingeweiden besondere Ganglienzellenanhäufungen, mit welchen zusammen sie das sogenannte sympathische Nervensystem bilden. Letzteres hat man früher als ein besonderes Nervensystem dem Centralnervensystem gegenüber gestellt. Eine weitgehende Abhängigkeit des sympathischen vom Centralnervensystem ist aber jetzt zweifellos festgestellt.

Die Stämme der Rückenmarksnerven entstehen aus der Vereinigung der vorderen und hinteren Wurzeln des Rückenmarkes, unmittelbar peripher von den Spinalganglien. Sie theilen sich bald darauf in Aeste, von denen die einen in dorsaler, die anderen in ventraler Richtung abbiegen. An diesen Aesten ist die Zusammensetzung aus den dorsalen sensiblen und ventralen motorischen Wurzeln noch insofern erkennbar, als die dorsalen Aeste medial vorwiegend sensibel, lateral vorwiegend motorisch, die ventralen Aeste medial wesentlich motorisch, lateral wesentlich sensibel sind. Nicht weit rom Rückenmark gehen die aus den primären Nervenstämmen abgezweigten Nervenäste, namentlich im Bereiche der für die Extremitäten bestimmten Nerven in Bildungen ïber, welche man Nervenplexus nennt, und welche darin bestehen, dass je mehrere Nervenäste mit einander zusammenfliessen, nach kürzcrem oder längerem gemeinsamem Verlauf, während dessen sie ihre Fasern theilweise austauschen, sich wieder trennen, um vielleicht nochmals anderweitige Verbindungen einzugehen. Die eigentliche Bedeutung dieses in den Nervenplexus stattfindenden Faseraustausches muss wohl darin gesucht werden, dass die Faserkategorien, welche in einem bestimmten Nervenast enthalten sein müssen, im Allgemeinen aus einer grösseren Zahl von Nervenwurzeln stammen werden, und dass diese 
Nerrenwurzeln ihrerseits auch noch anlere Nervenäste zu versorgen haben werden. Ganglienzellen finden sich in diesen Nervenplexus nicht, wie es denn iiberliaupt ron den somatischen Nerrenfasern im Gegensatz zu den visceralen fast ausnahmslos gilt, dass sic auf dem Wege vom nervösen Centralorgan bis zu ihrem peripherischen Bestimmungsort durch Nervenzellen nicht unterbrochen sind.

Die Beriehung, in welcher mehrere vordere Wurzeh des Ruickenmarkes zu je einem anatomisch einheitlichen Muskel stehen, ist schon hervorgehoben worden; Aehnliches gilt für dic Beziehungen der hinteren Wurzeln zu den sensiblen Hautflächen. Im Allgemeinen sendet jede Hautstelle auf der Bahn mehrerer benachbarter Riickenmarkswurzeln sensible Erregungen in das Centrum. Eine merkwürdige Erfahrung der Chirurgen ist noch nicht völlig aufgeklärt, sie besteht darin, dass nach Durchschneidung eines, bestimmte Hautgebiete scheinbar ausschliesslich mit sensiblen Fasern versorgenden Nerren die betreffende Hautfläche zwar ummittelbar nach der Durchschneidung sensibel gelähmt ist, dass aber schon im Verlaufe von Stunden jedenfalls in einer für Verheilung des durchschnittenen Nerven viel zu kurzen Zeit die Empfindlichkeit wiederkehren kann. Bei der Erklärung dieser Beobachtung wird die anatomische Thatsache zu berücksichtigen sein, dass die Nervenstämme der Hant Plexusbildungen eingehen. An den Gliedern dieser Plexus zeigt sich iibrigens gelegentlich eine Erscheinung, welche der Sensibilité récurrente der vorderen Rückenmarkswurzeln ähnlich ist. Durch Reizung eines scheinbar mit der Peripherie verbundenen Nervenstumpfes kann man manchmal Empfindung erregen.

Gehirnnerven zählt die Anatomie zwölf, obgleich zwei derselben (I und II) eher als Hirntheile aufzufassen sind und einer seinem Ursprung nach nur partiell dem Gehirn angehört (XI). Die Functionen, welchen die Hirnnerven dienen, sind: a) höhere Simneswahrnehmung (sensorielle); b) willkürliche Muskelbewegung (motorische); c) Sensibilität in engerem Sinne und centripetale Reflexleitung (sensible); d) Innervation von Gefässen und Eingeweiden (viscerale).

a) Ausschliesslich sensorieller Natur ist nur der sogenannte Nerrus olfactorius. Ein einfacher Ricchnerr existirt beim Menschen freilich nicht, da Tractus und Bulbus olfactorius als Theile eines Hirnlappens, des Lobus olfactorius, aufzufassen sind. Als Riechnerv zu betrachten ist vielmehr die Summe der Fäden (Fila olfactoria), welche rom Bulbus olfactorius durch die Siebplatte zur Riechschleimhaut ziehen. Die Regio olfactoria, welche die Endigungen dieser Riechnerren enthält und welche der Geruchswahrnehmung dient, ist derjenige Theil der Nasenschleimhaut, welcher die oberen Theile der Nasenscheidewand, sowie die der letzteren zugekehrten Flächen der oberen und mittleren Muscheln bedeckt. 
Der Nervus opticus ist ebenfalls kein Nerv im gewöhnlichen Sinne des Wortes, sondern er stellt eine intracentrale erregungsleitende Bahu dar, welche der Verbindung von Centren des Thalamus opticus, des Pulvinar, der Vierhügel und der Corpora geniculata mit der aus der primären Augenblase des vorderen Hirnbläschens hervorgegangenen, also als Hirntheil zu betrachtenden Retina dient. Dieser sogenannte zweite Gehirnnerv vermittelt in erster Linie die Gesichtswahrnehmung, doch ist nicht zu übersehen, dass er ausser sensoriellen Fasern auch solche enthält, welche reflectorisch auf die Bewegungen der Iris, sowie des Accommodations- und Fixationsapparates Einfluss ausüben.

Als rein sensorieller Nerv wird rielfach der achte Gehirnnerr, der Nervus acusticus, betrachtet, doch stehen seine Beziehungen zur Gehörswahrnehmung nur für denjenigen Theil seiner Fasern fest, welche ihre Endausbreitung in der Lamina spiralis der Schnecke finden, und welche im Nervus Cochleae vereinigt sind. Welche Function denjenigen Fasern zukommt, die im Sacculus, Utriculus und in den Ampullen ihre Ausbreitung finden, ist strittig. Von den Nerven des Sacculus und Utriculus ist vermuthet worden, dass sie die Wahrnehmung der Geräusche vermitteln, doch fïhrt eine genaue Analyse der als Geräusch bezeichneten Sinneseindrücke dazu, sie den Ton- und Klangwahruehmungen einzuordnen, vou denen es feststeht, dass sie durch das Corti'sche Organ ler Schnecke vermittelt werden.

Die Ampullarmerven sind auf Grund gewichtiger experinenteller Thatsachen zu dem Gleichgewichtssinn in Beziehung gebracht worden. Adäquate Reize für die Endigungen dieser Nerven würden Druck und Bewegungsänderungen sein, welche die Endolymphe der Bogengänge bei Bewregungen des Kopfes erführe. Für das Bewusstsein klar gesonderte Sinneseindrücke würden mit der Erregung dieser Nerven nicht verbunden sein. Vielmehr würde aus der Summe derselben in Verbindung mit anderen von der Peripherie zugeleiteten Erregungen die Vorstellung von liewegung, Stellung und Haltung des Körpers im Raum resultiren, welche auch ohne dass sie die Schwelle des Bewusstseins zu überschreiten braucht, coordinirte Muskelinnervation im Interesse der Erhaltung des Körpergleichgewichtes und der zweckmässigen Locomotion auslösen kann. ZWreifellos steht fest, dass Reizungen der Ampullarnerven Störungen des Körpergleichgewichtes und der Bewegungscoordination zur Folge haben. Bei Vögeln, uamentlich bei Tauben, kann man die knöchernen Bogengänge ohne bedeutende Nebenverletzungen freilegen und eröffnen. Thut man dies zum Beispiel mit einem der beiderseitigen horizontalen Bogengänge und setzt man eine fein ausgezogene Glascapillare in den eröffneten häutigen Bogencanal ein, so macht die Taube in dem Moment, wo die Endolymphe durch Capillarkraft angesaugt wird, eine zuckende 
Bewegung um eine verticale Axe. Das analoge Experiment an dem nächst zugänglichen verticalen transversalen Bogengang ergiebt eine zuckende Kopfdrehung $n$ eine zur Ebene dieses Bogenganges senkreelite (etwa in der Richtung des Schnabels gelegene) Axe. Die in diesen Experimenten durch die Capillarattraction bedingte Bewegung von Endolymphe muss die sogenannten "Hörhaare" an der Crista acustica der zu dem betreffenden Bogengang gehörigen Ampulle verbiegen und die hierdurch ausgelöste Kopfdrehung ist dieselbe, welche, wenn sie primär bei unverletzten Bogengängen erfolgte, die "Hörhaare" derselben Ampulle durch Fliissigkeitsbewegung erregen miisste. Diese gesetzmässige Beziehung der räumlichen Anordnung der Bogengänge zur Richtung der bei experimentell erzeugter Flüssigkeitsbewegung eintretenden Kopfdrehung macht die Betheiligung des Bogengangapparates mit den Ampullarnerven an der Erhaltung des Körpergleichgewichtes sehr wahrseheinlich. Derselbe Schluss folgt für den Otolithenapparat und seine Vestibularnerven aus rergleichend physiologischen Untersuchungen bei niederen Thieren.

Der letzte sensorielle Gehirnnerv ist der neunte, der Nervus Glossopharyngeus, welcher der Geschmackswahrnehmung dient, daneben aber viele Fasern anderer Function, motorische, sensible und viscerale fiihrt. Strittig ist, ob die Nerrenfasern, welche den Geschmack vermitteln, aussehliesslich durch die Wurzeln des Glossopharyngeus in das Gehirn gelangen. Allgemein angenommen, weil durch directe anatomische Präparation zu erhärten, ist dies nur für diejenigen Geschmacks-

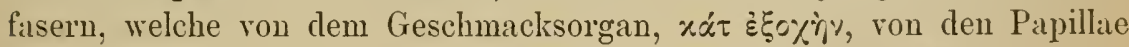
circumvallatae und den Papillae foliatae kommen. Bei vielen Menschen, wie es scheint aber nicht bei allen, rermittelt auch die ebenfalls rom Glossopharyngeus innervirte Schleimhant des weichen Gaumens und der Gaumenbögen Gesehmacksempfiudung. Ausserdem dient aber auch der vordere Theil der Zunge dem Geschmack und hier wird die Schleimhaut sicher ron dem Nerrus lingualis, nicht rom Glossopharyngeus mit Nervenfasern rersorgt. Dass die dabei in Betracht kommenden Geschmacksfascrn durch die Chorda Tympani dem Trigeminusast beigemischt werden, ist nach pathologischer Erfahrung sicher. Meinungsterschiedenlieit besteht aber iiber die Bahn, welche die Geschmacksfasern der Clorda bis zum Centrum einschlagen. Vermuthlich wird die einfachste Annahme, dass ron den Wurzeln aller Gehirnnerren nur die des Glossopharyngeus Geschmacksfasern führt, der Wahrheit entsprechen und die Bahn der Gesehmacksfasern der Chorda wird sein: Ganglion oticum, Nervus petrosus superfacialis minor, Plexus tympanicus, Ganglion petrosum, Nervus glossopharyngeus.

b) Rein motoriseh sind unter den Wurzeln der Hirnnerven sicher nur die des rierten und sechsten, sowie die rordere des fünften. Ton 
den rein motorischen Hirnnerven versieht der vierte ausschliesslich den Musculus obliquus superior (Trochlearis), der sechste ausschliesslich den Musculus rectus lateralis (Abducens). Wesentlich motorisch ist auch der dritte Hirnnerv, Nervus oculomotorius, dessen Wurzel aber ausser den motorischen Nervenfasern für den Musculus palpebrae superioris, Rectus internus, superior et inferior und Obliquus inferior, noch viscerale Fasern führt (Iris). Alle Augenmuskelnerven erhalten in ihrem Verlaufe sensible Fasern vom Trigeminus beigemischt.

Die rein motorische vordere Wurzel des Nervus trigeminus versorgt die Kaumuskeln, das heisst den Musculus Masseter, Pterygoideus internus und externus, ferner den Musculus hyoideus und den vorderen Bauch des Musculus digastricus, ausserdem den Musculus tensor veli palatini und den Musculus tensor tympani.

Vorwiegend motorisch ist die Wurzel des siebenten Hirnnerven, des Nervus facialis, durch welche die motorischen Fasern für alle mimischen Gesichtsmuskeln, ferner für den Musculus stylohyoideus, den hinteren Bauch des Musculus digastricus und für den Musculus subcutaneus Colli austreten. In die motorische Innervation des Levator veli palatini und des Azygos uvulae theilen sich mit Fasern des Vagus (Rami pharyngei), eigene Fasern des Facialis, welche auf der Bahn des Nervus petrosus superfacialis major durch Vermittelung des Ganglion sphenopalatinum und dessen Nervus palatinus posterior $\mathrm{zu}$ den genannten Muskeln gelangen. Der Musculus stapedius wird ebenfalls vom Nervus facialis innervirt. Der Nervus facialis enthält ausserdem schon bei seinem Ursprung viscerale Fasern (Chorda Tympani); sensible Fasern werden ihm in seinem Verlaufe vielfach vom Trigeminus beigemengt.

Von den motorischen Nervenfasern, welche der zwölfte Hirnnerv, der Nervus hypoglossus in seinen Verzweigungen führt, sind in seinen Wurzeln nur diejenigen für die Zungenmuskeln, Musculus styloglossus, hyoglossus, genioglossus (Geniohyoideus?) und lingualis enthalten. An der Bildung der Ansa cervicalis profunda nimmt er nur scheinbar Antheil. Die von letzterer versorgten Muskeln, Musculus sternohyoideus, sternothyreoideus, omohyoideus, sowie die aus dem Arcus hypoglossi durch die gleichnamigen Nervchen versehenen Musculus thyreohyoideus und geniohyoideus, erhalten ihre motorischen Nervenfasern durch Vermittelung der vorderen Wurzeln der drei oberen Halsnerven. $\mathrm{Ob}$ von den sensiblen und visceralen Fasern, welche der Nervus hypoglossus in seinem weiteren Verlaufe führt, schon einige in seinen Wurzelfäden enthalten sind, ist nicht bekannt; in Anbetracht der vielen Verbindungen, welche er mit anderen Nerven eingeht (Ganglion cervicale supremum, Plexus nodosus Vagi, Ramus lingualis Vagi, Nervus lingualis 
Trigemini, Nervus cervicalis I-III, Sympathicus) und in Anbetracht des grossen Kalibers der ausschliesslich myelinhaltigen Fasern, aus denen die Hypoglossuswurzel besteht, ist es jedoch nicht wahrscheinlich. Vermuthlich entspringt also der Nervus hypoglossus als rein motorischer Nerv fiur die eigenen Muskeln der Zunge.

Dass die motorischen Fasern, mit denen der neunte Hirnnerv, der Nervus glossopharyngeus, den Musculus stylopharyngeus (durch den gleichnamigen Nervenast) und den Musculus constrictor Pharyngis medius (durch Vermittelıng des vom Glossopharyngeus, Vagus und Accessorius gebildeten Plexus pharyngeus) versorgt, schon in der Wurzel des Zungenschlundkopfnerven vorhanden sind, wird auf experimenteller Grundlage behauptet. Auch soll der genannte Hirnnerv den Musculus glossopalatinus beherrschen und es ist vermuthet worden, dass ihm die betreffenden Fasern auf dem Wege des Ramus communicans Nervi facialis et Glossopharyngei zugeführt werden.

An der motorischen Innervation des Schlundkopfes betheiligen sich und in diejenige des Kehlkopfes theilen sich der zehnte Hirnnerv, Nervus vagus und der cerebrale Theil des sogenannten elften Hirnnerven, Nervus accessorius, in schwer aus einander zu haltender Weise. Ansser vom Nervus facialis werden Musculus palato-pharyngeus, Constrictor superior und inferior, vom Vagus - vielleicht auch Accessorius - innervirt. Die Kehlkopfmuskeln erhalten ihre motorischen Nervenfasern zwar auf der Bahn des Nervus vagus durch den Nervus laryngeus superior und inferior, doch ist es strittig, wie weit diese Fasern aus der Wurzel des Nervus vagus oder aus der des Nervus accessorius oder aus beiden stammen. Die cervicalen Wurzeln des Nervus accessorius werden als rein motorisch betrachtet, jedenfalls führen sie die Nervenfasern, mit denen sich der Ramus externus desselben an der Beherrschung des Musculus sternocleidomastoideus und cucullaris betheiligt.

c) In die Kategorie der sensiblen Nervenfasern sind nicht nur diejenigen einzubegreifen, welche bewusste Tast-, Temperatur- und Schmerzempfindungen vermitteln, sondern auch diejenigen, welche unabhängig von bewussten Empfindungen coordinirte Reflexe auslösen, oder welche hemmend in den Ablauf coordinirter Bewegungen eingreifen.

Sensible Fasern in dem ersteren strengeren Sinne des Wortes enthalten von den Hirnnerven (schon bei ihrem Ursprung) sicher nur der Trigeminus, sowie auch der Vagus, von denen aber ersterer die bei Weitem überwiegende Mehrzahl der sensiblen Hirnnervenfasern überhaupt führt. Zu dem Ausbreitungsgebiet des Glossopharyngeus gehört zwar die empfindliche Schleimhaut erstens der Mandeln, der Gaunenbögen und des Schlundkopfes, und zweitens der Paukenhöhle, der Tuba Eustachii und der Zellen des Processus mastoideus. An der Innervation 
der erst genannten Partie betheiligen sich aber anch Endrerästelungen des Trigeminus, und die demuächst aufgeführten Schleimhäute werden zwar vom Nervus tympanicus, aus dem Ganglion petrosum des Glossopharyngeus, innervirt, aber erst nachdem diesem Nerven durch Vermittelung des Ganglion oticum und Nervus petrosus superfacialis minor Trigeminusfasern beigemischt sind, sodass es zweifelhaft bleibt, ob der Glossopharyngeus überhaupt andere als die ihm eigenthümlichen Geschmacksempfindungen vermittelt.

Der Trigeminus versieht mit empfindlichen Fasern erstens die äussere Haut des Kopfes und des Gesichtes vor respective oberhalb einer Linie, die hinter dem Scheitel zur Ohrmuschel herabsteigt, diese an ihrer lateralen Fläche zwischen Anthelix und Antitragus schneidet und weiter längs des absteigenden und des horizontalen Randes des Unterkiefers verläuft; zweitens die Conjunctiva palpebrarum und oculi und die Cornea; drittens die Schleimhänte der Trase mit Nebenhöhlen, der Mundhöhle einschliesslich des harten und weichen Gaumens und der Zunge, des Schlundkopfes (wahrscheinlich auch der Tonsillen und Gaumenbögen, der Paukenhöhle, der Tuba Eustachii und der Zellen des Processus mastoideus); viertens die Zahnpulpen; fünftens einen Theil der Dura mater (Tentorium); sechstens die Augen- und Gesichtsmuskeln.

Diejenigen Partien, welche Vagusendigungen ihre Empfindlichkeit verdanken, sind erstens ein Theil der Dura mater (Gegend des Lobus sigmoideus), sowie der Sinus transversus und occipitalis; zweitens der äussere Gehörgang; drittens der Kehlkopf und die Trachea, der Oesophagus und Magen, vielleicht auch Leber, Pankreas und Milz.

Als sensible in dem angedeuteten weiteren Sinne des Wortes anzusehen sind Fasern des Opticus, welche unabhängig von bewussten Gesichtseindrücken in Folge von Petinareizung reflectorische Bewegungen der Iris oder des Accommodations- und Fixationsapparates vermitteln.

Reflexe, welche durch Erregungen ausgelöst werden, die auf Trigeminusbahnen dem Gehirn zufliessen, sind erstens Lidschluss und Thränensecretion von den Conjunctiven und von der Cornea aus; zweitens Niesen, Hemmung der Inspiration und Verlangsamung des Pulses von der Nasenschleimhaut aus; drittens Secretion der Speichel- und Magendrüsen von der Zunge und Mundschleimhaut aus; viertens Schlucken, Würgen oder Erbrechen vom Schlunde aus.

Sehr mannigfach und von grosser Wichtigkeit für das normale Verlialten des Organismus sind die centripetalen Bahnen des Vagus, welche an der reflectorischen Regulirung der hauptsächlichsten vegetativen Functionen betheiligt sind; derartige Vagusfasern vermitteln erstens Verlangsamung des Herzschlages und Erniedrigung des Blutdruckes (durch Erweiterung der Gefässe in der äusseren Haut und im Abdomen) vom 
Herzen aus. Die centripetalen Fasern, welche diesen Reflex vermitteln, verlaufen beim Kaninchen vom Plexus cardiacus his zum Laryngeus superior in einem selbststïndigen Nerven, dem Nervus depressor. Die peripherischen Enden dieser Fasern werden wahrscheinlich erregt, wenn die Herzwand unter höhere Spannung rersetzt wird. Zweitens Pulsbeschleunigung von der Lunge aus und zwar werden die Lungenendigungen der betreffenden Nervenfusern durch Ausdehnung des Lungengewebes gereizt. Drittens Hemmung der Inspiration und Anregung activer Fxspiration ebenfalls bei inspiratorischer Lungendehnung. Viertens Hemmung activer Exspiration und Anregung tiefer Inspiration bei Lungencollaps. Fünftens Husten, bei Erregung der Vagusendigungen in der Schleimhaut des Kehlkopfes und der oberen Trachea. Sechstens Secretion der Speichel- und Magendrüsen bei Reizungen von Vagusendigungen im Magen. Erreicht dieser Reiz hohe Grade der Intensität, so erfolgt Erbrechen. Noch auf einer anderen Bahn können Vagusfasern merkwürdiger Weise Erbrechen vermitteln, nümlich vom äusseren Gehörgang atus. Siebentens Schluckbewegungen können bei Thieren durch Reizung des centralen Stumpfes des Laryngeus superior ausgelöst werden.

Eine reflectorische Henmungswirkung von grosser Bedeutung wird den Fasern des Glossopharyngeus zugeschrieben. Bei Hunden soll nänılich Reizung des centralen Stumpfes dieses Nerven jede Schluckbewegung unterdriicken.

d) Unter den Begriff der visceralen Fasern kann man alle diejenigen zusammenfassen, welche zwar centrifugaler Function sind, aber keinen willkürlichen Bewegungen dienen. Hierher gehören erstens Fasern, welche die Bewegungen des Herzens, des Verdaunngsrohres und anderer Eingeweide beeinflussen, oder welche an der Beherrschung des Gefässtonus und der Weite der Pupille theilnehmen; zweitens solche, ron denen die Secretionsthätigkeit der Drïsenzellen abhängt, und drittens solche (wenn es deren ïberhaupt giebt), welche direct in den, die nutritive und formative Thätigkeit ausmachenden Stoffumsatz der Gewebselemente eingreifen (trophische Fasern). Von Fasern der ersten Kategorie sind enthalten im Halsvagus pulsverlangsamende und pulsbeschleunigende, constrictorische für Oesophagus, Magen (inclusive Cardia und Pylorus) und Darm, und auch solche für eine active Erweiterung der Cardia, welche letztere auf Contraction der vom Oesophagus in die Mageuwand iibergehenden Längsmuskeln zurückzuführen ist.

Der Stamm des Nervus facialis führt gefässverengernde Fasern für die Wangen und Lippen; in der Wurzel des Facialis sind, wie Experimente an Hunde ergeben haben, gefässerweiternde Fasern für die Schleimhaut folgender Partien vorhanden: vordere zwei Drittel der Zunge oben und unten, Boden der Mundhöhle, Frenulum, innere Fläche 
des Alveolarfortsatzes, weicher Gaumen, Gaumensegel und Gaumenbögen bis zur Tonsille. Die Röthung der Zunge erfolgt durch Vermittelung der Chorda tympani, deren Reizung auch Gefässerweiterung in der Glandula submaxillaris zur Folge hat. Ob die Wurzeln des Glossopharyngeus an der Röthung des Gaumensegels betheiligt sind, blieb zweifelhaft. Centrifugale Reizung des Nervus Trigeminus, central vom Ganglion Gasseri, veranlasst Gefässer'weiterung in der Schleimhaut der Lippen, der Wangen, des Zahnfleisches und der Nase, peripher vom Ganglion, ausserdem Röthung der Conjunctiva oculi.

Der Stamm des Nervus hypoglossus führt gefässverengernde Fasern für die Zunge.

Zur Orientirung ïber die Frage, welche der Fasern schon in den Wurzeln der genannten Hirnnerven vorhanden seien, kann man vorläufig an einer Eintheilung der Fasern in zwei Gruppen festhalten, für die erste Gruppe, welche die pulsverlangsamenden, die gefässerweiternden und die pupillenverengernden Fasern umfasst, liegt die grössere Wahrscheinlichkeit ihres Ursprunges mit den Hirnnervenwurzeln vor; die Fasern der anderen Gruppe (pulsbeschleunigende, gefässverengernde, pupillenerweiternde) werden wahrscheinlich erst den Nervenstämmen vom Sympathicus aus beigemischt.

Secretorische Fasern sind enthalten in den Wurzeln des Trigeminus, des Glossopharyngeus und Vago-accessorius. Vom Trigeminus und zwar von seiner hinteren Wurzel aus, wird auf der Bahn des ersten und auch des zweiten Astes die Thränendrüse innervirt. Der Nervus buccalis aus dem dritten Ast des Trigeminus erhält die Fasern, mit denen er der Secretion der Glandulae molares, labiales und buccales vorsteht, von dem Glossopharyngeus. Aus letzterem stammen auch - und zwar auf dem Wege des Nervis petrosus superficialis minor und des Ganglion oticum - die secretorischen Fasern, welche der Nervus auriculotemporalis der Parotis zufiihrt. Die Herrschaft, welche der Nervus lingualis über die Secretion der Submaxillardrüse ausübt, verdankt er Fasern der Chorda tympani aus dem Facialis. Im Stamme des Glossopharyngeus des Kaninchens sind Fasern enthalten, deren Reizung Secretion der acinösen Drüsen zwischen den Falten der Papilla foliata zur Folge hat. Der Vago-accessorius beherrscht die Magendrüsen.

Iie Existenz trophischer Fasern in dem Trigeminus für die Cornea, die Conjunctiva und die Mundschleimhant, sowie in dem Vagus für die Lungen und das Herz, ist auf Grund von experimentellen Erfahrungen behauptet worden, deren Vieldeutigkeit zu lösen aber nicht gelungen ist. Fasern von merkwürdiger nicht völlig aufgeklärter Function sind in der Chorda tympani enthalten. In der Zeit, während welcher nach Durchschneidung des Hypoglossus die Nervenendigungen der Zungen- 
muskeln in Degencration begriffen sind, löst centrifugale Reizung der Chorda eigenthümliche Bewegungen von protrahirtem Verlauf in den Zungenmuskeln aus. Es scheint, dass die motorischen Nervenendigungen bei gewissen Degenerationszustïnden empfindlich gegen vermehrte interstitielle Lymphströmung sind und dass die dic Zungenbewegungen vermittelnde Lymphausscheidung durch Reizung der Chorda angeregt werden kann. Ob hierbei die Fasern des Paukenstranges nur durch ihre gefässerweiternde Function wirksam sind, oder ob sie durch anderweitigen directen Einfluss auf celluläre Gewebselemente die Lymphbewegungen beeinflussen, steht noch in Frage.

Sympathicus oder besser sympathisches Nervensystem nennt man die Nervenplexus und Nervenzellenanhäufungen, welche die meisten visceralen Nerven auf dem Wege von ihrem Ursprunge im Medullårrohr bis zu ihrer peripherischen Endigung in den Körpereingeweiden zu passiren haben. In den Verlauf der somatischen, für die Bewegungen des Körperskelettes und für die Sinnesflächen bestimmten Nerven sind zwischen dem cerebrospinalen Rohr mit den Spinalganglien einerseits und dem peripherischen Endapparat andererseits keine Nervenzellen eingeschaltet. Anders ist dies bei den visceralen Nerven. Für die den Blutgefässen, dem Herzen, dem Verdaunngsrohre, dem Bronchialbaum, der Leber, Milz und den Nieren, dem Uterus, der Harnblase, der Iris zustrebenden Nervenfasern ist es charakteristisch, dass in ihre Baln Nervenzellen eingeschaltet sind, welche sich durch ilıre Lage, Anhäufungsart und Struktur als nicht zum Centralnervensystem gehörig kennzeichnen.

Es giebt wesentlich zwei Kategorien solcher sympathischer Nervenzellenanhäufungen. Die der einen Kategorie angehörigen liegen lïngs der Wirbelsäule bilateral symmetrisch angeordnet und jedes Paar derselben entspricht im Allgemeinen je einer Körpermetamere. Es sind dies die durch den sogenannten Grenzstrang des Sympathicus unter einander verbundenen sympathischen Ganglien. Diese werden als laterale, den collateralen oder distalen Ganglienzellenanhäufungen der zweiten Kategorie gegenüber gestellt, welche zum Theil in der Nähe der Eingeweide liegen, für welche ihre Fasern bestimmt sind (Ganglion coeliacum, Ganglien des Plexus hypogastricus), zum Theil in den Eingeweiden selbst (Herzganglien, Auerbach'sche und Meissner'sche Plexus, Ganglien der Cardia, Ganglien des Uterus und der Blase).

Die Nervenzellen der sympathischen Ganglien sind beim Menschen und den höheren Wirbelthieren multipolar; sie sind von einer Scheide 
umgeben, welche die an Zahl sehr variablen Fortsätze als Schwann'sche Scheide begleitet.

- Die vom cerebrospinalen Centralorgane den sympathischen Nervenzellen zustrebenden Nervenfaseru sind myelinhaltige Fasern mittleren und kleineren Calibers; sie verhalten sich zu den sympathischen Nervenzellen wahrscheinlich wie die Axencylinderfortsätze zu den Deiters'schen Zellen; inwieweit sich die iibrigen Zellfortsätze, indem sie zu Nervenfasern werden, mit einem Myelimmantel umgeben, ist schwer zu entscheiden, für einen grossen Theil der der Peripherie zustrebenden Fasern wird behauptet, dass sie es nicht thun: diese Fasern, welche jedenfalls kleinsten Calibers sind, werden als myelinfreie Nervenfasern beschrieben. Peripher von den letyten sympathischen Zellenstationen sollen nur noch myelinfreie Fasern vorkommen, und bei jeder Zellenstation soll in der sympathischen Nervenbahn die Zahl der myelinhaltigen Fasern ab-, die Zahl der myelinlosen dagegen in weit stärkerem Maasse zunehmen. Hiernach müssten die aus dem cerebrospinalen Centralorgane stammenden Fasern bei dem Durchtritt durch sympathische Nervenzellen den Myelinmantel verlieren (oder wenigstens an Caliber sehr bedentend abnehmen) und sich gleichzeitig in eine grössere Zahl von Bahnen theilen.

Zwei functionell antagonistische Gruppen visceraler Nervenfasern sollen in ihren Beziehungen zu den sympathischen Zellenanhäufungen einen bestimmten Gegensatz zeigen. Die der Vasoconstriction, der Herzbeschleunigung und der Contraction der Ringmuskeln der Hohlorgane (Darm, Blase, Uterus) vorstehenden Faser'n sollen zu dem System der lateralen Ganglien (Grenzganglien des Sympathicus und Ganglion truncivagi) in nähere Beziehung treten; die Fasern der anderen Gruppe (Vasodilatation, Herzhemmung und Längsnuskelcontraction) zu den collateralen oder distalen Ganglien.

Die in cerebrospinalen Centralorgane wurzelnden visceralen Nervenfasern werden dem sympathischen Nervensystem grösstentheils auf der Bahn der Rami communicantes zugeführt. Die Rami communicantes, welche hauptsächlich Fasern aus den vorderen Spinalwurzeln führen, verlassen die Spinalnerven bald nach deren Formation und begeben sich in regelmässiger Folge zu den metamerisch zugehörigen Grenzganglien des Sympathicus.

Die meisten Fasern dieser Rami communicantes sind myelinhaltig; die wenigen myelinfreien Nervenfasern derselben konnten nur bis zur Duralscheide der Spinalwurzeln verfolgt werden; sie scheinen also zu den Nervenzellen der Grenzganglien im Verhältniss peripherischer Nervenfasern (Gefässnerven der Dura mater?) zu stehen. Die dem Grenzstrang des Sympathicus beigemischten Nervenfasern jedes dieser Rami communicantes bleiben für die Strecke mehrerer Metameren in dieser Bahn, 
um sich dann auf verschietene Weise abzulösen. Ein Theil der Fasern bilket ein ziemlich regelmässiges System einer zweiten Art ron Rami communicantes, welche sich von den Grenzganglien in peripherischer Richtung zu den Stïmmen der Spinalnerven zuriickbegeben. Das weitere Schicksal dieser sympathischen Nervenfasern ist schwer zu ermitteln, da sie sich den cerebrospinalen Nervenfasern innig beimischen. Vermuthlich werden diese Bahnen von den Gefäissnerven für den Rumpf und für die Extremitäten eingeschlagen.

Andere sympathische Nerrenfasern bleiben auf längeren Strecken zu anatomisch gut verfolgbaren Stämmen vereinigt, hierher gehören der Halssympathicus and die Nerri splanchnici.

Der Halssympathicus ist eigentlich der den Metameren des Halses zugehörige Theil des Grenzstranges. Doch ist die Zahl der Ganglien hier weit kleiner, als die der Metameren. Sicher findet man beim Menschen nur ein oberstes sympathisches Halsganglion als anatomisch gut differenzirtes Gebilde. Das unterste Ganglion ist oft mit dem obersten Brustganglion zu dem Ganglion stellatum verschmolzen. Häufig aher nicht regelmässig, findet man auch ein kleines mittleres Halsganglion. Die Hauptmenge der Fasern erhält der Halssympathicus aus dem Ganglion stellatum, doch geht jedes seiner Ganglien auch mit mehreren cervicalen Spinalnerven Verbindungen ein.

Bei Thieren erzengt elektrische Reizung des mit dem Kopf in Verbindung stehenden Stumpfes des Halssympathicus allgemeine Verengerung der Gefässe am und im Kopfe (ausser an der Schleimhaut von Wange, Lippen und Zahnfleisch, wo Röthung eintritt), ferner Erweiterung der Pupille und Vortreten des Augapfels (in Folge ron Contraction des glattfaserigen Müller'schen Musculus orbitalis). Die Herkunft der diese complicirte Wirkung bedingenden Nervenfasern des Halssympathicus aus dem cerebrospinalen Centralorgane ist mit aller Sicherheit erwiesen. Es besteht hier jedoch kein einheitliches Centrum, mit dessen Erregung sich der geschilderte Symptomencomplex ohne weiteres verbände; im Verlaufe des normalen Geschehens können vielmehr die verschiedenartigsten Combinationen eintreten, zum Beispiel Pupillenerweiterung bei Conjunctivalröthung, oder Erweiterung der Gehirngefässe bei Blïsse der Gesichtshaut. Die Reizung des Halssymphaticus hat auch einen bestimmten, später genaner zu erörternden Einfluss auf die Speichelsecretion, welche nicht nur durch Vermittelung der Vasoconstriction, sondern auch durch eine directe Einwirkung von Nerven anf secretorische Zellen zu Stande zu kommen scheint. Bei einem Kaninchen, welchem der Halssympathicus anf der einen Seite durchschnitten ist, zeigt sich das zugehörige $\mathrm{Ohr}$ geröthet und fühlbar erwärmt, die Pupille etwas (aber nicht viel) enger, als auf der anderen Seite, die Conjunctiva geröthet. 
Aus dem distalen Ende des Ganglion cervicale superius entspringt der Ramus cardiacus superior und aus dem Ganglion stellatum der Ramus cardiacus inferior, welche gemeinschaftlich mit Nervenzweigen des Vagus den Plexus cardiacus formiren. Beim Thiere ergiebt elektrische Reizung der in den genannten Plexus eintretenden Fasern des Vagus sicher Verlangsamung des Herzschlages (bis zum Stillstand in Diastole), während durch elektrische Reizung des Ramus cardiacus inferior sympathici ebenso sicher Beschleunigung des Herzschlages zu erreichen ist. Die Herkunft der Fasern des letzteren Nerven ist ebenfalls bekannt, sie stammen aus dem Dorsalmark und gesellen sich dem Grenzstrang des Sympathicus durch Vermittelung der fünf bis sechs obersten thoracalen Rami communicantes bei.

Der Nervus splanchnicus major besitzt eine deutlich weisse Farbe, welche er seinem Gehalt an myelinhaltigen Nervenfasern verdankt. Diese werden ihm durch die Rami communicantes des vierten bis neunten Dorsalnerven direct aus dem Rückenmark zugeführt; im Grenzstrang angelangt ziehen sie zunächst an der medialen Seite der Ganglien festgeschlossen herab, um früher oder später in einer der Splanchnicuswurzeln den Grenzstrang zu verlassen. Letzterer besteht innerhalb dieses Gebietes deshalb aus der Ganglienkette mit weisslich grauen Längscommissuren und einem medianwärts angelagerten weissen Strange von Fasern, welche an den Ganglien vorbeiziehen. Der Nervus splanchnicus minor entwickelt sich gewöhnlich mit zwei Wurzeln aus dem Grenzstrange im Gebiete der beiden letzten Dorsalganglien.

Die beiderseitigen Splanchnici vereinigen sich mit den Vaguszweigen zur Formation des an Nervenzellen ungemein reichen Plexus solaris. Die umfangreichste Zellenanhäufung dieses Plexus ist das Ganglion coeliacum, welches den Ursprung der Arteria coeliaca und Arteria mesenterica superior umgiebt. Von dem Ganglion coeliacum gehen reichliche Nervenverbindungen zu Magen, Darm, Leber, Pancreas, Milz und Nieren. Eine dieser Verbindungen ist der Plexus mesentericus superior, welcher die Arteria mesenterica und ihre Verzweigungen begleitet und auf diesem Wege noch Vagusfasern aufnimmt: er versorgt Pancreas, Duodeuum, Jejunum, Coecum, Colon ascendens und Colon tranversum. Am Mesenterialrande angekommen, treten die Nerven zunächst unter der Serosa in geflechtartige Verbindungen und gelangen dann in den Plexus mesentericus externus ( $\mathrm{A} u \mathrm{er} \mathrm{bach}$ ) und durch dessen Vermittelung zum Plexus myentericus internus (Meissner). Die aus den Nervenzellen dieser Plexus in der peripherischen Richtung hervorgehenden Nervenfasern stehen zweifellos mit den Muskelfasern der Darmwand in Verbindung; über centripetale Fasern dieses Gebietes ist wenig bekannt.

Aus dem unteren Rande des Ganglion coeliacum entwickelt sich der 
parige Plexus aorticus abdominalis, welcher die Bauchaorta beiderseits beglcitet, und Fascru aus dem lumbalen Grenzstrang aufnimmt. Zur Wurzel der Arteria mesenterica inferior entsenden beide Stränge dieses Plexus eine Anzahl ron Nerren, welche nach Durchsetzung des Ganglion mesentericum inferius als Plexus mesentericus inferior die genannte Arterie mit ihren Verzweigungen begleitet, um das Colon descendens, die Flexura sigmoidea und den oberen Theil des Mastdarms zu versorgen. Sie verhalten sich hierbei in analoger Weise wie die Fasern des Plexus mesentericus superior.

Unterhalb der Theilungsstelle der Bauchaorta wird der Plexus abdominalis unpaar und zieht als Plexus hypogastricus superior bis zum Promontorium, um sich hier wieder bei dem Eintritt in das kleine Becken zu theilen und als Plexus hypogastricus inferior bis zum Beckengrunde zu gelangen. Auf dem Wege dorthin treten riele Fasern aus dem Sacraltheil des Grenzstranges und mindestens ebenso viele direct aus den sacralen Spinalnerven hinzu.

Aus dem Geflecht des Beckengrundes entwickehn sich für dic Beckeneingeweide zahlreiche Nerrenfäden, die somit aus spinalen und sympathischen Nerrenfasern zusammengesetzt sind. Sie bilden kleinere Geflechte, welche theilweise in Begleitung der visceralen Aeste der Arteria hypogastrica zu ihren Organen verlaufen. Zwei der Geflechte sind dem männlichen und weiblichen Geschlecht gemeinsam, nämlich das Mastdarm- und Blasengeflecht; zwischen beiden schiebt sich beim Manne der Plexus seminalis und deferentialis ein, der nach unten und vorn durch den Plexus prostaticus in den Plexus cavernosus übergeht, überdies nit dem Plexus resicalis zusammenhängt. Beim Weibe tritt an die Stelle dieser Geflechte der Plexus utero-raginalis, während ein schwacher Plexus cavernosus hier vorzugsweise rom Blasengeflecht geliefert wird. Den Ureter versorgt der Plexus hypogastricus inferior direct mit einigen Nervenfäilen.

Was mun die Function der nervösen Fasern und Zellen der Bauchund Beckeneingeweide betrifft, so ist einerseits ein bedeutender Einfluss des Centralnervensystems auf dieselbe zwar mit Sicherheit erkannt, andererseits kann aber auch eine gewisse Selbstständigkeit der distalen sympathischen Ganglienzellenanhäufungen nicht geleugnet werden. Zweifellos sind die Zellen derselben in ihrem Erregungszustande nicht nur von centrifugal auf Nerrenbahnen zugeleiteten Erregungen abhängig, sondern auch ron der chemischen und physikalischen Beschaffenheit ihrer unmittelbaren Umgebung. Man pflegt dieses so auszudrïcken, dass man ihnen automatische Thätigkeit zuschreibt. Zweifelhafter kann es erscheinen, ob diese Zellen auch als Reflexapparate wirken.

Die den distalen sympathischen Ganglien zustrebenden centrifugalen 
Nervenbahnen scheinen in einem gewissen functionellen Gegensatz zu einander zu stehen, je nachdem sie durch Vermittelung der Grenzganglien und des Grenzstranges des Sympathicus ihr Ziel erreichen oder directere Wege von dem Cerebrospinalorgane aus einschlagen (Vagus, sacrale Spinalnerven). Seit lange hat man sich die Ansicht gebildet, dass der Nervus splanchnicus die peristaltische Bewegung des Darmes hemme, der Vagus sie anrege. Freilich fielen die zur Demonstration dieser Ansicht angestellten Experimente in der Hand bewährter Forscher nicht immer zweifellos aus. Am häufigsten gelang es, wenigstens beim Kaninchen, die Hemmung der Peristaltik durch Reizung der Splanchnici zu zeigen. Gleichzeitig erblassen die Därme. Neuerdings wurde angegeben, dass es beim Hunde gelinge, Peristaltik in den Dünndärmen durch Yagusreizung sicher anzuregen, wenn vorher gewisse Hirntheile zerstört seien; diese sollen, so lange sie erhalten sind, einen dauernden hemmenden Einfluss ausïbẻn, welchen die stärkste Vagusreizung selten zu überwinden im Stande sei. Nach Zerstörung der betreffenden Hirntheile soll auch Röthung des Darmes eintreten.

Speciellere Angaben ïber den fraglichen Antagonismus sind folgende: bei Hunden sollen die Nervi erigentes (aus dem Sacralgeflecht) motorische Fasern für die Längsmuskeln des Rectum führen, die Nervi hypogastrici dagegen (aus dem Ganglion mesentericum inferius) motorische für die Ringmuskeln und hemmende für die Längsmuskeln. Für den Dünndarm des Hundes wird dem Nervus splanchnicus motorischer Einfluss auf die Längsmuskeln und hemmender auf die Ringmuskeln zugeschrieben, während der Nervus Vagus ihm in diesen beiden Beziehungen antagonistisch sein soll.

Von centripetalen Nervenfasern im Sympathicus sind am sichersten dicjenigen nachgewiesen, welche bei Reizung des Splanchnicus oder seiner Ausbreitungen in den Därmen reflectorisch Herzstillstand erzeugen. 


\section{Sechster Abschnitt.}

\section{Physiologie der Sinne.}

Die Sinne liefern uns den Inhalt fuir das Bewusstsein. $\mathrm{Zu}$ einer rollkommenen Sinnesfunction gehört die Betheiligung des Bewusstseins, wenn auch Theile ron Sinnesapparaten mit ihrer Thätigkeit in unbewusste Reactionen gegen die Aussenwelt eingreifen, und weun auch bei dem Gebrauch der Sinne die Aufmerksamkeit sich stets nur einem kleinen Theile der jeweiligen Sinneseindrücke zuwenden kann.

Das Element des Bewusstseinsinhaltes ist das Gewahrwerden einer Aenderung unseres inneren Zustandes. Solche Aenderungen rerknüpfen sich in regelmässiger Weise mit Erregungen, welche auf bestimmten, nicht allen, centripetalen Nerrenbahnen in unser Centralnerrensystem und dort bis zu bestimmten Theilen der Hirnrinde gelangen. Die peripherischen Endigungen der meisten dieser Sinnesnerren sind so gelegen, dass sie der Einwirkung ron Zustandsänderungen der unseren Körper umgebenden Medien in flächenartiger Ausbreitung ausgesetzt sind. Die eigentlichen nerrösen Endigungen der Sinnesnerrenfasern sind an den rerschiedenen Sinnesflächen mit rerschiedenen, an sich nicht nerrösen Apparaten rerbunden, welche nur bestimmten äusseren Zustandsänderungen eine Einwirkung auf die zugehörigen Nerrenfasern gestatten, für die Umsetzung dieser Zustandsänderungen in Nerrenerregung aber auch ganz besonders leistungsfähig sind. Vermittelst der einen Sinnesfläche wirken auf unser Bewusstsein nur diejenigen rhythmischen Zustandsänderungen des Aethers, welche man Licht nennt; rermittelst der anderen nur rhythmische Druckschwankungen der Luft, innerhalb gewisser Grenzen, als Schall und so weiter. Diejenige äussere Einwirkung, fuir deren Uebertragung auf Sinnesnerven eine Sinnesfläche eingerichtet ist, nennt man den a d̈̈ quaten Reiz derselben.

Die Abgrenzung rerschiedener Sinnesgebiete ron einander entspringt einerseits der Kenntniss ron der Verschiedenheit in den Beziehungen der einzelnen Sinnesflächen zu der Aussenwelt, andererseits den Erfahrungen der inneren Selbstbetrachtung. Wenn wir das ganze Material des uns ron den Sinnen gelieferten einfachen Bewusstseinsinhaltes durchmustern, so finden wir Gruppen rou Bewusstseinszuständen, deren Glieder sich ohne Weiteres als zusammengehörig und ron den Gliedern anderer 
Gruppen getrennt darstellen. Die Gruppen entsprechen ungefähr dem, was man im gewöhnlichen Leben die fünf Sinne zu nennen pflegt, Gesicht,-Gehör, Geschmack, Geruch, Gefühl. Die Mannigfaltigkeit der innerhalb eines jeden dieser Sinnesgebiete verschiedenartig erscheinenden Sinneseindrücke ist eine sehr grosse, aber alle möglichen Gesichtseindrücke haben unter einander, schon für das unmittelbare Pewusstsein, einen höheren Grad ron Aehnlichkeit, als werin man sie mit denen des Gehöres oder eines der anderen Sinne vergleicht. Dieses unmittelbare Bewusstsein von der Trennung der gesammten Sinneswalırnehmungen in Qualitäten-Kreise ist vielleicht entstanden und wird jedenfalls wachgehalten durch die Erfahrungen der Zugehörigkeit der verschiedenen Qualitäten-Kreise zn verschiedenen Sinnesflächen: die Wahrnehmungen der Gesichtsqualität erhalten wir gemeinhin nur bei offenen Augen; die der Gehörsqualität schwinden uns, wenn wir die Ohren verschliessen, und so weiter.

Eine zweite Ursache fiur die Trennung liegt in der Erfahrung, dass es kaum möglich ist, zwischen zwei einzelnen Sinneswahrnehmungen, welche verschiedenen Qualitäten-Kíreisen angehören, einen Vergleich in Bezug auf die Intensität anzustellen. Sie erscheinen uns incommensurabel. Zwei einfache Gehörswahrnehmungen können sich durch verschiedene Tonhöhen qualitativ deutlich von einander unterscheiden, und es drängt sich uns doch ein Urtheil darüber auf, welche von beiden lauter, das heisst quantitativ stärker war. Zu einem quantitativen Vergleich zwischen einem Gehörs- und einem Gesichtseindruck fühlen wir uns aus innerem Antriebe kaum jemals bewogen, und wenn ein derartiges Urtheil von uns verlangt werden sollte, so wïrden wir wegen der Antwort meistens in Verlegenheit gerathen.

Uebrigens ist ein genauer quantitativer Vergleich zwischen verschiedenartigen Sinneswahrnehmungen auch innerhalb desselben Qualitäten-Kreises nicht möglich, und wemn er uns auch möglich erscheinen sollte, so fehlt hier die genaue Controlle durch das Experiment. Wenn wir zwei gleich grosse Flächen durch denselben Theil des Spectrums rerschieden stark beleuchten, so kömnen wir einerseits aussagen, welche Flïche uns heller erscheint, und wir können andererseits in zuverlïssiger oljectiver Weise die Energiemengen mit einander vergleichen, welche den die beiden Flächen treffenden Lichtmengen entsprechen. An der Hand dieser Controlle lässt sich feststellen, dass noch sehr kleine Helligkeitsunterschiede in der Beleuchtungsintensität der beiden Flächen richtig erkannt werden. Verwendet man zur Beleuchtung beider Flächen verschiedene Theile des Spectrums, so kann man zwar auch noch die objectiven Energiemengen des die Flächen treffenden Lichtes in ihrem geniuten Verhältniss angeben, nicht aber deu etwaigen Unterschied im 
Energieverlust, welchen die Aetherschwingungen rersehiedener Frequenz anf dem Wege bis zur Sinnestüche erleiden können.

Welche $\Lambda$ rt ron :̈usseren Zustandsänderungen den adäquaten Reiz fuir ein Sinnesgebiet abgiel,t, hängt in theilweise erkannter, jedenfalls principiell nicht nnerkennbarer Weise ron der Lage und inneren Einrichtung der Sinnesfläche ab; dass dagegen mit der Erregung der ron einer Sinnestläche kommenden Nerrenfasern Sinneswahrnehmungen eines bestimmten Qualitäten-Kreises verbunden sind, ist eine Thatsache, welche wir als solche hinnelmen müssen, ohne Aussicht auf eine Erklärung derselben zu haben. Man driickt diese Thatsache aus, indem man sagt: die specifische Energie des Nerrus opticus ist das Sehen, des Nerrus acusticus das Hören, nnd so weiter.

Nit der Erregung eines bestimmten Sinnesnerven rerbindet sich nicht nur dann eine, einem bestimmten Qualitäten-Kreise zugehörige Sinneswahrnehmung, wenn die Erregung in normaler Weise ron der Sinnesfläche ausgegangen war, sondern auch dann, wenn der Nerr in seinem Verlauf gereizt wurde. Durch plötzliches Seitlichwenden des Blickes kann man die Nervi optici zerren; thut man dies im dunkelen Zimmer oder bei rerschlossenen Augen, so hat man die Erscheinung zweier aufblitzender Lichtringe. Es ist öfters rorgekommen, dass Personen, denen ein Auge ohne Narkose exstirpirt werden musste, wenn sie durch den Schmerz und durch den Affekt ihrer peinlichen Lage nicht zu sehr in Anspruch genommen waren, bei Durchschneidung des Sehnerren angegeben haben, sie hätten die Erscheinung eines starken Blitzens gehalst. Wenn man den Stamm des Nervus ulnaris in dem Sulcus ulnaris tetanisirt, oder zwischen den Fingern drïckt, so hat man Empfindungen in seinem Ausbreitungsgebiet an den Fingern, welche den Druck- und Temperaturempfindungen zwar nicht gleichen, denselben aber doch ähnlicher sind, wie anderen Sinnesempfindungen.

Nimmt man zu den an Sinnestlächen und an Stämmen ron Sinnesnerren sich darbietenden Beobachtungen die anf anatomischem und experimentellem Wege gewonnene Erkenntniss hinzu, dass die Hirnrinde des Hinterhauptlappens zum Sehnerven und zum Gesichtssinn und diejenige des Schläfenlappens zum Gehörsinn in naher Beziehung steht, so kommt man zu der Vorstellung, dass Sinneswahrnehmungen, welche einem bestimmten Qualitïten-Kreise angehören, entstehen, wenn innerhalb einer bestimmten Partie der Hirnrinde Erregung eintritt, und dass die Erregung fuir gewöhnlich auf der Bahn der zugehörigen Sinnesnerven zugeleitet wird, nachdem sie in der zugehörigen peripherischen Sinnesfläche unter der Einwirkung des adäquaten Reizes entstanden ist. Dafür, dass wir Actherschwingungen innerhalb einer gewissen Breite der Frequenz mit dem Gesichtssinn als Licht wahmehmen, gäbe es also zwei Gründe, erstens, dass das Auge 
so eingerichtet, dass es diese Aetherschwingungen und nichts weiter in Nervenerregung der Opticusausbreitung am Augengrunde umzusetzen im Stande-ist, und zweitens darin, dass der Nerrus opticus die in ihm entstandene Erregung einer bestimmten Partie der Hirnrinde zuleitet. Das Analoge kann man mit dem gleichen Grade von Verständlichkeit von dem Gehörsinn aussagen.

Eine weitere Vertiefung hat die Lehre von den specifischen Sinnesenergien dadurch erhalten, dass man sie ron der Betrachtung der Sinnesnerrenstämme auf die Betrachtung der diese Stämme zusammensetzenden einzelnen Nervenfasern übertragen hat. Als nerröses Element eines Sinnesapparates wird danach angesehen eine Sinnesnervenfaser mit ihrer peripherischen und centralen Endigung. Mit der Erregung dieses Elementes rerknïpft sich eine specielle, dem betreffenden QualitätenTíreise von Sinneswahrnehmungen angehörige Elementarempfindung. Eine bestimmte Nerrenfaser, zum Beispiel des Nervus acusticus, hat ihre peripherische Endigung an einem bestimmten Punkte des inneren Ohres und ihre centrale Endigung in einer bestimmten Ganglienzelle des Schläfenlappens; tritt diese Ganglienzelle in Erregung, so tritt die Empfindung eines bestimmten Tones, etwa des c (von 128 Schwingungen) ein. Beim gewöhnlichen Hören wird die Erregung dieser Ganglienzelle durch die zugehörige Acusticusfaser von der peripherischen Endigung derselben aus zugeleitet. Letztere ist im inneren $\mathrm{Ohr}$ mit einem mechanisch wirksamen Apparat verbunden, welcher in Mitschwingung geräth, weun die das Trommelfell berührende Luft 128 Mal in der Secunde schwingt. Der adäquate Reiz für das betrachtete Hörsinneselement ist der Schwingungszustand der Luft, welcher entsteht, wenn im Hörbereich eine Stimmgabel c angestrichen wird und die specifische Energie desselben Hörsinneselementes ist das Hören des Tones c.

Ein Hauptrorzug dieser Vorstellung beruht darin, dass man bei derselben den Erregungsprocess in der Nervenfaser überall als gleichartig und nur der Quantität oder Intensität nach abstufbar betrachten kann. Der einzige Unterschied im materiellen Substrat verschiedenartiger Elementarempfindungen würde nur in der Individualität der Sinnesnervenelemente liegen; auf dem Gebiete des Gehörsinnes hat sich bisher noch nicht der Versuch geltend gemacht, diese einfachste der möglichen Vorstellungen zu verlassen. Auf dem Gebiete anderer Sinne aber hat man wiederholt versucht, schwer verständliche Erscheinungen dadurch der Erkenntniss zugänglicher zu machen, dass man die Möglichkeit qualitativer Unterschiede des Erregungsprocesses in der Nerrenfaser voraussetzte. Zur Zeit der Entstehung und Ausbildung der Lehre von den specifischen Energien fehlte es für diese Voraussetzung an jedem thatsächlichen Anhalt; seitrlem sind allerdings Erscheinungen bekannt ge- 
worden, welche auf zeitliche Verschiedenartigkeit in den Intensitätsinder'ungen der Nervenerregung linweisen. Zu der Annahme solcher Versehiedenartigkeit sind wir oben bei Betrachtung des verschierlenen Verhaltens centripetaler und centrifugaler Nerven gegen dieselben Reizmittel genöthigt worden (Seite 75 ).

In der That muss ja auch die Erregungsintensität in jeder motorischen Nervenfaser, während sie den zugehörigen Muskelfasern Impulse zu einem willkürlichen Tetanus zuleitet, in rhythmischer Schwankung begriffen scin, und wenn sie 8 bis 16 Mal in der Secunde zwischen zwei Grenzwerthen auf und nieder geht, so kann dies nach Gesetzen stattfinden, welche in analoger Weise verschieden sind, wie die Gesetze, nach denen sich die Stromintensität in einem Telephondraht ändert, während er verschiedene Laute zwischen Geber und Empfänger vermittelt. Man kann dicsen Vergleich als solchen gelten lassen, auch wenn man sich vollkommen dessen bewusst ist, dass die Leitung der Erregung im Nerven auf anderen Processen beruht, als die Leitung der Elektricität in einem metallischen Draht.

Auch in einer Nervenfaser des Acusticus könnte die Erregungsintensität rhythmisch schwanken, während sie die Wahrnehmung eines Tones rermittelt, und Analoges gilt ron den übrigen Simesnerven. Die wenigen Andentungen aber, welche wir darïber besitzen, dass der Rhythmus der Erregungsschwankung in der Nerrenfaser variiren kann, berechtigen uns noch nicht zu der Annahme einer solchen Mannigfaltigkeit der Variationsfähigkeit, wie sie erforderlich sein würde, wenn den Qualitätsunterschieden in der Empfindung Unterschiede in der Schwankungsform der Erregung entsprechen sollten; es wïrde also auch jetzt noch an einer genügenden thatsächlichen Grundlage gebrechen, um die Annahme der Lehre ron den specifischen Energien zu verlassen, dass sich mit der Erregung einer bestimmten Sinnesuervenfaser eine Empfindung verbindet, welche in ihrer Qualität ein für allemal durch die centrale Verknüpfung dieser Nervenfaser bestimmst ist, und welche quantitativ ron der Gesimmtintensität des zugeleiteten Erregungsprocesses abhängt.

Im Laufe des gewöhnlichen Geschehens wird es nie vorkommen, dass eine Sinnesnervenfaser allein erregt wird, wohl aber, dass die gleichzeitig erregten Nervenfasern nicht nur denselben sinnlichen QualitätenKrreisen zugehören, sondern auch, dass sie qualitativ gleiche Empfindung vermitteln; es kann dann noch, abgesehen von quantitativen Unterschieden, ein Unterschied bestehen, wolcher sich an die Orte der Sinnesfläche knïpft, von denen die Erregung ausgeht. Man drückt dies ans, indem man sagt, die Empfindungen seien durch ihr Localzeichen unterschieden; ein fernerer Unterschied kann bestehen in Bezug auf den psychischen Affekt, welcher sich mit der Empfindung verbindet. Es giebt Empfin- 
dungen, welche uns weder Behagen noch Missbehagen verursachen, und andere, welche uns nicht nur das Material für eine affektlose Orientirung -in der Aussenwelt liefern, sondern welche unmittelbar unser Begehren oder unseren Abscheu erwecken. Die vollständigen Attribute einer elementaren Sinnesempfindung sind also Quantität oder Intensität, Qualität, Localzeichen und Beziehung zum Affekt. Jede einzelne unserer Sinneswahrnehmungen besteht aus einem Complex von Empfindungselementen, welche sich durch alle oder einzelne ihrer Attribute von einander unterscheiden, welche sich aber doch in ihrer Gesammtheit für unser umbefangenes Bewusstsein als etwas Einheitliches darstellen können. Es ist eine wichtige, aber oft schwer zu lösende Aufgabe der Sinnesphysiologie, aus den scheinbar einheitlichen Sinneswahrnehmungen die dieselben constituirenden Empfindungselemente herauszuschälen.

Thatsächlich belehren uns unsere Sinneswahrnehmungen nur ïber Zustandsänderungen unserer eigenen Sinnesflächen; da aber diese Zustandsänderungen in regelmässiger Weise durch äussere Gegenstände hervorgerufen werden, welche mit ihren verschiedenen Eigenschaften auf unsere Sinnesflächen zu wirken in die Lage kommen, so beziehen wir unsere Sinneswahrnehmungen meistens auf diese Eigenschaften der Körper ausser uns, wir projiciren sie nach aussen. Der Zwang, mit welchem dies geschieht, ist auf verschiedenen Sinnesgebieten ein verschieden starker: bei offenem Auge und am hellen Tage erscheinen uns alle Gesichtswahrnehmungen umwiderstehlich als der Ausdruck von Eigenschaften im Raume ausser uns vorhandener Gegenstände; bei der Berührung eines warmen Körpers können wir zweifelhaft bleiben, ob wir unsere eigene Haut warm fühlen oder die Wärme eines äusseren Objektes empfinden.

So umfassend auch die Mittel sind, welche uns unsere Sinne zur richtigen Orientirung über die Zustände unseres eigenen Körpers und über die Beziehungen desselben zur Aussenwelt gewähren, so sind sie doch nicht lïckenlos. Es giebt ganze Gebiete materieller Zustände und Zustandsänderungen, welche sich unserer directen sinulichen Wahrnehmung entziehen; so ist aus der ganzen Reihe der Aetherschwingungen verschiedener Frequenz nur ein verhältnissmässig kleiner Theil dem Auge und ein anderer Theil dem Wärmesinn direct wahrnehmbar. Vou den Vorhandensein der iibrigen erfahren wir nur dann etwas, wenn sie bei ihrer Wirkung auf äussere Körper eine solche Umwandlung erleiden, dass ihre Frequenz in den Bereich der sichtbaren geräth, zum Beispiel durch Fluorescenz, oder wenn sie an äusseren Körpern wahrnehmbare Veränderungen erzeugen, wie bei der Photographie ultravioletter Strahlen. 


\section{Gefïhl.}

Die grösste Austehumug besitzt die Sinnesfläche, welche uns die dem Qualitäten-Krreise des Gefühls zugehörigen sinneswahrnehmmugen rermittelt: sie erstreckt sich über die ganze äussere Haut und die sichtbaren Schleimhautpartien. Auch ron Zustandsänderungen imnerer Organe kann uns das Gefühl eine wenn auch dunkele Kenntniss geben. - Ueberhaupt treten auf dem Gebiete der Gefïhle zwei Kategorien derselben in einen auffallenden Gegensatz zu einander: die einen werden auf $\mathrm{Zu}$ stände unseres Körpers selbst und zwar weniger auf Zustände der einzelnen Theile als auf das Gesammtbefinden bezogen, es sind dies die Gemeingefiihle; die anderen dienen zur Orientirung ïber die Beziehungen des Körpers und speciell der einzelnen Theile seiner Oberfläche zur Anssenwelt, es sind dies die Druck- und Temperaturempfindungen, welche mit ihren specifischen Qualitäten den Drucksinn und Temperatursinn atusmachen und, insofern sie mit Localzeichen rerbunden sind, in das (iel)iet rles Ortsinnes zusammengefasst werden. Drucksinn, Temperatursinn und Ortsinn liefern zusammen mit den die Bewegungen begleitenden Empfindungen auch innerer Theile (Gelenke, Sehnen) das Material fiir die Leistungen des Tastsinnes. Gemeingefühle sind Schmerz, Frost, Hitze, Kitzel, Schauder, Wollust und dergleichen mehr.

Wahrnehmbare Zustandsänderungen unserer Hautsinnestläche kömnen herbeigeführt werden durch äussere oder immere Ursachen. Die häufigste Ursache ist die Berührung mit äusseren Gegeuständen: je nach der Druckstärke, mit welcher die Beriihrung erfolgt und je nach den physikalischen oder chemischen Eigenschaften des äusseren Gegenstandes entstehen mannigfache unterscheidbare Wahrnehmungen. Der am einfachsten zu übersehende Fall ist der, dass ein fester Körper von bekanntem Gewicht, mit ebener Oberflïche ron bekannter Ausdehnung, welcher die Temperatur der Haut besitzt, durch sein eigenes Gewicht auf einen unterstiitzten Körpertheil drüickt: die hierbei entstehende Empfindung nennen wir Druck. Die Druckempfindlichkeit ist an rerschiedenen Hautpartien sehr rerschieden und hängt in hervorragender Weise ron der Dicke der Epidermis und der Nähe des unterliegenden Ḱnochens ab. An der Stirn, deren Oberhaut und Fettpolster sehr diunn sind, geniigt der Druck von 2 Milligramm auf einer Grundfläche von 9 Quadratmillimeter zur Erregung einer deutlichen Empfindung. An der Volarseite' der Finger mit bedeutend dickerer Epidermisschicht müssen 15 und mehr Milligramm auf 9 (Quadratmillimeter Grundtläche aufgelegt werden, um eine deutliche Empfindung zu reranlassen. Auf den Nägeln der Hände und Füsse ist hierzu sogar ein ganzes Gramm erforderlich. Sehr bedeutend wird der Schwellenwerth des Druckreizes herahgesetzt durch 
die kurzen Härchen, welche sich auf dem grössten Theil der Haut finden, offenbar weil sie den ganzen Druck einer grösseren Masse auf einen Punkt concentriren. Am Daumenrïicken wurden zum Beispiel von einem Beobachter 2 Milligramm auf 9 Quadratmillimeter Grundfläche empfunden; als er aber den Daumenriicken rasirt hatte, musste er 35 Milligramm auf derselben Grundfläche auflegen, um eine Druckempfindung zu erhalten.

Die Druckempfindung scheint hauptsächlich dort zu entstehen, wo gedriickte und nicht gedriickte Stellen der Haut aneinander grenzen; in sehr auffallender Weise tritt dies hervor, wenn man einen Finger in Quecksilber von solcher Temperatur taucht, dass es sich weder warm noch kalt anfühlt: dann hat man an der eingetauchten Fläche, an deren tieferen Stellen sicher mehr als 5 Gramm auf 9 Quadratmillimeter Grundfläche driicken, keine Empfindung, sondern nur an dem Hautring, wo das Quecksilber an die Luft grenzt.

Findet die Berührung mit minimalem Druck statt, so wird die Lebhaftigkeit der Empfindung sehr beträchtlich gesteigert durch langsame Verschiebung des berührenden Gegenstandes; es beruht dies ebenfalls auf der Anwesenheit der Tasthärchen, welche bei diesem Vorgang stärker erschüttert werden, als bei dem Druck eines ruhenden Gewichtes; die Qualität der hierbei entstehenden Empfindung, welche man Berührungsempfindung nennen kann, ist deutlich verschieden von der Qualität der Druckempfindung. Durch Steigerung der Lebhaftigkeit kann man das Berührungsgefühl in den Kitzel überführen, welcher den Gemeingefühlen zugerechnet wird, und welcher bei aller Aehnlichkeit mit der Wollust unerträglichen Widerwillen erzeugen und ununterdrückbare Ausweichund Abwehrbewegungen hervorrufen kann. Bei Wollust und Kitzel steht die Lebhaftigkeit des Gefühls in keinem Verlältniss zu der Energie des Reizes, sondern zu der Art der Wiederholung.

Eine Empfindung, welche mit der Druckempfindung Aehnlichkeit besitzt, tritt deutlich hervor in der gespannten Haut ïber stark flectirten Gelenken. Ein Wechsel in solchen die Stellungsänderungen der Gelenke begleitenden Spannungsempfindungen der Haut scheint einen Theil der Bewegungsempfindungen auszumachen.

$\mathrm{Zu}$ den Leistungen, deren der reine Drucksinn fähig ist, gehört die Vergleichung von Gewichten, welche nach einander derselben Hautstelle aufgesetzt werden. Hierbei unterscheidet man kleine Gewichte schon bei einer kleineren Differenz als grosse, und genaue Beobachtungen haben ergeben, dass die Differenz immer ungefähr denselben Bruchtheil des einen Gewichtes ausmachen muss, um einen merklichen Unterschied der Druckempfindungen zu bedingen. Dieser Satz ist unter dem Namen des Weber'schen Gesetzes bekannt. Man kann diesen Satz anch so auș- 
sprechen: wenn zwei Gewichte durch den Drucksinu unterschieden werden sollen, so muss nicht ihre Differenz immer denselben Werth haben, sondern ihr Verhältniss. Für die auf fester Unterlage ruhende Hand ist der Werth dieses Verhältnisses $29 \mathrm{zu} 30$, das heisst ein normalsinniger Mensch kanı bei gehöriger Aufmerksamkeit unterscheiden 29 rou 30 Gramm, oder 58 von 60 Gramm, u. s. w. Die nach diesem Maasse gemessene Feinheit des Drucksinnes ist erheblich verschieden in verschiedenen Körpergegenden. Die Scala dieser Empfindlichkeit ist etwa: Stirn, Lippe, Zungenrïcken, Wange, Schläfe, Finger, Hand, Unterund Oberarm, Vorderseite des Ober- und Unterschenkels, Fissrïicken, Dorsum der Zehen, Plantarseite der Zehen, Planta, Hinterseite des Ober- und Unterschenkels. Intermittirende Druckschwankungen werden aber durch die Fingerspitze feiner walngenommen als durch die Stirnlaant. Vibrationen von Saiten erkennt man an den Fingern noch als solche bei 1506 bis 1552 Schwingungen in der Secunile.

Der Wärmezustand der Haut giebt zu eigenartigen Empfindungen hauptsächlich insofern Veranlassung, als er einen Wechsel erleirlet; wird eine Hautstelle wärmer, so empfinden wir sie als warm und umgekehrt. So lange die Haut ihre Temperatur nicht ändert, fülılen wir sie, ausser unter extremen Bedingungen, werler warm noelı kalt; bei starken $\mathrm{Ab}$ weichungen der Haut von ihrer mittleren Temperatur können wir andanernd lirost oder Hitze als Gemeingefühle empfinden, oder auch Schmerz mit dem Bewusstsein, dass er von Kälte oder Wärme herrïhre.

Im Allgemeinen findet ein beständiger Wärmestrom rom Innern des Körpers nach aussen statt; so lange die Bedingungen für das Gefälle dieses Stromes an allen Körperstellen constant bleiben, bleibt auch die Temperatur aller Hautpunkte constant, und wir empfinden, so verschieden auch die Temperatur an verschiedenen Hautpunkten sein mag, keine Unterschiede zwischen denselben. Der die Haut durchsetzende Wärmestrom kann von innen oder ron aussen geändert werden; wird der Wärmefluss von innen nach aussen an einer Hautgegend gesteigert, was zum Beispiel bei Erweiterung der Blutgefässe der Haut eintritt, so steigt, ceteris paribus, die Temperatur der Haut und bei dem Erröthen fühlen wir in der That unsere Wangen warm. Bas Umgekehrte tritt bei Verengerung der Hantgefässe unter Erblassen der Haut ein.

Wird der Wärmeabfluss nach aussen verringert, zum Beispiel durch Bedecken eiver bis dahin freien Hautfläche, so nimmt die Temperatur der Hautstelle ebenfalls zu und wir empfinden warm, auch wenn der bedeckende Gegenstand nicht wärmer war, als die Hautstelle, welche bedeekt wurde. Umgekehrt kann der Wärmealjfluss von der Haut durel Herabsetzung der Temperatur des beriihrenden Mediums vermehrt werden, oder auch, vorausgesetzt, dass die äussere Temperatur unterhalb 
derjenigen der Haut liegt, dadurch, dass nur ein Medium von grösserer Wärmecapacität oder von besserem Leitungsvermögen für Wärme an Stelle-des bisherigen tritt. Wemn wir.den Finger aus Luft in Wasser' tauchen, welches die Zimmertemperatur angenommen hat, so empfinden wir kühl.

Unter den Factoren, welche den Wärmestrom durch die Haut beeinflussen, nimmt die äussere Temperatur in hervorragender Weise unser Interesse in Anspruch: den absoluten Werth dieser Temperatur auf Grund unserer Temperatursinneswahrnehmungen $\mathrm{zu}$ beurtheilen sind wir sehr wenig im Stande. Es liegt dies hauptsächlich an den Schwankungen der Hauttemperatur, welche aus inneren Grïnden erfolgen. Bei dem Vergleich der Temperatur zweier äusserer Gegenstände können wir leicht irregeführt werden, wenn das specifische Leitungsvermögen für Wärme und die Wärmecapacität beider Gegenstände verschieden sind. So erscheint uns ein Stïck Metall, welches kälter ist als unsere Haut, kälter als ein gleich temperirtes Stück Holz. Wenn aber die beiden berührenden Körper gleichartig sind und sich eben nur durch ihre Temperatur unterscheiden, dann ist das Urtheil nach dem Gefühl im Allgemeinen richtig: wenn wir zum Beispiel denselben Finger nach einander in Wasser von verschiedener Temperatur eintauchen, so können wir durch den Temperatursinn richtig unterscheiden, welches Wasser wärmer und welches kälter ist. Dieses Unterscheidungsvermögen ist sogar, weun es sich um Temperaturen zwischen $12 \frac{1}{2}{ }^{\prime \prime}$ und $25^{\circ} \mathrm{C}$. handelt, ausserordentlich fein. In dem genannten Intervall braucht der Temperaturunterschied nur wenige Hundertstel Grade zu betragen, um merkbar zu sein; geht man zu höheren Temperaturen über, so nimmt die Feinheit der Unterscheidung rasch ab, noch rascher, wenn man zu niedrigen Temperaturen unter $12 \frac{1}{2}{ }^{0}$ heralogeht.

Die Intensität der Temperaturempfindung kamn von dem eben merklichen Werth anfangend in erheblichem Maasse gesteigert werden, ohne dass eine Aenderung in der Empfindungsqualität eintritt, und zwar kann die Steigerung nicht nur herbeigefülırt werden durch die Aenderung der Ledingungen für den W:irmestrom einer bestimmten Hantstelle, sondern anch durch Vergrösserung des Hautgebietes, welche dieser Aenderung ansgesetzt wird. Wasser von $27^{\circ}$, in welches die ganze Hand eingetaucht wird, erzeugt eine stärkere Wärmeempfindung als solches von $40^{0}$, wenn nur ein Finger eingetaucht wird. Verschiedene Hautgebiete verhalten sich aber in dieser Beziehung nicht gleichartig; gleich grosse Areale verschierlener Hautgebiete empfinden gleiche Temperaturdifferenzen verschieden stark. Ueberschreitet der Temperaturunterschied zwischen dem äusseren berülırenden Körper und der Haut gewisse Grenzen, so mischt sich zunächst der Temperaturempfindung Schmerz- 
gefühl bei, derart, dass zwischen Wärmeschmerz und Kälteschmerz unterschieden werden kann. Wird der Unterschied noch grösser, so tritt schlechtweg Schmer\% auf. Die untere Temperaturgrenze für das beginnende Schmer\%gefühl ist ron der Hautstelle, ron der Grösse der Hautfläche und von der Dawer der Einwirkung abhängig; im Allgemeinen kann man die untere Temperaturgrenze für den Wärmeschmer\% bei $48^{\circ}$ C. und die obere für den Kälteschmerz bei $+9^{\circ}$ annehmen.

Taucht man die Hand in Wasser ron $50^{\circ}$ C., so ist im erşten Angenblick die Empfindung eine eigentliche Temperaturempfindung olne Schmerz, aber sehr intensiv. Hierauf nimmt sic etwas ab, dann aber wicder zu, um sich bis zum Schmerz zu steigern. In Wasser ron $48^{\circ} \mathrm{C}$. kann man einen einzehen Finger lange eingetaucht halten, ohne Schmerz zu emptinden. Taucht man eine ganze Hand hinein, so hat man sehr' bald unerträglichen Schmerz; ähnlich geht es mit kaltem Wasser von etwa $+9^{\circ} \mathrm{C}$.

Ein eigenthümlicher Conflikt zwischen Temperatur- und Druckempfindung tritt darin hervor, dass von zwei gleichen auf die Haut gelegten Metallstiicken das kältere schwerer erscheint, als das wärmere.

Während sich für die Schnelligkeit, mit welcher auf die äussere Einwirkung das Bewusstwerden der Empfindung folgt, die Kälteempfindung der Druckempfindung zur Seite stellt, schliesst sich die Wärmeemptindung dem Schmerzgefühl an. Die beiden letzteren treten schon beim normalen Menschen mit wahrnehmbar grösserer Verzögerung ein, als die ersteren und diese Verzögerung erreicht bei gewissen Erkrankungen auffallend hohe Werthe, bis zu einer Secunde und mehr. Es sind dies Erkrankungen, welche das Rückenmark betreffen, und man nimmt an, dass die Leitungsverhältnisse im Riickenmark für Kälteempfindung analog denen für Druckempfindung und für Wärmeempfindung analog denen für den Schmerz sind.

Bis in die neueste Zeit war man zweifelhaft, ob man fuir Druckund Temperaturempfindung Nerven von verschiedener specifischer Energie anzunehmen habe, oder ob die verschiedenen Qualitäten der Wärmeund Kälteempfindung nur verschiedenen Complexen von Druckempfindungen entsprächen; in letzterer Beziehung stellte man sich ror und glaubte es auch durch Experimente wahrscheinlich machen zu können, dass bei Erwärmung und Abkühlung der Haut Drucksinnesuerven in verschierlenen Schichten in verschiedenen Intensitätsverhältnissen erregt wïrden, und dass auf diesen Intensitätsverhältnissen die Empfindungscomplexe beruhten, welche uns in den Qualitäten der Kälte- oder Wärmeempfindung erscheinen.

Für die erstere Auffassung, das heisst für die Annahme verschiedener specifischer Energien, hat aber die ron mehreren Forschern unab- 
hängig und gleichzeitig gemachte Beobachtung entschieden, dass man bei punktförmig begrenzter Reizung der Haut das Vorhandensein besonderer Kälte-, Wärme- und Druckpunkte feststellen kann. An den Kältepunkten wird bei leichter Berührung nur ein kalter Gegenstand empfunden, und zwar kalt; an den Wärmepunkten nur ein warmer, und zwar warm. Gegen vorsichtige Berïhrung mit Objekten von Hauttemperatur sind Kälte- und Wärmepunkte unempfindlich. Der faradische Strom oder stärkerer Druck auf einen Temperatursinnespunkt angewandt, giebt punktförmiges Kälte- oder Wärmegefühl. Das Kältegefühl bei Reizung eines Kältepunktes ist ein momentan erfolgendes aufblitzendes. Das Wärmegefïhl bei Reizung eines Wärmepunktes dagegen erfolgt nicht momentan, sondern erscheint anschwellend und ist diffuser. Die Temperatursinnespunkte vermitteln kein Schmerzgefühl, weder bei mechanischen noch bei calorischen, auf sie beschränkten Insulten. Die punktförmige Temperaturempfindung überdauert die Einwirkung des adäquaten Reizes beträchtliche Zeit. Erwärmung und Abkïhlung der Haut setzt die Empfindlichkeit der peripherischen Apparate beider Temperatursinnesqualitäten herab.

Das allgemeine Princip der Anordnung der Temperaturpunkte ist folgendes: dieselben reihen sich in Linien aneinander, welche meist leicht gekrümmt verlaufen. Die Linien oder Punktketten strahlen radienartig von gewissen Punkten der Haut aus, welche demgemäss als Ausstrahlungspunkte oder Temperaturpunktcentren bezeichnet werden. Die Ketten der weit zahlreicheren Kältepunkte fallen im Allgemeinen nicht zusammen mit denen der Wärmepunkte; ihre Ausstrahlungspunkte sind aber gemeinsam. Diese Ausstrahlungspunkte fallen an den behaarten Hautregionen vorwiegend mit den Härchen zusammen, genauer gesagt mit den Haarwurzeln oder Haarpapillen; nur hier und da kommen auch in behaarten Gegenden Ausstrahlungspunkte ohne Haare vor, demgemäss finden sich auch an den Haaren immer Temperaturpunkte, und an wenig temperaturempfindlichen Hautstellen kommt es vor, dass Temperaturpunkte nur an den Haaren zu finden sind.

Aus dem, was von der Anordnung der Temperaturpunkte gesagt ist, geht hervor, dass auf gleich kleinem Areal benachbarter Hautstellen die Ziahl der Temperaturpunkte eine sehr verschiedene sein wird. Von dieser Zahl und ron dem Empfindlichkeitsgrade der einzelnen Punkte, welche, wie die punktförmige Untersuchung lehrt, in weiten Grenzen verschieden ist, hängt die specifische Sinnesempfindlichkeit solcher kleiner Areale ab. Bei der Untersuchung mit verschieden temperirten metallischen Flächen von 3 bis 4 Millimeter Durchmesser trifft man Stellen, welche ausschliesslich oder vorwiegend kälteempfindlich sind, andere, an denen sich beide Temperatursinne gleich stark veṛtreten finden, noch 
andere, an denen die W:irmeempfindung rorlerrscht und schliesslich thermoanïsthetische. Ausschliesslich mit Wärmeempfindung begabte Hautflächen kommen nicht ror.

Bei der Untersuchung mit Flïchen ron einem Contimeter Durchmesser treten die Discontinuitäten der Temperaturempfindlichkeit in den Hintergrund und die .topischen“ Differenzen in der Anlage des T'emperatursinnes in Bezug auf die verschiedenen Körperregionen deutlich hervor. Nimmt man als Maass für die Temperaturempfindlichkeit die kleinste Differenz zwischen der Temperatur der prüfenden Fläche und der gepriiften Hautstelle, welche eben wahrgenommen wird (also den Schwellenwerth der Empfindung), so kommt man zu Resultaten, welche durch die Uebung stark beeinflusst zu sein scheinen, demn der Schwellenwerth stellt sich im Allgemeinen an den unbedeckten Hautgegenden niedriger heraus, als an den gewöhnlich bekleideten.

Die Differenzen in der urspriinglichen Anlage scheinen reiner herrorzutreten, wenn man als Maass die rerschiedene Empfindungsintensitiit bei gleichen und zwar grossen Temperaturdifferenzen wählt. Prüft man mit Flächen, deren Temperatur 15 bis $17^{\circ}$ ïber oder unter der Hauttemperatur liegt, so giebt jede Körperregion eine Temperaturempfindung ron annähernd bestimmter Intensität, welche durch Vergrösserung der Differenz nicht gesteigert werden kann. Die maximalen Temperaturempfindungen, deren die einzelnen Körperregionen fähig sind, lassen sich nach der Vergleichung des unmittelbaren Bewusstseinsinhaltes bei dem Kältesimn in 12, bei dem Wärmesinn in 8 Stufen anordnen. Der Stand einzelner Körperregionen in dieser Scala geht aus folgender Zusammenstellung herror, in welcher die niedrigste Ordnungszahl der Stufe der kleinsten erreichbaren Intensität der Temperaturempfindung entspricht.

K äl te.

1. Finger- und Zehenspitzen, Malleolen, Ferse.

2. Stirnmitte, Olekranon.

3. Glabella, Kinn, Hohlhandmitte, Schamgegend.

4. Hinterhaupt, Patella.

5. Fossa supraclaricularis, Clavicula, Jugulum, Brustbein oben.

6. Nates.

¡. Tub. frontale, Unterlid, Kniekehle, Fusssohlemmitte.

\section{Wärme.}

Finger- und Zehenspitzen.

Stirnmitte, Olekranon.

Glabella, Kinn, Hinterhaupt, Clavicula, Schamgegend.

Hohlhandmitte, Nates, Kniekellle. Fossa supraclavicularis, Jugulum, Brustbein oben.

\section{Riicken.}

Unterlid, Maxillargegend, Stellen der Bauchhaut. 
Kält e.

8. Femurmitte, rorn innen.

9. Intercostalräume in der Parasternallinie.

10. Mamillargegend.

11. Mamilla, Regio iliaca.

12. Stellen der Regio lumbalis, Stellen der Bauchhaut.
Wä r m e.

Mamilla, Regio iliaca.

Die Fähigkeit, Berührungsgefühl zu vermitteln ist, mit Ausschluss der meisten Temperatursinnespunkte, anf der ganzen Haut nachzuweisen. An besonderen Punkten ist aber das Berührungsgefühl durch rorzugsweise schwache mechanische Reize hervorzurufen und an diesen Punkten macht das Berührungsgefühl bei Verstärkung des Reizes einer Gefühlsempfindung ron besonderer Qualität Platz. Diese ausgezeichneten Punkte werden den Kälte- und Wärmepunkten zur Seite gestellt und Druckpunkte genannt.

Die histologische Untersuchung von kleinen exstirpirten Hautstücken, deren Centrum vorher als Kälte-, Wärme- oder Druckpunkt erkannt worden war, hat keine besonderen Nerrenendigungen, wohl aber einen specifischen Unterschied in der Endausbreitung der Temperaturuerren einerseits und der Drucknerven andererseits ergeben. An einem Temperaturpunkt findet sich auf einem engen Raume zusammengedrängt eine Anzahl von feinsten Nervenfäden büschelförmig zur Epidermis aufstrebend, in unmittelbarster Nähe ron Blutgefässen zwischen diesen und der Epidermis gelegen. An einem Druckpunkt dagegen findet sich die Haut ron einer Anhäufung ron Nervenfäden durchsetzt, welche in der subepithelialen Cutisschicht flach ausgebreitet daliegen und durch zahlreiche Aestchen ein relatir grosses Stück ron Cutisoberfläche imnerviren.

Mit der Erregung eines Temperatur- orler Drucksinnespunktes durch den adäquaten Reiz verbindet sich in unserem Bewusstsein nicht nur die Vorstellung einer Qualität und Intensität, sondern auch die eines Ortes. Wir erkennen durch das Gefühl, ob wir an Stirn oder an Hand berührt worden sind. Die Ortsrorstellung entsteht nicht nux, wenn der Reiz an der Nerrenendigung in der Haut angreift, sondern auch, wenn Hautsimnesnerven irgendwo in ihrem Verlanf gereizt werden. Wird der Nerrus ulnaris am Ellenlogen gedriickt, so entstehen Empfindungen, welche uns ron der Haut des Ausbreitungsgebietes dieses Nerven an der Ulnarseite der Hand auszugehen scheinen. Man kann danach erwarten, dass das Localzeichen an jede im Nervenstamm vorhandene Primitivnervenfaser respective an ihre celluläre Endligung im Centralnervensystem geknüpft ist. Jerle Primitivnervenfaser der Nervenstämme versorgt kraft ihrer 
Terminalverzweigungen ein mehr oder weniger grosses Hautgebiet und die den einzelnen Primitivnervenfasern entsprechenden Hautgebiete greifen vielfacl ineinander ïber. In liezug auf jerle Primitirnerrenfaser haben wir also zwei Gebietsarten zu unterscheiden, ein Gebiet, an dessen Innervation sich die hetreffende Nervenfaser nur hetheiligt, und ein Gebiet, welches sie ausschliesslich rersorgt. Je reichlicher die Innervation einer Hautgegend ist, um so mehr wirl das letztere Gebiet jeder Nervenfaser: cingeengt und umgekehrt.

Nach der rorgetragenen Vorstellung kömnen zwei Hautpunkte eines ausschliesslichen Gebietes keine Empfindung mit rerschiedenen Localzeichen geben; fassen wir aber drei benachbarte Primitivnervenfasern $A, B, C$, in das Ange und nehmen wir an, dass zuerst ein Punkt des gemeinschaftlichen Gebietes AB und dann ein Punkt des gemeinschaftlichen Gebietes CB berührt wurde, so werden sich die beiden entstandenen Empfindungen durch ihre Loealzeichen ron einander unterscheiden kïnnen, und wir werden die Aussage machen, dass zwei rerschiedene Punkte der Haut nach einander beriihrt worden sind. Berïhren wir aher dieselben Hautpunkte gleichzeitig, so haben wir nicht das Gefühl zweier örtlich getrennter Eindrüicke; um dies bei gleichzeitiger Berüllr'ung zu erhalten, müssen wir die Berïhrungspunkte in grösserer Entfernung ron einander wählen, voraussichtlich in einer solchen, dass das Ausbreitungsgebiet der Faser B rollkommen umgangen wird, das heisst, dass ron drei mit benachbarten Localzeichen behafteten centralen Elementen das mittlere ganz unerregt bleibt.

Der Ortsinn der Haut liefert uns ein um so feineres Hülfsmittel zur Orientirung in der Umgebung, je mehr örtlich getrennte Wahnnehmungen er uns auf gleichem Flächenraum zu machen gestattet; als Maass für die Feinheit des Ortsinnes wird deshalb die kleinste Entfernung ron Hautstellen benutzt, deren Berïhrung Veranlassung zu örtlich getrennten Wahrnehmungen wird. Wie zu erwarten ist, stellt sich der Ortsinn der Haut, auf diese Weise gepriift, an rerschiedenen Körpergegenden als sehr verschieden fein heraus. Vergleichbar sind die Resultate der Prïfung nach dem vorher Gesagten jedoch nur, wenn die Beriihrung an allen geprïften Stellen entweder gleichzeitig oder ungleichzeitig erfolgte; so müssen zum Beispiel zwei gleichzeitig aufgesetzte Cirkelspitzen am Handriicken etwa 20 Millimeter, am Riicken des Oberarms etwa 40 Millimeter von einander abstehen, um als deutlich getrennt wahrgenommen zu werden, während bei successiver Berihhrung an ersterer Stelle schon eine Entfernung ron etwa 5 Millimeter, an letzterer ron 10 Millimeter genügt, um eine Verschiedenheit des Beriihrungsortes wahrnehmen zu lassen.

Es bietet ein grosses Interesse, die nach einer dieser Methoden be- 
stimmte Feinheit des Ortsinnes nicht nur desselben Menschen an verschiedenen Körperstellen mit einander zu vergleichen, sondern auch bei rerschiedenen Menschen verschiedenen Lebensalters. Finden wir bei dem jugendlichen Individuum eine grössere Feinheit des Ortsinnes, als bei dem Erwachsenen, wie es in der That der Fall ist, so werden wir anzunehmen haben, dass bei dem Wachsthum der Körperfläche nicht die Zahl der Empfindungskreise in der Haut zunimmt, sondern ihr Durchmesser. Die angedeuteten Vergleiche können an der Hand folgender, mit der Methode gleichzeitiger Aufsetzung der Cirkelspitzen ermittelten Tabelle durchgefiihrt werden.

Erwachsener Mann. Knabe von 12 Jahren.

Zungenspitze

$\mathrm{Mm}$

Volarseite des letzten Fingergliedes . . 2,3

Rother Lippentheil . . . . . . . . 4,5

Volarseite des zweiten Fingergliedes . . 4,5

Dorsalseite des dritten Fingergliedes.

Mittellinie des Zungenriuckens, $27 \mathrm{Mm}$.

von der Spitze

Plantarseite des letzten Grosszehengliedes

Rücken des zweiten Fingergliedes

Unterer Theil der Stirn

Hinterer Theil der Ferse

Rücken der Hand

Unterarm und Unterschenkel . . . . 40,6

Fussrïcken in der Höhe der Zehen . . 40,6

Brustbein . . . . . . . . . . . 45,1

Rückgrat, Nacken unter dem Hinterhaupt 54,1

Rückgrat, Mitte des Rückens . . . . 67,7

Mitte des Oberarmes und Oberschenkels 67,7
$\mathrm{Mm}$

1,1

1,7

3,9

3,9

4,5

6,8

6,8

9,0

18,0

20,3

22,6

36,1

36,1

33,8

36,1

$31,6-40,6$

$31,6-40,6$

Bei dieser Prüfung des Ortsinnes wurden die Cirkelspitzen stets ohne Rücksicht auf das Vorhandensein ausgezeichneter Hautsinnespunkte aufgesetzt und es geschieht dies stets, wenn man ein Urtheil über die Brauchbarkeit des Ortsinnes für die Orientirungszwecke gewinnen will; man erhält dann bei wiederholter Prüfung derselben Hautgegend mit Benutzung verschiedener Hantpunkte etwas abweichende Werthe, deren Mittel der Beurtheilung zu Grunde gelegt wird. Die genaue Localisirung von 'Temperatur- und Druckpunkten hat aber zur Ermittelung ïnsserster Werthe der Ortsinnesempfindlichkeit gefülırt, welche iiber die sonst ermittelten Werthe und iiler die praktische Verwerthbarkeit beim Gẻnauche der Sinne weit hinans gehen. Zwei punktförmige adäquate 
Reize, welche auf benachbarte Sinnespunkte sucessive applicirt werden, kömnen in erstamnlich kleiner Distanz als örtlich getrennte Reize wahrgenoumen werlen: Kälte an Stirn, Wange und Kinn in 0,8 Millimeter Entfermung; Kälte oder Wärme an den Beugeflïchen des Vorderarmes in 2 Nillimeter Entfernung; Beriilırung am Kleinfingerballen und an der Volarseite des Nagelgliedes in 0,1 Millimeter Entfernung. Mit ganz besonderer Deutlichkeit und in äusserst kleinen Distanzen werden namentlich dicjenigen Punkte doppelt wahrgenommen, welche in der Nähe des Ausstrahlungscentrums liegend zwei verschiedenen Ketten angehören. Das gegenseitige räumliche Lageverhältniss wird hierbei im Gebiete des Drucksinnes, abgesehen vou der Grösse der Distanz, richtig erkannt, auf dem Gebietc des Temperatursinnes nicht. Die Distanz wird bei dieser Untersuchungsart in allen Fällen viel zu gross geschätzt.

\section{Tastsinn.}

Der Tastsinn dient zu unserer Orientirung in der Aussenwelt unter Benutzung der Hautsinnesfläche. Mit den ron der Haut gelieferten Empfindungen der Temperatur und des Druckes, sowie mit den den letzteren anhaftenden Localzeichen reicht der Tastsinn aus zur Beurtheilung gewisser Beschaffenheiten von Objekten, sowie zur Erkennung der äusseren Form nicht zu grosser' und nicht zu kleiner Gegenstände. Die Gestalt von Gegenständen mittlerer Ausdehnung erkennen wir bei blosser Beriihrung mit der Haut darum, weil wir von der gegenseitigen Lage der bei der Beriihrung getroffenen Drucksinnespunkte eine unmittelbare Vorstellung haben. Durch die Feinheit des Ortsinnes ist die untere Grenze der Ausdehnung von Gegenständen bestimmt, deren Form durch Berührung mit der Haut erkannt werden kam. Bei ausschliesslicher Benutzung des Druckortsinnes liegt die obere Grenze in der Ausdehnung des grössten zusammenhängenden Theiles der Hautsinnesfläche, welche mit einem Gegenstand ohne tastende Bewegung zur Deckung gebracht werden kann. Für dic Beurthcilung der Form grösserer Objekte mittelst des Tastsinnes ist es erforderlich - was auch übrigens bei kleineren vielfach geschieht - dass die tastende Hantfläche an der Oberffäche des Gegenstandes entlang geführt wird. Bei diesem Akt, den man eigentlich das Tasten neunt, tragen viele Empfindungen zur Liefermug des Materials für die Beurtheilung der Form bei, welche nicht an der Hautsinnesflïche entstehen, und zwar alle diejenigen, welche den Bewegungsvorstellungen und den Vorstellungen von der gegenseitigen Lage der Glieder zu Grunde liegen. Es sind dies, ausser den dem Drucksinn zugehörigen Empfindungen von den Spannungszuständen der Haut ïber den an den Bewegungen betheiligten Gelenken, Empfindungen, welche 
an den Gelenkflächen selbst, sowie in den Muskeln und ihren Sehnen entstehen und vielleicht auch das sogenannte Innervationsgefühl, das heisst eine unnittelbare Vorstellung ron den Intensitätsverhältnissen der den einzelnen Muskeln ertheilten Bewegungsimpulse.

Zu unserer räumlichen Orientirung in der Aussenwelt mittelst des Tastsimnes reichen also im Allgemeinen die rom Drucksinn gelieferten Empfindungen nicht aus; es ist auch wahrscheinlich, dass die Verbindung des letzteren mit Localzeichen, welche den Ortsinn der Haut ausmacht, erst im individuellen Leben unter Betheiligung der Bewegungsempfindungen associatorisch erworben wird.

$\mathrm{Zu}$ den tastbaren Eigenschaften äusserer Objekte gehören die Rauhigkeit und Glätte, die Schärfe und Stumpfheit, die Wärme und Kälte, die Härte und Weichheit, und wenn man will, auch die Schwere. Ton diesen sind die ersteren vier eigentlich Besonderheiten der äusseren Form und werden wie diese mittelst der Haut durch Beriihrung ohne Benützung von Bewegungen der Tastfläche oder unter Zuhilfenahme derselhen erkannt. Zur Beurtheilung des Härtegrades und des Gewichtes kann der Drucksinn mit benutzt werden, doch kommt man hierbei auch ohne ihn aus; keinesfalls ist er allein hierfuir zureichend. Maassgebend ist hier rielmehr das Gefïhl von der zur Ueberwindung eines Widerstandes gemachten Anstrengung und die ausserhalb der Haut, namentlich in Gelenken, Muskeln und Sehnen entstehenden Empfindungen ron der Ausfïhrung der intendirten Bewegung.

Die Abschätzung von Widerstand und Schwere ohne Zuhilfenahme des Drucksinnes und mit ausschliesslicher Benützung der BewegungsVorstellungen und -Empfindungen hat man als eine Leistung des Muskelsinnes bezeichnet - und bei Prüfung der Feinheit des Muskelsinnes hat man die Einmischung des Drucksinnes dadurch eliminirt, dass man das zu prïfende Gewicht in ein Tuch legt, dessen Zipfel ein für allemal mit maximalem Druck zwischen Daumen und Zeigefinger gehalten werden. Die kleinste Verschiedenheit von Gewichten, die wir noch auf diesem W'ege unterscheiden können, ist erreicht, wenn die beiden Gewichte sich ungefähr verhalten wie 39 zu 40, das heisst, wenn das eine ungefähr $1 m 1^{1 / 40}$ schwerer ist, als das andere. Der Muskelsinn ist also geeigneter zur Schätzung von Gewichten, als der Drucksinn, denn mittelst des Gefiihles rom Drucke, den die beiden Gewichte auf die Haut der auf fester Unterlage ruhenden Hand ausïben, können wir nur noch einen Gerichtsunterschied entdecken, der $1 / 30$ beträgt. 


\section{Gesehmack.}

Die schmeckende Sinnesflïche erstreckt sich auf den hinteren und rorderen Theil des Zungenrïckens, die Zungenränder, die Zungengaumenbögen und auf einen schmalen Streif des weichen Gaumens, dicht hinter dem harten Gaumen. In die Immervation dieser Gebiete theilen sich der Nerrus glossopharyngeus und der Nervus trigeminus; mit der specifischen Energie des Geschmackes begaht sind die Fasern des Glossopharyngeus, deren peripherische Enden auf dem hinteren Drittel des Zungenrïckens (in der Gegend der Papillae circumrallatae), auf den Zungengaumenbögen und dem weichen Gaumen liegen, und Fasern aus der Chorda Tympani, welche, dem Nerrus lingualis trigemini sich anschliessend, einen schmalen Streif der Schleimhaut am Zungenrande beiderseits bis zur Spitze innerviren. Alle übrigen Trigeminusfasern der Mundschleimhaut haben mit der eigentlichen Geschmacksempfindung nichts zn thun. Die Qualität der durch sie rermittelten Empfindungen hat die grösste Aehnlichkeit mit den Hautsinnesempfindungen und ist mit Localzeichen behaftet.

Als specifische Nervenendapparate des Geschmacksinnes werden eigenthümliche Epithelanordnungen in der Schleimhaut, namentlich in der ringförmigen Spalte zwischen Papille und Wall angesehen, welche als Geschmacksknospen bezeichnet werden. Nerrenfasern scheinen sich bis in das Innere der Geschmacksknospen zu begeben und stehen hier vielleicht mit Zellen eigenthümlicher Erregbarkeit in Verbindung. Für die nicht ganz oberflächliche Lage der schmeckenden Sinnesnervenendigungen spricht die Thatsache, dass das Schmecken durch die eigenthümlichen Schmeckbewegungen stark unterstïtzt wird. Die Schmeckbewegungen bestehen im Reiben und Drücken der Schmeckflïche gegen den Gaumen, wobei die schmeckenden Substanzen schneller und ausgiebiger als durch einfache Diffusion in die Tiefe befördert werden können.

In Bezug auf die Qualität bieten die Geschmacksempfindungen scheinbar eine grosse Mannigfaltigkeit dar, und wir sind im Stande, dureh das, was man gemeinhin Geschmack nennt, eine grosse Anzahl ron Substanzen sicher von einander zu unterscheiden; es ist aber zu beachten, dass uns hierbei vielfach Kriterien nicht nur von den eigentlich schmeckenden Fasern der Mundschleimhant, sonder'n auch ron anderen Trigeminusfasern und sogar ron den Geruchsnerren der Nasenschleimhaut geliefert werden. Das für den Pfeffer charakteristische Brennen ist kein Gesehmack, und wenn wir etwas Zwiebelsaft auf lie Zunge bringen, während wir die Nase mit den Fingern zuhalten, entgeht uns das charakteristische Aroma, wir schmecken nur süss. Auf dem Gebiete des 
eigentlichen Geschmackes können wir vier Qualitäten scharf von einander unterscheiden und aus den Combinationen dieser vier Qualitäten in verschiedenen Intensitätsverhältnissen, verbunden mit Gefühlen und Gerüchen, resultirt eine grosse Mannigfaltigkeit der für die einzelnen Substanzen charakteristischen Empfindungscomplexe.

Die vier Qualitäten des Geschmacksinnes sind süss, sauer, salzig und bitter; es giebt Substanzen, welche ausschliesslich eine der genannten Geschmacksqualitäten erregen: reine Zuckerlösung oder Saccharin schmeckt nur süss; rerdünnte Phosphorsäurelösung nur sauer; Kochsalzlösung nur salzig; Chinin nur bitter. Die einfachste zur Erklärung dieser Thatsachen ausreichende Annahme wäre die, dass die Geschmacksnerven Fasern mit rier specifischen Energien enthielten, und dass die peripherischen Endigungen der süss schmeckenden Fasern nur oder vorwiegend erregbar wären durch Zucker und in dieser Beziehung rerrandte Körper, die sauer schmeckenden von Säuren, und so weiter. Diese Annahme würde auch folgende Thatsachen leicht verständlich erscheinen lassen. Für den bitteren Geschmack ist hauptsächlich der hintere Theil der Zunge empfindlich, vorzugsweise dort rufen die geeigneten Körper der bitteren Geschmack hervor; man könnte sich leicht rorstellen, dass gerade hier die bitter schmeckenden Fasern besonders stark vertreten wären. Ferner erregen manche Körper je nach Umständen verschiedene Geschmacksqualitäten, so zum Beispiel zeigt Schwefelsäure in nicht allzu verdünnter Lösung an der Zungenspitze neben dem sauren auch den siissen Geschmack, was sich im Sinne dieser Hypothese leicht so denten liesse, dass die Säure bei einiger Concentration neben den sauerschmeckenden Fasern auch noch die süssschmeckenden erregte.

Geschmacksempfindungen können nicht nur durch Einwirkung auf die peripherischen Endigungen der Geschmacksnerven hervorgerufen werden, sondern auch durch Reizung eines Nervenstammes. Die Chorda Tympani liegt in der Paukenhöhle im Bereiche therapentisch nothwendiger Eingriffe, und es ist oft bei dieser Gelegenheit die Beobachtung gemacht worden, dass die elektrische oder mechanische Reizung derselben sauren Geschmack, aber auch nur diesen erzeugt. Wenn ein constanter elektrischer Strom die Zunge durchsetzt, so entsteht ein eigentlicher Geschmack und zwar der sauere nur, wenn die Eintrittsstelle des Stromes an einem schmeckenden Theil der Schleimhant liegt; fällt die Austrittsstelle des Stromes auf eine solche Stelle, so entsteht kein eigentlicher Geschmack, sondern ein Brennen, welches allerdings vielfach als laugenartiger Geschmack bezeichnet wird. Dass es sich bei dieser Reizungsart wirklich um eine unmittelbare Wirkung des elektrischen Stromes und nicht un gewöhnliche Geschmackserregung durch ausgeschiedene Jonen handelt, lässt sich leicht nachweisen, indem man den Strom mit- 
telst Schwämmchen zuleitet, welche mit physiologischer Kochsalzlösung getränkt sind; ob aber der clektrische Strom die specifischen Nerrenendigungen oder die Nerrenfisern auf dem Wege zu denselben reizt, ist schwer zu entscheiden.

Es ist im höchsten Grade wilhrscheinlich, dass die schmeckenden Substanzen kraft ihrer chemischen Eigenschaften auf die peripherischen Endigungen der Geschmacksnerven wirken, und dass es Unterschicde in der chemischen Constitution sind, wclche die Einen befähigen, hauptsächlich süssschmeckende, Andere satuerschmeckende Fasern zu erregen, und so weiter. Eine verständliche Beziehung zwischen chemischer Constitution und Geschmack ist freilich noch nicht erkannt; immerhin muss es auffallen, dass durch den Geschmacksinn grosse Gruppen von Körpern zusammengestellt werden, welche auch ihrer chemischen Constitution nach rerwandt sind: so gehören zum Beispiel alle samerschmeckenden Körper derjenigen Klasse von Verbindungen an, welche die Chemie als saure Hydrate bezeichnet, aber freilich sind nicht alle samen Hydrate auch sanerschmeckend (Gerlö̈ure). Süsssehmeckend sind vorzugsweise die als mehratomige Alkohole bezeichneten Körper, zum Beispiel Glycol, Glycerin, Traubenzucker, indess giebt es doch auch andere süssschmeckende Stoffe, zum Beispiel essigsaures Bleioxyd, Sacharin. Der salzige Geschmack kommt fast nur den leicht löslichen Neutralsalzen der Alkalien zu. Auffallend bitter schmecken neben manchen Verbindungen von unbckannter Constitution namentlich die sogenannten Alkalö̈le.

Sehr verschieden sind die kleinsten Mengen rerschieden schmeckbarer Stoffe, welche eben genügen, um die betreffenden Faserenden der Geschmacksnerven zu reizen, so zum Beispiel schmeckt Rohrzucker schion gar nicht mehr in einprocentiger Lösung, während Aloëextrakt in 900000 facher Verdünmung, bei aufmerksamer Vergleichung mit reinem Wasser, geschmeckt werden kann, und bei 120000 facher Verdiimmung einen intensiv bitteren Geschmack hat. Andere Körper stehen zwischen diesen Extremen, zum Beispiel schmeckt Schwefelsäure bei 100000 facher Verdünnung noch eben merklich sauer. Yon Kochsalz bedarf es einer viel stärker concentrirten Lösung, mindestens 1 auf 426 Wasser, und selbst davon müssen grosse Mengen in den Jund genommen werden, um eben merklich Geschmack zu geben. Es ist die Angabe gemacht worden, dass der Verdünnungsgrad bei Säuren um so weiter getrieben werden kann, ohne dic Geschmacksempfindung aufzuheben, jc kleiner das Moleculargewicht ist.

\section{Geruch.}

Der Geruchsinn vermittelt dem Bewusstsein Wahrnehmungen äusserer Einwirkungen, welche von chemisch differenten Substanzen auf einen be- 
schränkten Theil der Nasenschleimhant ausgeiibt werden. Dem Riechen dienen ausschliesslich die oberen Partien der Nasenscheidewand und die der lètzteren zugekehrten Flächen der oberen und der mittleren Muschel (der letzteren in ihrem oberen Theile). Dieser Theil der Nasenschleimhant wird als Regio olfactoria der Regio respiratoria gegenüber gestellt. Die Schleimhaut der Regio olfactoria ist dicker und, namentlich bei manchen Thieren (Schaf), gelb gefärbt; sie trägt eine einfache Schicht hoher cylindrischer Zellen, welche an ihren, oft verzweigten Fussenden das Pigment, wo es vorhanden ist, enthalten. Zwischen diesen Epithelzellen zerstreut, liegen andere Zellen, welche nur in der Umgebung ihres Kernes einigen Umfang besitzen, zwischen den äusseren Theilen der Cylinderzellen aber nur sehr dïnne Stäbchen darstellen, welche bis zur freien Schleimhautfläche reichen und dort mehrere sehr zarte Härchen tragen.

Die Regio respiratoria besitzt Flimmerepithel und acinöse Drüsen, während die Drüsen der Regio olfactoria tubulös sind. In der Regio olfactoria endigen die Nervenfasern der Fila olfactoria, welche allein mit der specifischen Energie des Riechens begabt sind. Die ïberall in der Nasenschleimhaut endigenden Fasern aus dem Trigeminus vermitteln Empfindungen, welche keine eigentlichen Gerüche sind, welche aber für das unbefangene Bewusstsein mit den gleichzeitig anftretenden Gerïchen zu einheitlichen Sinneswahrnehmungen verschmelzen, sodass als Geruchsqualitäten der auf die Nasenschleimhaut sinneserregend einwirkenden Substanzen auch "stechende“, „prickelnde", „brennende" und so weiter angefuihrt werden.

Die riechenden Substanzen gelangen für gewöhnlich mit dem Inspirationsluftstrom auf die Regio olfactoria der Nasenschleimhant, und zwar geschieht dies nur, wenn der vorderste Theil der Nasenlöcher offen ist. Verlegt man diesen Theil mit den Fingerspitzen, so macht man sich unempfindlich für Gerüche, während die Athmung durch die Nase unbehindert weiter geht. Der Exspirationshuftstrom scheint gewöhnlich niclit die Regio olfactoria zu treffen, denn in ihm enthaltene Düfte werden vou den meisten Menschen nicht gerochen. Dagegen tritt beim Schlucken, vorausgesetzt, dass man die Nase nicht zuhält, ein Geruch ein, wenn sich in der Luft des Rachens duftende Substanzen befinden. Die so entstehenden Geruchswahrnehmungen werden meistens fälschlich dem Geschnacksinn zugeschrieben. Am deutlichsten werden die Geriiche wahrgenommen mittelst wiederholter kurzer und schneller Inspirationen, welche bei dem sogenannten Schnïffeln ausgeführt werden; überhaupt scheinen rlie in der Luft enthaltenen Stoffe nur so lange gerochen zu worden, als die Luft an der Regio olfactoria vorbeistreicht, nicht aber, wenn sie in Ruhe ist. 
Dic wälırend langer Zeit giltig gewesene Ansicht, dilss nur gasförmige orler in Luft suspendirte Substanzen gerochen werlen könnten, ist schlagend widerlegt worden. Den älteren Versuchen haftete der Fehler an, dass bei der Prüfung flüssiger Substanzen als Trüger der Riechstoffe Flïssigkeiten benutzt worden waren, welche die Schleimlaut der Regio olfactoria unempfindlich machen oder schädigen, wie Alkohol orler Brmnenwasser. Benutzt man dagegen als Menstruum eine körperwarme Kochsalzlïsung von $0,75 \%$, welche fiir die Riechschleimhant ganz indifferent ist, so zeigt sich, dass alle bei ihrer Vertheilung in Luft riechbaren Substanzen ilnen charakteristischen Geruch geben, wenn dic mit ihnen versetzte Flïssigkeit bei vorn übergebengter Haltung in die Nase gegossen wird. Die Fliissigkeit erreicht die Regio olfactoria nur, wenn sie längs dem Nasenrïcken rom Naseneingang zur Nasenwurzel herablaufen kann. Dic Substanzen, welche man auf diese Weise riechen will, miissen in der Fliissigkeit genügend verdünnt sein. Der Geruch hält so lange an, als die Flïssigkeit in der Pars olfactoria weilt. Anch nicht duftende Substanzen sollen, wenn sie in gleicher Weise applicirt werden, charaktcristische Gerüche erzeugen, so zum Beispiel das Hydrat, Phosphat, Sulfat, Carbonat von Natrium, das Sulfat von Magnesium u. a.

Die untere Grenze der Verdünnung, bei welcher eben noch Geruchswahrnehmung eintritt, scheint für beide Applicationsweisen (in Luft und in Wasser) ungefähr die gleiche zu sein; für Bromdampf zum Beispiel wird sie in beiden Fällen zu etwa 1/200000 des Volums angegeben. Als die am stärksten duftende Substanz wurde bisher der Moschus betrachtet, ron dem 1/2000no eines Milligramms ausreicht, um die Gernchsnervenenden zu erregen. Nach neueren Untersuchungen geniigt jedoch rom Mercaptan $\left(\mathrm{C}_{2} \mathrm{H}_{5} \mathrm{HS}\right)$ schon $1 / 46000000$ Milligramm, um Geruch zu erzengen. Der elektrische Strom, durch Vermittelung indifferenter Kochsalzlösung der Regio olfactoria zugeleitet, soll einen charakteristischen anodischen und davon verschiedenen kathodischen Geruch geben.

Un die Geruchsschärfe verschiedener Personen zu rergleichen, ist ein einfacher Apparat, der Riechmesser, geeignet. Er besteht aus einer Röhre ron nicht riechender Substanz, welche mit ihrem einen Ende in ein Nasenloch eingeführt wird; iiber diese Röhre ist eng anschliessend, aber leicht verschieblich, eine andere Röhre gesteckt, welche entweder selbst aus einer riechenden Substanz (Kautschuk, Wachs) gefertigt oder so eingerichtet ist, dass sie mit riechender Substanz imprägnirt werden kann. Je mehr das letztere Rohr nach aussen über das innere herrorgeschoben wird, auf einem um so grösseren Theile seines Weges hat der Inspirationsluftstrom Gelegenheit, sich mit dem Riechstoff zu beladen. Man kann dem äusseren Rohre eine solche Stellung geben, dass eben Geruchswahrnehmung eintritt und die Länge, mit welcher das äussere 
Rohr das innere hierbei überragt, dient als Maass für den Schwellenwerth des Reizes. Wenn es bei Anwendung dieses Instrumentes gelingt, dem Luftstrom in der Nase eine constante Richtung zu geben, so kann man von demselben gute Auskunft über die relative Riechschärfe beider: Nasenhälften oder iiber die verschiedenen Riechschärfen verschiedener Individuen erhalten. Dem Vergleich müssen natürlich dieselben Riechstoffe zu Grunde gelegt werden. Es ist dies von praktischem Werth für die klinische Untersuchung, welche auch insofern theoretisches Interesse gewinnen kann, als es möglich ist, dass bei Erkrankungen die Schärfe für verschiedene Gerüche in verschiedener Weise afficirt werde. Auch der Ermüidungsfrage wird man mit Hülfe dieser Methode näher treten können, als es bisher geschehen ist.

Mit Hülfe des Riechmessers ist untersucht worden, was entsteht, weun zwei verschieden riechende Substanzen gleichzeitig den beiden Nasenhälften derart dargeboten werden, dass sie selbst sich vorher nicht mischen, also auch nicht physikalisch oder chemisch auf einander wirken können; es wird in dieser Bezielung angegeben, dass stets nur die Wahrnehmung des einen der beiden Geriiche, nie eine solche aus der Combination beider entsteht; bei einem gewissen Intensitätsverhältnisse wurde die eine Substanz gerochen, bei einem anderen die andere, und bei einem mittleren Intensitätsverhältnisse soll gar kein Geruch zu Stande kommen: beide Gerüche sollen sich gegenseitig aufheben.

Auf keinem Sinnesgebiet gelang es bisher weniger als auf dem des Geruchsinnes, die in einer bestimmten Wahruehmung enthaltenen Empfindungselemente von einander zu sondern. Dem entsprechend besitzt keine Sprache Ausdrïcke für einzelne specifische Geruchsempfindungen, welche wie die Ausdrücke für die einzelnen farbigen Empfindungen roth, grün, blau etc., oder für die einzelnen Geschmacksempfindungen salzig, süss, saner, bitter, die Empfindungsqualität rein und ohne erkennbare Beziehung auf ein den Sinneseindruck veranlassendes Objekt bezeichneten. Alle Ausdrücke vielmehr, welche zur Mittheilung über die eigentlichen Geruchswahrnehmungen benutzt werden, - wir sehen ab von den fälschlich hierher gezogenen über Empfindungen des Tastsinnes, über Gefühle der Lust oder Unlust - enthalten den Hinweis auf bestimmte Substanzen, welche die einzelnen zu bezeichnenden Gerïche hervorrufen: man sagt, dies riecht wie Veilchen, wie Wein, u. s. w. Der Grund für diese Unvollkommenheit der sprachlichen Entwickelung und wissenschaftlichen Zergliederung ist wohl darin zu suchen, dass es einerseits weder einfach riechende Substanzen giebt, wie wir einfach schmeckende Substanzen kennen, noch Nittel, um complicirte Geruchserreger objectiv in einfachere zu zerlegen, - nach Analogie der Zerlegung des weissen Lichtes durch das Prisma in die Farbenreihe des Spectrums, oder zusammen- 
gesetzter Klänge durch Resonatoren in die Partialtöne, - und daıs andererseits die Endigungen der mit der specifischen Energie einfacher Geruchsqualitäten begalbten Nerven nicht kategorienweise örtlich gesonderten Erregungen zugänglich sind, wie die bitterschmeckenden Fasern auf dem hinteren Theile der Zunge und die sïssschmeckenden an der Zungenspitze. Für die Betheiligung mehrerer specifischer Faserngattungen in verschiedenen Intensitätsrerhältnissen an der Erzeugung qualitativ rerschieden erscheinender Geruchswahrnehmungen spricht der Umstand, dass bei Ermüdung des Geruchsinnes für einen bestimmten Geruch die Ermiidung für einige andere Gerüche ebenfalls rollkommen ist, während sie für andere nicht bemerkt wird.

Den bisher behandelten Qualitätenkreisen der Sinne kommt in weit höherem Grade als dem Gesicht und dem Gehör die Eigenschaft zu, dass sich die einzelnen Wahrnehmungen derselben mit dem Gefühle von Lust oder Unlust, Behagen oder Unbehagen, Wollust oder Ekel parren: ein Musikstïck oder ein Gemälde können uns ästhetischen Genuss bereiten, doch sind uns die Empfindungselemente, aus denen sich so complicirte Sinneswahrnehmungen zusammensetzen, an sich einzeln gleichgiltig: eine einzelne Farbe oder ein einzelner Ton ist uns für gewöhnlich weder angenehm noch unangenehm. Gegenïber den einzelnen, rou den ïbrigen Sinnen gelieferten Findrïcken, namentlich denen des Geruchs und Geschmacks, wird es uns aber schwer, dieselbe Gleichgiltigkeit zu bewahren. Ein Geruch ist uns stets entweder angenehm oder unangenehm, und der stärkste Missklang kann uns nicht in einen so hohen Grad körperlichen Missbehagens rersetzen, wie ein widerwärtiger Geruch oder Geschmack. Es mag dies damit zusammenhängen, dass Geruch und Geschmack als Hüter an den Pforten für den Eintritt fremder, möglicherweise schädlicher Substanzen in unseren Körper gesetzt sind.

\section{Gesicht.}

Der Gesichtsinn rernittelt unserem Bewusstsein die Waln'nehmung ron Eigenschaften der Körper, dureh welehe dieselben Lichtstrahlen aussenden, oder auf ihrem Wege beeinflussen. Lichtstrahlen beruhen auf der Fortpflanzung ron Schwingungen des Aethers, deren Häufigkeit zwischen 480 und 760 Billionen in der Secunde ist, und deren Wellenlänge zwischen 0,70 und $0,43 \mu$ liegt. Die Endausbreitungen des Nervus opticus sind so gelegen, dass sie unter gewöhnlichen Bedingungen ron keinen anderen äusseren Einwirkungen als von Lichtstrahlen getroffen werden können, ron diesen aber in ausgezeichueter Weise; empfindlich sind sie freilich auch für andere Einwirkungen, als für ihren adäquaten 
Reiz, das Licht. Drïckt man zum Beispiel bei verschlossenen Augen und im Dunkel bei etwas nach unten aussen gewendeten Augen im inneren oberen Orbitalwinkel mit dem Rand des Fingernagels durch das Lid auf den Augapfel, wobei man mit dem Druck die vordere Grenze der Sehnervenausbreitung erreicht, so hat man eine bogenförmige Lichtfigur, welche unten aussen zu liegen scheint, und welche sich bei kleinen Bewegungen des Auges oder des Fingers ebenfalls bewegt. Der Druck, welcher sich auf die Opticusendigungen fortpflanzt, ist also ein Reiz für dieselben und da ihre Erregung, mag sie durch Licht oder durch Druck erzeugt sein, mit einer Gesichtswahrnehmung verbunden ist, sagen wir, dass das Gesicht die specifische Energie des Sehnerven sei. Für den adäquaten Reiz sind die Sehnervenfasern nur durch Vermittelung ihrer Endapparate empfindlich, denn die Eintrittsstelle des Sehnerven in den Augapfel, wo seine Fasern dem Licht bloss liegen, ohne von Endapparaten bedeckt zu sein, ist blind; ob der Nageldruck auf Endapparate oder Fasern wirkt, ist ungewiss, doch scheint wegen der Figur der Druckerscheinung ersteres wallrscheinlich.

Die Eigenschaften, vermöge deren die Körper auf unseren Sehapparat zu wirken im Stande sind, sind im Allgemeinen mannigfach verschieden auf kleinem Raum. Das Erkennen dieser Verschiedenheiten liegt dem Sehen zu Grunde, und wir werden also erwarten müssen, dass der Sehapparat zweien Anforderungen genügt, erstens derjenigen, dass in der peripherischen Sehsinnesfläche Sehsinneselemente in einer Anordnung vertreten sind, bei welcher auf kleinem Raum eine grosse Anzahl von quantitativ, qualitativ und local verschiedenen Erregungen entstehen können, und zweitens derjenigen, dass von den Aussengegenständen ein deutliches Bild auf der Sehsinnesfläche entsteht. Der ersteren Anforderung ist genïgt durch eine mosaikartige Anordnung der lichtempfindlichen Nervenendigungen im Augenhintergrunde, der zweiten dadurch, dass die durchsichtigen Theile des Augapfels ein optisches System nach Art einer Camera obscura darstellen.

Das Wesentliche der anatomischen Einrichtung des Auges kann in Folgendem zusammengefasst werden: jeder Augapfel stellt einen annähernd sphärischen Körper von praller Elasticität dar, an dem wir Inhalt und Wand unterscheiden. Die Wand ist aus drei Schichten aufgebant, aus der Tunica sclerotica, der Tunica uvea und der Tunica retina. Zu äusserst liegt die Tunica sclerotica oder die harte Haut des Luges, welche aus der undurchsichtigen und der durchsichtigen Hornhaut besteht. I)ie harte Haut giebt dem Augapfel seine Festigkeit und ist vermöge ihrer prallen Füllung stark gespannt. Die durchsichtige Hornhaut bildet den vorderen Theil des Augapfels und wird auch schlecht- 
weg Hornhaut oder Corneil genannt. Der weitaus grössere hintere $\mathrm{Ab}$ schnitt, welcher zum Theil auch noch in der Iugenlidspalte sichtbar ist, ist weiss, nur schwach durchscheinend und wird $\% \alpha \tau$ ' $\dot{\xi} \xi_{\circ} \% \dot{r}_{y}$ die Sclerotica genannt. Die Cornea ist beträchtlich stärker gekrïmmt, als die Sclerotica. Dic Mitte der Cornea wird als vorderer Pol des Augapfels bezeichnet. Hierdurch gegeben ist, was man die Axe, die Meridiane und den Aequator zu nemnen hat, unter Innehaltung der Analogic mit der Erdkugel.

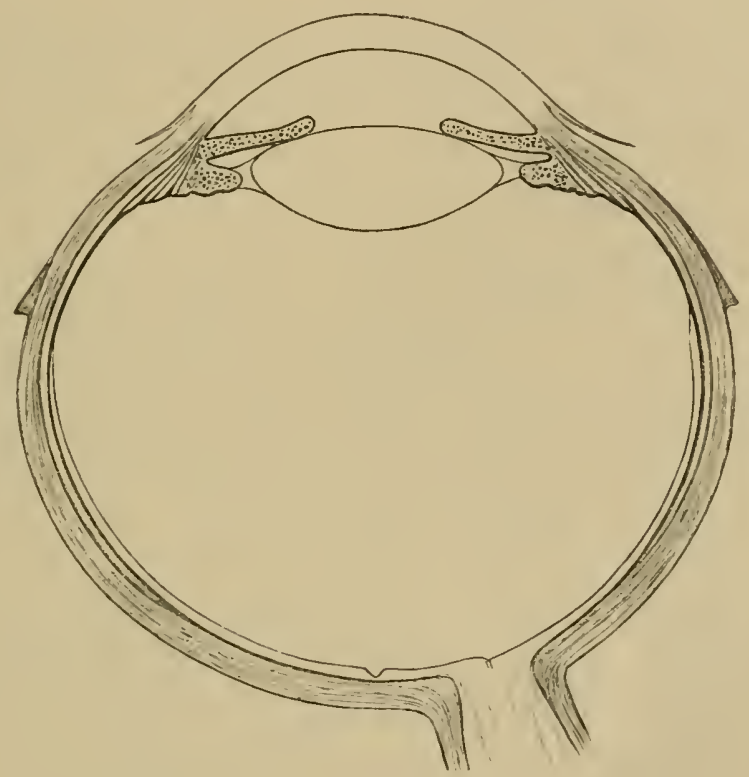

22.

Die zweite Schicht, die Tunica uvea, ist sehr reich an Gefässen, und namentlich auf ihrer inneren, das heisst dem Centrum des Augapfels zugekehrten Seite, stark schwarz pigmentirt; an der ganzen Sclerotica liegt die Urea dicht aber verschieblich an und wird in diesem Bereiche Chorioidea genannt. An der Grenze der Cornea gegen die Sclerotica, besteht eine festere Verwachsung der Chorioidea mit letzterer; von da ab nach vorne bleibt die zweite Schicht mit der ersten nicht in Berïhrung, sie setzt sich vielmehr in dem Wölbungszuge der Sclerotica fort und so entsteht zwischen ihr und der stärker gekrimmten Hornhaut ein freier Raum, die vordere Angenkammer. Der freie Theil der Tunica uvea wird Iris genannt, er hat in der Mitte ein rundes Loch, die Pupille. Letztere wird ron glatten Muskelfasern umkreist, durch 
deren Zusammenzichung sie verengert wird, und welche man als Ringmuskel der Iris oder als Sphincter pupillae zusammenfasst. Muskelfasern der Iris, welche dem Ringmuskel antagonistisch wirken sollten, mïssten radiär verlaufen. Die Existenz eines Systems solcher Faserzïge, welche man unter den Begriff eines Dilatator pupillae zusammenfassen könnte, ist behauptet aber nicht bewiesen worden; allerdings strahlen von dem Umfang des Sphincters Faserziige speichenartig aus, die Faserzüge erreichen aber nicht den Anheftungsrand der Iris und sind ausserdem beim Menschen sehr spärlich.

An ihrem vorderen Theile gegen die Iris hin ist die Chorioidea verdickt zu dem sogenannten Ciliarkörper; von dem verdickten Grunde aus erheben sich etwa 80 faltenartige Vorsprünge in das Innere des Auges hinein; diese Ciliarfortsätze sind vorn am höchsten und laufen in meridionaler Richtung gegen den Aequator des Auges flach aus. Von der ringförmigen Verwachsungsstelle zwischen Sclerotica, Cornea und Uvea entspringen glatte Muskelfasern, welche meridional gerichtet in die Chorioidea einstrahlen und den sogenannten Tensor chorioideae bilden.

Die dritte Schicht der Augapfelwand, die Tunica retina, liegt der inneren Fläche der Uvea dicht an und enthält in ihrem hinteren Theile bis in die Gegend des Aequators die Ausbreitung der Sehnervenfasern mit ihren terminalen Anhangsgebilden. In der vorderen Augenhälfte ist sie nur durch eine einfache structurlose Lamelle vertreten.

Das Innere des Augapfels ist durch den Glaskörper, die Krystalllinse und den Humor aqueus ausgefüllt. Die Krystalllinse ist ein durchsichtiger elastischer Körper mit eigener Gleichgewichtsfigur; sie ist vorn und hinten durch je einen Kugelabschnitt begrenzt, von denen der vordere einen beträchtlich grösseren Krümmungsradius hat, als der hintere. Das Lichtbrechungsvermögen der Linsensubstanz ist erheblich grösser, als das des Wassers und nimmt von der Peripherie der Linse bis zu ihrem Kern continuirlich zu. Der Körper der Linse besitzt eine faserige Structur mit sehr regelmässiger radiärer Anordnung der Fasern in concentrischen Schichten, und ist allseitig umschlossen von einer festen, sehr elastischen Membran, der Linsenkapsel. Nahe dem Linsenrande helot sich von der vorderen und hinteren Linsenkapsel je eine Membran ab. Diese beiden Membranen convergiren gegen die Pars ciliaris retinae und sind mit derselhen verwachsen; wegen ihrer physiologischen Bedeutung werden sie als zwei Blätter eines Ligamentes, des I igamentum suspensorium Lentis aufgefasst. Man kann sich dies Ligament auch herrorgegangen denken aus der Spaltung der inneren Grenzschicht der Retina, welche als Membrana hyaloidea bezeichnet wird. Das vordere stärkere Blatt folgt den Ausbuchtungen und Erhebungen 
der Ciliarfortsïtze und spannt sich ron diesen zur vorderen linsenkapsel als sogenannte Zonula Zinnii hiniiber; das hintere Blatt spaltet sich am flacheren Theil der Ciliarfortsütze ab, folgt der vorderen Flïche des Glaskïrpers und gelangt so zur hinteren Linsenkapsel. Der ringförmige Raum mit dreiseitigem Querschnitt zwischen den beiden Blättern des Suspensoriums und der Linse wird Petit'scher Kianal genannt; den Raum zwischen Zonula Zinnii und Iris nennt man hintere Augenkammer. Die Membrana hyaloidea ist mit der Urea festrerwachsen, sodass sie allen durch den 'Tensor chorioideae reranlissten Bewegungen derselben folgt.

Den grössten Theil des Augeninhaltes bildet der Glaskörper, eine durchsichtige Masse von gallertartiger Consistenz, welche durch eine sehr dümne eigene Membran eingehïllt, den ganzen Raum zwischen Linse, hinterem Blatt des Suspensorium Lentis und Retina einnimmt; die Grenzfläche zwischen hinterer Linsenkapsel und Glaskörper nennt man die tellerförmige Grube. Der Humor ist eine wasserklare Flïssigkeit mit schwachem Salzgehalt, welche die Räume des Augenimnern zwischen den beschriebenen Gebilden ausfïllt, namentlich also rordere Augenkammer, lintere Augenkammer und Petit'schen Kanal.

Das dioptrische System des Auges ist gebildet durch die an ihrer vorderen Fläche stets mit Thränenflüssigkeit befenchtete Cornea, den Humor aqueus der vorderen Kammer, die Linse und den Glaskörper; die Retina stellt den Bild-auffangenden Schirm und die Iris ein Diaphrigma dar.

Vom physikalischen Standpunkte aus kann man das dioptrische System des Auges charakterisiren als ein centrirtes System sphärischer Trennungsflächen zwischen verschieden brechenden Medien, mit collectirerWirkung.

Ein collectives dioptrisches System kann von Gegenständen, welche anf der einen Seite desselben gelegen sind, reelle Bilder auf seiner anderen Seite entwerfen; die Beziehungen zwischen der Lage der Bilder und der Lage der Gegenstände ist von besonderem Interesse. Um dieselbe bei dem Auge übersehen zu können, müssen wir von der Betrachtung eines einfacheren Systems ausgehen.

Der denkbar einfachste hierher gehörige Fall wäire realisirt, wenn wir zwei beliebig ausgedlehnte Medien von verschiedenem Brechungsindex, in einer sphärischen Trennungsfläche an einander stossend, vor uns hä̈ten. Die Convexitüt des trennenden Kiugelabschnittes möge nach inks sehen und dort möge sich das schwächer brechende Medium, etwa Luft, rechts das stärker brechende, etwa Glas, befinden. Der betrachtete Kúgelabschnitt liege symmetrisch zu einer durch den Kugelmittelpunkt gezogenen Horizontalen, der Axe des Systems. Strahlen, welche aus 
dem einen Medium in das andere übertreten, ändern hierbei ibre Richtung, sie werden gebrochen. Ziehen wir nur solche Strahlen in Betracht, welche einen kleinen Winkel mit der Axe bilden, so gilt für die Brechung der Satz, dass Strahlenbündel, welche auf der einen Seite der sphärischen Trennungsfläche homocentrisch sind, dies auch auf der anderen bleiben. Homocentrisch nennt man Strahlen, welche sich in einem Punkt schneiden: den Durchschnittspunkt der Strahlen eines homocentrischen Bündels nennt man das Centrum des letzteren. Jeder Punkt eines abzubildenden Gegenstandes stellt das Centrum eines divergirenden Strahlenbündels dar und wird Objektpunkt genannt. Durch die Brechung wird das von dem Objektpunkt ausgehende und divergent auf die Trennungsfläche auffallende Strahlenbündel entweder convergent oder schwächer divergent gemacht. Im ersteren Falle spricht man von collectiver Wirkung des Systems; das Centrum, auf welches die Strahlen des Bündels convergiren, liegt auf der zweiten Seite der Trennungsfläche und wird reeller Bildpunkt genannt, reell, weil man ihn durch einen diffus reflectirenden Schirm als leuchtenden Punkt zur Anschauung bringen könnte. In dem zweiten Falle liegt der Bildpunkt auf derselben Seite der Trennungsfläche wie der Objektpunkt, er ist nicht reell, das heisst man kann ihn auf einem Schirm nicht zur Anschauung bringen, er existirt vielmehr nur in der Vorstellung als Schnittpunkt der rückwärts verlängert gedachten Strahlen, und wird virtueller Bildpunkt genannt.

Die Bedingung, dass die in Betracht zu ziehenden Strahlen vor und nach der Brechung nur einen kleinen Winkel mit der Axe des Systems bilden, ist erfüllt, wenn éinerseits nur ein kleiner Theil des Kugelabschnittes in der Umgebung der Axe durchsichtig ist, und wenn andererseits die von den Grenzen des abzubildenden Objektes nach dem Kugelmittelpunkt gezogenen Linien kleine Winkel mit der Axe bilden, das heisst, wenn die abzubildenden Punkte selbst nicht weit von der Axe liegen, und zwar um so weniger weit, je kleiner die Entfernung vom optischen System ist. In diesem Falle gilt Folgendes:

Jeder Bildpunkt liegt auf der Verbindungslinie des zugehörigen Objektpunktes mit dem Kugelmittelpunkt; diese Linie nennt man die Richtungslinie des Strahlenbündels.

Dic auf der Richtungslinie gemessene Entfernung des Bildpunktes von der brechenden Fläche $\left(\mathrm{p}^{\prime}\right)$ ist ausser von dem Kugelradius (r) und von dem Brechungsindex (n) des Glases nur noch abhängig von der auf der liichtungslinie gemessenen Entfernung zwischen Objektpunkt und 'T'rennungsfläche (p).

Wenn $p, p^{\prime}$ und $r$ von der Trennungsfläche aus positiv gerechnet werden, so gilt die Bezichung: 


$$
\left.\frac{\mathrm{n}-1}{\mathrm{r}}=\frac{1}{\mathrm{p}}+\frac{\mathrm{n}}{\mathrm{p}^{\prime}}{ }^{1}\right)
$$

Aus dem Umstand, dass $\mathrm{p}^{\prime}$ ausser ron den Constanten des Merlienpaares (n und r) nur von p abhängt, folgt, dass einem System ron Objektpunkten, die in gleicher Entfernung ron dem brechenden Kugelabschnitt, das heisst auf einer dazu eoncentrischen Kingelschale liegen, ein System von Bildpunkten entspricht, welche gleichfalls sümmtlich gleiche Entferumng vom brechenden Kungelabschnitt haben, also gleichfalls auf einer zu ihm concentrischen Kugelschale liegen. Ein System ron Objektpunkten nennt man ein Objekt, und das zugehörige System ron Bildpunkten sein Bild; liegt also ein Objekt auf einer zur breehen-

1)

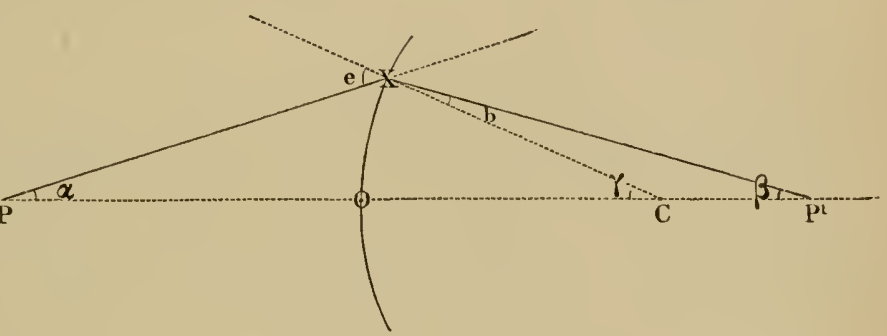

23.

Bezeichnungen: POP' Axe des Systems; OX sphärische Trennungsfläche, C ihr Mittelpunkt; P Objektpunkt, P' Bildpunkt, PX einfallender Strahl; XP' gebrochener Strahl; CX Einfallsloth; e Einfallswinkel; b Brechungswinkel; $\gamma$ Centriwinkel; $\alpha$ Axenwinkel des einfallenden, $\beta$ des gebrochenen Strahls.

$$
\mathrm{OP}=\mathrm{p} \quad \mathrm{OC}=\mathrm{r} \quad \mathrm{OP}^{\prime}=\mathrm{p}^{\prime} .
$$

Nach dem Brechungsgesetz ist: $\frac{\sin e}{\sin b}=n$

und wenn e und b genügend klein sind: $\frac{\mathrm{e}}{\mathrm{b}}=\mathrm{n}$

oder identisch:

$\mathrm{e}=\mathrm{nb} \quad 1)$

Als Gegenwinkel sind: $e=\alpha+\gamma$

$\gamma=\beta+b$

oder identisch: $\quad b=\gamma-\beta$

Durch Einsetzen in 1): $\alpha+\gamma=n(\gamma-\beta)$

oder identisch: $\quad \gamma(\mathrm{n}-1)=\alpha+\mathrm{n} \beta$

Wenn $\mathrm{OX}$ genügend klein, so ist:

$$
\operatorname{tg} \alpha=\frac{O X}{p} ; \quad \operatorname{tg} \beta=\frac{O X}{p^{\prime}} ; \quad \operatorname{tg} \gamma=\frac{O X}{r}
$$

und wenn $\alpha, \beta$ und $\gamma$ gentigend klein

$$
\alpha=\frac{O X}{p} ; \beta=\frac{O X}{p^{\prime}} ; \gamma=\frac{O X}{r} .
$$

Durch Einsetzen in 2): $\frac{O X}{r}(n-1)=\frac{O X}{p}+n \frac{O X}{p^{\prime}}$

oder identisch: $\frac{\mathrm{n}-1}{\mathrm{r}}=\frac{1}{\mathrm{p}}+\frac{1}{\mathrm{p}^{\prime}}$. 
den Fläche concentrischen Kugelschale, so liegt auch sein Bild ganz auf einer eben solchen. Man sieht ohne Weiteres, dass das Bild und Objekt einander geometrisch ähnlich sind und dass jede Dimension des Bildes sich zu der entsprechenden Dimension des Objektes verhält wie der Abstand des Bildes einerseits und des Objektes andererseits ron der brechenden Fläche. Mit einer für unseren Zweck genügenden Annäherung gelten diese Beziehungen noch, wenn die Objektpunkte in einer zur Axe senkrechten Ebene liegen, in welchem Falle anch das Bild als eben betrachtet werden kann. Man darf auch die Längen $p, p^{\prime}$ und $r$ statt ron der sphärischen Trennungsfläche ron einer in ihrem Scheitelpunkt errichteten, zur Axe senkrechten Ebene messen.

Der Beziehung zwischen den Entfernungen rou Objekt und Bild kann man eine einfachere Form geben, wenn man zwei ausgezeichnete Punkte des Systems in die Betrachtung einführt, deren Lage ein für allemal durch die Constanten des Systems bestimmt ist, es sind dies die Brennpunkte. Ein Objektpunkt, der auf der Axe des Systems in unendlicher Entfernung liegt, sendet ein Bündel aus, dessen Strahlen parallel unter sich und parallel zur Axe die Trennungsfläche treffen und welches zu einem in der Axe gelegenen Bildpunkt hinter der Trennungsfläche vereinigt wird; diesen Punkt nennt man den zweiten Brennpunkt des Systems. Umgekehrt giebt es auf der Axe einen Objektpunkt, dessen Strahlen durch die Brechung an der Trennungsfläche parallel gemacht werden, diesen Punkt nennt man den ersten Brennpunkt. Die Entfernungen der Brennpunkte von der Trennungsfläche nennt man die Brennweiten (erste Brennweite $f$, zweite $f^{\prime}$ ) und die in den Brennpunkten senkrecht zur Axe errichteten Ebenen, die Brennebenen. Die Brennweiten ergeben sich aus der ersten Formel als Function ron $r$ und n, wenn man für $\mathrm{p}$ respective $\mathrm{p}^{\prime}$ die Werthe unendlich einsetzt. Auf diesem Wege erhält man die Gleichungen:

$$
\frac{\mathrm{n}-1}{\mathrm{r}}=\frac{1}{\mathrm{f}} ; \frac{\mathrm{n}-1}{\mathrm{r}}=\frac{\mathrm{n}}{\mathrm{f}^{\prime}} ; \mathrm{n}=\frac{\mathrm{f}^{\prime}}{\mathrm{f}} ; \mathrm{r}=\mathrm{f}(\mathrm{n}-1) .
$$

Unter Bewutzung dieser Gleichungen können wir aus der Gleichung (1) $n$ und $\mathrm{l}^{*}$ eliminiren und dafür $\mathrm{f}$ und $\mathrm{f}^{\prime}$ einführen und wir erhalten

$$
1=\frac{\mathrm{f}}{\mathrm{p}}+\frac{\mathrm{f}^{\prime}}{\mathrm{p}^{\prime}}
$$

In einem System wie dasjenige, welches wir der Betrachtung zu Grunde gelegt haben, in welchem also die Trennungsfläche ihre convexe Seite dem schwächer brechenden Medium zukehrt, sind $f$ und $f^{\prime}$ positiv; für ein solches, als collectiv bezeichnetes, System ergiebt die Formel (2), dass jedem endlichen Objekte, dessen Abstand $\mathrm{p}$ grösser als $\mathrm{f}$ ist, ein reelles Bild entspricht, dessen Abstand $p^{\prime}$ grösser als $f^{\prime}$ ist. Man kaun 
ferner noch den folgenden Satz aus der Formel herauslesen: wenn man einen Objektpunkt mit constanter Geschwindigkeit aus sehr grosser Ferne gegen die erste Brennebene heranrücken lässt, so bewegt sich der Bildpunkt ron der zweiten Brennebene ans in derselben Richtung und zwar anfangs sehr langsam, dann aber immer schneller, bis er mit unendlich grosser Geschwindigkeit die unendliche Ferne erreicht, wenn der Objekt-

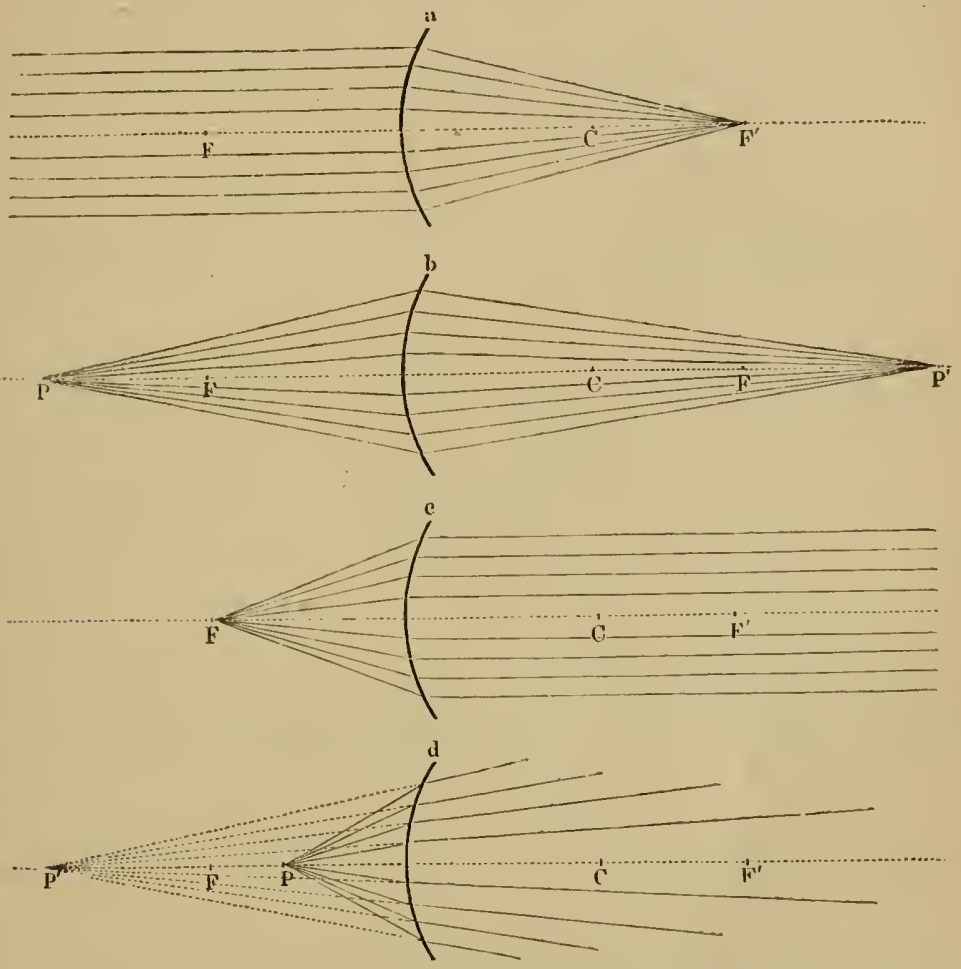

24.

punkt in die erste Brennebene eintritt. Man erkennt dies auch durch Anschanung aus den Constructionen a--c der Fig. 24. Es hindert nichts, einen reellen Objektpunkt über die erste Brennebene hinaus bis zur Trennungsfläche weiter wandern zu lassen (Fig 24, d); der Bildpunkt ist in diesem Intervall nicht mehr reell ( $\mathrm{p}^{\prime}$ ist negativ), die Strahlen des Lichtbiindels sind vielmehr in dem zweiten Medium so gerichtet, als wenn sie von einem in grösserer Entfernung als der Objektpunkt liegenden Punkte herkämen: diesen Punkt nennt man einen virtuellen Bildpunkt. Während sich der Objektpunkt ron der ersten Brennebene bis zur Trennungsfläche bewegt, läuft der aus nnendlicher Ent- 
fernung auftauchende virtuelle Punkt hinter ihm her, um ihn in der Trennungsfläche zu erreichen.

Bèi der bisherigen Betrachtung hatten wir als Objektpunkt einen thatsächlich Licht aussendenden Punkt angenommen; die von diesem Punkt ausgehenden Strahlen trafen die Trennungsfläche, indem sie zuerst untereinander parallel waren, dann mehr und mehr divergirten. Die Trennungsfläche kann aber in derselben Richtung nicht nur von parallelen oder divergenten Strahlen, sondern auch von convergenten homocentrischen Strahlen getroffen werden; das Centrum eines solchen die

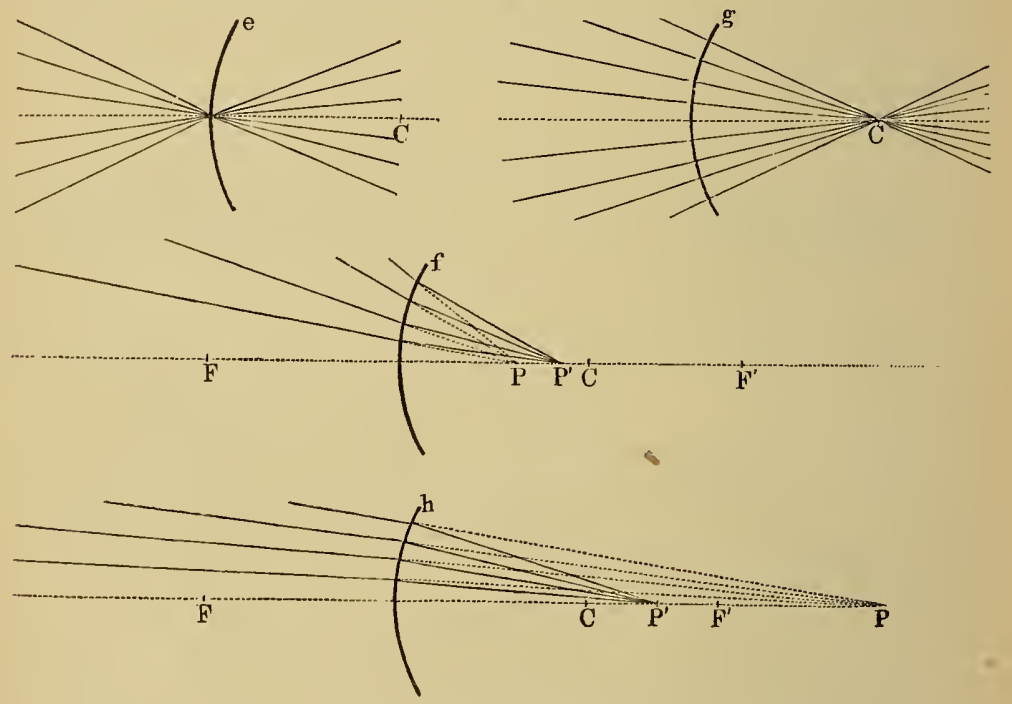

25.

Trennungsfläche convergent treffenden Bündels ist reell nicht vorhanden, sondern kann nur als Durchschnittspunkt der ïber die Trennungsfläche linaus verlängert gedachten Strahlen vorgestellt werden. Ein solches Centrum nennt man einen virtuellen Objektpunkt und man sagt, dass der Ol,jektpunkt, indem man ihn aus dem ersten Medium durch die Trennungsfläche in das zweite Medium wandern lässt, aus einem reellen zu einem virtuellen werde. Strahlen, welche von links auf einen Punkt der Trennungsfläche selbst convergiren, auf einen Punkt, den man also als virtuellen Objektpunkt auffassen kann, gehen zwar mit Richtungsänderung (schwächer divergirend) nach rechts weiter, aber so, als ob sie von demselben Punkte kämen, und man kann diesen Punkt also auch als virtuellen Bildpunkt auffassen. Hierin liegt die Berechtigung zu sagen, die Trennungsflüche sei der Ort ihres eigenen Bildes (Fig. 25, e). 
Auf dem Wege ron der Trennungsfläche his zum Kugelmittelpunkt schreitet der Bildpunkt, welcher nun wieder reell geworden ist, dem virtuellen Oljektpunkt roran (Fig. 25, f); in diesem Bereiche werden also die convergent auf die T'rennungsfläche auffillenden Strahlen weniger convergent gemacht. In dem lingelmittelpunkt treffen Billpunkt und Objektpunkt wieder zusammen (Fig. $25, \mathrm{~g}$ ), denn alle radiür auffallenden Strahlen gehen ungebrochen durch den Kungelmittelpunkt. Der Mittelpunkt der sphärischen Trennungsfläche ist also der Ort seines eigenen Bildes. Von da ab schreitet der Objektpunkt dem Bildpunkt wieder roran (Fig. 25, h), zuerst mit kleinem, dann mit immer grösser werdendem Unterschiede in der Geschwindigkeit, bis beim Eintreffen des Objektpunktes in unendlicher Entfernung der Bildpunkt im zweiten Bremupunt liegt und der Anfangszustand, von dem wir ausgingen, wieder elreicht ist.

Aus dieser Betrachtung ergeben sich als besonders bemerkenswerth folgende Resultate: durch die Brechung an unserer Trennungsfläche werden parallele Strahlen convergent; ron links nach rechts divergirende Strahlen werden convergent, parallel oder weniger divergent; ron links nach rechts convergirende Strahlen werden, wenn sie auf einen rechts rom Kungelmittelpunkt gelegenen Punkt convergiren, stärker convergent, und nur in den Fall, dass dieser Punkt zwischen Kugelmittelpunkt und Tremnungsfläche liegt, wirkt das System zerstrenend, das heisst die convergirenden Strahlen werden weniger convergent. Besonders beachtenswerth ist ferner, dass in der Tremmungstläche und in dem Kugelmittelpunkte Objekt- und Bildpunkt zusammenfallen.

Denken wir in unserm System das zweite Medium nicht beliebig weit ansgedelınt, sonder'n durch eine zweite sphärische Trennungsfläche, deren Mittelpunkt auf derselben Axe liegt, gegen ein anders brechendes Medium abgegrenzt, so können wir jedes durch die erste TrennungsHäche geliefertes, virtuelles oder reelles, Bild eines beliebigen Objektes in Bezug auf die zweite Trennungsfläche wieder als Objekt betrachten, und für das hierzu gehörige Bild gelten dieselben Principien wie für das erste Bild (vorausgesetat, dass auch die Brennweiten der zweiten Trennungsflïche beide positiv sind). Dasselbe Verfahren können wir uns beliebig oft wiederholt denken, doch wiirde es sehr umständlich und wenig ïbersichtlich sein. Man macht vielmehr, wo es sich um Systeme coaxialer sphärischer Trennungsfl̈̈chen zwischen rerschieden brechenden Medien handelt, von folgenden, hier nicht zu beweisenden Eigenschaften solcher Systeme Gebrauch.

Fin jedes derartiges System lat eine erste und eine zweite Hauptbrennebene. In dem hier allein interessirenden Falle, dass die Brenn- 
weiten aller einzelnen Tremnungsflächen positiv sind, liegt die erste Hauptbrennebene ror der ersten, die zweite hinter der letzten Trennungsfläche.

Strahlen, welche ron einem beliebigen in der ersten Brennebene, nicht zu meit ron der Axe, gelegenen Punkt ausgehen, werden hinter der letzten Trennungsfläche parallel, und Strahlen, welche parallel in der Nähe der Axe auf die erste Trennungsfläche auffallen, werden in einen Punkt der zweiten Brennebene vereinigt; die Brennweiten des Systems rechnet man nicht ron einer der Trennungsflächen bis zu der Brennebene, sondern von zwei zur Axe senkrechten Ebenen, deren Lage aus den Constanten des Systems, das heisst aus allen Krümmungsradien, Brechungsindices und Scheitelpunktdistanzen berechnet wird, und welche man die Hauptebenen des Systems nennt (E und E'); die erste Hauptbrennweite $(F)$ rechnet man von der ersten Hauptebene bis zur ersten Hauptbrennebene und die zweite Hauptbrennweite $\left(F^{\prime}\right)$ von der zweiten Hauptebene bis zur zweiten Hauptbrennebene. Die Hauptbrennweiten sind durch die Constanten des Systems bestimmt, und wenn man auch die Objektabstäncle $(\mathrm{P})$ sowie die zugehörigen Bildabstände $\left(\mathrm{P}^{\prime}\right)$ von den Hauptebenen rechnet, so gilt wieder die Gleichung

$$
1=\frac{\mathrm{F}}{\mathrm{P}}+\frac{\mathrm{F}^{\prime}}{\mathrm{P}^{\prime}} \text {. }
$$

Ebenso wie in einem Systeme mit einer einzigen Trennungsfläche diese Fläche der Ort ihres eigenen Bildes ist, so ist jede der beiden Hauptebenen eines zusammengesetzten Systems das Bild der anderen Hauptebene. In analoger Weise tritt an die Stelle des Kugelmittelpunktes des einfachen Systems ein Punktpaar in zusammengesetzten System; rliese Punkte, deren Lage ebenfalls durch die Constanten des Systems bestimmt ist, nennt man den ersten und den zweiten Knotenpunkt ( $K$ und $K^{\prime}$ ). Die Knotenpunkte liegen auf der Axe des Systems. Den Richtungsstrahl eines das System treffenden homocentrischen Strahlenbïndels nennt man die Verl,indungslinie zwischen dem Centrum des Bündels und dem ersten Knotenpunkt; der diesem Centrum zugehörige Bildpunkt liegt auf einer durch den zweiten Knotenpunkt gelegten Parallele zum Richtungsstrahl und zwar in einer Lntfernung hinter der zweiten Hauptebene, welche durch die obige Gleichung bestimmt ist.

Will man für ein zusammengesetztes System von den voransgesetzten Ligenschaften den zu einem gegebenen Objektpunkt gehörigen Bildpunkt durch Construction bestimmen (nachdem die Cardinalpunkte und Ebenen durch liechnung gefunden sind), so verfährt man folgendermaassen: man zieht zunächst von dem Objektpunkt (P, Fig. 26) eine Parallele zur' Axe; will man den Giang eines in dieser Richtung das zusammengesetzte 
System treffenden Strahles, unbekiimmert uim seine wirklichen Richtungsinderungen innerhalb des Systems, nach seinem Austritt aus der letzten 'Trennungsflïche erfahren, so muss man, da die beiden Hauptebenen an die Stelle aller wirklichen Trennungsflïchen getreten sind, dem Strihl bis zur ersten Hauptebene (E) die ursprüngliche lichtung lassen, und da die zweite Hauptebene das Bild der ersten Hauptebene ist, so trifft ein der Axe paralleler Strahl auch die zweite Hauptebene $\left(E^{\prime}\right)$ in derselben Entfernung von der Axe wie die erste. Alle das System von links her treffenden Strahlen, welche unter einander und mit der $\Lambda x e$ parallel sind, gehen durch den zweiten Hauptbrennpunkt. Der betrachtete Strahl verlässt also das System auf der Verbindungslinie zwischen seinem Schnittpunkt mit der zweiten Hauptebene und dem zweiten Hauptbrennpunkt $\left(\mathrm{F}^{*}\right)$. Der Richtungstrahl des von dem betrachteten Objektpunkt ausgehenden Strahlenbündels trifft den ersten Knotenpunkt und geht

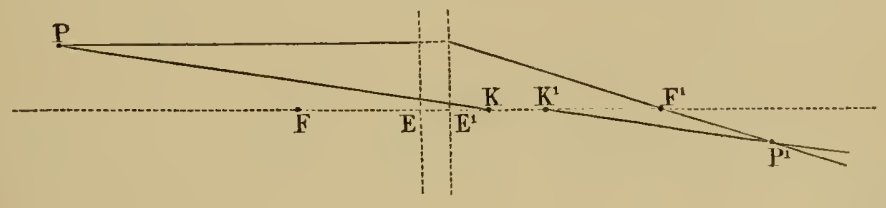

26.

vom zweiten Knotenpunkt parallel mit seiner ersten Riclitung weiter, denn der zweite Knotenpunkt ist das Bild des ersteu Knotenpunktes. Wo der so verlängerte Richtungsstrahl den durch den zweiten Hauptbrennpunkt gegangenen ersten Strahl schneidet, liegt der Bildpunkt P', denn wo sich zwei Strahlen eines homocentrischen Bündels schneiden, schueiden sich auch alle ïbrigen.

Der dioptrische Apparat des Auges stellt ein centrirtes System sphärischer Trennungsflächen zwischen verschiedenen brechenden Medien dar; die Trennungsflichen sind vordere und hintere Fliiche der Cornea, vordere und hintere Fläche der Linse. Von diesen scheidet jedoch die hintere Corneafläche aus, weil der Brechungsindex des Humor aqueus annähernd gleich dem der Corneasubstanz ist; die vordere Corneafläche stösst nicht unmittelbar an Luft, sondern ist von einer eapillaren Schicht Thränenflïssigkeit ïberzogen, aber auch dies kommt nicht in Betracht, da auch die Thränenflïssigkeit dasselbe Lichtbrechungsvermögen besitzt wie Cornea und Humor aqueus. Die wirklich in Betracht zu ziehenden Medien und Trennungsflächen sind also Luft, vordere Corneafläche, IIumor aqueus, vordere Linsenfläche, Linsensubstanz, hintere Linsenfläche, Glaskörper.

Man besitzt bisher keine Methode, um die Brechungsindices der 
durchsichtigen Augenmedien am lebenden Auge zu bestimmen. Nach dem Tode stösst die Untersuchung des Lichtbrechungsvermögens von Humor aqueus (respective Cornea und Thränenflïssigkeit) und von Glaskörper auf keine Schwierigkeiten, da diese Substanzen als optisch homogen betrachtet werden können; anders verhält es sich bei der Krystalllinse, da das Lichtbrechungsvermögen von den peripherischen Schichten bis zum Kern continuirlich und in erheblichem Maasse zunimmt. Im Mittel aus einer grossen Zahl von Untersuchungen menschlicher Linsen ergab sich der Brechungsindex der äusseren Linsenschichten zu 1,4053, der mittleren zu 1,4294 und des Kernes zu 1,4541. Will man, um die Betrachtung zu vereinfachen, an die Stelle der geschichteten Krystalllinse eine homogene von gleicher Form und gleicher brechender Kraft setzen, was bei Ausschluss von Strahlen mit grösserem Einfallswinkel angängig ist, so darf man der homogenen Linse nicht einen Brechungsindex beilegen, welcher den Mittelwerth der Brechungsindices der verschiedenen Schichten darstellt; der sogenannte Totalindex der Linse ist vielmehr noch etwas grösser als der Index der Kernschicht, das heisst die geschichtete Linse wirkt stärker brechend, als eine homogene, deren Substanz durchweg den Index des Kernes besässe: der Grund hierfür ist mathematisch einzusehen, aber nicht mit Hülfe elementarer Methoden. Der Totalindex der menschlichen Krystallinse, auf den es hier ankommt, ist so bestimmt worden, dass die Lage der Brennebenen an der möglichst frischen Leichenlinse empirisch ermittelt und der Brechungsindex einer homogenen Linse von gleicher Form berechnet wurde, welcher dieser Linse die gleiche brechende Kraft geben würde.

Die Lage und die Gestalt der Trennungsflächen lässt sich am lebenden Auge bestimmen; man benutzt hierzu das jedem bekannte Spiegelbild, welches die vordere Corneafläche von äusseren Gegenständen entwirft, und die analogen, von der vorderen und hinteren Linsenfläche gelieferten Spiegelbilder, welche die Sans on-P urkinje'schen Bilder genannt werden. Um den Krümmungsradius der Cornea zu bestimmen, misst man die Grösse des Corneabildes eines Gegenstandes, dessen Grösse und Entfernung bekannt ist. Nach einfachen Gesetzen der Katoptrik ergielst sich der Krümmungsradins durch Rechnung aus diesen drei Grössen. Für die Messung des Hornhautbildchens erwächst aus der nicht zu unterdrückenden Bewegung des beobachteten Auges eine analoge Schwierigkeit, wie sie für die Messung der Sonnenhöhe auf dem Schiffe besteht. In ähnlicher Weise wie die Schwierigkeit in letzterem Falle dur'ch den Spiegelsextanten ïberwunden wird, geschieht es beim Auge mit Hiilfe des sogenannten Ophthalmometers.

Um die Sanson-Purkinje'schen Bilder schen zu können, bedarf es der folgenden Anordnung: in gleicher Höhe mit dem zu be- 
obatchtenden Ange hringt man wenige Decimeter von demselben entfernt cine helle Kerzenflamme an, und in grosser Entfernung ron ihm ein zu fixirendes Zeichen. Der Winkel zwischen der Gesichtslinie des bcobachteten Auges und seiner Verbindungslinic mit der KerzenHamme mag etwa $35^{\circ}$ betragen; die Kierzenflamme muss einen dunklen Hintergrund haben, damit keine störenden Reflexe entstehen. Der Beobachter bringt nun sein Auge, in der für das deutliche Sehen passenden Entfernung, in gleiche Höhe mit dem beobachteten Auge und blickt in einer Richtung linein, welche mit dessen Gesichtslinie auf der anderen Seite ungefähr denselben Winkel bildet wic die Richtung von der Flamme zum beobachteten Ange. Der Beobachter gewahrt dann nach einigem Suchen durch kleine Hin- und Herbewegungen die drei Reflexbilder in der durch die Figur 27 dargestellten Reihenfolge, wenn er die Lichtflamme zu seiner Linken hat. Die schwarze Scheibe soll die Pupille des beobachteten Auges bedeuten. Das ron der Hornhaut gelieferte Spiegelbild a braucht nicht nothwendig im Bereiche der Pupille zu erscheinen, wird es aber in der Regel bei der vorhin beschriebenen Anordnung thun; die Sanson-Purkinje'schen Bilder dagegen sieht man entweder im Bereiche der Pupille oder überhaupt nicht. b ist das von der vorderen Linsenfläche gelieferte Spiegelbild: es ist wie der Hornhautreflex ein aufrechtes Bild, doch ist seine Intensität weit geringer und seine Grenzen sind nicht so scharf. Die Form der Flamme ist gleichwohl auch in diesem Bild ungefähr zu erkennen und man bemerkt, dass es bei Weitem grösser ist, als der Hornhautreflex.

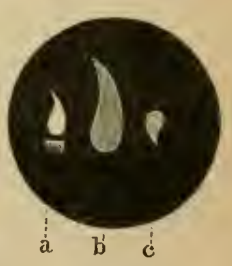

27. Wenn man das eigene Auge ein wenig hin- und herbewegt, so ändert das Bildchen seine Stellung in der Pupille bedeutend im gleichen Sinne mit der Bewegung des beobachtenden Anges: daraus geht hervor, dass der Ort dieses Bildchens weit (etwa 8 bis 12 Millimeter) hinter der Pupille ist.

Das dritte Bildchen c rerdankt seine Entstehung der Spiegelung an der hinteren Linsenfläche; es ist bedeutend lichtschwächer und auch kleiner als der Hornhautreflex. Es ist das reelle Spiegellild von einem Hohlspiegel und also umgekehrt; aus seinen kleineren Verschiebungen bei Bewegungen des beobachtenden Auges kann man schliessen, dass sein Ort nur wenig (etwa 1 Millimeter) hinter der Pupillenebene liegt.

Die Beobachtungen geben, wenn sie genau messend durchgeführ't werden, Grössenbestimmungen, welche der Berechnung von Lage und Gestalt der Tremnungsflächen zu Grunde gelegt werden können; da es 
nun aber keinesfalls möglich ist, alle dioptrischen Constanten eines bestimmten lebenden Auges genau zu ermitteln, so legt man den allgemeinen Betrachtungen ein System von Werthen in abgerundeten Zahleu unter, welche sich im Bereiche der normalen individuellen Schwankungen finden. Das diesem System von Werthen eutsprechend gedachte Auge nennt man das schematische Auge; die Werthe selbst sind folgende.

Brechungsindex der Luft . . . . . . . . . . . . . 1

des Humor aqueus . . . . . . . . . 103/77

der Linsensubstanz . . . . . . . . . 16/11

des Glaskörpers . . . . . . . . . . 103/77

Krümmungshalbmesser der Hornhaut . . . . . . . . $8 \mathrm{Mm}$

" der vorderen Linsenfläche . . . . 10

"der hinteren $"$. . . . 6

Entfernung des vorderen Linsenscheitels vom Hornhautscheitel 3,6 des hinteren vom vorderen Linsenscheitel . . . 3,6

Aus diesen dioptrischen Constanten des schematischen Auges erhält man durch Rechnung die Lage der Cardinalebenen und -Punkte desselben in Beziehung zum Hornhautscheitel; die Entfernung von diesem Punkt nach der Richtung des Augeninnern wird positiv, in der entgegengesetzten Richtung negativ gerechnet.

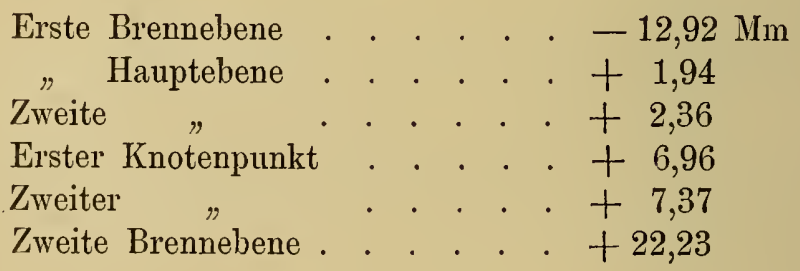

Hieraus ergiebt sich als die erste Hauptbrennweite (F) $12,92+1,94$ $=14,86 \mathrm{Mm}$, die zweite Hauptbrennweite $\left(\mathrm{F}^{\prime}\right) 22,23-2,36=19,87 \mathrm{Mm}$. Ferner sieht man, dass die beiden Hauptebenen und die beiden Knotenpunkte im Auge so nahe zusanmenfallen, dass man sie ohne merkliche Ungenauigkeit in eine Hauptebene und in einen Knotenpunkt verschmelzen kann: das bedeutet, dass man die Objekt- und Bildabstände $\left(\mathrm{P}, \mathrm{P}^{\prime}\right)$ von einer und derselben zur Axe senkrechten Ebene (E) aus messen kann, welche etwa 2,15 Mm hinter dem Horuhautscheitel liegt, und dass jedem einfallenden Strahl, der auf einen etwa 7,17 Mm hinter dem Hornhautscheitel gelegenen Punkt der Axe zielt, im Glaskörper 
seine eigene Verlängerung als gebrochener Strahl entspricht, dass also im Auge der Richtungsstrahl des Bildpunktes mit dem Richtungsstrahl des Objektpunktes merklich zusammenfällt. Den aus der Verschmelzung der beiden Knotenpunkte hervorgehenden Punkt der Axe nennt man daher den „Kreuzungspunkt der Richtungsstrahlen" (D in Fig. 28).

Dass im Auge die beiden Hauptebenen und ebenso die beiden Krnotenpunkte fast zusanmenfallen, bedeutet auch, dass sein ganzer dioptrischer Apparat dieselbe Wirkung hervorbringt, welche eine einzige sphärische Trennungstläche hervorbringen wïrde, deren Scheitel 2,15 Mm und deren Mittelpunkt 7,17 Mm hinter der Hornhaut läge, deren Radius

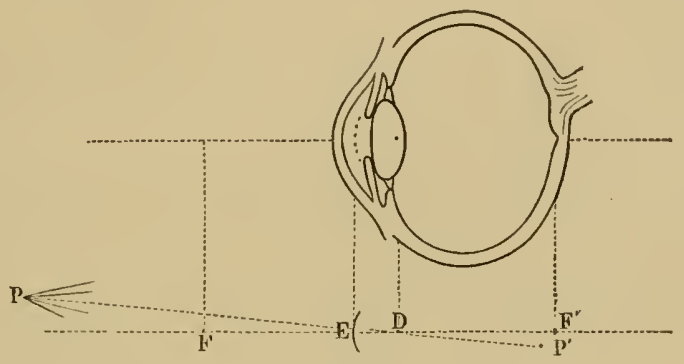

28.

also gleich 5,02 $\mathrm{Mm}$ anzunehmen wäre und welche unmittelbar die Luft von einem Medium mit bestimmtem Brechungsindex trennte. Dieser einfachere optische Apparat, das sogenannte "reducirte Auge", ist dem wirklichen brechenden Apparat des Auges optisch äquivalent, das heisst es bringt von denselben Objektpunkten die Bildpunkte an denselben Orten zu Stande, wenigstens sofer'n man nur Objektpunkte in Betracht zieht, welche nicht weit seitwärts von der Axe liegen.

Am Augengrunde ist die Retina ausgebreitet und diese ist so eingerichtet, dass sie uns die Gegenstände zur deutlichen Wahrnehmung bringt, wenn jeder Punkt derselben nur Licht von einem bestimmten Punkt des Objektes erhält, das heisst, wenn jedem Objektpunkt ein scharfer Bildpunkt auf der Netzhaut entspricht. Worauf diese Eimrichtung der Netzhant beruht, wird später genauer zı erörtern sein. Bei dem schematischen Auge ist diese Bedingung für unendlich entfernte Gegenstände (insofern die Verbindungslinien ihrer Grenzpunkte mit dem Kreuzungspunkt der Richtungsstrahlen nur einen kleinen Winkel gegen die Augenaxe bilden) erfuillt, wenn die Retina mit der zweiten Hauptbrennebene zusammenfällt. Dieses trifft fiir die Polarzone der Netzhaut, mit dem für das scharfe Sehen besonders fein ausgebildeten gelben Fleck, ịn den meisten Fällen zu, denn beim normalen Auge beträgt der Ab- 
stand des hinteren Scheitels der äusseren Scleroticafläche vom Hornhantscheitel etwa $24 \mathrm{Mm}$, während die zweite Hauptbrennebene im schematischen Ange 22,23 Mm hinter dem Hornhautscheitel liegt. Es wïrden also auf die Dicke der Sclerotica und Chorioidea 1,77 Mm zu rechnen sein (ein durchaus wahrscheinlicher Werth), wenn der gelbe Fleck mit der hinteren Brennebene zusammenfallen sollte. Diese Annahme liegt der Zeichnung (Fig. 28) zu Grunde, in welcher F und F' die Durchschnittspunkte der Hauptbrennebenen mit der Axe, D den Kreuzungspunkt der Richtungsstrahlen und E den Durchschnittspunkt der verschmolzenen Hauptebene mit der Axe bedenten. Der punktirte Kreisbogen deutet die einzige Trennungsfläche des reducirten Anges an.

Das Zusammenfallen der Polarzone der Netzhaut mit der hinteren Brennebene sieht man als die eigentliche normale Beschaffenheit des Auges an und nennt ein Auge, bei dem es statthat, ein emmetropisches. Streng genommen würdle man erwarten müssen, dass das so definirte emmetropische Auge nur Gegenstände in unendlicher Entfernung deutlich sehen könne, also etwa die Gestirne; für alle näher gelegenen Objekte riickt die Bildebene hinter die Retina. Die Folge davon ist, dass die von den einzelnen Objektpunkten ausgehenden Strahlenbündel die Retina nicht in je einem Punkt schneiden, sondern dass sie die Retina je in einem Kreise treffen; jeder dieser Kreise, welche man die Zerstreuungskreise nennt, entspricht dem Durchschnitt der Retina durch einen Kegel, dessen Spitze im Bildpunkt gelegen ist und dessen Basis die Pupille bildet. Die Zerstreuungskreise müssen um so grösser sein, je weiter die Bildebene von der Retina abrïckt, und je weiter die Pupille ist. Für das emmetropische Auge kann man die Beziehungen des Durchmessers der Zerstreuungskreise zu den Entfernungen der Objekte leicht berechnen; thut man dies, so findet man zunächst, dass bei Annäherung des Objektes ans der Unendlichkeit bis zu etwa 10 Meter Entfernung der Durchmesser der Zerstreuungskreise sehr langsam zunimmt und bei 10 Meter erst etwa $6 \mu$ beträgt, also noch sehr annähernd als punktförmig betrachtet werden kann. Bei grösserer Annäherung nimmt der Durchmesser der Zerstreuungskreise ungeführ in demselben Verhältnisse zu wie der Objektabstand abnimmt und beträgt bei 1,5 Decimeter Objektabstand etwa $1 / 3$ Millimeter, also eine verhältnissmässig recht beträchtliche Grösse. Um sich die Wirkung der Zerstreuungskreise für das deutliche Sehen klar zu machen, kann man sich vorstellen, dass von zwei benaclibarten Punkten des Objektes verschieden farbiges Licht ausgehe, etwa rothes und blaues; fällt die Bildebene mit der Retina zusammen, so wird von den entsprechenden benachbarten Punkten der letzteren dor eine nur rothes, der andere nur blaues Licht erhalten, 
man wird einen rothen und einen blatuen Punkt sehen. Fällt dagegen dic Bildebene nicht mit der Retina zusammen, so werden zwei Zerstreuungskreise entstchen, ein rother und ein blauer, welche sich theilweise iberdecken, und man wird ein Feld in der Mischfarbe mit reinfarbigen Rändern zu sehen bekommen.

Den Einfluss der Pupillenweite auf die Grösse und Wirkung der Zerstreuungskreise kann man sich durch den sogenannten Scheiner'schen Versuch rerdeutlichen: mit einer Nadel sticht man zwei Löcher in ein Kartenblatt in kleinerer Entfernung von einander, als der Durchmesser der Pupille beträgt; dies Blatt hält man dicht vor ein Auge und sieht durch die Löcher auf einen in grosse Nähe gebrachten kleinen Gegenstand, etwa eine Stecknadel. Wïhrend die Stecknadel bei Betrachtung mit blossem Auge aus derselben Entfernung mit verwascheneu Contouren erschien, sieht man bei Benützung des Blattes zwei wenig helle aber scharf contourirte Nadeln. Durch Vorhalten des Blattes hat man gewissermassen an Stelle der einen Pupille deren zwei von viel kleinerem Durchmesser gesetzt und man hat dadurch aus jedem von den Objektpunkten ausgehenden Lichtbïndeln zwei kleine Kegel herausgeschnitten, deren Durchschnitte mit der Retina, trotz der Entfernung des Bildpunktes ron letzterer, klein genug sind, um wie erleuchtete Punkte z.ı wirken. Beiläufig sei bemerkt, dass man in dem Scheiner'schen Versuch ein Mittel hat zu entscheiden, ob in einem gegebenen Falle die Bildfläche hiuter oder ror der Retina liegt; in ersterem Falle rerschwindet bei Verdeckung des einen Stichlochs das gekreuzte Bild, das heisst bei Verdeckung des oberen Stichloches das untere Bild.

Die Emmetropie ist ein besonderer Fall unter unzähligen möglichen Fällen, in denen die zweite Brennebene vor oder hinter der Retina liegt. Angen, bei denen die zweite Brennebene vor der Retina liegt, heissen myopische, und Augen, bei denen die zweite Brennebene hinter der Retina liegt, hypermetropische. Ein Auge, dessen dioptrisches System sonst die Eigenschaften wie im schematischen Auge besitzt, kann so starke Abweichungen ron der Kugelform haben, dass die Entfernung des hinteren vom vorderen Pol zu gross oder zu klein wird: zu lange Augen sind myopisch, zu kurze sind hypermetropisch. Bei normaler Gesammtform des Auges kann aber auch die brechende Kraft des dioptrischen Systems entweder grösser oder kleiner sein, als im schematischen Auge, im ersteren Falle besteht dann Myopie, im letzteren Hypermetropie.

Ein myopisches Auge wird sehr ferne Objekte nicht deutlich sehen, da deren Bilder in die Brennebene fallen, welche bei myopischen Augen vor der Retina liegt; dagegen wird es für jedes bestimmte myopische Auge eine endliche Entfernung geben, in welcher es deutlich sieht, denn 
wenn wir das Objekt aus unendlicher Ferne an das Auge heranrüicken lassen, so bewegt sich das Bild von der zweiten Brennebene nach hinten, und es-muss also bei einer gewissen Lage des Objektes die hinter der Brennebene gelegene Retina erreichen. Je myopischer das Auge ist, das heisst je weiter die Retina hinter der Brennebene liegt, um so kleiner wird die Sehweite sein, das heisst die Entfernung, in welcher die deutlich gesehenen Objekte liegen: der reciproke Werth der Sehweite, das heisst die Längeneinheit dividirt durch die Sehweite; ist also eine Zahl, welche als Maass der Myopie dienen kann und dient.

Um einem myopischen Auge die Möglichkeit zu geben, Objekte in grosser oder unendlicher Entfernung deutlich zu sehen, muss man die parallel oder zu schwach divergent das Ange treffenden Strahlen so stark divergent machen, als wenn sie von Punkten der Ebene der Sehweite ausgingen: dies erreicht man durch biconcave Brillengläser, welche eine lichtzerstreuende Wirkung besitzen.

Da es gar keinen reellen Objektpunkt giebt, dessen Bild vor der zweiten Brennebene entsteht, so kann ein hypermetropisches Auge ohne Weiteres gar kein reelles Objekt deutlich sehen, weder in endlicher noch in unendlicher Entfernung. Ein Strahlenbïndel, das in einem Punkte der vor der zweiten Brennebene liegenden Retina zur Vereinigung kommen soll, muss schon convergent in das Auge fallen: es muss einem virtuellen Objektpunkte entsprechen. Parallele Strahlen oder divergente Strahlenbündel werden convergent gemacht durch biconvexe Glaslinsen; je hochgradiger die Hypermetropie eines Auges ist, um so stärker convergent müssen die Strahlenbündel gemacht werden, damit deutliches Sehen erreicht werde. Als Maass der Hypermetropie eines Auges kann also dienen und dient der reciproke Werth der Brennweite einer Convexlinse, die das Auge braucht, um ferne Gegenstände deutlich zu sehen.

Für die Giltigkeit der bisherigen dioptrischen Betrachtungen war die doppelte Voraussetzung massgebend, dass die Richtungsstrahlen der Objektpunkt ein kleinem Winkel die Augenaxe treffen und dass nur ein kleiner 'Theil der sphärischen Trennungsfläche von den einzelnen Strahlenbündeln getroffen werde. Letzterer Bedingung ist beim Auge unter allen Umständen genügt, da die Iris mit der Pupille als Diaphragma wirkt und aus jedem die Cornea treffenden Strahlenbündel einen genügend grossen Theil der rom Richtungsstrahle entfernteren Strahlen (der Randstrahlen) abblendet, sorlass sic die vordere Linsenfläche nicht mehr treffen können. Die erste Bedingung ist jedloch im Allgemeinen nicht erfüllt, denn die Pupille lässt Strahlenbündel hindurch, auch wenn ihr Richtungsstrahl einen grossen Winkel mit der Augenaxe bildet, man bezeichnet diese Strahlenbiindel als solche schiefer Incidenz. Eine genaue Abbildung äusserer 
Objekte ist allerdings auch nur für den die Augenaxe zunäichst umgebenden Theil der Retina ron Werth, demn hier ist das Mosaik der peripherischen Sehsinneselemente am feinsten und wir bringen die Augenaxe stets in die Richtung derjenigen Objekte, welche wir dentlich sehen wollen: dies Sehen nennt man das direkte Sehen. Aber die Retina mit den peripherischen Selınervenendigungen besitzt eine weit grössere Ausdehnung, als bei dem direkten Sehen benutzt wird, und wälırend wir ein bestimmtes Objekt ron beschränkter Ausdehnung deutlich sehen, erhalten wir gleichzeitig Kenntniss ron dem Vorhandensein seitlich weit abliegender Gegenstände, deren Einzelheiten wir freilich nicht unterscheiden können. Es miissen also Bilder, wenn auch geringer Güte, auf

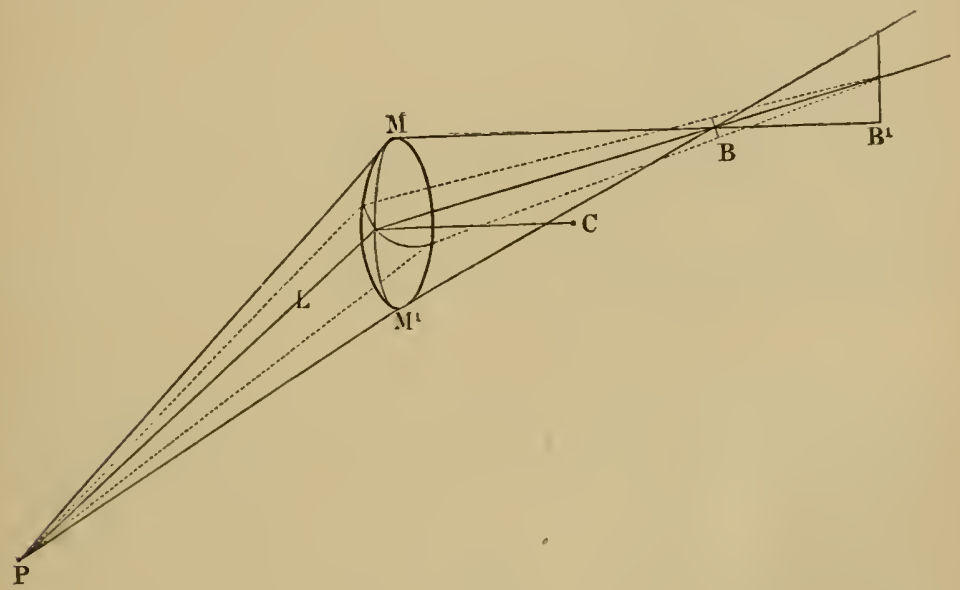

29.

weit seitwärts gelegenen Theilen unserer Netzhaut zu Stancle kommen und es erwächst die Aufgabe uns klar zu machen, was aus homocentrischen Strahlenbïndeln rerschieden schiefer Incidenz im Auge wird.

Im Allgemeinen werden homocentrische Strahlenbiindel schiefer Incidenz, nach dem Durchgang durch ein centrirtes System sphärischer Trennungsflächen zwischen rerschieden brechenden Medien, nicht wieder homocentrisch. Legen wir ein homocentrisches, schief auf einen kreisförmig begrenzten Abschnitt einer sphärischen Trennungsfläche auffallendes Strahlenbiindel der Betrachtung zu Grunde. Den rom Centrum des Bündels zum Scheitelpunkt der Trennungsfläche ziehenden Strahl nennen wir den Leitstrahl (L in Fig. 29); das Strahlenbïndel füllt einen auf der kreisförmigen Trennungsfläche schief errichteten Kegel aus, die durch den Leitstrahl und durch den Scheitelradius der Trennungsfläche gelegte Ebene nennen wir die meridionale Ebene des Bündels (PMI'), die senkreclit zu dieser Ebene durch den Leitstrahl gelegte Ebene lieisse die 
Querebene und die in dieser Ebene gelegenen Strahlen des Bündels bilden ein Büschel, das wir Querbiischel nennen wollen. Dieses Büschel ist durch die in Fig. 29 gestrichelt gezeichneten Strahlen begrenzt. Es vereinigen sich nun die Strahlen des Querbüschels in einem ron der Trennungsfläche weiter entfernt gelegenen Punkte des gebrochenen Leitstrahles als die Strahlen des Meridianbiischels. In der Entfernung, wo die Strahlen des Querbüschels zur Vereinigung kommen, gehen die sämmtlichen iibrigen Strahlen des Bündels durch Punkte einer in der Meridianebene gelegenen Linie, der hinteren Bremnlinie $\left(\mathrm{B}^{\prime}\right)$, welche durch die beiden äussersten Strahlen des hier schon divergirenden Meridianbiischels begrenzt sind. Ebenso sind in der Entfernung, wo der Vereinigungspunkt des Meridianbiischels liegt, sämmtliche Strahlen rereinigt in einer geradlinigen Strecke, deren Richtung senkrecht zur Meridianebene steht, und die begrenzt ist durch die beiden äussersten Strahlen des Querbüschels, die hier noch nicht zur Vereinigung gekommen sind; sie heisst die vordere Brennlinie (B). Vergleicht man den Ort der Abbildung eines gleich entfernten Objektpunktes bei gerader und schiefer Incidenz, so findet man, dass der Bildpunkt in ersterem Falle weiter hinter der Trennungsfläche liegt, als die hintere Brennlinie in letzterem Falle.

Die Entfernung zwischen den beiden Brennlinien nennt man die Brennstrecke. Mit Hilfe einer nicht zu kleinen biconrexen Linse kann man die, einer seitlich gelegenen punktförmigen Lichtquelle entsprechenden Brennlinien auf einem Schirm leicht zur Anschauung bringen; hat man die vordere Brennlinie auf dem Schirm anfgefangen (dieselbe möge horizontal liegen) und geht man mit dem Schirm weiter nach hinten, so wird ans der hellen Linie eine weniger helle Ellipse, deren horizontaler Durchmesser ab- und deren verticaler Durchmesser zunimmt bei weiterer Bewegung des Schirms in derselben Richtung; dann wird das schwach erleuchtete Feld kreisförmig begrenzt, noch weiter hinten entsteht eine Ellipse mit horizontalem kleinem und rerticalem grossen Durchmesser, aus welchem letzteren dann die hintere Brennlinie wird. Bringt man das Objekt bei gleichem Abstand von der Linse in deren $\Lambda x e$, so findet man das deutliche Bild desselben weiter ron der Linse entfernt, als die hintere Brennlinie bei schiefer Incidenz.

Es handelt sich bei schiefer Incidenz im Allgemeinen nicht um \%erstrenungskreise, sondern $u m$ andere Zerstreuungsfiguren und diejenige Stellung des Lichtschirmes wird für die Erlangung eines am wenigsten verzerrten und eines annähernd scharfen Bildes die günstigste sein, bei welcher am wenigsten eine Dimension der Zerstreuungsfigur vorwiegt und gleichzeitig der kleinste Flächenranm ron der Zerstrenungsfigur eingenommen wirl. Letzteres ist innerhalb der Brennstrecke der Fall. 
Legt man der Berechnung des Strahlenganges, nach den verwickelten fuir die schiefe Incidenz geltenden Formeln, das reducirte Auge zu Gruude, so riickt die ganze Breunstrecke schon bei geringer Schiefheit der Incidenz vor die Retina, und bei Zunahme der Schiefheit riickt die hintere Brennlinie immer weiter vou der Retina ab in das Augenimnere hincin.

Trägt man dagegen bei der Ermittelung des Strahlenganges im Auge der Zusammensetzung des dioptrischen Systems aus den thatsächlich vorhandenen Trennungsflächen Rechnung und berücksichtigt man namentlich auch den geschichteten Bau der Kx́rystallinse, so findet man, dass die Retiua im ganzen Bereiche der Sehnervenendigungen, also bei allen möglichen Incidenzwinkeln in die Brennstreckeu selbst fällt. Jeder Punkt der Retina scheint also für den zugehörigen Incidenzwinkel die Lage des relativen Optimums der Bildgïte zu haben: man nennt diese Eigenschaft des Auges die Periskopie, und man sieht, dass es dieselbe der eigenthïmlichen Zusammensetzung seines dioptrischen Systems, namentlich aber dem geschichteten Bau der Krystallinse verdankt, und dass das reducirte Auge, welches wir den Betrachtungen über das direkte Sehen zu Grunde legen durften, beim indirekten Sehen nicht maassgebend ist; das reducirte Auge ist nicht periskopisch.

Das emmetropische Auge erhält im Gebiet des direkten Sehens nur ron fernen Objekten gute Bilder auf der Retina. Objektpunkten, welche näher als 5 Meter liegen, entsprechen schon Zerstreumgskreise vou störenden Dimensionen; das normale Auge ist aber im Stande, in weit grösserer Nähe deutlich zu sehen, es muss also bei dem Uebergang von dem Sehen in die Ferne zu dem Sehen in die Nähe eine Veränderung in dem Auge vor sich gehen, durch welche die zweite Hauptbrennebene vor die Retina verlegt, das emmetropische Auge gewissermaassen myopisch gemacht wird: diesen Vorgang nennt man den der Accommodation. Die gegenseitige Lage zwischen zweiter Hauptbrennebene und Retina könnte verändert werden entweder durch eine Formünderung des Augapfels, bei welcher, um die Breunebene vor die Retina zu bringen, der Längsdurchmesser des Augapfels vergrössert werden miisste, oder durch eine Aenderung in den Constanten des dioptrischen Apparates, dessen brechende Krraft, um densellen Zweck zu erreichen, zunehmen miisste.

Der Augapfel ist ein Körper von grosser Elasticität, man kamu ihn zwar durch den Druck mit dem Finger etwas deformiren, doch ist die dieser Deformation widerstehende Kraft, anch wenq es sich um Druck auf einen kleinen Theil der Oberfläche handelt, sehr beträichtlich. Man sieht auch ein, warum dies so sein muss; der Augeninhalt verhält sich wie eine tropflare Fliissigkeit mit erhehlicher Spannung; diese Spannung, 
welche man den intraocularen Druck nennt, kann man bei Thieren nach Einstich einer feinen Canïle in die rordere Augenkammer manometrisch und beim Menschen auch ohne Verletzung des Auges auf anderem Wege bestimmen: er beträgt etwa $40 \mathrm{Mm} \mathrm{Hg}$.

Der Augapfel ist nahezu sphärisch, das Verhältniss seiner Oberfläche zum Inhalt also nahezu ein Minimum. Jede Deformation muss also zu einer Vergrösserung dieses Verhältnisses führen, und da weder Verminderung noch Compression des Augeninhaltes eintreten kann, muss das Volum constant bleiben, die Oberfläche also beträchtlich zunehmen; da die Dehnbarkeit der harten Augenhäute, namentlich bei der in Folge des intraocularen Druckes schon vorhandenen Dehnung sehr klein ist, so sieht man ein, dass grosse Kräfte zu einer allgemeinen Deformation des Augapfels erforderlich sein würden.

Der Richtung nach würden solche Kräfte vorhanden sein, denn die Augenmuskeln schmiegen sich dem Augapfel in der Aequatorialebene an; sie müssen bei ihrer gleichzeitigen Contraction auf Streckung der ihnen durch den Augapfel angewiesenen Biegung hinwirken und dadurch den Aequator zu verkleinern streben. Ein gemeinsamer Tonus sämmtlicher Augenmuskeln ist unter normalen Verhältnissen wohl vorhanden, aber schwach, und die einseitigen Augenmuskelcontractionen führen wesentlich nur zur Richtungsänderung der Augenaxe. Deformirende Kräfte werden nur entstehen, wenn bei dauernder Einhaltung einer extremen Augeurichtung unzweckmässige Synergie aller Augenmuskeln eintritt, wie zum Beispiel bein anhaltenden Sehen in grosser Nähe; in der That ist man auch geneigt anzunehmen, dass axiale Verlängerung des Augapfels bei erworbener Myopie (Schulmyopie) auf diese Weise zu Stande kommt. Für eine schnelle und feine Veränderung der gegenseitigen Lage von Bremebene und Retinapol, zum Zwecke der Accommodation, ist dieser Mechanismus offenbar schlecht geeignet.

Die Accommodation des Auges findet also nicht statt wie die Einstellung der Camera obscura; bei dieser bleibt das dioptrische System unverändert und die Entfernung der bildauffangenden Platte von dem System wird der Entfernung des abzubildenden Objektes von der Camera angepasst; im $\Lambda$ uge wird das dioptrische System selbst geändert. Bei Finstellung des emmetropischen $\Lambda$ uges für das Nahesehen muss die brechende Liraft des Systems grösser gemacht werden, als sie beim schematischen $\Lambda$ uge ist.

Fine solche Aenderung könnte crzielt wcrden durch Vergrösserung: der Brechungsindices, durch Verkleinerung der Halbmesser der Trennungsflächen und durch ihre Annäherung an die vorderste derselben. Dass in Wirklichkeit durch eine Vergrösserung der Brechungsindices die Accommodation bewirkt werde, ist nicht wohl anzunehmen: 
zu einer etwaigen Verdichtung der brechenden Medien in dem erforderlichen Grarle sieht man durchaus keine Veranstaltung; man ist also darauf hingewiesen, in einer Veränderung der Kriummung und Stellung der 'Trennungsflächen die Mittel zur Verkürzung der Brennweite zu suchen. Von den Tremmungsfiichen ist aber wiederum eine sofort auszuschliessen; die Hornhaut nämlich verändert ihre krüummung bei der Accommodation entschieden nicht um eine Spur, wie sich aus Versuchen ergeben hat, in denen dieselbe beim l'ern- und Nahesehen sehr genau ophthahmometrisch gemessen wurde. Diese thatsïchlich erwiesene Unveränderlichkeit der Hornhautform enthält auch einen Beweis gegen die Einstellung des Anges nach Art der Camera obscura durch Deformation des Augapfels.

Lis bleibt somit nichts anderes übrig, als in der Linse den accommodirbaren Theil des Systems zu suchen; in der That lassen sich Veranderungen, welche die Linsenflaichen bei der Einrichtung des Auges für die Niihe erfihren, beobachten und messen, es dienen hierzu die Sanson-Purkinje'schen Bildchen. Die oben beschricbene Versnchsanordnung ist für diesen Zweck dahin zu erweitern, dass ausser dem fernen Sehzeichen noch ein solches in grosser Nähe, etwa ein Decimeter von dem beobachteten Auge, und zwar ebenfalls in seiner Sehaxe angebracht wird; hierzu eignet sich eine feine Nadelspit\%e. Zunächst lässt man das beobachtete Auge wie früher das ferne Sehzeichen ansehen und bringt das eigene Auge in eine Stellung, in welcher die drei Bildchen deutlich wahrgenommen werden. Während man diese scharf beobachtet, fordert man die heobachtete Person auf, das nahe Gesichtsobjekt zu fixiren, sofort wird man an dem von der vorderen Linsentlïche gelieferten Bild eine dentliche Verkleinerung und schwache Erhellung wahrnehmen; es nähert sich gleichzeitig ein wenig dem Hornhautbildehen. Dieses und das von der hinteren Linsenflïche gelieferte Bildchen lassen keine Veränderung wahrnehmen.

Dem Plane nach ähnliche Versuche, mit messenden Apparaten angestellt, hahen mit voller Sicherheit ergeben: die Einrichtung für die Nühe wird bewirkt durch Vergrössermung der Krï̈mmung beirter Linsentlächen, las heisst Verkleinerung ihrer Halbmesser'; der hintere Linsenscheitel bleibt dabei an Or't und Stelle, der vordere rückt etwas vor, sodass der Alsstand beider etwas grösser wird.

Die an einem bestimmten lebenden Auge durch Berechnung aus den angestellten Messungen gefundenen Kírümmungshalbmesser und Scheitelabstände beim Sehen in die Ferne und in die Nïhe (etwa 10 Centimeter) hatten folgende Werthe: 
Beim Fernsehen. Beim Nahesehen.

$\mathrm{Mm}$

$\mathrm{NIm}$

Krïnnmungshalbmesser im Hornhautscheitel 7,646

7,646

Abstand des vorderen Linsenscheitels vom Horn-

hautscheitel . . . . . . . . . . 3,597

3,431

Halbmesser der vorderen Linsenfläche . . . 8,8

5,9

Abstand des hinteren Linsenscheitels vom Horn-

hautscheitel

Halbmesser der hinteren Linsenfläche . . . 5,13

Eine Verkleinerung des Halbmessers der hinteren Linsenfläche ist zwar wahrnehmbar, aber zu gering, um gemessen zu werden.

Berechnet man für diese beiden Zustände des Auges, mit Zuhülfenahme der wahrscheinlichsten Werthe der Brechungsindices, die optischen Cardinalpunkte, so ergeben sich im zweiten Zustande in der That kürzere Brennweiten, und es fällt für denselben das Bild eines ein wenig über 10 Centimeter entfernten Punktes in diejenige Ebene, in welche im ersten Zustande die Vereinigıngsweite paralleler Strahlenbündel fiel; das Auge muss also im zweiten Zustande etwas über ein Decimeter abstehende Gegenstände deutlich sehen, wenn es im ersten unendlich weite deutlich sah, was wirklich der Fall war.

Wollte man unser obiges schematisches Auge für die Nähe einrichten, so könnte man den Halbmessern und Scheitelabständen etwa nachstehende, mit den ursprünglichen tabellarisch zusammengestellte Werthe beilegen. Die Lage der Cardinalpunkte in dem so veränderten Systeme ist ebenfalls angegeben und ihre Lage im ursprünglichen System zur Vergleichung daneben gestellt.

Halbmesser der Hornhaut. . . . . . . $8,0 \quad \begin{array}{rr}\text { Fernsehend. } & \text { Nahesehent. }\end{array}$

" $\quad$ vorderen Linsenfläche . . $10,0 \quad 6,0$

" " hinteren $\quad " \quad$. $6,0 \quad 5,5$

Ort des vorderen Linsenscheitels . . . . $3,6 \quad 3,2$

" " hinteren $\quad$. . . . . $7,2 \quad 7,2$

" " vorderen Brennpunktes . . . . - - 12,9 - 11,24

" " ersten Hauptpunktes . . . . . 1,94 2,03

" " zweiten $"$. . . . . . 2,36 2,49

" " ersten Knotenpunktes . . . . . $6,9696,6,51$

" " zweiten " . . . . 7,37 . 7,37

" " hinteren Brennpunktes . . . . 22,23 20,25

Die Zahl, welche in der Tabelle den Ort eines Punktes angiebt, ist seine Entfermung rom Hornhautscheitel in Millimetern ausgerlriickt, wobei 
natiirlich der Ort des vorderen Brennpunktes mit negativen Vorzeichen rersehen werden musste, weil er in entgegengesetzter Richtung ron dem Horuhautscheitel entfernt ist wie die anderen.

Man sieht aus dieser Tabelle, dass die Brennweiten beim Nahesehen kuirzer sind, als beim Fernsehen, dass freilich auch die Hauptpunkte und die Ḱnotenpunkte nicht ganz. an Ort und Stelle geblieben sind: die Hauptpunkte sind ein wenig nach linten, die Kinotenpunkte ein wenig nach rorn gegangen. Construction oder Rechnung zeigen nun, dass in dem so veränderten schematischen Ange das Bild einer 130 Millimeter entfernten Ebene dahin fällt, wo rorher das Bild einer unendlich entfernten Fbene lag; das heisst es fällt an den früheren Ort der

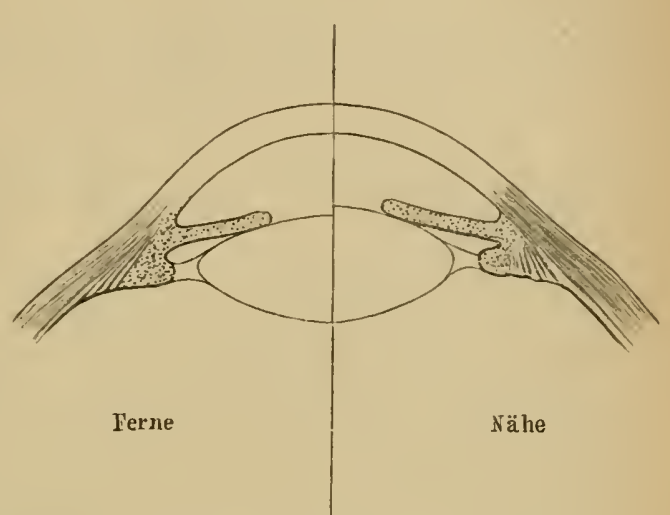

30 . hinteren Brennebene, also in die Netzhaut, welche bei der Accommodationsveränderung ihre Entfernung vom Hornhautscheitel behauptet hat, mithin noch immer am Ort der urspringlichen Brennebene gelegen ist. Die Trennungsfläche des reducirten Auges würde ihren Scheitelpunkt bei dieser Accommodation 2,1 Millimeter linter dem Hornhautscheitel haben, ihr Halbmesser würde 4,8 Millimeter betragen.

Als wesentlichen Vorgang bei der Accommodation haben wir die stärkere Kriimmung der vorderen Linsenfläche und das Vorriicken ihres Scheitelpunktes gegen den Hornhautscheitel erkannt, und es fragt sich, durch welchen Mechanismus diese Veränderung zu Stande kommt. Von den Erscheinungen, welche bei der Accommodation für die Nähe an dem Auge ohne Weiteres zu beobachten sind, wurden bisher nicht erwähnt die Verengerung der Pupille und das Vorrücken der Pupillarebene. Um erstere Erscheinung deutlich zu sehen, braucht man nur dafür zu sorgen, dass das beobachtete Auge beim Sehen in die Ferne und Nähe nicht $z u$ viel und nicht wechselndes Licht erhält, da die Lichtmenge an sich ron grossem Einfluss auf dic Pupillenweite ist.

Das Vorrücken des Pupillarrandes ergiebt sich als einzig mögliche Deutung folgenden Phänomens. Beobachtet man ein Auge ron der Seite, und etwas ron hinten, so bemerkt man darin als schwarzen Streifen neben dem Sclerarande das verzerrte Bild der Pupille und als schwarzen beiderseits spitz. auslaufenden Streifen, dem Profil der Hornhaut entlang, 
das verzerrte Bild der beschatteten Innenseite des über die Iris vortretenden Randes der Sclera in der abgewandten Hälfte des Auges. Zwischen diesen beiden schwarzen Streifen zieht sich ein hellerer farbiger Streifen hin, das verzerrte Bild der abgewandten Irishälfte; dieser hellere Streifen wird nun schmäler, sowie sich das beobachtete Auge für die Nähe anpasst, ohne seine Stellung zu verändern. Da wir schon wissen, dass die Pupille sich beim Uebergang zum Nahesehen verengert, die Iris also an Breite zunimmt, so folgt, dass die Verschmälerung des hellen Streifens nur durch Vorrücken des Pupillarrandes bedingt sein kann. Bisweilen wird auch noch zwischen dem schwarzen Bild der Pupille und dem Sclerarande ein wenig von der diesseitigen Hälfte der Iris beim Nahesehen sichtbar.

Die Pupillenverengerung weist auf eine Thätigkeit der Irismuskulatur hin, zunächst freilich nur auf eine solche des Ringmuskels. Immerlin könnten noch gleichzeitig radiäre Muskelfaserzüge der Iris in Thätigkeit treten und in Augen, deren vordere Linsenfläche bis zum Pupillarrande der Iris, diese in der Ruhe vorwölbend, anliegt, kann durch eine gleichzeitige Contraction der circulären und radiären Muskelfasern der Iris die Wölbung der Iris, und da die Linse nicht nach hinten ausweichen kann, auch der Randzone der vorderen Linsenfläche abgeplattet werden; die Folge davon müsste eine Vorwölbung des Linsencentrums durch die Pupille hindurch sein. In der That hat man am Seehundsauge einen Abdruck des Pupillarrandes bemerkt, wenn es unmittelbar vor der Dissection anhaltend elektrisch gereizt worden war. Beim Seehund liegt die Linse der Iris in weiter Ausdehnung an und dieses Thier bedarf eines besonders starken Accommodationsvermögens, um beim Untertauchen unter Wasser den Verlust der brechenden Wirkung zwischen Hornhaut und Luft auszugleichen. Beim Menschen dagegen liegt die Iris der Linse nur in der Umgebung des Pupillarrandes an, sodass eine Abflachung der Iriswölbung wesentlich nur zu einer Verdrängung von hinterem Kammerwasser führen kann. Ueberdies lehrt die Beobachtung des thatsächlichen Vorrückens des Pupillarrandes beim Menschen, dass hier der Mechanismus der Accommodation auf etwas Anderem beruhen muss.

Die Messungen an lebenden Augen ergeben zweifellos eine Zumahme des axialen Durchmessers der Linse beim Uebergang vom Fernesehen zum Nahesehen. Der grösste Werth dieses Durchmessers, welcher beim lebonden Menschen beobachtet wurde, ist aber noch kleiner, als der kleinste durch direkte Messung mit dem Tasterzirkel constatirte an isolirten Leichenlinsen; es scheint also, dass die Linse im lebenden Auge beim Fernesehen am meisten von ihrer Gleichgewichtsfigur entfernt ist, und dass sie bei der Einrichtung für die Nähe siclı dieser Gleichgewichts- 
figur nähert, ohne sie zu erreichen. Eine heständige Abplattung der Linse kamn im lebenden luge auf folgende Weise zu Standle kommen. Die Linse ist zwischen den beiden Blättern des Suspensorium lentis so gelagert wie zwischen zwei Tiichern, welche in einiger Entfernung rom Linsenrand znsammengefasst sind; ülst man an zwei so zusammengefassten Tüichern einen Zug in radiürer Richtung aus, so muss ein zwischen denselben liegender elastischer linsenförmiger Körper alogeplattet werden, und lässt man mit dem Znge nach, so muss er seine frühere Gestalt wieder annehmen.

Die ringförmige Vereinigungsstelle der beiden Blätter des Suspensoriums ist mit der Chorioidea, wo sie sich zum Ciliarkörper verbreitert, fest rerwachsen. Durch den intraocularen Druck sind die Augenhäute stark gespannt; die Spannung der Chorioidea ïlst einen in Bezug auf die Linse radiüren Zug an dem Suspensorium aus. Der Stärke des intraocularen Druckes entsprechend muss also die Linse in dem ruhenden Ange, das heisst in dem Auge, dessen innere Muskeln schlaff sind, abgeplattet sein, wie es bei der Einrichtung für das Fernsehen der Fall ist. Hierbei hat aber die Linse das Streben, aus der ilur aufgezwungenen Form in ihre natuirliche Gleichgewichtsfigur iiberzugehen, sobald der radiür nach aussen gerichtete Zug an der Vereinigungsstelle der Blätter des Suspensoriums nachlässt oder sobald sich der Durchmesser dieser ringförmigen Vereinigungsstelle rerkleinert. Letzteres zu hewirken, ist nun der Musculus tensor chorioidea sehr geeignet, welcher mit seinen Hauptfaserzügen ron der Vereinigungsstelle zwischen Sclera und Cornea radiär zum Uebergang der Chorioidea in den Ciliarkörper zieht. Die grösste Componente dieses Zuges muss in jeder meridionalen Ebene letztere Stelle der Augenaxe nähern.

Indem die Chorioidea dem Zuge ihres Spannmuskels folgt, kann sie entweder, zwischen Glaskörper und Sclera gleitend und dem Zuge entsprechend sich verlängernd, auf der Kugelfläche sich bewegen, oder sie kann, bis zum Aequator hin sich etwas abflachend, von der Scleri abgehoben werden. Ersteres wiirde der Fall sein, wenn der Glaskörper keine Deformation duldete, und wenn die Chorioidea selbst genügende Dehubarkeit besässe. Wahrscheinlicher ist jedoch, dass der Chorividealraum an Dicke etwas zunimmt, was bei Bluteintritt in seine zahlreichen dümnwandigen Venen leicht möglich ist, und dass der Gliskörper zum Ausgleich für die Abplattung, welche er hierbei seitlich erfährt, vorne am Rande der tellerfürnigen Grube ausgebuchtet wird. Die Verengerung, welche der Raum der hinteren Augenkammer hierdurch erfährt, kann durch Blutaustritt aus den Venen des Ciliarkörper's leicht ausgeglichen werden. Am Boden der tellerförmigen Grube selbst erleidet der Glas- 
körper, wie die Messungen an der hinteren Linsenfläche lehren, nur eine minimale Deformation.

Dass in Folge von Reizung der Ciliarnerven eine Verschiebung der Chorioidea thatsächlich nach vorn eintritt, wurde durch folgenden Versuch bewiesen. Eine feine Nadel wurde durch die Sclera in die Chorioidea eingestossen, da wo der Ciliarmuskel schon sein Ende erreicht hat; wenn nun die Ciliarnerven oder das Ganglion ciliare elektrisch gereizt wurden, so bewegte sich das frei hervorstehende Ende der Nadel merklich nach hinten; da die Nadel in der Sclera ihren festen Drehpunkt hat, so ist hierdurch eine Verschiebung der Chorioidea unter der Sclera nach vorn erwiesen. Dieser Versuch gelang am Auge des Hundes, der Katze, des Affen und auch des Menschen (an Hingerichteten).

Die Zustände des Auges bei seiner Einrichtung für die Nähe und für die Ferne haben wir uns demnach so vorzustellen, dass bei letzterer die Linse durch den Druck zwischen den radiär gespannten Blättern des Suspensoriums stark gespannt, der Ciliarmuskel aber unthätig ist; dass bei ersterer dagegen die Spannung in der Linse verringert, der Ciliarmuskel dagegen in starker Contraction begriffen ist. Die Spannung der Linse wird unterhalten durch den intraocularen Druck, in letzter Instanz durch den Blutdruck, durch Ernährungs- und Wachsthumsverhältnisse, erfordert also keine besondere Anstrengung. Die Entspannung der Linse dagegen zum Zwecke des Nahesehens erfordert Anstrengung eines inneren Muskels, des Tensor chorioideae. Diese Anstrengung erklärt zum Theil das Gefühl der Ermüdung, welches bei anhaltendem Sehen in grosse Nähe eintritt. Beim Sehen in die Ferne ruht das Auge aus.

Den Inbegriff aller der Entfernungen, für welche sich ein Ange durch Accommodation einzurichten im Stande ist, als Stücke der Axenrichtung gemessen, bezeichnet man als sein Accommorlationsspatium. Das dem Auge nähere Ende desselben heisst der Nahepunkt, das dem Auge fernere der Fernpunkt. Für das schematische Auge liegt der Nahepunkt in $130 \mathrm{Mm}$ Abstand, der Fernpunkt in unendlicher Ferne. Der Punkt, für welchen ein bestimmtes Ange in einem Moment genau eingestellt ist, heisst der Accommodationspunkt; der Definition nach miisste ein mit dem Accommodationspunkt zusammenfallender Objektpunkt als genauer Bildpunkt in der lichtempfindlichen Schicht der Retina erscheinen. Eine so vollkommene Abbildung kommt aber im Auge aus später zu erörternden Gründen nicht zu Stande und die lichtempfindliche Schicht der Retina stellt auch keine Ebene im mathematischen Sinne des Wortes dar. Es entstehen also Ablildungen gleicher Bildgiite, stets nicht nur. von einem bestimmten Accommodationspunkt, sondern von Reihen mehr oder weniger benachbarter Punkte, deren Ort, in der Sehaxe gemessen, 
man die Accommodationslinie nennt. Die Accommodationslinic ist also der Inbegriff aller Punkte der Schaxe, welche bei eincm bestimmten Accommodationszustand Bilder von merklich gleicher Güite geben.

Die Länge der Accommodationslinie kamm nicht ron vornherein angegeben werden, hängt auch nicht allein von dioptrischen Umständen ab, sondern daneben von der Vollkommenheit des empfindenden Appatrates. Aus Grïnden, welche allein der Dioptrik zu entnehmen sind, folgt aber, dass die Accommodationslinie um so länger sein muss, je weiter sie rom Auge entfernt ist; man sieht dies sofort, wenn man sich erinnert, dass unter Annahme einer Annäherung des Objektes mit constanter Geschwindigkeit aus unendlicher Ferne, das Bild um so langsamer nach hinten riickt, je weiter vom dioptrischen Apparat das Objekt noch entfernt ist. In der Gegend eines fernen Accommodationspunktes wird also das Objekt einen grösseren Raum (eine längere Accommodationslinie) durchlaufen können, ehe das Bild weit genug hinter die Netzhaut gegangen ist, um störende Zerstreuungskreise zu erzeugen. Die Länge einer bestimmten Accommodationslinie haben wir schon unendlich gross gefunden, es war diejenige, welche der Einrichtung für unendliche Ferne entspricht; sie reicht ron dieser bis in den endlichen Abstand ron etwa 10 Meter, denn die Rechnung ergiebt, dass alle so weit abstehenden Punkte noch keine merklichen Zerstreuungskreise hervorbringen, wenn das Bild eines unendlich entfernten Punktes genau in die Netzhaut fällt.

Man kann die Accommodationslinie sichtbar machen, wenn man eine Linie betrachtet, welche möglichst nahe mit der Sehaxe zusammenfällt. Man zeichne zum Beispiel eine feine Linie auf ein grosses Blatt Papier und halte dies horizontal dicht unter das Auge: fixirt man nun einen beliebigen Punkt der Linie, so erscheint nicht nur dieser selbst, sondern ein ganzes Stïckchen der Linie merklich scharf begrenzt, während ihre näher und ferner liegenden Theile verwaschen erscheinen. Je weiter der fixirte Punkt rom Auge entfernt ist, um so länger ist das deutlich erscheinende Stuick der Linie.

Es folgt hieraus, dass es verschieden grosser Veränderungen des dioptrischen Apparates bedarf, um gleich grosse, aber in verschiedenen Entfernungen gelegene Theile des Accommodationsspatiums zu bewältigen. Beispielsweise erfordert es eine äusserst kleine Veränderung bei Uebergang der Einstellung des Auges von 1 zu 0,99 Meter Abstand, aber es erfordert eine sehr merkliche Veränderung und eine subjectiv sehr merkliche Anstrengung, wenn dasselbe Auge ron der Einrichtung auf 0,1 Meter zu der auf 0,09 Meter Abstand ïbergehen soll, und doch hat beide Male der Accommodationspunkt 0,01 Meter zu durchlaufen.

Wenn die Myopie auch durch Ueberanstrengung des Auges unter 
zu starkem äusserem Muskeldruck bei anhaltendem Sehen auf zu nahe und zu tief gelegene Gegenstände (Schulhefte) entstehen mag, so braucht doch das myopische Auge andauernd weniger innere Muskelanstrengung zn leisten, als das hypermetropische, welches ohne Accommodationsanstrengung überhaupt nicht scharf sehen kann, es sei denn, dass es seine Refractionsanomalie durch Brillengläser corrigirt. Wenn der Myope sein Accommodationsspatium in die Ferne ausdehnen will, so kann er dies ïberhaupt nur durch Linsencorrection. Der Hypermetrope wird aber, ehe er zu diesem Mittel greift, geneigt sein die Ausdehnung seines Accommodationsspatiums in die Nähe durch Accommodationsanstrengung zu bewirken und diese dauernde Anstrengung kann auch bei geringgradiger Hypermetropie und bei anhaltender Nahearbeit der Gesundheit nachtheilig werden. Mit zunehmendem Alter nimmt die Fähigkeit aller. Augenarten, den Accommodationspunkt zu nähern, mehr und mehr ab, das Auge wird "presbyopisch"; für die Nahearbeit ist das presbyopisch myopische Auge dem presbyopisch hypermetropischen und auch dem presbyopisch emmetropischen überlegen.

Der dioptrische Apparat eines jeden menschlichen Auges besitzt gewisse Unvollkommenheiten, in Folge deren homocentrische Strahlenbündel, auch wenn ihr Centrum in der Augenaxe liegt, und wenn das Auge für die Entfernung des Objektpunktes so genau wie möglich accommodirt ist, nicht in einem Punkte der Retina vereinigt werden. Eine dieser Unvollkommenheiten besteht in einer Verschiedenheit der Hornhantkrïmmungen in den verschiedenen Meridionalebenen. Diese Eigenschaft, von welcher kein Auge frei ist, nennt man den regulären Astigmatismus. Von dem Vorhandensein desselben im eigenen Auge kann sich Jeder leicht auf folgende Weise uiberzeugen.

Man ziehe auf weisses Papier einen Stern von etwa acht möglichst feinen schwarzen Linien, die sich alle in einem Punkte schneiden, je zwei benachbarte unter einem Viertel eines rechten Winkels. Man betrachte jetzt diesen Stern in wechselnder Entfernung recht aufmerksam mit einem Auge und man wird finden, dass nur eine Linie jeder Zeit mit vollendeter Deutlichkeit gesehen wird. Erscheint beispielsweise die lothrechte dentlich, so erscheinen die übrigen ein wenig verwaschen, respective weniger schwarz, am meisten die wagerechte. Erscheint aus anderer Entfernung oder bei einer anderen Accommodation die wagerechte vollkommen deutlich, so erscheint die lothrechte am verwaschensten.

Unregelmässige Abweichungen von der Symmetrie sind bei der normalen Cornea nicht zu erwarten, da sie der elastischen Wand eines Hohlkörpers mit flüssigem Inhalt von beträchtlicher Spannung angehört. Die einfachste $\Lambda$ bweichung von der Rotationsfläche ist diejenige, bei welcher die Meridiane stärkster Krümmungsdifferenz senkrecht zu einander 
stehen. Betrachten wir eine derartige Trennungstläche als reducirtes Auge und nehmen wir an, dass der Meridian stärkster Krümmung senkrecht steht; ein homocentrisches Strahlenbïndel, dessen Centrum vor dieser Trennungsfläche und in der Axe derselben liegt, wird hinter derselben, selbst bei kleiner Basis des Strahlenkegels, nicht wieder homocentrisch. Das horizontale und das verticale Strahlenbüschel sehneiden sich je in einem Punkt, ron denen der letztere der Trennungstläche natürlich näher liegt, als der erstere; sümmtliche Strahlen des Bündels sind zweimal linear vereinigt in zwei Brennlinien, von denen die vordere den Bremupunkt des Meridians grösster Krümmung enthält und senkrecht zur Ebene dieses Meridians stelit und deren hintere den liuteren Brenupunkt enthält und senkrecht zur Meridianebene kleinster Krrïmmung stelıt. Die vordere Brennlinie steht in dem angenommenen Falle also horizontal, die hintere rertical. Die Entfernung zwischen den beiden Brennlinien nennt man die Brennstrecke; in jedem Verticalschnitt durch die Brennstrecke hat der Strahlenkegel eine andere Begrenzungsfigur, zuerst elliptisch mit horizontalen grossem Durchmesser, dann kreisförmig, dann elliptisch mit rerticalem grossem Durchmesser. Nehmen wir an, dass die Retina mit der vorderen, also horizontalen Brennlinie zusanmenfällt, so wird jeder Punkt einer horizontalen Objektlinie in einer horizontalen Brennlinie zur Abbildung kommen. Die zu benachbarten Objektpunkten gehörigen Breunlinien decken sich theilweise und zwar derart, dass die abgebildete Linie nicht rerbreitert, nur etwas verlängert ist, eine -solche Linie wird also scharf gesehen, während das Bild der verticalen Linie bei derselben Objektdistanz und bei derselben Accommodation um die Länge der rorderen Brennlinie verbreitert ist, die Linie selbst also verwaschen erseheinen muss.

Nähert man die Sternfigur einem Auge mit den Eigenschaften des angenommenen reducirten Auges, welches aber accommodationsfäling ist, so fällt zuerșt die hintere Brennlinie mit der Retina zusammen, das heisst die verticale Linie wird deutlich gesehen, und geht man mit der Annäherung ïber den Nahepunkt heran, so ist das letzte, was deutlich gesehen wird, die horizontale Linie. Die Lage des Meridians grösster Kirümmung im Auge ist also senkreeht zu der Richtung der Linie einer Sternfigur, welche bei fortschreitender Annäherung ans Auge zuletzt noch deutlich gesehen werden kann.

Der Meridian kleinster Krimmung liegt in den meisten Augen thatsächlich horizontal und derjenige der grössten Krrümmung senkrecht dazu. Für die Eutstehung gerade dieser Asymmetrie können verschiedene Momente geltend gemacht werden: die Asymmetrie der Orbitallı̈hle, der Lidspalte und der äusseren Augemmuskeln. Dem retrobulbären Drucke wird durch die offenen Lider und durch die Orbitalränder 
oben und unten ein stärkerer Widerstand entgegengesetzt als seitlich. Die graden Augenmuskeln umgreifen den Aequator des Augapfels nach vorn und indem sie bei ihrer Contraction auf den Aequator drïcken, ziehen sie zugleich an dem vor ihm gelegenen Theile der Augenhäute. Die zur Augenaxe senkrechte Compenente dieses Zuges kann zur Abplattung der Cornea beitragen, und da die in horizontaler Ebene antagonistisch angreifenden Muskeln Rectus externus und internus die stärkeren und mehr in Anspruch genommen sind, so kann hieraus eine stärkere Abplattung der Cornea im horizontalen Meridian resultiren.

Auf einer unregelmässigen Vertheilung des Brechungsvermögens im Ange beruht das für die meisten Menschen strahlenförmige Aussehen der Gestirne: jeder leuchtende Punkt erscheint sternförmig, sobald das Auge zwar annähernd, aber nicht genau auf denselben accommodirt ist: ist die Accommodation sehr unvollkommen, so erscheint er als ein kleiner Fleck mit verwaschenen Rändern; ist die Accommodation vollkommen, so erscheint er punktförmig.

Der normale irreguläre Astigmatismus beruht auf der eigenthïmlichen Art, in welcher die gegen die Linsenpole convergirenden Linsenfasern durch eine Kittsubstanz von etwas kleinerem Brechungsindex verbunden sind. Diese Kittsubstanz bildet an jedem Linsenpol eime sternförmige Figur. Durch diesen Bau der Linse ist es bedingt, dass die Wellenfläche der von einen beobachteten Punkt ausgegangenen Lichtbewegung in Auge hinter der Linse derartig von der Kugelfläche abweicht, dass sie strahlenförmig angeordnete Verbiegungen mit kleinerer Krïmmung zeigt. Die Helligkeitsdifferenzen niïssen am bedeutendsten erscheinen, das heisst die Strahlenfigur muss am deutlichsten hervortreten, wenn die Krümmungsmittelpunkte der abweichend gestalteten Theile der Wellenfläche Brennlinien auf der Netzhaut erzeugen; dies findet statt, wenn die Netzhaut etwas hinter dem Gesammtbrennpunkt liegt. Bei einem sehr wenig myopischen Auge oder bei einem emmetropischen, welches seine Accommodation nicht vollkommen entspannen kann, fallen die vollkommensten Abbildungen der Sterne des Himmels etwas vor die Netzhaut und die strahlenförmigen Brennlinien in die Netzhaut selbst. Personen mit schwach hypermetropischen Augen können den Sternenhimmel mit Punkten crfüllt sehen. Man erhält iibrigens auch eine Sternfigur, wenn der Accommodationspunkt entfernter ist, als der betrachtete leuchtende Punkt.

Ein fernerer Grund für die Unvollkommenheit der Abbildung äusserer Objekte auf der Retina liegt in der verschiedenen Brechbarkeit des Lichtes verschiedener Wellenlänge. Der Unterschied der Refraction im Auge ist zwar recht beträchtlich, denn ein Auge, welches in monochromatisch rother Beleuchtung emmetropisch ist, hat in monochromatisch 
violetter Beleuchtung seinen Fermpunkt in etwa drei Viertel Meter Abstand vom Auge. Trotzdem stört die sogenanute chromatische Aberration im Auge das deutliche Sehen selır wenig. Bei den Bildverzerrungen, welche durch zu schicfe Incidenz des Richtungsstrahles oder der Randstrahlen oder durch regulären Astigmatismus oder durch unvollkommene Accommodation entstehen, ist die jedem Objektpunkt zugehörige Zerstreumngfigur auf der Retina bis zu ihrer Peripheric gleichmässig hell, während, wenn ein bis auf die Chromasie vollkommenes Auge etwa fuir blaues Licht genau eingestellt ist, uur das Centrum jedes durch chromatische Aberration bedingten Zerstreuungskreises alle Lichtarten enthält und dadurch stärker erregend auf die Netzhaut wirkt, als der nur von langwelligen Strahlen getroffene Rand. Immerhin kann sich Jeder von der Thatsache, dass sein Auge nicht aclnomatisch ist, auf folgende Art überzeugen: man betrachtet einen leuchtenden Punkt aus Sonnenoder Lampenlicht durch Kobaltglas, welches die Eigenschaft besitzt, vorwiegend rothe und blane Strahlen durchzulassen. Der Punkt erscheint dann bei grösserem Abstand des Accommodationspunktes mit einem rothen und bei einem kleineren Abstand mit einem blauen Hof.

Die Zerstreuungsbilder auf der Retina werden verkleinert, wenn sich die Pupille verengert; hierdurch wird die Bildgiite verbessert, aber nur bis zu einer gewissen Grenze der Pupillenweite, welche einerseits gegeben ist durch die Helligkeitsabnahme des Bildes, andererseits durch die Abweichung, welche der Strahlengang bei der Beugung am Pupillarrande erleidet. Der letztere Einfluss muss sich geltend machen, sobald die Randstrahlen einen erheblichen Bruchtheil des gesammten Strahlenkegels ausmachen.

Die Umwandlung der Energie, welche in Form von Aetheroscillationen des Lichtes zu dem Augengrunde gelangt, in Nervenerregung geschieht in der Retina, welche die Ausbreitungen und die unit besonderen Apparaten versehenen Endigungen der Sehnerven enthält. Die Retina hat zwei ausgezeichnete Punkte, den einen dort, wo der Sehnervenstamm die Augeuläute durchsetzt (Papilla nervi optici) und den zweiten dort, wo die Augenaxe die Retina schneidet; wegen der besonderen Färbung nennt man die weitere Umgebung des letzteren Punktes den gelben Fleck, während die nächste Umgebung desselben wegen der hier vorhandenen starken Verdïnnung der Netzhaut die Netzhautgrube genannt wird, oder die Forea centralis. Die Papilla nervi optici liegt nasalwärts um ca. $4 \mathrm{Mm}$ von der Fovei centralis entfernt. Im Gegensatz zur Forea centralis werden die seitlichen und die rorderen Theile der Netzhaut als peripherisch bezeichnet.

Der Bau der Retina ist ein sehr zusamnengesetzter und wir können hier nur auf diejenigen Elemente derselben eingehen, deren functionelle 
Bedeutung einigermassen klar ist. Die Structur der Retina erweist sich unter dem Mikroskop als dentlich geschichtet; bei der anatomischen Aufzählung dieser Schichten betrachtet man die dem Glaskörper anliegende Grenze als innen, die der Chorioidea anliegende als aussen.

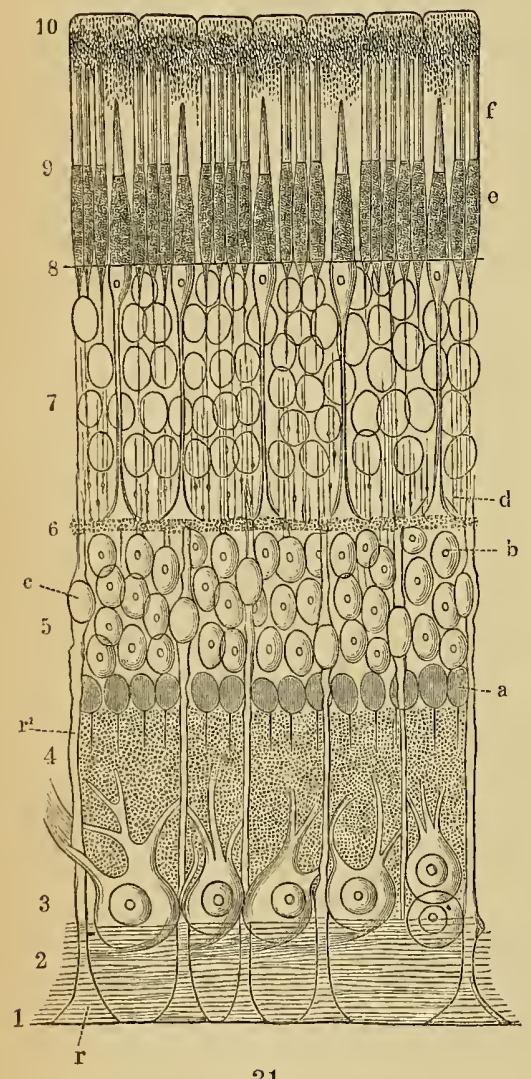

31.

Die innerste, also die auf der Seite des Lichteinfalls gelegene und an die Membrana hyaloidea des Glaskörpers anstossende Schicht enthält die Ausstrahlungen der Fasern des Nervus opticus, man nennt sie die Nervenfaserschicht; dieselbe enthält auch die gröberen Retinalgefässe. Daran schliesst sich nach anssen eine Lage multipolarer Ganglienzellen, deren Axencylinderfortsätze mit den Sehnervenfasern zusammenhängen und deren verästelte Fortsätze nach aussen gerichtet sind. Die Gesammtzahl dieser Ganglienzellen wird als kleiner geschätzt wie die Zahl der Sehnervenfasern; sie liegen in dem peripherischen Theil der Netzhaut zerstreut, rücken nach dem Centrum, zunächst nur eine Schicht bildend, zusammen, ordnen sich in der Nähe des gelben Fleckes in zwei Reihen, schichten sich gegen das Centrum zu 8 bis 10 Reihen hinter einander, fehlen aber ebenso wie die Opticusfasern im mittleren Theil der Netzhautgrube (vgl. Fig. 33). Die verästelten Fortsätze der multipolaren Nervenzellen des sogen. Opticus-Ganglion sind in eine Schicht eingetancht, welche auf dem Querschnitt fein granulirt erscheint, deren netzfömige Structur aber nachgerviesen ist, sie heisst die innere reticuläre Schicht. Das Netzwerk besteht wesentlich aus Durehschnitt dureh die Netzhaut de
Hensehen. (Schematisch nach Sehwalbe.) 1 Marge limitans (internus); 2 Nervenfaserschicht; 3 Ganglienzellenschicht (Ganglien nervi optici); 4 innere retieuläre Schicht: 5 Körnerschicht (innere Körnerschicht); a Spongioblasten; b Zcllen des Ganglion retinae; c Kerne der Müller'schen
ladialfasern: 6 änssere reticuläre oder subepitheliale Schicht; $7-9$ Schicht der Selizellen; 7 ihre Kerne (äussere Körner); 8 Membrana limitans externa; 9 Stäbchen und Zapfen; d kernfreie Zone der üsseren Körnerschicht; e Innenglieder t Anssenglieder der Stäbchen; 10 Pigmentepithel r. Kegel der Müller'schen Stütz- oder liadialfasern $r^{\prime}$ Müller'sche Fasem.

Hornspongiosa, wie sie als Stiitzsulstanz im Centralnervensystem vorkommt. Die nach aussen sich anschliessende innere Körnerschicht enthält hauptsäcblich bipolare Ganglienzellen (Ganglion der Retina), deren 
nach innen gerichtete dünne, zu varicösen Anschwellungen neigende Fisern bis in die innere reticuliire Schicht hinein zu verfolgen sind und wahrscheinlich nmmittelbar in den Rest der Fasern der Nervenfaserschicht übergehen. Die nach aussen gerichteten fortsütze sind reriistelt und treten in eine diinne Lage einer :̈usseren reticulären Schicht iiber.

Die bisher behandelten Schichten werden durchsetzt ron starken Fasern bindegewebiger Natur, den sogenannten Mïller'schen Stiitzfasern; dieselben verbreitern sich gegen die Grenzfliche zwischen Glaskörper und Retina in ebensoviele an einander stossende dïnne Platten, welche den sogenannten Margo linitans internus bilden. Im Gebiete der inneren Körnerschicht enthält jede dieser Stiitzfasern einen Kern.

Die nach aussen anf die äussere reticuläre Schicht folgenden nächsten Schichten gehören den Sehzellen an, das Gebiet der Sehzellen wird durch eine starke gefensterte Membran, die Membrana limitans externa, in zwei Theile geschieden, in die der äusseren reticulären Schicht anliegende Schicht der äusseren Körner und in die Schicht der Stäbchen und Zapfen. Jedes Element der letzteren Schicht setzt sich durch eine Oeffnung der Membrana limitans externa durch die ganze äussere Körnersehicht bis zur äusseren reticulären Schicht fort. Die Kerne dieser Sehzellen sind die Körner der äusseren Körnerschicht. Die Mïller'schen Stïtzfasern erstrecken sich verfeinert durch die äussere reticuläre, äussere Köornerschicht und die Membrana limitans externa hindurch, die Basaltheile der einzelnen Stäbchen und Zapfen mit ihren letzten Ausläufern umgebend. Die

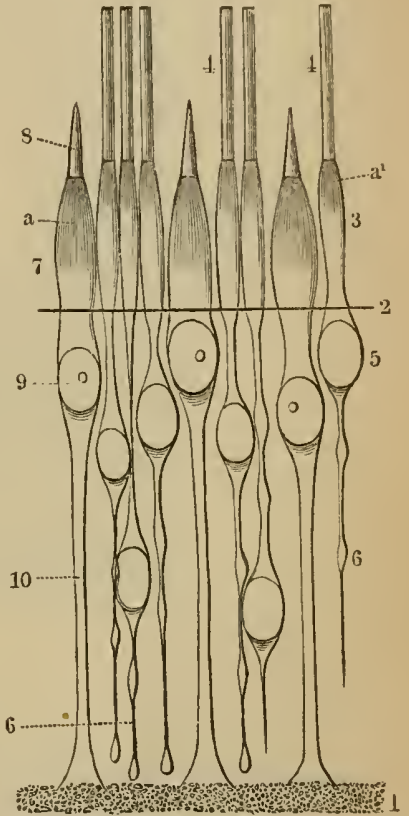

32.

Aeussere reticuläre und sehzellenschicht dermenschliehen Netzhaut. (Schematiseh nach II. $\mathrm{Sehultze}, 800 / 1$.)

1 Aeussere reticuläre oder subepitheliale Schicht: 2 Membrana limitans externa; 3 Innenglieder: 4 Aussenglieder der Stäbchen: a' St ibchen-Ellipsoid mit faseriger Textur: 5 Stäbchenkorn (kernlıaltige Anschwellung der StäbchenSehzelle); 6 Stābchenfaser ; $3-6$ Stäbchen-Sebzelle; 7 Zapfen - Innenglied; 8 Aussenglied des Zapfens : a Ellinsoid desselben: 9 Zapfenkorn (kernhaltige Anschwellung der Zapfen-Sehzelle); 10 Zapfenfaser; $7-10$ Zapfen-Sehzelle. Stäbchen und Zapfen sind besonder's differenzirte Theile der Sehzellen. Jedes dieser Elemente besteht aus zweien, der Form und Substanz nach verschiedenen Theilen, dem Innenglied und dem Aussenglied. Die Innenglieder geben Reactionen wie Protoplasma, die Substanz der Aussenglieder scheint dem Myelin ähnlich zu sein. Der äussere Theil jedes 
Innengliedes unterscheidet sich im Lichtbrechungsvermögen ron dem inneren Theile und wird wegen der gekrümmten Trennungsfläche zwischen beiden_Substanzen Stäbchen- oder Zapfen-Ellipsoid genannt. Die Aussenglieder sind stark glänzend und doppelt brechend und sie zerfallen bei gewissen Macerationen der Quere nach in Plättchen; die Aussenglieder der Stäbchen (und nur diese) sind diffus gefärbt durch eine stark lichtempfindliche Substanz, den Sehpurpur.

Die Stäbchen sind langgestreckte Gebilde, deren Aussen- und Innenglieder nicht stark rerschiedene Formen zeigen, die Aussenglieder sind cylindrisch, die Innenglieder etwas gebaucht. An den Zapfen besitzt jedes Innenglied einen grösseren Durchmesser und ist stärker gebaucht;

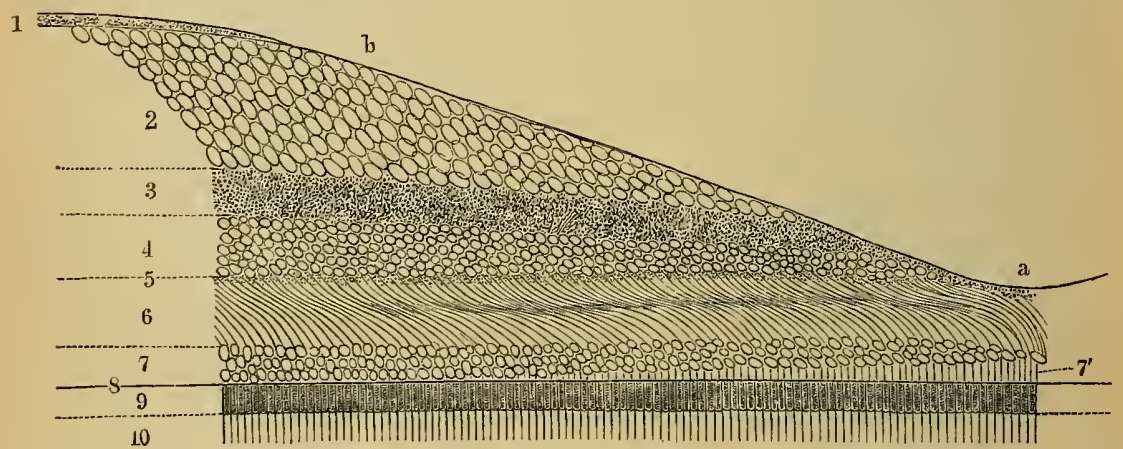

33.

Durchschnitt durch die Macula lutea und Fovea centralis des Menschen. (Schematisch nach Schwalhe.)

a Fundus foveae; h Abhang der Macula lutea nach der Forea zu; 1 Nervenfaserschicht; 2 Ganglienzellenschicht; 3 innere reticulirte Schicht; 4 Körnerschicht; 5 äussere reticulirte Lage; 6 äussere Faserschicht von $\mathrm{Henle}$, bestehend aus den gebogenen Zapfenfasern; 7 Schicht der Zapfenkerne (āussere Körnerschicht); 7 ' kernfreie Zone zwischen Zapfenkernen und Membrana limitans externa (8); 9 Innenglieder der Zapfen-Sehzellen; 10 deren Aussenglieder.

das kürzere Aussenglied ist nicht cylindrisch, sondern conisch. Das Zahlenverhältniss zwischen den Stäbchen und Zapfen ist in den verschiedenen Retinazonen sehr verschieden. In der Gegend des Aequators stehen die Zapfen sehr vereinzelt in der fast continuirlichen Schicht von Stäbchen; gegen die Macula lutea hin nimmt die Zahl der Zapfen mehr und mehr zu, und in dem Centrum des gelben Fleckes, der Netzhautgrube, besteht das Sehepithel nur aus Zapfen, welche aber hier weit schlanker sind, als in der Peripherie.

Die Grenzschicht der Tunica retina gegen die durch Pigmentirung ausgezeichnete Tunica urea ist von einer ebenfalls Pigment fuihrenden Zelllage gehildet. Das Pigmentepithel der Retina entstammt dem äusseren Blatt der secundären Augenblase, während alle anderen Schichten der Retina auf das innere Blatt derselben zurückzuführen sind, sodass also ursprünglich ein Spaltraum die Schicht des Pigmentepithels von den 
iibrigen Schichten der Retina trennte. Die Zellkörper des Pigmentepithels begrenzen sich gegenseitig hexagonal und stellen cine zusammenliängende Schicht dar, von wolcher sich lange protoplasmatische Fortsätze biirstenartig zwischen die Aussenglieder und zum Theil auch bis zwischen die Innenglieder der Stäbchen und Zapfon fortsetzen, die von denselben freigelassenen Rïume ausfüllend. Der Zellkörper träigt einen ellipsoiden Kern; das Protoplasma der glatten Zellknppe ist stets pigmentfrei, in dem ïbrigen Protoplasma finden sich zahlreiche lirystallinische Köornchen eines dunkelbrannen Pigments, des Fuscins, eingebettet, je nach den Beleuchtungsverhältnissen verschieden zwischen dem Zellkörper und den Fortsätzen vertheilt.

Die Unterschiede, welche wir mit den Augen an ̈̈usseren Gegenstïnden wahrnehmen, nemnen wir Unterschiede der Helligkeit und Unterschiede der Farbe: die Lichtempfindung kamn farbig oder farblos sein. Die farblosen Empfindungen unterscheiden sich von einander nur durch die rerschiedenen Grade der Helligkeit. Farbig er Lich temp find ungen giebt es eine sehr grosse Zahl, jede derselben nennt man eine Farbe oder einen Farbenton; jede Farbe kann nicht nur verschiedene Grade der Helligkeit besitzen, sondern sie kann sich auch in verschiedenem Maasse von dem Farblosen unterscheiden; je grösser diescr Unterschied ist, um so gesättigter nennen wir die Farbe, je kleiner, um so blasser. Die farbigen Lichteindrücke können also sein: gesättigt und hell, oder gesïttigt und dunkel, oder blass und hell, oder blass nnd dunkel. Die gesättigtston farbigen Eindrïcke, welche uns das Ange liefert, lassen sich derartig in eine Reihe anordnen, dass die in der Reihe einander näher stehenden Glieder eine grössere Aehnlichkeit unter eịnander besitzen, als die entfernteren. Ein Theil dieser Reile entspricht der Anordnung der Farben im Spectrum, dessen sichtbares Gebiet sich von der Wellenlänge $700 \mu \mu$ am Ende des Roth, durch Orange, Gelb, Griin $(520 \mu \mu)$, Blan, Violett $(400 \mu \mu)$ erstreckt und das eine continuirliche Reilie von Farbentönen enthïlt, ans welchen die angeführten nur herausgegriffen sind, weil die Sprache kurze gemeinverständliche Ausdrücke fuir diesclben besitzt. Die volle Zahl der im Spectrum zu unterscheidenden Farbentöne bekommt man zur Anschauung, wenn man aus einem ausgedehnten und lichtstarken Spectrum sehr schmale Streifen ansschneidet und mit dem ron ihnen gelieferten Licht nicht zu kleine farlolose llächen gleichnü̈ssig belenchtet.

Die Zahl der, dem Farbenton nach, verschiedenen Lichteindrïcke ist aber noch weit grösser, als die Zahlıl der im Spectrum vertretenen Farbentöne; in letzterem fehlen alle Purpurtöne. Da diese sich einerseits an die violetten und andererseits an die rothen continuirlich anreihen und in sich sellost eine continuirliche Aehnlichkeitsreihe darstellen, 
so können wir sämmtliche mögliche Farbentöne, der Aehnlichkeit nach, durch die Punkte eines in sich geschlossenen Linienzuges darstellen.

Der symbolischen Darstellung der Farbentöne durch eine in sich zuruicklaufende Linie kann man einen weitergehenden Sinn beilegen, sodass auch jeder Punkt der von der Linie umschlossenen Fläche einer qualitativ bestimmten Lichtempfindung entspricht, und dass alle möglichen, der Qualität nach verschiedenen Lichtempfindungen durch Punkte der Fläche vertreten sind. Die

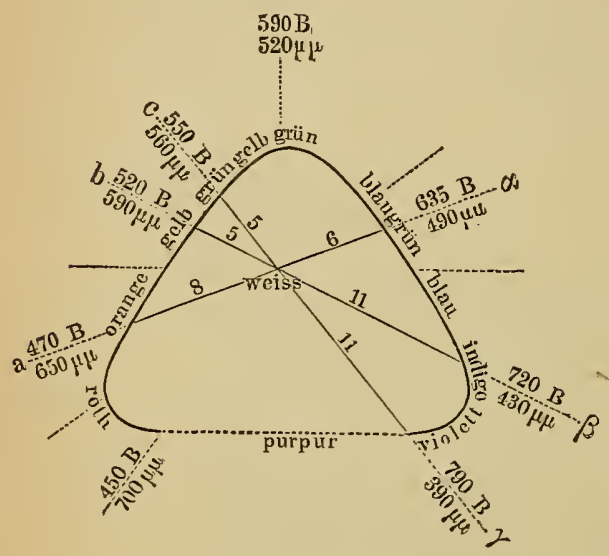

34.

$1 \mathrm{~B} .=1$ Billionen Schwingungen in 1 Sec. $1 \mu \mu=$ $0,001 \mu ; 1 \mu=0,001$ Millimeter; dies Maass bezieht sich auf die Wellenlânge der Lichtart. Umgrenzungslinie der Fläche muss zu diesem Zwecke eine bestimmte Form erhalten und die Wahl dieser Form beruht auf den Erfahrungen der Farbenmischungen. Fig. 33 trägt diesen Erfahrungen Rechnung.

Beleuchtet man dieselbe farblose Fläche mit zwei Lichtarten des Spectrums, so erhält man im Allgemeinen wieder einen farbigen Eindruck und zwar, wenn die Lichtarten im Spectrum nicht weit ron einander abstehen, den farbigen Eindruck, welchen eine dazwischen gelegene Lichtart allein hervorbringen würde: bei Mischung von Roth und Violett des Spectrums in verschiedenen Intensitätsverhältnissen erhält man die im Spectrum nicht vorhandenen Farbentöne des Purpur. Sämmtliche Farbentöne, die spectralen sowohl als die purpurnen, sind aber paarweise so zusammengeordnet, dass das Resultat der Mischung jedes Paares in einem bestimmten Intensitätsverhältnisse ein Lichteindruck ist, welcher nichts Farbiges enthält. Diesen Eindruck nennt man bei genügender Intensität weiss. Das Weiss ist subjectiv dadurch charakterisirt, dass es mit keiner der gesättigten Farben eine grössere Achnlichkeit hat, als mit den anderen. Jedes Paar von Farbentönen, für welches sich ein Intensitätsverhältniss finden lässt, bei welchem seine Nischung Weiss giebt, nennt man ein Paar ron Complementärfarben: lecispielsweise sind nachstehend einige solcher Paare von Complementärfarben aufgeführt:

Orange - Blau

Gelb - Indigoblau

Griingelh - Violett. 
Das heisst zum Beispiel: homogene Stralilen, welche den Eindruck von Orange hervorbringen, zusammen mit solchen, die den Eindruck des Blaugrün geben, machen (in gewissem Intensitätsverhältnisse gemischt) den Eindruck weiss u. s. w.

In der symbolischen flächenhaften Darstellung der Lichtempfindungen muss die Beziehung der Umgrenzungslinie zu dem Weisspunkt (wenn es ïberhaupt einen solchen geben soll) eine derartige sein, dass sich die Verbindungslinien der complementären Farbenpunkte in einem Punkte (dem Weisspunkte) schneiden, und dass diese Linien durch ihren Schnittpunkt in demselben Verhältniss getheilt werden, in welchem die zur Erzielung des Weiss erforderlichen Intensitiiten der Complementärfarben stehen. Diese Construktion ist nun thatsächlich ausfühılbar.

Welche Bedeutung kommt nun den ïbrigen Punkten unserer symbolischen Fläche 7u? Es wird dies am klarsten, wenn wir die Punkte einer Verbindungslinie etwa zwischen Gelb und Indigo ins Auge fassen. Die Lage des Punktes Weiss auf dieser Linie ist bedingt durch ein bestimmtes Intensitätsrerhältniss zwischen Gelb und Indigo. Wird homogenes Gelb mit homogenem Indigblan in einem anderen Intensitätsrerhältniss gemischt, so entstelıt entweder ein gelber oder indigoblauer Eindruck, welcher aber nicht so gesättigt ist, als wenn Gelb oder Indigoblau allein eingewirkt hätte: je mehr sich das Intensitätsverhältniss dem für das Weiss erforderlichen nähert, um so mehr nimmt die Sättigung der Farbe ab, um so blasser wird sie.

Die Umgrenzungslinie unserer Fläche ist durch das Bedürfniss, den Erfahrungen ïber die Complementärfarben Rechnung zu tragen, vollkommen bestimmt; die Verschiedenheit in den Krümmungen dieser Linie wird aber auch auf Grund anderer Erfahrungen als nothwendig eingesehen. Bei Mischung homogener Strahlen aus dem orangen und grüngelben Theil des Spectrums resultiren gelbe Farbentöne, welche an Sättigung kaum hinter denen des gleichen Theiles des Spectrums zuriickstehen; dasselle gilt für Mischung von Blaugrïn und Blau. Mischt man dagegen Grüngelb und Blaugrün, so ist das resultirende Grün erheblich blasser, als das spectrale.

Wenn mehr als zwei homogene Strahlenarten zusammenwirken, so kommen keine neuen Eindrücke zum Vorschein, die nicht schon durch Punkte unseres Täfelchens vertreten wären. Sind drei Componenten vorhanden, so erhält man den dem resultirenden Eindruck entsprechenden Punkt, wenn man zunächst nur zwei derselben gemischt und dann die dritte hinzugefügt denkt. Hieraus folgt, dass die symbolische Farbentafel ihre Bedeutung behält, wenn man beliebige farbige Eindriicke, mögen sie vom Spectrum oder von Pigmenten geliefert sein, der Combination zu Grunde legt. Dieses gilt jedoch allgemein nur für die Mischung der 
Eindriicke, nicht für die Mischung ihrer Ursachen, denn wenn man Nischfarben dadurch herzustellen sucht, dass man Pigmente mit einander verveibt oder farbige Flüssigkeiten mit einander mischt, so erhält man andere farbige Eindricke, als wenn man zwei Combinationen verschiedener spectraler Lichtarten gemeinsam zur Belenchtung einer farblosen Flïche benutzt; es liegt dies daran, dass der Farbenton der Pigmente derjenigen Summe spectralen Lichtes entspricht, welche vom Pigment nicht absorbirt, sondern zurïckgeworfen oder durchgelassen nird; mischt man solche Pigmente, so addirt man also nicht einfach die ron jedem einzelnen gelieferten spectralen Lichtarten, sondern man erhält eine Combination, in welcher nur diejenigen Lichtarten vertreten sind, welche ron keinem der gemischten Pigmente absorbirt werden. Will man die ron Pigmenten gelieferten Farbentöne durch einfache Additionen mit einander mischen, so muss man dies mit den von ihnen gelieferten Eindrücken thun: es geschieht dies so, dass man schnell rotirende weisse Scheiben mit Sectoren des einen und anderen Pigmentes belegt. Betrachtet man solche Scheiben, so wird jede Stelle der Netzhaut in so raschem Wechsel ron den verschiedenen Combinationen der Lichtarten getroffen, dass derselbe Eindruck entsteht, als wenn alle in den Combinationen enthaltenen Lichtarten gleichzeitig die Netzhautstellen träfen. Bei den sogenannten Farbenmischungsversuchen der physiologischen Optik handelt es sich stets um die Mischung farbiger Eindrïicke.

Die symbolische Farbentafel mit ihren Bezeichnungen bezieht sich auf eine Intensität des Lichtes, welche zwar stark ist, aber nicht so stark, dass das Auge dadurch geschädigt oder schnell ermïdet würde; bei dieser Intensität nennt man den farblosen Eindruck weiss. Beim Abnehmen wird er grau und schliesslich schwarz genannt: Schwarz entspricht dem Mangel jeglichen Lichteinfalles in das Auge. Man kann sich dem Schwarz also nicht nur von Weiss aus durch Grau, sondern von jedem blasseren oder gesättigteren Farbentone aus durch Abnahme seiner Helligkeit nähern. Da alle Lichteindrücke mit Abnehmen der Helligkeit gegen das Schwarz convergiren, so erhält man eine symbolische Darstellung aller möglichen Lichteindrücke, wenn man auf der Farbentafel einen Kegel errichtet und dessen Spitze schwarz nennt.

Die wichtigsten Thatsachen, welche aus den Farbenmischungsversuchen folgen, und welche ron der symbolischen Farbentafel abgelesen werden können, sind die, dass einerseits jeder farbige oder farblose Lichteindruck auf eine mendlich mannigfaltige Art durch Combinationen homogener Lichtarten erzengt werden kann (nur die ganz gesättigten Farbeneindrücke sind hiervon ausgenommen) und dass andererseits zur Erzeugung jedes bestimmten Lichteindruckes drei verschiedene homogene Lichtarten ausreichen. Sollte jedes Leitungselement des Nervus 
opticus jeden beliebigen Lichteindruck zu rer'nitteln im Stande sein, so müsste jedem dieser Lichteindrücke eine bestinunte Erregungsform des Leitungselementes entsprechen und es bliebe zu erklären, wie eine und dieselbe Erregungsform durch rerschiedene Combinationen ron Aetheroscillationen hervorgerufen werden könne. Mag man sich auf den Boden der Lehre rou den specifischen Simnesenergien stellen, und bei der Erregung in nerrösen Leitungsbahnen nur quantitative Unterschiede gelten lassen, oder mag man derselben Nerrenfaser qualitativ (das heisst dem Rhythmus nach) rerschiedene Erregungsformen zutrauen, immer muss man zwischen Licht und Bewusstsein eine Vorrichtung annehmen, vermöge welcher rerschiedene Mischungen objectiren Lichtes denselben Lichteindruck zu erzeugen im Stande sind. Da die Lösung des Grundproblems durch Terlassen der Lehre ron den specifischen Energièn nicht erleichtert wird, so thun wir gut dieselbe, da sie den leichtesten Ausdruck gestattet, beizubehalten.

Die Thatsache, dass jeder beliebige Lichteindruck hervorgerufen werden kann, wenn nicht mehr als drei, verschiedenem homogenem Licht entsprechende Eindriicke combinirt werden, findet den einfachsten Ausdruck in der Annahme, dass es drei Kategorien ron Sehelementen (Leitungsfaser mit peripherischem und centralem Endapparate) giebt, deren jede, wenn sie erregt ist, einen bestimnten farbigen Eindruck rermittelt; diese elementaren Farbeneindrücke mïssen derart sein, dass aus ihrer Combination alle möglichen Lichtempfindungen resultiren können, es sind dies, wie ein Blick auf die Farbentafel lehrt, Roth, Grün und Violett. Die specifische Energie der drei Kategorien ron Sehelementen wäre also Empfindung ron Roth, von Grïn, und Violett, das heisst, wenn nur die Rothkategorie erregt wäre, wïrden wir ganz gesättigtes Roth sehen u. s. w. Bei Betrachtung des langwelligen Endes des Spectrums sehen wir nun in der That ein ziemlich gesättigtes Roth, doch lässt sich die Sättigung dieses Farbeneindruckes noch steigern, wenn man das Auge rorher durch griines und riolettes Licht ermiidet hat; man schliesst hieraus, dass homogenes Licht grösster Welleulänge nicht nur die Rothelemente, sondern auch die Grün- und Violettelemente, wenn auch in weit geringerer Intensität, erregt.

Hiernach ist die Annahme berechtigt, dass als adäquater Reiz für die peripherischen Endapparate aller drei Kategorien zwar das Licht gilt, dass aber das Licht grosser Wellenlänge ha uptsächlich auf die Pothelemente, dasjenige mittlerer Wellenlänge auf die Grünelemente, und das kleinerer Wellenlänge auf die Violettelemente wirkt.

Die einfachste Annahme zur Erklärung der Entstehung weissen Lichteindruckes bei Mischung rerschiedener homogener Lichtarten ist 
die, dass farblos gesehen wird, wenn keine der drei Kategorien von Sehelementen stärker erregt ist, als die andere.

Experimentell ausführbar ist Folgendes: man kann homogenes Licht beliebiger Wellenlänge $(\lambda)$ in einer für alle Lichtarten gleichen Intensität (J) zur Beleuchtung einer ein für allemal gleich grossen Fläche herstellen. Als Maass der Intensität ist hier die Strahlungsenergie gedacht. Man kann auch die zur Verwendung kommenden homogenen Lichtarten der Intensität nach variiren und das Intensitäts-Verhältniss genal angeben, in welchem zwei solche Lichtarten zur Anwendung gekommen sind. Benutzt man je zwei complementäre Lichtarten $(\lambda=\mathrm{a}$ und $\lambda=\alpha$ ) zur Erleuchtung derselben Fläche, so ermittelt man auf diese Weise das Verhältniss der Intensitäten

$$
\begin{aligned}
& \mathrm{J}_{\mathrm{a}}: \mathrm{J}_{\alpha}=\chi \\
& \mathrm{J}_{\mathrm{b}}: \mathrm{J}_{\beta}=\chi \\
& \mathrm{J}_{\mathrm{c}}: \mathrm{J}_{\gamma}=\psi
\end{aligned}
$$

in welchen diese Lichtarten gemischt, den Eindruck weiss geben. Die Farbentafel Fig. 34 ist mit Berücksichtigung solcher Erfahrungen con-

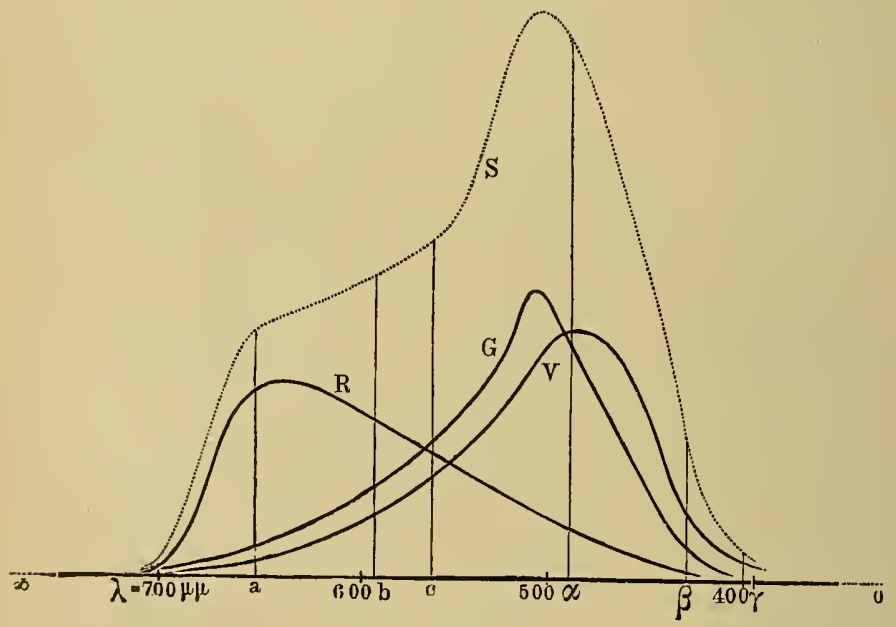

35.

struirt und der Weisspunkt theilt die Verbindungslinien je zweier complementärer Lichtartpunkte in den so ermittelten Verhältnissen. Man kann diese Intensitätsverhältnisse nun auch zur Construction dreier Curven benützen, deren jede die Erregungsintensität je eines der drei hypothetischen Sehelemente (Rothelement, Grünelement, Violettelement) als Function der Wellenlänge des einwirkenden Lichtes bei ein für allemal gleicher Intensität (Strahlungsenergie) derselben darstellt. Nennt man die Function für das Rothelement $f_{r}(\lambda)$, für das Grïnelement $f_{g}(\lambda)$ 
und für das Violettclement $\mathrm{f}_{v}(\lambda)$, so sind die der Lichtart $\lambda=a$ entsprechenden Ordinaten wit $f_{r}(a), f_{g}(a), f_{v}(a) z u$ bezcichnen, die der complementären Lichtart $\lambda=\alpha$ entsprechenden mit $f_{r}(\alpha), f_{g}(\alpha), f_{v}(\alpha)$ und so weiter. Die drei Curven miissen den Bedingungen genügen:

$$
\begin{aligned}
& f_{r}(a)+\chi f_{r}(\alpha)=f_{g}(a)+\chi f_{g}(\alpha)=f_{v}(a)+\chi f_{v}(\alpha) \\
& f_{r}(b)+\chi f_{r}(\beta)=f_{g}(b)+\chi f_{g}(\beta)=f_{v}(b)+\chi f_{v}(\beta) \\
& f_{r}(c)+\psi f_{r}(\gamma)=f_{g}(c)+\psi f_{g}(\gamma)=f_{v}(c)+\psi f_{v}(\gamma)
\end{aligned}
$$

etc. für alle Paare complementärer homogener Lichtarten.

In Fig. 35 sind solche Curven ( $R, G, V)$ construirt auf einer $A b-$ scisse, deren Länge umgekehrt wie die Wellenlänge des Lichtes zunimmt. ' Zu jeder homogenen Lichtart zwischen a und $\mathrm{c}$ ist je eine homogene Lichtart zwischen $\alpha$ und $\gamma$ complementär. Fïr die Lichtarten von $\mathrm{c}$ bis gegen $\alpha$ hin giebt es keine homogenen complementären Lichtarten. Zur Construction der Curven in diesem Bereiche ist also das bisherige Verfahren nicht zureichend, hier mïssen andere Erfahrungen herangezogen werden. Wir wissen, dass Licht, welches aus allen Lichtarten in gleicher Intensität zusammengesetzt ist, den Eindruck Weiss macht. Hieraus kann man als Bedingung, welcher die Curven genügen müssen, herleiten, dass die von ihnen begrenzten Flächenstuicke gleich sein müssen, das heisst, dass:

$$
\int_{\infty}^{0} \mathrm{f}_{\mathrm{r}}(\lambda) \mathrm{d} \lambda=\int_{\infty}^{0} \mathrm{of}_{\mathrm{g}}(\lambda) \mathrm{d} \lambda=\int_{\infty}^{0} \mathrm{of}_{\mathrm{v}}(\lambda) \mathrm{d} \lambda .
$$

Fernere Bedingungen, denen die 3 Curren genïgen müssen, wenn sie iiberhaupt den Thatsachen entsprechend construirt werden können, ergeben sich aus den Erfahrungen über die Reihenfolge, in welcher die verschiedenen Lichtarten bei gleichmässig zunehmender Intensität die Reizschwelle ïberschreiten. Zuerst thun dies die Strahlen der Wellenlänge von etwa $520 \mu \mu$ (im Grïn). Hier muss also die auf derselben Abscisse construirte Curre $S$ deren Ordinaten gleich

$$
f_{r}(\lambda)+f_{g}(\lambda)+f_{b}(\lambda)
$$

sind, ihr Maximum haben etc. Schliesslich kann man zwei Vergleichsfelder A und B beleuchten, und zwar jedes mit einem Paar complementärer Lichtarten, etwa $\mathrm{A}$ mit $\mathrm{a}+\% \alpha$ und $\mathrm{B}$ mit $\mathrm{b}+\chi^{\beta}$ und man kann die Intensitäten so wählen, dass A und B nicht nur gleich farblos, sondern auch gleich hell erscheinen; dies möge der Fall sein, wenn

$$
\frac{a+x \alpha}{\beta+\chi^{\beta}}=\zeta \text {. }
$$

Hieraus ergeben sich als Berlingungen, denen die Curven genïgen mïssen, Gleichungen von der Form:

$$
\begin{aligned}
& f_{r}(a)+x f_{r}(\alpha)=\zeta\left[f_{r}(b)+\chi f_{r}(\beta)\right] \\
& f_{g}(a)+x f_{g}(\alpha)=\zeta\left[f_{g}(b)+\chi f_{g}(\beta)\right] \text { etc }
\end{aligned}
$$


Die beigefügte Curvenconstruction kann nicht den Anspruch elheben, Ausdruck des wirklichen Sachverhaltes in jeder Beziehung zu sein, sie ist aber wohl geeignet einige von den Bedingungen anschaulich zı machen, welchen bei der Construction genügt werden müsste, wenn anders die vorgetragene Hypothese zur Erklärung der Thatsachen ausreicht.

Die bisher betrachtete Mannigfaltigkeit der Farbenempfindungen hat nur Statt in der polaren Region der Netzhaut; auf den seitlichen Theilen beschränkt sie sich mehr und mehr und verschwindet gegen den Aequator der Netzhaut gänzlich, sodass hier jede Lichtart den Eindruck weiss macht. Diese Thatsache lässt sich mit der zur Erklärung der Farbenmannigfaltigkeit vorgetragenen Hypothese von $\mathrm{Young}$ und Helmholtz in Einklang bringen, wenn man annimmt, dass gegen die Peripherie der Netzhaut hin, die Unterschiede der Erregbarkeit der drei Gattungen von Sehelementen durch verschiedene Strahlenarten, allmählich immer geringer werden und zuletzt ganz verschwinden. Diese Annahme reicht nicht nur zur Erklärung der physiologischen Schwäche des Farbensinnes in der Netzhautperipherie aus, sondern man kann auch in analoger Weise die Thatsachen der als Farbenblindheit bezeichneten Abnormitäten des Farbensinnes auf Abweichungen der Erregbarkeitscurven von der Norm beziehen.

Die Form der Erregbarkeitscurven ist auch nachweislich von der Intensität des in das Auge fallenden Lichtes abhängig; die unmittelbare Beobachtung weist hierauf hin dadurch, dass einerseits grelle Beleuchtung gesättigte Farben blasser erscheiner lässt - worauf die Bevorzugung satter Farbentöne in der Architektur sïdlicher Völker beruben mag -, dass andererseits kleine farbige Flächen, bei allmählich von Null wachsender Beleuchtungsintensität, frïher als hell von dunklem Grunde sich abheben, ehe ihre Farbe erkannt werden kann. Hierbei spielt allerdings auch die Grösse des vom Licht getroffenen Netzhauttheiles eine sehr bemerkenswerthe Rolle, denn eine kleine Fläche wird frïher farbig erkannt, als ein Punkt und mehrere discrete Punkte früher als ein einzelner. Sterne, aus deren Spectrum geschlossen werden muss, dass sie farbiges Licht aussenden, erscheinen uns bei ziemlicher Helligkeit doch weiss.

Die Grenzen der Sichtbarkeit des Spectrums können dadurch bedingt sein, dass Aetherschwingungen von grösserer Wellenlänge als $0,75 \mu$ oder ron kleinerer als $0,4 \mu$ durch die Substanzen des dioptrischen Apparates absorbirt werden, oder dadurch, dass die Retina für diese Strahlen nicht empfindlich ist. Von der Strahlungsenergie, welche im ultrarothen Theile des Spectrums vorhanden sein kann, ohne gesehen zu werden, erhält man einen Eindruck, wenn man Licht der Sonne oder 
einer elektrischen Bogenlampe durch eine Sammellinse gehen lässt, welche mit einer Lösung ron Jod in Schwefelkohlenstoff gefüllt ist; im Brennpunkt dieser Linse geräth ein dünnes Platinblech ins Gliihen, während die Linse selbst vollkommen schwarz crscheint. Andererseits leuchten fhorescirende Körper auf, wenn sie in den ultravioletten, bis dilhin rollkommen dunkelen Theil eines auf cinen Schirm projicirten Spectrums gebracht werden.

Die Augenmedien sind nun in der 'That, wie besonderc Untersuchungen ergeben haben, sehr wenig diatherman und sie absorbiren auch stark die ultravioletten Strahlen; letzteres gilt namentlich ron der Linse. Fiir Augen, welche durch die Staaroperation aphakisch geworden sind, soll sich der kurzwellige Theil des sichtloaren Spectrums weiter erstrecken als vorher. Auf dieser Seite des Spectrums scheint also die Grenze der Sichtbarkeit für das normale Auge durch die Absorption in den Augemmedien und nicht durch die Empfindlichkeit der Netzhitut gegeben zu sein. Dass die Retina für ultrarothe Strahlen empfindlich wäre, erscheint unwahrscheinlich, weil sonst die ron den Augenwandungen ausgehenden Wärmestrahlen die Unterscheidbarkeit der Bilder äusserer Objekte stören mïissten.

Am grössten ist die Empfindliclıkeit der Retina für Strahlen des grïnen Theiles des Spectrums. Dann folgt die Empfindlichkeit für den grïblauen, den blauen, dann für den gelben und schliesslich el'st für den rothen Theil. Bei allmählicher Erhitzung des Platins, wobei mit Steigerung der Temperatur die Intensität der Strahlung für alle Wellenlängen gleichmässig wächst, zeigt das Spectrum zuerst im Grün einen sichtbaren Streif, welcher sich gegen das Blau hin schneller ausbreitet, als nach dem Roth.

In ähnlicher Weise wie der Schwellenwerth vertheilt sich die Fähigkeit des Auges Intensitätsunterschiede zu erkennen auf die Theile des Spectrums; am grössten ist die Fähigkeit in grïnen Theil, wo schon eine Aenderung der Intensität ron 1/250 ausreicht, um einen merklichen Unterschied der Empfindungsstiirke hervorzubringen; für Violett muss die Aenderung 1/100 betragen, für Roth 1/70. Die Unterschiedsenpfindlichkeit für weisses Licht steht in der Mitte, sie beträgt bei geniigender Helligkeit 1/150, nimmt aber mit abnehmender Helligkeit sehr beträchtlich $a b$.

Auch die Fähigkeit des Auges, homogene Lichtarten mit geringem Unterschiede der Wellenlänge durch den Farbenton zu unterscheiden, zeigt an den einzelnen Theilen des Spectrums erhebliche Unterschiede; am grössten ist diese Unterschiedsempfindlichkeit für Farbentöne in Blaugrïn, wo bei der Wellenlänge des Lichts ron $490 \mu \mu$ eine Aenderung der Wellenlänge von weniger als $1 \mu \mu$ an der Aenderung des 
Farbentones bemerkt wird. Ein zweites Maximum liegt im Gelb bei $580 \mu \mu$, während gegen die beiden Enden des Spectrums hin diese Unterschiedsempfindlichkeit stark abnimmt, das heisst bei $450 \mu \mu$ eine Aenderung von $2,16 \mu \mu$ erforderlich ist, um bemerkt $\mathrm{zu}$ werden; bei $650 \mu \mu$ eine Aenderung von 4,6 $\mu \mu$. Am rothen und violetten Ende des Spectrums ist je ein Gebiet, wo bei Aenderung der Wellenlänge des Lichtes nur noch Aenderungen in der Helligkeit und nicht mehr solche im Farbenton wahrgenommen werden. Da das ganze Intervall der dem Farbenton nach unterscheidbaren Aetherschwingungen etwa $240 \mu \mu$ Wellenlänge und der mittlere erforderliche Unterschied etwa 1,7 $\mu \mu$ beträgt, so folgt, dass im spectralen Licht etwa 120 Farbennuancen unterschieden werden können.

Wenn Licht, welches die Retina trifft, plötzlich von einer geringen Intensität zı einer höheren anschwillt, so ist nicht auch sofort die volle Empfindungsstärke vorhanden, es vergeht vielmehr eine messbare Zeit bis die Empfindung den bei der neuen Intensität möglichen Werth erreicht, man nennt diese Zeit die Dauer des Anklingens der Lichtempfindung, welcher eine analoge Dauer des Abklingens gegenübersteht. Diese Zeiten weisen auf eine gewisse Trägheit der Netzhaut hin und lassen darauf schliessen, dass Energie, wenn sie aus der Form von Aetherschwingung des Lichtes in diejenige, welche der Nervenerregung zu Grunde liegt, übergehen soll, Zwischenformen annehmen muss. Die verhältnissmässig beträchtliche Grösse der Zeit, etwa $1 / 6$ Secunde, macht es wahrscheinlich, dass es sich um die Zwischenschaltung chemischer Processe handelt.

Von der Thatsache des An- und Abklingens der Netzhauterregung kann man sich iiberzeugen durch Betrachten einer in schwarze und weisse Sectoren getheilten Scheibe, welche man mit allmählich zunehmender Geschwindigkeit sich drehen lässt. In der Ruhe und bei ganz langsamer Drehung sieht man die Grenzen zwischen Schwarz und Weiss scharf; bei zunehmender Geschwindigkeit werden die Grenzen verwaschen. Es kann dies nur daran liegen, dass die Aenderung der Empfindungsstärke langsamer vor sich geht, als die Aenderung der Beleuchtungsintensität der Retinaclemente. Bei weiterem Zunehmen der Drehungsgeschwindigkeit erkennt man nicht mehr Sectoren, sondern nur noch ein Flackern. Ist die Geschwindigkeit so weit gesteigert, dass auf jedem Punkte der Retina hell und dunkel etwa 25 Mal in der Secunde mit einander abwechseln, so glaubt man eine ganz gleichmässig helle, schiefergraue Fläche zu sehen. Die Erregungsintensität an jeder Netzhautstelle hat beim Vorübergang eines weissen Sectors nicht mehr die Zeit, zur vollen Höhe anzuwachsen und während des Vorüberganges eines schwarzen, auf Tull zu sinken — so kommt das Flackern zu Stande; schliesslich werden 
die Schwankungen in der Erregungsintensitiit untermerklich und dann sieht man gleichmässig grau. Dic Helligkeit dieses Grau verhält sich zu der Helligkeit der weissen (ruhenden) Sectoren wie der Flächenraum der wcissen Sectoren zum Flächenraum der ganzen Scheilse. Während nun das Auge von einem Wechsel zwischen hell und dunkel, welcher sich 25 Mal in der Secunde vollzieht, keine Kunde giebt, empfinden wir mit der äusseren Haut noch 1500 einzelne Reize in der Secunde als Discontinuitäten in der Erregung.

Lüisst man plötzlich Licht von einiger Stärke auf eine bis dahin unbelichtete Netzhautstelle fallen und darauf in gleicher Stärke verweilen, so nimmt die Empfindungsstärke, nachdem sie etwa in 1/6 Sec. ihr Maximum erreicht hatte, bald beträchtlich ab. Die Netzhaut ist also ermüdbar, auch dieses spricht für die Betheiligung chemischer Processe. Hat man einige Zeit lang eine weisse Scheibe auf dunklem Grunde betrachtet und schiebt man daun plötzlich vor das Objekt eine gleiclmässig weisse Fläche, so glaubt man auf derselben eine dunkle Scheibe von der Grösse der bis dahin betrachteten hellen zu sehen. Das von der weissen Fläche in gleichmässiger Intensität ausgehende Licht kann den durch vorherige andauernde Belichtung ermüdeten Theil der Retina nicht mehr so stark erregen wie den übrigen Theil: die entstehende Sinnestäuschung nennt man ein negatives Nachbild. Sendet die zur Hervorrufung der Ermuidung benutzte Scheibe nicht weisses, sondern farbiges Licht aus, so ist das negative Nachbild complementär gefärbt. Benutzt man zur Beleuchtung der ermüidenden Scheibe eine Mischung von spectralem Grüngelb und spectralem Blau, so erscheint mit der ermïdeten Netzhaut betrachtet, spectrales Roth gesättigter, als wenn man es mit unermüideter Netzhaut betrachtete, man schliesst hieraus, dass das spectrale Roth nicht nur die rothempfindenden Netzhautelemente, sondern auch, freilich in weit schwächerem Maasse, die grün- und die violettempfindenden erregt, wodurch bei unermüdeter Netzhaut die Sättigung der Rothempfindung melır leidet, als wenn die Erregbarkeit der griin- und violettempfindenden Elemente durch Ermüdung herabgesetzt ist.

Hat man mit ausgeruhtem Auge kurze Zeit einen hellen Gegenstand, zum Beispiel eine Lampenglocke angeschaut, so iiberdauert das helle Bild noch kurze Zeit den Schluss des Auges, dann schwindet es, um nach kurzem empfindungslosem Intervall noch einmal in beträchtlicher Helligkeit und mit grosser Deutlichkeit aufzutauchen, man nennt dieses ein positives $\mathrm{Nachbild}$.

Betrachtet man helle Felder auf schwarzem Grunde, so erscheinen ihre Randpartien heller als ihre Mitte, und der schwarze Grund erscheint in der unmittelbaren Umgebung der hellen Felder dunkler, als 
in grösserer Entfernuug. Die Verstärkung von Hell und Dunkel an der Grenze zwischen beiden nennt man einen Contrast, und man stellt sich vor, dāss die Erregbarkeit der einzelnen Netzhautelemente von dem die benachbarten Elemente treffenden Lichte nicht unabhängig sei, dass speciell in der Umgebung unbelichteter Elemente grössere Empfindlichkeit herrsche, als in der Umgebung belichteter. Eine farbige Contrasterscheinung erhält man, wenn man eine weisse, nicht zu helle Scheibe auf farbigem Grunde betrachtet, man sieht die Scheibe nicht weiss, sondern in der Complementärfarbe des Grundes.

Betrachtet man helle, sich mit den Ecken genau berïhrende Quadrate auf dunklem Grunde, so erscheinen die hellen Quadrate vergrössert, sich an den Ecken nicht mehr punktförmig berührend, sondern breiter in einander ïbergehend; die unbelichteten Theile der Retina in unmittelbarer Umgebung der belichteten nehmen also an der Erregung derselben Theil, durch Irradiation, wie man sich ausdrïckt.

Als Maass für die Empfindlichkeit der Netzhaut gegen Licht kann der Schwellenwerth der Empfindung gelten, das heisst die kleinste Lichtintensität, welche eben ausreicht, eine Lichtempfindung zu erzeugen. Dieser Schwellenwerth wird wesentlich beeinflusst durch den Umstand, dass auch die vollkommen unbelichtete Netzhaut nie frei von jeder Erregung ist. In einem vor jedem Lichteinfall geschützten Raume sieht man nicht vollkommen schwarz, sondern einen zeitlich, räumlich und auch in Bezug auf die Farbe beständig wechselnden sehr schwachen Schein, man nennt ihn das Eigenlicht der Retina. Die kleinste wahrnehmbare Intensität äusseren Lichtes ist abhängig von der Grösse der beleuchteten Retinafläche; ein schwach leuchtender Punkt wird noch nicht gemerkt, wenn schon eine kleine Fläche, deren eiuzelne Punkte dieselbe Lichtmenge aussenden, gesehen wird. Auch eine Anzahl, durch dunkle Zwischenräume von einander getrennter, schwach leuchtender Punkte kann gesehen werden, wenn ein einzelner derselben dem Auge geboten, unbemerkt bleibt. In der Nähe der Schwelle ist jede Lichtempfindung, auch wenn sie von einfachem spectralem Licht hervorgerufen wird, farblos. Die richtige Farbe wird erst bei etwas gesteigerter Intensität erkannt und auch hierbei unterstiitzen sich gleichzeitig belichtete Punkte gegenseitig, mag die Belichtung von einer Fläche oder von discreten Punkten ausgehen.

Für den Gebrauch des Auges ist der Schwellenwerth der Lichtempfindung von geringerer Bedeutung, als die Unterschiedsempfindlichkeit der Retina. Wir sind weniger darauf angewiesen den schwächsten Lichtschimmer in vollkommenem Dunkel zu erkennen, als verschieden stark belichtete Theile der Aussenwelt von einander zu unterscheiden. Die Unterschiedsempfindlichkeit der Retina ist am grössten bei mittlerer 
Empfindungsstärke, und die Empfindungsstärke selbst ist nicht nur ahhängig von der Intensitït und Menge des einfallenden Lichtes, sondern in hohem Grade von dem jeweiligen Zustande der Netzhaut. Treten wir aus heller Tagesbeleuchtung in ein mässig rerdunkeltes Zimmer, so können wir in diesem zunächst kaum Gegenstände erkennen; nach einiger Zeit jedoch reicht dic unveränderte Belenchtungsintensität aus, um uns auch feine Details unterscheideu zu lassen, das Auge hat sich fuir dieselben adaptirt; das Ungekehrte findet statt bei der Riickkehr in volle Tagesbeleuchtung, durch welche das Ange zunächst geblendet wird. Im Zustande dieser Blendung ist die Unterschiedsempfindlichkeit so klein wegen eines zu grossen Werthes der Empfindungsstärke.

An der Adaptation des Anges für verschiedene Belenchtungsintensitäten betheiligen sich die Iris und die Netzhant. Die Lichtstärke der Netzhautbilder hängt in leicht ïbersichtlicher Weise von der Weite der Pupille ab und erfahrungsgemäss regelt sich diese nach der Summe der auf beide Augen fallenden Lichtmengen. Bei längerem Aufenthalte im Dunkeln erweitern sich die Pupillen maximal, sodass die Regenbogenhäute nur ganz schmale Sïume um dieselben bilden; es geht dies aus Angenblicksphotographien, die bei Magnesiumblitzlicht gewonnen wnrden, hervor. Bei gewöhnlicher Belenchtung findet man die Pupillenweite gesunder Menschen an beiden Augen gleich; diese Gleichheit der beiderseitigen Pupillenweite zeigt sich, auch wenn man beide Angen verschieden stark beleuchtet. Die Beobachtung der Pupillenändernngen an Anderen und an sich selbst ist dadurch sehr erleichtert, denn man kann das eine Auge zur Beobachtung, das andere zur Aenderung der Beleuchtungsintensität benutzen. Die Aenderungen der Pupillenweite am eigenen Auge beobachtet man am leichtesten und genauesten, wenn man einen leuchtenden Punkt (Reflex eines Quecksilberkügelchens, oder eines blanken Ringes, oder einen Nadelstich in einem Kartenblatt zwischen Lampe und Auge), erheblich diesseits des Nahepunktes betrachtet, man erhält dann einen Zerstreunngskreis, dessen Durclmesser mit der Pupillenweite zu- und abnimmt. Schliesst man während der Betrachtung dieses Zerstreungskreises das andere Ange, so sieht man, wie sich der Zerstreuungskreis ausdehnt, doch wird die nene Gleichgewichtslage erst nach einigen Oscillationen um dieselbe erreicht; das Umgeliehrte tritt, und zwar etwas schneller, bei dem Wiederöffnen des anderen Auges ein.

Bei diesen Beobachtungen erkennt man, dass die Schnelligkeit, mit welcher sich die Pupillenweite ändert, weit grösser ist als diejenige der Anpassung des Auges für das deutliche Sehen bei stark veränderter Beleuchtungsintensität. In der That dient die Irisbewegung auch nicht nur der letzteren, sondern in hervorragender Weise auch dem Schntz des Augengrundes gegen Schädigung durch zu grelles Licht. Dagegen 
liat man an Elementen der Netzhaut selbst, langsam sich abspielende Vorgänge kennen gelernt, welche sich unter dem Einfluss veränderter Beleuchtung vollziehen und welche wohl bedingen können, dass die Netzhaut beim Verweilen im Dunkeln empfindlicher und beim Verweilen im Hellen weniger empfindlich werde. Das Sehroth in den Aussengliedern der Stäbchen findet man nur in sogenannten Dunkel-Augen, das heisst in Augen, welche bis zu ihrer schnell nach der Tödtung erfolgten Präparation vor Lichteinfall geschützt waren. Auch in der präparirten Retina wird das Sehroth sehr schnell durch gemischtes Licht gebleicht, nur in rothem Licht erhält es sich. Die Innenglieder der Zapfen findet man in Dunkel-Augen weit länger und schmäler als in belichteten Augen, es scheint, dass sie sich unter dauernder Lichteinwirkung contrahiren. In der Retina des Dunkel-Auges findet sich das Fuscin des Pigmentepithels um den Kern so angehäuft, dass sowohl die Endflächen der Stäbchenaussenglieder als auch die zwischen den Stäbchen befindlichen Protoplasmafortsätze der Epithelzellen ziemlich frei davon sind. Versucht man an diesen Augen die Netzhaut abzuziehen, so löst sie sich in der Regel von der Schicht der Pigmentzellen, indem deren zwischen die Stäbchen und Zapfen eindringenden Fortsätze herausgezogen werden. In belichteten Augen dagegen findet sich das Fuscin sowohl an der Endfläche der Stäbchen angehäuft, als auch in die Fortsätze zwischen die Aussenglieder, theilweise sogar zwischen die Innenglieder der Stäbchen und Zapfen vorgedrungen; da gleichzeitig die Aussenglieder der Stäbchen geschwollen sind, so liegen sie fester zusammengedrängt zwischen den gefüllteren Pigmentfortsätzen. In Folge dessen haftet die Retina des Hell-Auges fest am Pigmentepithel; zum vollständigen Vordringen des Pigments sollen etwa 10 bis 15 Minuten genügen, zur Rückbildung dagegen anderthalb bis 2 Stunden nöthig sein. Für eine künftige Deutung der Beziehungen dieser objektiven Aenderungen der Netzhaut zu der Adaptation für Hell und Dunkel wird wohl in Betracht kommen, dass eine chemische Wirkung des Fuscins auf die Sehzellen erkannt worden ist: im Licht gebleichtes Sehroth kann nämlich durch Berührtung mit dem Pigmentepithel regenerirt werden.

Die Unterschiedsempfindlichkeit für Licht ist bei gewöhnlicher Beleuchtung im Netzhautcentrum am grössten und nimmt nach der Peripherie zu ziemlich schnell ab. Bei stark herabgesetzter Beleuchtung hat man aber bisher die Unterschiedsempfindlichkeit in der Umgebung der Macula lutea grösser gefunden, als in der Fovea centralis, vermuthlich, weil sich an letzterer Stelle die Adaptation für das Dunkel langsamer vollzieht.

Das Gebiet der $\Lambda$ ussenwelt, von welchem jedes Auge, ohne dass es Bewegungen ausfiihrt, Gesichtseindruicke erhalten kann, heisst sein Ge- 
sichtsfeld; innerhall, desselben findet sich cine Stelle, welche vicht gesehen wird, fïr welche das Auge blind ist. Einen ummittelbaren Eindruck von dieser Thatsache erhält man, wenn man ron den beiden schwarzen Feldern das linke mit dem rechten Auge bei verschlossenem
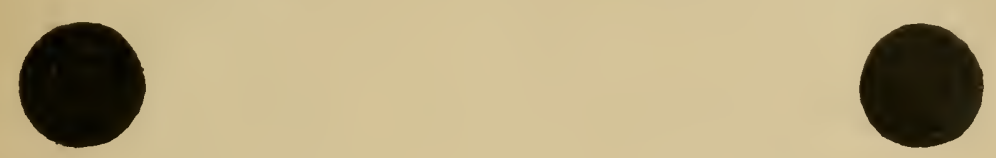

linken Ange aus der Entfernung, in weleher das Buch bei dem Lesen gehalten wird ( 4 facher Abstand der Felder) betrachtet; dasselbe gilt für das linke Auge und den rechten Punkt. In ersteren Falle sieht man, wenn der linke Punkt deutlich erscheint, nach rechts die weisse Fläche des Papiers ununterbrochen, es ist als ob die rechte schwarze Scheibe nicht vorhanden wäre; letatere erscheint jedoch sofort bei einer kleinen Augenbewegung in irgend welcher Richtung; es muss sich also um eine circumscripte Stelle der Netzhant handeln, welche entweder kein Bild ron der Anssenwelt erhält oder für letzteres nicht empfindlich ist. $\mathrm{Zu}$ ersterer Annahme liegt kein Grund vor, dagegen führt die Construction der Abbildung des rechten Punktes im linken Auge bei Betrachtung des linken Punktes, auf die Eintrittsstelle des Sehnerven in den Augapfel, wo in der Papilla nervi optici die Netzhaut in ihrer ganzen Dicke nur ron Nervenfasern gebildet ist und alle ïbrigen Elemente derselben fehlen. Diese Stelle der Netzhaut nennt man ihren blinden Fleck. Dass wir uns des Vorhandenseins desselben bei dem gewöhnlichen Gebrauch der Augen nicht bewusst werden, liegt daran, dass im Bewusstsein die dem blinden Fleck entsprechende Stelle der Aussenwelt durch, der Umgebung gleichende Eindrïcke ausgefüllt erscheint: so erscheint in unserem Falle das geschwärzte Papier so weiss wie die Umgebung, und wenn wir weisse Scheiben anf schwarzem Grund betrachten, so erscheint das Schwarz an der Stelle des blinden Fleckes durch kein Weiss unterbrochen zu sein. Also auch Stellen der Aussenwelt, welehe erhebliche Mengen Licht aussenden, erzeugen, wenn ihr Bild auf die Papilla nerri optici fällt, keine Lichtempfindung, und wir haben daraus zu sehliessen, dass die Sehnervenfasern selbst unempfindlich für Licht sind. Ausserhalb des blinden Fleckes sind alle Stellen der Netzhaut, welche ïberhaupt von einfallendem Licht getroffen werden, lichtempfindlich, wenn auch in verschiedenem Grade.

Die Lichtempfindungen, welche die einzelnen Stellen der Retina rermitteln, können unter sich rerschieden sein nach Helligkeit, Farbenton und Sättigung. Wenn die Lichtempfindungen, welche zwei rerschiedene Netzhautstellen vermitteln, in diesen Beziehungen gleich sind, so unter- 
scheiden sie sich doch noch von einander und zwar durch ihre Beziehungen zum Raume; man nennt diesen Unterschied denjenigen des Localzeichens und man sagt, dass die von jeder Netzhautstelle vermittelte Empfindung mit einem besonderen Localzeichen behaftet sei.

Jeder Punkt der Retina erhält Licht von einem Objektpunkt, welcher ausserhalb des Auges, auf der Verbindungslinie des Netzhautpunktes mit dem reducirten Knotenpunkt gelegen ist. Nehmen wir vier, nahe dem Netzhautcentrum symmetrisch zu demselben gelegene Punkte in unserer Netzhaut an, a oben, b unten, c links, d rechts, so erhält a von einem Objektpunkt unterhalb der verlängerten Augenaxe und c ron einem solchen rechts derselben Licht. Den oberen von zwei Punkten nennen wir einen solchen, zu dessen Berührung wir den tastenden Finger der Schwerkraft entgegen weiter bewegen miissen. Um von zwei Punkten den einen als den weiter rechts gelegenen zu erkennen, genügt die Erfahrung, dass wir den rechten Arm, um ihn zu berühren, weiter von der Medianebene entfernen müssen. Da Punkte, welche durch das Getast als oben erkannt werden, auf der Netzhaut stets unten abgebildet werden, so verbindet sich mit den, von dem unteren Theil der Netzhaut gelieferten Gesichtseindrücken die Vorstellung von oben u. s. w. Dies gilt natürlich nicht nur für die obere und untere, rechte und linke Hälfte der Netzhaut, sondern auch für alle beliebig gegen einander orientirten Punkte derselben, deren zugehörige Empfindungen auf diese Weise ganz bestimmte räumliche Beziehungen zu einander in der Vorstellung erhalten, welche man eben Localzeichen nennt.

Lassen wir in der Vorstellung zwei der betrachteten Netzhautpunkte sich mehr und mehr einander nähern, so wird es einen Abstand geben, bei welchem sie eben noch durch das Localzeichen unterschieden, das heisst als getrennte Punkte wahrgenommen werden können. Zieht man bei dieser Lage der Punkte von jedem derselben eine gerade Linie durch den reducirten Knotenpunkt, so grenzt die Verlängerung dieser Linie in der Aussenwelt ein Gebiet ab, innerhalb dessen das Auge Einzelheiten nicht mehr zu sondern vermag: den Winkel, welchen die beiden Linien mit einander bilden, nennt man den kleinsten Gesichtswinkel. Man hat denselben dadurch empirisch zu ermitteln gesucht, dass man ein System äquidistanter punktförmiger Sehzeichen allmählich so weit von dem Auge entfernte, bis sie eben noch als ein System getrennter Punkte erkannt werden konnten: aus der so ermittelten Entfernung vom Auge und aus dem gegenseitigen Abstand der Punkte berechnet sich der kleinste Gesichtswinkel, er beträgt etwa eine Winkelminute. Die Distanz zweier Punkte auf der Retina, deren Verbindungslinien mit dem Knotenpunkt des Auges eine Winkelminute einschliessen, stehen etwa um eine Zapfenbreite ron einander ab; die einfachste Deutung der Erfahrung wäre also 
die, dass wir zwei Punkte gesondert ron einander wahrnehmen können, wenn zwischen ihren Bildern auf rler Retina wenigstens ein, nicht ron Licht getroffener Zapfen liegt.

Dass die Zapfen für das deutliche Sehen von besonderer Wichtigkeit sind, geht daraus herror, dass die Retina in der Netzhautgrube, abgesehen ron Pigmentepithel, auf sie reducirt ist. Dass sich mit der Erregung einzelner Zapfen die Erregung einzelner Nervenfasern des Nerrus opticus rerbinden kann, ist durch die Zergliederung des Aufbanes der Retinaschichten, wenn auch nicht bewiesen, so doeh sehr wahrscheinlich gemacht. Allerdings ist die Zahl der Zapfen in der gesammten Retina ein Vielfaches der Zahl der Nervenfasern im Nervus opticus, doch steht Nichts der Annahme im Wege, dass innerhalb des Gebietes des deutlichsten Sehens jedem Zapfen eine besondere Faser des Nerrus opticus entspreche, nach der Peripherie der Netzhaut hin jedoch zu einer einzelnen Nervenfaser eine immer grössere Zahl der hier ohnedies zerstreuter stehenden Zapfen zugeordnet sei. Denken wir uns das einzelne Localzeichen als einen Theil der speeifischen Energie an die einzelne Opticusfaser gekniipft, so wïrde durch die gemachte Annahme der Verschiedenheit des kleinsten Gesichtswinkels in Centrum und in der Peripherie der Netzhaut Rechnung getragen werden. Erweitern wir die gemachte Aunahme noch dahin, dass die zu versehiedenen Optieusfasern gehörigen Zapfengruppen in der Peripherie nicht getrennt, sondern in einander ïbergreifend liegen, so wird noch ein anderer wesentlicher Untersehied der Netzhautleistungen im Centrum und in der Peripherie erklïrlich. Die Peripherie, welche uns sehr wenig deutliche Bilder liefert, ist in höherem Grade geeignet als das Centrum, die Anfmerksamkeit Bewegungserscheinungen zuzulenken. Hierzu ist nur erforderlich, dass ein sich ïber die Peripherie der Netzhaut bewegender Bildpunkt oder Zerstreuungskreis schnell hinter einander Gebiete mit verschiedenen Localzeichen passirt.

Wemn schon die Thatsache, dass die Retina an der Stelle des deutlichsten Sehens in der Netzhautgrube auf ihre äussersten Schichten reducirt ist, dafür spricht, dass hier die eigentliche Lichtempfindlichkeit, das heisst die Fähigkeit zur Umwandlung von Licht in Erregung lebender Substanz zu suchen ist, so haben wir dafür noch andere Beweise. Die Unempfindlichkeit der Nerrenfasernsehicht für Licht geht daraus hervor, dass die Papilla nervi optici, welehe nur Nervenfasern enthält, blind ist. Ferner sind für die vorliegende Frage die Bedingungen von Bedeutung, unter denen man die Netzhantgefässe dem eigenen Auge sichtbar machen kann. Stellt man sich mit einer brennenden Kerze an das Ende eines dunklen Ganges, sehliesst das eine Auge, starrt mit dem anderen in das Dunkele und bewegt die Kerze in einigem Abstand rom 
Auge auf kreisförmigen Bahnen um die Augenaxe, so taucht auf matt metall-glänzendem Grunde eine imposante und in ihren Einzelnheiten doch zierliche baumartige Figur auf, welche sich bewegt, so lange man das Licht bewegt, still steht und dann rerschwindet, wenn man das Licht still hält, sofort wieder auftaucht, sobald das Licht wie vorher bewegt wird. Wem die charakteristische Form der Verzweigungen der Arteria centralis retinae aus anatomischen Injectionspräparaten bekannt ist, erkennt diese sofort mit aller Sicherheit wieder, es kann sich bei dem Phänomen also nur um die Wahrnehmung des Schattens der Retinagefässe auf der lichtempfindlichen Schicht handeIn. Der Richtungsstrahl des von der Kerze ausgehenden Lichtes bildet einen beträchtlichen Winkel mit der Augenaxe und es entsteht, der schiefen Incidenz entsprechend, ein unvollkommenes Bild des Lichtes auf der Peripherie der Netzhaut. Die ron dem Bilde eingenommene peripherische Netzhautstelle wird diffuse leuchtend und dadurch geeignet, von undurchsichtigen Körpern Schatten zu entwerfen, welche natürlich auf der dem Lichte abgewendeten Seite der Körper liegen müssen. Die stärkeren Retinalgefässe liegen in der Nervenfasernschicht, ron wo sich die Capillaren bis in die innere Körnerschicht, aber nicht über die äussere reticuläre Schicht hinaus erstrecken; bei Versuchen, in denen die Winkelverschiebungen der Lichtquelle und die dazu gehörigen des Schattenbildes eines gröberen Gefässastes bestimmt wurden, haben sich Werthe ergeben, aus denen man folgern muss, dass die Wahrnehmung des Schattens durch die äussersten Schichten der Retina vermittelt wird.

Hiernach können als lichtempfindlich nur in Betracht kommen die Stäbchen und Zapfen oder das Pigmentepithel. In jeder dieser drei Arten histologischer Elemente sind auch Veränderungen erkannt worden, welche durch das Licht erzeugt werden: Bleichen des Sehrothes in den Aussengliedern der Stäbchen, Contraction der Innenglieder der Zapfen und Wanderung des Fuscins in dem Pigmentepithel. Eine unmittelbare Betheiligung an dem Sehacte kann der Bleichung des Sehrothes durch Licht und seiner Regeneration unter der Betheiligung des Fuscins nicht zukommen, denn nur Stäbchen haben Sehroth und nicht Zapfen, welche ausschliesslich in der Fovea centralis vorhanden sind. Immerhin sind alle Erfahrungen, welche sich an das Sehroth knïpfen, von grossem Weith, weil sie die Thatsache chemischer Wirkung des Lichtes im Auge beweisen und die Annahme rechtfertigen, dass es hier noch andere, vielleicht für das Sehen wesentlichere chemische Lichtwirkungen giebt, welche nur objektiv nicht so leicht nachweisbar sind.

Die Contraction der Innenglieder der Zapfen kann eine Theil- oder Begleiterscheinung der wesentlichen Processe des Sehaktes sein. Nach dem Grundsatz "Lux non agit nisi absorpta" hat man Bedenken 
getragen, der allerdings sehr durchsichtigen Zapfensubstanz die Fähigkeit zuzuschreiben, Licht in eine andere Energieform überzufïhren, um so mehr, als das unmittelbar benachbarte Fuscin wegen seines hohen Absorptionsrermögens für Licht hierfïr sehr geeignet erscheint. Dass dem Fuscin nicht einfach eine Rolle wie dem zur Schwärzung der Innenwand eines Mikroskoptubus benutzten Farbstoffe rukommt, ist auch wegen seiner Beziehungen zum Sehroth wahrscheinlich. Schwierigkeiten fuir die Annahme, dass das im Fuscin absorbirte Licht den dèr Lichtempfiudung dienenden Process auslösen solle, hat man darin zu erkennen geglaubt, dass eine protoplasmatische Continuität zwischen Pigmentepithel und Opticusfasern weder nachgewiesen noch entwickelungsgeschichtlich wahrscheinlich ist und darin, dass der Durchmesser jeder Pigmentzelle mehreren Zapfendurchmessern entspricht. Nach den Frfahrungen über die Grösse des kleinsten Gesichtswinkels kann die einzelne Pigmentzelle nicht Glied eines Sehelementes sein, denn sie bedeckt eine Retinatläche, innerhalb deren mehrere getrennte Gesichtswahrnehmungen möglich sind. Immerhin wäre es möglich, dass bei dem auf einen kleinen Theil einer Pigmentepithelzelle beschränkten Lichteinfall nicht die ganze Zelle, sondern nur der rom Licht unmittelbar getroffene fuscinhaltige Theil in Mitleidenschaft gezogen würde, derart zum Beispiel, dass das im Fuscin absorbirte Licht in dem unmittelbar benachbarten Protoplasma einen chemischen Process auslöste, dessen Produkt erregend auf den damit in Berïhrung stehenden Zapfen wirkte. Die Möglichkeit, dass das im Fuscin absorbirte Licht dem Sehen diene, kam also nicht ron der Hand gewiesen werden; andererseits darf man nicht vergessen, dass unsere Erfahrungen ïber die Durchsichtigkeit der Zapfen nur an sehr diinnen Schichten der Zapfensubstanz gewonnen sind, dass letztere gewiss Licht, wenn auch in kleiner Menge, absorbirt, und dass der Kleinheit der absorbirten Lichtmenge eine grosse Empfindlichkeit der chemischen Structur fiir Licht gegeniiber stehen könnte.

Den Stäbchen wïrde nach den bisher rorgetragenen Ansichten kein Antheil an der Erzengung ron Gesichtswahrnehmungen zukommen und doch haben wir keinen Grund, nur den Zapfen und nicht auch den Stäbchen Erregbarkeit dureh Licht einerseits und protoplasmatische Verbindung mit Opticusfasern andererseits zuzuschreiben. Nan muss aber beachten, dass die Retina auch unbewusste Reactionen anf Licht rermittelt, ron denen die reflectorische Aenderung der Pupillenweite gewiss nur ein Beispiel ist.

Ton dem kleinsten Gesichtswinkel und ron der Unterschiedsempfindlichkeit für Licht hängt hauptsächlich der Grarl der Befähigung ab, die Aussenwelt optisch zu zergliedern; den Grad dieser Fähigkeit nennt man, insofern er von den Eigenschaften der Retina abhängt und unab- 
hängig ron dem Accommodationsvermögen ist, die Sehschärfe. Als normale Sehschärfe bezeichnet man die Fähigkeit, eine gewisse Form von Druckschrift oder andere Zusammenstellungen von senkrechten und wagerechten Strichen schwarz auf weissem Grunde zu erkennen, wenn ihre Lïnge unter einem Gesichtswinkel von 5 Winkelminuten erscheint. Will man zwei Augen in Bezug auf ihre Sehschärfe vergleichen, so muss man dafür sorgen, dass in beiden von dem Sehzeichen gleich gute Bilder entstehen können und zwar, wenn dies bei der gewählten Entfernung des Selizeichens durch Accommodation nicht zu erreichen ist, durch Unterstiitzung mit passenden Brillengläsern. Die conventionell gewählte Einheit der Sehschärfe ist ïbrigens kleiner, als man sie in vielen normalen Augen trifft.

Die Sehschärfe ist, wie aus den obigen Angaben ïber Unterschiedsempfindlichkeit und kleinsten Gesichtswinkel folgt, am grössten im Netzhautcentrum und nimmt von da nach der Peripherie schnell ab, sie hängt ausserdem in hohem Grade von der Beleuchtungsintensität und von der Adaptation des Auges für diese Beleuchtung ab.

Bis jetzt haben wir nur Gesichtseindrïcke in Betracht gezogen, welche uns das einzelne feststehend gedachte Auge liefern kann, für gewöhnlich sehen wir aber mit beiden Augen, welche noch dazu mannigfaltiger Bewegungen in und mit der Orbita fähig sind. Bleiben wir zunächst noch bei den dem Sehen mit einem Auge dienenden Bewegungen stehen, so tritt uns als die bemerkenswertheste Erscheinung der Zwang entgegen, mit welchem wir das Ange so richten, dass die uns gerade am meisten interessirende Stelle der Aussenwelt anf das Gebiet des deutlichsten Sehens fällt. Dieser Zwang ist so mächtig, dass starker Wille und viel Uebung dazu gehört, gute Beobachtungen ïber das Sehen mit den peripherischen Theilen der Netzhant, über das sogenannte indirekte Sehen, anzustellen. Für gewöhnlich dient das indirekte Sehen nur dazu, uns gröblich im Raume zu orientiren und uns auf Erscheinungen aufmerksam zu machen, welche uns mehr interessiren könnten, als der gerade fixirte Theil der Aussenwelt. Da bewegte Körper am schnellsten unser Interesse herausfordern und von uns ein schleuniges, auf richtiger optischer Erkenntniss gegriundetes zweckmässiges Handeln erheischen, so erscheint die hervorragende Eindrucksfähigkeit der Netzhantperipherie für Bewegungen sehr zweckmässig.

Wie klein das Gebiet ist, innerhalb dessen wir beim unbewegten Auge deutlich sehen, erkennt man, wenn man ein Buch wie zum gewöhnlichen Lesen vor sich nimmt, dasselhe mit einem weissen Blatt bedeckt und dieses für kurze Zeit wegzieht und wieler vorschiebt; die Zahl rer in dieser nur zu einmaligem Fixiren ausreichenden Zeit er- 
kannten Buchstaben ist nur klein; lïsst man mehr Zeit rergehen, so wächst zwar die Zahl der Buchstahen, aher man merkt auch bei scharfer Selbstbeobachtung, dass das Auge bewegt wurde. Bei dem gewöhnlichen Lesen lassen wir den Fixationspunkt durch Augenbewegung beständig die Zeilen entlang laufen. Die Schätzung der Ausdehnung successive in gleicher Entfernung einem Ange gebotener Sehzeichen, zum Beispiel geruler Linien, beruht zum Theil auf der Verschiedenheit. der Zahl der beim ruhenden Ange von dem Bild jedes Sehzeichens bedeckten Sehclemente und ausserdem auf dem Umfange der Bewegung, welche erforderlich ist, um den Fixationspunkt von einem Ende jeder Linie zum anderen zu führen. Die Feinheit der Tasthewegungen des Anges scheint bis zu einem sehr hohen Grade entwickelt werden zu können: intelligente Individuen wilder Volksstämme haben Sehzeichen unter einem Gesichtswinkel erkannt, dessen Basis auf der Retina beträchtlich kleiner ist, als der mittlere Durchmesser eines Zapfens in der Fovea centralis. Entweder besassen diese Individuen in der That schmälere Zapfen, als die bisher anatomisch daranf untersuchten Angen, in welchem Falle sie auch Punktsysteme unter entsprechend kleinerem Gesichtswinkel hätten auflösen müssen, was nicht untersucht werden konnte, oder es kommen iiberhaupt schmälere Zapfen an einer noch merkannten berorzugten Stelle der Fovea centralis vor, deren Vorziige nur bei besonderer Uebung im Tasten ausgenutzt werden können.

Ziehen wir die Thatsache in Betracht, dass wir für gewöhnlich mit beiden Augen sehen, so verdient in erster Linic die fernere Thatsache unsere Anfmerksamkeit, dass wir beim Sehen mit beiden Angen die einz.clnen Dinge der Anssenwelt einzeln sehen und nicht doppelt. Doppelbilder treten beim binocularen Sehen anf, wenn einzehe Augenmuskeln gelähmt sind, die Vermeidung der doppelten Wahrnelmung der doppelt alggebildeten Aussenwelt muss also auf der richtigen Thätigkeit der Augenmuskeln beruhen. Anch bei gesunden Angenmuskeln können wir uns leicht binoculare Doppelbilder verschaffen: halten wir zum Beispiel eine Stecknadel in der Medianebene etwas ansserhalh unseres Nahepunktes und eine zweite einige Centimeter gerade dahinter, so können wir bei wechselnder Richtung der Aufmerksamkeit anf die nähere oder die fernere Nadel die andere doppelt erscheinen lassen. Beobachten wir die Augen eines auf diese Weise Experimentirenden, so bemerken wir, dass, wenn er uns angiebt, er sehe die nähere Nadel einfach, die andere doppelt, seine Hornhautpole der Nedianebene mehr genähert sind, als in dem entgegengesetzten Falle. Der Punkt, welchem sich unsere Aufmerksamkeit zuwendet, wird bei dem Sehen mit jedem einzelnen Auge durch passende Bewegung des Augapfels in die Augenaxe gebracht. Beim binocularen Sehen müssen sich also die Augenaxen in dem 
aufmerksam betrachteten Punkte schneiden, und wenn dieser Punkt näher gelegen ist, müssen die beiderseitigen Augenaxen einen grösseren Winkel einschliesșen, sie müssen stärker convergiren; die Hornhautpole sind dabei der Medianebene stärker genähert.

Aus dem Vorhergehenden können wir schliessen, dass jeder Punkt der Aussenwelt, welcher gleichzeitig auf beiden Netzhautcentren zur Abbildung gelangt, einfach gesehen wird; correspondirende Punkte beider Netzhäute, welche diese Eigenschaft mit den Netzhautcentren theilen, nennt man identische Punkte derselben. Die identischen Punkte beider Netzhäute liegen im Allgemeinen symmetrisch zum Netzhautcentrum.

Betrachtet man mit beiden Augen einen körperlichen Gegenstand, zum Beispiel einen Finger in deutlicher Sehweite, so fallen im Allgemeinen die beiderseitigen Bildpunkte nicht genau auf identische Stellen der Netzhäute, und doch erscheint uns der Gegenstand einfach, wobei das Urtheil durch mannigfache Nebenumstände, die Continuität der Färbung, Schattirung und so weiter mitbestimmt wird. Das Resultat des complicirten psychophysischen Vorganges ist der Eindruck der Körperlichkeit, das heisst der Ausdehnung des Gegenstandes nach drei Richtungen des Raumes. Der Eindruck des Körperlichen wird wesentlich unterstützt durch die, übrigens schon durch monoculares Sehen zu beurtheilende Vertheilung von Licht und Schatten an dem Gegenstande in ihrer Bezichung zur Richtung des einfallenden Lichtes. Köörper mit vorwiegend verticaler Ausdehnung und horizontaler Beleuchtungsrichtung sind hierbei im binocularen Sehen bevorzugt, weil in dem einen Auge ein grösserer Theil der schattigen, in dem anderen ein grösserer Theil der belichteten Seite zur Abbildung kommt. Diese Differenz nimmt bei Annäherung des Gegenstandes zu, bei Entfernung ab und trägt dadurch wesentlich dazu bei, die Urtheilsbildung über den Abstand des Gegenstandes rom Auge beim binocularen Sehen gegeniiber dem monocularen Sehen zu verschärfen. Wesentlich unterstützt wird dieses Urtheil dadurch, dass wir beim Fixiren eines näheren Gegenstandes die Augenaxen zu stärkerer Convergenz bringen, und dass wir, um den näheren Gegenstand deutlich zu sehen, die Accommodation stïrker anspannen miissen. Die unmittelbare Empfindung der erforderlichen Convergenzund Accommodationsanstrengung beeinflusst in hohem Grade die Schätzung der Entfernung. Bei den grösseren Entfernungen, wo die bisher genannten Factoren an Wirksamkeit verlieren, unterstiitat uns die Abtönung, welche die Gegenstände in Helligkeit und Farbe durch die verschiedene Dicke dazwischen gelegener Luftschichten erleirlen.

Sehen wir eine lange Reihe gleichartiger Gegenstïnde, von denen wir schon wissen, dass sie gleich gross sind, so nehmen wir die unter kleinerem Gesichtswinkel erscheinenden schon aus diesem Grunde für 
die entfernteren; in der weitaus grössten Zahl von Fällen wird aloer der Grösse des Gesichtswinkels nicht das Urtheil ziher die Entfernung des Gegenstandes entlehnt, sondern wir sind im Gegentheil darauf angewiesen, uns auf die oben angegebene Weise ein Urtheil iiber die Entfernung zu bilden, und erst dieses Urtheil setzt uns in den Stand, aus der Grösse des Gesichtswinkels anf die Grösse des Gegenstandes zu schliessen.

Die Mannigfaltigkeit der Bewegungsmöglichkeiten jerles. Augapfels für sich und die der gleichzeitigen Bewegnngen beider Augüpfel sollte man auf Grund der anatomischen Verluältnisse, von rein mechanischem Gesichtspunkte aus für sehr gross halten; der annähernd kugelige Augapfel liegt in das weiche Fettpolster der geräumigen Orbita eingebettet, seine Muskehn haben ilure beweglichen Insertionspunkte, die geraden an der vorderen, die schiefen an der hinteren Augenhalbkugel, und ilure festen, theils an der hinteren, theils an der vorderen und seitlichen Wand der Orbita. Man sollte also meinen, dass der Augapfel sowohl im Ganzen nach hinten und vorn, nach rechts und links geschoben und um eine grosse Zahl verschieden gerichteter Drehaxen gedreht werden und diss jede dieser Bewegungen des einen Augapfels unabhängig von denen des anderen ausgeführt werden könnte. Kraft centraler Coordinationseinrichtungen erfolgt aber die Erregung der an den Augenbewegungen betheiligten Muskeln stets in Verhäiltnissen der Intensitiit, welche nicht willkürlich geändert werden können, sodass die Zalıl der thatsächlich ausführbaren einzelnen und combinirten Augenbewegungen weit hinter der Zahl der mechanisch möglichen zurüickbleibt.

Die auffallendsten Erseheinungen bei abnormen Zuständen in den Centren für die Augenbewegungen sind Augenstellungen und Bewegungen, welche andeuten, um wie viel grösser die Zahl der mechtanisch möglichen im Verhältniss zu den normaler Weise vorkommenden Bewegungen ist; es handelt sich nicht nur um Missverhältnisse zwischen den beiden Seiten, sondern auch um zuckende Bewegungen der einzelnen Augen, wie sie so deutlich objectiv wahrnehmbar unter normalen V'erhältnissen nie vorkommen und bei denen auch die Iris radartig gedreht wird.

Erfahrungsgemäss können wir alle Verschiebungen des Augapfels im Ganzen ausser Betracht lassen, es bleiben somit nur Bewegungen iibrig, welche als Drehungen um einen im Augapfel und in der Orljita festliegenden Drehpunkt erfolgen. Derselbe liegt ungefähr in der Mitte des Augapfels und in ihm schneiden sich alle Drehaxen, um welche sich der Augapfel thatsiichlich bei seinen Bewegungen dreht; im Verlaufe der Bewegungen ïndert sich oft die Richtung der Drehaxe. Wenn man sich jedoch zunächst nur über die thatsächlich vorkommenden Augenstellungen verständigen will, so thut mim gut, von den in den einzelnen Fällen von Augenbewegungen thatsächlich benutzten Dreh- 
axen zu abstrahiren und jede Augenstellung als hervorgegangen zu betrachten aus einer bestimmten Anfangsstellung durch successive Drelung um $^{-}$drei zu einander senkrechte Drehaxen. Als eine dieser ideellen Drehaxen wählt man zweckmässiger Weise die optische Axe jedes Augapfels; diese beiderseitigen Angenaxen denkt man sich bei aufrechter Kopfhaltung horizontal einander parallel und gerade nach vorn gerichtet; das zweite Paar von ideellen Drehaxen nimmt man so an, dass es bei der beschriebenen Kopfhaltung und Augenrichtung vertical steht, und das dritte transversal. Die Richtungen der optischen Augenaxen nennt man die Blicklinien und die Ebene, welche die den beiden Augen gemeinschaftliche transversale Drehaxe sowie die Blicklinien enthält, die Blickebene. Durch Drehung der Augen um die transversale Axe wird die Blickebene gehoben und gesenkt, durch Drehung um die zur Blickebene verticalen Axen werden die Blicklinien in der Blickebene nach rechts oder nach links gedreht. Bei allen Hebungen und Senkungen der Blicklinien bleiben dieselben in der Blickebene, das heisst, man kann die Blicklinie des einen Auges nur gerade so viel senken oder heben, wie es gleichzeitig mit der anderen geschieht. Innerhalb der horizontalen, gehobenen oder gesenkten Blickebene können die Blicklinien parallel sein oder verschieden stark convergiren; der Convergenzpunkt kann in der Medianebene oder rechts oder links von derselben liegen.

Um alle Augenbewegungen zu definiren, muss man noch die Drehungen um die zu den beiden vorigen senkrechte, zuerst genannte Axe in Betracht ziehen; diese liegt in der Blicklinie selbst. Die Drehungen des Augapfels um diese Axe nennt man Rollungen, bei ihnen wird eine die Cornea in der Anfangsstellung des Auges halbirende Horizontallinie temporal gehoben und nasal gesenkt oder umgekehrt. Jede Richtung der Blicklinie könnte mit einer grossen Zahl von Rollungsgraden des Augapfels combinirt werden. Dieses geschieht jedoch thatsächlich nicht, sondern mit jeder Richtung der Blicklinie verbindet sich erfahrungsgemäss stets eine bestimmte Rollung des Augapfels. Für jedes Auge giebt es zwei zu einander senkrechte Ebenen, innerhalb deren die Blicklinie geführt werden kann, ohne dass Rollung des Augapfels eintritt; die Stellung des Augapfels, bei welcher die Blicklinie mit der Schnittlinie dieser beiden Ebenen zusammenfällt, nennt man die Primärstellung des Auges, dieselbe deckt sich nahezu mit der Anfangsstellung, von welcher wir bei der Beschreibung der Augenbewegungen ausgingen. Für jeden Menschen gielst es eine bestimmte, durch den Versuch zu ermittelnde Erhebung des Kopfes, bei welcher die horizontal, parallel und gerade nach rorn gerichteten Blicklinien in der Primärstellung stehen. Diese Primärstellung ist vorhanden, wenn bei Hebungen und Senkungen der 
Blicklinie in der die primä̈re Blickrichtung enthaltenden Verticulebene und bei Wendungen in der die primïre IBlickrichtuug enthaltenden Horizontalebene keine Rollung des Augipfels eintritt. Aus der Primärstellung wird also die Blicklinie ohne Rollung längs eines Krenzes mit horizontalem und verticalem Schenkel entlang geführt, während jedem Richtungspunkt innerhalb der durch das Kreuz getrennten Quadranten eine Rollung in bestimmtem Sinne und ron bestimmter Grösse entspricht. In Bezug auf' den Sinn der Rollung lässt sich die hier herrschende Gesetzmässigkeit leicht ausdrücken, wenn man den Hebungswinkel 11, den Wendungswinkel W, den Rollungswinkel R nennt und für dis Vorzeichen dieser Winkel bestimmte Festsetzungen trifft. Der Hlebungswinkel H sei positiv bei Erhebungen der Blickebene, und der Wendungswinkel IV positiv bei Wendungen der Blicklinie atus der Primärlage nach links. Ein positiver Werth ron R soll bedeuten, dass die in der Primärlage horizontale Halbirungslinie der Cornea rechts sich neigt. Bezieht man, wie wir es gethan haben, die Winkel $\mathrm{H}, \mathrm{W}$ und $\mathrm{R}$ auf die Primärstellung, so gilt der Satz, dass $R$ einerlei Vorzeichen hat mit dem Produkt von H und IV, und dass R Null ist, wenn das Produkt von H und IV Null ist. Nemnen wir die Durchschnittslinie der Blickebene in der Primïrstellung mit der Netzlıaut den Netzhauthorizont, so bleibt also dieser Netzhauthorizont bei allen Bewegungen der Blicklinie längs des vorhin definirten Kreuzes horizontal. Er neigt sich mit seiner rechten Seite unter die Blickebene bei Richtung der Blicklinie auf einen Punkt des linken oberen oder rechten unteren Quadranten und er erhebt sich mit seiner rechten Seite über die Blickebene bei Richtungen der Blicklinie auf Punkte im rechten oberen oder linken unteren Quadranten. Wit einem, fuir nicht zu umfangreiche Angenbewegungen ansreichenden Grade ron Genauigkeit gilt auch der Satz, dass die Orientirung des Netzhauthorizontes bei jeder Blickrichtung derart ist, als weun der Augapfel aus der Primärstellung in die neue Stellung gebracht wäre durch Drehung um eine Axe, welche man erhält, wenn man durch die Blicklinie in der primären und in der Endstellung eine Ebene legt und zu dieser eine verticale in der Aequatorialebene des Anges errichtet. Es geht hieraus hervor, dass nicht nur der Sinn, sondern auch der Grad der Drehung des Netzhauthorizontes fuir jede Blickrichtung eindeutig bestimmt ist.

Da der Blick aus jeder beliebigen Anfangsrichtung ohne Durchgang durch die Primärstellung des Auges in jede beliebige andere Richtung iibergeführt werden kann, und zwar auf mannigfaltigen Wegen, so weicht die thatsächliche Richtung der Drehaxe im Allgemeinen von der der vorstehenden Betrachtung zu Grunde gelegten ilb, ja im Allgemeinen wechselt während der Aenderung der Blickrichtung die Richtung der Drehaxe, nur der Drehpunkt bleibt constant. Bei dieser Freiheit in den 
Aenderungen der Blickrichtung ist es nun von grosser Wichtigkeit, dass zu jeder Blickrichtung, auf welchem Wege sie auch immer erreicht sein möge, stets ein und dieselbe bestimmte Orientirung des Netzhauthorizontes gehört. Ohne diese Gebundenheit gäbe es keine feste Beziehung zwischen den einzelnen Netzhautpunkten und einer festen (etwa horizontalen) Orientirungslinie der Aussenwelt, und ohne eine solche Beziehung wäre eine geordnete räımliche Anschauung nicht denkbar.

Der Bewegungsapparat, welcher dem Auge diejenigen Stellungen ertheilt, die nach den vorstehenden Sätzen thatsächlich vorkommen, besteht bekanntlich aus sechs Muskeln. Ihre Zugrichtungen sind in Fig. 36 im Grundriss dargestellt. Durch punktirte Linien mit entsprechenden Bezeichnungen sind die Axen angedeutet, um welche die Muskeln, einzeln

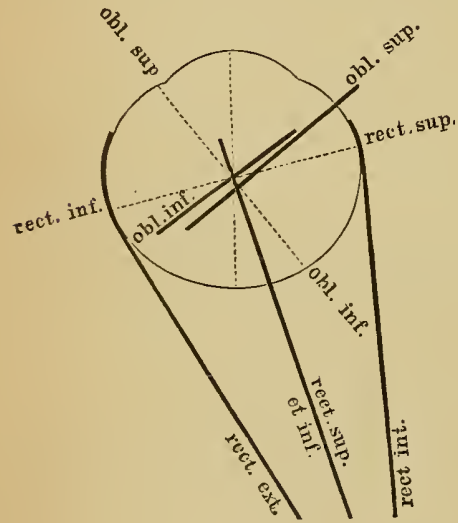

36.

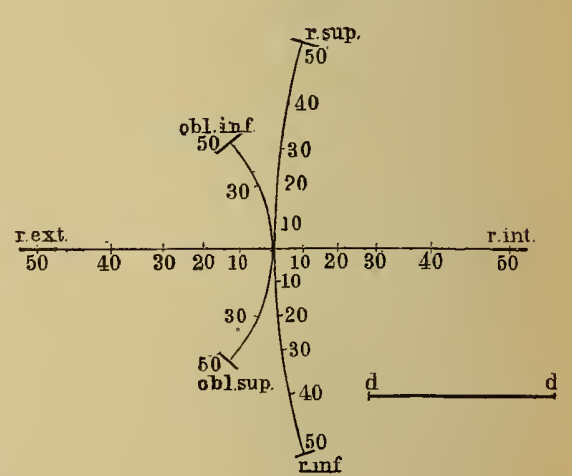

37.

wirkend gedacht, das Auge drehen würden. Nur die Axe des Rectus externus und Rectus internus konnte nicht angegeben werden, da sie im Mittelpunkt senkrecht zur Ebene der Zeichnung steht. Man sieht, dass die Muskeln paarweise fast genau Antagonisten sind, nämlich der Rectus externus und internus, der Rectus superior und inferior, der Obliquus superior und inferior.

Fig. 37 giebt eine Anschanung davon, welche Bahnen der Blickpunkt auf einer zur Primärlage der Blickrichtung senkrechten Ebene beschreiben würde, wenn sich jeder der sechs Muskeln allein fïr sich contrahiren könnte, der Drehpunkt ist in der durch die nebengezeichnete Linie da gegebenển Eutfernung senkrecht ïber dem Mittelpunkt der Figur zu denken. Die stärkeren Striche an den Enden der Bahnen deuten an, welcher Linie Bild bei der betreffenden Lage des Auges auf den Netzhauthorizont fallen würde. Die Zahlen an den Linien bedeuten, um wie viel Winkelgrade das Auge durch den betreffenden 
Muskel gedreht ist, weun der Blickpunkt den Punkt bei der Zahl erreiclit liat.

Aus der letzten Zeichnung leuchtet ohne Weiteres ein, dass weder der Ob)liquus inferior noch der Rectus superior allein in Stande wären, die Blickrichtung aus der Primïrstellung ohme Drehung des Netzhantlorizontes zu erheben, dass dies aber bei entsprechendem Zusammenwirken beider Muskehn geschehen muss. In der That werden Obliquus inferior und liectus superior stets gleichzeitig innervirt und sie bilden gemeinschaftlich die Gruppe der Blickheber, Obliquus superior und Rectus inferior die Gruppe der Blicksenker. Die beiderseitigen Blickheber und Blicksenker werden stets in gleichem Malasse innervirt; die beiderseitigen Recti interni bewirken bei ihrer Synergie Steigerung der Convergenz der Blickrichtungen, die beiderseitigen Recti externi Verminderung der Convergenz, erstere nähern den binocularen Blickpunkt, letztere entfernen ihn; der linke Rectus extermus und der rechte Rectus internus bewirken bei ihrer Synergie binoculare Linkswendung des Blickes, der rechte Rectus externus und der linke Rectus internus Rechtswendung.

Es giebt deutliche Anzeichen dafür, dass die unter dem Gesichtspunkte der besonderen Zweckerfüllung zusammengehörigen Muskeln in gemeinsamen und von den anderen getrennten motorischen Nervenzellengruppen des Hirnstammes ihre centrale Vertretung finden, sodass zum Zwecke der Blickhebung ein bestimmtes Centrum die Erregung vermittelt, zum Zwecke der Annäherung des Blickpunktes ein anderes und so fort. An der Ueberführung des Blickpunktes aus einer Richtung und Entfernung in eine andere sind diese Centren in entsprechenden Intensitätsverhältnissen betheiligt.

Bei der gewöhnlichen Lähmung eines Rectus externus, zum Beispiel des rechten Auges, ist dieses Auge weder im Stande den Blick nach rechts zu wenden, noch auch den Blickpunkt zu entfernen, während die übrigen Augenmuskeln sich normal verhalten, speciell auch der linke Rectus internus; in diesen Fällen liandelt es sich um eine Erkrankung des Nervus oder Musculus rectus externus, um eine peripherische Lähmung. Es giebt aber auch Fälle, in denen zunächst nur die Lähmung des einen, zum Beispiel des rcchten Rectus externus bemerkt wird, in denen aber bei genauer Untersuchung auch das linke Iuge Bewegungsstörungen zeigt; dieses functionirt zwar normal, wenn es sich um Annäherung des Blickpunktes handelt, kann aber, wenn ein rechts gelegenes Objekt angeschaut werden soll, seine Blicklinie nicht zur Kreuzung mit der Medianebene bringen. Der linke Rectus internus functionirt also in Dienste der einen Zweckerfüllung, bei Synergie mit dem anderseitigen Rectus internus, versagt aber im Dienste der anderen Zweckerfüllung, wenn Synergie mit dem ebenfalls gelähmten Rectus externus der anderen 
Seite verlangt wird; in solchen Fällen handelt es sich nachgewiesener Maassen um centrale Erkrankung des sogenannten Abducenskernes (der rechten Seite) bei Intactheit der Oculomotoriuskerne.

Auch physiologische Erfahrungen sprechen für die vorgetragene Ansicht von der centralen Zusammenfassung der Augenmuskeln mit Rücksicht auf die, besonderen Zwecken dienenden Synergien. Ein übersichtliches Beispiel derselben ist folgendes: nähert man ein binocular fixirtes Selnzeichen ans einer Entfernung, bei welcher die Fixation mit merklich parallelen Sehaxen erfolgt, nicht in der Medianlinie, sondern in der Sehaxe des einen Auges, etwa des rechten Auges, so darf dieses Ange, um die binoculare Fixation festzuhalten, seine Stellung nicht ändern, man sollte auch meinen, dass keiner seiner Muskeln in Thätigkeit geriethe; betrachtet man aber ein solches Auge scharf, so sieht man es bei dem beschriebenen Vorgange kleine Zuckungen machen, man hat auch an solchen Augen unter den genannten Bedingungen Muskelgeräusche auscultirt. Man muss also annehmen, dass sein Rectus internus im Interesse des Annäherns des Blickpunktes synergisch mit dem linken Rectus internus innervirt wurde, und dass sein Rectus externus zur Erhaltung der Fixationsrichtung ebenfalls synergisch mit dem linken Internus, aber antagonistisch zum rechten Internus mitgewirkt hat. Diese Deutung wird um so wahrscheinlicher, als bei der Annäherung des Objektes Accommodationsanstrengung erfolgen muss, und erfahrungsgemäss auch Pupillenverengerung erfolgt. Ebenso wie Contraction des Sphincter Pupillae und des Tensor Chorioideae zwangmässig bei jeder Convergenz der Blickrichtung erfolgt, so wird anch umgekehrt die in Dienste der Accommodation für die Nähe eintretende Pupillenverengerung und Contraction der Tensores Chorioideae die Synergie der Annäherer des Blickpunktes, das heisst beider Recti interni, fordern.

\section{Gehör.}

Die Gehörswahrnehmungen haben das Gemeinschaftliche, dass ihnen Schwingungen der den Hörenden umgebenden Materie (meistens der Luft) entsprechen. Zu jedem bestimmten Schwingungszustande der Umgebung gehört ein für allemal eine bestimmte, von jeder anderen zu unterscheidende und in ihrer Eigenart stets wieder zu erkennende Gehörswahınehmung. Innerhalb des Qualitätenkreises der Gehörswahrnehmungen sind die einzelnen Wahrnelmmungen sowohl der Qualität als auch der Quantität (Intensität) nach unterscheidbar. Qualitativ sondert man die Gehörswahrnehmungen in die beiden Gruppen der "Klänge“ und der "Geräusche". Das subjective Kriterium zwischen diesen beiden Gruppen 
besteht darin, dass die Klänge uns ästhetisch anmuthen und einen musikatischen Werth haben, die Gerüusche nicht.

An einem Klange unterscheiden wir zunïchst seine Intensitiit und seine Tonhöhe. Bekanntlich ist es leicht den Nachweis zu führen, dass die Stärke eines Klanges mit der Amplitude der unser Ohr treffenden Luftschwingungen wächst, die T'onhöhe mit ihrer Frequenz. Zwei Klïnge gleicher Stärke und gleicher Tonhöhe sind aber im Allgemeinen noch durch ein Drittes verschieden, welches mit der Natur der Schallquelle, von der sie ausgehen, zusammenhängt. Ein Klang, beispielsweise von der Höhe des e", der also 512 Schwingungen in der Secunde entspricht, erscheint uns verschieden, je nachdem er von einer Stimmgabel oder ron einer Geige herrorgebracht wird, man sagt: der Kklang der Stimmgabel unterscheidet sich durch seine Klangfurbe von dem Klange einer Geige. Zwei Schwingungen, welche der Frequenz und Amplitude nach gleich sind, können sich nur noch unterscheiden durch die zeitliche Vertheilung der Elongationswerthe oder, was auf dasselbe hinaus kommt, der Geschwindigkeitswerthe auf die Schwingungsperiode; man bezeichnet diesen Unterschied als den der Schwingungsform.

Um den Begriff der Schwingungsform klar zu fassen, kann man von der Betrachtung einer Curve ausgehen, welche ein Punkt eines schwingenden Pendels mit Hilfe eines Pinselchens auf eine parallel der Schwingungsebene vertical bewegte berusste Glasplatte aufschreibt. Wiederholt man die Bewegung der Platte bei angehaltenem Pendel, so erliält man zu der Curve eine Abscisse, durch welche sie in zwei symmetrische Hälften zerlegt wird; man erkennt leicht, dass die Durchschnittspunkte der Curve durch die Abscisse den Momenten des Durchganges des Pendels durch die Ruhelage entsprechen, und die Kuppen der Curve den Momenten der Umkehrung der Bewegungsrichtung. Erfolgte die Bewegung der Platte mit constanter Geschwindigkeit, so ist die Neigung der an einen beliebigen Punkt der Curve gelegten Tangente gegen die Abscisse ein Maass für die Geschwindigkeit, welche das Pendel in dem dem Curvenpunkte entsprechenden Zeitmomente gehabt hat. Diese Neigung ist am grössten an den Durchschnittspunkten der Curve mit der Abscisse; in der That hat ja anch die Geschwindigkeit des Pendels beim Durchgang durch die Ruhelage ein Maxinumn. Die Neigung ist am kleinsten und zwar gleich Null an den Kuppen der Curve, weil die Geschwindigkeit des Pendels im Moment der Umkehrungen aus der einen Bewegungsrichtung in die andere Null sein muss. Die charakteristische Vertheilung der Neigung gegen die Abscissenlinie ist das, was uns an der Curve als ihre Form auffällt.

Die Bewegungen eines nicht zu weit ausschlagenden Pendels sind die denkbar einfachsten schwingenden Bewegungen. Damit ein Massen- 
punkt schwingende Bewegungen ausführe, ist erforderlich, dass bei seiner Bewegung aus der Anfangslage eine Krraft wachgerufen werde, welche ihn in die Anfangslage zurïckzuführen strebt; der denkbar einfachste Fall ist der, dass die Intensität der wachgerufenen Kraft in linearem Verhältnisse zu der Elongation stehe. Dieses ist bei dem Pendel der Fall, so lange sein Elongationswinkel klein genug bleibt, um seinen Sinus ohne merklichen Fehler gleich seinem Bogen setzen zu dürfen.

Für alle Schwingungen von der hier definirten Natur der Pendelschwingungen kann man nun leicht einen mathematischen Ausdruck der Schwingungsform herleiten; um dies in ïbersichtlicher Form zu thun, muss man sich allerdings der fundamentalen Ausdrücke des Infinitesimalcalcüls bedienen. Die Differentialgleichung der Pendelbewegung schreibt man $\frac{\mathrm{d}^{2} \mathrm{x}}{\mathrm{dt^{2 }}}=-\mathrm{cx}$, wo die Elongation ( $\mathrm{x}$ ) als Function der Zeit ( $\mathrm{t}$ ) betrachtet wird. Der Ausdruck der linken Seite heisst der zweite Differentialquotient von $x$ nach $t$. Der erste Differentialquotient $\frac{d x}{d t}$, das heisst das Verhältniss des in einem kleinen Zeittheilchen (dt) zurückgelegten Weges (dx) zu der Zeit bedeutet die Geschwindigkeit. Betrachtet man die Geschwindigkeit selbst als Function der Zeit, so misst das Verhältniss der in einem kleinen Zeittheilchen eingetretenen Geschwindigkeitsänderung zu dieser Zeit die Bescllleunigung. Der Ausdruck $\frac{\mathrm{d}^{2} \mathrm{x}}{\mathrm{dt}^{2}}$ ist eine abgekürzte Form für den Ausdruck $\frac{d\left(\frac{d x}{d t}\right)}{d t}$, welchen wir als Maass der Beschleunigung kennen gelernt haben. Die zu einer thatsächlich eingetretenen Geschwindigkeitsänderung oder Beschleunigung hinzugedachte Ursache ist ganz allgemein das, was wir in mechanischem Sinne eine Kraft nennen. Die Formel $\frac{d^{2} x}{d t^{2}}=-c x$, sagt also weiter nichts aus, als dass für die Bewegung des schwingenden Massenpunktes eine Kraft malassgebend ist, welche ungekehrt gerichtet ist, als der Weg des Punktes von der Anfangslage aus gerechnet, und deren Intensität proportional der Grösse dieses Weges ist.

Die Differentialgleichung der Pendelbewegung $\frac{\mathrm{d}^{2} \mathrm{x}}{\mathrm{dt}^{2}}=-\mathrm{cx}$ auflösen, heisst eine Function von $\mathrm{t}$ finden, welche statt $\mathrm{x}$ eingesetzt der Gleichung genuigt; dies thut die Function $\mathrm{x}=\mathrm{a} \sin \left(2 \pi \frac{\mathrm{t}}{\tau}\right)$, denu es ist $\frac{\mathrm{dx}}{\mathrm{dt}}=$ $a \cos \left(2 \pi \frac{t}{\tau}\right)$ und $\frac{d^{2} x}{d t^{2}}=--a \sin \left(2 \pi \frac{t}{\tau}\right)$. Die Curre, welche man er- 
hält, wenn man in der Gleichung $x=a \sin \left(2 \pi \frac{t}{\tau}\right)$ den Abscissen sucessive Werthe ron $t=0$ bis $t=\tau$ beilegt und den Ordinaten die nach aler Gleichung zugehörigen Werthe ron $x$, nennt man eine Sinuscurre, weil die Ordinate zur Abscisse sich rerhält wie der Sinus zum Bogen. Iiczieht man die Sinuscurve anf dic P'endelberegung, so entspricht der Zeitpunkt $t=0$ einem Durchgang des Pendels durch die Ruheligre, der Zeitpunkt $t=\frac{\tau}{2}$ dem nächsten Durchgang in umgekehrter Richtung und in dem Zeitpunkt $\mathrm{t}=\tau$ ist ein Hin- und Hergang voll-

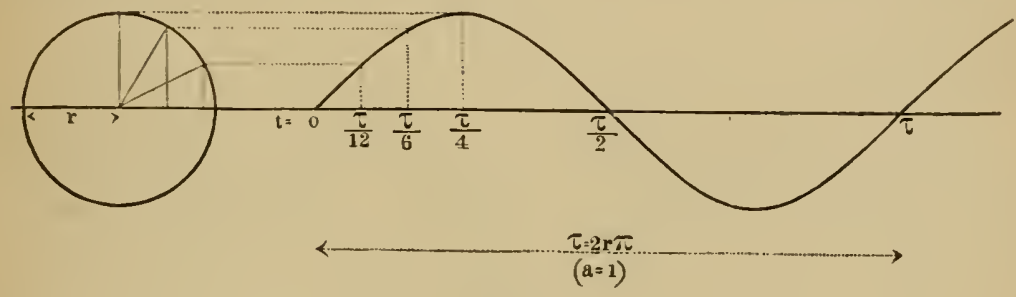

38.

endet. Die Zeitdauer $\tau$ entspricht also im Sinne der deutschen Akustiker der einfachen Schwingungsdauer, in französischem Sinne der doppelten. Bei dem Secundenpendel ist $\tau=1^{\prime \prime}$. Bei der Construction der Sinuscurre ist der Längenwerth der Abscisse für $\tau$ willkürlich. Um die einzelnen Ordinatenwerthe zu gewimnen, construirt man einen Lireis, dessen Peripherie $2 \pi \mathrm{r}=\tau$ ist. Wählt man als Längeneinheit die so definirte Länge ron r, so erhält man die Ordinatenlängen, wenn man die den cinzelnen Bögen entsprechenden Längen der Sinuslinien im Kreise mit dem Factor a multiplicirt; der Factor a war als eine ron $t$ unablı̈̈ngige Constante definirt und man sieht jetat, dass er die Grösse der Ampliturle bestimmt. Die Ordinate $\mathrm{x}$ nimmt den maximalen Wertl $\pm \mathrm{a}$ bei allen Werthen des Bogens an, für welche der Sinus gleich \pm 1 wird. Dieses ist der Fall für $t=\frac{\tau}{4} \cdot \frac{3 \tau}{4}$ etc., das heisst nach cin Viertel Schwingung, nach drei Viertel Schwingung u. s. w. Construirt man nach den angegebenen I'rincipien Sinuscurren, so findet man, dass sic in der Form mit der rom schwingenden Pendel gezeichneten Curve übereinstimmen.

Bei dem Pendel ist die Krraft, welche den bewegten Massenpunkt in seine Ruhelage zurücktreibt, eine Componente der Schwerkraft; bei tönenden Körpern ist es die Elasticität. Der Fall, dass die Intensität der elastischen Kraft einfach proportional der Grösse der Elongation ist, 
findet sich auch bei tönenden Kö̈rpern realisirt. Man kann die Bewegungen einer Zinke einer tönenden Stimmgabel auf eine bewegte Fläche aufschreiben lassen und man erhält eine Schwingungscurve, deren Form die einer Sinuscurve ist. Man ist also zu dem Ausspruch berechtigt, dass die Zinken der Stimmgabel und die Luftheilchen in dem Raume, in welchem eine Stimmgabel tönt, pendelartige oder Sinusschwingungen ausführen, und durch diese Angabe ist die Klangfarbe der Stimmgabeln physikalisch definirt. Kilänge, welche dieser einfachsten Form ron Schwingungen entsprechen, nemnt man Töne. Die Töne unterscheiden sich, abgesehen von der Intensität, nur durch die Schwingungsfrequenz. Die Stimmgabel, welche den Ton c giebt, macht 128 Schwingungen in der Secunde, man sagt ihre Schwingungszahl ist $\mathrm{n}=128$ und die Schwingungsdauer der reciproke Werth davon $\tau={ }_{1 / 28}^{1}$ Secunde.

Lässt man einen Punkt einer nach dem Zupfen ausklingenden Saite seine Bewegungen aufschreiben, so erhält man im Allgemeinen keine Sinuscurve, sondern eine Linie, welche zwar auch äquidistante Durchgangspunkte durch die Abscisse (bei constanter Geschwindigkeit der Zeichenfläche) aufweist, deren Neigungen gegen die Abscisse zwischen je zwei solchen äquidistanten Durchgangspunkten aber nicht so regelmässig vertheilt sind, wie bei der Sinuscurve. Immerhin wiederholt sich dieselbe Vertheilung der Neigungen in derselben Weise von Periode zu Periode. Es handelt sich also um regelmässig periodische Schwingungen, welche man aber im Gegensatz zu der einfachen pendelartigen oder Sinusschwingung (aus einem sofort einzusehenden Grunde) als zusammengesetzte Schwingungen bezeichnet.

Legen wir uns die Frage vor, durch welche Schwingungscurve die Bewegungen eines Luftheilchens dargestellt werden müssten in einem Raumo, in welchem gleichzeitig eine Stimmgabel c von 128 Schwingungen in der Secunde und eine Stimmgabel $c^{\prime}$ von $2 \times 128$ Schwingungen zum 'Tönen mit gleicher Intensität gebracht sind; die Sinuscurve A (Fig. 39) möge der Lufthewegung entsprechen, welche durch das alleinige Tönen von c erzeugt wäre, und die Sinuscurve B möge dieselbe Bedeutung in liezug auf die Stimmgabel $\mathrm{e}^{\prime}$ haben. Fassen wir einen bestimmten Zeitmonent $\mathrm{t}=\tau^{\prime}$ ins Ange, so wïrde ein bestimmtes Luftheilchen durch den ron c erhaltenen Impuls um eine der Ordinate a proportionale Länge aus seiner Ruhelage entfernt sein; wenn nun gleichzeitig die Stimmgaloel c' tönt (nachdem sie in demselben Zeitmoment zu tönen angefingen hatte wio e), so erhält dasselhe Lufttheilchen in demselben Moment von $\mathrm{c}^{\prime}$ aus einen Impuls, welcher, wenn or allein gewirkt hïtte, eine der Ordinate b proportionale Elongation hewirkt haben würde, die wirklich erreichte Elongation wirl also proportional der Summe von a unr h sein. Dieselbe Betrachtung gilt, unter Beriicksichtigung der Vor- 
zeichen, für alle Zeitmomente und man gelangt auf Grund derselben zur Construction der Curve C. In analoger Weise kann man durch Superposition von einfichen Sinuscurven verschiedener Frequenz und beliebiger Amplitude in beliebiger Zahl sehn rerschiedene Schwingungsformen darstellen; die Mannigfaltigkeit der so zu erhaltenden Curvenformen wächst noch sehr bedeutend, wemn man die oben aufgestellte einschr:̈̈nkende Bedingung aufgiebt, dass der Anfangspunkt der. superponirten Curven dem Durchgangsmoment durch die Ruhelage in der-
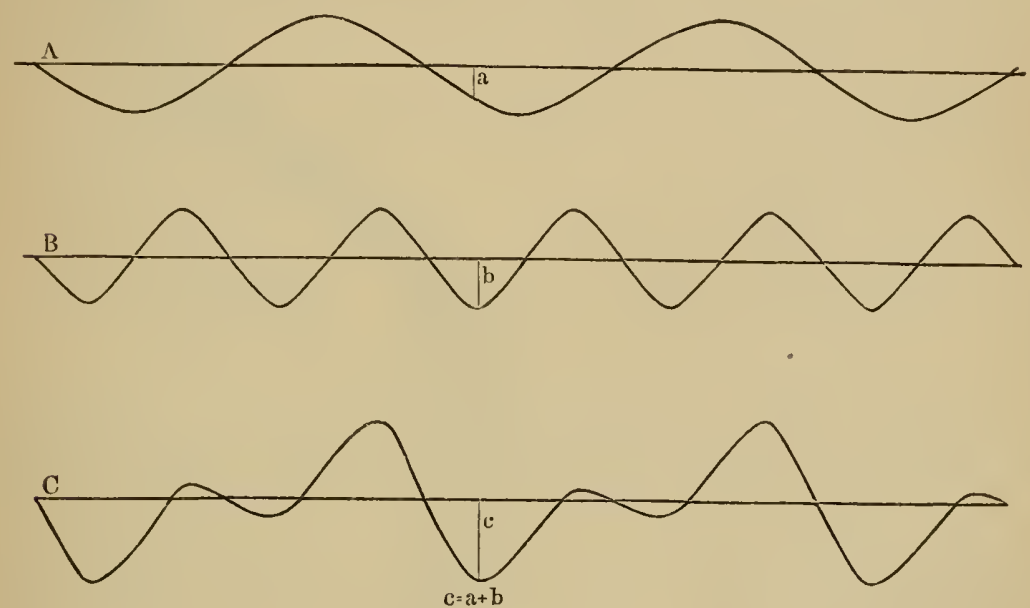

39.

selben Richtung entsprechen soll, wenn man also die Curren mit „Phasenverschiebung" superponirt.

Diese so zu erzielende grosse Mamnigfaltigkeit lïsst es weniger erstaunlich erscheinen, lass, mathematisch streng bewiesen, der Satz gilt: jede Schwingungscurve, ihre in periodischer Regelmässigkeit wiederkehrende Form möge sein, welche sie wolle, kann entstanden gedacht werden aus der Superposition einer bestimmten Anzahl ron Sinusschwingungen, deren Schwingungszahlen im Verhältniss ganzer Zahlen stehen. Die mathematische Analyse giebt auch Methoden an die Hand, die zu jeder gegebenen regelmässig periodischen Schwingung gehörigen einfichen Componenten, der Schwingungszahl und der Amplitude nach zu bereehnen. Hieraus geht hervor, dass man der Luft jede gewünschte Form regehmässig periodischer Schwingung muss ertheilen können dadurch, dass man in demselben Raum Stimmgabehn von geeigneter Tonhöhe in geeigneten Intensitätsverhältnissen ertönen lässt.

Ein specieller Fall hat in dieser Beziehung eine besonders genaue Bearbeitung erfahren. Schlägt man eine Klaviersaite, welche auf die 
Note c gestimmt ist, das lieisst 128 Schwingungen in der Secunde vollzieht, in ein Siebentel ihrer Länge mit dem Hammer derart an, dass der Hammer etwa 1/600 Secunde mit der Saite in Berührung bleibt, so erhält man einen Kilang von hestimmter Höhe und Farbe, und zwar lässt sich mathematisch zeigen und experimentell nachweisen, dass die ziemlich complicirte Schwingungsform, in welche die Theilchen der Saite gerathen und mithin die Luftheilchen versetzen, letzteren auch auf folgende Weise mitgetheilt werden könnte. Man müsste sechs Ursachen zusammenwirkend denken, deren jede einfach pendelartige Schwingungen erregt, etwa Stimmgabeln und zwar

$$
\begin{aligned}
& \text { die } 1 \text { te } 1 \times 128 \text { in } 1 \text { " mit der Amplitude 1,00 (Grundton) } \\
& \text { " } 2 \text { te } 2 \times 128 \quad, \quad, \quad, \quad . \quad \quad . \quad 2,49 \text { (1 te Oberton) } \\
& " 3 \text { te } 3 \times 128, \quad, \quad, \quad, \quad 2,42(2 \text { te }, \quad) \\
& \text {, } 4 \text { te } 4 \times 128, ", \quad, \quad, \quad, 1,19(3 \text { te }, .) \\
& \text { " } 5 \text { te } 5 \times 128, \quad, \quad, \quad, \quad, \quad 0,26(4 \text { te }, \quad) \\
& " 6 \text { te } 6 \times 128, ", \quad, \quad, \quad 0,01(5 \text { te } ")
\end{aligned}
$$

Die durch Anschlagen der Saite erzeugte Ḱlangmasse enthält also als componirende Elemente sechs Partialtöne, deren tiefster der Grundton ist, die übrigen die Obertöne verschiedener Ordnungszahl; die Obertöne sind harmonisch zum Grundton, das heisst die Schwingungszahl jedes derselhen durch eine ganze Zahl (die Ordnungszahl) dividirt, giebt die Schwingungszahl des Grundtons. Die Ḱlangmasse wäre durch die vorliegende Angabe der in ihre Zusammensetzung eingehenden Componenten rollkommen definirt, wenn man die als Einheit gewählte Amplitude des Grundtones, welche von der Stärke des Anschlages abhängig ist, noch in absolutem Masse angeben wïrde. Nach dieser Angabe liesse sich die Kilangmasse synthetisch vollkommen nachahmen; wie immer aber auch die derselben entsprechende Form der Luftschwingung entstanden sein mag, wenn sie eimmal vorhanden ist, so lassen sich auch stets auf experimentellem analytischem Wege die angegebenen Componenten in derselben nachweisen, und zwar mit der Hilfe von Resonatoren.

Jeder schwingnngsfühige elastische Kö̈rper führt, wenn er durch cinen einmaligen $\Lambda$ nstoss aus seiner Gleichgewichtsfigur gebracht ist, Schwingungen von bestimmter Frequenz aus. Ein einmaliger Anstoss muss, un eine Stimmgabel zum Tönen zu bringen, ziemlich stark sein; lat man aber zwei genau gleich gestimmte Stimmgabeln in nicht zu grosser Intfernung von einander so aufgestellt, dass die Oeffnungen ihrer Resonanzkästen einander zugekehrt sind, so genügt es, die eine anzustreichen, um auch die andere zum Tönen zu bringen: es rührt dies 
daher, dass die der secundär erregten Stimmgabel ron der primären, durch die Luft zugehenden Impulse dieselbe immer so treffen, dass die erzengte Beschleunigung stets gleiches Vorzeichen hat mit der schon rorhamlenen Bewegung; die stärksten Impulse erfolgen beim Durchgang der primüren Stimmgabel durch die Gleichgewichtslage, denu zu dieser Zeit ist die Geschwindigkeit der bewegten Iasse, also auch die lebendige Kraft ein Maximum. Während die primäre Stimmgabel die erste halbe Schwingung ausfiihrt, ist die Bewegung der secundïren schon im Entstehen, wenn sie auch noch sehr klein ist; die secundiire Stimmgabel passirt hierhei in demselben Moment die Gleichgewichtslage wie die primäre und erluält zu derselben Zeit einen nenen Impuls in Richtung der rorhandenen Bewegung ron der primären. Es ist ein analoger Vorgang wie derjenige, welcher instinctmässig rom Kïsterknaben hervorgerufen wirl, wenn er, um die schwere Kirchenglocke allein in Bewegung zu setzen, immer dann an dem Seile zieht, wemn dieses schon ron selhst in Abwïrtsbewegung ist. Die Impulse erfolgen auch hier im Rhythmus der als Pendel schwingenden Glocke. Terstimmt man die secundüre Stimmgabel nur wenig durch Aufkleben eines Wachsstückes, so kann sie durch Anstreichen der primären nicht mehr z.um Tönen gebracht werden, weil jetzt ein Theil der Impulse die, schon durch andere Impulse entstandene Bewegung immer wieder rernichtet.

Es giebt Körper, welche viel leichter wiedertönen, resoniren, als Stimmgabeln: zu diesen gehören Lufträıme ron gewisser Grösse und Form. Hält man eine austönende Stimmgabel, welche man ohne Weiteres nicht mehr hört, iiber dlie Oeffnung eines solchen Resonators, welcher auf deuselben Ton gestimmt ist wie die Stimmgabel, so hört man sofort wieder die Stimmgabel tönen: man lat solchen Resonatoren auch eine derartige Form gegeben, dass man sie einzeln fest in das Ohr stecken kann, die Hörschürfe des Ohres ist dann für diesen Ton hesonders gesteigert und derselbe ertönt im Ohr fast ansschliesslich, wenn er in der den Raum erfiillenden Kilangmasse gerade rorhanden ist, aber auch nur dann; solche Resonatoren sind also sehr geeignet, um Ḱlangmassen experimentell zu analysiren. Ist die Ḱlangmasse die oben definirte, wie sie dureh das Anschlagen der Saite herrorgebracht werden kann, so hat man, wenn das eine Ohr rerschlossen ist, nur Tonwahrnehmungen, wenn man einen auf $c, c^{\prime}, g^{\prime}, c^{\prime \prime}, e^{\prime \prime}$ oder g gestimmten Resonator in das andere Ohr setzt, und die Intensitätsrerhïiltnisse stimmen auch in genügend anuähernder Wreise mit den oben angegebenen, durch Rechnung gefundenen überein.

Die unmusikalíschen Gehörswahrnehmungen, welche wir, nach einem subjectiven Kriterium, als Gerïusche den Klängen gegenïber gestellt haben, unterscheiden sich objectir ron diesen dadurch, dass ihnen 
keine perindisch regelmässigen Schwingungen entsprechen, immerhin kann man die den Geräuschen entsprechenden Bewegungsformen als solche auffassen, deren Componenten pendelartige Schwingungen sind, nur dass die Schwingungszahlen der Componenten nicht harmonisch sind und dass die Componenten zeitlich schnell wechseln, die einen schnell verklingen und durch andere ebenfalls schnell verklingende ersetzt werden. Wenn die Geräusche auch ästhetisch von geringerem Werth erscheinen, sls die Klänge, so besitzen sie doch eine hohe Bedeutung für den Ausbau un-

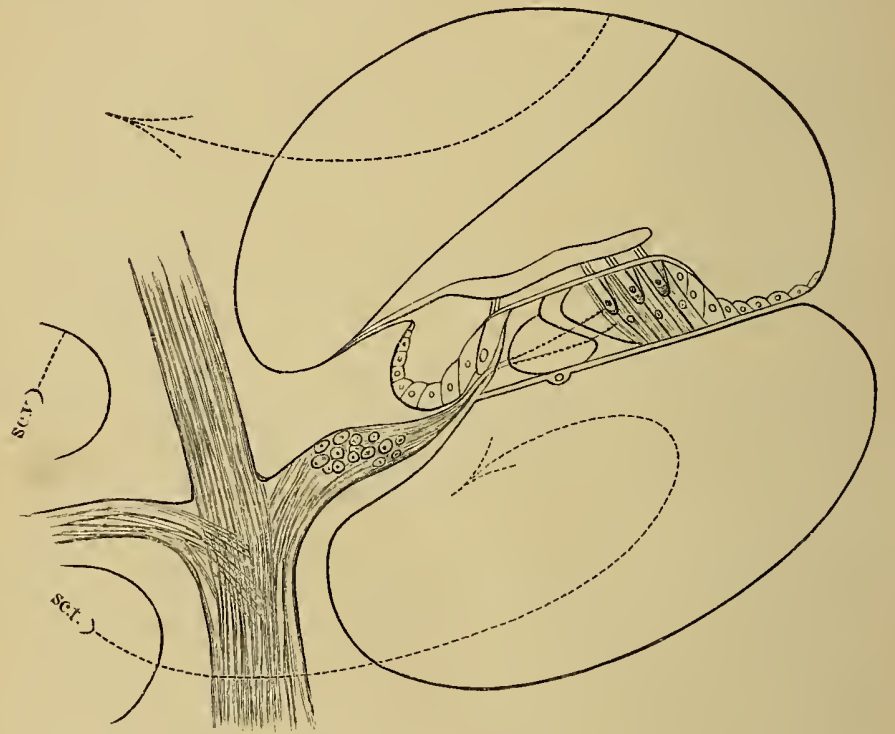

40.

serer Vorstellungswelt. Die Consonanten sind Geräusche, die Vocale sind Klänge.

Der nicht nervöse Theil des Ohres ist ein Apparat, welcher durch Resonanz die Schallschwingungen der Luft auf Nervenfasern des Acusticus überträgt. Die mit der specifischen Energie des Hörens ausgestatteten Nervenfasern des Acusticus endigen in flächenartiger Ausbreitung an der Lamina spiralis der Schnecke; in den Verlauf der Fasern des Nervus Cochleae, welche im Modiolus der Schnecke aufsteigen, sind kurz vor ihrem Austritt aus der Lamina spiralis ossea bipolare Ganglienzellen eingeschaltet. Die von der Lamina spiralis ossea zur Aussenwand der Schnecke ausgespannte Membran, die Membrana spiralis membranacea oder die Basilarmembran, ist elastischer Schwingungen fähig, sie enthält selbst quergespannte elastische Fasern und sie trägt ein complicirtes Organ, welches aus elastischen Elementen, Epithelien und'Sinneszellen aufgebaut 
ist und das Corti'sche Organ genamnt wird. Die clastischen Elemente sind vertreten durch zwei continuirliche Reihen von Fasern, die inneren und äusseren Bogenfisern. Die inneren Bogenfasern erhelen sich rou der Anheftungsstelle der Basalmembran an den Morliolus, die äusseren in einiger Entfernung davon; die oberen Enden beiler Faserarten berühren sich, sodass cin kuppelförmiger Raum, der Tunnelraum entsteht, welcher ron den Bogenfasern überdacht ist. Von der Kuppe eines, der inneren Bogenfaser innen anliegenden Epithelwulstes spannt sich über die Kuppe der Bogenfasern hinweg eine Membran zur Kuppe eines weiter auswïrts auf der Basilarmembran stehenden Epithelwulstes, welcher durch die in ihm enthaltenen sogenannten Stïtzzcllen aufrecht erhalten wird. Die Membran wird ron Härchen durchbohrt, welche mit Zellen in Verbindung stehen; die Haarzellen finden sich zum Theil im inneren Epithelwulst, in grösserer Zahl jedoch, ron den Stützzellen getragen, im äusseren Epithelwulst. Die Haarzellen werden als Sinneszellen aufgefasst, weil man die Nervenfasern bis zu ihmen rerfolgen zu kömnen glaubt; jedenfalls ziehen feine, im Präparat varicös erscheinende Nervenfasern aus Spalten an der Spitze der Lamina spiralis ossca, der sogenamnten Habenula perforata, in den inneren Epithelwulst und durch den Basaltheil des Tunnelranmes in den äusseren Epithclwulst hinein. Ueber der Habenula perforata crhebt sich die Lamina spiralis ossea zu einem zahnartigen Fortsatz, dessen Spitze eine hier einseitig angeheftete voluminöse Membran trägt, die Membrana tectoria, welche mit ihrem freien Theil auf den Haaren der Haarzellen aufzuruhen scheint; man stellt sich ror, dass, wenn ein Querstreifen der Membrana basilaris bewegt wird, die Haarzellen durch Reibung der Haare an der Membrana tectoria erregt werden, und dass die Erregung sich den mit den Haarzellen verbundenen Fasern des Nerrus aeusticus mittheilt. Oberhall, der Membrana tectoria durchquert eine andere Membran, die Reissner'sche Membran, den ganzen Schneckencanal; das Corti'sche Organ liegt also in einem spiraligen Sack mit dreiseitigem Querschnitt (häntiger Schneckencanal). Dieser Sack gehört zu dem sogenannten endolymphatischen System und ist mit Flïssigkeit gefüllt, der Endolymphe. Stellt man sich ror. dass man durch das ovale Fenster in das Labyrintl einträte, un die Schnecke zu durchwandern, so müsste man oberhalb des hä̈tigen Schneckencanals durch die sogenannte Scala restibuli in $2 \%$. Windungen bis zu dem Helicotrema aufsteigen und gelangte nach Wendung um dasselbe herum durch die Scala tympani, unter der Membrana basilaris zur Schneckenbasis zurïck an das runde Fenster: Scala restibuli und Scala tympani enthalten Perilymphe. Das runde Fenster ist durch eine elastische Jembran geschlossen, das orale durch die elastisch eingesetzte Platte des Steig- 
biigels, sonst ist die Perilymphe - abgesehen von dem engen Aquaeductus restibuli - (und die Endolymphe, abgesehen vom Aquaeductus Cochleae) ïberall ron fester Wand begrenzt, sodass, wenn die Steigbiigelplatte in das ovale Fenster hineingedriickt wird, das runde Fenster um den gleichen Betrag (dem Volum nach) ausgebaucht werden muss. Die hier'zu erforderliche Druckübertragung und Flüssigkeitsverschiebung kann auf zwei Wegen geschehen, einmal auf dem vorher beschriebenen um das Helicotrema herum, und dann durch Vorbauchung des häutigen Schneckencanals ron der Scala vestibuli gegen die Scala tympani; bei letzterer Vorbauchung muss Wölbung der Basilarmembran eintreten, wobei die Härchen an der Membrana tectoria gerieben werden können. Rhythmische Bewegungen des Steigbügels werden also rhythmische Bewegungen der Basalmembran und rhythmische Nerrenerregungen erzeugen können.

Um die rhythmische Schallbewegung der Luft der Steigbügelplatte mitzutheilen, sind die Gehörknöchelchen und das Trommelfell vollkommen geeignet: Hammer und Ambos stellen einen Winkelhebel dar, dessen Drehaxe in dem Processus folianus des Hammers und im kurzen Fortsatz des Amhos liegt. Der nach vorn sehende Processus folianus ist in der Fissura Glaseri durch eine elastische Bandmasse befestigt, welche ihm Drehungen um seine Längsaxe gestattet. Der kurze Ambosfortsatz

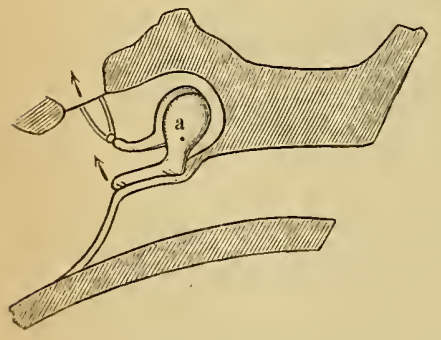

41. ist in ähnlicher Weise an der gegenüber liegenden Wand der Paukenhöhle inserirt. Der Schnittpunkt der Drehaxe mit dem Hammer ist in der schematischen Figur 41 mit a bezeichnet. Der Hammerstiel ist gleichsam als ein Radius in das Paukenfell eingewebt, sodass die Spitze des Hammerstiels die Mitte des Paukenfells einnimmt. Wenn daher das letatere unter dem Einflusse von Luftschwingungen abwechselnd tiefer und weniger tief eingeArïckt wird, so kann der Hammer diese Bewegung, vermöge seiner Drehbarkeit um die oben bezeichnete Axe, mitmachen. Betrachten wir den Hammerstiel als den einen Schenkel des Winkelhebels, so ist der lange Ambosfortsatz rler andere und zwar etwas kiurzere; am Ende dieses Fortsatzes, etwa senkrecht zur Richtung seiner Axe, steht der Steigbiigel. Bei jeder Einwïrtsbewegung des Trommelfells muss sich also die Platte des Steigbügels ebenfalls nach innen bewegen und zwar in kleineren Maasse, aber mit grösserer Kraft, als die Spitze des Hammerstiels. Die Gelenkverbindung zwischen Hammer und $\Lambda$ mbos stellt ein sogenanntes Sper'rgelenk dar, welches Einwärtsbewegungen des Hammer- 
stiels ungeschwächt den langen Ambosfortsat\% mittheilt, bei duswärtshewegungen desselben jedoch sich etwas löst und dem Ambos gestattet, den an ihn direct oder durch Vermittelung des Steighiigels angreifenden Kŕäften zu folgen. Es scheint, dass der Steigbiigel dieses Schutzes gegen zu starken Zug nach aussen, welcher ihm vom 'Trommelfell aus ertheilt werden könnte, bedarf.

Die Kette der Gehörknöchelchen liegt in der Paukenhöhle, einem lufthaltigen Raume, welcher gegen den äusseren Gehörgang durch das 'Trommelfell alggeschlossen ist und welcher mit den Rachenraum durch die Ohrtrompete communicirt. Die Ohrtrompete ist ein der Luftleitung dienender Canal, dessen Schliessung oder Oeffnung dem Wettstreit zwischen elastischen Kräften und Muskelkräften iiberlassen ist; die Luft im Rachenraum wird bei manchen Gelegenheiten, zum Beispiel beim Schnïuzen, unter hohen Druck gesetzt, und wenn nicht gleichzeitig die Ohrtrompete geschlossen wird, kann das Trommelfell einen plötzlichen starken Impuls nach aussen erhalten. Functionirt die Ohrtrompete richtig, so wird in Allgemeinen dẹr Druck zu beiden Seiten des Trommelfelles gleich sein; zu einem Sinken des Luftrdruckes in der Paukenhöhle kommt es, wenn bei Katarrhen das Lumen in der Ohrtrompete dauernd geschlossen ist und Luft von der Wand der Paukenhöhle absorbirt wird, das 'Trommelfell ist dann mehr als normal nach innen gewölbt und stärker gespannt. Man kann diesen Zustand vorïbergehend willkürlich hervorrufen, wenn man bei zugehaltener Nase leer schluckt. Beim Schluckakt öffnet sich die Ohrtrompete und es strömt Luft ans der Paukenhöhle in den Rachenraum, wo die Luft zur selben Zeit bei verschlossener Nase verdünnt ist; man kann sich auf diese Weise davon iberzeugen, dass bei zu straff gespanntem Trommelfell die Hörschärfe (namentlich für tiefe Töne) ziemlich gering ist. Durch wiederholtes Schlucken bei offener Nase stellt sich der normale Zustand schnell wieder her; dass iibrigens anch der Grad von Spannung des Trommelfells, welcher sich einstellt, wenn nur die elastischen Krü̈fte des Trommelfelles und der Gehörknöchelchen in Wirksamkeit treten, nicht derjenige ist, welcher die besten Bedingungen für das scharfe Hören mit sich bringt, wird wahrscheinlich durch die Existenz des Musculus tensor tympani, dessen Wirkung in Einwärtsdrehung des Hammerstiels und Spannung des Trommelfells bestehen muss. Betreffs der Function des Musculus stapedius kaun man eine begrïndete Vermutluung nicht aussprechen.

Dass das Tronmelfell durch Schallschwingungen der Luft bewegt wird, erscheint selbstverständlich, da es aber elastisch und gespannt ist, so köunte man erwarten, lass es wie andere resonirende Körper, einen oder wenige Töne durch Resonanz hevorzugen würde. Wir könnten dann nur schwer dic grosse Mannigfaltigkeit der möglichen Wahrneh- 
mungen verstehen; kreisförmig gespannte Membranen sind aber überhaupt, wie die Telephonplatten zeigen, zur Wiedergabe mannigfaltiger Schwingungszustände geeignet und beim Trommelfell kommen noch zwei Nomente hinzu, welche in dieser Beziehung günstig zu wirken scheinen: die radienartige Einfügung des Hammerstiels und die nabelartige Einziehung. Wir haben also zu erwarten, dass die spritzenstempelartige Bewegung der Steigbügelplatte stets in gleichem Sinne und in proportionalem Umfange erfolgt, wie die Schallbewegung der dem Trommelfell unmittelbar anliegenden Luftheilchen. In demselben Verhältniss müssen auch die Bewegungen des runden Fensters zu den Bewegungen der Steigbiigelplatte stehen; zwischen letzteren beiden ist aber die Gelegenheit zu einer selectiven Resonanz gegeben. Die Membrana basilaris, welche durch ilire Ausbuchtungen, wie wir oben gesehen haben, an der Uebertragung der Druckschwankungen von der Steigbïgelplatte auf das runde Fenster Theil nimmt, enthält in regelmässiger Anordnung eine Schicht quer gespannter elastischer Elemente, deren etwa vier auf jede Bogenfaser kommen, die übrigen Elemente der Basilarmembran sind weit zarter, sodass es wahrscheinlich ist, dass die elastischen Querfasern einzeln oder wenigstens in nicht zu grossen Gruppen unabhängig von der Nachbarschaft schwingen können. Die Länge der Querfasern (das heisst die Breite der Basilarmembran) nimmt nun von der Schneckenbasis bis zur Schneckenspitze erheblich zu, im Verhältniss von 1 zu 12, sodass man erwarten darf, die eigene Schwingungszahl der basalen Elemente sei erheblich grösser, als die der apicalen. Man nimmt nun in der That ziemlich allgemein an, dass die Basilarmembran ein continuirliches System versehieden gestimmter Saiten darstelle und dass hierdurch eine sehr feine räumliche Gliederung der selectiven Resonanz bedingt sei. Danach wïrde, wenn eine Stimmgabel c im Hörbereich ertönt, nur eine kleine Gruppe benachbarter Fasern der Basilarmembran in Schwingung und die ïber ihr endigende Gruppe von Acusticusfasern in Erregung versetzt werden. Als specifische Energie dieser Nervenfasern wird dann das Hören des Tones c bezeichnet; das Analoge geschehe, wenn eine Stimmgabel c' ertönt, und zwar würde hierbei ein der Schneckenbasis näher gelegener Theil der Basilarmembran mit den zugehörigen Nervenfasern betheiligt sein. Auf diese Weise würde die Mannigfaltigkeit der unterscheidbaren Tonwahrnehmungen, welche Frequenzen von 30 bis 38000 Schwingungen in der Secunde entsprechen, verständlich sein.

Als Empfindungsclement des Gehörsinmes erscheint das Hören eines einfachen 'Tones von bestimmter Tonhöhe. Ein feines Urtheil über die Intensitït ron Gehörswahrnehmungen lässt sich nur bei gleicher Tonhöhe albgeben und auch nur für Töne gleicher Höhe gilt eine einfache Beziehung zwischen der Intensität der Wahrnehunung und der Grösse 
der Schwingungsimplitude; wahrscheinlich ist die Intensität der Walnnehmung bei gleicher Tonhöhe dem Quadrat der Schwingungsamplitude proportional. Bei Vergleichung ron Tönen verschiedener Höle macht sich ein Einfluss der Schwingungsfrequenz auf die Intensitït der Wahrnehmung geltend, indem höhere Töne mit kleinerer Amplitude ebenso stark erscheinen wie tiefere Töne mit grösserer Amplitude.

Handelt es sich nicht um das Hören eines einzelnen Tones, sondern ist die das Ohr treffende Klangmasse complicirt, so werden ebenso viele discrete Theile der Basilarmembran in Schwingung und cbenso viele discrete Gruppen von Nervenfaserendigungen in Erregung gerathen, wie einfache Componenten in der Klangmasse enthalten sind. Das Resultat ist die Wahrnehmung eines Klanges von bestimmter Höhe und Farbe und der Gegenstand dieser Wahrnehmung ist ein Complex von Empfindungselementen des Gehörsinnes. Die zusammengesetzte Natur der K'langwahrnehmungen im Gegensatze zur einfachen Natur der Tonwahrnehmungen tritt nicht ohne Weiteres in das Bewusstsein, wenu man den Gehörsinn in gewölnnlicher Weise zur Orientirung in Verkehr mit der Aussenwelt oder unter der Herrschaft des ästhetischen musikalischen Interesses benutzt. Ein bestimmter Klang, zum Beispiel ein Vocallaut, erscheint zunächst als etwas ebenso Einheitliches von bestimmtem Charakter, wie der Ton einer Stimmgabel. Nit musikalisch geschultem Ohr gelingt es aber doch, wenn die Aufmerksamkeit auf jedes Einzelne der Empfindungselemente nacheinander concentrirt wird, Klangmassen ohne weitere Hilfsmittel zu analysiren, $d$. h. die Componenten, aus denen sie zusammengesetzt sind, richtig anzugeben. Hierin ist der Gehörsinn dem Gesichtssinn überlegen, welch letzterer irgend eine farbige oder farblose Gesichtswahrnehmung nicht auf bestimmte componirende Empfindungselemente verschiedener Qualität zurïckzufiihren im Stande ist. Er kann dies auch nie lernen, weil die Zahl der Combinationen objectiv verschiedener Lichtarten, welche alle zu derselben Lichtwahrnehmung Veranlassung geben, unendlich gross ist.

Eine andere Ueberlegenheit des Gehörsinnes iiber den Gesichtssinu besteht in der grossen zeitlichen Uebereinstimmung zwischen den Aenderungen der Gehörswahruehmung und den Aenderungen der objectiven Schallvorgänge. Dagegen steht der Gehörsinn dem Gesichtssinn weit nach in der Fähigkeit, die Quelle der Sinneswahrnehmung mit richtiger Localisation nach Aussen zu projiciren. Die Entfernung der Schallquelle beurtheilen wir nur nach der Intensität der Wahruehmung. Die Richtigkeit der Schätzung hängt also ganz von unserer Kenntniss der Schallintensität am Orte der Entstehung ab. Ehenso unvollkommen wie deren Keuntniss meistens ist, ist auch die Schätzung der Entfernung ungenatu. Unser Lrtheil ïber die Lage der Schallquelle zur rechten oder linken 
Seite unseres Kööpers wird wahrscheinlich unterstiitzt durch kleine Unterschiede in der Intensität der beiderseitigen Gehörswahrnehmungen. Es besteht aber die Neigung, Gehörswahrnehmungen in den eigenen Körper zu localisiren, eine Neigung, welche besonders deutlich hervortritt, wenn Schall gleicher Qualität den beiden Ohren in erheblich verschiedener Intensität geboten wird, wo dann eine auffallende Localisation in dem stärker getroffenen Ohre oder in einer diesem Ohre näheren Stelle des Kopfes stattfindet.

Es besteht ein Streit darïber, ob die Wahrnehmung der Geräusche ebenso wie die der Klänge durch den Schneckenapparat vermittelt wird, oder ob den ersteren ausschliesslich gewisse Einrichtungen des uibrigen Labyrinthes dienen. Da sich die Geräusche von den Klängen nicht durch die Natur der Empfindungselemente, sondern durch die Art ihrer Combinationen unterscheiden diirften, so liegt zu der Annahme einer besonderen Einrichtung für erstere keine Nöthigung vor. Der Ramus vestibularis des Nervus acusticus mit seinen peripherischen Endorganen scheint gar nicht dem Hören zu dienen; jedenfalls ist er an der unbewussten Regulirıng des Körpergleichgewichtes betheiligt. (Vgl. Seite 164.)

\section{Stimme und Sprache.}

Die für den Menschen wichtigsten akustischen Phänomene sind diejenigen der Stimme und Sprache. Unter den Begriff der menschlichen Stimmbildung fallen diejenigen hörbaren Lebensäusserungen, welche auf Grund der Schwingungsfähigkeit der Stimmbänder des Kehlkopfes entstehen, und welche in ästhetischer Beziehung den Eindruck des Musikalischen machen; die Sprache beschränkt sich nicht nur auf den Gebrauch ron Stimmerzeugnissen, deren musikalischer Charakter im Dienste der Sprache übrigens zurücktritt, sondern sie rerwendet auch in hervorragender Weise unmusikalische Geräusche, welche durch den Exspirattionsluftstrom auf dem Wege zwischen Glottis und Lippenspalte erzeugt werden und ausserdem mannigfacher nicht akustisch sondern optisch wirkender Muskelbewegungen. Der optische Eindruck solcher Bewegungen kann ein vorïbergehender sein, wie bei den die Rede begleitenden Gesticulationen oder bei der selbstständigen Gebärdensprache; ein sichtbarer Effect ron Gliederbewegungen kann aber auch durch besondere Hilfsmittel, zum Zwecke wiederholter Betrachtung fixirt werden in der Schrift.

Da die Stimme ein akustisches Erzeugniss ron musikalischem Charakter ist, so kitun derjenige Theil des Organismus, welcher der Stimmbildung dient, als musikalisches Instrument betrachtet werden und es 
fragt sich, mit welchem der gebrïuchlichen musikalischen Instrumente der menschliche Stimmapparat am besten verglichen werden kann. Es ist dies die Zungenpfeife, deren wesentlichsten Theile sind: erstens die Windlate, zweitens die Pfeife mit Zungenwerk und drittens das Ansatzrohr. Die Windlade liefert den Luftstrom rou regulirburer Intensität, welcher zum Anblasen jeder Pfeife erforderlich ist, ron der Windlade gelangt der luftstrom zunächst in das Rohr der Pfeife, ans welchen er nur nach Durchgang ilurch das Zungenwerk wieder entweichen kann. In dem Zungenwerke hat der Luftstrom eine Enge ron rhythmisch variabler Weite, zwischen den Rändern der Zunge und einem die Zunge umgebenden Rahmen, zu passiren. Die Zunge besteht bei den in der Musik zur Verwendung kommenden künstlichen Zungenpfeifen aus einer elastischen Metallplatte, welche an ihrem einen Ende fest geklemmt ist, sodass sie mit ihrem freien Theile regelmüssige Schwingungen ausführen kamn. Die Lä̈nge des schwingungsfähigen Theiles der Metallzunge kann durch einen Stinmstift regulirt werden, welcher derselben in einer leicht variirharen Entfernung von ihrem fest geklemmten Ende eine feste Anlagerung giebt. Der Rahmen hat einen scharfrandigen Ausschnitt, in welchem - wenigstens bei den hier in Betracht kommenden Pfeifen mit „durchsehlagender" Zunge - die Zunge frei anf- und abschwingen kann und welcher von der Zunge in ihrer Ruhelage ziemlich genau ausgefiillt wird. Je weiter sich die Zunge aus ihrer Gleichgewichtslage nach der einen oder der anderen Seite entfernt, um so mehr erweitert sich der Spalt zwischen dem Riande der Zunge und dem Rande des Ausschnittes im Rahmen.

Der Yorgang beim Anblasen der Zunge ist folgender: der aus der Windlade anlangende Luftstrom erzeugt in dem Pfeifenrohr eine Drucksteigerung, unter deren Wirkung die Zunge nach oben abgelenkt wird. Hierdurch wird zweierlei veranlasst: erstens steigt mit wachsender $\mathrm{Ab}$ lenkung der Feder die elastische Kraft, welche sie in ilıre Gleichgewichtslage zurückzuführen strebt, und zweitens nimmt der Luftdruck unterhallb der Zunge ab, wegen des freieren Abströmens der Luft durch den erweiterten Spalt. Beide Momente mischen sich zusammen, um die Rückkehr der Zunge in ihre Gleichgewichtslage herbeizuführen, welche sie wegen der Trägheit ihrer Masse überschreitet. Der Beginn des hierauf eintretenden Rïckschwunges erfolgt, sobald die lebendige Kraft der bewegten Masse Null geworden ist. Das rhythmische An- und Abschwellen der Intensität des Luftstromes jenseits des Spaltes erzeugt dort entsprechende rhythmische Druckänderungen, welche weit ïber den Bereich des translatorischen Luftstromes hinaus sich wellenartig fortpflanzen, und wemn sie ein Ohr treffen, Veranlassung zur Wahrnehmung eines Klanges von bestimmter Intensität, Höhe und Farbe geben. 
Dic Intensitait ist, ausser von der Entfernung zwischen Ohr und Pfeife, wesentlich abhängig von der Stärke des durch die Windlade gelieferten Luftstromes und von dem Unfange, in welchem die Spaltbreite schwaukt, die Tonhöhe innerhalb weiter Grenzen nur von der eigenen Schwingungszahl der Zunge, die Klangfarbe von der Schwingungsform der Zunge und von ihrer räumlichen Beziehung zur Oeffnumg des Rahmens. Es giebt metallische Zungen, deren Schwingungen wie die der Stimmgabeln dem Pendelgesetz gehorchen. Diese Zungen geben, wenn man sie ausserhalb der Pfeife in Schwingungen versetzt, zum Beispiel durch Anstreichen, einen einfachen Ton, d. h. sie erzengen Druckschwankungen in der Luft, deren zeitlicher Ablauf sich durch eine einfache Sinuscurve darstellen lässt; bläst man aber eine Pfeife an, welche eine solche Zunge enthält, so giebt sie doch keinen einfachen Ton, sondern einen Klang, welcher aus einer Anzahl von Tönen zusammengesetzt ist. Dass der zeitliche Verlauf der Druckschwankungen in der Luft jetzt nicht mehr durch eine einfache Sinuscurve darstellbar, sondern verwickelter ist, muss erwartet werden, da der Luftdruck jenseits des Zungenwerkes direct von der Stromintensität abhängt, und da die Spaltweite im Allgemeinen nicht einfach proportional dem Ausschlagswinkel der Zunge ist.

Für den im Zungenwerk von Zungenpfeifen entstehenden Klang gilt also allgemein, dass er ausser dem Grundton eine beträchtliche Zahl harmonischer Obertöne enthält, deren Intensität (im Verhältniss zur Intensität des Grundtones) in verschiedener Weise mit der Ordnungszahl zusammenhängen kann. Aus diesen Componenten, welche die im Zungenwerk erzeugte Klangmasse zusammensetzen, kann nun durch den dritten Haupttheil der Zungenpfeife, durch das Ansatzrohr eine Auswahl getroffen werden. Das Ansatzrohr ist ein Resonator, welcher je nach seinen räumlichen Verhältnissen die einen Obertöne verstärkt, die anderen unterdrïckt.

An dem menschlichen Stimmapparat ist die Windlade durch den lirustkasten mit der Lunge vertreten, das Zungenwerk durch den Kehlkopf mit den Stimmbändern, das Ansatzrohr durch Rachen-, Mund- und Nasenhöhle. Durch die inspiratorische Erweiterung des Brustkastens wird, bei offen stehender. Glottis, eine beträchtliche Menge Luft unhörbar in rlie Lungen aufgenommen. Behufs Stimmbildung wird, nachdem die Gilottis bis auf einen engen sagittalen Spalt zwischen den gespannten Stimıbändern geschlossen ist, durch die zweckmässig abgestufte Thätigkeit der Ansathmungsmuskeln, die Luft in der Lunge unter erhöhten I)ruck gesetzt, sorlass sie, nur zwischen den Stimmbändern hindurehstreiclıend, diese in Schwingung versetzt. Jie Stimmbänder kann man, im Gegensatz zu der metallischen Zunge der künstlichen Zungenpfeife, 
als membranöse /ungen bezeichnen. Während in dem Zungenwerke der metallischen /ungenpfeife der Spalt von rhythmisch veränderlicher Weite zwischen den Rändern der \%unge und denen des liahmens eingeschlossen ist, und die Veränderung in der Weite des Spaltes nur durch die Bewegung des einen diescr Stücke erzengt wird, bewegen sich in dem Kehlkopf beide den Spalt einschliessenden Stïcke, nämlich die Stimmbänder. An den Stimmbändern sind nur die einander zugekehrten scharfen Ränder frei, in ihrem übrigen Umfange sind die Stimmlaänder mit den Wänden des Kehlkopfes verwachsen. Die in die Schwingungen einbezogenen Theile der Stimmbänder erstrecken sich bei rerschiedenen Schwingungszuständen derselben verschieden weit von den freien Rändern nach aussen. Jeder transversale Streifen eines Stimmbandes fiihrt bei der Schwingung Bewegungen aus, ähnlich denen einer einzelnen metallischen Zunge, und das Zustandekommen der Schwingungen erfolgt durch ein Kräftespiel, welches dem bei der metallischen Zunge beschriebenen entspricht: Drucksteigerung unterhalb der Stimmbänder, Ausschlag derselben nach oben mit Zunahme der elastischen Spannung und mit Erweiterung des Spaltes; in Folge dessen Vermehrung des Abflusses von Luft und Druckrerminderung unterhalb der Glottis, Rïckschwingen der Stimmbänder mit Verengerung des Spaltes u. s. f. Der weitere causale Zusammenhang fiur Erzeugung des Klanges ist rhythmische Aenderung erstens der Spaltweite, zweitens der Stromintensität im Glottisspalt und drittens des Druckes oberhalb der Glottis. Die rhythmischen Druckschwankungen pflanzen sich ebenfalls wellenartig weit über deu Bereich des translatorischen Luftstromes hinaus fort und veranlassen, wenn sie ein Ohr treffen, die Wahrnehmung des Stimmklanges.

Die Schwingungsform der Stimmbänder ist unter allen Umständen keine einfach pendelartige und uiberdies eine, je nach den Spannungszuständen der in Betracht kommenden Muskehn verschiedene. Noch verwickelteren Gesetzen folgt, aus den bei Betrachtung der Zungenpfeife angegebenen Gründen, der zeitliche Ablauf der rhythmischen Druckschwankungen. In dem Kehlkopf werden also stets Klänge erzeugt, welche ausser dem Grundton eine beträchtliche Anzahl ron harmonischen Obertönen entlialten. Die Auswahl, welche aus diesen Partialtönen getroffen wird, ist eine in breiten Grenzen variirende wegen der stark veränderlichen Form der Mund- und Rachenhöhle.

Auf die anatomischen Verhältnisse, welche bei den phonatorischen Bewegungen des Thorax und bei den Formänderungen der Mund- und Rachenhöllle in Betracht kommen, braucht hier nicht eingegangen zu werden, doch lassen sich einige derartige Bemerkungen mit Bezug auf den Kehlkopf nicht umgehen. Für den mechanischen Aufbau des Kehlkopfes kann der Ringknorpel als die Grundlage betrachtet werden, er 
wird deshalb anch der Grundknorpel genannt. An der Seitenfläche der Platte des Ringknorpels ist der Schildknorpel mit seinen kurzen unteren Hörnern so eingẹlenkt, dass beide Knorpel um eine horizontale, transversale Axe gegen einander gedreht werden können.

Die Drehung, bei welcher der vordere Spalt zwischen Ring- und Schildknorpel verkleinert, die sagittale Entfernung der Stimmbandinsertion an der vorderen Kante des Schildknorpels von der oberen Kante der Ringplatte vergrössert wird, wird durch Zusammenziehung der Musculi cricothyreoidei antici bewirkt und erfolgt thatsächlich durch Hebung des vorderen Theiles des Ringknorpels gegen den unteren vorderen Rand des feststehenden Schildknorpels. Die Auffassung des in Betracht kommenden Verhältnisses wird aber etwas erleichtert, wenn man sich den Schildknorpel gegen den Ringknorpel abwärts gedrelht vorstellt. Bei dieser Drehung - wie man sie sich auch vorstellen möge - werden die hinteren Insertionspunkte der Stimmbänder von den vorderen entfernt, vorausgesetzt, dass die hinteren Insertionspunkte durch Feststellung der Giessbeckenknorpel auf der Ringplatte fixirt sind. Andernfalls würde die Zusammenziehung der Musculi cricothyreoidei antici nicht zur Spannung der Stimmbänder, sondern zum Vornüberkippen der Giessbeckenknorpel auf dem oberen Rande der Ringplatte führen. Dieselben sind nämlich dort so eingelenkt, dłass sie folgende Bewegungen ausfiihren können: erstens Drehung um eine horizontale transversale Axe, wobei die Spitzen der Processus vocales sich in verticalen sagittalen Bögen bewegen unter Beibehaltung ihres gegenseitigen Abstandes; zweitens um je eine verticale Axe, wobei die Spitzen der Processus vocales sich von einander entfernen oder sich nähern; drittens Gleiten in transversaler Richtung, wobei die einander zugekehrten Flächen der Giessbeckenknorpel sich ohne Drehung nähern oder entfernen.

Die zuerst aufgefiihrte Drehung, und zwar nach vorn unten würde zu Stande kommen, wenn von allen Kehlkopfmuskeln sich die Cricothyreoidei allein zusammenziehen würden. Eine Spannung der Stimmbänder würde hierbei nicht erzielt werden; dazu müsste die durch die Cricothyreoidei angestrebte Drehung der Giessbeckenknorpel verhindert sein. Ein in dieser Beziehung dem Cricothyreoideus antagonistischer Muskel ist der Musculus cricoarytïnoideus posticus, aber nur mit einer Componente seiner Bewegungsrichtung (Fig. 42). Letzter'e enthält noch eine andere Componente, welche gleichzeitig zur Drehung um die zweite der genannten Axen, die verticale führt (Fig. 43). Durch die alleinige antagonistische Thätigkeit der Cricothyreoidei und der Cricoarytänoidei postici kommt es also zwar zur Spannung der Stimmbänder, gleichzeitig aber auch zur Auswärtsdrehung der Processus vocales, d. h. zur Eröffnung der Glottis. Für das Ausprechen der Stimmbänder ist aber 
nicht nur ein gewisser Spanmmgsgrarl derselben erforderlich, sondern auch eine gewisse Enge der Stimmritze. Es ist also behufs Stimmbildung das Eingreifen ron Muskeln erforderlich, welche, ohne die durch die Cricoarytänoidei postici hewirkte Drehung der Giessbeckenknorpel

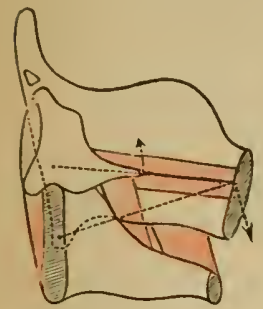

42.

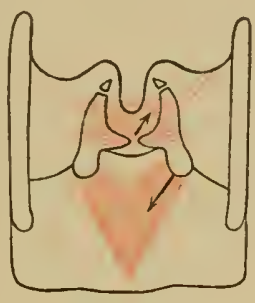

43.

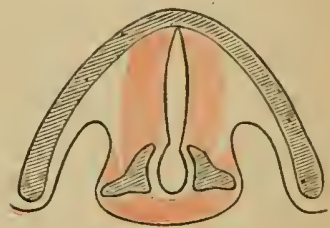

44.

$u m$ die transversale Axe nach hinten aufzuheben, der die Glottis erweiternden Componente derselben entgegen wirken. Dieses thun die arytïnoirlei proprii, welche die Giessheckenknorpel ohne Drehung gegen einander gleiten machen, und welche zusammen mit den Cricoarytänoidei laterales und Thyreoarytïnoidei eine Art Sphincter der Stimmritze darstellen (Fig. 44).

Den Musculi thyreoarytänoidei interni et externi fällt ausserdem, dass sie an der Verengerung des Glottisspaltes betheiligt sind, noch eine andere wichtige Aufgabe zu; diese besteht in der Absteifung des auf frontalem Querschnitt dreieckig, mit breiter nach aussen gerichteter Basis erscheinenden Körpers der Stimmbänder (Fig. 45). Sind die letztgenannten Muskeln contrahirt, so schwingt der ganze Körper jedes Stimmbandes als cin Ganzes, sind sie schlaff, so bildet sich eine, dem Stimmbandrande parallele Knotenlinie, und der sehnige, scharfe Rand des Stimmbandes bewegt sich bei der Schwingung jedesmal in entgegengesetztem Simne wie die schlaffe Basis; es kommt dies so zu Stande: die Drucksteigerung unterhalb der Glottis bei Contraction der Exspirationsmuskeln bewirkt

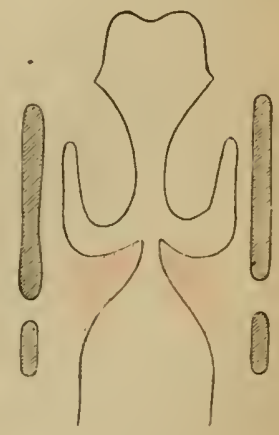

45. zunächst Ausbauchung der schlafferen Basis nach oben. Ist die Basis hierdurch gespannt, so wächst der Druck und bewegt anch die strafferen, sehnigen Ränder nach oben; in Folge dessen sinkt der Druck unterhalb der Glottis, zunächst fällt die Basis ein, dann schwingt auch der Rand zuriick u. s. f.

Bei der Schwingung der Stimmbandränder um die Knotenlinie ist die schwingende Masse kleiner, als wenn jeder Stimmbandkörper als ein 
Ganzes schwingt und die Länge jedes transversalen, in gleicher Schwingungsrichtung begriffenen Abschnittes ist auch kürzer. Bei dieser Schwingungsart, welche dem besonderen, Falsett oder Kopfstimme genannten Stiminregister entspricht, ist also die Dawer jeder einzelnen Schwingung kleiner, der Ton im Allgemeinen höher. Durch die Contraction der Thyreoarytänoidei dagegen wird das Schwingen der Stimmbänder im Ganzen bedingt, und es ertönt die Bruststimme mit ihren tieferen Tonlagen.

Die Contraction der Thyreoarytänoidei allein würde zu einer gegenseitigen Annälnerung der vorderen und hinteren Insertion des Stimmbandes und damit zu einer Entspannung des schwingenden Randes des letzteren führen. Damit die Stimmbänder in der Bruststimme ansprechen, ist also eine stärkere Gegenspannung der Cricothyreoidei und der Cricoarytänoidei postici erforderlich, und da durch die Wirkung der letzteren die Glottis nicht erweitert werden darf, auch der Arytänoidei proprii und der Cricoarytänoidei laterales. Bei den Brusttönen fühlt man auch eine grössere Spannung im Kehlkopf, als bei der Kopfstimme (die höchsten Töne der letzteren machen eine Ausnahme). Dagegen ist bei der Stellung der Stimmbänder für das Falsett die Glottis weiter und, wegen des hierdurch bedingten stärkeren Luftverbrauches, die Spannung der Exspirationsmuskeln stärker, als bei den Brusttönen. Die grössere Enge der Glottis bei letzteren bewirkt stärkeres Mitschwingen der Luftsäule unterhalb der Stimmritze und des Brustkastens. Der Stimmfremitus ist bei den Brusttönen stärker am Thorax fühlbar, bei der Kópfstimme stärker am Kopf. Das Schwingen der Stimmbänder im Ganzen wie es bei der Bruststimme eintritt, bringt einfachere Bedingungen für dic Schwingungsform der Luft mit sich, die entstehende Klangmasse ist einfacher, enthält weniger Obertöne, dic Klangfarbe ist weicher, als beim Falsett, welches leicht etwas Schmetterndes erhält.

Im Bereiche des Registers der Brusttöne wird die Erhöhung des Tones der Stimme einfach durch Vermehrung der Spannung der Stimmbänder er\%ielt. Auf welche Weise hieran alle inneren Kehlkopfmuskeln betheiligt sind, ist schon erörtert. Von einer gewissen, individuell verschiedenen Tonhöle an kann die Stimmbildung in beiden Registern erfolgen, eine fernere Steigerung ist dann aber nur im Falsett möglich.

IBei den für beide liegister gemeinschaftlichen Tonhöhen ist die Spamming der Stimmbänder im Falsett geringer, als im Brustton. Im Falsett treten bei den höheren Tonlagen zu der durch die Contraction der inneren Kehlkopfmuskeln erzielten Spannungsvermehrung der Stimmbänder noch zwei weitere Hilfsmittel hinzu. Durch kräftigere Contraction der Cricoarytänoidei laterales können die Processus vocales fest an cinander gerlrïckt werden, hierdurch werden die hinteren Theile der 
sehnigen Stimmbänder zur gegenseitigen Beriihrung gehracht. Je weiter sich diese Berührung nach rornhin erstreckt, ein um so kïrzeres Stück der Stimmbänder, in sagittaler Richtung gemessen, bleibt schwingungsfïhig und um so schneller müssen die Seluwingungen erfolgen. Es handelt sich $\mathrm{um}$ eine Wirkung, analng derjenigen des Stimmstiftes in der metallischen Zungenpfeife.

Dass dic hinteren Theile der Stimmbandränder bei der Koptstimme in dauernder gegenseitiger Berïhrung bleilsen kïnnen, sodass sie sich an der Schwingung nicht betheiligen, ist sicher constatirt, die Ursache hierfür ist wohl noch nicht ganz aufgeklärt; es wäre möglich, dass sie in der Contraction derjenigen Fasern der Thyreoarytänoidei interni gelegen wäre, welche aus der sagittalen Richtung transversal umbiegend, sich am ligamentösen Stimmbandrand inseriren. Durch die Wirkung solcher Fasern kann ein Theil des Stimmbandes ror der Insertion gespannt und nach aussen bewegt, der dahinter gelegene Theil entspannt und nach innen gedrückt werden.

Bei weichen Kiehlköpfen, um welche es sich bei der Hervorbringung der höchsten Stimmtöne handelt, werden die Cricothyreoidei antici und Cricnarytänoidei postici in ihrer antagonistischen, die Stimmbänder spannenden Wirkung durch äussere K'ehlkopfmuskeln unterstiitzt. Hierzu können alle Muskeln beitragen, welche den Winkel zwischen den beiden Platten des Schildknorpels zu verkleinern im Stande sind, namentlich die obere Portion des Constrictor pharyngis infimus und auch, bei nach oben fixirtem Zungenbein, die Sternothyreoidei und die Thyreohyoidei, besonders die letzteren, welche gleichzeitig den Kehlkopf heben. In der That wird beim Hinaufgehen mit der Stimme der Kehlkopf gehoben.

Die Grösse des Antheiles der Tonscala, welchen ein Individuun beherrscht, der Stimmumfang, ist hauptsächlich von der Uebung abhängig, die Stimmlage dagegen, d. h. der mittlere Ort des Stimmumfanges in Bezug auf die Tonscala, wird in erster Linie durch die anatomischen Verliältnisse bedingt. Die kleineren Abmessungen des Kehlkopfes und die grössere Weichheit seiner Kinorpel bei Kindern und Frauen enthalten die Bedingungen für die höheren Stimmlagen im Gegensatz zu den Männern. Fïr den Umfang und die Stimmlage der Singstimmen gelten folgende Angaben, in Bezug auf deren Form zu bemerken ist, dass die in [] stehenden Noten die Mitte jeder Stimmlage ausmachen, in der sie sich am krïftigsten entfaltet, während die in () angefügten für gewöhnlich keinen guten Klang mehr haben.

Sopran: (c1) $d^{1} e^{1} f^{1}\left[g^{1} a^{1} h^{1} c^{2} d^{2}\right] e^{2} f^{2} g^{2}\left(a^{2} h^{2}\right)$.

Alt: (g) a h $c^{1}\left[d^{1} e^{1} f^{1} g^{1} a^{1} h^{1}\right] c^{2}\left(d^{2}\right)$.

Tenor: (c d) e f $g$ [a h $\left.c^{1} d^{3} e^{1}\right] f^{1} g^{1} a^{1}\left(h^{1}\right)$.

Bass: (F) G A H c $\left[d\right.$ e f g a $\left.h_{1}\right] c^{1} d^{1}\left(e^{1}\right)$. 
Ausnalumswcise wurde rom Bass das Contra $F$ (42 Schwingungen) und rom Discant das $a^{3}$ (1708 Schwingungen) erreicht.

Die Intensität des Stimmklanges ist ceteris paribus von der Stärke des exspiratorischen Luftstromes alhängig. Eine eigenthümliche Schwierigkeit erwächst, wenn dieselbe Tonhöhe bei wechselnder Tonstärke innegehalten werden soll, wie es beim crescendo und decrescendo des Gesanges gefordert wird, denn die Tonhöhe membranöser Zungenpfeifen ist in nicht unerheblichem Maasse ron der Stärke des Anblasens abhängig. Schwillt der exspiratorische Druck im crescendo an, so werden durch den Luftdruck an sich die Stimmbänder schon stärker gespannt, und es wird behufs Festhaltung der Tonhöhe eine compensatorische Entspannung des Muskelzuges erforderlich. Das Erforderniss eines für jede bestimmte Tonstärke bestimmt abgemessenen Grades dieser Compensation erschwert auch den richtigen Stimmeinsatz bei beliebiger Tonstärke. Um so erstaunlicher ist der Grad der Genauigkeit des Stimmeinsatzes, iiber welchen geïbte Sänger verfügen, und welche ihnen das Treffen des beabsichtigten Tones bis auf Fehler von etwa $1 \%$ der Schwingungszahl gestattet. Bemerkenswerth ist auch, dass der Stimmeinsatz mit kleineren Fehlern erfolgt, als das Aushalten des Tones. Die Fähigkeit, die Tonhöhe abzustufen, ist zwar anscheinend keiner sehr feinen Ausbildıng fähig: das Intervall, in welchem der Sänger von Stimmton zu Stimmton auf- und absteigen kann, beträgt kaum weniger als 1/4 Ton; dies reicht für das musikalische Bedïrfniss aber auch vollkommen aus.

Der Reichthum von Partialtönen, welcher dem in der Glottis erzeugten Stimmklange eigen ist, bringt es mit sich, dass derselbe je nach den Resonanzverhältnissen des Ansatzrohres eine grosse Mannigfaltigkeit von Klangfarben annehmen kann. Dies kommt der Verwendung des Stimmklanges für die Zwecke der Sprache zu statten. Wohl ist eine sprachliche Verständigung möglich ohne Stimmklang, wie die Fliistersprache lehrt, bei welcher die Glottis nicht zum Tönen gebracht wirl, auch reicht der Stimmklang nicht aus, um diejenige Zahl leicht unterscheidharer Laute zu lieferm, deren jede Sprache bedarf. Damit aber die Rerle Kraft und Wohllaut liabe, ist eine Klasse ron Lauten erforderlich, welche klangvoll und musikalisch wirkend die Grundpfeiler darstellen, an welche sich die akustisch und ïsthetisch geringerwerthigen Laute mit dem Charakter von Gerïuschen anfïgen lassen. Letztere sind die Consonanten, erstere die Vocale, und die Vocale sind nichts Anderes, als farbliche Modificationen, welche der Stimmklang bei den Formänderungen des Ansatzrohres erfährt.

Lm rlas Thatsäichliche der Beziehungen zwischen den Formwandlungen in der Rachen- und Mundhöhle einerseits und den $A$ bänderungen der Vocallaute andererseits vollkommen iblersehen $z u$ kïmen, ist aus 
einem später einleuchtenden Grunde nur die genaue Betrachtung dreier Vocale erforderlich, des $A$, des I und des $U$. Ehe wir auf diese Betrachtung eingehen, muss hier jedoch im Allgemeinen bemerkt werden, dass zu jeder vollkommenen Vocalbildung der Verschluss des Rachenraumes gegen den Nasenraum erforderlich ist. Wird dieser nicht gebildet, so erhält man die sogenannten nasalirten Vocale, auf welche später einzugehen sein wird. Die zur vollkommenen Vocalisirung erforderliche Abgrenzung zwischen Nasen- und Rachenraum erfolgt durch die gleichzeitige Contraction des obersten Schlundschniirers und der Musculatur des weichen Gaumens, sowie des Gaumenschlundbogens. Der oberste Schlundschnürer und der Pterygopharyngeus pressen die hintere und seitliche Pharynxwand wulstförmig (Passavant'scher Wulst) dicht an den hinteren Rand des erhobenen und gespannten Gaumensegels, wobei sich zugleich die Ränder des hinteren Gaumenbogens nähern, um das durch den Azygos uvulae gespannte Zäpfchen zwischen sich zu nehmen.

Gehen wir nun auf die einzelnen der genannten Vocale ein, so gilt fiir das A folgendes: Kehlkopf, Zunge und Lippen bleiben in ihrer Ruhelage, der Unterkiefer wird zur mässigen Oeffnung des Mundes einfach gesenkt, ohne vorgeschoben oder zurückgezogen zu werden. Die willkiirliche Muskelaction bei Vocalisirung des A beschränkt sich also auf die Stimmgabe in der Glottis, die (nicht sehr vollkommene) Abgrenzung zwischen Nasen- und Rachenraum und die Oeffnung des Mundes. Die Form, welche das Ansatzrohr erhält, ist ebenfalls einfach, es ist die eines nach vorn erweiterten Trichters, freilich nicht mit geraden, sondern nach vorn unten concaven Mantellinien; das Ansatzrohr ist weder verlängert noch verkürzt, der Stimmfremitus ist am Scheitel und Brustkorb ziemlich gleich deutlich zu fühlen.

Bei dem $J$ ist der Kehlkopf empor-, der Unterkiefer zurückgezogen unter nur geringer Abwärtsdrehung (Mundöffnung); die Abgrenzung zwischen Nasen- und Rachenraum ist fester wie bei dem $A$ und $U$; die Mundspalte ist in transversaler Richtung rerbreitert zwischen den gespannten und an die Schneidezähne angedrückten Lippen. Die Zungenspitze ist gegen die unteren Schneidezähne gestemmt, die grösste Masse des Zungenfleisches in der Mitte der Zunge zusammengezogen und in Form eines grossen Wulstes dem harten Gaumen stark angenähert; das Ansatzrohr ist im Ganzen verkïrzt, und durch die Enge zwischen Zungenrïcken und hartem Gaumen in zwei Räume geschicden, deren jeder etwa die Form einer Birne oder Retorte hat. Der Stimmfremitus ist rorwiegend am Scheitel zu fühlen.

Bei dem U ist der Kehlkopf herabgezogen, der Unterkiefer unter geringer Abwärtsdrehung rorgeschoben, die Mundspalte ist transtersal 
rerschmälert, im Ganzen abgerundet zwischen den vorgeschobenen Lippen. Die Zungenspitze liegt, verschmälert, dem vordersten Theile des Mundbodens rühig auf, die Masse des Zungenfleisches ist über der Zungenbasis zusammengezogen und bildet dort gegenüber dem weichen Gaumen einen Wulst. Das Ansatzrohr ist im Ganzen verlängert und hat die Form einer Retorte mit weitem, nach hinten und unten gebogenem Halse und

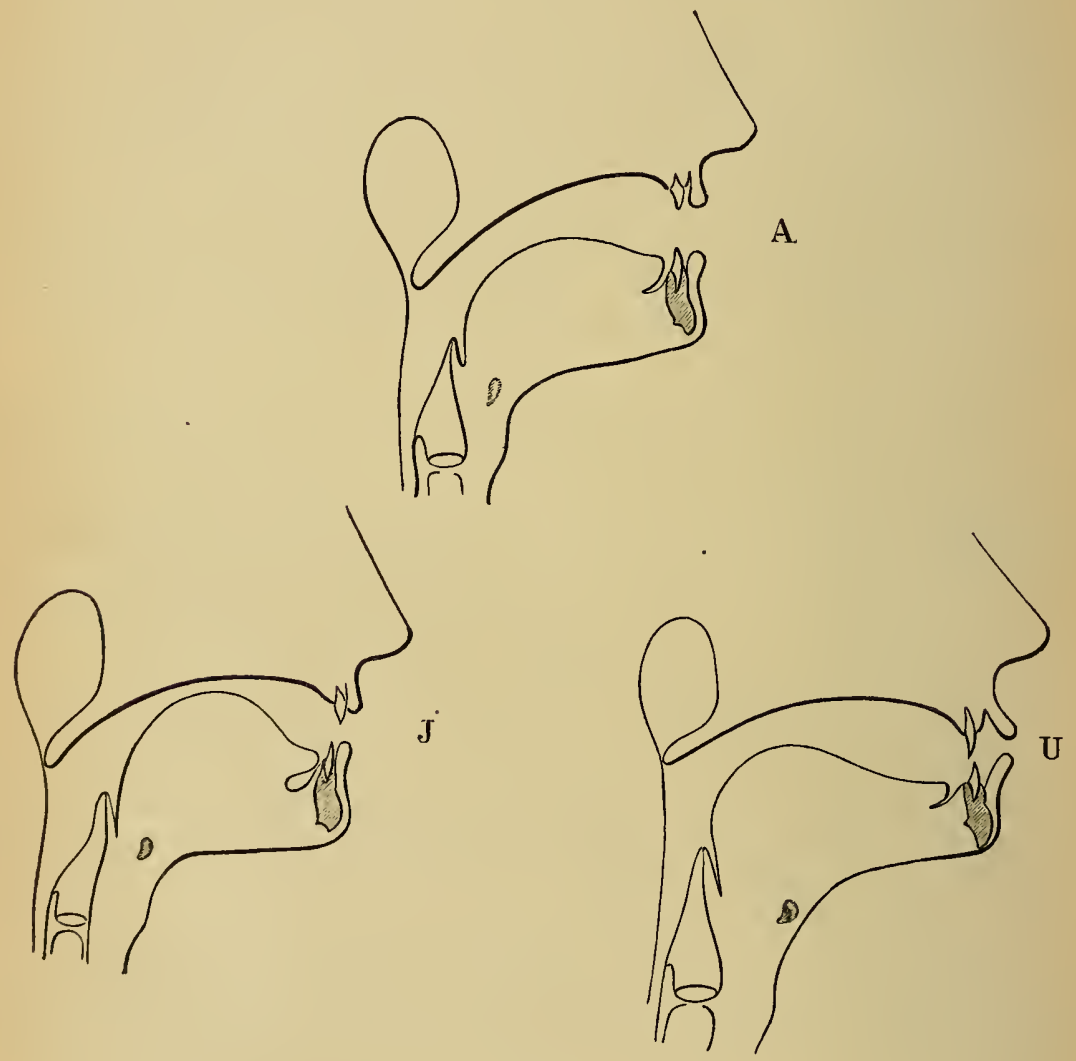

46.

mit einem stumpflegeligen, rund geöffueten $\Lambda$ nsatz an dem nach vorn gerichteten Blasenborlen. Der kegelförmige Ansatz ist von den vorgeschobenen Lippen und den Schneidezähnen eingeschlossen, die Wände der Retortenblase sind gebildet von den Zähnen und Alveolarrändern beider Kiefer, von der nach vorn oben concaven vorderen und mittleren Partie des Zungenrückens und von dem harten Gaumen. Der Stimmfremitus ist rorwiegend am Brustkorb zu fülllen.

Die gegebenen Beschreibungen gelten für den Fall des Strebens nach möglichst vollkommener Ausbildung der einzelnen Laute. Bei der 
gewöhnlichen Rede können manche ron den als charakteristisch bezeichneten Punkten etwas rernachlïssigt werden, ohne dass die Verstïndlichkeit leidet. Die Riuicksicht auf Schönheit des Ḱlanges gestattet weniger Alweichungen. Benerkt muss freilich werden, dass der Stärkegrad, in welchem die einzelnen coneurrirenden Bewegungen nothwendig werden, etwas von den individuellen anatomischen Verhältuissen abhängt. So miïssen Ǩinder behufs deutlicher Aussprache des $U$ die Lippen mehr vorschieben als Männer, während Letztere hehufs scharfer Vocalisirung des I den Kiehlkopf stärker heben miissen als jene.

In Bezug auf rlie Vocallaute herrscht nun eine merkwürdige Gesetzmäissigkeit, welche es gestattet, das ganze Gebiet dureh einen dreiseitigen Flïchenraum darzustellen, dessen einzelne Punkte in leicht äberschbarer Weise den einzelnen vocalischen Lautmöglichkeiten entsprechen und dessen Gesammtheit die ganze Nannigfaltigkeit der Lautmöglichkeiten auf diesem Gebiete erschöpft. In den Ecken des Dreiecks müssen die Laute $\Lambda, I, U$ ihren Platz finden, denn alle iibrigen Voeale werden bei Mundstellungen gebildet, welche auf dem Uebergang der einen der oben geschilderten extremen Mundstellungen in eine der anderen liegen. Geht man z. B. aus der Mundstellung für das A allmählich in diejenige für das I ïber und rocalisirt auf verschiedenen der Zwischenstufen, so erhält man die Reihe a $a^{e} e^{n}$ e i. Die Regelmässigkeit bezieht sich aber nicht nur auf den Uebergang der Mundstellungen ineinander, sondern auch auf die Aenderung der akustischen Wirkung, denn der akustische Findruck des e erscheint uns deutlich ähnlicher dem i als dem a, und der des $a^{\mathbf{e}}$ ähnlicher dem des a, als dem des $\mathrm{i}$.

Nach dem Gesagten wird folgendes Diagramm des natïrlichen Systems der Tocallaute verständlich sein:

$$
\begin{aligned}
& \text { a } \\
& a^{e} a^{n} \\
& e^{a} \quad a^{0 e} \quad o^{a} \\
& \text { e } e^{n} \quad o^{e} \quad \\
& \text { i } \mathrm{i}^{\mathrm{u}} \quad \mathrm{u}^{\mathrm{i}} \mathrm{u}
\end{aligned}
$$

Auf Grund rein subjectiver Beobachtung ist behauptet worden, dass das Wesentliche in der Klangmasse des $\mathrm{U}$ sei: alleiniges Vorhandensein des Grundtones oder Combination des Grundtones mit nur einem und zwar dem ersten Oberton; in der Ḱlangmasse des $A$ : Combination des Grundtones mit einer continuirlichen Reihe ron Obertönen bis zu hoher Ordnungszahl und unter Abnahme der Intensität der Obertöne mit wachsender Ordnungszahl; in der des I: die Combination des Grundtones mit nur wenigen Obertönen ron ausschliesslich hoher Ordnungszahl. Diese Auffassung hat etwas ungemein Bestechendes dadureh, dass 
man bei derselben auch vom physikalischen Standpunkt aus dem A, I, U extreme Stellungen anweisen kann, zwischen welchen sich Uebergänge bilden lassen; das $\mathrm{O}$ wïrde z. B. mehr Obertöne haben wie das U, und zwar niederer Ordnungszahl, während dem E mehr Obertöne zukämen, wie dem I, aber von höherer Ordnungszahl. Die subjective Beobachtung, welche dieser Auffassung $\mathrm{zu}$ Grunde liegt, beruht auf einer grossen Uebung in der unmittelbaren Zerlegung von Klangmassen in ihre Componenten mit Hilfe eines fein entwickelten, musikalischen Gehörs. Es hat auch nicht an Untersuchungen gefehlt, welche die Auffassung mittelst objectiver Methoden zu stützen schienen. Andere Forscher sind aber durch andere objective Methoden wieder zu anderen Resultaten gelangt, welche aber auch unter einander in Widerspruch stehen.

Da der Uebergang aus einer der extremen Mundstellungen in die andere continuirlich erfolgen kann, so erscheint die Fixirung der bestimmten, durch die obigen Lautzeichen repräsentirten Zwischenstationen zunächst als willkürlich. Unı dieselbe zu begründen, und um zugleich die mit den Zeichen gemeinten Laute klar hervortreten zu lassen, wollen wir für jedes Zeichen und den ihm entsprechenden Laut Beispiele aufführen. Mit der deutschen Sprache werden wir hierbei nicht auskommen, weil sie ebensowenig wie irgend eine andere Sprache von der ganzen Lautmöglichkeit Gebrauch macht, doch wird das Hinzuziehen allgemein zugänglicher Sprachen genügen. Nach Durchsicht der gegebenen Beispiele wird man zu der Ueberzeugung kommen, dass man einerseits mit den gewählten Zwischenstationen auskommt und dass andererseits keine derselben überflüssig ist. Ehe wir zur Aufstellung der Beispiele übergehen, müssen wir jedoch noch auf eine besondere, dies Gebiet betreffende Frage aufmerksam machen, wie weit nämlich die zeitliche Kürzung des Vocallautes auf seine akustische Nuancirung von Einfluss ist. Von einer Seite ist dieser Einfluss ganz geleugnet, ron anderer vielleicht $\mathrm{zu}$ stark betont worden. Wir denken das Urtheil hierüber zu erleichtern, wenn wir für jeden Laut Beispiele kurzen und langen Gebrauches aufführen.

\section{Die A-I-Reihe.}

a lang: Aar, Wahll, Abend - l'âme, gâteau, l'art — dare, lato father, rather (nicht ganz rein);

kurz: Ast, arm, alt - dame, battre - fatto, pranzo -- engl. vacat;

$a^{e}$ lang: Schwäne, wäre - e ouvert in père, crême - ital. vacat - there;

kurz: Bänder, Wälder, Fässer - franz. vacat - ital. vacat man, fat, lad. 
$e^{a}$ lang: deutsch vacat - paire - ital. vacat - hair, bare, their; kurz: Eltern (im Gegensatz zu ältern) - lettre, mettre - petto, diletto - let, get, whet;

e lang: ewig, selig, kehren - e fermé, aimé - tremo - wave, name (aber nicht hate, siehe unter Diphthongen);

kurz: wenn iiberhaupt vorhanden, so im ital. z. B. in den beiden letzten Silben von credere;

i lang: mir, ihr, Lied - écrire - giro - wheel;

kurz: Ritt, Hirt, Bild — fritte - scritto (im ital. am reinsten) - little.

\section{Die A-U-Reihe.}

a siebe unter 1 .

$a^{0}$ lang: schwedisch ¿̊, dänisch aa - deutsch, franz., ital. vacat walk, law, all;

kurz: Trommel - l'homme - ital. vacat - come;

$0^{a}$ lang: deutsch dialectisch, z. B. ich mog nicht - or, encore ital. vacat - lord, scorn;

kurz: Horn, Gold - bonne - troppo, fossa - not, on (nicht rein);

o lang: Mohr, Oper - oreille, anneau - Roma, Como - gold, bold (aber nicht stone, bone, siele unter Diphthongen);

kurz: wenn iiberhaupt vorhanden, so im ital. fosse im Gegensatz zu fossa;

u lang: Muth, Bube - trou, courage - fiume - room, roof;

kurz: Gurt, Duldung - goutte - brutto - englisch vacat.

In dieser Reihe wäre zwischen o und u noch eine Zwischenpause zu fixiren, deren Laut aber nur gekürzt vorkommt im italienischen "corso", das o der ersten Silbe.

\section{Die I-U-Reihe.}

i siehe unter 1 .

$i^{u}$ lang: Physik, ostpreussisch: über;

kurz: Myrthe;

$u^{i}$ lang: Schüler - tuer - ital., engl. vacat;

kurz: Würde, Brücke - lutter - ital., engl. vacat.

4. Die Mittel-Vocale.

$\mathrm{a}^{\text {oe }}$ lang: deutsch vacat - veuve, soeur - ital., engl. vacat;

kurz: Moerder, Koerper - franz., ital., engl. vacat; 
$e^{0}$ lang: deutsch racat - franz. racat - earl, girl - ital. vacat;

$o^{\mathrm{e}}$ lang: Loerre, hoeren - leur, peur - ital., engl. racat.

kurz: koennen - veuillez - ital., engl. vacat.

Dass es Vocale giebt, welchen man bei der Kürzung nur schwer ihre volle Ausprägung geben kann, erkennt man an dem Beispiele des e. Im Allgemeinen gelingt es aber recht wohl, am leichtesten bei dem u und a. Freilich wird wohl ron dieser Möglichkeit bei der gewöhnlichen Rede nicht immer voller Gebrauch gemacht. Treibt man die Kürzung iiber ein gewisses Maass hinaus, so muss allerdings jeder Vocal undeutlich werden; deun nimmt man selbst an, dass das Sprachorgan vor Beginn der Intonation des Vocals die völlig richtige Einstellung erhalten hat, so rergeht doch immer einige Zeit, bis die Stimmbänder ansprechen und bis die Resonanz der zur speciellen Klangmasse gehörigen Partialtöne im richtigen Intensitätsverhältniss erfolgt. Anders ist dies bei der Verlängerung des einfachen, nicht diphthongischen Vocals über die gewöhnliche Dauer hinaus. Hier liegt die Grenze nur in der Menge der zur Verfügung stehenden Exspirationsluft und diese Grenze wird wohl selten erreicht. Von der Dehnung der Vocale wird im Allgemeinen ein geringerer Gebrauch gemacht, als von ihrer Kürzung, doch wird auch sie in einigen Fällen benutzt. Gelegentlich geschieht es im Interesse genaueren Verständnisses. Will man zum Beispiel lautlich scharf unterscheiden zwischen "du sasst (sedebas)" und "du sahst (videbas)", so giebt man dem a in dem zweiten Falle eine grössere Länge, eine Länge zweiten Grades, wie man es nennt. Längen zweiten Grades werden auch schon in der gewöhnlichen Rede bevorzugt bei Worten, welche eine gewisse Seelenstimmung andeuten, wie: sehnen, ahnen, flehen etc. und auf Katheder, Kanzel und Bühne wird von der Dehuung der Vocale ein noch häufigerer Gebrauch gemacht. Das Bedeutendste hierin sollen die professionellen Koranleser leisten, welche sich stets in Längeu zweiten, dritten oder vierten Grades bewegen.

Bei Vorstehendem haben wir nur möglichst vollkommen gebildete Vocallaute im Sinne gehabt. In Bezug auf die Deutlichkeit und Reinheit in der Ausprägung der Vocale stehen die verschiedenen Sprachen niclıt gleich, das Italienische am höchsten, das Englische am tiefsten. Das Italienische bevorzugt auch, was ebenfalls mit dem Sinne für Reinheit des Vocalklanges zusammenhängen mag, die den Grenzen des natürlichen Systems näher stelıenden Vocallaute, während die Mittel-Vocale fehlen. Auch hierin tritt das Englische in Gegensatz zum Italienischen. Das Evglische geht aber noch weiter, es hat eine besondere Classe von Vocallauten entwickelt, für welche gerade die Unvollkommenheit der Bildung als charakteristisch angegeben wird. Ihre wissenschaftliche $\mathrm{Be}$ - 
handlung ist darum auch schwierig. Es sind Laute von kurzer Dauer, deren Stellung im System der Vocale eine nittlere ist und behufs deren Hervorbringung die Ruhelage des Sprachorgans nur um ein Mindestmass in der einen oder anderen Richtung verlassen wird.

Zur Bezeichnung der ,unvollkommen gebildeten Vocale* bedient man sich eines unter das Vocalzeichen gesetzten, nach links oftenen Häkchens. Die hierher gehörigen Laute mit Beispielen ihres Vorkommens sind:

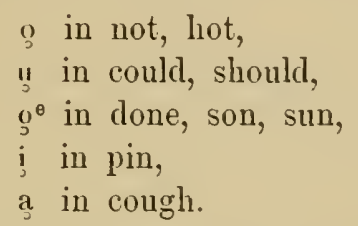

Von diesen Lauten unterschieden hat man nun noch einen ...unbestimmten Vocal“" (Lepsius). Bei näherer Betrachtung sieht man jedoch, dass dieser an Stellen gesetzt wird, wo grammatikalisch zwar ein Vocal zwischen Consonanten zu erwarten wäre, wo aber thatsïchlich die consonantische Lautfolge durch gar keinen Vocallaut unterbrochen wird. Deutlich tritt das hervor in Worten wie "werden", in welchem bei der gewöhnlichen Rede die zweite Silbe den unbestimmten Vocal haben soll. Nun ist aber bei dem d sowohl als bei dem $n$ der Weg fuir den Exspirationsluftstrom durch den Mund zwischen Zunge und Oberkiefer fest verschlossen und in diesem Verschluss tritt bei der gewöhnlichen Aussprache des Wortes „werden“ keine Aenderung ein. Sollte zwischen d und n irgend ein, wenn auch noch so unbestimmter Vocal erklingen, so mïsste die Zungenspitze gelüftet werden.

Um zu der Lehre von den zusammengesetzten Vocalen iibergehen zu können, mïssen wir nun eine genaue Definition dessen geben, was wir einen einfachen Vocal nennen. Alle diejenigen Vocallaute nemnen wir einfach, bei deren Hervorbringung eine bestimmte Mundstellung, mag sie eine mittlere in Bezug auf das natiirliche System oder eine extreme sein, dauernd festgehalten wird. Ob die Bezeichnung durch ein einfaches oder zusammengesetztes Schriftzeichen erfolgt, ist hierbei ohne Belang. Durch die doppelten Schriftzeichen ae oder ue werden Laute bezeichnet, welche in Bezug auf die Einfachheit gleichwerthig sind mit a und u. Es werden auch Lautfolgen einfacher Vocale gebildet, bei denen wegen der Unterbrechung der Stimme zwischen den einzelnen Vocalen (Hiatus) nichts weiter entsteht, als eben eine Folge einficher Vocallate, wie im Worte „fuimus“. Wird aber bei ununterbrochener Stimmgabe der Cebcrgang der Mundstellung für den einen Vocal in diejenige für den nächsten schnell gebildet, so entsteht ein Vocalklang mit neuen, eigenurtigem 
Charakter, wie im Worte „pfui“. Diese Vocalklänge, welche man in der That als zusammengesetzte den einfachen gegenüber stellen kann, nennt man die-Diphthonge. Zum Hervortreten des diphthongischen Charakters ist es erforderlich, dass weniger Gewicht auf den Anlaut und Auslaut, als auf den Uebergang zwischen beiden gelegt werde. Die Italiener bilden vocalische Lautfolgen ohne Hiatus und doch keine Diphthongen, weil sie den An- und Auslaut betonen und den Uebergang nicht schnell bilden. In "paura" wird au als Lautfolge ohne Hiatus gesprochen, nicht als Diphthong wie in "Maus“.

Nach dieser Definition der Diphthonge sollte man die Mannigfaltigkeit der Lautmöglichkeiten auf diesem Gebiete für eine grosse halten. Die Zahl der verschiedenen Combinationen der 14 im System aufgestellten einfachen Vocallaute zu je zweien ist $13 \times 14=182$.

Die Zahl der Verbindungen, welchen man diphthongischen Charakter geben kann und welche als Diphthonge thatsächlich vorkommen, ist aber erstaunlich viel kleiner. Eine gute Ausprägung des diphthongischen Charakters ist nur möglich bei dem Uebergang von offener Mundstellung zu geschlossener, also von a zu i oder u. Die Classe der Lautcombinationen, welche in umgekehrter Richtung erfolgen, werden deshalb als Halbdiphthonge von dem Gebiet ausgesondert. Unter den eigentlichen Diphthongen sind die reinsten diejenigen "mit grosser Spannweite“, das sind diejenigen, deren combinirte Laute im System weit von einander abstehen: ai, $\mathrm{a}^{\mathrm{e}} \mathrm{i}$ und au, die einzigen Diphthongen, welche schon im Sanskrit rorkommen.

1. Diphthonge grosser Spannweite.

ai: Kaiser ;

$\mathrm{a}^{\mathrm{e} i}$ : heisel - life;

au : kaum - cow.

2. Diphthonge kleiner Spannweite.

$\mathrm{e}^{\mathrm{a}} \mathrm{i}$ : Rheinland (dialectisch);

èi: mit verlängertem Anlaut und nur kurz anklingendem Auslaut: day, name, hate, an Stellen, wo früher im Englischen reines e; $\mathrm{a}^{0} \mathrm{u}$ : tau (plattdeutsch);

$a^{e} u^{i}$ : Häuser;

oi $^{u}$ : Neun - oil, coil;

ōu: mit verlängertem Anlaut und nur kurz anklingendem Auslaut in bone, stone, an Stellen, wo früher im Englischen reines o; oii: mit bevorzugtem Auslaut in hout (holländisch). 


\section{Halbdiphthonge.}

0a: roi ;

ua: water (mit bevorzugtem Auslaut);

io: yonder (mit cousonantischer Färbung des Anlautes);

ıi: pfui.

Im Französischen, welches den Hiatus meidet, tritt eine annähernd diphthongische Verbindung ein zwischen dem Schlussvocal eines Wortes und dem Anfangsvocal des nächsten:

armée ennemie, journéc admirable, vie atile.

Eine diphthongische Verbindung von melı als zwei Vocalen tritt gelegentlich, wenn auch selten, auf. So spricht der Westphale statt des a in ja einen Tetraphthong: jeoau.

Wir haben gleich anfangs hervorgehoben, dass eine wesentliche Bedingung für die vollkommene Bildung der Vocale die Abgrenzung zwischen Nasen- und Rachenraum ist. Unterbleibt dieselbe, so erhält der Vocal eine nicht gerade angenehme Aenderung seiner Klangfarbe, er wird "nasalirt". Beim Nasaliren streicht der Exspirationsluftstrom fuir gewöhnlich durch Mund und Nase, doch kann man einen Vocal auch dauernd nasalirt sprechen, wenn man die Nasenlöcher verschliesst. In der deutschen, englischen, italienischen, spanischen Sprache wird nicht nasalirt. Der Deutsche erlernt das Nasaliren auch schwer, er spricht zum Beispiel statt des nasalirten a gerne ang. Hieran kann man ihn verhindern und zum richtigen Nasaliren kann man ilın veranlassen, wenn man ihm anfgiebt, einen Vocal dauernd nasalirt zu sprechen bei zugehaltener Nase. Auch in denjenigen Sprachen, welche vom Nasaliren Gebrauch machen, wird nur eine beschränkte Zahl einfacher Vocale, kein Diphthong nasalirt. Un die Nasalirung anzudeuten, setzt man unter das Vocalzeichen ein nach rechts offenes Häkchen.

\section{Nasalirte Vocale.}

ą: an, en, dans, vent )

$e^{\mathrm{a}}$ oder $\mathrm{a}^{\mathrm{e}}:$ vin $\mathrm{j}$ enfin ;

$a^{00}:$ l'un ;

: on, mon.

Im Portugiesischen ausserdem auch $\mathrm{i}$ und $\mathrm{u}$.

Dass das Nasaliren aus der Lautfolge: Vocal - Semivocal entstanden ist, geht aus folgendem Beispiel hervor: Sanskrit, dastra mit der Urform danstra, entsprechend dem dens und óóóvtos.

So leitet der nasalirte Vocal uiber zu einer Classe von Lauten, welche ebensowenig wie jene durch Geräusche complicirt sind und welche man 
doch schon zu den Consonanten zu rechnen pflegt. Es sind die Rhinophone $\mathrm{m}, \mathrm{n}$ und $\mathrm{ng}$, welche wegen ihrer Zwischenstellung auch Semirocale grenannt werden. Bei ihnen ist der Weg durch den Mund für den Exspirationsluftstrom geschlossen und nur derjenige durch die Nase offen. Sie werden, ausser in der Fliistersprache, stets nur mit Stimme, das heisst bei tönender Glottis, gesprochen. Letzteres gilt auch von den durch ein eigenartiges Geräusch charakterisirten Zitterlauten, den RLauten. Die meisten uibrigen Sprachlante sind charakterisirt durch bestimmte Geräusche, erhalten aber, je nachdem dies Geräusch mit oder ohne begleitenden Stimmklang hervorgebracht wird, verschiedene Nuancirungen und werden dementsprechend auch durch besondere Schriftzeichen wiedergegeben. Nur die in der Glottis selbst erzeugten Geräusche; deren Prototyp das $\mathrm{H}$ ist, können nie von Stimmklang begleitet werden.

Das Vorstehende könnte die Grundlage zu einem natürlichen System der Consonanten abgeben, doch würde ein solches der Uebersichtlichkeit entbehren. Wir ziehen es deshalb vor, in hergebrachter Weise die Consonanten in eine Tabelle zu ordnen, deren Grundlage dadurch gegeben ist, dass in dem einen Eingang die Articulationsgebiete, in dem anderen die Geräuscharten die Eintheilung beherrschen. Die dann weiter noch erforderlichen Untertheilungen sind an den entsprechenden Stellen eingefügt. Die Tabelle bedarf aber noch der ausführlicheren Erläuterung, weil innerhalb der meisten Articulationsgebiete besondere Articulationsstellen zu unterscheiden sind und weil sonst noch Manches auszusagen ist, was sich in die Tabelle nicht leicht aufnehmen lässt.

System der Consonanten.

\begin{tabular}{|c|c|c|c|c|c|c|c|}
\hline \multirow[t]{2}{*}{ Articulationsgebiete } & \multirow{2}{*}{ 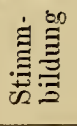 } & \multicolumn{3}{|c|}{$\begin{array}{c}\text { Reibungsgeräusche bei } \\
\text { Ausfluss }\end{array}$} & \multirow{2}{*}{ 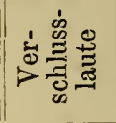 } & \multirow{2}{*}{ 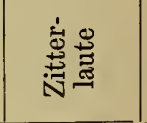 } & \multirow{2}{*}{ 宫最 } \\
\hline & & mitten & seitlich & allseitig & & & \\
\hline \multirow{2}{*}{$\begin{array}{l}\text { Unterlippe mit Ober- } \\
\text { lippe oder oberen } \\
\text { Schneidezähnen }\end{array}$} & ohne & $\mathrm{F}$ & - & - & $\mathrm{P}$ & - & - \\
\hline & mit & W & - & - & B & Lippen $\mathrm{R}$ & M \\
\hline \multirow{2}{*}{$\begin{array}{l}\text { II. } \\
\text { Zungenspitze mit } \\
\text { Sc:hneidezähnen oder } \\
\text { Alveolarrand }\end{array}$} & ohne & $\begin{array}{l}\mathrm{S} \text { in heiss } \\
\mathrm{Th} \text { in thick }\end{array}$ & (L) & $\begin{array}{l}\text { Sch in } \\
\text { Schaum }\end{array}$ & $\mathrm{T}$ & - & - \\
\hline & mit & $\begin{array}{l}\mathrm{S} \text { in sausen } \\
\mathrm{Th} \text { in those }\end{array}$ & $\mathrm{L}$ & $\begin{array}{c}J \text { in } \\
\text { jamais }\end{array}$ & $\mathrm{D}$ & Zungen $\mathrm{R}$ & $\mathrm{N}$ \\
\hline \multirow{2}{*}{$\begin{array}{l}\text { III. } \\
\text { Zungenrücken mit } \\
\text { Gaumen }\end{array}$} & ohne & $\begin{array}{c}\text { CH in zechen } \\
\text { lachen }\end{array}$ & - & - & $\mathrm{K}$ & - & - \\
\hline & mit & $\mathrm{J}$ in ja & - & - & G & Uvular $\mathrm{R}$ & $N G$ \\
\hline \multirow{2}{*}{ Kehlkopf IV. . . . . } & ohne & $\mathrm{H}$ & - & - & $\begin{array}{l}\text { arabisch } \\
\text { Hamze } \\
\end{array}$ & - & -- \\
\hline & mit & - & -1 & - & - & GutturalR & - \\
\hline
\end{tabular}


Das Wesen der Reibungsgeräusche ist lcicht $z$ fassen, sie entstehen, wenn der Exspirationsluftstrom mit einiger Kraft durch eine Enge hindurch gepresst wird. Dass hierbei (ausser beim H) je nach Belieben Stimme gegeben werden kann oder nicht, ist selbstverständlich. Innerhalb der einzelnen Articulationsgebiete kann man noch verschiedene Stellen unterscheiden, an denen die Enge für Entstehung des Gerïusches gebildet werden kann. Im ersten Articulationsgebiete kann die Enge gebildet werden 1. zwischen Unterlippe und oberen Schneidezähnen, labiodental, oder 2. zwischen den beiden vorgeschobenen Lippen, bilabial.

$f^{\prime}$ (labiodental) Fall, Vater, Vetter, fetter - feu, faire - Firenze - for, five.

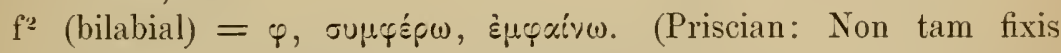
labris pronuntianda est $f$ quomodo $\varphi$ ).

$w^{1}$ Wunder.

$w^{2}$ wool, wood - Quelle.

Zwischen $\mathrm{f}^{1}$ und $\mathrm{w}^{1}$ : vin, vérité — vanity, cough — vezel (holländisch).

Bei den Reibegeräuschen des zweiten Articulationsgebietes ist zu unterscheiden zwischen mittlerem, seitlichem und allseitigem Ausfluss. Die Bedeutung hierron wird klar, wenn man die Aufmerksamkeit der Zungenbewegung zulenkt und erst S, dann L, dann Sch spricht. Bei den S liegen die seitlichen Zungenränder den oberen Backenzähnen an und die Luft entweicht nur ïber die Zungenspitze. Geht man zum L über, so stellt die Zungenspitze den Verschluss her und die seitlichen Zungenränder machen Raum für den Luftdurchtritt. Das Sch kann gesprochen werden - und wird auch wohl meist so ausgesprochen - indem der Zungenrand in seinem ganzen Unfange frei ist und die Zunge allseitig rom Luftstrom umspült wird.

Die S-Laute können in drei Articulationsweisen gebildet werden, je nach der Stelle, an welcher, und nach der Art, in weicher die Enge hergestellt wird. Die erste Stelle ist am Alveolarrand iiber den Schneidezähnen des Oberkiefers. Hier kann die Enge entweder dadurch gebildet werden, dass die Zungenspitze gegen die unteren Schneidezähne gestenmt und der Rïcken der Zungenspitze dem Alveolarrande des Oberkiefers stark angenähert wird (linguodental), oder dadurch, dass man die Zungenspitze erhebt und die Luft zwischen dem Rande der Zungenspitze und dem Alveolarrande des Oberkiefers hindurchpresst (alveolar). Erstere Bildungsweise ist die häufigere, aber auch die zweite kommt vor, z. B. in der Lautfolge $t s=z$. Ein akustischer Unterschied tritt je nach der einen oder anderen Bildungsweise an der ersten Articulationsstelle nicht herror. Dies findet jedoch in sehr bemerkenswerther Weise statt, wenn man statt 
der ersten die zweite Articulationsstelle wählt. Diese liegt zwischen dem Riicken der Zungenspitze und den oberen Schneidezähnen. Die Enge wird hier gebildet, indem der Unterkiefer etwas zurückgezogen und die Zungenspitze, auf den unteren Schneidezähnen

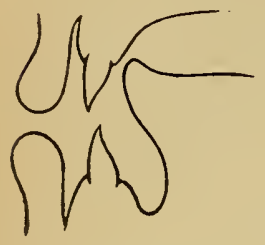

alveolar. (1)

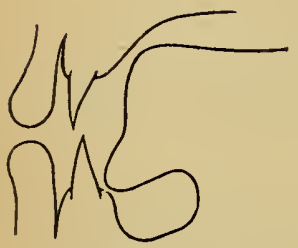

linguodental. (2)

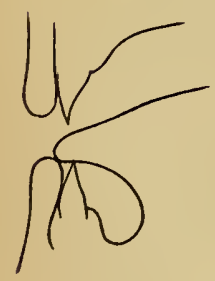

interdental. (3)

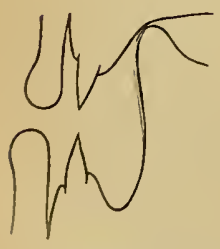

cacuminal. (4) ruhend, bis zur leichten Beriihrung der Unterlippe vorgeschoben wird. Dies ist die als interdental zu bezeichnende Bildungsweise des englischen th, welches klanglos gleich dem hellenischen $\vartheta$, klingend gleich dem hellenischen $\delta$ ist. Fiir das linguodentale $\mathrm{s}$ hat, je nachdem es klanglos oder klingend gesprochen wird, keine Sprache eine schriftliche Unterscheidung ausgebildet. Wir wollen das erstere mit der deutschen Letter $\mathfrak{g}$, das zweite mit der lateinischen Letter $\mathrm{s}$ bezeichnen.

פ: das, Last, heiss - sou, c'est ça - rosso, cosi - house;

s: sausen - hasard, raison - paese, sguardo - gazing, reason - $\sigma \beta \varepsilon \dot{\varepsilon} v u \mu l$.

$\vartheta$ : thing - spanisch $\mathrm{z}$ vor a, o, u; c vor e, i;

o: that.

Die interdentale Bildung des $\mathrm{S}$ kommt im Hochdeutschen, Plattdeutschen, Italienischen nicht vor (das Isländische soll sie besitzen). Dass die Bildungsweise allgemein nicht als leicht empfunden wird, geht daraus hervor, dass $\delta$ im Englischen oft in ds oder d abwandelt, $\vartheta$ in ff (Dickens

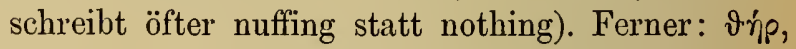

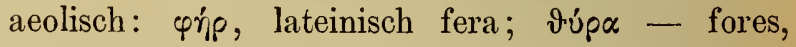
Эupós - fumus. Russisch: Feodor aus Theodor, Marfa aus Martha, Afanasia aus Athanasia.

Bei den L-Lauten wird dort, wo bei den S-Lauten die Enge gebildet wurde, der Verschluss mit der Zungenspitze hergestellt, während die Seitenränder der Zunge gelöst werden. Es kehrt die linguodentale, alveolare und interdentale Bildungsweise wieder und hierzu tritt die cacuminale, bei welcher die Zungenspitze oberhalb des Alveolarrandes dem Gaumen selbst angelegt wird. Die klanglose Bildung des $\mathrm{L}$, ist selten, kommt aber vor, zum Beispiel in dem aus dem Wälischen stammenden Worte Lloyd. 
1' (alveolar) ist das gewöhnliche L der Deutschen;

l' (linguodental) ist bei dem einfachen L selten.

Diese Bildungsweise erleichtert aber das sogenannte Mouilliren des $\mathrm{L}$, woron später bei den zusammengesetzten Consonanten.

$l^{3}$ (interdental) bei Lisplern (und im Sanskrit?)

$\mathrm{I}^{+}$(cacuminal) ein L der Veden, von Bopp in lra transscribirt.

Nach Einigen das 1 der Polen. Norwegisch in $\overline{-1}{ }^{4} \mathrm{a}^{0}$, Eigenname, dänisch Olaf gesprochen.

Englisch will, well, bell. - Im Italienischen wird das L vielfach zwischen I' und l' gesprochen. Ausserdem am besten geeignet zur klanglosen Hervorbringung des $\mathrm{L}$ in Lloyd.

Die Sch-Laute sind einfache Consonanten, trotz der widersprechenden Behauptung einer gewichtigen Autorität und obgleich merkwürdigerweise nur sehr wenige Sprachen (sanskrit, semitisch, altslavisch, russisch) ein eigenes und einfaches Lautzeichen für die klanglose, doch sehr verbreitete Sprechweise ausgebildet oder bewahrt haben. Die klingende Sprechweise kommt selten vor, wird aber dann durch einen einzelnen (wenn auch nicht eigenen) Buchstaben bezeichnet. Sch ist weder eine Lautfolge, noch ein zusammengesetzter Consonant in dem Sinne, dass bei seiner Bildung die Bedingungen für die gleichzeitige Hervorbringung zweier verschiedener Consonanten vorhanden wären. Die Hauptschwierigkeit für eine richtige Auffassung liegt wohl darin, dass ein Sch auf verschiedene Weise gebildet werden kann. So erhält man ein solches zum Beispiel, wenn man ein klangloses $\mathrm{l}^{+}$(cacuminal) gebildet hat und nun den Unterkiefer etwas mehr erhebt und die Lippen vorschiebt. Voller wird das Geräusch dann aber, wenn man die bei dem 1+ dem Gaumen anliegende Zungenspitze frei macht, sodass die Zunge als ein überall, ausser an der Basis, freier Zapfen in die Mundhöhle hineinragt und allseitig von dem Exspirationsstrom umspült wird. Man kann dann die Zunge auch mannigfach bewegen, ohne dass das Sch unterbrochen würde. Es ändert hierbei allerdings etwas seine Nuance. Am deutlichsten ist der Einfluss, welchen die Stellung der frei umspïlten Zunge auf die Nuancirung des Sch hat, wenn man die zum Zapfen geformte Zunge einfach vorschiebt oder zuriickzieht. Das Sch ist ein Gerüusch, an welchem sich nicht nur die Schärfe, sondern auch die Tonhöhe deutlich ändern lässt; bei kurzem Zungenzapfen ist es weich und tief, bei langem scharf und hoch. Von dieser Nuancirung wird namentlich in der Lautfolge nach $d$ und $t$ Gebrauch gemacht. Je kiirzer der Zungenzapfen, um so melr müssen ausserdem die Lippen bei der Lautbildung mitwirken, das heisst um so mehr müssen sie rorgeschoben werden. Je nach der Länge des Zungenzapfens wählen wir die Indices 1 für kurz 
und 2 für lang. Zur Bezeichnung des Lautes selbst wählen wir ŝ für den klanglosen und ’ für den klingenden.

s': Schaar - charme - ocean — polnisch sz - böhmisch š;

$\hat{s}^{2}$ : deutsch vacat -- französisch? - ruscello, scimia, sciolto precious, passion, conscience, patience - ungarisch Pest $=$ Pescht - schwedisch skön $=$ schön, Nordenskiöld $=$ Nurdenschiöld.

ẙ: deutsch vacat - génie, jamais - ital. nur in der Lautfolge nach d - pleasure, mansion, pretension;

t $\hat{s}^{1}$ : church;

$\mathrm{ts}^{2}$ : ciceri. Dieser verhängnissvolle Laut ist in der That nichts Anderes, als eine schnelle Folge von t linguodental und sch, bei langem Zungenzapfen, ganz kurz, mit möglichst geringer Zungenbewegung zwischen $t$ und sch und ohne Betheiligung der Lippen ausgesprochen;

dỳ ${ }^{1}:$ joy ;

dy $\hat{y}^{2}:$ gibbo.

Für die Reibungsgeräusche des dritten Articulationsgebietes wird die Enge zwischen Zungenrücken und hartem Gaumen gebildet; je nachdem dies weiter vorn oder hinten stattfindet, wollen wir die Indices 1, 2, 3 anwenden. Die klanglosen Laute sollen mit $\chi$, die klingenden mit y bezeichnet werden. Das Französische, Italienische, Englische hat weder ein $\%$ noch $y$.

$\chi^{t}$ : recht, richtig. Im Anlaut deutsch nur dialectisch in morgen und in der Diminutiv-Silbe chen, aber im Hellenischen $\chi \varepsilon i p$;

$\chi^{2}$ : Bach, Woche, Wucher - schottisch loch. Die Engländer haben es zu Shakespeare's Zeiten gehabt und der Londoner cabman sagt noch jetzt ächt shilling (eight sh.);

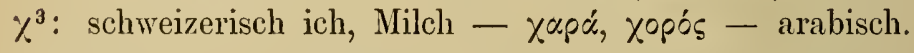

Deutlich ist der Einfluss des vorangehenden Vocals auf den Bildungsort des $\chi$; nach e, i, ei vorne, nach a, o, u weiter hinten. Scheinbare Ausnahme bildet schweizerisch ich, doch wird hier nach dem i ein flïchtiges a gesprochen. Auffallend, aber leicht zu erklären ist auch: Aachen - aber Mamachen, rauchen - aber Frauchen, Kúchen (placenta) -- aber Kuhchen (vaccula).

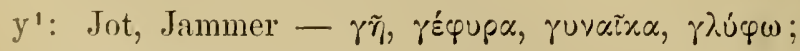

$\mathrm{y}^{2}:$ im Niederdeutschen: sagen;

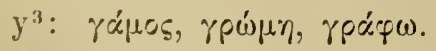

Zwischen $\%$ und $y^{1}$ : nature, moisture, young; vielleicht gehört auch der Verbindungslaut zwischen journée admirable hierher. 
Die Consonanten des ricrten Articulationsgebietes lassen sich am besten im Zusammenlange bchandeln.

Die Verschlusslaute umfissen die in der Grammatik als Tenues und Mediae hezeichneten Consonanten. Je nachdem einer dieser Consonanten im Anslaut, im Aulaut oder zwischen zwei Vocalen gebraucht wird, kommt das charakteristische Gerïusch bei dem Verschluss, oder bei der Oeffnung einer Enge für den Exspirationsstrom, orler bei beiden zu Stande. Wegen des zweiten und dritten Falles nennt man die Laute auch Explosirlaute. Bei den Tenues erfolgt Verschluss und Oeffinung plötzlich, letztere in der That explosionsartig. Vor der Oeffnung des Mundschlusses wird der Druck im Thorax unterhalb der verschlossenen Glottis erheblich gesteigert, dann wird die Glottis plötzlich geöffnet und der jühe Exspirationsluftstrom sprengt den Mundrerschluss. Bei den Mediae erfolgt Verschluss und Oeffnung allmällich, die Glottis wird nicht geschlossen, der Mundschluss wird nicht gesprengt, sondern durch fein abgestufte Muskelaction aufgehoben. Da bei den Tenues die Glottis fest geschlossen wird, so kann nicht bei ihnen Stimme gegeben werden, sie mïssen klanglos gesprochen werden. Bei den Mediae dagegen kann Stimme gegeben werden und wird meistens Stimme gegeben, wenn sich auch die klanglose Media ron der Tenuis wohl unterscheiden lässt durch die grössere Weichheit des Geräusches. Auf den ersten Blick kamn es als ein Widerspruch erscheinen, dass bei Mundschluss Stimme gegeben werden soll, denn zum Ansprechen der Stimmbänder gehört Exspirationsluftstrom. Etwas Luft kamn nun in der That auch bei verschlossenem Mund die Glottis passiren, so riel nämlich, als in dem durch Blähung weicher Begrenzungen wachsenden Raum zwischen Glottis und Mundschluss Platz hat. Man nennt deshalb auch den die Mediae begleitenden Stimmklang den Blählaut.

Die Tenuis des ersten Articulationsgebietes ist P, die Media B. Jeder dieser Laute wird nur auf eine Weise gebildet, indem der Mundschluss zwischen den Lippen erzengt wird.

Im zweiten Articulationsgebiete, dessen Tenuis T und dessen Media D ist, bewerkstelligt die Zungenspitze den Mundschluss. Es kann dies auf die rier verschiedenen, beim $L$ angegebenen Weisen geschehen. Das T wird am häufigsten alreolar gebillet, linguodental in Lautfolgen wie st, sp, interdental ron Lisplern, cacuminal gelegentlich im Sanskrit. Die Media D geht im Auslaut, ebenso wie die anderen Mediae, leicht in die Tenuis über, doch ist hier zu bemerken, dass die Engländer deutlich unterscheiden zwischen bad und bat.

In dritten Articulationsgebiet wird bei der Tenuis $\mathrm{K}$ und bei der Media $G$ der Verschluss zwischen Zungenrïcken und Gaumen gebildet, 
und zwar ebenso wie die Enge bei $\mathrm{Ch}$ und $\mathrm{J}$ verschieden weit vorn oder hinten:

$$
\begin{array}{ll}
\mathrm{k}_{1}: \text { chiesa, kegel, } & \mathrm{g}_{1}: \text { ghirlanda, gêben, } \\
\mathrm{k}_{2}: \text { corso, kugel, } & \mathrm{g}_{2}: \text { Gurt, } \\
\mathrm{k}_{3}: \text { im Arabischen, } & \mathrm{g}_{3}: \text { im Arabischen. }
\end{array}
$$

Die Zitterlaute entstehen, wemn bei dauernder Stimmgabe ein zitternder Mundschluss gebildet wird. Die beim Erzittern entstehende abwechselnde Schliessung erfolgt schnell genug zur Erzeugung eines charakteristischen Geräusches und zu selten für die Bildung eines Tones, selbst des tiefsten. Der zitternde Schluss kann in jedem Articulationsgebiet gebildet werden. Das Lippen-R wird nicht nur häufig bei dem Haltruf der Kutscher Brr! gebraucht, sondern es findet auch sprachliche Verwendung, freilich nur bei Wilden. Eine Insel bei Neu-Guinea heisst Ambrim, aber das br dieses Wortes ist keine Lautfolge, sondern es wird von den Eingeborenen durch zitternden Lippenschluss hervorgebracht. Das Zungen-R soll das eigentliche $R$ der Deutschen sein. Es lässt sich am leichtesten bei cacuminaler Haltung der Zungenspitze erzeugen. Lautlich am vollkommensten ist das Uvular-R, welches als $R$ der Franzosen bezeichnet wird.

Die Entstehungsweise der Rhinophone ist dadurch charakterisirt, dass bei dauernder Stimmgabe und bei verschieden hergestelltem Mundschluss die Luft ausschliesslich durch die Nase entweicht. Innerhalb des ersten Articulationsgebietes wird der Schluss nur auf eine Art erzeugt, durch Zusammenpressen der Lippen, dann ertönt das M. Innerhalb des zweiten Articulationsgebietes wird zur Hervorbringung des $\mathrm{N}$ der Schluss meist aveolar gebildet; doch ist zu bemerken, dass das Mouilliren des $\mathrm{N}$, ebenso wie das des L leichter bei linguodentaler Bildungsweise erfolgt. Für den Rhinophon des dritten Articulationsgebietes giebt es kein eigenes einfaches Schriftzeichen (ausser im Sanskrit). Der Schluss zwischen Zungenrücken und Gaumen wird auch hier weiter vorn oder hinten gebildet, weiter vorn nach e, i und weiter hinten nach a, o, u.

Engel, Fnkel, Dinge, Winkel;

Wange, Anker, long, Onkel, Schwange, Trunk;

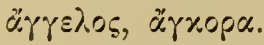

Um die lautlichen Erscheinungen auf dem vierten Articulationsgebiete zu übersehen, muss man sich vergegenwärtigen, dass die Glottis entweder so weit geöffnet sein kann, dass die Ausathmung unhörbar erfolgt, oder dass sie zweitens so fest geschlossen sein kann, dass sie zwar gegen einigen Ueberdruck der thoracalen Luft dicht hält, dass der Verschluss aber durch plötzliche Steigerung des Exspirationsdruckes in lautlich wirksamer Weise gesprengt werden kann (Hamze der Araber), 
oder dass drittens der Glottisspalt nur soweit verengert ist, dass die Stimmbänder zwar nicht zum Tönen gebracht werden, wohl alser ein Reibungsgeräusch veranlassen (H), und dass viertens der Giad des Verschlusses und der Spannung der Stimmbänder die Bedingungen für den dem Vocallaut zu Grunde liegenden Kklang bietet. Yon der Art der Herstellung des letzteren Zustandes liängt nun wieder eine Verschiedenheit im Ansprechen des Vocallautes ab. Der Vocal klingt geräuschlos, aber plötzlich und hart an, wenn die zuvor fest verschlossene Glottis zwar nicht durch den Exspirationsluftstrom gesprengt, wohl aber durch Action der inneren Kélılkopfmuskeln plötzlich geöffnet wird, und wenn das 'Tönen der Glottis in der für den Vocal erforderlichen Weise sofort in voller Stärke beginnt. Es ist dies die Art, wie der Vocal nach dem Hiatus gesprochen wird. Dic zweite, weiche Art, den Vocal auszusprechen, entsteht, wemn der Glottisschluss allmählich gelöst wird, und wenı der Exspirationsluftstrom ebenso allmählich anschwillt, wie auch die Genauigkeit der Einstellung der Glottis für den Vocal allmählich hergestellt wird. Es ist dies die Art, wie der Vocal im Anlaut ron denjenigen Völkern gesprochen wird, welche den Hiatus meiden. Der Spiritus lenis bedeutet den Hinweis auf diese Art, den Vocal im Anlaut auszusprechen. Schliesslich kann die Glottis auch intermittirend zum Tönen gebracht werden, wobei eine Art Zitterlaut entsteht.

Reibungsgerïusche des Kehlkopfes.

1. Spiritus asper, h: Haus - house - harpe - ital. vacat - he der Araber.

2. Hha der Araber, bei welchem ausser der Glottis auch der Kehlkopfausgang verengert und der Exspirationshuftstrom verstärkt ist.

$$
\text { Verschlusslaute des Kehlkopfes. }
$$

1. Hamze der Araber, ein wirklicher Explosivlaut wie beim Husten (Tenuis).

2. Hiatus: See - adler - no ordre - sara a casa - franz. vacat. Im Deutschen auch im Anlaut nach Consonanten, besonders deutlich im Interesse bestimmter lautlicher Unterscheidungen, z. B. mein Eid im Gegensatz zu Meineid (klanglose Media).

3. Spiritus lenis, Aleph der Semiten, h non aspiré (homme, ordre) gelinde h der Engländer (hour, our). Im Italienischen bevorzugt, im Deutschen vernachlïssigt oder vermieden (klingende Media).

$$
\text { Zitterlaute des Kehlkopfes. }
$$

1. Mit tieferem Ton: soft R der Engländer, girl, bird. - Im Nieder'deutschen Platt: ōrt, wūrt, dïrt.

2. Mit höherem Ton: Das Ain der Araber. 
Unter zusammengesetzten Consonanten verstehen wir diejenigen, beı denen die Bedingungen für die Entstehung zweier lautlicher Geräusche gleichzeitig vorhanden sind. Die Zahl der Consonanten, welche in dieser Weise combinirt werden können, ist eine beschränkte. Sehr deutlich tritt das Wesen der zusammengesetzten Consonanten hervor bei dem Böhmischen ř in dři und patř. Man kann in der That gleichzeitig ein urulares $\mathrm{R}$ ertönen lassen und den hierbei vorhandenen intermittirenden Luftstrom zur Erzeugung des Reibungsgeräusches im zweiten Articulationsgebiet mit allseitigem Ausfluss, unter Stimmgabe bei drri, ohne Stimmgabe bei patř verwenden. Letzteres ist übrigens einer der seltenen Fälle, in denen auch das $\mathbf{R}$ klanglos gesprochen wird.

Aehnlich wie mit dem ř der Czechen verhält es sich nun mit den mouillirten Lauten der romanischen Sprachen. Mouillirt werden 1 und n, wobei es sich nicht um die Bildung der Lautfolgen lj und nj handelt, sondern um die Herstellung der Bedingungen für die andauernd gleichzeitige Hervorbringung des $l$ und $j$ oder des $n$ und $j$. Man kann freilich nicht sagen, dass ein ganz reines $j$ gleichzeitig mit einem ganz reinen 1 oder $n$ hervorgebracht werde, vielmehr hat die Bedingung für die Herrorbringung jedes dieser Consonanten eine Modification erfahren. Bei dem 1 sollte nur seitlicher Ausfluss vorhanden sein, dies würde aber die Bildung des $\mathrm{j}$ verhindern, denn bei $\mathrm{j}$ muss der Exspirationsstrom eine in der Mitte gelegene Enge zwischen Zungenrïcken und hartem Gaumen passiren. Man erhält das mouillirte l, wenn man $j$ bei wenig gelüfteten seitlichen Zungenrändern, also mit Anklang an das 1 spricht. Analoges gilt für das mouillirte $n$. Streng genommen kann man nicht gleichzeitig $\mathrm{n}$ und $\mathrm{j}$ sprechen, denn bei $\mathrm{j}$ soll die Luft ausschliesshich durch den Mund, bei n ausschliesslich durch die Nase entweichen. Das mouillirte $n$ verhält sich aber ganz ähnlich zu dem gewöhnlich gesprochenen $j$, wie ein nasalirter Vocal zu dem rollkommen gebildeten Tocal, man könnte das mouillirte $n$ mit gutem Recht als ein nasalirtes $j$ bezeichnen. Die mouillirten Laute werden mit Stimme gesprochen.

ñ: champagne - deutsch, ital., engl. vacat - span. î̀ - portugies. nh;

İ: famille - gli, famigli - deutsch, engl. vacat - span. llama (flamma) llanos.

Ebenso wie die Vocale können alle mit Stimme gesprochenen Consonanten und auch dic klanglosen Reibungsgeräusche beliebig gedehnt werden. Es geschieht dies sogar bei den Verschlusslauten, wenigstens hei den Tenues, doch tritt uns hicr ein eigenthümliches Problem entgegen. In dem Worte Pappel ist das pp ein verschärftes und gedehntes 1. Terschluss- und Explosivgeräusch ist stärker als bei dem p in Papier 
und ausserlem vergeht lïngere Zeit zwischen Verschluss und Oeffnung. Obgleich hier während der Daner des Mundschlusses gar nichts gehört wird, hat eine Verlängermng dieser Dauer doch die Wirkung, uns den Consonant verstïrkt erscheinen zu lassen. Vermuthlich spielt hierbei die in dem Hörenden angeregte Vorstellung von der Anstrengung, welehe er selbst bei derartiger Lautbildung machen würde, eine wesentliche Rolle.

Die bisher ausschliesslich festgehaltene Aufstellung, dass die Sprachlaute mittelst des Exspirationsluftstromes gebildet werden, gilt zwar fiir alle Sprachen gebildeter Völker; eine sehr interessante Ausnahme bieten jedoch die Zulu-Sprachen, deren sogenannte Schnalzlaute bei der Inspiration erzeugt werden. Die Zulus bilden in jedem Articulationsgebiete einen oder mehrere Schnalzlaute. Ebenso wie bei dem Gesange der Vögel spielen auch bei dem Gesange der Alpenbewohner die Inspirationslaute eine grosse Rolle; die "Juchzer" der Jodler werden meist inspiratorisch erzengt. Der Esel bringt die erste Silbe seines "I-A" inspiratorisch, die zweite exspiratorisch hervor. Das Grunzen und Quietschen des Schweines erfolgt vorwiegend inspiratorisch. 


\title{
Theil II. \\ Physiologie der vegetativen Processe.
}

\author{
Siebenter Abschnitt.
}

\section{Blut, Lymphe und Kreislauf.}

Die Körpermuskeln verrichten, indem sie die Aussenwelt dem Organismus dienstbar machen, Arbeit. Um die hierfür erforderliche Energie aufwenden zu können, bedürfen sie der Ergänzung ihrer Substanz und der Befreiung von den Endproducten der in ihnen ablaufenden chemischen Processe. Diesem Bedürfniss wird genügt durch das kreisende Blut und durch die Lymphe. Im Nervensystem und in den Sinnesorganen wird zwar eine unvergleichlich kleinere Menge von Energie umgesetzt, als in den Muskeln, doch sind die in ihnen ablaufenden chemischen Processe viel feiner gegliedert und deshalb bedürfen sie, trotz verschwindend kleiner Arbeitsleistung in noch höherem Maasse als die Muskeln der beständigen Stoffzufuhr und Stoffabfuhr durch Blut und Lymphe.

Das Blut ist ein Gewebe, welches etwa $1 / 13$ des ganzen Körpergewichtes ausmacht und welches durch die flüssige Beschaffenheit seiner Intercellularsubstanz befähigt ist, im Körper zu kreisen und dadurch den Stoffverkehr zwischen der Körperoberfläche und den functionirenden Elementen der inneren Organe zu unterhalten. Als Oberfläche kommt hier nicht nur die äussere Haut in Betracht, sondern in viel stärkerem Maasse noch die Schleimhaut von Organen, welche in ihrer Anlage oberflïchlich gelegen, bei der Entwickelung des Körpers nach innen gelangt sind. An eingestiilpten Oberflächen nimmt das Blut die Substanzen auf, welche den functionirenden Gewebselementen zur Bestreitung der Lebensarlscit nöthig sind, und zwar im Darmtractus die Verdauungsproducte der Nahrungsmittel, in den Lungen den Sauerstoff der Luft; an eingestülpten Oberflächen giebt das Blut die Substanzen ab, deren Zurückhaltung ren Rost des Lebensheerdes verstopfen wïrde, und zwar in den Nieren, den Schweissdrüsen und in der Leber flüssige und gelöste 
Stoffwechselproducte, in den Lungen Kohlensäure nnd Wasser. Es muss hierzu jedoch bemerkt werden, dass das Blut nirgends direct mit ileu resorbirenden, functionirenden und secernirenden Gewebselementen in Berührung kommt, sondern dass dies durch Vermittelung der Lymphe geschieht.

Ausserdem bringt das kreisende Blut die im Körperinnern gebildete Wärme schnell an die äussere Oberfläche und dient dadurch dem Wärmchaushalt des Organismus.

Das Blut ändert also bei dem Umlauf durch den Körper fortwährend seine Zusammensetzung und Beschaffenheit; bei dem Verlasseu eines jeden Organes ist es ein anderes Ding; die anffallendsten Unterschiede zeigt es jedoch, wenn man seine Beschaffenheit vor dem Eintritt in die Lungen, wo man es venös nennt, und nach dem Verlassen der Lungen, wo es arteriell genannt wird, vergleicht.

Den grob wahrnehmbaren Eigenschaften nach ist das Blut eine, selbst in diinnen Schichten undurchsichtige rothe Fliissigkeit, von schwach siisssalzigem Geschmack und eigenthïmlichem Geruch. Das Roth des arteriellen Blutes ist das des Scharlach. Das venöse Blut erscheint nur im auffallenden Licht roth, und zwar dunkel blauroth, im durchfallenden Licht dagegen grün, es ist dichroitisch. Eine sehr merkwürdige und wichtige Eigenschaft des Blutes besteht in seiner Fähigkeit, nach dem Austritt aus den natürlichen Gefässwänden zu einer gallertigen nicht mehr fliessenden Masse zu gerinnen. Ohne die Gerinnungsfähigkeit des Blutes wären die blutführenden Thiere im Kampf ums Dasein längst untergegangen oder hätten sich erst gar nicht entwickelt.

Die chemische Reaction des Blutes wird als alkalisch angegeben, und in der That bläut sich ein empfindlicher Lakmuspapierstreif, welcher in Blut getaucht wurde, an der Grenze des blutgefärbten Theiles. Das specifische Gewicht des Blutes beträgt im Mittel 1,055.

An der Zusammensetzung des Blutes betheiligen sich geformte Elemente, die Blutkörperchen und eine flïssige intercellulare Substanz, das Blutplasma. Die Auffassung des Blutes als eines Gewebes ist nicht nur in der Entwickelungsgeschichte begründet, sondern auch dadurch gerechtfertigt, dass seine geformten Bestandtheile Zellen und Zellabkömmlinge sind, welche während des Lebens in steter Wechselwirkung mit dem Plasma stehen. Die Blutkörperchen unterscheiden sich in rothe und farblose.

Die rothen Blutkörperchen des Menschen sind kreisrunde, beiderseits napfartig eingedruickte kernlose Scheiben. Auch bei den iibrigen Sängethieren findet sich dieselbe Form, nur die Gattungen Camelus und Lama haben elliptische Blutscheiben. Körperchen der letzteren Form sind auch jene der Vögel, der Amphibien und der meisten Fische, doch 
besitzt Petromyzon kreisscheibenförmige Blutkörperchen. Die Blutkörperchen der' Vögel, Amphibien und Fische besitzen in ihrer Mitte einen Zellkern.

Die einzelne Blutscheibe eines Menschen erscheint unter dem Mikroskop gelblich oder grïnlich. Hat man das Mikroskop auf die obere Grenzebene des Scheibenrandes eingestellt, so erscheint die Randzone heller und die Mitte dunkler, wodurch die Anwesenheit eines Kernes vorgetäuscht werden könnte; dass es sich aber um ein durch die Lichtbrechung an den gekrïmmten Oberflächen bedingtes Phänomen handelt, erkennt man durch die Einstellung des Mikroskopes auf die Mittelebene der Scheibe, wo dann der Rand dunkler und die Mitte heller erscheint. Liegen mehrere derselben übereinander, dann erscheint ihre Farbe roth. Dieselbe Farbe zeigt sich, wenn die Scheiben unter dem Mikroskope auf der hohen Kante stehen. Letztere Beobachtung hat man darum oft Gelegenheit zu machen, weil die Blutscheiben die noch nicht aufgeklärte Neigung haben, sich nach der Entfernung aus dem Organismus geldrollenähnlich zusammenzuschichten.

Die rothen Blutscheiben werden durch verhältnissmässig kleine Kräfte stark deformirt, nehmen aber bei Nachlass dieser Kräfte vollkommen ihre friihere Gestalt wieder an; ihre Substanz ist also sehr dehnbar, aber vollkommen elastisch. Unter dem Einfluss der Wärme, des elektrischen Stromes und von Concentrationsänderungen treten Formwechselungen ein, welche bei vorsichtig geleiteter Einwirkung wieder rückgängig gemacht werden können. Im Ganzen handelt es sich um Quellungen, bei denen sich die napfartigen Vertiefungen ausgleichen und um Schrumpfungen, bei denen die sogenannte Maulbeerform und Stechapfelform eintritt. Die Formänderungen, welche die Blutscheiben bei Erhöhung der Temperatur zeigen, haben in einem gewissen Stadium einige Aehnlichkeit mit amöboiden Bewegungen, doch treten diese erst weit über Körpertemperatur ein und führen unter Abschnürung ansgetriebener Fortsätze zu einem definitiven Untergang der Scheiben. Eine eigene Beweglichkeit kann den rothen Blutscheiben also nicht zugesprochen werden. Die Grösse der Blutscheiben bei den verschiedenen Thierarten scheint in einiger Beziehung zu dem Athmungsbediurfniss zu stehen; eine kleine Gesammt-Oberfläche wird erreicht, wenn die gleiche Menge Scheibensubstanz auf Scheiben von grossen Abmessungen vertheilt wird; dies ist der Fall bei Thieren, welche geringes Athmungsbedürfniss haben, wie zum Beispiel Protens anguineus, dessen elliptische Blutscheiben $58 \mu$ im langen und $35 \mu$ im kleinen Durchmesser besitzen; eine einzelne dorselben kann mit blossem $\Lambda$ uge wahrgenommen werden. Die Blutscheiben der Frösche messen 22 und $15 \mu$, die kleinsten Blutscheiben besitzt das Moschusthier mit 2,5 $\mu$ Durchmesser. 
Beim Menscheu beträ̈gt der Durchmesser des grössten Querschnittes der Schcibe ungefähı $8 \mu$, dic grösste Dicke der Scheibe $2 \mu$, doch sind die Schwankungen der Dimensionen bei verschiedenen Personen und auch bei demselben Individuum nicht unerheblich.

Bei den Angaben ïber die Zahl der rothen Blutkörperchen legt man den Kubiknillimeter zu Grunde; die Zühlhlung geschieht an einem durch Narlelstich gewomnenen Blutstropfen bei entsprechender Verdünnmug des Blutes. Fin in allen seinen Theilen genau calibrirtes gläsernes Capillarrohr mit angeblasener Ausbauchung wird bis zu einer bestimmten Marke mit einem Theil des frisch hervorperlenden, noch nicht der Verdunstung ausgesetzten Blutes gefüllt, dann wird eine ebenfalls genau bestimmte weit grössere Mcnge (das 100 fache) einer VerdïmungsHüssigkeit nachgesaugt. Diese Fliissigkeit muss die Eigenschaft laben, keine rothen Blutkörperchen aufzulösen und sie eher etwas schrumpfen zu machen, sodass sie sich auf dem Objectträger schnell zu Borlen senken. Nachdem die Mischung in der Ausbauchung des Rohres, welches für diesen Zweck ein frei bewegliches Glasstïck eingeschlossen enthält, vollkommen geschehen ist, wird ein eigens construirter Objectträger mit einem Tropfen der Mischung beschickt. Derselbe besitzt eine trogartige Vertiefung, deren Boden genau parallel zu der Oberfläche des Objectträgers und in genau bestimmter kleiner Entfernung unter derselben ist. Dieser Boden besitzt eine eingeritzte quadratische Theilung. Ueber jeder Quadrattläche, deren Seitenlänge genau bekannt ist, befindet sich nach Auflegen des Deckglases eine gewisse Menge des Gemisches ron bekanntem Volum, das Mikroskop wird nun auf die Bodenfläche des Troges eingestellt und es werden die auf den einzelnen Quadratflächen niedergesunkenen Blutscheiben ausgezählt. Begreiflicherweise wïrde eine Berechnung, welche auf der Auszählung nur eines oler weniger Quadrate beruhte, zu groben Fehlern führen. Die Genauigkeit des Resultates wächst mit der Zahl der ausgezählten Felder. Bei einem der gebräuchlichen Apparate beträgt der wahrscheinliche relative Fehler, bei Abzählen von 16 Quadraten $5 \%$, von 100 Quadraten $2 \%$.

Nach diesen und ähnlichen Nethoden sind sehr viel Zählungen bei Menschen und Thieren mit Berïcksichtigung von Lebensalter und Geschlecht, Körperzustand und Gefïssgebiet ausgefiihrt worden: als ungefähren Mittelwerth kann man beim Menschen 5 Millionen in einem Kubiknillimeter annehmen: bei Männern ist die genaue Zahl etwas grösser als bei Frauen, bei Kindern etwas kleiner als bei Erwachsenen und Neugeborenen. Einfliisse, welche mit starkem Wasserverlust des Körpers verbunden sind, erhöhen begreiflicherweise die Blutkörperchenzahl. Starkes Wassertrinken setzt sie heral); in den Venen ist die Zahl im Allgemeinen grösser, als in den Arterien. Verbesserungen der allge- 
meinen äusseren Lebensbedingungen erhöht die Zahl wahrscheinlich durch Ueberwiegen der Bildung über den Untergang. In vielen krankhaften Zuständen, namentlich in der Bleichsucht, ist die Zahl aus dem entgegengesetzten Grunde herabgesetzt.

An Modellen von der Form der Blutscheiben mit vielfach vergrösserten Abmessuugen hat man das Volum und die Oberfläche bestimmt, sodlass man mit Berücksichtigung der Vergrösserungszahl Volum und Oberfläche der einzelnen Blutscheiben berechnen konnte; hierdurch erhielt man als Volum der 5 Millionen in einem Kubikmillimeter Blut enthaltenen Blutscheiben etwa 1/3 Kubikmillimeter und als Oberfläche derselben 640 Quadratmillimeter. Das gesammte Gewicht der Blutscheiben eines 78 Kilogramm schweren Mannes, dessen Blutmenge $1 / 13$ seines Körpergewichtes beträgt, macht also etwa 2 Kilogramm aus und die gesammte Oberfläche derselben bedeckt etwa 3840 Quadratmeter.

Von der inneren Structur der rothen Blutkörperchen ist es schwer, sich eine genaue Vorstellung zu machen; zu berücksichtigen ist hierbei, dass der die Farbe bedingende Stoff, das Hämoglobin, in dem Blutplasma leicht löslich ist und doch unter normalen Verhältnissen nicht in dasselbe ïbertritt. Der Gedanke an eine für das Hämoglobin undurchgängige Membran ist, abgesehen davon, dass sich eine solche Membran nicht hat darstellen lassen, nicht aufrecht zu erhalten, angesichts der elastischen Eigenschaften und der bei den Deformationen und Zertrümmerungen eintretenden Erscheinungen. Lehrreich ist eine Beobachtung, welche sich an kernhaltigen Blutkörperchen machen lässt; man findet nach Einwirkung gewisser Agentien, zum Beispiel von $2 \%$ Borsäurelösung, die äussere Contour des Blutkörperchens unverändert, aber von dieser Linie begrenzt eine glashelle Masse, in welche entweder um den Kern zusammengeballt oder sternförmig vom Kern gegen die Umfassungslinie ausstrahlend, eine zweite Substanz eingelagert ist, welche den ganzen Farbstoff' des Blutkörperchens in sich fasst. Die erste dieser Substanzen, welche man das Oikoid genannt hat, erscheint glatt, weich und dehnbar und erinnert durch diese Eigenschaften noch an die ursprïnglichen Blutkörperchen, die zweite Substanz, das Zooïd, ist tingirbar, die erste nicht. Das Zooïd kann aus dem Oikoid ausschlïpfen, wie aus einer zähflüssigen Masse.

In den unversehrten Blutkörperchen müssen sich diese Substanzen gegenseitig innig durchdringen und das Hämoglobin muss durch physikalische Kräfte oder durch chemische Bindung vor der lösenden Wirkung des Blutwassers bewahrt bleiben. Die Substanz des Blutkörperchens, an welcher das Hämoglobin haftet, nennt man auch das Stroma.

Die Verljindung zwischen Stroma und Farlostoff wird aufgehoben durch Verdünnung des Blutes mit destillirtem Wasser, bei Zusatz von 
Gallensäuren und ihren Salzen, beim Vermischen ron Blut verschiedener Thierarten mit einander, beim Schütteln des blutes mit Aether, Chloroform, Alkohol oder Schwefelkohlenstoff, beim Entgasen, bei wiederholtem Gefrieren und Wiederaufthauen des Blutes und beim Hindurchleiten starker elektrischer Schlïge durch dasselbe. Bei all diesen Einwirkungen diffundirt das in Wasser leicht lösliche IIämoglobin in das Plasma, und das Blut verliert seine Eigenschaft wie eine "Deckfarbe" zu wirken, d. h. in dïnner Schicht undurchsichtig zu sein, es wird „lackfarben“. Bereitet man sich durch Gefrieren lackfarbenes Blut und vergleicht man eine Probe davon in gleich dicker Schicht mit einer Probe des ursprünglichen Blutes, so erscheint letztere weit heller im auffallenden Licht. Das Licht wird von den gefärbten Blutscheiben des ursprünglichen Blutes in erheblicher Menge, von dem gleichmässig tingirten Plasma des wieder anfgethauten Blutes fast gar nicht reflectirt. Fügt man zu frischem Blute wasserentziehende Mittel hinzu, zum Beispiel Kochsalz, so kann man die Menge des reflectirten Lichtes noch vergrössern; das Blut erscheint damn im auffallenden Lichte noch weit heller und sieht damn ziegelroth aus; es muss dies auf einer Aenderung der Form der Blutscheiben beruhen. Spektroskopisch rerhält sich dieses, das genuine und das lackfarbene Blut bis auf die Helligkeitsunterschiede gleich. Wahrscheinlich haben auch Aenderungen in Gasgehalte des Blutes Einfluss auf die Form der Blutscheiben und dadurch auf die Helligkeit des Blutes.

Im lackfarbenen Blut kamn das Stroma der Blutscheiben in alter Form, aber entfärbt bestehen bleiben; da es sich mit Jod brïunt, so kann man es hierdurch deutlicher sichtbar machen.

Das Hämoglobin kann, obgleich es eine eiweissartige Substanz ist, leicht in gut ausgebildeten krystallen gewonnen werden. Wenn es sich nicht um Reingewinnung der Substanz in grösseren Mengen, sondern nur um die Beurtheilung der Krystallform unter dem Mikroskope handelt, so kann man sich die merkwïrdige Thatsache zu Nutzen machen, dass das Iämoglobin am leichtesten aus faulendem Bhte krystallinisch sich ausscheidet. Mit wenig Luft in Glasröhren eingeschlossenes Blut, der 'Temperatur des Brütofens ausgesetzt, ergiebt bei nachträglichem Verdunsten reichliche Krrystalle, manchmal von bedeutender Grösse; es sind auf diese Weise 3 bis 5 Centimeter lange Prismen aus Hundeblut gewonnen worden; besonders leicht soll auch Erstickungsblut krystallisiren.

Obgleich das Hämoglobin des Blutes verschiedener Thierarten in verschiedenen Formen krystallisirt, so weiss man doch jetzt, dass diese Formen fast alle demselben Krystallsystem, nämlich dem rhombischen, angehören. Sicher bekannt ist nur eine Ausnahme, das Hämoglobin des Eichhörnchenblutes, welches im hexagonalen System krystallisirt. 
Aus dem wässerigen ätherischen Extract eines an Blutscheiben möglichst reichen Blutes krystallisirt das Hämoglobin in der Kälte beim Verdunsten des Aethers gut aus und lässt sich durch Umkrystallisiren rein gewinnen. Umkrystallisirtes Hämoglobin kann man bei $0^{0}$ olıne Zersetzung trocknen, und es giebt dann, über $100^{\circ}$ Celsius elwärmt, sein Krystallwasser ab. Für diese bei $100^{\circ}$ getrocknete Substanz von IIunden ergab eine Analyse folgende Zusammensetzung: In 100 Theilen Hlämoglobin waren: C 53,85 ; H 7,$32 ; \mathrm{N} 16,17 ; \mathrm{O} 21,84 ; \mathrm{S} 0,39$; Fe 0,43 .

Unter Einwirkung von Luft und Wasser zerfällt das Hämoglobin leicht, es bildet sich hierbei Ameisensäure, Buttersäure und Nilchsäure, und die Lösung von Hämoglobin trübt sich hierbei unter Braunfärbung; der sich hierbei bildende Farbstoff wird Methämoglobin genannt und ist dar'um von besonderer Wichtigkeit, weil ex sich im Blut auch bei gewissen Vergiftungen, z. B. mit chlorsaurem Kali, bildet. Bei Behandlung des Hämoglobins mit eingreifenden Agentien, wie z. B. mit starken Alkalien und Säuren, wird ein anderer Farbstoff, das Hämatin, abgespalten, welches das Eisen des Hämoglobins enthält.

Das Hämoglobin ist jedenfalls ein chemisch sehr complicirter Körper, noch complicirter als das Eiweiss, denn solches findet sich bei der Zerlegung des Hämoglobins mit starken Säuren oder Alkalien als Syntonin oder Alkalialbuminat in den Zersetzungsproducten neben dem Hämatin, und zwar in bei weitem grösseren Mengen als letzteres. Es scheint ein bestimmtes Aequivalentverhältniss zu bestehen, nach welchem sich das Iämoglobin mit dem Sauerstoff derart verbindet, dass es denselben, olne eine weitergehende Zersetzung zu erleiden, an das Vacuum wieder abgiebt. Mit $1 \mathrm{gr}$. Hämoglobin verbinden sich auf diese Weise etwa 0,0024 gr. Sauerstoff. Hierauf kann man eine Schätzung des Moleculargewichtes des Hämoglobins gründen, welches danach sehr hoch, zum mindesten auf 13000 veranschlagt werden müsste. Wichtig für die chemische Charakterisirung des Hämoglobins ist die Thatsache, dass es sich bei der Elektrolyse des Blutes unzersetzt in krystallinischem Zustande am positiven Pol ausscheidet, woraus man auf seine Säurenatur schliessen kann.

Jie lockere Verbindung des Hämoglobins mit Sauerstoff nennt man Oxyhämoglobin; sie entsteht schon beim Schütteln der Hämoglobinlösung mit Luft, und giebt den Sauerstoff an das Vacuum ab, oder schneller an reducirende Sulstanzen, wie z. B. an Schwefelammonium, Eisenoxydulsalze oder an metallisches Eisen. Das reducirte Hämoglobin zeigt bei passender Verdiinnung spektroskopisch einen breiten Reductionsstreifen im gelben Theile des Spektrums zwischen D und E des Sonnenspelztrums. Schuittelt man die reducirte Lösung wieder mit Sauerstoff, so zerfällt 
der Absorptionsstreifen in zwei, ron denen der eine der Linie I, der andere der Linie E näherrückt, während der dizwischen gelegene Raum, welcher dem Absorptionsstreifen des reducirten IÏ̈moglobins entspricht, hell wird.

Eine ähnliche Verbindung wie mit dem Sauerstoff geht das Hämoglobin ein mit Kolilenoxyd und vielleicht mit Blausäure. Dis Spektrum des Kíohlenoxydblutes ist fast identisch mit dem des Oxyhämoglobins, doch unterscheidet sich ersteres dadurch ron letzterem, dass es sich durch reducirende Substanzen nicht in dasjenige des rerlucirten Hämoglòbins umwandeln lässt. Kohlenoxyd und Blausäure verdrängen den Sauerstoff rom Hämoglobin und lassen sich ihrerseits durch Sanerstoff nur schwer verdrängen; wahrscheinlich beruht hierauf die giftige Wirkung des Kohlenoxyds und zum Theil auch die der Blausäure.

Dà Verhältniss der Lichtalssorption in rerschiedenen Theilen des Spektrums bei verschiedenen Concentrationen geht aus den beigegebenen Figuren 47 und 48 hervol, auf deren Abscissen die Fraunhofer'schen Linien angegeben sind und deren Ordinaten den procentischen Gehalt der Farbstoffe, bei einer Dicke der Schicht ron 1 Centimeter bedeuten. Bei dieser

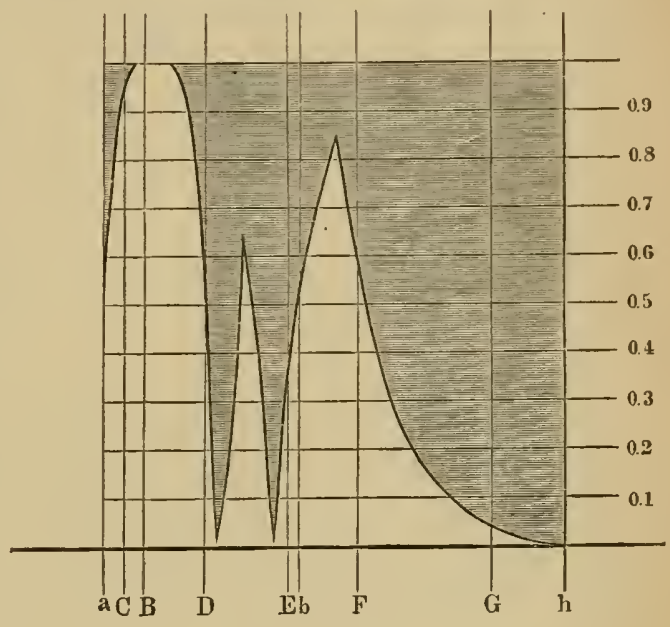

47.

Oxyhämoglobin.

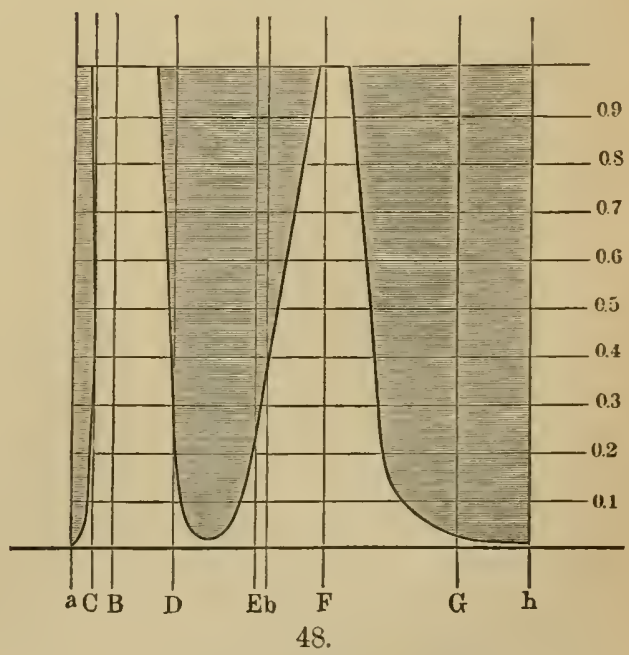

lèducirtes Hämoglobin.

Dicke der Schicht und bei Abnahme der Concentration der Lösung des Oxyhämoglobins erscheint das erste Licht im Grün zwischen 0,9 und $0,8 \%$. Indem man den Grad bestimmt, bis zu dem man ein mit Luft 
gut geschïtteltes Blut verdïnnen muss, um bei 1 Centimeter dicker Schicht das erste Licht im Grün erscheinen zu lassen, kann man den Gehalt des Blutes an Hämoglobin annähernd und leicht bestimmen. Genauere Resultate erhält man durch eigens für diese Zwecke ausgebildete spektrophotometrische Methoden.

In 100 Gramm normalen menschlichen Blutes hat man im Mittel 14,5 Gramm Hämoglobin gefunden; bei den durch Lebensalter, Geschlecht, Ernährungsverhältnisse und ähnliche physiologische Umstände bedingten Abweichungen ändert sich der Hämoglobingehalt meist in demselben Sinne und in demselben Verhältnisse wie der Blutkörperchengehalt. In krankhaften Zuständen kann ersterer jedoch stärker sinken, als letzterer, was nicht nur auf einen Unterschied in der Grösse, sondern auch im Hämoglobingehalt der einzelnen Blutkörperchen zu beziehen ist.

Das kreisende Blut enthält Oxyhämoglobin und reducirtes Hämoglobin in verschiedenen Verhältnissen; das arterielle Blut des gesunden Menschen ist nahezu vollständig mit Sauerstoff gesättigt, d. h. es enthält nur wenig reducirtes Hämoglobin. Lässt man in den Spalt des Spektroskops Sonnenlicht fallen, welches zwischen 2 bis zur Berührung einander genäherten Fingern hindurchgegangen ist, so erhält man dasselbe Spektrum wie von einer Oxyhämoglobinlösung, es ist dies zugleich ein Beweis dafür, dass das Ḧ̈moglobin im lebenden Blute präformirt ist. Umschnürt man die Finger, sodass der Blutstrom gehemmt wird, so beobachtet man den Uebergang des Spektrums in dasjenige des reducirten Hämoglobins; aus der Ader gelassenes venöses Blut enthält nicht nur reducirtes Hämoglobin, sondern auch Oxyhämoglobin in verschiedenen Verhältnissen.

Der Unterschied in Farbe und Helligkeit zwischen arteriellem und venösem Blut beruht wesentlich auf dem Unterschiede im Verhältniss zwischen Oxyhämoglobin und reducirtem Hämoglobin, daueben aber wahrscheinlich auch auf einem, die Reflexionsverhältnisse des Lichtes beeinflussenden Unterschiede in der Form der Blutscheiben. Jedenfalls ist der Unterschied im Sauerstoffgehalt beider Blutarten das maassgebende, nicht der Unterschied im Kohlensäuregehalt.

Unter den Zersetzungsproducten des Blutfarbstoffes ist von besonderem praktischem und theoretischem Interesse das Hämin. Wenn man zu trockenem Blut wenig Kochsalz bringt und es dann mit Eisessig zum Kochen crhitzt, so bildet sich Hämin in Krystallen; dieselben sind in auffallentlem Lichte blauschwarz, glänzend, bei durchfallendem Lichte dunkelmahagonibraun. In wohl ausgebildeter Form bilden sie rhombische Täfelchen oder rhombische Stäbchen; da diese Häminkrystalle, die mit Nichts verwechselt werden können, aus den kleinsten Mengen eingetrock- 
neten Blutes darzustellen sind, so haben sie fiir forensische Zwecke eine weitgehende Bedeutung gewonnen.

Das Hämin ist salzsaures Hämatin und zur reinen Darstellung des Hämatin geht man von ersterem aus; durch Auflösen des Hämins in verdünnter Kalilauge und Neutralisiren mit verdünnter Schwefelsäure erhält man das Hämatin, welches ein amorphes blaugraues Pulver darstellt, unlöslich in Wasser, Alkohol und Aether ist, aber leicht löslich in Säure oder in alkalihaltigem Alkohol oder saurem Aether. Als Formel für das Hümatin ist ermittelt $\mathrm{C}^{68} \mathrm{H}^{7}{ }^{0} \mathrm{~N}^{8} \mathrm{Fe}^{2} \mathrm{O}^{10}$. Es ist also frei von Schwefel, aber viel reicher an Eisen wie das Hämoglobin, es enthält daron $8,82 \%$.

Methämoglobin in alkalischer Lösung, sowie Hämatin in alkalischer und saurer Lösung haben je ein charakteristisches Spektrum; dasjenige des Hämatin in alkalischer Lösung wird durch Reductionsmittel in ein anderes eigenartiges ïbergeführt; das Spectrum des Methämoglobins in saurer und neutraler Lösung stimmt mit dem des Hämatins in saurer Lösung überein; das Methämoglobin-Spektrum wird durch reducirende Substanzen in das des Hämoglobins zurückgeführt.

Man kann dem Blute durch Schwefelsäure alles Eisen entziehen, ohne dass es dabei seine rothe Farbe einbüsst; der resultirende Farbstoff wird Hämatoporphyrin genannt und als eisenfreies Hämatin aufgefasst.

Das Hämoglobin muss das Material für die Bildung ron Gallenund Harnfarbstoffen abgeben; anf künstlichem Wege ist es bisher freilich nur gelungen aus dem Hämoglobin oder dem Hämatin einen im Harn vorkommenden Farbstoff, das Urobilin, darzustellen.

Ueber die organischen Bestandtheile, welche die rothen Blutscheiben neben dem Hämoglobin enthalten, ist es noch nicht möglich, etwas Bestimmtes auszusagen; jedenfalls lïsst sich aus denselben ein Körper darstellen, welcher Phosphor und Stickstoff enthält, von dem aber noch nicht erwiesen ist, ob er als Lecithin orler als Protagon aufgefasst werden soll, und ausserdem Cholesterin; ferner scheidet sich aus dem gewässerten Blute ein gequollener, wahrscheinlich aus verklebten Resten der Blutscheiben bestehender Rückstand aus, welcher Eiweissreactionen giebt und die Eigenschaften einer Globulinsubstanz haben soll. Von den Aschebestandtheilen der Blutscheiben ist zu bemerken, dass sie wenig orler kein Natron enthalten und an Stelle darour Kalium.

Die farblosen oder weissen Blutkörperchen, auch Lencocyten genannt, sind Zellen ohne doppelt contourirte Membran, deren kernhaltiges Protoplasma in Folge starker Reize und anch im Tode Kugelgestalt annimmt. In diesem Zustande zeigeu sie einen körnigen Zellleib, innerhalb dessen man bei genauerem Zusehen auch den Kern erkennt, 
welcher stets vorhanden ist, und welcher morphologisch verschieden beschaffen sein kann. Der Durchmesser dieser Kngeln iibertrifft etwas den der̆ Blutscheiben, das Volum des farblosen Blutkörperchens ist also erheblich grösser, als das der rothen Blutscheibe.

Im lebhaft kreisenden Blute sind die farblosen Blutkörperchen sphärisch und da sie geringeres specifisches Gewicht haben wie die rothen, so gelangen sie aus dem schnelleren Strom der Gefässmitte in den langsameren an der Wand, längs welcher sie in den Capillaren dahinrollen. Hierbei bleiben sie öfters haften, woraus man auf ihre klebrige Natur schliesst. Wird dieses Haften durch grosse Langsamkeit des Blutstromes in den Capillaren unterstützt, so hören die Bedingungen für Einhaltung der Kugelform auf und die farblosen Blutkörperchen bekommen Gelegenheit, ihre hochentwickelte Fähigkeit zur Ausführung amöboidler Bewegungen zu bethätigen. Diese Bewegungen kann man an den Leucocyten des Froschblutes ohne Weiteres und des Menschenblutes anf dem erwärmten Objecttisch unter dem Mikroskop verfolgen. Wichtiger jedoch ist die.Beobachtung an der lebenden Gefässwand. Es dient hierzu in hervorragender Weise das Mesenterium des Frosches; das an der Capillarwand haftengebliebene Blutkörperchen nimmt durch Aussenden und Einziehen von Fortsätzen unregelmässige und langsam wechselnde Contouren an; einer der Fortsätze durchdringt dann die Gefässwand, der nach aussen gelangte Fortsatz wächst mehr und mehr und rielit daun den Rest der Zelle hinter sich her. Diese Auswanderung der Leucocyten wird erleichtert durch hohen Druck im Capillargefässe. Hoher Druck und langsamer Strom findet sich in Capillaren entzündeter Gewebe, sodass die auch normaler Weise-vorkommende „Diapedesis" farbloser Blutkörperchen in der Entzündung oft zu holem Grade gesteigert ist. Alle Eiterkörperchen sind vielleicht ausgewanderte farblose Blutkörperchen.

Ausser der Diapedesis hat die amöboide Natur der Leucocyten noch eine andere sehr wichtige Consequenz; wie man unter dem Mikroskop bei Hinzufügung von etwas Zinnober, chinesischer Tusche oder einer anderen Suspension feiner unlöslicher Partikelchen leicht beobachten kann, umfliessen die Lencocyten bei ihren Bewegungen solche Theilchen und nelımen sie dabei in ihre Leibessubstanz auf. Innerhalb des Organismus wird dieser für den Kampf mit Eindringlingen wichtige Process wohl weniger bei lehhafter Bewegung stattfinden, als an Stellen grösserer Riuhe entweder ausserhalb der Blutbahn oder in Blutdrüsen.

Genaue Werthe für die Zahl der farblosen Blutkörperchen anzugeben, ist darum schwer, weil diese Gebille wach dem Austritt des Blutes aus dem Organismus theilweise sehr schnell zerfallen. Die Methode zur Bestimmung der Zahl ist wesentlich dieselbe, wie sie für 
die rothen Bhutkörperchen angegeben wurke; in normalem Blut ist the Zahl der farblosen Blutkörperchen jedenfalls viel kleiner als die der rothen, auf 400 der letzteren kommt vielleicht eins der ersteren. In gewissen krankhaften Zuständen, welche man leukämische nemnt, ist die Zahl der Leucocyten enorm rermehrt.

Aus normalem Bhut sind die farblosen Blutkörperchen noch nicht so isolint worden wie es zu einer Erkenntniss ihrer chemischen $\mathrm{Zu}$ sammensetzung erforderlich sein sollte; aus Untersuchungen an leuk:̈imischem Blute und am Eiter kann man aher schliessen, diss die weissen Blutkörperchen, wie junge Zellen im Allgemeinen, Protagon oder Lecithin oder beides und Cholesterin enthalten. Eine andere phosphorhaltige, den Eiweisskörperu rerwandte Substanz wude in dem Kern der Eiterkörperchen zuerst entdeckt und später auch in zahlreichen anderen Kerngebilden nachgewiesen, das Nuclein, welches mit derjenigen Substanz identisch sein dïrfte, welche von den Histologen wegen ihrer mikrochemischen Reactionen als Chromatin bezeichnet worden ist. Glycogenreaction ist besonders in weissen Blutkörperchen des Pferdes nachgewiesen worden. Unter den Eiweisskörpern der farblosen Blutkörperehen wird wegen ihrer Contractilität das Myosin rermuthet. Die Köruchen des Protoplasmas sind zum Theil stark lichtbrechend, glïnzend und kugelig: einige von diesen werden wegen ihrer Löslichkeit in Aether und Alkohol für Fett gehalten.

Die geformten Bestandtheile des Blutes fallen beständig dem Lntergange anheim, und werden in demselben Maasse wieder neu gebildet. Reichliche Ausstossung von Leucocyten findet statt an der Schleimhantfläche der Tonsillen und aller folliculärer Lymphdrüsen des Verdaunngsund Athmungsrohres. Rothe Blutkörperchen gehen in der Leber und Milz zu Grunde. Bildungsheerde für die Leucocyten sind die Lymphdriisen. Die Bildung neuer Elemente geschieht durch mitotische Theilung, deren Anzeichen man ïbrigens nicht nur in den Lymphdrüisen, sondern auch an Zellen findet, welche in den Blutstrom übergegangen sind.

Die Bildung der rothen Blutkörperchen ist cine verschiedene im jugendlichen und im erwachsenen Organismus. Beim Embryo entstehen die ersten farbigen Blutkörperchen im Gefäss- und Fruchthofe gleichzeitig mit den Gefässen. Die ersten Anlagen ron Gefässen und Blutkörperchen der Area vasculosa liegen an rerschiedenen Orten zerstreut im mittleren Keimblatt und treten erst später unter einauder und mit dem Herzen in Verbindung. In einem grossen Theile des embryonalen Lchens der Säugethiere sind riele der rothen Blutkörperchen, welche hauptsächlich in der Leber und später in der Milz gebildet werden, noch kernhaltig. Bei jungen Thieren hat man, im Bindegewebe des Netzes 
und der Unterlaut, Zellen der Capillargefässwand und darin liegende rothe Blutkörperchen aus denselhen Mutterzellen hervorgehen sehen. Bei dem erwachsenen Säugethiere scheinen die Hauptbildungsstätten der rothen Blutkörperchen im Knochenmarke und vielleicht in der Milz zu liegen. Im rothen Knochenmarke gehen die arteriellen Capillargefässe nicht unmittelbar in die renösen über, sondern ergiessen sich in seeartige, von Zellbalken durchsetzte Räume, durch welche das Blut in die weiten venösen Capillaren hinübersickert. Elemente der Zellbalken entwickeln in ihrem Protoplasma Hämoglobin. Der hämoglobinhaltige Theil sondert sich ron dem Kern und dem kleineren übrigen Protoplasmarest, wird dann scheibenförmig, und gelangt in den Blutstrom.

Ausser den gut charakterisirten rothen und farblosen Blutkörperchen kommen im Blute noch andere geformte Elemente vor, welche als Blutplättchen, Hämatoblasten, gefärbte Körnchenkugeln und Blutkörnchen beschrieben werden. Am besten charakterisirt sind die Blutplättchen. Dieselben sind zwei bis dreimal kleiner, als rothe Blutkörperchen; je eins derselben kann man etwa auf 25 der letzteren anzutreffen erwarten; sie sind nicht durch Hämoglobin gefärbt, ihre Substanz ist etwas körnig und besitzt anderes Lichtbrechungsvermögen, als das Plasma. Wahrscheinlich handelt es sich um Zerfallsproducte von Zellkernen. In dem geschlagenen Blute fehlen sie. Man kann Hunde dadurch blutplättchenfrei machen, dass man ihnen wiederholt Aderlässe macht und ihnen ihr eigenes Blut, nachdem es geschlagen worden war, wieder einspritzt. Solche Hunde bieten keine Abweichungen von der Norm; nach einigen Tagen zeigt ihr Blut wieder den gewöhnlichen Gehalt an Blutplättchen.

Jas Blutplasma ist Blut minus Blutkörperchen, von denen befreit man es jedoch nur bei gewissen Blutsorten darstellen kann. Das Ijlutplasma hat nämlich geringeres specifisches Gewicht, als die Blutkörperchen. In langsam gerinnenden Blutsorten, zum Beispiel im Pferdeblute hei $0^{\circ} \mathrm{C}$., haben die Blutkörperchen Zeit, sich zu senken und eine abhebhare Schicht reinen flüssigen Plasmas zurückzulassen. An dem so gewonnenen blutkörperchenfreien Plasma kann man sich davon überzeugen, dass die Fïhigkeit zu gerinnen dem Blutplasma selbst zukommt: hebt man dasselbe ab und lässt es sich auf Zimmertemperatur erwärmen, so gerinnt es zu einem Kuchen, welcher, indem er sich später von der Wand des Glasgefäisses zuriickzicht, eine spontan nicht weiter gerinnende Flüssigkeit ausstösst. Fs ist dies reines Blutserum. Indem man dann den Kuchen auspresst und auswäscht, erhïilt man reines Fibrin.

Fängt man von Thieren mit schnell gerinnendem Blute bei gewöhnlicher Temperatur Blut in einem cylindrischen Glasgefäiss anf, so gesteht die ganze Masse, nach wenigen Minuten bei Vögeln, nach etwa zehn Minuten hei Menschen und Hunden derart, dass man das Gefäss 
unkehren kann, olne dass etwas herausfliesst; spüter löst sich der Blutkuchen ron der Gefïsswand ab und presst, sich zusammenziehend, cin meln oder weniger pigmentfreies Serum aus. In langsam gerinnenden Blutarten wie in Pferdeblut und im IBlut bei entziindlichen Krankheiten, kommit der Unterschied im specifischen Gewicht der rothen und farblosen Blutkörperchen dadurch zar Geltung, dass der rothe Blutkuchen eine grane speckartige Kuppe träigt, welche man die Crusta phlogistica genamnt hat.

Verzögert wird die Gerinnung durch sofortiges Abkïhlen auf $0^{\circ}$ oder durch Erhitzen auf mehr als $55^{\circ}$. Zusatz ron Alkalien, namentlich ron Ammoniak, ron Alkalisalzen, ron schwachen Säuren (auch Kiohlensäure), ron Peptonen hindert die Gerinnung oder rerzögert sie wenigstens. Dasselbe thut das Mundsecret des Blutegels. An sichersten wird die Gerinnung rerhindert durch Oxalate, ron denen schon kleine Mengen geniigen, oder durch schwefelsaure Magnesia in grösserer Menge und genügender Concentration. Beschleunigt wird die Gerinnung durch Warmhalten oder Erwïmen bis höchstens $50^{\circ}$; desgleichen durch Zusutz ron Wasser in nicht zu grosser Menge. Arterielles Blut gerinnt etwas früher als renöses. Während des ersten Theiles der embryonalen Entwickelung ist das Blut gerinnungsunfühig.

Schlägt man das aus der Ader fliessende Blut, so tritt die Gerinnung etwas schneller ein, als beim ruhigen Stehen: aber es gesteht nicht das ganze Blut zu einer gallertigen Masse, sondern das Fibrin scheidet sich in Flocken aus, die sich mit Wasser rein auswaschen lassen. Nimmt man die Fibrinflocken, welche den Stäben aus Glas, Holz oder Fischbein, mit denen man geschlagen hat, anliaften, heraus, so hat man das sogenannte defibrinirte Blut. Hier sind die Blutkörperchen im Serum suspendirt, beim genuinen Blut im Plasma. Lässt man das defibrinirte Blut stehen, so senken sich die Blutkörperchen und lassen eine obere Schicht Serum frei. Man kann diesen Process bcschleunigen und verstïrken durch lienutzung der Centrifuge; die untere, körperchenreiche Schicht, ron welcher man das Serum abgehoben hat, nennt man Cruor.

Das Blutserum ist eine klare, in dïnner Schicht gelblich, in dicker rüthlich gefärbte und schwach alkalisch reagirende Flüssigkeit mit einem Gehalt an festen Stoffen ron nahezn $10 \%$. Mchr wie drei Vicrtel hierron sind Eiweisskörper.

Die Eiweisskörper oder Alhumine bilden eine Gruppe stickstoffhaltiger organischer Substanzen, welche alle nahezu dieselbe procentische Zusammensetzung ergeben. Wegen ilurer Cnfähigkeit oder geringen Neigung zum Krystallisiren und wegen ihrer geringen Fähigkeit zum Diffundiren durch feuchte Membranen werden sie als colloid bezeichnet. Ga d u, Hе ymans, Physiologie. 
Sie drehen die Polarisationsebene des Lichtes links. Zu den ihnen gemeinschaftlichen chemischen Reactionen gehören folgende: Mit Salpetersäure erhitzt, färben sie sich schwach und bei Hinzufügen von Ammoniak dann stärker gelb (Xanthoproteinreaction); mit Millon'schem Reagens - einer Lösung von Mercuridnitrat $\left[\mathrm{Hg}\left(\mathrm{NO}_{3}\right)_{2}\right]$ in Salpetersäure, welche etwas salpetrige Säure enthält — färben sie sich beim Erhitzen roth; mit Zuckerwasser oder Essigsäure und daranf mit Schwefelsäure behandelt, werden sie purpur bis violett gefärbt; mit concentrirter Salzsäure werden sie beim Stehen violett; alkalische Lösungen, mit Kupfersulfat versetzt, werden violett-blau. Alle Eiweisskörper werden aus ihren Lösungen gefällt durch Gerbsäure und Sublimat. Mit Ausschluss der als Pepton bezeichneten, bei der Verdauung entstehenden Modification sind die Liweisskörper auch fällbar durch andere schwere Metallsalze, durch concentrirte starke Mineralsäuren und durch Alkolool. Aus dem, seiner Constitution nach unbekannten Eiweiss hat man eine Reihe von Körpern mit bekannter Molekularstructur abspalten können, unter welchen sich Harnstoff und die Amidosäuren: Leucin, Tyrosin und Asparaginsäure befinden.

Das Blutserum hat viel Aehnlichkeit mit der aus geschnittenem Hühnereiweiss durch Verdünnen mit Wasser und Filtriren gewonnenen Fliissigkeit. Beide coaguliren beim Erwärmen auf etwa $70^{\circ} \mathrm{C}$. Sie unterscheiden sich dadurch von einander, dass der durch Salzsäure oder Salpetersäure gefällte Niederschlag des Blutserums sich im Ueberschuss der Säure wieder leicht löst, der des Eiereiweisses nur schwer. Von grösserer physiologischer Bedeutung ist, dass in die Venen eingespritztes Eieralbumin unverändert im Harn ausgeschieden wird, während Serum, in die Venen injicirt, keine Albuminurie erzeugt.

Denjenigen Eiweisskörper, welchem das Blutserum seine Aehnlichkeit mit dem Hühnereiweiss verdankt, nennt man das Serumeiweiss. Ausser diesem enthält es in beträchtlicher Menge einen der Gruppe der Globuline zugehörigen Eiweisskörper, das Serumglobulin oder Paraglobulin. Die Globuline, zu denen auch das Myosin gehört, coaguliren ebenfalls beim Erhitzen ihrer Lösungen, man kann sie aber auch durch Verdünnen mit Wasser und Durchleiten von Kohlensäure ausfällen. Das auf letztere Art dargestellte Serumglobulin ist unlöslich in Wasser, aber löslich in verdlïnnter Kochsalzlösung. Diese Löslichkeit verliert es bei lïngerem Stehen unter Wasser, nicht aber, wenn es über Schwefelsäure getrocknet und dann über $100^{\circ} \mathrm{C}$. erhitzt wird.

Bei der Einwirkung concentrirter Alkalien auf Eiweiss, aber auch, wenn bei schwächerer Alkalescenz erhitzt wird, bildet sich eine dem Casïin der Milch nahestehende Modification: Alkalialbuminat. Dieses ist, cbenso wie das durch Einwirken starker Säuren entstehende Acidalloumin (wozn das Syntonin gehört) in saurer und alkalischer Flüssigkeit 
löslich, in neutraler nicht. Die Lösungen gerimnen nieht durch Hitze. Wenn man in Filtrat ron Blutserum, aus welchem Serumeiweiss und Serumglobulin durch Hitze ausgefiillt sind, bei genauer Neutralisirung einen Niederschlag erhält, so kann dies Alkalialbuminat sein, welches sich bei der Erwärmung erst gebildet hat. Für das Vorkommen ron Alkalialbuminat im genuinen Blutserum liegt kein Beweis vor.

Die durch Erlitzen coagulirbaren Eiweisskörper scheiden sich bei um so niedrigeren Temperaturen aus, je concentrirter und je weniger alkalisch die Eiweisslösung ist. Mit rorschreitender Coagulation nimmt die Alkaleseenz zu, und man muss deshalb, wenn man schmolle und vollkommene Ausscheidung dureh Coagulation erzielen will, rorsichtig ansäuern.

Die stickstofthaltigen krystallisirbaren Stoffe, welche die Formen darstellen, unter denen das Eiweiss nach seinem Zerfall im Organismus mit dem Harn ausgeschieden wird, Kreatin, Kreatinin, Harnsäure, Harnstoff, Hippursäure, sind sämmtlich auch im Blutserum nachgewiesen worden.

Zucker, und zwar Traubenzucker, ist ein regelmässiger Bestandtheil des Blutserums. Auch ist Milchsäure in demselben gefunden worden.

Von Fetten entliält das Blutserum selır wechselnde Mengen. Nach fettreichen Nahlzeiten ist dasselbe milchig getriibt ron suspendirten Fettkïgelchen. Seifen und Cholesterin sind stets in nachweisbaren Spuren im Serum rorhanden.

Unter den mineralischen Stoffen wiegt das Kochsalz im Blutserum bei weitem vor, es beträgt etwa $1 / 2 \%$ desselben. Etwa die Hälfte dieses Gewichtes rertheilt sich noch auf Kali, Natron, Kalk und Magnesia, die an Chlor, Schwefelsäure, Phosphorsäure und Kohlens:iure gebunden sind.

Das Spectrum des reinen Serums ist von den des Hämoglobins rerschieden. An der Hervorbringung der Färbung betheiligen sich mehrere und, wie es scheint, bei rerschiedenen Thieren rerschiedene Farbstoffe, ron denen einige auch in der Galle rorkommen.

Das Fibrin, welches durch Selılagen des Blutes gewonnen ist, stellt nach dem Auswaschen nit Wasser ein Gewirr weisser zïher Füden dar. In getrocknetem Zustande macht es nur 7 pro Mille des Blutgewichtes aus, obgleich es doch bei seiner spontanen Ausscheidung den Aggregatzustand des ganzen Blutes in der auffallendsten Weise ändert. Eine Fibrinflocke in wasserstoffsuperoxydhaltiges Wasser gebracht, zersetz.t dasselbe unter lebhafter Entwickelung ron Sauerstoff. Dats Fibrin ist ein eiweissartiger Körper. Unter der Einwirkung verdünnter Salzsäure quillt das Fadengewirr zu einer gallertigen Masse auf und löst sich auch theilweise. Das Gelöste rerhält sich wie ein Acidalbuminat. Das Fibrin 
ist im flüssigen Blut oder im Blutplasma nicht in gelöster Form vorhanden, sondern es bildet sich erst bei der Gerinnung des Blutes aus zwei als Fibringeneratoren bezeichneten Substanzen unter der Einwirkung eines Fermentes.

Die fundamentalen Thatsachen, welche bei der Erklärung der Blutgerinnung Beriicksichtigung finden müssen, sind folgende. Es giebt Körperfliissigkeiten, an welchen man ohne weiteren Zusatz, auch wenn man sie bis zu eintretender Fäulniss beobachtet, keine Gerinnung wahrnehmen kann, die aber sofort gerinnen, wenn man ihnen Blutserum zusetzt. Im normalen Organismus kommen solche Fliissigkeiten nicht vor, es sind krankhafte Transsudate, und sie finden sich in reinster Eigenschaft, das heisst mit völligem Fehlen spontaner Gerinnbarkeit hauptsächlich in serösen Höhlen des Pferdes, zum Beispiel im Pericard. Auch Hydrocelenflüssigkeit von Menschen (Ausschwitzung in den serösen Sack (les Hodens) gehört hierher. Dieselbe Wirkung wie das Blutserum übt auf diese Flïssigkeiten die Substanz aus, welche man aus demselben als Niederschlag erhält, wenn man es stark mit Wasser verdïnnt und Kiohlensäure hindurchleitet. Diese Substanz ist der Hauptmenge nach der schon früher als Paraglobulin bezeichnete Eiweisskörper. Durch Anwendung desselben Verfahrens auf ein gerimnbares aber spontan nicht gerinnendes Transsudat erhält man einen ähnlichen, aber nicht identischen Eiweisskörper. Lösungen dieser beiden gefällten Substanzen gerinnen, wenn man sie zusammengiesst. Zur Gerinnung sind also wenigstens zwei Substanzen erforderlich, welche man die Fibringeneratoren genannt hat. Das Blutplasma enthält beide fibrinbildenden Substanzen, ron denen aber in das Serum nur die eine, das Paraglobulin, oder die "fibrinoplastische Substanz" übergeht, während das Transsudat nur die andere, die "fibrinogene Substauz" enthält.

Das aus gewöhnlichem Blutserum dargestellte Paraglobulin ist nun aber nicht rein, sondern es enthält eine Beimengung, welche für die Fibringerinnung ebenfalls wesentlich ist. Gelıt man nämlich bei der Darstellung der fibrinoplastischen Substanz von einem Serum aus, welches aus schnell auf $0^{\circ}$ abgekühltem Pferdeblut stammt, dessen Plasma bei derselben 'Temperatur durch doppeltes Filtrirpapier filtrirt und dann erst der Erwärmung und Gerinnung iiberlassen wurde, so erhält man cine Sulsstanz, welche an und für sich das Transsudat oder eine Lösung von Fibrinogen gar nicht oder nur sehr langsan zur Gerinnung bringt. Diese Cierinnung erfolgt aber sofort, wenn man ausserdem noch eine Sulsstan\% hinzufügt, welche man aus gewöhnlichem Blutserum durclı Ausfällen rlesselhen mit Alkohol und Digeriren des Niederschlages mit Wasser erhält. Diese Sulsstanz verhält sich wie ein Ferment, denn die Menge des crhaltenen Fibringerinnsels ist nicht von der zugefügten 
Menge dieser Substanz abhängig (nur die Schnelligkeit der Gerinnung wird hierdurch beeinflusst), ferner wird die Substanz bei der Gerinnung nicht verbrancht, sondern sie erhïlt sich wirksam in dem ausgeschiedenen Serum, dagegen helst Erwärmung auf $50^{\circ}$ ihre Wirkungsfähigkcit auf. Mit anderen fermentativen Processen hat die Blutgerinnung auch das gemein, dass bei ilu eine geringe Wärmeentwickelung eintritt.

Es wurde schon friiher gesagt, dass in dem ohne besondere Vorsichtsmaassregeln aus dem Organismus entnommenen Blute ein Theil der farblosen Błutkörperchen schnell zerfällt. Es ist höchst wahrscheinlich, dass hierbei das Fibrinferment entsteht, denn die fermentfreie orler fermentarme fibrinoplastische Substanz erhält man unter Unständen, welche die Beimengung von Zerfallsproducten farbloser Blutkörperchen möglichst einschränken. Bei $0^{\circ}$ ist der Zerfall derselben ein sehr langsamer und in der Kälte gehen sie auch unzerfallen durch doppeltes Filtrirpapier schwer hindurch. Die rothen Blutkörperchen haben mit der Entstehung des Fibrinfermentes nichts zu thun, denn der Cruor giebt eine sehr geringe Ausbente an Ferment. Wenn die Gerinnung nach eingetretener Schichtung des Blutes abläuft, so bildet sich das festeste Gerinnsel dort, wo die meisten farblosen Blutkörperchen sind, in der Speckhaut oder Crusta phlogistica. Unter dem Vikroskop hat man aus zerfallenden rothen Blutkörperchen oder rothen Körnchenhaufen Fusern hervorgehen sehen, doch handelt es sich bei solcher Ausscheidung von "Stromafibrin" um Processe, welche mit der massenhaften Gerinunng des Blutes oder gar des körperchenfreien Plasmas nichts zu thun haben.

Das Fibrinogen ist nicht nur aus Transsudaten, sonder'n auch aus dem Blutplasma dargestellt worden. Es gelingt dies, weil seine Löslichkeit in anderer Weise von der Salzconcentration abhängt, als die des Serumeiweisses und des Paraglobulins. Das Fibrinogen unter'scheidet sich von dem Paraglobulin unter Anderem auch durch seine niedrige Gerimmungstemperatur (zwischen $50^{\circ}$ und $60^{\circ} \mathrm{C}$ ). Durch iiberschiissige alkalische Laugen wird Fibrinogen in Alkalialbuminat, durch Sïuren in Syntonin verwandelt.

Die Gerinnung bleibt nicht mur in dem kreisenden Blute aus, sondern auch in beiderseits abgebundenen Blutgefäissen, so lange deren Wand gesund ist. Tödtet man Theile der Gefässwand durch äussere Application von Aetzmitteln, so bildet sich, der Aetzungsstelle entsprechend, ein Gerinnsel. Es muss also der Verkehr des Blutes mit der gesunden Gefässwand sein, welcher die Gerimmung in demselben hintanhält, zum Theil wohl durch Bewahrung der farblosen Blutkörperchen ror dem Zerfall. Es scheint aber, dass die Verhältnisse noch weit verwickelter liegen.

Es ist nämlich gelungen, aus frischem Zellbrei driisiger Organe, 
namentlich der Lymphdrïsen, eine Substanz zu gewinnen, welche in spontan gerinnenden Flüssigkeiten die Gerinnung verhindert. Der nach Erschöpfen des Zellbreies mit Alkohol zurückbleibende Rückstand giebt an Wasser einen Körper ab, der, mit Alkohol gefällt und getrocknet, ein weisses im trockenen Zustande haltbares Pulver darstellt: es ist dies die die Gerinnung hemmende Substauz, welche Cytoglobin genannt worden ist: das Cytoglobin zersetzt Wasserstoffsuperoxyd unter heftigem Aufbrausen. In wässriger Lösung zersetzt sich das Cytoglobin beim Stehen in Zimmertemperatur sehr bald und büsst hierbei die Fähigkeit ein, $\mathrm{H}^{2} \mathrm{O}^{2}$ zu zersetzen und die Gerinnung zu hemmen. Dasselbe geschieht beim Kochen und unter der Einwirkung von Essigsäure und verdünnten Mineralsäuren; in letzterem Falle scheidet sich ein in Wasser unlöslicher Eiweisskörper ans, welcher sich auch sonst wie Paraglobulin verhält: es ist sehr bemerkenswerth, dass ein die Gerinnung hemmender Zellbestandtheil bei seiner Zersetzung einen der Fibringeneratoren liefert.

Das alkoholische Extract des Zellbreies bedingt in dem bei Kälte filtrirten Pferdeblutplasma die Entstehung von Fibrinferment; die durch Cytoglobinzusatz zum filtrirten Blutplasma bewirkte Gerinnungshemmung wird durch Hinzufïgen jenes alkoholischen Extractivstoffes wieder aufgehoben. Ruft man nach stattgehabtem Cytoglobinzusatz zu filtrirtem Plasma durch genügenden Zusatz von Extractivstoffen die Gerinnung wieder hervor, so steigt das Fibrinprocent auf das Doppelte und mehr von demjenigen des sich selbst überlassenen Plasmas an.

Die Wirkung des alkoholischen Extractivstoffes kann übrigens durch einen darauf folgenden genügend grossen Cytoglobinzusatz wieder aufgehoben werden und man erhält dann ein völlig gerinuungsunfähiges Plasma.

Im Allgemeinen kann ein hoher Grad vou Gerinnungsfähigkeit als Zeichen der Gesundheit des Blutes gelten; die für die Gerinnungsfähigkeit erforderlichen Stoffe erhält das kreisende Blut bei seinem steten Wechselverkehr mit den fixen Körperzellen; ein Theil der von diesen Zellen golieferten Stoffe verhindert auf einem gewissen Stadium ihrer im Blut fortschreitenden Zersetzungen die Gerinnung. Nach der Entfernung des Blutes aus dem Organismus zerfällt die gerinnungshemmende Substanz, ohne dass neue nachgebildet wïrde und es kommt zur Gerinnung.

- Dass auf die Gerinnungsfähigkeit des Blutes auch die chemische Bindungsweise, in welchem sich das Calcium desselben befindet, von Einfluss ist, geht daraus hervor, dass ein geringer Zusatz von oxalsaurem Natron zu einem als gut gerinnungsfähig erkannten Blute die 
Gerinnung verhindert, welche dimn aber durch /usatz ron wenig Kalkwasser eingeleitet werden kann.

Ebenso wie das Hämoglobin und wie das aus dem Zellprotoplasma zu gewinnende Cytoglobin erst bei ihrem Zerfall Körper gelsen mit Eigenschaften wie sie als charakteristisch für die Eiweisskörper betrachtet werden, so sind die aus dem Blutserum darstellbaren Eiweisskörper wahrscheinlich auch nicht als solche in dem genuinen Serum oder Blut vorhanden: folgende Beobachtungen sprechen zu Gunsten dieser Auffassung. Genuines Blutserum mancher Thiere wirkt vernichtend auf gewisse Bacterienarten; durch einfache Dialyse gegen Wasser verliert das Serum die bacterientödtende Eigenschaft, welche auch nicht auf die Fliissigkeit ausserhalb des Dialysators iibergegangen ist. Bẹi der Dialyse hat das Serum nur Salze abgegeben. Stellt man die ursprïnglichen Concentrationsrerhältnisse wieder her, so erhält damit das Serum die bacterientödteuden Eigenschaften nicht wieder. Es verliert dieselbe auch durch Erwärmen auf $50^{\circ}$; man hat sich deshall die Vorstellung gebildet, dass im Blut und in dem genuinen Serum Stoffe rorhanden sind, welche erst bei ihrer Zersetzung die Eiweisskörper der Chemiker liefern.

Die Gase, welche das Blut enthält, zum Theil einfach absorbirt, zum Theil locker chemisch gebunden, sind Stickstoff, Sauerstoff und Kohlensäure; sie fallen sehr' wenig in's Gewicht, denn das arterielle Blut enthält in Gewichtsprocenten nur etwa 0,026 Sauerstoff, 0,075 Kohlensäure und 0,002 Stickstoff. Sie sind aber doch, wenigstens was den Sauerstoff und die Kohlensäure anbelangt, von der grössten physiologischen Bedeutung.

Aus dem defibrinirten Blute oder dem Serum kann man im Vacuum unter Zuhilfenahme von Erwärmen und Säurezusatz alle Gase austreibeu und so zur volumetrischen Bestimmung gewinnen. Im ungefähren Mittel enthält das Blut in Volumprocenten (reducirt auf $0^{0}$ und 1 Meter Quecksilberdruck):

\begin{tabular}{|c|c|c|c|}
\hline & & & \\
\hline Arterielles & . & & \\
\hline Venöses & & & 1 \\
\hline
\end{tabular}

Der Stickstoff des Blutes, welcher einfach absorbirt ist, scheint in Haushalte des Organismus keine Rolle zu spielen. Der Sauerstoff ist zum grössten Theile in den rothen Blutkörperchen, die Kohlensäure zum grössten Theile im Blutserum enthalten: erstere an das Hämoglobin, letztere an Alkalien leicht dissociirbar gebunden.

Das arterielle Blut ist unter normalen Bedingungen vollständig oder nahezu vollständig mit Sauerstoft' gesättigt, das heisst es nimmt beim Schïtteln mit Sauerstoff wenig oder gar nichts mehr davon auf. Die Menge Sauerstoff, welche es enthält, hängt von seinem Hämoglobin- 
gehalt $a b$. Es hat lange Zeit als sicher gegolten, dass das Hämoglobin auf je ein Atom Eisen ein Molekül Samerstoff zu binden vermöge: hiernach wïirde die Nenge Sauerstoff, welche ein Blut aufzunehmen im Stande ist, nur von der Grösse seines Hämoglobingehaltes abhängèen; es liegen jetzt aber Untersuchungen vor, aus welchen hervorzugehen scheint, dass es verschiedene Modificationen des Hämoglobins mit verschiedener Sauerstoffcapacität giebt.

Auf die Menge auspumpbaren Sauerstoffes, welche Blut oder eine Hämoglobinlösung aus der Luft aufzunehmen im Stande ist, hat der Partiärdruck des Sauerstoffes in dieser Luft nur geringen Einfluss. Die Zeit, innerhalb welcher die Sättigung eintritt, längt aber ausser von der Grösse der Oberfläche auch von dem Partiärdruck ab. In den Lungencapillaren ist die Flächenausdehnung, in welcher das Blut mit der Lungenluft in Austausch tritt, sehr gross, sodass in wenigen Secunden bei dem gewöhnlichen Partiärdruck des Sauerstoffes die Sättigung erfolgen kann. Die Arterialisirung des Blutes erfolgt sogar, wenn auch weniger vollkommen, bei sehr geringem Sauerstoffdruck.

Die Abgabe von Sanerstoff aus den Körpercapillaren an deren Umgebung ist verständlich, weil hier das äusserst sauerstoffbedürftige Protoplasma der functionirenden Gewebselemente nahezu ein Sauerstoffvacuum unterhält; dagegen ist die Abdunstung der Kohlensäure aus dem scheinbar alkalischen Blute in den Lungen eine ebenso räthselhafte Erscheinung wie die vollständige Austreibung der Kohlensäure im Vacuum. Einen wichtigen Fingerzeig enthält freilich die Thatsache, dass im Vacuum bei rascher Auspumpung nicht nur die ganze Kohlensäure des Blutes entweicht, sondern sogar noch Kohlensäure von einfach kohlensaurem Natron, das man dem Bhute eigens zugesetzt hat. Es kommt hierbei in Betracht, dass die Alkalien des Blutes theilweise an die dreibasische Phosphorsäure gebunden sind, und dass die phosphorsauren Salze, welche noch ein durch Alkali ersetzbares Wasserstoffatom enthalten, Lakmuspapier bläuen, das Blut also zu der Reaction befähigen können, welche man die alkalische nennt. Ausserdem müssen wir uns erinnern, dass das Hämoglobin, welches bei der gewöhnlichen Alkalescenzbestimmung des Bhtes nicht zur Wirkung kommt, sich wie ein saurer Körper verhält; in der That kann man auch nur aus dem gesammten Blute, nicht aus dem körperchenfreien Serum alle Kohlensäure durch einfaches Auspumpen abscheiden. Soll aus reinem Serum alle Kohlensäure ausgetrieben werden, so muss man eine stärkere Süure hinzusetzen. Auch der Sanerstoff des Hämoglobins spielt bei der Kohlensäure-Abscheidung in den Lungen eine Rolle, denn das Auspumpen der Kohlensäure gelingt um so besser, je sauerstoffreicher das Blut ist.

Der Gasgehalt ändert sich auch in dem aus dem Körper gelassenen 
Bhute: der auspumpbare Siuerstoff nimmt alb unter Vermehrung der liohlensiure: bei diesem Process, welchen man die Siunerstoffzehrung des Blutes genaunt hat, uimmt auch die Alkalescenz des letzteren ab. Der Siluerstoff ist im kreisenden Blute nicht als Ozon, sondern in inaktiver Form enthalten. Auf Reagentien, welche Sauerstoff in aktiver Form nachzuweisen gestatten, wirkt das Blut erst einige Zeit, nachdem es den Organismus rerlassen hat.

Das Verfahren, un die gesammte Blutmenge eines Thieres zu bestimmen, ist ziemlich umständlich; der ermittelte Werth hat nur eine hestimmte Berleutung, wenn er auf das Körpergewicht des Thieres bezogen wird: das Thier wird also zunächst gewogen und von diesem Gewicht wird später dasjenige des Magen- und Darminhaltes in Abrechnung gebracht. Man lässt das Thier aus einer in die Carotis gebundenen Caniile in ein Messgefäiss verbluten und setzt eine Probe des defibrinirten Blutes bei Seite; dann lässt man unter Benutzung derselben Canïle eine 0,6\% ige Lösung ron Kóchsalz in das Gefässsystem des Thieres einfliessen und fïngt die Spülflüssigkeit aus einer Vene auf, bis dieselbe nicht melur gefürbt ist. Darauf wird der ganze Körper nach Entleerung des Magen- und Darminhaltes zerhackt, in Wasser vertheilt und nach 24 Stunden ausgepresst. Die so gewonnene Fliissigkeit mit der Spülflïssigkeit vereint, wird gemessen; ihr procentischer Gehalt an Blut wird dadurch bestimmt, dass man ermittelt, wie stark nan die Blutprobe verdünnen muss, damit sie in gleich dicker. Schicht ebenso gefärbt erscheint, wie die vereinigte Fliissigkeit. Auf diese Weise ist man dazu gelangt, die normale Blutmenge zu etwa 1/1з der Körpersubstanz anzunchmen.

Einen Ueberblick iiber die gesammte Zusammensetzung des Blutes gew:ihrt folgende, abgerundete Zahlen enthaltende Tabelle, welche Analysen von Pferdeblut entnommen ist. Für das Menschenblut ist in den Hauptrerhältnissen keine grosse Abweichung zu erwarten.

1000 Theile Blut enthalten:

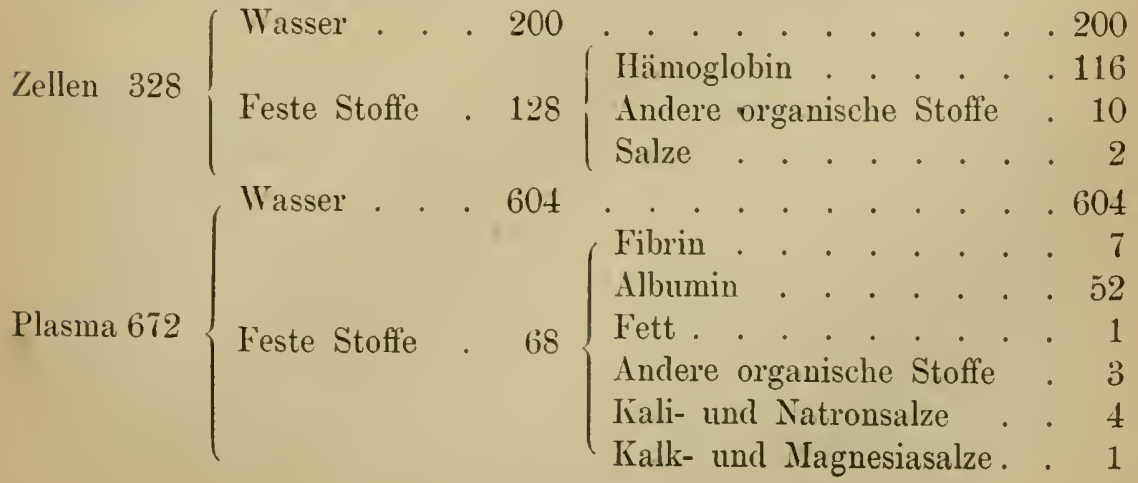


Die Lymphe ist Blut olne rothe Blutkörperchen, und zwar trifft diese Definition sowohl die Zusammensetzung, als auch die Herkunft der Lymphe. Das Blut selbst bespült nur die Innenwände der Blutgefässe; um zu den übrigen Geweben zu gelangen, muss die das Ernährungsmaterial tragende Flïssigkeit die Gefässwände durchsetzen. Das Grundsätzliche, das bisher über die Zusammensetzung der Lymphe bekannt war, erschien verständlich, wenn man annahm, dass es sich wesentlich um einen Filtrationsprocess handele. Das Wasser und die darin gelösten krystalloiden Bestandtheile unterliegen in gleichem Maasse der Filtration, die colloiden jedoch in geringerem und die geformten noch weniger. Daher der Mindergehalt der Lymphe an Eiweiss und die $\mathrm{Ab}$ wesenheit der rothen Blutkörperchen in derselben.

Neuere Untersuchungen haben aber Thatsachen ergeben, aus denen hervorgeht, dass für die Lymphbildung weniger der Druck in den capillaren Blutgefässen als der Zustand und vielleicht auch die Thätigkeit ihrer Endothelzellen von Belang ist. Aus einer Reihe schwer zu deutender Beobachtungen hat man sogar den Schluss gezogen, dass die Lymphe das Product einer Secretionsthätigkeit dieser Zellen sei.

Die aus den Blutcapillaren ausgetretene Flüssigkeit tränkt die Gewebe und umspïlt die functionirenden Zellen, sowie die anderen protoplasmatischen Gebilde, namentlich auch den Inhalt der Muskel- und Nervenfasern. Alle diese schöpfen aus ihr Stoff und Energie für ihre Ernährung und für ihre Arbeitsleistung und geben zum Theil auch an sie die Producte der regressiven Metamorphose ab. (In letzterer Beziehung machen die secernirenden Drüsenzellen eine Ausnahme.)

Der Sanerstoff tritt nicht nur in dem Maasse aus dem Blute zu den fixen Geweben, wie er in der aus den Capillaren tretenden Lymphe gelöst ist, sondern er diffundirt in stärkerem Maasse durch die zu langsam fliessende Lymphe hindurch. Dasselbe gilt wahrscheinlich auch von manchen, der Ernährung dienenden Substanzen, welche, wenn sie auf den Transport durch die langsam fliessende Lymphe angewiesen wären, den jeweiligen Bedarf nicht decken könnten.

Aus den Gewebsspalten des Parenchyms der Organe sammelt sich die Lymphe im interstitiellen Gewebe wieder in Gefässen mit geschlossener Wandung, um sich schliesslich durch den Ductus thoracieus wieder in die Blutbahn zu ergiessen. Der Natur der Sache nach ist zu erwarten, dass die den einzelnen Organen entströmende Lymphe eine wesentlich verschiedene Zusammensetzung haben muss. Doch sind die meisten dieser Unterschiede an den Stellen, wo die Lymphe der Untersuchung zugänglich wird, schon verwischt. Fin dentlicher Unterschied besteht zwischen der Flïssigkeit aus einem Hautlymphgefäss einer Extremität und der Lymphe aus dem Ductus thoracicus während der Ver- 
daunng, da letztere zum Theil aus dem Lymphsystem des Darmes stammt. Dieses, welches man auch das System der Chyylusgefässe nennt, führt dem Lymplistrom des Ductus thoracicus ans dem Darm resorbirte Stoffe zu, namentlich Fett, durch wolches der Inhalt des Ductus thoracicus milchig getribt erscheinen kann. In die Bahn der Lymphgefïsse sind die Lymphdriisen eingeschaltet, in welchen die Lymphe durch dichte Anhïufungen von Leucocyten hindurchfiltrirt wird, und wo sie auch Gelegenheit hat, mit dem Blute in Diffusionsverkehr zu treten.

Ein anmähernd richtiges Bild von der Zusammensetzung der Lymphe beim Menschen, welche stets von alkalischer Reaction, fast farblos und schwach opalescirend ist, geben folgende Zahlen: In 100 Theilen Lymphe sind enthalten: Wasser 95,0; feste Stoffe 5,0 - und zwar: Fibrin 0,1; Albuminstoffe 3,8 (Serum-Albumin, Globulin); Extractirstoffe 0,3 (Zucker, Ilarnstoff etc.); Salze 0,8 (Kochsalz, Soda, Spur von Eisen und Phosphate von Natrium, Calcium, Magnesium); Fettkörper 0,1 (Neutralfett, Seife, Cholesterin, Lecithin).

Reine Lymphe gerinnt an der Luft nur langsam und unvollkommen; sie enthält geniigende Mengen Fibrinogens, denn auf Zusatz von defibrinirtem Blut oder fibrinoplastischer Substanz erfolgt schnelle und ziemlich vollkommene Gerinnung. Das immerhin etwas lockere Gerinnsel zieht sich mit der Zeit zu einem "Lymphkuchen“ zusammen, welcher "Lymphserum“ auspresst. Ersterer enthält zwischen den Fibrinfäden eingeschlossen reichliche Menge „Lymphzellen“, welche wolıl zum Theil ausgewanderte, farblose Blutzellen, zum Theil junge, in den Lymphdrisen gebildete und erst dort dem Lymphstrom beigemengte Elemente sind.

Von Gasen enthält die Lymphe nur eine Spur freien Sauerstoffes, dagegen bis zu 46 Volumprocent Kohlensäure, diese theils fest an Natrium gebunden, theils einfach auspumpbar.

\section{Der Kreislauf des BIntes.}

Das Blut muss, um dem Stoff- und Wärmeaustausche zwischen den Körperobertlächen und den inneren Organen, sowie zwischen verschiedenen ron einander entfernt liegenden Organen selbst zu dienen, eine beständige Bewegung ausfiihren, bei welcher es abwechselnd ein weit verzweigtes System engster Canälchen durchströmt, um dann immer wieder in ein gemeinsames Becken zurïckzukehren, in welchem eine rollkommene Mischung stattfindet; diese kreisende Bewegung, welche man die Circulation des Blutes nennt, geschieht in einem Röhrensystem mit eigenen Wandungen, dem Blutgefässsystem. Ein gewisser Theil des 
Blutes tritt beständig als Lymphe aus diesem Gefässsystem aus, in ein anderes Gefässsystem, dessen Stämme mit eigenen Wänden wie die Blutgefässe versehen sind, dessen Anfänge aber Spalträume in allen weichen Körpergeweben darstellen. Die Wandungen dieser Spalträume bestehen aus einem einschichtigen Endothelzellbelag der begrenzenden Gewebsmassen. Zu diesen lymphatischen Spalträumen gehören die „serösen" Spalträume zwischen innerem und äusserem Blatt von Pleura und Peritonäum, die Hohlräume des Centralnervensystems, vordere und hintere Augenkammer, vielleicht Gelenkhöhlen und Sehnenscheiden. Der Theil der kreisenden Fliissigkeit, welcher sich auf den Wegen der Lymphbahnen befindet, wird zu $1 / 300$ derjenigen in der Blutbahn geschätzt.

Das centrale Becken, zu welchem die kreisenden Flïssigkeiten immer wieder zurïckkehren, ist das Herz. Steht das Herz still, so hört der Kreislauf des Blutes auf, der Herzschlag muss also die Ursache für diese Blutbewegung sein.

Das Herz besteht wesentlich aus Muskelsubstanz; es wiegt beim Menschen 300 bis 350 Gramm. Die Muskelfasern des Herzens sind quergestreift, besitzen kein Sarkolemm und sind verzweigt; die Zweige benachbarter Faserzellen, deren jede einen wandständigen Kern besitzt, sind mit ihren Endflächen in inniger Berïhrung; auf diese Weise entsteht ein allseitig zusammenhängendes, die Erregung leitendes Netzwerk contractiler Substanz. Am Froschher-

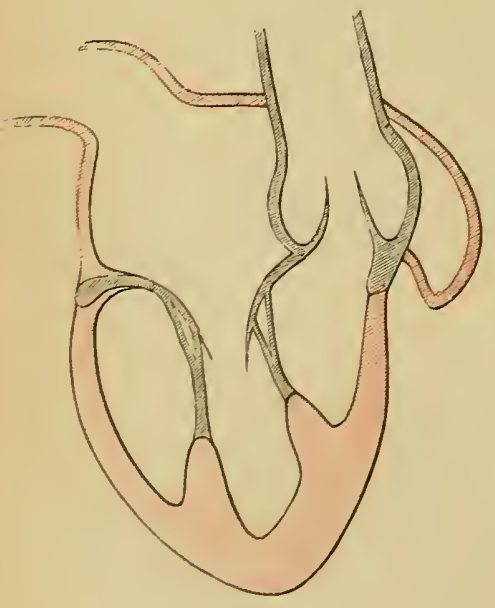

49. zen ist es nachgewiesen, dass an den Zellgrenzen, welche die Erregungswellen durchlassen, das einem Schnitt unmittelbar folgende Absterben Einhalt thut wie an den Einschnürungen der myelinhaltigen Nervenfaser'n.

Das musculöse Hohlorgan, welches das Herz darstellt, besteht aus vier Abtheilungen, den beiden Vorhöfen und den beiden Kammern. Zwischeu Vorhöfen und Kammern ist die Muskelsubstanz vollkommen unterbrocheu durch den Arcus fibrocartilagineus: die Muskelfaserzüge der Kammern gehen jedoch von der Wand der eimen auf die der andern und auch auf die ihnen beiden gemeinschaftliche Scheidewand über; dasselbe gilt von den Vorhöfen. Die Vorhofswände sind rechts und links nicht sehr verschieden; die Wand der linken Kammer ist weit stärker, als die der rechten. Die Muskelzellennetze sind durch bindegewebige Lamellen in Faserzüge 
eingetheilt, die innere und iussere Oberflïche ist mit Endothel bekleidet (Endocard und Pericard). Die Hohlräume der bciden Herzhälften haben gleiche Capacität, die Vorhöfe mit ihren, als Iferzohren bezeichneten Anlı̈̈ngen können einen unerheblich kleineren Inhalt aufnehmen als die Kammern. Der Annulus fibrocartilagineus, welcher äusscrlich in der Atrioventriculargrenze sichthar ist, sendet in jede Herzhälfte einen ringförmigen, an den Rüindern ausgezahnten Fortsatz in Duplicaturen des Endocards hinein. Es sind dies die bei der Herzthätigkeit als Ventile wirkenden Atrioventricular-Klappen. Die rechte wird wegen dreier Hauptzipfel, welche an dem ausgefranzten freien Rande zu unterscheiden sind, als tricuspidalis, die linke aus dem analogen Grunde als bicuspidalis bezeichnet. Von den Spitzen der Haupt- und Nebenzipfel der Kilappen gehen Selınenfïden zu der Kammermuskelwand. Den grössten dieser "Chordae tendineae" kommt die Kammerwand mit musculösen Elhebungen, den Herzpapillen oder Papillarmuskeln, entgegen. Ausser den Chordae tendineae, welche sich ron den Zipfelspitzen bis zu den Papillenspitzen erstrecken, gieht es eine gleiche Zahl solcher, welche sich in einiger Entfernung rom Rande der Klappen an ihre untere Fläche ansetzen. Durch einen ron der Herzspitze zur Herzbasis gerichteten Flüssigkeitsstrom müssen diese Ḱlappen geblälht werden wie durch Tane gehaltene Segel und hierdurch muss wegen des Aneinanderlagerns der freien Klappenränder dieser Strom abgeschnitten werden; in umgekehrter Richtung sind die Klappen durchlässig; man nennt sie Segelrentile.

Die Anordnung der Faserzïge des Herzmuskels ist am leichtesten zu verstehen, wenn man sich als eigentlichen Hohlraum den linken Ventrikel vorstellt und die rechte Herzhöhle nur als einen Spalt in der Wand betrachtet, was ïbrigens auch der Entwickelungsgeschichte entspricht; dann kann man sagen, dass die äusserste und innerste Muskelfaserlage in ihrer Richtung sich kreuzen und dass die mittleren Lagen mit ihren Richtungen Cebergänge dazwischen bilden. Alle Faserzïge kann man sich einerseits rom Annulus fibrocartilagineus ausgehend und anderer-
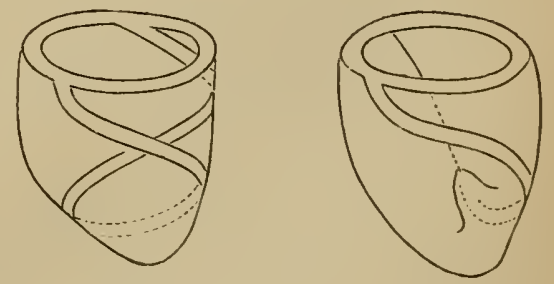

50. seits wieder zu demselben zurïckkehrend denken; ihr Verlauf kann sich auf zwei Weisen gestalten, entweder umschlingen sie den Herzconus in einer Spirale, welche auf der einen Seite ron dem Annulus herah, auf der anderen Seite wieder zu ihm hinaufsteigt, sodass annähernd eine 8 beschrieben wird (Achterturen), oder sie senken sich, nachdem sie in spiraligem Lauf bis gegen die 
Herzspitze abgestiegen sind, durch die Wandmasse in den Hohlraum hinein und betheiligen sich hier am Aufbau der Papillen, deren Chordae tendineae und entsprechende Klappenantheile als ihre Fortsetzung zum Annulus zuriick betrachtet werden können. Von den Vorhofswänden einerseits und den Kammerwänden andererseits setzen sich dünne Muskellager ein Stiick weit auf die Atriorentricular-Klappen fort.

Die Richtung, in welcher die Atrioventricular-Klappen durchgängig sind, giebt uns die Richtung an, in welcher wir das Gefässsystem vom Herzen aus weiter zu verfolgen haben, wenn wir hierbei die Richtung des Blutstromes innehalten wollen. An der Atrioventicular-Grenze erhebt sich aus jeder Herzkammer je eine der beiden Hauptarterien, so nennt man die Gefässe, welche das Blut vom Herzen, dem Centrum der Blutbewegung fort zur Peripherie führen; die beiden arteriellen Hauptstämme sind die Aorta aus dem linken und die Arteria pulmonalis aus dem rechten Herzen; aus ihnen gehen zwei arterielle Gefässsysteme durch meist dichotomische Theilungen, welche sich etwa 30 Mal wiederholen, hervor; aus der Arteria pulmonalis dasjenige in den Lungen, aus der Aorta dasjenige im ganzen iibrigen Körper. Es gilt hierbei im Allgemeinen, dass der Querschnitt jeder aus einer Theilung hervorgehenden Arterie kleiner ist, als der Querschnitt der Arterie vor der Theilung; dass dieser aber wiederum kleiner ist, als die Querschnittssumme der aus der Theilung hervorgehenden Arterien. Eine Ausnahme hierron machen die Arteriae iliacae, deren Gesammtquerschnitt kleiner ist, als der der Aorta abdominalis. $\mathrm{Zu}$ den Abweichungen ron diesem Schema gehört, dlass aus der Wand der grösseren Arterien solche von sehr viel kleineren Durchmesser abgehen, wie die Arteriae intercostales aus der Aorta, oder die Arteriae arteriarum, und dass Communicationen zwischen mehr oder weniger weit von den Endverästelungen entfernten Zweigen des arteriellen Baumes vorkommen, welche man Collateralarterien nennt. An die Endverzweigungen der Arterien schliesst sich ein vielfach anastomosirendes Netz von Gefässen an, welches man das System der Haaroder Capillargefässe nennt.

Aus dem Capillargefässsystem entsteht in umgekehrter Richtung, als sich die Arterien aufgelöst haben, durch Wiedervereinigung das Venensystem. Beim Vergleich von Venen und Arterien gleicher Ordnungszahl findet man den Querschnitt der Venen erheblich grösser. In zwei drüsigen Körperorganen und zwar in ren Nicren auf der arteriellen, in der Leber auf der venösen Seite, findet auch ausserhalb des eigentlichen Capillargefässnetzes eine Auflösung grösserer Gefässe zu kleinsten und Wiederrercinigung der letzteren zu grossen statt.

Die grossen Venenstämme münden in die Vorhöfe ein, in den 
rechten die das Bhut aus dem Körper zuriickführenden Venae cavae superior und inferior, in den linken die Pulmonalyenen.

Da die Höhlen beider Herzhälften (im extrauterinen Leben) durch die Scheidewände der Vorhöfe und der Ventrikel vollkommen gegen einander alogeschlossen sind, so muss das Blut, um an denselben Ort der Gefïssbahn wieder zurückzugelangen, wenigstens zweimal rom Herzen fort und zum Herzen zuriickgehen. Das rechte und das linke Herz nehmen in der gesammten Kreishahn des Blutes eine sehr entfernte Stellung ein; doch ist ihre Vereinigung zu einem einzigen Organ von grosser Wichtigkeit, was später rerständlich werden wird. Die eine Hïlfte des Kreislaufes vom linken Ventrikel durch die Aorta, die Körperarterien, Körpercapillaren und Körperrenen bis zum rechten Vorhof nennt man den Körperkreislauf oder grossen Kireislauf, den andern Theil rom rechten Ventrikel durch die Lungen zurück zum linken Vorhof den Lungenkreislauf oder kleinen Kreislauf.

Eine Seitenbahn zum Körperkreislauf bilden die eigenen Gefässe des Herzens, welche mit den beiden Arteriae coronariae aus dem Anfangstheile der Aorta entspringen, deren Capillaren die Muskelfaserzellen des Herzens umspinnen und deren Venen sich in den Venae coronariae sammeln, um sich in den rechten Vorhof zu entleeren.

Wenn anch beim Menschen im extranterinen Leben im Wesentlichen alles Blut, welches in den grossen Kreislauf getrieben wird, frisch den Lungen entstammt, so wird doch dem Blute im linken Ventrikel auf zwei Wegen eine, praktisch allerdings nicht ins Gewicht fallende, Menge zugefiilnrt, welche zuletzt mit Arbeit leistenden Gewebselementen in Verkehr gestanden hatte und hierbei venös geworden ist. Ein kleiner Theil der Herzrenen mündet durch die ïber die ganze innere Oberfläche (auch des linken Ventrikels) zerstreuten Foramina Thebesii, ausserdem kehrt das Blut aus den Arteriae bronchiales nicht durch Körperrenen, sondern durch Pulmonalvenen zum Herzen zuriick. Es ist hier der Ort, kurz darauf hinzuweisen, dass die Lungenarterien renöses und die Lungenvenen arterielles Blut führen.

An deu Wandungen der Gefïsse unterscheidet man drei Schichten, die Tunica intima, media und adventitia, an deren Aufban sich Bindlegewebe, elastisches Gewebe, glatte Muskelfasern und Endothelzellen betheiligen. Letztere Elemente sind platte, kernhaltige, protoplasmatische Gelikile, welche sich gegenseitig polygonal begrenzend und in einfacher zusammenhängender Lage das ganze Gefüsssystem auskleidend, die wesentlichen Bestandtheile der 'Tunica intima, im Capillarsystem sogar der ganzen Gefïsswand darstellen.

Die glatten Muskelfasern sind, meistens in circulärer Anordnung, hauptsächlich in der Tunica media enthalten, und zwar sind sie am stärksten 
in den mittleren und kleineren Arterien, weniger stark in den mittleren und kleineren Venen, schwach in den kleinsten Arterien und Venen entwickelt. Ausser in den Capillaren fehlt die glatte Muskulatur in dem Anfangstheil der Aorta und der Arteria pulmonalis, in den Venen der Netzhaut, der Knochen und des Centralnervensystems, sowie in den grossen Venenstämmen, an deren Ende in der Nähe der Vorhöfe dafür quergestreifte Musculatur auftritt. Das elastische Gewebe ist am stärksten entwickelt in den grossen Arterienstämmen, namentlich in der Aorta.

Am Ursprung der grossen Arterien und weit verbreitet in den Venen und Lymphgefässen finden sich in das Lumen vorspringende, nach derselben Richtung wie die Atrioventricular-Klappen ventilartig wirkende Klappen. In Aorta und Pulmonalis sind es die "Semilunar-Klappen“, je drei mit ihrem parabolischen festen Rande unten bis auf die musculöse Ventrikelwand hinabreichende wagentaschenartige Lamellen, deren jede in der Mitte ihres freien Randes eine kleine Verdickung (Nodulus Arantii) und daneben jederseits bis zum Ansatz halbmondförmige Verdünnungen (Lunulae) trägt. Füllt man in den Anfangstheil der Aorta oder der Pulmonalis Wasser unter gehörigem Druck, so legen sich die Klappen mit ihren freien Rändern so aneinander, dass sie eine regelmässige dreistrahlige Figur bilden, in deren Mittelpunkt die Noduli liegen. Namentlich die Lunulae schliessen so dicht aneinander, dass kein Wasser hindurch fliesst. Jede der Klappen begrenzt einen taschenförmigen Raum, dessen äussere Wand von der hier ausgebuchteten Gefässwand gebildet wird (Sinus Valsalvae). Wird vom Herzen her Wasser in eines dieser Gefässe hineingetrieben, so weichen die Klappeuränder auseinander und bauchen sich nach aussen vor, ohne sich (wegen der Sinus Valsalvae) an die Gefässwand anzulegen; aus zweien der Sinus an der Aorta entspringen, gegenüber dem oberen Rande der Klappen die Coronararterien.

Die Kílappen der Venen- und Lymphgefässe sind ähnlich, aber einfacher gebildet; es sind meist je zwei einander gegenüber stehende 'Taschen, welche den Rïckfluss der Flïssigkeit vom Herzen weg verhindern; sie befinden sich in den grösseren Lymphgefässstämmen und in den Körpervenen, namentlich in denen der Extremitäten.

Um die für die Auffassung der Blutbewegung erforderlichen Begriffe klar zu stellen, wollen wir uns zunächst an einen schematischen Versuch wenden. An dem unteren Enrle eines geräumigen Wassergefässes ist ein langes, starkes, horizontales Rohr von überall gleichem Querschnitt befestigt; das letztere trägt dicht bei seinem $\Lambda$ nfang ein senkrechtes, gläsernes Steigrohr und in gleichen Abständen von hier bis zum Ende noch melirere derselben. Auf passende Weise wird das Vorratlisgefäiss andauernd bis zu derselben Höhe mit Wasser gefültt erhalten, und das Wasser strömt 
damn aus dem Ende des horizontalen Rohres in gleichmässigem Strahle aus; das Wasser in dem Steigrohre ( $\left.{ }^{1}\right)$ steht erheblich niedriger, als in dem Reservoir, die Kuppe in dem letzten Steigrohre ist ganz unten und die Kuppen in den ïbrigen Steigröhren liegen auf einer geraden Linie, welche die liuppen im ersten und letzten Steigrohr verbinden. Misst man die Fliissigkeitsmenge, welche in der Zeiteinheit etwa in 1" ansfliesst, so erhält man diejenige Grösse, welche man Stromintensität nemnt und welche angiebt, eine wie grosse Flïssigkeitsmenge in der Zeiteinheit durch jeden beliebigen Querschnitt des Stromrohres hindurchgeht. Aus der Stromintensität berechnet man die mittlere Geschwindig-

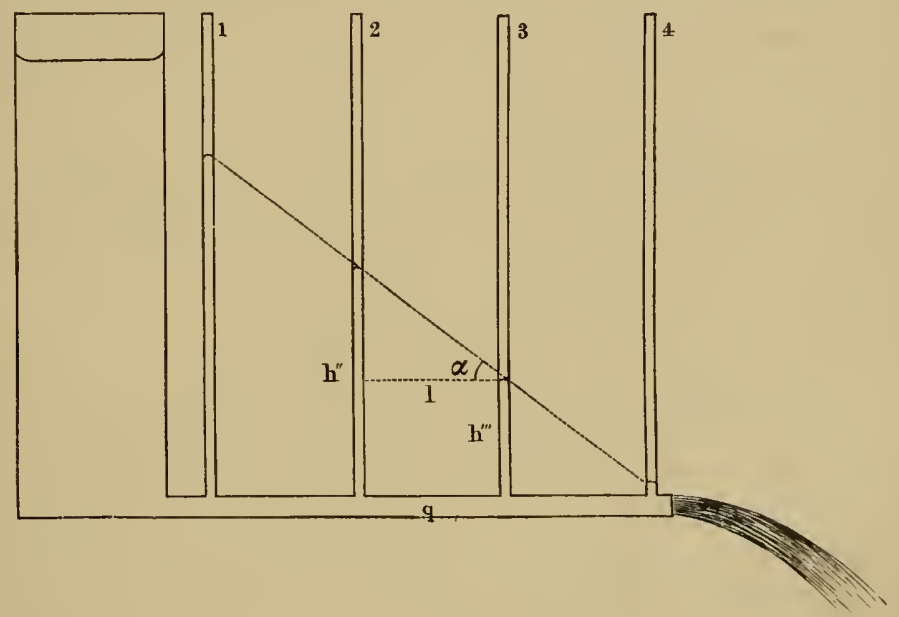

51.

keit der strömenden Fliissigkeitstheilchèn, indem man die Länge des Rohrstiickes bestimmt, welches die in der Secunde ausfliessende Flüssigkeitsmenge fasst. Ein Fliissigkeitscylinder ron dieser Länge ( $\lambda$ ), welcher am Anfang der Secunde die Rohröffnung eben erreicht hatte, hat sie am Ende derselben verlassen. Der Cylinder hat sich also mit der Geschwindigkeit von $\lambda$ Centimeter in der Secunde bewegt. Es folgt hieraus ohne Weiteres, dass die mittlere Geschwindigkeit, bei gleicher Stromintensität und bei Röhren verschiedener Weite, umgekehrt proportional sein muss dem Querschnitt des Rohres. Die auf die angegebene Weise ermittelte Geschwindigkeit ist nicht diejenige, mit welcher sich jedes einzelne Theilchen bewegt, sondern die mittlere Geschwindigkeit aller Theilchen: die Geschwindigkeit in den centralen Stromfäden ist erfahrungsgemäss grösser, als in den peripherischen Schichten.

Um uns ron der Ursache der Fliissigkeitsbewegung eine brauchbare Vorstellung zu machen, fassen wir die Fliissigkeitssäule im Stromrohre Ga d u. Heymans, Physiologie. 
zwischen zwei benachbarten Steigröhren ( ${ }^{2}$ und ${ }^{3}$ ) in's Auge. Auf die rerticalen Endflächen dieser Säule wird in axialer Richtung nach dem Inneren der Süule hin je ein Druck ausgeübt, welcher gleich dem Gewicht eines Wassercylinders von gleichem Querschnitt und der Höhe des Wasserstandes in dem entsprechenden Steigrohr ( $h^{\prime \prime}$ und $\left.h^{\prime \prime \prime}\right)$ ist. Als Ueberschuss des Druckes in der Richtung des Stromes bleibt also das Gewicht eines Wassercylinders mit der Basis q und der Höhe $h^{\prime \prime-h} h^{\prime \prime}$, also mit dem Volum $q\left(h^{\prime \prime}-\mathrm{h}^{\prime \prime}\right)$. Dieses Gewicht misst die beschleunigende Kraft, welche auf die Masse der Flüssigkeit zwischen den beirlen Steigröhren wirkt. Letztere ist proportional dem Volum, d. h. dem Werthe ql, wenn 1 den Abstand zwischen den beiden Steigröhren bedeutet. Die Beschleunigung muss um so grösser sein, je grösser $q\left(h^{\prime \prime}-h^{\prime \prime \prime}\right)$ und je kleiner ql, d. h. je grösser die Druckdifferenz in den Steigröhren im Verhältniss zu ihrem Abstande ist. Dieses Verhältniss nennt man das Gefälle des Flüssigkeitsstromes. Man beurtheilt die Grösse des Gefälles am leichtesten nach dem Winkel, welchen die Verbindungslinie der Flüssigkeitskuppen in den Steigröhren mit dem Horizont bildet; nennt man diesen Winkel $\alpha$, so ist $\frac{h^{\prime \prime}-h^{\prime \prime \prime}}{l}=\operatorname{tg} \alpha$.

Das Gefälle misst eine gleichmässig beschleunigende Kraft, welche, wenn sie allein wirkte, eine beschleunigte Strömung hervorrufen müsste. Die unmittelbare Anschaunng lehrt uns aber, und die Messung bestätigt es, dass die Stromintensität bei unveränderten Versuchsbedingungen constant bleibt, also auch die mittlere Geschwindigkeit. Es müssen also der beschleunigenden Kraft andere Kräfte entgegenwirken; man nennt diese Krräfte die Stromwiderstände und man hat sie wesentlich in der Reibung zwischen Rohrwand und Flüssigkeit, sowie zwischen den verschieden schnell bewegten Flïssigkeitsschichten selbst zu suchen, bei welcher Reibung tranislatorische Massenbewegung in unregelmässige moleculare Bewegung; das heisst in Wärme verwandelt wird.

Den Einfluss, welchen verschiedene Bedingungen auf die Grösse des Stromwiderstandes haben, kann man beurtheilen, weun man zunächst bei demselhen Rohre verschiedene Stromintensitïten herstellt und die hierfiir erforderlichen Differenzen des Druckes am Anfang und Ende des Rohres misst. Auf diese Weise hat man ermittelt, dass die Widerstände proportional der Stromgeschwindigkeit wachsen. Vergleicht man Röhren von verschiedener Form und verschiedenen Dimensionen, in denen man nun wieder die Stromintensitïten gleich macht, so erhält man bei verschicrlenem Querschnitt der Röhren zwar nicht gleiche Geschwindigkeit, da aber der Einfluss der Geschwindigkeit jetzt bekannt ist, so kann man aus dem zu messenclen Gefälle auf den Einfluss der übrigen Bedingungen schliessen; so hat man ermittelt, dass dic Wirlerstände bei 
Röhren von der Weite der Gefïssstämme bis zu etwa 1/4 Millimeter Durchmesser hinah, sich umgekehrt rerhalten, wie die Quadrate der Durchmesser, bei noch engeren, wie noch höhere Potenzen derselben. Begreiflicherweise wachsen die Widerstände proportional der länge des liohres; sie sind ausserdem grösser bei gekrümmten Röhren als bei geraden und scheinen ron der Substanz der Rohrwand gar nicht hecinflusst zu werden, von der Viscosität der Flïssigkeit dagegen in hohem Naasse abzuhängen; Blut findet bei seinem Strömen grösseren Widerstand als Wasser.

Fertigt man sich ein Rohrsystem, welches sowohl aus einem gemeinschaftlichen Zuflussrohr hervorgeht, als auch in ein gemeinschaftliches Abflussrohr endigt, und welches plötzliche Verengerungen und

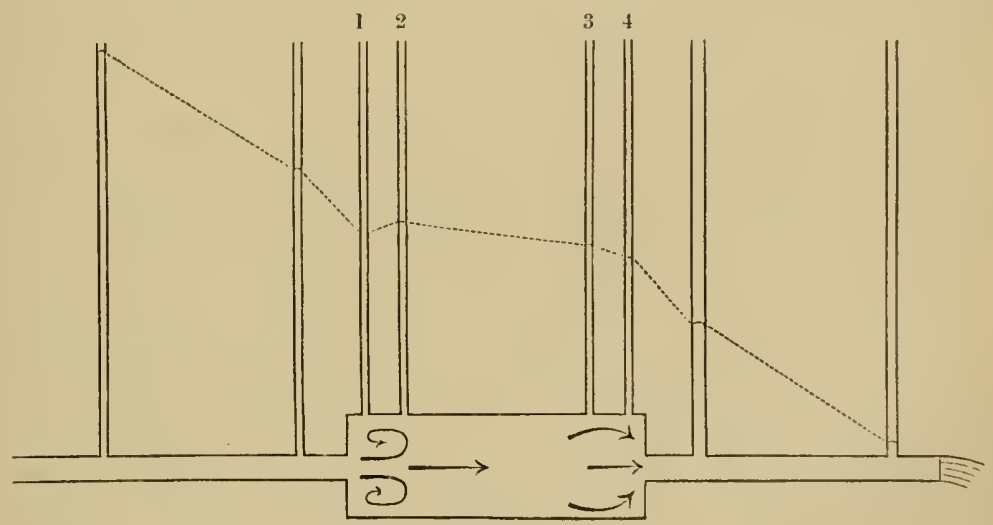

52.

Erweiterungen, sowie unter rerschiedenen Winkeln abgehende symmetrische Verzweigungen enthält, so zeigen passend angebrachte Steigröhıen sehr verschiedenes Gefälle an. Bei gleicher Stromintensität giebt das Gefïlle ein Maass für die zwischen den betreffenden Steigröhren zu ïberwindenten Widerstände. An unverzweigten Theilen des Systems muss die Stromintensität wegen der Starre der Wand ïberall gleich sein. Dasselbe gilt von Rohrstiicken, welche um ebenso viele Verzweigungen vor wie hinter den feinsten Verzweigungen liegen. An einem solchen System kitnn man demonstriren, dass bei Erweiterungen, sowie bei der Theilung und bei der Zusammenmündung von Strombahnen besondere Widerstände vorhanden sind. Der Widerstand an Verzweigungsstellen des Stromes wächst mit dem Winkel, den die Zweige mit einander bilden.

Plötzliche Erweiterungen und Verenger'mngen (ohne gleichzeitige Verzweigungen) kommen im normalen Gefäisssystem nicht vor - abgesehen rom Herzen, wo besondere Complicationen hinzutreten -, doch kann eine plötzlich erweiterte Glasröhre benutzt werden, um Wirbelerscheinungen zu 
demonstriren, welche denen ähnlich sind, die für das Spiel der Herzklappen Bedeutung haben; freilich haben sie einen anderen Grund. Hat man auf dem weiten Theile des Glasrohres (Fig. 52) vier Steigröhren aufgesetzt, von denen zwei sich ganz nahe an den beiden Enden und die beiden anderen sich zwischen ihnen und in ihrer Nähe befinden, so ist die Steighöhe in dem ersten Rohre kleiner, wie in dem zweiten, hier ist also das Gefälle negativ; da aber Flüssigkeit nur von Punkten höheren Druckes zu solchen niederen sich bewegt, so muss hier eine gegenlänfige Bewegung stattfinden, welche im Wirbel zur normalen Stromrichtung wieder umbiegt. Mit Wasser, welchem etwas Bernsteinpulver beigemengt ist, lässt sich diese Wirbelbewegung zur Anschauung bringen. Zwischen den beiden mittleren Röhren, wo keine Wirbelbewegungen störend eingreifen, ist das Gefälle entsprechend dem grösseren Querschnitte kleiner, als in dem Rohre vor der Erweiterung; zwischen dem dritten und vierten Rohre ist ein stärkeres und zwar positives Gefälle.

Um die Vorstellung zn vereinfachen, kann man das Gefässsystem des Körperkreislaufes betrachten als ein symmetrisch dichotomisch vertheiltes und wieder vereinigtes Röhrensystem; denkt man sich dieses System längs einer geradlinigen Abscisse ausgespannt, mit den Arterien links, den Venen rechts, so nimmt die von Ordinatenebenen getroffene Zahl der Stromzweige bis zur Mitte in geometrischer Progression zu; in etwas geringerem Maasse, aber doch auch sehr stark wächst der Gesammtquerschnitt der getroffenen Gefässe. Die Gesammtstromintensität muss in allen Ordinatenebenen des Systems gleich sein. Würde durch eine Ordinatenebene in der Zeiteinheit mehr Blut strömen, als durch eine weiter rechts gelegene, so würde es zwischen beiden zu einer Anhäufung von Flïssigkeit kommen, welche ohne Aenderung der Röhrenweite nicht möglich ist und diese soll zunächst ausgeschlossen sein. Bei gleicher Gesammtstromintensität verhält sich die mittlere Geschwindigkeit umgekehrt wie der Gesammtquerschnitt; die mittlere Geschwindigkeit nimmt also von der Aorta bis zu den Capillaren in immer wachsendem Maasse $a b$, um dann auf der venösen Seite wieder erheblich zuzunehmen; hierbei bleibt sie aber rechts von der Mittellinie des Systems immer niedriger wie an den entsprechenden Stellen links, wegen des Ueberwiegens des Querschnittes der Venen über den der Arterien.

Nicht mit gleicher Sicherheit können wir Angaben machen über den Verlauf der Curve des Gefälles; selbstverständlich muss der durch Steigröhren messbare Druck im Anfang der Aorta am grössten, am Ende der Hauptvenenstïmme am niedrigsten sein. An letzterer Stelle ist er erfahrungsgemäss etwas unter Null. Wären die Widerstände symmetrisclı vertheilt, so müsste der Druck in den Capillaren etwa dem halbeu Drucke in der Aorta entsprechen. In Bezug auf die Vertheilung der 
Widerstände stehen sich aber zwei Ansichten gegenüber, zwischen denen experimentell noch nicht sicher entschieden ist. Nach der einen Ansicht sollen die am meisten ins Gewicht fallenden Widerstände in dem Gefässsystem an den Wiedervereinigungsstellen der Stromzweige, also im venösen Theile des Capillarsystems und in den Venen liegen. Gegen diese besonderen Uebergangswiderstände sollen die Reibnngswiderstände längs der ïbrigen Strombahn zu vernachlässigen sein; hiernach müsste man in den Capillaren einen Blutdruck erwarten, nicht viel niedriger als in der Aorta.

Ein Urtheil darüber abzugeben, welchen Einfluss die Zersplitterung des Gefässsystems auf die Vertheilung der Widerstände ausiibt, ist darum schwer, weil sich zwei Factoren mit entgegengesetzter Wirkung an diesem Einflusse betheiligen. Die mit fortschreitender Verzweigung zunehmende Verkleinerung des Durchmessers der einzelnen Stromröhren wirkt aut zunehmende Vergrösserung des Widerstandes von der Aorta bis zu den Capillaren hin. Mit der Verkleinerung des Durchmesser's der einzelnen Strombahnen geht aber eine Vergrösserung des Gesammtquerschnittes aller Strombahnen gleicher Ordnung Hand in Hand; die dadurch bedingte Verkleinerung der Stromgeschwindigkeit wirkt aber verkleinernd auf die Widerstände. Welcher von beiden Factoren iiberwiegt und in welchem Maasse, kann man beurtheilen, wenn man das mittlere Verhältniss des Querschnittes der einzelnen aus jeder Theilung hervorgehenden Röhren zu dem Querschnitt der getheilten Röhren (Theilungscoëfficienten) kennt. Der Theilungscoëfficient muss zwischen 1 und $1 / 2$ liegen, da der Querschnitt der einzelnen Röhren bei der Theilung abnimmt, die Summe der Querschnitte aber zunimmt. Durch mathematische Entwickelung lässt sich beweisen, dass der den Widerstand vermehrende Einfluss der Zersplitterung um so mehr überwiegt, je näher der Werth des Theilungscoëfficienten dem unteren Grenzwerthe liegt, und dass der den Widerstand rermindernde Einfluss um so mehr ïberwiegt, je mehr sich der Theilungscoëfficient dem Werthe 1 nähert; es muss also einen mittleren Werth des Theilungscoëfficienten geben, bei welchem der Einfluss der Zersplitterung auf die Widerstände Null ist. Den wahren Wertli der Theilungscoëfficienten wïrden wir (unter Voraussetzung der Symmetrie des Systemes) berechnen können auf Grund der Kenntniss folgender Grundwerthe des Gefïsssystemes und des Blutstromes, crstens: Querschnitt und Länge der Aorta, zweitens: mittlerer Werth für Querschnitt und Länge der einzelnen Capillaren, drittens: Stromgeschwindigkeit in der Aorta und in den Capillaren. Macht man für diese Werthe Annahmen, welche in möglichst guter Uebereinstimmung mit den Erfal1rungen sind, so gelangt man zu einem Werthe des Theilungscoëfficienten, bei welchem der widerstandsvermehrende Einfluss der Zersplitterung 
betrïchtlich ïberwiegen muss. Hiernach wïrden wir als Hauptursache für die Widerstände im Gefässsysteme eine mit fortschreitender Zersplitterung der Bahnen zumehmende Reibung anzusehen haben und wir wiirden, da diese Reibungswiderstände annähernd symmetrisch im Gefässsysteme vertheilt sein mïssen, den Druck in den Capillaren auf die Hälfte des Druckes in der Aorta schätzen.

Wenn wir jetzt zur Angabe der absoluten Werthe iibergehen, welche man für die einzelnen Factoren des Kreislaufes annimmt, so müssen wir wieder von der Stromintensität ausgehen. Eine Vorstellung von der Grösse der Stromintensität in der Aorta kann man sich bilden, wenn man die Blutmenge, welche ein Herzventrikel bei jedem Herzschlage fördert - das "Schlagvolumen" des Herzens - und wenn man die Anzahl der Herzschläge in der Zeiteinheit kennt.

Jeder Ventrikel des erschlafften menschlichen Herzens kann etwa $180 \mathrm{Ccm}$ Fliissigkeit fassen; das Herz fuihlt man im Mittel $72 \mathrm{Mal}$ in der Minute schlagen, und bei der Annahme, dass sich der linke Ventrikel vor jedem Herzschlage vollkommen füllt und bei jedem vollkommen entleert, werden also $13 \mathrm{Liter}$ in der Minute oder $216 \mathrm{Ccm}$ in der Secunde den Querschnitt der Aorta passiren.

Um die mittlere Stromgeschwindigkeit in der Aorta auf Grund der Stromintensität zu berechnen, müssen wir den Querschnitt der Strombahn kennen: der Durchmesser des Aortenanfanges beim Menschen wird von den Anatomen zu $28 \mathrm{Mm}$ angegeben, der Querschnitt beträgt danach etwa 6 Quadrat-Centimeter und man erhält für die Hölıe eines Cylinders mit diesem Querschnitt und $216 \mathrm{Ccm}$ Inhalt eine Höhe von $36 \mathrm{Ctm}$. Dies wäre der Werth der absoluten mittleren Geschwindigkeit des Blutes für eine Secunde im Anfangstheil der Aorta des Menschen bei Giltigkeit der benutzten Schätzungswerthe. Es muss aber bemerkt werden, dass der Anblick des freigelegten schlagenden Herzens von Thieren es wenig wahrscheinlich macht, diss der Ventrikel zwischen zwoi Schlägen sich maximal füllt. Auch aus anderen Grüuden ist man zur Annahme einer weit kleineren Zahl für die bei einem Herzschlag ansgeworfene Blutmenge gelangt (70 Ccm statt 180).

Bisher haben wir unter der Stromintensität immer die Blutmenge verstanden, welche in der Zeiteinheit jeden Gesammtquerschnitt des Gefiisssystems durchfliesst; man muss sich stets gegenwärtig halten, dass diese Stromintensität ïberall gleich ist, an welcher Stelle des ganzen Stromkroises man sich den Gesammtquerschnitt auch angebracht denkt, so lange es nicht zu $\Lambda$ nhäufung von Blut in dem einen Theil des Stromkreises auf Kosten des Inhaltes des übrigen kommt. So könnte zumn IBeispiel rlie Stromintensität in der Arteria pulmonalis nur auf kurze Zeit grösser sein, als in der Aorta, weil sich sonst immer mehr Blut 
im Lungenkreislatuf ansammeln müsste. Unter normalen Verhältnissen ist die Stromintensität in der Aorta und in der Arteria pulmonalis thatsächlich immer gleich wegen der gleichen Calpacität und der gleichen Schlagzahl beider Ventrikel. Mit der auf den Gesammtrlurehschnitt be\%orenen Stromintensität nicht zu verwechseln ist aber die Stromintensität in einzehnen Röhren der verzweigten 'I'heile des Gefiisssystems. Diese ist natiirlich an den verschiedenen Stellen sehr verschieden. Dic Stromintensitiit in oberflächlichen Körperarterien ist der directen Messung zugänglich; die einfachste Methode besteht darin, dass in dic Arterie eine liurze Glasröhne eingeschaltet wird, welche eine U-förmige Seitenleitung und ein Hahnsystem träigt, unter dessen Benutzung man den Blutstrom zunächst nur durch das kurze Rohr gerarleswegs un:t dann plötzlich mit Versperrung dieses Weges durch das U-Rohr strömen lässt. Der dem Herzen zugewandte Schenkel dieses Rohres ist mit Oel, der

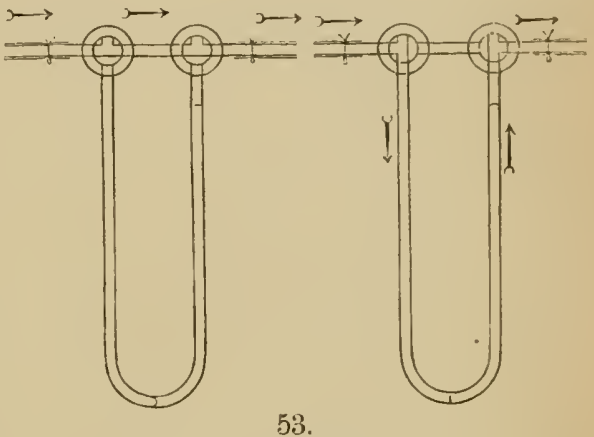

Volkmann's llämodromometer. andere mit $0,6 \%$ iger Kochsalzlösung gefuilt, und trägt, ausser an der Grenze zwischen Oel und Kochsalzlösung, noch eine zweite Marke. Das aus dem centralen Arterienende fliessende Blut verdrängt nun das Oel, und dieses schiebt eine gleiche Menge Kochsalzlösung ror sich her in das peripherische Entle der Arteric hinein; man misst die Zeit von der IIahndrehung bis zum Passiren der vorderen Oelgrenze durch die zweite Marke. In diesem Moment wird ansserdem durch eine zweite Hahndrehung das alte Stromverhältniss wiederhergestellt, sodass nur die unschädliche Kochsalzlösung und kein Oel in dis Crefïsssystem des Thieres gelangt; das Volum der Rühre zwischen den beiden Marken ist bekannt und man erfiihrt also, eine wie grosse Blutmenge in gemessener \%cit den Quersehnitt der Arterie passirt hat. Bestimmt man nun noch durch directe Messung diesen Querschnitt, so kann man die mittlere absolute Geschwindigkeit in der Arterie berechnen. Anf diesem Wege wurde beim Pferde cliese Geschwindigkeit in der Carotis zu $30 \mathrm{Ctm}$, in der Maxillaris zu 23 Ctm, in der Metatarsea zu $5 \frac{1}{2}$ Ctm ermittelt. Dir der Gesammtquerschnitt des Arteriensystems im Bereiche der Carotis grösser ist als in der Aorta, sollte man in letzterer eine noch grössere Creschwindigkeit erwarten. Macht man auf Grund der Querschnittsverhältnisse Schätzungen dieser Geschwindigkeit und berechnet man ans diesem Schätzungswerth und dem gemessenen Querschnitt ler Aorta die Stromintensität in derselben, 
so erhält man als Stromvolum für die Zeit eines Herzschlages 1/400 des Körpergewichtes, also für den Menschen wieder etwa $180 \mathrm{Ccm}$, das heisst die ganze Flüssigkeitsmenge, welche ein Ventrikel überhaupt zu fassen vermag. Nichtsdestoweniger werden wir, wie schon oben (S. 342) angedeutet wurde, und unter Berücksichtigung von später anzustellenden Erwägungen, das „Schlagvolumen“ des Herzens weit kleiner, etwa zu $70 \mathrm{Ccm}$ anzunehmen haben. Der scheinbare Widerspruch löst sich wahrscheinlich so, dass wir nicht berechtigt sind, einfach auf Grund der Querschnittsverhältnisse eine Berechnung der Geschwindigkeit in der Aorta aus der gemessenen Geschwindigkeit in der Carotis anzustellen. Die Geschwindigkeit in der Carotis kann grösser sein, als diejenige in der Aorta ascendens, weil der Blutstrom aus diesem Gefässe sich ungleich auf die Anonyma und die Aorta descendens vertheilen kann. Dies kann geschehen wegen des besonderen Widerstandes, welchen der Blutstrom bei der starken Richtungsänderung im Aortenbogen finden muss, und weil die Gesammtwiderstände im Ausbreitungsgebiete der Anonyma kleiner sein können, als in dem der Aorta descendens.

Die Geschwindigkeit der Blutkörperchen in den Capillaren einiger Organe, namentlich des Frosches, ist der directen Messung unter dem Vikroskope zugänglich; zur mikroskopischen Beobachtung des Blutkreislaufes eignen sich das Mesenterium, die Schwimmhant, die Lunge, die Zunge und die Nickhaut des Frosches, sowie der Schwanz von Froschlarven. An letzterem Objekt wurde die Geschwindigkeit der einzelnen Blutkörperchen in den Capillaren zu der Hälfte eines Millimeters in der Secunde bestimmt. Bei diesen Beobachtungen hat man zunächst den Eindruck einer weit grösseren Geschwindigkeit, man muss sich aber gegenwärtig halten, dass die Geschwindigkeit einen Quotienten von Länge durch Zeit bedeutet, und dass das Mikroskop nur die Länge grösser erscheinen lässt, nicht aber auch die Zeit. Für den normalen Menschen nimmt man die Blutgeschwindigkeit in den Capillaren etwas grösser an, als sie am Kaltbliiter unter Umständen, welche die Circulation stören können, gemessen wurde, man scliätzt sie $\mathbf{3} / \mathbf{4}$ Millimeter in der Secunde. Hiernach wäre der Gesammtquerschnitt des Capillarsystems des Körperkreislaufes etwa õo0 Mal grösser zu schätzen, als der Querschnitt der $\Lambda$ orta ascendens (6 Q. Ctm $\times 500=3000$ Q. Ctm).

Die aufmerksame Beobachtung des Blutkreislaufes unter dem Mikroskope ist noch in mancher anderen Richtung lehrreich; man kann Bilder einstellen, in denen man gleichzeitig zusammengehörige Arterien, Venen und Capillaren ïbersieht; obgleich der Querschnitt der ersten beideu Gefässarten weit grösser ist, als der der einzelnen Capillaren, so ist doch die Geschwindigkeit in ersteren eine reissende im Verhältniss zu der in deu Capillaren, weil hier der Gesammtquerschnitt ein viel grösserer 
ist. In deu Capillaren ist die schembare Geschwindigkeit auch bei möglichst ungestörtem Ḱreislaufe und bei starker Vergrösserung nicht so gross, dass man nicht den einzelnen Blutkörperchen bequem mit dem Ange folgen könnte, man hat hierbei Gelegenheit, sich von den pliysikalischen Eigenschaften derselhen eine Vorstelhung zи bilden. Wenn auch die engsten Capillaren so weit sind, dass sie das einzelue Blutkörperchen, ohne die Form zu ändern, passiren kann, so bilden sich doch gelegentlich durch farblose Blutkörperchen, welche an der Wand haften geblieben sind, engere Stellen; beim Passiren solcher Engen wird jede Blutscheibe lang ausgezogen, nimmt aber sofort darauf wieder die normale Gestalt an; es kommt auch vor, dass eine Blutscheibe gerade auf den Sporn einer Theilungsstelle stösst, und dass sie, auf diesem Sporn reitend, zu der Form eines Quersackes ansgezogen wird; bald wird davon mehr in die eine, bald mehr in die andere Capillare hineingezogen, unter oft starker Verdiinnung des Verbindungsfadens; dann rutscht die Blutscheibe ab und hat sofort wieder die normale Form. Die Geschwindigkeitsdifferenz zwischen dem Centralfaden und der Wandschicht beobachtet man am besten in den kleinen Arterien und Venen.

In dem einleitenden schematischen Experiment haben wir gesehen, wie der Druck an einer bestimmten Stelle eines Stromrohres gemessen wird durch die Höhe einer ruhenden Flïssigkeitssäule, welcher in einem mit der betreffenden Stelle seitlich in Verbindung gesetzten Messrohre (Manometer) das Gleichgewicht gelıalten wird. Auf die Flächeneinheit der Wandung des Stromrohres wird in radiärer Richtung ein Druck ansgeübt, welcher dem Gewichte einer Flïssigkeitssäule von der im Messrohre beobachteten Höhe und von dem der Flächeneinheit gleichen Querschnitte entspricht. Derselbe Druck, bezogen auf die Flächeneinheit, wird ausgeübt in senkrechter Richtung zu jeder, irgendwie in der Fliissigkeit orientirten Fläehe.

Man hat sich daran gewöhnt den Binnendruck oder den Wanddruck der Plutgefässe, welchen man kurzweg den Blutdruek nemit, in Längenmaassen anzugeben, nämlich in der Länge der Flïssigkeitssäule, welcher in Messrohr das Gleichgewicht gehalten wird. Kennt man ausserdem das specifische Gewicht der Flüssigkeit dieser Säule (Wasser, Quecksilber), so hat man auch alle erforderlichen Daten, um den Druck auf die Flächeneinheit in Gewichten zu berechnen. Deshalb muss bei Angabe ïber den Blutdruck zu der Längenangabe in Centimetern oder Millimetern die Bemerkung Wasser, Quecksilber und dergleichen hinzugefügt werden. Der Querschnitt des Messrohres braucht nicht angegehen zu werden, denn eine Fliissigkeitssäule von bestimmter Höhe und beliebigem Querschnitt ïbt auf jede beliebig orientirte Flächeneinheit im 
Innern oder an der Begrenzung einer Flüssigkeitsmasse, mit welcher die Säule communicirt, denselben Druck aus.

Die fundamentale Thatsache der bedeutenden Ueberlegenheit des Druckes auf der arteriellen Seite des Gefässsystems über den auf der venösen Seite, lässt sich am lebenden Thiere leicht durch die Verbindung einer Arterie und einer Vene mit je einem einfachen, gläsernen Steigrohr demonstriren. Dieser anschaulichen Druckdifferenz entsprechend muss das Blut von den Arterien durch die Capillaren zu den Venen strömen. Dass der Blutstrom diese Richtung nimmt, haben wir uibrigens schon aus der Richtung, in welcher die Herzklappen sich öffnen, gefolgert, und es ist auch unmittelbar mit dem Mikroskope im lebenden Gewebe zu beobachten, wo man sieht, dass in den durch ihre histologische Beschaffenheit als Arterien erkennbaren Gefässen das Blut zu den Capillaren hin und in den Venen von ihnen fortströmt.

Für eine correcte Messung des Blutdruckes bedient man sich nicht einfacher Steigröhren, um nicht die zur Füllung derselben erforderliche Blutmenge dem Thiere zu entziehen; zur Messung des arteriellen Blutdruckes bedient man sich vielmehr U-förmiger, theilweise mit Qnecksilber gefüllter Röhren, deren einer Schenkel mit einer in die Arterie gebundenen Canüle in Verbindung gesetzt wird. Dieses Verbindungsrohr, sowie der mit demselben in Verbindung stehende Schenkel des U-Rohres ist bis zum Quecksilberniveau mit concentrirter Sodalösung gefiillt, welche die Gerinnung des in das Verbindungsrohr vordringenden Blutes hintanhält. Die auf diese Weise mit der Blutsäule in Communication gebrachte Quecksilbermasse ist in rhythmischer Bewegung begriffen, welche die Ablesung eines Mittelwerthes an der Scala des Manometers erschwert. Durch Anbringung einer Verengerung im Verbindungsrohr kann man die Oscillationen auf ein Minimum beschränken, ohne die Genauigkeit der Angabe des mittleren Druckes zu beeinträchtigen. Der Durchmesser des Quersclinittes des Manometers darf nicht so gross sein, dass das Volumen, welches der bei der Messung eintretenden Nivealuänderung entspricht, einen erheblichen Bruchtheil des Blutvolums im Gefässsystem des untersuchten Thieres bildet. Bei den Arterien würde Letzteres auch hei kleinem Querschnitt des Manometers schon der l'all sein, wenn min statt Quecksilbers Wasser anwenden wollte. Für die Blutdruckmessungen in den Venen ist dagegen das Wasser vorzuziehen, weil die Ausschlïge des Quecksilbermanometers für genaue Messungen hier zu klein ausfallen wïrden.

Iiei demselben Thiere zeigt der mittlere Blutdruck in allen für diese Untersuchungen überhaupt zugänglichen Arterien keinen merklichen Unterschied, wenn die Messung an zwei Stellen gleichzeitig vorgenommen wird; das Gefälle ron dem Anfange der Aorta bis zu den mittleren Ar- 
terien muss also klein sein; dasselbe gilt von den Widerstiinden, nicht aber, wie noch eimmal hervorgehoben werden mag, ron der mittleren absoluten Geschwindigkeit, welche am Ende der grossen Arterien schon erheblich kleiner ist, wie in der Aorta. Unter verschiedenen Bedingungen, ron denen später die Rede sein wird, kann sich der mittlere arterielle Blutdruck bei demselben Thiere sehr verschieden erweisen; unter annähernd normalen Bedingungen findet man diesen Druck beim llunde zu etwa $150 \mathrm{Mm}$ Quecksilber, beim Kaninchen zu etwa $80 \mathrm{Mm}$, bei dem Menschen schäitat man ihn etwas niedriger als beim Hunde, zu $120 \mathrm{Mm}$ IIg. Einer Messung nach der bei dem Thiere ïblichen Methode ist der arterielle Blutdruck des Mensehen begreiflicherweise nicht zugänglich. An oberflächlichen, auf knöcherner Unterlage verlaufenden Gefïssen, zum Beispiel der Art. temp. superf., kamn min den Blutdruck aber annähernd genau so bestimmen, dass man das Gefiiss mittelst einer, eine feste, mit Quecksilber gefüllte, Kapsel nach unten begrenzenden Membran comprimirt; die Kinssel ist mit einem gläsernen Steigrohr versehen, in welchem das Quecksilber mit zunehmender Compression steigt; controllirt man gleichzeitig mit dem Finger die fühlbare rhythmische Druck- und Volumänderung (Puls) der Arteria temporalis peripher von der Compressionsstelle, so bemerkt man, dass mit zumehmender Compression dieser Puls schwächer und schwächer wird, um zu versehwinden, wenn das Quecksilber in dem Steigrohr eine gewisse Höhe erreicht hat. In liesem Moment ist der Druck, welcher anssen auf der Flächeneinheit der Gefässwand lastet, gerade um ein Minimum grösser, als der Druck, welchen das Blut im Maximum der pulsatorischen Erhebungen von imnen auf dieselbe Flïcheneinheit ausiibt. Der von aussen auf die Gefïsswand ausgeübte Druck entspricht nicht genau dem Quecksilberdrueke im Steigrohr, dem dieser muss, um anf die Gefässwand wirken zu kömnen, die ditzwischen gelegenen Gewebe spannen. Je nach der Dicke und Straffhcit dieser Gewebe erhält man also Quecksilberhöhen, welche mehr oder weniger ïber dem höchsten Werthe liegen, welchen der Blutdruck erreicht; diese Methode, welche man die sphygmomanometrische nemnt, ist also weniger geeignet Angahen iiber den wirklich vorhandeneu Blutdruck zu liefern, als dazu, Aenderungen dieses Druckes, welehe sich an derselben Person bei Aenderungen des Körperzustandes einstellen, zu verfolgen; Voraussetzung ist hierbei, dass sich wïhrend der Untersuchungsperiode die Dicke und Straffheit der äusseren Gewebe nicht wesentlich ändert, wie es bei Aenderung des Ernïhrungszustandes wohl geschieht.

Es ist schon auseinandergesetzt worden (S. 341), weshall wir über die Vertheilung der Widerstände von den mittleren Arterien bis zu den mittleren Venen zur Zeit nichts Sicheres aussagen können. Die sehr wichtige Frage, wie hoch der Blutdruck in den Capillaren sei, wo das Blut ja 
seine Wirkung entfaltet, kann also auch nur mit Vorbehalt beantwortet werden; immerhin spricht die grössere Wahrscheinlichkeit dafür, dass der Blutdruck in den Capillaren auf etwa die Hälfte des Blutdruckes in der Aorta zu schätzen sein wird. In den Venen der Körperextremitäten hat der Blutdruck noch einen geringen positiven Werth, doch nimmt er in den Hauptvenenstämmen negatives Vorzeichen an, woraus auf eine vom Centrum des Circulationssystemes ausgehende sangende Kraft geschlossen werden muss.

Einen Ueberblick über die fundamentalen Verhältnisse, welche bei der Vertheilung von Blutdruck, Geschwindigkeit und Querschnitt auf die

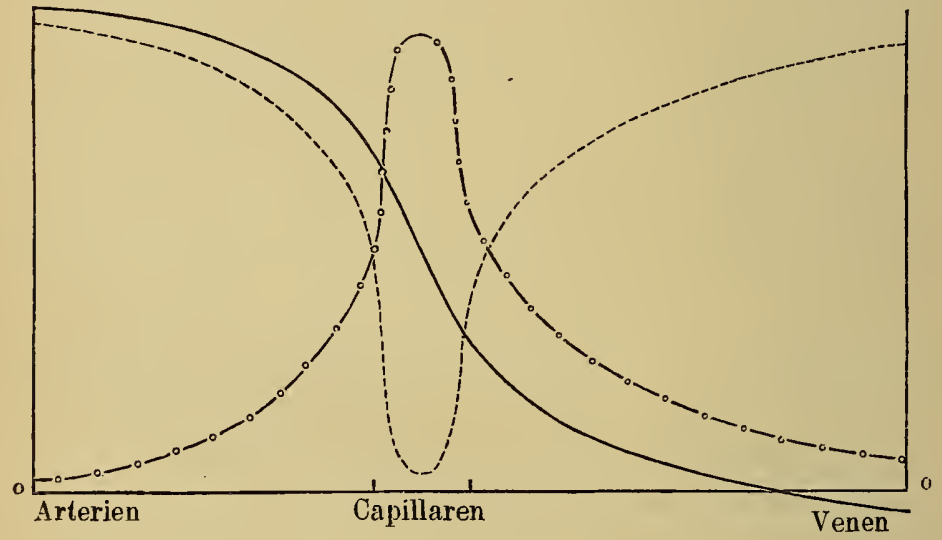

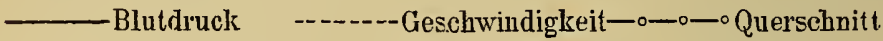

54.

einzelnen Theile des Körperkreislaufes (Arterien, Capillaren und Venen) in Betracht kommen, geben die Curven der Fig. 54.

Der Blutdruck in der Arteria pulmonalis ist bedeutend niedriger, als derjenige in der Aorta, er beträgt nur etwa $2 / 5$ des letzteren; dementsprechend muss der Blutdruck in den Lungencapillaren auch kleiner sein, als in den Capillaren des Körperkreislaufes, für den absoluten Werth desselben gilt aber hier dasselbe wie dort; der Druck in den Lungenvenenstämmen hat einen geringen negativen Werth. Angesichts des grossen Druckunterschiedes in Aorta und Arteria pulmonalis muss noch einmal hervorgehoben werden, dass die Stromintensität in beiden Gefässen gleich sein muss; wo dieselbe Flüssigkeitsmenge in der Zeiteinheit hei kleinerem Gefälle strömt, müssen kleinere Widerstände vorhanden sein; dass die Widerstände in dem Lungenkreislaufe kleiner sind, als im Körperkreislaufe, leuchtet auf Grund der groben anatomischen Verbältnisse ein. 
Man hat sich die Frage gestellt, wieviel \%eit eine Portion Blut zu einem eimmaligen ganzen Umlauf dureh Herz, Lunge, Herz, Körper und zurïck zum Herzen braucht; man hat diese Zeit so zu ermitteln gesucht, dass man in einem genau bestimmten Zeitmomente eine fremde Beimengung, entweder Ferrocyankalium oder eine Probe von Blut mit anders geformten Blutkörperchen in eine Vene des Körperkreislaufes injicirte. Aus derselben Vene der anderen Körperseite wurde das gleichmässig fliessende Blut von Seeunde zu Seeunde getrennt aufgefangen; die Ordnungszahl derjenigen Blutprobe, welche bei der Prüfung mit Eisenchlorid und Salzsäure die erste Blaufärbung in Serum ergab, oder welche die ersten fremden Blutkörperchen beigemengt zeigte, sollte den gesuchten Werth darstellen. Man hat die Bestimmungen der sogenannten "Kireislaufszeit" bei einer Reilie verschiedener Thierarten ausgeführt und ist so zu den Resultate gekommen, dass sie im Allgemeinen gleich der Zeit ist, welche bei jeder der Thierarten auf etwa 27 Herzschlïge entfällt, danach schïtzt man sie beim Menschen auf etwas über 20 Seeunden. Streng genommen bedeutet die sogenannte Kreislaufzeit diejenige Zeit, welche ein Theilchen der dem Blute beigemengten Probeflüssigkeit für den einmaligen ganzen Kreislauf auf dem kürzesten der möglichen Wege und, in der axialen Schicht grösster Geschwindigkeit sich bewegend, gebraucht.

Der Ueberdruck des Blutes in den Arterien über das in den Venen wird dadurch erzeugt und unterhalten, dass das wie eine Pumpe arbeitende Herz fortwährend Blut aus dem Venensystem schöpft und in das Arteriensystem hineintreibt. Je mehr das Herz in dieser Beziehung leistet, um so stärker werden die Arterien mit Blut gefüllt, was nur dadurch möglich ist, dass die Wände der Arterien mehr und mehr gedehnt werden. Mit zunehmender Dehnung der elastischen Gefässwände setzen diese der weiteren Dehnung einen immer grösseren Widerstand entgegen und streben mit um so grösserer Kraft dem ungedehnten Zustande zu. Diese Kraft, welche als Blutdruck in der Aorta gemessen wird, muss ron der Spannung der Herzkammermuskeln bei deren Zusammenziehung überwunden werden, und durch diese Kraft wird das Blut, welches wegen der Semilunarklappen anch bei der Erschlaffung der Herzmuskeln nicht zurückweichen kann, in der Richtung nach den Capillaren und Venen zu fortgetrieben. Je stärker der Füllungsgrad im Anfangstheile des Arteriensystemes ist, um so höher wird hier der Blutdruck, um so grösser die Druckdifferenz zwisehen Arterien und Venen, un so grösser die Geschwindigkeit, mit weleher das Blut aus den 
Arterien durch die Capillaren zu den Venen abströmt. Ist diese Geschwindigkeit so gross geworden, dass in der Zeiteinheit ebensoriel Blut aus den Arterien durch die Capillaren abfliesst, wie von dem Herzen hineingepumpt wird, so hat der arterielle Blutdruck einen Grenzpunkt erreicht, auf dem er verharrt, so lange das Herz gleich stark pumpt und so lange die Widerstände in der Strombahn die gleichen bleiben.

So lange der Zufluss rom Herzen constant bleibt und so lange die Widerstände der Strombahn sich nicht ändern, ist der Blutstrom in einem gleichmässigen Zustande, den man den stationären nennt, begriffen; ein gerade bestehender stationärer Zustand des Kreislaufes kann verlassen werden und es kann nach einem Uebergangsstadium ein neuer stationärer Zustand erreicht werden, wenn die Widerstände in der Strombahn von einem constanten Werthe in einen anderen Werth ron constanter Grösse übergehen. Solche Widerstandsänderungen treten hauptsächlich ein durch Aenderungen in der Weite der mit Muskeln versehenen Gefässe. Den elastischen Elementen verdanken die muskelfreien Gefässe ihre Eigenschaft, ein für allemal in derselben Weise mit dem Blutdruck ihren Querschnitt zu ändern. Die Muskelfasern greifen modificirend in die gegenseitige Abhängigkeit von Blutdruck und Querschnitt ein, sodass auch bei hohem Blutdrucke der Querschnitt constant bleiben oder sogar rerkleinert werden kann. Nimmt der Tonus der Gefässmusculatur zu, so verengert sich die Strombahn, es wachsen die Widerstände, es steigt der arterielle Druck, ohne dass darum die mit Muskeln rersehenen Gefässe wieder gedehnt zu werden brauchen, so lange der Muskeltonus noch einer Verstärkung fähig ist; der Tonus der Gefässmusculatur wird durch das Centralnervensystem auf reflectorischem Wrege geregelt. Die Beziehungen der die Wände der Capillarröhren bildenden protoplasmatischen Zellen zu den Aenderungen des Blutdruckes sind noch nicht aufgeklärt. Ob chiese Zellen durch active Acnderungen in ihrer Configuration die Weite der Capillarbahnen und damit die Widerstände in denselben modificiren können und ob den Nerven hierauf ein Einfluss zukommt, muss dahingestellt bleiben.

Bei Termehrung der Widerstände in der Strombahn kann die Blutmenge, welche das Herz in gleichen Zeiten aus dem Venensysteme in das Arteriensystem fördert, dieselbe bleiben, wenn mit der Vergrösserung iler Druckdifferenz eine entsprechende Vermehrung der Herzarbeit einhergeht, was oft der Fall ist; dann ändert sich auch die Stromintensität in der Gesammtstrombahn nicht, doch wird die absolnte Geschwindigkeit des Blutes an den verengerten Stellen grösser. Dieses gilt genau, wenn man annimmt, dass sich der Gefässtonus aller collateralen Bahnen gleich rerhält. Die Gefässweite ändert sich aber unter nervösem Einflusse in den verschiedenen collateralen Theilen der Gesammtstrombahn meist 
in rerschiedener Weise; so können sich die Gefüsse des Darmes erweitern, wïhrend sich die Hantgefïsse rerengern, orler es können die Gefüsse einer oder beider Nieren oder die Grefïsse arbeitender Muskelgruppen ihre Weite ändern, während die Weite der iibrigen Gefüsse unrerïndert bleibt oder sich in entgegengesetztem Sinne ändert; als collaterale Theile der Strombahn in diesem Sinne kamn man auch betrachten den Blutstrom durch Hals und Kopf einerseits und durch Rumpf mit Extremitïten andererseits. Ob sich innerhalb jedes einzelnen der collateralen Gefïsssysteme die Arterien, Capillaren und Venen immer gleichmïssig rerhalten, oder ob sich zum Beispiel die Venen der Nieren rerenger'n können, während die Arterien von der Verengerung nicht mitbetroffen werden, ist leirler nicht sicher zu beantworten.

Für den Druck in der Aorta kommt die Summe der gesammten Widerstände aller Strombahnen in Betracht. Bei beträchtlichen partiellen Aenderungen kann die Summe der Aenderungen Null sein; es kann zum Beispiel eine Widerstandszunahme im Hautgefässsystem durch eine Widerstandsabnahme im Darmgefässsystem ausgeglichen werden, was oft rorkommen wird. Bleiben wir bei diesem Beispiele stehen und nehmen wir der Einfachheit wegen an, dass die Verengermng der Arterien und Venen in der Hant, sowie die Erweiterung der entsprechenden Gefässabschnitte im Darme gleichmässig erfolgt, so wären die Consecquenzen der gemachten Voraussetzungen: keine Veränderung des Druckes, des Gefilles, der Stromintensität, der Capacität und der Geschwindigkeit in der Aorta und in allen nicht zu den genannten Systemen gehörigen Arterien, Capillaren und Venen, keine Veränderung des Gefälles in den ron den Widerstandsänderungen getroffenen Systemen, aber Verkleinerung der Stromintensitiit, sowie der Capacität in dem Hantgefässsystem und umgekehrtes Verhalten dieser Grössen im Darmgefüsssystem ; zweifelhaftes Verhalten der absoluten Stromgeschwindigkeit in den verengerten und erweiterten Gehieten, weil auf die Grösse der Geschwindigkeit gleichsinnige Aenderungen ron Stromintensitït und Querschnitt in umgekehrtem Sinne wirken.

Betrachten wir eines von den vielen collateralen Gefässsystemen, zum Beispiel das einer arbeitenden Muskelgruppe gesondert, so können wir sagen, dass die mit der Muskelarbeit einhergehende Erweiterung der Muskelgefässe, wenn das in Betracht kommende Gefässgebict im Verhältniss zu der gesammten Strombahn klein ist, die Summe der gesammten Widerstäinde wenig ändert; die Stromverhältnisse in den nicht zn dem betrachteten Gebiete gehörigen Gefässen bleiben also gleich, namentlich Druck und Gefälle; da dann auch der Druck am Anfange und Fnde des betrachteten Gefässgebietes unverändert bleibt, so ist anch diss Gefälle in letzterem unverändert. (Es wird wieder rorausgesetzt, dass 
Arterien und Venen von der Erweiterung gleichmässig getroffen werden; wäre dies nicht der Fall, so würde zwar auch die Druckdifferenz zwischen Anfang und Ende des Gefässgebietes sich nicht ändern, wohl aber das Gefälle innerhalb des Gebietes.) Bei gleichem Gefälle und vermindertem Widerstande muss die Stromintensität im Gefässgebiete dieser arbeitenden Muskelgruppe gesteigert sein, während sich über die absolute Geschwindigkeit der einzelnen Bluttheilchen aus dem oben angeführten Grunde nichts Bestimmtes aussagen lässt. Die Capacität des betrachteten Gefässsystems, d. h. der Blutgehalt der dazu gehörigen Organe, ist vergrössert. Macht das betrachtete Gefässgebiet einen grossen Theil der gesammten Strombahnen aus, zum Beispiel bei gleichzeitiger Anstrengung vieler Muskelgruppen, so muss die beträchtliche Verringerung der Summe der gesammten Widerstände durch Verengerung anderer Gefässgebiete oder durch Vermehrung der Herzthätigkeit oder durch Beides in der Wirkung auf den Aortendruck ausgeglichen werden, wenn Vermehrung der Stromintensität in dem betrachteten Gebiete gleichzeitig mit seiner Erweiterung eintreten soll.

Wird eine Gefässverengerung in einem beträchtlichen Theile des Krreislaufsystems nicht durch eine entsprechende Erweiterung in einem collateralen Theile compensirt, sodass es also bei gleichbleibender Blutförderung durch das Herz zu einer Erhöhung des Blutdruckes in der Aorta kommt, so kann man bestimmt sagen, dass die Stromintensität in allen Gefässen, deren Weite sich nicht geändert hat, oder welche erweitert sind, zunehmen muss. In den verengerten Gefässen muss dagegen die Stromintensität abnehmen, und so kann es kommen, dass hier trotz der Verkleinerung der Querschnitte und bei erhöhtem Gefälle die absolute Geschwindigkeit abnimmt, die Widerstände haben in dem verengerten Theile zugenommen und die Vertheilung der Stromintensität auf verschiedene collaterale Theile des Gefässsystems erfolgt umgekehrt proportional dem Widerstande.

Ist das betrachtete Gefässgebiet in einer absolut oder relativ festen Ḱapsel eingeschlossen wie in der Schädelhöhle, im Knochenmark, im Augapfel, in den Nieren, so hat gleichmässige Herabsetzung des Tonus aller Gefässe dieses Gebietes Erweiterung der Arterien und Verengerung der Venen zur Folge, weil Arterien und Venen sich in die Erfüllung eines liaumes von constantem Volum zu theilen haben und der Druck in den Arterien der grössere ist. Das Gefälle in den Arterien nimmt also ab, das in den Venen zu, der Druck in den Capillaren wächst mit der Abnahme des Gefälles in den Arterien. Ueber die Aenderung der Stromintensität ist hier ebensowenig etwas Allgemeines auszusagen, wie über diejenige der absoluten Geschwindigkeit. Die Capacität des Stromgebietes, d. l. der Blutgehalt des Organes, bleibt constant, wenn nicht 
durch Aenderung im Lymphgehalt Gelegenheit zur Aenderung dieser Grösse geboten wird.

Aehnliche Verhältnisse würden eintreten, wenn in einem nicht ron fester Kapsel eingeengten Organe der 'Toms in den Venen mabhängig ron dem Tonus in den Arterien zmmehmen wiirde. Wiirde dagegen der Tomus der Arterien unablängig rom 'l'onus der Venen wachsen, so würde das Gefälle in den Arterien vermehrt und der Druck in dơn Capillaren dementsprechend verringert werden. Stromintensitiit und Cilpacitit wïrden in beiden letztgenannten Fïllen abnehmen.

Als Bedingung für Erhaltung eines stationären Zustandes des Kreislaufes gilt ausser der Constanz der Widerstïnde anch die Constanz der Leistung des Herzens. Pumpt dieses in der Zeiteinheit mehr Blut aus dem Venensystem in das Arteriensystem iiber, so steigt der Druck in der Aorta, das Gefälle in dem gesammten Stromkreise nimmt zu, und damit, bei gleichbleibender Gefïssweite, die Intensität und dic Geschwindigkeit des Stromes. Die Widerstände wachsen hierbei trotz unveränderter Gefiissweite wegen der Zunalume der Geschwindigkeit.

Die Pumpwirkung des Herzens ist abhängig von der /ahl der Herzschläge in der Zeiteinheit und von dem Volum des mit jedem Schlage geförderten Blutes. Wäre letzteres Volum unter allen Umstïnden gleich, so würde Vermehrung der Häufigkeit des Herzschlages stets zur Vermehrung des Aortendruckes, des Gefälles, der Stromintensitït und der Blutgeschwindigkeit führen. Das Herz brancht aber Keit, um sich zwischen den einzelnen Schlägen gehörig mit Blut zu füllen. Ueber eine gewisse mittlere Schlagzahl des Herzens hinaus fülırt also weitere Vergrösserung dieser Zahl zur Herabsetzung des arteriellen Druckes und zur Verminderung der Stromintensitït.

Wenn wir den normalen Strömungszustand bisher als einen stationïren betrachtet haben, so ist jetzt zu hemerken, dass diese Betrachtungsweise nur gilt, wenn man die Zeiteinheiten, für welche die Const:nz der Stromintensität behauptet wird, nicht zu klein wählt, jeckenfalls grösser, als die Zeit zwischen zwei Herzschligen. Die $\Lambda r$ t, in welcher die Pumpvorrichtung des Herzens das Gefïlle in dem Gefïsssysteme unterhält, bringt es mit sich, dass alle Strömmngsfactoren imerhalb der Zeit ron einem Iterzschlage zum anderen Schwankungen unterliegen.

Die Aufgabe, welche dem Herzen zufiillt, ist die, zweimal innerhalb des gesammten Kreislaufes, eimmal zwischen Köppervenen und Lungenarterien, dann zwischen Lungenvenen und Körperarterien, Flïssigkeit von Orten niedrigen Druckes zu Orten höheren Druckes zu befördern. Es ist dies eine Arbeit im physikalischen Sinne des Wortes. Dimnit das Herz diese Arbeit leisten kann, muss der Druck in seinem Innern einnal unterhalb desjenigen in den Venen sein, demn nur so füllt es sich ron 
dort her und dann muss er über denjenigen im Anfang der Arterien steigen, denn nur so entleert es sich dorthin, da Flïssigkeit nur von Orten höheren Druckes nach Orten niedrigeren Druckes strömt. Während der Druck in der Herzhöhle den niedrigen Werth besitzt, muss dieselbe gegen die Arterien und im andern Falle muss sie gegen die Venen abgeschlossen sein; diesen wechselnden Verschluss besorgen die rentilartig wirkenden Herzklappen. Die Drucksteigerung in der Herzhöhle kommt durch die in regelmässigem Rhythmus wiederkehrende Contraction der Kammermusculatur zu Stande, welche man die Systole der Ventrikel nenut; bei der darauf folgenden Erschlaffung, der Diastole, stellt sich die Druckerniedrigung ein. Bei der Kammersystole übt das Herz einen Pumpendruck aus, bei der Diastole eine Pumpensaugung, man sagt, das Herz wirkt wie eine Saug- und Druckpumpe.

Die Systole der beiden Herzkammern ist gleichzeitig und die Systole der Vorhöfe ist ebenfalls gleichzeitig, aber während der Ventrikelsystole sind die Vorhöfe in Diastole und während der Vorhofsystole sind die Ventrikel erschlafft; ausserdem besteht während eines Theiles jeder ganzen Herzrevolution gleichzeitig Diastole der Vorhöfe und der Ventrikel, es ist dies die sogenannte Herzpause. Zuerst fallen die Vorhöfe in Systole und dann setzt gleichzeitig mit der Diastole der Vorhöfe die Systole der Ventrikel ein, nach deren Beendigung Ventrikel und Vorhöfe gemeinschaftlich in Diastole verharren, bis die Systole der Vorhöfe wieder beginnt.

Während der Diastole der Vorhöfe haben sich diese mit ihren Anhängen, den Herzohren, schon vollkommen mit Blut gefïllt; während der Herzpause fliesst das aus den Venen kommende Blut in die inzwischen erschlafften Ventrikel. Der Blutstrom aus den Venen durch dic Vorhöfe in die Ventrikel dauert während der Vorhofsystole fort, die in der Zeiteinheit den Ventrikeln zuströmende Blutmenge wird jetzt noch vermehrt durch das Blut, welches bei der systolischen Verkleinerung der Vorhöfe aus diesen entweicht. Während der Füllung der Ventrikel muss eine centrale Flïssigkeitssäule in der Richtung zur Herzspitze und eine marginale in der Richtung zur Herzbasis zwischen AtrioventricularKlappe und Kammerwand fliessen. Gegen das Ende der Vorhofsystole nimmt zunächst die Stromintensitït in der ersteren ab, sodass die Klappen durch die zweite von der Wand abgehoben und mit ihren freien Rï̈ndern einander genälıert werden. Hierdurch werden die Ḱlappen so gestellt, dass sie sich beim Beginne der Ventrikelsystole sofort schliessen, olne rlass vorher Blut in den Vorlof zurückströmt. Wenn die Klappen geschlossen sind, ist auch der Vorhof schon erschlafft, sodass der Zustrom aus den Venen gleichmïssig fortdauern kann; wären die Vorhöfe nicht rorhanden, so würde der Blutabfluss aus den Venen 
während der Kammersystole verlangsamt und während der Kammerdiastole beschleunigt sein.

Die Atriorentricular-KKlappen werden geschlossen gehalten durch den Ueberdruck auf der Kammerseite iiber den auf der Vorhofseite; da der Druck im Vorhof niedrig ist, muss dieser Ueberdruck sofort bei Beginn der Kammersystole erreicht sein. Die Semilunar-Klappen können aber erst geöffnet werden, wenn der Druck im Ventrikel über denjenigen im Anfang der grossen Arterienstämme gestiegen ist, und da letzterer hoch ist, so vergeht einige Zeit, während welcher die Kammer beiclerseits abgeschlossen ist, das Volum derselben also constant bleiben muss; während dieser Zeit, der "Anspannungszeit des Ventrikels" fuihrt die zunehmende Erregungsintensität des Herzmuskels reniger zu einer Aenderung seiner Form als seiner Spannung. Verkürzen können sich die Herzmuskel-

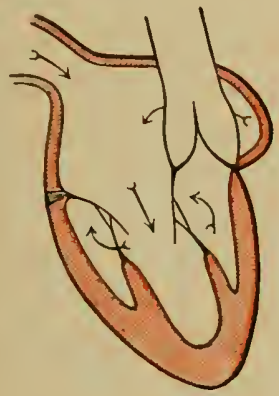

Anfüllungszeit des Ventrikels.

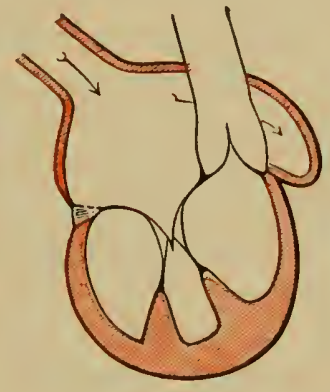

55. Anspannungszeit
des Ventrikels.

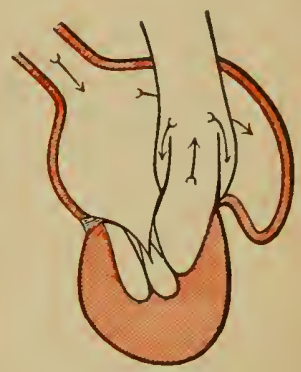

Austreibungszeit tles Ventrikels.

fisern jetzt nur dadurch, dass der Ventrikel bei gleichbleibendem Volum der Kungelform sich annähert, denn von allen Köörpern gleichen Volums hat die Kungel die kleinste Oberfläche.

Der Spannungszunahme der Ventrikelwand entsprechend wächst der Druck in dem Hohlraume, und sobald dieser den augenblicklich im Anfangstheil der Arterien vorhandenen Druck ïberschreitet, öffnen sich die Semilunarklappen und das Blut fängt an, ans dem Ventrikel auszuströmen, es beginnt die "Austreibungszeit des Ventrikels"; auch jetzt nimmt noch die Spannung der Wand und der Druck im Innern des Ventrikels weiter zu, aber gleichzeitig treten mit der Möglichkeit der Volumänderung sehr erhehliche Formänderungen ein. Dic wesentlichste derselben ist die Verkïrzung der Herzaxe durch Annäherung der beweglicheren Herzbasis gegen die der Thoraxwand dauernd anliegende Herzspitze. Die Herzbasis zieht den Anfangstheil der grossen Arterienstämme mit sich herab, welche dadurch der Länge nach und, durch das unter wachsendem Druck eintretende Blut auch in radialer Richtung, 
ausgedehnt werden. Das Blut wird hierbei gewissermaassen in eine neue Form gepresst, an deren Begrenzung der Ventrikel einen immer kleiner werdenden Antheil nimmt; während der Anspannungszeit ruhte das Blut in einer Form ron rerhältnissmässig grossem Querschnitt und kleiner Höhe, während der Austreibungszeit schiebt sich die neue Form theilweise über das Blut hinüber, dieses selbst erhält hierbei aber auch eine erhebliche Beschleunigung, da die neue Form eine viel grössere Länge bei kleinerem Querschnitt hat. Es ist ein Vorgang, welchen man einigermaassen nachahmen kann, wenn man in einen mit Flüssigkeit gefüllten Cylinder einen durchbohrten Stempel hineinstösst; der Flüssigkeitsstrahl wird um so weiter geschleudert, je enger die Bohrung im Verhältniss zum Querschnitt des Cylinders ist und je schneller man die Stempelberegung macht. Lässt man die Stempelbewegung durch gespannte und arretirte Federn ausführen, welche rom Cylinderboden zum Stempel gehen und deren Arretirung man plötzlich entfernt, so macht der Apparat, wenn man ihn pendelnd aufgehängt hat, einen Ausschlag in entgegengesetzter Richtung, als in welcher die Flüssigkeit fortgeschossen wird; es geschieht dies darum, weil die Vertheilung der Massentheile des Systems in Bezug auf den Schwerpunkt durch innere Kräfte geändert wird, während die Lage des Schwerpunktes im Raume sich nicht ändert, da eben die Veränderung der Massenvertheilung durch innere Irräfte erfolgte. Es ist derselbe Vorgang wie derjenige, durch welchen ein abgefeuertes Geschütz zurückrollt, während das Geschoss nach rorn fliegt; man nennt ihn den Rückstoss. Die Herzspitze muss durch den Rïickstoss fester gegen die Brustwand angedrïckt werden.

Es ist zweifelhaft, ob am Ende der Austreibungszeit sofort die Diastole des Ventrikels einsetzt, oder ob er in entleertem Zustande noch eine klcine Zeit contrahirt bleibt. Diese Phase der Herzrevolution würde man, wo sie rorkommt, "systolische Verharrungszeit des Ventrikels" nennen können.

Während der Diastole hat der Kammerkörper des Herzens die Form eines Kegels mit elliptischer Basis, auf welcher die Axe schief steht; in der Anspannungszeit nähert sich die Basis der Kreisform und richtet sich die Axe auf. Da das Herz mit seiner Axe ron rechts oben hinten nach links unten rorn auf dem Centrum tendineum des Zwerchfelles aufliegt - und zwar mit der Herzspitze im sechsten Intercostalraum links ron der Mammillarlinie - so wird an dieser Stelle durch die Aufrichtung der Herzaxe ein Druck auf das weiche intercostale Gewebe nach aussen erzeugt; dieser wächst in der Austreibungszeit erheblich durch den Tiückstoss; als ein in derselben Richtung wirkendes Moment kommt noch folgendes limzu: Aorta ascendens und Stamm der Arteria julmonalis kreuzen sich und sind in cinem Theile ciner steilen Spiral- 
windung umeinandergedreht; die in der Austreibungszeit erfolgende I) hnung dieser Gefässe wirkt auf Geraderichtung der gebogenen Gefäisse und Aufhebung der Spiralwindung; die hinten liegende Aorta dreht sich etwas nach rorn, die Pulmonalis etwas nach reehts, dadureh wirl dem ganzen Herzen eine Drelnung im Sinne der Pronation der linken Hand ertheilt, welche beim Thiere nach eröffneter Brusthöhle direct zu sehen ist und welche bei rersehlossenem Thorax die Herzspitze fester an dic Brustwand andrïcken muss. Drückt man den Finger an der angegebenen Stelle in den Intercostalraum ein, so fühlt man in regelmä̈ssigem Rhythmus einen Stoss, den sogenannten Spitzenstoss des Herzens, weleher mit der Ventrikelsystole zusammenfallen muss. Schnallt man eine Metallkapsel, über welche eine Gummimembran gespannt ist, so um den Thorax, dass eine Pelotte, welche auf die Mitte der Membran aufgeleimt ist, gegen die Stelle des Spitzenstosses gegengedrüickt wird, und rerbindet man diese Kapsel dureh einen Schlauch mit einer anderen ähnlichen Krapsel, an deren Membran ein Fühlhebel anliegt, und lässt man die Bewegungen dieses Hebels sich auf eine rotirende berusste 'Trommel aufschreiben, so erhält man ein Cardiogramm oder eine Spitzenstosscurve, welche mehr Einzelheiten im zeitlichen Druckrerlauf erkennen lässt, als das einfache Gefühl, doch sind die einzelnen Theile dieser Curve nicht einwandfrei gedeutet.

Während der Austreibungszeit müssen die Atrioventricular-KKlappen, wenn das Herz richtig wirken soll, geschlossen bleiben; die freien Klappenränder werden durch die Chordae tendineae verhindert, bei wachsendem Ventriculardruck nach dem Vorlofe hin umzuschlagen; bei der Annïherung der Herzbasis an die Herzspitze würden die Chordae in dieser Beziehung insufficient werden, wenn sie nicht an den Spitzen der Papillarmuskeln befestigt wären; in demselben Maasse wie die Angriffspunkte der Chordae an den Ḱlappen sich während der Austreibungszeit der Herzspitze nähern, thun dies auch ihre papillären Insertionen wegen der Contraction der Papillen.

Ueber die Stellung, welche die Semilunarklappen annehmen, während sie in der Austreibungszeit geöffnet sind, besteht nicht rolle Sicherheit; der freie Rand jeder dieser Klappen muss, während sie sieh an dem Verschluss betheiligt, einen nach imen convexen Bogen bilden, weleher lïnger ist, als die durch die festen Punlte des Ḱlappenrandes gelegte Selne, und auch länger, als der von dieser Sehne abgeschnittene Kireisbogen des Gefässumfanges, vorausgesetzt, dass das Gefiiss an dieser wie an seinen übrigen Stellen cylindrisch wïre; dann müssten also die Ḱlappen durch das rom Herzen einströmende Blut fest an die Wand gedriickt werden. Nun sind aber die Aussenwände der durch die Semilunarklappen gebildeten Taschen in den Sinus Valsalvae ausgebaucht, 
und es ist zweifelhaft, ob die freien Klappenränder so lang sind, wie es ibre Anlagerung an die Wände der Sinus erfordern würde. Von der Annahme solcher Anlagerung ausgehend hat man geschlossen, dass die aus den Sinus Valsalvae entspringenden Coronararterien bei jeder Systole durch die an die Wand gedrückten Semilunarklappen verschlossen würden, und dass die darauf folgende diastolische Erschlaffung des Herzens eine Folge verhinderter Blutzufuhr sei. Es ist nun aber schwer einzusehen, wie die Semilunarklappen am Ende der Austreibungszeit oder auch am Ende der Verharrungszeit sich behufs schnellen Abschlusses der Ventrikelhöhle gegen die Aorta von der Wand der letzteren fortbewegen sollten, wenn sie derselben bis dahin fest angelegen hätten; es ist viel wahrscheinlicher, dass beständig ein mit Fliissigkeit gefüllter Raum zwischen den Klappen und der Wand bestehen bleibt, dass in diesem Raume, welcher wegen seiner elastischen Wandungen der Vergrösserung

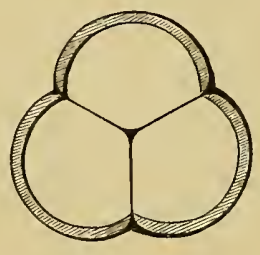

Semilunarklappen geschlossen.

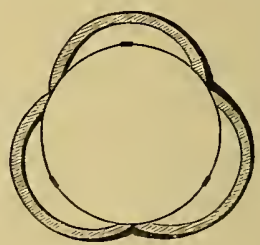

56.

Semilunarklappen

fähig ist, während der Austreibungszeit Blut im Bogen um den freien Klappenrand herum, also im Wirbel einströmt, dass diese Wirbelbewegung die Fliissigkeitsbewegung in der Gefässaxe ïberdanert und dadurch die den Klappenschluss vorbereitende Klappenstellung am Ende der Austreibungszeit bewirkt.

In diesem Zusammenhange sieht man auch ein, wie zweckmässig das Vorhandensein einer, wenn auch noch so kurz dauernden systolischen Verharrungszeit des Ventrikels sein mïsste. Ueberdanert die Contraction der Ventrikelwand die Austreibungszeit, so können sich die Semilunarklappen unter der Wirkung der Wirbel in den Sinus Valsalvae bis zur Berührung nähern, ehe im Ventrikel ein Hohlraum fuir zurïckfliessendes Blut entsteht und, tritt die Diastole damn bei schon gestellten Klappen ein, so werden, bei der plötzlichen Entstehung der grossen Druckdifferenz zu beiden Seiten der Klappen diese nun plötzlich gespannt werden, olhne dass ein Tropfen Blutes in den Ventrikel zuriickzufliessen braucht.

Mit dem Spiel der Herzklappen hängen akustische Phänomene zusammen, welche an der äusseren Thoraxwand in der Herzgegend mit 
dem aufgelegten Ohre wahrgenommen werden können. Der Zahl nach entsprechen jeclem Spitzenstosse zwei Herztöne ron deutlich verschiedenem Charakter; ils ersten Herzton bezcichnet man cin Goräusch von etwas lïngerer Dauer und tieferer Tonlage als sie dem anderen, dem zweiten Herzton zukommit; das Intervall zwischen erstem und zweitem Herzton ist kïrzer, als das zwischen dem zweiten und dem nüchsten ersten; es ist als ob man: "lup-dup", mit einem kleinen Intervall zwischen beiden Silben, den Accent auf der zweiten, und die Tonhöhe der ersteren etwas tiefer, aussprechen hörte. Der erste Herzton ist etwa synchron mit dem fülllbaren Spitzenstosse, er entspricht dem Schlusse der AtrioventricularKlappen, welche bei ihrer plötzlichen Spannung in Schwingung rersetzt werden; beigemischt ist ilum das Muskelgeräusch des sich contrahirendeu Ventrikels, denn auch an dem leergehenden, freigelegten Thierherzen lïsst sich mittelst eines aufgesetzten Hörrohres (Stethoskops) ein Geräusch, älınlich dem ersten Herztone bei der Systole der Ventrikel wahrnehmen; der zweite Herzton muss dem Schlusse der Semilunarklappen (oler genauer gesagt, der plötzlichen Spannung derselben am Ende der systolischen Verharrungszeit der Ventrikel) entsprechen.

Die Frequenz der Herzschläge beträgt beim normalen erwachsenen Menschen etwa 72 in der Minute; die Zahl ist erheblich grösser bei Kindern, wie auch bei kleineren Thieren; beim Weibe etwas grösser wie beim Nanne; bei grossen kräftigen Männern, in der Vollkraft der Jahre, nur etwa 60, und nimmt mit dem Alter wieder zu. In umgekehrtem Verhältnisse der Schlagzahl des Herzens steht dic auf die einmalige Herzrevolution entfallende Zeit. Der Theil der letzteren, welcher zwischen dem ersten und dem zweiten Herztone liegt und welcher auf die Dauer der Ventrikelsystole bezogen wird, hat sich bei genau darauf gerichteten Untersuchungen an einer Reilie von Individuen, welche zwischen 74 mud $9 t$ Systolen in der Minute aufwiesen, als wesentlich gleich und zwar zu beinalıe einem Drittel der Secunde ergeben. Die Schwankungen bei verschiedener Ziahl der Herzschlïge beziehen sich also hauptsächlich auf die diastolische Zeit der Ventrikel. Die Systole der Vorlıöfe erscheint bei Beobachtung des freigelegten Thierherzens von etwas kürzerer Damer als die Systole der Ventrikel. Die Anspaumungszeit der Ventrikel kann nach einer später rerständlich werdenden Methode bestimmt werden und ergiebt sich zu 0,08 Secunden.

Den rhythmischen Bewegungen des Herzens entsprechen rhythmische Veränderungen im Gefïsssysteme, welche als Aenderungen von Spannung und Volum an oberflächlich liegenden Arterien durch das Gefülıl und zum Theil auch durch das Auge wahrgenommen werden können: diese Erscheinungen nennt man den Puls der Arterien. Am besten fühlt man den Puls an oberflächlichen Arterien auf ciner knöchernen Grundlage, 
7. B. an der Arteria radialis. Driickt man diese Arterie zwischen den Fingerspitzen und der vorderen Fläche des darunter liegenden Radius tastend zusammen, so fühlt man eine rhythmisch wiederkehrende Steigerung der Druckempfindung; die Frequenz ist dieselbe wie die des Spitzenstosses; mit dem Finger kann man an dem Pulse mehr Einzelnheiten unterscheiden als am Spitzenstosse; die Drucksteigerung kann mehr oder weniger umfangreich sein, danach bezeichnet man den Puls als voll und leer, oder auch als gross und klein. Im Allgemeinen fühlt sich der Druckanstieg steiler an als der Druckabfall; ist der Druckabfall ebenfialls steil, so nennt man den Púls schnellend. Den Gegensatz dazu bilctet ein Puls mit ungewöhnlich langsamenı Anstieg, der langsame Puls. Während der Zeit der Abnahme der Druckempfindung kann man oft eine erneute kurze Erhebung wahrnehmen; der Puls ist zweischlägig. Nit der eigentlichen Pulswahrnehmung verbindet man leicht Wahrnehmungen über Weite oder Enge der Arterie, welche man auf ihren verschiedenen Füllungsgrad bezieht, sowie über die grössere oder geringere Leichtigkeit, mit welcher man den Pnls unterdrücken kann, was einen Schlnss auf die Höhe des Blutdruckes gestattet, oder auch auf verschiedene Starrheit der Arterienwand.

Ein Apparat, welcher die mit dem Finger zu machenden Erfahrungen ergänzen soll, ist der Sphygmograph. Die Fingerspitze ist durch eine Pelotte ersetzt, die mittelst einer regulirbaren Feder gegen die Arteria radialis so angedrückt wird, dass sie von derselben möglichst grosse Bewegungen erhält; diese Bewegungen der Pelotte werden mittelst eines leichten Hebelwerkes in vergrössertem Maassstabe der Spitze einer Zeichenfeder mitgetheilt, welche anf einer berussten, an derselben durch Uhrwerk rorbeibewegten Zeichenfläche schreibt; der ganze Apparat ist so construirt, dass er an den passend gelagerten Arm angeschnallt werden

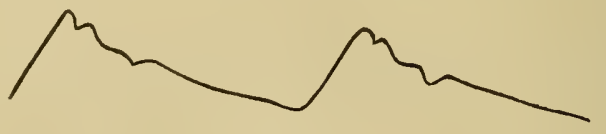

57.

kann; das mit demselben gezeichnete Sphygmogramm (Fig. 57) zeigt rliythmische Erhebungen und Senkungen, welche proportional den Aenderungen des Durchmessers der Arterie sind; an allen Splygmogrammen ist die Frheljung steiler wie die Senkung. Die erste grosse und steile Erhebung entspricht dem Anfangstheile der Ventrikelsystole. An dem absteigenden Theile der Curve sind secundäre Zacken zu erkennen, von denen eine an guten Sphygmogrammen constant und meistens auch besonders dentlich horrortritt. Es ist eine plötzliche Drucksenkung mit darauf 
folgender geringerer Hebung etwa am Ende des ersten Drittels der Curve. Diese Senkung an der Pulscurve entspricht, wie ziemlich sicher ermittelt ist, dem Beginne der Yentrikel-Diastole. Ueber die Art, wie diese negative Zacke im Beginne der Diastole entsteht, und iibcr die Bedentung der übrigen Zacken herrscht noch Mcinungsrerschiedenheit. Die der Senkung folgende Erhebung hat man die Rückstosselevation genannt. Der derzeitige Mangel einer klaren Einsicht in die Entstehungsweise der Einzelnheiten des Sphygmogrammes beeinträchtigt nicht sehr die Brauchbarkeit desselben für klinische Zwecke, da sich empirisch herausgestellt hat, dass gewissen Aenderungen im Circulationssystem charaliteristische Aenderungen der sphygmographischen Curren entsprechen. Im Allgemeinen zeigt das Sphygmogramm dasselbe, nur in leichter autfassbarer Form, was auch der zufühlende Finger wahrnehmen kann. Durch die zweckmässige Benützung des Sphygmographen kiunn die Erlernung der Kunst des Pulsfühlens also sehr unterstützt werden.

Die pulsatorische Querschnittsänderung ist an der Arteria radialis oft direct zu sehen; deutlicher sichtbar ist sie an manchen anderen Gefässen, z. B. an der Carotis des Pferdes, unter gewissen Bedingungen an den Arterien des Kaninchenohres oder im Augenspiegelbilde an der Arteria centralis retinae, an welcher sichtbarer Puls übrigens nicht zur Norm gehört. Dass den pulsatorischen Druckänderungen nicht nur Querschnittsänderungen der Arterien, sondern auch solche ihrer Länge entsprechen, kann man ebenfalls manchmal an oberflïchlich gelegenen Arterien, z. B. an der Schlïfengegend magerer Menschen, sehen; leicht gewundene Gefïsse werden hierbei stärker gekrümmt. Eine pulsatorische Aenderung in der Röthung des Nagelbettes ist in pathologischem Zustande beobachtet worden; man hat sie wohl mit Recht auf einen Puls in den Capillaren bezogen, welcher normalerweise nicht rorkommt. In den Halsrenen kann man ebenfalls unter abnormen Bedlingungen Füllungsänderungen mit dem Rhythmus des Herzschlages eintreten sehen. Die Volumszunahme in den Arterien füllt immer in die Zeit des Spitzenstosses; der Systole des Herzens entspricht also eine Diastole der Arterien und umgekehrt. In den Venen kann der Herzsystole eine Vermehrung oder eine Verminderung des Volums entsprechen; im ersteren Falle spricht man ron einem positiven, im letzteren ron einem negativen Venenpuls.

Die pulsatorische Drucksteigerung tritt an den verschiedenen Arterien des Körpers nicht genau gleichzeitig ein. Fühlt man mit der einen Hand den Puls der Arteria maxillaris exterua, mit der anderen den der Arteria pediea, so merkt man deutlich, dass er an letzterer Stelle um einen kleinen Bruchtheil einer Secunde später eintritt, welcher auf $1 / \%$ Sec. geschätzt worden ist. Der Puls pflanzt sich als Welle in einem elas- 
tischen Schlauchsysteme vom Herzen nach der Peripherie zu fort, und zwar mit einer Geschwindigkeit von etwa 9 Metern in der Secunde.

Beim Menschen kann man den zeitlichen Ablauf der Druckänderungen in verschiedenen Theilen des Gefässsystems nicht so unmittelbar untersuchen wie bei Thieren, in deren Gefässe man Canülen einführen kann; die Instrumente, welche man mit diesen Canülen in Verbindung setzt, um von ihnen den zeitlichen Ablauf der Blutdruckschwankungen aufschreiben zu lassen, nennt man Blutwellenzeichner.

Der wesentliche Theil des Blutwellenzeichners ist eine kleine Metallkapsel, mit einem Tubus zur Herstellung der Verbindung, nach der Gefässcaniile hin, und geschlossen durch ein dünnes gewelltes Metallblech, wie es an den Aneroid-Barometern gebräuchlich ist; die sehr kleinen, mit der Druckänderung einhergehenden Verrückungen der Membranmitte werden auf einen möglichst masselosen Fühlhebel übertragen, dessen Spitze seine Bewegungen aufschreibt. Das Instrument ist so eingerichtet, dass man, je nachdem man es bei verschiedenen Thieren mit verschiedenem mittlerem Blutdrucke anwenden will, Metallmembranen von verschiedener Nachgiebigkeit einsetzen kann; auch ist Gelegenheit gegeben, den Maassstab der Vergrösserung, in welchem der Hebel schreibt, zu verändern. Für dieselbe Metallmembran und dieselbe Vergrösserungszahl ist das Verhältniss zwischen der Grösse der Ablenkung der Zeichenspitze und dem Drucke der Flüssigkeit ein constantes, welches empirisch durch Vergleichung mit einem Quecksilbermanometer bestimmt wird. Hat man die Aichung des Instrumentes vorgenommen, so kann min für jeden Punkt der Blutwellencurve die entsprechende Höhe des Blutdruckes angeben.

Die lehrreichsten Blutdruckcurven erhält man, wenn man zwei Blutwellenzeichner mit gleichen Eigenschaften gleichzeitig, den einen mit der IIöhle des linken Ventrikels, den anderen mit der Aorta in Verbindung setzt; man benutzt hierzu einen doppelläufigen Katheter, welchen man durch die linke Carotis eines nicht zu kkeinen Hundes in die aufsteigende Aorta vorschiebt. Bei einiger Geduld und vorsichtigem, rhythmisch wiederholtem Weitersondiren gelingt es oft, die Katheterspitze gerade während einer Klappenöffnung in das Herz vorzuschieben, sodass keine Klappen verletzt werden. Wenn der Katheter richtig liegt, so befindet sich die Mündung der einen Röhre des Doppelrohrs im Ventrikel, die andere in der Aorta; man erhält also, wenn man die äussere Verlängerung der einen Rölre mit einem Blutwellenschreiber und die entsprechende der anderen mit einem zweiten solchen Apparat von gleichen Abmessungen und Eigenschaften verbindet, vergleichbare Druckcurven des Ventrikels und der Aorta. Der Klappensehluss ist durch den Katheter nicht gestört. Der auffallendste Unterschied zwischen den 
beiden Blutdruckcurven bestelit darin, dass diejenige des Ventrikels jedesmal zwischen zwei Herzschlïgen bis unter die Yullinie absinkt, während die minimalen Druckwerthe in der Aorta stark positiv sind, etwa die Hälfte der maximalen Druckwerthe betragen. Der Ueberschuss des maximalen Druckes im Ventrikel iiber den maximalen Druck in der Aorta, welcher nach hydrodynamisehen Gesetzen bestehen muss, lïsst sich nicht demoustriren. Der Druckabfall im Ventrikel ist viel jüher, als der in der Aorta. In der kurzen Zeit des steilen Druckalbfalls im Ventrikel vollzieht sich der Uebergang des Herzmuskels aus dem contrahirten in den erschlifften Zustand (Erschlaffungszeit des Ventrikels).

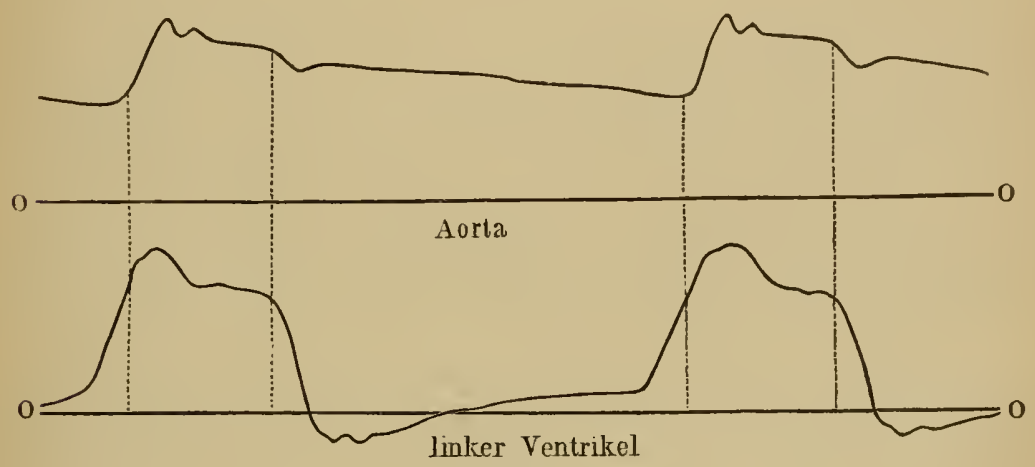

58.

Der negative Theil der ventriculären Blutdruckeurve ist schwer zu deuten. Auf einer Täuschung durch Schleuderungen im angewandten Apparate beruht er nicht, denu er zeigt sich auch bei Zwischenschaltung eines Ventils, welches sich nur öffnet, sobald der Druck im Veutrikel negativ geworden ist; am wichtigsten wäre es, zu wissen, ob der zur Beobuchtung kommende negative Druck geeignet ist, Blut aus den Venen zu aspiriren. Dieses braucht nänlich nicht der Fall zu sein, wenn ron den Amahmen, welche betreffs der Ursache der negativen Druckschwankungen geïussert worden sind, folgende die richtige ist. Die bei der Systole des Ventrikels ausgetriebene Blutsäule verlässt denselben mit erheblicher Geschwindigkeit, und da die im Katheter befindliche Flïssigkeit damit communicirt, so kann sie in der Richtung der Blutsäule mit fortgerissen werden; man kann diesen Vorgang nachahmen, wenn man ans einem Reservoir Wasser mit erheblicher Geschwindigkeit durch ein starres, langes, horizontales Rohr abströmen lïsst, an welehem sich in der Nähe des Reservoirs ein U-förmiges Nanometer befindet; unterbricht man den Fliissigkeitsstrom durch Schliessung eines Hahnes zwischen Manometer und Reserroir, so muss sich das Manometer natürlich auf Null 
stellen. Findet der Hahnschluss aber sehr plötzlich statt, so wird es voriibergehend unter Null herunter gerissen.

An einem freigelegten Herzen würde ein auf diese Weise im Ventrikel erzengter negativer Druck nur dazu führen, dass die Ventrikelwände unter dem Ueberdruck der Atmosphäre gegen einander gepresst würden. Innerhalb des Thorax lastet aus später zu erörternden Gründen nicht der atmosphärische, sondern ein kleinerer Druck, oder, wie man sagt, ein negativer Druck auf der äusseren Herzoberfläche; ist der absolute Werth dieses negativen Druckes grösser, als der des negativen intraventriculären Druckes, so werden die Ventrikelwände nicht gegen einander gepresst, und es kann auf diese Weise Blut von den Venen her in den Ventrikel eingesaugt werden. Die Resultate der vorliegenden Druckmessungen gestatten noch nicht zu sagen, welchen Einfluss die Trägheit der geschleuderten Blutsäule hat. Auch abgesehen von demselben muss sich am Ende der Erschlaffungszeit des Ventrikels ein negativer Druck in der sich hierbei erweiternden Höhle desselben einstellen, sobald die Aspiration des Thorax die nachlassende Spannung des Kammermuskels überwindet. Hierdurch wird Blut von den Venen her aspirirt. Die Aspiration des Thorax könnte auch unterstützt werden, wenn, wie vermuthet worden ist, die dem Ventrikel in der Diastole zukommende Form eine solche mit einem Hohlraum im Innern wäre; für die, eine solche Form etwa bedingenden Kräfte, sind verschiedene Annahmen gemacht worden; man hat gemeint, es handele sich beim Uebergange des Ventrikels in die Diastole um einen Vorgang, wie ilın ein dickwandiger Kautschukballon nach Aufhebung eines von aussen auf ihn wirkenden Druckes zeigt; dieser nimmt hierbei seine elastische Gleichgewichtsfigur wieder an, zu welcher ein Hohlraum im Innern gehört; dass der erschlafften Ventrikelwand an sich eine solche elastische Gleichgewichtsfigur nicht zukommt, kann man deutlich an jedem herausgenommenen Herzen, welches noch nicht der Todesstarre verfallen ist, sehen. Alle seine Theile folgen einfach der Schwere.

Eine plötzliche Steigerung des Druckes und der Füllung der Herzgefässe, und dadurch gewissermaassen eine Erection der Kammerwand, könnte eintreten unter der Voraussetzung, dass während der Austreibungszeit die Coronararterien durch die Semilunarklappen geschlossen gehalten würden; kurz vor dem Schlusse der Aorta durch die Klappen würde darn in den Coronararterien plötzlich eine erhebliche Drucksteigerung cintreten. Man hat auch gemeint, dass die Diastole wicht einfach auf der Eirschlaffung sämmtlicher Kammermuskelfasern beruhe, sondern dass eine gewisse Faserkategorie gerade bei der Diastole in Erregung gerathe und dadurch eine Erweiterung der Herzhöhle herbeifiihre; zwingende 
Beweise für die Existenz einer solchen ,activen Diastole" sind nicht beigebracht worden.

In der Bhutdruckeurve des Ventrikels muss der Beginn der positiven I)rucksteigerung zeitlich zusammenfallen mit dem Beginne der Kammersystole; der Druckanstieg in der Aorta dagegen kann erst beginnen, wenn der Druck im Ventrikel die Höhe des Druckes in der Aorta erreicht hat, erst dann öffnen sich die Klappen und es beginnt die Austreibungszeit; der Zeitwerth der Abscissenlänge zwischen den Beginne des Druckanstieges im Ventrikel und dem Beginne des Druckanstieges in der Aorta (Fig. 58 ) entspricht also der Daner der Anspannungszeit; der oben hierfür angegebene Werth ron $0,08^{\prime \prime}$ ist auf diese Weise ermittelt worden.

In den rechten Ventrikel kann man ron der rechten Vena jugularis aus einen Herzkatheter einführen; rerbindet man diesen mit einem Blutwellenschreiber, so erhält man Curren, welche den ron der linken Herzkammer gelieferten analog und synchron sind, jedoch geringere positive Druckwerthe zeigen.

Um die kleinen Druckschwankungen aufuschreiben, welche sich in dem ebenfalls ron der rechten Vena jugularis aus zug̈̈uglichen rechten Vorhof abspielen, muss man die Kapsel an dem Blutwellenschreiber mit einer dïnnen Kautschukmembran schliessen; dic wichtigste dieser Schwankungen ist eine Drucksenkung, welche sich synchron mit der Ventrikelsystole und zwar besonders bei uneröffnetem Thorax zeigt; sie entsteht dadurch, dass mit der Entleerung des Ventrikels sich der Inhalt des Pericards zu verkleinern strebt, dass aber eine Verkleinerung des Herzbeutels wegen seiner Lage im geschlossenen Thorax Einschränkungeu erleidet; die Volumverminderung der Ventrikel wird durch eine Volumvermehrung der Vorhöfe annähernd ansgeghichen; ehe es zu dieser Ausgleichung kommt, ist hier Drucksenkung rorhanden.

Um sich eine Vorstellung daron zu bilden, wie dic Blutwellen in der Aorta entstehen, und wie sie sich durch die Arterien fortpflanzen, kann man zunächst einmal die Annahme machen, dass es sich um ein System starrer Röhren handele. Es wïrde dann jerler Ventrikelsystole eine an allen Stellen des Systemes gleichzeitige Beschleunigung des Stromes und Vermehrung des Wanddruckes ${ }^{1}$ ), bei iiberall unveränderter Grösse des Querschnittes entsprechen; während der Dauer der Systole wïrde sofort die auf Contraction des Herzmuskels rerwandte potentielle Energie als lebendige Krraft beschleunigter Masse erscheinen, doch würde am Ende der Systole diese ganze lebendige Kraft durch Reibung auf-

1) Gleichzeitig in Bezug auf die hier in Betracht kommenden Grössenordnungen. Es treten an den rom Herzen entfernteren Stellen des Systemes Verzögerungen ein wie bei der Fortleitung des Schalles. 
gebraucht worden sein und nur noch in Gestalt von Wärmebewegung vorliegen. Wegen der in Wirklichkeit vorhandenen Elasticität der Wandungen wird num aber der Anfangstheil des arteriellen Systemes unter dem Drucke der Ventrikelsystole in dem Maasse gedehnt, wie die der Dehnung widerstehenden elastischen Krräfte kleiner sind als die der Beschleunigung der Flüssigkeitssäule in der Stromrichtung entgegenwirkenden Kräfte (Trägheit und Reibung). In Folge dessen wird ein Theil der bei der Contraction des Herzmuskels aufgewandten potentiellen chemischen Energie zunächst als potentielle mechanische Energie (Wandspammung) aufgespeichert und nicht sofort ganz in lebendige Kraft beschleunigter Massen umgesetzt. Während der Austreibungszeit entwickelt sich ziemlich plötzlich im arteriellen System die vordere Hälfte eines Wellenberges, dessen Fuss das Capillarsystem schon vor der Beendigung der Austreibungszeit erreicht hat, denn die Blutwelle braucht nur etwa $1 / 7$ Secunde, um bis in die Arteria pediea zu gelangen, und die Austreibungszeit dauert etwa $1 / 4$ Secunde (Zeit zwischen beiden Herztönen 0,33" weniger Anspannungszeit 0,08"). Der Gipfel liegt im Anfangstheile der Aorta und nimmt bis zum Ende der Austreibungszeit an Höhe zu. Am Orte des Gipfels haben Druck, Volum und Geschwindigkeit maximale Werthe. Die Entwickelung des Wellengipfels kommt dadurch zu Stande, dass in ein, durch benachbarte Querschnitte begrenztes Element der Aorta, während der Zeiteinheit mehr Blut von dem Herzen her hineingepresst wird, als nach der Peripherie zu abfliessen kann; mit dem Ende der Austreibungszeit hört der Zufluss auf, während der Abfluss durch die Wandspannung weiter unterhalten wird. Die aus dem betrachteten Elemente der Aorta hierdurch entleerte Flïssigkeitsmenge trägt zunächst vorwiegend zur Dehnung des benachbarten Elementes bei; der Wellengipfel rückt in dieses und so fort. Der voranschreitende Fusspunkt der Welle befindet sich stets dort, bis wohin die Beschleunigung des Flüssigkeitsstromes reicht; das Ausbreitungsgebiet der Beschlemnigung ist dadurch beschränkt, dass die vom Orte des Wellengipfels aus fortbewegte Flüssigkeit vorübergehend aus der translatorischen Bewegungsrichtung in die radiale abgelenkt wird, um zur Füllung des in Erweiterung begriffenen Gefässabschnittes zu dienen. Wegen dieser Einbusse an Beschleunigung in der Richtung der Gefässaxe ist es schwer $z u$ ibersehen, welchen Werth die lebendige Kraft der aus dem Ventrikel entleerten Blutmasse am Ende der Austreibungszeit haben wird, und ob sie gross genug ist, um zur Entstehung einer, der positiven Welle folgenden negativen Welle Veranlassung zu geben; eine solche negative Welle entsteht in elastischen Röhren, deren Inhalt mit erheblicher Geschwindigkeit strömt, bei plötzlicher Unterbrechung des Zuflusses; man nennt sie hier die Schliessungswelle. Sie ist Veranlassung zu einer zeitweise 
riicklïnfigen Flüssigkeitsbewegung, welche dann als kleine positive Welle reflectirt wird.

An dem absteigenden Aste des Sphygmogrammes haben wir eine secundïre Erheloung unter dem Namen der Rïckstosselevation kennen gelernt; diese zeigt sich auch an den Bhtwellencurven, welche man von beliebigen Arterien des 'Thieres gewinnt; die der Riickstosselevation vorangehende, mit dem Beginne der Diastole des Ventrikels synchrone Einsenkung hat man als Schliessungswelle und die Riickstosselevation selbst als die dieser negativen Welle folgende positive gedentet. Nach Ansicht Anderer soll die Riiickstosselevation ein Ausdruck der Reflexion der primären Blutwelle von der Peripherie her sein; eine solche Reflexion mit deutlich nachweisbarer, rückläufiger, positiver Welle tritt an einem unverzweigten, am Fnde verschlossenen oder verengten Schlanche sicher ein. I)ie Verhältnisse liegen aber bei dem Blutgefässsysteme darum sehr verwickelt, weil die Bedingungen für Wellenreflexion nicht anf einen einzelnen Punkt beschrïnkt sind, sodass selı viele Reflexionen stattfinden miissen, deren Interferenz von vornherein nicht zu übersehen ist.

Scheinbar miisste es sich entscheiden lassen, ol) die Rïickstosselevation in Folge ciner Schliessungswelle eintritt, oder ol sie der Ausdruck einer von der Peripherie aus reflectirten positiven Welle sei, wenn man zwei Sphygmogramme oder zwei Blutwellencurven mit einander vergliche, welche Arterien in verschiedener Entfernung vom Herzen entnommen sind; falls die zweite Anmahme richtig wäre, müsste die Rïckstosselevation um so mehr vom primären Curvengipfel abrücken, je näher dem IIerzen man die Curve genommen hat; andernfalls mïsste der Abstand iilserall derselbe sein. Es hat auch nicht an Versuchen gefehlt, die Frage auf diesem Wege zu lösen, doch ist man noch nicht zu ganz ïbereinstimmenden Resultaten gelangt; immerhin spricht die grössere Wahrscheinlichkeit gegen dic Reflexion von der Peripherie.

Allgemein anerkannt sind die Resultate, zu wolchen dic Vergleichungen von Sphygmogrammen oder Blutwellencurven in Bezug auf die Fortpflanzungsgeschwindigkeit des Pulses geführt haben; zeichnet man gleichzeitig zwei solehe Curven derart auf, dass man die eine von einer dem IIerzen näheren, die andere von einer entfernteren Stelle desselben Gefïsses in messbarem Alsstande ron einander nimmt, so ergiebt die zeitliche Differenz zwischen dem Erhebungsmoment beider Curven in Verbindung mit den Abstïnden der beiden Gefässstellen die Fortpflanzungsgeschwindigkeit in dem Gefïsse. Es ist dies ein ganz analoges Verfahren, nur mit verfeinerten Hilfsmitteln, wie es bei einfacher Bemntzung des tastenden Fingers zur Schïtzung der Zeitdifferenz zwischen Puls im Fusse und Kopfe anf 1/; Secunde nud unter Benntzung dieses Schätzungswerthes und der gemessenen Körperlänge zur Annahme einer Fort- 
pflanzungsgeschwindigkeit der Pulswelle von etwa 9 Meter in der Secunde gefiihrt hatte; die genaueren Messungen haben diesen Werth im Allgemeinen bestätigt, nur hat sich im Besonderen ergeben, dass die Fortpflanzungsgeschwindigkeit in den oberen Extremitäten kleiner ist als in den unteren, beim Kinde etwas kleiner als beim Erwachsenen, bei hohem Blutdruck grösser als bei niederem Blutdruck. Die besonderen Ermittelungen fallen alle unter das gemeinsame Gesetz, dass die Fortpflanzungsgeschwindigkeit der Welle in elastischen Röhren mit der Grösse des Elasticitätscoëfficienten der Wand wächst. Die Nothwendigkeit dieses Gesetzes sieht man leicht ein, wenn man bedenkt, dass unter sonst gleichen Bedingungen der Fusspunkt des entstehenden Wellenberges am Ende der Austreibungszeit um so weniger weit vorgerückt sein wird, je mehr Fliissigkeit, aus der Bewegung in der Stromrichtung, in radiale Richtung hat ausweichen können; dieses ist in um so höherem Maasse der Fall, je dehnbarer die Gefässwand, das heisst je kleiner der Elasticitätscoëfficient ist. Die Arterien von Kindern sind nun in der That dehnbarer als die von Erwachsenen. Ferner ist die Dehnungscurve der Arterienwände gegen die Abscisse concav, das heisst, je grösser die Dehnung geworden ist, um so mehr Widerstand setzt die Arterie ihrer weiteren Dehnung entgegen, oder mit anderen Worten, un so grösser wird ihr Elasticitätscoëfficient. Je höher der mittlere Blutdruck ist, um so stärker ist die Gefässwand gedehnt, um so grösser ist ihr Elasticitätscoëfficient und um so schneller muss sich also die Pulswelle in dem Gefässe fortpflanzen.

Unter Länge der Pulswelle versteht man den Weg, welchen der vorausschreitende Fusspunkt der Welle durchlaufen hat im Moment, wo der Wellenberg am Entstehungsorte der Welle sein Maximum erreicht. Der Fuss der Welle geht am Aufang der Austreibungszeit vom Herzen aus, und der Wellenberg erreicht hier am Ende der Austreibungszeit sein Maximum. Es fragt sich also, wie weit der Fusspunkt während der Austreibungszeit, das ist in $1 / 4$ Secunde läuft; dies wäre bei etwa 9 Meter Fortpflanzungsgeschwindigkeit in der Secunde iiber 2 Meter, also erheblich mehr als die Entfernung vom Herzen bis zu irgend welchen Körpercapillaren beträgt; da die Pulswelle im Capillarsystem erlischt, so ist sie also nie in der ganzen, ihr zukommenden Lünge vorhanden; der vordere Theil ist schon im Erlöschen, während der hintere sich noch weiter ausbildet.

Dass die Pulswelle am Ende des arteriellen Systemes augenscheinlich verschwindet, ist verständlich, wenn man bedenkt, dass mit Zunahme des gesammten Querschnittes die dem einzehnen $\Lambda$ rterienpulse entsprechende Volumzunahme einen immer kleineren Bruchtheil des Gesammtrolumens bilden muss, dass also die Querschnittszunahme jedes 
einzehen Capillargefiisses verschwindend klein sein und dass auch die lieschleunigung der grossen im Capillarsystem rorhandenen Blutmasse klein ausfallen muss. Diese Gründe würden es nicht erklären, weshalb der Puls in den Venen nicht wieder erscheint, doch kommt hierbei woh! in Betracht, dass der Weg durch die verschiedenen Capillaren zu derselhen Vene ein verschieden langer ist, sodass hier ein Erlöschen durch Interforenz eintritt.

Die pulsatorischen (und auch andere) Volumänderungen eines ganzen Kïrpergliedes - zum Beispiel des Vorderarmes - kann man sichtbar machen, wenn man dasselbe in einen mit Wasser gefuillten festen Behültter einfiuhrt, unter Anbringung eines wasserdichten Kautschukabschlusses, welcher das Glied nicht zu fest umschnürt; der feste Behälter ist mit einem Manometer verbunden, dessen Schwankungen mittelst eines in dem offenen Schenkel befindlichen Schwimmers auf eine rotirende Flïche aufgeschrieben werden. Die so gewonnenen Curren nemnt man plethysmographische. Die pulsatorischen Schwankungen der Plethysmogramme sind ähnlich denen der Sphygmogramme, während aber in letzteren jede Erhebung einer Querschnittszunahme der Arterie entspricht, zeigen die Erhebungen der ersteren den Ueberschuss des Zuflusses ron Blut zum Gliede iiber den gleichzeitigen Abfluss aus demselben an. Ausser den pulsatorischen Schwankungen zeigen die Plethysmogramme langsam ablaufende Hebungen oder Senkungen, welehe mit Aenderungen des Gefässtonus im Gliede einhergehen.

Durch das bestïndige Umtreiben des Blutes im Körper leistet das Herz eine erhebliche Menge von Arbeit. Um sich ron der Grösse derselben eine Vorstellnng zu machen, geht man von der - beim Froschherzen übrigens realisirbaren - Fiction aus, das Herz pumpe das Blut aus einem niedrigeren Reservoir in ein höheres. Die Niveaudifferenz zwischen beiden Reservoiren mïsste gleich der Differenz zwischen dem Drucke in den grossen Venen und dem Drucke in den grossen Arterien anzunehmen sein, gemessen durch die Höhe einer Flüssigkeit rom specifischen Gewichte des Blutes. Diese Höhe beträgt beim linken Herzen des Menschen etwa 21/2 Meter. Das menschliche linke Herz würde also bei einem Schlagrolum von $70 \mathrm{Ccm}$, einem arteriellen Drucke ron $130 \mathrm{Mm}$ Hg und einer Schlagzahl von 72 in der Minute, während dieser Zeit etwa 8,5 Kílogramm-Meter Arbeit leisten, das ganze Herz also etwa 14 Kilogramm-Meter in der Minute. Lis braucht kaum noch einmal darauf hingewiesen zu werden, dass bei der Art wie das Herz thatsächlich arbeitet, die Hebung schwerer Massen auf eine gewisse Höhe nur eine verhältnissmïssig kleine Rolle spielt. Die im Herzmuskel zum Umsatz kommende chemische potentielle Energie durchliuft die Formen ron mechanischer potentieller Energie der Herzwand, ron lehendiger Kraft beschleunigter schwerer 
Masse, und ron mechanischer potentieller Energie der Gefässwände, um schliesslich nur als Wärmebewegung übrig zu bleiben. Betrachtet man einen Längsstreifen der Kammermuskelwand für sich, so kann man sagen, dass er ähnlich arbeitet wie ein überlasteter Muskel. Belastet ist er durch die Kräfte, welche die Kammerwand in der Diastole zu dehnen streben (Aspiration des Thorax, Füllungsdruck bei Systole des Vorhofes); mit der Ueberlastung in Analogie zu setzen ist der Druck in der Aorta, welcher die Semilunarklappen geschlossen hält. Während der Anspannungszeit sind die Bedingungen für den Kammermuskelstreifen wesentlich diejenigen der Isometrie, er kann seine Länge jetzt nur so weit ändern als die Form des Ventrikels bei gleichem Volum verändert werden kann. IVährend der Anspannungszeit führt der Erregungsprocess im Kammermuskel wesentlich nur zum Anwachsen der Spannung der Kammerwand und des Druckes im Kammerinhalt. Hat letzterer die Höhe des Druckes in der Aorta überschritten, so kann der Ventrikel durch Austreibung des Inhaltes sein Volum verkleinern und seine Muskelfasern können sich jetzt erheblich verkürzen. Es kommt nun zur Beschleunigung von Massen und, so lange der Zufluss zur Aorta den Abfluss aus derselben iiberwiegt, zur Aufspeicherung von Energie in Form vermehrter Aortenspannung. Diese Spannung dient dann wieder zur Forthewegung von Blut und so fort. Bei der Spannung und Entspannung der Arterienwände, sowie bei der Reibung des strömenden Blutes geht fortwährend Energie in die Form von Wärmebewegung iiber, sodass schliesslich alle beim Erregungsprocesse im Herzmuskel umgesetzte Energie als Wärme erscheint.

Die Erkenntniss, dass der Zustand des Circulationsapparates unter nervösem Einflusse steht, drängt sich ohne Weiteres auf durch die Erfahrung der Aenderung des Herzschlages und der Gesichtsfarbe bei psychischen Erregungen; da das Erröthen und Erblassen im Affecte auf das Gesicht beschränkt ist, sich höchstens auf Hals und den oberen Brusttheil ausdehnt, müssen hier Nerveneinflüsse direct auf die betreffenden Gefässpartion einwirken, da die mit Aenderung der Herzthätigkeit einhergehenden Füllungsänderungen der Gefässe nicht auf einzelne Kö̈rperregionen beschränkt sein können.

Wenn man den Halssympathicus eines Kaninchens durchschneilet und den mit dem Kopfe zusammenhängenden Theil desselben tetanisirt, so sieht man die Conjunctivalgefässe des umgeschlagenen Augenlides sich bis zum Verschwinden verengern und die im normalen Zustande mässig geröthete Conjunctiva vollkommen erblassen; es muss also Nerven- 
fasern geben, welehe die Gefüssmusculatur zur Contraction bringen, und der Sympathicus muss solche Nervenfasern für die Conjunctivalgefässe führen; ebenso verlaufen im Hypoglossus Nervenfasern, auf deren Reizung die betreffende Zungenhälfte erblissst. Reizung des Nervus lingualis dagegen macht die zugehörige Zungenhälfte in den vorderen Partien, Reizung des Glossopharyngeus in den hinteren Partien erröthen, hier miissen also Nervenfasern im Spiele sein, welche gefässerweiternd -wirken; die gefäisserweiternden Nerven (Vasodilatatoren) und die gefässverengenden Nerven (Vasoconstrictoren) verlaufen im Allgemeinen nicht in rerschiedenen Nervenstämmen, der Nervus ischiadicus des Hundes zum Beispiel führt beiderlei Nervenarten für die Pfote; an frisch durchschnittenen Nerven überwiegt bei gewöhnlicher faradischer Tetanisation die Wirkung der Constrictoren; man sieht dann bei zarten, schwach pigmentirten Thieren die Haut zwischen den Zehen erblassen, oder die Quecksilbersïule eines empfindlichen, zwischen die Zehen gedrückten Thermometers sinken. Bei secundenweise intermittirendem faradischem Reiz oder bei Anwendung constanter Ströme können schon an frisch durchschnittenen Nerven die Vasodilatatoren zu iiberwiegender Thätigkeit angeregt werden; mit grösserer Wahrscheinlichkeit tritt dieser Effect einen Tag oder zwei Tage nach der Durchschneidung des Nerven ein; die Vasoconstrictoren scheinen ihre Erregbarkeit nach ihrer Abtrennung vom Centralnervensystem schneller einzubüssen als die Vasodilatatoren.

Eine Verengerung der Gefüisse muss zu Stande kommen, wenn sich ihre Ringmuskelfasern contrahiren; dass dieselben durch die Vasoconstrictoren hierzu angeregt werden, entspricht dem, was wir sonst iiber die Wirkungsweise von Nerv auf Muskelfaser wissen; auf Schwierigkeiten dagegen stösst die Deutung der Gefüsserweiterung unter Nerveneinfluss; man hat diese Schwierigkeiten zu verringern gemeint durch die Annahme, dass peripher in der Nähe der Gefässe Ganglienzellen vorlianden seien, von deren Erregungszustand der Tonus der Gefüssmusculatur durch Vermittelung von Nervenfasern abhinge, und dass die Vasoconstrictoren, sowie die Vasodilatatoren in diesen Ganglienzellen endigten; die ersteren würden den Erregungszustand derselben steigern, die letzteren herabsetzen. Es ist aber bisher nicht gelungen, diese Annahme auf eine genïgende histologische Grundlage zu stellen. Man hat auch gemeint, die Vasodilatatoren hingen direct mit den Längsmuskelfasern zusammen; zugleich mit der Verkürzung der Gefässe würde die Contraction dieser Fasern eine Erweiterung des Lumens herbeiführen können; denn stellt man sich die Längsmuskelschicht als aus einer Lage von Fasern mit kreisförmigem Querschnitt bestehend vor, so müssen diese Kreise bei der Zunahme ihres Durchmessers auscinander rücken, wenn sie sich vorher berïhrten und wenn sie sich gegenseitig nicht ab- 
platten können; ob letztere Bedingung aber erfuillt ist, kann man nicht iibersehen. Es wäre natürlich auch möglich, dass der Tonus aller Gefïssmuskelfasern durch die directe Einwirkung besonderer Nervenfaserarten für Constriction und Dilatation beeinflusst würde.

Hat man den Halssympathicus eines Kaninchens durchschnitten, so sieht man die Gefässe des gleichseitigen Ohres sich bald röthen und dies Ohr fühlt sich wärmer an als das andere; am stärksten sind die Unterschiede an beiden Ohren am Tage nach der Durchschneidung ausgebildet, später verschwinden sie wieder mehr und mehr. Das Centralnervensystem unterhält also durch Vermittelung des Sympathicus und seiner Vasoconstrictoren einen beständigen Tonus der Ohrgefässe. Fällt nach Durchschneidung des Sympathicus diese Erregungsursache für die Gefüssmuskeln fort, so geben die Gefässwände dem Blutdruck mehr nach als bisher. Der später wiederzunehmende Tonus kann darauf beruhen, dass Vasoconstrictoren den Ohrgefäissen auch auf anderer Bahn als der des Sympathicus zugeleitet werden, oder dass sich der Tonus der hypothetischen peripherischen Ganglienzellen oder auch der Muskelfasern selbst nach der Abtrennung vom Centralnervensystem allmählich wiederherstellt. Bewiesen ist für das Kaninchenohr die erste der genannten Möglichkeiten, es erhält Vasoconstrictoren auch auf der Bahn des Nervus auricularis magnus.

Reflectorisch tritt eine Erweiterung der Ohrgefässe der Kaninchen ein, wenn man den centralen Stumpf des durchschnittenen Nervus auricularis magnus tetanisirt. Im Allgemeinen tritt bei centripetaler Nervenreizung Verengerung der Körpergefüsse ein, es ist dies wenigstens aus dem Steigen des in der Carotis gemessenen Druckes zu schliessen; diese Drucksteigerung ist um so bedeutender, je grössere Nervenstämme gereizt werden, es ist also wahrscheinlich, dass jede schmerzhafte Reizung reflcctorisch eine Erweiterung der Hautgefüsse an der schmerzhaft gereizten Stelle und gleichzeitig eine Verengerung der iibrigen Gefässe bedingt, es würde dies die Erscheinungen bei der Entzündung verständlich machen. Dass Entzündungsursachen bei erweiterten Gefïssen schneller beseitigt werden, geht aus der 'Thatsache hervor, dass von den beiden Ohren eines Kaninchens, welche man durch Aetzung der Haut in gleicher Weise geschädigt hat, dasjenige schneller heilt, dessen Sympathicus ausserdem durchschnitten worden war.

Der psychische, automatische und reflectorische Einfluss auf die Gefüssmusculatur kommt zu Stande unter hervorragender Betheiligung ciucr Partie unter dem Borlen des vicrten Ventrikels zwischen Striae acnsticae unl Calamus; man nennt diese Partic das Gefïssnervencentrum der Medulla oblongata; in Folge eines distal hiervon durch dic Medulla gefiilırten Schuittes sinkt der Blutdruck bei allgemeiner Erweiterung der 
lï̈rpergefïsse sehr belentend ab; reizt man dagegen die distale s'chnittHäiche, nachlem man das 'Thier zur Vermeidung allgemeiner Krämpfe curarisint liat (bei Unterhaltung künstlicher Respiration), so erhält man eine beträichtliche Steigerung des Blutdruckes ïber die Norm. Dieselben Effecte crhält man mit abnehmender Intensität, je weiter distal man den Schnitt dureh die Medulla spinalis geführt lat. Die vom Gefïssnervencentrum in der Medulla absteigenden Vasoconstrictoren miissen also nach und nach durch Rïckenmarkswurzeln austreten. Durch die Wurzeln des Cervicalmarkes soll ein solcher Austritt nicht erfolgen. Die Gefïssnerven begeben sich grossentheils aus dem Rï̈ckenmark zunächst in den Grenzstrang des Sympathicus, auf dem Wege der weissen Rami communicintes. Reizung des Bauchtheiles des sympathischen Grenzstranges bewirkt meistens Erblassen und Abkiihlung der Hinterpfoten; je weiter linauf dic Reizung erfolgt, um so mehr kämpfen scheinbar erweiternde und rerengernde Einfliisse miteinander; bei Reizung des Brusttheils tritt lı̈̈ıfig Erweiterung hervor. Durchschneidet man den Nervus splinnchnicus, so erweitern sich alle Darmgefüsse und da die Capacität des Dilrmgefüsssystemes sehr gross ist, so sinkt der Blutdruck nach Splanchnicus-Durchschmeidung sehr stark, so stark, als wenn man das Halsmark durchschnitten hätte; tetanisirt man den peripherischen Stumpf des durchschnittenen Splanchnicus, so erhält man umgekehrt Contraction der Dir'mgefïsse und starke Blutdrucksteigerung.

Nicht alle Gefässnerven nehmen ihren Verlauf durch den Grenzstrang des Sympathicus; namentlich im Becken und am Kopfe sind Ausnalımen bekamnt; ein gut studirtes Beispiel im Becken betrifft die Nervi erigentes des Penis beim IHunde; jeder Nervus erigens hat mehrere Urspriinge atus benachbarten Sacralwurzeln; der stärkste der Ursprïnge erhält licine Anastomose rom Sympathicus und bei seiner isolirten Reizung tritt Erection des Penis ein; dic Fasern der Nervi erigentes mischen sich den aus dem Plexus hypogastricus stammenden Fasern der Nervi pudendi bei und gelangen mit diesen zu den Corpora carernosi penis. Die Erection beruht auf einer Erweiterung der für gewöhnlich stark contralirten Arterien der Corpora carernosi, also auf einer Wirkung gefïsserweiternder Nerven, welche wenigstens zum Theil direct aus dem Raickenmark stammen, ohne den Grenzstrang des Sympathicus passirt zu haben. Die Nervi erigentes sind bis in die vorderen Sacralwurzeln verfolgt worden; nur centrifugale Reizung dieser und nicht der hinteren Wurzeln ergab Erection. Diese Verfolgung gefüsserweiternder Nerven in die rorderen Nervenwurzeln des Rïckenmarkes ist darmm von besonderer Wichtigkeit, weil der Ursprung ron Vasodilatatoren aus hinteren Wurzeln behauptet worden ist, und weil bei Richtigkeit dieser Behauptung das Bell'sche Gesetz eine wesentliche Einschränkung erfahren 
würde. Vasoconstriction ist bisher stets nur bei centrifugaler Reizung vorderer Spinalwurzeln, nie bei der centrifugalen Reizung der hinteren Spinalwurzeln beobachtet worden. Vasoconstrictoren des Kopfes, welche direct (ohne Vermittelung des Sympathicus) aus dem obersten Halsmark stammen und an denen vom Centralnervensystem bis zur Endausbreitung an den Gefässen keine Ganglienzellen aufgefunden wurden, finden sich im Nervus auricularis magnus des Kaninchens.

Ausser dem Gefässnervencentrum in der Medulla oblongata sind noch durch das ganze Rückenmark Centralstellen vertheilt, deren Erregungszustand auf den Tonus der Gefässe von Einfluss ist. Junge Hunde können die Durchtrennung des Rïckenmarkes am oberen Ende der Lumbalanschwellung lange Zeit überleben, und dann zeigen die vom Lumbalmarke abhängigen Gefässgebiete später wieder normale Verhältnisse des Tonus und der Reflexe.

Der Tonus der Gefässnervencentren wird wahrscheinlich durch beständig von der Peripherie zufliessende Nervenerregung unterhalten, sodass der Gefässtonus wesentlich reflectorischer Natur ist; die Gefässnervencentren hängen aber in ihrem Erregungszustande ausserdem von der Beschaffenheit des sie durchströmenden Blutes ab, denn vor der Erstickung tritt - auch beim curarisirtem Thiere - eine starke Blutdruckerhöhung ein; der Tonus der Gefässcentren wird also wahrscheinlich auf automatischem Wege beeinflusst.

Die Thätigkeit des Herzens st,eht unter Nerveneinfluss, doch schlägt dasselbe nach Unterbrechung aller nervösen Verbindungen mit dem Centralorgan weiter; das Froschherz thut dies unter günstigen Bedingungen sogar noch lange Zeit und es kann dabei erhebliche Mengen Arbeit leisten. Die Bedingungen und Aeusserungen der Thätigkeit des isolirten Herzens sind darum hauptsächlich an dem des Frosches studirt worden.

In dem Froschherzen finden sich an mehreren Stellen Ganglienzellenanhäufungen; die Aeste der Nervi vagi gelangen mit den Jugularvenen zum Herzen und bilden bei der Eimmündung derselben einen Plexus mit eingestreuten mikroskopisch sichtbaren Ganglienzellhaufen, den Vorhofsganglien; aus dem Plexus gehen zwei Nerven hervor, welche in der Vorhofscheidewand verlaufen und mit Ganglienzellen durchsetzt sind. Diese liegen theils vereinzelt, theils bilden sie kleinere oder grössere Gruppen. An der Atrioventriculargrenze bildet jeder der beiden Scheidewandnerven eine, durch Einlagerung zahlreicher Ganglienzellen entstehende Anschwellung, das Atrioventricular- oder Kammerganglion. Von dem Kammerganglion dringen Fasern in die Substanz des Ventrikels ein; myclinfreie, an Muskelzellen knopfförmig endigende Nervenfasern sind neverdings als regelmässige Bestandtheile der Ventrikelwand bei Frosch 
und Matus beschrieben worden, doch scheinen nicht alle Muskelzellen Nervenendigungen zu erhalten.

Als diejenigen Theile, ron denen der Antrieb zur Bewegung des isolirten Herzens und die Regulirung dieser Bewegung ausgehe, hat man auf Grund eines alten berühmten Versuches, des Stan nius'schen Her\%versuches, die Ganglienzellen des Herzens geglaubt ansehen zu müssen. An dem Froschherzen beginnt die Systole mit der Contraction der cardialen Theile der grossen Venenstämme. Von diesen "Venensinus" schreitet die Systole auf die Vorhöfe fort, von ihnen auf den Ventrikel, um zuletzt den (beim lrosch) musculösen Anfangstheil der Aorta, den Bulbus aortae zu ergreifen. Legt man nun eine Ligatur um die Grenze zwischen Venensinus und Vorhöfen, so schlagen die Venensinus weiter, wihrend das iibrige Herz stillsteht, und legt man dann eine zweite Ligatur um die Atrioventriculargrenze, so beginnt der Ventrikel wieder zu schlagen. Man sehloss aus diesem Versuche, dass das Froschherz zwei bewegungsantreibende (excitomotorische) Ganglien in den Sinus und im Ventrikel und ein hemmendes in den Vorhöfen besässe. Die beiden excitomotorischen zusammen seien stärker wie das hemmende, aber dieses sei stärker als das excitomotorische des Ventrikels allein. $\mathrm{Zu}$ dieser Deutung ist man jedoch nicht gezwungen, denn der Herzstillstand nach der ersten Ligatur kann auf Vagusreizung beruhen und das, übrigens nur vorïbergehende, Schlagen des Ventrikels nach der zweiten Ligatur beruht auf Reizung der atriorentricularen Ganglien.

Es ist leicht möglich, dass man die Bedeutung der Herzganglien fuir die Rhythmik des Herzschlages iiberschätzt hat. An isolirten Skeletmuskeln bekommt man eine scheinbar spontane rhythmische Bewegung wur unter ganz besonderen, noch wenig studirten Bedingungen zu sehen (Musculus sartorius rom Frosch in gewissen verdïnnten Salzlösungen). Die Aussendung rhythmischer Bewegungsimpulse ist dagegen als ein, vielen Ganglienzellen zukommendes Attribut angenommen, und so glaubte man vielfach die Antriebe für die rhythmischen Bewegungen der Herzmuskelfasern auf Ganglienzellen zurïckführen zu mïssen. Dass aber contractile Elemente rhythmischer Bewegungen fähig sind, welche unmittelbar in ihnen selbst entstehen, beweist das schlagende Herz des Embryo zu einer Zeit, wo noch keine Nerrenzellen vorhanden sind.

Auch der ron nerrösen Zellen scheinbar freie Theil des Ventrikels des Froschherzens (die sogenannte Herzspitze) kann unter gewissen Bedingungen noch stundenlang regelmässig fortschlagen. Ferner ist der nerrenarme Theil der Herzmusculatur des Frosches im Stande, die an irgend einer Stelle durch kïnstlichen Reiz erzeugte Erregung nach allen Richtungen hin fortzuleiten. Die Herzmuskelfasern scheinen also Eigenschaften embryonaler Zellen bewahrt zu haben, welche den 
höher differenzirten Skeletmuskelfasern abhanden gekommen sind; immerhin werden die intracardialen Nerven bei der Fortleitung der Erregung von einem Herztheil auf den anderen namentlich von den Vorhöfen über den die Herzmuskelsubstanz völlig unterbrechenden Arcus fibrocartilagineus zu den Ventrikeln eine wesentliche Rolle spielen. Da das Herz nur wirksam arbeiten kann, wenn der Beginn der Ventrikelsystole durch ein passendes zeitliches Intervall von dem Beginne der Vorhofsystole getrennt ist, so ist es wahrscheinlich, dass dieses Intervall entsteht und regulirt wird durch den Aufenthalt, welchen die Erregungswelle in Ganglienzellen der intracardialen Nerven findet.

Wenn auch das, aller nervöser Verbindungen mit dem Centralnervensystem beraubte Herz weiter schlagen kann, so steht dasselbe doch normaler Weise unter dem beständigen Einflusse centrifugaler Nerrenerregung. Man kennt zwei Kategorien extracardialer Herznervenfasern; die einen bewirken bei ihrer künstlichen Reizung Verlangsamung des Herzschlages durch Verlängerung der Herzpause, man nennt diese die Herzhemmungsfasern; die anderen bewirken Beschleunigung des Herzschlages, man nennt sie die Acceleratoren.

Die Herzhemmungsfasern benutzen grösstentheils oder ausschliesslich die Bahn der Nervi vagi; durchschneidet man bei einem Thiere einen Halsvagus und brückt man seinen peripherischen Stumpf ïber ein Paar Elektroden, so erhält man mit zunehmender Stärke der tetanisirenden Stromstösse an der Blutwelleneurve zunehmende Verlängerung des Abstandes zwischen benachbarten Curvengipfeln. Da mit dem zeitlichen Abstande zwischen den einzelnen Systolen die Menge des Blutes wächst, welche aus dem arteriellen Systeme bis zum nächsten Herzschlage in die Capillaren abfliesst, sieht man gleichzeitig den mittleren Blutdruck absinken; bei genïgend starken Reizen kann es zu einem, Secunden lang dauernden, Aussetzen des Pulses kommen. Beobachtet man diesen Herzstillstand bei eröffnetem Thorax, so sieht man, dass das Herz während desselhen röllig erschlafft ist. Diese Vaguswirkung auf das Herz hat, als man sie zuerst fand, grosses Aufsehen erregt; man hatte erwartet, bei Tetanisirung eines zu dem Herzmuskel verlaufenden Nerven tetanische Contractionen zu erhalten, wie sie bei Reizung motorischer Nerven in den zugehörigen Skeletmuskeln eintritt, und man sah statt dessen dauernde Erschlaffung.

Es war der erste Fall, in dem man als Resultat des Eingreifens ron Nerventhïtigkeit Hemmung von Muskelthätigkeit beobachtete. Hemmungen ähnlicher Art hat man später als durch das Centralnervensystem rermittelt kennen gelernt, und man ist darum geneigt, sich die Herzhonnung bei Vaguserregung durch die intracardialen Herzganglien vermittelt vorzustellen; einiger Zweifel ist aber hier noch geboten, da 
es bisher noch nieht gelungen ist, Verbindungeu von Vagusfasern mit Nervenzellen des Ilerzens nachzuweisen, die Existenz solcher Verbindungen ron guten Anatomen sogar ausdriiekliel geleugnet wird. Fs wäre immerhin möglich, dass die Herzmuskelfasern auch in dieser Bezichung von den Skeletmuskelfisern verschieden wären, dass sie nicht nur erregende sondern auch hemmende Einfliisse von Nerven aufuehmen köunten. In Skeletmuskeln ist hiervon bis jetzt noch keine Spur wahrgenommen worden, doch wird Aehuliches für den aus glatten Muskelfilseru bestehenden Schliessmuskel von Muscheln behauptet.

Das Centrum für die Herzhemmung liegt in der Medulla oblongata, nalle dem vasomotorischen Centrum; wie dieses sendet es beim Menschen wahrscheinlich beständig centrifugale Erregungen aus, welche die Iler\%thätigkeit ziigelı; beim Kaninchen allerdings ist die Durchschneidung beider Halsvagi selten ron einer Aenderung der Pulsfrequenz gefolgt, woll aber tritt heim IIunde in Folge dieser Operation Pulsbeschleunigung ein, sorlass also schon hier ein beständiger Touns des Herzhemmungscentrums angenommen werden muss; ebenso wird es wolıl auch beim Menschen sein. Unterhalten wird dieser Tonus zum Theil automatisch, da in der Dyspnoë bei intacten Vagis die Pulsfrequenz sinkt, zum Theile auf reflectorischem Wege. Centripetale Theile des Reflexbogens sind im Vagus selbst und in Aesten desselben enthalten. Reizt mitn den centralen Stumpf eines durchschnittenen Halsvagus, so erhäit man, so lange der andere Vagus intact ist, Pulsverlangsamung. Centripetale Vagusfisern, welche an dieser Wirkung betheiligt sind, kommen wahrscheinlich von den Lungen, denn beim Hunde ist regelmässig eine inspiratorische Pulsbeschleunigung zu beobachten, welche nach Durchschneidung der Vagi versehwindet und auch beim Menschen findet, wenigstens bei verlangsamter Athmung, eine mit den Athemphasen wechselnde Aenderung der Pulsfrequenz statt.

Bei dem Kaninchen verlaufen einige wenige Nerrenfasern (\& lis 16) als ein besonderes kleines Nervenstïmmchen rom Herzen, nehen dem Stamme des Nervus ragus, zum Nervus laryngeus superior, mit welchem zusammen sie in den Vagusstamm eintreten. Dieses Nerrenstämmchen hat man den Nervus depressor genannt; durchschneidet min ihn am Halse und reizt seinen centralen Stumpf, so erhält mau, so lange beide Vagi intact sind, Pulsverlangsamung und Blutdrueksenkung. Dass letztere nicht allein ron der Verlangsamung des Herzschlages herrührt, wie bei centrifugaler Vagusreizung, erkennt man daran, dass sie auf centripetale Depressorreizung noch in erheblichem, wenn auch geringerem Grade eintritt, nachdem beide Vagi am Halse durchschnitten sincl.

Der Nerrus depressor des Kaninchens leitet also Erregungen, über deren Entstehungsart im IIerzen noch nichts bekannt ist, ron hier zum 
Centralnervensystem, wo sie in doppelter Weise reflectirt werden, erstens zım Herzen zuriick und zweitens wahrscheinlich durch Vermittelung der rasomotorischen Centren zu den Gefässen der Peripherie; beide Wirkungen, Verlangsamung des Pulses und Herabsetzung des Tonus im Gefässsysteme vereinigen sich dazu, den vom Herzen zu überwindenden arteriellen Druck zu ermässigen; es müsste also als zweckmässig erscheinen, wenn wachsender intracardialer Druck den Reflex auslöste; an der menschlichen Leiche kann man nicht wie beim Kaninchen einen besonderen Nervus depressor präpariren, doch besitzt der Mensch gewiss Nervenfasern der gleichen Function.

Ein wichtiger, centripetaler Herzhemmungsnerv ist der Nervus splanchnicus; durch Reizung seines Ausbreitungsgebietes in den Därmen kann reflectorisch Herzstillstand in Diastole entstehen.

Acceleratorische Nervenfasern werden dem Herzen hauptsächlich auf Bahnen des Sympathicus zugeführt, es betheiligen sich hieran einige Aestchen aus dem Halssympathicus, vor allem aber Nervenzweige, welche aus dem Ganglion stellatum entspringen und diesem durch den Grenzstrang des Sympathicus zugefuihrt werden; diese Nervenfasern werden von den fünf obersten Rami communicantes geliefert, in denen sie von unten nach oben aufsteigend mit zunehmender Zahl vertreten sind. Hat man beim Thicre Acceleratoren präparirt, und tetanisirt man dieselben, so erhält man Pulsbeschleunigung durch Verkürzung der Herzpause, ja man soll auch eine Verkïrzung der Systolenzeit erreichen können. Eine Blutdrucksteigerung braucht dabei nicht einzutreten, da der läufigeren Entleeruug des Herzens eine geringere Füllung desselben in verkiirzter Diastole gegenïbertreten kann.

Acceleratorische Nervenfasern kommen neben den herzhemmenden auch im Halsvagus vor; hat man den peripherischen Stumpf eines durchschnittenen Vagus durch wiederholtes Tetanisiren ermiidet, so bekommt man oft bei wiederholtem Tetanisiren Pulsbeschleunigung statt Pulsverlangsamung zu sehen.

Die herzhemmende Wirkung der Vagusreizung bleibt aus, wenn man dem Thiere vorher $\Lambda$ tropin gegeben hat; Muscarin erzeugt Herzstillstand in Diastole, welcher durch $\Lambda$ tropin beseitigt oder hintangehalten werden kann. Digitalis verlangsamt den Herzschlag wahrscheinlich durch Wirkung auf das Herzhemmungscentrum in der Medulla oblongata. Reicht man Digitalis bei stark beschleunigtem Herzschlage, so wird zugleich mit Verringerung der Pulsfrequenz der gesunkene Blutdruck wieder auf eine ausreichende Höhe gebracht. 


\section{Lymphstrom.}

Der Lymphstrom entspringt aus den Blutcapillaren. Da diese nirgends histologisch nachweisbare Lücken ihrer Wandungen anfweisen, welche den 1)urchtritt von I'lasma zwar gestatten, den der geformten Elemente aber verhindern könnten, so muss die Lymphe durch unsichtbare Poren der Capillarwände anstreten. Es wiirde dies auch sicher durch Filtration geschehen, wenn sich die Gefässwände wie todte thierische Membranen verhielten; die Triebkraft für eine solche Filtration ist in dem Unterschiede des Fliissigkeitsdruckes gegeben, welcher durch das Blut auf die innere Flïche und durch die Lymphe auf die Aussenfläche der Haargefïsse ausgeiibt wird. In der That wird auch die Lymphbildung vermehrt, wenn durch Vergrösserung der Stromwiderstände in den Venen oder durch Verkleinerung der Widerstände in den Arterien der Capillardruck erhöht wird. Die Capillarwände bestehen nun aber aus lebenden Zellen, welche eine einfiche Filtration entweder verhindern oder, wenn sie dieselbe zwischen ihren Rändern hindurch gestatten, durch eigene Thätigkeit modificiren können; diss zum mindesten letzteres der Fall ist, wenn nicht etwa gar die Lymphe als ein Secret des Capillarendothels aufzufassen ist, geht daraus hervor, dass es Substanzen giebt, deren Einführung in dis Blut die Lymplbildung unabhängig von einer Steigerung des Capillardruckes in die Höhe treibt.

Nach Injection grösserer Mengen von Zucker, Harnstoff oder von Salzen (Kochsalz, Glaubersalz, Salpeter u. s. w.) schwillt der Lymphstrom im Ductus thoracicus auf ein Vielfaches an. Die schneller fliessende Lymphe ist reicher an Wasser als die Lymphe vor der Injection. Da gleichzeitig auch der Wassergehalt des Blutes steigt, so kam der Wasseriberschuss der Lymphe nicht aus dem Blut herstammen; die Quelle kann nur das Tränkungswasser der Gewebsbestandtheile (Zellen, Fasern etc.) sein, welches in die Lymphe, beziehungsweise das Blut iibertritt. Ferner aher zeigt sich, dass die in das Blut injicirte Substanz (Zucker, Kochsalz) in der Lymphe in weit höherem procentischem Verhältnisse erscheint, als sie im Blute kurze Zeit nach der Injection vorgefunden wird.

Durch Filtration oder Osmose ist diese Concentrationsänderung der Flüssigkeit bei ihren Austritte aus den Blutgefässen nicht zu erklären; es miissen noch andere Factoren hierbei im Spiele sein, welche ihren Sitz entweder in den Gefässzellen oder in protoplasmatischen Bestandtheilen der von den Gefässen durchsetzten Gewebe haben; die Bereiche- 
rung ron Lymphe und Blut mit Wasser kann dadurch zu Stande kommen, dass die in die Lymphe gelangte Substanz aus den Gewebsbestandtheilen Wasser anzieht, welches theils durch die Lymphgefässe abgefuihrt wird, theils in das Blut zurïckgelangt.

Eine Reihe anderer Substanzen bringt ebenfalls gesteigerte Lymphbildung zu Stande, aber auf ganz verschiedene Weise. Wird Eiweiss oder Pepton in das Blut injicirt, so schwillt der Lymphstrom im Ductus thoracicus zwar ebenfalls an, die Lymphe wird aber procentisch nicht ärmer, sondern reicher an festen Bestandtheilen, und zwar an organischen, gleichzeitig wird das Blut reicher an festen Theilen, speciell an Hämoglobin; während der Blutdruck nicht gesteigert, ja beim Pepton sogar erheblich herabgesetzt ist, tritt durch die Capillarwände mit beschleunigter Geschwindigkeit eine Lymphe aus, welche reicher an Eiweiss ist, als die normale. Der schnelle Verlust an Flïssigkeit ändert das Verhältniss der Blutkörperchen zu dem Plasma im Blute, zu Gunsten der ersteren. Deshalb nimmt der Procentgehalt des Blutes an festen Bestandtheilen, im besonderen an Hämoglobin, zu. Die Ursache dieser Vermehrung der Lymphbildung kann nur durch eine Vermittelung der Capillarwände gedacht werden, welche entweder in einer secretorischen Thätigkeit der Endothelzellen bestehen kamn, oder in dem Entstehen von Spalträumen zwischen den durch die eingeführten Substanzen geschädigten Zellen.

Der Flüssigkeitsaustausch zwischen den Gefässsystemen der Lymphe und des Blutes spielt eine grosse Rolle bei schnell eintretenden Aenderungen der Blutmenge. Bei plötzlichen ausgiebigen Blutungen, wie sie zum Beispiel bei Verletzungen grösserer Arterien eintreten, sinkt der Blutdruck zunächst beträchtlich; es ist dies auch zur Abwendung der unmittelbaren Gefahr des Verblutens sehr vortheilhaft, da in dem jetzt collabirenden verletzten Gefässe sich leichter ein Verschlıss durch Gerinnen des Blutes (ein Thrombus) bilden kann. Bei dauernd herabgesetztem Blutdrucke wïrde die Ernähı'ung des Centralnervensystemes aber in bedrohlicher Weise geschädigt werden. In der That hebt sich nun auch, wenn der Bhutverlust nicht zu gross war, der Blutdruck olne weiteres Zuthum sehr ball wieder zur normalen Höhe; es geschieht dies theilweise wohl durch Verengerung peripherischer Gefüsse, zum Theil aber auch durch Aufuahme von Fliissigkeit aus dem Lymphgefässsysteme und den Gewelssbestandtheilen in die Blutbahn. War der Blutverlust so gross, dass dieses Mittel des Organismus nicht ausreicht, so kann man, wenigsteus vorübergehend, den für Untcrhaltung einer ausreichenden Circulation erforderlichen Blutdruck wiederherstellen durch Einspritzen $3 / 4 \%$ iger Kochsalzlösung in die Blutbahn (Kochsalztransfusion). 
Länger wie 24 Stunden hält diese rein mechanische Aufbesserung des Kreislaufes allerdings nicht vor, es muss dann zur Transfusion ron lebendem Blute geschritten werden. Das Blut muss ron einem Individuum derselhen Thierart stammen, oder darf wenigstens, wenn lies nicht der Fall ist, nicht die Eigenschaft besitzen, die rothen Blutkörperchen des Blutes, welches vermehrt werden soll, aufzulösen. Lammblut soll zum lieispiel den rothen Blutkörperchen des Menschen unschädlich sein. Selbstrerständlich darf man nur defibrinirtes Blut in dic Gefïssbahn einspritzen. Die Gefahr zu viel Blut einzuführen, ist nicht gross, wenigstens wenn man schon sicher ist, dass die Quelle der Blutung rerschlossen ist. Fine kïnstliche Plethora, so nennt man einen ühermässigen Füllungszustand des Blutgefüsssystems, schwindet sehr schnell unter Abgabe von Flüssigkeit an die Lymphe.

Flüssigkeit, welche bald in das Blut gelangen soll, braucht ibrigens nicht direct in das Blutgefässsystem cingespritzt zu worden; in das Untcrhauthindegewebe oder in das Peritoneum injicirt, wird sie schnell resorbirt; hicrbei spielt an letzterer Stelle das Diaphragma cine besondere Rolle. Hat man einem Kíaninchen eine erhobliche Menge Blutes in die Bauchlöhle injicirt, so findet man nach zwei Stunden nichts mehr davon vor; tödtet man es etwa cine Stunde nach der Injoction, so findet man die Lymphgefüsse des Zwerchfelles, welche auf seiner pleuralen Seite verlaufen, mit Blut gefuillt; dass die Resorption durch das Zwerchfoll hindurch stattgefunden hat, ist darum verstïndlich, weil man auf sciner peritonealen Fläche durch Silberfürbung regelmässige Lücken zwischen den Endothelzellen (Stomata) nachweisen kann.

Vermehrter Fliissigkeitsaustritt aus dem Blute führt unter abnormen Zuständen zu eincr Ansammlung von Lymphe in Geweben oder Körperhöhlen, welche man "Oedem" neunt; ob an rer Oedembildung nur vermehrter Flïssigkeitsaustritt oder auch eine Verlangsamung des Abflusses durch die Lymphgefüsse betheiligt sei, ist noch nicht entschieden. Bei Thieren lommen besoudere Hilfsapparate für die Forthewegung der Lymphe vor, in Gestalt von Belegungen bestimmter Stellen ron Lymphgefïssen mit quergestreifter Musculatur; diese pulsiren rhythmisch und werden Lymphherzen genannt. Der Frosch hat vier solcher Lymphher'zen, ron denen zwei an dor Eintrittsstelle der Beingefïsse in das Becken gelegen sind; diese sicht man bei Rana temporaria $7 . n$ beiden Sciten des Afters durch die Haut hindurch pulsiren. Nicht nur bei Amphibion kommen Lymphherzen vor, sondern auch beim Strausse sind solche an den Unterextremitäten aufgefunden worden. Aelmliche Hilfsherzen finden sich an den Venon des Fledermansfliigels und an den Schwanzarterien des Aals. Boi dem Monschen, den iibrigen Säugethieren und den Vögeln wirkt die gesammtc Körpermusculatur wie ein Hilfs- 
herz für das venöse Blut und die Lymphe. Jede ausgiebige Muskelbewegung, welche zu einer Aenderung der Flüssigkeitsvertheilung in ihrem Bereiche geeignet ist, muss wegen der Klappen in den Venen und Lymphgefässen Blut und Lymphe in der Richtung zum Herzen befördern.

\section{Achter Abschnitt.}

\section{Die Athmung.}

Bei der Athmung des Menschen tritt in regelmässigem Rhythmus Luft durch die Nase, die Glottis und die Trachea in den sich erweiternden Thorax ein, um dann auf demselben Wege und in gleicher Quantität aus dem sich wieder verkleinernden Thorax ausgetrieben zu werden. Die Bedeutung der Athmung für den Organismus muss hervorgehen aus dem Vergleiche zwischen der Beschaffenheit der eingeathmeten und der ausgeathmeten Luft. Die Unterschiede zwischen beiden Luftarten sind mannigfaltig, die grösste Tragweite kommt aber dem Umstande zu, dass die ausgeathmete Luft reicher an Kohlensäure und ärmer an Sauerstoff ist, als die eingeathmete. Es lässt dies auf chemische Processe im Organismus nach Art von Verbrennungen schliessen, deren Sitz man, da sie geeignet sind, Arbeitsleistungen zu bestreiten, in den Elementen der die Functionen des Organismus bestreitenden Organe erwarten muss. Die gesammten der Athmung zu Grunde liegenden Processe spielen sich also nicht in einem einzelnen Organe $a b$, und man unterscheidet deshalb den durch die Lungen vermittelten Gasaustausch zwischen dem thicrischen Organismus und der Aussenwelt als äussere Athmung von dem in den übrigen Organen stattfindenden Gasaustausche zwischen den functionirenden Gewebselementen und der Gewebsflüssigkeit, beziehungsweise dem Blute, als innere Athmung. Ferner stellt man denjenigen Stoffumsatz im lebenden Protoplasma selbst, durch welchen unter Sauerstoffbindung Energie für Arbeitsleistung und Wärmebildung frei wird, als intramoleculare Athmung in Gegensatz zu dem umgekehrten Processe, welchor sich unter der Wirkung der Sonnenstrahlen in den grünen Pflanzentheilen abspielt, und welcher von den Botanikern als Assimilation bezoichnet worden ist. 
Die Chemie der $\Lambda$ thmung wird verständlich, wenn man bedenkt, dass die lebenden Zellen und die Gewebselemente des thierischen Körpers zur Leistung ihrer Arbeit auf den Verbrauch derjenigen chemischen Spamnkraft angewiesen sind, welche bei der Assimilation in der Pflanzenwelt entsteht. Die einzige reichlich fliessende Kraftruelle, durch welche das organische Leben auf unserer Erde unterhalten werden kann, ist die Energie der Sonnenstrahlung; diese führt auf bisher unergrïndete Weise in den chlorophyllhaltigen Pflanzentheilen zu einer Abspaltung von Sauerstoff aus Kohlensäure; die Trennung der Sauerstoffatome von den Kohlenstoffatomen ist eine Arbeitsleistung, bei welcher kinetische Energie verloren geht und chemische Spannkraft erzeugt wird; eine der aufgewendeten Arbeit gleiche Menge von Arbeit kann geleistet werden bei der Wiedervereinigung des Sauerstoffes und des Kohlenstoffes, wobei die chemische Spannkraft verbraucht wird. Der Reductionsprocess in der Pflanze liefert einerseits freie Sauerstoffmoleküle für die Atmospluäre, andererseits chemische Verbindungen, welche reich an Kohlenstoff und Wasserstoff, arm an Sauerstoff sind. Kohlehydrate, Fette und Eiweisskörper, welche mehr oder weniger mittelbar dem Reductionsprocesse der Pflanzen entstammen, werden rom thierischen Organismus als Nahrungsmittel aufgenommen, von dem lebenden Protoplasma angeeignet und zur Bestreitung seiner Leistungen verbrannt.

Den für diesen Verbrennungsprocess erforderlichen Sauerstoff nehmen die lebenden Gewebselemente direct aus der sie umspiilenden Gewebsfliissigkeit, indirect aus dem Oxyhämoglobin der die Capillaren durcheilenden rothen Blutkörperchen. Der Sauerstoff gelangt hierbei auf dem Wege der Diffusion von den Orten höherer Spannung im Blute zu denen geringerer Spannung in den unmittelbaren Umgebungen des den Sauerstoff bindenden Protoplasmas: man wird nicht fehlgehen in der Annahme, dass sich eine thätige Zelle des Warmblïters fortwährend befleissigt, ein Sauerstoffvacuum in ihrer Ungebung herzustellen.

Die chemischen Producte der Verbrennung sind Kohlensïure, Wasser und stickstoffhaltige Spaltlinge des Eiweisses. In der Ausathmungsluft erscheinen von ihnen nur die beiden ersteren. Aus der Nahrung stammender Stickstoff tritt, wenn überhaupt, nur in unbetrïchtlicher Menge gasförmig auf.

Die Kohlensäurespannung in der unmittelbaren Umgebung des functionirenden Protoplasmas erhält Zuwachs durch die intramoleculare Athmung des letzteren und würde schädliche, das heisst die Dissociation der im lebenden Moleküle gebildeten Kohlensäure hindernde Werthe erreichen, wenn nicht fuir Abfulır von Kiohlensäure aus der Umgebung des Moleküls nach Orten geringerer Kiohlensäurespannung, das ist normaler Weise nach dem Blute in den Capillaren, gesorgt wïre. Das Blut muss 
also, um die das Leben ausmachende intramoleculare Athmung durch den Diffusionsprocess der inneren Athmung unterhalten zu können, geeignet sein, in den Körpercapillaren Sauerstoff abzugeben und Kohlensäure aufzunehmen. Diese Eigenschaft wird ihm durch die äussere Athmung bei jerlesmaligem Durchströmen durch die Lungencapillaren wiederertheilt, doch ist dies nur möghich, wenn die Lungenfuft in dem Maasse wie sie ihren Sanerstoff an das Blut verliert und sich mit Kohlensäure aus demselben beladet, ihrerseits aufgefrischt wird; es geschieht dies, indem bei jeder Ausathmung ein Theil der Lungenluft sich entfernt und dieser Theil bei der darauf folgenden Einathmung durch neue, reine ersetzt wird.

Die Ausathmungsluft des Menschen enthält beim ruhigen Athmen in gewöhnlicher Luft circa 4⿳⿲丶丶㇒一八: Volum-Procent Kohlensäure mehr und circa 5 Volum-Procent Sauerstoff weniger, als die Einathmungsluft; nicht sämmtlicher von dem Körper aufgenommene Sauerstoff wird also zur Verbrennung von Kohlenstoff, ein Theil desselben wird vielmelir zur Verbrennung von Wasserstoff verbraucht. Das Verhältniss der Menge der ausgeschiedenen Kohlensäure zur Menge des verbrauchten Sanerstoffes wird der respiratorische Quotient genannt und $\mathrm{CO}^{2} / \mathrm{O}$ geschrieben. Derselbe ist beim Menschen normaler. Weise ein echter Bruch und beträgt etwa 9/1". Der respiratorische Quotient ist kleiner bei Frnähı'ung mit Fleisch und beim Hungern; er ist grösser bei Ernährung mit Kiohlehydraten und bei angestrengter Muskelthätigkeit. Das Ansteigen des respiratorischen Quotienten in letztgenannten Falle beruht, wenigstens zum Theile, auch darauf, dass an der die Muskelarbeit bestreitenden intramolecularen Verbrennung Sauerstoff betheiligt ist, welcher wälurend der Ruhe im Molekiil aufgespeichert worden war.

Die Ausathmungsluft ist wärmer als die Einathmungsluft, im Mittel beträgt die Temperatur der ersteren etwa $36^{\circ}$ C. Da dic Ausathmungsluft ausserdem stets mit Wasserdampf gesättigt ist, giebt der Organismus mit derselben beträchtliche Mengen Wassers nach aussen ab. Durch die Erwärmung der Einathmungsluft und durch die zur Sättigung der letzteren bei der höheren Temperatur erforderliche Verdunstung von Wasser in den Luftwegen wird dem Körper Wärme entzogen. Die Atlumung dient also ausser zur Aufnahme von Sauerstoff und Abgabe von Kohlensä̈ure auch zur Abgabe von Wasser und Wärme.

Um sich die Leistung der Athmung des Menschen unter gewöhnlichen mittleren Verhältnissen in absoluten Worthen vorzustellen, kamn man für je 24 Stunden die Grösse der Sauerstoffaufuahme zu 520 Liter (750) Gramm), der Kohlensïurealogabe zu 450 Liter (900 Gramm), der Wasscrabgabe zu 500 Gramm und die der Wärmealogabe zu 300 Kílogrammcalorien annehmen. 
Fs ist hier der Ort, eine Berechnung anszufiuhren, anf Grund deren man zи einer Schätzung des Schlagrolums des Herzens gelangen kann. Aus den bei Besprechung des Gasgehaltes des Blutes (S. 327) angegebenen Zahlen folgt, dass das Blut beim Uebergange aus dem renösen in den arteriellen Zustand, das heisst bei dem cinmaligen Durchströmen durch die Lungen 7,1 Volum-Procent Sauerstoff aufnimmt. Aus den iiber den täglichen Sauerstoffbedarf soeben mitgetheilten Zahlen folgt, dass das in ciner Minute aufgenommene Sauerstoffvolum. $360 \mathrm{Ccm}$ beträgt. Da 100 Cem Blut beim Durchgange durch die Lungen 7,1 Ccm Sanerstoff anfuehmen, so muss die Stromintensität in dem Lungenkreislanfe pro Ninute betragen

$$
\mathrm{x}=\frac{360 \times 100}{7,1}
$$

damit in der Minute $360 \mathrm{Ccm}$ Sanerstoff in der Lunge vom Blute anfgenommen werden können. Um im Lungenkreislanfe eine Stromintensität von etwa $5070 \mathrm{Ccm}$ in der Minute zu unterhalten, muss der rechte Ventrikel bei jedem Herzschlage etwa $70 \mathrm{Ccm}$ weiterbefördern, wenn 72 Herzschläge in der Minute erfolgen. Das Schlagvolum des linken Herzens muss gleich demjenigen des rechten sein (vgl. S. 344).

Sauerstoffverbranch und Kohlensäurebildung im Körper nehmen zu nach Nahrungsaufnahme, bei Körperanstrengung, bei Erhöhung der Körperwärme und bei Erhaltung der eigenen Temperatur gegen den Einfluss kalter Umgebung. Die Intensitätscurve, bezogen anf das Lebensalter, zeigt ein Maximum beim Kinde (herechnet anf die Einheit des Körpergewichtes); diejenige bezogen auf die Tageszeit hat das Hauptmaximum nach dem Mittagsmahl, das Hauptminimum zur Zeit des tiefsten Nachtschlafes, secundäre Maxima Morgens nach Verlassen des Bettes und Abends nach der Abendmahlzeit; secundäre Minima vor den Mahlzeiten. Stcigerung und Verringerung des Gehaltes der Einathmungsluft an Sanerstoff hat innerlualb weiter Grenzen nur geringen Einfluss auf den Sauerstoffverbrauch; die Grösse des letzteren wird weniger von der Menge des dargebotenen Sauerstoffes als ron dem Bediirfnisse der lebenden Zellen selbst bestimmt.

Sell)st wenn der Partiärdruck des Sauerstoffes in den Lungenalveolen sehr gering ist, nimmt das Hämoglobin der Blutkörperchen solchen in sich auf, um ihn an das Protoplasma der functionirenden Zellen, welche ihn mit noch grösscrer Encrgic an sich reissen, abzugeben. Lässt man ein Thier in einem beschränkten Luftraume athmen, und sorgt für Absorption der ausgeschiedenen Kohlensïure aus dieser Luft, so wird der ganze Sauerstoffrorrath des Raumes bis auf Spuren vom Thiere verhrancht. Vollkommener Sauerstoffmangel wirkt sehr schnell tödtlich, doch kann der Sanerstoffgelıalt der Luft 1 m $12 \%$ unter 
die Norm für längere Zeit verringert werden, ohne dass das Leben bedroht wird, während die Kohlensäureanhäufung in der Einathmungshft schon letal wirkt, wenn sie sich dauernd auf der Höhe oder nahe der Höhe des Kohlensäuregehaltes der Lungenluft hält, also beim Menschen auf 4 bis $5 \%$. Vorübergehend wird aber auch stärkere Kohlensäureanhäufung vertragen, wenn nicht gleichzeitig der Sauerstoff fehlt; die Erstickung erfolgt also meistens durch Sauerstoffmangel.

Hält man den Athem längere Zeit an und entnimmt in regelmässigen Abständen Proben der Lungenluft, so findet man, dass der Kohlensäuregehalt zunächst schnell, dann langsam ansteigt und den Werth von etwa $7 \%$ nicht überschreitet. Die Abnahme. des Sauerstoffgehaltes schreitet proportional der Zeit vor. Letzterer Umstand zeigt wiederum, was wir schon wissen, dass die Aufnahme des Sauerstoffes unabhängig vom Partiärdruck durch chemische Bindung an das Hämoglobin erfolgt. Das Verhalten der Kohlensäure dagegen weist darauf hin, dass sich das Blut nur in dem Maasse derselben entledigen kann, als ihr Partiärdruck hier sich über demjenigen in der Lungenluft hält. Diese Ansicht wird gestiitzt durch folgende Versuche am Hunde. Führt man bei diesem einen dünnen elastischen Katheter durch ein Trachealfenster in einen Bronchus ein, verschliesst sein oberes Ende und tamponirt den Bronchus um den Katheter durch Aufblasen eines denselben umschliessenden Kautschukbeutelchens, so stagnirt die Luft in dem zum Bronchus gehörenden Theile der Lunge, während das Thier mit der übrigen Lunge ausreichend athmet, um sein Blut normal zu lüften; der. stagnirende Theil der Lungenluft steht also mit venösem Blute von normaler Beschaffenheit in I)iffusionsverkehr, nicht wie die Lungenluft eines Mensehen, welcher den Athem anhält mit einem Blute, dessen Venosität zunimmt. Durch Aspiration in ein Quecksilbergefäss kann man eine Probe der Luft aus dem Katheter zur Analyse gewinnen, und fängt man gleichzeitig etwas Venenblut unter den geeigneten Vorsichtsmaassregeln auf, so findet man die Kohlensïurespannung im letzteren ein wenig höher als in ersterer. Eine besondere Fähigkeit, Kohlensäure geringerer Spannung aus dem Ijlute zu Kohlensäure höherer Spannung in der Lungenluft hinüber zu treiben, scheint der Lunge also nicht zuzukommen.

Die Ausathmungsluft enthält geringe Mengen von Ammoniak, von Wasserstoff und ron Kollenwasserstoffen, die von geringer Bedeutung sind; daneben alyer vielleicht noch Spuren eines oder mehrerer dem Organismus schädlicher Stoffe von geringer Dampfspannung, deren durch geringen äusseren Partiärdruck veranlasste Zuriickhaltung im Kööper die Ursache für die unangenehme Wirkung der Luft in menschenüberfüllten Räumen sein mag. Temperatur, Wassergehalt und Kohlensäureanhäufung scheinen nicht ausreichend, um diese Wirkung zu crklären. 
Frei ist dagegen die Ausathmungsluft gesunder Mensehen ron allen denjenigen kleinsten festen Partikelchen, die in jeder Einathmungshuft, ausser auf dem Neere und auf hohen Bergen, suspendirt sind; auf ihnen beruht die Sichtbarkeit eines in das Zimmer fallenden Sonnenstrahlenbiindels; dass sie in der Ausathmungsluft fehlen, erkennt man daran, dass man mit einem Glasrohre ein schwarzes rundes Loch in das Strahlenbündel blasen kann. Dic Sonnenstäubchen werden auf der feuchten Schleimhaut der Luftwege fixirt, und so lange letztere gesund ist, grossentheils durch die Flimmerbewegung nach aussen befördert. Ein Theil derselben dringt jedoch in die Gewebe ein und wird in den bronchialen Lymphdrüsen festgehalten; hierauf beruht die mit dem Alter zunehmende Schwarzfärbung der Lungen und der Bronchialdrüsen des Menschen durch Russtheilchen. Da die organisirten Krankheitskeime z.u jenen kleinsten Theilchen gehören, so ist es begreiflich, wie eine krankhaft afficirte Schleimhaut der Luftwege ein breites Invasionsgebiet fuir dieselben darstellt.

Die Bedingungen für Reinigung, Vorwärmung und Wasserdampfsättigung sind beim Hindurchstreichen der Luft durch die Nase erheblich besser, als beim Athmen durch den Mund. Der Mensch athmet normalerweise (ausser beim Sprechen und Singen) durch die Nase; manche Thiere können gar nicht dauernd durch das Maul athmen; hierauf beruht es, dass beim Pferde die Durchschneidung des Nervus facialis tödtlich wirkt, weil nur durch das Spiel von Muskeln, welche der Nervus facialis innervirt, die Niistern bei der Inspiration offengehalten werden. Kaninchen, welchen man beide Nasenlöcher tamponirt, sterben in 24 Stundelı.

Der Mensch ist also vielen Thieren ïberlegen durch die Fähigkeit, sich der Mundathmung ebenso wie der Nasenathmung zu bedienen, doch ist es seiner Gesundheit nicht zuträglich, wenn er davon in grösserem Umfange Gebrauch macht, als es im Dienste der Phonation erforderlich ist.

Die Mechanik der Athmung umfasst diejenigen Vorgänge, durch welche die Erneuerung der Luft in den Lungenalveolen bewirkt wird; die Lüftung der Lungen erfolgt unter abwechselnder Vergrösserung und Verkleinerung des Thoraxraumes durch Muskelthätigkeit. Wenn alle auf die Form und das Volum des Thorax wirkenden Muskeln erschlafft sind, befindet sich weder der Thorax in seiner Gleichgewichtslage, noch sind die Lungen in der ihrigen. Beide gehen erst in dieselbe über, wenn durch Eröffnung der Thoraxwand Gelegenheit zum Eindringen von Luft in den für gewöhnlich nur mit einer capillaren Flüssigkeitsschicht gefüllten Ramm zwischen der Innenwand des Thorax (Pleura costalis) und der Aussenwand der Lunge (Pleura pulmonalis) gegeben 
wird. Sobald Luft in den Pleuraraum eindringen kann, nimmt dieser iiberall greifbare Dimensionen an, dureh Ausweichen der Thoraxwand nach aussen, der Lungenoberfläche nach innen.

Nimmt man die Eröffnung des Thorax an der menschlichen Leiche ror, nachdem man vorher mit dem Hohlraume der Trachea ein Manometer luftdicht verbunden hat, so zeigt dieses nach dem Eindringen der Luft in den Pleuraraum einen Ueberdruck in der Trachea von ungefähr 6 Millimeter Quecksilber an. Dieser Druck, welchen man als den D o nders'schen Druck bezeichnet, ist ein Maass für die Kraft, mit welcher die elastischen Elemente der Lungen ror der Herstellung des Pneumothorax die Lungen von dem Thorax zu entfernen strebten. Dieses Streben ist so lange vergeblich, wie der atmosphärische Druck sich nicht in den Pleuraraum fortsetzen kann und so lange der Luftdruck in den Alreolen grösser ist als die elastische Spannung der Lungen.

Während der Erschlaffung aller Athemmuskeln herrscht bei offener Gilottis in den Alveolen der Druck der Atmosphäre. Der Druck in dem Plenraraume ist um den Werth des Donders'schen Druckes kleiner; denn der auf die Lungenwand von innen und auf die Thoraxwand von aussen wirkende atmosphärische Druck setzt sich in den Pleuraraum um eine Grösse vermindert fort, welche gleich der auf die Oberfläche senkrechten Componente der Spannung beider elastischen Wände ist. Diese Componente, welche bei der Lunge nach innen, bei dem Thorax nach aussen gerichtet ist und an beiden in der Ruhe gleich sein muss, haben wir an der Lunge mittelst des Manometers als Donders'schen Druck bestimmt. Am Thiere müssen wir einen dem Donders'schen Drucke nahezu gleichen Werth (absolut genommen) erhalten, wenn wir vor der zur Messung des Donders'schen Druckes nothwendigen Tödtung und hei uneröffnetem Thorax ein Minimummanometer mit dem Hohlraume des rechten Vorhofes in Verbindung bringen. Bezeichnen wir den atmosphärischen Diruck als den Nullpunkt des Druckes, so hat der an der Trachea bei Eröffnung des Thorax bestimmte Donder'sche Druck positives Vorzeichen, der im Herzen bei uneröffnetem Thorax bestimmte Minimaldruck negatives Vorzeichen. Dass beide Werthe, abgesehen rom Vorzeichen, nicht ganz gleich sind, kann daran liegen, dass es während der Diastole nicht $\% u$ einer vollen Druckausgleichung kommt, oder daran, Tlass das Pericard als elastische Membran zwischengeschaltet ist oder an anderen Umständen. Völlige Gleichheit müsste bestehen, wenn man an linde einer Systole das Herz in Diastole zur Ruhe bringen und gleichzeitig alle Gefässe bis auf dasjenige, welches den Vorhof mit dem Manometer verbindet, verschliessen könnte. Es kommt hier nur darauf an, sich an diesen idealen Falle die principielle Beziehung zwischen Donders'schem und pleuralem Drucke klar zu machen. Der negative 
pleurale Druck stammt aus der Entwickelungszeit, in welcher der Thorax stärker gewachsen ist wie die Lungen.

Der Druck im Pleuraraume wird zwar als negativ bezeichnet, weil er kleiner ist als der atmosphürische Druck; man muss sich aber gegenwärtig laalten, dass er in Bezng auf den absoluten Nullwerth des Druckes (im Vacuum) einen sehr erheblichen positiven Werth hat, einen Werth, (ler nur um den geringen absoluten Werth des Do nder's'schen Druckes kleiner ist als der atmosphärische Druck. Thoraxwand und Lungenobertlïche drücken beiderseits auf den Pleuraraum mit dem Ueberschusse des atmosphärischen Druckes ïber den Donder's'schen Druck, und mit der gleichen Kraft werden die beiden Pleuraflächen gegen einander gedriickt, wo der Pleuraraum nur einen capillaren Spalt darstellt. Wïrde der atmospliärische Druck unter den Werth des Donders'schen Druckes sinken, so müssten Lungen und Thoraxwand, ihren elastischen Krä̈ten folgend, auch bei uneröffnetem Thorax sich von eimander entfernen; es könnte sie höchstens noch das capjillare Haften der Oberflächen daran verhindern. Es ist also wesentlich der Luftdruck, welcher die Lungen in ausgedehntem Zustande erhält und welcher sie zwingt, bei Erweiterung des Thorax diesem angelagert zu bleiben und sich ebenfalls zu erweitern.

Wird der Thorax durch die an ihm angreifenden Muskeln erweitert, so muss die Lunge dieser Erweiterung folgen, so lange der alssolute Werth des Druckes in der Alveolenluft grösser ist, als der alssolute Werth des Druckes im Pleuraraume. Mit der Erweiterung der Lungen wïchst die elastische Kraft, mit welcher sie sich zu rerkleinern streben, un so mehr also auch die auf die Oberflïche senkrechte Componente derselben, welche wir als Donder's'schen Druck bezeichnet haben. Indem der Donders'sche Druck zumimmt, rermindert sich der ibsolute Werth des pleuralen Druckes, welcher nicht rerwechselt werden darf mit der Grösse, um welche dieser Werth kleiner ist als der atmosphärische Druck. Letztere Grösse, welche wegen des conventionellen Ausganges der Druckrechnung ron dem Atmosphärendruck als negativ betrachtet wird, neunt man gewöhnlich den pleuralen Druck; man thut aber gut, diesen Begrift' des relatiren (negativen) Pleuradruckes ron dem des absoluten (positiren) Pleuradruckes zu unterscheiden. Der absolute Pleuradruck hat einen positiven Werth, der um den des relativen Pleuradruckes kleiner ist als der atmosphärische Druck; bei der Erweiterung des Thorax nimmt also der relative Pleuradruck zu, während der absolute abnimmt. Dem absoluten Pleuradrucke gleich ist die Krraft, mit welcher die Pleuraflïchen gegen einander gedriickt werden. Bei stärkster Thoraxerweiterung kann der Donders'sche Druck den Werth ron 30 Millimetern Quecksilber erreichen. Hat bei der Thoraxerweiterung. 
die Glottis offen gestanden, so behält der Druck, mit welchem die Pleuraflächen aneinander gedriickt werden (Barometerdruck weniger 30 Millimeter Quecksilber) unter den gewöhnlichen Bedingungen noch einen ansehnlichen Werth. Denkt man sich die Glottis bei so starker Erweiterung des Thorax geschlossen, so bleibt der Druck in den Alveolen nicht mehr gleich dem atmosphärischen Druck, da dasselbe Luftquantum einen grösseren Raum auszufüllen hat, doch kaun auch hierbei der alveolare Druck nicht unter den absoluten pleuralen Druck sinken, sodass es auch hierbei nicht zu einer Trennung der Pleuraflächen von einander kommen kann. Wird bei verschlossener Glottis der Thorax verengert, so wird die Lungenluft zusammengedrückt, der Druck in den Alveolen steigt, und gleichzeitig, wegen Fortpflanzung des alveolaren Druckes durch die Lungenwand und wegen Nachlassens der Spannung der Lungenwand, steigt auch der absolute Druck im Pleuraraume; letzterer kann hierbei den Werth des Atmosphärendruckes iibersteigen, sodass der Zufluss von Blut zum Herzen aufhört. In der That kann man durch willkürliche Exspirationsanstrengung bei fest verschlossener Glottis den eigenen Puls zum Verschwinden bringen. Es ist dies ein nicht ungefährlicher Versuch, bei welchem wegen Unterbrechung der Circulation in dem Centralnervensystem, Bewusstlosigkeit eintreten kann. Ist die Glottis bei Erweiterung des Thorax offen, so kommt es nur vorübergehend zu einer Drucksenkung in den Alveolen. In dem Maasse wie die in den Lungen bei Beginn der Erweiterung vorhandene Luft ausgedehnt wird, stellt sich ein Gefälle des Druckes von der Nasenöffnung zı den Alveolen her, welches zum Einströmen nener Luft in die Lungen fiihrt und welches aufhört, sobald die Lunge wieder mit Luft von Atmosphären-Druck gefüllt ist. Das Umgekehrte tritt ein, wenn der Thorax bei offen stehender Glottis verengert wird.

Nennen wir, der gebräuchlichen Redeweise folgend, negativen Druck einen solchen, der kleiner ist als der Atmosphärendruck, positiven Druck einen solchen, der grösser ist, so muss man sagen, dass bei Muskelruhe und offener Glottis in den Alveolen der Druck Null ist und im Pleuraraume ein negativer Druck herrscht; dass bei Zunahme der Thoraxweite durch Muskelzug und bei offenen Luftwegen der Druck in den Alveolen vorübergehend, und zwar nur so lange diese Zunahme dauert, negativ ist; dass aber der negative Druck im Pleuraraume mit der inspiratorischen Erweiterung derart zusammenhängt, dass der höhere Werth dieses negativen Druckes nicht nur während des Ueberganges, sondern während der ganzen Dauer des erweiterten Zustandes besteht. Bei Verkleinerung des Thoraxraumes durch Nachlassen des inspiratorischen Muskelzuges oder bei der Thätigkeit exspiratorisch wirkender Muskeln ist der Druck in den Alveolen, offene Luftwege vorausgesetzt, 
voriibergehend positiv, der Werth des negativen Druckes im Pleurar'sume dauernd verringert. Den datuernden Druckänderungen im Pleuraraume, welche vou den Spannungsänderungen der Lungenwand lıerïhren, superponiren sich noch vorïbergehende Druckschwankungen, welche von den Druckschwankungen in den Alveolen abhängen und durch die diunne Lungenwand hindurch mitgetheilt sind. Die danernden Druckänderungen im Pleurarame sind proportional dem Umfange der Volumsänderungen der Lunge, die vorïbergehenden Druckschwankungen in den Alveolen und in dem Pleuraraume sind proportional der Geschwindigkeit, mit welcher sich die Volunsänderungen vollziehen und ausserden proportional der Grösse der Widerstände in den Luftwegen. Ist die Geschwindigkeit der Exspiration gross, bei Enge der Glottis, wie es das Husten mit sich bringt, so kann der Druck im Pleuraraume voriibergehend positiv werden. Dauernd positiv wird er bei dem oben angedeuteten Verfahren zur willkiirlichen Unterdrückung des eigenen Pulses durch anhaltende Exspirationsanstrengung bei verschlossener Glottis.

Die respiratorischen Druckänderungen im Plcuraraume sind ron wesentlichem Einflusse auf die Blutbewegung. Indem der Werth des negativen Pleuradruckes bei der Inspiration wächst, wird wegen des grossen Dickenunterschiedes zwischen den venösen und arteriellen Gefïsswänden der Blutzufluss zum Thorax durch die intratloracalen Venen mehr begiinstigt, als der Abfluss aus den intrathoracalen Arterien verzögert wird. Das Herz speist sich jetzt in der Diastole besser mit Blut und kann die grössere Menge bei der Systole ungehindert auswerfen. Allerdings wirkt der negative Pleuradruck auch der Zusammenziehung des Her'zumuskels entgegen, diese erfolgt aber normalerweise stets mit mehr als ausreichender Energie. Hiernach miisste man eine Blutdrucksteigerung in Folge der Inspiration, eine Blutdrucksenkung in Folge der Exspiration erwarten, welche Folgen mit einiger Verspätung in die Erscheimung treten wïrden. So einfach liegen die Verhältnisse nun aber nicht, es wirken vielmehr noch cinige andere Factoren mit.

Die in den Lungen verlaufenden Gefïsse verhalten sich wie Röhren, die ans der Dicke einer elastischen Membran ausgespart sind. In schematischen Versuchen ist gezeigt worden, dass die Capacität solcher Röhren bei Dehnung der Membran durch Krräfte parallel der Längsaxe der Rölıren zunimmt, bei der Dehnung dureh Kíräfte, deren Richtung in der Ebene der Membran zur Längsaxe der Röhren senkrecht ist, abnimmt, und dass bei gleichmässiger Dehnung nach allen in der Ebene der Membran gelegenen Richtungen die Capacitïtsabnahme bedeutend iiberwiegt. Letzteres ist das, was bei der inspiratorischen Lungenerweiterung erwartet werden muss, und an herausgenommenen Thierlungen 
ist diese Erwartung als zutreffend bestätigt worden. Die Capacität der Lungengefüsse ist bei ausgedehnter Lunge kleiner, bei zusammengefalleñer grösser. Indem sich die Capacität der Lungengefässe bei der Inspiration verringert, beschleunigt sich im Anfange der Inspiration der Blutzufluss aus den Lungenvenen zum linken Herzen. Durch die verengerten und verlängerten Lungengefässe kann aber dann wegen Vermehrung der Stromwiderstände weniger Blut in der Zeiteinheit vom rechten Herzen ans hindurchströmen, im zweiten Theile der Inspiration wird also der Blutzufluss zum linken Herzen wieder verringert. Umgekehrt muss bei der Exspiration zuerst weniger, dann mehr Blut in der Zeiteinheit dem linken Herzen zur Speisung des Blutdruckes in den Körperarterien zufliessen. Auch diesem Umstande ist es zuzuschreiben, dass, wenn man an Blutwellencurven von Thieren ausser den pulsatorischen Druckschwankungen solche zu sehen bekommt, welche mit den Athemzïgen gleiche Frequenz haben, die Berge und Thäler dieser als "Athemschwankungen des Blutdruckes" bezeichneten Wellen nicht mit Inspiration und Exspiration zeitlich genau zusammenfallen, sondern Phasenverschiebungen zeigen, welche bei verschiedenen Thieren und auch bei demselben Thiere unter verschiedenen Umständen verschieden sein können. Als weitere Complicationen kommen noch hinzu die Einfliisse, welche die Druckschwankungen im Abdomen auf den Blutzufluss zum Thorax ausüben und Aenderungen der Pulsfrequenz, welche sich bei manchen Thieren in sehr deutlicher Weise synchron mit dem Rhythmus der Athmung zeigen. Solche Thiere sind Hund und Schwein, bei denen eine inspiratorische Pulsbeschleunigung die Regel ist. Diese Thiere zeigen bei natïrlicher Puls- und Athemfrequenz meist Blutdrucksteigerung synchron mit der Inspiration; nach Atropinisirung dagegen, welche die Schwankung in der Pulsfrequenz aufhebt, zeigen diese Thiere das entgegengesetzte Verlalten, welches auch bei Thieren mit natürlich gleichmässiger Pulsfrequenz und schneller Athmung, wie Kaninchen, Kalb, Hammel, Meerschweinchen die Regel bildet. Hieraus wird geschlossen, dass die den Blutdruck steigernde inspiratorische Pulsbeschleunigung so schnell wirkt, dass der Erfolg in derselben Inspiration sich geltend macht, die iibrigen blutdrucksteigeruden Factoren der Inspiration aber mit solcher Verspätung, dass ihre Wirkung bei normaler Athemfrequenz während der folgenden Exspiration zur Erscheinung kommen kann. IHierfuir spricht, dass auch bei Thieren mit gleicher Pulszahl in beiden $\Lambda$ themphasen, welche von sellost eine geringe $\Lambda$ themfrequenz haben, wie IIaln und Gans, oder deren Athemfrequenz man kïnstlich herabgesetzt hat, Kaninchen etc., die Blutdrucksteigerung schon während der Inspiration sich voll entwickelt und die darauf folgende Exspiration unter Blutdrucksenkung verlüuft. Da bei dem Menschen die inspiratorische 
Pulsheschleunigung, ausser bei willkürlich verlangsamter Atlımung, meist wenig ausgesprochen ist, wird man hier Athemschwankungen des Blutdruckes nicht nach dem Typus des IIundes, sondern elier nach dem der Kiuninchen, das heisst Drucksenkung bei der Inspiration (als Folgezustind der voraufgegangenen Exspiration) erwarten diurfen.

Dass die Athemschwanknngen des Blutdruckes in hervorragender Weise mit den pleuralen Druckschwankungen zusammenhängen; geht daraus hervor, dass sie bei Kaninchen, denen man eine Canüle init Dreiweghahn so in die Trachea gebunden hat, dass man sie abwechselud durch die Caniile oder durch Glottis und Nase athmen lassen kann, bei Nasenathmung viel stärker hervorteten, als bei Trachealathmung, auch wenn der Umfang der respiratorischen Lungenvolumsänderungen hierbei unverändert bleibt. Die Aenderung der Capacität der Lungengefässe ist nur von dem Umfange dieser Vulumsänderung abhängig, die Druckschwankungen in dem Pleuraraume aber ausserdem noch von der Grösse der Widerstände, welche die Luft in den Luftwegen findet und die Widerstände sind auf dem Wege durch Glottis und Nase nicht unbeträchtlich. Auch die directe Messung der Druckschwankungen im Pleuraraume bei Tracheal- und Nasenathmung ergiebt eine erhebliche Ueberlegenheit derselben in letzterem Falle. Hiermit kann auch die Thatsache zusammenhängen, für welche eine anderweite Erklärung bisher nicht bekannt ist, dass für jede Inspiration beim Menschen die Glottis, bei Thieren Glottis und Nase sich erweitert. Nimmt man hinzu, dass die Inspiration schneller rerläuft als die Exspiration, so kann man in der inspiratorischen Erweiterung der Luftwege eine zweckmässige compensatorische Einrichtung erblicken, durch welche die in verschiedenem Sinne verlaufenden pleuralen Druckschwankungen dem Wertle nach ausgeglichen werden.

Die maximalen positiven und negativen Druckïnderungen, welche sich bei Verschluss der Luftwege, durch willkürliche exspiratorische oder inspiratorische Nuskelanstrengung, in der Alreolenluft erzeugen lissen, werden mit dem sogenaunten Pneumatometer gemessen. Es ist dies einfach ein Quecksilbermanometer nit Schlauch, Mundstück und Hahn. Nach einer tiefen Inspiration nimmt man das Mundstück in den Mund, hïilt die Nase mit der Hand zu und bläst so stark min kann. Wenn man die Anstrengung nicht weiter steigern kann, schliesst man den Hahn und liest den Stand des Manometers ab. In umgekehrtem Sinne rerfährt man, um die mit dem Thorax zu erzeugende Saugkraft zu messen, nur hat man hierbei noch darauf zu achten, dass man die Zunge aus dem Spiele lässt und nicht etwa durch spritzenstempelartige Bewegung der Zunge saugt. Auf letztere Weise kaun man bei engem Rohre begreiflicherweise Quecksilber auf eine sehr beträchtliche Höhe 
heben. Der am Pneumatometer bestimmte grösstmögliche exspiratorische Druck beträgt bei normalen Menschen im Mittel +87 und der grösstmögliche inspiratorische Zug im Mittel -57 Millimeter Quecksilber.

Um die Volumsänderungen des Thorax beim Thiere und beim Menschen dem Umfange und dem zeitlichen Verlanfe nach zur Anschauung zu bringen, dient der "Athemvolumschreiber". Derselbe besteht aus einem rechteckigen Kasten mit doppelten Seiten- und Stirnwänden. Zwischen den doppelten Wänden ist Wasser, im innersten

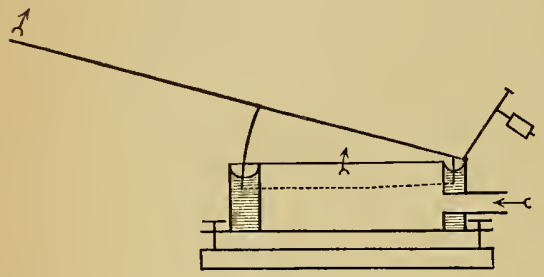

59. Raume Luft. Hier mündet am Boden oder an der Hinterwand ein Luftrohr. Ein Deckel aus fein gespaltenem Glimmer, dessen Ränder in das Wasser tauchen und welcher um eine, über der hinteren Stirnwand befindlichen Axe drehbar ist, schliesst den Luftraum von oben. Bläst man und saugt man abwechselnd am luftrohre, so hebt und senkt sich in entsprechender Weise der Deckel, welcher in Verlängerung einer seiner obereil Längskanten mit einem Schreibarm versehen ist und so seine Bewegungen auf eine rotirende berusste Trommel aufschreiben kann. Der Deckel muss bei allen vorkommenden Stellungen äquilibrirt sein. Damit dies leicht erreicht werden kann, ist er aus diunngespaltenem Glimmer verfertigt. Wegen der Dünne der Deckelwände ist das Volum des durch dieselben verdrängten Wassers sehr klein, also auch der Auftrieb sehr klein und die Veränderungen des Auftriebes bei verschieden tiefem Eintauchen noch viel kleiner. Die Ordinatenwerthe der von dem Deckel bei seinen Bewegungen geschriebenen Curven werden empirisch ermittelt und in Cubikcentimetern angegeben. Würde man unmittelbar durch das Luftrohr des Volunschreibers athmen, so würde die Ventilation der Lunge wegen der Kleinheit des abgeschlossenen Luftratumes sehr unvollkommen sein. Nan lässt den Menschen oder das Thier deshalb aus einer entsprechend grossen Vorlage athmen, in welcher man die Luft in den Zwischenzeiten zwischen den Versuchen ernenert und welche durch einen Schlanch mit dem Luftrohre des Volumschreibers in Verbindung gesetzt wird. In den Curven, welche der Volumschreiber auf diese Weise liefert, bedenten die Erhebungen Exspiration, die Senkungen Inspiration.

An den Volumcurven, welche man von dem ruhig athmenden gesunden Menschen gewinnt (Fig. 60 links), sielt man wie die Einathnung im Ganzen schneller verläuft als die Ausathmung; erstere ist in ihrem ganzen Verlaufe ziemlich gleich schnell, während die Ausathmung zwar anch steil beginnt, aber immer flacher wird. $\Lambda \mathrm{m}$ Ende derselben ist die Luft- 
bewegung gering oder Null und man kann diese $\Lambda$ themphase füglich eine Pause nennen; bei der gewölnlichen $\Lambda$ thmung, deren Frequen\% beim Menschen etwa 16 Athemziige in der Minute betrïgt, ist die Panse nur angedeutet. Bei Verlangsamung der Athmung, zum Beispiel im Schlafe, ist es namentlich die Datuer der Pause, welche zunimmt. Der senkrechte Abstand zwischen den Gipfeln und Thälern dieser Curve misst die Grösse, um welche das Thoraxvolum am Ende einer gewöhnlichen Inspiration dasjenige am Ende einer gewöhnlichen Exspiration iibertrifft und welche man „Respirationsluft" nennt. Sie betrïgt 500 bis 700 Cubikcentimeter. "Respirationsgrösse" nennt man die Luftmenge, welche in der Zeiteinheit, etwa in der Minute, die Lungen passirt; sie ist gleich dem Product aus Respirationsluft in Athemzahl und repräisentirt den Nutzeffect der Athemanstrengung. Ueber die Grösse dieser Anstrengung gewinnt man aus der Athemvolumcurve ebenfalls ein Urtheil. Es ist hierbei zu berücksichtigen, dass auf der Höhe der normalen Exspiration der Thorax nicht in seine Gleichgewichtslage zurïckgekehrt ist, sondern in inspiratorischer Richtung aus derselben entfernt bleibt. Am Thiere kann man sich hiervon dadurch ïberzengen, dass man während der Aufzeichnung der Athemrolumeurve alle Muskeln durch einen geschickt geführten Stich in das Nackenmark plötzlich elschlaffen macht. Die Athemcurve geht dann plötzlich in eine gerade Linie ïber, welche höher liegt, als die exspiratorischen Gipfel. In der Cadaverstellung ist das Volum des Thorax kleiner, als auf der Höhe der normalen Exspiration, die Athemanstrengung wächst also mit Umfang und Dauer der inspiratorischen Thoraxerweiterung und kann gemessen werden durch den Flächenraum, der nach oben durch die Linie der Caldaverstellung, nach unten durch die Athemeurve begrenzt ist. In absoluten Werthen lïsst sich dieses Maass nicht angeben, doch kann man so viel sagen, dass die Athemanstrengung zugenommen haben muss, wenn sich dieser Flïchenraum vergrössert hat, sei es dadurch, dass sich die ganze Athenrcurve gesenkt hat, oder dadurch, dass die Inspirationen rertieft oder auch dadurch, dass sie verlängert sind. Zunahme der Athemanstrengung kann mit Zunahme des Nutzeffectes der Athmung einhergehen, braucht es aber nicht. Mit Zunahme der Einathmungsdauer zum Beispiel wïchst die Anstrengung und nicht der Notzeffect. Das Verhältniss zwischen Anstrengung und Nutzeffect ist ein Maass der Zweckmässigkeit des A themtypus.

Lässt man einen Menschen, dessen Athemcurve man aufnimmt, eine möglichst tiefe Einathmung und im Anschlusse daran eine möglichst grosse Ausathmung machen, so erhält man in der Curve ein sehr tiefes Thal mit darauf folgendem sehr hohem Berge. Die senkrechte Entfernung zwischen Thal und Berg misst die Grösse der Volumsänderung, 
deren der Thorax unter dem Einflusse des Willens iiberhaupt fähig ist, man nennt sie die "Vitalcapacität". Sie setzt sich aus drei Grössen zusammen, erstens aus der Respirationsluft, zweitens aus dem Volum, um welches sich der Thorax am Ende einer gewöhnlichen Inspiration durch forcirte Inspirationsanstrengung noch erweitern lässt, genannt "Complementärluftraum", und drittens aus demjenigen Volum, um welches sich der Thoraxraum nach beendigter gewöhnlicher Exspiration durch besonderen exspiratorischen Willensimpuls noch verkleinern lässt, ge-

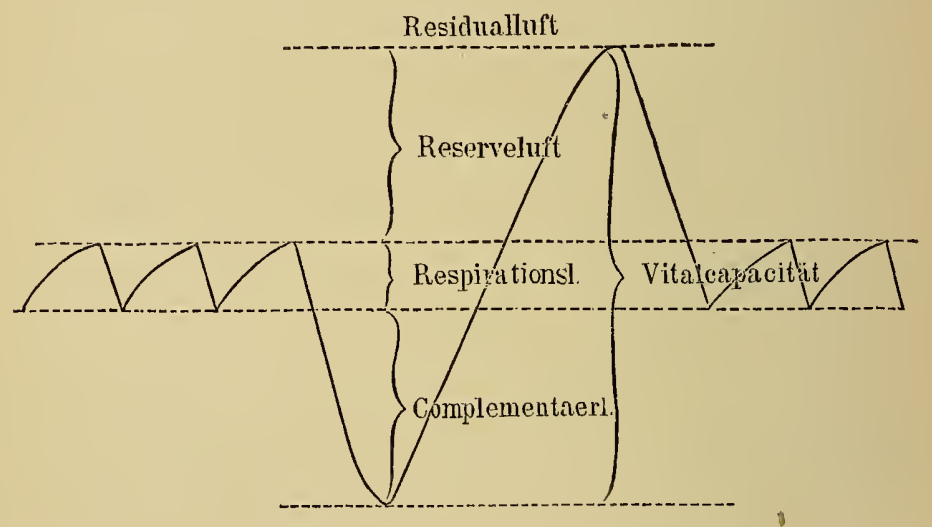

60.

nannt „Reserveluftraum“. Normalerweise ist der Complementärluftraum etwa gleich dem Reserveluftraum und jeder derselben beträgt etwa 1500 bis 2000 Cubikcentimeter. Sind beide Grössen verschieden, so lässt sich aus ihrem Verhältniss ein Schluss ziehen auf die mittlere inspiratorische Entfernung des Thorax aus der Cadaverstellung; diese ist um so grösser zu erwarten, je grösser das Verhältniss des Reserve- zum Complementärluftraume ist.

Auf der Höhe der angestrengtesten Exspiration enthält die Lunge noch reichliche Mengen Luft, die "Residualluft". Die Menge derselben ist auf directem Wege nicht zu bestimmen, deshalb hat man folgendes Verfahren eingeschlagen. Man füllt einen Kantschukbeutel mit etwa 500 Cubikmeter reinen Wasserstoffes, saugt dieses Gas am Ende einer Exspiration bei verschlossener Nase durch den Mund ein, bläst etwa die gleiche Menge Luft in den Beutel und wiederholt dies etwa fünf Mal, bis man annehmen kann, dass völlige Mischung des Wasserstoffes mit der Lungenluft eingetreten sei, damn bestimmt man den Geliclt der zuletzt in den Beutel geblasenen Luft an Wasserstoff; derselbe betrage etwa $12 \%$. Bezeichnet man die Menge Luft, welche bei Beginn des Versuches in der Lunge war mit $x$, so besteht unter der als wahrscheinlich 
zu bezeichnenden Voraussetzung, dass keine in letracht kommende Menge Wasserstoffes ron den Wïnden der Luftwege und Alveolen absorbirt worden ist, die Gleichung $\frac{(500+x) 12}{100}=500$.

Hieraus ergielt sich der Werth von x zu 3666 Cubikcentimetern und nach $\Lambda$ bzug von 600 Cubikcentimetern Respirationsluft und 1500 Cubikcentimetern Reserveluft der Werth der Residualluft zu 1500 Cubikcentimetern. Die Werthe des gewählten Beispiels sind die mittleren der Wirklichkeit.

Auch mit Hilfe des Athemvolumschreibers kann man die Grösse des Residualluftraumes zu bestimmen versuchen. Die Vorlage dieses für den Menschen bestimmten $\Lambda$ pparates ist so eingerichtet, dass sie nicht nur zwischen Mund oder Athemmaske und eigentlichem Volumsehreiber eingeschaltet werden, sondern dass sich die Versuchsperson auch hinein begeben kann. Letztere athmet dann durch ein in der Wand befindliches Rohr aus der freien Luft, und eine der eingeathmeten Luft gleiche Luftmenge entweicht hierbei aus der Vorlage in den Volumschreiber und hebt dessen Deckel. Man erhält bei diesem Verfahren Curven, welche derart umgekehrt sind, dass die Curvenerhebungen Inspirationen bedeuten, nicht wie bei dem zuerst beschriebenen Verfahren Exspirationen. Der aus der Vorlage nach aussen vorstehende Theil des Athemrohres, durch welches die Versuchsperson athmet, trägt ein Seitenrohr, welches z,u einem Quecksilbermanometer führt, und an seinem Ende ein Stück Kautschukschlauch. Auf der Quecksilberkuppe des freien Nanometerschenkels befinclet sich ein Schwimmer, der an einem Stabe eine Zeichenfeder trägt, sodass sich die Ausschläge des Manometers zugleich mit der Athemvolumscurve aufschreiben können. Man nimmt nun zuerst ein Stiick einer gewöhnlichen Athemeurve auf, dann wird unter Abgabe eines hörbaren Signals der Kautschukschlauch am Ende des $\Lambda$ themrohres zugeklemmt und die Versuchsperson macht eine Inspirationsanstrengung, bei welcher keine Luft in die Lungen eingesogen, sondern die gerade in der Lunge rorhandene Luft ausgedehnt und das Manometer angesangt wird. Es schreiben sich die zusammengehörigen Werthe der Aenderungen des Volums und des Druckes, welche sich an derselben Luftmenge gleichzeitig vollziehen, auf. Hieraus kann man das Volum dieser Luftmenge vor der Aenderung, also bei Barometerdruck nach dem Mariotte'schen Gesetze berechnen. Vor Beendigung des Versuches wird noch die Vitalcapacitit bestimmt. Nennen wir die zu berechnende Luftmengo $\mathrm{V}$, den barometrischen Druck $B$, den doppelten Werth des Ausschlages des Manometerschreibers d und die zugehörige, aus der Volumscurve abzulesende Volumsänderung v, so ist 


$$
\mathrm{BV}=(\mathrm{B}-\mathrm{d})(\mathrm{V}+\mathrm{v}) ; \mathrm{V}=\frac{\mathrm{v}(\mathrm{B}-\mathrm{d})}{\mathrm{d}} .
$$

Von dem so berechneten Werthe $\mathrm{V}$ ist der Volumwerth des senkrechten Abstandes der Volumcurve von dem Beginne der Inspirationsanstrengung bis zum Maximum der Exspiration bei Nehmen der Vitalcapacität abzuziehen, um die Grösse des Residualluftraumes zu erhalten. Die mit dieser Methode bestimmten Werthe sind etwas grösser ausgefallen, als sie die zuerst beschriebene Methode ergeben hat. Im Allgemeinen wird man annehmen können, dass bei dem gesunden Menschen der Residualluftraum etwa die Hälfte der Vitalcapacität beträgt.

Die Nothwendigkeit des Vorhandenseins eines Residualluftraumes ergiebt sich aus der Erfahrung, dass es auch bei der herausgenommenen Lunge nicht gelingt, durch beliebig starken und gleichmässigen Druck auf die äussere Oberfläche alle Luft auszutreiben; die kleinen Bronchien werden hierbei offenbar früher bis zum Verschwinden ihres Lumens zusammengedrïckt als die Alveolen. Will man eine herausgenommene Lunge in den luftleeren Zustand versetzen, welcher vor der Geburt bestand, und welchen man den "atelektatischen" nennt, so muss man dieselbe mit Kohlensäure auswaschen. Ueberlässt man sie, mit reiner Kohlensäure gefüllt, sich selbst, so wird clieses Gas von den feuchten Wänden vollkommen absorbirt und man erhält eine atelektatische Lunge.

Wenn nach angestrengter Exspiration in jeder Alveole noch Luft zurückbleibt, so muss die Summe dieser Luftmengen einen erheblichen Werth repräsentiren. Für die Functionen der Lunge ist die Grösse des Residualluftraumes von doppelter Bedeutung. Das Verhältniss der Summe ron Reserveluft plus Residualluft zu Respirationsluft bestimmt den ventilatorischen Nutzen des einzelnen Athemzuges. Dieses Verhältniss ist bei Zugrundelegung der oben angenommenen Werthe etwa $6: 1$, sodass bei jedem Athemzuge etwa $1 / 6$ der in der Lunge verdorbenen Luft durch frische ersetzt würde, wenn nicht noch ein Theil der Respirationsluft für den ventilatorischen Effect verloren ginge. Die nicht unerhebliche Luftmenge nämlich, welche in den Luftwegen bis zu den Alveolen Platz findet, wird zwar erwärmt und mit Wasserdampf gesättigt, aber in Kohlensäure- und Sauerstoffgehalt fast unverändert wieder ausgestossen. Hiernach könnte rom teleologischen Standpunkte aus der ohen angenommene Werth des Residualluftraumes als zu gross erscheinen. Andererseits müssen aber die alveolaren und pleuralen Druckschwankinngon um so kleiner ausfallen, je grösser der Residualluftranm ist. Jerle respiratorische Volumsänderung führt zunächst zu einer Spannungsänderung der Alveolenluft, welche erst durch die Luftbewegung in den Luftwegen wieder ausgeglichen wird. Diese Spanuungsïnderungen sind 
um so kleiner, an einem je grösseren Luftvolum sich die Volumsänderung vollzieht.

Anı Ende einer gewöhnlichen Exspiration ist das Thoraxrolum grïsser als nach Erlahmen aller Muskelkräifte, das heisst in der Carlarerstellung. Letztere ist eine Gleichgewichtsstellung, welche allein von den elastischen Krïiften des Thorax und der Lunge abhängig ist. Diese wirken in der Cadaverstellung einander entgegen. Im Leben ist der Thorax meistens, und zwar auf der Höhe der gewöhnlichen Exspiration stets, in inspiratorischem Sinne soweit aus dieser Gleichgewichtslage entfernt, dass die elastische Kraft der Thoraxwand in gleichem Sinne wirkt wie die elastische Kraft der Lungen. Die Inspirationsmuskeln sind also fortwïhrend gespannt, während der Inspiration stärker als während der Exspiration. Einem Tetanus der Inspiratoren von constanter Intensitiit superponirt sich ein solcher von schwankender Intensität. Durch Zunahme der tetaniselıen Spannung der Inspirationsmuskeln wird die inspiratorische Erweiterung des Thorax bedingt, durch Nachlassen derselben die gewöhnliche exspiratorische Verengerung.

An der Begrenzung des Thorax betheiligen sich die Wirbelsäule, der Brustkorb mit Sternum und das Zwerchfell. An der Wirbelsäule ist jede knöcherne Rippe derart befestigt, dass ihr Capitulum in einer Gelenkpfanne der Wirbelkörper und das Tuberculum an einer Gelenkfläche des Processus transversus schleift; die Bänder dieser Gelenke sind ziemlich straff, sodass schlotternde Bewegungen wenig in Betracht kommen; die Hauptbewegung jeder Rippe besteht in einer Drehung um eine Axe, welche durch die Gelenkfläche am Wirbelkörper und dureh diejenige am Processus transversus hindurchgeht und deren Richtung ungefähr mit derjenigen des Rippenhalses zusammenfällt; jede Rippe dreht sich also um ihren Rippenhals, die Richtung aller Rippenhälse ist annähernd horizontal, weicht aber bei den Rippen verschiedener Ordnungszahl in verschiedenem Grade ron der Transversallinie ab; nur bei den obersten Rippenbögen, an denen die Rippenhälse transversal gerichtet sind, haben die zu demselben Bogen gehörigen Rippen eine gemeinsehaftliche Drehaxe, welche also horizontal und transversal gerichtet ist. Den obersten Rippenbögen kommt in Folge dessen eine Drehbewegung zu, deren Freiheit vollkommen wäre, wenn die mit den einzelnen Bögen verbundenen Theile des Sternums ron einander isolirt wären. Durch den obersten Rippenbogen zum Beispiel kann man eine Ebene legen, welche gleichzeitig durch die gemeinschaftliche Drehaxe der beiderseitigen ersten Rippen, durch die ganze Lü̈nge der Rippen selbst und durch ihre Ansätze am Sternum geht; diese Ebene ist in der Ruhe nach rorn geneigt; eine Drehbewegung, bei welcher sie der horizontalen Ebene genähert würde, wïre rollkommen frei, doch würde die Vorderfläche 
des zum Rippenbogen gehörigen Theiles des Sternums hierbei ihre Neigung gegen die Verticale ändern; da die den tieferen Rippenbögen zugehörigen Theile des Sternums diese Neigung nicht in demselben Maasse mitmachen können, so ist hierdurch die Bewegung auch des obersten

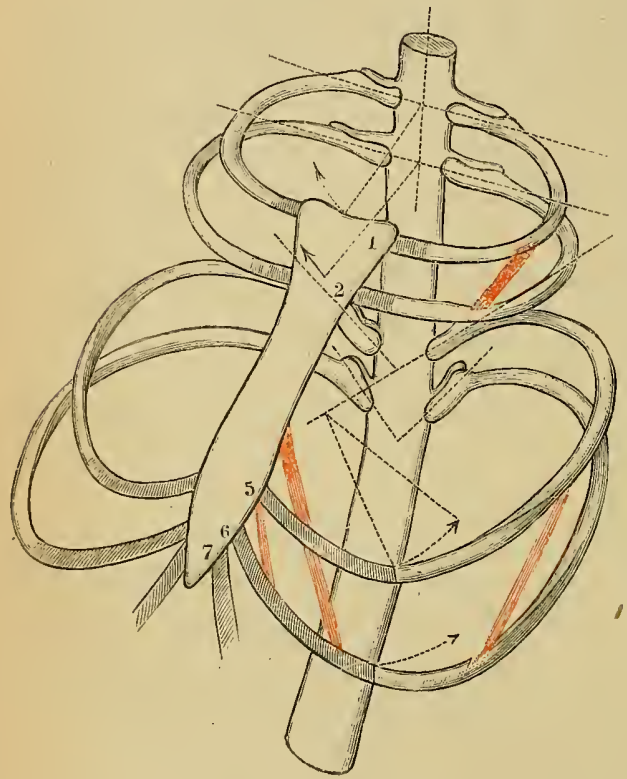

61.

Rippenbogens eine unfreie. Sie könnte noch frei sein, wenn die Rippen mit dem Sternum durch Drehgelenke verbunden wären; die obersten Rippenknorpel sind aber einerseits mit dem Sternum, andererseits mit den knöchernen Rippen fest verwachsen, sodass die durch die sternale Verbindung der Rippenbögen erzeugten Unfreiheiten der Bewegung zur Torsion der Rippenknorpel (und in geringerem Maasse auch der knöchernen Rippen) um ihre Längsaxe führen müssen.

Den Typus der obersten Rippen zeigen ziemlich rein diejenigen des ersten und zweiten Rippenbogens; da die Drehaxen horizontal transversal gerichtet sind, erfolgt die Bewegung jedes Punktes dieser Bögen, durch welche Kräfte sie auch entstanclen sein mag, in je einer verticalen, der Medianebene parallelen Ebene. Da die Bewegungen eine durch die Drehaxe gelegte Horizontalebene nie ïberschreiten, tritt jeder Punkt dieser Bögen bei der Hebung gleichzeitig nach vorn, bei der Senkung nach hinten. Die Bewegung ist an den von der Drehaxe am weitesten entfernten Punkten, also am Sternum, die umfangreichste, bei der inspiratorischen Heloung des Brustkorbes tritt das Manubrium Sterni nach vorne, der sagittale Durchmesser des Thorax vergrössert sich hier, der transversale bleibt unverändert.

Je weiter man an der thoracalen Wirbelsäule hinalggeht, um so mehr findet man die Richtung der Processi transversi der Wirbelkörper von der transversalen aloweichend. Die Rippenhälse sind mehr und mehr von vorn medial, nach hinten lateral gerichtet; die Drehaxen der denselben Rippenhogen bildenden Rippen schneiden sich unter Winkeln, deren Spitzen vor der Wirhelsäule liegen, ihre Richtung bleibt dabei annähernd horizontal, anch die Form der Rippen ändert sich wesentlich; 
man kann nicht mehr durch je einen Rippenbogen je eine Ebene legen. Denkt man sich durch den Schnittpunkt der beiderseitigen Drehaxen eines tieferen Rippenbogens und den zum Bogen gehörigen Theil des Stermmms eine Ehene gelegt, so ist diese nach rorm geneigt, der Sternaltheil des Rippenbogens liegt tiefer, als die Rippengelenke an der Wirbelsäule; in dieser Beziehung besteht nur ein gradueller Unterschied gegen die oberen Rippenbögen. Während aber bei den obersten Rippenbögen auch die seitliehen Partien in derselben nach vorn geneigten Ebene liegen, weichen bei den tieferen Rippenbögen die seitlichen Partien noch mehr nach unten ab. Die stärkste Abweichung nach unten liegt an jedem Rippenbogen ungefïhr am Vereinigungspunkte des knöchernen mit dem knorpeligen Theile der Rippen, sodass hier ein nach oben offener Winkel entsteht. Dieses Verhalten ist schon deutlich anı fünften Rippenbogen und nimmt an den tieferen zu. Betrachiten wir znnächst die Bewegung einer dieser Rippen, etwa der fünften odler sechsten, wie sie erfolgen müsste, wenn die Verbindung mit dem Ḱnorpel zersehnitten wïre; die Bewegung wäre eine freie Drehung um die horizontale schräg von hinten lateral nach rorn medial gerichtete Drehaxe; jeder Punkt der Rippe bewegt sich also in einer Ebene, senkrecht zur Drelaxe, und diese Ehene ist vertical von hinten medial nach vorn lateral gerichtet.

Der in einer solchen Ebene gelegene Krreisbogen, welchen ein Rippenpunkt bei der freien Drehung einer dieser Rippen beschreibt, liegt in einem der unteren Quadranten. Zugleich mit seiner Hebung tritt also jeder Punkt nach vorn und lateral; beide diese Bewegungscomponenten sind um so grösser, je tiefer der betrachtete Punkt, unter der Horizontalebene der Drehaxe, oder, was auf dasselbe hinauskommt, je tiefer er unter der geneigten Ebene dureh Krenzungspunkt der beiderseitigen Drehaxen und Sternaltheil des Rippenbogens liegt. Dieser Punkt ist, wie wir oben gesehen haben, das vordere Ende der knöchernen Rippe. Die lateralwärts gerichtete Componente, welehe an den obersten Rippenbögen fehlte, rührt von der Schiefstellung der Drehaxe gegen die Transversalebene her und ïberwiegt um so mehr gegen die Berregungseomponente nach vorn, je mehr die Schiefstellung zunimmt. Die freie Bewegung einer Rippe von dem betrachteten Typus wiirde also bei der Erhebung der Rippe mehr zur Verbreiterung des Thorax als zur Vergrösserung seines sagittalen Durehmessers beitragen.

Betrachten wir einen der hierher gehörigen Rippenbögen im Zusammenlange mit dem Steruum, so ist die vorwärts und namentlich die auswärts gerichtete Bewegung des rorderen Endes der knöchernen Rippen nicht mehr frei, sie kann nur gesehehen unter Torsion der Rippen und Rippenknorpel um die Längsaxe und unter Abflachung des Winkels 
zwischen Rippenknorpel und Rippe; durch Verbiegung der Längsaxe dieser Theile führt die Abflachung des genannten Winkels ebenfalls zu Erzeugung elastischer Spannungen. Diese elastischen Spannungen sind um so kleiner, je länger der knorpelige Theil der Rippe und je loser seine Verbindung mit dem Sternum ist, deshalb nimmt die freie Beweglichkeit der Rippen vom achten Bogen abwärts wieder zu, die elfte und zwölfte Rippe. sind ganz beweglich.

Nach unten ist der 'Thorax geschlossen durch das Zwerchfell, welches sich von seiner, an der Wirbelsäule, den unteren Rippen und der Spitze des Sternums gelegenen Basis als ein Gewölbe in die Thoraxwand erhebt; in dieser Wölbung wird es erhalten durch den elastischen Zug der Lungen; die Kuppe des Gewölbes ist abgeplattet durch den sehnigen Theil des Diaphragma, das Centrum tendineum; das Centrum tendineum ist nahezu eben, von seinen Rändern spannen sich die Muskelfasern des Zwerchfelles in einem gegen den Thorax convexen Bogen zu ihren unteren I sertionen aus. In der Cadaverstellung und in der Stellung der gewöhńlichen Exspiration liegt ein ringförmiger Streifen des Diaphragma zunächst seiner Basis der Thoraxwand unmittelbar an; contrahiren sich die Muskelfasern des Zwerchfelles, so wirken sie auf Herabziehung des Contrum tendineum, auf Abflachung des seitlichen Bogens und auf Abziehen des basalen Streifens von der Thoraxwand und tragen durch diese drei Momente zu Vergrösserung des Thoraxvolums bei. Der Nutzeffect würde aber durch Hebung und Einziehen der Insertionslinie des Zwerchfelles an den unteren Rippen erheblich verringert werden, wenn nicht andere Momente dem entgegen wirkten.

Das Zwerchfell bildet den oberen Abschluss der Bauchhöhle, deren Holliaum in der Ruhestellung ungefähr die Form eines abgestumpften Oroids hat. Der Raum der Bauchhöhle kann sich bei dem Herabsteigen der Zwerchfellskuppe der Grösse nach nicht wesentlich ändern. In dem Maasse wie die diaphragmatische Begrenzungsfläche der Bauchhöhle sich verkleinert, muss der übrige Theil der Grenzfläche einer Form zustreben, bei welcher einer kleineren Oberfläche der gleiche Inhalt entspricht. Diese Form ist die Kugelform. Bei dem Uebergange der Banchlıölle aus der ovoiden in die sphärische Form verbreitert sich die Basis des Zwerchfelles und tritt tiefer.

Jiesem aus den Verhältnissen der geschlossenen Bauchhöhle mit Nothwendigkeit zu folgernden Antagonismus gegen die $\Lambda$ uf- und Einwïrtszichung der unteren Rippen durch das Zwerchfell kommt ein in demselben Sinne antagonistischer Maskelzug zu Hilfe. Man hat beim Menschen im Verlaufe von Operationen mit weiter Eröffnung der Bauchlöhle beobachtet, dass auch hier das Herabtreten des Zwerchfelles nicht mit Einziehung der unteren Rippen verbunden war. Der Muskel, welcher 
dies unter den genannten Umstïnden zu verhindern im Stande ist, ist (ler Musculus serratus posticus inferior, welcher sich von der Fascia lumbo-dorsalis in der Gegend der untersten Brust- und oberen Bauchwirbel schräg aufwärts und lateralwärts zu den vier untersten Rippen begiebt, und sie herabzuziehen und aufzubiegen im Stande ist.

Die stïrkste Contraction des Zwerchfelles führt zu einer nur kleinen inspiratorischen Luftbewegung, wenn nicht Thoraxmuskeln gleichzeitig in 'Thätigkeit treten; man kann sich hiervon bei Kaninchen leicht iiberzeugen, indem man unmittelbar nach der Tödtung, also nach Fortfall spontaner Athembewegungen, aber bei noch hochgradiger Erregbarkeit der Nerven und Muskeln die motorischen Zwerchfellsnerven, die Nervi phrenici, elektrisch reizt. Der Athemvolumschreiber zeigt bei hochgradiger Zusammenziehung des Zwerchfelles nur einen kleinen Ausschlag, dagegen sieht man, wie der ganze Brustkorb herabtritt und einsinkt. Das Missverhältniss zwischen der Bewegung des Zwerchfe $e_{1}$ und der Luft tritt stïrker hervor, wenn man das Thier durch eine luı.dicht auf Nase und Maul gesetzte Kappe bei uneröffneter Trachea mit dem Volumschreiber in Verbindung gesetzt hat, als wenn dies mit Hilfe einer Trachealcanüle geschehen ist; die Widerstände, welche die Luftbewegung in Glottis und Nase findet, sind beträchtlich, und wenn das sich contrahirende Zwerchfell das Thoraxvolum zu vergrössern strebt, so geschieht dies zunächst durch Ausdehnung der in den Lungen vorhandenen Luft. Die hierdurch bedingte Druckverminderung in den Alveolen kann ebenso schnell dazu führen, dass der anderweit nicht fixirte Thorax von dem aussen auf ihm ruhenden Atmosphärendruck zusammengepresst wird, als dass Luft, dem Gefälle ron der Nasenöffnung bis zu den Alveolen folgend, die widerstandsreichen Luftwege passirt. Praktisch ist die Kenntniss dieser Verhältnisse von Bedeutung, weil aus ihnen folgt, dass man bei Wiederbelebungsversuchen durch künstliche Respiration keine Hoffnung auf den Erfolg elektrischer Plirenicusreizung setzen darf (es giebt zuverlässige mechanische Methoden); die theoretische Consequenz ist, dass man kein rein diaphragmatisches Inspirium annehmen darf. Auch wenn der Thorax bei der Inspiration sich nicht merklich hebt und erweitert, so sind Muskelkräfte im Spiele, welche die Senkung und Verengerung desselben verhindern. Es miissen dies wenigstens theilweise dieselben sein, welche bei sichtharer Hebung und Erweiterung des Thorax diese Veränderungen bedingen.

Muskeln des Thorax, deren inspiratorische Wirkung am leichtesten verständlich ist, sind die Musculi scaleni. Von der Halswirbelsäule zu den vorteren Theilen der oberen Rippenbögen herabsteigend, müssen sie diese um ihre transversale Drehaxe aufwärts drehen und durch Vermittelung des Sternums auch den übrigen Brustkorb heben und er- 
weitern. Die Musculi scaleni treten aber nur ausnahmsweise bei sehr starker Inspirationsanstrengung augenscheinlich und fühlbar in Thätigkeit. Bei gewöhnlichen Athemzügen, auch wenn diese mit deutlicher Hebung und Erweiterung des Thorax verbunden sind, sind sie scheinbar in Ruhe.

Von dem Nackenbande und vom Processus spinosus des sechsten Hals- bis zweiten Brustwirbels entspringen die Fasern des Musculus serratus posticus superior, welche sich zur Dorsalfläche der vier obersten Rippen begeben; ähnlichen Verlauf haben die sogenannten Musculi levatores costarum, welche von allen Processus transversi bis hinunter zum rorletzten Brustwirbel entspringen: diesen Muskeln wird als Wirkung eine Hebung des Brustkorbes zugeschrieben, da letztere aber in ausgiebigem Maasse nur erfolgen kann, wenn sich jede Rippe um ihre dem Rippenhalse parallele Axe dreht, so kann die Wirkung dieser Muskelzüge, deren Rippeninsertion fast in die Drehaxe oder ihre Verlängerung fällt, für den genannten Zweck nicht sehr in Betracht kommen. Damit dieses der Fall wäre, müssten sie einen längeren Verlauf haben und an Punkten der Rippen angreifen, deren senkrechte Entfernung von der Drehaxe eine erhebliche ist. Man kann sich nun in der That die Faserzüge der Musculi intercostales externi als Verlängerungen derjenigen der sogenannten Levatores costarum vorstellen, nur unterbrochen, wie durch sehnige Inscriptionen, durch die einzelnen Rippenbögen: von diesem Gesichtspunkte aus kann man auch verstehen, wie die Muskelzüge der Intercostales externi inspiratorisch wirken können. Eine genaue Einsicht in den Mechanismus ihrer Wirkung erhält man aber auf dem Wege einer anderen Betrachtung.

Zur Veranschaulichung der Wirkung der Intercostalmuskeln hat man folgenden Apparat construirt: an eine feste Stange, welche die Wirbelsäule repräsentirt, sind zwei die Rippen darstellende Stäbe eingelenkt, welche an ihrem Ende wiederum durch eine, Drehbewegungen gestattende Leiste verbunden sind, das Sternum (Fig. 62). Spannt man zwischen den Rippenstäben ein Froschmuskelpräparat aus in der Richtung, wie sie den Intercostales externi zukommt und tetanisirt man dieses Präparat, so wird das Sternum gehoben. Dass die Zusammenziehung des Muskels an dem Schema diese Wirkung haben muss, geht aus der Anwendung des Satzes vom Parallelogramm der Kräfte hervor. In der Richtung der Muskelfasern wirken zwei gleiche, aber entgegengesetzte Krïfte $\mathrm{K}$ auf den oberen und unteren Insertionspunkt des Muskels; jede der Kriäfte kann man in zwei Componenten zerlegen, von denen je eine in der Richtung der Rippen wirkt, für die Bewegung also nicht in Betracht kommt, die andere senkrecht zur Rippe. Die letzteren Componenten, $g$ an der oberen, $g^{\prime}$ an der unteren Rippe, haben den 
Werth von $K \sin \alpha$, wenn wir mit $\alpha$ den spitzen Winkel zwischen dem Muskel und den Rippen bezeichnen. Nennen wir $\lambda$ und $\lambda^{\prime}$ die lintfernungen der Muskelinsertionen von der Wirbelsäule und I die gleiche Länge beider Rippen, so können wir die an den Insertionspunkten des Muskels senkrecht zu den Rippen wirkenden Krräfte $g$ und $g^{\prime}$ ersetzt denken durch zwei ihnen gleich gerichtete Krä̈fte $h$ und $h^{\prime}$, welche an den Verbindungspunkten zwischen den Rippen und dem Sternum angreifen, wenn

$$
\begin{aligned}
& \mathrm{h}=\frac{\lambda}{\mathrm{l}} \mathrm{K} \sin \alpha \\
& \mathrm{h}^{\prime}=\frac{\lambda^{\prime}}{\mathrm{l}} \mathrm{K} \sin \alpha
\end{aligned}
$$

gemacht wird. Die einzige Bewegung, welche das Sternum an dem, bis auf die vier Drehpunkte, starr gedachten Systeme ausfülıren kann, ist eine Hebung und Senkung mit gleichzeitiger Verschiebung parallel sich selbst. Nennen wir i und $i^{\prime}$ die in

Richtung des Sternums wirkenden Componenten von h und h', so wirkt $i$ auf Senkung und $i^{\prime}$ auf Hebung des Sternums. Wird mit $\beta$ der spitze Winkel zwischen den Rippen und dem Sternum bezeichnet, so ist

$$
\begin{aligned}
& \mathrm{i}=\frac{\lambda}{1} \mathrm{~K} \sin \alpha \sin \beta \\
& \mathrm{i}^{\prime}=\frac{\lambda^{\prime}}{\mathrm{l}} \mathrm{K} \sin \alpha \sin \beta
\end{aligned}
$$

und $\quad i^{\prime}: i=\lambda^{\prime}: \lambda$.

Die auf Hebung des Sternums hin-

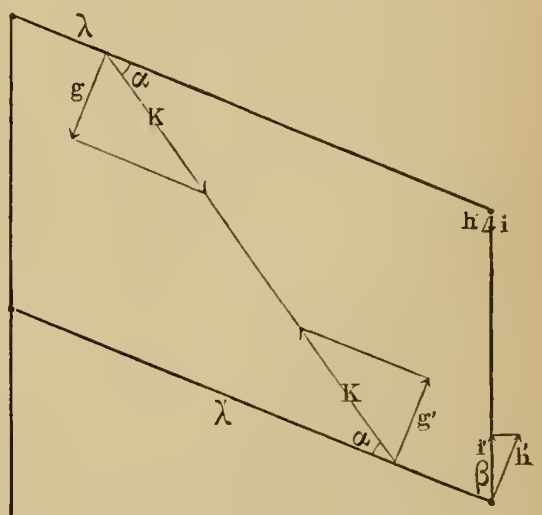
wirkende Kraftcomponente ist also so viel mal grösser, als die auf Senlkung hinwirkende, wie die Entfernung des oberen Insertionspunktes des Muskels von der Wirbelsäule in der entsprechenden Entfermung des unteren enthalten ist. In analoger Weise lelren Experiment und Betrachtung, dass Muskeln von der Richtung der Intercostales interni bei ihrer Zusammenziehung die Sternalleiste senken und die Rippen hierbei abwärts drehen müssen.

Dass dieses, als das Hamberger'sche bezeichnete Schema auch für die weit complicirteren Verhältnisse am Brustkorbe das Richtige trifft, kann man wenigstens für die oberen Rippenbögen einsehen, wenn man sich eine Verticalebene durch die Wirbelkörpergelenke einer ersten und zweiten Rippe und durch das Sternum gelegt denkt. Projicirt man 
die beiden Rippen mit ihren Intercostalmuskeln auf diese Ebene, so elhält man das Ha mberg er'sche Schema, mit dem einzigen Unterschiede, dass die Bewegung des Sternums gegen die Rippen nicht durch Gelenke, sondern durch elastische Deformation der Rippenknorpel ermöglicht ist. Was für die Projection der Rippen auf diese Ebene gilt, muss auch für die Rippenbögen selbst gelten, wenigstens in Bezug auf das Vorzeichen der Summe der auf verticale Verrïckung des Sternums hinwirkenden Kraftcomponenten; der Ermittelung des absoluten Werthes dieser Summe müssen allerdings umfassendere Betrachtungen zu Grunde gelegt werden.

Für die Rippenbögen vom Typus des fünften und sechsten lässt sich die Analogie mit dem Hamberger'schen Schema nur schwer durchführen; man thut besser, sich klar zu machen, dass die vereinigte Wirkung der Intercostales externi und der Intercartilaginei hier darauf gerichtet ist, den aach oben offenen Bogen zwischen knöcherner und knorpeliger Rippe abzuflachen, wobei der Verbindungspunkt beider Rippentheile lateral aufwärts sich bewegen muss, eine Bewegung, deren das vordere Ende der knöchernen Rippe, wie wir oben gesehen haben, Kraft der Richtung der Drehaxe der Rippe, fähig ist.

Denkt man sich die Intercostales interni und die Intercartilaginei am Thorax allein in Thätigkeit treten, so müssen sie zu einer Formänderung des Thorax führen, bei welcher alle longitudinalen Durchmesser, ferner im oberen Theile mehr die sagittalen, im mittleren und unteren Theile mehr die transversalen Durchmesser vergrössert werden. Das Gesammtresultat ist, wenn das Diaphragma im Raume fest bleibt, oder gar gleichzeitig herabsteigt, eine beträchtliche Volumvergrösserung des Thorax. Die gesammte von den Externi und Intercartilaginei hierbei durch Hebung von Masse und Ueberwindung elastischer Spannungen zu leistende Arbeit ist sehr beträchtlich, und man hat die an den einzelnen Stellen des Thorax gemessene Dicke der Muskelschicht für zu klein gehalten für die erforderliche Spannungsentwickelung. Man muss aber bedenken, dass für die Bemessung des physiologischen Muskelquerschnittes die ganze Länge des Intercostalraumes in Betracht kommt.

Zwerchfell und Rippenheber sind bei jeder normalen Inspiration zusammen thätig, allerdings in verschiedenem Verhältnisse. Ueberwiegt die Thätigkeit des Zwerchfelles, so kommt es zum sogenannten abdominalen oder männlichen $\Lambda$ thmungstypus, für welchen die durch das Herabtreten des Zwerchfelles bewirkte Vorwölbung des Abdomen charakteristisch ist. Die Athmung, bei welcher die Rippenheber überwiegen, sodass es zur inspiratorischen Hebung des Thorax kommt, nennt man ren thoracalen oder den weiblichen Athmungstypus.

Lassen die Muskelkräfte, welche eine Einathmung bewirkt haben, nach, so muss es auch ohne Inanspruchnahme anderer Muskeln zur 
Ausathmung kommen, in Folge von Kräften, welche bei der Einatlımung selbst wachgerufon wurden. Dies sind bei rein abdominalem 'Typus die elastische Kraft der gedehnten Lungenwände, die Spannung der Bauchwandungen, in horizontaler Lage auch die Schwere der Bauchcingeweide; bei thoracalem oder gemischtem Athmungstypus kommen noch hinzu das Gewicht der gehobenen Thoraxwand und die elastischen Krräfte der un die Längsaxe gedrehten und in der Längsaxe verbogenen Rippen, namentlich in ihrem knorpeligen Theile. Bei ruhiger langsamer Athmung scheint die exspiratorische Verkleinerung des Thoraxraumes diesen Kräften überlassen zu sein. Wenn aber in kurzer Zeit grössere Mengen Luft die langen engen Luftwege passiren sollen, so müssen zur Ueberwindung der nicht unbeträchtlichen Widerstände Muskelkiäfte beihelfen. Diese Leistung fällt zunächst den Bauchmuskeln und den Musculi intercostales intermi zu.

Wird die Athmung besonders stark in Anspruch genommen, so treten für die Inspiration als Hilfsmuskeh hinzu die Musculi scaleni und bei \%urückziehung der Schulterblïtter durch die Rhomboidei und den Cucullaris oder bei Feststellung des Schultergürtels durch Aufstemmen der Arme die Musculi pectorales; für die Exspiration der Latissimus dorsi. Vor jeder Einathmung erweitert sich die Glottis, um sich nach derselben wieder zu verengern, doch nicht bis zu Cadaverstellung. Bei angestrengtem Athmen tritt zur präinspiratorischen Erweiterung der Glottis eine solche des Naseneinganges hinzu.

Hinsichtlich der Innervation der Athmung kommen als motorische Bahnen lauptsächlich in Betracht die Nervi laryngei inferiores für die Glottis, die Nervi phrenici für das Diaphragma und die Nervi intercostales für dic intercostalen und abdominalen Muskeln. Den unmittelbaren Ursprung nehmen diese Nerven - abgesehen vom Laryngeus inferior - - aus segmental gruppirten Ganglienzellen der granen Rückenmarkssäulen, welche auf eine grosse Länge des Markes rertheilt liegen. Da zweckmässige Athembewegungen feine Abstufungen der Erregungen aller betheiligter Muskeln in quantitativer und zeitlicher Beziehung voraussetzen, so ist zu erwarten, dass die spinalen Athemmuskelcentren unter einander und mit höher gelegenen coordinatorischen Centren, den Athemcentren, verbunden sind. Da Einathmung und Ausathmung besondere Coordinationen verlangen, wird man besondere Coordinationscentren für Inspiration und Exspiration annelımen dïrfeu. Diese Athemcentren würden Erregungen, welche ihnen auf centripetaler Bahn oder 
auf dem Wege vom Gehirn her zugehen, oder auch in ihnen selbst entstehen, in zweckmässig coordinirter Weise den spinalen Athemmuskelcentren und durch Vermittelung dieser den Athemmuskeln zuzusenden haben; als anatomisches Substrat solcher Centren hätten wir Summen von Ganglienzellen mit ihren zuführenden und abführenden Leitungsbahnen zu erwarten, für deren genauere Localisirung Folgendes in Betracht kommt. Da man das Hirn bis zu einer Fläche abtragen kann, welche durch die Tubercula acustica und den unteren Rand des Pons geht, ohne dass das Thier aufhört spontan regelmässig und ausreichend zu athmen, und da andererseits erwachsene Warmblïter nicht mehr spontan athmen, nachdem ihnen das Nackenmark an der Spitze des Calamus scriptorius vom Halsmarke getrennt ist, so muss man die Athemcentren zwischen den genannten Schnittflächen in Nackenmarke annehmen. Neugeborene Warmblüter athmen allerdings nach der Enthauptung noch einige Zeit fort, wenigstens, wenn man ihnen etwas Strychnin gegeben hat, und man hat hieraus auf eine grössere Selbstständigkeit der spinalen Athemmuskeleentren auch während des späteren Lebens schliessen wollen. Es lässt sich aber mit ziemlicher Sicherheit erweisen, dass beim normalen Athmen des erwachsenen Warmbliiters die spinalen Athemmuskelcentren ihre Erregung nur von Athemcentren oberhalb des Spinalmarkes erhalten.

Die Bahnen für Zuleitung dieser Erregung liegen in den medialen Partien der Seitenstränge des Rückenmarkes. Die Fortsetzung der spinalen Seitenstränge finden wir in der Formatio reticularis des Nackenmarkes. Der Zusammenhang dieser Formation mit der respiratorischen Leitungsbahn des Halsmarkes, sowie ihr histologischer Aufbau aus vielen Nervenzellen und mannigfach durchkreuzten Nervenfasern, die zu Vagus, Glossopharyngeus, Trigeminus in Beziehung stehen, lassen sie geeignet erscheinen, dem Athemcentrum als anatomisches Substrat zu dienen. Die Resultate von vorsichtigen Exstirpations- und Reizversuchen bestätigen diese Erwartung.

Die Ursache für den Antrieb zu den regelmässigen rhythmischen Athembewegungen muss man zweifellos in der Beschaffenheit des Blutes suchen; steigert man bei einem Thiere den Kohlensüuregehalt des Blutes dadurch, dass man es kohlensäurehaltige Luft athmen lässt, so werden die Einathmungen tiefer und wohl auch häufiger. Dasselbe tritt ein, wenn man das Thier sehr sauerstoffarme Luft athmen lässt. Der Schluss liegt sehr nahe, dass, wie hier die Inspirationsthätigkeit gesteigert wird durch eine Aenderung im Gasgehalte des Blutes, und zwar in erster Limie durch Vermehrung des Kohlensäuregehaltes, so auch die nor'male Athmung durch den gewöhnlichen Gehalt des Blutes an Kohlensäure unterhalten wird. Diese Schlussfolgerung wird gestiitzt durch die Be- 
trachtung der holen Zweckmïssigkeit, welche einer solchen Einrichtung zukommen wïrde. Die Athembewegungen dienen dazu, dem Blute Siuerstoff zu liefern und es ron Kohlensäure zu befreien. Der Zweck kann nicht besser erreicht und das Maass der Anstrengung kann nicht besser dem jeweiligen Bedïrfniss angepasst werden, als wenn dic Kohlensäure des Blutes selbst als Reiz zur Erzengung der Athembewegung dient; es ist zweckmässig, dass in erster Linie die Kohlensäure dies thut und nicht der Sauerstoffmangel, weil bei Kohlensäureanhäufung die lebenden Gewebe nicht so stark geschädigt werden wie bei Sauerstoffnangel. Durch die rorwiegende Wirkung der Kohlensäure als Athemreiz ist dafiir gesorgt, dass die Athmung für gewöhnlich so ausgiebig ist, dass es in den Gereben gar nicht erst zu Sanerstoffmangel kommt.

Den Angriffspunkt der Kohlensïure als Athemreiz hat man frïher in die Peripherie, zum Theil in die Lunge, zum Theil in die liörpergewebe selbst rerlegt. Nach dieser Ansicht würden die normalen Athembewegungen dem allgemeinen Typus der Reflexbewegungen einzuordnen sein. Es scheint aber - wenn auch völlig beweisende Experimente sehr schwer anzustellen sind - dass regelmässige Athmung fortbestehen kann nach Abtrennung des Hirns und nach Unterbrechung aller centripetalen zum Nackenmarke laufenden Nerrenbahnen. Hiernach nuss man annehmen, dass die Nervenerregungen, welche den Athembewegungen zu Grunde liegen, in den Athemcentren selbst unter der Einwirkung des dieselbe durchströmenden Blutes entstehen; man bezeichnet solche Entstehung von Erregungen im Nervencentrum, nicht eben gliicklich, als a to matische; man könnte sie besser eine autochthone nennen, eine an Ort und Stelle, unter der directen Einwirkung des Blutes oder eigentlich der Lymphe entstandene, im Gegensatze zu der auf erregungsleitenden Nervenbahnen hinzugetragenen.

Wenn aber auch die Athembewegungen ihrer Entstehung nach nicht als reflectorische aufzufassen sind, so greifen doch in den Ablauf derselben centripetal zugeleitete Frregungen wesentlich mit ein. Der wicltigste hier in Betracht kommende Reflexrorgang ist folgender. In dem Halsvagus verlaufen centripetale Nervenfasern, welche ron den Lungen kommen und zu dem Athencentrum der Medulla oblongata gehen, die Endausbreitungen dieser Fasern in den Lungen werden gereizt durch jede Dehnung des Lungengewebes und die Erregung, welche die Fasern dem Centrum zuführen, hat eine Hemmung der Inspiration, bei stärkerem Grade anch eine Anregung der exspiratorischen Muskelthätigkeit zur Folge. Man kaun sich hierron dadurch überzeugen, dass man ein Kaninchen durch ein Ventil athmen lässt, welches die Inspiration gestattet und die Exspiration rerhindert. Die Lungen werden dadurch in ausgedehntem Zustande erhalten; schon die zweite Inspiration durch 
das Ventil erfolgt verspätet, sie ist tiefer, weil der Kohlensäuregehalt des Blutes zugenommen hat, sie führt deshalb $\mathrm{zu}$ einer noch grösseren Dehnung der Lunge, die nächste Inspiration, welche allerdings noch mehr vertieft ist, erfolgt mit noch grösserer Verspätung und so fort. Später kommt es auch zu einer exspiratorischen Thätigkeit der Bauchmuskeln. Wiederholt man den Versuch, nachdem beide Halsvagi durchschnitten sind, so atlimet das Thier in unverändertem Rhythmus fort, obgleich es auch hier zu einer fortschreitenden Füllung und Dehnung der Lungen kommt. Die activen Exspirationen bleiben aus.

In noch einfacherer Weise kann man sich von dem Vorhandensein dieser Faserkategorie in dem Vagus überzeugen; hat man einem Kaninchen eine Trachealcanüle eingelegt, beobachtet man die Athembewegungen desselben scharf und hält man genau am Ende einer gewöhnlichen Inspiration die Trachealcanüle zu, so bleibt die nächste Inspiration länger ans, als nach dem bisherigen Rhythmus der Athmung zu erwarten war; man hat nichts weiter gethan als die Lunge in der Ausdehnung, welche sie durch eine gewöhnliche Inspiration erreicht hatte, festgehalten. Dass der die nächste Inspiration hemmende Erfolg von Fasern des Vagus abhängt, erkennt man daran, dass derselbe ausbleibt, wenn beide Vagi am Halse durchschnitten sind. Auf eine Existenz einer anderen Faserkategorie im Vagus, welche sich zu der ersten sowohl in Bezug auf die Erregungsursache als auch in Bezug auf die reflectorische Wirkung antagonistisch verhält, muss man daraus schliessen, dass im Momente des Entstehens eines Pneumothorax, so lange die Vagi intact sind, eine tiefe Inspiration erfolgt. Durch mannigfaltig variirte Versuche ist die Existenz dieser beiden Faserkategorien über allen Zweifel sicher gestellt; wir haben also im Halsvagus Nervenfasern, welche bei der Dehnung der Lunge erregt werden und welche hemmend auf die Inspiration, erregend auf die Exspiration wirken und daneben Fasern, welche bei der Verkleinerung des Lungenvolums erregt werden und deren reflectorische Wirkung in Anregung der Inspiration bestelit.

Wegen des Vorhandenseins antagonistischer Faserkategorien im Ilalsvagus ist der Erfolg der elektrischen Reizung derselben in Bezug auf die $\Lambda$ thmung nicht mit Sicherheit vorherzusagen. Allerdings kann man, wenn der centrale Stumpf eines durchschnittenen Halsvagus des Kaninchens auf die mit der secundären Spirale cines Inductoriums verbundenen Elektroden gelegt ist, meist Stromstärken ausprobiren, bei denen als Erfolg der Reizung Feststellung des Zwerclifelles in Inspirationstetanus auftritt, ein Erfolg, wclcher mit Hartnäckigkeit als gesctzmüssig fiir jede reine centripetale Vagusreizung behauptet worden ist. Bei anderen Stromstärken, und zwar auch oft bei sehr geringen, erhält man Athemreflexe im Sinne der Exspiration. 
Zur Aufklärung darïber, wie dic genannten Faserkategorien an der Regulirung der normalen Athmung betheiligt sind, kann die elektrische Reizung des Nerren iibcrhaupt nicht beitragen; man muss sich nach cincm Mittel umsehen, welches geeignet ist, die Frregungsleitung in Vagus plötzlich zu unterbrechen, olıne selbst cinc Reizwirkung hervorzurufen. Fïr den motorischen Froschnerven besitzen wir ein solches Nittel im Ammoniak; betupft man eine Stelle des Ischiadicus am Nervmuskelpräparat mit concentrirtem Liquor ammonii caustici, so stirbt die Stelle ab und wird fuir die Erregungswelle undurchgängig, ohne dass der Muskel die geringste Bewegung zeigt. Beim Nervus vagus lässt dieses Mittel im Stiche; hat man bei einem Kaninchen, dessen Athmung man durch den Volumschreiber aufzeichnen lässt, den einen Vagus durchschnitten, so kehrt die Athmung einige Zeit nach der Durchschneidung zum normalen Typus zuruick. Betupft man nun eine Stelle des centralen Stumpfes dieses Nerven mit Ammoniak, so crhïlt man meistens erhebliche Athemreflexe, vorwiegend exspiratorischer Natur, wie sie der chemischen Vagusreizung überhaupt eigenthümlich sind. Legt man dagegen den centralen Stumpf eines frisch durchschnittenen Halsvagus in einiger Entfernung von dem Schnittende auf einen beträchtlich unter $0^{0}$ abgekühlten Metalldraht, so friert der Nerv an der Berïhrungsstelle sofort fest, olne dass sich an der Athemcurve eine Aenderung zeigt, und tetanisirt man nun den Nerven zwischen Draht und Schnittende mit den stärksten Strömen, so erhält man ebenfalls keine Wirkung; man hat also die Erregungsleitung im Nerven unterbrochen, ohne eine Reizwirkung hervorgerufen zu haben. Wenn man nun den umfänglich frei präparirten undurchschnittenen Vagus der anderen Seite auf einen ebenso abgekühlten Draht legt, so hat man den Erfolg ansschliesslich auf den Fortfall der im Vagus normalerweise centripetal geleiteten Erregungen zu beziehen. Der Erfolg besteht darin, dass sofort die nächste Einathmung vertieft und rerlängert ist, und dass die späteren Athmungen um eine tiefere Nittellage bei verlängerter Inspirationsdauer siclı abspielen.

Dieselbe Erscheinung tritt oft ein, wenn man den zweiten Vagus mit einem Glasstabe aus der Wunde hebt und ihn mit sehr scharfer Scheere so durchschneidet, dass sein centraler Stumpf nicht in die Wunde fallen kann. Lüsst mau dann den Stumpf von dem Glasstabe abgleiten, so bekommt man meistens einen Athemreflex, welcher auf Reizung des Nerven durch seinen eigenen Strom, bei Herstellung der Leitung zwischen Quer- und Längsschnitt durch die feuchten Gewebe, bezogen wird. Ist die Durchschneidung der Nervi vagi von unregelmässigen Reflexerscheinungen begleitet gewesen, was ohne Anwendung besonderer Vorsichtsmaassregeln das Gewöhnliche ist, so stellt sich nach einiger Zeit wieder' 
regelmässige Athmung ein, von demselben Typus, wie er oben als reine Ausfallerscheinung beschrieben worden ist. Dieser Athemtypus nach Fortfall der reflectorischen Regulirung durch die Vagi ist als äusserst unzweckmässig zu bezeichnen. Die Athemanstrengung hat wegen der vertieften Mittellage und wegen des verlängerten Inspiriums bedeutend zugenommen und dabei ist die Athemgrösse, das heisst der Nutzeffect der Athmung, nicht gewachsen, kann sogar abgenommen haben. Nach dem Verhältniss von Anstrengung zu Nutzeffect muss man aber den Grad der Zweckmässigkeit beurtheilen.

Nach Durchschneidung beider Vagi erschöpft sich der Athemapparat in iibermässigen unfruchtbaren Inspirationsanstrengungen. Dass sein Verhalten bei intacten Vagi ein zweckmässiges ist, liegt offenbar daran, dass jede Inspiration, wenn sie eine mässige Tiefe erreicht hat, durch Vermittelung der ersten der oben genannten Kategorien von Vagusfasern sich selbst ein Ziel setzit, man nennt dies die Selbststeuerung der Athmung; die gewöhnliche Entstehung und Regulirung der Athembewegungen hat man sich also so vorzustellen, dass das Inspirationscentrum wegen des Kohlensäuregehaltes des vorbeiströmenden Blutes sich dauernd in Erregung befindet; in Folge dieser Erregung tritt Inspirationsbewegung ein; diese ist von Lungendehnung begleitet, welche diejenigen Vagusfasern reizt, deren Erregung hemmend auf den Erregungszustand des Inspirationscentrums wirkt; in Folge dessen lässt die Inspirationsanstrengung nach, es kommt zur Exspiration. Die Lunge verkleinert sich, die Reizung der inspirationshemmenden Vagusfasern fällt fort, die Erregung im Inșpirationscentrum nimmt dem Kohlensäuregehalte des Blutes entsprechend wieder $\mathrm{zu}$, und dies kommt in der nächsten Inspirationsbewegung zum Ausdruck.

Alle Einwirkungen, welche durch Vermittelung veränderter Ventilationsbedingungen im Gewebe der Medulla oblongata die Athembewegungen verstärken, haben als gemeinsames Resultat, dass die einzelnen Inspirationsbewegungen verstärkt werden, und dass die mittlere Entfernung des Thorax in inspiratorischem Sinne aus der Gleichgewichtslage sich vergrössert, mag man das Thier Luft athmen lassen, welche durch die eigene Inspirationsluft verschlechtert ist, oder solche, deren Kohlensäuregehalt allein man gesteigert hat, oder solche, deren Sauerstoffgehalt verringert ist, oder mag man den Blutfluss im Kopfe durch Cefässcompression beeinträchtigen, oder mag man die allgemeine Circulation durch einen starken Aderlass schädigen, immer antwortet die Athmung mit dem angegebenen Zeichen verstïrkter inspiratorischer 'Thätigkeit, nie zeigt sich unter diesen Bedingungen ein Ueberwiegen exspiratorischer Muskelanstrengungen. Wo solche überhaupt auftreten, sind sie schwächer als die inspiratorischen, sodass sie auf Reflexwirkung 
dureh die vermehrte Lungendehmung bezogen werden können. Wir haben also keinen Grund, auch autochthon in einem Exspirationscentrum entstehende Erregung anzunehmen. Diese scheint nur dem Inspirationscentrum zuzukommen.

Durch das vorstehend Mitgetheilte ist zwar der Rhythmus der normalen Athembewegungen verständlich gemacht, doch darf man die Thatsache nicht unbcachtet lassen, dass nach der Durchschneidung der Vagi die Athmung auch noch rhythmisch erfolgt, ohne dass man Nerven aufweisen könnte, auf welche jetzt eine Selbststenerung der Athmung zu beziehen wäre. Es ist auch nicht wahrscheinlich, dass eine periodische Aenderung im Gasgehalte des die Medulla durehfliessenden Blutes Ursache für die Rhythmik der Athembewegungen nach Vagusdurchschneidungen sei. Allerdings ist bei der Langsamkeit dieser Athmung die Möglichkeit nicht von der Hand zu weisen, dass zu der Zeit, wenn die Ausathmung beginnt, Blut in die Medulla gelangt, welches bei Beginn der vorigen Einathmung in die Lungen gelangt war und dort besser arterialisirt wurde; aber abgesehen davon, dass ein Beweis hierfuir nicht erbracht ist, würden die ferneren Thatsachen immer noch der Erklärung bedïrfen, dass der Kopf nach der Trennung vom Rumpfe noch rhythmische Athembewegungen macht und dass die Athmung zunächst auch noch fortfährt, sich rhythmisch abzuspielen, wenn man durch Unterbindung der vier Schlagadern des Kopfes den Blutstrom in der Medulla anhïlt. Es bleibt also nichts ïbrig als anzunehmen, dass es eine wesentliche Eigenschaft des Athemcentrums und zwar wahrscheinlich seiner Ganglienzellen ist, unter constanten Erregungsbedingungen rhythmische 'Thätigkeitsäusserungen zu zeigen. Dieser Phythmus der Thätigkeitsäusserung ist dabei noch zu unterscheiden von einem anderen mit weit kürzerer Periode, denn jede centrifugale inspiratorische Erregung ist eine tetanische; speciell für das Zwerchfell ist es nachgewiesen, dass jede einzehne Inspirationsbewegung aus einem kurzdanernden Tetanus ron etwa zwanzig einzelnen Erregungen in der Secunde und nicht aus einer einzigen langsam verlaufenden Zuckung besteht.

Man kann den Rhythmus der Athmungsinnervationen ohne Schäiligung des Organismus unterbrechen durch Herstellung der sogenannten kiinstlichen Respiration. Legt man cinem Thiere eine Caniile in die Trachea, deren äussercr Schenkel cine kleine seitliche Oeffnung trägt und rerbindet man diesen Schenkel mit einem Blascbalge, so wird bei jedem Zusammendrücken des letzteren die Lunge mit frischer Luft aufgeblasen; bei der Erweitcrung des Blasebalges sinken dam Thorax und Lunge durch eigene Elasticität wieder zusammen und treiben die Exspirationsluft durch die seitliche Oeffnung der Caniile hinaus. Ventilirt man die Lunge auf diese Weise in grösserem Umfange und in schnel- 
lerem Rhythmus als das Thier es selbst thun würde, so hören die eigenen Athemanstrengungen desselben bald auf, und unterbricht man nach einiger Zeit die kïnstliche Athmung, so bleibt das Thier zunächst ruhig liegen, ohne $\mathrm{zu}$ athmen; man nennt diesen Zustand des Thieres den der Apno ë; derselbe bietet darum grosses Interesse, weil er viel Aehnlichkeit mit dem Zustande des Fötus vor Unterbrechung des Placentarkreislaufes hat. Die Nabelarterien führen das durch die innere Athmung der fötalen Gewebe venös gewordene Blut der Placenta zu, wo es durch den Gasaustausch mit dem mütterlichen Blute arterialisirt wird. In diesem Zustande wird es durch die Nabelvenen dem Fötus wieder zugeführt und noch unverändert auch zur Speisung der Gefässe in der Medulla oblongata verwendet. Schon zwei Monate vor der Geburt ist beim menschlichen Fötus der ganze Athemapparat vollkommen functionsbereit, denn ein um diese Zeit $\mathrm{zu}$ früh geborenes Kind erhält sich durch eigene Athmung am Leben. Dass die Athmung nicht schon während des intrauterinen Lebens beginnt, liegt zum Theil daran, dass die Arterialisirung des Blutes in der Placenta erfolgt; ausserdem muss aber auch die Erregbarkeit des Athmungscentrums beim Fötus vor der Geburt geringer sein als bei der Mutter, denn das die Medulla oblongata durchströmende Blut des Fötus kann nicht arterieller sein, als das Blut der Mutter, welches bei dieser danernd die Athmungsthätigkeit anregt. Bei der Geburt wird der Athemreiz für den Fötus plötzlich gesteigert wegen Unterbrechung des Placentarkreislaufes und gleichzeitig wird die Erregbarkeit des Athmungscentrums gesteigert in Folge mächtiger, die ganze Hautoberfläche treffender Rieize mechanischer und thermischer Natur.

Der apnoische Zustand ist immer an ein gewisses Verhältniss ron Athemreiz und Erregbarkeit im Athemcentrum gebunden. Bei dem nach Unterbrechung ausgiebiger kiinstlicher Athmung in Apnoë daliegenden Thiere ist die Lungenluft in ihrer Zusammensetzung zunächst noch mehr derjenigen der atmosphärischen Luft ähnlich, als bei der spontanen Athmung und ist deshalb besser geeignet zur Arterialisirung des die Lungen durchströmenden Blutes; die Apnoë hält aber meist länger an, als dass man sie allein auf diesen Umstand beziehen könnte; hat man bei einem Kaninchen durch Herausnahme des Sternums das Herz freigelegt, ohne die Pleura zu eröffnen, was bei diesen Thieren wegen der Grösse und Persistenz der Thymusdrüse möglich ist, und hat man durch ausgiebige künstliche Athmung Apnoë hergestellt, so sieht man nach Unterbrechung der künstlichen Ventilation das rechte Herzohr in gewöhnlicher venöser Farbe und das linke sehr hell scharlach roth. Letzteres färlst sich bald dunkler, aber nicht so schnell, als wenn man die gewöhnliche Ventilation der Lungen durch Verschluss der Trachealcauüle unterbrochen hätte; die Athmungen des rorher künstlich renti- 
lirten Thieres begimnen, die $\Lambda$ pnoë unterbrechend, meist erst, wenn die Farbe des linken Herzohres beträchtlich dunkler geworden ist als in der Norm. Ein Blut, welches beim gewöhnlichen Thiere die $\Lambda$ themthätigkeit schon weit iiber die Norm steigern wïrde, ist also eben erst im Stande, die Apnoë mit ganz schwachen, nur nach und nach an Umfang zunehmenden Athembewegungen zu unterbrechen. Durch die Manipulation der kïnstlichen Athmung muss also auch dic Erregbarkeit des Athemcentrums herabgesetzt sein und es geschieht dies wahrscheinlich durch Vermittehung der die Lungendehnung mit Inspirationshemmung beantwortenden Nervenfasern. In der That gelingt es nach Durchschneidung der Vagi viel schwerer, cine die künstliche Respiration iiberdauende Apnoë zu erzengen als rorher.

Auch ohne künstliche Athmung kann man beim Thiere Apnö̈ erzeugen, dadurch, dass man die Erregbarkeit des Athmungscentrums im Verhältnisse zum Athemreiz herabsetzt. Beim Kaninchen kann man die beiden Arteriae rertebrales und die eine Carotis unterbinden, ohne dass dic Athemvolumeurven erhebliche Aenderungen zeigen. Kklemmt man dann die zweite Carotis ab, sodass der Blutstrom im Hirne plötzlich stockt, so nehmen die Athemziige zunächst schnell an Tiefe und auch an Frequenz zu, bald aber werden sie bei unveränderter Tiefe sehr selten und das Thier rerfällt in epileptiforme Krämpfe. Die Verlangsamung der Athmung und die ausgiebige exspiratorische Lrschlafiung bis zur Carlaverstellung weist auf cine Vermindermng der Erregbarkeit des Athmungscentrums hin, wie sie eintreten muss, wenn dic Sauerstoffzehrung in der Medulla oblongata darniederliegt. Nimmt man die Compression der zweiten Carotis sehr allmählich vor, so ändert sich die Athmung nur wenig und allmählich; giebt man den Blutstrom in der Carotis dann plötzlich wieder frei, noch che Krämpfe eingetreten sind, so tritt Apnoë cin. Während der Compression war der Athemreiz gestiegen und gleichzeitig die Erregbarkeit gesunken, sonst hïtte es wie bei plötzlicher Compression zı anfänglicher starker Zunalıme der Athembewegungen kommen müssen. Bei plötzlicher Freigehung des Blutstromes durch das Hirn nimmt der Athemreiz schneller ab, als die Erregbarkeit sich wiederherstellt, daher dic $\Lambda$ pnoë. Auf ähnliche Weise zu erklären ist jedenfalls auch die Apnö̈, welche man bei Thieren zu sehen bekommt, wenn man ihnen nach lebensgefïhrlicher Blutentzichung eine schnelle reichliche Injection von körperwarmer physiologischer Kochsalzlüsung in eine Venc macht. Diese $A_{p}$ mö̈ hat insofern besonderes Interesse, weil man darauf gefasst sein muss, sie anch am Menschen bei eincr lebensrettenden Transfusion zu sehen.

Von centripetalen Nervenbahnen, durch deren Vermittelung die gewöhnlichen Athembewegungen, besonderen Umständen entsprechend, modi- 
ficirt werden, kommt zunächst der Nervus trigeminus mit seinen Endausbreitungen auf der Nasenschleimhaut in Betracht. Reizung der Nasenschleimhaut durch ätzende Gase, wie zum Beispiel durch Ammoniak, stellt den Athemapparat plötzlich still, meistens in derjenigen Athemphase, welche beim Beginne der Reizung gerade bestand. Aehnlichen Effect hat starke Reizung des oberhalb der Glottis gelegenen Theiles der Schleimhaut des Kehlkopfes durch Vermittelung des Laryngeus superior. Ein kitzelnder Reiz in der Nase ruft einen coordinirten Complex besonders modificirter Athembewegungen hervor, das Niesen; dasselbe beginnt mit einer tiefen Inspiration bei weit geöffneter Glottis, dann wird, während der Rachenraum nach vorn durch die Zunge, gegen die Nase durch das Gaumensegel geschlossen ist, die Exspirationsmusculatur angestrengt, sodass die Luft in der Lunge und in dem Rachenraume unter hohen Druck kommt, und dass bei plötzlicher Aufhebung des hinteren Nasenverschlusses ein Luftstrom grosser Intensität durch die Nase streicht, welcher geeignet ist, die Ursache für den Kitzelreiz zu entfernen.

Mechanische Reizung der Schleimhaut des Schlundes und des Kehlkopfes löst Schluckbewegungen aus, ebenso elektrische Reizung des Laryngeus superior, welcher die Kehlkopfschleimhaut mit sensiblen Fasern versorgt; bei jedem Schluck steht die Athmung in Exspiration still, doch zeigt sich während dieses exspiratorischen Stillstandes eine ganz kurze und schnelle Inspirationsbewegung, man nennt sie die Schluckathmung. Die Glottis ist während derselben geschlossen. Gegen Gase und Dämpfe ist die Schleimhant des Kehlkopfes oberhalb der Glottis sehr wenig empfindlich. Die Schleimhaut des Athemrohres von der Glottis bis zu den Bronchien wird bei dem Kaninchen fast ausschliesslich vom Laryngeus inferior innervirt, beim Hunde nimmt hieran der Laryngeus superior durch Vermittelung der Galen'schen Anastomose Theil; beim Menschen ist diese Anastomose weniger entwickelt als beim Hunde; der Laryngeus inferior nimmt bei ihm wie beim Kaninchen von oben nach unten an Stärke zu, nicht wie beim Hunde von unten nach oben. Beim Menschen werden also die Reflexe von den genannten Schleimhantpartien vorwiegend durch Vermittelung des Laryngeus inferior zu Stande kommen. Der wichtigste dieser Reflexe ist das Husten, welches schon durch selır geringe hier einwirkende mechanische Reize ausgelöst wird. Dem Husten geht eine ausgiebige Inspiration voraus, dann wird durch starke Anstrengung der Exspirationsmuskeln die Lungenluft bei verschlossener Glottis unter hohen Druck gesetzt, sodass, wenn nun die Glottis geöffnet wird, eine starke exspiratorische Luftbewegung in den Athemwegen entsteht.

Auch für gewisse Gase und Dämpfe ist die Trachealschleimhant 
empfindlich; es kommen hier namentlich in Betracht Chloroform, Aether, Bromäthyl und Pental, welche man zum Zwecke der Narkotisirung einathmen lässt, und welche reflectorisch ron der Trachea aus die Athmung beeinflussen; in Folge dessen werden die Inspirationsbewegungen klein und häufig, jedoch ist dieser Reflex schnell rorübergehend; es stellt sich bei fortgesetzter Inhalation wieder ausgiebige Athmung ein, welche erst bei iibertriebener Anwendung der Nittel durch Schädigung der Centren wieder gestört wird. Vom Lungenhilus an scheint die Schleimhaut der Luftwege ganz unempfindlich zu sein.

Nicht nur ron den Lungen selbst und ron den Athemwegen aus wird die Athmung reflectorisch beeinflusst; jede schmerzhafte sensible Erregung ruft reflectorisch — zum Theil auf kurzen Reflexbögen durch die spinalen Athemmuskelcentren - active Exspiration hervor. Nicht schmerzhafte Reizungen der sensiblen Körperoberflächen haben je nach der Art des Reizes und je nach der getroffenen Körperstelle verschiedene Wirkung: Besprengung oberer Körpertheile, namentlich des Nackens mit kaltem Wasser, ruft bei den meisten Menschen starke Inspiration hervor.

Bei allgemeiner Erhöhung der Körpertemperatur tritt ein eigenthümlicher Athmungstypus auf, welchen man Tachypnoë nennen kann: die Athmung wird sehr beschleunigt und oberflächlich, aber ohne Annäherung an die Cadaverstellung; während also die einzelnen Inspirationsberegungen nur klein sind, besteht doch ein erheblicher Tonus im Inspirationscentrum, der sogar gegen die Norm gesteigert sein kann. Diese Athmungsform, welche man übrigens bei ganz gesunden Hundeu an heissen Tagen oft zu sehen bekommt, kann ausschliesslich auf thermischer Reizung der Hautnerven beruhen. Dieses ist beim normalen Hunde wahrscheinlich der Fall, welcher sich durch diese, mit starker Wasserverdunstung und Wärmeabgabe verbundene Athmung gegen eine Temperaturerhöhung seines Blutes schützt; ist aber eine solche Temperaturerhöhung erst eingetreten, wie es beim fiebernden Menschen der Fall ist, so ist an der Unterhaltung dieses Athmungstypus wahrscheinlich auch der unmittelbare Einfluss des fieberwarmen Blutes auf das Athencentrum betheiligt. Bei Thieren kann man diese Tachypnoë unter Vermeidung einer allgemeinen Temperaturerhöhung erzeugen, wenn man die Carotiden auf doppeltwandige Blechkästchen legt, durch welche man stark erhitztes Wasser fliessen lässt; die Temperatur im Rachen steigt hierbei auf Fieberhöhe, während diejenige im Rectum unverändert bleibt, diese Tachypnoë tritt auch ein, wenn die sensiblen Nerven des Kopfes von der Medulla abgetrennt sind. Fieberwarmes Blut hat also auch einen directen Einfluss auf die Form, in welcher sich der Erregungszustand des Athemcentrums äussert. 
Dass dem Athemcentrum in der Medulla oblongata auch ron höher gelegenen Centralorganen aus Erregungen zufliessen, geht daraus herror, dass wir die Athmung willkürlich in mannigfaltiger Weise modificiren können, und daraus, dass die Athemform in hohem Maasse durch Affecte beeinflusst wird. Das Lachen ist eine Athemform, welche mit einem bestimmten Gemiithszustande in ganz typischer Weise rerbunden ist. Der respiratorische Ausdruck eines entgegengesetzten Gemüthszustandes ist das Gähnen. Angst, Sorge, Erwartung, Freude verändern die Athmung bei manchen Menschen in hohem Grade, aber nicht so typisch. Willkürlich halten wir in dem gewöhnlichen Leben den Athem an, wenn wir wissen, dass uns unter den gegebenen Umständen das Athemholen schaden wïrde, zum Beispiel beim Untertauchen unter Wasser oder beim Passiren ron Räumen mit schlechter Luft. Je länger die Athmung willkürlich angehalten wird, um so stärkerer Willensanstrengung bedarf es; es tritt dabei cine sehr unangenehme, dem Gemeingefühle angehörende Empfindung ein, welche man Lufthunger nennt. Schliesslich wird der Athemreiz so stark, dass auch der stärkste Wille nicht mehr gegen ihn aufkommen kann.

Zum Zwecke des Studiums des Athemmechanismus an sich selbst kann man die Athmung willkürlich auf die mannigfaltigste Art modificiren, man kann in rein abdominalem, oder in rein thoracalem, oder in gemischtem Typus athmen; man kann unter starker Zusammenziehung des Zwerchfelles exspiriren, wenn man unterlässt, den Brustkorb durch seine eigenen Muskeln zu fixiren; man kann durch Anspannung der Bauchmuskeln das Zwerchfell hoch in dem Thorax hinaufwölben und dabei doch inspiriren durch genügende Anspannung der Heber des Brustkorbes und dergleichen mehr. Man kann sich auch durch Selbstbeobachtung davon überzeugen, dass der Wille hemmend in die natürliche Entwickelung der Inspirationsanstrengung in jeder Phase derselben eingreifen kann, ohne dass Antagonisten hierbei zu Hilfe gezogen werden.

Um den Nutzeffect rerschiedener Athmungstypen für die Lungenrentilation $\mathrm{zu}$ studiren, hat man die Athemgrösse willkürlich auf zwei verschiedene Weisen vermehrt, einmal dadurch, dass man Athemzïge von gewöhnlicher Tiefe häufiger in der Zeiteinheit ausgeführt hat, und dann dadurch, dass man bei derselben gewöhnlichen Athemfrequenz die einzelnen Athemzüge in verschiedenem Maasse vertieft hat; man bestimmte dann den procentischen Gehalt der Ausathmungsluft an Kohlensäure und den Gesammtgehalt derselben in derselben Zeiteinheit bei den verschiedenen Athemtypen und gelangte zu Resultaten, wie sie folgende Tabelle dar'stellt. 


\begin{tabular}{|c|c|c|c|}
\hline $\begin{array}{l}\text { Zahl der Atlsemzüge } \\
\text { in einer Minute. }\end{array}$ & $\begin{array}{l}\text { Kolılensäuregehalt der } \\
\text { ausgeathmeten lutt. }\end{array}$ & $\begin{array}{c}\text { In der Minute ausgeatl- } \\
\text { metes Luftrolun } \\
\text { in Kubikcentimetern } \\
\text { (Athemgrösse). }\end{array}$ & $\begin{array}{l}\text { In der Minute ausgeath- } \\
\text { metes Kohlensüurevoluin } \\
\text { in Kubikcentimetern. }\end{array}$ \\
\hline I. 12 & $4,1 \%$ & 6000 & 246 \\
\hline 24 & 3,3 & 12000 & 396 \\
\hline 48 & 2,9, & 24000 & 696 \\
\hline II. 12 & 4,5, & 6000 & 270 \\
\hline 12 & 4,0 & 12000 & 480 \\
\hline 12 & & 24000 & 816 \\
\hline
\end{tabular}

Man sieht, dass bei gleicher Vermehrung der Athemgrösse die aus der Lunge entfernte Kohlensäuremenge mehr zunimmt, also die Ventilation der Lunge ïberhaupt besser erfolgt, wenn die einzelnen Athemzüge vertieft werden, als wenn die Athmung bei gleicher Tiefe beschleunigt wird; es liegt dies daran, dass ein nicht unbeträchtlicher Theil der bei jedem Athemzuge bewegten Luftmenge gar nicht bis in die Lungenalveolen gelangt und mit fast unverändertem Gehalt an Kohlensäure und Sauerstoff bei der Ausathmung wieder entfernt wird; diese Luftmenge ist bei jedem Athemzuge die gleiche und macht also bei alleiniger Steigerung der Athemfrequenz einen grösseren Theil der gesammten Athemgrösse aus, ạls bei Vertiefung der einzelnen Athemzïge.

Unter allen Bedingungen, welche Lufthunger zu erzeugen im Stande sind und bei denen das Bedürfniss nach Steigerung der Lungenventilation besteht, tritt auch in der That unwillkiirlich mehr eine Vertiefung der einzelnen Athemzïge als eine Zunahme ihrer Frequenz ein. Die beschleunigte und oberflächliche Athmung der Wärmetachypnoë entspricht den Bedingungen, unter denen sie eintritt insofern, als es sich hier weniger um das Bedürfniss nach gesteigerter Abgabe von Kohlensäure oder Aufnahme von Sauerstoff handelt, als um die rermehrte Abgabe von Wärme. Die Erwärmmng und Wasserdampfsättigung der Einathmungshuft kommt aber schon grossentheils auf dem Wege bis zu den Alveolen zu Stande.

Zur Coordination mannigfacher Bewegungscomplexe, welche anderen Functionen als der Athmung dienen, gehören entsprechende Modificationen der Athembewegungen; bei der Sprache und dem Gesange wird dem Athembedürfnisse nicht auf die gewöhnliche Weise genïgt; die Einathmungen sind im Allgemeinen tief, selten und erfolgen in verschiedenen Intervallen, dann, wenn eine Unterbrechung der Rede oder des Gesanges dem Sinne und dem Ausdrucke dienlich ist. Der Strom der Ausathmungsluft tritt ganz in den Dienst des akustischen Zweckes. In anderer Weise wird die Athmung modificirt bei dem Saugen, Schlucken, 
Erbrechen, Aufstossen, bei den Defäcationen und bei dem Pressen im Gebärakte.

Es ist wahrscheinlich, dass dasselbe anatomische Substrat, das heisst derselbe Complex ron Ganglienzellen, in dem die Anregung zur gewöhnlichen Inspiration entsteht, auch die die Inspiration betreffenden Reflexe vermittelt, sowie Modificationen der Athmung durch den Willen und ihre Einordnung in Bewegungscomplexe, welche anderen Zwecken dienen. Den Apparat, von dem wir voraussetzen, dass er dies leistet, nennen wir Inspirationscentrum und nehmen neben ihm ein Exspirationscentrum mit analoger Function an, nur dass wir in letzterem die autochthone Entstehung von Erregungen nicht voraussetzen. Inspirationscentrum und Exspirationscentrum fassen wir zusammen unter den Begriff des Athmungscentrums in der Medulla oblongata.

Das Athmungscentrum in der Medulla oblongata ist bilateral symmetrisch angelegt, und zwar gehorcht jeder Hälfte die Athemmusculatur der zugehörigen Seite. Nach medialer Spaltung des Calamus scriptorius in der Mittellinie bleibt die Athmung für gewöhnlich zwar symmetrisch, verliert die Symmetrie aber sofort, wenn einseitig Vagus oder Trigeminus gereizt werden. Den hierdurch hervorgerufenen Reflex zeigt nur die zugehörige Seite, und nachdem die Symmetrie der Athmung einmal auf diese Weise gestört ist, stellt sie sich nur allmählich, wenn überhaupt, wieder her. In der Norm muss also die Symmetrie der Athembewegungen durch Commissurfasern gesichert sein, welche bei der medialen Spaltung des Calamus zerschnitten werden. Bei der Localisation des Athmungscentrums in der Medulla oblongata, für welches man jetzt die Formatio reticularis in Anspruch zu nehmen Grund hat, hielt man sich bis in die neueste Zeit zu oberflächlich an den Boden des vierten Ventrikels. Man umgrenzte dasselbe dem Umfange nach zu eng, und zwar auf Grund berühmter Versuche von Flourens. Da Thiere, denen man mit einem Locheisen von kleinem Durchmesser die Spitze des Calamus scriptorius entfernt, unter sofortigem Athemstillstand sterben, nannte man diese Stelle den Lebensknoten und rerlegte in denselben das Athemcentrum. Diese Ansicht muss fallen gelassen werden, da man diese Stelle und ihre Umgebung bis $\mathrm{zu}$ grosser Tiefe allmählich wegätzen kann, ohne dass die Athmung stillsteht.

Die Aetzung muss, wenn man dies Resultat crreichen will, mit Vermeidung jeglichen Druckes auf die Ungebung vorgenommen werden; es treten auch dann oft $A$ themstillstände ein, welche wahrscheinlich auf Reizung ron Hemmungsbahnen bezogen werden müssen. War dic einzelne Reizung nicht zu stark, so klingt sie bald ab und die Athmung erholt sich; dann kann man vorsichtig weiter ätzen. Ist man auf diese Weise vorsichtig und langsam vorgegangen, so tritt der definitive Athem- 
stillstand erst ein, wenn man nit der Exstirpation tief in die Formatio retieularis vorgedrungen ist. Dieser definitive Athemstillstand beruht gewiss auf Durehtrennung der respiratorischen Bahnen zum Rïekenmarke, doch werden auch Nervenzellen der Formatio retieularis unter der Spitze des Calamus scriptorius noch zum Athemcentrum der Medulla oblongata gehören, da eng begrenzte Reizung hierselbst mit Hilfe von feinen Nadeln, welche bis zu ihrer Spitze gefirnisst sind, eine Aenderung des Athemrhythmus, und nicht, wie Reizung der reinen Bahnen in den Seitenstrüngen des Halsmarkes, Tetanus der Inspiratoren ergiebt. Achnliehe Reizeffeete erhält man bei Anwendung solcher feiner Nadelelektroden aueh von beträchtlich weiter cerebralwärts gelegenen Stellen der Formatio retieularis; dem Athemeentrum kommt also eine grössere Ausdehnung zu, als man nach Flourens annahm.

Auch oberhalb der Medulla oblongata sind Stellen im Hirnstamme aufgefunden worden, durch deren Reizung Einfluss auf die Athmung in regelmässiger Weise gewonnen werden kann. Eine solche Stelle mit inspiratorisehem Reizeffecte liegt hinten am Boden des dritten Ventrikels; eine mit exspiratorisehem in der Umgebung des vorderen Theiles des Aquaeduetus Sylvii und eine zweite inspiratorisehe weiter hinten zwischen den Vierhiigeln. Ob man bereehtigt ist, diesen Stellen die Bedeutung von Athemeentren beizulegen, erseheint zweifelhaft, sie dürften zu den Reflexen in Beziehung stehen, welche von den höheren Sinnesnerven auf die Athnung ausgeübt werden können.

Der eentrale Athemapparat, wie wir ihn uns vorzustellen Veranlassung haben und wie wir ihn in Vorstehendem den wesentlichsten Ziigen nach gesehildert haben, erseheint in hohem Grade geeignet, die Athembewegungen allen jeweiligen Bediirfnissen des Organismus anzupassen. Bei jedem gesunden Thiere und auch bei dem, welches schwere Sehädigungen erlitten hat, die aber nicht den Athemapparat selbst in wesentlichen Theilen zerstört haben, ist die Athmung immer zweckmässig, welehen Typus sie auch zeigen mag. Es kann deshalb als nicht ganz passend erscheinen, dass man die meisten Abweichungen der Athmung von der gewöhnlichen Form als Dyspnoën bezeiehnet und sie der gewöhnlichen Athmung als der Eupnoë gegeniiber stellt. Es kann Nichts zweckmässiger sein, als dass sich die Athmung eines Menschen, der durch Bergsteigen mit seinen Muskeln starke Arbeit leistet, vertieft, denn der starke Ueberschuss an gebildeter Kohlensäure muss entfernt werden. Auch die Athmung, welche unter diesen Umständen auftritt, nennt man dyspnoisch.

Die dyspnoisehe Athmung kann nach Entstehungsursache und Form sehr verschieden sein. Vermehrung der Reizung des Inspirationscentrums, gewissermaassen ein Lufthunger seiner Nervenzellen, muss ein- 
treten, wenn die Kohlensäurebildung die Kohlensäureabfuhr überholt. Dies kann einerseits stattfinden durch Vermehrung der Kohlensäurebildung, wie bei der Arbeit oder im Fieber und andererseits durch Verringerung der Kohlensäureabfuhr: aus dem Gehirn durch Stagniren des Blutes bei localer oder allgemeiner Circulationsstörung, aus dem ganzen Körper bei Verkleinerung der Athemfläche der Lungen, oder bei Behinderung des Luftstromes in den Athemwegen, oder bei Athmung kohlensäurehaltiger Luft.

Diejenige allgemeine Circulationsstörung, welche jeden gesunden Organismus plötzlich durch äusseren Zufall treffen kann, ist die durch starken Blutverlust. Hat die Blutmenge bei einer Verwundung so stark abgenommen, dass die Ventrikel bei jeder Contraction nur noch einen Bruchtheil des normalen Quantums auswerfen, so sinkt der arterielle Blutdruck und damit die Stromgeschwindigkeit in den Capillaren dauernd; das Blut hat bei dem Durchströmen durch die Hirncapillaren die normale Sättigung mit Kohlensäure überschritten, ehe es noch aus dem Bereiche der Ganglienzellen im Athemcentrum gekommen ist; nur verstärkte Lüftung des Blutes in den Lungen kann verhindern, dass der Kohlensäuregehalt des Blutes im Athemcentrum eine Höhe erreicht, welche das Leben der Zellen bedroht; das Analoge gilt natïrlich auch für den Sauerstoffgehalt der rothen Blutkörperchen. In der That antwortet auch der bis dahin normale Organismus auf einen starken Blutverlust zunächst mit einer Dyspnoë, wie sie unter den übrigen Bedingungen eintritt, bei denen Lufthunger in den Zellen des Athemcentrums $\mathrm{zu}$ erwarten ist [pneumatorektische ${ }^{1}$ ) Dyspnoë]: die einzelnen Athemzüge sind vertieft, an Frequenz wenig oder gar nicht vermehrt, der Thorax bleibt auch auf der Höhe der Exspiration stärker erweitert als normal. Diese Form der Dyspnoë ist bei einem Thiere, welchem man einen lebensgefährlichen Aderlass gemacht hat, das sichere Zeichen, dass das Leben noch nicht unmittelbar bedroht ist; macht man einem solchen Thiere eine, der Blutentnahme an Menge gleiche Transfusion von defibrinirtem Blute derselben Thierart oder von körperwarmer physiologischer Kochsalzlösung, so kehrt die Athmung sofort wieder zur Norm zurïck, das Thier kann sicher gerettet werden. Durch einen vorübergehenden Athemstillstand bei Beginn der Injection darf man sich nicht irre machen lassen; es hạdelt sich un eine ganz ungefährliche Apnoë. Die Sicherheit der Lebensrettung gilt freilich nur für die Transfusion mit Blut; bei der Transfusion mit Kochsalzlösung kann später, etwa am nächsten Tage, ein Verfall der Kräfte eintreten; der sichere Nutzen der Kochsalztransfusion besteht nur in einer zeitweisen Verbesserung der mechanischen Circulationsbedingungen.

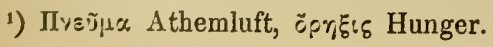


Wartet man bei dem Thiere, welches einen starken Blutverlust erlitten hat, lïnger mit der lebensrettenden Transfusion, so nimmt die Dyspnoë andere Formen an; man sieht oft ein Stadium, in welchem die Athmung verlïuft wie in der Wärmetachypnoë; in diesem Stadium hat dic Transfusion nicht mehr sicheren Erfolg. Immerhin ist dic Mittellage, um welche die kurzen hastigen Athemzïge crfolgen, noch erheblich ron der Cadaverstellung entfernt, der im Inspirationscentrum vorhandene Tonus, auf welchen man hieraus schliessen kaun, spricht dafuir, dass seine Zellen noch nicht zu stark geschädigt sind. Letzteres ist sicher erst der Fall, wenn die Dyspnoë in ein späteres Stadium getreten ist. In diesem werden die Athemzïge immer seltener; die einzelnen Inspirationen können dabei tief, sogar erheblich tiefer als normal sein, aber in den lange damernden Respirationspausen nähert sich der Thorax mehr und mehr der Cadarerstellung. Diese Dyspnoëform bekommt man immer zu sehen, wenn es sich um einen allmählichen Kräfteverfall im Inspirationscentrum handelt; man kann sie deshalb die synkopische nemnen. Ganz charakteristisch für das Absterben des Athemapparates ist ein nochmaliges kurzes Aufflackern der Athemthätigkeit kurz vor dem definitiven Ende.

Die Tachypnoë durch Temperaturerhöhung hat man als Wärmedyspnoë bezeichnet; der Mechanismus für die Antheilnahme des Centralorganes an ihrer Entstehung ist noch nicht anzugeben.

Die pneumatorektische Dyspnoë bei angestrengter Muskelarbeit hat man lange Zeit als Hauptstiitze für die Ansicht betrachtet, dass die Intensität der Athemthätigkeit in erster Linie durch den Kohlensäuregehalt des Blutes bestimmt werde. In der That wird die Bildung von Kohlensäure im Organismus durch Nichts so stark beeinflusst wie durch die Thätigkeit der Muskeln; eine Vorstellung von der Grösse dieses Einflusses bekommit man, wenn man nachstehende Zahlen betrachtet, welche angeben, wie viel Kohlensäure in Grammen von derselben Versuchsperson während einer Minute in verschiedenen Zuständen ausgeathmet wurde:

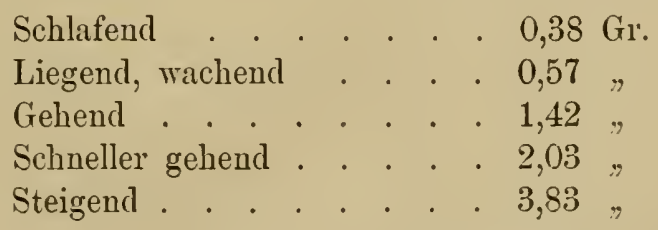

Beim angestrengten Steigen ist die Kohlensäureausscheidung also 10 Mal so reichlich, als im Schlaf; nichts liegt näher als die Annahme, dass eine durch rermehrte Kohlensäurebildung reranlasste Zunahme des Kohlensäuregehaltes des Blutes erregungssteigernd auf das Inspirations- 
centrumi wirke, und dass dadurch die Steigerung der Inspirationsthätigkeit bedingt sei, welche zur Entfernung der ïberschüssigen Kohlensäure aus dem Blute führt. Die gasanalytische Untersuchung des arteriellen Blutes von Thieren, welche sich bei starker Arbeitsleistung in dem Zustande pnenmatorektischer Dyspnoë befanden, hat aber ergeben, dass nicht nur der Sauerstoffgehalt dieses Blutes normal oder sogar grösser als in der Ruhe war, sondern dass auch der Kohlensäuregehalt des Blutes wegen seines zu geringen Werthes für die Vermehrung der Inspirationsthätigkeit nicht in Anspruch genommen werden kann. Besondere Versuche haben anch gezeigt, dass es sich um eine Vermehrung der Athemthätigkeit nach dem Bilde von Mitbewegungen, durch centrale Irradiationen von anderen Bewegungscentren aus, und auch nicht um reflectorische Anregung der Athmung durch Reizung peripherischer Endigungen centripetaler Nerven in den Muskeln handelt. Dagegen fand sich die Alkalescenz des Blutes verringert; man muss also entweder annehmen, dass hier ein anderes Stoffwechselprodukt der Muskeln als die Kohlensäure die Reizung der Nervenzellen des Inspirationscentrums übernimmt, oder dass dieses Produkt, so lange es noch nicht ausgeschieden oder weiter verbrannt ist, die Aufnahmefähigkeit des Blutes für Kohlensäure verringert. Letzteres würde zu einer Stauung von Kohlensäure in den die Kohlensäure bildenden Geweben, also auch in der Umgebung des Athemcentrums führen; und so könnte auch in diesem Falle die Kohlensäure selbst die reizende Ursache für die Athemzunahme sein. Die Kohlensäurestauung brauchte keine grosse $\mathrm{zu}$ sein und auch die vermehrte Kohlensäureansscheidung würde noch nicht unverständlich werden, wenn man auch zugeben muss, dass eine verminderte Aufnahmefähigkeit des Blutes für Kohlensäure diesem Zwecke nicht gerade förderlich ist. Hier könnten nur Bestimmungen der Kohlensäurespannung im Blute zur Entscheidung fühıren, welche unter den genannten Bedingungen noch nicht ausgefiihrt wurden. 


\section{Neunter Abschnitt.}

\section{Die Drüsen.}

Die Berleutung der Drïsen fuir den Organismus ist eine doppelte; anch in ihnen treten, wie in den Muskeln, dem Nervensysteme und den Sinnesapparaten, die circulirenden Flïssigkeiten in Wechselverkehr mit fixen Gewebselementen; während wir aber sahen, dass der Blutstrom hier wesentlich in den Dienst der speciellen Organfunctionen tritt, ist die Function einiger Drïsen gänzlich, anderer theilweise, auf eine zweekmässige Aenderung in der Beschaffenheit des sie durchströmenden Blutes oder der Lymphe gerichtet.

Die erstere Kategorie von Driisen ist gebildet durch die Lymphdrüsen und die Blutdrüisen; zu den Blutdrüisen gehören die Milz, das Knochenmark, die Schilddriise, die Brustdriise (Thymus), sowie wahrscheinlich die Hypophyse und die Zirbeldriise, vielleieht anch die Nebennieren. In diesen Organen kommt das Blut mit fixen Zellen in ausgedehnte Beriihrung und verlässt dieselben mit einer zweckmässigen Aenderung seiner Mischung; da in der Mischungsänderung des Blutes die ganze Function dieser Organe anfzugehen scheint, kann man sie als metakerastische $\mathrm{D}_{\mathrm{r}}$ ii e $\mathrm{n}$ bezeichnen.

Auch bei den ïbrigen Drüsen spielt zwar eine, für die anderen Körperorgane zweckmässige Mischungsänderung des Blutes eine mehr oder weniger grosse Rolle, anf anderem Wegeaber als mit dem Blute treten aus ihnen Flïssigkeiten aus, dic dem Blute entnommen sind; man nennt dieselben Secrete und man kann diese Kategorie von Drïsen, im Gegensatze zu den rein metakerastischen, als secretorische ezeichnen. Es ist zweekmässiger die Eintheilung der Drüsen nach ihren positiven Leistungen vorzunehmen und die secretorischen den rein metakerastischen gegenüberzustellen, als für die letzteren die einem negativen Kriterium entlehnten Ausdrücke „Drüsen ohne Ausfïhrungsgang", oder "unächte Drüsen" beizubehalten.

Unter den metakerastischen Drüsen hatten wir zuerst die L y mphdriisen genannt; dieselben sind in den Strom der Lymphe und des aus den Darmzotten stammenden Chylus eingeschaltet. Die Function der Lymphdrüsen spielt sich in den Lymphfollikeln ab; diese treten entweder als selbstständige kleine sphärisehe Gebilde, als sogenannte Balgfollikel auf, oder sie bilden, in mannigfaltig modificirter Form, die 
wesentlichen Bestandtheile grösserer Lymphdrüsen, welche auch als zusammengesetzte den einfachen gegenïber gestellt werden. Jeder Lymphfollikel ist von einer bindegewebigen, kleine Arterien und Venen führenden Kapsel umgeben und enthält in den Naschen eines reticulären Bindegewebes dichte Anhäufungen von Lymphzellen; durch diese sickert die Lymphe in langsamem Strome hindurch; das Reticulum führt Blutcapillaren. In den Lymphdrïsen werden Bestandtheile der zuströmenden Lymphe festgelialten und andere an die weiter strömende Lymphe abgegeben. Festgehalten werden geformte Bestandtheile, namentlich Eindringlinge von aussen, welche, insofern sie unlöslich und chemisch stabil sind, in den fixen Drüsenelementen dauernd zurïckgehalten werden. So findet man Kohlenpartikelchen in Zellen der Bronchiallymphdrüsen des Menschen, in einer mit dem Alter zunehmenden Zahl; oder Zinnober in den Lymphdrïsen von Extremitäten, welche mit diesem Stoffe tätowirt worden sind. Organische Eindringlinge, welche der Lymphstrom von der Peripherie her mitbringt, namentlich geformte Krankheitserreger, werden nicht nur festgelialten, sondern auch grossentheils durch chemische Zersetzung unschädlich gemacht. Gealterte lymphoide Wanderzellen werden in submucösen Lymphdriisen, namentlich in den Tonsillen, sowie in Balgdrïsen des Intestinal- und Respirationstractus aufgespeichert, gelangen unter Durchbruch durch das bedeckende Schleimhautepithel an die Oberfläche und gehen dort zu Grunde. Beigemengt werden dem Lymphistrome in den Lymphdrüsen neugebildete lymphoide Zellen.

Die Milz hat eine Kapsel aus fibrillärem Bindegewebe, von welcher ausgehend zunächst grobe, dann durch Theilung feiner und feiner werdende bindegewebige Balken und Bälkchen das ganze Innere durchsetzen; dieses maschenbildende Gerüst enthält reichlich elastische Fasern und glatte Muskelzellen; die Hohlräume der Maschen sind von einem feinen bindegewebigen Reticulum durchzogen; die Maschen dieses Reticulums sind mit lymphoiden Zellen erfüllt und werden vom Blute durchsickert; das bluthaltige lymphoide Gewebe nennt man die Milzpulpa. Die reichlichen und starken Arterien der Milz sind Verzweigungen der Arteria lienalis; sie lösen sich, vor ihrem endlichen Uebergange in einen lacunären Theil der Strombahn, auf eigenthümliche Weise in pinselartige Büschel, die Penicilli, auf. An der Wand der kleinen Arterien vor ihrer büschelförmigen Auflösung, finden sich graue Knötchen, die Malpighi'schen Bläschen; es sind dies solitäre Lymphfollikel, welche in die Bahn perivasculärer Lymphräume eingeschaltet sind. Blutcapillaren gewöhnlichen Baues kommen in der Milzpulpa nicht vor; es muss dahingestellt bleiben, ob das Blut auf dem Wege zwischen den Arterien und Venen in der Milz Räume ohne besondere Endothelauskleidung durchfliesst oder wie 
etwa die Anordnung des Endothels, wenn ein solches vorhanden ist, anfgefasst werden solle; jedenfalls scheinen die Elemente des Blutes mit lymphoiden Elementen in der Milzpulpa sich unmittelbar zu berühren. Aus der Pulpa wird das Blut durch Venen gewöhnlicher Art abgeführt; zu bemerken ist jedoch, dass die starke Vena lienalis cinen erheblichen Antheil an der Speisung der Pfortarler nimmt, dass also nahe Beziehungen zwischen den Functionen der Milz und den Functionen der Leber zu erwarten sind. Arterie, Venc und Lympligefässc durchsetzen die Milzkapsel gemeinsam an einer Stelle, welche der Hilus genannt wird, und hier treten auch reichliche Nerven in das Milzgewebe ein; durch Reizung dieser Nerven kann man erhebliche Verkleinerung des Milzrolums erzielen.

Das Blut der Milzvene führt im Verhältnisse zur Zahl der rothen Blutkörperchen eine viel grössere Menge farbloser als irgend ein anderes Blutgefäss. Die rothen Blutkörperchen der Vena lienalis sind verhältnissmässig klein, hell und resistent gegen verschiedene Reagentien; sie nehmen nicht geldrollenartige Anordnung an. Das Serum ist oft von Hämoglobin röthlich gefärbt gefunden worden. Das Milzvenenblut selbst, namentlich aber der durch Auspressen des Organes zu gewinnende Milzsaft enthält Leucin, Tyrosin, Harnsäure, Glycerimphosphorsäure und andere Zersetzungsproducte eiweissartiger Substanzen, ferner eisenhaltige Pigmente und freies Eisenoxyd. Trotz des Vorhandenseins verschiedener Glieder der Fettsïurereihe ist die Reaction im Nilzsaft alkalisch.

Die lymphoiden Elemente der Milzpulpa zeigen erheblich rerschiedene Grösse; sie sind theilweise gequollen und mit Körnchen gefüllt; man findet unter ihnen solche, welche als Bildungsstadien rother Blutkörperchen angesehen worden sind; andererseits findet man sehr grosse lymphoide Elemente, deren jedes mehrere, manchmal viele rothe Blutkörperchen (in scheinbarem Zerfall) enthält.

Die Befunde im Milzvenenblute, im Milzsafte und in der Milzpulpa sprechen dafür, dass eine der wesentlichen Functionen der Milz in Neubildung und Zerstörung geformter Blutelemente besteht. Da aber die Milz bei Thieren olne dauernden Nachtheil entfernt werden kann, miissen noch andere Organe dieser, für den Organismus jedenfalls sehr wichtigen Function dienen. Brutstätten farbloser Blutkörperchen sind ausser der Milz sicher auch die Lymphdrüisen; es giebt einen krankhaften Zustand, in welchem eine enorme Vermehrung der farblosen Blntkörperchen vorhanden ist (Leukämie), und in welchem entweder die Milz oder die Lymphdrïsen oder beide stark geschwollen und mit den histologischen Merkmalen reichlicher Proliferationen gefunden werden. In Bezug auf die Neubildung rother Blutkörperchen scheint das rothe Knochenmark der Milz zur Seite zu stehen; seine Structur ähnelt sehr derjenigen 
der Milzpulpa, und auch in ihm finden sich, namentlich nach starken Blutverlusten, zahlreiche lymphoide Elemente, welche Bildungsstadien rother Blutkörperchen erkennen lassen; ferner findet man bei Thieren nach Exstirpation der Milz oft zahlreiche kleinere und grössere rothe Anschwellungen im Mesenterium und im Netze von ähnlicher Structur wie die Milz.

- Die Milz ist grossen Volumsänderungen unterworfen. Unter normalen Verhältnissen schwillt die Milz an zur Zeit der Verdauung; die Anschwellung erfolgt unter starker Vermehrung des Blutgehaltes. Die Milznerven verhalten sich wie Vasomotoren, doch erstreckt sich ihr Einfluss wahrscheinlich ausser auf die contractilen Elemente der Milzgefässe auch auf die glatten Muskelzellen des bindegewebigen Gerüstes; die Centren dieser Nerven sollen im verlängerten Marke und im Halsmarke, bis zum vierten Halswirbel herab, liegen. Die Bahnen zur Peripherie verlaufen im linken Nervus splanchnicus und enthalten im Ganglion semilunare Nervenzellen eingeschaltet; aus diesem Ganglion entspringt das Milzgeflecht. Bei electrischer Reizung der Medulla oblongata und der genannten peripherischen Bahnen contrahirt sich die Milz, ebenso bei der Erstickung. Wie in den Lymphdrüsen unlösliche Partikelchen aus dem Lymphstrome festgehalten werden, so geschieht dies in Bezug auf das Blut in der Milz. Die Milzanschwellung, welche bei infectiösen Krankheiten eintritt, weist darauf hin, dass hier pathogene Beimischungen des Blutes zersetzt werden. Die Milz soll ferner Vorstufen oder Bildungsfermente der wirksamen Bestandtheile des Magen- und Pankreassaftes aus frisch resorbirten Nahrungsstoffen erzeugen.

Die Glandula Thymus, welche auch die innere Brustdrüse genannt wird, ist einer Lymphdrüse ähnlich gebildet, doch hat man an ihr oft Hohlräume nachweisen können, welche durch einen secretartigen Inhalt mehr oder weniger ausgedehnt waren; die centralen Hohlräume der einzelnen Läppchen communicirten mit einem gemeinschaftlichen, blind endigenden Gange. Die Function der Thymus scheint sich hauptsächlich auf das fötale Leben zu beziehen, doch wächst das Organ noch im ersten und zweiten Lebensjahre, um dann mehr oder weniger zu verkümmern oder sich mit unveränderten Resten bis in das hohe Alter zu erhalten.

An der Schilddrü se, Glandula thyreoidea, fällt die verhältnissmässig reiche Versorgung mit Blutgefässen auf; man hat deshalb ihre Bedeutung darin zu erkennen geglaubt, dass sie eine Collateralbahn zu den Hirnarterien enthalte, welche durch die Veränderlichkeit ihrer Widerstände und ihrer Capacität der Regulirung des Blutstromes in dem Gehirne diene. Das Gewebe der Drüse selbst besteht aus einem bindegewebigen Gerüste mit Hohlräumen, welche sowohl gegen einander als auch nach aussen ab- 
geschlossen sind; jeder dieser Hohlrüume ist mit einer glashellen Basalmembran ausgekleidet, welche in jugendlichem Zustande eine einfache continuirliche Schicht von mässig hohen vollsaftigen Epithelzellen trägt. Der Inhalt jedes dieser "Acini“ besteht ans einer klaren eiweissreichen Flüssigkeit. Mit fortschreitendem Alter in zunehmendem Maasse findet man zwischen solchen Acinis andere, deren epithelialer Wandbelag mehr oder wenig plattgedriickt, auch wohl ganz verödet ist, und deren Inhalt sich als eine sehr zähe "colloide" Masse erweist. Die Function der Driise ist nicht aufgeklïrt, doch ist es sehr bemerkenswerth, dass die totale Entfernung derselben nicht ohne schwere Folgen für den Organismus ist, welche wahrscheinlich nicht nur auf unvermeidlichen Nebenverletzungen in der an wichtigen Nerven und Gefässen reichen Umgebung des Organes beruhen.

Die Hypophyse, die Zirbeldrïse und die Nebennieren sind zum Theile druisenartig gebaut, verrathen aber in ihren anderen Theilen, die Hypohyse in ihrer hinteren Partie, die Nebennieren in ihrem Marke, nahe Beziehungen zum Nervensysteme; namentlich das Mark der Nebennieren ist reich an polypolaren Nervenzellen mit zugehörigen Nervenfasern. Entartungen der Schilddriuse oder der Hypophyse oder der Nebennieren sind bei krankliaften Zuständen gefunden worden, welche durch Ernährungsstörungen oder Wachsthumsanomalien weit verbreiteter Körpergewebe charakterisirt sind.

Den rein metakerastischen Drüsen kann man rein secretorische gegeniiber stellen; in diesen erfolgt, wie in allen functionirenden Organen, zwar auch eine Mischungsänderung des durchströmenden Blutes, aber hier ist nicht die Metakrasie des Blutes, sondern die Leistungsfähigkeit des gelieferten Secretes das für den Organismus Wesentliche. Repräsentanten dieser Kategorie sind die Speicheldrüsen, die Drüsen des Athemrohres, des Rachens und des Oesophagus, die Magen- und Darmsaftdrüsen, die Thränendrüsen, die Milch- und Talgdrüsen und die Hoden. Zwischen den rein metakerastischen und rein secretorischen Drïsen steht eine dritte Kategorie gemischter Function und zwar die Leber, die Nieren, das Pankreas und die Schweissdrüsen. Bei den secretorischen Driisen bilden die eigentlichen Drüsenzellen epithelartige Auskleidungen von Hohlräumen, welche mehr oder weniger mittelbar mit der Körperoberfläche communiciren; die Driisenzellen kehren in regelmässiger Anordnung ihre eine Seite dem Strome der Gewebsfliissigkeit, ihre andere dem Drïsenhohlraume zu, und ihre secretorische Function besteht darin, dass sie eigene Stoffwechselprodukte oder auch ihre eigenen geformten Abkömmlinge oder aber Bestandtheile der Gewebsfliissigkeit in den Driisenhohlraum hinein abscheiden.

Die Form dieses Hohlraumes, ob acinös oder tubulös, scheint für 
die wesentliche Function der Drüse von wenig Bedeutung zu sein; dasselbe gilt ron dem (nur anatomisch bemerkenswerthen) Unterschiede, ob jeder dieser Hohlräume durch einen besonderen Ausführungsgang mit der Oberfläche der äusseren Haut oder einer der Schleimhäute communicirt, oder ob mehrere oder viele Drüsenhohlräume die Enden eines gemeinschaftlichen verzweigten Ausführungsganges bilden.

Bei den Drüsen gemischter Function, wie bei der Leber, werden gewisse Stoffwechselproducte der Drüsenzellen in den Drüsenhohlraum (Galle in die Gallengänge) secernirt, andere (Zucker, Harnstoff und so weiter) an das Blut abgegeben, oder die Function ist deshalb als gemischte zu bezeichnen, weil, wie bei den Nieren, die in den Vordergrund tretende secretorische Function wesentlich im Dienste der Metakrasie des Blutes erfolgt, eine Metakrasie freilich, welche hier nicht in Beimischung neuer Stoffe zum Blute, sondern ausschliesslich in der Entnahme ïberflüssiger oder schädlicher Bestandtheile aus demselben besteht.

Früher unterschied man zwischen Secret und Excret, zwischen secretorischen und excretorischen Drüsen, indem man als Secret ein Drüsenproduct bezeichnete, welches im Blute nicht präformirte Bestandtheile enthält, oder welches nach seinem Ergusse noch Leistungen für den Organismus, das Individuum oder die Art entfaltet. Da sich beide Kriterien nicht immer decken, so erscheint es zweckmässig, diese sprachliche Unterscheidung aufzugeben.

Als Prototyp der reinsecretorischen Drüsen kann die Glandula submaxilla $r$ is dienen, welche beim Hunde in den Bedingungen und Aeusserungen ihrer Thätigkeit genau studirt ist. Hat man den Ausführungsgang dieser Drüse, den Ductus Whartonianus längs des horizontalen Kieferastes freigelegt und mit einer passenden Canüle versehen, so sieht man aus dem offenen Ende derselben in längeren Intervallen Tropfen einer klaren fadenziehenden Flïssigkeit austreten; man hat es mit einer der Quellen zu thun, aus welchen sich der Mundspeichel ergänzt. Der Speichelffuss aus der Canüle nimmt erheblich $z u$, wenn man die Mundschleimhant des Thieres reizt. Als eines der wirksamsten Reizmittel erweist sich hier rerdünnte Essigsäure; es ist dies die leichteste Art, experimentell am Thiere die Thatsache zu demonstriren, dass die Drüsenthätigkeit unter Nerveneinfluss steht, denn die Vermehrung des Speichelflusses bei Reizung der Mundschleimhaut kann nur auf einem Reflexvorgange beruhen. Von der Herrschaft, welche das Centralnervensystem auf die Speichelsecretion ausübt, überzeugt man sich übrigens leicht durch Selbstbeobachtung; bei vielen Menschen genügt die willkürlich gesteigerte Torstellung schmeckender, namentlich saner schmeckender Substanzen, um den Speichel im Munde zusammenfliessen zu lassen; stets 
gelingt dies, wenn man bei leerem Munde Bewegungen mit Zunge, Wangen und Kiefer ausführt, wie sie \%ur zwcckmässigen Behandlung eines Bissens dienen würden; auf letztere Weise gelingt es, grosse Mengen reinen Speichels zum Zwrecke der Untersuchung zu gewinnen; dass es sich um eine Vermehrung der Speichelbildung und nicht nur um ein Austrücken schon gebildeten Speichels aus den Drüsenhohlräumen und Ausführungsgïngen handelt, geht aus der Speichelmenge hervor, welche an Gewicht dasjenige sämmtlicher Speicheldrüsen iibertreffen kann. Es handelt sich hierbei um den gemischten Einfluss der Vorstellung und des Reflexes auf die Drüsenthätigkeit, welche ausserdem vielleicht nach dem Bilde von Vitbewegungen gesteigert wird. Wie es coordinatorische Centren giebt, welche das zweckmïssige Zusammenwirken rerschiedener MIuskeln dadurch sichern, dass sie denselben Erregungsantriebe in passenden zeitlichen und intensiven Verhältnissen zusenden, so ist eine ähnliche Coordination auch zwischen Muskeln und Drüsen denkbar.

Die reflectorische Vermehrung des Speichelflusses beim Hunde bleibt aus, wenn der Nerrus lingualis an einer Stelle durchschnitten ist, an welcher er schon die aus dem Nervus facialis stammende Chorda tympani aufgenommen lat. Letzterer Nerv muss also centrifugale, die Speichelsecretion anregende Fasern führen; eine erhebliche Steigerung des Speichelflusses erhält man auch in der That jedesmal, wenn man entweder die Chorda tympani vor ihrem Eintritte in den Nervus lingualis oder diesen Nerv zwischen der Eintrittsstelle der Chorda und dem Abgange des Nerven für die Glandula submaxillaris oder letzteren Nerven elektrisch tetanisirt. Hat man die Canüle des Ductus Whartonianus mit einem gläsernen Steigrohre verbunden, so sieht man bei jedem Tetanisiren des Nerven die Kúupe der Speichelsänle im Steigrohre um ein Erhebliches rorriicken; die Drüse gehorcht ihrem Nerven durch Speichelabsonderung beinahe wie der Muskel dem seinigen durch Tetanus, nur ist bei der Driise die Latenzzeit und die Zeit, während welcher die Wirkung den Reiz ïberdauert, viel grösser; während beim Muskel diese Zeiten nur durch besondere Hilfsmittel anschaulich gemacht werden kömnen, fallen sie bei der Drüse ohne Weiteres auf, und namentlich die letztere Zeit kann sich iiber mehrere Secunden erstrecken.

Günnt man der Drüse zwischen den einzelnen Nervenreizungen etwas Ruhe, und giebt man jeder einzelnen derselben nicht zu grosse Stärke und Dauer, so treibt jede neue Reizung die Speichelsäule zu immer grösserer Höhe und man kann den Versuch in dieser Art fortsetzen bis der Druck der Speichelsäule einen gewissen Werth erreicht hat, welchen man den maximalen Secretionsdruck der Speicheldriise nennen kann; es ist sehr bemerkenswerth, dass dieser Druck meistens 
löher ist, als der zu derselben Zeit in der Carotis desselben Thieres gemessene maximale Blutdruck.

Entleert man das Steigrohr, nachdem der maximale Absonderungsdruck erreicht war, so kann man es durch wiederholte Reizungen wiederum füllen und die auf diese Weise zu gewinnenden Speichelmengen iibertreffen an Masse bei weitem die der Drïsen, es handelt sich auch hier sicher um eine Steigerung der Speichelbildung.

In der Chorda tympani verlaufen nicht die einzigen Nervenfasern, deren Reizung die Absonderungsthätigkeit der Submaxillardrüse anregt; eine solche Anregung erfolgt auch bei Reizung des Halsstranges des Sympathicus; die die Erregung vermittelnden Nervenfasern verlassen diesen Strang oberhalb seines Ganglion supremum, und rerlaufen, in einer grösseren Anzahl von Aestchen die Gefässe begleitend, zum Hilus der Drüse. An der frischen Drüse unterscheidet sich das bei Chordareizung gelieferte Secret, welches man auch kurzweg Chordaspeichel oder Trigeminusspeichel nennt, von dem Sympathicusspeichel. Der letztere ist weit spärlicher, concentrirter und trübe; ermüdet man die Drüse durch oft wiederholte Nervenreizung, so schwindet der Unterschied mehr und mehr. Der Chordaspeichel der frischen Drüse enthält etwa $2 \%$, der Sympathicusspeichel etwa $6 \%$ feste Bestandtheile. Die grössere Zähigkeit verdankt letzterer dem grösseren Mucingehalte, die Trübung der Beimischung geformter Elemente. Diese sind mehr oder weniger veränderte, kernlose und kernhaltige Zellreste und Niederschläge von Kalksalzen. Nach Ermüdung der Drüse durch Chordareizung wird der Sympathicusspeichel klar und weit ärmer an festen Bestandtheilen. Der feste Rückstand des Chordaspeichels nimmt in Folge der Ermüdung lurch Sympathicusreizung ebenfalls $a b$, aber in geringerem Verhältnisse, und die Menge sinkt.

Auf die Circulationsverhältnisse in der Drüse hat die Reizung der Chorda und diejenige des Sympathicus entgegengesetzten Einfluss. Reizt man die Chorda, so röthet sich die Drüse, das Blut in den abführenden Venen wird hellrotl, beinahe wie arterielles, und schneidet man eine solche Vene an, so spritzt das Blut aus derselben pulsatorisch; misst man den Druck in einer Drüsenvene während der Chordareizung, so \%eigt er verhältnissmässig sehr hohen Werth, bis über 35 Millimeter Quecksilber. Alles dieses spricht für eine starke Erweiterung der Blutgefässe in der Drüse; die Chorda tympani führt rasodilatorische Nerven für die Unterkieferdrüse. Nervenfasern, welche die Gefässe in antagonistischem Sinne beeinflussen, werden der Drüse durch den Sympathicus zugeführt; bei seiner Reizung wird die Drüse blass, das Venenblut ist dunkel und fliesst langsam. Die starken Aenderungen der Circulation. welche hei Nervenreizungen mit den Aenderungen der Secretion Hand 
in IIand gehen, machen es mabweislich, Bezichungen zwischen beiden anzunehmen, doch diirfen wir uns diese liezichungen nicht zu einfach vorstellen. Kömnte man den Speichel als ein Transsudat ans dem Bhlute auffassen, so crsehiene die Steigerung der Speichelsecretion bei ('horkitreizung einfach erklärt dureh die beträichtliche Steigerung des l)rnckes in den Capillaren, welche mindestens so gross sein muss, als die l)rucksteigerung, wie sie in den Venen gemessen wurde. Von einem einfachen Transsudate unterseheidet sich der Speichel aber schon durch seine dhemisehe Beschaffenheit. Incin, welchem der Speichel die Eigenschaft des Fadenziehens rerdankt, ist im Blute nicht enthalten; es muss ein Product der Iriisenzellen sein; dass es einem, den Zellbelag etwa durchsetzenden Transsudationsstrome nicht einfach beigemengt wird, geht laraus hervor, dass ein solcher 'Transsudationsstrom aufhören miisste, sobald der Druck in den Ausführungsgängen den Druckwerth in den Capillaren erreicht hat; wir haben aber gesehen, dass der mögliche Secretionsdruck sogar den maximalen Druck in der Carotis erheblich ïbersteigen kann. Die Function der Drüsenzellen kann also nicht nur in einer chemischen Umbildung der rom Blute gelieferten Substanzen bestehen, sondern diese Zellen müssen anch Arleeit im mechanischen Sinne des Wortes leisten können, da sie im Stande sind, Flïssigkeit ron einem Orte niedrigeren Druckes an einen Ort höheren Druckes zn befördern. Als Begleiterscheinung mechanischer Arbeitsleistung am Muskel haben wir Entstehung von Wärme und ron Lohlensäure kemen gelernt; auch in dieser Beziehnng zeigt die Drüisenthätigkeit Analoges. Die Temperatur der ron der Chorda ans energisch gereizten Unterkieferdriise kann um einen Grad ïber die Tenperatur des zuströmenden Blutes gesteigert werden, und der Kohlensäuregehalt des Speichels iibertrifft den des Blutes.

An der Bildung von Speichelsubstanzen und an der Speichelabsonderung mïssen chemische Processe in den Drüsenzellen betheiligt sein, welche, da sie mit Arbeitsleistung rerbunden sind, es rollauf rechtfertigen, von einer thätigen Betheiligung der Drüsenzellen zu reden. Diese Thätigkeit kann wesentlich ron der Beschaffenheit der die Drüisen trä̈kenden Gewebstliissigkeit abhängen. In erster Linie lommt hier die Lymphe in Betracht, denn nur mit dieser können die Drïsenzellen in directen Stoflaustausch treten, da das in seinen Bahnen strömende Blut nirgends mit denselben in unmittelbare Berührung kommt. Wir wissen aber, dass die Reizung rasodilatatorischer Nerren, sei es dureh Vermehrung des Gefälles zwischen dem Blute in den Capillaren und der Lymphe, sei es durch Veränderung der Capillarwände, sei es durch Anregung einer eigenen Thätigkeit der Endothelzellen, die Intensität des Lymphstromes steigert. Eine schnell fliessende Lymphe muss eine 
wesentlich andere Zusammensetzung haben, als eine stagnirende, da in ersterem Falle die in den Stoffaustausch mit den functionirenden Gewebselementen getretene Flüssigkeit durch frische ersetzt wird, ehe ihre Veränderung hohe Werthe erreicht haben kann; schnell strömende Lymphe wird also auch andere chemische Processe in den Drïsenzellen anregen und unterhalten können als stagnirende. Die bisher mitgetheilten Erfahrungen würden uns also nicht zwingen, besondere Nerrenfaseru anzunehmen, welche die Drüsenzellen unmittelbar zur Thätigkeit anspornen sollten, so wie es die motorischen Nerren mit den Muskelfasern thun, durch continuirliche Erregungsleitung und directe Mittheilung des Erregungszustandes. Die Annahme besonderer Nervenfasern für die Drüsenzellen darf in der That nur unter dem äussersten Zwange anderweit unerklärbarer physiologischer Thatsachen erfolgen - aus dem schrerwiegenden Grunde, weil ihr histologischer Nachweis bisher nicht geglückt ist.

Die schon angeführten Thatsachen, dass der Speichel Substanzen enthält, welche im Blute nicht rorhanden sind, dass der Speicheldruck über den Blutdruck steigen kann, dass bei der Drüsenthätigkeit Wärme und Kohlensäure gebildet werden, sowie die später zu besprechenden, mit der Secretion zusammenhängenden histologischen Erscheinungen an den Drüsenzellen können nur'als Berreis dafür gelten, dass die Secretion auf besonderen Leistungen der Drüsenzellen beruht, und dass sie nicht der Ausdruck eines einfachen Filtrationsprocesses durch die Wände der Blutcapillaren in die Lymphräume und von hier durch die Drüsenmembran in den Drüsenhohlraum hinein ist. Wo der unmittelbare Angriffspunkt der Nerren liegt, welche erwiesenermaassen die Secretion beherrschen, ob in Elementen der Blutgefässwände, oder in Drüsenzellen, oder im interstitiellen Gewebe, geht hieraus nicht hervor. Fiir den Angriff in den Drüsenzellen selbst ist Folgendes geltend gemacht worden. An einem mit Atropin rergifteten Thiere stockt die Speichelsecretion; tetanisirt man die Chorda, so treten die Circulationsänderungen in der Drüse wie am unvergifteten Thiere ein, doch ist die Nervenreizung jetzt nicht im Stande, Secretion herrorzurufen, auch nicht, wenn man den Blutdruck durch Reizung der Medulla oblongata maximal steigert. Es könnte dies darauf berulien, dass, wie man angenommen hat, die Endigungen der specifischen Drüsennerven durch Atropin gelähmt worden sind. Ohne Weiteres wäre aber auch nicht die Möglichkeit ron der Hand zu weisen, dass das Atropin die Driisenzellen selbst so rerändert habe, dass sie auf eine Aenderung des Lymphstromes nicht in normaler Weise reagiren könnten. Dass eine Vermehrung des Lymphstromes unter den rorliegenden Bedingungen eintrete, ist allerdings geleugnet worden, aber auf Grund unzureichenden Erfahrungsmaterials. Bemer- 
kenswerth bleibt freilich noch, dass die Reizung des Sympatlicus die ihr eigenthiimliche Speichelsecretion auch bei der Atropinvergiftung unverïnder't lervor'ufen soll.

Eine andere Beobachtung, ans welcher auf die Existenz specifischer Drïsemnerven geschlossen wurde, ist folgende: spritzt man in den Ductus Whartonianus verdiimuten Speichel, welchem Chininlösung 7.11gesetzt ist, so tritt eine, Minuten lang anhaltende, derartige Beschleunigung des Blutstromes in der Drïse ein, dass das Blut bei jedem Herzpulse in hohem Strahle aus der Drüsenvene spritat, aber keine $\mathrm{Ab}$ sonderung; letztere ist aber sofort durch Reizung der Chorda in lebhaftester Weise hervorzurufen. Es muss also entweder eine locale Steigerung des Blutdruckes und der Stromgeschwindigkeit in den Bluteapillaren (durch Chinin) möglich sein, ohne gleichzeitige Beschleunigung des Lymphstromes (welche letztere dann durch Reizung der Chorda hervorgerufen wïrde), oder wenn dies auszuschliessen wäre, müsste man specifische Drüsennerven amnehmen. Zum Beweise der Existenz der letzteren ist auch geltend gemacht worden, dass ohne jeden Blutstrom, unmittelbar nach dem Tode des Thieres, oder bei vorrübergehendem Versehlusse der vier Kopfschlagadern (beim Kaninchen) durch Chordareizung noch etwas Speichelsecretion zu erzielen ist. Die Speichelmengen scheinen dann aber so geringe gewesen zu sein, dass sich der Zweifel, es habe sich um Ausdriicken schon vorher gebildeten Secretes gehandelt, nicht unterdrïcken lïsst.

Hierher gehören auch noch folgende Angaben. Auf der Höhe einer Nicotinvergiftung stockt die Speichclseeretion und weder diese noch Circulationsheschleunigung lïsst sich durch Chordareizung herrorrufen. Klingt aber die Nicotinvergiftung ab, so soll die Chordareizung schon Speichelsecretion ergeben, noch ehe sie Circulationsbeschleunigung in der Drüse reranlasst. Ferner soll einige Tage nach Durchschneidmng der Chorda in der Paukenhöhle, welche schliesslich zur Degeneration ihrer centrifugalen Nerren führt, die Chordareizung noch SpeichelHuss ohne gleichzeitige Beschleunigung des Blutstromes ergeben.

Gute Gelegenheit, Secretion und Circulation gleichzeitig zu beobachten, bieten die Papillae foliatae am Zungengrunde des Kíninchens, an denen sich die Aenderungen beider Factoren durch einfachen Augenschein heurtheilen lassen. Reizung des Glossopharyngeus ruft gleichzeitig Erguss ron Secret an die Oberflïche und hellrothe Färbung der Papillenschleimhant hervor. Bei dem atropinisirten Kaninchen hat rie Reizung denselben Finfluss anf die Fürbung, nicht aber auf die Secretion. Hat man die eine Carotis unterbunden, so zeigt sich die Papilla foliata derselben Seite von blaurother Fïrbung, hier stockt also die Circulation 
und trotzdem ruft die Reizung des Glossopharyngeus, bei dem nicht atropinisirten Kaninchen, Secretion hervor.

Bei aller gebotenen Zurückhaltung gegenüber der physiologischen Annahme histologisch nicht demonstrirter Drüsenzellennerven ist nicht zu leugnen, dass sich viele Einzelheiten in den Erscheinungen der Drüsensecretion, bei dem jetzigen Stande unserer Kenntnisse, besser unter diesen Gesichtspunkt als unter irgend einen anderen gruppiren lassen. Die wichtigsten unter diesen Einzelheiten sind folgende.

Vergleicht man den Speichel, welcher bei schwacher und bei starker Reizung der Chorda gewonnen ist, so unterscheidet er sich nicht nur durch die in der Zeiteinheit gelieferte Menge; die noch nicht ermüdete Drüse liefert bei stärkerer Reizung nicht nur mehr Speichel, als bei schwächerer, sondern dieser hat auch einen grösseren Procentgehalt an organischen Bestandtheilen (bei der Unterkieferdrüse namentlich an Mucin) als an Salzen. Bei der schon ermüdeten Drüise vergrössert die Reizverstärkung mit der Absonderungsgeschwindigkeit zwar auch noch deu Salzgehalt, aber nicht mehr den Gehalt an organischen Bestandtheilen, welcher vielmehr sinkt. Wird zwischen zwei schwachen Reizungen eine recht starke eingeschoben, so sinkt bei der zweiten schwachen die Absonderungsgeschwindigkeit ganz oder doch nahezu auf die ursprüngliche Grösse, während 'der Gehalt an organischen Bestandtheilen zwar ebenfalls wieder abgenommen hat, aber einen erheblich grösseren Werth hat als vor der starken Reizung. Hieraus geht zunächst die wichtige Erkenntniss hervor, dass diejenigen Processe in der Drüse, bei denen die specifischen organischen Secretbestandtheile gebildet oder löslich gemacht werden, im Allgemeinen nicht zeitlich zusammenfallen und quantitativ nicht proportional sind mit denjenigen Processen, auf denen die Ausscheidung des Wassers und der Salze beruht; erstere Processe hat man unter die trophischen subsummirt und man hat sie den letzteren als den eigentlich secretorischen entgegengestellt. Man ist noch darüber hinausgegangen und man hat für die Anregung jedes dieser Processe besondere Gattungen von Nervenfasern angenommen: besondere trophische und besondere secretorische Drüsennerven.

Ueber die trophischen Processe in der Drüse erhält man am besten Auskunft durch Vergleichung histologischer Präparate, welche ungereizten und gereizten Drüsen-entuommen sind. Was das Stroma der Speicheldrüsen betrifft, so ist als physiologisch bemerkenswerth hervorzuheben, dass Nervenzellen in beträchtlicher Zahl dort nachgewiesen sind, dass die Blutcapillaren die einzelnen Acini in zicmlich dichten Netzen umspinnen und dass zwischen ihnen und der Grenzmembran der Acini sich iiberall nachweisliche Lymphspalten befinden. In aussergewöhnlicher lireite treten diese hervor, wenn man die Drüse bei verschlossenem Ans- 
führungsgange gereizt hatte, oder wenn man sie, nachdem sie ein Steigrohr bei der Reizung gefïllt, mit diesem in Verbindung gelassen hatte: in beiden Fïllen entsteht Oedem der I)rïse. Ein solches Oedem ist nieht nachweislich, wenn durch Atropinvergiftung die Secretion aufgehoben und durch Chordareizung der Blutdruck in den Capillaren gesteigert worden war. Die Grenzmembran der einzelnen Acini wird als eine eontinuirliche Basalmembran beschrieben, in deren Substanz platte kernhaltige, unter einander anastomosirende Zellen (die Korbzellen) eingebettet sind; ron eigentlichen Epithelzellen finden sich in den Acinis der Glandula submaxillaris und der iibrigen nach ihrem Typus gebauten Drïsen, welche später aufgezählt werden sollen, zwei Arten; die einen, welche mit einem Theile ihres Leibes die unmittelbare Begrenzung des ganzen acinösen Hohlraumes bilden, erweisen sich nach ihrer Isolirung (zum Beispiel in Jodserum) als unregelmässige birnen-, keulen- oder triehterförmige Gebilde; sie besitzen eine Membran und einen stark lichtbrechenden, in Carmin fürbbaren Fortsatz; an der Grenze zwischen diesem Fortsatze und dem iibrigen Zellkörper liegt der Kén von etwas Protoplasma umgeben, welches sich ron hier als ein feines Fadennet\% durch die ganze Zelle ausbreitet. Die Zwischenräume des zarten Netzes sind, ausser an dem mit Carmin fürbbaren Fortsatze, ron einer hellen Masse ausgefüllt, in welcher mattglänzende Körnchen zerstreut liegen. Die helle Masse, welche den bei weitem grössten Theil der Zelle ausmacht und welcher nur wenig Eiweiss beigemischt ist, zeigt die meisten der für das Iucin charakteristischen Reactionen. Innerhalb des Acinus liegen diese Zellen (die Schleimzellen) derart, dass die Fortsätze sich ihrer Länge nach an die Membrana propria anschmiegen; kommen die Fortsätze benachbarter Zellen hierbei nahe bei einander zu liegen, so entstehen in Carminpräparaten dicht an der Membrana propria breite ins Auge fallende Streifen, welche bei fliichtiger Betrachtung mit Complexen der anderen Art von Epithelzellen verwechselt werden könneu. Die letzteren Zellen liegen breit der Basalmembran an, man nemnt sie deshalb Randzellen. Beim Hunde bilden die Randzellen Gruppen von annähernd halbmondförmiger Gestalt (Halbmonde, Lunulae Gianuzzi), zwischen der Membrana propria und den, den centralen Theil des Acinus einnehmenden Zellen der ersteren Art gelegen. Bei der Katze sind jene Randzellencomplexe stärker entwickelt, so dass sie nicht selten den grösseren Theil des Acinus umgreifen. Die Randzellen sind selur albuminreich, sie fürben sich stark mit Carmin und anderen Farbstoffen. Der einzelne Halbmond enthält meist mehrere Kerne und es ist schwer zu sagen, ob er aus eben so vielen Zellen bestelit, oder ob es sich um Zellen handelt, welche in Theilung begriffen sind; letzteres ist wahrscheinlicher. In Folge anhaltender Reizung gehen beiderlei Zellarten sehr be- 
dentende Aender'ungen ein; die helle Masse der Schleimzellen, welche an der ruhenden Drüse nicht mit Hämatoxylin färbbar war und sich hierdurch noch von dem Mucin unterschied, hat diese Färbbarkeit angenommen, man sagt das Mucigen hat sich in Mucin verwandelt. Schon allein durch Behandlung mit Hämatoxylin kann man die thätige von der ruhenden Drïse unterscheiden. Die helle, jetzt mit Hämatoxylin fürbbare Substanz in den Schleimzellen hat an Menge abgenommen. Die früher abgeplatteten der Basalmembran naheliegenden Kerne der Schleimzellen sind gerundet, mehr nach der Mitte gerïickt; das Zellprotoplasima vermehrt, die ganze Zelle dadurch getrübt und durch $\mathrm{Ab}$ gabe von Schleim verkleinert. Die Randzellcomplexe haben an Grösse zugenommen, die Zahl ihrer Kerne ist vermehrt. Bei langem Anhalten der gesteigerten Zellthätigkeit kommt es zum Untergange von Schleimzellen und zum Wiederersatze derselben aus den Randzellcomplexen. Sind nach sehr anhaltender Reizung die Schleimzellen reichlich zu Grunde gegangen, so haben sich die Acini der Drüse zum grossen Theile mit nengebildeten kleinen eiweissreichen Zellen gefüllt, der Gegensatz zwischen Randzellen und centralen Zellen ist geschwunden, die Halbmonde sind deshalb in dem grössten Theile der Acini unsichtbar geworden.

Aus diesen Beobachtungen, welche auf die mit Ruhe und Thätigkeit verbundenen trophischen Vorgänge in den Drüsenzellen ein Licht werfen, muss man Folgendes schliessen. In der Ruhe wird in den zu der Secretionsthätigkeit differenzirten Drüsenzellen eine Vorstufe des Secretes gebildet, von welcher man annehmen muss, dass sie ein Stoffwechselproduct des Zellprotoplasmas ist. Der specifische Secretbestandtheil selbst entsteht aus einer Vorstufe erst bei beginnender Secretion und wird nun in dem Maasse wie er gebildet wird, von dem durch besondere Processe des Zellprotoplasmas unterhaltenen Wasserstrome, zulgleich mit den Salzen fortgeführt. Die Menge des fortgeführten specifischen Secretbestandtheiles hängt nicht nur von der Intensität des Wasserstromes, sondern in hervorragender Weise von der Geschwindigkeit seiner Bildung ab. Während der Drïsenthätigkeit ist die Ernährung und das Wachsthum des Protoplasmas aller Drüsenzellen, der höher differenzirten sowohl wie der wenig differenzirten gesteigert. In ersteren bildet das Protoplasma die Vorstufe des specifischen Secretbestandtheiles, jedoch hält bei sehr angestrengter Thätigkeit diese Neubildung nicht Schritt mit der Weiterbildung und Ausscheidung; die Zelle geht selbst hierbei zu Grunde, die weniger differenzirten Drüsenzellen vermehren sich durch Theilung und ihre Abkömmlinge differenziren sich zu Secretionszellen.

Es ist nicht zu erwarten, dass in der Unterkieferdrüse unter normalen Bedingungen die trophischen Processe der Drüsenzellen zeitlich 
so gedrängt verlaufen, wie man es dureh kïnstliche übermïssige Reizung erzielen kamn; letzteres ist auch bei anderen Drüisen nicht in demselben Malisse der Fall; immerhin kionnen die Verhältnisse, wie wir sie an der Unterkieferdrüse kennen gelernt haben, als typisch für eine grosse, ja für die grösste Zahl der secretorischen Drüisen gelten. Am ähnlichsten der Unterkieferdrïse verhalten sich die ül)rigen Schleindrïsen; hierher gehören die Glandula sublingualis (und orbitalis beim Hunde), die Drüsen des Schlundes, des Kehlkopfes, der Luftröhre und der Speiseröhre. In Bezug auf den Process der Absonderung haben die "Eiweissdrüsen" Aehnliclilieit mit den "Schleimdrüsen", von welchen sie sich aber durch wesentliche Bestindtheile ilures Seeretes und ihrer Secretionszellen unterscheiden. Prototyp der Eiweissdrüsen ist die Ohrspeicheldruise des Menschen, sowie aller Sängethiere. In der Unterkieferdriise des Menschen und einiger anderer Süugethiere gehört ein Theil der Acini den Schleim-, ein anderer den Eiweissdrüsen an. Ebenso sind beim Menschen die Drüsen der Mundhöhle und der Nasenhöhle zwischen beiden Formen getheilt. Zu den reinen Eiweissdrüsen gehört die Ohrspeicheldrüse aller Sïugethiere und die Unterkieferdrïse des Kaninchens. Das Secret der Eiweissdrüsen, namentlich der Parotis, enthält unter Umständen eine solche Menge ron Albuminaten, dass es in der Siedhitze durch Eiweissgerinnung vollkommen fest erstarrt.

Die genauesten Beobachtungen ïber die Bedingungen und Vorgänge der Secretion ron Eiweissdriusen sind an der Parotis des Kaninchens und des Hundes angestellt worden; auch diese Drïse erhält Nerrenfaser'n auf dem Wege des Sympathicus und eines cerebralen Yerven. Letztere werden der Dr üse durch den Nerrus auriculo-temporalis zugefïhrt, stammen aus dem Nervus glossopharyugeus und nehmen den Weg durch den Nervus Jacobsonii, den Nerrus petrosus superfacialis minor und das Ganglion otieum. Der Unterschied in der Wirkungsweise der cerebralen und sympathischen Nervenfasern tritt hier noch stärker hervor; die Secretmenge ist bei Reizung der letzteren noch geringer, der Einfluss auf das histologische Bild der Drüse aber grösser. Weun bei anhaltender Reizung des Sympathicus nur wenig oder gar kein Secret geliefert ist, so treten histologische Verïnderungen doch sehr deutlich herror, deutlicher als nach reichlicher Secretion bei anhaltender Reizung der cerebralen Fasern. Die Acini der ruhenden Parotis weisen nur eine Art von Epithelzellen auf, welche den Schleimzellen der Unterkieferdrüse entsprechen; der Hauptunterschied hesteht darin, dass die helle Substanz derselben nicht Mucigen sondern Eiweiss ist. Diese helle Substanz nimmt bei Sympathicusreizung al), die körnige oder eigentlich netzförmige Substanz, welche in Carmin fürbbar ist (das Protoplasma) nimmt $z u$, die Kerue, welche in Alkoholcarminpräparaten der 
ruhenden Driise zackig erscheinen, sind in dem gleichen Präparate der gereizten Drüsen rund. Das Volum der Zellen hat abgenommen, doch scheinen diese Zellen bei der Thätigkeit nicht zu Grunde zu gehen.

Das Secret der Ohrspeicheldrüse ergiesst sich durch den Ductus Stenonianus in der Mitte der Wangenschleimhaut, das der Unterkieferdriise durch den Ductus Whartonianus und das der Unterzungendrüsen durch die Ducti Bartholiniani zu den Seiten des Frenulum der Zunge in die Mundhöhle; dazu kommt das Secret der Zungen- und Wangendrïsen, um das zu bilden, was man den Mundspeichel nennt: Zusammensetzung und Bedentung desselben soll bei der Lehre von der Verdauung besprochen werden.

Die Thränendrüsen schliessen sich in ilırem Baue und in ihren Absonderungsverhältnissen am nächsten an die Eiweissdrüsen an. Ihr Secret, die Thränenfliissigkeit, enthält nur etwa 0,8 bis $0,9 \%$ feste Bestandtheile, in Wasser gelöst. Etwa $0,5 \%$ sind Salze, vorzugsweise Chlornatrium und geringe Mengen Phosphorsäure, Alkalien und Erden, der Rest ist eiweissartig, unter Umständen auch schleimig; Spuren von Fett werden der Thränenfliissigkeit von den Meibom'schen Driisen beigegeben, welche auf der inneren Seite der Lidknorpel gelegen, dem Typus der Hauttalgdrüsen angehören. Die Ausführungsgänge der Thränendrüsen münden in der Conjunctivalfalte des oberen Augenlides und ergiessen das Secret in den Conjunctivalsack, wo es zur Feuchterhaltung des freiliegenden Theiles des Augapfels dient. Für gewöhnlich ist die Absonderungsthätigkeit der Thränendrïsen sehr gering; lange Zeit muss dieselbe Thränenflüssigkeit im Conjunctivalsacke bleiben; bei jedem Lidschlage wird sie zwischen den mit Secret der Meibom'schen Drïsen eingefetteten Lidrändern zusammengeschoben und entweicht unter dem erheblichen Drucke der Oberflächenspannung nach dem gleichzeitig erweiterten Thränensacke; bei jeder Lidöffnung wird sie zurïckgesaugt und durch das Zusammensinken des Thränensackes anch zuriickgedruickt. Während des Offenstehens der Lider verdunstet ein erheblicher Theil des Wassers, welches durch Ausschwitzung des Conjunctivalepithels ergänzt werden muss.

Steigt die Secretion der Thränendrüse erheblich iiber das, für gewöhnlich sehr geringe Maass an, so wird die Thränenflüssigkeit, welche im Conjunctivalsăcke und zwischen den Lidrändern nicht Platz findet, zunächst durch den hydrostatischen Druck und durch die Oberflächenspannung auf dem Wege der in den Thränempunkten der Augenlider entspringenden 'Thränengänge des Thränensackes und durch den Thränennasengang auf die Nasenschleimhaut unter der mittleren Muschel befördert. Werden die Widerstände auf diesem Wege, bei reichlichem Zuflusse, von 'Thränenfluissigkeit in den Conjunctivalsack grösser, als die Ober- 
flächenspannung zwischen den Lidränderı, so fliessen Tropfen über die Wange, die Thrïnen.

Die Abhängigkeit der Thränensecretion vom Affecte ist allgemein bekannt, sie weist ohne Weiteres auf den Einfluss hin, welchen das Nervensystem auf die Secretion der Thränendrüsen ausüht. Reflectorisch wird Thränenfluss erzengt durch Reizung der conjunctivalen und nasalen Schleimhaut, sowie durch Einfall sehr starken Lichtes in das Auge. Centrifugale 'Thränennervenfasern sind hauptsächlich enthalten im Nervus lacrymalis trigemini, ferner im Subcutaneus malie, anch soll der: Sympathicus Einfluss auf die Thränensecretion haben.

Die Bauchspeicheldrïse oder das Pankreas schliesst sich den Eiweissdrüsen unter den Speicheldrüsen am nächsten an; dass seine secernirenden Räume nicht die Gestalt von Acini, sondern von Schläuchen und Kolben haben, ist vom physiologischen Gesichtspunkte aus ein nebensächlicher Unterschied, ebenso das, was sich über den eigenthïmlich lockeren morphologisehen Aufbau und über das eigenthümliche Verhalten der Drüisengänge zum Ausführungsgange anssagen lässt. Der Quersehnitt durch die Drïsenschläuche hat an Alkoholearminpräparaten einige Aehnlichkeit mit dem Querschnitte der Acini von Fiweissdrüisen. Mau unterscheidet an Alkoholcarminpräparaten, welehe dem hungernden Thiere entnommen sind, zunächst der Basalmembran eine stark mit Carmin gefärbte niedrigere Zone, welche die meist eckigen Kerne enthält und eine das Lumen begrenzende schwach körnige uugefärbte und helle höhere Zone. Im ganz frischen Zustande ist dagegen die der Basalmembran anliegende Zone hell und scheinbar homogen, die andere ‘unkelkörnig. Als nur scheinbar homogen ist die erstere Zone zu bezeichnen, weil sie mitunter schon im ganz frischen Zustande, meist noch schärfer nach Behandlung mit verdïnnter Osmiumsäure, feine Lüngslinien erkenuen lässt; diese Längslinien entsprechen fadenartigen Bildungen, welehe am Macerationspräparate zu isoliren sind.

Bei der Bauchspeicheldrüse kann man nicht, wie bei der Unterkiefcrdrüse, die Thätigkeitszustände mit Hilfe von Durchschneidung oder Reizung bestimmter Nerven beherrschen; dass das Pankreas im IIungerzustande ruht, schliesst mau aus Beobachtungen über den Ausfluss von Secret aus Caniilen, welehe in ihren Ausfïhrungsgang, den Ductus Wirsungianus, bei Thieren eingebunden wurden. Das Riesultat dieser Beobachtungen ist leider stets lurch viele Nebenumstände getrüht; beim Hunde reagirt die Drïse auf den unvermeidlichen schweren Eingriff sofort und fuir längere Zeit mit Erblassen und Auflıören etwa vorhandener Thätigkeit oder mit der Unfähigkeit, in den thätigen Zustand ïberzugehen. Hat man aber die Bauchwunde geschlossen und die Caniile durch eine Fistelöffnung herausgefiihrt, so tritt nach einiger Zeit eine 
profuse, sichtlich abnorme Secretion ein. Die scheinbar zuverlässigsten Resultate haben bisher Pankreasfisteln ergeben, welche so angelegt waren, dass ein die Mündung des Ductus Wirsungianus enthaltendes Darmstiick oben und unten vom iibrigen Darme abgetrennt, aufgeschnitten und in die Banchwunde eingenäht wurde, nachdem der obere und untere Darm durch Darmnaht wieder vereinigt waren. Hunde, welche sich von diesem Eingriffe erholt hatten, zeigten in niichternem Zustande keinen Erguss pankreatischen Saftes. Bei Kaninchen und anderen Pflanzenfressern scheint die Drüse unter normalen VerhäItnissen beständig, auch in den Zeiten zwischen den Fütterungen, zu secerniren. Bei Hunden mit gut geheilter Pankreasfistel beginnt die Secretion unmittelbar nach der Fütterung und steigt zu einem Maximum, welches innerhalb der ersten drei Stunden erreicht wird; darauf sinkt sie bis zur fünften oder siebenten Stunde, steigt danu nochmals bis zur neunten oder elften in geringem Maasse; dam sinkt sie langsam und die Fistel wird, wenn keine nene Fïtterung eintritt, nach 24 Stunden ganz trocken. Die Veränderungen, welche in den Drïsenschläuchen eintreten, sind der Zeit nach verschieden; bis zur zehnten Stunde und später nimmt die dem Lumen zugekehrte Zone stärkere und dichtere Trübung an und wird färbbarer in Carmin, namentlich auch in Hämatoxylin. Diese Zone wird dabei kleiner, die der Basalmembran anliegende grösser, aber nicht in demselben Maasse, sodass die Zeillen in Ganzen an Höhe abnehmen. Die Kerne werden kreisrund; in dem späteren Stadium findet wieder starke Zunahme der Körner bei Verbreiterung ihrer Zone, Vergrösserung der Zellhöhe, Verkleinerung der homogenen Zone und Eckigwerden der Kerne statt.

Das Pankreassecret ist unter verschiedenen Umständen sehr verschieden reich an festen Bestandtheilen. Bei Hunden ist es oft klebrig, fast fadenziehend und erstarrt in der Kälte zu einer durchsichtigen Gallerte; ebenso erstarrt es oft, wenn man es auf dem Wasserbade kocht. Der Gehalt an festen Bestandtheilen, welcher 6 bis $10 \%$ betragen kann, ist im Allgemeinen umgekehrt proportional der Secretionsgeschwindigkeit, doch kommt es vor, zum Beispiel nach Milchfuitterung, dass der procentische Gehalt gleichzeitig mit der Secretionsgeschwindigkeit wächst, ja dass ersterer noch ansteigt, wenn letztere schon wieder fällt. Wird bei einem nüchternen Hunde die Absonderung durch Pilocarpin hervorgerufen, so fällt der Procentgehalt immer sehr hoch aus, bei geringer Secretionsgeschwindigkeit. Es muss also auch bei diesen Drüsen die Wasserabscheidung nicht auf dieselben Processe in den Zellen bezogen werden wie die Bildung und Absonderung der festen, namentlich der organischen Bestandtheile.

Bei dem Pankreas tritt auch noch deutlicher als bei den Schleim- 
driisen dic Thatsache hervor, dass specifische Secretbestandtheile nicht als solche, somdern als eine nahe stehende Vorstufe in aler Driisenzelle enthalten sind. Ein wichtiger, in der Lohre von der Verdamung ausfiihrlich zu behandelnder Bestandtheil des P'ankreassecretes ist ein, Trypsin genamntes Ferment, welehes in alkaliseher Lösmng verlaunend auf Fiweisskörper wirkt. Tödtet man einen Hund nach 24 stïndigem Hungern, matht von dem einen Theile des Pankreas sofort ein Glycerinextract und prüft dieses in einer Sodalösmng von 1 bis $2 \%$ anf seine Fähigkeit Eiweiss zu verdauten, so erweist es sich als unwirksalnx; eler 2t Stunden an der Luft gelegene Rest der Driise ergiebt ein unter gleichen Bedingungen sehr wirksames Extract; das Pankreas des hungernden Hundes, welches zwar nicht secernirte, aber bereit war, bei Fütterung sofort ein trypsinhaltiges Secret zn liefern, enthielt also kein Trypsin, sondern eine Vorstufe desselben, ein Zymogen, welches sich beim Liegen des Pankreas an der Luft in Trypsin umwandelt; das Zymogen des Trypsins geht selbst in das Glyeerinextract über, denn das Glycerinextract der frischen Hungerdrïse wird beim Verdïnnen mit lufthaltigem Wasser allmählich wirksam; besehleunigt kamn diese Veränderung werden, wenn man Sauerstoff hindurchstreichen lässt, oder mit Platimmohr schiittelt, oder mit Essigsäure ansänert; verhindert wird der Uebergang dureh Sodalösung von 1 bis $2 \%$.

Aus den oben beschriebenen histologischen Veränderungen der Drüisenzellen bei der Secretion und aus Zymogenbestimmungen der Drüsensubstanz in verschiedenen Secretionsstadien muss man schliessen, dass das Zymogen und die ibrigen specifischen Secretbestandtheile in demselben Maasse wie die Körner der das Drüsenlumen begrenzenden Zellzone gebildet und ausgeschieden werden; ferner, dass diese Bildung in der protoplasmatischen, den Kern umgebenden Zone geschieht, welehe selbst in dem ersten Seeretionsstadium durch Substanzanfnalume aus der Lymphbahn wächst, im zweiten Stadium aber mehr Substanz alogiebt als anfnimmt. Dies wïrden wir als die mit der Secretion verbundenen trophischen Processe zu bezeichnen haben, mit welchen die den Transport von Wasser und Salzen betreffenden secretorischen Processe nicht proportional zu gehen brauchen. In auffallender Weise tritt diese Trennung hervor, wemn nach Anlegung der Fistel die Dritse in eine alonorme und andanernde Secretion verfallen ist; das hierbei in ziemlicher Menge Hiessende Secret wird arm an festen Bestandtheilen, verliert das Trypsin und die anderen specifischen Secretbestandtheile, und die Drüse weist bei ihrer histologischen Untersuchung Verödung der Kï̈rnerzone der Driisenzellen anf.

Aus der Schnelligkeit, mit welcher die Pankreassecretion nach Fütterung eintritt, muss man auf einen Reflexvorgang schliessen; reflec- 
torische Hemmung der Secretion tritt ein bei starker Reizung der verschiedensten sensibeln Nerven und des centralen Vagusstumpfes, sowic beim Erbrechen. Bedingung für diesen Hemmungsvorgang ist, dass die zur Drüse tretenden Nerven erhalten sind; nach Durchschneidung aller dieser Nerven secernirt die Drüse dauernd; es sind ziemlich viel Nervenzellen in ihrem Stroma enthalten. Bei intacten Drüsennerven ruft Reizung der Medulla oblongata Secretionsthätigkeit hervor oder beschleunigt sie. Besondere Nervenfasern, welche einen hervorragenden secretorischen Einfluss hätten und andere, welche vorwiegend trophisch wirkten, sind beim Pankreas nicht nachgewiesen. Jedenfalls steht die Circulation in der Drüse einerseits unter Nerveneinfluss und andererseits in Beziehung zur Secretionsthätigkeit. Das secernirende Pankreas ist schön hell roth gefärbt; stockende Secretion pflegt mit hochgradigem Erblassen des Drüsengewebes einherzugehen; dies tritt bei reflectorischer Hemmung der Drüsenthätigkeit und bei Reizung des Splanchnicus deutlich hervor; beim Kaninchen, dessen stellenweise sehr dïnnes Pankreas im lebenden Zustande mit dem Mikroskope bei genügend starken Vergrösserungen beobachtet worden ist, sah man die Röthung der Drüse von einer hochgradigen Erweiterung der Blutcapillaren begleitet.

Der höchste Druckwerth, welcher an einem in den Pankreasgang eingesetzten Manometer beobachtet wurde, betrug 17 Millimeter Quecksilber; die Absonderung dauerte bei diesem Druckwerthe fort und führte zı einem Oedem der Drüse; der beobachtete Druck giebt also keinen Maassstab für die Triebkraft ab, deren das thätige Pankreas fühig ist, sondern nur für die, wie sich zeigte, sehr geringe Widerstandsfähigkeit der Drïsengänge gegen Transsudation nach innen.

Nach totaler Exstirpation des Pankreas bei Hunden nimmt der Gehalt des Blutes und des Harnes an Zucker krankhaft zu und die Thiere gehen unter Abmagerung und Kräfteverfall zu Grunde. Dieser Erfolg scheint nicht nur auf Verdauungsstörungen nach Wegfall der Beimischung pankreatischen Saftes zum Darminhalte zu beruhen, denn er bleibt aus, wenn Drüsenreste ohne jede Verbindung mit dem Darmrolıre zurückgelassen sind. Die Drüse scheint also auch, olne Secret in den Darm zu ergiessen, auf die Stoffwechselvorgänge im Organismus einen Einfluss auszuiuben, der auf Metakrasie des Blutes beruhen könnte.

Die Schleimhant des Magens nimmt mit allen ihren Epithelzellen an der Secretion des Magensaftes Theil ; die secernirende Fläche ist vergrössert durch makroskopisch sichtbare Faltungen und durch mikroskopisch nachweisbare schlauchförmige, an dem Boden der Faltungen mïndende Finstiilpungen, welche als Magendrïsen bezeichnet werden. Schon mit blossem Auge unterscheidet man an der Magenschleimhant zwei Theile, von denen der eine die Pylorusgegend, der andere den 
Fundus und die Curvaturen einnimnt. Frsteren nenut man den Pylorustheil, letzteren den Fundustheil. Ersterer ist blass, weisslieh und mit wenig zahlreichen hohen Falten versehen, welche sich selten mit einander rerbinden; letzterer hat eine röthlich gelbe oder röthlich graue Färbung und zahhreichere, ein unregelmässiges Netz bildende, weniger tiefe Falten; da die Magentrüsen ïberall bis zu glcicher Tiefe in die Mucosa vordringen, so sind die Pylorusdruisen kürzer als die Fundusdrïsen. Gleich grossen Stiicken der Magenschleimhat entspricht im Pylorustheile cine kleinere secernirende Oberfläche als im Fundustheile. Da dic Fundusdriisen ausserdem viel dichter stehen als die Pylorusdrüsen, so ist im l'undustheile das Verhältniss des Drüsenepithels zum Oberflächenepithel ein riel grösseres.

Die Zellen des Oberflïchenepithels scheiden Schleim aus und gehen dabei nach und nach zu Grunde; man findet ihren, der Oberfläche zugekehrten Theil, besonders nach gewissen Behandlungsmethoden entleert, die an den Seitenwïnden erhaltenen Membranen, die Tüten, nur im unteren Theile gefüllt mit Protoplasma und einem in der Zellaxe verlïngerten Kerne. Wo der obere Theil des Zellinhaltes erhalten geblieben ist, erweist er sich als aus stark mit Fiweiss gemischtem Schleim bestehend. Zwischen diesen Zellen des Oberflächenepithels und der Basalmembran liegt eine, nicht zusammenhïngende Schicht kleiner protoplasmatischer Zellen, welche als Bildungsstufen der secernirenden Zellen angesehen werden. In der Tiefe der Falten ändert das Oberflächenepithel gegen die Drüsenmündungen hin etwas sein Aussehen, die Zellen werden niedriger und schmaler und zeigen weniger Andeutungen des Zerfalles. Yon dem Drïsenepithel ist das Obertlächenepithel iiberall zu unterseheiden. Es ist dies hesonders für die Pylorusdruisen herrorzuheben, deren Epithel frïher mit dem Oberflächenepithel identificirt wurde. Die Zellen der Pylorusdriisen finden sich nach keiner Behandlungsweise theilweise entleert wie die Zellen des Oberflächenepithels; in letzteren ist nur der nicht ausstosshare Rest tingirbar, in ersteren die gauze Zellsubstanz; der Kíern der Pylorusdriisenzelle ist querverlängert; in AlkoholCarminpräparaten zeigt sich das Oberflächenepithel von einer Schleinlage ïberzogen, während das Secret der Driisenzellen in dem Drüsenhohlraume eine durch Pikrocarmin färbbare Masse darstellt.

Die Fundusdriisen enthalten zwei Arten von Zellen; die einen, welche in der ganzen Ausdehnung des Drüsenschlauches rorkommen, werden die Hauptzellen genannt, die anderen, welche zerstreut zwischen den Hauptzellen und der Basalmembran liegen, die Belegzellen oder Laabzellen. In der Nähe der Mündung, am sogenannten Drïsenhalse, nimmt die Zahl der Belegzellen im Verhältniss zu derjenigen der Hauptzellen bedeutend zı. Die Pelegzellen sind sehr eiweissreiche, im Hunger- 
zustande kleine, unregelmässig geformte, oft eckige Zellen, welche durch Färbbarkeit in Anilinblau ausgezeichnet sind; die Hauptzellen sind den Zellen der Pylorusdrüsen sehr ähnlich, unterscheiden sich aber von ihwen in frischem Zustande durch eine gröbere dunkelkörnige Granulirung.

$\mathrm{Zu}$ Beobachtungen iiber Secretion und Zusammensetzung des Magensaftes dienen Hunde, denen eine Magenfistel angelegt ist; die Magenwand wird mit der Bauchwand zur Verheilung gebracht und in die, beiden Wänden gemeinschaftliche Fistelöffnung eine weite Canüle mit rorstehenden Rändern eingeheilt, welche für gewöhnlich durch einen Kiorken geschlossen wird. Hunde vertragen solche Magenfistel Jahre lang. Auch bei Menschen hat man manchmal Gelegenheit zu Beobachtungen an der Magenfistel; ja die durch ein Trauma entstandene Magenfistel eines canadischen Pelzjägers hat auf diese Untersuchungsmethode geftihrt, welche sich sehr nutzbringend erwiesen hat. Ohne dass die Verdauungsthätigkeit gestört ist, kann man aus solcher Magenfistel reinen Magensaft oder Mageninhalt in verschiedenen Zeiten nach Nahrungsaufnahme entnehmen; man kann mit Hilfe eines Spiegels die Magenschleimhaut beobachten, mit Hilfe eines Thermometers die Temperatur messen und so fort. Bei der Gewinnung reinen Magensaftes hat man allerdings darauf $\mathrm{zu}$ achten, dass er nicht mit rerschlucktem Speichel gemengt ist, was man leicht an der schaumigen Beschaffenheit erkennt. Reiner Magensaft ist eine klare, kaum fadenziehende Flïssigkeit. Schwer zu erlangen, dafür aber auch um so werthroller sind Magenfisteln, welche bei Hunden so gebildet sind, dass nach Ausschneidung eines Stückes entweder aus dem Pylorustheil oder aus dem Fundustheil, die Continuität des Verdauungsrohres durch Vernähung der Magenwunde wiederhergestellt und aus dem isolirten Stücke ein, in die Bauchöffnung mündender Blindsack gebildet wird.

Hat man einen Hund mit gewöhnlicher Magenfistel einen Tag lang hungern lassen, stellt ihn mit geöffneter Canüle auf den Tisch und zeigt ilım, während man ilın festhält, ein Stück Fleisch, so fliesst zunächst reiner Magensaft aus der bis dahin trockenen Canüle aus, welchen man in ein untergestelltes Gefäss auffangen kann. Bald mischen sich weisse schaumige Schleimklumpen bei, welche von verschlucktem Mundspeichel herrühren; wir sehen, dass der Magen im nüchternen Zustande wenig orler gar keinen Saft absondert, dem entspricht auch der Befund bei der Section nüchterner Hunde; doch finden wir hier die Schleimhaut mit einer Schleimschicht bedeckt, welche am stärksten am Pylorustheile ist. Um die Secretion von Magensaft hervorzurufen, genügt die Anregung einer Vorstellung. Bei cinem Menschen, welchem wegen einer gan\% undurchgängigen Oesophagusstrictur eine Magenfistel angelegt wor. den war, beolachtete man ausserdem Magensaftsecretion beim Kauen 
schmeckender Substanzen. Die Magensaftsecretion muss also unter dem Einflusse des Centrahnervensystemes stehen. Diesen Schluss werlen wir aufrecht erhalten miissen, auch wenn es bisher noch nicht gelungen ist, dureh Reizung oder Trennung von Nerren zweifellose Einwirkungen auf die Magensaftabscheidung zu gewinnen. Geprift wurden darauf ohne sicheren Erfolg Vagus, Splanchnicus und Plexus coeliacus; nach $\mathrm{Ab}$ tremmung aller bekannten Nervenverbindungen bestand Absonderung wirksamen Magensaftes fort; der Magen zeigt hierin Analogien mit dem Herzen, dessen Thätigkeit normalerweise rom Centralnervensystein geregelt wird und welches doch nach Trennung der nerrösen Verbindungen fortarbeitet. Die Magenwand enthält beträchtliche Mengen ron Ganglienzellen eingelagert, sodass die Annahme ron Reflexen, welche sich in iler Magenwand selbst abspielen, erlaubt scheint.

Für einen directen Einfluss ron Nervenerregungen auf die Stoffwechselvorgänge in den Drüsenzellen liegen bei dem Magen keine Anzeichen ror. Die Wirkung centraler und peripherischer Nervencentren muss eine mittelbare scin; die Vermittelung könnte durch die Gefïsse erfolgen, denn die Röthung der Magenschleimhant bei beginnender oder rermehrter Secretionsthätigkeit ist direct beobachtet worden. Splanchnicusreizung macht die Magenschleimhant erblassen. Die Vermittelung wäre aher auch denkbar durch Contractionsrorgänge in rer Magenwand, welche zu mechanischer Schleimhautreizung führen könnten. Von der Wirksamkeit mechanischer Reize iilserzeugt man sich an einem Hunde mit Darmfistel leicht, indem man einen Glasstab in die Canïle einführt und mit demselben die Magenschleimhaut streicht. Es fliesst Magensaft, wenn auch in geringer Menge, aus. Führt man einen dünnwandigen Kautschukbeutel in den Magen ein und wechselt öfters mit Aufblasen und Zusammenfallenlassen desselben, so erhält man erheblich grössere Mengen; es geht hieraus herror, dass die Menge des Secretes bei mechanischer Reizung von der Grösse der direct getroffenen Schleimhantfläche abhängt, dass also eine Mittheilung der Erregung ron einem Theile der Magenfläche auf eimen anderen nicht statthat.

Wirksamer als mechanische Reizung ist chemische, namentlich durch alkalisch reagirende Substanzen; einen höchst bemerkenswerthen Einfluss auf die Magensaftsecretion ibt die Resorption nahrhafter Substanzen aus; Versuche an einem Hunde mit isolirtem Fundusblindsack haben in dieser Beziehung sehr werthrolle Resultate ergeben; bei gewöhnlicher Fütterung mit verdaulichen Speisen begann der Blindsack zu secerniren, aber nicht sogleich, sondern erst nach 15 bis 30 Minuten und er fuhr mit der Absonderung fort, bis der Magen sich vollstïndig entleert haben konnte, also bei einer mittelstarken Mahlzeit 1:3 bis 14 Stunden lang, bei einer sehr starken 16 bis 20 Stunden hindurch. Wurde dem Hunde 
dagegen sehr schwer verdauliche Kost gereicht, zum Beispiel gröblich zerkleinertes Ligamentum nuchae, so trat in dem Blindsacke längere Zeit, selbst eine Stunde lang, gar keine Absonderung ein; sie kounte herrorgerufen werden, wenn das Thier nachträglich zu saufen bekam, dauerte aber auch dann nur kurze Zeit an.

Unter den specifischen Bestaudtheilen des Magensaftes nehmen freie Salzsäure und ein in saurer Lösung Eiweiss rerdauendes Ferment, das Pepsin, die Hauptstelle ein. Ein Pylorusblindsack giebt alkalisches aber pepsinhaltiges Secret, ein Fundusblindsack saures und pepsinhaltiges. Pepsin wird also ron den Pylorus- und von den Fundusdrüsen, die freie Säure nur von den Fundusdrïsen geliefert; der Schleim, von welchem in dem aus Fisteln entleerten Magensafte nur wenig erscheint, ist ein Product des Oberflächenepithels; er findet sich als Ueberzug der Magenschleimhaut einerseits und der Speiseballen andererseits. Pepsin kann aus der Schleimhaut des Fundustheiles und des Pylorustheiles gewonnen werden, in Mengen, welche mit dem Verdauungszustande wechseln. Mit diesem ändert sich auch, aber nicht in einfach proportionaler Weise, der Pepsingehalt des Magensaftes. Der Pepsingehalt der Magenschleimhaut nimmt bis zur neunten Stunde ab, um dann allmählich wieder auf die alte Höhe zu steigen; der Pepsingehalt des Magensaftes steigt, nachdem er nur bis zur zweiten Stunde gefallen war, erheblich über den ursprïnglichen Werth und fällt langsam von der fünften Stunde ab.

Der Pepsingehalt der Schleimhaut steht in Abhängigkeit ron dem Zustande der-Hauptzellen der Fundusdrüsen und der Zellen der Pylorusdrüsen, dagegen in keinem Verhältnisse zu dem Befunde an den Belegzellen der Fundusdrüsen; grosse helle Hauptzellen, respective Pyloruszellen gehen einher mit hohem Pepsingehalt, Trübung der Zellen und Verkleinerung ihres Volums mit Abnahme des Pepsingehaltes der Schleimhant. Da die Belegzellen dagegen am kleinsten sind bei grossem Pepsinreichthum der Schleimhaut im Hunger, am grössten dagegen in der sechsten bis fünfzehnten Verdauungsstunde, wo die Schleimhaut pepsinarm ist und die Hauptzellen klein sind, so schliesst man, dass die Pepsinbereitung in den Hauptzellen der Fuudusdrüsen, sowie in den Pylorusdrüsen und nicht in den Belegzellen geschieht. Dieser Schluss wird bekräftigt durch die Thatsache, dass bei Fröschen im Magen, der ausschliesslich Belegzellen enthält, nur Säurebildung stattfindet, während das Pepsin in alkalischer Lösung im Oesophagus ausgeschieden wird, dessen Zellen im Wesentlichen den Hauptzellen entsprechen.

Der gemischte Magensaft ist beim Beginne der Verdauung weniger sauer als in späteren Stadien, dies rührt von einer verschiedenen Verdïnnung des stets mit ziemlicher Acidität ausgeschiedenen Fundussaftes durch den alkalischen Speichel und durch den alkalischen Pylorussaft 
her. Der gemischte Magensaft enthält im Maximum 3 pro Mille freie Salzsïure, das Secret eines Fundusblindsackes 5.j pro Mille. Dass die Hauptmenge des während der normalen Verdauung abgesonderten Magensaftes seine Acidität wesentlich freier Salzsäure verdankt, wird jetzt ziemlich allgemein anerkannt, wenn auch unter pathologischen Verhältnissen, sowie in den ersten Proben bei beginnender normaler Verdauung freie Milchsäure nachgewiesen ist: fraglich bleibt allerdings, ob die Salzsïure als solche ron den Drüsenzellen ausgeschieden wird, oder ob sie im Secrete durch Einwirkung freier Milchsäure auf Chloride entsteht: dass Milchsäure in mässriger Lösung bei gewöhnlicher Temperatur langsam Chloride zerlegt und dabei Salzsäure frei macht, ist experimentell nachgewiesen. Es ist aber iberhaupt fraglich, ob das Secret in saurem Zustande die Zellen rerlässt: an den Belegzellen selbst ist es bisher nicht gelungen, saure Reaction nachumeisen und auch in Bezug auf den Inhalt der Drüsenschläuche sind die Versuche zweifelhaft ausgefallen. Saure Reaction kann man sicher erst an der Oeffinung der Drïsengänge bei der Terdaumng demonstriren. es ist also möglich, dass ein organisches Secretionsproduct erst in den Drüsengängen zu Yilchsäure oxrvirt wird, und dass diese ihrerseits (rielleicht im status nascendi) zerlegend auf Chloride wirkt, welche gleichzeitig ansgeschieden werden. Dass Chloride aus dem Blute durch die Drüsenzellen angezogen werden, geht daraus herror; dass die Magenschleimhaut in denjenigen Zuständen, in welchen sie pepsinreich ist, auch einen grösseren Gehalt an Chloriden besitzt. In fieberhaften Kirankheiten, in welchen das Blut regen übermässiger Ausscheidung ron Chlor mit dem Harn an Chloriden rerarmt, liegt die Salzsäurebildung im Magen darnieder. Die bei der Spaltung der Chloride im Magen frei werdenden Alkalien führen dazu, dass der Harn mährend der Verdauung an Acidität rerliert oder alkalisch wird.

Ausser dem Pepsin enthält der Magensaft noch zwei andere Fermente, ein Milchsäureferment. welches die Spaltung ron Kohlehỵdraten in Milchsäure bewirkt und das Laabferment, welches Milch zum Gerinnen loringt. Das Laabferment rerhält sich in Bezug auf den Ort und die Menge seiner Bildung wie das Pepsin. Beide Fermente künnen durch Glyceerin aus der frischen oder getrockneten Schleimhaut extrahirt werden, doch enthält diese gewisse Mengen beider Fermente in einem unmittelbaren Vorstadium (als ein Zrmogen), analog dem Zrmogen des Trypsins, denn die Schleimhaut giebt nach Behamllung mit rerdünnter Lösung ron Kochsalz oder Silzsïure eine grössere Menge der Fermente an Glycerin ab: der Uebergang anch dieser Zrmogene in die ihnen entsprechenden Fermente soll durch Sodalösung ron 1 bis $2{ }^{0}$ o rerbindert werden. 
Auf der Darmschleimhaut sind Einrichtungen für Secretion und Resorption mit einander gemischt. Wahrscheinlich ist die ganze, durch Aus- und Einstülpungen stark vergrösserte Oberfläche im Stande zu secerniren, an den Zotten des Dünndarms tritt aber die Resorption entschieden in den Vordergrund. Die mit Epithel bekleideten Einstülpungen der Mucosa, welche im Dickdarme frei münden, und welche im Dünndarıne sich um die Grundflächen der Zotten gruppiren, bilden den hauptsächlichen Theil der secernirenden Darmfläche, man nennt sie die Lieberkühn'schen Drüsen. Von diesen zu unterscheiden sind die Brunner'schen Drüsen, welche im Duodenum gelegen sind und deren zu je einem Ausführungsgange gehörige mehrfach gespaltene Drüsenschläuche bis in die Submucosa vordringen und hier acinöse Erweiterungen tragen. Das Epithel der Brunner'schen Drüsen ähnelt sehr demjenigen der Pylorusdrïsen und enthält wie dieses Pepsin, dessen Menge wie bei den Pylorusdrüsen mit der Verdauungsperiode schwankt und das Aussehen der Zellen beeinflusst. Die Zellen der Lieberkühn'schen Drüsen sitzen einer besonder's leicht nachweisbaren structurlosen doppeltcontourirten Membran auf. Im Dünndarme überwiegen hier bei Weitem schmale cylindrische Zellen mit ovalem längs gestelltem, der Basalmembran genähertem Kerne; dieselben sind mit Carmin stark tingirbar, zeigen oft einen Stäbchensaum wie die Epithelien der Zotten (Näheres über diese bei der Verdauung) und lassen bei gewissen Erhärtungsmethoden eine sehr feine, den ganzen Zellleib durchziehende Längsstreifung erkennen. Zwischen ihnen finden sich in wechselnder Menge die Gebilde, welche als Becherzellen beschrieben werden und welche, wie es scheint, durch schleimige Metamorphose aus ersteren Zellen hervorgehen; ihr bauchig aufgetriebener Körper ist in Carmin nicht färbbar, nur das der Basalmembran anliegende zugespitzte Ende, welches den Kern enthält. In den Mastdarmdrïsen bilden die in schleimiger Metamorphose begriffenen Epithelzellen die Hauptmenge; die Becherzellen können hier nach stark angeregter Secretionsthïtigkeit continuirliche Reihen bilden; zwischen ihren zugespitzten Enden findet man dann kleine protoplasmareiche Zellen, welche wahrscheinlich der Regeneration dienen; in dem Secret der Mastdarmdrüsen überwiegt der Schleim, in dem der Dünndarmdrüsen die Fliissigkeit; deshalb spricht man auch von den Darmschleimdrüsen im Dickdarm und von den Darmsaftdrïsen im Dünndarm.

Zum Studium der Absonilcrungsverhältnisse und der Zusammensetzung des Darmsaftes dienen Darmfisteln. Ein Stück des Dünndarmes wird durch zwei Querschnitte aus der Continuität des Darmes ausgesehaltet, mit sorgfältiger Schonung des Mesenteriums, und das Magenende des Darmes wird mit seinem Dickdarmende durch Naht vereinigt; man schliesst das ausgeschnittene Darmstück an einem Ende blindsack- 
artig und nïht es mit dem anderen in die Bauchwunde ein. Die im niichternen Zustande ruhende Darmschleimhaut secernirt während des Verdauungsaktes am stïrksten in der sechsten bis siebenten Stunde. Durch mechanische, elektrische und chemische Reizungen kann man jederzeit Secretion anregen; am wirksamsten sind Flüssigkeiten, welche schwach sauer reagiren, doch soll Injection ron Magensaft in die Darmfistel ebenso wie die ron Galle erfolglos bleiben. Der 1)armsaft reagirt alkalisch und enthïlt etwa $2 \frac{1}{2} \%$ feste Bestandtheile, davon etwa ein Drittel Eiweiss, ein Drittel andere organische Stoffe und ein Drittel fenerfeste Salze.

Bei den Hauttalgdrüsen ist die Bildung des Secretes nicht eine Function ron Zellen, welche eine grössere Anzahl ron Secretionsperioden iiberleben, wie bei den Eiweissdrïsen; es tritt hier vielmehr ein Verhalten in extremer Ansbildung hervor, welches wir bei den Schleimdrïsen schon angedeutet gefunden haben. Bei diesen scheint die Bildung und Ausstossung des Mucin jedesmal mit erheblicher Beeinträchtigung der Zellen in ihrer Lebensfähigkeit einherzugehen; hierauf deuteten die leeren Tüten der Magenschleimzellen und die Becherzellen des Darmes hin, ferner die rerschiedenen als Matrix fuir Zellenneubildung gedeuteten Randzellencomplexe, deren Prototyp die Halbmondbildung in der Unterkieferdrüse des Hundes ist. Bei den Hauttalgdriisen tritt die Abstossung und Neubildung ron Zellen in den Vordergrund; in den zur Abstossung heranreifenden Zellen findet eine Umwandlung ron Zellsubstanz, wahrscheinlich ron Eiweiss zu Fett, in umfassendem Maasse statt und das Secret ist gebildet aus den Zerfallsproducten dieser Zellen.

Die Talgdrüsen stellen birnförmige, einfache oder mehrfach getheilte Säckchen dar, welche meistens in die Haarbälge ausmiinden; die Säckchen sind mit einem geschichteten Epithel ausgekleidet; es bleibt nur ein kleines Lumen frei und dieses ist mit Zelldetritus, namentlich mit Fetttröpfchen gefüllt. Bei den Haarbalgdrïsen dient das Secret zum Einfetten der Haare, bei den Meibom'schen Drïsen, welche Aggregate ron Talgdrïsen mit gemeinschaftlichem Ausführungsgange darstellen, dient es zum Einfetten der Wimpern und der Lidränder. Die Unbenetzbarkeit der fetten Lidräinder verhindert das Ueberfliessen von Thränenflissigkeit. Die Entleerung des Secretes geschieht bei den Talgdriisen nicht unter dem Drucke einer ron den Zellen secernirten Fliissigkeit, sondern theilweise ganz allmählich in dem Tempo des Wachsthums und der Abstossung der Zellen, theils zeitweise verstärkt durch äussere Kräfte und zwar bei den Meibom'schen Drüisen durch die des Lidschlages, bei den Hauttalgdrïsen durch Contraction der Arrectores pili.

Bei den Milehdrïsen, welche genetisch den Hauttalgdriisen nahe stehen, findet Fettbildung in Zellen statt, wie bei diesen, doch iiberleben 
dic Zellen die Bildung und Ausstossung des specifischen Secretbestandtheiles in dem Maasse, wie wir es bei den Zellen der Schleimdrüsen kennen gelernt haben. Die Secretion der Milchdriisen gehört bekanntlich nicht zu den gewöhnlichen Erscheinungen des Lebens; sie findet, von seltenen Ausnahmen abgesehen, nur bei dem weiblichen Geschlechte statt und auch bei diesem nur in den der Schwangerschaft folgenden Zeiten, vorausgesetzt, dass ein regelmässiges Absaugen oder Abmelken geschieht. Findet in regelmässigen Abständen Saugen oder Melken statt, so strömt das Secret in reichlicher Menge; unterbleibt es, so fliesst von selbst nur wenig Secret aus. In den Ruhepausen wird Secret gebildet, welches die Mamma oder das Euter strotzend füllt; da beim Melken beträchtlich mehr Milch gewonnen werden kann als auf einmal im Euter Platz hat, so muss eine gesteigerte Secretionsthätigkeit angeregt worden sein, und da die in späteren Theilen eines Abmelkens gewonnenen Milchportionen reicher an Fett sind, so kann es sich nicht nur um vermehrten Flüssigkeitsstrom handeln, sondern man muss auch eine Steigerung der Fettbildung in den Drüsenzellen annehmen. Die Flïssigkeit giebt sich durch ihren Unterschied im Salzgehalte gegen das Blutserum als ein Product der Secretion und nicht der Transsudation zu erkennen. So zweifellos der secretionserregende Einfluss dès Saugens oder Melkens ist, so ist der Mechanismus dieser Anregung doch nicht aufgeklärt. Man hat an reflectorische Wirkungen in Folge von Reizungen der sehr empfindlichen Warzenhaut gedacht, doch ist es nicht gelungen, Nerven nachzuweisen, deren Reizung oder Durchschneidung einen sicheren Einfluss auf die Milchsecretion ausübt. Bemerkenswerth ist, dass die Secretion stockt, ja dass eine Rückbildung des ganzen Organes eintritt, wenn keine Entleerung der in der Ruhe allmählich prall gefüllten Drüse vorgenommen wird. Da die Secretion unter dem Anwachsen des Druckes in den Drïsenhohlräumen stockt, so liegt der Gedanke sehr nahe, dass die Druckentlastung ausreicht, um den secretbereitenden Kräften der Drïsenzellen freies Spiel zu lassen.

Die frisch entleerte Milch stellt eine weisse, selbst in dünner Schicht undurchsichtige Fliissigkeit von alkalischer Reaction dar; die weisse Farbe und Undurchsichtigkeit rührt davon her, dass die Milch aus einer Aufschwemmung feiner Fetttröpfchen in einer wässrigen Flïssigkeit, das heisst aus einer Emulsion besteht. Unter dem Mikroskope sicht man eine grosse Zahl kleinerer und grösserer Fetttröpfchen, welche meist frei in der Flüssigkeit schwimmen. Einige derselben liegen eingeschlossen in Zellen oder Zellresten. Die meisten Zellen findet man in Milch von den letzten Tagen vor und den ersten Tagen nach der Geburt. Diese \%ellen, welche man Colostrumkörperchen nennt, sind in frischem \%ustande granulirt, rund oder maulbeerförmig, einige derselben 
zeigen auf dem heizbaren Objecttische amöboile Bewegungen; nach Behandlung mit Essigsäure oder Carmin lassen sic einen liern erkennen.

Eine Emulsion ist nur laaltbar, wenn der Auftrieb der einzelnen Fettröpfchen kleiner ist als der Reibungswiderstand. Falls das specifische Gewicht eines einzelnen Tröpfehens auch nu wenig kleincr ist als das der Suspensionsfliissigkeit, so muss es an die Oberflïche liommen, nach einer Zeit, deren Länge allerdings durch die Viscositait der Flïssigkeit mitbestimmt wird und an der Oberfläche müssen die Tropfen zu einer continuirlichen Fettschicht zusammenfliessen, wenn sie nicht durch Membranen abgeschlossen sind. Wenn Milch in der Kälte vor chemischer Zersetzung geschützt steht, so kommen allerdings die grösseren Fetttropfen an die Oberfläche; sie fliessen hier aber, Fettangen bildend, nur zum kleinsten Theile zusammen, bleiben viclmehr der grossen Menge nach bestehen und unterscheiden sich als Rahm ron der Butter. Dic abgerahmte Vilch ist zwar etwas weniger undurchsichtig geworden, sie bleibt aber "dauernd weiss; die kleineren Fetttröpfchen steigen nie an die Oberfläche. Dieses ist am leichtesten erklärlich, wenn man annimmt, dass das specifische Gewicht jedes Tropfens gleich dem specifischen Gewichte der Suspensionsflüssigkeit ist. Anf die Amahme einer Membran sind wir schon durch das Phänomen der Rahmbildung gefuihrt worden; das Mittel aus dem specifischen Gewichte von Membran und Fett kann bei jedem kleinen Tropfen gleich dem specifischen Gewichte der Fliissigkeit sein. Die Möglichkeit des Vorhandenseins von Membranen an den Tropfen ist in der Hilch gegeben durch ilıren Gehalt an Eiweiss. Lässt man anf einem Objectträger einen Tropfen Fett mit einem Tropfen Eiweisslösung zusammenfliessen, so bildet sich an der Grenze beider Fliissigkeiten eine unter dem Mikroskope an ihren Faltungen leicht erkennbare Membran, die sogenannte Haptogenmembran. Um die Milehkügelchen des Rahmes zur Vereinigung zu bringen, sind sehr starke und oft wiederholte Stösse erforderlich, wie sie bei dem Geschäfte des Butterns ausgefïhrt werden. Die Butter stellt das Milchfett dar, dessen Schmelzpunkt unter $20^{\circ}$ liegt und welches in frischem Zustande nur Buttersäure an das dreiatomige Alkoholradical Glycerin gebunden enthält.

In der frisch entleerten Milch kommen zwei Eiweisskörper vor, gewöhnliches Serumeiweiss in geringerer Menge und ein Alkalialbuminat, das Caseïn. Beim Stehen der Milch verschwindet das Serumeiweiss unter Vermehrung des Caseïns; dem Caseïn rerdankt die Milch die Eigenschaft der Gerinnbarkeit. Lässt man Milch bei gewöhnlicher Temperatur an der Luft stehen, so nimmt sie eine locker gallertige Consistenz an, nachdem ihre Reaction saner geworden ist; die in den Magen gelangte Milch des Menschen wird dort flockig, die der Kunh fest krïmelig. Das Caseïn, 
welches weder bei der natürlichen alkalischen Reaction der Milch, noch bei ganz schwacher Ansäuerung, selbst durch Kochen nicht zum Gerinnen gebracht werden kann, gerinnt schon in der Kälte bei stärkerer Ansäuerung. Ausserdem gerinnt das Milchcaseïn bei Zusatz von Magensaft, selbst wenn dessen Säuremenge zu klein ist, als dass auf diese allein die Gerinnung bezogen werden könnte; in der That lässt sich, wie schon gesagt, aus der Magenschleimhaut ein Ferment darstellen, das Laabferment, welches Milch oder Caseïnlösung ohne Beihilfe von Säure zur Gerinnung bringt.

Die Säuerung, welche in der Milch beim Stehen an der Luft eintritt, beruht auf einer fermentativen Spaltung des in der Milch enthaltenen Kohlehydrates; dieses ist ein Zucker eigenthümlicher Art, welcher wegen seines ausschliesslichen Vorkommens in der Milch als Nilchzucker bezeichnet wird. Er unterscheidet sich vom Traubenzucker unter Anderem durch süsseren Geschmack, durch Krystallisationsfähigkeit und geringeres Reductionsvermögen. Die Salze der Milch übertreffen an procentischer Menge diejenigen des Blutes und unterscheiden sich ausserdem von ihnen durch ein Zurïcktreten des Natriums und starkes Vorwiegen von Kali und Kalk; der Eisengehalt ist für eine dauernde ausschliessliche Ernährung mit Milch unzureichend.

Das Caseïn und der Milchzucker sind im Blute als solche niclit vorhanden, sie müssen also bei der Secretion oder im Secrete gebildet werden; an letztere Möglichkeit ist bei dem Caseïn darum zu denken, weil auch in der entleerten Milch noch Serumeiweiss in Caseïn übergeht. Der Milchzucker stammt nicht aus dem Traubenzucker des Blutes, sondern er wird aus Eiweiss in der Drüse abgespalten. Auch das Milchfett stammt nur zum kleineren Theile aus dem Fett, welches das Blut führt, die Hauptmenge desselben entsteht ebenfalls aus Eiweiss in der Driise. Der Gehalt der Milch an Fett und Zucker bleibt nämlich fast unverändert bei Darreichung von Nahrung, welche keine Kohlehydrate und Fette enthält, oder wenigstens sehr arm daran ist. Dies zeigen Hündinnen, welche man mit ganz magerem Fleische fuittert; auch gelingt es nicht, durch Steigerung der Zufuhr von Kohlehydraten und Fetten den Gehalt der Milch an diesen Substanzen wesentlich in die Höhe zu treiben; von dem grössten Einflusse auf die normale Zusammensetzung der Wilch ist dagegen die Eiweisszufuhr. Einen gewissen Einfluss hat auch das mit der Nahrung gereichte Fett.

Von der mittleren Zusammensetzung normaler Menschen- und Kuhmilch giebt folgende Tabelle eine Vorstellung. 


\begin{tabular}{|c|c|c|c|c|c|c|}
\hline & & & & & Frauenmilch & Kuhmilch \\
\hline Wasser & . & . & . & . & . 88,908 & 87,22 \\
\hline Caseïn & . & . & . & . & 3,924 & 3,18 \\
\hline Albumin & . & . & . & . & - & 0,48 \\
\hline Fett. & . & . & . & . & 2,666 & 3,62 \\
\hline Zucker & . & & . & . & 4,364 & 4,82 \\
\hline Salze. & . & . & . & . & 0,138 & 0,68 \\
\hline
\end{tabular}

Eine gute Kunh von $500 \mathrm{~kg}$ Köörpergewicht kann auf der Höhe der Lactation täglich 25 Liter Milch und mehr geben. Die höchste bcobachtete Menge waren 44,5 Liter bei $721 \mathrm{~kg}$ Lebendgewicht.

Die Leber liefert als Secret die Galle, welche in das Duodenum ergossen wird, bei den Menschen an derselben Stelle wie der Banchspeichel, bei manchen Thieren mehr oder wenig entfernt daron. Der Ductus Wirsungianus mündet zum Beispiel beim Kaninchen $30 \mathrm{~cm}$ unterhalb des die Galle ausfïhrenden Ductus choledochus.

Durch die Secretion der Galle tritt die Leber in den Dienst der Verdauung, da die Galle durch ihren Alkaliüberschuss und durch ihren Gehalt an gallensauren Salzen in die chemische Umwandlung der Ingesta eingreift; andererseits dient die Leber durch die Gallensecretion aber auch der Blutreinigung, insofern gewisse Gallenbestandtheile, namentlich das Gallenpigment aus Zerfallsproducten von Bluttheilen entstehen. Aber nicht allein hierdurch entfaltet die Leber eine metakeratische Thätigkeit, sie thut es auch dadurch, dass sie aus dem Blute der Pfortader gewisse, an der Darmoberfläche resorbirte Nalırungsbestandtheile aufnimmt. Lösliche Kohlehydrate werden durch die Pfortader der Leber zugefuihrt, hier als schwer lösliches Glycogen aufgespeichert und nach Maassgabe des Bediurfnisses dem Blute in löslicher Form wieder beigemengt.

Die Wichtigkeit der Kohlehydrate für die Arbeitsleistungen in den Muskeln haben wir kemnen gelernt; in löslicher Form wïrden die Kohleliydrate ebenso schnell ausgeschieden wie aufgenommen werden; die Form, unter der sie resorbirt werden, ist Traubenzucker, und spritzt man eine Lösung dieser Substanz in eine Körpervene eines Thieres ein, so erscheint fast die ganze Menge schnell im Harne. Ausser der Leber kann noch der Muskel das Kohlehydrat in Glycogen umbilden, aber bei Weitem nicht so schnell; die mit der Nahrung aufgenommenen Kohlelyydrate würden also olıne die Dazwischenkunft der Leber für die Arbeitsleistung des Organismus zum grössten Theile verloren gehen, 
An der Oberfläche und auf dem Querschnitte grenzen sich in der Leber; für das blosse Auge erkenntlich, polygonale Felder gegen einander ab, es sind dies die Querschnitte der Acini. Jeder Acinus baut sich auf aus Zellsäulen, welche mannigfach miteinander communiciren, aus Blutcapillaren mit den sie einscheidenden Lymphräumen und aus den Gallencapillaren. Die letzteren sind überall durch Drïsenzellen von ersteren getrennt, und jede Drüsenzelle grenzt ansser an andere Drüsenzellen mindestens an eine Blutcapillare und eine Gallencapillare.-Die letzteren sind sehr enge Gänge mit structurloser Wandung. Die Leberzellen sind verhältnissmässig grosse polyedrische Gebilde mit Korn und Protoplasmanetz, welche eine besonders differenzirte Membran nicht erkennen lassen; nur die Wand der Gallengänge wird als Cuticularbildung der angrenzenden Leberzellen aufgefasst. In manchen Zuständen ist Kern und Protoplasmanetz in eine helle Grundsubstanz eingebettet, welche man das Paraplasma genannt hat. Der Kern liegt dann den Blutcapillaren genähert, von dichterem Protoplasma umgeben; das Protoplasmanetz lässt eine gewisse Richtung von den Blut- zu den Gallencapillaren erkennen. In anderen Fällen ist von dem eigentlichen Zellleib wenig zu erkennen; so ist nach einer an Kohlehydraten reichen Nahrung jede Zelle dicht mit Glycogenschollen erfüllt; nach Auswaschung derselben sieht man den Kern in der Mitte; das Protoplasma ist in der Peripherie angehäuft und zeigt spärliche Verbindungen mit dem den Kern umgebenden Protoplasma. In anderen Fällen, zum Theil normalen, namentlich aber in pathologischen, findet man die Leberzellen stark mit Fetttröpfchen durchsetzt.

Die Blutcapillaren jedes Acinus sammeln sich nach der Witte zu der sogenannten Centralvene; die Centralvenen münden $\mathrm{zu}$ den Lebervenen zusammen. Das interacinöse Gewebe ist reich an Bindegewebe, welches mit der Leberkapsel in Verbindung steht; es führt die letzten Verzweigungen der Pfortader (vor ihrer Auflösung zu den acinösen Blutcapillaren) und die Anfänge der Gallenausfülırungsgänge. Die Leberarterie verzweigt sich ebenfalls in diesem interacinösen Bindegewebe; sie versorgt hier die Wandungen der Pfortaderzweige und der Gallenausführungsgänge mit Blutcapillaren, welche das venös gewordene Blut in die Pfortadercapillaren ergiessen. Das interacinöse Bindegewebe führt auch Nervenfasern, deren directer Zusammenhang mit Leberzellen früher behauptet worden ist, durch nähere Untersuchung aber nicht hat bestätigt werden können. Schliesslich liegen in dem interacinösen Bindegewebe auch Lympligefässe.

Die Circulationsverlı̈ltnisse in der Leber sind dadurch ausgezeichnet, dass die durch die Pfortader zugeführte Hauptmenge des Blutes schon vorher einmal Capillaren passirt hat, von denen hauptsächlich die in 
den Darmzotten und in der Milz bedeutungsroll sind. In den Leberacini passirt dieses Blut ein zweites Capillarsystem, dessen Widerstände nicht unbetrïichtlich sein können. Da die Lebervenen in das wenig nachgiebige Lebergewebe eingebettet sind, so kann sich der negative Druck des Thorax weithin geltend machen, sodass also auch bei geringem positirem Drucke in der Pfortader ein genïgendes Gefälle zwischen ihr und der Lebervene besteht und die Respirationsbewegungen dem Blutstrome in der Leber zu Gute kommen. Druck und Stromintensität in der Pfortader sind am stärksten bei der Erweiterung der Darmgefïsse, welche die Verdaunng begleitet. Das Blut der Leberarterie scheint wesentlich nur zur Ernährung des interacinösen Bindegewebes mit seinen Gefässen für das Blut und die Galle und mit seinen Nerven zu dienen. Bei Kaninchen, deren Leber aus einzelnen ziemlich selbststïndigen Lappen besteht, hat man an einem einzelnen dieser Lappen Gefässunterbindungen rorgenommen; man kaun solche Versuche nicht an der ganzen Leber ausführen, weil Thiere nach Unterbindung der Pfortader schnell zu Grunde gehen, sie verbluten sich gewissermaassen in das Quellgebiet der Pfortader, welches die ganze Blutmenge des Thieres zu fassen im Stande ist. Der einzelne Leberlappen fährt nach Unterbindung ihres Pfortaderastes sowohl als ihres Leberarterienastes fort, Galle ron gewöhulicher Beschaffenheit zu secerniren, doch ist in ersterem Falle die Secretmenge sehr klein. In krankhaften Fällen führt Obliteration der Leberarterie zunächst nicht zur Störung der Gallenbereitung, sondern zu Ernährungsstörungen der interstitiellen Gefässe. Da die Verzweigungen der Leberarterie und der Gallenausführungsgänge mit denen der Pfortader gemeinsam zwischen unnachgiebigem Lebergewebe verlaufen, so wird es bei Paralyse der Arterienmusculatur oder bei Stauung der Galle in den Gängen zur Behinderung des Blutstromes in der Pfortader kommen können.

Die wesentlichen Bestandtheile der menschlichen Galle sind die gallensauren Salze, das glycocholsaure Natron und das taurocholsaure Natron; ferner das Gallenpigment, Bilirubin. Die Taurocholsäure und die Glycocholsäure sind sogenannte gepaarte Säuren, denen beiden die Cholalsäure gemeinsam ist, eine nur aus $\mathrm{C}, \mathrm{H}$ und $\mathrm{O}$ bestehende Verbindung noch unbekannter Constitution. Wit ihr gepaart finden sich das Glycin, auch Glycocoll genannt (Amidoessigsäure) oder das Taurin (AmidoAethylschwefelsäure). Den gallensauren Salzen rerdankt die Galle ihr starkes Lösungsrermögen für Seife; die gallensauren Salze werden, wenn auch nicht als solche, im Darme wieder resorbirt, wahrscheinlich nachdem die in Verlust gehende Cholalsäure abgespalten ist.

Dem Bilirubin verdankt die Galle ihre braune Färbung; obgleich seine Abstammung aus dem Blutfarbstoffe nicht direct nachgewiesen ist, 
so ist sie doch sehr wahrscheinlich, denn es verhält sich in krystallographischer und spektroskopischer Beziehung wie das Hämatoidin, welches sich in alten Blutextravasaten vorfindet.

Weder gallensaure Salze noch Bilirubin haben im normalen Blute aufgefunden werden können. Da sie bei pathologischem oder experimentellem Verschlusse der Gallenausführungsgänge im Blute erscheinen, da aber bei entleberten Fröschen, welche die Exstirpation der Leber wochenlang ïberlebten, weder im Blute noch im Gewebe Anhäufungen von Gallenbestandtheilen beobachtet wurden, so muss man als ihre Bildungsstätte die Leber selbst ansehen.

Aus so zellenreichen Organen wie Leber, Milz, Lymphdrüsen lassen sich die specifischen Zellen durch Ausschaben, Waschen mit 0,6\% iger Kochsalzlösung und Centrifugiren rein darstellen; wenn man auch darüber streiten kann, ob solche Zellen noch als lebend zu betrachten sind, so unterliegt es doch keinem Zweifel, dass sie je nach ihrem Ursprungsorte verschiedene Umwandlungen in Lösungen organischer Substanzen, denen sie zugesetzt sind, hervorbringen können, Umwandlungen, welche zu den normalen Vorgängen in den verschiedenen Organen, aus denen sie stammen, in naher Beziehung stehen; so besitzen die Zellen aus der Milz die Fähigkeit, Hämoglobinlösung zunächst zu entfärben, beim längeren Stehen aber wieder zu restituiren, und zwar findet sich auf der Höhe dieses Processes eine grössere Hämoglobinmenge in Lösung als ursprïnglich vorhanden war. Ganz anders verhalten sich die Leberzellen; dieselben verlieren durch die ausgiebige Behandlung mit der 0,6\% igen Kochsalzlösung ihr Glykogen, dagegen enthalten sie noch gallensaure Salze und ein gelbes Pigment. In reiner physiologischer Kochsalzlösung wird Hämoglobin von den durch Waschen ihres Glykogens vollkommen beraubten Zellen nicht angegriffen. Dies geschieht jedoch, wenn man der hämoglobinhaltigen Lösung einen Gehalt von circa 0,6 Glykogen giebt; es hinterbleibt nach mehreren Tagen bei allmählichem Schwunde der Blutbänder eine hellgelbe Fluissigkeit, welche gar keinen charakteristischen Einfluss auf das Spectrum des Sonnenlichtes ausübt. Der anfänglich gelb gefärbte Leberzellbrei wird hierbei immer dunkler, zuletzt kaffeebraun; die einzelnen Leberzellen zeigen unter dem Mikroskope eine Vermehrung des schon anfangs in ihnen vorhandenen gelben Farbstoffes; dieser ist kein Bilirubin, scheint aber in naher chemischer Beziehung zu ihm zu stehen.

Nach seiner Zerstörung durch Leberzellen wird das Hämoglobin weder durch diese selbst, noch durch nachträglich zugefügte Milzzellen wiederhergestellt. Durch Milzzellen, im ersten Stadium ihrer Einwirkung, entfärbte Hämoglobinlösung verliert durch Leberzellen ihre Regenerirbarkeit. Eine Traubenzuckerlösung wirkt qualitativ ebenso, wie 
eine Glycogenlösung von gleicher Concentration, nur stärker; Traubenzucker oder Glycogen verschwinden hierbei aus der Lösung, ebenso das Eiweiss des Hämoglobins; der trockene Rückstand der Lösung nimmt aber nicht ab; unter den Umwandlungsproducten, welche entstanden sein miissen, nehmen die gallensauren Salze einen erheblichen Platz ein. Leberzellbrei plus Zusatzflüssigkeit enthält davon nach der Zersetzung des Hämoglobins beträchtlich mehr als vorher. Diese Vermehrung der gallensauren Salze tritt auch ein, wenn dem Leberzellbrei verdiinntes Blutserum statt der Hämoglobinlösung zugesetzt wird; auch hierbei ist die Gegenwart von Glycogen oder Traubenzucker erforderlich. Fliissige Fette oder Seifenlösungen verhalten sich ganz indifferent.

Angesichts dieser Angaben - von welchen die auf die Restitution des Hämoglobins bezüglichen neuestens allerdings wieder in Frage gestellt sind - muss man es als sehr wahrscheinlich bezeichnen, dass in den Drïsenzellen der lebenden Leber aus Stoffen, welche die Pfortader zufïhrt (namentlich also aus Traubenzucker von den Darmvenen und aus Unwandlungsproducten des Hämoglobins von der Milzvene aus) die specifischen Gallenbestandtheile gebildet werden. Ein Theil dessen, was die lebende Zelle leistet, ist nicht an das Leben der Zellen gebunden, denn die Vermchrung der gallensauren Salze findet nicht nur unter der Finwirkung eines Breies scheinbar intacter Zellen statt, sondern auch nach absichtlicher mechanischer Zertrümmerung derselben; der Zelldetritus wirkt in dieser Beziehung sogar energischer als der Zellbrei. Andere Wirkungen derart isolirter Zellen sind strenger an die Erhaltung der Zellform gebunden. Der Detritus aus Milzzellen kann Hämoglobin noch zersetzen, aber nicht mehr regeneriren. Der Zellbrei unterscheidet sich aber auch dadurch von den zelligen Organen, dass der Unfang der Wirkung ein beschränkter ist; eine bestimmte Quantität von Leberzellbrei kann nur eine begrenzte Nenge von Hämoglobin zersetzen und in Form des gelben Pigmentes aufspeichern.

Glycogen findet sich in der Leber selır reichlich nach einer an Kohlehydraten reichen Nahrung; sie kann unter diesen Umständen iiber $10 \%$ daron enthalten; bei hungernden Thieren verschwindet das Glycogen rollkommen aus der Leber, schneller als aus den Nuskeln, aber auch bei einer von Kohlehydraten freien, dagegen genügend eiweisshaltigen Nahrung werden erhebliche Nengen Glycogens in der Leber aufgespeichert. Die Leberzellen miissen also im Stande sein, aus Eiweiss Kohlehydrate abzuspalten; dasselbe gilt auch für Fette. Diesem Processe entstammen wahrscheinlich auch Leucin und Tyrosin, welche man in Leberextracte findet und wenigstens theilweise der Harnstoff, welcher in kleinen Mengen stets im Blute verhanden ist. Dass die Leber aus ihrem Glycogenvorrathe Zucker an das Blut abgiebt, ist schon gesagt 
worden; es geschieht dies unter normalen Verhältnissen nur in demselbeu Maasse, als die Muskeln und andere arbeitsleistende Gewebselemente den Zucker wieder zu binden vermögen, sodass der Zuckergehalt des Blutes nur gering ist und der Zucker nur in schwer nachweisbaren Spuren mit dem Harne ausgeschieden wird. Bei der merkwïrdigen Krankheit jedoch, deren greifbarstes Symptom starker Gehalt des zu reichlichen Harns an Traubenzucker ist, führt das Blut zum Schaden vieler Gewebe und Organe zu viel Zucker mit sich; es kann dies daran liegen, dass die Leber in ihrer Function die Kohlehydrate der Nahrung aufzuspeichern geschwächt ist, oder daran, dass die Leber oder andere Gewebe zu viel Kohlehydrate aus Eiweiss bilden, oder daran, dass der Zucker von den arbeitenden Geweben ungenïgend fixirt oder verbrannt wird. Die Krankheit heisst Diabetes mellitus oder Zuckerharnruhr.

Die reichlichen chemischen Processe, welche sich in der Leber abspielen und bei denen grossentheils Producte geringerer Verbrennungswärme entstehen, lassen das Freiwerden ziemlicher Wärmemengen erwarten, und man hat auch in der That das Lebervenenblut stets hoch temperirt gefunden.

Aufschlüsse über Intensität und zeitliche Verhältnisse der Lebersecretion verdanken wir Gallenfisteln, welche gelegentlich bei Menschen zur Beobachtung kommen, und welche bei Thieren, namentlich bei Hunden, vielfach experimentell angelegt worden sind. In eine Bauchwunde wird die Wand der Gallenblase eingenäht und danach gespalten; eine eingebundene Canïle gestattet, die Galle entweder ausfliessen oder sie ihren natürlichen Weg durch den Ductus choledochus in den Darm nehmen $\mathrm{zu}$ lassen; lässt man letzteres für gewöhnlich geschehen, so wird das Befinden des Thieres durch die Gallenfistel nicht dauernd gestört.

Die Galle wird stetig abgesondert, wenn auch unter beträchtlichem Wechsel der Geschwindigkeit; die Menge der täglich von der Leber gelieferten Galle ist sehr beträchtlich, man schätzt sie auf Grund von Beobachtungen an Menschen mit Gallenfisteln auf iiber 500 Gramm in 24 Stunden; es ist hierbei aber noch zu bedenken, dass, wie Thierversuche ergeben haben, die Galle reichlicher abgesondert wird, wenn die Bestandtheile derselben oder deren Zerfallsproducte, soweit sie resorbirbar sind, im Darme wieder aufgenommen werden können, als wenn die Galle nach aussen abfliesst und dem Körper verloren geht. Die Nahrungsaufnahme wirkt zweimal beschleunigend auf die Gallensecretion, einmal unmittelbar nach der Aufnahme in den Magen, wahrscheinlich reflectorisch, und dann im Maasse der fortschreitenden Verdauung, ein erstes Maximum etwa in der vierten, ein zweites etwa in der zehnten Stuncle erzeugend. Bei der Verdauung steigt mit der Secretionsgeschwindigkeit 
meist auch der Procentgehalt an festen Substanzen, umgekehrt nimmt aber auch der Procentgehalt meist zu, wenn bei lïngerer Nahrungsentziehung die Secretionsgeschwindigkeit minimal wird. Die Wasserabsonderung ist also grösseren Schwankungen unterworfen, als die Alssonderung der festen Bestandtheile. Einen erheblichen Einfluss auf die Gallenmenge hat die Art der Ernährung: Eiweissnahrung steigert die Gallenbereitung sehr erheblich, Fettuahrung gar nicht. Das Nerrensystem scheint nur insofern dic Secretionsthätigkeit der Leber zu beeinflussen, als es die Circulationsverhältnisse in dem Organe beherrscht. Die Nerven der Leber selbst kommen zum Theil direct rom Vagus, zum Theil rom Plexus cocliacus; Reizung und Durchschneidung dieser Nerven hat keine bedeutenden Resultate ergeben; ron starker Wirkung dagegen ist die Reizung des Riickenmarkes oder des Splanchnicus; die zunächst beschleunigte, dann gehemmte Gallensecretion bezieht man darauf, dass bei der Verengerung der Blutgefässe der Baucheingeweide der Blutstrom in der Pfortader zunächst beschleunigt, dann rerzögert wird.

Die Druckhöhe, bis zu welcher in einer mit den Gallenwegen in Verbindung stehenden verticalen Glasröhre die Galle ansteigt, beträgt bei Thieren etwa 200 Millimeter und zwar wurde dieser Druck jedesmal höher gefunden, als der gleichzeitig in der Vena mesenterica superior gemessene Druck; es kann also auch in der Leber die Secretion des Wassers nicht als mechanische Folge des Blutdruckes angesehen werden. Ueber den Druckwerth, welchen die Leberzellen durch Secretion zu überwinden im Stande wären, erfährt man aus diesem Experimente nichts Bestimmtes; die Secretion steht bei diesem Druck ebenso wenig wie bei experimentellem oder pathologischem Verschlusse der Gallenwege still; die in den Acinis abgesonderte Galle kommt aber in dem interacinösen Gewebe zur Resorption, es entsteht der als Icterus bezeichnete Zustand, bei welchem eine allgemeine durch resorbirtes Gallenpigment bedingte Gelbfärbung auffällt.

Bei dem Menschen und bei denjenigen Thieren, welche eine Gallenblase besitzen, wird die continuirlich abgesonderte Galle in derselben aufgespeichert, nm bei beginnender Verdauung nach Maass des Bedürfnisses in das Duodenum entleert zu werden; in der Gallenblase und in den gröberen Gallengängen findet Resorption ron Wasser und Beimengung ron Schleim statt, welcher aus traubenförmigen, ganz nach dem Typus der Schleimdrüsen gebildeten Drüschen in den Wandungen der Blase und der Gänge stammt.

Dass die Zusammensetzung der Galle erheblichen Schwankungen unterliegt, geht aus dem Vorstehenden herror; um aber für die Vorstellung einigen Anhalt zu geben, möge hier eine Tabelle folgen, welche 
auf der Analyse der aus der Gallenblase einer frischen Menschenleiche gewonnenen Flüssigkeit beruht.

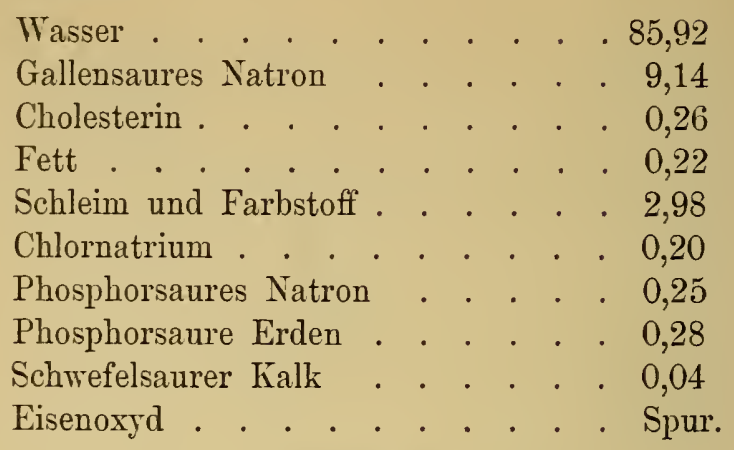

Die Nieren liefern als Secret den Harn, dessen Ausscheidung eines der wesentlichsten Mittel zur Erhaltung der normalen Zusammensetzung des Blutes und der Gewebsflüssigkeiten ist; in diesem Sinne ist die Niere eine metakerastische Drüse, doch unterscheidet sie sich von den übrigen Drüsen dieser Kategorie und auch ron der Leber dadurch, dass keine in derselben gebildeten Stoffe oder Formbestandtheile an das Blut abgegeben werden. Es findet ausschliesslich Stoffabgabe nach aussen statt, und zwar Abgabe ron Stoffen, welche zur Erhaltung der Gesundheit aus dem Organismus entfernt werden müssen und welche nach ihrer Secretion durch die Niere nicht weiter in den Dienst des Organismus treten.

Die im Laufe von 24 Stunden ausgeschiedene Harnmenge beträgt beim Menschen im Mittel etwa $1500 \mathrm{Gr}$., woron etwa $60 \mathrm{Gr}$. auf feste Bestandtheile entfallen; die Nieren dienen also in erster Linie der Regulirung des Wassergehaltes des Organismus. Mit dem Essen und Trinken wird dem Organismus täglich eine wechselnde, aber immer beträchtliche Menge Wassers zugeführt, und dazu kommt das Wasser, welches sich bei Verbrennungsprocessen im Organismus durch Oxydation des Wasserstoffes bildet. Der Theil des durch die Lungen aufgenommenen Sauerstoffes, welcher nicht mit der ausgeathmeten Kohlensäure die Lungen rerlässt, und dessen Menge durch den sogenannten respiratorischen Quotienten gemessen wird, rerlässt den Köorper zum grössten Theile als Wasser. An der Ausscheidung des Wassers betheiligen sich in grösserem Maassstabe die Lungen, die Nieren und die Haut; die von den Oberflächen der Lungen und der Haut abdunstenden Wassermengen steigen mit der Wärme und Trockenheit der umgebenden Luft, sowie mit der Muskelarbeit; in demselben Maasse nimmt die Wasserausscheidung durch die Nieren ab; bei den Menschen, den übrigen Säugethieren und den 
nackten Amphibien findet die den normalen Wassergehalt des Organismus regulirende Wasserausscheidung in den Nieren statt. Bei den Vögeln und den beschuppten Amphibien, deren Nierensecret ein hald nach der lintleerung erstarrender Brei ist, liegen andere Verhältnisse ror.

Die mit dem menschlichen Harne ausgeschiedenen festen Bestandtheile sind sämmtlich oder fast sämmtlich schon im Blute und in Gewelsfluissigkeiten rorhanden; als specifische Bildungsstätte für Harnbestandtheile kann die Niere im Allgemeinen nicht gelten, wenn auch die Fïhigkeit des ïberlebenden Nierengewebes Hippursäure aus Benzoesïure und Glycocoll durch Synthese zu bilden nachgewiesen ist, und wenn auch kein Grund rorliegt, daran zu zweifeln, dass Harnstoff als Endproduct des Eiweissstoffwechsels arbeitender Nierendrüsenzellen ebenso erscheint wie an anderen Stellen des Organismus, wo Eiweiss dem Verbrauche anheimfällt.

Der Menge und der Bedeutung nach nimmt unter den festen Bestandtheilen des menschlichen Harnes der Harnstoff die erste Stelle ein, von welchem in 24 Stunden etwa $35 \mathrm{Gr}$. ausgeschieden werden; es unterliegt jetzt keinem Zweifel mehr, dass der Harnstoff zu den normalen Bestandtheilen des Blutes und der Gewebsflüssigkeiten gehört, allerdings ist der relative Gehalt nur gering, weniger als 1 per mille. Die Methoden zur quantitativen Bestimmung des Harnstoffes in Körperfliissigkeiten sind aber so verfeinert, dass man Aenderungen so kleiner Mengen mit Sicherheit verfolgen kann; wären die Nieren die wesentlichen Bildungsstellen des Harnstoffes, so hätte man im Blute von Thieren zwar nach Unterbindung der Ureteren eine Anhäufung von Harnstoff finden miissen, nach Exstirpation der Nieren jedoch nicht; thatsächlich hat man aber nach der letzteren Operation eine Anhäufung gefunden, welche unter sonst gleichen Umständen als gleich betrachtet werden muss derjenigen, welche nach Ureterenunterbindung eintritt. Von der nach Nierenexstirpation mit der Zeit fortschreitenden Anreicherung des Blutes mit Harnstoff giebt folgendes den Hund betreffende Versuchsbeispiel eine Vorstellung.

Gehalt des Arterienblutes

Vor der Nephrectomie
3 St. 40 .
.

Da der Harn ïber $2 \%$ Harnstoff enthält, so muss derselbe, wenn er auch nicht rorzugsweise in der Niere gebildet wird, hier doch weit stïrker zur Ausscheidung kommen, als das Wasser und auch stärker 
als die übrigen Harnbestandtheile. Besondere Beziehungen zwischen dem Harnstoff und den Drüsenzellen der Niere müssen also bestehen.

Der Harnstoff ist ein Oxydationsproduct von Eiweiss, aber kein directes; iiber die Zwischenstufen ist nicht so viel bekannt, dass man eine gesetznässige Reihe derselben, innerhalb welcher ein Glied aus dem anderen hervorginge, aufstellen könnte. Immerhin kann man eine Reihe aufstellen, deren Glieder, je weiter sie sich von dem Eiweisse entfernen, eine Zunahme im procentischen Gehalte an Stickstoff und eine Abnahme im procentischen Gehalte an Kohlenstoff und Wasserstoff zeigen; das Endglied dieser Reihe von Stoffen der regressiven Metamorphose ist der Harnstoff.

Seiner Constitution nach ist der Harnstoff als Carbamid $\left(\mathrm{CO}<\mathrm{NH}^{2}\right)$ aufgefasst worden. Die seit lange zur quantitativen Bestimmung des Harnstoffes benutzte Fällung desselben mittelst salpetersauren Quecksilberoxyds, wobei sich eine Verbindung des Harnstoffes mit Quecksilberoxyd und Quecksilbernitrat bildet $\left(2 \mathrm{CON}^{2} \mathrm{H}^{4}, 3 \mathrm{HgO}, \mathrm{HgN}^{2} \mathrm{O}^{6}\right)$, hat bisher aus der angegebenen Constitutionsformel nicht genügend erklärt werden können.

Die bis jetzt wichtigsten Thatsachen, welche für die Auffassung von der Constitution und Entstehungsweise des Fiarnstoffes im Organismus in Betracht kommen können, sind folgende: Wenn Kohlensäure und Ammoniak zusammentreffen, so entsteht unter allen Umständen zunächst carbaminsaures Ammon, welches erst durch Wasseraufnahme in kohlensaures Salz übergeht.

$$
\mathrm{CO}^{2}+2 \mathrm{NH}^{3}=\mathrm{NH}^{2}-\mathrm{CO}^{2}-\mathrm{NH}^{4}+\mathrm{H}^{2} \mathrm{O}=\mathrm{NH}^{4}-\mathrm{CO}^{3}-\mathrm{NH}^{4}
$$

Carbaminsaures Ammon ist gewonnen worden durch Oxydation von Leucin, Glycocoll und Tyrosin in alkalischer Lösung.

Eine Lösung von carbaminsaurem Ammon hat bei Durchleitung von Wechselströmen eine sicher nachgewiesene, wenn auch kleine Ausbeute an Harnstoff gegeben. Da hierbei an jeder Elektrode in kurzen Zwischenräumen Oxydations- und Reductionsprocesse hintereinander abwechseln, so hat man sich die Entstehung von Harnstoff aus carbaminsaurem Ammon als das Resultat einer, dasselbe Molekül treffenden Oxydation mit darauf folgender Reduction vorgestellt.

$$
\begin{aligned}
& \text { I. } \mathrm{NH}^{2}-\mathrm{CO}-\mathrm{O}-\mathrm{NH}^{4}+\mathrm{O}=\mathrm{NH}^{2}-\mathrm{CO}-\mathrm{O}-\mathrm{NH}^{2}+\mathrm{H}^{2} \mathrm{O} \\
& \text { II. } \mathrm{NH}^{2}-\mathrm{CO}-\mathrm{O}-\mathrm{NH}^{2}+\mathrm{H}^{2}=\mathrm{NH}^{2}-\mathrm{CO}-\mathrm{NH}^{2}+\mathrm{H}^{2} \mathrm{O}
\end{aligned}
$$

Achnliche Bedingungen für abwechselnde Oxydationen und Reductionen, wie sie hier bei Elektrolyse mit Wechselströmen vorhanden sind, künnen im Organismus vorkommen. Bei langsamer Verbrennung ron 
Wasserstoff, wie sie an der Obertläche eines mit Wasserstoff beladenen Palladiumbleches in wässeriger Lösung stattfindet, tritt Sauerstoff in atomischer Form auf, welcher seinerseits in der Lösung rorhandene Körper oxydiren kann; hier wirkt also der Wasserstoff reducirend und durch Vermittelung des ron ilım gespaltenen Sauerstoffmolekiils oxydirend.

Die mit dem Harne täglich ausgesehiedene Menge ron Harnstoff hängt bei gewöhnlicher Ernährung in erster Linie ab ron der Menge des mit der Nahrung eingeführten Eiweisses; bei gesteigerter Muskelarbeit nimmt die Menge des Harnstoffes und der iibrigen stickstoffhaltigen Harnbestandtheile in erheblichem Maasse nur zu bei ungenügender L̇nährung, oder wenn bei der Arbeitsleistung lange Zeit Dyspnoë rorhanden gewesen war. Im Hungerzustande besteht Harnstoffausscheidung bis zuletzt fort, sie erfolgt dann auf Kosten des Körpereiweisses.

Unter den stickstoffhaltigen Hambestandtheilen kommt nächst dem Harnstoffe der Harnsäure die grösste Bedeutung zu; der Gehalt des Harns an Harnsïure ist bei dem Menschen nie gross, am grössten nach reichlicher Fleischnahrung, beträgt aber auch dann nur etwa $0,6 \%$; auch die Harnsäure kommt normaler Weise im Blute vor; ron besonderer Bedeutung für den Organismus ist die Schwerlöslichkeit ihrer Salze. Der Harn der Vögel und der beschuppten Amphibien besteht aus einem Kirystallbrei von harnsauren Salzen.

Der Harnsäure nahestehend und im Harne regelmässig rorkommend ist das Xanthin.

$$
\begin{aligned}
& \text { Harnsäure . . . . . . . . } \mathrm{C}^{5} \mathrm{H}^{4} \mathrm{~N}^{4} \mathrm{O}^{3} \\
& \text { Xanthin . . . . . . . . } \mathrm{C}^{5} \mathrm{H}^{4} \mathrm{~N}^{4} \mathrm{O}^{2}
\end{aligned}
$$

Xanthin und rerwandte Körper wurden in ziemlich reichlicher Menge bei der Zersetzung des Nucleïns erhalten.

An Menge der Harnsäure ungefähr gleichkommend ist in dem normalen menschlichen Harne Kreatinin enthalten, welches in höherem Maasse aus der Nahrung als aus dem im Körper zersetzten Eiweisse zu stammen scheint; vermehrte Einfuhr von Kreatin oder Kreatinin führt zu einer Steigerung der Ausscheidung von Kreatinin, nicht zu der von Harnstoff.

Der Stoff, welchem der Harn seine gelbe bis gelbrothe Färbung verdankt, ist das Uróbilin, welehes einerseits durch Behandlung ron Bilirubin mit Natriumamalgam, andererseits von Hämatin mit Zinn und Salzsïure erhalten werden kam; diese Thatsachen lassen das Urobilin als ein Derirat des Gallenfarbstoffes und weiter des Blutfarbstoffes erkennen, welches aus denselben durch Reductionsprocesse entsteht; die Reduction scheint im Organismus oft noch weiter $\mathrm{zu}$ gehen, denn es 
komment vor, dass frischer Harn den für das Urobilin charakteristischen Streifen im Spectrum nicht zeigt, wohl aber nach einigem Stehen an der Luft. Gewisse Farbenänderungen, namentlich eine bläuliche, welche der Harn beim Stehen zeigen kaun, verdankt er seinem Gehalte an sogenannten Chromogenen, namentlich an Indican; dieses ist an sich farblos, entstammt den in Darme normalerweise vorkommenden Fäulnissprocessen und liefert bei seiner Zersetzung Indigo.

Eine regelmässig in kleiner Menge beim Menschen, sehr reichlich aber bei den Pflanzenfressern, mit dem Harne ausgeschiedener Kiörper, welcher für den Chemismus des Organismus und der Nieren besondere Bedeutung hat, ist die Hippursäure. Die Menge der ausgeschiedenen Hippursäure kamn ebenso beim Menschen und Hunde, wie bei Pflanzenfressern willkürlich gesteigert werden durch die Einfuhr von Benzoësäure. Hippursäure entsteht unter Wasserabspaltung durch Synthese aus Benzoësäure und Glycocoll (Amidoessigsäure) 1 Benzoësäure + 1 Amidoessigsäure $=1$ Hippursäure +1 Wasser.

$$
\begin{array}{r}
\mathrm{C}^{6} \mathrm{H}^{5}(\mathrm{COOH})+\mathrm{CH}^{2}\left(\mathrm{H}^{2} \mathrm{~N}\right)-\mathrm{COOH}=\mathrm{C}^{6} \mathrm{H}^{5}-\mathrm{CO}(\mathrm{HN}) \mathrm{CH}^{2}-\mathrm{COOH} \\
+\mathrm{H}^{2} \mathrm{O} .
\end{array}
$$

Im Blute ist die Hippursäure nicht nachgewiesen, man hat deshalb den Nieren die Fähigkeit zur Ausführung von Synthesen zugeschrieben, und in der That, wenn man durch die Blutgefässe einer ausgeschnittenen Hundeniere sauerstoffhaltiges, mit Benzoësäure und Glycocoll oder selbst mit Benzoësäure allein versetztes Blut leitet, so entsteht Hippursäure. Für die Synthese der Hippursäure durch die Niere ist Zufuhr von Samerstoff nöthig. Denn wird mit den zu ihrer Bildung erforderlichen Substanzen Kohlenoxydblut oder Serum durchgeleitet, so tritt in ersterem Falle die Synthese gar nicht, in letzterem nur spurweise ein. Durch gröbere Zerkleinerung der Niere wird die Fähigkeit ihrer Zellen, bei Digestion mit benzoësäure- und glycocollhaltigem Blute unter Zutritt von Sauerstoff Hippursäure zu bilden, nicht aufgehoben; durch Zerstampfen oder Ausfrieren zerstört, werden die Zellen unwirksam. Die reichlichen Mengen von Hippursäure bei den Pflanzenfressern erklären sich aus dem Gchalte ihrer Nahrung an Süuren der aromatischen Reihe, welche der Benzö̈s̈̈ure nahestehen. Bei den Fleischfressern und hungernden Pflanzenfressern muss die Benzoësïure von zersetztem Fiweiss stammen. Ausserhalb des Organismus entsteht Benzoësïure bei Behandlung von Eiweiss oder auch von Fäulnissproducten des Eiweisses mit oxydirenden Mitteln; das Glycocoll stammt rermuthlich von der Zersetzung des leimgebenden Gewebes her.

Der sichere Nachweis der synthetischen Ijildung von Hippursäure 
durch lebende thierische Gewebe ist darum von allgemeincrer Bedeutung, weil ja im Allgemeinen im thierischen Organismus Oxydationsprocesse und, mit Wasscraufnahme einhergehende, Spaltungsprocesse rorwiegen, in Gegensatze zu dem Chemismus der P'tlinze, in weleher durch Reductionen und Synthesen Torrath an ehemischer Energie geschaffen wird. Auf eine Reihe anderer im thierischen Organismus zu Stande kommender Synthesen ist man durch die Form aufmerksam geworden, in welcher ein 'Theil der Schrefelsäure mit dem Harne den Organismus verlässt. Nur ein Theil der Schwefelsäme des Harns ist direct mit Baryt füllbar, ein anderer Theil orst nach Zerlegung durch Salzsäure. I) welcher namentlich im Harne der Pflanzenfresser reichlich rorhanden ist, ist an aromatische Verbindungen geknüpft, in Gestalt sogenannter gepaarter Schwefelsäure oder Aetherschwefelsäure; als Prototyp dieser Verbindungen gilt das phenolätherschwefelsaure Káli

$$
\mathrm{SO}^{2}<\mathrm{OK}^{\circ} \cdot \mathrm{C}^{6} \mathrm{H}^{5}
$$

Phenol ist unter den Producten der Fäulnissprocesse im Darme nachgewiesen. Die Schwefelsäure des Harns stammt zum Theil aus den mit der Nahrung aufgenommenen schwefelsauren Salzen, zum Theil aus zersetztem Eiweiss. Der Schwefel des Eiweisses wird ror sciner Entfernung aus dem Organismus grösstentheils zu Schwefelsäure oxydirt, ein kleiner Theil wird aber auch mit dem Harne und mit dem Speichel als Rhodanwasserstoff, an Kalium und Natrium gebunden entfernt.

Die anorganischen Bestandtheile des Harns sind dieselben, welche auch sonst im Organismus angetroffen werden, in grösster Menge sind vorhanden: Kochsalz, Salze von Phosphorsäure und Schwefelsäure, gebunden an Natron, Kali, Kalk und Magnesia; in geringen Mengen, bezüglich in Spuren: Ammoniak, Eisen, liieselsäure, salpetrige und Salpetersïure, Wasserstoffsuperoxyd; einfach auspumplare, also physikalisch absorbirte Kohlensäure enthält der Harn reichlich (circa 14 Volumprocent); die durch Phosphorsäure austreibbare Menge ist beim Menschen fiir gewöhnlich gering, weniger als 1 Volumprocent, und nimmt nur nach reichlicher Aufnahme pflanzensaurer Salze, welche als kohlensaure Salze erscheinen, erhebliche Werthe an.

In welcher Weise die rerschiedenen Basen und Säuren im Harne mit einander rerbunden sind, lïsst sich ebenso wenig mit Sicherheit cutscheiden, wie bei allen gemischten Salzlösungen. ChIornatrium müssen wir im Harne annehmen, da alle ïbrigen Basen ausser dem Natron zulsammengenommen kaum hinreichen, um 1/3 der vorhandenen Salzsäure zu binden. Die normaler Weise saure Reaction des Harns beim Menschen und bei den Fleischfressern muss auf saures phosphorsaures Natron oder 
Kali bezogen werden. Das Chlornatrium des Harns stammt aus der Nahrung, mit welcher es in reichlicher Menge in den Organismus eingeführt wird. Ist die Nahrung frei von Chlornatrium, so verschwindet auch das Chlor fast rollständig aus dem Harne, ebenso beim Hungern; zur Zeit der stärksten Salzsäureausscheidung im Magen, bei der Verdaumng, wird der Harn ärmer an Chloriden und gleichzeitig weniger sauer oder auch alkalisch. Umgekehrt ist der Harn reicher an Chloriden bei krankhaft darniederliegender Magensecretion.

Ammoniak enthält der frische Harn des Menschen und der Fleischfresser constant in kleiner Menge, am reichlichsten bei reiner Fleischkost, ausserdem werden freie Mineralsäuren, welche in den Magen eingeführt werden, an Ammoniak gebunden mit dem Harne entfernt; Salmiak geht bei Hunden unverändert in den Harn über; in den Magen eingeführtes kohlensaures oder pflanzensaures Ammoniak wird dagegen bei Menschen, Hunden und Kaninchen als Harnstoff, bei Hühnern als Harnsäure ausgeschieden. Unterliegt der Harn ausserhalb des Organismus, oder unter pathologischen Verhältnissen schon bei Stagnation in der Harnblase, der Einwirkung der in der Luft vorhandenen Keime von Mikroorganismen, so verfällt der Harnstoff einem Gährungsprocesse, dessen Producte kohlensaures Ammoniak ist.

$$
\mathrm{CO}<\mathrm{NH}^{2}+2 \mathrm{H}^{2} \mathrm{O}=\mathrm{CO}^{3}<\mathrm{H}^{4} \mathrm{~N}
$$

Der dem frischen Harne eigenthümliche aromatische Geruch geht hierbei in den Geruch nach Ammoniak über.

$\mathrm{Zu}$ den normalen Bestandtheilen des Harnes gehören ein peptisches und ein saccharificirendes Ferment, wahrscheinlich resorbirte Verdauungsfermente, deren Wirksamkeit in unverdünntem Harne wegen zu starkel Salzconcentration nicht zur Geltung kommt; nach genügender Verdünnung kann man jedoch mit Harn Stärke in Zucker umwandeln und nach Zufügung von Salzsäure Fibrinflocken verdauen.

Dem aus der Urethra entleerten Harne ist etwas Schleim beigemengt, welcher nicht aus der Niere, sondern aus den Harnwegen mit ihren Anhangsdrüsen und aus der Harnblase stammt.

Für pathologische Verhältnisse hat das Vorkommen grösserer Mengen ron Zucker oder Eiweiss im Harne eine grosse Bedeutung; ob von diesen Stoffen bei gewöhnlicher Ernährung und Anstrengung nachweisbare Spuren in den Harn übergehen, ist zweifelhaft. Bei ganz gesunden Menschen kann nach besonders zuckerreicher Nahrung vorübergehend Zucker im Harne erscheinen, ebenso Eiweiss, wenn grössere Mongen ungekochten Eierciweisses genossen sind, oder nach besonders starker und andaucrnder Körperanstrengung. Bei Thieren wird Zucker oder 
Eiereiweiss nach der Einspritzung in das Blut schnell mit dem Harne entfernt, Serumeiweiss nicht.

Die mittleren quantitativen Verhältnisse für den menschlichen Harn sind in folgender Tabelle zusammengestellt.

In 24 Stunden ausgeschieden

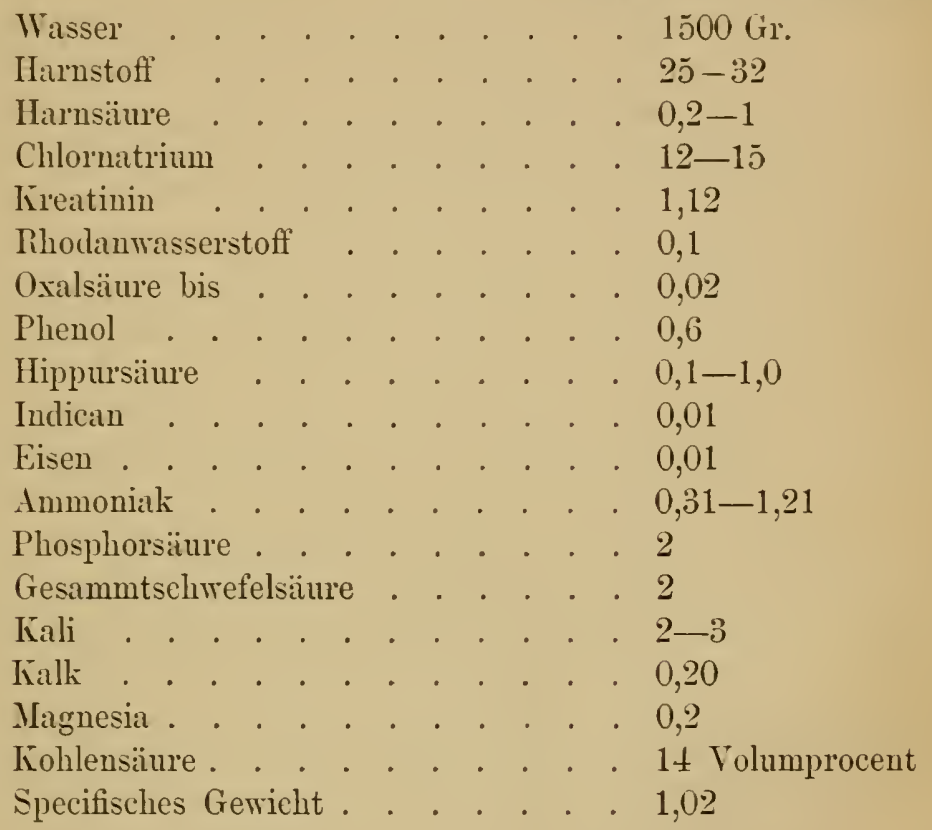

Die eigentliche Driisensubstanz der Niere liegt, zusammen mit den sehr reichlichen Blutgefässen und den Secretausführungsgängen, in einer gemeinschaftlichen, festen, bindegewebigen Kapsel, welcher reichliches Fettgewebe aufgelagert zu sein pflegt. Am medialen Rande löst sich die Kiapsel ron der Nierensubstanz ab, um in den, mit einer mïchtigen Lage glatter Musculatur belegten Harnleiter, den Ureter, überzugehen. Der Hohlraum zwischen der Nierensubstanz und der Kapsel, vor seiner Verengerung zum Ureter heisst das Nierenbecken. Beim Menschen ragen in das Nierenbecken mehrere pyramidenartige Erhebungen (Papillen) der Nierensubstanz herror, welche die Oeffnungen tragen, durch welche das Secret in das gemeinschaftliche Becken ergossen wird. Die Kiapsel des Nierenbeckens wird durchbrochen ron den zu deu Nieren hinzutretenden Gefäissen und Nerren. Innerhalb des Beckens rerästeln sich die Gefïsse und dringen am Grunde der Papillen in die Nierensubstanz ein. Letztere zeigt auf Radiärschnitten eine Tremnung in die heller gefärbte Marksubstanz, deren je ein Kegel je einer Papille entspricht und 
in die dunklere, bräunlichrothe Rindensubstanz. Zwischen Mark und Rinde unterscheidet man eine Grenzschicht, in welcher radiäre Streifen ron stärkerer und schwächerer Blutfärbung abwechseln; bis gegen die Rindensubstanz dringen die im Umfange der Papillen eingetretenen Gefässstämmchen radiär vor und biegen dann in Bogeu um, welche nach aussen convex sind; es gilt dies für die Arterien und Venen; aus den Arcus arteriosi zweigen sich radiär in der Richtung des Markes viele unregelmässig gestellte kleine Aestchen ab, welche sich schnell in radiäre Büschel anflösen, die Arterioli recti; in die Rinde linein begeben sich in sehr regelmässigen kleinen Abständen Arterienstämmchen, die Arteriae radiatae, welche als Anhänge Gefässbildungen von sehr charakteristischer, nur in den Nieren vorkommender Form tragen, die Malpighi'schen Gefässknänel (Glomeruli); an jeder Arteria radiata sitzt, beinahe bis unter die Nierenkapsel hin, eine Anzahl Malpighi'scher Körperchen, ähnlich den Johannisbeeren an ilrem gemeinschaftlichen Stiele; das kurze von der Arteria radiata zu einem Knäuel gehende Gefäss heisst das Vas afferens. Dasselbe löst sich in der Peripherie des Knäuels in eine grössere Anzahl läppchenbildender Capillarschlingen auf. Im Innern des Kinäuels vereinigen sich die Capillaren aller Schlingen zu einem gemeinschaftlichen abführenden Gefässe, dem Vas efferens, welches nahe dem Vas afferens den Knäuel verlässt. Der Zusammenhang des Vas afferens mit peripherischen, des Vas efferens mit central gelegenen Capillarschlingen sichert die Freiheit der Strombahn in normaler Richtung, da im Vas afferens der höhere Druck herrscht, und die durch diesen Druck gewissermaassen erigirten peripherischen Capillaren den Raum für das Vas efferens mit den ihm benachbarten Capillarschlingen freilualten; bei Strömung in umgekelırter Richtung könnten leicht die peripherischen Schlingen gegen die Kapselwand des Glomerulus gedrängt und so rerlegt werden. In der That gelingt es zwar leicht, Injectionsmassen von der Arterie aus durch die Knäuel bis in die umspinnendeu Capillaren und weiter hin fort zu treiben, während einer Injection von der Vene aus durch die Knäuel ein Halt gesetzt wird. Die Vasi efferentia, welche im Allgemeinen enger sind, als die Vasa afferentia, sind wie kleine Tenen gebaut, vereinigen sich aber nicht zu grösseren Venen, sondern lösen sich nochmals in Capillaren auf.

Das Gebiet jeder Arteria radiata und ilurer Gefässknäuel zeigt unter dem Mikroskope das Bild vou, sich gegenseitig durchschlingenden, vielfach gewundenen Drüsenschläuchen. Diese Nierenlabyrinthe confluiren mit eimander atn der Peripherie und bilden hier unter der Nierenkapsel eine zusammenhängende Schicht; zwischen den den einzelnen Arteriae radiatae entsprechenden Labyrinthgebieten zeigt das Mikroskop ebenso wie im Marke und in der Grenzschicht regelmässig radiär gestellte 
Drüsenean̈̈lchen, man nennt diese markartig gebauten Rindenpartien die Markistrahlen; die aus der Auflösung der Vasa efferentia herrorgehenden Capillaren umspinnen in dichterem Netze lie gewundenen Schlïuche des Labyrinthes, in loserem die geraden der Markstrahlen; sie vereinigen sich zum Theil zu Venen der Kapsel, wo sie charakteristische sternförmige Figuren, die Stellulac Verheinii bilden, zum Theil zu Venae radiatae, welehe die Arteriae radiatae begleiten. Dem Capillargebiete des Nierenlabyrinthes dienen nicht nur die Vasa efferentia zum Ursprunge; demselben wird viehmehr auch Blut zugefïhrt, welches, ohne Gefässknäuel durchsetzt zu haben, zum Theil aus den subeapsulären Auflösungen der Arteriae radiatae, zum Theil aus Arterien der Nierenkipsel stammt. Die Vasa efferentia der, der Grenzschicht zunächst gelegenen Knäuel ziehen zum Theil in diese Schicht hinein und dienen dort Gefïssbiischeh ähnlich denen der Arteriolae rectae zum Ursprung (Arterioline rectae spuriae); diese und die aus den drteriolae rectae hervorgehenden Capillaren umspinnen die Drüsencinäle der Grenz- und Markschicht in weitmaschigen Netzen. Die Sammlung des Blutes dieses Capillargebietes geschieht in Venen, welche ähnlich wie die Arteriolae rectae Büschel in der Grenzschicht bilden. Die gruppenweise Lagerung dieser Gefïssbüschel bedingt das radiärgestreifte Aussehen der Grenzsehicht; die Venenbüsehel der Grenzschicht ergiessen ihr Blut in Areus renosi, welehe die Areus arteriosi begleiten. Es ist bemerkenswerth, dass sich der Blutstrom in den Nieren von den Areus arteriosi ans in zwei collaterale Bahnen theilt, von denen die eine durch die Arterioli recti auf kürzerem Wege als die andere durch die Arteriae radiatae und die Malpighi'schen Knn̈̈uel zu Capillaren und Venen führt. Es ist wolıl möglich, dass rom Centralnervensystem abhängige Verengerungen oder Erweiterungen der ersteren Bahn regulirend in den Stromlauf der zweiten eingreifen. Bei Fröschen erhält die Niere ihr Blut nicht nur durch die Nierenarterien, sonder'n auch von einer lö̈pervene, der Vena renalis adrehens oder Nierenpfortader; die Glomeruli in den Nieren sind atuch hier den Verzweigungen der Nierenarterien angefügt, doch erhalten die umspinnenden Capillaren auch Blut aus der Vena renalis adrehens.

Derjenige Theil der Drüseusubstanz, welcher am meisten auf eine besondere Function hinweist, liegt im Nierenlabyrinthe, dessen gewundene Canälchen mit einem mächtigen, eigenthümlich entwickelten Epithel ausgekleidet sind und welches die, nur in den Nieren anzutreffenden, Gefässknäuel träigt. Die gewundenen Canälchen oder Tubuli contorti sind verhäItnissmässig breite Röhren von etwa $50 \mu$ Durchmesser; ilır mächtiges, einer zarten Membrana propria aufsitzendes Epithel lïsst nur ein enges Lumen. Dieses Epithel lïsst ohne besondere Behandlungsweise kaum Zellgrenzen erkennen und auch die Kerne erscheinen nicht sehr 
deutlich in der triiben Masse. Die Triibung ist auf eine, wie es scheint im Leben präformirte, Differenzirung eines Theiles des Zellleibes in Stäbchenform zurïckgefiuhrt worden; die Stäbchenformation ist am vollkommensten in dem der Basalmembran zugewandten Theile des Epithels, erstreckt sich aber zu den Seiten des Kernes hinauf bis in die Nähe des Lumens; in der Umgebung des Kernes und gegen das Lumen hin finden sich Protoplasmareste, welche diese Differenzirung nicht eingegangen sind, und welche sich durch eine bei verschiedenen Thieren rerschieden dentliche Cuticularschicht gegen das Lumen abgrenzen.

Jeder Gefässknänel tritt zu einem Tubulus contortus, durch Vermittelung der Müller'schen Kapsel, in innige Beziehung; für das Verständniss dieser Beziehung ist es nützlich sich rorzustellen, dass der Tubulus contortus in einen Blindsack ron grösserem Durchmesser und etwa doppelter Länge als das Knäuel endige und dass das Knänel so in diesen Sack eingestülpt sei, dass einerseits seine Schlingen ron der Wand des Sackes bekleidet werden, und andererseits das Vas afferens und das Vas efferens frei herausragen. Der Tubulus contortus rerengert sich ror dem Uebergange in die Müller'sche Kapsel bei gleichzeitiger Erniedrigung des Epithels; letzteres setzt sich daun in Gestalt sehr flacher Zellen zunächst auf die äussere durch eine stärkere Membran gebildete Wand des Kapselraumes fort, um dann alle einzelnen Capillarschlingen des Knäuels in continuirlicher Schicht zu überziehen. Beim Menschen ist der rerengerte Uebergangstheil des Tubulus contortus zur liapsel kurz und wird als Hals bezeichnet. Bei den Reptilien, Amphibien und Fischen ist der entsprechende Theil lang und trägt kleine Flimmerzellen mit sehr grossen Cilien.

Könnte man einen einzelnen Tubulus contortus rom Kapselhalse an verfolgen, so würde man finden, dass er nach einer gewissen Anzahl von Windungen die Richtung nach der Grenzschicht der Niere zu festhält und beim Eintritt in diese Schicht sich wieder stark verengert unter gleichzeitiger Abnahme der Epithelhöhe; dieses radiär gerichtete Canälchen führt aber noch nicht zu einer Ausflussöffinung in der Papille, sondern es kehrt in der Grenzschicht oder auch erst tiefer im Marke mit kurzer Biegung um und führt nochmals in das Nierenlabyrinth zurück, hier nimmt es noch einmal einen gewundenen Verlauf an und unterscheidet sich hier in den Abmessungen und in der Structur seines Epithels wenig ron den uibrigen Tubuli contorti. Das Verbindungsglied zwischen den beiden gewundenen Theilen des Canalverlaufes nennt man die Henle sche Schleife. Bei seinem zweiten Austritt aus dem Labyrinthe gelangt das Harncauälchen in einen Markstrahl und verläuft num in radiärer Richtung zur Papille, wo es, mit anderen zusammenmündend, zur Formation der, an der Oberfläche der Papille in geringerer Zahl 
ausniïndenden Ausflussröhrchen beiträgt. Der in einzelnen Theilen der Henle'schen Schleife, in den übrigen geraden Harncanälchen und in den Ausflussröhren ctwas verschicelene Charakter der Epithclbekleidung ist ron keiner besonderen physiologischen Berleutung. In den geraden Theilen ist das Lumen im Allgemeinen von grösserem Durchmesser, als die Höhe der Epithelauskleidung.

Dats interstitielle Gewebe der Nieren ist am stärksten entwickelt in dem Marke, namentlich in den Papillen, am schwächsten im Labyrinthe; von der Nierenkapsel gehen Bindegewebsfortsätze in die Rindensubstanz hinein, welche zu den Mïller'schen Kapseln in Beziehung treten; diese sind normaler Weise von zarter Bindegewebslage umgeben, welche aber unter pathologischen Verhältnissen zu dicken fibrösen Scheiden ausarten. Zwischen den gewundenen Canälchen ist das Bindegewebe auf vereinzelte kleine, spindelförmige Zellen reducirt, welche den Raum zwischen der Tunica propria der letzteren und den Blutcapillaren durchsetzen; dieser Raum gehört dem Lymphsysteme an, dessen Stämmchen die Nieren zum Theil durch den Hilus, zum Theil durch die Kapsel verlassen; die Zwischenschaltung von Lymphe zwischen das Blut und die specifischen Nierenepithelien ist bei den gewundenen Harncanälchen mit Sicherheit nachgewiesen; eine solche Zwischenschaltung fehlt dagegen ebenso sicher in den Malpighi'schen Knäueln, in welchen der Epitheliiberzug den Zellen der Blutcapillaren unmittelbar anliegt. Wo das Bindegewebe der Nieren reichlich entwickelt ist, sind in demselben glatte Muskelfaser'n nachgewiesen worden. Die Nerven, welche grösstentheils durch den Hilus, ansserdem aber auch durch die Kapsel zu den Nieren gelangen, schliessen sich wesentlich an die Gefässe an, Verbindungen derselben mit specifischen Drüsenzellen sind nicht nachgewiesen.

Die Intensität der Harnsecretion ist erheblichen Schwankungen unterworfen; um genau messende Versuche über dieselbe anzustellen, ist es erforderlich, bei Thieren Canïlen in die Ureteren selbst einzulegen, da die spontane Harnentleerung aus der Blase nie gleichen Schritt hält mit dem Harnzuflusse aus den Ureteren, und da sich künstliche Blasenentleerungen in geniigend exacter Weise nicht ausfiihren lassen. Die bei Thieren gemachten Erfahrungen sind zum Theil bestätigt worden an Menschen mit Ectopia resicä, bei denen es olne weiteres möglich ist, Canülen zum Auffangen des Harns in die freiliegenden Blasenmïndungen der Ureteren einzulegen. Einfach in die Ureteren eingeschobene Glasröhrchen genïgen zur Messung der Secretionsintensität bei unrerändertem Harnabfluss; will man Versuche ïber den Secretionsdruck an- 
stellen, so muss man die Röhrchen bei Thieren in die Ureteren einbinden. Bei Menschen muss man auf solche Versuche überhaupt verzichten, wegen der schädlichen Wirkung, welche die Harnstaung auf die Nieren hat. Die Geschwindigkeit, mit welcher Harn aus Ureterencanülen tropft, ist im Allgemeinen auf beiden Seiten selır verschieden, bald rechts, bald links grösser, woraus hervorgeht, dass die Harnsecretion nicht nur von allgemeinen Bedingungen abhängt, sondern auch von der zur Zeit in jeder einzelnen Niere xorhandenen.

Alle Mittel, durch welche wir die Intensität des Harnflusses variiren können, thun dies durch Vermittelung zweier Factoren, das Strömungsverhältniss des Blutes und die Beschaffenheit des Blutes; in erster Beziehung gilt der fundamentale Erfahrungssatz, dass bei gewöhnlicher Blutbeschaffenheit Harnsecretion iiberhaupt nur bei einer gewissen Höhe des in der Carotis gemessenen Blutdruckes eintritt. Die beträchtlichsten Blutsenkungen erhält man beim Thiere nach Durchtrennung des Halsmarkes; ist in Folge dieser Operation der Blutdruck auf etwa 40 Millimeter Quecksilber herunter gegangen, so hört die Harnsecretion auf; durch Tetanisirung des distalen Halsmarkstumpfes kann man den Druck in der Carotis wieder erheblich steigern, sogar über den anfänglichen Werth hinaus, die Harnsecretion kehrt aber nicht ohne weiteres wieder; die experimentelle Blutdrucksteigerung hängt in diesem Falle ab von einer energischen Contraction der peripherischen Blutgefässe, an welcher diejenige der Nieren mit Theil nehmen. Durchtrennt man die Nerven der einen Niere, wodurch ihre Gefässe dem Einflusse der Halsmarkreizung entzogen werden, so tritt in dieser Niere bei der durch Halsmarkreizung hervorgerufenen Blutdrucksteigerung erhebliche Harnsecretion auf, in der anderen Niere bleibt sie nach wie vor ans. Blutdrucksenkungen geringeren Grades erreicht man durch Vagusreizung am Halse oder durch starken Aderlass: in beiden Füllen nimmt die Intensität der Harnsecretion in dem Maasse ab, wie der Blutdruck sinkt; das Umgekehrte findet statt, wenn der Aortendruck durch Schliessung einer grösseren Zahl von Arterien oder durch Hervorrufung von Dyspnoë gesteigert wird; bei Menschen erhöht sich der Harnfluss bei Abkühlung der Körperoberfläche und sinkt im entgegengesetzten Falle: man bezieht dies darauf, dass bei Abkühlung der Haut umfangreiche Gefüsscontractionen eintreten, welche zur Erhöhung des Blutdruckes führen können und ungekehrt.

Bei gleichbleibendem Aortendrucke muss der Druck und die Stromintensität in den Blutcapillaren der Nieren selbst, zu- und abnehmen mit der Weite der Nierenarterien; dementsprechend sinkt die Harnsecretion, wenn man die Nerven der Nieren im Hilus, oder wenn man den Nervus splanchnicus reizt, und man erhält dasselbe Resultat, weun 
man die Nicrenarterie durch eine Ḱlemme stark rerengert; die Durchschneidung der Nierennerven hat nicht nur unter den oben angefïhrten speciellen Bedingungen, sondern anch soust eine Steigerung der Harnsecretion zur Folge. Bei Verengerung der Nierenvenen muss der Druck in den Blutcapilliren der Niere ebenfalls steigen, doch ist diese Drucksteigerung nicht wie die durch Erweiterung der Nierenarterien hervorgerufene mit Zunalme der Stromintensität, sondern mit Abnahme derselben geparart. Die Harnsecretion sinkt bei Terengerung der Nierenvenen; rerschliesst man entweder die Nierenarterien oder die Nierenvenci vollkommen, so steht die Harusecretion in beiden Fällen still. Hatte man die Nierenarterie einige Zeit geschlossen gehalten und giebt man den Blutstrom dann wieder völlig frei, wobei schnelle Wiederherstellung hoher Werthe fuir Druck- und Stromintensität in den Capillaren zu erwarten ist, so stellt sich die Harnsecretion doch nur langsam wieder her. Ausnahmsweise sind Fälle rorgekommen, in denen bei Säugethieren nach vollkommenem Verschlusse der Nierenarterie Harnsecretion an derselben Niere fortbestand: man muss anmehmen, dass in diesen Fällen die Blutrersorgung ron der Kapsel her ausgereicht habe.

Hat man zwischen einem Ureter und einem Quecksilbermanometer eine directe Verbindung hergestellt, so steigt der Druck in letzterem anfänglich schneller, später langsamer, bis höchstens 60 Millimeter Quecksilber. Lässt man den Harn gegen einen kleineren Widerstand ausHiessen, so tropft er um so langsamer ab, je mehr sich der Widerstand dem genannten Druckwerthe nïhert.

Die Beschaffenheit des Blutes hat Einfluss anf die Intensitiit der Harnsecretion, insofern es sich um verschiedenen Gehalt desselben an Wasser und an sogenannten harnfühigen Substanzen handelt. Bei reichlichem Wassertrinken erreicht die Harnfluth in zwei bis drei Stunden ihr Maximum, in fünf bis sechs Stunden ihr Ende, wobei je nach Umständen die ganze iiberschïssige Wassermenge durch die Nieren oder ausserdem auch durch Hantansdünstung entfernt wird. Hierbei, wie uiberhaupt, compensiren sich Nierensecretion und Hautansdünstung. Be völliger Abstinenz geht zwar in den allerersten Tagen die Harnabsonderung schnell herunter, sehr bald aber wird sie für längere Zeit constant, um erst kurz ror dem Tode nochmals wieder abzunehmen; der zur Harnabsonderung erforderliche Gehalt des Blutes an Wasser wird hier, wo die Wasseraufnahme von aussen ganz aufgehört hat, offenbar durch Wasserabgabe ron den Geweben und durch Bildung ron Wasser innerhalb des Organismus erhalten. Bei der Eindickung des Blutes, wie sie im Stadium algidum der Cholera vorliegt, stockt die Harnsecretion rollkommen. Lässt man Kochsalzlösung von $1{ }^{0}{ }_{0}$ in die Vene eines Kaninchens fliessen, so erhält man, ohme dass der Blutdruck wesentlich steigt, ver- 
hältnissmässig sehr grosse Mengen Harns, bis zu 250 CC. pro Stumde, ron qualitativ normaler Zusammensetzung. Versucht man die Concentration des Blutes zu steigern durch Einspritzung concentrirter Lösungen von Kochsalz, Zucker oder Harnstoff in eine Vene, so reichert sich dias Blut sofort mit Wasser aus den Geweben an und es kommt zu gesteigerter Harnsecretion. Die wirksamste der sogenannten harnfähigen Substanzen ist der Harnstoff; fügt man so geringe Quantitäten desselben dem Blute zu, dass eine Aenderung der Concentration kaum erfolgen kann, so erhält man vermehrte Harnsecretion.

Für eine Theorie der Harnsecretion kommen ausser den angeführten Erfahrungen wesentlich noch die Thatsachen in Betracht, dass der Harn im Gegensatze zu den meisten anderen Drïsensecreten beim Menschen und den Fleischfressern sauere Reaction besitzt, und dass er ausser den im Blute vorhandenen Stoffen auch Substanzen führt, wie die Hippursäure, welche sonst im Körper nicht vorkommen. Dies weist auf die Betheiligung chemischer Processe hin, welche sich in specifischen Drüsenzellen abspielen mïssen, und lässt die Versuche, die Harnsecretion als das Resultat physikalischer Filtration und Osmose aufzufassen, wenigstens als zu einseitig erscheinen. Ein solcher Versuch ist in der That gemacht worden, und da Vieles im Baue der Niere zu seinen Gunsten zu sprechen scheint, so hat er sich lange Zeit allgemeinen Beifalls erfreut.

Es ist sehr verfïhrerisch, die Glomernli als Filtrationsapparate aufzufassen: der Druck innerhalb der Capillaren der Malpighi'schen Knäuel muss hoch sein, derjenige im Hohlraume der Kapsel niedrig, die trennende Membran ist dünn und hat eine grosse Gesammtoberfläche. Den Druck im Kapselraume niedriger zu schätzen, ist man veranlasst durch die Kleinheit des Widerstandes, welche der sehr langsam fliessende Harn in den Harncanälchen nur finden kann; für die Höhe des Druckes in den Capillaren kommt in Betracht, dass das Vas afferens eine kleine Arterie ist, dass das Vas efferens enger ist, als das Vas afferens, und dass zwischen dem Vas efferens und dem Venensysteme noch eine Auflösung in Capillargefässe eingeschaltet ist. Der Gesammtwiderstand zwischen den Knäueln und den Nierenvenen muss also weit grösser sein, als der Gesammtwiderstand zwischen der Nierenarterie und den Knäıeln, der Druck in den Knäuelcapillaren muss dementsprechend auch dem Drucke in der Arterie viel näher stehen, als dem Drucke in der Vene. Diese Betrachtung, verbunden mit den Erfahrungen ïber die Abhängigkeit der Harnsecretion von dem Aortendrucke und der Weite der Nierenarterien, hat zu der Annahme geführt, dass durch die Capillarwände des Glomerulus in den Kapselraum eine Flïssigkeit filtrirt werde, deren Zusammensetzung nur von der Zusammensetzung des Blutes und von der Diffusibilität der einzelnen Bestandtheile desselben abhinge. Diese Fliis- 
sigkeit wiirde dementsprechend keine geformten Bestandtheile, kein Eiweiss, oder nur Spuren daron, und viel Wasser mit dem gleichen Gehalte an krystallisablen Stoffen, wie das Blutserum, enthalten. Die Fliissigkeit könnte auch saure Reaction haben; es ist nachgewiesen, dass bei der Filtration einer alkaliseh reagirenden Fliissigkeit, welche ein Gemenge ron einbasischem und zweibasischem Phosphorsäure-Alkali enthält, durch todte thierische Membran eine Flüssigkeit resultirt, welche dureh Vorwiegen ron einbasischem phosphorsaurem Alkali sauer reagirt. Der Harn wïrde sich ron dem in dem Kapselraume zu erwartenden Filtrate also hauptsäichlich unterscheiden durch grössere Concentration, und man nahm an, dass das Filtrat bei seinem langsamen Durchfliessen durch die gewundenen Canälchen Wasser abgebe. Diese Canälchen sind umsponnen ron Capillaren, welche das in den Kü̈ueln zu einer concentrirten Eiweisslösung gewordene Blut führen. Das Eiweiss dieses Blutes könnte durch Osmose Wasser aus dem Lumen der Harncanälchen anziehen.

Eine wesentliche Grundlage dieser Theorie bildet, wie wir geschen haben, die Beziehung der Harnsecretion zu dem Drucke in der Aorta und zu der Weite der Nierenarterien: mit diesen beiden Factoren muss ja allerdings der Blutdruck in den Knäuelcapillaren steigen und sinken, doch nicht nur der Druck, sonder'n auch die Stromintensität; der Druck steigt aber auch bei Verengerung der Nierenvenen, diese Drucksteigerung geht aber Hand in Hand mit Abnahme der Stromgeschwindigkeit und gleichzeitig auch mit Abnahme der Harnsecretion; es scheint also, dass letztere in höherem Iaasse ron der Stromgeschwindigkeit in den Kunäuelcapillaren beeinflusst wïrde, als ron dem Drucke. Vollkommen bindend ist diese Schlussfolgerung nicht, weil es bei Verschluss der Nierenrenen zu einer Anfiillung der Nieren mit Blut kommen muss, die Sistirung der Harnsecretion könnte also eine scheinbare sein, rorgetäuscht ron einer Compression der Sammelröhren des Harns durch die erweiterten Blutgefässe. Die mechanische Bedingung scheint für eine solche Compression guinstig zu sein, da die Canalsysteme des Blutes und des Harnes gemeinschaftlich in einem wenig nachgiebigen Gewebe, umschlossen ron einer ziemlich festen Kapsel, liegen. Von demselben Gesichtspunkte aus kann man auch den Einfluss rermehrten Widerstandes gegen den Harnabfluss aus den Uretcren auffassen, indem es hicrbei umgekehrt zu einer Compression ron Blutgefïssen durch die ausgedehnten Harncanälchen kommen kann. Am grössten kamn der gegenseitige Einfluss beider Canalsysteme in der Grenzschicht sein, wo Gefässbündel mit Bündeln von Harncanälchen abwechseln.

In höherem Maasse als die Folge der Venenabklemmung spricht gegen dic rorwiegende Betheiligung des Blutdruckes an der Harusecretion, 
dass nach der zeitweisen Abklemmung der Nierenarterie die Harnsecretion nicht sofort nach Freigebung des Blutstromes wieder beginnt; man muss doch erwarten, dass hierbei der Blutdruck in den Knäuelcapillaren die normale Höhe schnell wieder erreicht; dass trotzdem Zeit vergeht, weist auf die Abhängigkeit der Secretion von Zellen hin, welche sich nach wiederhergestellter Circulation nur langsam von den Folgen der Stase erholen.

Das Blut in den Knäuelcapillaren ist überall durch Zellen der Capillarwand und durch die Zellen des Knäuelepithels von dem Kapselraume getrennt; von den Zellen der Capillarwände wird zwar allgemein angenommen, dass sie nicht nur Blutwasser, sondern auch Eiweiss unter Druck hindurchtreten lassen; das Knäuelepithel könnte aber der Filtration Widerstand leisten, diese Voraussetzung hat man durch Hinweis auf das Epithel der Descemet'schen Hornhautmembran gestützt; es verdient in der That volle Beachtung, dass die Hornhaut trotz des hohen Druckes, unter welchem der Humor aqueus steht, durch denselben normaler Weise nicht gequellt wird, dass dies aber eintritt, wenn das Fpithel der Descemet'schen Membran defect geworden ist; auch experimentell hat man den Widerstand, welcher die noch mit der Descemet'schen Membran bekleidete Hornhaut der Filtration entgegengesetzt, als sehr hoch ermittelt, unter Bedingungen, bei denen die Zellen der Membran sich in einem ähnlichen Zustande der Erstickung befunden haben mögen, wie das Knäuelepithel während oder bald nach der Arterienklemmung; nach Entfernung des Epithelïberzuges verhält sich die Cornea zur Filtration wie andere todte thierische Membranen.

Wenn man dem Knäuelepithel einen Widerstand gegen einfache Filtration durch Druck zuschreibt, so braucht man ihm darum nicht eine grosse Fähigkeit zur Unterhaltung osmotischer Vorgänge abzusprechen; es scheint eine allgemeine Eigenschaft lebenden Protoplasmas zu sein, seine Fühigkeit zur Wasseraufnahme schnell und in regelmässiger Beziehung zu seinen normalen chemischen Processen zu ändern; ein zur Hervorrufung solcher Veränderungen sehr geeigneter Factor scheint der Gehalt der die Zellen bespülenden Flüssigkeit an den verschiedenen im Wasser gelösten Stoffen zu sein. Gewisse Concentrationsverhältnisse, die sogenannten isotonischen, lassen Zellen einer bestimmten Art ganz unberührt, und es wäre nicht zu verwundern, wenn eine Schicht solcher Zellen dieser Flüssigkeit den Durchtritt auch bei hoher Druckdifferenz auf beidon Seiten der Schicht verwehrte.

Sind lebende Zellen allseitig von einer nicht isotonischen Flïssigkeit umgeben, so tritt Aufnahme oder Abgabe von Wasser und darin gelöster Substanzen ein, bis sich wieder ein Gleichgewichtszustand hergestellt = hat; die \%elle kann hierbei je nach Umständen zu Grunde gehen orler 
an Leben bleiben und sich wiederholten Aenderungen der umspülenden Fliissigkeit anpassen; was in dem besonderen Falle eintreten muss, wenn nur die eine Seite einer Zellschicht ron einer nicht isotonischen Flïssigkeit bespiilt wird, kann man zur Zeit nicht angeben, doch kann maln sich wohl rorstellen, diss es liraft bestimmter räumlicher Orientirung in der chemischen Structur der \%elle auf der einen Seite zur Aufnahme ron Wisser und darin gelöster Substanzen, auf der anderen Seite zur Abgabe derselben kommt.

Un eimen kurzen Ausdruck zu gebrauchen, könnte man sagen; dass Fliissigkeiten je nach der Natur und Concentration der in ihnen gelösten Substanzen die Zellschicht zu Secretion anregten; bei stagnirender Fliissigkeit muss der Secretionsreiz in Folge der Secretion mehr und mehr abnehmen; auf diese Weise wiirde es rerständlich, wie ein schnell dic linäuelgefüsse durchströmendes Blut die Secretmenge vermehren kann.

Die Herkunft des Wassers und der Blutsalze aus Malpighi'schen Knäueln ist unbestritten; in Betreff anderer und, wie es scheint, anch gerade der specifischen Harnbestandtheile liegen aber Erfahrungen vor, welche auf die Betheiligung des Epithels der gewundenen Canälchen an ihrer Secretion hiwweisen. Bei Vögeln und Reptilien findet man Harnsïnreablagerungen in den Kapseln schon unter normalen Verhältnissen ror, nach Ureteren-Unterbindung aber auch seln reichlich im Epithel der gewundenen Canälchen. Die Zcllen dieses Epithels scheinen hier mit der Harnsäureausscheidıng sogar zu Grunde zu gehen, denn Trümmer derselben treten als zähe, fadenziehende, eiweisshaltige Einbettungsmassen in das Secret iiber, dessen geringer Wassergehalt der auffallenden Kleinheit der Kapseln entspricht. In den Nieren ron Säugethieren finden sich selbst bei verhältnissmässig reichlicher Harnsäureabsonderung harnsaure Salze nie in den Kapseln, sondern nur in den Harncanälchen ror. Es ist also wahrscheinlich, dass die Epithelzellen der gewundenen Canälchen aus der Lymphe die, hier in äusserst verdünntem Zustande vorhandene Harnsäure sammeln und dieselbe in das rorüberströmende Secret der Malpighi'schen Knnäuel abscheiden. So lange von dort her nicht zu viel Alkalien orler alkalische Salze mitgebracht werden, um die gesammte Harnsinre in neutrales Salz zu rerwandeln, bleibt die Reaction der weiterströmenden Fliissigkeit saucr, weil sich saure phosphorsaure Alkalien neben saurem Harnsïurealkali bilden.

Dia sich der Harnstoff optisch auf seinem Secretiouswege nicht rerfolgen lïsst, so ist man in Betreff desselben auf Analogie-Schlüsse angewiesen; man verwendet hierzu namentlich Erfahrungen, welche man nit einem Farbstoffe gesammelt lat: reines iudigoblauschwefelsaures Natron ist mit blaner Farbe in Wasser löslich und wirt durch concentrirten Alkohol oder Kalksalze aus demselben gefüllt; man kann erheb- 
liche Mengen der wässerigen Lösung, ohne dem Organismus zu schaden, in die Tene eines Thieres einspritzen, und der Farbstoff wird schnell durch die Nieren entfernt. Aufschlüsse über den Weg, welchen der Farbstoff in den Nieren genommen hat, kann man gewinnen, wenn man das Organ dem, in passender Zeit nach der Injection getödteten Thiere, sofort entnimmt und ron der Arterie aus schnell mit concentrirtem Alkohol ausspritzt; der Farbstoff wird dadurch an den Stellen, wo er beim Tode lag, sofort fixirt und vor postmortaler Diffusion bewahrt.

Wurden einem Kaninchen einige Zeit nach der Halsmarkdurchschneidung, sobald der Blutdruck stark gesunken war, geringe Mengen des Salzes in die Vena jugularis injicirt, so findet man bereits nach wenigen Minuten die Epithelien der gewundenen Canälchen gebläut. Dieselben haben also aus der umspülenden Lymphe, deren Farbstoffgehalt so gering ist, dass sie farblos erscheint, das Pigment aufgesammelt. Nach einer. Stunde hat sich das Epithel wieder entbläut, man findet das durch die Alkoholeinwirkung gefällte blaue Salz als Körnchen oder Kryställchen im Lumen der gewundenen Harncanälchen; die Epithelien haben also das aufgenommene Salz wieder abgegeben, dabei hat keine merkliche Wassersecretion stattgefunden, denn nicht nur die Harnblase ist leer, sondern auch das Nierenmark zeigt sich völlig farbstofffrei. Nach Injection grösserer Mengen von Farbstoff sind die Epithelien der secernirenden Canälchen stärker mit demselben beladen, ihre Kerne erscheinen noch dunkler gefärbt als die Zellkörper, letztere können gelegentlich das Pigment schon wieder abgegeben haben und farblos erscheinen, während die Kerne noch tingirt sind; die Müller'schen Kapseln sind auch in diesem Falle von Farbstoff frei.

Wurde die Farbstofflösung einem Thiere eingespritzt, bei welchem der Harnfluss nicht durch Halsmarkdurchschneidung unterbrochen worden war, so findet man den Farbstoff auch in den geraden Harncanälchen, sowie in den Sammelröhren des Markes, aber nur in dem Lumen; ron Epithelien sind auch hier nur diejenigen der gewundenen Canälchen gefärbt, die Müller'schen Kapseln sind stets frei. Man muss also annehmen, dass der vom Epithel der gewundenen Canälchen secernirte Farbstoff durch das in den Müller'schen Kapseln ausgeschiedene Wasser in die geraden Canälchen und Sammelröhren fortgespült worden ist.

Aehnlich wie das indigschwefelsaure Natron wird wahrscheinliclı auch der Harnstoff aus seiner sehr verdünnten Lösung in der Lymphe ron dem secernirenden Epithel der gewundenen Canälchen gesammelt und in concentrirter Form an das vorbeisickernde Harnwasser abgegeben. Dass diese Epithelien zu seiner Ausscheidung in nähere Beziehung treten als die Müller'schen Kapseln, ist durch Experimente am 
Frosche wahrscheinlich gemacht worden; bei diesem 'Thiere kann man, wie oben erwälnt wurde, durch Unterbindung rler Nierenarterie den Blutstrom in den Gefïssknäucln unterdrïcken, während derjenige in den, die gewundenen Canälchen umspülenden Capillaren, von der Vena renalis adrehens aus, unterhalten bleibt; auch nach Unterlindung der Nierenarterie lat beim Frosche die Einspritzung von Harnstofflösung in das Blut Vermehrung des Harnflusses zur Folge. Hieraus folgt nicht nur, dass die Harnstoffausscheidung durch das Epithel der gewundenen Canälchen erfolgt, sondern auch, dass diese zugleich mit dem Harustoft Wasser auszuscheiden rermögen. Hiernach ist auch das Ergebniss des folgenden Experimentes beim Kaninchen zu beurtheilen: hat man bei diesem Thiere durch Halsmarkdurchschneidung den Harnfluss unterbrochen, so kann man ihn durch Einführung von Harnstoff in das Blut wieder beleben, dieser Erfolg ist nicht eindentig, weil durch die Harnstoffeinspritzung auch der durch Halsmarkschneidung gesunkene Blutdruck wieder gehoben, der Blutstrom in den Nierenknäueln also rermuthlich wieder beschleunigt wird. Die Regelung des Harnflusses durch Harnstoffeinspritzung ist aber auch an chloralisirten Kaninchen gelungen, bei denen die Blutdrucksteigerung ausbleibt. Hier hat man keinen Grund rorauszusetzen, dass die Secretion in den Müller'schen Kapseln sich wiederhergestellt habe, wahrscheinlicher ist die Annahme, dass Ausscheidung von Harnstoff, und zugleich von Wasser in den gewundenen Canälchen erfolgt.

Von der Hippursäure und rerwandten Stoffen, welche im Blute nicht vorgebildet sind, haben wir keinen Grund anzunehmen, dass sie in den Knäueln ausgeschieden würden; es ist viel wahrscheinlicher, dlass sie in dem hochdifferenzirten Epithel der gewundenen Canälchen gebildet und an den rorbeifliessenden Harn abgegeben werden.

Wenn Hühnereiweiss oder Zucker unter den oben angegebenen Bedingungen im Harne erscheinen, muss man zunächst annehmen, dass sie in den Knäueln ausgeschieden worden sind, da sie bei dem Frosche nach Unterbindung der Nierenarterien im Harne nicht mehr erscheinen, auch wenn sie in sonst genïgender Menge in das Blut gebracht worden sind; auch das Serumeiweiss pathologischer Harne wird wahrscheinlich in den Knäueln abgeschieden, Blutfarbstoff dagegen und Gallenfarbstoff, wemn sie im Harne auftreten, durch das Epithel der gewundenen Canälchen.

Der auffallendste Einfluss, welchen man rom Nerrensysteme aus auf die Harnsecretion ausüben kann, zeigt sich in dem Erfolge der sogenannten Piqure Claude Bernard's; dieselbe besteht in einem Stich, welcher in die Mittellinie des vierten Ventrikels zwischen Tuberculum acusticum und Calamus eindringt, und sie hat eine mächtige Harnfluth 
mit oder ohne Ausscheidung ron Zucker zur Folge. Die Mittelglieder zurischen dem Fingriffe und dem Erfolge sind noch nicht aufgeklärt; was iiberhaupt die Beziehung der Nerven zu der Harnsecretion angeht, so kann man augenblicklich nur so viel sagen, dass ein directer Einfluss von Nerren auf secernirende Elemente weder nachgewiesen noch wahrscheinlich ist, und dass alle Erfolge der Reizung oder Durchschneidung von Nierennerven rerstanden werden können, wenn man von ersterer eine Verengerung und ron letzterer eine Erweiterung der Nierenarterien abhängig macht.

Von den harntreibenden Mittelu wirken einige, wie zum Beispiel Digitalis, durch Vermittelung allgemeiner Blutsteigerung, von anderen, wie zum Beispiel von Caffeïn, wird auf Grund von Durchströmungsversuchen an überlebenden Nieren behauptet, dass sie die Secretionsthätigkeit specifischer Drüsenzellen direct beeinflussen.

Bei seinem durch den Secretionsdruck bewirkten Uebertritte aus dem Nierenbecken in den Ureter wird der Harn von peristaltischen Wellen des letzteren erfasst und ziemlich schnell in die Harnblase übergeführt; hier sammelt er sich, bis die Wand der Harnblase eine gewisse Dehnung erfahren hat; die dadurch veranlasste Empfindung bewirkt die willkürliche Harnentleerung durch die Urethra.

Die menschliche Haut ist in ihrem ganzen Umfange und an einzelnen Stellen in bevorzugter Weise dazu geeignet, Wasser in Dunstform oder als tropfbare Flüssigkeit abzugeben; in letzterem Falle sagt man, sie schwitzt. Das Auftreten von $\mathrm{Schwe}$ is s wird begünstigt durch hohe Temperatur, durch Körperanstrengung, gesteigerte Wasserzufuhr und hohen Wassergehalt der umgebenden Luft. Am stärksten schwitzt die Haut in den Achselhöhlen, an der Planta pedis et manus und im Gesichte. Dort findet man auch bei mikroskopischer Untersuchung die Knäueldrüsen, welchen die Schweissabsonderung zugeschrieben wird, am stärksten entwickelt, sowohl der Zahl als der Grösse nach. Jedes Drüichen besteht aus einem linäuelförmig aufgewickelten Schlanche, welcher zunächst gerade aufsteigend die Lederhaut, dann korkzieherförmig gewunden die Epidermis durchbricht und hier frei endigt, auf den Hautleisten der Handfläche mit blossem Auge eben sichtbar. Bei dem geringsten Grade der Schweissbildung erkennt man die Fliissigkeit in jeder dieser Miindungen an dem Lichtreflexe; wird die Schweissbildung stärker, so perlen kleine Tropfen hervor, welche confluirend die Haut mit einer capillaren Flüssigkeitsschicht überziehen. Wird die Secretion noch stärker, so fliesst die Flüssigkeit in Tropfen ab. Indem man einen schwitzenden 
Menschen in einem mit Wasserdampf gesättigten Raume auf eine Metallrinne legte, ron welcher der Schweiss ablaufen konnte, erhiclt man in $1 \frac{1}{2}$ Stunde über 2000 Kubikcentimeter davon. So aufgefangener Schweiss enthält nur $1 / 2 \%$ fester Stoffe, deren Hälfte aus Kochsalz besteht; ferner sind darin enthalten kleine Mengen Harnstoff und Fett. Ob der Schweiss sauer oder alkalisch reagirt, scheint ron dem Zustande des Fettes abzuhängen, welches, wenn er stagnirt hat, freie Fettsäuren zu enthalten pflegt. Nach sorgfältiger Reinigung der Haut mit neutralem Alkohol und Aether soll es stets gelingen, an dem hervorperlenden Schweisse alkalische Reaction nachzuweisen.

Bei warmer, sehr trockener Luft braucht die Secretion der Schweissdrüsen nicht zum Auftreten ron Schweiss zu führen, wenn das Wasser in dem Maasse wie es ausgeschieden worden ist, an der Oeffuung der Ausführungsgïnge verdunstet: man nennt diese Art der Wasserabgabe durch die Haut Perspiratio insensibilis. Die Abgabe von Wasser und diejenige von Wärme durch Verdunstung von Wasser kann hierbei beträchtlich sein. Die Wärmeabgabe durch Verdunstung ist beträchtlicher, wemn der Schweiss die Hautoberfläche in capillarer Schicht ïberzieht, wird aber nicht weiter gesteigert, wemu der Schweiss in Tropfen abfliesst; bei hochgradigem Schwitzen tritt also die Wasserabgabe sehr in den Vordergrund. Dieser Factor bleibt allein übrig bei prolongirtem Aufenthalte in warmem Bade, wo erwiesenermaassen beträchtliche Wasserahgabe durch die Haut stattfindet. Im Allgemeinen geht die Schweissbildung mit Röthung und Erwärmung der Haut Hand in Hand, doch tritt in krankhaften Zuständen auch Schweiss auf kalter blasser Haut auf; lebhafte Durchblutung der Haut gehört also zu den, die Schweissbildung begïnstigenden Momenten, ist aber keine unerlïssliche Bedingung.

Da die Fähigkeit zu schwitzen bei den, dem Experimente am besten zugänglichen Thieren durchaus nicht allgemein verbreitet ist, so ist man erst spät dazu gelangt, die bei der Schweissbildung betheiligten Factoren genau zu analysiren. Das beste Ergebniss in dieser Beziehung haben Beobachtungen an den Pfotenballen junger Katzen geliefert. Am meisten eignen sich unausgewachsene, wenig pigmentirte Thiere, welche aber wenigstens einige Wochen alt sein müssen. Bei solchen Thieren kann man, wenn die äussere Temperatur nicht zu niedrig ist, durch Reizung des Ischiadicus den Schweiss an den Ballen der Hinterpfoten hervorperlen lassen. Ist der Ischiadicus noch intact, so erhält man auch Schweissbildung, wenn man das Thier erwärmt oder dyspnoisch macht; da dieser Versuch noch gelingt, nachdem das Halsmark durchschnitten ist und nicht mehr, wenn der Ischiadicus durchtrennt wurde, so muss man annehmen, dass überwarmes oder dyspnoisches Blut Centren in Riuckenmarke reizt, deren Erregung die Schweisssecretion zur 
Folge hat. Das Gleiche gilt auch ron gewissen pharmakologischen Mitteln, wenn sie in die Blutbahn gebracht wurden, namentlich rom Strychnin, Picrotoxin, Kampher und Ammonium aceticum; andere Mittel regen die Schweissbildung auch noch nach Durchschneidung der Extremitätennerven an, namentlich Pilocarpin und Muscarin, in geringerem Grade Nicotin und Physostigmin. Stärker wirken übrigens diese Mittel beim Erhalten der Nervenverbindung. Atropin hebt die Schweissbildung auf, bis es aus dem Organismus eliminirt ist.

Es kann als allgemeine Regel gelten, dass sich die Schweissnerren, um zur Peripherie zu gelangen, grossen Nervenstämmen anschliessen; bei der Katze ist dieser Verlauf ermittelt im Ischiadicus für die Hinterpfote und im Plexus brachialis für die Vorderpfote; bei dem Pferde, welches am ganzen Körper schwitzt, und beim Schweine, welches Schweissbildung am Rïssel zeigt, in Aesten des Nervus trigeminus für den Kopf. Zwischen dem Rïckenmarke und diesen Nervenstämmen passiren die Schweissnerven, vielleicht nicht sämmtlich, aber doch grösstentheils den Grenzstrang des Sympathicus; zu den Versuchen, welche dieses beweisen, gehört Folgender: bei Kätzchen gelingt es auch noch nach Ausrottung des Rückenmarkes, unterhalb des letzten Brustwirbels, Schweisssecretion an den Hinterpfoten durch Dyspnoë zu erzielen; durchschneidet man aber auch noch den Bauchstrang des Sympathicus, so bleibt die Wirkung aus.

Auch durch das Thierexperiment bekommt man den Eindruck, dass lebhafte Circulation in der Haut zu den begünstigenden Momenten für die Schweissbildung gehört, vermuthlich wegen der reichlichen Zufuhr von Sauerstoff, Wasser und Wärme, dass aber Vermehrung der Schweisssecretion nicht nothwendig an eine Beschleunigung der Circulation gebunden ist; bei Reizung des Ischiadicus sieht man zum Beispiel an den Pfotenballen weisser Kätzchen Erblassen und Temperaturerniedrigung mit der Schweisssecretion Hand in Hand gehen. Es gelingt sogar, an der frisch amputirten Pfote durch Ischiadicusreizung noch Schweissperlen hervorzutreiben. Für die Beurtheilung der Fragen, ob die Schweissnerven direct auf Drüsenzellen wirken, bleibt immerhin zu berücksichtigen, dass die Nerven zwar bis in die unmittelbare Ungebung der Drüsenknäuel verfolgt sind, dass ein Zusammenhang derselben mit Drïsenzellen sich aber nicht hat nachweisen lassen, und dass in der Ungebung der Kinäuel glatte Muskelfasern liegen. Beim Pferre erhält man nach älteren, wiederholt bestätigten Erfahrungen in Folge von Durchschneidung des Halssympathicus eine, tagelang andanernde, profuse Schweissbildung auf derselben Seite des Kopfes. Man hat hieraus auf das Volhandensein secretionshemmender Fasern im Sympathicus schliessen wollen, doch ohne zwingenden Grund. Vermehrte Scliweissbildung besteht nur so lange wie die, nach Sympathicusiturchschneidung zunächst auftretende 
Erweiterung der Gefäisse, mit dieser schwindet nach einigen Tagen auch die Schweisssecretion; da wir nun wissen, dass Reizung von Trigeminusïsten Schweissbildung an der Gesichtshaut des Pferdes hervorrutt, so können wir auch erwarten, dass die normalerweise auf dieser bahu fliessende Erregung, bei plötzlich verbesserter Berlingung für die Schweisssecretion, zu einer sichtbaren Schweissbildung führen werde.

Beim Menschen tritt als Symptom einer Lähmung des Halssympathicus zunächst ebenfalls vermehrte Schweissbildung und dam Trockenheit der Haut ein.

Nach starkem Schwitzen in bewegter Luft fühlt man das eigene Gesicht mit Körnchen überzogen, welche salzig schmecken. Stärker als der Menseh schwitzt bei angestrengter Thätigkeit das Pferd. Die auffallende Erscheinung, dass bei diesem Thiere der nasse Schweiss Schaum bildet und beim Eintrocknen keine Körnchen sondern Häutchen hinterlässt, findet seine Erklïrung in der merkwürdigen Thatsache, dass der Pferdeschweiss nicht unbetrïchtliche Mengen von Eiweiss enthält, eine Thatsache, iiber deren Bedeutung für den Stoffwechsel zunächst Nichts zu sagen ist.

\section{Kehnter Abschnitt.}

\section{Nahrung und Nahrungsaufnahme.}

\section{(J. F. Heymans.)}

Abgesehen von einigen seltenen Ausnahmen, wie sie zum Beispiel das Latenzleben niederer Thiere darstellt, und abgesehen von einigen pathologischen Zuständen höherer Thiere, ist der normale Organismus der Sitz zahlreicher chemischer Reactionen, wobei potentielle Energie in actuelle Energie umgewandelt wird. Complicirte Molekiile des lebenden Protoplasmas zerfallen und bilden einfachere festere Verbindungen mit Freimachung von Elektricität, Wärme und Arbeitsleistung: es findet also im Organismus eine stetige Desassimilation und Ausscheidung der desassimilirten Producte statt. Da der thierische Organismus nicht im Stande ist, kinetische Energie in chemische potentielle Energie zum 
Zwecke der Aufspeicherung umzuwandeln, oder einfache feste Verbindungen in complicirte lockere Verbindungen synthetisch ïberzufithren, so besteht für ihn die absolute Nothwendigkeit, um das dynamische Gleichgewicht seiner potentiellen Energie zu erhalten, diese letztere durch ein qualitativ und quantitativ passend gewähltes Nährmaterial, sowie durch Assimilation des letzteren zu ersetzen. Als Hauptsubstanzen, welche ihm diese gewünschte potentielle Energie zuführen, sind zu nennen: eiweissartige Stoffe, Fette und Kohlehydrate, welche unter Hinzuziehung von unorganischen Stoffen (Wasser und Salzen) dem thierischen Organismus erlauben, seinen stofflichen Bestand zu erhalten, zu entwickeln und zu vergrössern.

Dementsprechend sind die chemischen Elemente der organischen $\mathrm{Nährst} \mathrm{offe} \mathrm{wie} \mathrm{C,} \mathrm{H,} \mathrm{N,} \mathrm{S,} \mathrm{P,} \mathrm{mit} \mathrm{Ausnahme} \mathrm{vielleicht} \mathrm{des} \mathrm{Eisens,} \mathrm{als}$ solche zur Assimilation unbrauchbar; ebenso ihre einfacheren unorganischen und organischen Verbindungen. Auf unserem Erdboden fällt es in jetzigen wie in früheren Zeiten den Pflanzen zu, die Elemente zu solcheu höheren chemischen Verbindungen synthetisch aufzubauen, welche für den thierischen und menschlichen Organismus brauchbar sind. Das Chlorophyll entnimmt den Sonnenstrahlen die nöthige Energie, um Kohlensäure zu zerlegen und sie unter Entbindung von Sauerstoff mit Hilfe von Wasser in Kohlehydrate und Fette umzuwandeln. Das pflanzliche Protoplasma bildet auch aus unorganischen, dem Erdboden entnommenen stickstoff haltigen Verbindungen synthetisch eiweissartige Stoffe. Die so entstandenen pflanzlichen Bestandtheile dienen theilweise unmittelbar als solche zu unserer Ernährung, theilweise kommen sie uns dadurch zu Gute, dass die thierischen Gewebe, welche wir geniessen, hauptsächlich von Pflanzenfressern entnommen werden. Letztere haben als ausschliessliche Nahrung pflanzliche Gewebe, deren Kohlehydrate sie theilweise in Fett umwandeln und deren Eiweisskörper sie zur Bildung von thierischen Albuminstoffen benutzen.

Der Organismus enthält circa $60 \%$ Wasser, welches grösstentheils den Körperflüssigkeiten angehört, ausserdem aber in Gewebszellen und deren complicirten Molekülen sich befindet. Da der menschliche Organismus durch Harnsecretion, Hantausdünstung, Lungenverdampfung und Koth gegen $2 \frac{1}{2}$ Liter Wasser in 24 Stunden verliert, und da bei der Verbrennung der Eiweisskörper, Fette und Kohlehydrate, welche täglich im Organismus stattfindet, höchstens nur 300-400 Gr. Wasser gebildet werden, so besteht, um den Gehalt an Wasser zu erhalten, die Nothwendigkeit, eine entsprechende Menge von Wasser aufzunehmen. Dieses geschieht theilweise durch das Geniessen von gewöhnlichem, der natiirlichen Quelle oder dem künstlich hergestellten Brunnen entnommenen Trinkwasser. Letzteres muss Sauerstoff, Kohlensäure und Salze enthalten. 
Gekochtes Wasser ist wegen Gasmangels, Regenwasser wegen Mangels an Salzen unbrauchbar, destillirtes Wasser sogar äusserst schädlich. Vou organischen Substanzen, respective lebendigen pathogenen, oder nicht pathogenen Mikroorganismen muss das Wasser möglichst frei sein; das Wasser wird beim Filtriren durch die Erdschichten auf natirliche Weise mit Salzen bereichert und von den oberirdischen, mitgeschleppten Mikroorganismen befreit. Wasser wird ferner aufgenommen durch die verschiedenen kïnstlich dargestellten Getränke, wie Bier, Wein und Abgiisse ron Kaffee, Thee und dergleichen; dizu kommt noch die beträichtliche Menge von Wasser, welche andere genossene Speisen reichlich enthalten, zum Beispiel Milch, Früichte, Brod, Kartoffeln, Fleisch und sonstige Nahrungsmittel.

Der Gehalt an mincralischen Bestandtheilen in allen Kööpertheilen und Säften, sowic die stetige Ausscheidung der entsprechenden Salze, welche im lebenden Organismus stattfindet, beweisen, dass die Aufnahme dieser unorganischen Salze zur Unterhaltung des normalen Nahrungszustandes unbedingt gehört. Chlornatrium wird täglich bis zu $15 \mathrm{Gr}$. ausgeschieden, dementsprechend muss dieser Verlust durch Aufnahme des in einigen Nahrungsmitteln natiurlich enthaltenen oder des ihnen beigesetzten Chlornatriums ersetzt werden. Die anderen Salze, wie Alkalibicarluonate, Erdphosphate und Eisen befinden sich normalerweise in genügender Henge in den Getränken und Speisen, welche der Organismus aufnimmt.

Die Kohlehydrate, welche als Nährstoffe in Betracht kommen, sind Stärke und Zucker, welche rerschiedenen Pflanzen entnommen werden. Die Stärkekörner, welche den Hauptbestandtheil der Cerealien und der Kartoffeln bilden, bestehen aus Granulose, Erythrogranulose und Cellulose. Unter den Zuckerarten nimmt der Rohrzucker den wichtigsten Ring ein; er wird aus rerschiedenen Pflanzen künstlich dargestellt und anderen Substanzen zum Zwecke des Genusses beigemengt; auch findet er sich in vielen Nahrungsmitteln schon ror. Der Milchzucker ist der Milch cigen und spielt eine sehr wichtige Rolle bei der Ernährung des Neugeborenen. Der Traubenzucker ist in den sïssen Friichten, im Honig und in den gegohrenen Getränken enthalten; er hefindet sich auch in einigen thierischen Geweben wie in der Leber und im Blute. Zu erwähnen sind ron Kohlehydraten noch das Inulin, das Glykogen, die Cellulose der Pflanzenmembranen und die Gummiarten: für die Ernährung spielen dieselben aber nur eine Nebenrolle. Die Fette, welche hituptsächlich aus einem Gemische ron stearin-, palmitin- und oleïnsaurem Glycerin bestehen, werden theils den Pflanzen (Olivenöl, Mandelöl), in grösserer Menge aber den Thieren (Butter, Talg, Schmalz) entnommen. Die für den Organismus nöthigen Albuminmengen werden 
den Pflanzen als Glutin und Legumin, den Thieren als verschiedene Proteïnstoffe entlehnt. Unter den thierischen Proteïnstoffen sind die wichtigsten: das Myosin, das Caseïn, das Eier- und Serumeiweiss, das Blutfibrin, das Hämoglobin. Die leimbildenden Substanzen können die Eiweisskörper als Nährstoffe höchstens theilweise ersetzen. Zahlreiche andere Substanzen, welche als Nahrung nicht nothwendig, aber fïr die Verdauung und Ernährung oft nützlich sind, werden fast immer zugleich mit den nothwendigen Nährstoffen aufgenommen; wir nennen hier Fettsäuren, Alkohol, Essenzen, Alkaloide u. s. w.

Wie aus dem oben Gesagten hervorgeht, werden die verschiedenen Nährstoffe nur ausnahmsweise isolirt verzehrt; in den Nahrungsmitteln sind sie in verschiedenen Verhältnissen gemischt vertreten. Da der normale ausgewachsene menschliche Organismus durch seinen Stoffwechsel durchschnittlich $120 \mathrm{Gr}$. Albuminstoffe, $80 \mathrm{Gr}$. Fette und $400 \mathrm{Gr}$. Kohlehydrate, $25 \mathrm{Gr}$. Salze und $2 \frac{1}{2}$ Liter Wasser täglich verliert, muss zu einer normalen Ernährung die entsprechende Menge von Nährstoffen in Gestalt von Nahrungsmitteln zugeführt werden. Die Nahrungsmittel sind die verschiedenen Getränke und Speisen, welche $\mathrm{zu}$ angenehmerem Geschmack und leichterer Verdauung auf die mannigfaltigste Weise mit Hilfe von Wasser und Wärme und unter Zufügung von Genuss- und Gewürzmitteln zubereitet werden. Da das eine Nahrungsmittel - wie Fleisch und Eier - mehr Eiweiss, das andere - wie Kartoffeln und Brod - mehr Kohlehydrate, das andere mehr Fette, oder Salze, oder Wasser enthält, so ist zur normalen Ernährung diejenige Aufnahme von Nahrungsmitteln erforderlich, welche von jedem Nährstoffe eine genügende Menge und von keinem einen Ueberschuss liefert.

Da die erforderlichen stickstoff haltigen Nährstoffe zu den stickstofflosen ungefähr im Verhältnisse wie 1 zu 4 stehen, so kann man leicht aus nebenstehender Tabelle, welche gleichzeitig die Zusammensetzung verschiedener Speisen angiebt, passende Combinationen von normaler Nahrung ersehen. 


\section{Animalische Vahrungsmittel.}

Erklarung der Zeichen.

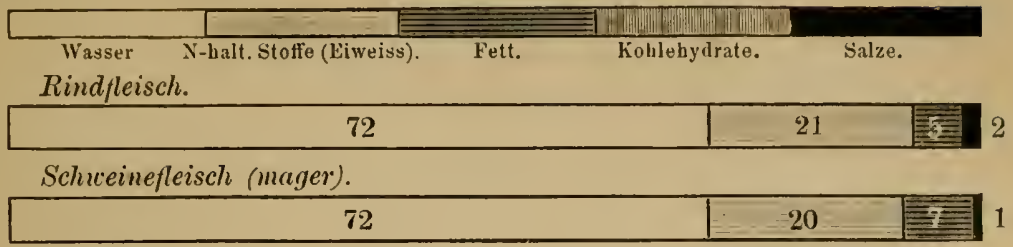

Geflügel.

\begin{tabular}{|c|c|}
\hline 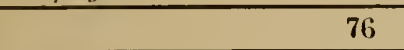 & 21 \\
\hline Fisch. & \\
\hline 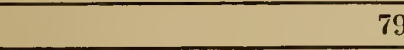 & 20 \\
\hline
\end{tabular}

Hühnerei.

\begin{tabular}{|l|l|}
\hline 75 & 12 \\
\hline
\end{tabular}

Franeminilch.

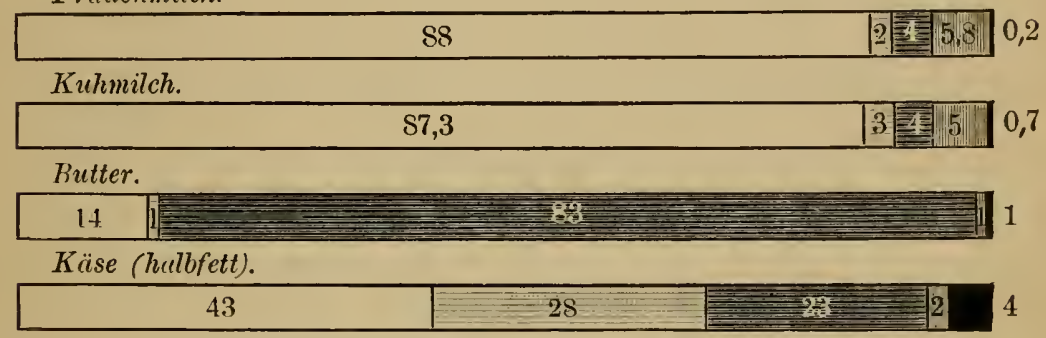

Vegetabilische Nahrungsmittel.

Erklärung der Zeichen.

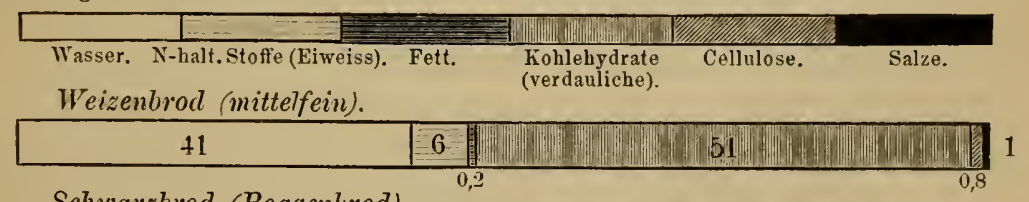

Schwarzbrod (Roggenbrod).

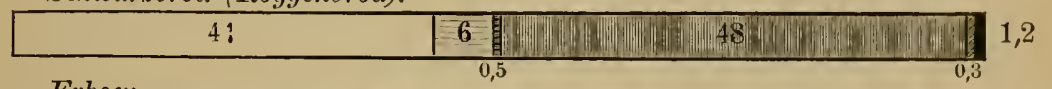

Erbsen.

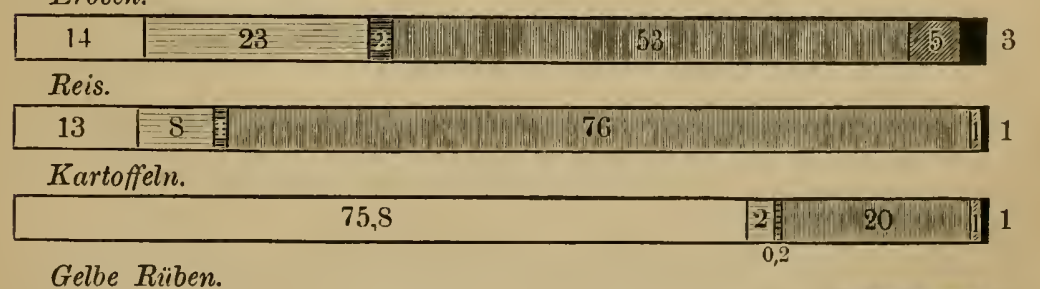

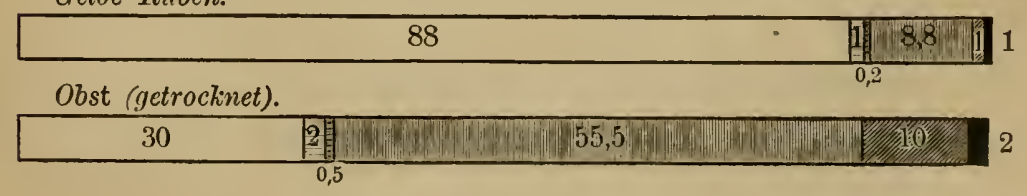


Die Antriebe zur Nahrungsaufnahme erhalten wir durch die Empfindungen, welche wir als Hunger und Durst bezeichnen, sowie auch durch die Erinnerungen an angenehme Empfindungen, welche bekannte Speisen und Getränke früher in uns hervorgerufen haben. Der Durst wird zuerst an der Mund- und Rachenschleimhaut empfunden, wo er sich durch ein Gefühl von Trockenheit kennzeichnet. Er kann eine locale Ursache haben und hervortreten, wenn ein übermässiges Verdunsten von Fliissigkeit an diesen Schleimhäuten stattfindet, wie zum Beispiel beim Sprechen, Singen, Athmen in heisser Luft. Eine tiefere Ursache für das Durstgefühl liegt in dem Verlust von Wasser, welchen der Gesammtorganismus an der Hautoberfläche, in den Lungen und durch Secretion erleidet. Warum dieser Verlust, welcher zu starken peinlichen Allgemeinempfindungen führen kann, sich anfänglich an der Rachen- und Nundschleimhaut äussert, ist ebenso wenig bekannt, wie die Art der nervösen Vermittelung, der localisirten Empfindung und des Gemeingefühls. Das Hungergefühl, obwohl weniger localisirt, wird doch meistens in die Nagengegend verlegt: im Anfange ist es ron angenehmer Natur und wird dann als Esslust oder Appetit bezeichnet; wenn aber keine Speisen zugeführt werden, steigert sich der Hunger allmählich zu schmerzhaften Empfindungen in der Magengegend und zu peinlichem Allgemeingefüll. Ob der Magenhunger ron peripherischen Reizen an der Magenschleimhaut herrührt, ist noch nicht bewiesen; die Durchschneidung der Magenäste der Nervi vagi und der sympathischen Nerven des Magens hat keinen Einfluss auf die Nahrungsaufnahme bei Thieren gezeigt.

Die Nahrungsmittel werden in flüssigem oder festem Zustande aufgenommen. Die Flüssigkeit kommt in die Mundhöhle entweder durch Saugen, wobei die Mundhölle durch das Gaumensegel hinten abgeschlossen ist und in ihr, durch Zuriickziehen der Zunge, welche oft von einem Herunterdrïcken des Mundbodens begleitet wird, ein Vacuum entsteht, oder durch Aspiration, wobei das Gaumensegel die Nasenhöhle rom Schlunde absperrt und die Erweiterung des Thorax einen negativen Druck hervorruft, oder durch Eingiessen, wobei die Fliissigkeit, der Schwerkraft folgend, in die Mundhöhle fliesst. Die in den Mund gelangte Fliissigkeit erfährt dort für gewöhnlich nur unbedeutende chemische oder physikalische Veränderungen durch den sich ihr beimengenden Speichel; sie reizt angenehm oder in anderen Fällen unangenehm die Geschmacksnerven und wird durch Zusammenziehung des Orbicularis labii, der Buccinatores und der Zungenmuskeln, welche letztere eine von der Spitze zur Basis vorschreitende Vorwölbung hervorrufen, in den Pharynx bineingedrückt, von wo sie, durch eine plötzliche Bewegung der Zungenbasis nach oben und hinten, in den Oesophagus hineingespritzt wird; peristal- 
tische Contractionen des Oesophagus, sowie die Schwerkraft, greifen fördernd ein.

Die weichen und die festen Speisen werden - letztere, wenn sic schon vorher zerkleinert sind - durch Lippen und Zunge aufgelesen; bei grösseren festen Stücken treten die Schmeide- und Eckzühne mit in 'Thätigkeit und dienen zum Abbeissen, oder auch zum Abreissen. Die Backzälnne zerschneiden, zerquetschen und zermalmen die festen Speisetheile. Hicrbei drücken die sich contrahirenden Masseteres, Temporales und Pterygoïdei interni den Unterkiefer gegen den Oberkiefer und erschlaffen dann wieder, sodass nun der Unterkiefer durch sein Gewicht und durch die Contraction der Genio- et Mylo-hyoüdei und der vorderen Bïuche der Digastrici wieder nach unten gezogen wird. Inzwischen wird durch zweckmässige Bewegungen der Wangen, Lippen und der Zunge, bei denen die Buccinatores, der Orbicularis labii und die 'Zungenmuskeln sich contrahiren, die Speise wieder zwischen die Mahlzähne geschoben und die Heber des Unterkiefers treten wieder in Thätigkeit. Die Pterygoïdei externi können durch alternirende Thätigkeit laterale Bewegungen und durch symmetrische Thätigkeit Vorschieben des Unterkiefers bewirken und dadurch den zermalmenden Druck mit reibenden Mahlbewegungen unterstützen. Der Speichel, dessen Secretion durch die Geschmacksnervemreizung und durch die Kaubewegungen erheblich gesteigert ist, fügt sich zu der Speise hinzu und mischt sich während des Kamens inuig mit ihr. Das Wasser des Speichels wirkt als Lösungsmittel auf die in ihm löslichen Stoffe; dic in ihm enthaltenen alkalischen Salze stellen meistens eine alkalische Reaction her, bei welcher das Ptyalin auf die Stärke und das Glykogen fermentartig wirkt und dieselben, unter Wasseraufuahme, in gelöstes Dextrin und Glykose iiberzuführen anfängt. Das Mucin des Speichels macht die Speisetheilchen .klebrig und ermöglicht dadurch das Bilden des Bissens, welchem es auch die Schliipfrigkeit ertheilt. Wenn sich die Empfindung genïgender Ausfïhrung der für die Verdauung sehr wichtigen Zerkleinerung und Durchtränkung mit Speichel kundgiebt, wird der Unterkiefer fixirt, die Zunge sammelt die Speise auf ilırer oberen Mitte, wölbt sich von der Spitze nach der Basis gegen den Gaumen und drängt den Bissen am Gaumenbogen und an den Mandeln vorbei in den Schlundkopf. Der mechanische Reiz, welchen der Bissen hier ausübt, löst sofort eine Reihe von reflectorischen Vorgängen aus. Durch Contraction der Gaumensegelmuskeln, der Stylo-pharyngei; der Constrictores pharyngis und der oberen Zungenbeinmuskeln wird der Pharyux dem Bissen entgegen gehoben. Gleichzeitig wird das Cavum pharyngo-nasale gegen das Carum pharyngo-orale durch die horizontale Anspannung des Gaumensegels mit Betheiligung der hinteren Gaumenbögen und des oberen 
Theiles der hinteren Schlundwand abgeschlossen. Die Gegenwart von festen und flüssigen Substanzen im Schlundkopfe, wo Luft- und Speisewege sich kreuzen, würde zum gefährlichen Verschlucken führen, wenn durch einen reflectorisch ausgelösten Mechanismus der Luftweg nicht auch gleichzeitig nach dem Thorax hin abgesperrt würde. Diese Absperrung vollzieht sich durch die Contraction der Mylo-genio-hyoïdei und Digastrici, welche den Larynx nach oben und vorn unter die Zungenwurzel drücken, sodass die Epiglottis durch den vordringenden Bissen zurïckgeklappt wird; ferner werden die Aryknorpel und die Stimmbänder fest gegen einander gedrückt zum festen Schluss der Glottis. Während also Nasenhöhle und Larynx abgeschlossen sind und der Zungenriicken noch gegen den Gaumen presst, treten die Constrictores pharyngis in Thätigkeit und drängen den Bissen in die einzige ihm freistehende Oeffnung, nämlich in den Oesophagus hinein. Eine peristaltische Welle des Oesophagus drängt nun den Bissen hinab und durch die Cardia in den Magen hinein. Nur die in der Mundhöhle sich abspielenden Schlingbewegungen sind der Willkür unterworfen; die übrigen Schlingacte werden durch mechanischen, von Trigeminus- und Vagusästen aufgenommenen Reiz reflectorisch in einer gut coordinirten Reihenfolge ausgelöst. Die Geschwindigkeit, mit welcher der Bissen in den Magen befördert wird, hängt von dessen Volum und Consistenz ab; Fliissigkeiten können in 0,1 Secunde ohne Beihilfe des Schlundkopfes oder des Oesophagus in den Magen gespritzt werden; festere und grössere Bissen erfordern mehr Zeit.

Bei dem Trinken wird selten nur ein einzelner Schluck ausgeführt, meistens eine Reihe von Schlucken, welche sich in kurzen Intervallen folgen. Die Peristaltik des Oesophagus betheiligt sich nur an dem letzten Schlucke einer solchen Schluckreihe. Jede Schluckvorbereitung im Munde hemmt zunächst eine schon in Entstehung begriffene peristaltische Welle. Als centripetaler Nerv ist an diesem merkwïrdigen Hemmungsvorgange der Glossopharyngeus wesentlich betheiligt. 


\section{Elfter Abschnitt. \\ Die Verdauung.}

\section{(J. F. Heymans.)}

Neben der mechanischen Zerkleinerung der Speisen kommt auf dem Wege bis zum Magen eine chemische Umänderung nur für einen Theil der Kohlehydrate in Betracht; der Dauer des Kanens und des Herunterschluckens, sowie der Menge des Ptyalins entsprechend, ist die Glycosebildung mehr oder weniger gross. Da dieses Enzym bei alkalischer Reaction wirksam ist, so hört die Stärkeumwandlung bald im Magen auf, um später im Duodenum unter der Wirkung des Pankreasptyalins wieder anzufangen.

Die durch Speisen oder Getränke hervorgerufene Erregung der Geschmacks- und Geruchsnerven, sowie der Anblick der Speisen bringt auf reflectorischem Wege durch das Centralnervensystem die Secretion des Magensaftes in Gang. Die Reizung, welche die Ingesta auf die Schleimhaut des Magens selbst ausübt, verursacht oder verstärkt ebenfalls die Secretion von Pepsin und Salzsäure. Der Mageninhalt wird sauer und die Speichelverdaunng ist aufgehoben. An deren Stelle tritt die Magenverdauung in Thätigkeit; sie lässt sich dahin zusammenfassen, dass das Pepsin mit Hilfe einer Säure - normalerweise Salzsäure - die verschiedenen unlöslichen oder gerinnbaren Eiweissstoffe grösstentheils, durch eine Anzahl von Zwischenstufen hindureh, bis zu Pepton umwandelt. Die gelösten und ungerinnbaren diffusiblen Peptone werdeu zum Theile von der Magenschleimhaut resorbirt, das Uebrige wird mit dem Speisebrei orler Chymus in das Duodenum ergossen. Der Magen, welcher im leeren Zustande mit gefalteter Schleimhaut auf sein kleinstes Volum zusammengezogen war, dehnt sich beim Aufnehmen der Speisen je nach deren Nenge aus und erfährt dabei eine leichte Umdrehnng nach rorn um seine kleine Curvatur. Eine regere Circulation tritt auf, sodass die vorher hlasse Mucosa roth wird und anschwillt. Bald fangen die Magenwandungen an, langsam hin- und herzugleiten, die sogenannten rotirenden Reibbewegungen auszuführen, welche zur Durchtränkung des Mageninhaltes mit Magensaft beitragen; ungeführ eine lialbe Stunde nach der Speiseaufnahme fangen Contractionswellen an, langsam ron der Cardia aus nach dem Pylorus hin zu verlaufen; diese von Zeit zu \%eit auftretenden peristaltischen Bewegungen befördern rerdaute Theile zum 
Pylorus, welcher sich durch einen noch unbestimmten reflectorischen Mechanismus eröffnet und den Chymus in das Duodenum überfliesseu lässt. Im Magen werden die in Wasser löslicheu und die durch Salzsäure löslich gemachten Substanzen gelöst. Salz-, Glycose- und Peptonlösungen werden in beträchtlicher Menge durch die Magenschleimhaut resorbirt; Fette werden hier durch die Körpertemperatur theilweise verflïssigt, aber reder resorbirt, noch zur Resorption rorbereitet. Die Magenrerdaunng, respectire die Peptonisirung der Eiweissstoffe dauert rerschieden lange, je nach der Form der Speisen, ron renigen Minuten bis zu 5 Stunden; nach dieser Zeit bemisst sich die Verdaulichkeit der Speisen für den Magen; sie hängt natürlich für jede Eiweissart von den ihr beigemischten Stoffen ab. Durchschnittlich werden die der Hitze nicht unterrrorfenen Eiweissstoffe schneller rerdaut. Die Milch wird in Magen durch das Laabferment erst geronnen, wobei seine Salze und der Milchzucker in Wasser gelöst bleiben; dieser Milchzucker und auch andere Zuckerarten können anormalerweise Milchsäure, Fettsäure und Kohlensäure bilden. Das Caseïn der geronnenen Milch wird peptonisirt und die Fettkügelchen der Butter werden hierdurch freigemacht. Die leimgebenden Substanzen des Fleisches werden als Leimpeptone gelöst; dadurch werden die Fetttropfen der Fettzellen und die Muskelfasern isolirt. Letztere zerfallen in Fibrillen und in Scheiben. Die Eiweissstoffe der thierischen Gewebe werden so dem Magensafte zugänglicher und die Peptonisirung schreitet schneller weiter. Das pflanzliche Eiweiss ist ron Cellulosemembran umgeben, welche die Verdauungsflüssigkeit des Magens nicht zu lösen rermag, daher ist das Eiweiss der pflanzlichen Gerrebe schwerer rerdaulich; das Kochen in Wasser: macht die pflanzlichen Zellen quellen und bersten und befördert also die Verdauung. Beim Menschen wie bei den meisten Thieren ist die Magenrerdauung intermittirend, bei Pflanzenfressern dagegen ist sie continuirlich.

Verschiedene Anhäufungen automatischer Ganglienzellen - denen des Herzens analog - liegen in der Magenwand zerstreut, sie empfangen die centripetalen Nerrenfasern der Schleimhaut und stehen durch Vagusund Sympathicusfasern mit Centren des Centralnervensystems (Medulla und Grosshirn) in Verbindung. Die peripherischen Centren stellen wahrscheinlich die coordinirten Bewegungen der Cardia, der Magenwand und des Iylorus her, und reguliren die Circulation und Secretion. Beim Erlorechen wird der Pylorus geschlossen und die Cardia geöffnet gehalten, während heftige Contractionen der Bauchmuskeln und des Diaphragma den Mageninhalt unter hohen Druck rersetzen und durch die ilm freistehende Oeffnung hinausspritzen; die Magenmuskulatur spielt hierbei keine wesentlich active Polle.

Der in das Duodenum übertretende Clymmus setzt reflectorisch die 
secernirenden Apparate des Dünndarmes in Thätigkeit: zu den an der Schleimhaut vorbeistreifenden Chymustheilen miseht sich also alkalischer Darmsaft, und in dem alssteigenden Theile des Duodenums ergiesst sich zu ihm - beim Menschen an einer und derselben Stelle - die alkalische Galle mit dem Pankreassaft. Der saure Chymusstrom wird dadurch von der Periphorie bis zur Axe allmählich alkalisch, so dass die weitere Verdauung durch Magensaft unmöglich wird; an ihre Stelle tritt die bei alkalischer Reaction sich vollziehende Dïnndarm-Verdauung. Das Pankreasptyalin, dem Fermente des Mundspeichels ähnlich, wandelt nicht nur Stärke und Glykogen, sondern theilweise auch Cellulose und Gummi in Zucker um. Dem Pankreatin oder Trypsin kommt eine stärkere peptonbildende Kraft zu wie dem Pepsin: die Eiweisskörper werden von ihm bei alkalischer Reaction und ohne vorhergehende Quellung rasch durch die Zwischenstufen hindurch bis zu Peptonen umgewandelt; wenn die gebildeten Peptone nicht entfernt werden und also die Trypsinwirkung auf die Peptone sich weiter äussern kam, wie es bei kïnstlichen Verdauungsversuchen vorkommt, dann werden die Peptonmoleküle zu Lencin, Tyrosin und selbst bis zu Fäulnissproducten wie Scatol, Indol u. s. w. gespalten. Der Pankreassaft ist endlich im Stande mittelst eines noch nicht isolirten Fermentes Fette in Glycerin und Fettsäure zu zerlegen. Directe Versuche haben erwiesen, dass fettsäurehaltige Fette sich in verdïnnter Natronlösung emulgiren. Alkalische Natriumsalze kommen im Darmsaft, in der Galle und im Pankreassaft vor und die säurehaltig ingerirten oder durch Pankreassaft säurehaltig gewordenen Fette werden in Darm thatsächlich emulgirt: das Fett wird also in kleinste mikioskopische Theilchen zerlegt und diese schwimmen in der durch die Verbindung der Fettsäure mit Soda entstandenen Seifenlösung. Pankreassaft mit Galle gemischt besitzt eine grössere fettspaltende Krraft wie für sich allein. Unter passenden Fiitterungsbedingungen können zwar Thiere, bei denen der Zufluss von Galle in den Darm vollkommen abgeschnitten ist, noch betrïchtliche Mengen vom Fette verdauen, doch ist man berechtigt anzunehmen, dass die Galle unter normalen Umständen betrïichtlich zu der Verdauung der Fettsubstanzen beiträgt. Auf die Verdauung von Kohlehydraten und Eiweisskörpern ist der Einfluss der Galle, wemn er iiberhaupt besteht, nur sehr gering. Die Galle regt aber die Darmperistaltik an und schränkt die faulige Zersetzung des Darminhaltes ein.

Der Darmsaft hat, abgesehen von seiner Betheiligung an der Emulgirung und Verscifung der Fette, nur einen geringen directen Einfluss auf die Umsetzungsvorgänge in Darme; speciell für die Peptonund Glycosebildung kommt er anch wesentlich nur durch seine alkalische Reaction und rlurch seinen Wassergehalt in Betracht. 
Bei Eröffnung der Bauchhöhle in einer auf Körperwärme gebrachten physiologischen Kochsalzlösung sind die Eingeweide, in leerem $\mathrm{Zu}$ stande, bewegungslos (Aperistaltik); während der Verdauung treten die schon angedeuteten peristaltischen Bewegungen hervor. Ringförmige Contractionen laufen von Zeit zu Zeit langsam den Dünndarm entlang, voin Magen aus nach dem Dickdarm. Bei Eröffnung der Bauchhöhle an der freien Luft erregen die äusseren Reize der Kälte und Verdunstung, zum Theil unter Verınittelung der dadurch hervorgerufenen Blutstauung, peristaltische Contractionen längs des ganzen Dünndarmes, und man hat dann die sogenannten wurmförmigen Bewegungen des Darmes vor Augen.

Die Peristaltik des Dünndarmes treibt allmählich den Chymus in dem langen Dünndarme weiter und ermöglicht dementsprechend das Vollziehen der oben beschriebenen Verdanungsprocesse und die Resorption der verschiedenen verdauten Nährstoffe. Die Salz-, Zucker-, Pepton- und Seifenlösungen werden von der ausgedehnten Schleimhaut des Darmes grösstentheils aufgenommen; die in den Darmcanal ergossenen Säfte werden theilweise als solche, theilweise nach Zerstörung einiger ihrer Bestandtheile resorbirt; einige Theile der Säfte, wie Mucin, die zu Hydrobilirubin reducirten Gallenfarbstoffe, Cholesterin und zerfallene Theile der Schleimhautzellen gehen mit den unverdaulichen und unverdauten Speisetheilen in den Dickdarm über.

Durchschnittlich nach drei Stunden gelangen die noch nicht resorbirten und nicht resorbirbaren Theile des breiigen Chymus durch die Bauhin'sche Klappe in den Dickdarm. Unter normalen Umständen übt das Secret des Dickdarmes kaum eine Verdauungswirkung auf seinen Inhalt aus, seine Schleimhant aber resorbirt allmählich weiter die gelösten Nährstoffe. Der eingedickte Inhalt wird durch reflectorisch angeregte, träge und seltene peristaltische Bewegungen weiter befördert und gelangt durchschnittlich nach zwölf Stunden als geformte Fäcalmasse in das S romanum und in den oberen Theil des Mastdarmes. Die Fäcalmasse, wenn sie zu einer bestimmten Menge angehäuft ist, erregt starke peristaltische Contractionen des unteren Theiles des Dickdarmes, worlurch sie gegen die tonisch geschlossenen Sphincteren gedrïckt werden. Die dadurch hervorgerufene Reizung ïberschreitet die Reizschwelle und das Gefühl des Stuhldranges wird bewusst. Willkïrlich können nun entweder die Sphincteren tonisch geschlossen gehalten werden, oder es können, durch Hemmungswirkung auf das ano-spinale Centrum, die reflectorischen Contractionen des äusseren und inneren Sphincters gehoben und die Banchpresse in Thätigkeit versetzt werden; die Contraction des Levator ani gieht dem Damme hierbei den erforlerlichen Halt, sodass der andringende Kothballen den Damm nicht vortreiben kann, 
sondern die Analöffnung erweiter'n muss. Hinter dem ausgetriebenen Kothballen contrahirt sich der Sphincter externus reflectorisch. Die Fäcalmasse beträgt tïglich im Durchschnitt circa $200 \mathrm{Gramm}$; bei einer vorwiegend aus verdaulichen Stoffen bestehenden Nahrung ist sie am geringsten und umgekelurt; sie besteht erstens aus unverdaulichen Resten der Ingesta, wie Horngewebe, elastischem Gewebe, einem grossen Theile der Cellulose, Holzfasern, unlöslichen Salzen; zweitens aus Bruchstücken der verdaulichen, aber nicht genügend zerkleinerten Nährstoffe, wie Muskelu, Sehneu, Knorpeln, Fettstïckchen, und drittens aus den den Ingesta im Darmtractus beigemischten Stoffen, wie den nicht resorbirten Theilen der Darmsäfte, desquamirten Zellen der Schleimhäute und massenhaften Spaltpilzen, welche überall im Verdauungsapparate regetiren. Die zahlreichen Mikroorganismen der Mundhöhle, des Magens, des Dünn- und Dickdarmes leben, ohne wesentlich den Verdauungsprocess zu stören oder zu befördern, jeder nach seiner Weise in dem ihm zur Verfügung stehenden Nährboden: durch ihre Gährungsprocesse werden Gase wie $\mathrm{CO}^{2}, \mathrm{CH}^{4}, \mathrm{H}^{2} \mathrm{~S}$, Säuren, wie die Fettsäuren und Fäulnissproducte, wie Indol, Scatol gebildet. Die oft saure Reaction der Fäces, sowie ihr Geruch werden durch diese Gährungsproducte bestimmt. Die Farbe der Fäces hängt theilweise von den aufgenommenen Nahrungsmitteln, theilweise von dem beigemengten zersetzten Gallenfarbstoffe ab.

Die verschiedenen Nährstoffe gelangen, zum Theil unverändert, wie Wasser, Salze, Zucker, zum Theil nach Umwandlung durch die Verdauung, wie Stärke, Fette und Eiweissstoffe, zugleich mit Theilen der in den Darm ergossenen Secrete durch Resorption in die Blutbahn, entweder direct durch dic Blutcapillaren der Darmmucosa, oder indirect durch die Chylusgefässe. Bei der Resorption spielen die physikalischen Processe der Diffusion, Endosmose und Filtration, welche hier durch das Kreisen des Blutes und der Lymphe noch begünstigt sind, eine wichtige aber nicht ausschliessliche Rolle; dazu kommen noch die durch die Schleimhantzellen des Darmes herrorgerufenen chemischen Processe, welche bis jetzt wenig genau bekannt sind. Das Wasser, die Salz- und Zuckerlösungen gehen unverändert hauptsächlich in die Blutcapillaren iiber, die osmotischen Krräfte erklären diesen Vorgang grösstentheils. Die Peptone werden ebenfalls durch die Blutcapillaren aufgenommen, bei ihrem Eintritte in das Blut sind sie aber schon wieder in Serumeiweiss umgewandelt; wo und wie diese Umwandlung innerhalb der. Mucosa sich abspielt, ist noch nicht bestimmt. Die rerdauten Fette gehen bei der Resorption ausschliesslich in die Chylusgefässe über: ob sie als Emulsionströpfchen oder als gelöste Seife und Glycerin durch Epithel- und Parenchymgewebe in die Lymphspalten hineinwandern, ist noch nicht entschieden, jedenfalls trifft man in den Chylusgefässen nur 
emulgirtes Fett und zwar wesentlich solches von neutraler Reaction. Für die Resorption besonder's entwickelte Organe sind die Zotten des Diinndarmes; das Stroma derselben besteht aus adenoidem Gewebe; lïngs der Mitte der Zotte erstreckt sich das centrale Chylusgefäss; zwischen diesem und der Oberfläche befindet sich zunächst eine zarte Schicht glatter Nuskelfasern und demnächst ein stark verzweigtes Netz ron Blutcapillaren angeordnet. Durch Contraction der Muskelfasern wird die Zotte stark verkiirzt und gerunzelt, hierbei entleeren sich das centrale Chylusgefäss und die Blutcapillaren. Bei Erschlaffung der Muskeln findet eine Erection der Zotte durch das wiedereinströmende Blut statt. Ein Riiickströmen vou Chylus in das centrale Chylusgefäss kann wegen der vorhandenen Kílappen nicht eintreten, zur Wiederanfiillung dieses Gefässes wird also Fliissigkeit aus dem Darmlumen herangezogen werden. Bekleidet sind die Zotten mit einer einfachen Schicht hoher Cylinderzellen, zwischen denen das adenoide Gewebe stellenweise bis an das Darmlumen vordringt. Die Epithelzellen tragen einen Saum cines in Stäbchenform differenzirten Protoplasmas, den Stäbchensaum. Während der Fettrerdauung bleibt der dem Darmlumen zunächst liegende Theil der Epithelzellen ungetrïbt, weiter gegen die Basis hin findet man Fett in staubförmiger, weit feinerer Vertheilung wie im Chymus; im adenoiden Gewebe und im centralen Chylusgefässe erscheint das Fett wieder in grösseren Tropfen.

Die in das Blutplasma gelangten Nährstoffe gehören dem Organismus noch nicht als organisirte Substanz an; damit sie hierzu werden, mïssen sie durch Gewebselemente aufgenommen und in ihnen assimilirt werden. Wie diese innere Absorption der Nährstoffe, speciell des Eiweisses, durch die Gewebselemente stattfindet, ist mit Bestimmtheit nicht anzugehen; wahrscheinlich spielen sich in jeder Zelle eines zusammengesetzten Organismus Prozesse ab, analog denen, welche wir an monocellularen Thieren als Verdauung und Absorption beoluachten können. Vic in den Zellleib gelangten Nährstoffe werden entweder als solche aufgespeichert, oder sie werden sofort weiter assimilirt, $d . h$. sie werden zu cinem Theile der organisirten Stoffe und dienen also dazu, um deren 'crfall zu decken oder um ihr Quantum zu vermehren. Letzteres findet speciell statt bei den in activer Theilung begriffenen Zellen, ersteres bei allen Kellen, da ihre ununterbrochene Thätigkeit stets mit Selbstverbrauch einhergeht. Das Wasser, die Salze, Kohlehydrate, Fette und Eiweisskörper dienen auf diese Weise zum Aufbaue der sehr complicirten organischen Moleküle des Zellprotoplasmas, welches durch Differenziation die rerschiedenen Gerrebe bildet. Wenn Nährstoffe im Ueberschusse resorbirt worden sind, werden sie aufgespeichert oder sofort wieder ansgeschieden; so verlassen Wasser und Salze in Ueberschuss schnell den 
Organismus; der Zucker wird in der Leber zu Glyeogen umgewandelt und aufgespeichert, das Fett wird in Bindegewebszellen abgelagert; Gewehe nnd Flïssigkeiten des Körpers, speciell die lymphoiden Gewebe nehmen Eiweiss auf, der Ueberschuss spaltet sich vielleicht in Kohlehydrate und in ein stickstofilhaltiges Product; diese Spaltung soll hatuptsäcllich in der Leber stattfinden und dort Glyeogen und Harnstoff bilden. Jeder im Organismus resorbirte Nïhrstoff befindet sich entwerler im Blute oder in der Lymphe oder im Innern der Gewebezellen.

\section{Zwölfter Abschnitt.}

\section{Bilanz des Stoffes, der Wärme und der Arbeit.}

\section{(J. F. Heymans.)}

In jeder Zelle sind je nach ihren speciellen Thätigkeiten die chemischen Reactionen oder Stoffwandelungen, deren Gesammtheit ihren Functionen zu Grunde liegt, mehr oder weniger verschieden; bei allen Zellen aber findet eine moleculare Zersetzung oder Desassimilation statt, aus welcher Kohlensäure, niedrige, stickstoffhaltige Produlite und unorganische Substanzen herrorgehen und bei welcher aus den chemischen Spannkräften lebendige Kraft zu Arbeitsleistung und Wärmebildung frei wird orler andere Energieformen herrortreten wie zum Beispiel Elelitricität. Arbeit und Wärme erfüllen ihre besonderen Zwecke und folgen ihren besonderen Gesetzen. Die Kohlensïure und die anderen aus der Zelle ausgestossenen Zerfallprodukte werden rom Lymph- und Blutstrom aufgenommen und aus dem Organismus als solche oder nach weiteren Umwandlungen, definitiv ansgeschieden. Jedes Nïhrelement beschreibt also - ron dem Momente seines Eintrittes durch die Absorptionsfläche in das Blut, und auf dem Wege ron dort in die Gewebselemente, ron wo es direct oder indirect in das Blut nach rerschiedener Frist zuriickkommt, um dann durch die Secretionsfäche den Organismus zu verlassen - eine schematische 8, deren Kíreuzungspunkt im Blute liegt.

Jede Zelle in loser Abhängigkeit von ihren Nachbarn, assimilirt und desassimilirt; sie hat zu dieser Lebensunterhaltung und Thätigkeitsausübung alle oben angedeuteten Nährstofłe nöthig, gebraucht und verbraucht sie aber, je nach ihrer speciellen Thätigkeit, in einem besonderen, bis jetzt noch wenig festgestellten Verhältnisse: wir wissen aber zum Beispiel, dass in den sich contrahirenden Muskelzellen der Verbranch 
ron Sauerstoff und von Kohlehydraten ein sehr gesteigerter ist. Diejenigen Zellen, welche zu demselben Organe gehören, bieten gewöhnlich gleichzeitige Schwankungen von Thätigkeit und Ruhe und üben oft iu dieser Weise einen merklichen Einfluss auf den Gesammtorganismus aus. Trotzdem ist es bis jetzt fast unmöglich, ein Urtheil über die Thätigkeit der einzelnen Organe in Verbindung mit ihren Functionserscheinungen und ihren Stoffwechselproducten zu gewinnen; man muss sich begnügen den Stoffwechsel des Gesammtorganismus ins Auge zu fassen. Dabei sind $\mathrm{zu}$ betrachten einerseits die Einnahmen, die Ingesta, andererseits die Ausgaben oder die Egesta. Als Ingesta kennen wir schon den durch die Einathmung gelieferten Sauerstoff und die bei der Ernährung angegebenen unorganischen und organischen Nährstoffe. Die Egesta sind Wasser, Salze und organische, fast ausschliesslich stickstoffhaltige Substanzen. Das Wasser wird normaler Weise nach kurzer Zeit in ungefähr demselben Quantum ausgeschieden, wie es aufgenommen worden ist; dieses geschieht durch die Haut (Perspiration, Transpiration), durch die Lungen und mit den Faeces, besonders aber in dem Harn. Die den Organismus verlassenden Salze sind in kleinen Mengen dem Schweisse und Kothe beigemengt, grösstentheils im Urin gelöst. Die Kohlehydrate und Fette werden zu Kohlensäure und Wasser verbrannt, mur in pathologischen Zuständen ist der Urin zuckerhaltig. Die stickstoffhaltigen Substanzen des Harnes und unter diesen weitaus in erster Linie der Harnstoff repräsentiren zu $\%$ die Zersetzungsprodukte der eiweissartigen Stoffe des Organismus; mit dem Kothe werden stickstofthaltige Substanzen, Gallenbestandtheile und Fäulnissprodukte ausgeschieden.

Folgende zwei Tabellen erlauben, einen Gesammtblick auf das durchschnittliche Quantum der Ingesta und Egesta des menschlichen Organismus für die Periode von 24 Stunden zu gewinnen. Die erste Tabelle giebt in Grammen die Menge der verschiedenen aufgenommenen Nahrungselemente und des eingeathmeten Sauerstoffes an, die zweite die Verluste, welche der Organismus durch Lungen, Haut, Urin und Faeces erleidet.

I. In g e s t a.

\begin{tabular}{|c|c|c|c|c|c|}
\hline & Total & Kohlenstoff & Wasserstoff & Stickstoff & Sauerstoff' \\
\hline Eigeathmeter Sauerstoff . . . . . & 744,11 & - & - & - & 744,11 \\
\hline Stickstoff haltige Substanzen . . & 120 & 64,18 & 8,60 & 18,88 & 28,34 \\
\hline 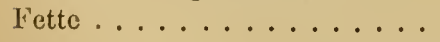 & 90 & 70,20 & 10,26 & - & 9,54 \\
\hline Kohlehydrate ......... & 330 & 146,82 & 20,33 & 一 & 162,85 \\
\hline Wasser ... & 2818 & - & - & - & - \\
\hline \multirow[t]{2}{*}{ Salze . . } & 32 & 一 & - & - & - \\
\hline & 4134,11 & 281,20 & 39,19 & 18,88 & 944,84 \\
\hline
\end{tabular}


II. Eg e s ta.

\begin{tabular}{|c|c|c|c|c|c|c|c|}
\hline & Total & Wasser & Kohlenst. & Wasserst. & Stickst. & Sauerst. & Salze \\
\hline Athmung $\ldots .$. & 1229,9 & 330 & 248,8 & - & $?$ & 651,15 & - \\
\hline Haut . . . & 669,8 & 660 & 2,6 & 一 & - & 7,2 & 一 \\
\hline Urin ....... & 1766,0 & 1700 & 9,8 & 3.3 & 15,8 & 11,1 & 26 \\
\hline Faeces ......... & 172,0 & 128 & 20,0 & 3,0 & 3,0 & 12,0 & 6 \\
\hline $\begin{array}{c}\text { In Organismus gebil- } \\
\text { detes Wasser } \ldots . .\end{array}$ & 296,3 & - & - & 32,89 & - & 263,41 & - \\
\hline & 4134,0 & 2818 & 281,2 & 39,19 & 18,8 & 944.86 & 32 \\
\hline
\end{tabular}

Bei absoluter Carenz oder Inanition, wo der Organismus nur Sauerstoff zur Verfügung hat, findet eine Selbstrerzehrung statt, deren Schnelligkeit mit der Functionsintensität zunimmt. Die functionirenden Zellen schöpfen aus ihrem eigenen Reservematerial, aus der Lymphe, aus dem Blute, aus den anderswo aufgespeicherten Nährstoffen und aus nicht oder wenig functionirenden Zellen so lange und so viel wie möglich die ihnen fehlenden Nährstoffe. Die Ausscheidung ron Kohlensäure, Harnstoff, Wasser und Salzen nimmt mehr und mehr ab und das Leben hört auf, wenn das Gesammtgewicht ungefähr um ein Drittel abgenommen hat; das Fett ist inzwischen $\mathrm{zu} \% / 10$ verbraucht worden, während das Centralnervensystem nur $2 \%$ seines Gewichtes verloren hat.

Werden die Nährstoffe in richtigen Verhältnissen, aber in ungenïgender Menge dargereicht, so nehmen die Ausscheidungen, das Körpergewicht, die Widerstands- und Leistungsfähigkeit so lange ab, bis ein neues Gleichgewicht eintritt; natürlich ist dieses nur möglich, wenn der Grad der Ernährung mit den Lebensbedürfnissen rereinbar ist. Wenn zu grosse Mengen von Nahrung aufgenommen und verdaut werden, dann nimmt die Ausscheidung in jedem Falle zu, das Gewicht des Körpers kann dabei dasselbe bleiben oder durch Entwickelung seiner Gewebselemente und speciell durch Ablagerung ron Fetten zunehmen.

Fehlt einer der wöthigen Nährstoffe vollkommen, so stockt die Ernährung, resp. die Assimilation, als ob sie alle fehlten. Ohne Wasser oder ohne Salze kann die Ernährung ebenso wenig sich vollziehen, wie ohne Kohlehydrate oder Eiweisskörper. Als besonders wichtige, durch das Experiment ermittelte Thatsache ist hier jedoch zu erwähnen, dass Fleischfresser, wie Hunde, bei Ernährung mit Wasser, Salzen und Eiweissstoffen ohne Kohlehydrate und Fette, normal weiter leben können. Die Eiweissstoffe müssen aber, um die Kohlehydrate und speciell die Fette zu ersetzen, in dreifacher Menge gereicht werden. Wenn die Eiweissstoffe in noch grösseren Mengen gegeben und verdaut werden, so nimmt sogar das Körpergewicht des Thieres, wie man aunimmt, durch Ablagerung rou Fett zu; dis Fett kann hier nur durch Spaltung von 
Eiweiss geliefert worden sein. Bei solchen Versuchsthieren ist die Ausscheidung des Harnstoffes sehr stark erhöht, sinkt aber schnell herunter, sobald Kohlelydrate oder Fette der Nahrung zugefuigt werden. Die Kiohlehydrate und Fette wirken eiweisssparend, d. h. sie können Eiweiss bis zu gewissem Maasse in der Nahrung ersetzen und schützen bei ihrer Zufuhr Körpereiweiss vor dem Zerfalle.

Abgesehen von einigen, unter speciellen Bedingungen sich vollziehenden endothermischen Reactionen, finden die chemischen Umwandlungen mit Freimachung von erheblicher Menge von lebendiger Kraft unter Form ron Wärme statt; dieses geschieht innerhalb des Organismus in sehr erheblichem Maasse, da die in Betracht kommenden organischen Substanzen, verglichen mit den unorganischen, eine beträchtliche Menge von chemischen Spannkräften aufgespeichert besitzen. Die bei den Lebensäusserungen stattfindenden chemischen Reactionen sind begleitet von einer Wärmebildung, welche den Kaltblïtern (wechselwarmen oder poikilothermen Thieren) eine Temperatur verleiht, die gewöhlich ein wenig die umgebende Temperatur übersteigt, und welche den Warmblïtern (gleichwarmen oder homoiothermen Thieren) eine für jede Species etwas verschiedene, aber constante hohe Temperatur zu bewahren gestattet: 40 bis $43^{\circ}$ für Vögel, 36 bis $40^{\circ}$ für Säugethiere; für den Menschen, in der Achsel gemessen $36,5^{\circ}$ bis $37,3^{\circ}$. Die für den Organismus in Betracht kommenden Reactionen, welche Wärme produciren, sind zum geringeren Theile Hydratationen, Combinationen von Säuren mit Basen, Spaltungen einiger endothermischer Molekïle, - in weit erheblicherem Umfange sind es die Verbrennungen oder Oxydationen der organischen Stoffe, welche unaufhörlich im Organismus Platz greifen: die complicirten Verbindungen des $\mathrm{C}, \mathrm{H}$ und $\mathrm{N}$ werden zu $\mathrm{CO}^{2}, \mathrm{H}^{2} \mathrm{O}$ und $\mathrm{CO}\left(\mathrm{H}_{4} \mathrm{~N}_{2}\right)$ verbrannt. Die Thermochemie würde uns genau die Wärmeproduction der Zellen, der Organe und des Gesammtorganismus angeben können, wenn wir die Stoffwechselbilanz der entsprechenden Theile genau kennten. In der That ist die Menge Wärme, welche in einer bestimmten Zeit in einem Organe und in Gesammtorganismus producirt wird, gleich der Wärme, welche während dieser Zeit durch die in ihm stattfindenrlen chemischen Umwandlungen producirt wird, minus derjenigen, welche zur Verrichtung äusserer Arbeit verbraucht wird. Wenn der stoffliche Gehalt qualitativ und quantitativ derselbe bleibt, ist diese Würmemenge, wenn sie nicht anderswo theilweise verwendet wird, gleich der Verbrennungswïrme der absor\})irten Nährstoffe, minus der Verbrennungswärme der Ansscheidungsprodukte. Um auf diese Weise experimentell approximative Werthe zu gewinnen, müssen die Verbrennungswärmen der aufgenommenen Nahrungsmittel, die der Faeces und die des Harnes bei gleichbleibendem Körpergewichte bestimmt werden. Wenu wir die Haupt- 
substanzen herausgreifen und beachten, dass 1 Gr. Fiweiss bei seiner' Verbrennung circa 5 grosse Calorien entwickelt, $1 \mathrm{Gr}$. Kohlehydrat circa 4 Calorien und $1 \mathrm{Gr}$. Fett circa 9 Calorien, so sehen wir, dass bei einer Absorption von $120 \mathrm{Gr}$. Liweiss $90 \mathrm{Gr}$. Fett und $330 \mathrm{Gr}$. Kohlehydrate dem Organismus eine, durch die Verbrennung mögliche Wïrmemenge ron $120 \times 5+90 \times 9+330 \times 4=600+810+1320=$ 2730 Calorien zugeführt wird. Die Verbrennungswairme von $1 \mathrm{Gr}$. Harnstoft beträigt 2,5 Calorien; 120 Gr. Fiweiss entsprechen dem Stickstoffgehalte ron ungefïhr $40 \mathrm{Gr}$. Harnstoff, so dass bei der Absorption und Verbrennung rou oben genannten Nïhrstoften im Organismus 2730 minus $40 \times 2,5$ Calorien oder 2630 Calorien frei werden. In einem entsprechenden Calorimeter und unter Beriicksichtigung des Stoftwechsels, der Wïrmecapacitiit sowie der Temperatur des Organismus zu Anfang und am Ende des Versuches könnte man die Wïrmeproduction und deren Verhältniss zu dem Stoffwechsel genau bestimmen, bis jetzt aber hat man auf diesem Wege speciell für den Menschen noch keine genauen Daten erwerben kömnen. An Thieren sind einige calorimetrische Versuche angestellt worden, bei denen gleichzeitig der absorbirte Sanerstoft und die eliminirte Kohlensïure, aber nicht alle übrigen zu einer Bilanz des Stoffwechsels erforderlichen Werthe gemessen worden sind. Die Ergebnisse hieraus mit Hülfe von rerschiedenen hypothetischen Annahmen auf den Meuschen übertragen, führen zu einer Wärmeabgabe von 2600 Calorien, welche Zahl mit der berechneten Verbrennungswärme von 2630 Calorien genügend übereinstimmt.

Beim ruhenden Organismus wird nur eine verschwindend kleine Menge äusserer Arbeit geleistet, nämlich durch die Erschiitterungen, welche die Kreislaufswellen und die bewegte Thoraxwand dem umgebenden Medium mitthcilen. Hierzu kommt eine sehr kleine Menge Arbeit bei der Excretion. Die sich bei der Circulation und Athmung contrahirenden Muskeln rufen Spannungen hervor und setzen Massen in Bewegung; da letztere aber zu ilrem Ausgangspunkte zuriickkehren, so wird keine definitive Arbeit geleistet, die herrorgerufene lebendige Kraft setzt sich wieder in Würme um. Die tägliche Herzarbeit, welche auf 20000 Kilogrammmeter, und die Respirationsmuskelarbeit, welche auf 13000 Kilogrammmeter geschï̈zt worden sind, ergeben also dureh ihre Cmwandlung in Wärmeenergie $\frac{20000+13000}{425}=$ circa 78 Calorien. Die tïgliche Wärmealogabe kamn zu

2630 Calorien oder zu 110 Calorien pro Stunde angenommen und die Kohlensäureausscheidung kann als Naass der im Organismus überhaupt stattfindenden Verbrenuungen betrachtet werden; bei der Muskelanstrengung kann bis zur fünffachen Menge von $\mathrm{CO}^{2}$ ausgeschieden werden; und dementsprechend wird die Wïrmeproduction ebenfalls die fünffache sein. 
resp. $5 \times 110=550$ Calorien pro Stunde. Die während einer Stunde durch Muskelanstrengung geleistete Arbeit kann auf verschiedene Weise, wie am Ergostat oder beim Aufsteigen mit oder ohne Belastung bestimmt werden_und hat sich mindestens zu 40000 Kilogrammmetern ergeben. Nach der Arbeitsäquivalenz, deren Gesetze innerhalb des Organismus ebenso zutreffend sind, wie ausserhalb desselben, entsprechen dieser Arbeit $40000 / 425=94$ Calorien, und um diese Wärmemenge wird während dieser Zeit die Wärmeabgabe vermindert sein; sie wird also $550-94=456$ Calorien betragen. Der menschliche Organismus kann also wenigstens $94 / 550=1 / 6$ der Verbrennungswärme in Arbeit übersetzen; er ist also, wenn man die Leistung mechanischer Arbeit als Zweeck betrachtet, der vollkommensten Dampfmaschine, welche höchstens 1/12 der auf dem Herde producirten Wärmemenge als mechanischen Effect verwendet, weit überlegen. Man hat bei isolirten Muskeln die Arbeitsleistung und die Wärmeerzeugung studirt und gefunden, dass sie durchschnittlich $1 / 5$ (und bis zu 1/3) der durch die chemischen Reactionen hervorgerufenen kinetischen Energie zur Arbeitsleistung benutzen. Während der Körperruhe sind es die Athmungsmusculatur, der Herzmuskel, die sich contrahirenden glatten Muskeln und die sonstigen in einem Tonus begriffenen Muskeln, welche verhältnissmässig am meisten die freiwerdende Wärme bilden; wenn die Körpermusculatur weiter in Thätigkeit tritt, so wird die im Organismus sich bildende Wärme entsprechend vergrössert. Man ist also berechtigt, das Muskelgewebe, welches quantitativ auch am reichlichsten vertreten ist, als den Hauptort der Verbrennungen, respective der producirten Wärme, anzusehen. Alle Gewebezellen des Organismus, in dem als Ruhe ebenso wie in dem als Thätigkeit bezeichneten Zustande, nehmen Sauerstoff auf und geben Kohlensäure $a b$, es finden in ihnen neben Spaltungsvorgängen auch Verbrennungen statt, sie bilden Wärme. Das aus den in Thätigkeit begriffenen Drüsen, wie Leber, Speicheldrüsen ausfliessende Blut hat eine höhere Temperatur wie das einfliessende. Die im Organismus sich stetig bildende Wärme kann also mehr oder weniger in allen Apparaten entwickelt werden, thatsächlich ist es, je nach den normalen Zuständen des Organismus, wie Schlaf, Ruhe, Verdauung oder Bewegung, bald dieses, bald jenes Organ, welches je nach seiner Thätigkeit mehr Wärme producirt. Im Schlafe kann die Wärmemenge bis auf die Hälfte herabsinken. Der Organismus besitzt also in seinem Innern zahlreiche, periodischen Schwankungen unterworfene Herde, welche den benachbarten, schlecht wärmeleitenden Gewebetheilen, je nach ihrer Temperatur mehr oder weniger Wärme abgeben; das durch diese Herde, welche die Organe sind, hindurchtretende Blut nimmt hauptsächlich die Wärme auf, führt sie, wie die wärmende Wasserleitung, ïberall in Organismus herum 
und stellt auf diese Weise eine relativ gleichmässige innere Temperatur her. Die Hant bildet eine umhüllende, schlecht wïrmeleitende Schicht deren Temperatur von innen nach aussen abnimmt. Ias Blut hat durchschnittlich eine Temperatur von $59^{\circ}$ und ist in dieser Beziehung nur geringen Schwankungen, je nach den Organen, welche es durchfliesst, unterworfen; die verschiedenen Hautstellen dagegen besitzen weit auseinandergehende Temperaturen, welche speciell durch die Blutcirculation des entsprechenden Unterhantgewebes und durch die äussere Ungebung bedingt sind. Während sie im Mastdarme $38^{\circ}$, in der Nundhölle unter der Zunge nur $37,2^{\circ}$, in der Achselhöhle zwischen $36,5^{\circ}$ und $37,2^{n}$ beträgt, nimmt sie an anderen Körpertheilen bedeutend $a b$; an den Wangen ist sie noch $30^{\circ}$, dagegen nur $22-24^{\circ}$ an der Nasenspitze und an den Ohrläppchen. Tägliche Schwankungen von bcinahe einem Grad treten hervor: bei Tage steigt die Temperatur allmählich bis gegen 5-8 Uhr Abends; bei Nacht geht sie allmählich herunter bis 2-6 Uhr Morgens.

Die Gleichmässigkeit der inneren Körpertemperatur wird dadurch erreicht, dass ein Gleichgewicht zwischen der producirten und abgegebenen Wärmemenge besteht; von den 2630 im Organismus erzengten Calorien werden circa 70 Calorien oder etwa 2,7\% zum Erwärmen cler Speisen und Getränke gebraucht; diese betragen durehschnittlich $3000 \mathrm{Gr}$. (1500 Gr. Wasser und ebenso viel an festen Speisen ron ungefähr derselben Wärmecapacität) und haben eine mittlere Temperatur von $12^{\circ}$. Wenn täglich $16400 \mathrm{Gr}$. Luft mit einer mittleren Temperatur von $20^{\circ}$ eingeathmet und mit einer Temperatur von $37^{\circ}$ ausgeathmet werden, so erfordert, da die Wärmecapacität dieser Luftmenge derjenigen von 4377 Gr. Wasser entspricht, die Erwärmung dieser Respirationsluft nur 70 Calorien; dagegen bei einer Temperatur der Respirationsluft von $0^{0}$ 140 Calorien, das heisst $2,7-5,4 \%$ der im Körper producirten Wärme. Die ausgeathmete Luft ist bei $37^{\circ}$ vollständig mit Wasserdampf gesättigt. Man nimmt an, dass in 24 Stuuden höchstens $650 \mathrm{Gr}$. Wasser auf diese Weise in den Lungen in Dampf verwandelt werden. Dieses erfordert 397 Calorien oder $15 \%$ des ganzen Wärmefonds.

Für die Wärmeausgabe durch die Haut bleiben also iibrig 100 minus $(2,7+2,7$ bis $5,4+15,0)$, also mindestens $76,9{ }_{10}^{01}$, das heisst mindestens 2022 Calorien. Die Wärmeabgabe durch die Haut geschieht durch Wasserverdunstung, Ausstrahlung und Leitung. Die Wasserverdunstung beträgt etwa $660 \mathrm{Gr}$. und verbraucht also 364 Calorien. Ausstrahlung und Leitung, welche nicht direct bestimmt werden können, wïrden den Rest ausmachen, nämlich 2022-364 = 1658 Calorien. Die Ausstrahlung durch die Haut ist hauptsächlich proportional der Differenz zwischen der Hauttemperatur und der Temperatur der Ungebung. Die Tempe- 
ratur der Haut selbst ist in hohem Grade abhängig von ihrer Blutfüllung, welche letztere durch die Thätigkeit des Herzens und der Vasomotoren regulirt wird. Die Wasserverdunstung wird einerseits durch den hygrometrischen Zustand des umgebenden Mediums beeinflusst; mittels der Schweisssecretion vermag andererseits der Organismus den Durchfeuchtungsgrad der äusseren Haut zu verändern. Bei gesteigerter Wärmebildung im Organismus oder bei erschwerter Wärmeabgabe in lochtemperirter und feuchter Luft findet durch einen besonderen nervösen Mechanismus eine Gefässerweiterung der Haut statt, es tritt Schwitzen ein, sowie Wärme-Dyspnoë; die Körpertemperatur kann in dieser Weise auf ihrer normalen Höhe gehalten werden. Das Umgekehrte kommt vor, wenn die Wärmeproduction abnimmt oder die Wärmeabgabe in einem kalten Medium zunimmt. Die Haut erbleicht und wird trocken. Gegen die Abkühlung schïtzen wir uns künstlich durch Heizung der Wohnungsräume, durch Bekleidung, durch reichlichere Ernährung, durch willkiirliche Bewegungen. Es fragt sich, ob der Organismus im Stande ist, seine Wärmebildung respective seine Verbrennungen direct zu steigern oder herabzusetzen, ohne merkliche Muskelcontractionen hervorzurufen? Wahrscheinlich werden durch die für Erwärmung und Abkïhlung empfindlichen Nerven Erregungen zu regulatorischen Centren geleitet, von wo reflectorisch nur die Factoren der Blutcirculation und die durch den Muskeltonus bedingten Verbrennungen modificirt werden.

\section{Berichtigungen.}

Auf Seite 12 in Fig. 3 muss an der Stimmgabelcurve statt: 0,01 stehen: 0,02.

Auf Seite 34 Zeile 17 von oben ist hinter: „dass man" einzuschalten: "den Ruhestrom compensirt und".

Auf Seite 40 Alinea 2 soll es statt: „zweites Kohlehydrat, das süssschmeckende Inosit, vor, welches" heissen: "süssschmeckender Körper, der Inosit, vor, welcher" und hinter "reagirt" ist anzufügen: „Der Inosit wurde früher zu den Kohlehydraten gerechnet, jetzt betrachtet man ihn aber als ein Benzolderivat".

Auf Seite 172 Zeile 6 von oben soll es statt: „Deiters'schen Zellen" heissen: "Nervenzellen der grauen Vordersäulen des Rïckenmarkes“. 


\section{Register.}

Ablominaltypus der Athmung 406.

Aberration, sphärische 220; chromatische $2: 35$.

Alkklingen der Netzhaut-Erregung bei weissem Licht 248; bei farbigem Licht 249.

Absolute Kraft des MInskels 46.

Absolutes limdenfeld 129.

Absorption 497; des Lichtes in Augenmedien 247; in der Netzhant 256 .

Absterben des MIuskels 37; des Nerven S3.

Acceleratorische Nervenfasern des Herzens 378.

Accommodation 223; objective Zeichen 224; Zustand des accommodirten Auges 227; NIechanismus 229; Breite 230; Linic 231.

Achromasie des Auges 235 .

Actionsströme des IIuskels 34 ; des Nerven 70.

Acusticus 164 .

Adaption des Auges für hell und dunkel 251 .

Adäquater Reiz 177.

Aderfigur 255 .

Aëroplethysmograph 394.

Aetherwellen 201, 239.

Aethersclıwefelsäure $46 \pi$.

Affecte, Wirking auf das Gefïsssystem 370; auf die Athmung 418; auf die Thränensecretion 441.

Albumin, s. Eiweisskörper.

Alkalialbuminat 322,453 .

Alkaloide 488.

Alkohol, Wirkung auf Nervenleitungsfialigkeit $i 7$.

Allgemeingefühle 183.

Altstimme 287.

Alveolenluft 386.

Amboss 276.

Amidoessigsäture 457, 466.

Ammoniak im Harn 467, 468; Wirkung auf Nerven it.

Amöboille Bewegung ter firblosen Blutkörperchen 43,318 .

Amphiarthrose 5 ?.
Ampullen 164.

Anäistliesie 120 .

Anatomiselier (Quersehnitt 46.

Anelektrototonus 66.

Anfüllungszeit 35 \%).

Anisotrope MIuskelsubstanz 28.

Anklingen ier Netzhauterregung 248.

Anode 32,66 .

Anschwellen ler Nervenerregung 84 .

Anspannungszeit $35 \supset$.

Aortendurchmesser 342.

Aphasie 130.

Apnoë 414.

Appetit 490 .

Arbeitsäquivalent 504.

Arbeitsleistung d. Muskels 17; l. Flimmerepithelien 44; des Herzens 369, 503 .

Arterien 334.

Arterielles Blut 309, 316.

Arterienpuls 359; Qualitäten 360 ; Registrirung 360,362 ; Fortpflanzungsgesehwindigkeit 361,368 .

Arthrodie 49 .

Articulation der Vocale 290; der Consollanten 300 .

Aspiration des Thorax 364, 391.

Assimilation 5.

Associationsfasern 123.

Associationstheorie 159.

Association ron Vorstellungen 126.

Astigmatismus 232.

Atelektasie 398.

Athembewegungen 387; Frequenz und Form 395; Eintluss des Blutes 408; der Tagi 410; sensibler Nerven 416; der Arbeit 423; Selbststenerung 41:2.

Athemcentrum 408, 420 .

Athemmuskelcentren 408 .

Athemnerven, motorisclie 407.

Athemschwankungen des Blutdruckes 392.

Athemvolumschreiber 394.

Athmung, Wesen 3S2; Gasaustausch zwischen Lungenblut und Lungenluft $3 S 5$; durch Nase und Mund 357; Mechanik 357: künstliche 413; beim Fötus 414. Athmungscentren im Nackenmark 408, 420. Atlumungsgrösse 395 . 
Athmungsinnervation 407.

Athmungstypen, reflectorische und absichtliche Acnderung 416.

Atrioventricularklappen 333.

Atropin, Wirkung auf das Herz 378; auf die Speicheldrüsen 434, 437; auf die Schweissdrüsen 484.

Aufmerksamkeit 124.

Aufrechtsehen 254 .

Aufrechtstehen 55 .

Aufsaugung 497.

Auge 202; brechende Medien u. Flächen 205 ; schematisches 216 ; reducirtes 217. Augenaxe 203.

Augenbewegungen 261.

Augenmuskeln 264.

Angenstellungen 262.

Ausathmungsluft 384; -Muskeln 406.

Ausgabe des Körpers 500 .

Austreibungszeit 355 .

Autoch thone Erregbarkeit 116, 409; automatische 409.

Axencylinder 63 .

Axendrehung des Herzens 367.

Axialer Nervenstrom 71.

Bakterien des Verdaungsapparates 497.

Basilarmembran 274.

Bauchpresse 419.

Bauchspeichel 442; Einwirkung auf die Nährstoffe 495.

Bauchspeicheldrüse 441, s. Pankreas.

Begriff des Blutdruckes 345 .

Belegzellen 445.

Bell'sches Gesetz 105.

Benzoësäure 466.

Beugecentren 149.

Bewegungen, Muskel- 10; Protoplasma43; Flimmer- 43; des Brustkorbes 399.

Bewegungstypen der oberen und der unteren Rippenlogen 401.

Bewegungsvorstellung 138.

Bewusstsein 123, 177; Inhalt 177.

Bilanz des Stoffwechsels 500.

Bildpunkte 206.

Bildungsheerde der rothen und weissen Blutkörperchen 319.

Bilirubin 457.

Binocularsehen 259.

Bissen 491.

Blickebene 262; -linie 262.

Blinder Fleck 253.

Blut 308; makroskopische Zerlegung 309; specifisches Gewicht 309; Lackfarbigwerden 313; Gehalt an Hämoglobin 316; Zusammensetzung 329; Menge 329; Umlaufszeit 349.

13lutdruck beim Thiere: in den Arterien 346 ; in den Capillaren 347 ; in den Venen 348; im Herzen 362; Senkung nach Ilalsmarkdurchtrennung 372, 474; respiratorische Schwankungen 392.
Blutdruck beim Menschen 347.

Blutgase 327.

Blutgerinnung 309, 320, 324.

Blutkörperchen, rothe 309; Zälılung 311;

Durchmesser 310; Structur 312; weisse B.-K. 317; Zahl 318; Zusammensetzung 319 ; Zerfall 325.

Blutkuchen 320 ; Plasma 320; Serum 321.

Blutplättchen 320 .

Blutstromgeschwindigkeit 343.

Blutwellencurve 362.

Blutwellenzeichner 362 .

Bogengänge 134, 164, 280.

Boll'sche Pinselzellen 103.

Brechung der Liehtstrahlen 205.

Brechungsgesetz 207.

Brechungsindices der Augenmedien 216.

Brennlinie 222.

Brennpunkt 208; -ebene 208; -weite 208.

Brod 489.

Brunner'sche Drüsen 450.

Brustkorb 399.

Bruststimme 286.

Burdach'sche Keilstränge 119.

Butter 453, 489.

Calorimetrie 502.

Capacität, vitale 396; der Herzkammern 342.

Capillaren 334; Gesammtquerschnitt 344.

Carbamid 464.

Carbaminsaures Ammon 464.

Cardinalpunkte 212.

Cardiograph 357.

Casein 453; Verdauung im Magen 494.

Cellulose 487, 497.

Centralnervensystem 89.

Centrifugale und centripetale Nervenfasern $62,71,74,105$.

Centrirte Systeme sphärischer Trennungsflächen 211.

Centrosoma 4.

Centrum anospinale 110 ; ciliospinale 113 ; vesicospinale 110.

Cerebrin 85.

Cerebrose 85 .

Charniergelenke 49 .

Chlornatrium 487.

Cholalsäure 457.

Cholesterin 85, 317.

Chorda tympani $432,435$.

Chorioidea 204.

Chromasie des Auges 235.

Chromatin 3.

Chylus 331.

Chylusgefässc 497.

Chymus 494.

Ciliarfortsätze der Chorioidea 204.

Ciliarmuskel 204, 229.

Circulation des Blutes 331 .

Coagulation s. Gerinnung.

Colostrum 452.

Commissuren des Gehirns 122. 
Complementärfarben 240.

Complementärluft 396 .

Conjunctivalsáck 440 .

Consonanten 298; -bildung 299.

Contraction des Muskels 11.

Contraction des Herzens 354.

Contractionswelle 29; Geschwindigkeit 30.

Contrast 250.

Coordination 131, 141 ; Centrum 112.

Coordination der Augenbewegung 265.

Coordinationsapparat des Körpergleichgewichtes $14 \pi$.

Coordinirte Reflexe 155.

Coronararterien 358.

Corti'sches Organ 274.

Crusta phlogistica 321.

Curare 10, 80.

Cytoglobin 326.

Cytomitom 3.

Darmschleimhaut 450.

Darmfistel 450; Saft 451; Verdaumng 495; Absorption 497; Gase 497.

Deckfarbe des Blutes 313.

Decussatio pyramidum 133.

Defäcation 496; Centrum 110.

Degeneration des Nerven 83.

Dehnungscurve der Arterienwänıle 368 .

Dehnungscurve des ruhenden Muskels 9; des erregten Muskels 17.

Dendritenfasern 87.

Depressor 377.

Diabetes 444,468 .

Diapedesis 318 .

Diaphragma 402.

Diastole 354, 364 .

Dickdarm, Verdauung 496.

Digitalis 378 .

Dioptrik des Auges 205.

Diphthonge 296.

Disdiaklasten 28.

Distanzschätzung 260.

Donders'scher Druck 388.

I)oppelbilder 259.

Doppelbrechung des Muskels 28.

Doppelsinnige Nervenleitung 72.

Drehaxe des Auges 261; Drehpunkt 261.

Drehungsmoment 53.

Druck des Blutes 346 .

Druckbild 202.

Drucksinn 183.

Drüsen 425 : metakerastische 425 ; secretorische 425,429 .

Ducti Bartholiniani 440.

Ductus, choledochus 455; Stenonianus 440; Whartonianus 430; Wirsungianus 441 .

Dünndarm 450, 495 .

Durst 490 .

Dyspnoëformen 423.
E.gesta 500.

Eigelenk 50.

Eigenlicht der Netzhaut 250.

Einathmung 393.

Einfluss collateraler Blutgefüsse aufeinander 351 .

Eingelenkige Muskeln 53.

Einsatz der Stimme 288.

Eisen im Hämoglobin 314; im Harn 467.

Eiweiss 321.

Eiweissdrüsen 439.

Eiweissharn 468.

Eiweisskörper des Muskels 38; des Blutes 321; der Milch 453; Verdauung 493.

Eiweissverbranch 501 .

Ejaculationscentrum 110.

Elasticität des Nuskels 9, 17; der Gefässe 368.

Electricität des Muskels 32; des Nerven 66.

Electroden, unpolarisirbare 33.

Electromotorische Kraft des Muskels 32; des Nerven 70.

Electrotonus 66.

Emmetropie 219.

Empfindungskreis 191.

Emulsion 453, 495.

Endolymphe 275.

Erbrechen 494.

Erbsen 489.

Erectionscentrum 110; Nerven 373.

Erfolgsapparat 62,75 .

Ergänzungsluft 396.

Erinnerungsbilder 160 .

Ermüdung des Muskels 21; der Netzhaut 249.

Erregbarkeit des Muskels 10, 36; des Nerven 66, 76 ; des Reflexapparates 149.

Erregbarkeitscurven der farbigen Sehelemente 244.

Erregbarkeit der Sehelemente als Function der Lichtintensität 246; als Function der Wellenlänge 247.

Erregung des Muskels 10 ; des Nerven 64.

Erregungswelle des IInskels 30.

- des Nerven 69.

Esslust 490.

Eupnoë 421.

Excitomotorische Ganglien 375.

Explosivlaute 303.

Exspiration 395, 406; Centrum 420; Luft 384; Muskel 407.

Exspiratorischer Druck 393.

Facialis 166.

Facces 497.

Falsettstimme 286.

Farben 239.

Farbenblindheit 246 .

Farbenmischung 240.

Farbentafel 241.

Farbensehen 239. 
Farblose Blutkörperchen 317.

Fäulniss 497.

Fermente 438, 443, 448, 449, 494, 495.

Fernpunkt des Auges 230.

Fettbildung 501.

Fette 487; Absorption 497.

Fibrin $320,323$.

Fibrinogene Substanz 324.

Fibrinoplastische Substanz 324.

Fick'sche Hypothese der Muskelcontraction 25.

Fisch 489 .

Fleisch 489.

Flimmerbewegung 44 .

Flïssigkeitsströmung in starren Röhren 336.

Flïstersprache 288.

Fravenmilch $455,489$.

Fontana'sche Bänderung 63.

Fortpflanzungsgeschwindigkeit der Contractionswelle 29; der Nervenerregung 69; der Pulswelle 368.

Fovea centralis 235, 238.

Frequenz der Herzschläge 359 ; der Athemzinge 395.

Fühlhebel 30.

Fühlsphäre 128.

Fundusdrüsen 445 .

Fuscin 257.

Gähnen 418.

Galle 455; Zusammensetzung 457, 462; Secretion 460; Wirkung im Darm 495.

Gallenfistel 460.

Gang 55.

Ganglienzellen 101, s. Nervenzellen.

Ganglion oticum 439 .

Gase des Blutes 327; des Darmes 497.

Gaswechsel 384.

Gefälle 338.

Gefässe 335; des Riickenmarks 103.

Gefässcentren des Riückenmarkes 113,374 ; in der Medulla oblongata 372.

Gefässnerven 371.

Gefässtonus. 372.

Gefühl 183.

Gehirn 122, 130.

Gehirnnerven 162.

Gehör 266; Empfindung 278.

Gehörgang 276.

Gehörknöchelchen 276.

Gelber Fleck 235.

Gelenke 47; Verbindungen 48.

Gemeingefühle 183.

Genuines Blut 313.

Genussmittel 488.

Gepaarte Schwefelsüuren 467.

Geränsch 266.

Gerinnung des Blutes 309, 320, 324; verhindernde Mittel 321, 326; der Milch 453.

Gerlach'sches Fasernetz 117.
Geruch 197; Organ 198; Schärfe 199; Qualitäten 200 .

Gesammtstromintensität 340 .

Gesammtquerschnitt der Gefässe 340, 344.

Geschmack 195; Qualitäten 195.

Gesicht 201; -feld 252; -winkel 254.

Ginglymus 49.

Glaskörper 205.

Glatte Mlusculatur 41.

Gleichgewicht des Körpers 147.

Globuline 322.

Glomerulus 470.

Glossopharyngeus 165.

Glutin 487.

Glycerinphosphorsäure 85 .

Glycin 457.

Glycocoll 457, 466.

Glycocholsäure 457.

Glycogen des Muskels 40; der Leber 459.

Glycogenbildung 455, 499 .

Glycosurie 444, 468.

Goll'sche Stränge 98, 101.

Gratiolet'sche Sehstrahlung 123, 125.

Graue Substanz 95.

Grosshirnrinde 125.

Grundton 272.

Grundvocale 289.

Gyri 122.

Haarlaalgdrïsen 451.

Haarzellen des Labyrinthes 275 .

Hamberger'sches Schema 405.

Hämatin 314, 317.

Hämatoblasten 320 .

Hämatoporphyrin 317.

Hämin 316 .

Hämodromometer 343.

Hämoglobin 312; Zusammensetzung 314; Zerfall 314; Quantitative Bestimmung 315; Gehalt im Blute 316.

Halbmonde Giannuzzi's 437.

Hammer 276.

Halssympathicus 370.

Harmonie der Töne 272.

Harn 462; Menge 462; Zusammensetzung 469; Absonderung 473; Secretionsdruck 474; Secretionstheorie 476.

Harnentleerung 110.

Harnsäure 323, 465 .

Harnstoff $323,462,499$.

Haubensystem 137.

Hauptbrennebene 211.

llauptzellen 445 .

Hauttalgdrüsen 451.

IIebelwirkung der Muskeln 53.

Hemmungen 117.

Hemmung des Reflexes 154.

IIemmungsnerv des IIerzens 376 .

Henle'sclie Scheide 63; Schleife 472.

Herz 332; Muskeln 332; Ganglien 374; = Nerven 374.

Herzarbeit 369, 503. 
Herzbewegung 354 .

Ilerzhemmungscentrum 377.

Herzrevolution 354.

Ilerzstoss 356 .

Herztöne 359 .

Ilintere Wurzelfusern 93.

Ilippursäure 323, 466 .

Hirmmantel 122 .

Hlirnstamm 130.

IIöhlengrau des vierten Ventrikels 140.

HIörnerv 164.

IIörsplïire 125, 128.

Homoiotherme Thiere 502.

Hornhaut 203.

Hubhöhe 13.

Humor aqueus 204.

IIungerempfindung 490.

Hungerzustand 465, 501 .

Husten 416.

Hyperästhesic 120.

Ilypermetropie 219.

IIypoglossus 166 .

Hypothese von Young und Helmholz 243.
Kniegelenk 51.

Knochen 46.

linochenmark 47, 320 .

Knotenpunkte 212, 226, 254.

Kochsalz 469, 487.

Körperbewegungen 45.

Körperkreislauf 335.

Körperliches Sehen 260.

Kohlehydrate 487.

Kohlenoxyd 315.

Kohlensäure im Blute 327 ; in der Lingenluft 384, 386.

Kohlentheilchen in der Lunge 387.

Kopfstimme 286.

Korbzellen 437.

Kreatin, Kreatinin 323, 465.

Kreislauf 308; des Blutes 331; der Lymphe 379.

Kreuzungen 133.

Krümmungsradien des Auges 216, 226.

Krystalllinse 204.

Krngelgelenk 49.

Kuhmilch 455, 489 .

Labdriisen 445.

Labferment $449,494$.

Labyrinth 164, 274.

Lachen 418.

I ackfarbiges Blut 313.

Lamina spiralis 274.

Latenzstadium, mechanisches 13 ; elektrisches 35 .

Lanf 58 .

Lawinenartiges Anschwellen 84.

Lebenserscheinungen 2.

I cebensknoten 420.

Leber 455; Ban 456; Circulation und Secretion 457; Leistungen der Lelierzellen 459 .

Lecithin $63,85,317$.

Legumin 488.

Leitungsbahnen des Rückenmarkes 118.

Leitungsfähigkeit des Nerven 78.

Leucin 459.

Lencocyten 317, s. Blutkörperchen.

Licht 201.

Lichtbrechung im Muskel 28.

Lichtempfindung 239.

Lieberkühn'sche Drüsen 450.

Lingualis 431.

Lippenconsonanten 298.

Localisation in der Hirnrinde 127.

Localzeichen der Sinnesempfindungen 181; des Gefïhles 190; des Sehens 254.

Lungen $387 \mathrm{ff}$.

Lingenkreislauf 335 .

Limulae 336, 437.

Iymphe 308, 330; Serum 31; Strom 379 ; Bildung 379; Gefisse 379.

Lymphdrïisen $42 \overline{5}$.

Lymphherzen 381.

Kỉleinhirn 135 
Magen, Drüsen 444; Fistel 446; Saft 44S; Verdauung 493; Bewegungen 493; Innervation 169, 447, 494.

Nanometer 345, 393.

Malpighi'sches Gefässkıäuel 470.

Markscheide 63.

Marksubstanz der Nieren 469.

Mastdarmdrüsen 450.

Naximalreiz 13.

Nehrgelenkige Muskeln 53.

Meibom'sche Drüsen 451.

MIembrana basilaris 274 .

Messung der Stromintensität 343.

Metaphysik 1.

Nethämoglobin 317.

Mikrosomen 3.

Milch 452, 489 .

Milchdrüse 451.

Milchferment 449.

Milchsäure 40, 323, 449.

Milchzucker 454 .

Millon'sches Reagens 322.

Milz 426; Wirkung anf Hämoglobin 458.

Mischfarben 241.

Mitose 5.

Mittelhirn 130.

Motorische Sphäre 128.

Mucigen 437.

Mucin 432, 436.

Mundspeichel 430, 440, 491, 493.

Muscarin 378.

Musculin 39.

Muskel, quergestreift 8; Elasticität 9, 17; Peize 10; Form und Volumänderung 10 ; glatte 41; Spannung 10; Verkürzung 11, 15; Tetanus 15; Ermüdung 13, 21; Arbeitsleistung 17; Chemie 20, 38; Spectren 29 ; Strom 33; Starre 37; Plasma 38; Serum 39; Kraft 46; Dienste im Körper 52.

Muskelasche 41.

Muskelsinn 194.

Myelin 63.

Myographion 11, 13.

IYopie 219.

Myosin 38.

Naclibilder 249, 250.

Nährstolie 486.

Nahepunkt des Auges 230.

Nahrung 485; Aufnalıme 485, 490; der Flüssigkeiten 490 ; fester Elemente 491.

Nabrungselcmente 486 .

Nalirungsmittel 488; animalische 489; vegetabilische 489 .

Nasalirte Vocale 297.

Nebennieren 429.

Negative Schwankung des Muskelstromes 34; des Nervenstromes 70.

Neigungsströme des Muskels 34.
Nervengewebe 61; Nervenfasern 62, 97; Mark 63; Endplatten 64; Erregbarkeit 64, 75; Reize 65; Strom 70, 71; Absterben 82; Chemie 85; Plexus 162.

Nervenzellen 62, 86, 96, 115.

Netzhaut 235.

Neuroglia 103.

Neurokeratin 63.

Nicotin 435.

Nieren 462; Bau 469.

Niesen 416.

Nodulus Arantii 336.

Nodus cursorius 137.

Nucleïn 319.

Nutzeffect verschiedener Athmungstypen $395,419$.

Nystagmus 261.

Obertöne 272, 291.

Obst 489.

Oculomotorius 165.

Oedem 381.

Oesophagusperistaltik 492.

Ohr 274.

Oikoid 312.

Olfactorius $163,198$.

Opticus 164, 236.

Organismus 3.

Ortssinn 183, 190.

Osmiumfärbung 85 .

Otolithenapparat 134, 165.

Oxyhämoglobin 314.

Pankreas 441; Bau 441; Innervation 441, 444; Fistel 442; Saft 442; Zymogen 443; Glycosurie 444.

Papillarmuskeln des Herzens 333, 357.

Papillen der Nieren 469.

Papille des Sehnerven 253.

Paraglobulin 322, 324.

Paradoxe Zuckung 71.

Parotis 439.

Partialtöne 272.

Pendelbewegung 58, 267.

Pepsin 448.

Peptone 322, 493.

Periskopie 223.

Peristaltik 491, 496.

Pfortader 456.

Phasenverschiebuug 271.

Phospliate des Harns 467.

Phrenicus 403, 407.

Physiologie, Definition 1.

Physiologischer Querschnitt 46.

Piqûre Claude Bernard's 141, 481.

Plethysmographie 369.

Plexus solaris 175 .

Pneumatometer 393.

Pncumatorektische Dyspnoë 422.

Poikilotherme Thiere 502. 
Projection, centrale der Muskeln 108, 142; der Gesichtsemplindungen nach aussen 182, 254.

Protagon $85,317$.

Protoplasma 3; Entwickelung 5; Bewegung 43.

Ptyalin 491, 493.

Puls 359; Eigensehaften 360 ; Welle 361.

Pulsbeschleunigende Centren 113.

Pumpwirkungen des Ilerzens 349 .

Pupille 139, 203, 251.

Pylorus-Drüsen 445.

Pyramidenbahnen 99, 119, 133.

Qualitätenkreise 178.

Quotient, respiratorischer 384.

Randzellencomplexe 437.

Ranvier'sche Einschnürungen 64 .

Raumsinn der Haut 190; der Augen 260.

Reaction centripetaler und centrifugaler Nervenfasern 75.

Reflexcentra 109, 139, 147; kurze und lange Reflexbögen 110; einfache Reflexe 149; Zeit 153; Hemmung 154; zweckmässig coordinirte 154 .

Regio olfactoria 198.

Register der Stimme 287.

Reibungsgerïusche 301,305 .

Reis 489.

Reizbarkeit des Muskels 36; des Nerven 66, 76 .

Reize 10.

Reizschwelle 13.

Reizung 10.

Relatives Rindenfeld 129.

Reserveluft 396.

Residualluft 396.

Resonanz 272.

Piesonatoren 272.

Resorption 497.

Respiration 382 ; künstliche 413.

Retina, Bau 236; des Dunkel-Auges 252. des Hell-Auges 252; Erregung 243.

Rhytmische Bewegung des Herzens 375.

Richtungslinie 206.

Richtungsstrahl 212.

Riechnerv 163, 198.

Riechmesser 199.

Rindenfelder 129.

Rindfleisch 489.

Rippen 400.

Rollgelenk 51.

Rollungen des Auges 263.

Rückenmark, Bau 89; weisse Substanz 93; graue Substanz 95; Nervenzellen 96; Nervenfasern 97 ; systematische Gliederung des Markmantels 98; Wurzelfasern 101 ; Arterien 103; Function 105; Reflexe 109 ; Centren 112; trophischer Einfluss 114; Verletzungen 121.
Rückstosselevation 361, 367.

Rüben 489.

\section{Salze 487, 501.}

Salzsäure des Magensaftes 449.

Samenfäden 45.

Sanson-Purkinje'sche Bildchen 214, 225.

Sattelgelenk 50.

Sauerstoff $383 \mathrm{ff}$.

Scatol 495, 497.

Schallleitung im Ohr 276.

Scheiner'scher Versuch 219.

Schilddrüse 428.

Schlagvolum des Herzens 342, 344, 385.

Schleim des Harns 468; des Speichels 43\%, 436.

Schleimdrüsen 439.

Schliessungswelle 366.

Schluckbewegung 416, 491.

Schmerzempfindung 120.

Schnecke 274.

Schritt 56.

Schwarzbrod 489.

Schwefelsäure des Harns 467.

Schweinefleisch 489.

Schweiss 482; Drüsen 482; Secretion 483; Centren 112; Nerven 483.

Schwingung, sinusoide 269 ; zusammengesetzte 271 .

Schwingungsform 267.

Schwungbein 56.

Secrete 430.

Secretion, in ihren Beziehungen zur Circulation 435.

Secretionsnerven 170, 436.

Secundäre Zuckung 35; Tetanus 36.

Seelenthätigkeit 123.

Sehen 201; monoculares 258; binoculares 259.

Sehhügel 137.

Sehnenreflex 110.

Sehnerv 164.

Sehroth 257.

Sehsphäre 126, 128.

Sehwinkel 254 .

Semilunarklappen 336, 358.

Sensibilité recurrente 107.

Sensible Nerven 167.

Sensorielle Hirnnerven 163.

Seröse Spalträume 332.

Serum des Blutes 321.

Serumeiweiss 322.

Serumglobulin 322 .

Sinne 177.

Sinnesattribute 182.

Sinnesempfindung 177.

Sinnesgebiete 177.

Sinusschwingung 269.

Sinus Vasalvae 336.

Sopran 287.

Specifische Energie 125, 179.

Speckbaut 321. 
Spectralfarben 239 .

Spectrum des Oxyhaemoglobins 315; des reducirten Hämoglobins 315.

Speichel $430 \mathrm{ff}$.

Speicheldriisen 431 .

Sphygmograph 360.

Spitzenstoss des Herzens 357.

Splanchnicus 174.

Sprachcentrum 130.

Sprache 280.

Sprung 60.

Stabkranz 123.

Stäbchen 237.

Stadium der steigenden und sinkenden Energie des Muskels 11.

Stärke 487.

Stationärer Zustand des Kreislaufes 349.

Stannius'scher Versuch 375.

Stehen 55.

Steigrohr 336.

Stickstoff im Blute 327; der Ingesta und Egesta 500.

Stimmapparat 282.

Stimmbänder 284.

Stimme 280.

Stoffwechsel 499 ; bei absoluter Carenz 501; Bilanz 501.

Stomata 381.

Streckcentren 149.

Streifenhügel 140.

Strom, Intensität 337; Geschwindigkeit 337; Beschleunigung 338; Widerstände 338 ; Verzweigung 343.

Strychnin 152

Stützbein 56 .

Submaxillaris 430 .

Substantia gelatinosa 102 .

Summation der Reize 16, 69, 150.

Sympathicus 171.

Synchondrose 47.

Synergie von Muskelfasern 109.

Systole 354.

T'achypnoë 417, 423.

Talgdrüsen 451 .

'Tastempfindung 183, 193.

'Tastsinn 193.

Taurin 457.

Taurocholsäure 457.

Temperatur, Einfluss auf Muskelzuckung 12; des Blutes 502.

Temperaturempfindende Nervenfasern 188.

Temperaturpunkte 188.

Temperatursinn 183, 185.

Tenor 287.

Tensor chorioideae 205, 229.

Tensor tympani 277.

Tetanus des Muskels 15.

Theilungscoëfficient 341 .

Thermische Centren 140, 506.

Thermischer Querschnitt 33.

Thoracaltypus der Athmung 406.
Thorax, Formänderung bei der Athmung 400.

Thränendrüsen 440 ; Innervation 441.

Thrombus 380 .

Thymusdrüse 428 .

Todtenstarre des Muskels 37.

Töne des Herzens 359.

Ton 266; Höhe 267.

Tonus der Muskeln 110; der Gefässe 372.

Tranfusion 380, 422.

Traubenzucker 323, 487.

Trennung von Leitungsfähigkeit und Reizbarkeit im Nerven 76 .

Triebkräfte des Lymphstromes 381 .

Trigeminus 166, 198.

Trommelfell 277.

Trophik 114.

Trophische Nervenfasern 170, 436.

Trophische Processe der Drüsen 436.

Trypsin 443, 495.

Tuba Eustachii 277.

Tubulus contortus 472 .

Türck'sche Methode 152, 154.

Tyrosin 459 .

Uebergang der Erregung vom Nerv zum Muskel 78.

Ueberlastung des Muskels 18.

Ueberleben des Muskels 36; des Nerven 82.

Ultrarothe Strahlen 246.

Ultraviolette Strablen 247.

Umlaufszeit des Blutes 349 .

Unermüdbarkeit des Nerven 80.

Unpolarisirbare Elektroden 33.

Unterschiedsempfindlichkeit der Retina 250.

Urobilin 465 .

Uterusinnervation $\mathbf{1 1 0 .}$

Vagus 168; Einfluss au die Herzthätigkeit 376; auf die Athembewegung 410.

Vasoconstrictoren 371.

Vasodilatatoren 371.

Vasomotorische Centren 113, 372, 374.

Venen 334.

Venöses Blut 309, 316.

Verbrennungswärme 502.

Verdauung 493; in der Mundhöhle 493; im Magen 493; im Darm 495.

Verharrungszeit, systolische 356 .

Verlängertes Mark 140.

Verschlusslante 298, 303.

Vierhügel 135.

Vitalcapacität 396.

Vocale, System 291; Grund- 289; einfache 292 ; unvollkommen gebildete 295 ; unbestimmte 295 ; zusammengesetzte 296 ; nasalirte 297.

Volumänderungen des Thorax 394. 
W ärme, thierische- 502 ; Production 503; Ausgabe 503; Topographie 505; Gleichgewicht 505; Regulation 506.

Wärmebildung im Nuskel 23, 503.

Värmedyspnoë $417,423$.

Wärmepunlite 188.

Wärmestarre des Nuskels 37.

Wärmestich 140.

Warmblüter 502 .

Wasser als Näbrstoff 486.

Weizenbrod 489.

Wellenreflexion 367.

Willkür 141.

Willkürliche Bewegungen 125, 157.

Wirbelerscheinungen 339.

Wollust 183.

Wurzeln der Rückenmarksnerven 101.

Xanthin 465.

Xanthoproteïnreaction 322.
Zapfen der Netzhaut 237.

Zellen 3 ; Theilung 5 .

Zerstreuungskreise 218.

Zirbeldrüse 429 .

Zitterlaute 298, 305.

Zooïd 312.

Zotten des Dünndarmes 450.

Zuckerarten 487.

Zuckerstich 141, 481.

Zuckung des Mruskels 10.

Zuckungscurve 11.

Zuckungsgesetz 68 .

Zungenpfeife 281 .

Zusammenhalten der Gelenke 52.

Zwangshaltungen 135; Lagen 135; Bewegungen 136.

Zweckvorstellung 124.

Zwerchfell 402.

Zweckmässigkeit des Athemtypus 395.

Zymogen 443. 



\section{COLUMBIA UNIVERSITY LIBRARIES}

This book is due on the date indicated below, or at the expiration of a definite period after the date of borrowing, as provided by the library rules or by special arrangement with the Librarian in charge.

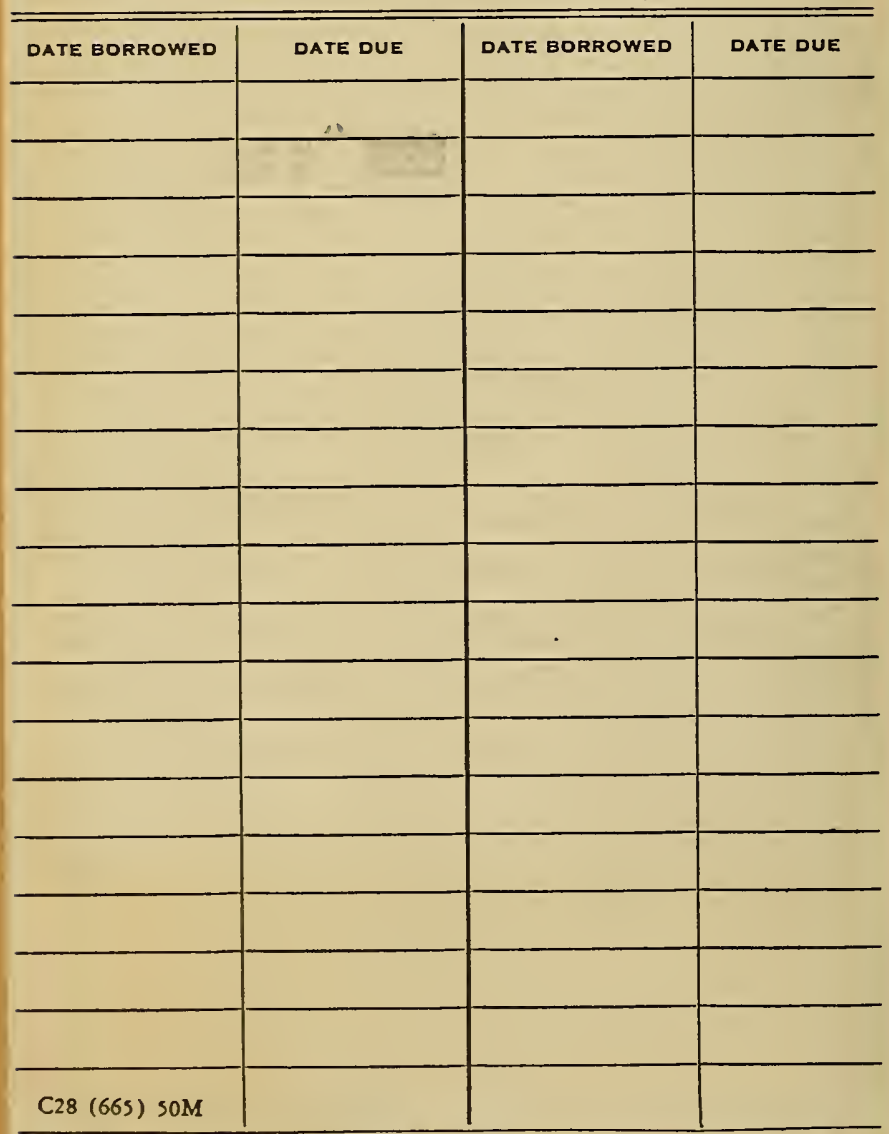




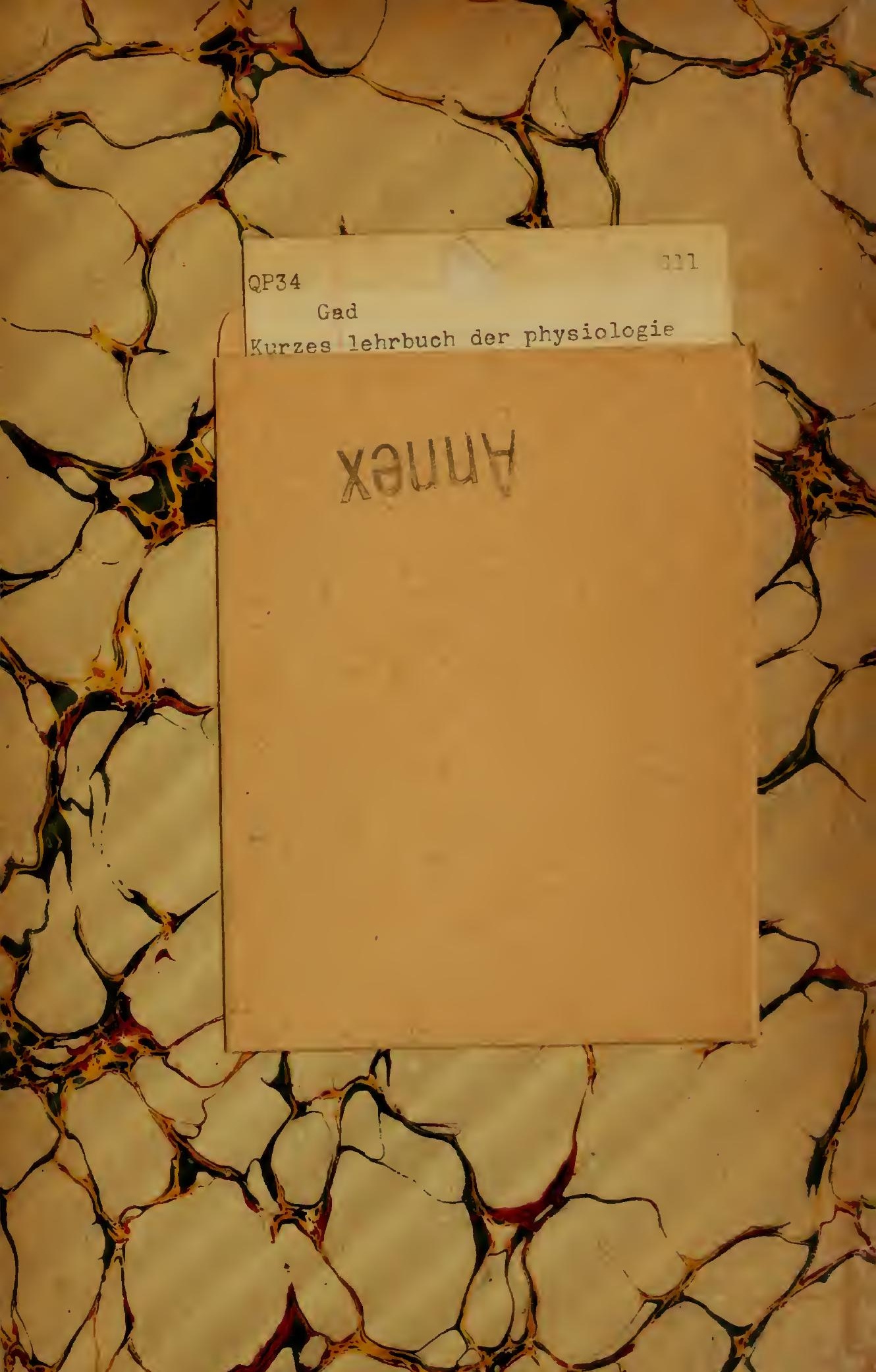


20.5

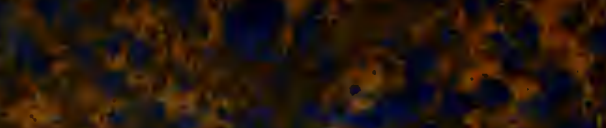

$$
\text { 1. }
$$

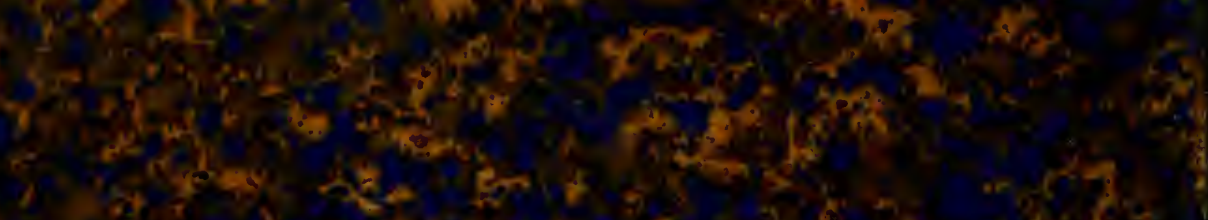

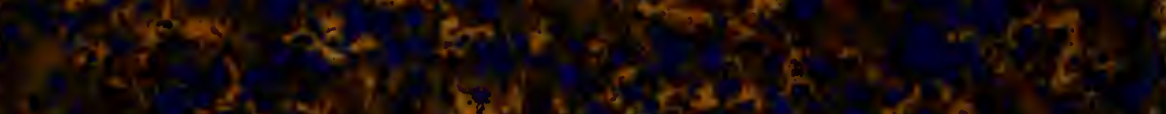

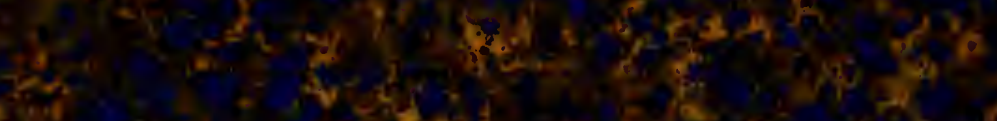

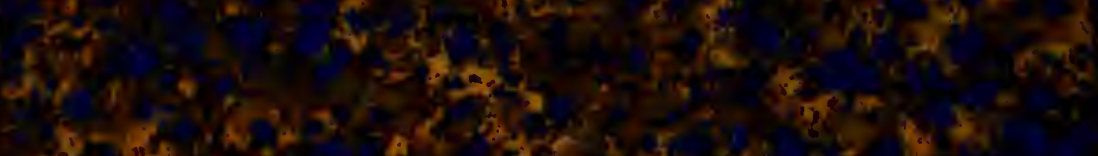

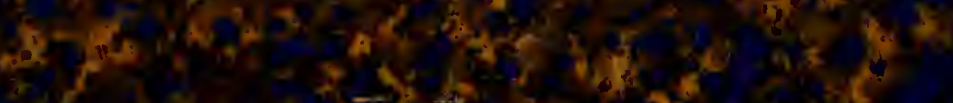

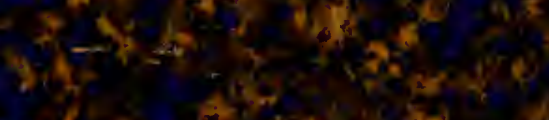

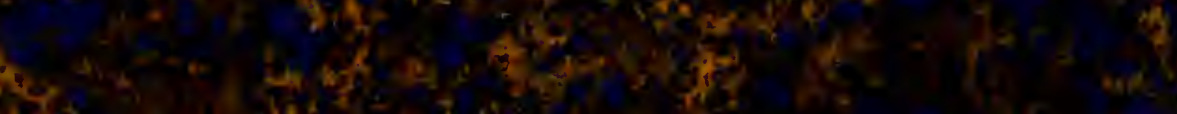

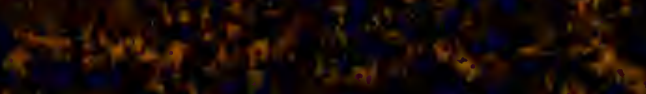
xix
tisis,

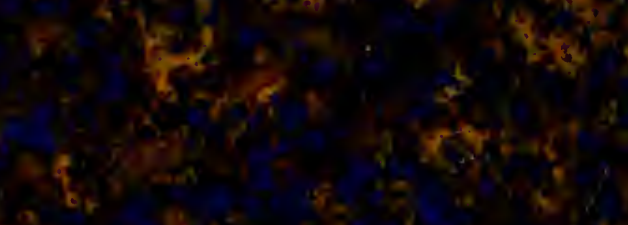
$x+2 x$

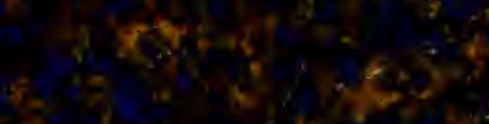

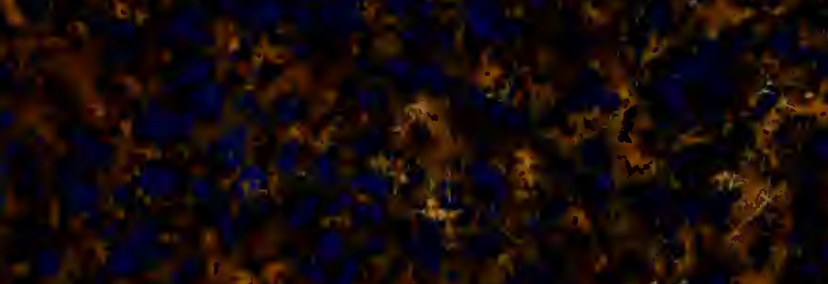

a

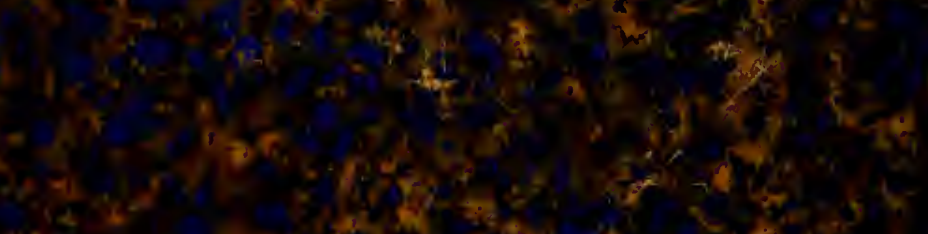
low, of

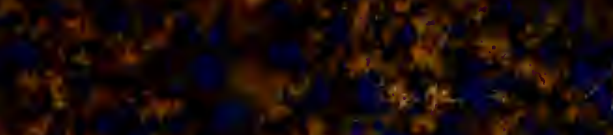

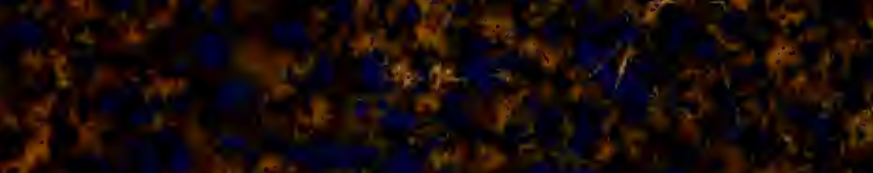

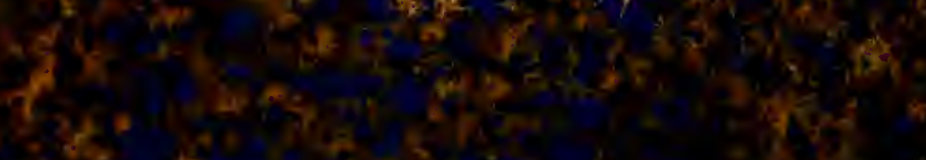
$20 x y$ is

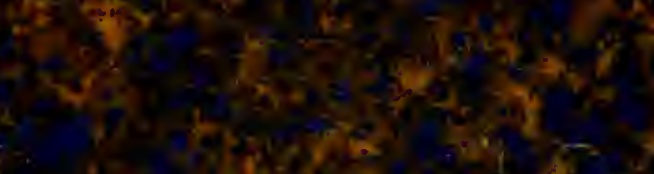

$$
\begin{aligned}
& \text { 5. }
\end{aligned}
$$

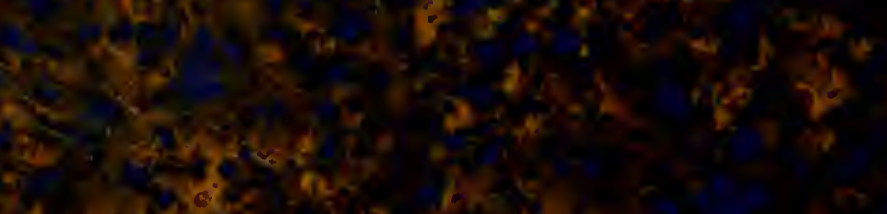

a.i.

$$
\text { (5) }
$$$$
\text { tiperty }
$$

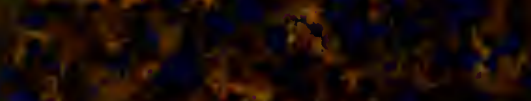

